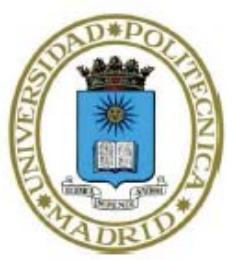

UNIVERSIDAD POLITÉCNICA DE MADRID ESCUELA TÉCNICA SUPERIOR DE ARQUITECTURA

\title{
CONSTRUCCIÓN MODULAR LIGERA ENERGÉTICAMENTE EFICIENTE
}

TESIS DOCTORAL

Juan Carlos Sánchez González

Arquitecto 


\title{
UNIVERSIDAD POLITÉCNICA DE MADRID \\ ESCUELA TÉCNICA SUPERIOR DE ARQUITECTURA
}

Departamento de Construcción y Tecnología Arquitectónicas

\section{CONSTRUCCIÓN MODULAR LIGERA ENERGÉTICAMENTE EFICIENTE}

TESIS DOCTORAL

\author{
Juan Carlos Sánchez González \\ Arquitecto \\ Universidad Autónoma de Santo Domingo \\ Universidad Politécnica de Madrid
}

Director: Benito Lauret Aguirregabiria

Doctor Arquitecto Universidad Politécnica de Madrid 
Tribunal nombrado por el Magfco. y Excmo. Sr. Rector de la Universidad Politécnica de Madrid, el día de de 20 .

Presidente:

Vocal:

Vocal:

Vocal:

Secretario:

Suplente:

Suplente:

Realizado el acto de defensa y lectura de la Tesis el día de 20 ,

en la Escuela Técnica Superior de Arquitectura de Madrid.

Calificación:

EL PRESIDENTE LOS VOCALES

EL SECRETARIO 


\section{ÍNDICE}

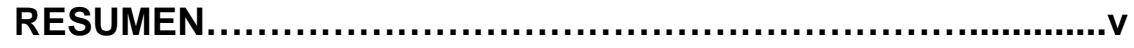

ABSTRACT ..............................................................ii

DEDICATORIA Y AGRADECIMIENTOS............................xi

1. INTRODUCCIÓN ................................................1

2. OBJETIVOS, JUSTIFICACIÓN E HIPÓTESIS......................3

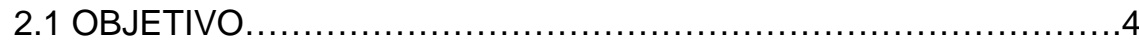

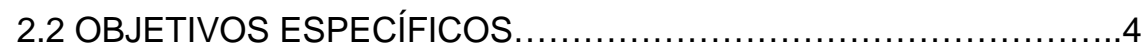

2.3 JUSTIFICACIÓN........................................................... 5

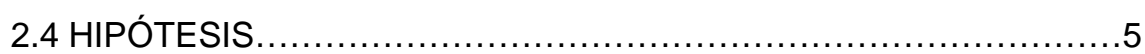

3. ESTADO DE LA TÉCNICA Y LA INVESTIGACIÓN............6

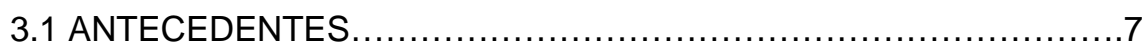

3.1.1 Industrialización, prefabricación y modulación........................7

3.1.2 Arquitectura modular y ligera en la historia. Algunos ejemplos a modo de recorrido cronológico ........................9

3.1.3 Aproximación a Principios Bioclimáticos aplicados a la CIL y la CML.....................................28

3.2 ESTADO ACTUAL DEL ESTADO DE LA TÉCNICA. .48

3.2.1 Construcción modular ligera y construcción industrial ligera de la segunda mitad del siglo XX a la actualidad. ...

3.3 TIPOS DE MATERIALES Y TÉCNICAS CONSTRUCTIVAS. 60

3.4 LA EFICIENCIA ENERGÉTICA. ANTECEDENTES

Y CONTEXTO ACTUAL.

3.5 SOLAR DECATHLON. ENTRE EL ESTADO DE LA TÉCNICA

Y LA INVESTIGACIÓN.

3.6 ESTADO DE LA INVESTIGACIÓN. 100

3.6.1 Artículos indexados JCR (Journal Citation Reports) .............100

3.6.2 Otros artículos, tesis y publicaciones científicas.

4. METODOLOGÍA DE INVESTIGACIÓN. 111

4.1 METODOLOGÍA DE ANÁLISIS DOCUMENTAL Y TEÓRICO 
4.1.1. Objetivos y esquema de trabajo

de la metodología documental.

4.1.2 Antecedentes históricos del Estado de la Técnica...........114

4.1.3 Estado Actual de la Técnica................................115

4.1.4 Materiales y sistemas constructivos.

Análisis datos ACV

4.1.5 Conceptos de Eficiencia energética nZEB y NZEB.

Contexto y comparaciones.

4.1.6 Metodología Documental. Entre la Técnica y la Investigación:

Concurso Solar Decathlon

4.1.7. Conclusiones parciales Metodología Documental ...

4.2.1. Objetivos metodología empírica o experimental.

4.2.2. Definición prototipos de ensayos y procedimientos empíricos

4.2.3. Conclusiones parciales Metodología Experimental. 126

4.3. METODOLOGÍA DE SIMULACIÓN 127

4.3.1. Objetivo de las simulaciones.

4.3.2. Validación de las herramientas informáticas 127

4.3.3 Validación del método de simulación y el modelo de análisis. .128

4.3.4. Propuestas, medidas de mejoras y escenarios climáticos

4.3.5. Cálculo de consumos estimados zonas climáticas equiparables.

4.3.6. Conclusiones parciales Metodología de Simulaciones 135

5. ANÁLISIS Y DISCUSIÓN DE RESULTADOS. 136

\subsection{ANÁLISIS Y DISCUSIÓN}

DE RESULTADOS DE LA METODOLOGÍA DOCUMENTAL...........137

5.1.1 Concurso Solar Decathlon.

5.1.2 Prototipos SD10 y SD12.

5.1.3 Ganadores: LumenHaus 2010 y Canopea 2012

5.2. ANÁLISIS Y DISCUSIÓN DE RESULTADOS

DE LA METODOLOGÍA EMPÍRICA O EXPERIMENTAL

\subsection{ANÁLISIS DISCUSIÓN} DE RESULTADOS METODOLOGÍA DE SIMULACIONES

5.3.1 Cálculos de consumo

y de los sistemas de generación fotovoltaica (FV)

por zonas climáticas Koppen/CTE para el Taller-Vivienda $52 \mathrm{~m}^{2} \ldots . .153$ 
5.3.2 Lugares, del mapa

de Koppen, donde el Taller-Vivienda $52 \mathrm{~m}^{2}$,

en estado actual. Cumple nzEB o NZEB.

5.3.3 Lugares, del mapa de Koppen, donde el

Taller-Vivienda $52 \mathrm{~m}^{2}$, cumple NZEB. Medida de mejora:

Incorporación del $100 \%$ de generación fotovoltaica (paneles),

en cubierta y a $0^{\circ}$ de inclinación.

5.3.4 Lugares del mapa de Koppen, donde el

Taller-Vivienda $52 \mathrm{~m}^{2}$, cumple o se acerca a nZEB.

Medidas de Mejoras: 1) Incorporación FV 100\% en cubierta;

2) Incorporación de geotermia.

6. CONCLUSIONES .181

6.1 CONCLUSIONES GENERALES. 182

6.2 CONCLUSIONES DOCUMENTALES .184

6.3 CONCLUSIONES EXPERIMENTALES. 186

6.4 CONCLUSIONES DE SIMULACIONES 187

7 LÍNEAS FUTURAS DE INVESTIGACIÓN .189

8. OTROS TRABAJOS

DE INVESTIGACIÓN YIO DIFUSIÓN 191

8.1 PATENTES. .192

8.2 COMUNICACIONES A CONGRESOS 192

8.3 OTRAS PUBLICACIONES .192

8.4 CONCURSOS 193

8.5 TRABAJO DE INVESTIGACIÓN PARA DEA

(Diplomado de Estudios Avanzados) 193

9. BIBLIOGRAFÍA 194

9.1 ARTÍCULOS INDEXADOS (JCR) 195

9.2 OTROS ARTÍCULOS Y PUBLICACIONES CIENTÍFICAS......196

9.3 PONENCIAS Y COMUNICACIONES A CONGRESOS 197 
....9.6 TRABAJOS DE INVESTIGACIÓN D.E.A.

(Diplomado de Estudios Avanzados) 203

9.7 OTROS TRABAJOS ACADÉMICOS 203

9.8 REVISTAS TÉCNICAS 203

9.9 NORMATIVAS

9.10 PORTALES Y SITIOS DE INTERNET.

9.10.1 Construcción Modular.

9.10.2 Eficiencia energética.... 208

\section{ANEXOS}

ANEXO 1

ARQUITECTURA SOLAR EN PAISES TROPICALES EMERGENTES

TECNOLOGIA FOTOVOLTAICA: EL ESCENARIO DOMINICANO.

Trabajo tutelado para la obtención del DEA/Suficiencia investigadora.

\section{ANEXO 2}

Documentación gráfica sobre la Casa Wichita de Richard Buckminster Fuller. Documentación gráfica sobre las casas tropicales de Jean Prouvé.

\section{ANEXO 3}

UPDATED WORLD MAP OF THE KOPPEN-GEIGER CLIMATE CLASSIFICATION. Artículo sobre zonificación climática según el mapa de Koppen-Geiger.

Peel, M. C.; Finlayson B. L. ; McMahon T. A.

\section{ANEXO 4}

Resultados de 131 certificaciones energéticas de viviendas en madrid, a modo de validación del uso de la herramienta informática $\mathrm{CE}^{3} \mathrm{X}$ utilizada en la tesis.

\section{ANEXO 5}

Cálculos de consumos generales, parámetros para instalación fotovoltaica y para sistema de bomba de calor geotérmica.

\section{ANEXO 6}

Certificados de calificación energética del Taller-Vivienda $52 \mathrm{~m} 2$. por zonas climáticas de acuerdo al código técnico de edificación (CTE). Resultados estado actual y estado con medidas de mejoras.

\section{ANEXO 7}

Ubicación de zonas climáticas según mapa de koppen (equiparables a las zonas climáticas definidas en el cte) en las cuales el taller-vivienda alcanza el nzeb y/o el NZEB .

\section{ANEXO 8}

Información gráfica taller de prototipos etsam y Taller-Vivienda 52 m². 
RESUMEN 


\section{RESUMEN}

Esta tesis trata sobre la construcción modular ligera, dentro del contexto de la eficiencia energética y de cara a los conceptos de nZEB (near Zero Energy Building) y NZEB (Net Zero Energy Building) que se manejan en el ámbito europeo y específicamente dentro del marco regulador de la Directiva 2010/31 UE.

En el contexto de la Unión Europea, el sector de la edificación representa el 40\% del total del consumo energético del continente. Asumiendo la necesidad de reducir este consumo se han planteado, desde los organismos de dirección europeos, unos objetivos (objetivos 20-20-20) para hacer más eficiente el parque edificatorio. Estos objetivos, que son vinculantes en términos de legislación, comprometen a todos los estados miembros a conseguir la meta de reducción de consumo y emisiones de GEI (Gases de Efecto Invernadero) antes del año 2020.

Estos conceptos de construcción modular ligera $(C M L)$ y eficiencia energética no suelen estar asociados por el hecho de que este tipo de construcción no suele estar destinada a un uso intensivo y no cuenta con unos cerramientos con niveles de aislamiento de acuerdo a las normativas locales o códigos de edificación de cada país.

El objetivo de nZEB o NZEB, e incluso Energy Plus, según sea el caso, necesariamente ( $y$ así queda establecido en las normativas), dependerá no sólo de la mejora de los niveles de aislamiento de los edificios, sino también de la implementación de sistemas de generación renovables, independientemente del tipo de sistema constructivo con el que se trabaje e incluso de la tipología edificatoria.

Si bien es cierto que los niveles de industrialización de la sociedad tecnológica actual han alcanzado varias de las fases del proceso constructivo - sobre todo en cuanto a elementos compositivos de los edificios- también lo es el hecho de que las cotas de desarrollo conseguidas en el ámbito de la construcción no llegan al nivel de evolución que se puede apreciar en otros campos de las ingenierías como la aeronáutica o la industria del automóvil.

Aunque desde finales del siglo pasado existen modelos y proyectos testimoniales de construcción industrializada ligera (CIL) e incluso ya a principios del siglo $\mathrm{XX}$, ejemplos de construcción modular ligera (CML), como la Casa Voisin, la industrialización de la construcción de edificios no ha sido una constante progresiva con un nivel de comercialización equiparable al de la construcción masiva y pesada.

Los términos construcción industrializada, construcción prefabricada, construcción modular y construcción ligera, no siempre hacen referencia a lo mismo y no siempre son sinónimos entre sí. Un edificio puede ser prefabricado y no ser modular ni ligero y tal es el caso, por poner un ejemplo, de la construcción con paneles de hormigón 
prefabricado. Lo que sí es una constante es que en el caso de la construcción modular ligera, la prefabricación y la industrialización, casi siempre vienen implícitas en muchos ejemplos históricos y actuales.

Con relación al concepto de eficiencia energética (nZEB o incluso NZEB), el mismo no suele estar ligado a la construcción modular ligera y/o ligera industrializada; más bien se le ve unido a la idea de cerramientos masivos con gran inercia térmica propios de estándares de diseño como el Passivhaus; y aunque comúnmente a la construcción ligera se le asocian otros conceptos que le restan valor (corta vida útil; función y formas limitadas, fuera de todo orden estético; limitación en los niveles de confort, etc.), los avances que se van alcanzando en materia de tecnologías para el aprovechamiento de la energía y sistemas de generación renovables, pueden conseguir revertir estas ideas y unificar el criterio de eficiencia + construcción modular ligera.

Prototipos y proyectos académicos- como el concurso Solar Decathlon que se celebra desde el año 2002 promovido por el DOE (Departamento de Energía de los Estados Unidos), y que cuenta con ediciones europeas como las de los años 2010 y 2012, replantean la idea de la construcción industrializada, modular y ligera dentro del contexto de la eficiencia energética, con prototipos de viviendas de $\pm 60 \mathrm{~m} 2$, propuestos por las universidades concursantes, y cuyo objetivo es alcanzar y/o desarrollar el concepto de NZEB (Net Zero Energy Building) o edificio de energía cero.

Esta opción constructiva no sólo representa durabilidad, seguridad y estética, sino también, rapidez en la fabricación y montaje, además de altas prestaciones energéticas como se ha podido demostrar en las sucesivas ediciones del Solar Decathlon.

Este tipo de iniciativas de desarrollo de tecnologías constructivas, no sólo apuntan a la eficiencia energética sino al concepto global de energía neta, Energía plus o cero emisiones de $\mathrm{CO}^{2}$.

El nivel de emisiones por la fabricación y puesta en obra de los materiales de construcción depende, en muchos casos, no solo de la propia naturaleza del material, sino también de la cantidad de recursos utilizados para producir una unidad de medida determinada ( $\mathrm{kg}, \mathrm{m}^{3}, \mathrm{~m}^{2}, \mathrm{ml}$, etc). En este sentido podría utilizarse, en muchos casos, el argumento válido de que a menos peso, y a menos tamaño, menos emisiones globales de gases de efecto invernadero y menos contaminación.

Para el trabajo de investigación de esta tesis se han tomado como referencias válidas para estudio, prototipos tanto de CML (Modular 3D) como de CIL (panelizado y elementos 2D), dado que para los fines de análisis de las prestaciones energéticas de los materiales de cerramiento, ambos sistemas son equiparables. 
Para poder llegar a la conclusión fundamental de este trabajo de tesis doctoral - que consiste en demostrar la viabilidad tecnológica/ industrial que supone la combinación de la eficiencia energética y la construcción modular ligera - se parte del estudio del estado de la técnica ( desde la selección de los materiales y los posibles procesos de industrialización en fábrica, hasta su puesta en obra, funcionamiento y uso, bajo los conceptos de consumo cero, cero emisiones de carbono y plus energético).

Además -y con un estado de la técnica que identifica la situación actual- se llevan a cabo pruebas y ensayos con un prototipo a escala natural y células de ensayo, para comprobar el comportamiento de los elementos compositivos de los mismos, frente a unas condicionantes climáticas determinadas. Este tipo de resultados se contrastan con los obtenidos mediante simulaciones informáticas basadas en los mismos parámetros y realizadas en su mayoría mediante métodos simplificados de cálculos, validados por los organismos competentes en materia de eficiencia energética en la edificación en España y de acuerdo a la normativa vigente.

\section{ABSTRACT}

This thesis discusses lightweight modular construction within the context of energy efficiency in nZEB (near Zero Energy Building) and NZEB (Net Zero Energy Building) both used in Europe and, specifically, within the limits of the regulatory framework of the EU Directive 2010/31.

In the European Union the building sector represents $40 \%$ of the total energy consumption of the continent. Due to the need to reduce this consumption, European decision-making institutions have proposed aims (20-20-20 aims) to render building equipment more efficient. These aims are bound by law and oblige all member States to endeavour to reduce consumption and GEl emissions before the year 2020 .

Lightweight modular construction concepts and energy efficiency are not generally associated because this type of building is not normally meant for intensive use and does not have closures with insulation levels which fit the local regulations or building codes of each country.

The objective of nZEB or NZEB and even Energy Plus, depending on each case, will necessarily be associated (as established in the guidelines) not only with the improvement of insulation levels in buildings, but also with the implementation of renewable systems of generation, independent of the type of building system used and of the building typology.

Although it is true that the levels of industrialisation in the technological society today have reached several of the building process phases - particularly in the composite 
elements of buildings - it is also true that the quotas of development achieved in the area of construction have not reached the evolutionary levelfound in other fields of engineering, such as aeronautics or the automobile industry.

Although there have been models and testimonial projects of lightweight industrialised building since the end of last century, even going back as far as the beginning of the $X X$ century with examples of lightweight modular construction such as the Voisin House, industrialisation in the building industry has not been constant nor is its comercialisation comparable to massive and heavy construction.

The terms industrialised building, prefabricated building, modular building and lightweight building, do not always refer to the same thing and they are not always synonymous. A building can be prefabricated yet not be modular or lightweight. To give an example, this is the case of building with prefabricated concrete panels. What is constant is that, in the case of lightweight modular construction, prefabrication and industrialisation are almost always implicit in many historical and contemporary examples.

Energy efficiency (nZEB or even NZEB) is not normally linked to lightweight modular construction and/or industrialised lightweight; rather, it is united to the idea of massive closureswith high thermal inertia typical of design standards such as the Passive House; and although other concepts that subtract value from it are generally associated with lightweight building (short useful life, limited forms and function, inappropriate toany aesthetic pattern; limitation in comfort levels, etc.), the advances being achieved in technology for benefitting from energy and renewable systems of generation may well reverse these ideas and unify the criteria of efficiency + lightweight modular construction.

Academic prototypes and projects - such as the Solar Decathlon competition organised by the US Department of Energy and celebrated since 2002, with its corresponding European events such as those held in 2010 and 2012, place a different slant on the idea of industrialised, modular and lightweight building within the context of energy efficiency, with prototypes of homes measuring approximately $60 \mathrm{~m} 2$, proposed by university competitors, whose aim is to reach and/or develop the NZEB concept, or the zero energy building.

This building option does not only signify durability, security and aesthetics, but also fast manufacture and assembly. It also has high energy benefits, as has been demonstrated in successive events of the Solar Decathlon.

This type of initiative for the development of building technologies, does not only aim at energy efficiency, but also at the global concept of net energy, Energy Plus and zero CO2 emissions.

The level of emissions in the manufacture and introduction of building materials in many cases depends not only on the inherent nature of the material, but also on the 
quantity of resources used to produce a specific unit of measurement $(\mathrm{kg}, \mathrm{m} 3, \mathrm{~m} 2, \mathrm{ml}$, etc.). Thus in many cases itcould be validly arguedthat with less weight and smaller size, there will be fewer global emissions of greenhouse effect gases and less contamination.

For the research carried out in this thesis prototypes such as the CML (3D Module) and CIL (panelled and elements) have been used as valid study references, becauseboth systems are comparablefor the purpose of analysing the energy benefits of closure materials.

So as to reach a basic conclusion in this doctoral thesis - that sets out to demonstrate the technological/industrial viability of the combination of energy efficiency and lightweight modular construction - the departure point is the study of the state of the technique (from the selection of materials and the possible processes of industrialisation in manufacture, to their use on site, functioning and use, respecting the concepts of zero consumption, zero emissions of carbon and Energy Plus).

Moreover, with the state of the technique identifying the current situation, tests and practices have been carried out with a natural scale prototype and test cells so as to verify the behaviour of the composite elements of these in certain climatic conditions. These types of result are contrasted with those obtained through computer simulation based on the same parameters and done, principally, using simplified methods of calculation, validated by institutions competent in energy efficiency in Spanish building and in line with the rules in force. 


\section{DEDICATORIA Y AGRADECIMIENTOS}

Doy gracias a Dios por sostenerme y a mi familia por apoyarme en todo momento.

A Eloísa....por todo.

A mis padres y abuelos; a mis hermanos.

A mis compañeros de doctorado: Belén, Juanmi, Luis y especialmente a Graciela por su apoyo.

A mi Director Benito Lauret Aguirregabiria por mostrarme el camino y apoyarme decididamente.

A Abuelita....in memoriam 
1. INTRODUCCIÓN 


\section{INTRODUCCIÓN}

La construcción modular es actualmente uno de los sistemas más avanzados de construcción industrializada. Aún contando con este sistema, en muchos aspectos, la arquitectura, y más específicamente las técnicas constructivas están más próximas a una manera artesanal de hacer las cosas que a procesos industrializados cerrados.

En la actualidad, la construcción de prefabricación industrializada no sólo representa durabilidad, seguridad y estética, sino también menor coste económico, rapidez en la fabricación y montaje, además de posibles prestaciones energéticas.

En el marco de la Unión Europea, el sector de la edificación representa el 40\% del total del consumo energético. Partiendo de este punto y de la necesidad de reducir este consumo, se han planteado los objetivos 20-20-20 que comprometen a todos los estados europeos a conseguir edificios energéticamente eficientes antes del año 2020.

Dentro de este escenario, la construcción industrializada se presenta como una alternativa favorable para los objetivos, toda vez que al realizar gran parte del proceso constructivo en fábrica se optimiza y reduce la utilización de materias primas y energía $y$ al mismo tiempo se genera menor cantidad de residuos no reciclables, y al momento de la puesta en obra, solo se llevan a cabo labores de montaje y ensamblaje, minimizando la posible contaminación que genera una construcción convencional.

Al utilizar el término modular, dentro del contexto de la construcción prefabricada, se hace referencia a un sistema alternativo dentro del mismo campo, que ofrece mayores ventajas a la hora de plantear soluciones a un coste razonable, confortable y por sus procesos y posibilidades, en dirección hacia la eficiencia energética.

Las ventajas y beneficios de esta solución constructiva y la posible incorporación de sistemas de generación renovables, sobrepasan los estereotipos sobre la construcción industrializada ligera y modular ligera como poco eficiente.

Esta tesis abordará el tema de la construcción industrializada ligera y modular ligera desde la perspectiva múltiple de un tipo de construcción eficiente y sostenible, desde la selección de los materiales y los procesos de industrialización en fábrica, hasta su funcionamiento y uso cotidiano, procurando el consumo cero o plus energético. 
2. OBJETIVOS, JUSTIFICACIÓN E HIPÓTESIS 


\section{OBJETIVOS, JUSTIFICACIÓN E HIPÓTESIS}

\subsection{OBJETIVO}

Demostrar que la Construcción Modular Ligera $(\mathrm{CML})$, puede ser energéticamente eficiente, apoyada en sistemas de generación de energía renovable de cara a criterios de nZEB (near Zero Energy Building) y/o NZEB (Net Zero Energy Building).

\subsection{OBJETIVOS ESPECÍFICOS}

Como objetivos específicos - para demostrar que la Construcción Modular Ligera $(\mathrm{CML})$ puede ser energéticamente eficiente - se plantean:

1) Proponer un método simplificado de cálculo para demostrar -dentro de un orden de magnitudes fiable- el planteamiento hecho en la hipótesis mediante:

a) Un estudio de fuentes documentales sobre CML y eficiencia energética.

b) Ensayos en prototipos existentes (construidos), que permitan conocer el comportamiento de los mismos - y sus posibles prestaciones - de manera empírica.

c) La realización de simulaciones de modelos teóricos (a partir de los prototipos construidos, sus características y resultados empíricos), con herramientas informáticas sencillas y disponibles (como las utilizadas para la certificación energética de edificios existentes por el método simplificado), que permitan evaluar la $\mathrm{CML}$, en su estado actual y con medidas de mejoras (de eficiencia energética), incorporadas.

d) Un sistema de equiparación simple basado en la zonas climáticas de España según el CTE (incorporadas a la base de datos del programa $\mathrm{CE}^{3} \mathrm{X}$, de referencia en este tesis) y las zonas climáticas del mapa de Koppen.

2) Establecer una primera aproximación de cálculo fiable que sirva como punto de partida, con datos y valores reales, para establecer una línea de acción hacia unos cálculos más específicos. 


\subsection{JUSTIFICACIÓN}

La eficiencia energética, aplicada en el ámbito de la construcción, ha pasado de ser una aspiración a convertirse en un objetivo o unos objetivos cuantificables (como los objetivos 20/20/20), en términos de ahorro de energía y/o reducción de la demanda, producción de energía, mediante fuentes renovables, y reducción de emisiones de GEI (Gases de Efecto Invernadero), en especial $\mathrm{CO}^{2}$.

El planteamiento de alternativas de construcción, incluso algunas de ellas mediante proyectos de investigación y desarrollo a niveles locales (ciudades y países) y a niveles europeos como los proyectos INVISO o ManuBuild, que permitan aumentar la eficiencia energética de los edificios (desde los procesos de construcción/fabricación, hasta su utilización), y reducir las emisiones, abre un espacio para la Construcción Modular Ligera como una de esas alternativas de construcción con bajos niveles de emisiones ( menos peso, menos emisiones) y óptimo rendimiento energético como muchos de los prototipos de los Concursos Solar Decathlon.

Con esta tesis se propone, además del planteamiento de la Hipótesis de trabajo, un método de análisis simplificado, basado en un sistema de equiparaciones climáticas y cálculos informáticos, que permite obtener resultados certeros a modo de números gordos, de cara a un diagnóstico rápido e inicial de una posible situación de proyecto.

\subsection{HIPÓTESIS}

Es posible demostrar las altas prestaciones que, en cuanto a eficiencia energética, puede llegar a tener la Construcción Modular Ligera (CML), dentro del contexto de su alto nivel de industrialización y de cara al cumplimiento de la Directiva 2010/31/UE, los objetivos 20/20/20 y en el contexto de los nZEB y NZEB (near Zero Energy Building y Net Zero Energy Building). Es posible demostrar estos niveles de eficiencia energética de una $C M L$, en varias zonas climáticas del mundo, mediante un sistema de equiparación simplificado entre las zonas climáticas de España - según el CTE- y el mapa de Koppen, combinado con una herramienta de calificación energética mediante la opción simplificada descrita y aprobada en la normativa española. 
3. ESTADO DE LA TÉCNICA Y LA INVESTIGACIÓN 


\section{ESTADO DE LA TÉCNICA Y LA INVESTIGACIÓN}

\subsection{ANTECEDENTES}

Al plantear los antecedentes que forman parte del estado de la técnica y de la investigación de la construcción modular ligera y la eficiencia energética relacionada a ésta, se hace un recorrido cronológico de los ejemplos más relevantes relacionados directamente con el tema. Se realiza una selección de las más notables referencias históricas, de la mano de grandes maestros de la arquitectura, desde un punto de vista técnico-constructivo y de alguna manera también simbólica, sirviendo de antesala para el desarrollo del eje central de este trabajo.

El concepto global construcción modular ligera y energéticamente eficiente no está definido como tal y para abordar el tema se hace necesario enfocarlo desde dos vertientes, a ser unificadas en la descripción del estado de la técnica y la investigación, y que son: construcción modular ligera y eficiencia energética.

Describir y cuantificar las prestaciones de eficiencia energética en los procesos y sistemas de este tipo de construcción (y edificación), acordes con los planteamientos de la Directiva Europea 2010/31/UE es parte del objetivo fundamental planteado en esta investigación.

En los siguientes epígrafes haremos un recorrido teórico en torno a estas dos vertientes antes señaladas.

\subsubsection{Industrialización, prefabricación y modulación.}

En términos generales la arquitectura modular, como un todo, se ha mantenido siempre como una opción alternativa a la construcción tradicional y que en términos reales de mercado no ha tenido mayor recorrido que el de una especie de subproducto en el mercado aún cuando grandes nombres de la arquitectura y emprendedores de otros sectores se han acercado para explorar esta opción constructiva.

Evidentemente gran parte de los componentes de una edificación tradicional pasan por un proceso de industrialización y/o modulación antes de su puesta en obra.

Tal es el caso de las carpinterías exteriores que como parte de la evolución natural de la arquitectura moderna de mediados del siglo pasado ha buscado conferir cierta ligereza al edificio y a su fachada mediante la utilización de vidrio, aluminio y/o acero.

Los tres términos que se manejan en este trabajo: industrialización, prefabricación y modulación, aún no siendo sinónimos entre sí, juntos, sirven para abordar el tema de la construcción ligera desde la perspectiva de la eficiencia energética, tanto desde los 
procesos de fabricación y puesta en obra, hasta las prestaciones de los materiales constructivos y de cerramiento.

La industrialización como tal, viene precedida de un proceso racional de estudio y selección de los mejores métodos de producción y las tecnologías más eficaces que pueden ser aplicadas a la trama constructiva.

De acuerdo a la definición del RIBA, tomada del libro "La Industrialización de la Edificación de Viviendas", Tomo 1 (Del Águila, 2006), vemos que la industrialización es "como una organización que aplica los mejores métodos y tecnologías al proceso integral de la demanda, diseño, fabricación y construcción". Del Águila cita a Blachère cuando expresa la definición mediante la siguiente ecuación:

\section{INDUSTRIALIZACIÓN = MECANIZACIÓN + RACIONALIZACIÓN + AUTOMATIZACIÓN}

En el libro "Tecnologías de la construcción industrializada" (Blachère, 1977), se justifica el uso del término industrialización toda vez que en la fabricación intervenga una máquina y deje de ser una producción artesanal: "los romanos fabricaban también en serie lámparas de aceite... El mismo era un procedimiento industrial, pues se realizaba mediante el empleo de una máquina muy simple, el molde, que permitía la producción por obreros no muy calificados, pero si especializados".

Al referirnos al término prefabricación volvemos a las definiciones planteadas por Del Águila cuando considera que la construcción prefabricada es aquella en la que sus elementos o sistemas son hechos en fábrica y no "in situ", es decir, que si un elemento es susceptible de poder ser hecho en obra y en su lugar es hecho en una fábrica, es un elemento prefabricado. Partiendo de estas dos definiciones genéricas, el autor hace una diferenciación en el tipo de industrialización/prefabricación y que separa en Método de Modelos y Método de Elementos. (Del Águila, 2006).

Para el desarrollo de este trabajo sobre la Construcción Modular Ligera Energéticamente Eficiente, se toman ambos métodos o enfoques como objeto de estudio indistintamente, partiendo de que para el análisis de la eficiencia energética, se puede utilizar cualquiera de los dos.

En la práctica esta diferenciación (2D y 3D) puede hacer variar algunos enfoques en cuanto a diseño y ejecución de la construcción. Aunque en sentido general no se evidencian diferencias sensibles en cuanto a la implementación de sistemas e instalaciones - su nivel de eficiencia y eficacia, y sus conexiones a las redes de suministro- sí que las hay en aspectos tales como el transporte de los módulos y su implantación en el emplazamiento o incluso en la fase de industrialización seriada de las partes del modelo o producto final. Estos factores sí que pueden influir en aspectos tanto financieros (en términos globales de la inversión), así como de economía de 
medios y tiempo, aunque también es cierto que esto siempre ha dependido de las circunstancias de cada caso particular.

Sin embargo y para los análisis que se realizan en este trabajo el factor de la eficiencia energética no es un aspecto que se vea afectado por la elección de una u otra forma de modulación.

\subsubsection{Arquitectura modular y ligera en la historia. Algunos ejemplos a modo recorrido cronológico.}

La construcción modular ligera, prefabricada y con cierto nivel de industrialización, ha tenido varios precedentes históricos destacados de los que, en este trabajo, se citan algunos de los más relevantes desde el punto de vista no solo histórico sino también constructivo y de prestaciones energéticas.

Tomando como referencia, parcialmente, la estructura cronológica propuesta por Ovando Vacarezza en su tesis "Criterios Técnicos del Proyecto con Módulos Tridimensionales Ligeros: Las Casas Del Solar Decathlon 2005 y 2007", (Ovando Vacarezza, 2015), se ha realizado un estudio, a modo de recorrido histórico, por varios ejemplos representativos de la construcción ligera industrializada (CLI), construcción modular ligera (CML), que abarca desde mediados del siglo XIX, pasando por el siglo XX y hasta nuestro días. Este recorrido se realiza tomando en consideración aspectos relacionados a las prestaciones energéticas de sus cerramientos y los posibles sistemas de acondicionamiento activo, así como a las posibles soluciones bioclimáticas con que pudieran contar estos ejemplos emblemáticos.

Para encontrar los orígenes de lo que sería la arquitectura modular y específicamente la arquitectura modular ligera primero habría que remontarse a los inicios registrados de la arquitectura prefabricada, cuyos orígenes se sitúan incluso antes de la mitad del siglo XIX.

Estos inicios se sitúan entre Inglaterra, Australia y Estados Unidos, siendo una de las primeras viviendas prefabricadas de las que se tiene constancia la Portable Colonial Cottage de Herbert Manning de 1833, fabricada en Gran Bretaña y siendo la madera, en todos los casos, el material predominante.

Para esas mismas fechas se desarrollaba en Estados Unidos el sistema del Balloon Frame, atribuido por algunos autores (Cobbers, 2010) a Agustine Taylor en Chicago y por otros autores (Lienhard; www.uh.edu/engines/epi779.htm), a George W. Snow en 1832.

Este sistema Balloon Frame y los sistemas de chapa ondulada, que permitían (ambos) un considerable nivel de prefabricación, fueron sin duda determinantes en la construcción de las viviendas que poblaron el oeste americano y hasta el Pacífico a causa de la fiebre del oro de la segunda mitad del siglo XIX. Estos sistemas también 
contribuyeron al asentamiento de los colonizadores que llegaron a tierras australianas y sudafricanas.

Entrando ya en el siglo XX, las casas prefabricadas con los sistemas antes mencionados pasaron a ser productos de catálogo de firmas como la Sears o Roedbuck and Co.que con modelos con sistemas como el Balloon Frame llegó a comercializar hasta 100.000 viviendas en las primeras cuatro décadas del siglo XX a un coste por unidad que oscilaba entre los 650 y los 2.500 dólares americanos. (Cobbers, 2010).

\section{American System-Built Houses}

Entre 1911 y 1917, Frank Lloyd Wright diseñó un tipo muy diferente de viviendas denominadas American System-Built Houses, con un espíritu más de diseño personalizado que de producción de prototipos o modelos de repetición.

Conservando la técnica de la industrialización de los elementos, Wright planteaba, en asociación con la Richard Company de Milwaukee, casas que aprovecharan este potencial de la producción en fábrica pero dotando a cada modelo de identidad propia a través del diseño. (Bergdoll, 2009).

El planteamiento consistía en reducir el tiempo de construcción mediante la producción sistematizada y en cadena de montaje de componentes como los bastidores de madera, elementos estructurales, cerramientos verticales y horizontales, molduras, revestimientos y carpinterías.

El resultado deseado era la reducción no solo del tiempo, sino de los costes de mano de obra y materiales ofreciendo, además de las ventajas inherentes a la industrialización, una alternativa fresca a las casas prefabricadas en el mercado.

Con este proyecto de las American System-Built Houses, el maestro hacía coexistir dos aspectos aparentemente contradictorios hasta ese momento: 1) la optimización de la construcción mediante los procesos de industrialización y la producción en serie y 2) un diseño individualizado para cada proyecto.

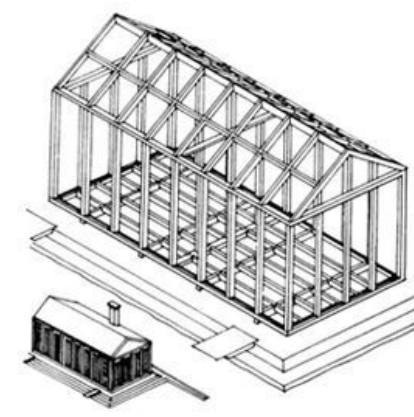

Fig. 1. Portable Colonial Cottage de Herbert Manning. 1833. (shelterpress.com. 2015)

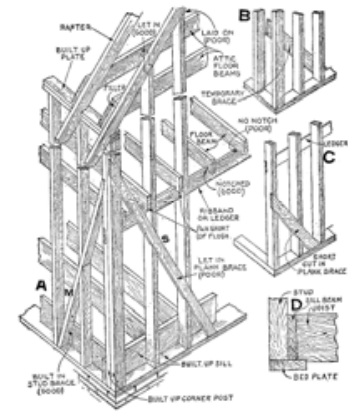

Fig. 2. Balloon Frame System, Siglo XIX. Agustine Taylor. (Wikipedia.com, 2015)

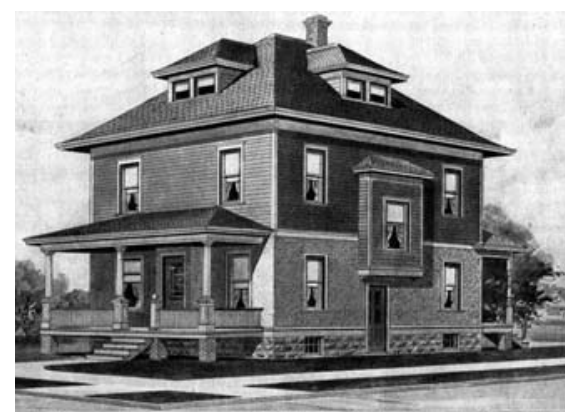

Fig. 3. Sears o Roedbuck and Co Houses. (searsarchives.com, 2015 ) 
Esta iniciativa empresarial que no tuvo el éxito deseado queda documentada en los más de 960 planos y dibujos de los múltiples diseños de las casas de la pradera de producción industrial del maestro Fran Lloyd Wright que se conservan en la Fundación que lleva su nombre. (http://www.franklloydwright.org, 2015).)

Este gran impacto de las viviendas prefabricadas encontró gran parte de su inspiración en el ejemplo de la cadena de montaje del modelo de automóvil Ford T de Henry Ford. Ciertamente todo este movimiento sirvió de motivación a los exponentes de la arquitectura mundial en Estados Unidos y Europa y en esta última sobre todo pasada la primera Guerra Mundial.

\section{Soluciones habitacionales mínimas}

Para estas mismas fechas, 1916, se construían en Inglaterra las Cabañas Nissen de Peter Herman Nissen, un oficial del ejército inglés.

Esta solución habitacional mínima, no era otra cosa que una especie de pequeña nave realizada en chapa corrugada de acero para el alojamiento de personal del ejército en tiempos de guerra.

Esta sencilla construcción sirvió, de alguna manera, como precedente testimonial de un tipo de solución mínima habitacional que se repitió más adelante con proyectos similares como las Cabañas Quonset (1941) de Otto Brandenberger y hasta la segunda guerra mundial e incluso más allá de escenarios de guerra en modelos como la Dymaxion Deployment Unit en 1941 de Richard Buckminster Fuller. (Bergdoll, Christensen, 2008). Con el modelo Nissen se pretendía garantizar: una producción en masa, incluso durante períodos de escasez de materiales, un sistema de despiece que permitiera su fácil transporte y un sistema de fácil montaje en pocas horas.

\section{Maison Voisin}

Un precedente importante para este análisis, por su condición de construcción modular, es la "Maison Voisin" de 1919, de Gabriel Voisin.

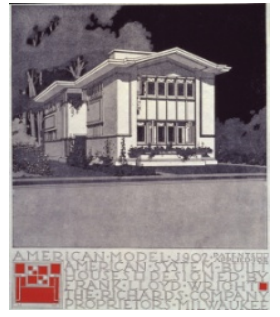

Fig. 4. America System Built Homes Brochure. 1911-1917. F. -Lloyd Wright. (architecture.about. com. 2015)

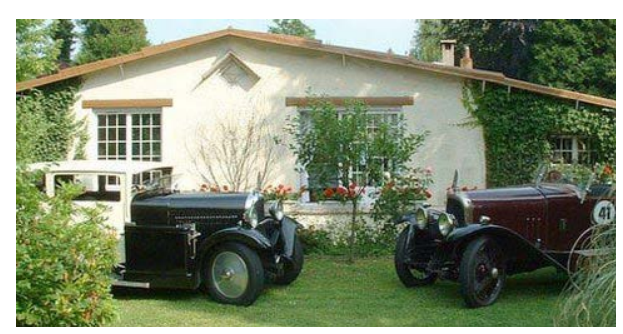

Fig. 5. Casa Voisin.1919. Gabriel Voisin (www.automobiles-voisin.fr . 2015)

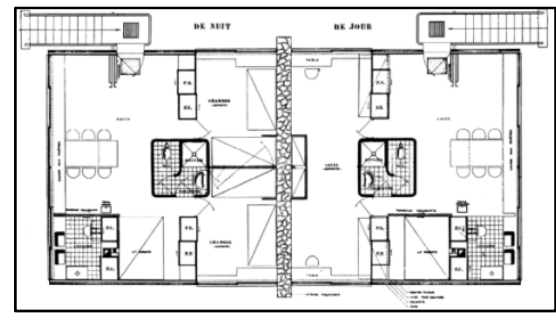

Fig. 6. Casa Loucher.1928. Le Corbusier (www.plansofarchitecture.tumblr.com. 2015) 
Este ingeniero francés dedicado al diseño y fabricación de aviones y automóviles proyectó tres modelos de viviendas prefabricadas, modulares y ligeras, de 39, 70 y 105 metros cuadrados respectivamente. Voisin, pasada la Primer Guerra Mundial propone, sobre todo para las zonas devastadas por la propia guerra, y como alternativa empresarial propia, unas viviendas que podían ser construidas en tres días. Como en tantos otros casos esta iniciativa no se pudo sostener en el tiempo quedando solamente, como testimonio material, dos modelos que aún siguen en pleno uso.

Estos modelos estaban compuestos por paneles tipo sándwich, con alma de corcho; en su cara interior eran de madera contrachapada y en su cara exterior también de contrachapado de madera más un recubrimiento con lámina de acero.

Partiendo de que el lugar de emplazamiento de la vivienda se encontraba en una latitud de $48^{\circ}$ norte con temperaturas media de las mínimas en invierno de $9^{\circ} \mathrm{C}$ (climatedata.eu. 2015) este tipo de aislamiento se presentaba, en principio, insuficiente.

Si bien es cierto que no se tiene constancia de que los modelos Voisin tuvieran algún sistema de aprovechamiento de energía pasivo o activo, sí es cierto que la puesta en obra y su rápida construcción, significaban un ahorro de recursos energéticos implícito, sobre todo situándolos en la época en que fueron creados.

\section{Casas Loucher}

Más adelante Le Corbusier, quien reseñó estos modelos creados por Voisin en su L'Esprit Nouveau n² de 1920, plantea su proyecto de Casas Loucher, de fabricación/ construcción en serie, en el año 1928.

Aunque no se puede decir que sea una construcción ligera en su totalidad, estos modelos de viviendas estaban pensados para ser construidos con parte de sus cerramientos en material ligero, prefabricado e industrializado, es decir fabricados en un taller y llevados a la obra para su montaje inmediato. Los cerramientos verticales quedarían resueltos con paneles prefabricados, anclados a una estructura de perfiles de acero. Si bien se definen los cerramientos como prefabricados y ligeros (en algunos casos se sugiere madera y en otros zinc), estos quedan vagamente definidos en la documentación del proyecto.

Estos modelos, que no llegaron a ser construidos, serían un tipo viviendas adosadas que contarían con un muro medianero de mampostería que separaría una vivienda de la otra. La cubierta se plantearía plana, con paneles prefabricados y una capa de grava sobre éstos aunque no transitable.

Aunque en el proyecto, Le Corbusier, no hace ningún énfasis especial sobre sistemas o elementos constructivos que mejoren las prestaciones energéticas del mismo, sí que es cierto que de alguna manera intentaba siempre dotar a sus proyectos de un 
carácter de complicidad con su entorno y las características climáticas del lugar. En todo caso queda claro en sus propias palabras su inclinación hacia la industrialización:

“... ¿No se podrían fabricar casas? Este es un estado del espíritu muy acorde con la época [...]. La casa ya no será esa cosa pesada y que pretende desafiar los siglos, el objeto opulento por el cual se manifiesta la riqueza; será una herramienta, como lo es el auto..."

Haciendo un paréntesis en este recorrido histórico, varios años más tarde en 1963, en Zúrich Le Corbusier proyecta la Maison de l'Homme la cual se lleva a cabo después de su muerte. Esta galería y museo que originalmente sería concebida en hormigón completamente, y aunque sí conserva una base de hormigón, sería finalmente construida en metal y vidrio.

Se diseña con un concepto de cubierta-paraguas de chapa de acero, bajo la cual se emplazarían los módulos habitables con las medidas del Modulor y una adecuada escala humana. Igual que en el "Cabanon de Vacances" en este proyecto se desarrollaron unidades cúbicas de 2,26 por cada lado por ende de fácil organización y disposición en el lugar de construcción. El pabellón consta de dos plantas, una terraza y la cubierta principal. Aunque este obra se caracteriza por la gran singularidad de sus formas, lo cierto es que también se puede tomar como un ejemplo válido de prefabricación y posible industrialización del quehacer constructivo, pudiendo ser factibles de ser replicados y fabricados en serie los módulos estándar de vidrio y acero creados por el arquitecto.

\section{Casa Prefabricada de Stuttgart, Casa de Acero y la Copper House}

Volviendo al orden cronológico, otro ejemplo importante, que sirve como referencia a un tipo de construcción modular y ligera a la que querían acceder los grandes maestros como Walter Gropius, es el modelo denominado Casa Prefabricada de Stuttgart de 1927, (Fig. 7).

Dos viviendas proyectadas con motivo de la Exposición de la Vivienda (Werkbund Exhibition) de ese mismo año. Una depurada racionalización y modulación (cuadrícula de 1,06 $\mathrm{m}^{2}$ ), además de un novedoso sistema experimental de montaje, conferían a estos modelos las características de un producto industrial y prefabricado, que quedaba en evidencia no solo en su depurado diseño, sino también en el rápido proceso de montaje de aproximadamente tres meses.

Con una estructura de acero (esqueleto aporticado) y tabiquería en paneles de corcho, revestidos de mortero, las viviendas solo llevaban el suelo en hormigón como construcción pesada. El material de cerramiento era chapa de acero. 
Partiendo de que el lugar de emplazamiento de la vivienda se encontraba en una latitud de $48^{\circ}$ norte (Stuttgart, Alemania), con temperaturas medias mínimas en invierno de $9^{\circ}$ (climatedata.eu . 2015) el este tipo de aislamiento se presentaba, en principio, insuficiente.

Otro ejemplo a tomar en consideración por su origen y autoría, es la llamada Steel House o Casa del Acero de 1927. Construida por encargo del municipio de Dessau como parte del proyecto residencial Törten Estate. Sus autores Muche y Paulick (del entorno profesional de Gropius), pretendían conjugar el tema de la producción industrial (una construcción industrial, modular, ampliable), con un lenguaje arquitectónico acorde a las tendencias de diseño del momento y propias de la Bauhaus. La creación ex profeso de algunas piezas especiales para su construcción fue una de las causas disuasorias, entre otros temas, para que su producción en masa no fuera posible.

La vivienda, de unos $80 \mathrm{~m} 2$ y compuesta por dos volúmenes contiguos de diferentes alturas, estaba construida con placas de acero de $3 \mathrm{~mm}$ que se fijaban a una estructura de esqueleto, también de acero, con perfiles tipo $\mathrm{T}$, apoyada en una cimentación de hormigón. La composición del cerramiento vertical consistía en la placa de acero exterior citada, cámara de aire de $6 \mathrm{~cm}$, aislamiento térmico $2 \mathrm{~cm}$ (tipo torfoleum 0 turba prensada), paneles de viruta de $5 \mathrm{~cm}$ y de tablero de yeso laminado. La cubierta, más sencilla y estaba compuesta por madera y una lámina bituminosa como impermeabilizante.

Esta vivienda no resultó ser confortable, siendo más bien fría en invierno y caliente en verano, ni tampoco duradera, sufriendo desgaste y corrosión en sus elementos y cerramientos. Esta experiencia fue sensiblemente mejorada en el proyecto desarrollado por el propio Gropius en 1927 llamado Kleinhaus, que sustituía los paneles metálicos por paneles de amianto por el exterior, para evitar la corrosión y contrachapado de madera en lugar de yeso laminado. En la actualidad el amianto es un material nocivo para salud y está prohibido su uso.

Años más tarde, en 1931 Gropius proyecta las Copper Houses (Fig. 8), de las que se llegaron a construir más de 50 unidades en Stuttgart y en tres modelos diferentes: 50 $m^{2}+25 m^{2}$ exterior, $90 m^{2}+35 m^{2}$ exterior y $130 m^{2}+50 m^{2}$ exterior.

Como un encargo de la Hirsch Kupfer de Berlín (empresa dedicada al cobre y al latón) Gropius plantea una vivienda de fácil montaje y con posibilidades de aplicación lo que le valió su participación en la Exposición Das Wascsende Haus (La Casa Ampliable), organizada y realizada en Berlín, en 1932 por Martin Wagner.

Este modelo de vivienda, tal como su nombre indica, estaba compuesto por cerramientos de láminas de cobre (chapa acanalada) en su parte exterior y visible, que recubrían una especie de placas de asbesto-cemento (o amianto) que también quedaban recubiertas en la parte interior por chapas de aluminio nervadas. 
La vivienda, con estructura de madera, se fabricaba en una cadena de montaje de la que salían los paneles 2D totalmente listos - carpinterías incluidas - para su montaje en obra. La cubierta, con estructura de madera, llevaba también un tablero de madera y material aislante recubierto por el exterior de planchas de cobre. Un tablero de madera en su parte interior, también estaba recubierta de cobre.

A pesar de que no se ideó, ex profeso, ningún sistema de aprovechamiento energético para estas viviendas, las mismas contaban con un invernadero anexo para cultivos y jardinería; el mismo pudiera haber sido, quizás si hubiese sido el propósito, una especie de sistema de calefacción pasivo para la vivienda. Estos modelos fueron, de alguna manera, el resultado de exploraciones previas, hechas por Gropius y su entorno en años anteriores tales como la Kleinhaus o Casa Pequeña de 1927 o la Steel House.

\section{Dymaxion House}

Hacia 1927, en Estados Unidos, Richard Buckminster Fuller concibió la propuesta de su modelo teórico Dymaxion (Fig. 9), un prototipo de vivienda que no se ejecutó como tal y con el que pretendía desarrollar valores relacionados a los procesos industrializados. La palabra Dymaxion fue creado mediante la combinación de partes de las palabras "dinámica" (DY), "máximo" (MAX), y "tensión" (ION).

La casa Dymaxion de planta hexagonal y cerramientos de aluminio contaba con un elemento estructural central, a modo de mástil, que sostenía con cables radiales todo el edificio. El proyecto tenía dos dormitorios, dos baños, una sala de estar, comedor, cocina, área de almacenaje, cocina y estantes giratorios adaptables de acuerdo al uso diario de la vivienda.

De acuerdo al proyecto, la temperatura interior de la vivienda, podría ser regulada moviendo la sección superior de la casa arriba o hacia abajo. En posición abierta los flujos de aire a través de la casa enfriarían con una especie de efecto chimenea o sistema de presión; en posición cerrada, la vivienda quedaría aislada conservando el calor interior.

El peso estimado total para dicho proyecto, fácilmente desmontable y transportable, sería de $2.721 \mathrm{~kg}$. Décadas después Buckminster Fuller continúa este proceso iniciado con la Dymaxion, desarrollando la Casa Wichita, que es analizada más adelante en este trabajo. (The R. Buckminster Fuller Digital Collection, Stanford University, 2015).

\section{Casa Aluminaire y Casa Von Sternberg}

Otros ejemplos destacables de CLI en la tercera década del siglo XX fueron la Casa Aluminaire (1931) de Albert Frey y la Casa Von Sternberg de Richard Neutra de 1935, 
ambas en Estados Unidos, que al igual que Europa presentaba ejemplos incipientes de una arquitectura que buscaba optimizar los procesos constructivos de la mano de la industrialización y la producción en serie. (Ovando Vacarezza, 2015). Albert Frey que había colaborado con Le Corbusier en Paris, la presenta en la exposición Allied Arts and Building Products, organizada en el marco de la $45^{\circ}$ exposición de la Architectural League en Nueva York en 1931.

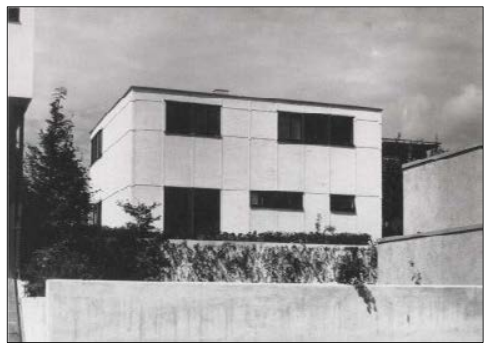

Fig. 7. Casa Prefab. Stuttgart 1927. Walter Gropius (proyectos4etsa.files. wordpress.com; 2015)

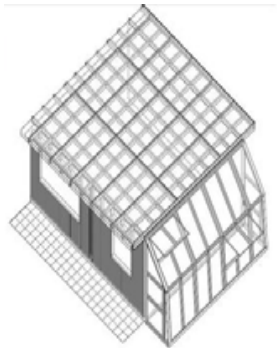

Fig. 8. Copper Houses de 1931. W. Gropius proyectos4etsa.files.wor dpress.com; 2014)

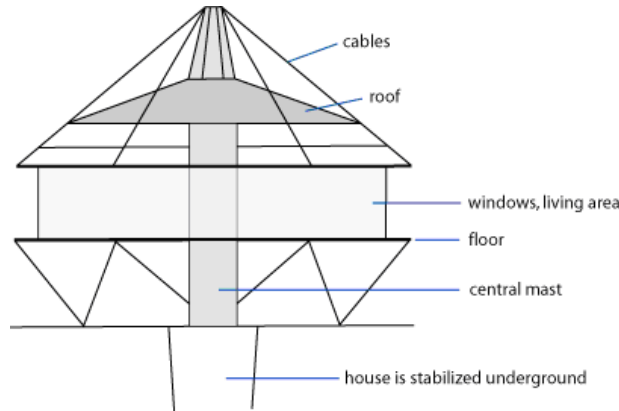

Fig. 9. Dymaxion House 1927. R. Buckminster Fuller. (R. Buckminster Fuller Digital Collection, Stanford University; 2015)

Los materiales predominantes eran el aluminio, el acero y el vidrio. La piel del edificio estaba compuesta por paneles de chapa de aluminio ondulado sobre aislamiento térmico.

Su primer emplazamiento fue en el Grand Central Palace de Nueva York, luego fue vendida y vuelta a ensamblar en Syosset en Long Island, estado de Nueva York, Estados Unidos.

La casa Von Sternberg de Richard Neutra de 1935, estaba construida con paneles tipo Robertson de chapa plegada tanto en cerramientos verticales como la cubierta. Dicha vivienda fue demolida a principio de los 70 (1971) quedando sólo las imágenes y documentación técnica.

\section{Club Roland Garros}

También en 1935 se llevó a cabo un proyecto emblemático de la construcción prefabricada desarrollado por Jean Prouvé, el Club de Aviadores Roland Garros considerado como una especie de manifiesto de la industrialización (Cobbers, 2010).

La totalidad del edificio se fabricó a partir de un armazón de perfiles plegados con chapa de $4 \mathrm{~mm}$ de espesor sujeto con uniones atornilladas. Como fallo se registra el movimiento térmico de las los paneles de fachada metálica que en invierno se retraían y en verano se dilataban sometiendo a las juntas y uniones a una gran tensión.

En cuanto a la impermeabilización, la misma se resolvió mediante bandas de betún ajustadas entre las uniones de la chapas. 


\section{Dymaxion Dwelling Unit}

La idea de la Dymaxion Deployment Unit (Fig. 10), anteriormente mencionada, surge por un viaje por carretera, a través de la América rural de 1940, realizado por su autor Richard Buckminster Fuller, que viendo los silos de grano de acero integrados en aquel paisaje propone una solución habitacional ligera, asequible y de fabricación en serie tanto para uso militar como para vivienda civil de bajo coste.

Para este nuevo emprendimiento Buckminster Fuller se asocia al propio fabricante de este tipo de silos la Butler Manufacturing Company. Así nació la Dymaxion Dwelling Unit (DDU) en 1941. (Buckminster Fuller Institute, 2015).

Las DDUs basadas en una interpretación del autor del concepto Dymaxion House de 1927 y utilizadas por el ejército americano en escenarios como Pearl Harbour, tenían paredes circulares, techo de metal en forma de cúpula y contaban con un ventilador/extractor en el vértice central para la extracción del aire caliente hacia fuera del edificio y asociado con un efecto de captación de aire fresco desde el suelo del edificio. (Camp Evans Home of Infoage, 2015).

\section{Casas de la TVA}

Un claro ejemplo de CML (módulos para ensamblar formados por secciones múltiples) (Ovando Vacarezza, 2015), fueron las casas de la TVA (Tennessee Valley Authority) a principios de los años 30 (1934), en el contexto de La Gran Depresión del 29, (Fig. 11).

Estas viviendas diseñadas por un equipo de arquitectos, dirigidos por Louis Grandgent y Carroll A. Town, sirvieron de alojamiento para el personal de la citada compañía eléctrica (parte del New Deal), en sus planes de expansión en esa zona de Estados Unidos.

Los módulos secciones múltiples se fabricaban de manera que pudieran ser fácilmente transportables (incorporaban ruedas que luego se retiraban) hacia los lugares de trabajo de la empresa (construcción de presas e hidroeléctricas) cosa que no era posible con los modelos de viviendas Norris, de construcción en madera que le antecedieron, y aunque se reconocía que las Norris tenían una proyección de vida más duradera que las casas modulares, para los fines de la empresa, era preferible la movilidad a la durabilidad.

Las casas TVA (Truckable Houses) estaban fabricadas de madera y tableros de fibra resistente a la intemperie y tanto el suelo como el techo estaban realizados con madera contrachapada. 
Cada sección de la vivienda era 2,10 m de largo por 2,70 de ancho y con un peso de $3,000 \mathrm{~kg}$. Como medida de eficiencia ya incorporaban de fábrica los sistemas de agua potable, saneamiento y electricidad.

\section{Packaged House System}

Ya para 1943/1945, junto con Konrad Wachsmann, y dentro de lo que sería la General Panel Corporation, Gropius lleva a cabo el Packaged House System (Fig. 12), que era un sistema de construcción a base de paneles prefabricados, apoyados en módulos intercambiables y combinables.

Con este sistema Gropius aspiraba a dotar de versatilidad el quehacer constructivo, aunque no tuvieron la aceptación que se esperaba por parte del público, ni contaron nunca con un sistema de piezas estandarizado como el mercado ameritaba, siendo incluso complicado montar otros tipos de carpinterías exteriores diferentes a las propias y con dimensiones genéricas.

Por otro lado, Gropius daba especial valor al tema de la fácil movilidad hacia el lugar de destino y el posterior emplazamiento de la casa en su parcela, de acuerdo a las condiciones climáticas y de entorno.

Estos dos últimos factores sería su aproximación al tema de la eficiencia energética toda vez que en ambos casos la repercusión sería directa en cuanto al ahorro de recursos económicos y energéticos.

La solución constructiva estaba basada en paneles de madera para paredes, suelo y techos. La modulación de los paneles permitía su fácil combinación y flexibilidad en cuanto a la dirección en que se instalaban, ya fuera horizontalmente como de manera vertical, gracias a su versátil sistema de uniones; pudiendo construir diferentes tipos de viviendas con partes y piezas estándar, de fácil ensamblaje y dejando la opción, a que de manera modular, se siguieran agregando espacios a la vivienda según fuera el caso, tanto hacia arriba como hacia abajo. En sentido general Walter Gropius tenía como idea de primer orden, en su concepción de una construcción industrializada, que la modulación sería la clave para poder estandarizar los procesos de fabricación y el resultado de los componentes, y que esto serviría para que este tipo de arquitectura cumpliera el objetivo de rapidez, optimización de costes/recursos y de flexibilidad en el diseño.

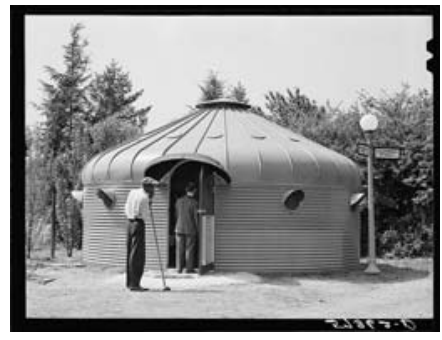

Fig. 10. Dymaxion Dwelling Unit, 1941. Richard Buckminster Fuller (.nytimes.com; 2013)

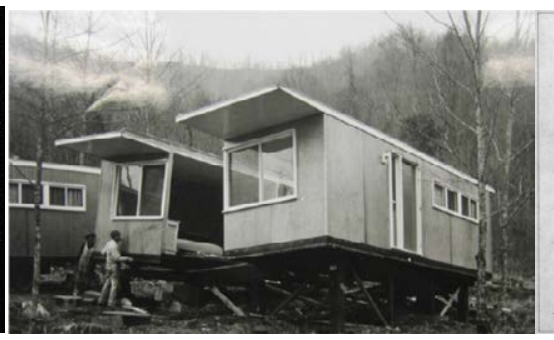

Fig. 11. TVA Truckable Houses, 1934. (Ovando Vacarezza, 2015)

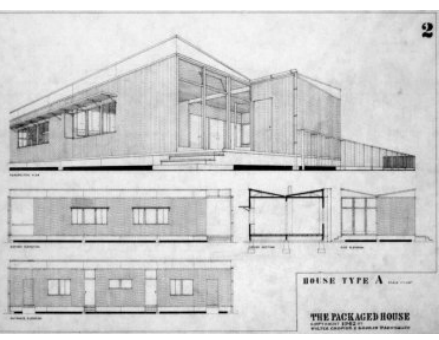

Fig. 12. Packaged House System 1943. W. Gropius (.lib.ncsu.edu; 2014) 


\section{Casa Lustron}

Pasada la II Guerra Mundial en 1947 en los Estados Unidos se fomentó la construcción de viviendas prefabricadas para resolver un tema habitacional que se relacionaba mucho al proceso de reactivación de la economía americana y el regreso de un gran número de veteranos de guerra.

Muchos de los proyectos antes señalados eran parte de este movimiento de dotar de viviendas de rápida construcción y precios accesibles al mercado postguerra. De todos estos proyectos sin duda las Casas Lustron de Carl Strandlund, fueron las que tuvieron mayor y mejor nivel de comercialización (Fig. 13).

Las casas estaban compuestas por más de 3.000 piezas que se montaban en unos 15 días con una estructura de marcos de acero y los muros y techo de paneles de acero esmaltados de porcelana, fijados entre sí mediante juntas plásticas para impedir el paso del aire o la lluvia.

Las casas Lustron estaban bien aisladas para su tiempo, pero desde el punto de vista de los estándares este aislamiento resultaría insuficiente ya que estaba compuesto por aislamiento (insowall) y fibras naturales dentro de los propios paneles de cerramiento.

Las casas Lustron contaban originalmente con un sistema de calefacción híbrido que combinaba el aire caliente como fuente de calor y la distribución por un sistema radiante (Fig. 14). Este sistema se componía de tres partes: un horno a gas, suspendido en el techo de la sala de máquinas, la cámara de sobrepresión situada en el espacio entre las cerchas de techo y el techo y un ventilador para provocar el movimiento del aire desde el horno y a través de las cámaras de distribución.

El principio de funcionamiento del sistema original se basaba en el aire caliente que se hacía circular continuamente con un ventilador centrífugo a través de una estrecha cámara de sobrepresión, o lo que es lo mismo, un sistema de conductos estrecho situado entre el techo y las vigas del techo.

El aire era calentado a $140^{\circ} \mathrm{F}$ por un horno de aceite o gas que producía $75.000 \mathrm{Btu}$ por hora para una temperatura media de $105^{\circ} \mathrm{F}$ en el techo. Un ventilador movía el aire caliente desde el horno en dos conductos de suministro en la cámara de sobrepresión, donde se calentaban los paneles de techo de metal/porcelana esmaltados.

Esto hacía que el calor se irradiara hacia abajo desde el techo a la casa. Al mismo tiempo se extendía el calor por entre los tabiques y paredes evitando la formación de condensaciones y proporcionando un calor uniforme. (ohiohistory.org; 2015). 


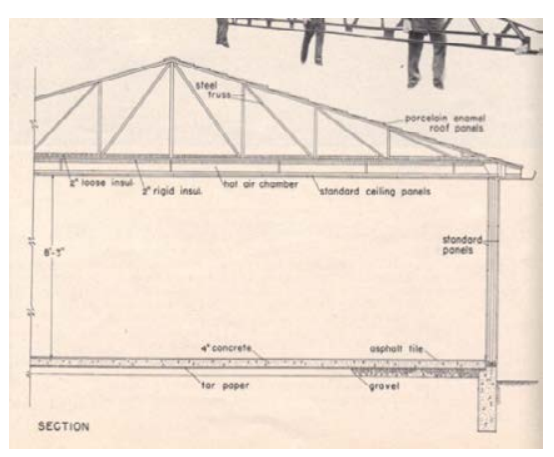

Fig. 13. Vista sección Casas Lustron, 1947. Carl Strandlund (ohiohistory.org; 2015).

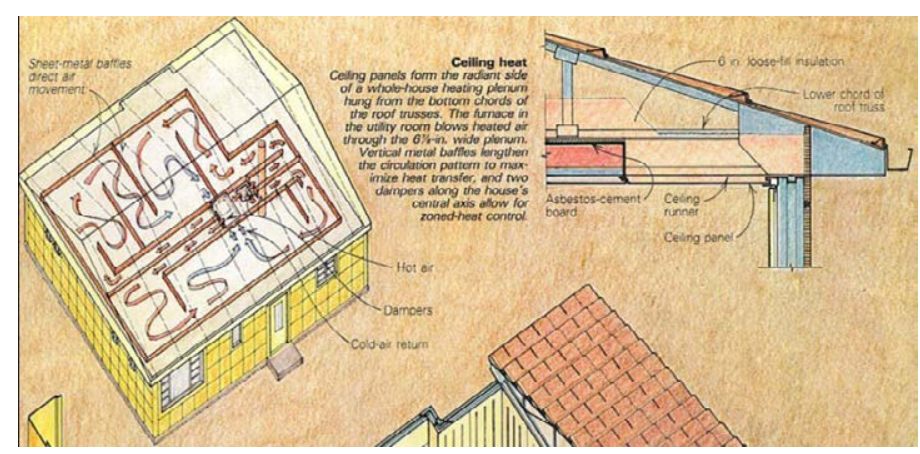

Fig. 14. Esquema sistema de calefacción Casas Lustron, 1947. Carl Strandlund (ohiohistory.org; 2015).

\section{Case Study Houses (CSH)}

En este recorrido histórico por algunos de los principales ejemplos de arquitectura industrializada y/o prefabricada cabe destacar los proyectos que se realizaron dentro del programa Case Study Houses, entre 1945 y 1966 (Los Ángeles, EE. UU), promovido por John Entenza y la revista Arts \& Architecture en el escenario de la posguerra.

Grandes arquitectos y diseñadores como Charles Eames, Richard Neutra, Pierre Koening, entre otros, realizaron algunos de los diseños que pretendían responder a la demanda de vivienda óptima, con materiales industrializados y asequibles - en principio - para la clase media de los Estados Unidos, posterior a la Segunda Guerra Mundial. Con estas viviendas (28 proyectadas pero 9 de ellas no construidas), se consiguió un importante avance en la cultura de la industrialización de la construcción, por el uso de estructuras metálicas, cubiertas planas, cerramientos con paneles modulares y grandes superficies con paneles de vidrio. (Kettenmann, 2014)

\section{CSH 4. Greenbelt}

Aun cuando no fue construida, uno de los ejemplos más claros del espíritu de una arquitectura aliada a nuevos sistemas constructivos industrializados y/o prefabricados fue la CHS (Case Study House) no 4 de Ralph Rapson proyectada en 1945 (Fig. 15).

El proyecto de unos $167 \mathrm{~m} 2$ integraba dos bloques (uno de uso privado y otro social) al entorno natural que unía y de ahí el nombre de Greenbelt con el que se conoce al proyecto. 
Rapson ideó un sistema constructivo prefabricado, compuesto por tableros modulares de contrachapados de madera y cemesto (fibra de caña de azúcar tablero aislante con asbesto y cemento) y vidrio con trama inferior de madera o acero. Como particularidad se proyectaba un tipo de suelo radiante para calefacción y un posible sistema de apoyo para la calefacción por aire circulante por conductos de material cerámico. El espíritu Greenbelt se mantiene al día de hoy a través de la firma Wieler que comercializa modelos inspirados en el original de Rapson. (Kettenmann, 2014)

\section{CSH 6. Omega}

Otro proyecto no construido, pero que merece especial atención por sus líneas maestras en pro de la industrialización e incluso la prefabricación ligera y desde luego las técnicas bioclimáticas de acondicionamiento es la $\mathrm{CSH} \mathrm{n}^{\circ} 6$ del maestro Richard Neutra de 1945 (Fig. 16).

Más allá de una ingeniosa propuesta, de mezcla entre materiales y técnicas tradicionales de construcción con elementos prefabricados ligeros, queda como testimonio documental la intención de dotar a la vivienda, gracias a sus técnicas pasivas de diseño, de sistemas de aprovechamiento para la refrigeración/ventilación interior.

Este sistema combinaba la simplicidad formal del diseño de los tabiques, que delimitan los espacios interiores permitiendo una adecuada circulación del aire, así como de la cubierta, tanto por su inclinación como por sus acabados reflectantes (gravilla blanca) que ayudarían para evitar el sobrecalentamiento de las mismas (con revestimiento de madera interior) e incluso la ventilación natural, mediante aberturas este-oeste.

Para este proyecto, Richard Neutra diseñó un tipo de fachada con cámara ventilada, que se formaba instalando perfiles omega y paneles, los cuales sujetarían la chapa, creando una "cámara de aire caliente" que la aclimataría. Esto serviría tanto para verano como para invierno, manipulando unas aberturas en la parte superior e inferior de los paneles por donde circularía el aire. (Smith y Gössel, 2013)

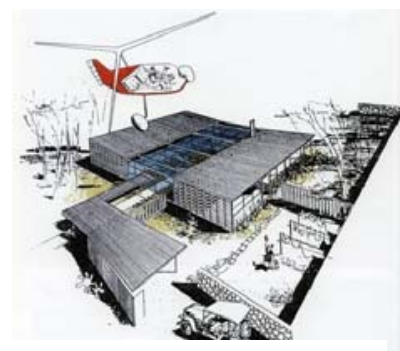

Fig. 15. CSH 4 _Greenbelt House 1945. R.Rapson (worksdifferent.com; 2015)

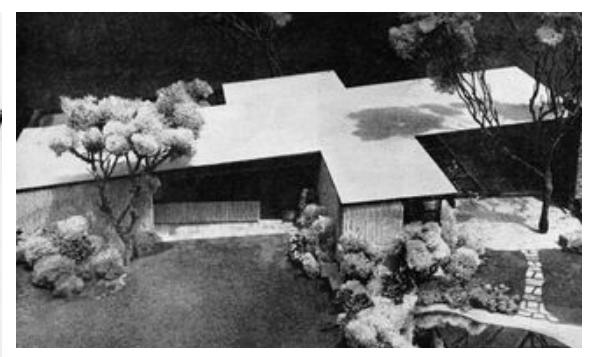

Fig. 16. CSH6. Omega House 1945. Richard Neutra. (Arts and Architecture.2015.)

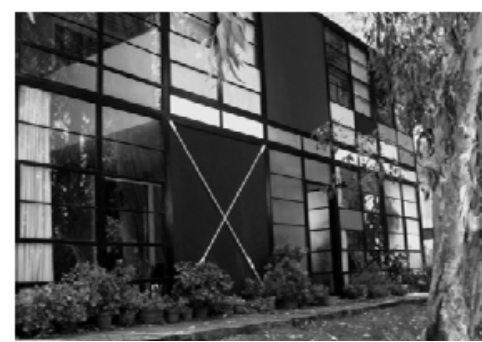

Fig. 17. CHS 8 Eames House, 1949. Charles Eames. (worksdifferent.com; 2015) 
Uno de los ejemplos más representativos de este programa es la CSH no 8 de Charles Eames de 1949 en Pacific Palisades, California (Fig. 17).

A parte de ser un icono en cuanto a diseño se refiere, es un buen caso de estudio desde el punto de vista de la construcción industrializada y/o prefabricada.

La casa que consta de dos volúmenes unidos por un patio, está construida de manera modular y con elementos prefabricados tanto en sus cerramientos verticales (cuyas partes opacas están hechos en contrachapado y cemesto y en vidrio para sus partes translúcidas), como en su cubierta plana (de láminas metálicas con gravilla blanca reflectante) y su sistema estructural metálico.

La casa, emplazada en el eje norte-sur, con su característica fachada combinada (paneles translúcidos y opacos) hacia el este, es una ilustración de las posibilidades de los métodos y materiales de construcción que serían aplicados más adelante en la construcción industrializada y el diseño. La fachada oeste se encuentra parcialmente cubierta por el terreno lo que le confiere a la misma la inercia de éste con los beneficios que esto supone a nivel de transmitancias térmicas. En términos prácticos esto mantiene una temperatura estable durante todo el año y equilibra el intercambio de temperatura con esta parte de la vivienda, tanto para condiciones de verano como de invierno.

El conjunto, que está edificado completamente con elementos industriales prefabricados (acero, vidrio y sistemas modulares de paneles de Cemesto o lo que es lo mismo fibra de caña de azúcar con tablero aislante con asbesto y cemento) (Kettenmann, 2014)

\section{CSH 9. Etenza House}

A la Case Study House no9 (1949) diseñada por Charles Eames y Eero Saarinen, emplazada en Pacific Palisades, Los Ángeles, California, para el promotor de CSH y editor de la revista Arts \& Architecture, John Entenza (Fig. 18), se le considera la continuación de los conceptos constructivos de la CSH 8.

Con el diseño de esta vivienda de pretendía conseguir diafanidad pero a la vez la versatilidad suficiente como para que su interiorismo fue flexible.

Para resolver la estructura de la vivienda sin alterar el objetivo de la diafanidad, se colocaron cuatro columnas de acero en el centro con un sistema de arriostramiento que permitiera transmitir la carga a la viga perimetral y dejar una carga uniforme para los elementos estructurales interiores. Esta estructura de acero carga un forjado pesado de hormigón. 
El vidrio y la madera (en los revestimientos interiores) cobran protagonismo en todo el proyecto. Estos paneles acristalados permiten una interacción con el exterior propia del espíritu de las CSH. (Kettenmann, 2014).

La vivienda integraba sistemas de ventilación en el techo (mediante difusores Air Factor) además de un sistema mecánico de aire forzado para la calefacción.
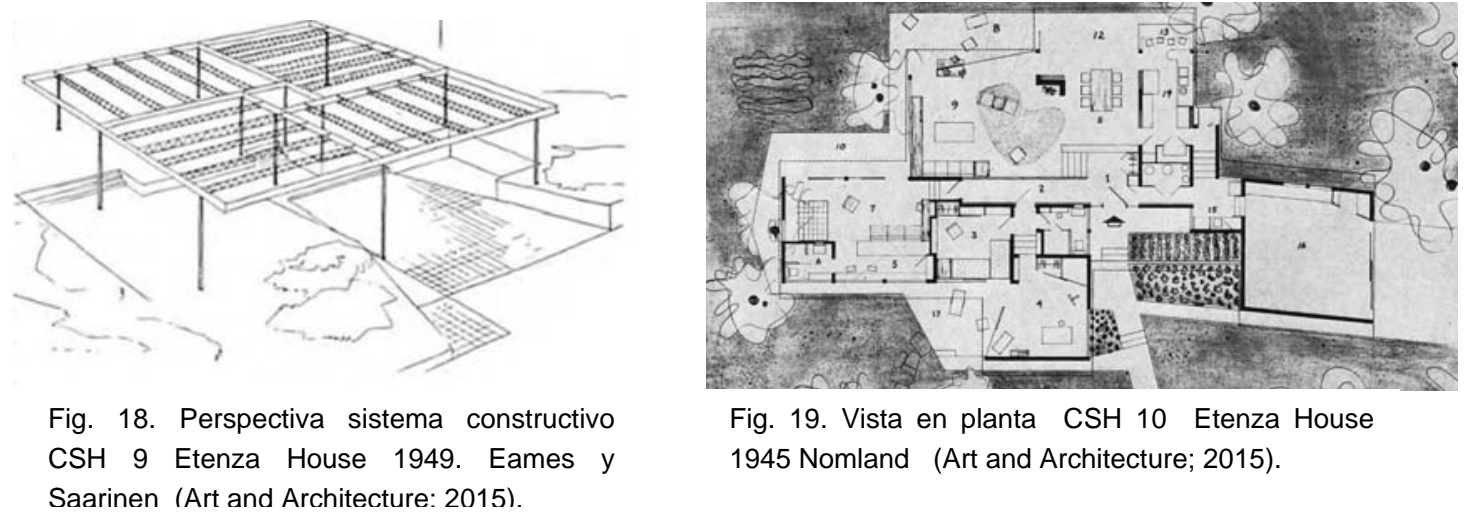

Fig. 19. Vista en planta CSH 10 Etenza House 1945 Nomland (Art and Architecture; 2015).

\section{$\mathrm{CSH} 10$}

Para el diseño de esta vivienda de Kemper Nomland (1945), ubicada en Pasadena, California, la orografía fue un factor determinante para definir su propia morfología. De esta manera varios espacios de la casa se ubicaron siguiendo la forma del terreno y confiriendo a la casa una cierta integración volumétrica con el entorno (Fig. 19).

Las transparencias, presentes en gran parte de la vivienda, mediante paneles de vidrio, permiten una interacción mayor con la naturaleza circundante acentuando la relación volumétrica con el terreno.

Un factor destacable es el sistema de calefacción por suelo radiante con que cuenta la casa que permite calentar de manera más homogénea los ambientes.

El sistema constructivo se basa precisamente, en un marco de postes y vigas de madera, así como cerramientos de madera, sobre una losa de hormigón que incorpora el suelo radiante, que permite grandes paneles de cristal. (Smith y Gössel, 2013) Los cerramientos opacos están conformados por tipos de madera de caoba o abedul.

\section{CSH16. Salzman House}

Las casa de Craig Ellwood en Los Angeles, California, conocida como Casa Salzman de 1952 (Fig. 20), fue en cierta medida el inicio de un proceso de experimentación por parte del autor en cuanto a arquitectura habitacional se refería. Esta vivienda, que siendo aún muy racional tiene un interesante juego de texturas y acabados, fue la primera de los tres proyectos con los que el arquitecto participó en el CSH. Las 
divisiones interiores estaban hechas de bastidores de acero visto que dan al espacio interior una interesante sensación de levedad combinada con la masividad del ladrillo. Esta combinación de arquitectura masiva con elementos industrializables confieren a la casa un estilo atemporal que sigue resultando atractivo a más de 50 años de su concepción.

Como en muchos otros casos de las $\mathrm{CSH}$ el hormigón resulta ser el elemento pesado presente, en un tipo de construcción que combina materiales como el acero, madera y el vidrio. También la casa contaba con varios muros de ladrillo interiores un muro de ladrillo exterior que conformaba la fachada sur. (AA.VV. Art and Architecture 1952).

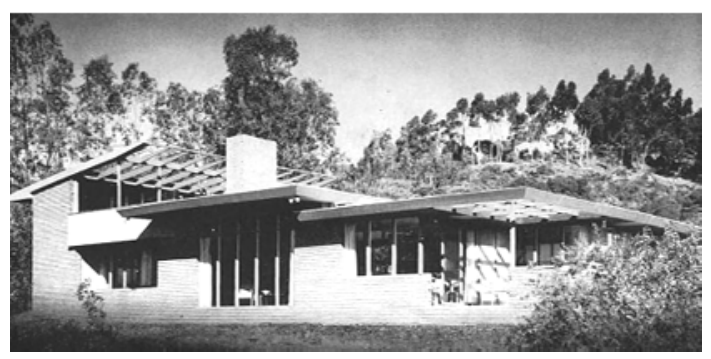

Fig. 20. CSH 16 Salzman House, 1952, Eames y Saarinen. (Art and Architecture; 2015).

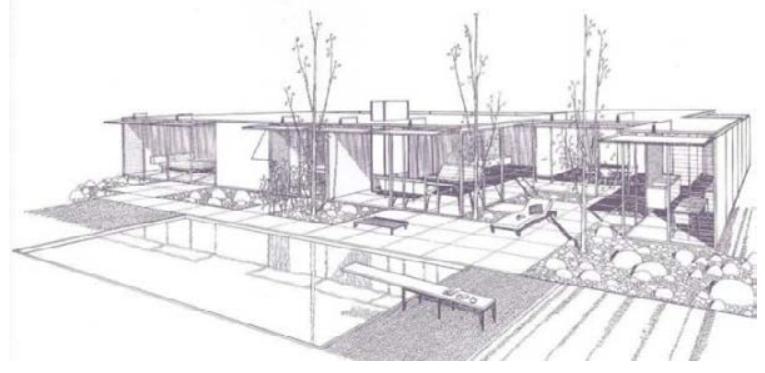

Fig. 21. Perspectiva CSH 18 Fields House, 1958, C. Ellwood. (Art and Architecture; 2015).

Esta construcción se levanta sobre una solera de hormigón desde la que se proyectan los pilares de acero que conforman, predominantemente, la estructura de la casa y soportan la cubierta de la misma.

Incorpora además un sistema de calefacción radiante por circulación de agua que combinado con superficies opacas y otras reflectantes climatizan los ambientes interiores activos. El combustible tanto para este sistema como para el de A.C.S. es el gas e incorpora un sistema de encendido automático con termostatos para optimizar los rendimientos. (AA.VV. Art and Architecture, 1952).

La iluminación natural es uno de los aspectos relevantes de la vivienda incluso incorporando superficies translúcidas, con propiedades termo absorbentes, en parte de la cubierta (en la parte del vestíbulo o logia).

\section{CSH 18. Fields House}

La Case Study $\mathrm{n}^{\circ}$ 18, o casa Fields (1956) (Fig. 21), de Craig Ellwood integra elementos prefabricados en el diseño y la construcción de manera más depurada que sus anteriores proyectos. La planta rectangular distribuye los dormitorios hacia la parte suroeste de la vivienda, dejando las zonas sociales hacia el centro. Hacia el este se disponen los espacios utilitarios como la cocina y área de desayuno y comedor. El intercambio visual con el exterior se produce hacia la cara sur, gracias a los 
cerramientos acristalados; también hacia esta parte se ubica la terraza y la piscina. Sin embargo y de acuerdo a Elizabeth A.T. Smith en su libro Case Study Houses; The Complete CSH Program 1945-1966 (Tachen, 2009), a pesar de su esqueleto en acero prefabricado y su sistema de paneles de cerramiento exterior, no se llega a conseguir una integración de materiales industriales del todo armónica.

Por otro lado, por la propia ubicación de la casa, junto al lecho de un río, se debió reforzar parte de su estructura para evitar derrumbes y desplazamientos del terreno, siendo esto un desafío añadido al proyecto.

El sistema general de estructura de la casa se basa en módulos de 2,5 m: columnas tubulares cuadradas de acero y vigas tubulares rectangulares de acero. Esta había sido la primera vez que se utilizaban tubos rectangulares de acero como vigas y probablemente la primera aplicación de una estructura modular de acero de manera prefabricada.

Los paneles de cerramiento de la casa son prefabricados y recubiertos de Harborite, un contrachapado de pino de Douglas marino, endurecido con un revestimiento de resina que garantiza una superficie lisa y dura y aislamiento de lana mineral o Celotex (Polysocianurato, también referido como PIR).

La cubierta está formada por paneles de acero Fenestra Holorib (tipo de chapa grecada) con aislamiento de Celotex, pre-sellado con un acabado con tejas tipo Pabco de fibra de vidrio. (AA.VV. Art and Architecture, 1952).

Se utilizó un sistema experimental de calefacción que consistía en un conducto de metal que captaba el calor de las cristaleras del sur y se conducía por las propias vigas hasta la parte norte.

Este sistema estaba aplica solo a la parte social de la casa quedando los dormitorios bajo un sistema de acondicionamiento convencional.

\section{CSH 20.}

La casa de planta rectangular y perfil bajo (1947) de la autoría de Richard Neutra, estaba fundamentalmente proyectada en vidrio, acero y madera (Fig. 22). La vivienda se desarrolla alrededor de un núcleo utilitario prefabricado, una unidad de sistemas que incluía las instalaciones de fontanería y de calefacción central. (AA.VV. Art and Architecture 1947).

Todas las habitaciones -sobre todo cocina y cuarto de baño- dependen de estas instalaciones y de disponen de manera adyacente a la misma. La casa, compacta, poseía poco más de $120 \mathrm{~m}^{2}$ llegando a conseguir más de $150 \mathrm{~m}^{2}$ más, con los futuros 
anexos que se realizarían. El arquitecto concibió espacios flexibles, recurriendo al esquema de casa de cuatro patios.

En toda la casa se ha utilizado una gran cantidad de madera natural, de grano, color y barniz variados, lo que permite reducir los costes de re-decoración. En las habitaciones se han utilizado dos tipos de madera, caoba y olmo claro.

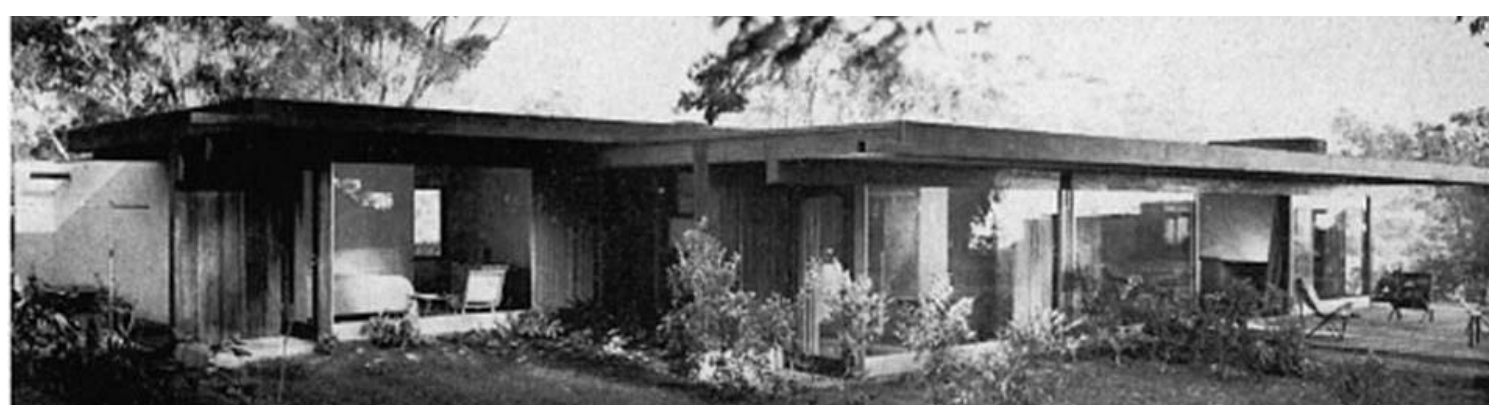

Fig. 22. CSH 20 , 1947, Richard Neutra. (Art and Architecture; 2015).

Se utilizó un sistema experimental de calefacción que consistía en un conducto de metal que captaba el calor de las cristaleras del sur y se conducía por las propias vigas hasta la parte norte.

Este sistema estaba aplicado solo a la parte social de la casa quedando los dormitorios bajo un sistema de acondicionamiento convencional.

\section{CSH 21.}

La casa CSH no21 (1956) fue diseñada por Pierre Koening y representa el resumen de las técnicas (ligereza, durabilidad, producción en serie, confort) que este arquitecto venía estudiando y trabajando durante los años 50 (Fig. 24).

La vivienda se sitúa en el eje Este-Oeste de la parcela U con cerramientos opacos en estas caras), dejando las vistas hacia el sur, mediante superficies de cerramiento vertical acristaladas.

La planta se organiza a partir de una isla central de baño-patio-baño, que sirve para dividir los espacios sociales y de descanso. Se simplifican los muros de cerramiento exterior (de paneles sándwich metálicos o acristalados y practicables) al no disponer los cuartos húmedos adyacentes a estos.

El diseño de la estructura constituye la clave del proyecto. Se compone de módulos, dispuestos en un rectángulo de $3 \times 2$, y otros tres módulos alineados. 


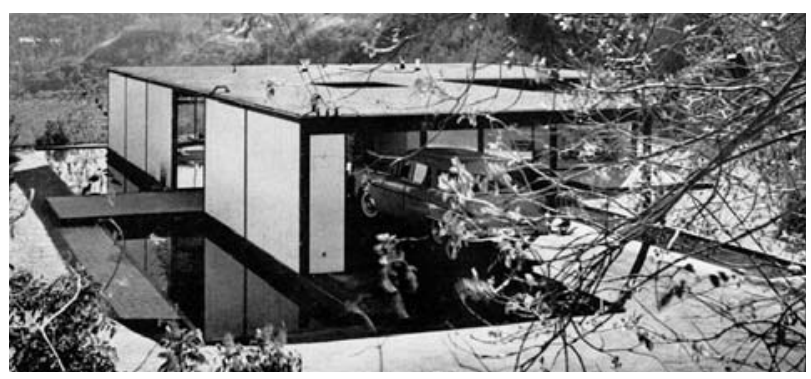

Fig. 23. CSH 21 Pierre Koening. (Art and Architecture; 2015).

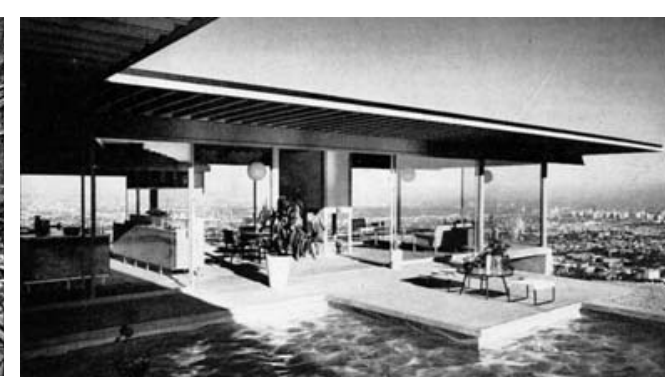

Fig. 24. CSH 22 Stahl House, 1947, Richard Neutra. (Art and Architecture; 2015).

El conjunto forma una $L$ con los espacios interiores y el porche (patio de acceso y la cochera). La casa se distribuye en un pabellón principal con los espacios cubiertos, y de otros espacios habitables, con diferente grado de protección. El porche, con un hueco central, se considera un espacio exterior pero cubierto en gran parte. En una zona del porche, se incorporan armarios con las instalaciones. Cuenta con un sistema de bombas hidráulicas que pone en movimiento el agua del estanque que se sitúa junto a la misma, para que esta circulación se convierta en un sistema de enfriamiento por efecto de la evaporación necesario para conseguir el confort interior en condiciones de verano.

Para condiciones de invierno se concibió la vivienda con grandes acristalamientos a Sur para aprovechar los beneficios de la captación directa. Estos cerramientos practicables también permitían la circulación del aire para provocar ventilación natural. Para evitar el sobrecalentamiento de los espacios se disponía de pantallas temporales de una malla tamizadora de luz en la fachada Sur.

\section{CSH 22. Stahl House}

Con el objetivo de lograr una vista despejada de 270 grados se emplaza la vivienda conocida como la Stahl House (1960), en la parte alta de Sunset Boulevard.

Para obtener estas vistas la casa no solo cuenta con un cerramiento acristalado en forma de $\mathrm{L}$ sino que la propia morfología (en ángulo de 90 grados), de la misma, se plantea hacia el lado suroeste permitiendo la captación solar directa.

En esta parte suroeste de la casa también se ubica la piscina que por encontrarse adyacente a la propia vivienda tiene una función alternativa de equilibrar las temperaturas en verano mediante el enfriamiento evaporativo.

En esta planta en forma de $L$ con unos $213 \mathrm{~m} 2$, los dormitorios se ubican en un ala y las zonas comunes en la otra siendo unidos, en la intersección, por los baños. (Smith; 2009). La transparencia de las paredes acristaladas se resalta con la planta diáfana y 
el juego con los paneles opacos - de acero hacia el exterior, aislamiento de fibra de vidrio y placas de yeso como acabado interior- y la propia cubierta de paneles de plancha metálica con $6 \mathrm{~cm}$ de fibra de vidrio de aislamiento. El suelo de la casa está compuesto por una losa de hormigón.

Como sistemas de calefacción la vivienda cuenta con una chimenea que al mismo tiempo sirve como elemento estructural y un sistema de calefacción radiante que climatiza toda la vivienda.

\subsubsection{Aproximación a Principios Bioclimáticos aplicados a la CIL y la CML.}

Varios de los ejemplos anteriormente citados, entre otros, más que marcar hitos y tendencias en este tipo de construcción- permiten hacer un estudio analítico sobre el tema energético y el confort de los usuarios. No siendo la eficiencia energética el objetivo primario de estos ejemplos, en cualquier caso sirven como paradigmas de un proceso evolutivo de optimización del quehacer constructivo.

En cualquier caso y aun no siendo el ahorro energético o la eficiencia energética, objetivos primordiales e históricamente planteados por la arquitectura industrializada, prefabricada, modular o modular ligera, sí que es cierto que en algunos de estos ejemplos encontramos puntos de origen para un desarrollo futuro en esta línea. En tal sentido, se destacan dos ejemplos que sirven para reforzar el estudio de una arquitectura ligera e industrializada asociada a principios bioclimáticos como antesala de la eficiencia energética: Las Casas Tropicales de Jean Prouvé y la Casa Wichita de Richard Buckminster Fuller.

Ambos arquitectos, prácticamente contemporáneos (Jean Prouvé, 1901 y Richard Buckminster Fuller, 1895), plantearon objetivos parecidos en sus carreras profesionales, incluso tomando, en muchos aspectos, fuentes referenciales parecidas (la industria del automóvil, la aeronáutica); intentaron dotar al oficio de las ventajas que ya estaban más que comprobadas en estos campos de la ciencia y la tecnología sobre todo el tema de la optimización de los sistemas de cerramiento y la producción en serie.

Es en torno a esta propuesta de materiales, que hasta el momento no habían sido utilizados en la construcción a un nivel protagónico, y la aplicación de estrategias de diseño y soluciones bioclimáticas que ambos profesionales establecen una línea de acción proyectiva que les conduce a los proyectos objeto de análisis en esta tesis.

Los escenarios de postguerra (tanto en América como en Europa) sirvieron de motivación para realizar propuestas habitacionales, que optimizando materiales y tecnologías, sirvieran a una sociedad global que retornaba a la paz, con todas las necesidades propias del momento ( $\mathrm{y}$ del mercado) histórico, combinadas con una industria que retornaba del servicio militar pero con toda su maquinaria operativa. 
Para un análisis correcto de los conceptos manejados en las Casas Tropicales conviene tomar como referencia de análisis y contexto la obra del autor.

Jean Prouvé nace en París en el año 1901 y se forma como arquitecto en la propia práctica del oficio. Se inicia profesionalmente como herrero desde los 18 años cuando entra como aprendiz en un taller en Enghien, Francia.

Muy pronto Prouvé hace su propio camino y comienza a recibir encargos para trabajos de herrería en su natal Nancy. Dado su destacado trabajo, entra en contacto con el maestro Le Corbusier y por iniciativa de éste mismo, entra a formar parte de uno de los más destacados gremios de diseñadores y arquitectos de la época, que era la Unión de Artistas Modernos.

De este grupo no solo formaba parte el propio Le Corbusier, sino arquitectos y diseñadores como Pierre Jeanneret, Pierre Chareau, Robert Mallet-Stevens o Charlotte Perriand.

Prouvé comenzó a destacar por sus innovadores diseños de mobiliarios, muchos de los cuales llegan hasta nuestros días en reediciones actualizadas y comercializadas por altas casas de diseño, tal es el caso de su famosa mesa Guéridon diseñada para la Universidad de París.

El taller que mantenía abierto pasó a convertirse en fábrica en 1947 creando diseños hasta 1953 en que cierra sus puertas.

Colaboró durante años con diferentes arquitectos de la época quienes conociendo su gran desempeño en el área del diseño en hierro y acero lo invitaban a participar como consultor o proveedor de productos y/o servicios, en las obras que éstos desarrollaban. Henri Prouvé, su hermano y arquitecto de formación académica fue sin duda su más cercano colaborador.

Prouvé llevó a cabo una labor propia de investigación y ejerció como proyectista quedando como grandes ejemplos de la historia proyectos tales como La Casa del Pueblo, (1939); La Casa del Sahara, (1939); Las Casas aporticadas (1947); La Casa Meudon, (1949) o Las Casas Tropicales, (1949).

El denominador común en su obra y que sirve como factor definitorio en su aporte histórico, es su sistema de construcción prefabricada y su inclinación hacia la industrialización de la arquitectura con elementos ligeros.

El Maestro intentaba hacer con cada una de sus obras, una apuesta hacia la optimización de los sistemas constructivos aplicados hacia esos días de post-guerra 
donde quedaba en evidencia la necesidad de dar soluciones habitacionales en tiempo y forma.

La propuesta de una estructura estandarizada, unos cerramientos ligeros y una arquitectura resolutiva, eran la promesa hacia una nueva manera de proyectar. Plazos cortos y costes de obra reducidos no siempre pudieron conseguirse, pero sí una nueva visión de la aplicación de los métodos de la industrialización al oficio del diseño de edificios y su posterior construcción. (Sánchez González, 2015)

Las Casas Tropicales (Maisons Tropicales), implementaban técnicas de aprovechamiento pasivo a nivel de ventilación y/o protección. En los modelos Niamey (1949) y Brazzaville (1951), que nos sirven de ejemplo se puede ver una clara tendencia hacia el diseño bioclimático como aliado fundamental para conseguir condiciones de confort que redundaría en un eventual ahorro energético.

Estos modelos tropicales, de la autoría conjunta de Jean y Henri Prouvé representaban el perfeccionamiento de las Maisons à portiques además de ser la evolución de las casa tipo Estándar.

Las Maisons à portiques (Fig. 25-a), (de las que se construyeron 400 unidades en el escenario de la posguerra francesa entre 1939/1947) igual que las Casas Tropicales, contaban con piezas o componentes de fácil transporte y montaje con no más de 100 $\mathrm{kg}$ de peso por cada pieza.

Las casas, formadas por un bastidor axial de acero, en forma de $\underline{\mathrm{V}}$ invertida (desarrollado anteriormente en colaboración con Pierre Jeanneret), que servía de estructura principal de la vivienda tenía la madera como material principal de cerramiento.

Se encontraban sobre elevadas sobre una plataforma de hormigón dejando un espacio disponible en planta baja, sin climatización, que permitía un uso de almacenaje y con unas dimensiones de $8,00 \times 8,00$ metros; sus componentes podían ser fácilmente intercambiables.
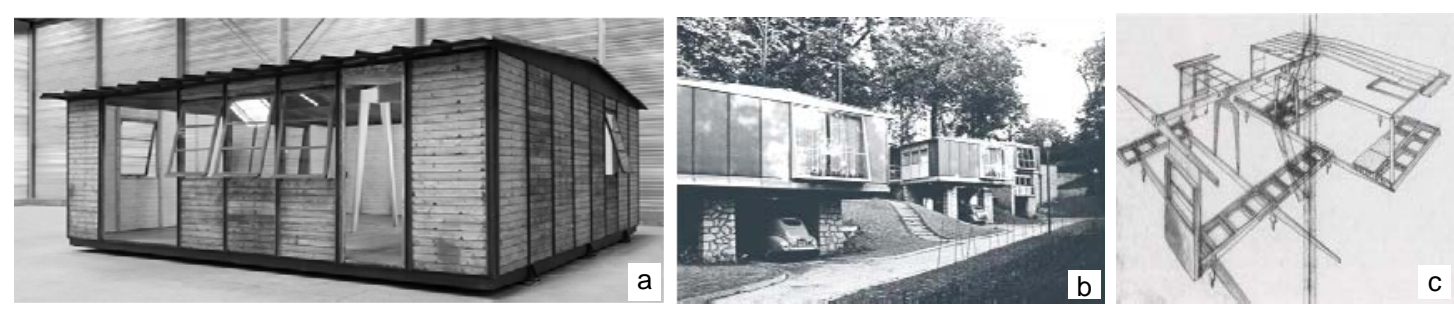

Fig. 25. a) Maisons à portiques. 1939-1947. J. Prouvé. (patrickseguin.com; 2015). b) Casas Estándar. 19491952.J.Prouvé. (proyectos4etsa.wordpress.com; 2015). 3) Estructura Casas Estándar (proyectos4etsa.wordpress.com; 2015). 
El otro referente conceptual directo de las Casas Tropicales, son las Casas Estándar en Meudon, Paris, (1949-1952) (Fig. 26), en colaboración con Henri Prouvé y André Sive. Se construyeron también por encargo del gobierno, para solventar la escasez de viviendas de la época.

Se proyectaron y montaron modelos de $8,00 \times 8,00$ metros y de 8,00 x 12, 00 metros, con bastidores de chapa de acero plegada $U$ invertida, sobre la que descansaba un caballete. Con estos bastidores se podía conseguir no solo soportar el peso de la casa, sino que luego de instalados, un solo operario pudiera finalizar la obra con los paneles de aluminio que servían de cerramiento.

Estos paneles, modulados a razón de un metro, contaban con un aislamiento de lana de vidrio que evitaba los puentes térmicos; además contaba con un sistema de calefacción por suelo radiante que permitía calentar de manera homogénea los espacios interiores.

Por su alto coste de producción solo fueron montadas 10 casas en Paris de un total de 25 originalmente proyectadas. Las restantes fueron montadas en otras partes de Francia y en Argelia. (Pieters, 2006).

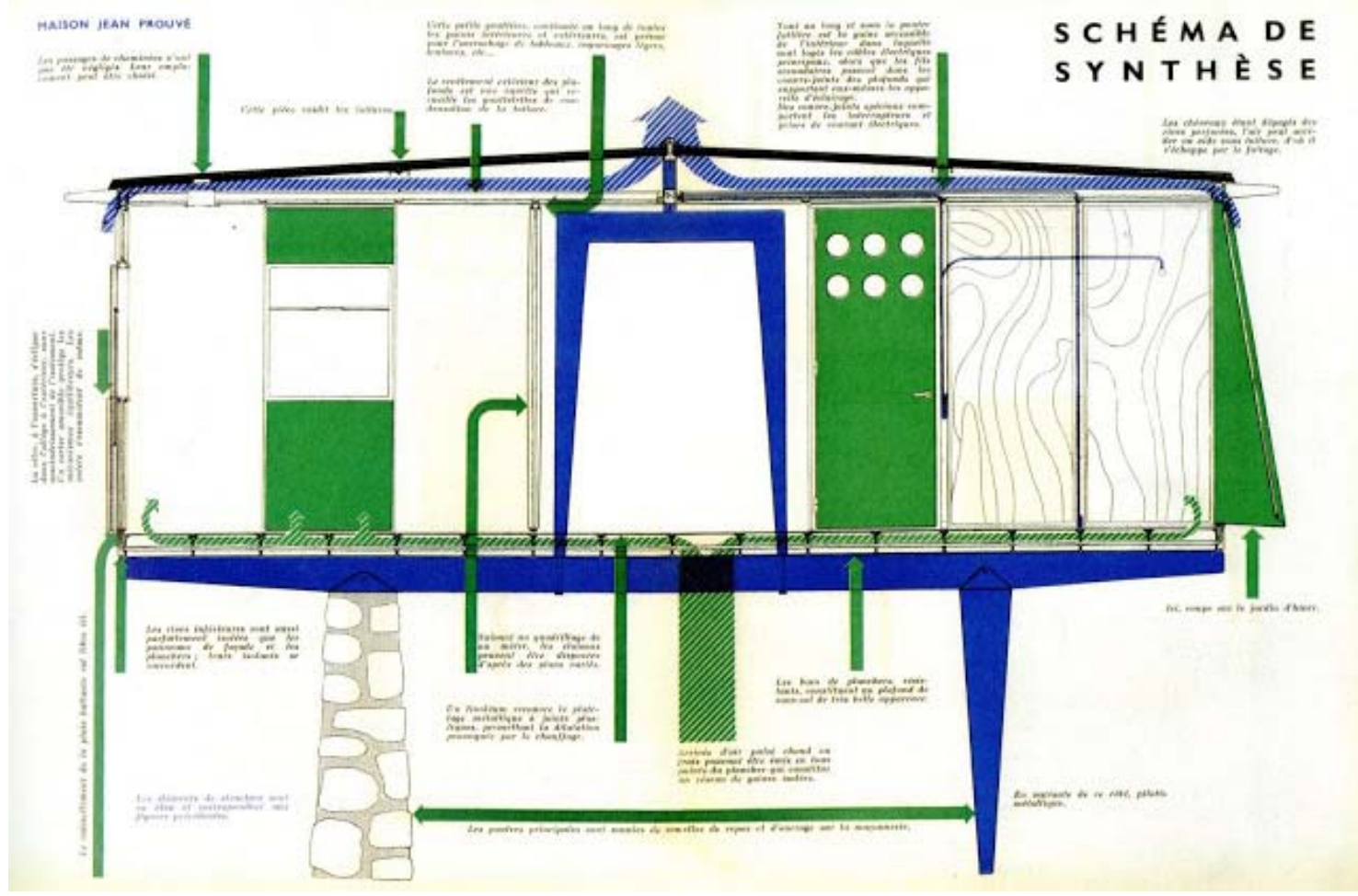

Fig. 26. Sistema de acondicionamiento interior Casas Estándar. 1949-1952.J.Prouvé (AA. VV. Jean Prouvé. Les maisons tropicales. Catalogue Exhibition large Brazzaville Tropical House . 2006) 
Volviendo sobre las Casas Tropicales, si bien es cierto que existieron algunos factores que repercutieron sobre los costes finales y la viabilidad de la puesta en obra del modelo Niamey (complejidad en el montaje y sobrecoste de ejecución), también es cierto que estos serían atribuibles al caso concreto del proyecto y las condicionantes propias del mismo más que a los procesos industriales asociados y al diseño del prototipo.

Prouvé planteaba de manera decidida que sus proyectos de Casas Tropicales, con un sistema de construcción ligera y un peso no superior a $50 \mathrm{~kg} / \mathrm{m}^{2}$, estaban diseñados para durar mucho tiempo y resistir el ataque de las termitas y las hormigas y otros agentes de la naturaleza e incluso que se podrían adaptar mejor al clima del lugar, mejor incluso que las propias construcciones autóctonas. En ambos proyectos los hermanos Prouvé procuraron tomar en consideración, como factor determinante, las condiciones climáticas y de entorno, del lugar de emplazamiento de las viviendas, incluso tomando inspiración de las técnicas constructivas autóctonas de los lugares de destino de los modelos (ciudades de Niamey en Niger y Brazzaville en El Congo respectivamente), para mejorar los mismos.

Originalmente estas viviendas fueron parte de numerosos estudios que sobre edificios desmontables para las colonias francesas, realizó el Atelier de Prouvé en 1948, incluso con la colaboración o influencias de Pierre Jeannerete.

Como resultado de estos estudios previos, los edificios escolares destinados a la universidad de Dakar, resultaron ser el primer encargo en firme, que sobre construcción tropical y ligera, recibió el Atelier de Prouvé.

Las Casas Tropicales de alguna manera se inspiraban en el espíritu de las viviendas autóctonas de la zona.

Estas viviendas autóctonas estaban construidas, en sus cerramientos verticales, con una mezcla de un tipo de adobe llamado banco. Este mismo tipo de adobe, "armado" con vigas de madera de palmera, servía para hacer las cubiertas de estas edificaciones.

\section{Niamey}

La primera de las Casas Tropicales es la de Niamey (1949) (Fig. 27), de un solo nivel; se proyectó y construyó para el director de la Universidad Niamey. Las dimensiones de la vivienda sobrepasaban los 100m2 (algunos autores señalan $108 \mathrm{~m} 2$ mientras que otros hablan de una planta de $10 \times 14 \mathrm{~m}$ ) repartidos entre espacios interiores y un porche perimetral a modo de galería que rodeaba toda la vivienda con un ancho de 1,00 m. Contaba con una especie de cella central de 6,00 x 12,00 m, que servía para 
emplazar el bastidor de soporte de la casa. Esta cella contaba además con un espacio que la circundaba de $1,00 \mathrm{~m}$ de ancho en sus lados y 2,00 al frente y al fondo. (Pieters, 2006).

El espacio comprendía: sala de estar, cocina y dormitorio para el criado y un aseo. La zona privada, separada por un patio tenía dos dormitorios con baños separados.

\section{Brazzaville}

Aunque el nombre del segundo prototipo fue casa Brazzaville (1951) (Fig. 28), realmente el uso destinado no era sólo para vivienda, sino el de oficinas de información regional de la compañía de aluminio Studal y el alojamiento de su director.

El programa del edificio estaba distribuido en una sola planta separada del plano de sustentación, elevada sobre pilares de hormigón, con cuerpos, uno de 10×20 metros y el otro de $10 \times 18 m$, formados por vigas y viguetas de chapa plegada.

El volumen más pequeño estaba formado por una sala de espera, una oficina principal, una oficina para la secretaria y un lavabo. El otro volumen, que servía de vivienda, estaba separado del anterior por un pasillo; contaba con una sala de estar, dos baños, cocina y tres dormitorios.

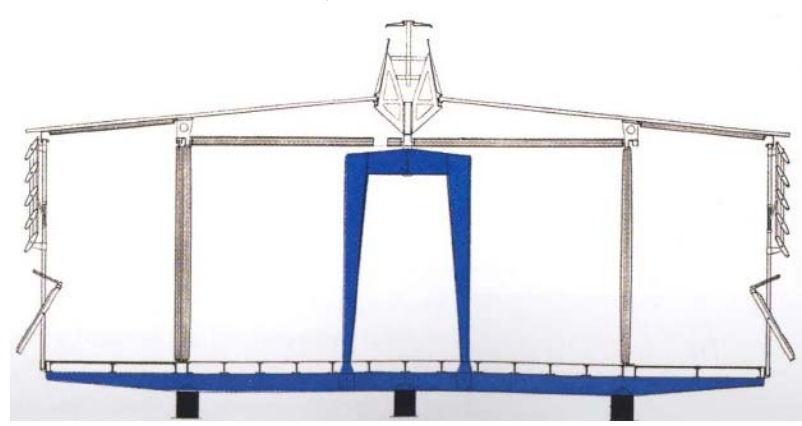

Fig. 27. Maison Niamey, 1949. Jean Prouvé. (AA.VV. Les maisons tropicales. Catalogue Exhibition large Brazzaville Tropical House . 2006).

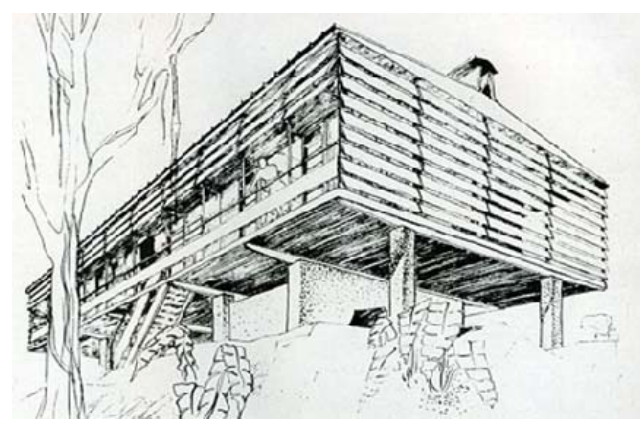

Fig. 28. Maison Brazzaville, 1951.Jean Prouvé. (AA.VV. Les maisons tropicales. Catalogue Exhibition large Brazzaville Tropical House . 2006).

La construcción de ambos modelos se realizó con chapa de aluminio y acero, dispuestos en planos de cerramiento (2D-panelizado) para facilitar tanto el transporte como el montaje. Estos modelos, igual que sus antecesores, (Casa Estándar y Casas Aporticadas) planteaban la posibilidad de estandarizar varios de sus elementos constructivos para su producción en serie.

En el caso de la casa Niamey, la misma, de una sola altura, estaba construida sobre una losa de hormigón, en contacto directo con el suelo, con un espacio de ventilación de $80 \mathrm{~cm}$ y cubierta de azulejos vitrificados.

Todos los componentes metálicos de la Casa Niamey (Fig. 29), se fijan a esta losa en cuatro pórticos que describen el eje central de la vivienda. De igual manera en la casa 
Brazzaville la serie de pórticos centrales servían de soporte para la vivienda y los cerramientos, se fijaban a una losa de hormigón (con acabado interior en madera de roble) que a su vez se encontraba separada del suelo - mediante pilares de hormigónentre 3,00 y 4,50 metros dependiendo de la cota del terreno con relación a la losa.
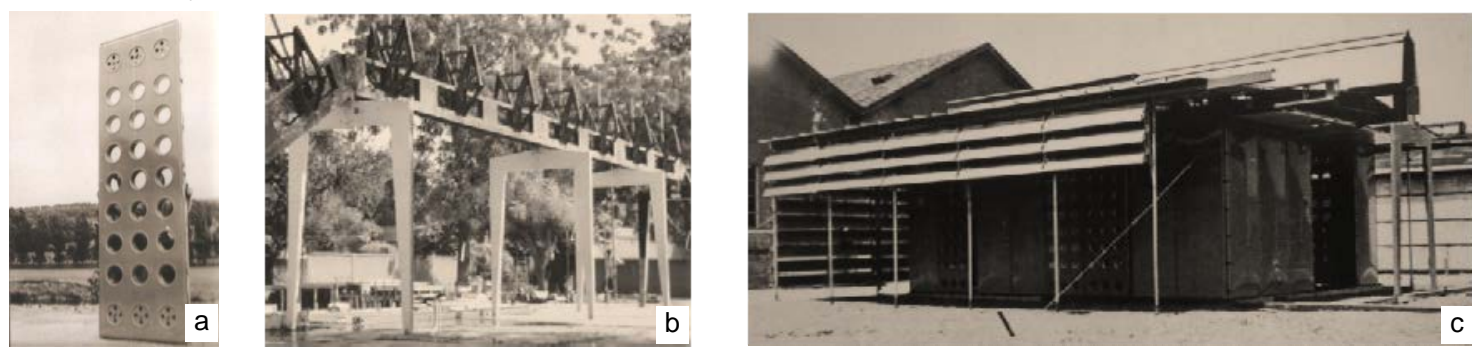

Fig. 29. a) Panel de cerramiento con huecos para iluminación natural; b) pórticos metálicos y c) montaje de prueba en taller de la Maison Niamey, 1949. Jean Prouvé. (AA.VV. Les maisons tropicales. Catalogue Exhibition large Brazzaville Tropical House . 2006)

Cada cerramiento, que definía cada espacio, venía con las instalaciones de electricidad y luminarias listas de fábrica, de manera que a la hora de montar el prototipo solo era necesario conectar todos los componentes.

En la documentación gráfica comercial original de la Casa Brazzaville se proyectaba una altura genérica de 2,00 $\mathrm{m}$.

La estructura en general de las casas tropicales era de chapa de acero y todas las paredes o cerramientos verticales estaban hechos de paneles de doble hoja de aluminio esmaltado, con aislamiento de lana de vidrio y un posible acabado de madera interior. De acuerdo a la propia documentación comercial relativa a las casas el nivel de aislamiento equivalía al de un muro de ladrillo de $90 \mathrm{~cm}$ o lo que sería lo mismo a $0,68 \mathrm{~W} / \mathrm{m} 2 \mathrm{~K}$. (AA.VV. Les Maisons Tropicales. Catalogue Exhibition large Brazzaville Tropical House. 2006).

Desde la perspectiva de este trabajo, y haciendo un análisis de la documentación gráfica disponible, se puede observar la composición típica de los paneles de cerramiento de las fachadas. Las casas, que no contaban con ventanas como tal, disponían de puertas correderas y giratorias, con aberturas para permitir la entrada de la luz natural regulada, efecto que se producía también por las lamas, de aluminios dobles y orientables, de la terraza.

Los techos de las casas estaban fabricados en aluminio de entre 10 y $15 \mathrm{~mm}$ (y una lámina de linóleo) de espesor, y cubrían tanto la superficie de la cubierta como de las terrazas perimetrales. En cuanto a sus cerramientos (tanto para un modelo como para el otro), los mismos estaban compuestos por paneles de altura aproximada de 2,40 m con dos láminas de chapa de aluminio de $10 \mathrm{~mm}$, con aislamiento térmico de entre 20 y $40 \mathrm{~mm}$, resistente a cualquier tipo de descomposición orgánica . Igual composición tenían los paneles de puertas y ventanas (AA.VV. Les maisons tropicales. Catalogue Exhibition large Brazzaville Tropical House. 2006). 
En el prototipo de Niamey (República Del Niger), una ciudad con temperaturas medias que rondan los $29,2^{\circ}$ y de clima semi-árido, no se utilizó plataforma elevada sobre el plano de sustentación, sino que se utilizó directamente una solera de hormigón como suelo, revestida de material cerámico para enfriar el espacio interior de la vivienda.

En la ciudad de Brazzaville (República del Congo), con temperaturas medias por el orden de los $25,5^{\circ}$, Prouvé proyectó para su modelo de edificio de oficinas y vivienda una plataforma separada del plano de sustentación, tal como se explica en el epígrafe anterior.

Con esto se dotaba al edificio de un espacio libre no acondicionado debajo del mismo y le independizaba de la orografía natural del terreno incorporando al diseño una reinterpretación de uno de los cinco puntos de la arquitectura de Le Corbusier: la planta sobre pilotes. Esta medida de separar la vivienda del plano horizontal no solo servía para jerarquizar el edificio.

Ambos modelos de casas tropicales contaban con lamas orientables, un sistema de protección solar tipo Brise Soleil (Fig. 30) que cubrían parte del porche perimetral a modo de piel exterior para impedir el sobre calentamiento interior. Esto confería al edificio una imagen atemporal en línea con un lenguaje también manejado por el Maestro Le Corbusier. Estas lamas, o persianas, se manipulaban mediante un sistema de bielas que se operaban desde el interior de la casa a través de mandos colocados bajo los pórticos axiales. Con esto se podía graduar el nivel de luz y ventilación deseado.

En el caso de la Casa Niamey (Fig. 31) las nervaduras de las persianas eran horizontales mientras que en caso de la Casa Brazzaville (Fig. 31) estas nervaduras eran verticales para facilitar el drenaje del agua en un país con abundantes lluvias como el Congo. (AA.VV. Les Maisons Tropicales. Catalogue Exhibition large Brazzaville Tropical House. 2006). Las condiciones climáticas tanto de Niamey como de Brazzaville responden a los patrones tropicales de esta parte del mundo. Dos aspectos fundamentales deben quedar resueltos para conseguir espacios interiores confortables en estas zonas: el sombreamiento y la ventilación. El primero queda resuelto con la incorporación de Brise soleil, como segunda piel en los porches o terrazas perimetrales, y el segundo quedaría resuelto con un sistema de ventilación natural a través de la cubierta.

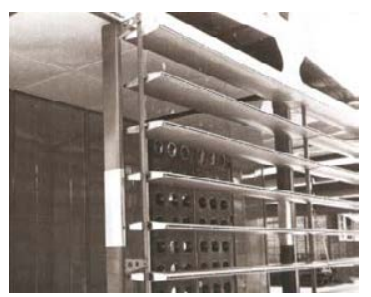

Fig. 30. Brise Soleil, Jean Prouvé (proyectos4etsa.files. wordpress.com. 2015)

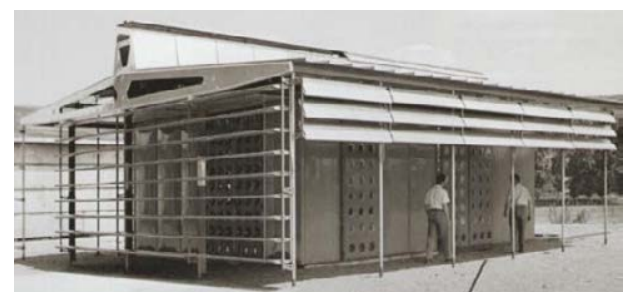

Fig. 31. Casa Niamey, 1949, Jean Prouvé (proyectos4etsa.files.wordpress.com. 2015)

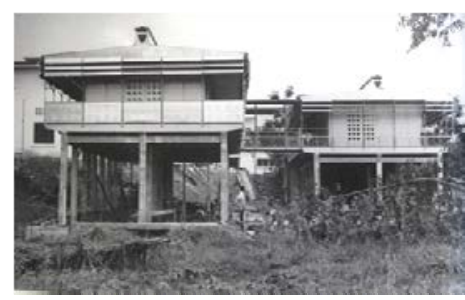

Fig. 32. Casa Brazzaville, 1951. J. Prouvé. (proyectos4etsa.files.wordpress.com 
La cubierta de las Casas Tropicales estaba diseñada como una especie de doble cubierta, con cámara ventilada interior, dispuesta de tal manera que fuera posible la circulación del aire a través de estructura de doble piel y una especie de chimenea. Esto junto al suelo en forma de plataforma elevada en un caso y de solera ventilada en el otro caso, dotaba a la vivienda de un sistema de refrigeración pasiva por medio de la ventilación natural. Con relación a las aberturas o ventanas y cuantificando en un 85\% las necesidades de ventilación, Olgyay propone (Olgyay; 2004), para las zonas cálidas y húmedas, una ventilación cruzada de acuerdo al eje de la dirección de los vientos y propone a su vez que los elementos practicables sean tipo pantallas correderas, lamas o celosías que permitan el paso del aire y la protección solar. En las zonas cálidas áridas, recomienda, tal como sucede con el modelo Niamey y sus ojos de buey, un tipo de abertura mínima además de protección solar, como las lamas, para reducir la intensidad de radiación hacia el interior. Igualmente recomienda una cubierta ventilada como es el caso de este prototipo.

Claramente muchas de las recomendaciones que se hacen, tanto para un tipo de clima, como para el otro son de aplicación en ambos proyectos. No todas las soluciones que plantea Olgyay, 14 años después en sus análisis y en su libro, están implementadas en los proyectos de las Casas Tropicales sin embargo sí que se aplican las que esencialmente son necesarias para un buen nivel de confort.

Prouvé se adelantó a unos postulados que descritos por Olgyay han servido como recomendaciones claves para una arquitectura bioclimática en la segunda mitad del siglo XX y hasta nuestros días.

Aunque el sistema de ventilación en la casa Niamey era un poco más completo, quizás por ser esta ciudad más caliente que la de Brazzaville, lo cierto era que en ambos casos el sistema general consistía en permitir la entrada de aire por los laterales de la cubierta, y el resto de la vivienda, y forzar su salida mediante el efecto chimenea por el calentamiento de la pieza central longitudinal del eje de la cubierta, produciendo una especie de tiro por sus extremos (Fig. 33).

Al mismo tiempo la superficie de la cubierta de aluminio, era lo suficientemente reflectante para permitir reflejar los rayos del sol moderadamente evitando sobre calentamientos.

Jean Prouvé se adelanta a las recomendaciones que para las zonas cálidas húmedas (Brazzaville) y cálidas áridas (Niamey) realiza Victor Olgyay (Olgyay; 2004), en cuanto a elementos constructivos, en su libro Arquitectura y Clima. Manual de Diseño Bioclimático para Arquitectos y Urbanistas, cuya primera edición es del año 1963; 14 años después de las Casas Tropicales. 


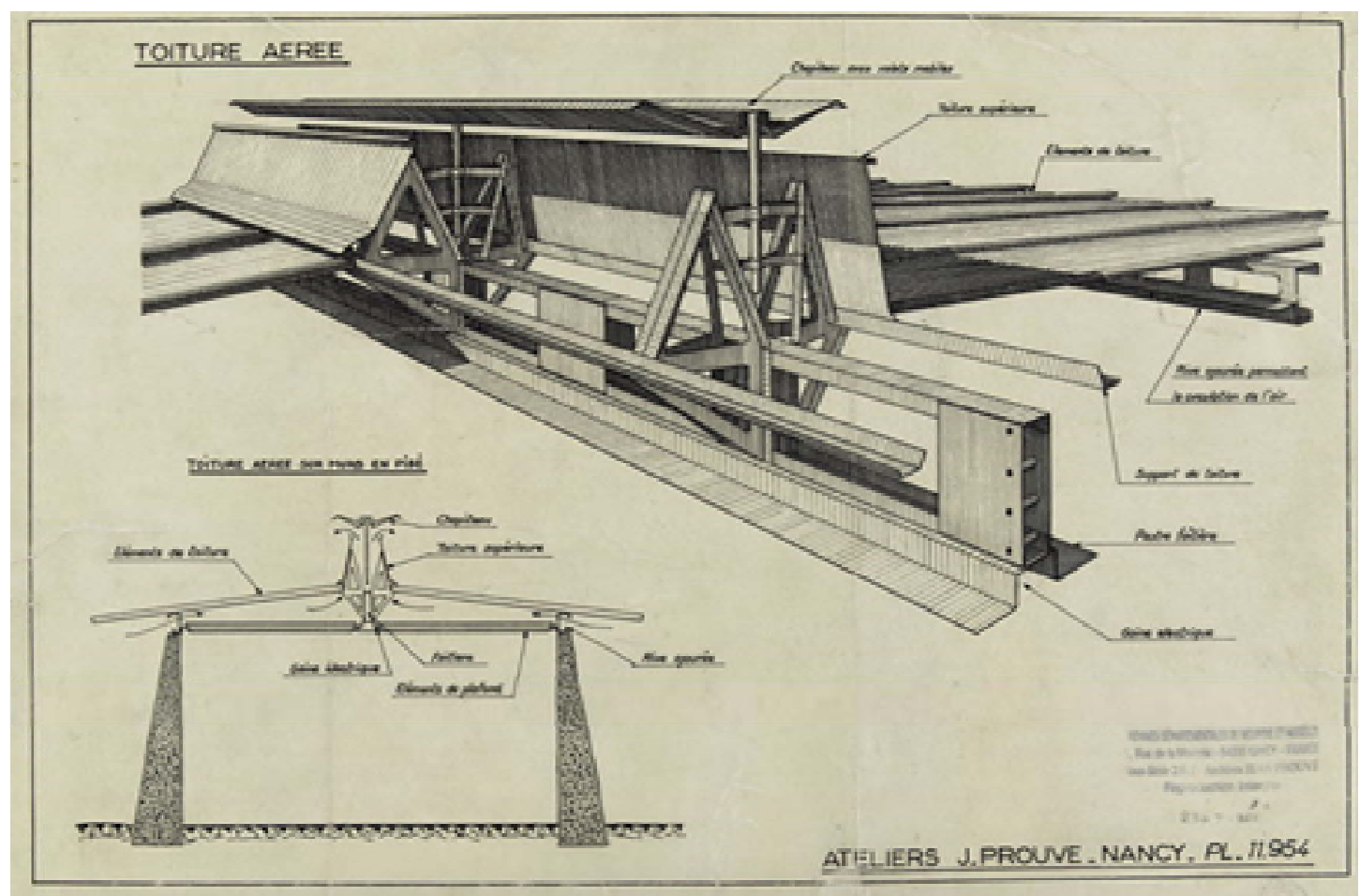

Fig. 33. Detalle tipo cubierta y sistema de ventilación natural para las Casas Tropicales; 1949. J. Prouvé. (AA.VV. Les maisons tropicales. Catalogue Exhibition large Brazzaville Tropical House. 2006).

En la edición revisada del mismo libro Olgyay plantea: que para zona cálida y húmeda recomienda una cubierta doble, ventilada que refleje los rayos solares y que forme voladizos para proteger del resplandor y la lluvia. (Olgyay; 2004) En cuanto a los elementos de protección solar, tal como sucede en Brazzaville, Olgyay plantea prestar atención a la protección solar al norte.

\section{Richard Buckminster Fuller. Casa Wichita (Dymaxion)}

Igual que con las Casas Tropicales para un análisis correcto de los conceptos manejados en la Casa Wichita, es recomendable estudiar la misma dentro del contexto de la obra global del arquitecto. A Richard Buckminster Fuller se le reconoce como una de las mentes más brillantes del siglo $X X$, gracias a sus aportes tecnológicos muy comprometidos con la innovación constante a favor de la sociedad.

Nació en Milton, Massachusetts, en 1895, e ingresa en Harvard en 1913 y luego de ser expulsado regresa en 1915 no pudiendo terminar una educación formal en esta universidad. En 1917 ingresa en la marina donde destaca por sus aptitudes hacia la ingeniería recibiendo formación oficial en la Academia Naval de Los Estados Unidos. Recibe formación hasta 1919, luego sirvió en la Marina de Estados Unidos. En 1926, junto a su suegro llega a patentar un nuevo método de producción de edificios de hormigón armado que transcurrido un año no reportó ningún éxito empresarial. Luego de un período de casi dos años sin un horizonte laboral claro y con pocas perspectivas positivas. 
Pasada esta etapa, en la que pudo reflexionar sobre sus ideas y aspiraciones, Fuller avanza en su idea de revolucionar la construcción y las condiciones habitacionales conocidas hasta el momento. (http://buckminsterfuller.net. 2015)

Teniendo la industria del automóvil como fuente de inspiración principal, la original Casa Dymaxion (del inglés dynamic, maxim y tension), comienza a ser concebida por su autor en 1927; sin embargo, este proyecto no se desarrolló como tal y sólo fue hasta 1946 cuando por una alianza con Beech Aircraft Industries, fabricante de aviones (con un superávit de aluminio, pasada la Segunda Guerra mundial), que se desarrollaron los prototipos Barswise y Danbury.

Estos dos prototipos que nunca fueron comercializados, fueron comprados por uno de los inversionistas del proyecto -William Graham- y fusionados en lo que conocemos como la Casa Wichita de 1948.

El catálogo de inventos relacionados con el concepto Dymaxion abarca desde el Dymaxion Car, un automóvil de tres ruedas aerodinámico que podía hacer giros en círculo prácticamente sobre su propio eje, las unidades habitacionales (DDU), anteriormente citadas en este trabajo y el Baño Dymaxion de fácil instalación y sistemas de aprovechamiento del agua, implementado en la propia Casa Wichita.

En el caso de DDUs, aunque no tuvieron un uso como viviendas civiles, sí que fueron casas de producción masiva basados en silos circulares muy utilizadas durante la Segunda Guerra Mundial como refugios, barracas para lugares remotos y de clima severos y centros de mando para radares militares. Durante la década de 1930, Buckminster Fuller publicó la revista Refugio, y desde 1938 hasta 1940 fue asesor de ciencia y tecnología para la revista Fortune. En estos medios de difusión fue transmitiendo su concepción global del planeta y las interrelaciones sociales.

Esta labor de difusión también tenía su versión académica y Fuller alternaba sus investigaciones y proyectos con clases y conferencias universitarias que en la década de 1940 incluyeron escenarios como el MIT (Massachusetts Institute of Technology) y a la propia Harvard. Años más tarde en 1950, se hizo profesor en la Universidad de Southern Illinois (SIU), donde él y su esposa vivían en una cúpula geodésica en las residencias universitarias. (http://buckminsterfuller.net. 2015) 
En el escenario de postguerra (I Guerra Mundial), Buckminster Fuller planteó una solución a la demanda de viviendas asequible de esos años, proponiendo la producción en serie de casas y tomando la industria aeronáutica de la década del 1920 como referente. Esta primera versión del concepto Dymaxion (1927), previamente explicado en este mismo trabajo, consistía en una vivienda para 5 habitantes.

De planta hexagonal con unos $148 \mathrm{~m}^{2}$ y un peso de $2.721 \mathrm{Kg}$ aproximadamente cumpliría con lo establecido como estándar de peso ligero para una construcción, que es menos de $200 \mathrm{~kg} / \mathrm{m}^{2}$ (Fig. 34).

Este modelo es sin duda el precursor del modelo de estudio (Casa Wichita) que se analiza en este trabajo.

Como estructura de sujeción principal contaba con un mástil de soporte central anclado al suelo por su base y la posibilidad de incorporar un ascensor con trayectoria en su eje vertical; un ascensor que funcionaría incluso en ausencia de energía eléctrica con un sistema manual que le permitiera seguir siendo más rápido que subir andando. (Kraussse, Lichtenstein, 1999). Los espacios vivideros interiores se encontraban en la planta primera siendo la planta baja un espacio diáfano en torno al mástil central y con uso recreativo para los habitantes de la casa. El material para su construcción fue el aluminio por su fácil manejo y ligereza.

El sistema estructural de la casas se basaba en un principio de tracción/tensión mediante un esquema de red de cables de acero, sujetos al mástil del que ya se ha hecho referencia anteriormente.

De esta manera todos los elementos de la construcción quedarían suspendidos desde arriba, empleando una especie de trípode, evitando el apoyo de la vivienda en el plano de sustentación (Fig. 35). Dicho sistema era muy similar a la de un puente colgante y con éste se evitaba el uso de materiales pesados de un alto consumo energético, además de aprovechar las ventajas que supone una construcción ligera a la hora del montaje y desmontaje de la misma.

Cuando menos a nivel teórico los conceptos desarrollados por Buckminster Fuller para la Dymaxion House abarcaban aspectos tales como el aprovechamiento de la ventilación natural mediante el factor de forma y un sistema mecánico que permitía abrir y cerrar parte de la cubierta para estos fines.

El modelo Dymaxion planteaba la autosuficiencia absoluta del modelo a nivel energético, incorporando además el modelo de baño con sistema de optimización del uso del agua e incluso gestionando sus propios residuos. 
Dos aspectos quedaban como objetivos principales a alcanzar: que la producción en serie de los edificios fuera posible y tan eficiente como la producción en serie de los automóviles, tanto en costes (precio/ $\mathrm{kg} / \mathrm{m}^{2}$ ) como en cuanto a tecnología (incluyendo aspectos de eficiencia energética) y que fuera ligera pero resistente.

En cuanto a la resistencia esta vivienda tendría que ser lo suficientemente resistente para que pudiera soportar catástrofes naturales, fenómenos atmosféricos e incluso incendios. (Kraussse, Lichtenstein. 1999) (Fig. 36). Los cerramientos exteriores estaban ideados para soportar solamente su propio peso apoyándose en cada nivel. Los mismos estarían compuestos por materiales ligeros (como el aluminio) con espesores y material aislante que garantizara el confort térmico y acústico.

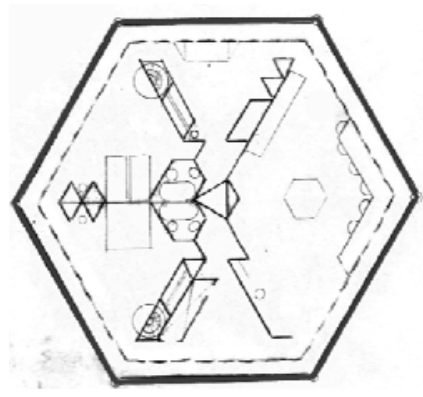

Fig. 34. Planta Casa Dymaxion. 1927. R. Buckminster Fuller. (b2dymaxionhouse.blogspot.com 2015.com)

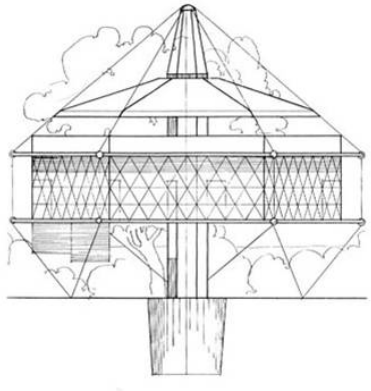

Fig. 35. Alzado Casa Dymaxion, 1927, R. Buckminster Fuller. (Krausse y Lichtenstein.1999)

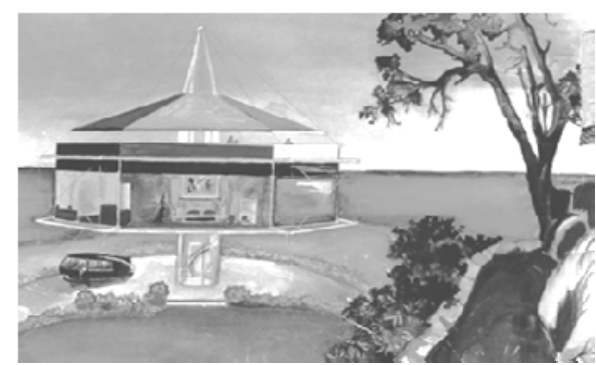

Fig. 36. Casa Dymaxion, 1927, R. Buckminster Fuller. (Krausse y Lichtenstein.1999)

\section{Torre Dymaxion 4D}

El proyecto 4D (1927) fue la idea de vivienda colectiva (12 o 25 viviendas) que desarrolló Buckminster Fuller (Fig. 37). Consistía en una torre con las zonas vivideras suspendidas de un mástil central como era el concepto central Dymaxion que luego derivó en vivienda unifamiliar. De esta manera, suspendiendo los diferentes niveles del mástil mediante tensores, procuraba conseguir una estructura más ligera y fácilmente transportable de la fábrica al sitio de erección. La planta de los pisos en la Torre 4D era hexagonal, igual que la Casa Dymaxion e igual que ésta todos los servicios estaban incorporados al mástil que además contaba con una especie de aerogenerador en la cúpula para captar la energía eólica y producir electricidad. (Krausse, Lichtenstein. 1999).

Los materiales utilizados fueron el aluminio y el plástico, los cuales aún siendo comunes en la industria del automóvil y la aeronáutica, no lo eran en la construcción de edificios cuyo nivel de industrialización Buckminster Fuller pretendía desarrollar 
hasta los niveles de estas industrias, convencido de que las necesidades habitacionales de la humanidad sólo se podrían resolver por medio de la industrialización de los procesos de producción.

El sistema de ventilación que incorporaría el edificio incluiría circulación de aire para ventilación en condiciones de verano y calefacción para condiciones de invierno. También incluía otro sistema central de aspiración y de aire comprimido para facilitar la limpieza de las zonas habitables.

La iluminación quedaría resuelta, de día, mediante la proyección de los rayos de sol a través del mástil para que a su vez fueran reflejados por espejos y prismas hacia cada vivienda. El abastecimiento de agua estaría resuelto con un sistema de captación y almacenamiento propios además de un sistema de depuración.
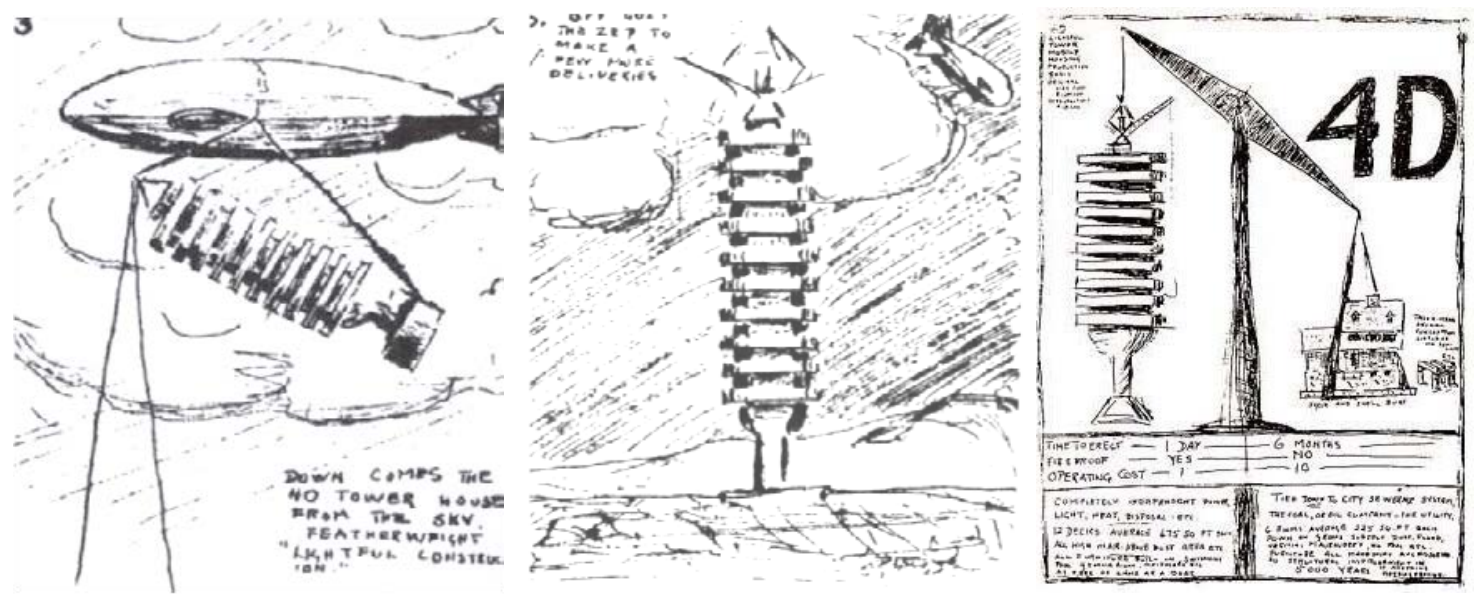

Fig. 37. Imágenes de transporte e implantación torre 4D. 1927. Richard Buckminster Fuller. (Krausse y Lichtenstein. 1999).

Espacialmente, el edificio estaba organizado de manera que los principales espacios vivideros se ubicaban próximos a la parte superior de la estructura, con mejor ventilación y mejor vista.

Cada vivienda tendría el forjado o losa neumática así como parte de las carpinterías, y que aislaban herméticamente la vivienda. Siendo el edificio un elemento de una sola pieza y fabricado con materiales ligeros que permitían su relativo fácil transporte, Fuller proyectaba que el mismo pudiera ser trasportado íntegramente por aire.

Este concepto innovador Dymaxion vio la luz con el proyecto teórico de la torre 4D. La ligereza de la propuesta contrastaba con la realidad constructiva de finales de los años 20 del siglo pasado y significaba un avance en cuanto a implementación de la tecnología industrial que aún al día de hoy no ha sido llevado a un nivel de realidad más allá de prototipos a escala, simulaciones informáticas y ensayos de laboratorio. 


\section{Casa Wichita (Dymaxion)}

Uno de los proyectos más decididamente sostenibles y/o eficientes que se puedan tomar como ejemplo dentro de la arquitectura modular ligera es el proyecto Casa Dymaxion de R. Buckminster Fuller. El modelo Dymaxion Dwelling Machine, como también se le conoce, fue utilizado con normalidad durante 30 años por la familia Graham, como parte de las dependencias de su rancho, antes de ser donada al Museo Henry Ford donde se encuentra expuesta luego de un minucioso proceso de restauración. El desarrollo de esta casa se prolongó de 1944 a 1946.

Las reacciones al prototipo eran muy positivas; sin embargo, no fue puesto en producción industrial, porque Buckminster Fuller insistía en que su perfeccionamiento absoluto era vital para poder producirlo en masa y que esto era materialmente imposible con los medios financieros disponibles. (Krausse y Lichtenstein. 1999).

\section{Diseño}

Esta Casa Wichita se convierte en un modelo diferente al modelo hexagonal de $148 \mathrm{~m} 2$ que originalmente concibió Buckminster Fuller en 1927 y que sólo fue un modelo teórico.

Esta versión, con un peso aproximado de tres toneladas, tendría una superficie de poco menos de $150 \mathrm{~m}^{2}$, una altura de 5 metros y llevaba como estructura de soporte principal un pilar central del cual se sujetaban, mediante cables, los demás elementos constructivos. En esta especie de mástil se ubican los servicios de la casa incluido el sistema de ventilación. Era en esencia la puesta en práctica de los conceptos teóricos de la Dymaxion 4D.

La casa original tenía forma de hexágono, pero con el modelo Wichita evolucionó a una forma circular gracias al tipo de revestimiento (materiales ligeros) que a su vez facilitaron el montaje de los mismos. Con un perfil que recuerda a las formas de un avión, reduce las fricciones del viento y las posibles pérdidas de calor.

El acceso a la vivienda se produce mediante una escalera dado que existe una diferencia de altura de $60 \mathrm{~cm}$ con relación al plano de sustentación. Un vestíbulo organiza el espacio circundante, dividido de manera radial en cinco espacios (vestíbulo, comedor y sala de estar, dormitorios 1 y 2, cocina y almacén), separados por tabiques que tienen función mixta de separación y almacenaje. En el centro de ubica el módulo de servicios con las unidades de baños prefabricados.

\section{Materiales y sistema constructivo}

El propio Fuller reconocería que las características de los materiales disponibles en su primer prototipo, el de 1927, no le permitían completar el sistema de tensión/tracción que sostenía la casa. Esto lo consiguió en la Casa Wichita con la colocación de un 
anillo de compresión, es decir, un arco horizontal, que trabajaba junto con el mástil (Fig. 38 y 39).

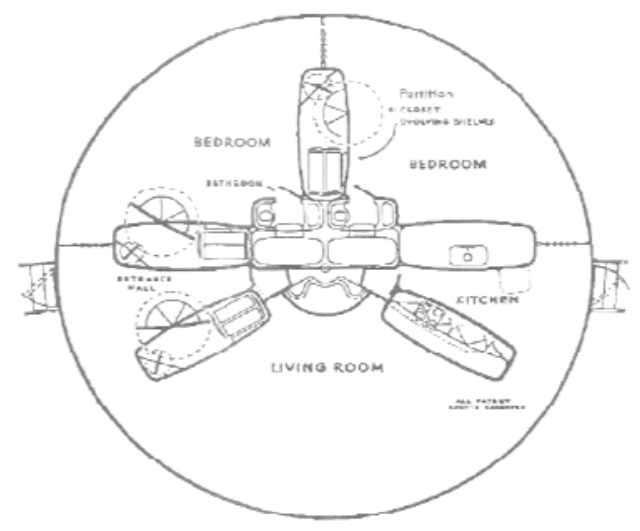

Fig. 38. Vista en planta Casa Wichita 1946, R. Buckminster Fuller. (Docomomo-us.org. 2015)

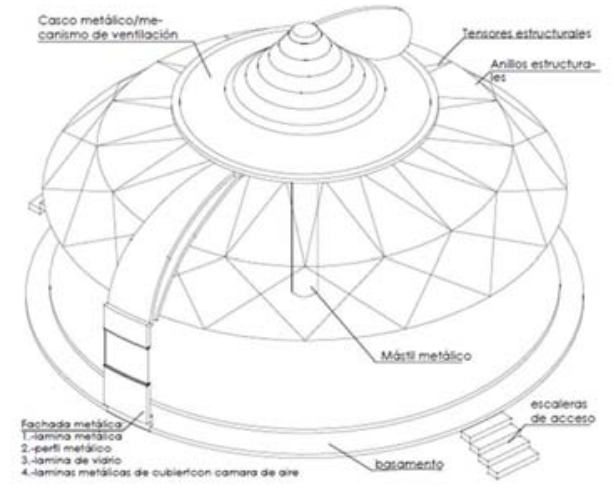

Fig. 39. Sistema constructivo. Casa Wichita 1946, R. Buckminster Fuller. (Sánchez. De León 2012)

Con este método se puede conseguir un espacio relativamente amplio, tomando como principio el sistema estructural de los puentes atirantados y de las carpas de circo. (Krausse y Lichtenstein. 1999).

Partiendo del mástil, los cables, como los radios de las ruedas se dirigían hacia el anillo de compresión horizontal, y a los demás anillos, que transmitían el esfuerzo a su vez al propio mástil fijado al suelo, evitando, con un sistema, en su conjunto, de anclajes verticales y diagonales, oscilaciones y/o movimientos indeseados incluso producidos por el viento. Al mismo tiempo el factor de forma (la curvatura de las planchas de cerramiento) dotaba al edificio de una considerable resistencia. (Krausse y Lichtenstein. 1999). La facilidad de montaje, desmontaje y transporte sería una de las características más relevantes de la Casa Wichita (Fig. 41), siendo que el transporte de la misma podía realizarse en un solo camión y su "construcción" se podía llevar a cabo en una jornada de trabajo por una cuadrilla de obreros.

La estructura de cerramiento horizontal era de acero, de 12 metros de diámetro con resistencia suficiente para más de 8 toneladas de peso. Como se ha mencionado antes, la estructura la fachada y sus elementos modulares, están suspendidos de un mástil central por la combinación de varios cables tensores en forma radial y anillos de compresión.

La parte exterior de la casa fue revestida con aluminio Duralumin brillante y reciclado, del excedente de producción para la fabricación de los aviones de la compañía Beech. El propio arquitecto reconocía el alto coste energético del aluminio pero lo justificaba alegando su fácil manejo, durabilidad y el superávit existente en la posguerra. 
De acuerdo a ensayos realizados y los cálculos de proyecto el aislamiento térmico conseguido en los cerramientos era el equivalente al de un cerramiento de corcho de 8 pulgadas.

\section{Estrategias Bioclimáticas}

La ciudad de Wichita (Kansas, Estados Unidos), registra una temperatura media anual de $13,6^{\circ}$. En sentido general sus condiciones climáticas son parecidas a las medias anuales de Madrid.

La vivienda contaba con un sistema que utilizando el núcleo central, diseñado como una chimenea, permitía el paso del aire frío desde la parte inferior de la casa, separada $60 \mathrm{~cm}$ del suelo. Con este sistema se conseguía una circulación de aire interior que expulsaba el aire caliente por la parte superior, mediante su ventilador convectivo. Este ventilador colocado en la parte de la cubierta, como un componente de la misma, trabajaba utilizando el cambio de presión del aire y el paso del viento por la cubierta $45^{\circ}$ a sotavento. Dicho ventilador fue desarrollado para proveer tanto frío como calor, según fuera la época del año, mediante una serie de pruebas experimentales que incluían túneles de viento para optimizar su funcionamiento, minimizando las posibles fricciones y oscilaciones. Buckminster Fuller lo planteó como una alternativa a los acondicionadores de aire convencionales. Este circuito alternativo de acondicionamiento del aire interior incluía la evacuación, mediante conductos de olores tanto de la cocina como del baño (Fig.40).

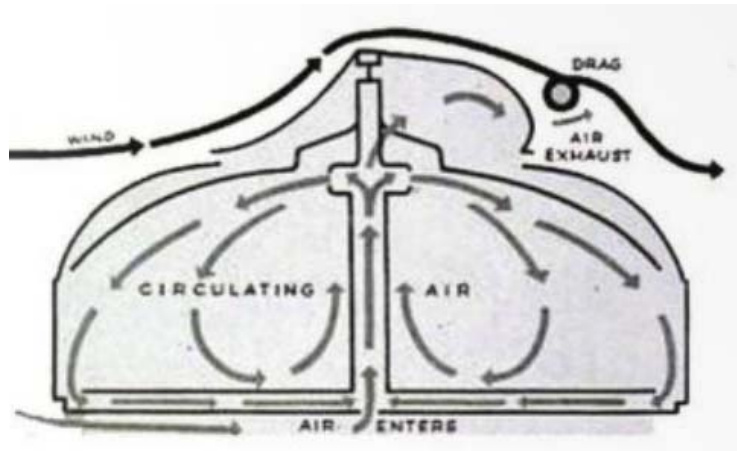

Fig. 40. Circulación del aire. Casa Wichita 1946. R. Buckminster Fuller. ( Avellaneda. 2015)

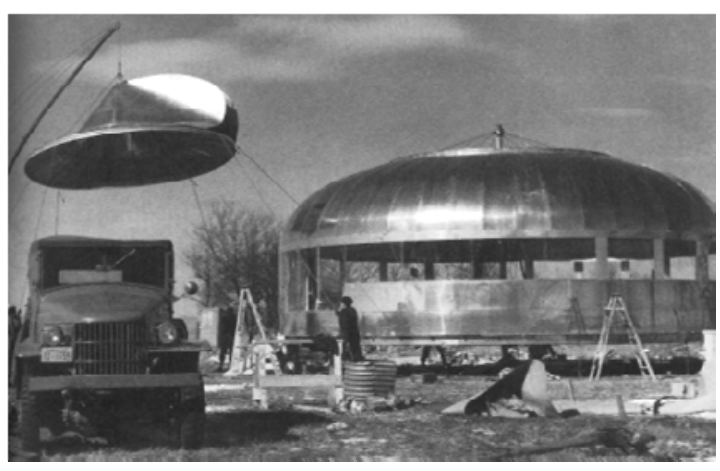

Fig. 41. Montaje Casa Wichita 1946.

R. Buckminster Fuller. ( Avellaneda. 2015)

Los silos de grano de Siberia fueron un punto de inspiración para que Buckminster Fuller intentara reproducir el "efecto de cúpula" en los modelos Dymaxion. Con este método y/o efecto físico se conseguía inducir con una cúpula un vórtice o especie de succión vertical de calor dejando el aire frío en la parte baja del local en cuestión. Mediante este método empírico pudo observar que era posible reducir la cantidad de energía calorífica necesaria para acondicionar el edificio gracias al factor de forma y el perfil aerodinámico del prototipo. (Krausse y Lichtenstein. 1999).

En el libro de Olgyay, en su descripción ideal de los tipos de materiales constructivos para el tipo de clima templado, correspondiente a Wichita, se establece que para los 
cerramientos se deben utilizar materiales que no sean absorbentes como es el caso del aluminio de la casa Wichita y que el nivel de aislamiento del mismo debe ser de 70. También recomienda que para la cubierta se instale un tipo sistema mecánico de ventilación. (Olgyay, 2004). Además aconseja que el nivel de evacuación de lluvia deba ser de al menos 25,5 mm en no más de 15 minutos. Siendo el caso de que la cubierta es parcialmente curva con las pendientes necesarias, esta condición se cumple de manera efectiva. Además sugiere la colocación de protecciones solares en las fachadas este y oeste y en el caso de la ventilación cruzada ésta queda garantizada en el proyecto (Olgyay, 2004).

Igual que sucede con los ejemplos anteriores de las Casas Tropicales, no todas las soluciones que plantea el autor de Arquitectura y Clima; Manual de Diseño Bioclimático Para Arquitectos y Urbanistas, están implementadas en la Casa Wichita (proyectada 19 años antes de la publicación del libro de Olgyay), sin embargo sí que se aplican las más evidentes necesarias para un nivel de confort adecuado.

Otro punto importante dentro del concepto de optimización energética de la Wichita era el módulo prefabricado de baño y su tecnología de ahorro del agua (Fig. 42 y 43). Partiendo de los consumos diarios de agua potable para uso doméstico, se planteó el modelo de Baño Dymaxion para que, integrado en la vivienda, garantizara cierto nivel de autonomía y en cualquier caso un nivel de ahorro sin precedentes hasta el momento.

Con este sistema patentado, de aprovechamiento y optimización del agua de uso sanitario, Fuller planteaba un circuito de recogida y reciclaje y un sistema de ducha que funcionaba con el equivalente a un recipiente pequeño de agua caliente (como un vaso), que mediante un proceso de vaporización permitía al usuario suplir sus necesidades higiénicas.

Ciertamente esto significó una especie de antesala a la micro-pulverización de los grifos eco-eficientes de la actualidad. La deposición de aguas negras procedentes del inodoro pasaba a un "Embalaje higiénico" que los convertía para el compostaje posterior. Tanto la Dymaxion como La Wichita contaban con la recolección del agua de lluvia desde el techo, como complemento al suministro de agua.

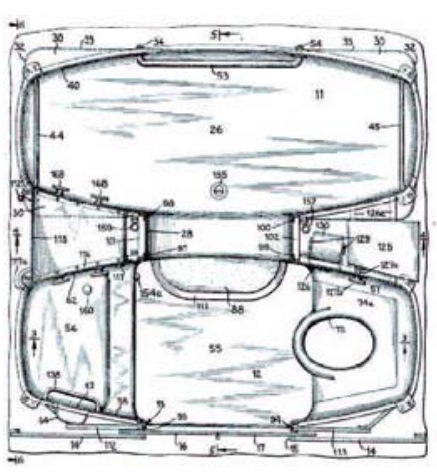

Fig. 42. Baño Dymaxion. Casa Wichita 1946. R. Buckminster Fuller. (Sánchez. De León. 2012)
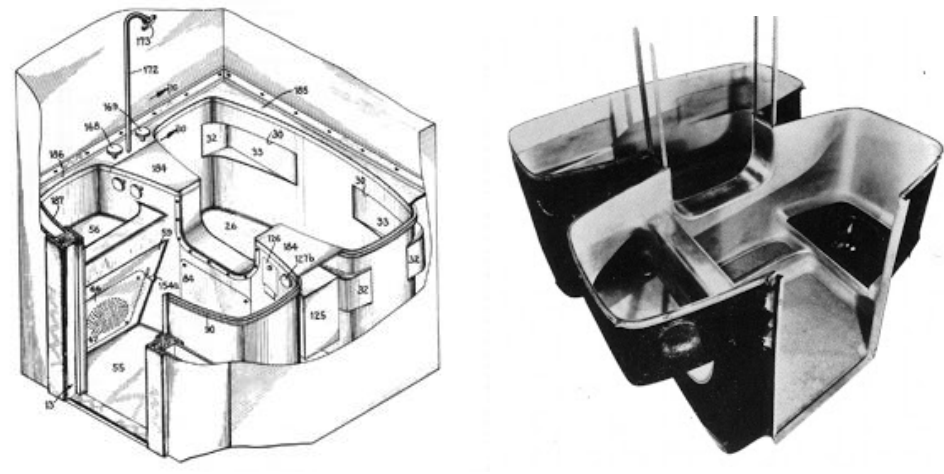

Fig. 43. Baño Dymaxion. Casa Wichita 1946. R. Buckminster Fuller. (b2dymaxionhouse.blogspot.com. 2015) 
Un enfoque que resulta ser complementario para la estructuración de la investigación objeto de este trabajo es el realizado sobre el nivel de sostenibilidad, en la comunicación Retro-Innovación y Arquitectura Sostenible, realizada al II Congreso UPC sostenible 2015 (Avellaneda \& Mrkonjic; 2015).

En estos trabajos la autora fijaba como objetivo central:

\section{“...determinar en qué grado la Ciencia del Diseño de Buckminster Fuller, a través de una combinación de las tres estrategias derivadas ("efimeralización", regeneración e industria de servicios), podría ser una aproximación al concepto actual de arquitectura sostenible en su aplicación a la casa Dymaxion, así como evaluar la validez de sus propuestas en el contexto actual...".}

La autora, teniendo en cuenta la posibilidad de poder estudiar el ciclo de vida entero de esta casa, y que además del hecho de que las estrategias (activas, pasivas y sostenibles), coincidían con las actuales, se planteaba un acercamiento posible para la implementación de las mismas de acuerdo al contexto actual.

En esa tesis se confirma el hecho evidente de que las casas Dymaxion (4D y Wichita) eran concebidas como viviendas autónomas y con un reducido impacto al entorno. De acuerdo a Mrkonjic La Wichita contaba con numerosos conceptos medioambientales como la minimización de gasto de material (utilizando el acero en tracción y la forma circular), el ahorro de energía (ventilación natural), el ahorro de agua (recolección de aguas pluviales, uso de vaporizadores en los grifos) y la gestión de la vivienda como un servicio en vez de a través de la venta asegurando de esta manera la custodia permanente sobre los materiales de construcción.

Plantea además que el uso de los materiales que hasta ese entonces eran, prácticamente, del uso exclusivo de la industria del automóvil y/o de la aeronáutica (aluminio, acero, acero inoxidable) dotaban al edificio de una de las características antes mencionadas ("efimeralización", o desmaterialización), sin embargo que su consideración como sostenible solo podría ser cierta si estos materiales (de alto consumo energético en su fabricación) entraban en un ciclo cerrado de vida útil (regeneración o reciclaje) .

Esto quedó parcialmente confirmado cuando para su restauración (de la casa Wichita) el Museo Henry Ford pudo utilizar gran parte de los materiales originales (Fig. 44).

Con un sistema de gestión integrado como característica de aproximación a la sostenibilidad según, Mrkonjic, Fuller intentaba implementar como alternativa a la venta del inmueble como tal, un sistema de alquiler de larga duración que garantizara centralizar el mantenimiento, las normas de utilización de la casa, etc. dentro de un ciclo cerrado de vida de los materiales y componentes. 

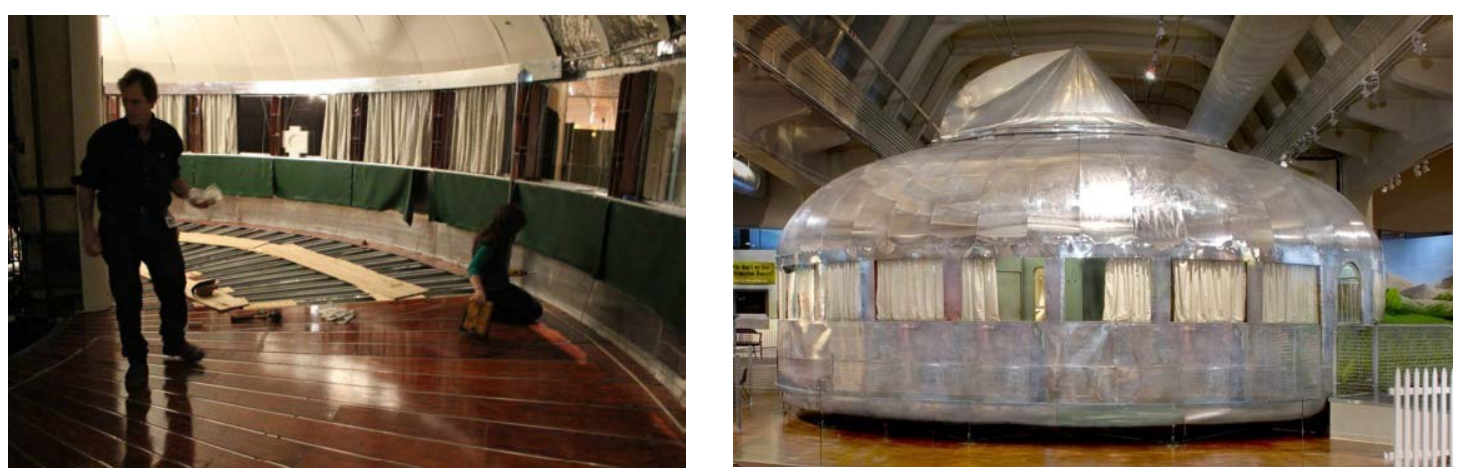

Fig. 44. Restauración Casa Wichita 1946. R. Buckminster Fuller. (.thehenryford.org. 2015) 


\subsection{ESTADO ACTUAL DEL ESTADO DE LA TÉCNICA}

3.2.1 Construcción modular ligera y construcción industrial ligera de la segunda mitad del siglo XX a la actualidad.

A partir de la segunda mitad del siglo XX y hasta nuestros días, la arquitectura ha seguido evolucionando y aunque conserva mucho de sus formas artesanales de épocas pasadas, también es cierto que ha habido avances en materia de soluciones constructivas innovadoras y ligeras. Algunos de estos ejemplos los planteamos en esta tesis por el aporte a la CML en cuanto a la creación de una idea y un sentido de conocimiento general sobre este tipo de construcciones. En este epígrafe se realiza un breve recorrido cronológico sobre estos ejemplos que configuraron la historia reciente de la CML.

\section{Los años 50 del Siglo XX}

En 1956 en Estados Unidos, Marvin Goody y Richard Hamilton, profesores del MIT (Massachusetts Institute of Technology) crearon la casa Monsanto, promovida como la casa del futuro por inversionistas de Disneylandia. Con base de hormigón su gran aporte era su forma curva que transmitía una cierta sensación de libertad morfológica y los materiales sintéticos utilizados tanto para su cerramiento (Glass fiber-reinforced concrete o GRC) y su aislamiento ligero de espuma de poliuretano expandido. La casa permitía su fácil montaje y desmontaje.

Otros ejemplos destacable de casa con material sintético y/o plástico fue la All Plastic House de 1956, de Ionel Schein, que se presentó en una feria de muebles en París y la House of Future presentada en la exposición "The House of the Future" de los Smithson, construida para la Daily Mail Ideal Home Exhibition. Estos ejemplos dieron un giro a la concepción del material sintético (plásticos y composites) y su utilización como materiales de construcción.

El tema de la construcción ligera industrializada o modular industrializada se asociaba habitualmente a situaciones de contingencia o contextos de déficit puntual habitacional. Tal es el caso del proyecto de La Casa de Abad Pierre o Casa de los Días Mejores (Maison des Jours Meilleurs), de 1956, diseñada por Jean Prouvé. La casa de unos $57 \mathrm{~m} 2$ Era una respuesta a la situación de emergencia en la vivienda social en Francia. La casa está asentada en una base de hormigón un bloque central de acero prefabricado. Los cerramientos son en panel sándwich de madera termoformada y la cubierta de una aleación de aluminio (www.patrickseguin.com. 2015).

Para la década del 50 en Japón se fueron desarrollando varios proyectos y/o iniciativas empresariales en torno a la construcción industrializada ligera y modular ligera. En 1952, e incluso desde 10 años antes, el arquitecto Maekawa, del entorno de 
Le Corbusier, desarrolló el sistema de casas prefabricadas de $52 \mathrm{~m}^{2}$ denominadas Premos. De este modelo se llegaron a construir hasta 1.000 unidades tomando como referencia formal la unidad tatami con unos paneles auto-portantes de contrachapado relleno de un aislamiento de nido de abeja y cubierta con estructura de madera. Entre el 1950 y el 1960 se desarrollaron prototipos experimentales como las casas con sistema modular GM o General Module ( 98 unidades) de Kiyoshy Ikebe en 1950; las Daiwa Houses y las Pipe House de 1955 y las Midget House de 1959 o las Sekiusui House y la Misawa House ambas de 1960. (Ovando Vacarezza, 2015).

\section{Los años 60 del Siglo XX}

En esa misma época, 1960 el grupo Archigram en Reino Unido realiza unos ejercicios teóricos entre los que se puede resaltar la casa cápsula Living Pod, de David Greene que intentaba combinar tecnología y arquitectura, abordando el tema de la arquitectura como un medio para proveer un producto flexible, adaptable y perecedero y no como un objeto definitivo, un edificio definitivo.

Mientras tanto en Suiza, el Arquitecto Pascal Häusermann de 1960, desarrolla la propuesta de un conjunto de capsulas prefabricadas en plástico y 1963 junto a Patrick Le Merdy construyó las unidades "Domobiles" (Ovando Vacarezza, 2015), a partir de un combinación de espuma de poliuretano recubiertas de poliéster reforzado.

Hacia 1963, en Alemania Dieter Schmid proyectó la Casa de Plástico (Biberach, Alemania), con la idea de desarrollar un modelo que fuera prefabricado y fácil de montar y transportar. Pionera en Europa la Casa de Plástico estaba compuesta por módulos rectangulares de fibra de vidrio y poliéster reforzado. Interiormente los paneles de cerramiento contaban con un aislamiento en fibra de vidrio y espuma de poliuretano cubierto por una placa de madera aglomerada para una $U$ teórica . La casa fue habitada por el propio Schmid y su familia hasta 1975 en que fue demolida.

En 1964 Peter Cook y Warren Chalk, también de Archigram, en Reino Unido hacían su propuesta Plug in City y el proyecto de casas cápsulas para viviendas en altura, con todo un sistema integrado de servicios para una gran mega-estructura habitacional. Este proyecto, quizás sin que fuera un objetivo claramente definido, bien pudo ser un antecedente de lo que hoy conocemos como Smart Grid, donde los servicios básicos se centralizan para mediante una gestión sostenible optimizar el funcionamiento de un proyecto urbanístico.

Volviendo a Suiza se puede ver otro ejemplo de cápsula, denominado Casa Rondo de $50 \mathrm{~m}^{2}$, y que fue proyectada por Casoni y Casoni para ser producidas en serie con resina de poliéster con refuerzos de fibra de vidrio, con piel auto-portante a base de dos capas de poliéster de $2,5 \mathrm{~mm}$, con aislamiento en el alma del panel. (arqueologiadelfuturo.blogspot.com. 2015). 
En 1967 el arquitecto japonés Kenzo Tange proyectó la torre Shizuoka Press and Broadcasting, dentro del movimiento metabolista japonés. Construido en el distrito de Ginza en Tokyo, la torre cuenta, aún en la actualidad, con un cilindro como núcleo estructural de diámetro $7,7 \mathrm{~m}$ y altura de $57 \mathrm{~m}$, El núcleo que sirve como eje de acceso contiene las escaleras y ascensores que comunican con las unidades de uso (oficinas) a modo de cajas de vidrio y acero en voladizo de $3,5 \mathrm{~m}$. (http://www.plataformaarquitectura.cl); (Ovando Vacarezza, 2015).

En 1968 Richard Rogers realiza su propuesta de vivienda Zip Up para el concurso House for Today con la que gana el segundo lugar (Fig. 45). El objetivo del autor con su propuesta era ofrecer al usuario un producto adaptable a sus necesidades cambiantes, mediante elementos prefabricados (la vivienda podía ampliar y reducir su tamaño, adoptando diferentes formas) y a precios asequibles.
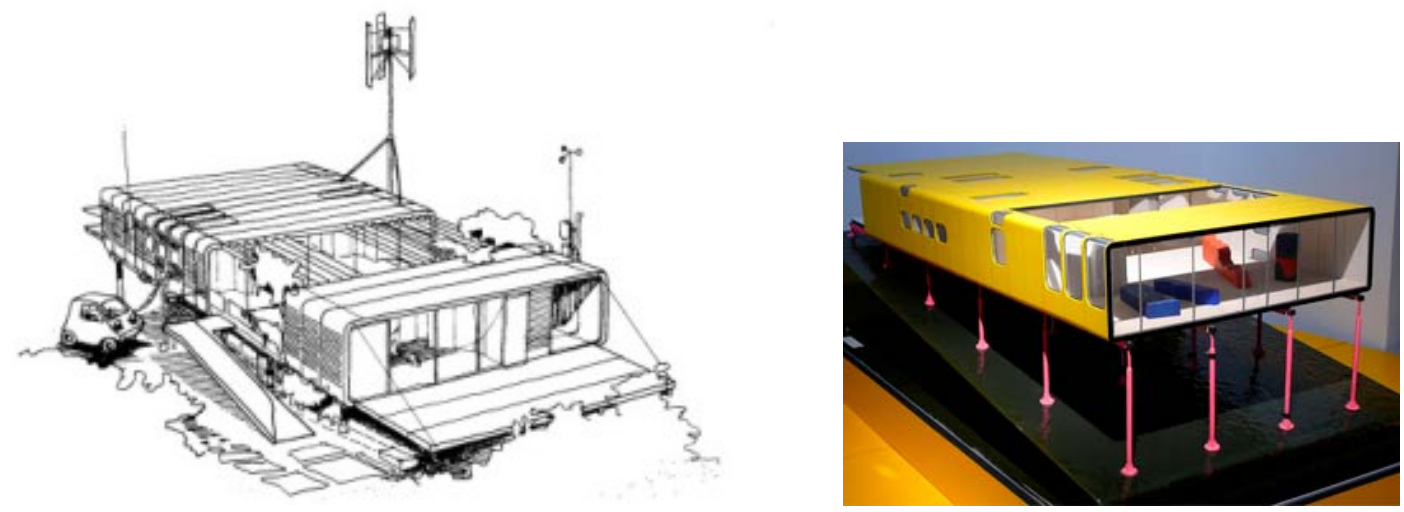

Fig. 45. Casa Zip UP; Richard Rogers 1968. (proyectos4etsa.files.wordpress.com. 2015)

En la propuesta se hacía una aproximación interesante hacia soluciones y sistemas de aprovechamiento energético tanto a nivel activo como pasivo. En ese sentido se incorporaba la generación renovable con eólica.

El nombre "Zip-up" deriva del uso de un sistema de cubierta y muros fabricados en serie con forma de anillos permitiendo el rápido ensamblaje de paneles sándwich de aluminio con aislamiento térmico, unidos mediante burletes de neopreno formando un volumen rectangular con bordes redondeados, apoyado en pilares de acero regulables, adaptables a cualquier tipo de terreno. (Davies, 2005). Estos paneles contaban con un de aislamiento siete veces mayor que una casa tradicional, por lo que sería suficiente un calentador de $3 \mathrm{Kw}$ para acondicionar la vivienda. (proyectos4etsa.wordpress.com. 2015).

En 1968, en Finlandia, Matti Suuronen, propuso un proyecto llamado Future House que fue un prototipo de vivienda prefabricada con una fuerte influencia del movimiento futurista que ganaba terreno entre algunos arquitectos nórdicos de la época (Fig. 46). Este prototipo con forma de elipse, fabricado con dos capas de fibra de vidrio y una espuma de poliuretano, se planteaba como un modelo de fácil montaje en cualquier parte del mundo y bajo cualquier condición climática. (proyectos4etsa.wordpress.com. 2015) 
Otro proyecto destacable de Suuronen fue la Casa Venturo (Fig. 47), con envolvente exterior compuesta por un entramado estructural de tubos de aluminio y revestimiento en fibra de vidrio con aislante de espuma de poliuretano, para un peso aproximado de La unidad básica pesaba 4 mil kg. (Ovando Vacarezza. 2015).

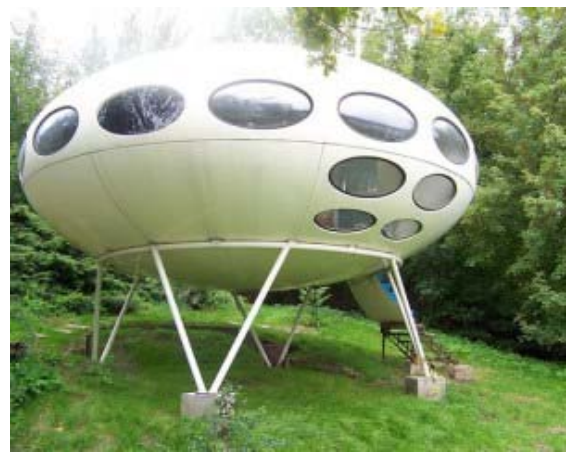

Fig. 46. Future House; Matti Suuronen 1968 (proyectos4etsa.files.wordpress.com. 2015)

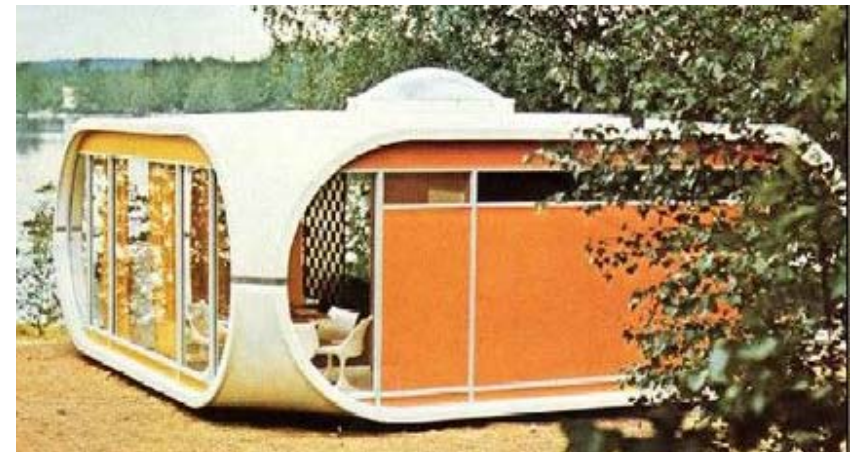

Fig. 47. Casa Venturo Matti Suuronen 1968. (http://www.treehugger.com. 2015)

También hacia 1968, el francés Jean Maneval proyectó la casa de plástico conocida como Maison Bulle 6 coques. Este prototipo estaba ejecutado con una serie de módulos radiales en forma de casquetes (desmontables) de poliéster reforzado con metacrilato y aislamiento térmico de espuma de poliuretano. La superficie de la vivienda era de $36 \mathrm{~m}^{2}$, repartida en 6 módulos, para un peso total de $1.260 \mathrm{~kg}$. El montaje de la vivienda se hacía mediante grúas y fueron fabricadas hasta 30 unidades hasta el 1970. (Mercier\&Associés, 2015); (www.jousse-entreprise.com. 2015)

En 1969, Arne Jacobsen junto a Hom Typehuse, proyecta la vivienda prefabricada Kubeflex como un prototipo de casa de verano. La vivienda puramente modular permitía añadir unidades para ampliar su superficie a partir de una medida estandarizada de unos $12 \mathrm{~m}^{2}$. La estructura de madera permitía utilizar varios componentes de cerramiento. Tanto el suelo como la cubierta contaban con material de aislamiento, siendo en el caso de la segunda un revestimiento de neopreno líquido. Los demás cerramientos estaban compuestos por combinaciones de fibra, asbesto y plástico. (Ortega, 2013).

\section{Los años 70 del Siglo XX}

Entre 1969 y 1971 Paul Rudolph diseñó las Oriental Masonic Gardens, que fueron construidas por la Prince Hall Masons con el apoyo financiero, a nivel hipotecario del Departamento de Vivienda y Desarrollo Urbano de Estados Unidos. Esta urbanización que consistía en 148 módulos construidos en más de 50 mil m2. Disponía las viviendas de cuatro en cuatro con un núcleo de servicios. Los módulos se montaban directamente en fábrica con las instalaciones de fontanería y electricidad ya listas. 
Estos módulos que estaban hechos básicamente en madera solo duraron en uso unos 13 años sin que nunca fueran aceptadas como parte del paisaje urbano del lugar.

(Official UMass Dartmouth Library Web Page, 2015).

En 1970 la empresa española Dragados y Construcciones, propone para su comercialización un tipo de viviendas modulares ligeras denominadas Caracola. Estos prototipos estaban diseñados en módulos 3D así como con elementos panelizados. Las instalaciones propias de la vivienda ya se vendían listas para su acoplamiento con la red general en el lugar de emplazamiento. En un principio el solado se había propuesto en hormigón en los prototipos, pero luego fue sustituido, para mayor facilidad por un elemento de madera.

Los cerramientos estaban hechos con un tipo de panel sándwich formado por dos planchas (exterior e interior) de un mortero a base de resinas de poliéster, armado con fibra de vidrio, unidas por un trillaje nido de abeja, relleno de un material aislante a base de espumas de urea-formol. (Mateo et al., 1978).

En 1971, en Estados Unidos y en Japón se crean empresas para la fabricación de viviendas modulares. Mod-U-Kraf Homes es una filial de All American Homes y construye "Manufacturer Homes" y "Modular Homes", en el primero, y Sekisui en el segundo.

En esta misma década de 1970 se sucedieron varios proyectos, concursos e iniciativas empresariales en los que se desarrollaron prototipos y modelos de edificaciones modulares o partes de las mismas. De estos, por su significación técnica y social, son destacables algunos de ellos como las Torres Nakagin y Sony de Kisho Kurokawa y la $K$ House del mismo (1972), las Toyota Home, y la House 55, esta última como resultado de un concurso sobre viviendas eficientes en Japón.

En el caso de la Torre Nakagin, ejemplo del metabolismo japonés y que con ciertas influencias del proyecto Plug in City de Archigram, Kurokawa plantea un concepto de alojamiento turístico flexible para la zona de negocios de Tokio. La torre, cuenta con dos núcleos de instalaciones y circulación de hormigón como eje del edificio, al cual se conectan los módulos prefabricados de chapa de acero galvanizado reforzado, terminados con pintura antioxidante para su conservación (Fig. 48). 


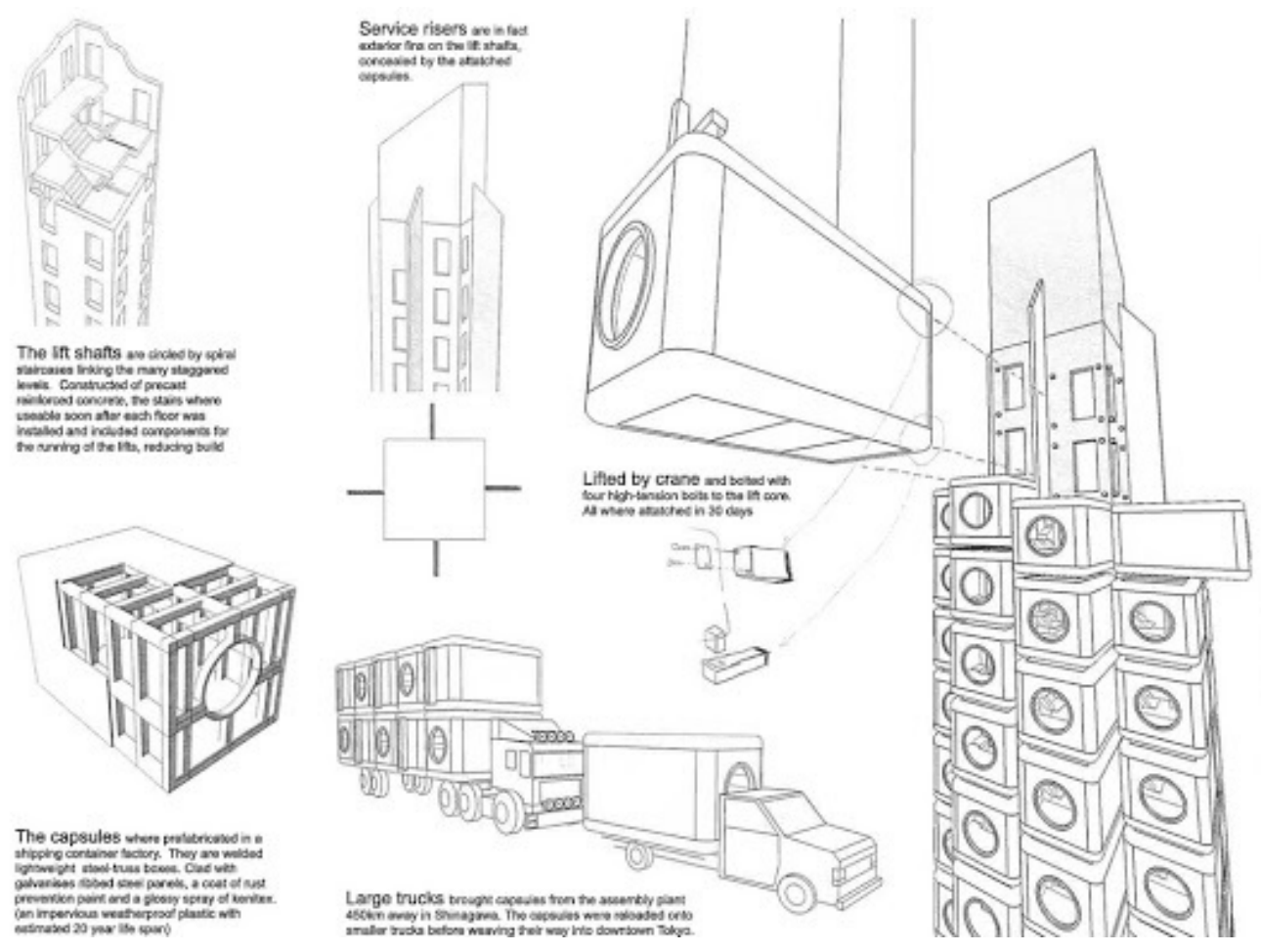

Fig. 48. Torre Nakagin. Kisho Kurokawa 1970/1972. (www.proyectos4etsa.wordpress.com. 2015)

Dichos módulos o cápsulas con espacio mínimo para el alojamiento de una persona podían combinarse para conformar espacios más amplios en el mismo núcleo de la torre de 14 niveles. Fue seleccionado como uno de los 125 edificios catalogados por el DOCOMOMO en Japón en la categoría de "Arquitectura Moderna en Japón", 2006. (http://www.kisho.co.jp. 2015).

La Torre Sony fue diseñada como una sala de exposición para Sony Electronics. Se diseñó para estar conectada en tiempo real con sus homónimas Torres Sony en Nueva York, Londres, París y otras grandes ciudades por satélite. Cuenta con cápsulas de servicios del mismo tamaño que las de la Torre Nakagin pero fabricadas en acero inoxidable. La Torre de Sony se le considera un prototipo de arquitectura sostenible, ganando en 1977 el Premio de Oro de la Japan Sign Design Association Award y el Premio Hiroba Award en el mismo año. (http://www.kisho.co.jp. 2015).

La Kaspel House (K House) fue la otra propuesta de Kurokawa que a partir de contenedores realizó capsulas habitables. Con estructura y cerramientos de acero, la vivienda contaba con varias cápsulas y cada una con una función determinada ya fuera de cocina, dormitorios o salón.

La Toyota Home fue una incursión - que continúa hasta nuestros días - que realizó la empresa automotriz en el año 1975, en el campo de la vivienda industrializada. Para las casas Toyota se ha desarrollado una estructura metálica antisísmica adaptando la tecnología automotriz para tales fines. De acuerdo a los fabricantes estas viviendas pueden estar listas y en uso en unos 45 días, luego de su implantación en el lugar de emplazamiento se completa tan solo el $15 \%$ de todo el proceso de construcción, 
siendo el sistema Steel Frame el que comúnmente utilizan. (http://www.toyotaglobal.com 2015).

A finales de los 70 se desarrolla en España un sistema de módulos ligeros (a partir de 27m2), de sistema panelizado (paneles sándwich), promovido por la empresa Dragados, llamado Sistemas Modulares Caracola y que sigue vigente hasta la acualidad mediante el Documento de Idoneidad Técnica (DIT) NN 593/12.

\section{Los años 80 del Siglo XX}

Un edificio emblemático, de la obra de unos de los arquitectos más influyentes de la actualidad, Norman Foster, es el Banco de Hong Kong y Shangai construido entre 1979 y 1986. En este proyecto Foster implementó sistemas y elementos prefabricados para poder no solo flexibilizar el proyecto sino viabilizar los trabajos de terminación y entrega en tiempo y forma. Acero de Reino Unido, Vidrio, suelos y aluminio de Estados Unidos y módulos de servicios desde Japón completan magistralmente el proyecto.

A partir de 1982 la All American Homes, fundada en 1970 en Estados Unidos comienza a fabricar viviendas modulares por todo el territorio americano, siendo su principal fundamente la flexibilidad de sus proyectos, siendo uno de los mayores fabricantes de este tipo de viviendas en aquel país.

\section{Los años 90 del Siglo XX}

Ya entrando en la década de 1990, se desarrolló en Estados Unidos un proyecto (Mobile Ecolab), de investigación que promovía la construcción de viviendas antisísmicas en California. Dentro de este contexto Jennifer Siegal, OMD (Office of Móvil Desing) proyectó un tipo de vivienda modular con estructura metálica y paneles SIP. En palabras de la propia firma de diseño, dentro de su filosofía de trabajo, el concepto sostenibilidad se hace presente en sus proyectos. (http://www.designmobile.com. 2015).

En España, para el año 1993, el arquitecto P. Oliva, proyectó unos módulos tridimensionales destinados a albergar los laboratorios de una empresa farmacéutica en Madrid. Estos módulos auto-portantes, estaban construidos con perfiles de acero, con suelo metálico de chapa grecada y con revestimiento de aislamiento de poliestireno y acabado interior de conglomerado de madera. Los demás cerramientos estaban constituidos por un panel sándwich de panel de melanina, yeso y lana mineral (Del Águila,1996)

En 1995, Wes Jones propone una arquitectura modular a partir de contenedores marinos con el nombre de High Sierra Rock Cabin. El proyecto que sería la vivienda de dos académicos de la Universidad de Stanford ponía en valor el uso de este tipo de contenedores de 6,10 m por 3,00 m de ancho aproximadamente, adaptándolos al uso de vivienda (Fig. 49). 


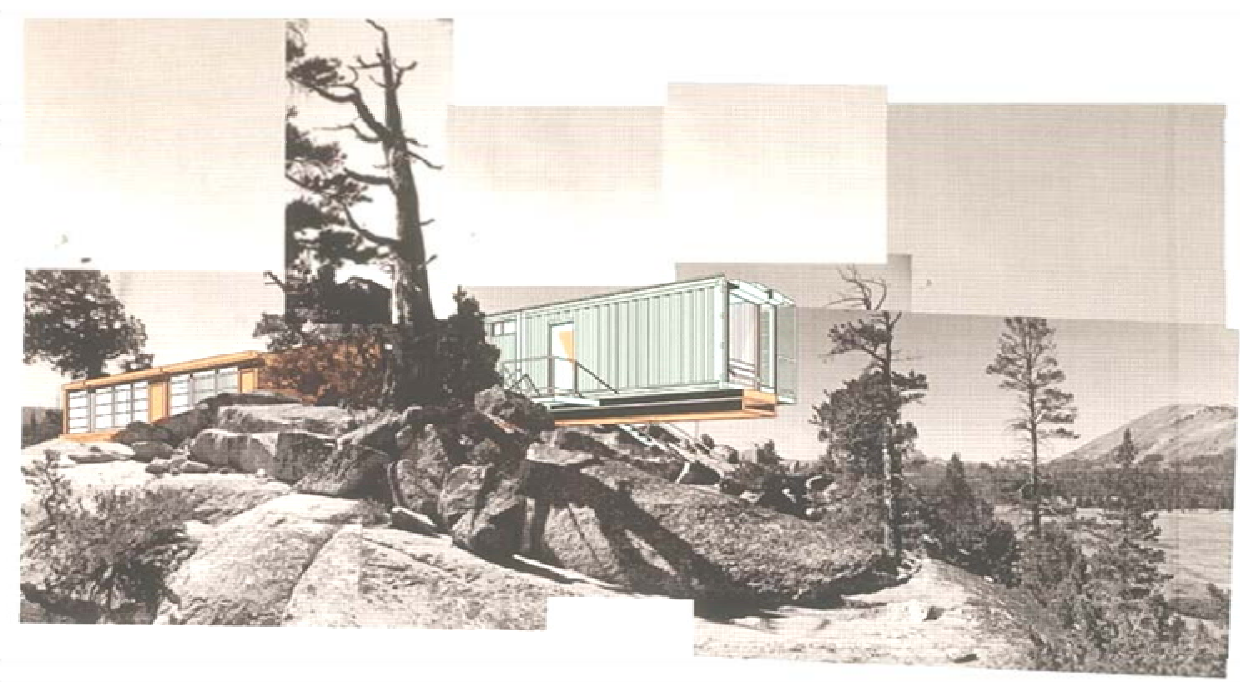

Fig. 49. High Sierra Rock Cabin. 1995 Wes Jones (http://www.frac-centre.fr. 2015)

Este tipo de soluciones se ha hecho muy popular por la relativa facilidad de adaptar estas unidades para el uso habitacional (viviendas, oficina etc.) y siempre que su utilización sea parte de un proceso de reciclado del contenedor, resulta favorable en términos de sostenibilidad y ciclo de vida del acero como material de fabricación de los mismos. (http://www.frac-centre.fr. 2015). Años más tarde (1998) el arquitecto Adam Kalkin también trabaja en esta línea.

Entre 1996 y 1997 se desarrollaron varios proyectos de arquitectura modular ligera con aportes en cuanto a su concepción como producto acabado para ser implantado en el lugar de destino quedando pendiente solo la conexión a las redes de suministro. Tal es el caso de los prototipos Su- si y Fred (Kaufmann \& Ruf) en madera y vidrio, en Austria o las viviendas y oficinas en Rathenow, de Klaus \& Keim, quienes haciendo de la arquitectura modular un recurso de optimización de medios acometieron la reforma de una vivienda del siglo XIX en Alemania con doce módulos prefabricados diseñados para tales fines. (Ovando Vacarezza, 2015). Este concepto de rehabilitación con elementos prefabricados resultaría ser cuando menos una declaración de intenciones sobre el tema de la optimización de recurso en el proceso constructivo mediante elementos prefabricados, cuyos procesos de producción pueden ser controlados desde esta perspectiva.

\section{Siglo XXI}

Wes Jones, el arquitecto de los contenedores proyecta su sistema Pro/Con, proponiendo dos tipologías (unifamiliares y en altura) de viviendas que aprovechaban estos módulo originalmente destinados al transporte de mercancías. En 2003 Robert Humble desarrolla el concepto Cargotecture a partir, también, de contenedores.

Para este mismo 2003, es convocado por la revista Dwell un concurso restringido con 16 arquitectos para diseñar una vivienda prefabricada por valor inferior a 200.000 dólares. Resolution 4 Architecture, de Nueva York, resultó ser el ganador de dicha 
convocatoria con su proyecto denominado la Dwell Home de $220 \mathrm{~m} 2$ cuyo material predominante, madera, e incluso madera reciclada (garantizando el ciclo cerrado del material), fue combinado con estructura metálica y cerramientos acristalados. (http://re4a.com, 2015).

También en el 2003 la empresa Du Pont (Francia) y el diseñador alemán Werner Aisslinger, proyectan la Loftcube, un prototipo de vivienda en dos versiones, una de 39 $\mathrm{m}^{2}$ y la otra de $55 \mathrm{~m}^{2}$ a razón de $200 \mathrm{~kg} / \mathrm{m} 2$ con estructura de steel frame (Fig. 50). La estructura principal de la vivienda está compuesta por cuatro apoyos que soportan el cubo ligero. Varios materiales se han utilizado para la fabricación de la casa, desde madera certificada FSC y una proporción de aluminio no mayor al $2 \%$, hasta membrana Ferrari 8000, muy típica en las cubiertas de los estadios, aeropuerto y revestimiento en fibra de vidrio. Las carpinterías de madera, van de suelo a techo, e incorporan un doble acristalamiento de vidrio de $8 \mathrm{~mm}$, con $27 \mathrm{~mm}$ de separación y cámara de aire. El LoftCube se ha concebido como una casa de baja energía. Los cerramientos opacos cuentan con un nivel de aislamiento de $0,03 \mathrm{~W} / \mathrm{mk}$, y los valores de consumo son inferiores a $100 \mathrm{kWh} / \mathrm{m}^{2}$ (http://www.loftcube.net. 2015).

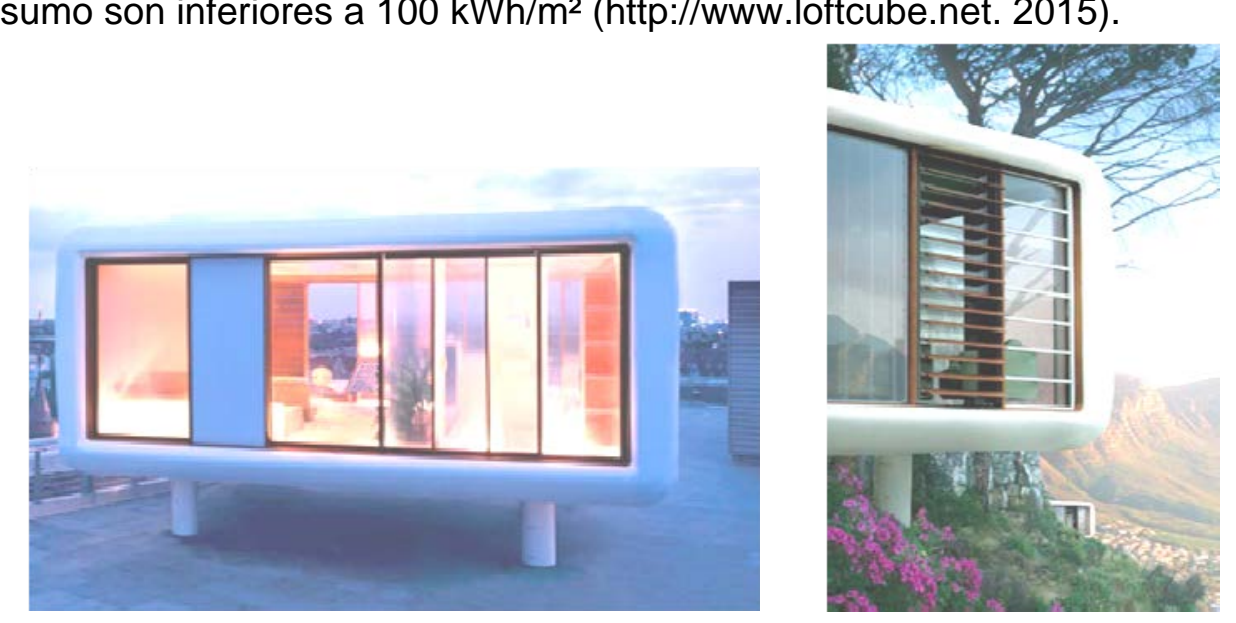

Fig. 50. Loftcube, 2003. Werner Aisslinger. (http://www.loftcube.net. 2015).

En 2004 y como parte de la feria de la construcción Constructec de ese año, el arquitecto J.M. Reyes proyectó las viviendas Dominó 21 con la colaboración de la empresa IDM (Ingeniería y Diseño de Edificaciones Modulares), de Madrid. El objetivo era, en cierta medida, hacer un ejercicio técnico/académico en el que se pudiera demostrar que era posible hacer un tipo de arquitectura modular y ligera a partir de componentes y elementos disponibles en el mercado y compatibles desde el punto de vista de la estandarización (Fig. 51).

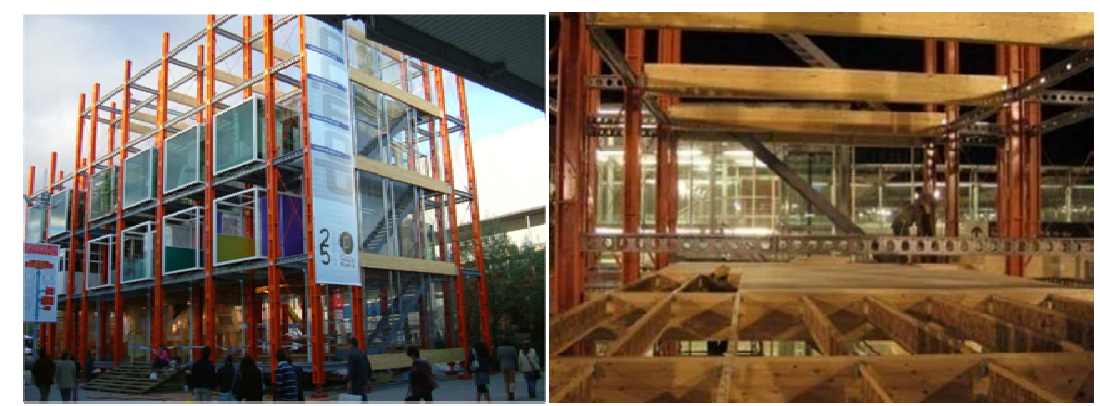

Fig. 51 y 52. Dominó 21; 2004. J.M. Reyes. (http://infomadera.net. 2015). 
De fácil montaje y desmontaje las 24 cabinas modulares estaban fabricadas con un sistema mixto de metal y vidrio apoyadas en una estructura de pilares de acero y entramados de madera laminada (http://infomadera.net, 2015). Como ventaja desde el punto de vista de la sostenibilidad como fase previa y contexto de la eficiencia energética, está el hecho de que los componentes industrializados forman parte de todo un sistema de producción controlado y producción en serie, de uso común en la construcción, no siendo necesario crear un esquema de fabricación nuevo para estos elementos.

En 2007 Richard Horden crea la Micro-Compact Home [m-ch] (Reino Unido) (Fig. 53), que es un vivienda compacta con medidas mínimas $(2,66 \mathrm{~m} \times 2,66 \mathrm{~m})$, ideal para estudiantes y/o usuarios de estancias cortas. Con una estructura de entramado de madera y aluminio anodizado o recubierto cuenta con unos acabados de revestimiento en polvo de poliéster externos, aislados con espuma de poliuretano y equipados con marco de aluminio con doble acristalamiento y puerta con doble cerradura de seguridad. Cuenta con aire acondicionado, agua caliente, alarma contra incendios y detectores de humo integrados en el prototipo y un sistema de termostato para el control de la climatización por aire o suelo radiante y optimización del consumo. (http://www.microcompacthome.com. 2015).

Por otro lado en Japón, con una larga tradición de construcción modular industrializada y construcción modular ligera, cuenta, de acuerdo a datos técnicos y estadísticos disponibles con un 53\% de viviendas equipadas con sistemas fotovoltaicos, de las cuales un total de 7.300 se clasifican como net zero energy (Ovando Vacarezza.2015).

A partir del año 2008, Blue Homes, propone en su catálogo de ventas de viviendas modulares, de diferentes tamaños y diseños, que de acuerdo a su información comercial, responden a criterios sostenibles de respeto al medioambiente con materiales certificados como la madera, y eco-amigables (Fig. 54).

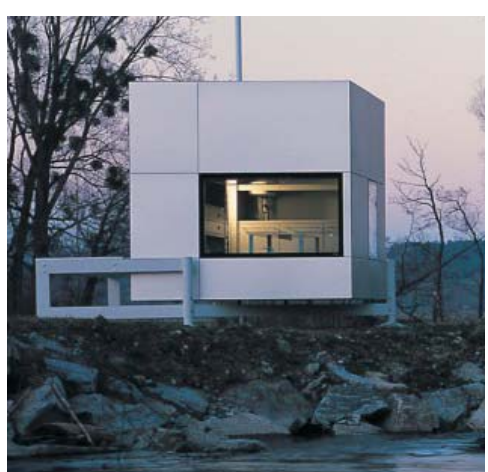

Fig. 53. m-ch; 2007. R. Horden (www.microcompacthome.com)

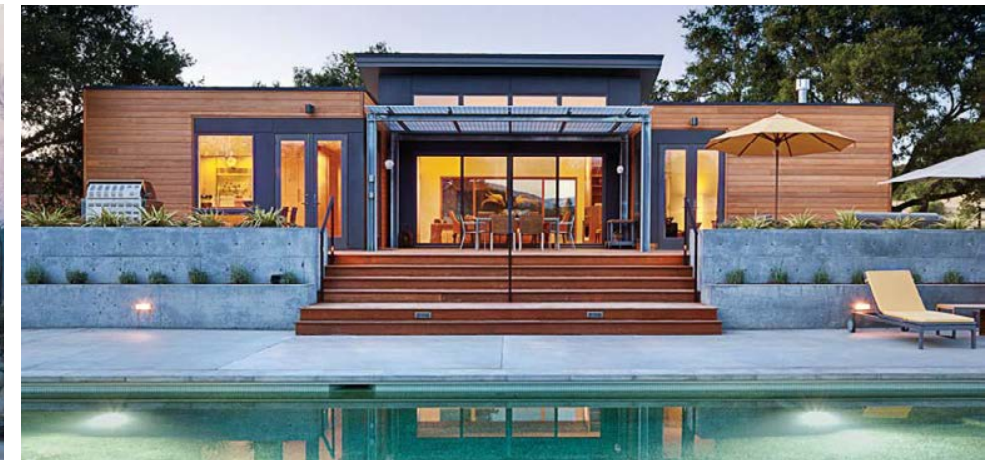

Fig. 54. Blue Homes. 2008. (www.bluhomes.com) 
Los diseños de Blue Homes, muchos de ellos de la autoría y/o influencia de M. Kaufman (desde 2002), presentan plantas flexibles sin grandes muros de carga que puedan interrumpir la diafanidad del espacio (www.bluhomes.com. 2015).

En 2009 el estudio CG Arquitectos proyectó y ejecutó la vivienda Crossbox a partir de contenedores de barcos. Como particularidad estas viviendas incorporaban una cubierta verde como proyección parcial de la huella del edificio en la parcela y como sistema de natural de aislamiento térmico.

De acuerdo a datos técnicos y estadísticos la empresa norteamericana que vendió más viviendas en el año 2011 fue Clayton Homes en Estados Unidos. De acuerdo a la propia información comercial servida por la empresa sus procesos son eco-amigables, con materiales reciclados como la madera y plástico. Cuentan con un sistema de control de desechos y contaminación por vertidos de partículas en sus procesos fabriles. (http://www.claytonhomes.com. 2015)

Desde 2010, Modulab, un estudio de arquitectura español que en asociación con IDM (Madrid) y Egoin (Bizkaia), ejecuta proyecta prototipos de vivienda modular industrializada auto-portantes en madera o acero. De acuerdo a su propia documentación comercial, el uso de materiales, la gestión de residuos, el ahorro energético, el bajo impacto en obra y la reciclabilidad de la totalidad de la edificación, convierten a su sistema en opción con características de sostenibilidad. (www.sistemamodulab.es. 2015).

Un año más tarde el estudio A-cero (España), de los arquitectos Torres y Llamazares inicia las operaciones comerciales de A-cero Tech con un catálogo de modelos estandarizados de construcción modular ligera. Con un sistema constructivo basado en el acero y cimentación de hormigón, cuenta con un sistema estructural compuesto por vigas y pilares de acero, y forjados y la cubierta son de chapa colaborante y en algunos casos de hormigón dependiendo el modelo. Su cerramiento está compuesto por una fachada trasventilada sobre rastreles y con un acabado en paneles de chapa tipo Euronit. Como ventaja sostenible o de eficiencia energética se podría plantear el hecho, inherente a la arquitectura prefabricada y ligera, de que una construcción con controles de prefabricación en taller garantiza un control de los procesos que trae como consecuencia una optimización de los recursos energéticos asociados a estos procesos. (http://www.a-cero.com. 2015).

En el 2013 Renzo Piano diseña la casa Diogene con una superficie de $6 \mathrm{~m}^{2}$ y un peso de 1,2 T (Fig. 55). Con este proyecto Piano plantea una vivienda pequeña para uso alternativo (espacio de estudio, descanso o recreo) que satisface las exigencias de sostenibilidad y eficiencia energética, tanto en términos de uso, producción y posterior fin de uso. La vivienda que aún se encuentra en fase de ensayo como prototipo de espacio mínimo habitable y eficiente y autónomo energéticamente hablando, ha sido patrocinada por la empresa Vitra, la misma que tiene los derechos sobre los diseños de mobiliario de Jean Prouvé. 


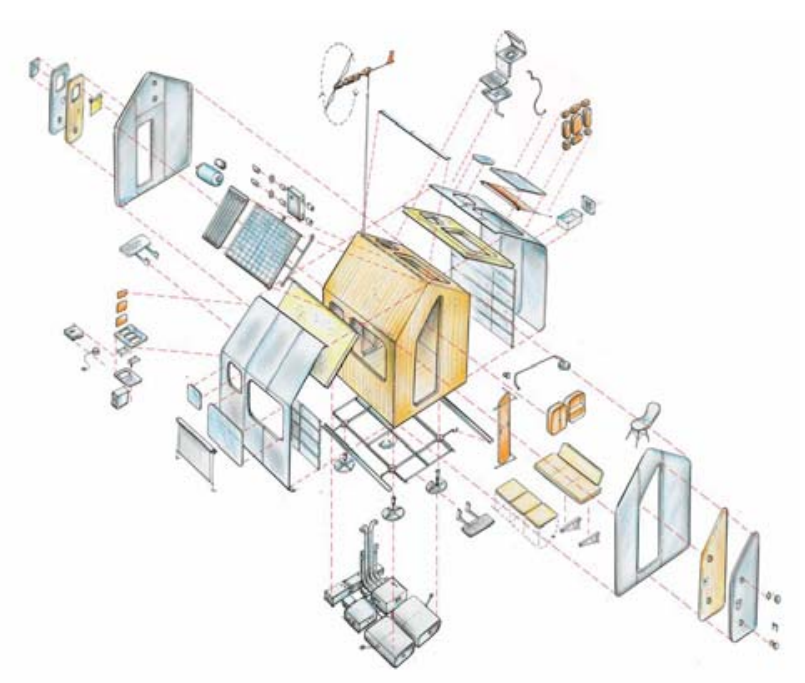

Fig. 55. Diogene House; 2013. Renzo Piano. (http://www.vitra.com. 2015).

\section{El proyecto INVISO}

Un proyecto de alto interés técnico y científico, que promovía la construcción industrializada, asociada a la eficiencia energética fue el proyecto INVISO de viviendas industriliazadas, desarrollado bajo los auspicios directos del gobierno de España. El proyecto "Industrialización de viviendas sostenibles" (INVISO), financiado originalmente por el Ministerio de Ciencia e Innovación de España, promovido en un principio por el Instituto de Ciencias de la Construcción EduardoTorroja y luego por la empresa DRAGADOS, fue creado en el año 2006 con los objetivos fundamentales de optimizar la producción de viviendas industrializada y sus procesos constructivos y/o de fabricación, innovando en la creación de nuevos materiales y sistemas. Estos objetivos se planteaban dentro del contexto de la sostenibilidad, asociada al diseño y la construcción/fabricación. (Queipo, J. et al. 2009)

\section{Manubuild}

La Empresa Municipal de la Vivienda y el Suelo de Madrid (EMVS) convocó en 2006, un concurso restringido de ideas arquitectónicas como primera fase para la construcción, en el contexto de la estrategia marcada por el Proyecto Integrado I+D+i Manubuild, con financiación de la Comisión Europea a través del $6^{\circ}$ Programa Marco, de un proyecto que conjugara industrialización y sostenibilidad. El objetivo de este concurso, con varios equipos europeos participantes, fue obtener propuestas con aplicación de sistemas constructivos industrializados, abiertos y sostenibles, y que a partir de esto se planteara un punto de partida conceptual para los edificios que la EMVS. (Ruiz-Larrea, C. et al. 2009). La propuesta ganadora, desarrollada por el Estudio RLA, pretendía abrir los procesos industriales para adaptarse a las necesidades de cada momento. Incorporaba sistemas de estructura portante, instalaciones y sistemas bioclimáticos pasivos y activos. 


\subsection{TIPOS DE MATERIALES Y TÉCNICAS CONSTRUCTIVAS.}

Un módulo ligero según la definición de Del Águila es aquel en el que se busca la disminución de peso mediante diversos procedimientos, como la utilización de estructuras metálicas, cáscaras de plástico o G.R.C. y uso de planchas de materiales ligeros, es decir, metacrilatos, contrachapados de madera, vidrio, chapas metálicas, PVC, etc.). (Del Águila García, 2006). Tanto el metal como la madera han sido los materiales que han dominado el escenario histórico en cuanto a construcción modular y/o ligera se refiere. Los demás materiales citados por el Del Águila en su libro, son de relativa reciente aparición.

La tendencia a lo largo del tiempo, o por lo menos la aspiración que se ha observado en esta forma de hacer arquitectura y sobre todo en la construcción industrializada, prefabricada y modular ligera (de no más de $200 \mathrm{~kg} / \mathrm{m}^{2}$ en sus elementos constructivos y de cerramiento), ha sido la optimización de plazos y el solventar temas de habitabilidad, ya sea para casos de contingencia (situaciones de emergencia o de déficit habitacional), como el caso de las Copper Houses de Walter Gropius y la Maison des Jours Meilleurs de Jean Prouvé de 1956; o para descanso y vacaciones como la Casa Aluminaire de 1931 de Frey ( discípulo de Le Corbusier) y que originalmente fue concebida para la Allied Arts and Building Products y luego emplazada en Long Island o el caso de las emblemáticas Casas Tropicales también de Prouvé con las que se buscaba facilitar las tareas constructivas en lugares alejados de los centros de producción de materiales, apoyándose en las ventajas de una construcción industrializada, construible o armable en poco tiempo y con características propias del lugar de emplazamiento como Niamey en Nigeria y Brazzaville en el Congo, ambos en África.

En cuanto a la construcción ligera industrializada, los avances e innovaciones en cuanto a la técnica se han quedado más bien del lado de la optimización y eficacia de los sistemas constructivos, más que de la eficiencia energética. Materiales como la madera y sus derivados (de uso común en el norte de Europa y Estados Unidos), los metales ferromagnéticos (tanto para uso estructural como de cerramiento), el aluminio (como componente en paneles compuestos tipo paneles sándwich y en las carpinterías), el vidrio (como elemento translúcido de cerramiento por excelencia) y los materiales como el PVC o el GRC entre otros, han sido explorados - y desarrolladas sus formas de aplicación- para intentar mejorar sus prestaciones constructivas y estructurales en el ámbito de la construcción modular ligera.

La utilización de uno $u$ otro material se ha determinado, en gran medida, por la evaluación de aspectos tales como las prestaciones constructivas y/o estructurales y la durabilidad del mismo (resistencia al uso y a los efectos de la naturaleza). De manera implícita se ha tomado como un punto de inflexión, para el desarrollo de la tecnología modular y ligera, el análisis de esa durabilidad de los componentes del organismo arquitectónico, en el caso de los elementos, y del todo en el caso de los modelos en su conjunto. 
Esta forma de abordar el tema ha venido a ser una fase cronológicamente previa - y parcial- de lo que hoy sería el ACV (Análisis de Ciclo de Vida); un ACV que en la actualidad es determinante para evaluar no sólo la eficiencia energética de cualquier obra de arquitectura, sino también su huella ecológica.

Los módulos de la Torre Nakagin son un claro ejemplo de un proyecto diseñado para el recambio de piezas durante la vida útil del edificio, tomando en consideración la durabilidad de los materiales. El arquitecto Kisho Kurokawa había estimado una vida útil aproximada de 25 años, al cabo de los cuales varias partes de los módulos - o los módulos completos- debían ser sustituidos cuando se suponía que cumplieran su ciclo de utilización en la torre. Sin embargo, a la fecha no ha habido ningún proceso de sustituciones de módulos ni de piezas, evidenciándose, por el paso del tiempo, el deterioro de los módulos y de muchas de sus partes. Estos recambios tendrían que haber sido el producto de una cadena de producción industrializada que serviría como banco de remplazo para proyectos de la misma naturaleza como La Casa Cápsula del propio arquitecto.

Lo cierto es que la idea de la cadena de montaje y/o producción en serie, propias de la aeronáutica o la industria automovilística se ha quedado en la fase de prototipo cuando se ha querido extrapolar la experiencia al campo de la arquitectura (en serie), quedando pendiente de desarrollar los conceptos de producción eficaz de módulos o componentes (como conjunto tridimensional o como partes de cerramiento en dos dimensiones), acordes a las necesidades del usuario y dentro de un ciclo cerrado de vida del material .

Una realidad contrastada es que muchos de los materiales que intervienen en la construcción ligera $(\mathrm{CL})$, ligera industrializada (CIL) y construcción modular ligera $(\mathrm{CML})$ tienen un alto coste energético por su nivel de emisiones; pero aun siendo esto así la cantidad de material utilizado en una construcción de carácter ligero es mucho menor que la cantidad de material utilizado en la construcción tradicional si hacemos el cálculo directo de $\mathrm{kg} / \mathrm{m}^{2}$ o $\mathrm{Kg} / \mathrm{m}^{3}$ según sea el caso. Un $\mathrm{m}^{2}$ de construcción tradicional tiene un peso aproximado de $2.300 \mathrm{Kg}$ (Wadel Raina, 2009), mientras un $\mathrm{m}^{2}$ de construcción ligera supone solamente 200 kg (Del Águila, 2006).

Siendo el peso una de las medidas válidas para determinar el nivel de emisiones de $1 \mathrm{~m}^{2}$ de construcción, queda claramente establecido, en esta comparativa, que es posible reducir emisiones si se reduce peso en la construcción; desde luego esta afirmación queda condicionada a que los procesos que van, desde la extracción del material hasta su deposición y/o reutilización, estén dentro de un ciclo cerrado de vida. Por otro lado el proceso de reciclaje de los materiales ligeros, aunque tiene implicaciones a nivel de emisiones, también es cierto que representa un proceso de menor carga ambiental que la producción no sólo de los materiales pesados sino de los propios materiales ligeros. 
Tal como se establece en las conclusiones del epígrafe anterior, los materiales más utilizados en la construcción modular ligera a través de la historia - y en la actualidad han sido la madera y los metales (en un primer orden), y en un segundo orden algunos materiales compuestos, tal y como se muestra en la siguiente esquema (Fig. 56). Por otro lado y dentro de la categoría de los materiales translúcidos y transparentes el vidrio es y sigue siendo el de mayor utilización siendo de uso relativamente reciente algunos materiales compuestos (sintéticos).

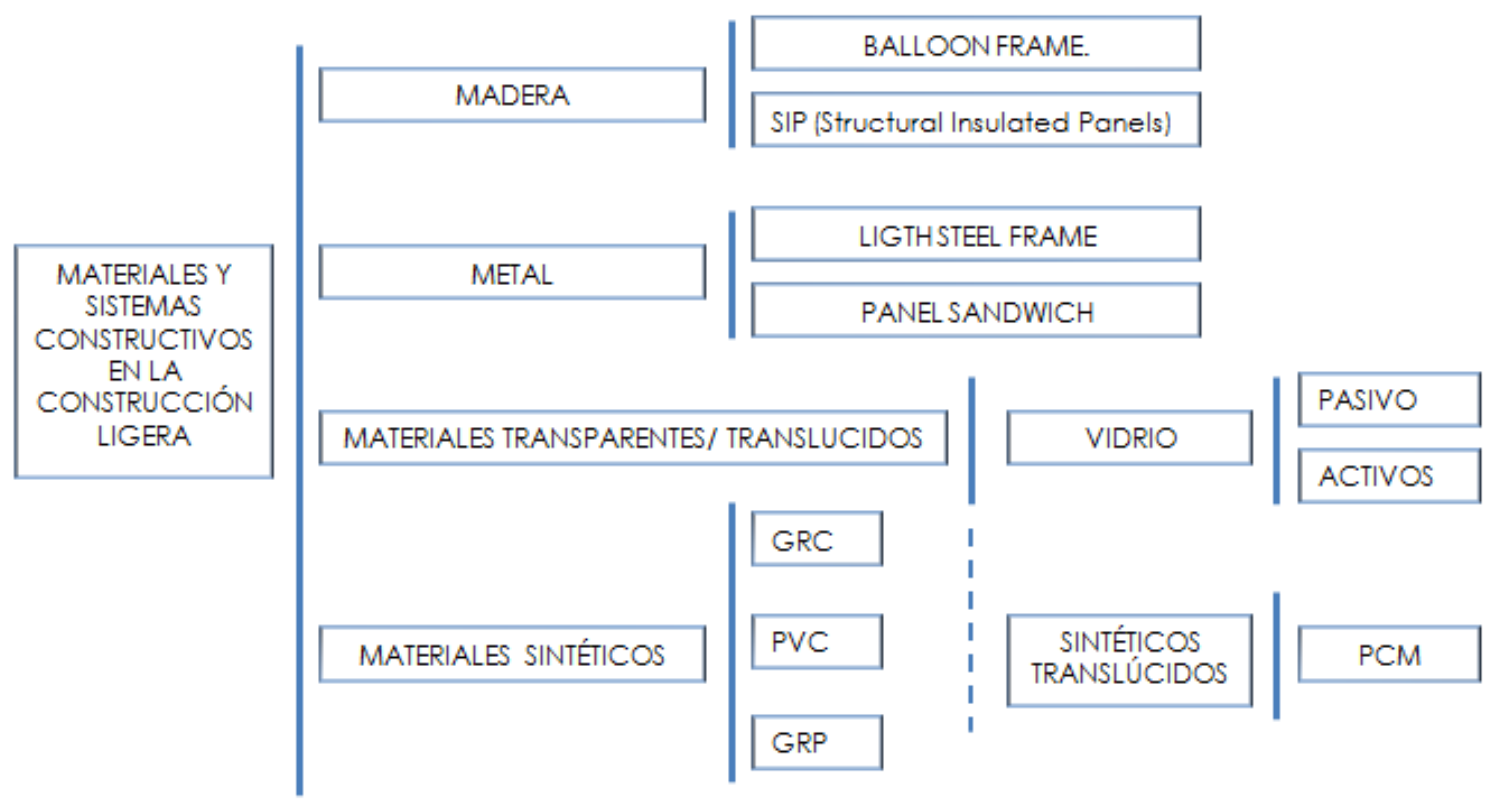

Fig. 56. Esquema de materiales y sistemas constructivos más habituales en la CML.

Elaboración propia 2015

Madera

La madera, sin duda, es el material con mejor balance energético de los que se utilizan en la construcción. En sus diferentes tipos y niveles de procesamiento industrial, se sigue utilizando tanto como elemento estructural así como para cerramiento, y en algunos casos, dependiendo de la envergadura del proyecto, en un uso mixto, es decir estructural y de cerramiento.

Dentro del amplio abanico de opciones de utilización de la madera y de acuerdo a las conclusiones que como consecuencia del análisis del estado de la técnica y antecedentes se ha realizado en este trabajo, dos técnicas o sistemas han resultado ser las de mayor utilización: el Balloon Frame y el Panelizado hoy evolucionado al SIP (Structural Insulated Panels). 


\section{Balloon Frame}

En la actualidad el Balloon Frame (y su evolución Platform Frame) sigue siendo una opción recurrente en la construcción ligera industrializada y en la construcción modular ligera.

Como se ha podido establecer en el capítulo de los antecedentes, el sistema Balloon Frame se desarrolla entre el 1.832 y 1.833 , en Chicago, Estados Unidos y se le atribuye tanto a Agustine Taylor como a George W. Snow dependiendo del autor. Este sistema consiste en una serie de piezas normalizadas de madera, separadas equidistantemente una de otra, a modo de esqueleto monolítico, para formar cerramientos exteriores, cubierta y suelos.

Esta estructura o entramado que está formada por piezas de madera (normalizadas y aserradas) con una longitud aproximada que pudiera combinarse para conseguir como máximo una doble altura en viviendas (u otro tipología de edificación) y una sección de $5 \mathrm{~cm} \times 10 \mathrm{~cm}$, luego queda recubierta por paneles ya sean de madera o algún otro tipo de material apto para el exterior, suele tener una capacidad portante para edificios de dos alturas. Las distancia aproximada entre ejes, entre cada pieza es de entre 40 y 60 cm (Fig. 57).

Además, el sistema, cuenta con una especie de pieza maestra con sección aproximada de $5 \mathrm{~cm} \times 10 \mathrm{~cm}$ que sirve como unión entre verticales y horizontales.

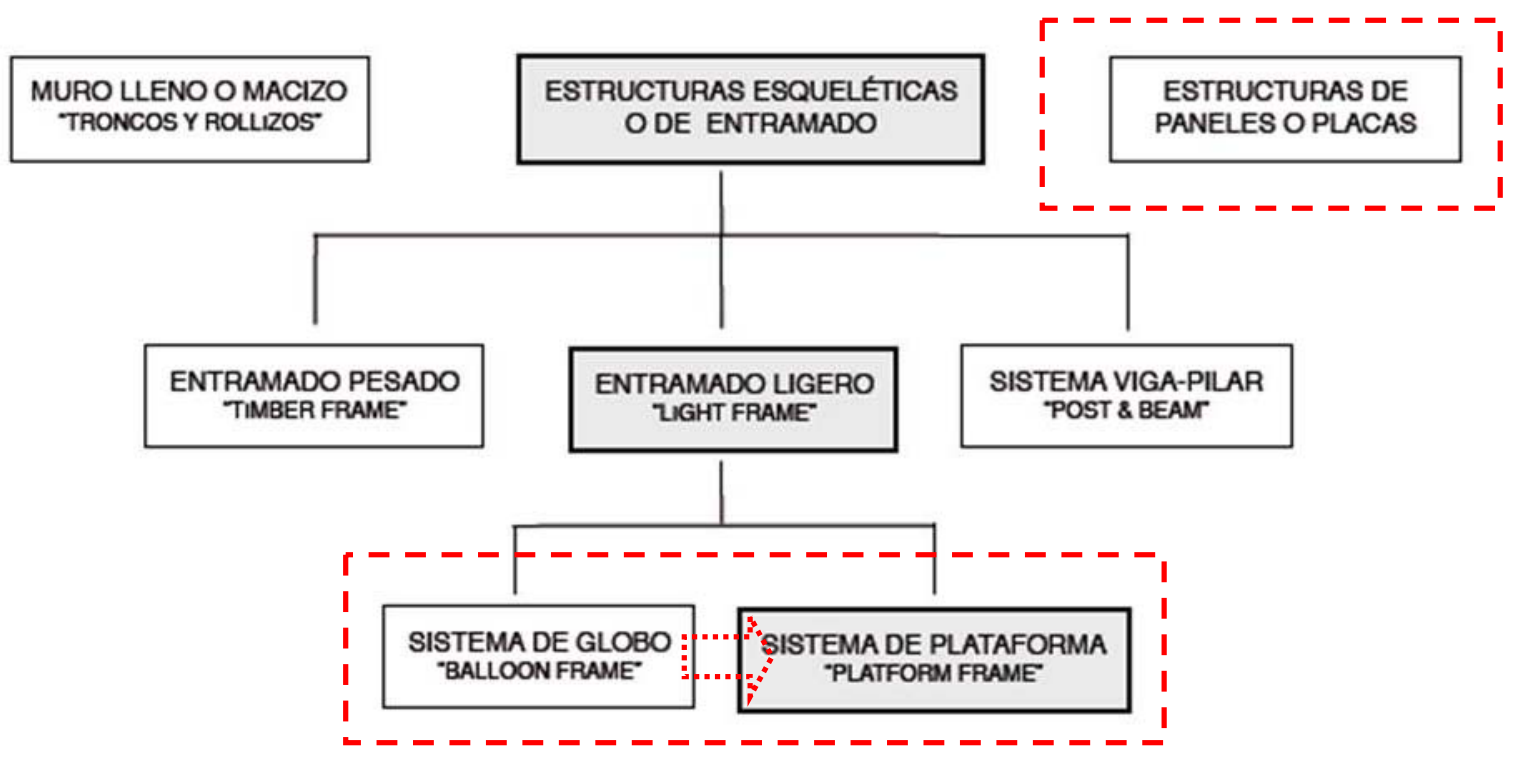

Fig. 57. Esquema de sistemas constructivos de madera. (Inat 2011). Modificado elaboración propia (resaltados en rojo); 2015

Con una cimentación que generalmente es de hormigón, la altura máxima que se puede alcanzar con este sistema (el original Balloon Frame) es de dos niveles o lo que sería, entre 5 y 7 metros de altura. Una edificación con altura superior, quedaría mejor resuelta con el sistema Platform Frame, una evolución del Balloon Frame. 
Este sistema se ha presentado siempre como una alternativa óptima en la construcción. Marca, si no el inicio de los procesos de industrialización, prefabricación y racionalización de viviendas para consumo masivo, por lo menos un punto de inflexión importante, siendo un sistema constructivo trabajable por manos no cualificadas y un plazo de tiempo relativamente corto y además con la posibilidad de poder construirse en lugares apartados por el fácil manejo del material y poco peso del sistema $\left(500 \mathrm{~kg} / \mathrm{m}^{3}\right)$.

El Platform Frame es una especie de modificación o evolución del Balloon Frame y se diferencia de éste en que aun tomando sus conceptos básicos, en lugar de dar continuidad a los pilares, como el Balloon Frame (en los dos niveles en que habitualmente se hace con este sistema), la estructura se va levantando planta por planta de forma que el forjado interrumpe la continuidad de los pilares entre la planta baja y la segunda planta. La razón fundamental para la evolución de la técnica ha sido la imposibilidad de dar continuidad a las piezas en más de dos niveles. Como ventaja añadida el Platform Frame reduce el riesgo de propagación de incendios entre las plantas al estar dividido el sistema estructural por plantas. Con este sistema, descansando la estructura en cada planta, siendo el entrepiso pasante entre los forjados, las cargas se transmiten de manera axial y no excéntrica como en el Balloon Frame (Fig. 58).

En términos de industrialización esta evolución de la tecnología permite, que siendo menor la altura de los montantes sea factible implementar el panelizado en un taller fuera de la obra. La utilización de esta técnica constructiva ha sido una de las razones por las que la construcción modular ligera ha podido competir de alguna manera- en cierta medida y en algunos escenarios- con la construcción tradicional y mantener un discreto nicho de mercado.

La velocidad en la ejecución de la obra es muy superior a la construcción húmeda tradicional, lo que evidentemente se traduce en ahorro de dinero y mayor aprovechamiento de los recursos. De acuerdo a algunos fabricantes (www.maderayconstruccion.com; 2015), es posible levantar una vivienda de $65 \mathrm{~m}^{2}$ entre dos meses y dos meses y medio.

Una ventaja que presentan los sistemas Balloon Frame/Platform Frame es el alto nivel de estandarización de las piezas de fijación que arman el conjunto y la fácil disponibilidad de las mismas en el mercado común de la industria y la construcción. Esto permite que los procesos de fabricación/construcción y puesta en obra se simplifiquen exponencialmente frente a otros sistemas más sofisticados como pudiera ser el caso de los materiales sintéticos y sus elementos de fijación. Actualmente, estos sistemas, por su sencillez en cuanto a la ejecución y por la disponibilidad de sus elementos (materia prima y piezas de ensamblaje), son uno de los sistemas más difundidos en el mundo, en cuanto a CML se refiere, e incluso con un alto nivel de mercadeo a nivel de la industria global de la construcción. De acuerdo a estadísticas 
de comercializadores sobre el $50 \%$ de los edificios de viviendas construidos en países como Estados Unidos, Canadá, Finlandia, Suecia o Noruega se basa en este tipo de tecnología. (www.maderayconstruccion.com; 2015).

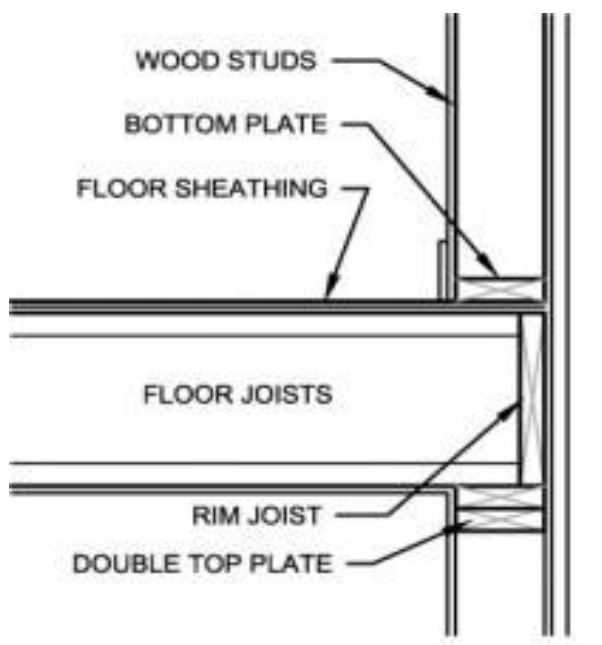

PLATFORM FRAMING

Fig. 58. Comparativa entre sistema Ballon Frame y el sistema Platform Frame, evolución del primero (www.maderayconstruccion.com; 2015) SIP

(Structural Insulated Panel)

El SIP o panel estructural aislado es en sí un sistema de construcción de alto rendimiento y versatilidad en la construcción. Este tipo de panel es un tipo de panel sándwich con núcleo de aislamiento (generalmente de poliestireno expandido, EPS o poliestireno extruido XPS o espuma de poliuretano PUR) y cerramientos laterales de tableros OSB ( Tableros de virutas orientadas); en algunos casos y dependiendo del fabricante se puede utilizar madera contrachapada, revestimiento de fibra de cemento, tablero de magnesio-óxido, estera de fibra de vidrio de revestimiento de yeso y paneles de revestimiento estructurales compuestos (Fig. 60 y 62), (www.wbdg.org; 2015).

En el Año 1935, el Forest Products Laboratory en Madison, Wisconsin introdujo la idea de lo que ahora se conoce como paneles estructurales aislados (SIP). En un principio, el sistema consistía en los elementos del bastidor, madera contrachapada y revestimiento de madera prensada más el aislamiento. Estos paneles que fueron utilizados inicialmente en edificios de viviendas, después de 30 años de uso demostraron conservar varias de sus propiedades en cuanto a resistencia (www.wbdg.org; 2015). El propio Frank Lloyd Wright utilizó un tipo de panel estructural aislado en las Usonians Homes, construidas en los años 1930 y 1940 . Ya hacia 1952, Alden B. Dow creó los primeros SIP con núcleo de espuma que comenzaron a ser producidos en masa por la década de 1960. (www.wbdg.org; 2015). 
Los SIP, siendo elementos prefabricados, sirven tanto para cerramientos verticales, como para cubiertas y techos, como elemento estructural y de cerramiento a la vez. Las dimensiones comerciales en España son de 2390, 2400, 2430, 2490, 2990, 3290, $3590,4190,4990 \mathrm{~mm}$ de longitud y anchura de $600 \mathrm{~mm}$; en algunos casos $540 \mathrm{~mm}$.

Una característica notable de los SIP es su capacidad para proteger y protegerse de la humedad. Su núcleo de aislamiento central actúa como una barrera de vapor pero permitiendo un rápido secado hacia el exterior del espacio a acondicionar.

En cualquier caso es recomendable disponer de una cámara de aire ventilada (que permita un efecto convectivo), entre el panel y el material de revestimiento final. Para zonas de alta humedad o con riesgo de inundaciones el material de revestimiento debe ser impermeable en sí para proteger los tableros de madera que conforman el SIP.

En España es de aplicación la norma. Dado que los aislamientos que componen los SIP pueden llegar a ser afectados por plagas de insectos y pequeños animales rastreros, en el proceso de fabricación se aplican insecticidas y desinfectantes que repelen este tipo de plagas. Los paneles SIP cuentan con un nivel de aislamiento acústico frente al ruido de alta frecuencia

El sistema SIP proporciona unos niveles de aislamiento equiparables - y en algunos casos superiores- a los de los cerramientos de construcción masiva tradicional.

Los valores de resistencia y/o transmitancia térmica quedan definidos de acuerdo a la composición del panel (en cuanto a formato y dimensiones) y también de acuerdo al tipo de aislamiento con el que se haya fabricado. Estos valores se expresan en la siguiente tabla (Fig. 59).

\begin{tabular}{|l|l|l|l|}
\hline Thickness & EPS & XPS & PUR \\
\hline Density in Panel $\left(\mathrm{lb} / \mathrm{ft}^{3}\right)$ & 0.90 & 1.5 & $2.3-2.5$ \\
\hline $4-1 / 2^{\prime \prime}$ & 13.1 & 17.7 & 22.7 \\
\hline $6-1 / 2^{\prime \prime}$ & 19.9 & 27.2 & 35.1 \\
\hline $8-1 / 4^{\prime \prime}$ & 26.0 & 35.5 & 46.0 \\
\hline $10-1 / 4^{\prime \prime}$ & 32.9 & 45.0 & NA \\
\hline $12-1 / 4^{\prime \prime}$ & 39.8 & 54.6 & NA \\
\hline
\end{tabular}

Fig. 59. Valores de aislamiento térmico para un muro de cerramiento en SIP con una altura no mayor de 2,45 m tomando en cuenta solo el panel con cada tipo de aislamiento. (www.wbdg.org; 2015)

Para el cálculo correcto en el ámbito español se deben tomar como referencia las normativas EN ISO 6946, y alternativamente la norma EN ISO 8990 además del CTE en caso de aplicación. 
El tablero OSB (Oriented Strand Board), con el que generalmente se forman a su vez los paneles SIP, está formado con virutas de madera que se unen entre sí con un aglomerante una vez se ha ejercido calor y presión sobre el material (Fig. 61).

Estas virutas están orientadas según la posición de colocación del tablero; en la cara interior las virutas están orientadas aleatoriamente o perpendicularmente a la dirección de las virutas de la cara exterior que generalmente se orientan paralelamente a la longitud del tablero. En el mercado, existe otro tipo de tablero, similar al OSB que se denomina waferboard pero de virutas más pequeñas y sin el criterio de orientación de las primeras.

La composición de los tableros, como se ha expresado en los párrafos anteriores se basa en virutas de madera, adhesivos o aglomerantes y aditivos (insecticidas, ignifugantes y fungicidas). Estas virutas suelen medir aproximadamente $80 \mathrm{~mm}$, con un grueso que no sobrepasa el milímetro. Los adhesivos pueden ser de Ureamelanina, Urea-formol y Fenol- formaldehido.

Las dimensiones de las planchas pueden variar de acuerdo al fabricante y al tipo de uso al que serán sometidas pero una medida más o menos estandarizada es de $2.400 \mathrm{~mm} \times 1.200 \mathrm{~mm}$, de $2.440 \mathrm{~mm} \times 1.220 \mathrm{~m}$ y en algunas ocasiones de $3.660 \times 1.220$ $\mathrm{mm}$, con espesores desde $6 \mathrm{~mm}$ hasta $38 \mathrm{~mm}$. (AITIM; 2015)

En la fabricación del OSB se hace distinción, en cuanto al futuro uso del producto, al momento de su fabricación siendo denominados para tales fines como OSB para uso general/interior, que abarca hasta el uso para mobiliario (OSB1); OSB para uso estructural en ambiente seco o en ambiente húmedo (OSB2 y OSB3) y OSB para altas prestaciones en ambientes húmedos (OSB4).

A parte de ser uno de los componentes principales del sistema SIP los tableros OSB tienen otros usos naturales, alternativos y complementarios al sistema SIP y que les son inherentes como uso en soporte de cubiertas y diafragma de cubiertas, entrevigado de forjados, cerramiento de fachadas, muros interiores, tabiques y divisiones internas, vigas prefabricadas y alma de viguetas en doble $\mathrm{T}$ a cajón. También y en un uso más doméstico el OSB es un material útil para realizar bastidores de muebles, elementos de carpintería e incluso puertas y ventanas. Un uso alternativo común es como embalaje industrial.

Con relación al propio contenido de humedad del material, la norma UNE-EN 300 exige un contenido de humedad entre el $2 \%$ (cuando sale de la fábrica) y el $12 \%$ para los tableros OSB 1 y OSB 2, y entre el $5 \%$ y el $12 \%$ para los tableros OSB 3 y OSB 4. 
De acuerdo a la normativa se establece que para aplicaciones estructurales, un peso específico superior a $650 \mathrm{~kg} / \mathrm{m}^{3}$ (y según los establecidos en la norma UNE EN 12.369 -1) en cuyo caso la conductividad térmica sería del orden de $0.13 \mathrm{~W} / \mathrm{mK}$ (según UNE EN 13.986).

Para el aislamiento acústico que se debe conseguir con este material se utiliza como referencia normativa también la UNE-EN 13986. En sentido general la norma que rige este tipo de producto es la UNE-EN 300:2007 que para su ultimación en todo el ámbito de la Unión Europea, debe contar con el marcado CE.

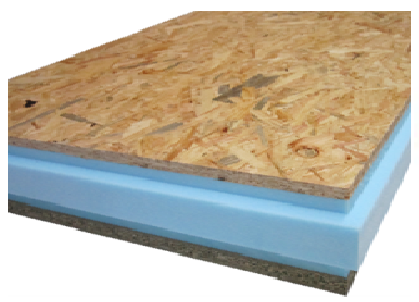

Fig. 60. Tablero SIP (www.thermochip.com; 2015)

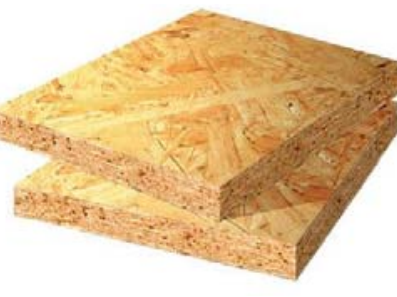

Fig. 61. Tablero de OSB (www.tableroshuertas.es; 2015).

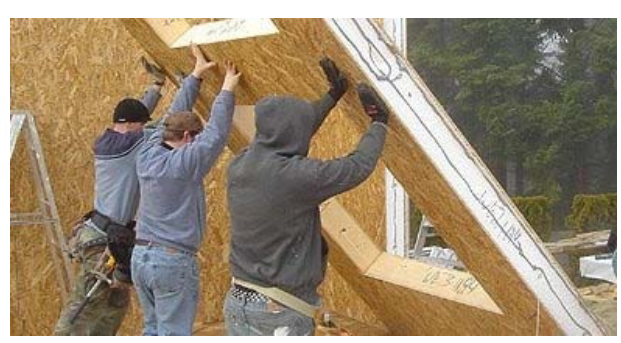

Fig. 62. Montaje de cerramiento con Panel SIP

Los materiales derivados de la madera y la madera como tal, resultan ser de fácil manejo tanto en su etapa de proceso industrial como en la fase de utilización y/o montaje. Por otra parte es sin duda el material con mejor balance energético disponible en la construcción.

Desde luego esta última afirmación es válida si se cuenta con que la madera disponga de la correspondiente certificación de explotación forestal sostenible como los del Forest Stewardship Council y el Endorsement of Forest Certification Schemes (FSC, PEFC, por sus siglas en inglés) que asegure la regeneración del recurso. (Wadel, 2009).

Estudios sobre ACV realizados y en trabajos de investigación sobre el tema (Zabalza, 2010), han demostrado que edificios cuya estructura está hecha con madera o derivados, tienen un menor nivel de consumo de energía y un menor nivel de emisiones de gases de efecto invernadero, en especial $\mathrm{CO}_{2}$, durante su ciclo de vida si se comparan con edificios con otro tipo de estructura.

En un estudio realizado por Cole y Kernan en el 1996 se determinó que para un edificio de oficinas (estudio realizado para el escenario canadiense), la energía que demanda una estructura de acero (la que queda incorporada en todo su proceso fabricación y puesta en obra) y que es computable al balance energético de la vida útil del edificio es 1,61 veces mayor que para un edificio con estructura de hormigón, y que éste a su vez es 1,27 veces mayor que la de una estructura de madera. (Zabalza; 2011). 
Otro ejemplo gráfico es el reseñado por Gustavsson, Joelsson y Sathre en su artículo del 2010 en Energy and Building (Towards a Sustainable Building Sector: Life Cycle Primary Energy Use and Carbon Emission of a Wood-Framed Apartment Building with Biomass Based Energy Supply) en el que demuestran como un edificio de viviendas (ubicado en Suecia), de 8 niveles, con estructura de madera y sistema de cogeneración con combustible de biomasa, puede llegar a tener un balance neto cero en cuanto a emisiones de $\mathrm{CO}_{2}$ en su vida útil.

De acuerdo a un estudio realizado por Zabalza en su Tesis del 2011 (Adaptación de la metodología del análisis de ciclo de vida para la evaluación y la mejora del impacto energético y ambiental de la edificación en España), las materias primas que son necesarias para fabricar $1 \mathrm{~m}^{3}$ de madera laminada (que es la que se utiliza para los sistemas Balloon Frame y Platform Frame), y sus cantidades son: 1,73 $\mathrm{m}^{3}$ de madera aserrada (de abeto, secada al aire para un contenido de humedad del orden del $20 \%$ ); resina de urea formaldehido, en cantidad de $12 \mathrm{~kg}$ (en uso interior) o $12 \mathrm{~kg}$ de melanina-formaldehido (si es para uso exterior). Además se calculan unos $700 \mathrm{~km}$ de transporte para las resinas y $150 \mathrm{~km}$ de transporte para la madera, con su consiguiente nivel de emisiones, y $0,012 \mathrm{~kg}$ de emisiones de GEl (gases de efecto invernadero) por el combustible utilizado en los equipos térmicos para procesar la madera (Fig. 63).

Zabalza también calcula $2.682 \mathrm{MJ} / \mathrm{m}^{3}$ de consumo energético por las virutas de madera residuales y $23 \mathrm{MJ}$ de gasóleo para la demanda térmica de la fábrica, más 129 kWh correspondientes al consumo eléctrico de la fábrica.

\begin{tabular}{|c|c|c|c|c|}
\hline \multirow[b]{2}{*}{ Categoría de impacto } & \multicolumn{3}{|c|}{ Etapa del ciclo de vida } & \multirow[b]{2}{*}{$\begin{array}{c}\text { Impacto } \\
\text { Total }\end{array}$} \\
\hline & Fabricación & $\begin{array}{c}\text { Transporte a } \\
\text { la obra }\end{array}$ & $\begin{array}{c}\text { Disposición } \\
\text { Final } \\
\text { (incineración) }\end{array}$ & \\
\hline \multirow{2}{*}{$\begin{array}{l}\text { Energia incorporada total } \\
(\mathrm{MJ}-\mathrm{Eq})\end{array}$} & $\begin{array}{c}27,28 \\
(26,69)\end{array}$ & 0,33 & 0,29 & \multirow{2}{*}{$\begin{array}{c}27,89 \\
(27,31)\end{array}$} \\
\hline & $97,8 \%$ & $1,2 \%$ & $1,0 \%$ & \\
\hline \multirow{2}{*}{$\begin{array}{l}\text { Potencial de calentamiento } \\
\text { global }(\mathrm{kg} \mathrm{CO}-\mathrm{Eq})\end{array}$} & $\begin{array}{c}-0,99 \\
(-1,03)\end{array}$ & 0,02 & 1,55 & \multirow{2}{*}{$\begin{array}{c}0.57 \\
(0,54)\end{array}$} \\
\hline & $-38,8 \%$ & $0.8 \%$ & $60,5 \%$ & \\
\hline \multirow[t]{2}{*}{ Huella hídrica (1) } & $\begin{array}{c}7,61 \\
(6,82) \\
\end{array}$ & 0,15 & 1,40 & \multirow{2}{*}{$\begin{array}{c}9,16 \\
(8,37)\end{array}$} \\
\hline & $83,1 \%$ & $1,6 \%$ & $15,3 \%$ & \\
\hline \multirow[t]{2}{*}{ Puntuación única $(\mathrm{mPt})$} & $\begin{array}{c}77,05 \\
(74,30)\end{array}$ & 1,76 & 12,46 & \multirow{2}{*}{$\begin{array}{c}91,27 \\
(88,51)\end{array}$} \\
\hline & $84,4 \%$ & $1.9 \%$ & $13,6 \%$ & \\
\hline
\end{tabular}

Fig. 63. Evaluación del impacto del ciclo de vida de 1Kg de madera laminada para uso exterior. (Zabalza, 2011)

En el caso de los tableros OSB, uno de los elementos que conforman el sistema SIP, su fabricación necesita grandes cantidades de pegamento siendo esto un factor de alto impacto ambiental en su balance energético. En la Fig. 64 se exponen los datos concernientes al nivel de impacto en el ciclo de vida del material en función de un tablero tipo 3 (OSB 3). 
En cualquier caso, tanto para las maderas laminadas como para los tableros de partículas orientadas (OSB) y otros productos derivados de la maderas, se registra un impacto ambiental reducido en comparación con otros materiales de la construcción.

Esto es así por el hecho de que la energía incorporada a la madera tiene un origen biomásico, que significa el $84 \%$ de la energía primaria del ciclo de vida en el caso de las maderas blandas y por el orden del $75 \%$ de las maderas laminadas y los OSB.

Adicionalmente el balance de $\mathrm{CO}_{2}$ que se considera en los procesos de fabricación y en el transporte es negativo puesto que el $\mathrm{CO}_{2}$ es absorbido por el árbol en mayor medida de lo que se emite luego como producto de construcción. (Zabalza; 2011).

En cuanto a la madera como depósito de $\mathrm{CO}_{2}$ se considera que cada $\mathrm{m}^{3}$ de madera (madera laminada en este caso y que no es incinerada al final de su vida útil, llega a absorber hasta $582 \mathrm{~kg}$ de Co2. En contraposición el hormigón armado emite $458 \mathrm{~kg}$ de $\mathrm{CO}_{2} / \mathrm{m}^{3}$; (Zabalza, Aranda; 2010).

El caso del acero es un caso muy particular puesto que aun cuando emite $12.087 \mathrm{Kg}$ de $\mathrm{CO}_{2} / \mathrm{m}^{3}$ (Zabalza, Aranda; 2010), su utilización se puede limitar en el ámbito de la construcción modular ligera e incluso intentar neutralizar dotando al edificio de sistemas de generación renovables.

Aun siendo la madera un material con un excelente balance energético tiene algún margen para mejorar el mismo. Esto sería posible sustituyendo las resinas convencionales de urea-formaldehido y melanina-formaldehido por resinas naturales, que ofrezcan las mismas especificaciones que amerita el producto. Una aproximación apunta a que la reducción de Co2 rondaría el 16\% para madera laminada y el 46 para los aglomerados.

A esto se le podría agregar una reducción adicional del orden del 11\% si se planifica el proceso de secado, coordinado con la obtención del material, y el mismo se realiza al aire en lugar de realizarlo con hornos de secado.( Zabalza , Aranda ; 2010).

Por otro lado y como se ha hecho referencia en párrafos anteriores es fundamental que para la utilización de la madera como material de construcción se cuente con las debidas certificaciones medioambientales que aseguren que la explotación de la materia prima se realiza bajo criterios sostenibles.

En este sentido dos de las certificaciones más reconocidas son la FCS que promueven -y certifican- el manejo ambientalmente apropiado, socialmente benéfico y económicamente viable de los bosques del mundo y que también impulsan, mediante certificaciones de sostenibilidad, la gestión sostenible de los bosques. 


\begin{tabular}{|c|c|c|c|c|}
\hline \multirow[b]{2}{*}{ Categoría de impacto } & \multicolumn{3}{|c|}{ Etapa del ciclo de vida } & \multirow[b]{2}{*}{$\begin{array}{l}\text { Impacto } \\
\text { Total }\end{array}$} \\
\hline & Fabricación & $\begin{array}{c}\text { Transporte a la } \\
\text { obra }\end{array}$ & $\begin{array}{c}\text { Disposición } \\
\text { Final } \\
\text { (incineración) }\end{array}$ & \\
\hline \multirow{2}{*}{$\begin{array}{l}\text { Energia incorporada total } \\
\text { (MJ-Eq) }\end{array}$} & 35,72 & 0,33 & 0,29 & \multirow{2}{*}{36,33} \\
\hline & $98,3 \%$ & $0,9 \%$ & $0,8 \%$ & \\
\hline \multirow{2}{*}{$\begin{array}{l}\text { Potencial de } \\
\text { calentamiento global }(\mathrm{kg} \\
\left.\mathrm{CO}_{2}-\mathrm{Eq}\right)\end{array}$} & $-0,95$ & 0,02 & 1,55 & \multirow[b]{2}{*}{0,62} \\
\hline & $-37,7 \%$ & $0,8 \%$ & $61,6 \%$ & \\
\hline \multirow{2}{*}{ Huella hídrica (1) } & 23,22 & 0,15 & 1,40 & \multirow{2}{*}{24,76} \\
\hline & $93,8 \%$ & $0,6 \%$ & $5,7 \%$ & \\
\hline \multirow{2}{*}{ Puntuación única $(\mathrm{mPt})$} & 53,41 & 1,76 & 12,46 & \multirow{2}{*}{67,62} \\
\hline & $79,0 \%$ & $2,6 \%$ & $18,4 \%$ & \\
\hline
\end{tabular}

Fig. 64. Evaluación del impacto del ciclo de vida de 1Kg de tablero OSB 3. (Zabalza, 2011)

El otro componente de los paneles SIP- y de otro tipo de paneles sándwich es el aislamiento. Tal como su nombre indica el aislamiento queda contenido entre dos capas de material, en el caso de los SIP, entre dos planchas de OSB y en el caso de otros tipos de paneles sándwich entre dos capas de Acero, aluminio o PVC.

Entre los materiales para aislamiento más comunes se puede contar con el poliestireno expandido (EPS), el poliestireno extruido (XPS), la espuma de poliuretano (PUR), citados anteriormente y la lana de roca. Existen otros tipos de aislamiento en el mercado que son menos comunes y que incluso tienen un excelente balance energético como son el corcho o la lana de madera. También se comercializan aislamientos de fibra de celulosa y lana de oveja.

De acuerdo a la propia Asociación Nacional De Fabricantes de Materiales Aislantes de España, el concepto de aislamiento térmico queda definido como la capacidad de control de la transmisión de calor cuando se desea que no exceda ciertos límites. En consecuencia un aislante térmico es un producto que reduce la transmisión de calor a través de la estructura a la que está asociado. En cualquier caso, la resistencia térmica de un sistema y/o el material aislante térmico debe ser superior al límite inferior aceptable para la aplicación que se especifica y de acuerdo a la normativa vigente en cada caso.

PUR (espuma de poliuretano).

La espuma de Poliuretano es un material aislante plástico y celular rígido - o semirrígido- con una estructura celular predominantemente cerrada basado en poliuretanos; (http://www.andimat.es; 2015).

Se forma básicamente por la reacción química de dos compuestos, un poliol y un isocianato (proceso químico a partir del petróleo y el azúcar), aunque pueden intervenir otros tipos de variantes y aditivos. Dicha reacción libera dióxido de carbono y gas que va formando las burbujas características del material. (http://www.construmatica.com; 2015). 
Gracias a su baja conductividad térmica, este material aislante cuanta con una gran capacidad aislante. Esta baja conductividad se debe al cerramiento de las células del gas espumante que forma el material y que puede situarse en $10^{\circ} \mathrm{C}=0,022 \mathrm{~W} / \mathrm{m} \cdot \mathrm{K}$, de acuerdo a la Norma UNE 92202.

Este valor, de acuerdo a la UNE 92120-1, tiene a estabilizarse hasta alcanzar los 10 ${ }^{\circ} \mathrm{C}=0,028 \mathrm{~W} / \mathrm{m} \cdot \mathrm{K}$.

De acuerdo a la información comercial genérica del producto, el mismo tiene unas prestaciones de hasta un $25 \%$ más con respecto a otros aislamientos térmicos como lanas minerales y las espumas de poliestireno extruido y expandido. La vida útil del material puede llegar a alcanzar hasta los 50 años sin perder sus prestaciones.

En la siguiente tabla se muestran un resumen de evaluación del impacto del ciclo de vida del material (Fig. 65).

\begin{tabular}{|c|c|c|c|c|}
\hline \multirow[b]{2}{*}{ Categoría de impacto } & \multicolumn{3}{|c|}{ Etapa del ciclo de vida } & \multirow[b]{2}{*}{$\begin{array}{c}\text { Impacto } \\
\text { Total }\end{array}$} \\
\hline & Fabricación & $\begin{array}{c}\text { Transporte a } \\
\text { la obra }\end{array}$ & $\begin{array}{c}\text { Disposición } \\
\text { Final } \\
\text { (incineración) }\end{array}$ & \\
\hline \multirow{2}{*}{$\begin{array}{l}\text { Energia incorporada total } \\
\text { (MJ-Eq) }\end{array}$} & 102,08 & 0,33 & 1,38 & \multirow{2}{*}{103,78} \\
\hline & $98.4 \%$ & $0.3 \%$ & $1.3 \%$ & \\
\hline \multirow{2}{*}{$\begin{array}{l}\text { Potencial de calentamiento } \\
\text { global }\left(\mathrm{kg} \mathrm{CO}{ }_{2}-\mathrm{Eq}\right)\end{array}$} & 4,30 & 0,02 & 2,47 & \multirow{2}{*}{6,79} \\
\hline & $63.3 \%$ & $0.3 \%$ & $36.4 \%$ & \\
\hline \multirow{2}{*}{ Huella hídrica (1) } & 346,66 & 0,15 & 4,18 & \multirow{2}{*}{350,98} \\
\hline & $98,8 \%$ & $0.0 \%$ & $1,2 \%$ & \\
\hline \multirow{2}{*}{ Puntuación única $(\mathrm{mPt})$} & 370,79 & 1,76 & 32,51 & \multirow{2}{*}{405,05} \\
\hline & $91.5 \%$ & $0.4 \%$ & $8.0 \%$ & \\
\hline
\end{tabular}

Fig. 65. Evaluación del impacto del ciclo de vida de 1Kg PUR. (Zabalza, 2011)

\section{EPS (poliestireno expandido)}

El Poliestireno Expandido o EPS, material plástico espumado, utilizado en el sector de la construcción, principalmente como aislamiento térmico y acústico, suele ser utilizado en algún tipo de composición de panel sándwich tipo SIP o de otras clases. Su

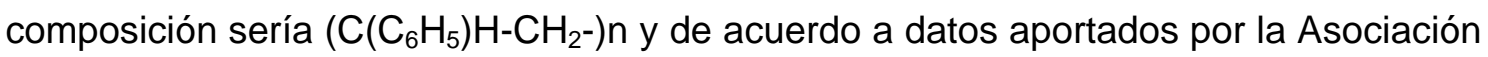
Nacional que agrupa a la industria española del Poliestireno Expandido (EPS), el poliestireno expandido no constituye substrato nutritivo, o lo que es lo mismo un ambiente apto para la aparición de microorganismos que pueda producir descomposición del material, es decir, que es imputrescible y no enmohece .

El poliestireno expandido (EPS) se define técnicamente como un material celular (plástico) y rígido fabricado a partir del moldeado de perlas preexpandidas de poliestireno expandible o de uno de sus copolímeros, que presenta una estructura celular cerrada y rellena de aire. También se le conoce como Porexpan, Poliespan o Corcho Blanco. (http://www.anape.es, 2015). 
La capacidad de aislamiento térmico del EPS, como la de cualquier material queda definida por el coeficiente de conductividad térmica $\lambda$ y con la densidad aparente.

Para el caso del EPS se estaría hablando de una conductividad térmica entre 0.035 a $0.040 \mathrm{~W} / \mathrm{mK}$ con una densidad de $30 \mathrm{~kg} / \mathrm{m} 3$. Su características como buen aislamiento térmico se debe a la propia estructura del material que consiste en aire ocluido dentro de una estructura celular a base de poliestireno, siendo el $98 \%$ del volumen del material aire y sólo el 2\% materia sólida (Zabalza; 2011).

Por efecto de las altas temperaturas el material podría sufrir algún tipo de alteración en sus características si superase los $100^{\circ} \mathrm{C}$ por acciones de corta duración y en torno al $80^{\circ} \mathrm{C}$ para acciones continuadas y con cargas del orden de $20 \mathrm{kPa}$.

Para la fabricación del EPS se necesita una importante cantidad de energía de la que $51 \%$ corresponde al petróleo, que se utiliza para la producción de benceno, y un $37 \%$ que corresponde al gas que sirve para producir etileno. Con relación a los procesos de fabricación la fase del termoformado implica el mayor impacto en cuanto a energía incorporada se refiere representando el $90 \%$. Si el material fuera incinerado esto significaría el $43 \%$ de emisiones de Co2 Eq. en su vida útil (Fig. 66).

A partir del estudio de la espuma de poliestireno expandido producida por termoformado del poliestireno expandido, es que se han obtenido los valores de la siguiente tabla, con un aprovechamiento de casi el 96\% del poliestireno expandido.

\begin{tabular}{|c|c|c|c|c|}
\hline \multirow[b]{2}{*}{ Categoría de impacto } & \multicolumn{3}{|c|}{ Etapa del ciclo de vida } & \multirow[b]{2}{*}{$\begin{array}{c}\text { Impacto } \\
\text { Total }\end{array}$} \\
\hline & Fabricación & $\begin{array}{c}\text { Transporte a } \\
\text { la obra }\end{array}$ & $\begin{array}{c}\text { Disposición } \\
\text { Final } \\
\text { (incineración) }\end{array}$ & \\
\hline \multirow{2}{*}{$\begin{array}{l}\text { Energia incorporada total } \\
\text { (MJ-Eq) }\end{array}$} & 104,89 & 0.33 & 0.27 & \multirow{2}{*}{105,49} \\
\hline & $99,4 \%$ & $0,3 \%$ & $0,3 \%$ & \\
\hline \multirow{2}{*}{$\begin{array}{l}\text { Potencial de calentamiento } \\
\text { global }(\mathrm{kg} \mathrm{CO}-\mathrm{Eq})\end{array}$} & 4,17 & 0,02 & 3,15 & \multirow{2}{*}{7,34} \\
\hline & $56.8 \%$ & $0,3 \%$ & $42.9 \%$ & \\
\hline \multirow{2}{*}{ Huella hídrica (1) } & 191.25 & 0,15 & 1.34 & \multirow{2}{*}{192,73} \\
\hline & $99.2 \%$ & $0,1 \%$ & $0,7 \%$ & \\
\hline \multirow{2}{*}{ Puntuación única $(\mathrm{mPt})$} & 375,06 & 1,76 & 24,46 & \multirow{2}{*}{401,28} \\
\hline & $93,5 \%$ & $0,4 \%$ & $6,1 \%$ & \\
\hline
\end{tabular}

Fig. 66. Evaluación del impacto del ciclo de vida de 1Kg EPS. (Zabalza, 2011

Metal

Otro de los materiales más utilizados en la construcción ligera es el metal, en sus diferentes tipos y elementos. Para el caso de la construcción modular ligera los sistemas y o elementos más comunes son el Ligth Steel Frame y los compuestos por Panel Sándwich. Desde luego diferentes tipos de perfiles sirven como elementos de uso habitual tanto para cerramientos como para las estructuras. 


\section{Ligth Steel Frame (LSF)}

El sistema Light Steel Frame o Ligth Steel Framing (LSF), es un sistema constructivo formado por perfiles de acero galvanizado conformados en frío, que son utilizados para la composición de paneles estructurales y no estructurales, vigas y otros componentes. Por ser un sistema industrializado, posibilita una construcción en seco de gran rapidez. El mismo está basado en la modulación de varios elementos metálicos o montantes (generalmente perfiles de acero $U \circ \mathrm{C}$ ), de manera que puedan resistir las cargas de manera homogénea. De esta manera es posible aligerar el manejo de las partes para su montaje (Fig. 67 y 68).

Este sistema tiene un excelente comportamiento estructural, transmitiendo las cargas verticalmente y además soportando de manera óptima las cargas de viento, trabajando a flexión. (Ruiz Valero, 2013). Entre los perfiles modulados es posible colocar aislamiento para luego colocar sobre la estructura el material de cerramiento. Como es de conocimiento general, el acero es un material ferroso compuesto, es decir, compuesto de hierro y carbono cuyo porcentaje (de este último) está comprendido entre el 0.05 y el 1,70 \%. La densidad del acero es de unos $7.900 \mathrm{~kg} / \mathrm{m}^{3}$, con una temperatura de fisión de aproximadamente unos $1.400{ }^{\circ} \mathrm{C}$. Podría decirse que el LSF es una evolución de los sistemas de Wood Frame (como el Ballon Frame o el Platform Frame). Partiendo de estos orígenes se podrían situar sus orígenes ya avanzado el siglo XX y específicamente en el escenario de la Feria Mundial de Chicago de 1933 para la que se desarrolló un prototipo de residencia que utilizó perfiles de acero tal y como se había hecho hasta entonces con la madera. Desde el punto de vista de este trabajo y en general desde la perspectiva de la $\mathrm{CML}$, se pueden enumerar varias ventajas y desventajas relacionadas a este sistema. Entre las se puede citar que es un sistema ligero, de fácil transporte y fácil montaje; tiene un coste competitivo sobre todo si se compara con los sistemas tradicionales de construcción masiva; su producción dentro de un proceso fabril, permite optimizar la puesta del producto en el mercado a gran escala y al mismo tiempo controlar los niveles de calidad.

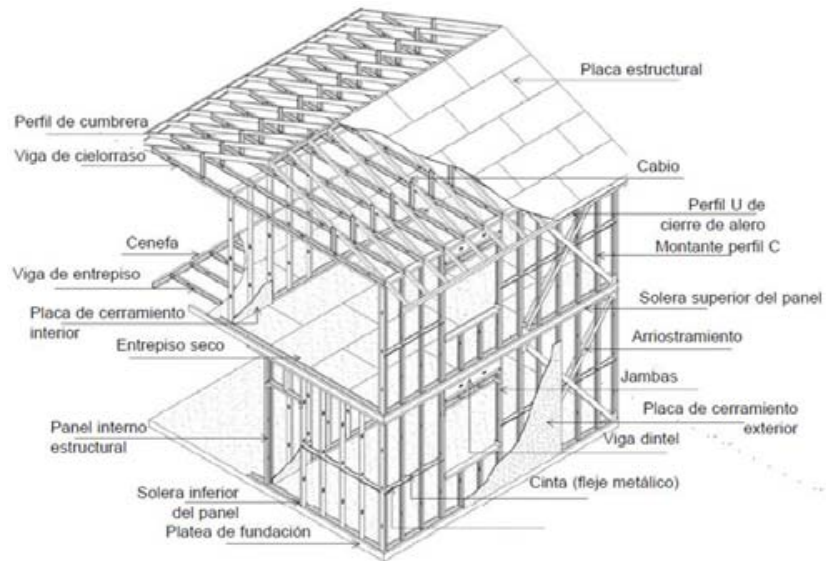

Fig. 67. Esquema estructura en LSF. (Sarmanho; Moraes. 2007)

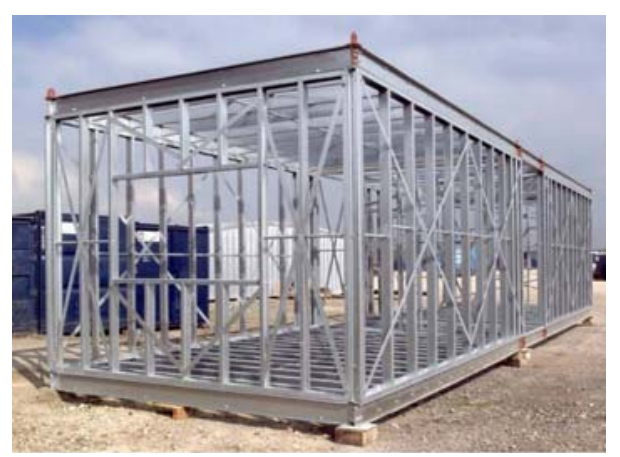

Fig. 68. Modulo vivienda multifamiliar UK (Eurobuild. Best practice for steel construction in housing and residential buildings in Europe 2015)

Otra ventaja es su fiabilidad y durabilidad, sobre todo frente a organismos, e insectos, además de su resistencia al fuego. Existen muchas más ventajas que son comunes a 
otros sistemas como su eficiencia estructural, su colocación y/o construcción en seco, etc. (Ruiz Valero, 2013).

Entre las desventajas se encuentran los puentes térmicos y/o la falta de inercia térmica propia de los metales. La conductividad térmica del acero es de $50 \mathrm{~W} / \mathrm{mK}$. Por otro lado - y lo que en algunos países con tradición de construcción metálica, resulta ser un sistema competitivo- en lugares donde no es habitual el uso del acero puede ser un sistema de coste elevado.

Otro aspecto negativo es el alto nivel de emisiones de GEI asociados a la producción del acero. En resumen, la gran ventaja que presenta el LGF como sistema constructivo y estructural es su mayor resistencia y durabilidad con relación a los sistemas de Wood Frame.

La respuesta del sistema en términos de prestaciones energéticas son las propias del material y tal como se expresa en el párrafo anterior su desempeño en términos de resistencia térmica está muy lejos de los resultados óptimos que pudiera tener un sistema tipo Wood Frame.

Siendo esto cierto, el balance en cuanto a transmitancias puede equilibrarse si se utilizan elementos que puedan producir una rotura de los puentes térmicos.

Aun así ha quedado demostrado en un estudio realizado por el US Departament of Housing and Urban Development. Office Policy Developmnet and Research, North American Steel Framing Alliance y la National Association of Home Builders que lleva por título "Acero vs. Madera", y que queda referenciado en la tesis de Ruiz Valero, del 2013 (Optimización y propuesta de sistema opaco de cerramiento multicapa ligero con estructura de light steel frame como alternativa competitiva a los sistemas tradicionales); que los sistemas como Balloon Frame y Platform Frame siguen teniendo un mejor desempeño en este sentido.

Este estudio comparativo sobre el rendimiento térmico, a largo plazo, de dos viviendas en Valparaíso (Indiana, EE.UU.), dio como resultado que al mediar y/o ensayar los comportamientos térmicos ( aislamiento e infiltraciones, pruebas de calor y frío) de cada una de ellas ( una de acero conformado en frío y la otra de madera convencional), entre la primavera del 2000 y la primavera del 2001, la que estaba hecha con acero consumía casi un 4\% más de energía en invierno (calefacción con gas natural) que la que estaba hecha de madera y que en verano consumía casi un 11\% más en refrigeración por aire acondicionado. En el año 2002 el American Iron and Steel Institute, Steel Framing Alliance and the U.S. Deparment of Energy, presentó un reporte de investigación- de ensayos probados por la Oak Rigde National Laboratory- sobre la mejora del rendimiento térmico de los edificios con estructura de Steel Frame. En el mismo se desarrollaron y estudiaron unos montantes con mejores características térmicas, como un punto de avance para esta técnica constructiva. 
La normativa que tiene que ver con las estructuras ligeras de acero queda contenida en el CTE, específicamente el DB-SEA en los apartados correspondientes la secciones esbeltas o clase 4. (Zornoza; 2009).

Para la producción de un $1 \mathrm{~kg}$ de acero mediante horno con soplado de oxígeno se registra un consumo de gas y de electricidad de $0.0375 \mathrm{MJ}$ y $0.219 \mathrm{kWh}$ respectivamente. Si este mismo kilogramo de acero se produce con un horno eléctrico el consumo sería 0.0424 kWh de electricidad.

En el proceso de producción del acero el mayor consumo de energía está asociado a la producción de arrabio, (para la fabricación de acero primario) que sería del orden del 59\%; el segundo mayor consumo estaría asociado al proceso de laminado y sería del orden del $20 \%$.

En la actualidad se cuenta con la tecnología suficiente (hornos de arco eléctrico) para poder reciclar el acero hasta el $95 \%$ del acero, sin que pierda sus propiedades; esto sumado a la capacidad desarrollada de recuperación del material en obra (hasta un 98\%), la opción de producir un acero secundario se presenta muy favorable en términos medioambientales. (Wadel, 2009). Reciclar el acero puede significar un ahorro de hasta el $75 \%$ de las emisiones de $\mathrm{CO}_{2}$ con respecto a la producción primaria (Fig. 69).

\begin{tabular}{|c|c|c|c|c|}
\hline \multirow[b]{2}{*}{ Categoría de impacto } & \multicolumn{3}{|c|}{ Etapa del ciclo de vida } & \multirow[b]{2}{*}{$\begin{array}{l}\text { Impacto } \\
\text { Total }\end{array}$} \\
\hline & Fabricación & $\begin{array}{l}\text { Transporte a } \\
\text { la obra }\end{array}$ & $\begin{array}{c}\text { Disposición } \\
\text { Final } \\
\text { (vertedero) }\end{array}$ & \\
\hline \multirow{2}{*}{$\begin{array}{l}\text { Energia incorporada total } \\
(\mathrm{MJ}-\mathrm{Eq})\end{array}$} & 22,90 & 0,33 & 1,11 & \multirow{2}{*}{24,34} \\
\hline & $94,1 \%$ & $1.3 \%$ & $4.6 \%$ & \\
\hline \multirow{2}{*}{$\begin{array}{l}\text { Potencial de calentamiento } \\
\text { global }(\mathrm{kg} \mathrm{CO}-\mathrm{Eq})\end{array}$} & 1,44 & 0,02 & 0,07 & \multirow{2}{*}{1,53} \\
\hline & $94,3 \%$ & $1,3 \%$ & $4,4 \%$ & \\
\hline \multirow{2}{*}{ Huella hídrica (1) } & 25,53 & 0,15 & 0,47 & \multirow{2}{*}{26,15} \\
\hline & $97.6 \%$ & $0,6 \%$ & $1,8 \%$ & \\
\hline \multirow{2}{*}{ Puntuación única $(\mathrm{mPt})$} & 105,48 & 1,76 & 7,43 & \multirow{2}{*}{114,67} \\
\hline & $92,0 \%$ & $1,5 \%$ & $6,5 \%$ & \\
\hline
\end{tabular}

Fig. 69. Evaluación del impacto del ciclo de vida de $1 \mathrm{Kg}$ Acero. (Zabalza, 2011)

\section{Panel Sándwich}

El panel sándwich, para cerramientos verticales y horizontales es, probablemente, el sistema de construcción ligera más conocido en la actualidad en muchos países y específicamente en España.

A parte del SIP, que en esencia es un tipo de panel sándwich, existen otros tipos de panel sándwich cuyos cerramientos laterales pueden ser tanto de acero, aluminio o algún tipo de compuesto como el PVC o fibra de vidrio. A diferencia del SIP, este tipo de paneles que también cuentan con alma de aislamiento de espuma de poliuretano 
(PUR o PIR) o bien con espuma de poliestireno (EPS, XPS), suelen ser mucho más ligeros y manejables que el SIP. Evidentemente cualquiera de los materiales que sirven para revestir el aislamiento en estos tipos de paneles sándwich, están más comprometidos medioambientalmente que la madera.

Las principales características (ventajas) de los paneles sándwich son su excelente relación peso, espesor y aislamiento térmico; son autoportantes y suficientemente rígidos para condiciones normales de uso de cerramiento; dependiendo del tipo de aislamiento utilizado suelen tener una densidad de entre los nueve y veinte kilos por $\mathrm{m}^{2}$; son resistentes a cambios bruscos de temperatura e inertes a microorganismos. (Luengo, 2007).

Las desventajas que este tipo de sistema o elemento constructivo pueden tener son, esencialmente, las que están asociadas a los materiales que las componen tanto en términos de prestaciones energéticas para su uso como en términos medioambientales.

En el caso de los paneles de chapa metálica su uso se ha extendido al mercado industrial pero su aplicación se va extendiendo al ámbito residencial. Las chapas metálicas más comunes son las de acero galvanizado y en menor medida, pero también con una incidencia importante en el mercado, están las de acero inoxidable, aluminio, cobre, PVC y PVC + fibra de vidrio. Los espesores que vienen definidos por cada fabricante están comprendidos entre los 0,5 y 0,6 mm, con alturas que pueden sobrepasar los de 12,00 según fabricante y ancho entre 900 y 1200 mm. (Fig. 70 y 71).

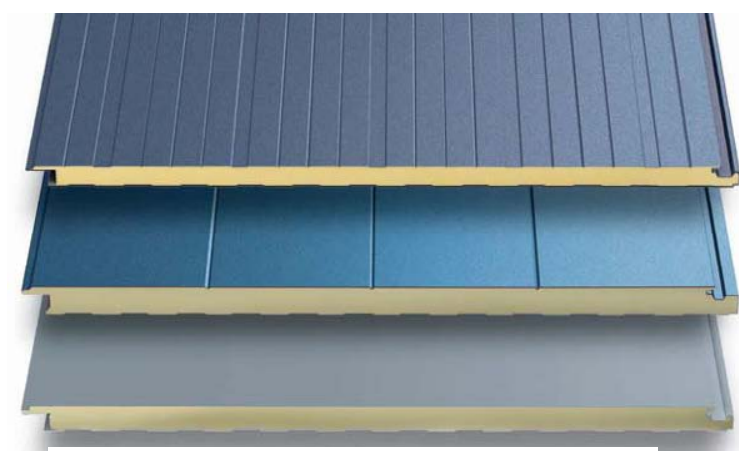

Fig. 70. Tipos de paneles sándwich (www.dovalbuilding.com. 2015

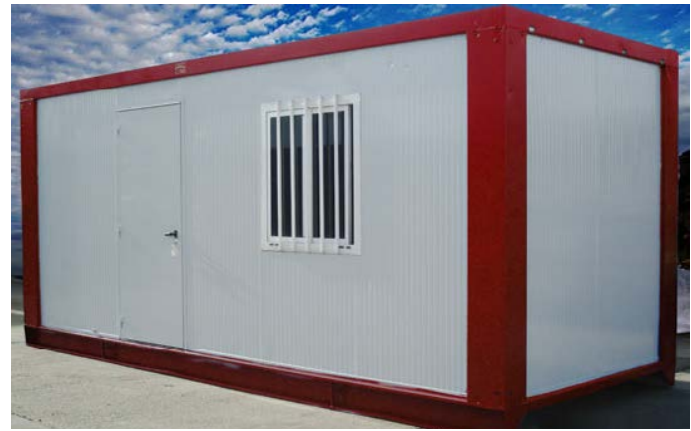

Fig. 71. Módulos de oficina con paneles sandwich de acero galvanizado ( www.eurobloc.com. 2015).

Igual que los espesores, el tipo de tratamiento de protección, galvanizado, pre-lacado o con recubrimientos plásticos diversos, varían de acuerdo a las especificaciones del fabricante. De igual manera sucede con el tipo de material de recubrimiento que queda definido según el fabricante, pudiendo ser alguno de los mencionados en el párrafo anterior. Los aislamientos también varían de acuerdo al fabricante, siendo los más comunes para cerramiento exterior la espuma rígida de poliuretano o su variante de polisocianurato. Para cerramiento interiores y tabiquería suelen utilizarse las espumas de poliestireno. (Luengo, 2007). 
El panel sándwich de poliuretano es un producto con un menor coeficiente de conductividad térmica. En términos generales su valor es inferior a 0,025 [W/m.K]. Debido a ello, los espesores necesarios son inferiores en comparación con otros tipos de materiales aislantes.

Otro tipo de panel sándwich, formado por un núcleo aislante térmico de espuma rígida de poliestireno expandido (EPS), en este caso con recubrimiento, en ambas caras, con plancha de poliéster reforzada con fibra de vidrio, cuenta con un coeficiente de conductividad térmica de $0,036 \mathrm{~W} / \mathrm{mK}$. que sería el mismo con otro tipo de recubrimiento.

Otros tipos de paneles con aislamiento en lana de roca están disponibles en el mercado pero con mucha menor presencia que los anteriormente citados. Un tipo de panel sándwich de lana de roca (MW) habitualmente comercializado es el tipo de panel pre-encolado mediante laminación en continuo. Las características genéricas de la lana de roca son: una densidad de $120 \mathrm{MW} / \mathrm{kg} / \mathrm{m}^{3}$ para un coeficiente de conductividad de $0.038 \mathrm{~W} / \mathrm{mK}$.

\begin{tabular}{|c|c|c|c|c|}
\hline \multirow[b]{2}{*}{ Categoría de impacto } & \multicolumn{3}{|c|}{ Etapa del ciclo de vida } & \multirow[b]{2}{*}{$\begin{array}{c}\text { Impacto } \\
\text { Total }\end{array}$} \\
\hline & Fabricación & $\begin{array}{c}\text { Transporte a } \\
\text { la obra }\end{array}$ & $\begin{array}{c}\text { Disposición } \\
\text { Final } \\
\text { (vertedero) }\end{array}$ & \\
\hline \multirow{2}{*}{$\begin{array}{l}\text { Energia incorporada total } \\
(\mathrm{MJ}-\mathrm{Eq})\end{array}$} & 25,82 & 0,33 & 0,25 & \multirow{2}{*}{26,39} \\
\hline & $97,8 \%$ & $1,2 \%$ & $0,9 \%$ & \\
\hline \multirow{2}{*}{$\begin{array}{l}\text { Potencial de calentamiento } \\
\text { global }(\mathrm{kg} \mathrm{CO}-\mathrm{Eq})\end{array}$} & 1,48 & 0,02 & 0,01 & \multirow{2}{*}{1,51} \\
\hline & $98,1 \%$ & $1,3 \%$ & $0,7 \%$ & \\
\hline \multirow{2}{*}{ Huella hídrica (1) } & 32,01 & 0,15 & 0,23 & \multirow{2}{*}{32,38} \\
\hline & $98.8 \%$ & $0.5 \%$ & $0.7 \%$ & \\
\hline \multirow{2}{*}{ Puntuación única $(\mathrm{mPt})$} & 143.66 & 1.76 & 2.08 & \multirow{2}{*}{147,50} \\
\hline & $97.4 \%$ & $1.2 \%$ & $1.4 \%$ & \\
\hline
\end{tabular}

Fig. 72. Evaluación del impacto del ciclo de vida de 1Kg Lana de roca. (Zabalza, 2011)

La lana de roca como material aislante está compuesta por un 96\% de fibras minerales con estructura cristalina, que se producen artificialmente del basalto natural, la lana de roca y la dolomita. Sobre la evaluación del ciclo de vida nos ilustra la Fig. 72.

La obtención de coque de hulla representa hasta el 30\% de toda la energía que queda incorporada al producto final; el $18 \%$ de esa energía incorporada corresponde a la producción de resina fenólica y el 13\% corresponde a la producción de electricidad.

La normativa vigente que regula los paneles sándwich con chapa de acero es la UNEEN 14509 del 2014 que sustituye a la versión del 1997. Esta nueva versión plantea mejoras para las prestaciones del panel sándwich sobre todo en lo concerniente al tema de protección contra incendios y de cara al CTE como norma fundamental de la edificación en España. 


\section{Aluminio}

Vistas ya, en epígrafes anteriores, las prestaciones energéticas del acero, otro de los materiales de uso común para la elaboración de paneles sándwich es el metal no ferromagnético conocido como aluminio. Este material, con una alta implicación medioambiental, también se presenta con un muy buen nivel de reciclaje.

Para la producción primaria del aluminio, que tiene una densidad de $2.700 \mathrm{~kg} / \mathrm{m}^{3}$, se parte de la bauxita como elemento principal, en producción primaria, y de la propia chatarra del aluminio en producción secundaria.

Aun cuando la conductividad térmica del aluminio es de $230 \mathrm{~W} / \mathrm{mk}$, las ventajas de este material como elemento compositivo para los paneles sándwich resultan muy competitivas con relación a otros materiales. Estas ventajas objetivas son su fácil manejo para la fabricación y para el montaje, siendo además fácilmente transportable y su resistencia a los agentes naturales.

$1 \mathrm{~kg}$ de aluminio primario lleva asociado a su producción un consumo elevado de electricidad del orden de los $16 \mathrm{kWh}$ aproximadamente, con el nivel de emisiones (monóxido de carbono, dióxido de carbono, fluoruros, óxido de azufre, óxido nitrógeno) que esto supone y asociado además a las emisiones por la extracción, procesamiento y transporte de varios de sus componentes como la alúmina (1.92 kg por $\mathrm{Kg}$ de aluminio) o el fluoruro de aluminio (0,19 kg por kilogramo de aluminio) (Zabalza, 2011).

La producción de $1 \mathrm{~kg}$ de aluminio secundario (el que proviene del reciclado de las chatarras de aluminio) lleva asociado un consumo eléctrico de $0.174 \mathrm{kWh}$. También conlleva un consumo térmico (con de gas natural) de 3.113 MJ. La evaluación del impacto del ciclo de vida de $1 \mathrm{Kg}$ Aluminio se puede ver abajo en la Fig. 73.

\begin{tabular}{|c|c|c|c|c|}
\hline \multirow[b]{2}{*}{ Categoría de impacto } & \multicolumn{3}{|c|}{ Etapa del ciclo de vida } & \multirow[b]{2}{*}{$\begin{array}{l}\text { Impacto } \\
\text { Total }\end{array}$} \\
\hline & Fabricación & $\begin{array}{c}\text { Transporte a } \\
\text { la obra }\end{array}$ & $\begin{array}{l}\text { Disposición } \\
\text { Final } \\
\text { (reciclado } \\
\text { total en } \\
\text { obra) }\end{array}$ & \\
\hline \multirow{2}{*}{$\begin{array}{l}\text { Energía incorporada total } \\
(\mathrm{MJ}-\mathrm{Eq})\end{array}$} & 136,48 & 0,33 & 0,00 & \multirow{2}{*}{136,80} \\
\hline & $99,8 \%$ & $0,2 \%$ & $0,0 \%$ & \\
\hline \multirow{2}{*}{$\begin{array}{l}\text { Potencial de calentamiento } \\
\text { global }(\mathrm{kg} \mathrm{CO}-\mathrm{Eq})\end{array}$} & 8,55 & 0,02 & 0,00 & \multirow{2}{*}{8,57} \\
\hline & $99,8 \%$ & $0,2 \%$ & $0,0 \%$ & \\
\hline \multirow{2}{*}{ Huella hídrica (1) } & 214.19 & 0,15 & 0,00 & \multirow{2}{*}{214,34} \\
\hline & $99,9 \%$ & $0,1 \%$ & $0,0 \%$ & \\
\hline \multirow{2}{*}{ Puntuación única $(\mathrm{mPt})$} & 556,56 & 1,76 & 0,93 & \multirow{2}{*}{559,24} \\
\hline & $99.5 \%$ & $0.3 \%$ & $0.2 \%$ & \\
\hline
\end{tabular}

Fig. 73. Evaluación del impacto del ciclo de vida de 1Kg Aluminio. (Zabalza, 2011)

Estos datos, obtenidos de otros trabajos de investigación (Zabalza, 2011) dejan claramente establecida la relación comparativa entra la producción de un $1 \mathrm{~kg}$ de aluminio secundario y $1 \mathrm{~kg}$ de aluminio primario. En el caso del aluminio secundario 
resulta altamente favorable para el medioambiente su utilización en contraposición al aluminio primario.

\section{PVC (Policloruro de vinilo)}

Otro de los materiales propios de algunos tipos de paneles sándwich es el PVC $\left(\mathrm{CH}_{2} \mathrm{CHC} 1\right)_{n}$, cuya primera fabricación se remonta al 1872. Este plástico se crea a partir del etileno y el cloro principalmente y su uso se ha extendido a diferentes campos entre ellos la construcción y dentro de ésta un uso común son las piezas de fontanería y tuberías para agua. Otro uso habitual y de relativa reciente generalización es el de carpinterías exteriores e interiores (puertas, ventanas, etc.).

Una de las características más valoradas del PVC en el ámbito de la construcción es su nivel de transmitancia Este valor se calcula en 0'16 W/m.K, siendo innecesaria la colocación de puentes térmicos en la uniones y/o encuentros con el material e incluso siendo éste, en sí mismo, un elemento de rotura del puente térmico.

En el siguiente cuadro de acuerdo a la normativa se presenta una comparativa del material para uso de perfilería en cuanto a carpinterías de acuerdo a la normativa vigente (Fig. 74).

\begin{tabular}{|c|c|}
\hline Material del Perfil & Transmitancia Térmica \\
\hline Metálico & 5,7 \\
\hline Metálico RPT $(4 \mathrm{~mm}<\mathrm{d}<12 \mathrm{~mm})$ & 4 \\
\hline Metálico RPT $>12 \mathrm{~mm}$ & 3,2 \\
\hline Madera Dura ( $\mathrm{p}=700 \mathrm{Kg} / \mathrm{m} 3$ y $60 \mathrm{~mm}$ de espesor) & 2,2 \\
\hline Madera Blanda ( $\mathrm{p}=500 \mathrm{Kg} / \mathrm{m} 3$ y $60 \mathrm{~mm}$ de espesor $)$ & 2 \\
\hline Perfiles huecos de PVC (2 cámaras) & 2,2 \\
\hline Perfiles huecos de PVC (3 cámaras) & 1,8 \\
\hline
\end{tabular}

Fig. 74. Transmitancia térmica de los perfiles según la norma UNE-EN ISO 100077-1 (http://www.kommerling.es. 20015)

EI PVC cuenta con una muy buena resistencia mecánica, al impacto (de acuerdo a condiciones de uso normales para un cerramiento) y a la abrasión.

Como material es estable e inerte y en lugares de alto nivel de higiene tiene excelente comportamiento para fines de limpieza y esterilización. Otro punto destacable es su durabilidad en el tiempo - señalada por algunas casas comerciales en más de 50 años para elementos de carpintería. Además es poco inflamable y su comportamiento frente al fuego es bueno gracias a los átomos de cloro que forman parte del polímero PVC, que impiden que se queme con facilidad. Evidentemente no siendo un material - o compuesto ferroso no se oxida ni corroe. Siendo éstas las partes positivas, por otro 
lado y entre sus desventajas están los altos niveles de compromiso medioambiental que implica su fabricación y aunque en ese sentido se hacen continuas certificaciones medioambientales que avalan sus procesos de fabricación (como la ISO 14001 de Gestión Ambiental), también es cierto que se realizan a partir de supuestos básicos que dan por sentado unos niveles de contaminación asumidos.

La evaluación del impacto del ciclo de vida de 1Kg PVC se puede ver en la Fig. 75.

\begin{tabular}{|c|c|c|c|c|}
\hline \multirow[b]{2}{*}{ Categoría de impacto } & \multicolumn{3}{|c|}{ Etapa del ciclo de vida } & \multirow[b]{2}{*}{$\begin{array}{c}\text { Impacto } \\
\text { Total }\end{array}$} \\
\hline & Fabricación & $\begin{array}{c}\text { Transporte a } \\
\text { la obra }\end{array}$ & $\begin{array}{c}\text { Disposición } \\
\text { Final } \\
\text { (incineración) }\end{array}$ & \\
\hline \multirow{2}{*}{$\begin{array}{l}\text { Energía incorporada total } \\
\text { (MJ-Eq) }\end{array}$} & 60,33 & 0,33 & 12,55 & \multirow{2}{*}{73,21} \\
\hline & $82,4 \%$ & $0,4 \%$ & $17,1 \%$ & \\
\hline \multirow{2}{*}{$\begin{array}{l}\text { Potencial de calentamiento } \\
\text { global }(\mathrm{kg} \mathrm{CO}-\mathrm{Eq})\end{array}$} & 1,97 & 0,02 & 2,28 & \multirow{2}{*}{4,27} \\
\hline & $46,2 \%$ & $0,5 \%$ & $53,3 \%$ & \\
\hline \multirow{2}{*}{ Huella hídrica (1) } & 454,79 & 0,15 & 57,07 & \multirow{2}{*}{512,00} \\
\hline & $88,8 \%$ & $0,0 \%$ & $11,1 \%$ & \\
\hline \multirow{2}{*}{ Puntuación única (mPt) } & 174,20 & 1,76 & 45,54 & \multirow{2}{*}{221,51} \\
\hline & $78,6 \%$ & $0,8 \%$ & $20,6 \%$ & \\
\hline
\end{tabular}

Fig. 75. Evaluación del impacto del ciclo de vida de 1Kg PVC. (Zabalza, 2011)

De acuerdo a trabajos de investigación realizados (Zabalza \& Aranda Usón, 2011), la producción de PVC supone el $66 \%$ de la energía incorporada al material, el $37 \%$ de las emisiones de CO2-Eq y el $74 \%$ de la huella hídrica. Un supuesto proceso de incineración del material implicaría el $57 \%$ de las emisiones de $\mathrm{CO}_{2}$ Eq.

\section{Cobre}

El cobre es un material que como algunos otros metales puede servir como componente del panel sándwich aunque no esté tan generalizado como el acero o el aluminio, debido a su alto coste. Es habitual que su utilización en proyectos de cierta singularidad sea por un encargo puntual.

Este material (como material industrializado), de color rojizo pardo, maleable y dúctil, puede producirse - en proceso primario - a partir de minerales oxidados como la cuprita y la malaquita, o también sulfurados como la calcopirita, calcosina y bornita; tiene una densidad de $8.920 \mathrm{~kg} / \mathrm{m}^{3}$ y una conductividad de $380 \mathrm{~W} / \mathrm{mK}$ (Zabalza, 2011).

En un proceso secundario -es decir de reciclaje- el cobre puede producirse a partir de chatarra del propio material siendo a nivel mundial el 34\% de la producción total y a nivel de Europa el 40\%. (Zabalza, 2011). 
Para obtener un $1 \mathrm{~kg}$ de cobre secundario se necesitan 1,421 Kg de chatarra de cobre, lo que implica un consumo de electricidad de 1,1 kWh/kg. Para producir $1 \mathrm{~kg}$ de cobre primario hacen falta $3,15 \mathrm{~kg}$ de cobre concentrado implicando esto una demanda de energía térmica de $9,157 \mathrm{MJ} / \mathrm{kg}$ y 0,492 $\mathrm{kWh} / \mathrm{kg}$ de electricidad y produciendo ácido sulfúrico en cantidad de $0,199 \mathrm{~kg} / \mathrm{kg}$.

A continuación, una evaluación del impacto del ciclo de vida de $1 \mathrm{Kg}$ de Aluminio:

\begin{tabular}{|c|c|c|c|c|}
\hline \multirow[b]{2}{*}{ Categoría de impacto } & \multicolumn{3}{|c|}{ Etapa del ciclo de vida } & \multirow[b]{2}{*}{$\begin{array}{c}\text { Impacto } \\
\text { Total }\end{array}$} \\
\hline & Fabricación & $\begin{array}{c}\text { Transporte a } \\
\text { la obra }\end{array}$ & $\begin{array}{c}\text { Disposición } \\
\text { Final } \\
\text { (reciclado total } \\
\text { en obra) }\end{array}$ & \\
\hline \multirow{2}{*}{$\begin{array}{l}\text { Energía incorporada total } \\
\text { (MJ-Eq) }\end{array}$} & 35,26 & 0,33 & 0,00 & \multirow{2}{*}{35,59} \\
\hline & $99,1 \%$ & $0,9 \%$ & $0,0 \%$ & \\
\hline \multirow{2}{*}{$\begin{array}{l}\text { Potencial de calentamiento } \\
\text { global }(\mathrm{kg} \mathrm{CO}-\mathrm{Eq})\end{array}$} & 1.98 & 0.02 & 0,00 & \multirow{2}{*}{2,00} \\
\hline & $99,0 \%$ & $1,0 \%$ & $0,0 \%$ & \\
\hline \multirow{2}{*}{ Huella hídrica (1) } & 77,65 & 0,15 & 0,00 & \multirow{2}{*}{77,79} \\
\hline & $99,8 \%$ & $0.2 \%$ & $0,0 \%$ & \\
\hline \multirow{2}{*}{ Puntuación única $(\mathrm{mPt})$} & 2064,53 & 1,76 & 0,93 & \multirow{2}{*}{$2.067,22$} \\
\hline & $99,9 \%$ & $0,1 \%$ & $0.0 \%$ & \\
\hline
\end{tabular}

Fig. 76. Evaluación del impacto del ciclo de vida de 1Kg Cobre. (Zabalza, 2011)

\section{Vidrio}

El vidrio es el material translucido de uso más difundido en el mercado de la construcción En la actualidad, en las construcciones de los últimos 15 años es más habitual la utilización de vidrio doble con cámara de aire, con una transmitancia de 2,7 $\mathrm{W} / \mathrm{m}^{2} \mathrm{~K}$, que el vidrio común con transmitancia de $5,7 \mathrm{~W} / \mathrm{m}^{2} \mathrm{~K}$, de utilización en la mayoría de las edificaciones anteriores a la norma NBE 79, e incluso posteriores.

\begin{tabular}{|c|c|c|c|c|}
\hline \multirow[b]{2}{*}{ Categoría de impacto } & \multicolumn{3}{|c|}{ Etapa del ciclo de vida } & \multirow[b]{2}{*}{$\begin{array}{c}\text { Impacto } \\
\text { Total }\end{array}$} \\
\hline & Fabricación & $\begin{array}{c}\text { Transporte a } \\
\text { la obra }\end{array}$ & $\begin{array}{c}\text { Disposición } \\
\text { Final } \\
\text { (vertedero) }\end{array}$ & \\
\hline \multirow{2}{*}{$\begin{array}{l}\text { Energía incorporada total } \\
\text { (MJ-Eq) }\end{array}$} & 14,94 & 0,33 & 0,25 & \multirow{2}{*}{15,51} \\
\hline & $96,3 \%$ & $2,1 \%$ & $1,6 \%$ & \\
\hline \multirow{2}{*}{$\begin{array}{l}\text { Potencial de calentamiento } \\
\text { global }\left(\mathrm{kg} \mathrm{CO} \mathrm{CO}_{2}-\mathrm{Eq}\right)\end{array}$} & 1,11 & 0,02 & 0,01 & \multirow{2}{*}{1,14} \\
\hline & $97,4 \%$ & $1,7 \%$ & $0,9 \%$ & \\
\hline \multirow{2}{*}{ Huella hidrica (1) } & 16,16 & 0,15 & 0,23 & \multirow{2}{*}{16,54} \\
\hline & $97,7 \%$ & $0,9 \%$ & $1,4 \%$ & \\
\hline \multirow{2}{*}{ Puntuación única $(\mathrm{mPt})$} & 79,22 & 1,76 & 1,15 & \multirow{2}{*}{82,13} \\
\hline & $96,5 \%$ & $2,1 \%$ & $1,4 \%$ & \\
\hline
\end{tabular}

Fig. 77. Evaluación del impacto del ciclo de vida de $1 \mathrm{Kg}$ de vidrio. (Zabalza, 2011)

En el cuadro anterior se muestra el nivel de impacto ambiental de un $\mathrm{kg}$ de vidrio simple.

La tecnología del cerramiento acristalado se ha desarrollado hasta conseguir cerramientos con mejores prestaciones energéticas, incorporando gases o geles en 
lugar de aire en sus cámaras o finos revestimientos o capas metálicas para control solar y/o térmico. Otros tipos de vidrios llamados dinámicos, con mejores prestaciones energéticas, aún más elevadas, incorporan circulación de agua en su cámara interior funcionando como un sistema de radiación para regular las temperaturas interiores.

Este tipo de vidrio, asociados a un sistema de bombeo de agua de baja temperatura puede llegar a tener una transmitancia de $1,12 \mathrm{~W} / \mathrm{m}^{2} \mathrm{~K}$.

El alto nivel de eficiencia de este tipo de acristalamiento queda comprobado en ensayos realizados (Pérez-Pujazón, et al.; 2015) en los que un vidrio simple colocado en una célula de ensayos permite ganancias de temperatura en el espacio interior de hasta $53,15^{\circ} \mathrm{C}$ en comparación a las ganancias térmicas registradas $\left(28,55^{\circ} \mathrm{C}\right)$ en otra célula de ensayos con características semejantes de aislamiento pero con vidrio doble con cámara de agua circulante. En este ensayo ambas células se orientaron a sur para poder registrar las ganancias por captación pasiva.

\subsection{LA EFICIENCIA ENERGÉTICA. ANTECEDENTES Y CONTEXTO ACTUAL.}

El concepto de la eficiencia energética ha estado muy vigente en los últimos años en todos los aspectos de la vida cotidiana y desde luego en el ámbito de la construcción.

Esta vigencia se produjo a partir de la crisis del energética de 1973, y la subida de los precios de los combustibles o lo que es lo mismo, de la energía. La realidad de que la dependencia, casi absoluta, del petróleo podía significar la repetición de situaciones críticas como la de la década de los 70 hizo que el tema de las energías alternativas, el ahorro y la buena gestión de los recursos energéticos fuera adquiriendo mayor importancia y se viera contenido en un solo concepto general: sostenibilidad. A partir de este punto de inflexión también el sector de la edificación comenzó a tomar medidas para la optimización de los recursos energéticos creando nuevas normativas de limitaciones de consumo y/o mejora del aislamiento global de los edificios. (Giménez. 2011). De alguna manera la crisis- económica y social- de 1973, originó un pensamiento colectivo orientado hacia la sostenibilidad ambiental y se comenzó a pensar en el calentamiento global y en los gases (GEI) que provocaban este fenómeno.

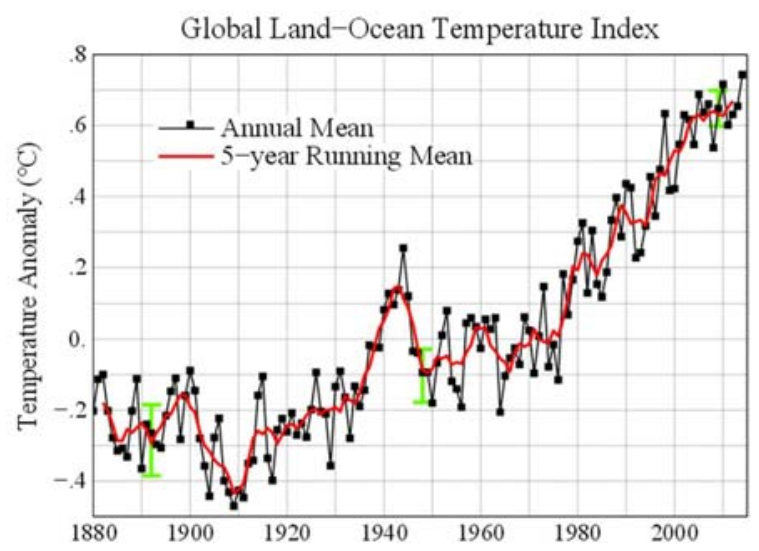

Fig. 78. Gráfico de la NASA sobre la temperatura del planeta a través de los años. (http://data.giss.nasa.gov. 2015). 
En el año 1988 se crea la International Panel on Climate Change (IPCC) con el objetivo de abordar el tema medioambiental y los cambios sobre su equilibrio ocasionados por la intervención humana.

Esta primera iniciativa fue lo que dio origen al conocido protocolo de Kioto (1997), que sirve como marco de referencia para las medidas globales que procuran disminuir las emisiones de GEI que dañan el medioambiente ocasionando daños en el equilibrio del planeta y su calentamiento.

A partir de la decimoctava Conferencia de las Partes (COP 18) sobre cambio climático, se ratificó y entró en vigor el segundo período del Protocolo de Kioto (desde el 1 de enero de 2013 hasta el 31 de diciembre de 2020) que ha servido de contexto para la normativa.

Varios otros acuerdos y protocolos han complementado, sucedido o antecedido al de Kioto. Tal es el caso del Protocolo de Bali (2007), que ha servido para ratificar varios de sus puntos y modificar otros tantos. Otro caso es el del Protocolo de Montreal, AGENDA 21 (1989) específico sobre los daños a la capa de ozono.

\section{Eficiencia energética en la edificación}

En términos generales la eficiencia energética consiste en la utilización eficiente de la energía, optimizando los procesos para producir lo mismo o más con menos.

La eficiencia energética en la edificación es un objetivo constante en la actualidad. Para tales fines se han ido sucediendo una serie de reglamentos y normativas que procuran conseguir el mejor rendimiento en los edificios.

De acuerdo a documentos de la Comisión Europea, el $40 \%$ del consumo total de energía en la Unión (UE) corresponde a los edificios. El sector se encuentra en fase de expansión, lo que hace aumentar la demanda de energía. (http://eur-lex.europa.eu. 2015).

En Europa, e incluso en el ámbito español, el impacto directo e indirecto de la edificación representa entre el 33\% y el $42 \%$ del consumo de energía primaria, de los cuales casi el $21 \%$ corresponde al gasto de climatización. De igual modo el sector de la edificación es responsable del $40 \%$ del consumo de recursos minerales, responsable del $50 \%$ de la generación de residuos sólidos, y responsable además del 18\% del consumo total de agua. (Zabalza \& Aranda. 2011).

Dentro de este contexto la eficiencia energética es la alternativa para conseguir mejorar los niveles de impacto ambiental del sector de la edificación.

Dentro de los datos recogidos por el IPCC se refleja la repercusión a nivel de emisiones de los edificios para el año 2014 tal y como se muestra en el siguiente gráfico. 


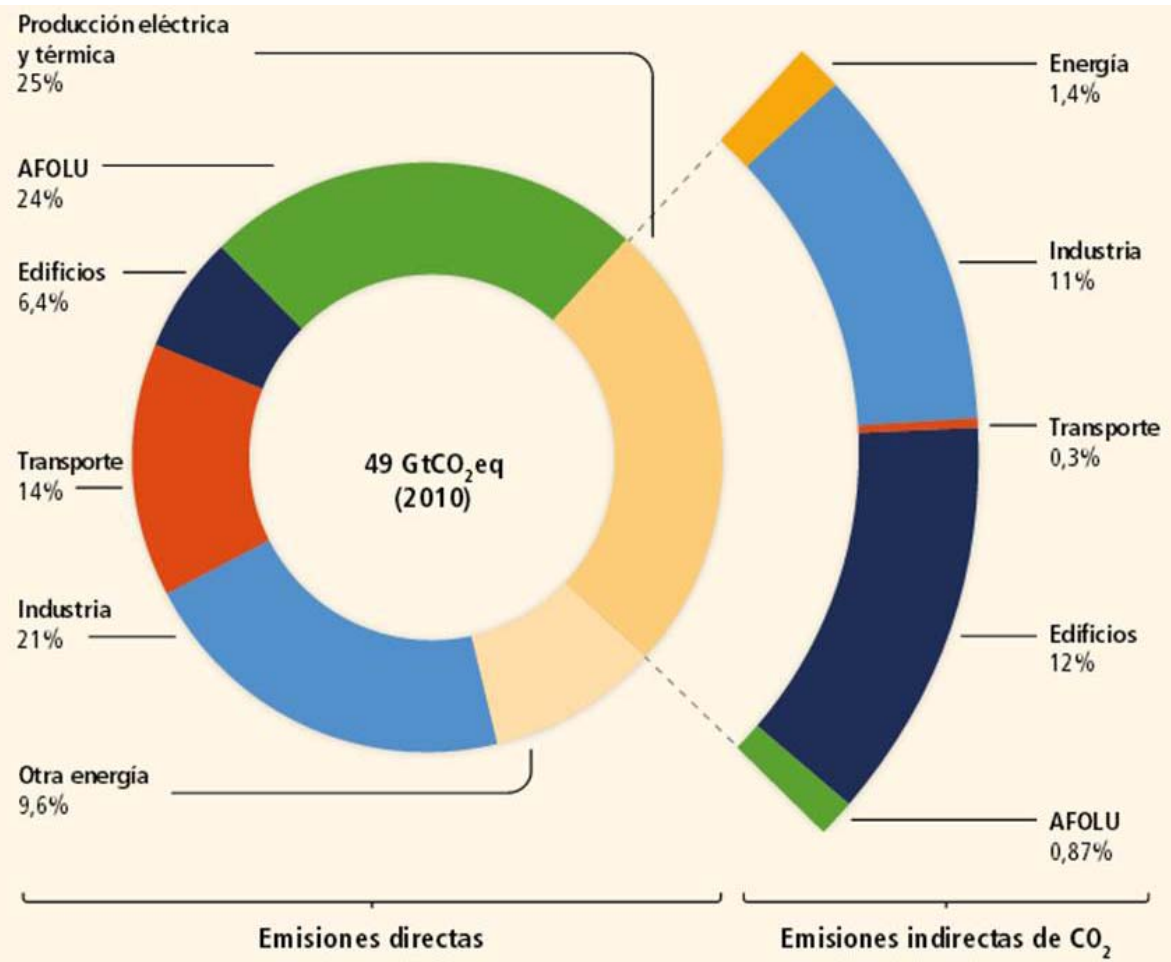

Fig. 79. Emisiones antropógenas de GEl totales $\left(\mathrm{GtCO}_{2}\right.$ eq/año) por sectores económicos. (www.ipcc.ch. 2015)

Ya desde el año 1993 a nivel europeo existía la Directiva 93/76 de 13.09 .93 que planteaba que:

“...Considerando que los edificios afectarán al consumo de energía a largo plazo; que conviene tanto que los nuevos edificios estén dotados de un aislamiento térmico eficaz, adaptado a las condiciones climáticas locales; que estas consideraciones son aplicables a los edificios que albergan a autoridades públicas, las cuales deberían dar ejemplo teniendo en cuenta consideraciones medioambientales y relativas a la energía..."

Más adelante se aprueba la Directiva 2002/91/CE entrando en vigor en enero de 2003, con un plazo máximo de aplicación para los estados miembros de la UE de tres años a partir de esa fecha. El objetivo, dando cumplimiento a los establecidos en el protocolo de Kioto, era reducir las emisiones de $\mathrm{CO} 2$ en un $8 \%$ en 2010, al 5,2\% por debajo de los niveles de 1990. Con esta directiva se refuerza la meta de reducir el consumo de los edificios o lo que es lo mismo dotarlo de mayores niveles de eficiencia.

A partir de esto se establecen herramientas para conseguir el fin último (la eficiencia energética) tanto para edificios nuevos como existentes.

Se promueve la creación de metodologías de cálculo para el mejor desempeño energético de los edificios; en este sentido se establecen como una de ellas los certificados energéticos que buscan entre otras cosas contribuir a la reducción de las 
emisiones de $\mathrm{CO}_{2}$. Entre el 2008 y el 2010, la Directiva 2002/91/CE fue revisada y refundida dando como resultado la Directiva 2010/31/UE.

Esta nueva normativa europea (Directiva 2010/31/UE) tiene como objetivo fundamental mejorar la eficiencia energética de los edificios de la UE a partir de las condiciones climáticas particulares de cada lugar. Esto se pretende conseguir estableciendo una serie de requisitos mínimos y una metodología general que regule la energía empleada para la calefacción, el calentamiento del agua, la refrigeración, la ventilación y la iluminación en los edificios del espacio europeo.

El compromiso de aplicación de esta normativa abarca a todos los estados miembros de la UE que deben cumplir los objetivos de reducción de emisiones en cuanto a los edificios de sus respectivos territorios, estableciendo requisitos mínimos para conseguir el objetivo. Dichos requisitos deben ser revisados como máximo cada cinco años.

Aunque cada país debe ejecutar y transponer la Directiva a sus respectivos códigos la Comisión es la responsable de establecer la metodología empleada para calcular los niveles de coste óptimos para los requisitos de eficiencia energética.

Concretamente estos requisitos consisten en que, por una parte, los edificios que estén ocupados y/o sean propiedad de autoridades públicas deben alcanzar un consumo de energía casi nulo * hasta el 31 de diciembre de 2018, un plazo que se amplía en dos años para el resto de edificios nuevos. Por otra parte, los edificios existentes en los que se hagan reformas de cierta importancia (en cuanto a superficie y cerramientos) deberán mejorar su eficiencia energética para cumplir los requisitos de la UE sobre consumos y emisiones para edificios existentes.

Cada estado miembro queda en la obligación de contar con un sistema de certificación de la eficiencia energética que ofrezca información sobre la calificación energética de un edificio, así como recomendaciones para la mejora de los niveles rentables, siendo las instalaciones de calefacción y aire acondicionado objeto de mejora e inspección por parte de los gobiernos locales.

Sobre los resultados de las medidas sería la Comisión quien evaluaría los progresos registrados con fecha tope a enero de 2017 y con la posibilidad de plantear nuevas propuestas si son necesarias de cara al cumplimiento de los plazos establecidos en la Directiva.

nZEB

Como concepto de referencia para la Directiva 2010/31/U, que ha entrado en vigor a partir del 8 de julio de 2010 está el de edificio de energía casi nula (EECN). En el ámbito europeo se maneja el término Near Zero Energy Building (nZEB) para definir un edificio cuyo consumo energético esta próximo al cero. Cuya definición puntual 
corresponde a cada estado miembro de la unión de acuerdo sus condicionantes propias, climáticas y sociales.

Por la misma naturaleza de la Directiva y la forma de aplicación por cada estado miembro, el término nZEB (near Zero Energy Building), a ser definido por cada país, se queda un poco difuso en su descripción plena. En algunos casos se confunde con el término NZEB (Net Zero Energy Building) que de acuerdo a varios autores se define más bien como edificio de energía neta cero y conectado a la red ( que es lo que significa Net) o a las redes de suministro de energía.

No existe un concepto unificado que defina a nivel global el nZEB o el NZEB.

La realidad es que incluso entre ambos términos existe cierta confusión tal como se expresa en el párrafo anterior. La idea de consumo cero o casi cero se intenta aclarar en algunos artículos científicos que plantean el tema siendo de referencia obligada los escritos de Torcellini y Sartori al respecto.

En este sentido Torcellini plantea tres definiciones de edificios cero energía.

En la primera de ellas la Net Zero Site Energy, el autor plantea un edificio que produce la suficiente energía para suplir sus necesidades durante un año calculada en el lugar de origen. La segunda definición Net Zero-Source Energy, se refiere a un edificio que produce la energía que consume en un año calculada en su lugar de origen o lo que es lo mismo, la energía primaria usada en la generación y transporte de la energía de consumo final. Con la tercera definición, Net Zero Energy Cost, Torcellini establece los parámetros de un edificio en que el dinero que la empresa de generación paga al propietario por la energía que éste le sirve (volcada a la red) es igual a lo que el propietario paga por la energía que consume durante un año. (Torcellini et al. 2006).

Sartori por su parte plantea en su artículo "Net zero energy buildings: A consistent definition framework" que el término Net ZEB indica que un edificio está conectado a las redes de energía y que el cálculo anual del balance del edificio no es suficiente para poder caracterizar un NZEB, haciendo falta, también, plantear la interacción entre los edificios y las redes de energía tomando en consideración el balance importación/exportación y el balance carga/generación. Resalta la necesaria capacidad que debe tener un edificio NZEB para igualar su propia carga a través de la generación on-site (en el mismo lugar del edificio) y para trabajar de manera provechosa con respecto a las necesidades de las redes locales. Se presentan posibles indicadores y el concepto de la flexibilidad de interacción de redes se debate como un fin deseable en el diseño energético de los edificios. (Sartori et al. 2012).

Estas definiciones que de alguna manera son complementarias no entran en el debate de su definición detallada, dejando éste, e incluso favoreciéndolo, a la decisión de cada lugar de aplicación. 
En el proyecto Towards Net Zero Energy Solar Buildings ( Task 40 Annex 52), promovido por la IEA ( International Energy Agency) o Agencia Internacional de Energía cuyo objetivo es desarrollar y estudiar llevando a la práctica constructiva, el concepto de NZEB con una metodología común, basada en el desarrollo de proyectos de demostración, no establecen de entrada un concepto unitario y reconocen la falta de una definición clara y un acuerdo internacional sobre las medidas de rendimiento .En cualquier caso plantean su proyecto como una alternativa unificadora de criterios a partir de un esquema que establezca el equilibrio entre la demanda a las redes y los créditos de exportación del excedente de la producción neta ( de energía) del edificio. (IEA SHC Task 40/ ECBCS Aneex 52. http://task40.iea-shc.org. 2015).

El resultado previsto del proyecto es apoyar la transformación del concepto NZEB de una idea y un 'slogan' a una realidad práctica en el mercado. Se prevé que demostrar y documentar proyectos reales fomentará la creación de una cultura técnica global asumible por la industria y el mercado de la construcción. (www.ecbcs.org/annexes/annex52. 2015).

El alcance del programa incluye a los principales tipos de edificios (residenciales y no residenciales), existentes y nuevos, para las zonas climáticas representadas por los países participantes. El trabajo se vincula a las actividades nacionales y abarcará edificios individuales, grupos de edificios y pequeños asentamientos. (www.ecbcs.org/annexes/annex52.2015).

Otra forma de definir el concepto nZEB o NZEB, indistintamente, es el planteado por Hernández y Kenny en su comunicación "Defining Zero Energy Buildings A life cycle perspective (2008)" y en su artículo "From net energy to zero energy buildings: defining life cycle zero energy buildings (LC-ZEB). (2011)". En estos documentos los autores plantean que la suma de la energía primaria consumida en la operación del edificio nZEB y la energía primaria incorporada en sus materiales y sistemas de construcción (incluyendo sistemas energéticos), y en la vida completa del edificio, debe ser igual o menor que la energía producida por los sistemas energéticos renovables del edificio en su ciclo de vida completo.

Otro concepto para ser tomado en consideración en este estado de la técnica es el de Energy Plus Building o edificio de energía plus. Este tipo de edificio es aquel cuyo balance entre consumo y energía producida (por fuentes renovables) no solo es positivo sino que sobrepasa, la parte de la generación, a la parte del consumo del edificio.

Este tipo de edificios puede estar o no conectado a la red siendo la palabra NET (o red en español) lo que definiría tal condición.

El artículo "Passive design strategies and performance of Net Energy Plus Houses" (Rodriguez. 2014) presenta un diagrama de las tipologías de ZEB que plantea el autor 
en el que se puede ver la relación entre demanda y generación de este tipo de edificios.

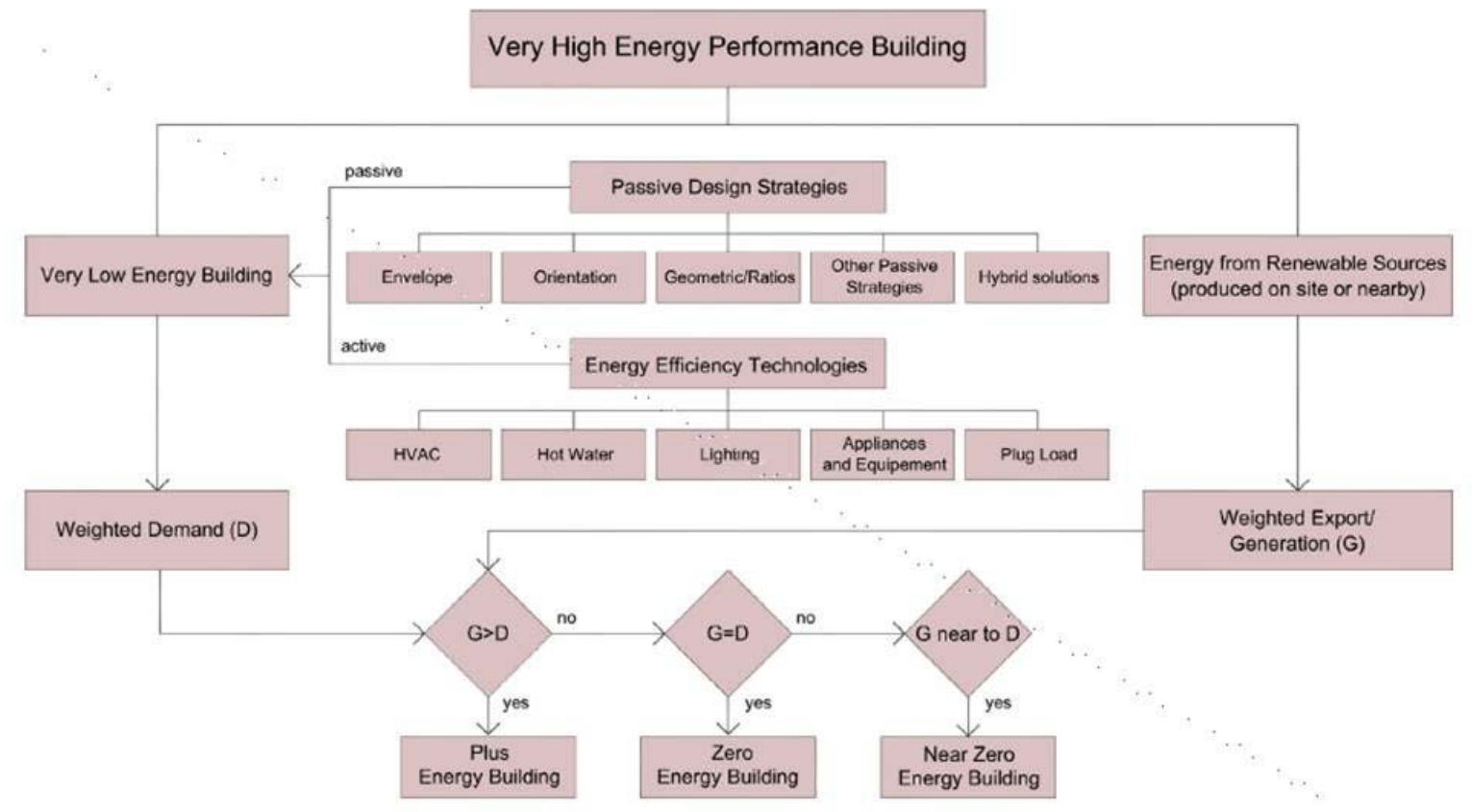

Fig. 80. Esquema de Zero Energy Buildings (Rodríguez; 2014)

La normativa en España

A partir del 1957 en España se han venido sucediendo diferentes normativas técnicas sobre edificación. Desde las MV promovidas por el Ministerio de la Vivienda hasta llegar a las primeras NBE de 1977 en el que se unificaban en un documento técnico las Normas Básicas de Edificación, las normas básicas MV, las NTE o Normas Tecnológicas de la Edificación (que eran una especie de dispositivo operativo no obligatorio de las NBE). (Giménez. 2011).

En 1979 se aprueba la NBE-CT-79, sobre Condiciones Térmicas en los edificios que de acuerdo al propio texto normativo planteaba que:

“...Se incluyen, además de prescripciones encaminadas al ahorro de energía, otros aspectos térmicos o higrotérmicos que afectan a la edificación y a sus condiciones de habitabilidad, incidiendo en aspectos hasta ahora no regulados, tales como los fenómenos de condensación en cerramientos exteriores que afectan al bienestar de los usuarios de los edificios..."

Para el año 2000 entra en vigor la LOE Ley de Ordenación de la Edificación, la cual autoriza la redacción y aprobación de un código técnico de la edificación. 
En este Código Técnico (CTE) quedarían establecidas las exigencias que en materia prestacional debían cumplir los edificios. Este CTE entró en vigor en el año 2006.

Este código del 2006 satisfacía los requisitos básicos de ahorro de energía y aislamiento térmico establecidos en el artículo 3 de la LOE 38/1999,

A partir del R.D. 47/2007 por el que se aprueba la calificación energética de edificios, se establece - con el marco regulador del CTE- el procedimiento básico para la certificación de eficiencia energética de edificios.

Esta calificación energética sería avalada por un certificado de eficiencia energética que incluiría información objetiva sobre las características y prestaciones energéticas de los edificios de nueva planta. Esta información trata sobre los consumos parciales de calefacción y refrigeración, así como de iluminación, valorando el tipo de combustible utilizado para climatizar el inmueble y las prestaciones de los cerramientos del edificio y/o comportamiento térmico del mismo.

La clasificación se realiza siguiendo una escala de letras desde la A a la G, siendo la A la mejor calificación, de acuerdo a los consumos y las emisiones de CO2, y la G la peor calificación. En el año 2013 se aprueba el Real Decreto 235/2013, por el que se establece el procedimiento básico - transponiendo la Directiva 2010/31/UE- para la certificación de la eficiencia energética de los edificios existentes. Su aplicación fue voluntaria hasta Julio del mismo año, fecha desde la cual su aplicación sería obligatoria.

En este contexto europeo, se realiza una modificación (en septiembre de 2013) sobre el CTE del 2006, con el objetivo de fomentar y enfatizar el ahorro energético y disminución de las emisiones de $\mathrm{CO}_{2}$ del país, siendo esto un paso más para conseguir los objetivos europeos 20-20-20 (20\% más de renovables+ 20\% menos de emisiones y todo esto de cara al 2020) y alcanzar futuras exigencias hacia el Edificio Consumo de Energía Casi Nulo.

Algunos de los cambios concretos que presenta el nuevo CTE son la creación de un nuevo Documento Básico (DB-HE0) que limita el consumo máximo de los edificios nuevos o los que amplían su superficie y exigir a los edificios no residenciales una calificación mínima de B.

En el DB-HE 1 se exige una demanda máxima de calefacción y refrigeración y se amplía su ámbito de aplicación hasta los edificios existentes. En los DB- HE 3, 4 y 5 varían las exigencias y se adaptan para ser aplicados las rehabilitaciones. Se le confieren al proyectista más libertades de diseño para reducir la demanda energética y se incluye a Canarias como zona climática.

Además en esta modificación del DB-HE se introduce el concepto de coste óptimo de las exigencias de la normativa o lo que es lo mismo se contemplan las soluciones que 
teniendo en cuenta todos los costes en el ciclo del vida del edificio se presenten como las más favorables económicamente hablando.

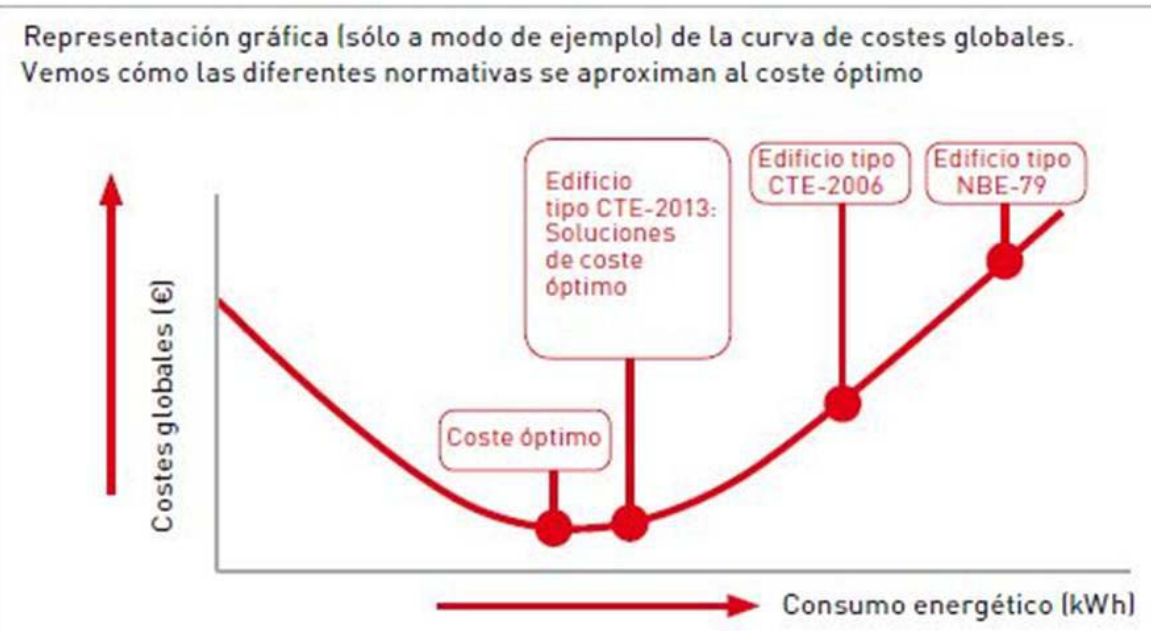

Fig. 81. (Coste óptimo, de las exigencias normativas. www.rockwool.es/. 2015)

Del nZEB a las normativas de aplicación

Visto que el concepto de edificio de consumo casi nulo o nZEB - que queda bajo la responsabilidad de cada estado miembro de la UE, para su aplicación local- no cuenta con un consenso global, aunque sí con una idea general, España asume que dicha calificación de consumo nZEB correspondería, objetivamente a lo establecido en el DB- HE del Código Técnico de la Edificación (CTE) como calificación A (González; 2010) expresada en emisiones de $\mathrm{CO}^{2}$ y en consumo global de energía primaria $\mathrm{kWh} / \mathrm{m}^{2}$.

En la Disposición adicional segunda del Real Decreto 235/2013, del 5 de Abril, por el que se aprueba el procedimiento básico para la certificación de la eficiencia energética de los edificios, se establece como en España se determinará que un edificio será de consumo de energía casi nulo:

1. Todos los edificios nuevos que se construyan a partir del 31 de diciembre de 2020 serán edificios de consumo de energía casi nulo. Los requisitos mínimos que deberán satisfacer esos edificios serán los que en su momento se determinen en el Código Técnico de la Edificación.

2. Todos los edificios nuevos cuya construcción se inicie a partir del 31 de diciembre de 2018 que vayan a estar ocupados y sean de titularidad pública, serán edificios de consumo casi nulo"

En otras palabras lo que se establece en la disposición adicional segunda, es que los requisitos mínimos que tiene que cumplir un "edificio de consumo de energía casi nulo, aunque no aparezca de forma explícita una definición de ámbito nacional, quedan 
definidos en el CTE tanto en los establecidos en el DB-HE 1 modificado como en el nuevo DB-HE 0. Limitar el consumo energético de energía primaria no renovable (en los edificios nuevos o en la ampliaciones de superficies de los existentes) es el objetivo y quedando establecido por normativa que la calificación energética - para el indicador de consumo energético de energía primara no renovable- sea igual o superior a la clase $B$, según el procedimiento básico para la certificación de la eficiencia energética de los edificios aprobado mediante el Real Decreto 235/2013, del 5 de Abril. (www.madrimasd.org; Gómez Prada. 2013). En el año 2010, precisamente el año de entrada en vigor de la Directiva 2010/31/UE, y de acuerdo a los datos servidos en los informes Implementing the Energy Performance of Building Directive (EPBD) de los certificados energéticos que se realizaron para los edificios de nueva construcción en España, la mayoría correspondía a una calificación E.

Esta calificación, para edificio de nueva planta, representa la más baja de la escala, correspondiéndole el $45 \%$ de la totalidad de los certificados. El 14\% de los edificios tendría una calificación entre Ay B, definición española de nZEB. (www.madrimasd.org; Gómez Prada. 2013).

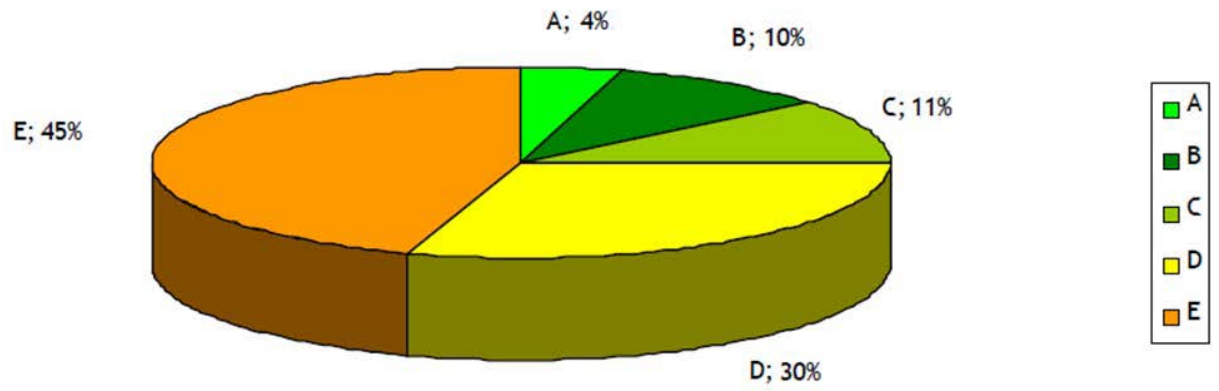

Fig. 82. Calificaciones obtenidas por los distintos edificios de nueva construcción en España hasta el 2010. IDAE

En la parte de la metodología de investigación se presentan los resultados de un total de 150 viviendas evaluadas, en las que la media de calificación de las mismas para el año 2013, año en que entra en vigor la certificación energética obligatoria para edificios existentes, ha sido de F.

\section{De las normativas al estándar PassivHaus}

Los organismos encargados de promover el nZEB en la normativa española y por vía de consecuencia en la práctica cotidiana sobre construcción de edificios de nueva planta y/o reformas de envergadura que sustituyan cerramientos o modifiquen superficies, han tomado como referencia un estándar internacional que surgido en Alemania, pretende establecer unos patrones característicos en pos del consumo cero o casi cero.

Publicaciones como "Guía del estándar Passivhaus: edificios de consumo energético casi nulo (2011)", editada por FENERCOM y el IDAE, fomentan la aplicación del estándar en España para alcanzar el nZEB. 
Este estándar de referencia es el Passivhaus, creado en 1988 por Bo Adamson y Wolfang Feist, profesores e investigadores, sueco y alemán respectivamente.

En 1990 se lleva a cabo el primer proyecto bajo el estándar; consistió en un edificio de 4 viviendas pareadas en la localidad de Darmastadt Kranichtei, Alemania. Aún a día de hoy el conjunto de viviendas continúa respondiendo, a nivel de prestaciones, a las proyecciones establecidas originalmente.

Las exigencias establecidas para cumplir con el estándar Passivhaus son las siguientes, con ellas en principio se alcanzaría como mínimo un 75\% de reducción de consumo:

\section{Una demanda de calefacción no superior a $15 \mathrm{kWh} / \mathrm{m}^{2}$ año o 10W/m² \\ Una demanda de refrigeración no superior a $15 \mathrm{kWh} / \mathrm{m}^{2}$ año \\ Una demanda de energía primaria total de $120 \mathrm{kWh} / \mathrm{m}^{2}$ año \\ La Estanqueidad al aire $n 50 \leq 0,60 \mathrm{r} / \mathrm{h}$ (renovación/hora) \\ Transmitancia cerramientos verticales 0,1 a $0,15 \mathrm{w} / \mathrm{m}^{2} \mathrm{~K}$ \\ Transmitancia $0,80 \mathrm{~W} / \mathrm{m}^{2} \mathrm{~K}$}

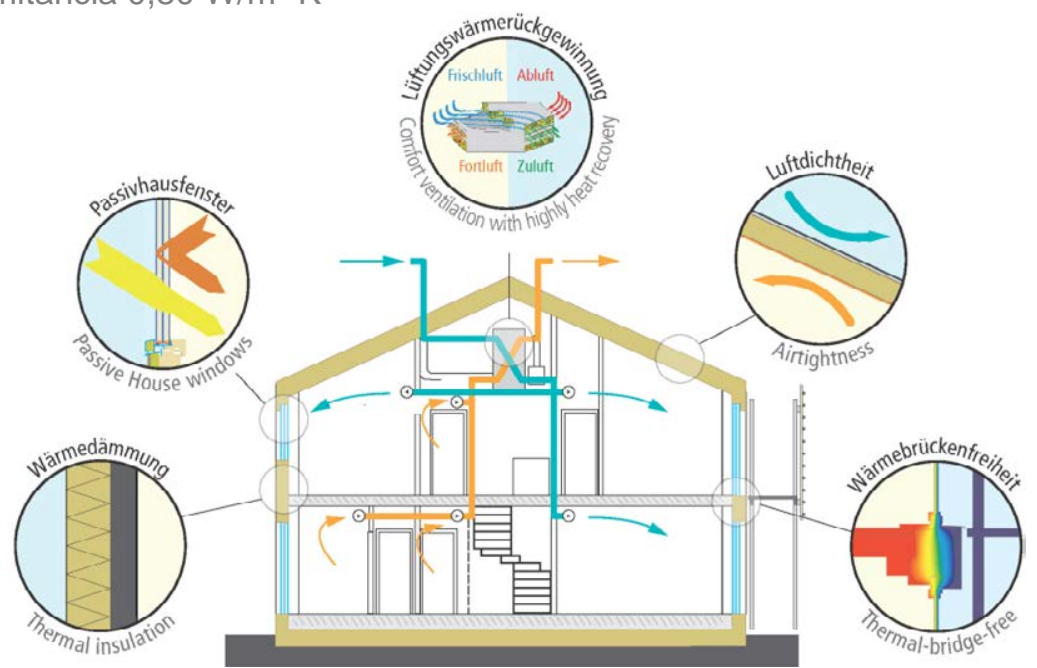

Fig. 83. Principios básicos del estándar Passivhaus ( http://passiv.de. 2015)

El Estándar que ha sido creado para climas fríos aún está en proceso de implementación plena en climas como los de de España. En su libro "De las Casa Pasivas al Estándar Passivhaus. La Arquitectura pasiva en climas cálidos", (2014) Micheel Wassouf analiza y aplica los conceptos del estándar a un modelo en Madrid para establecer las posibilidades reales de ahorro en climas mediterráneos.

Para un edificio de viviendas en bloque, en Madrid la calificación A implicaría un consumo máximo para calefacción de $15,8 \mathrm{kWh} / \mathrm{m}^{2}$ año $\left(5,1 \mathrm{kgCO}_{2}\right.$ año $)$ y un consumo para refrigeración máximo de $4,9 \mathrm{kWh} / \mathrm{m}^{2}$ año $\left(1,2 \mathrm{kgCO}_{2} / \mathrm{m} 2\right.$ año). Estos valores estarían dentro del estándar del Passivhaus y evidentemente en cumplimiento del CTE. 


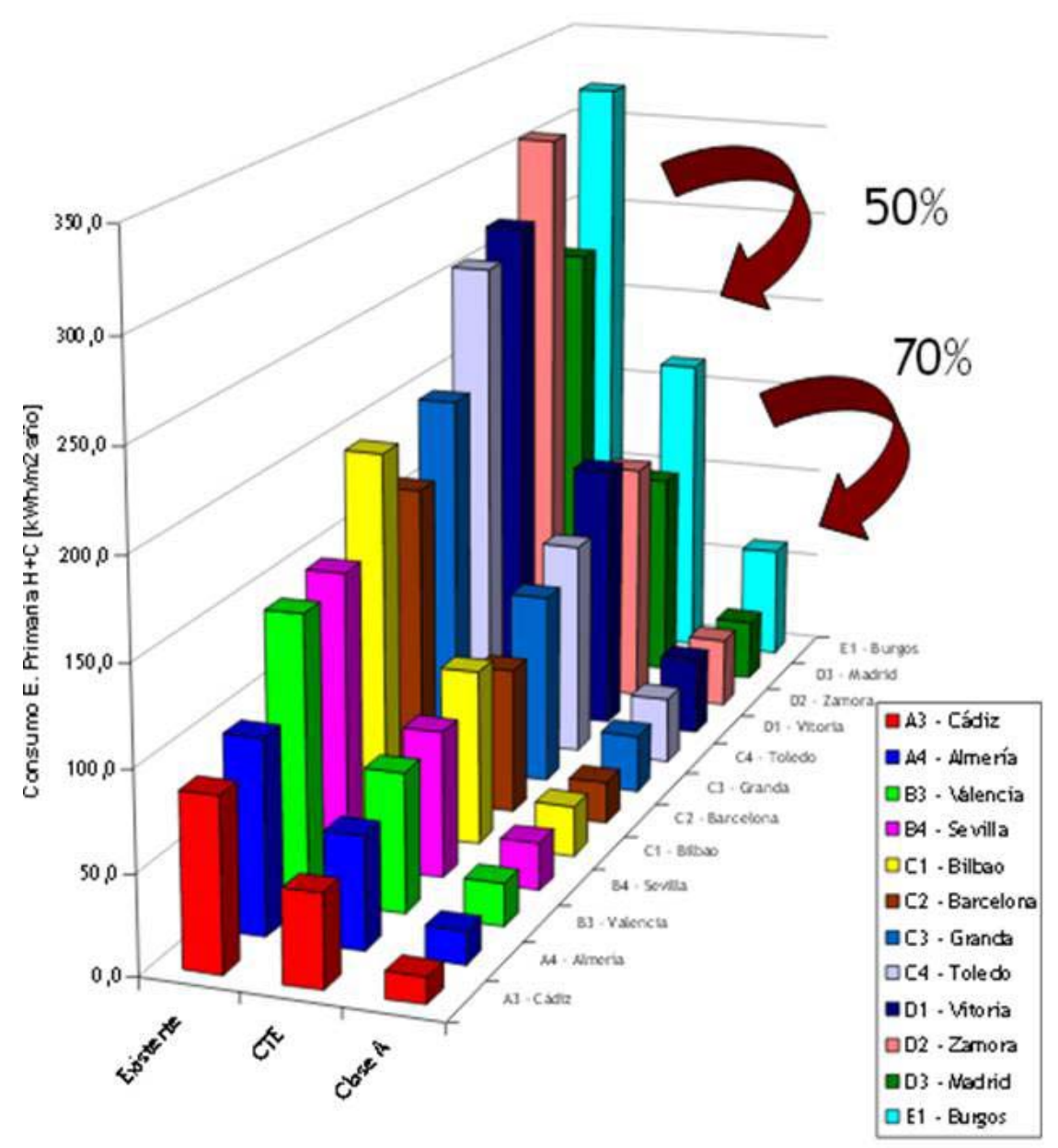

Fig. 84. Consumos primarios (kWh/m2 año) por zonas de España. IDEA.

En la figura 84 se muestran los distintos consumos por zonas de España, con relación a edificios existentes, con lo establecido como mínimo por el CTE para una calificación D y la calificación A que en todos los casos es inferior a lo establecido en el estándar Passivhaus, es decir $120 \mathrm{kWh} / \mathrm{m}^{2}$ año.

\section{Pirámide de Kioto}

La pirámide de Kioto es una especie de declaración de intenciones sobre las claves para una arquitectura pasiva y/o eficiente energéticamente.

Se apoya en una base fundamental que es la reducción de las pérdidas de calor del edificio, dotándolo de aislamiento adicional, gran nivel de estanqueidad del aire y un sistema de ventilación con recuperación del calor. Ascendiendo, el segundo nivel de la pirámide es el uso eficiente de la electricidad, utilizando electrodomésticos e iluminación eficientes y evitando el consumo innecesario. El tercer nivel de la pirámide es la utilización de la energía solar, apoyándose en una buena orientación y en la captación pasiva y activa. 
El penúltimo nivel de la pirámide consiste en medidas de gestión y control del consumo energético del inmueble. Por último, en la cima de la pirámide se encuentra la selección de la fuente de energía renovable y/o sostenible más adecuada para el proyecto: biocombustibles, bombas de calor de alta eficiencia, calefacción tipo district heating y/o sistema de gas o electricidad de la ciudad.

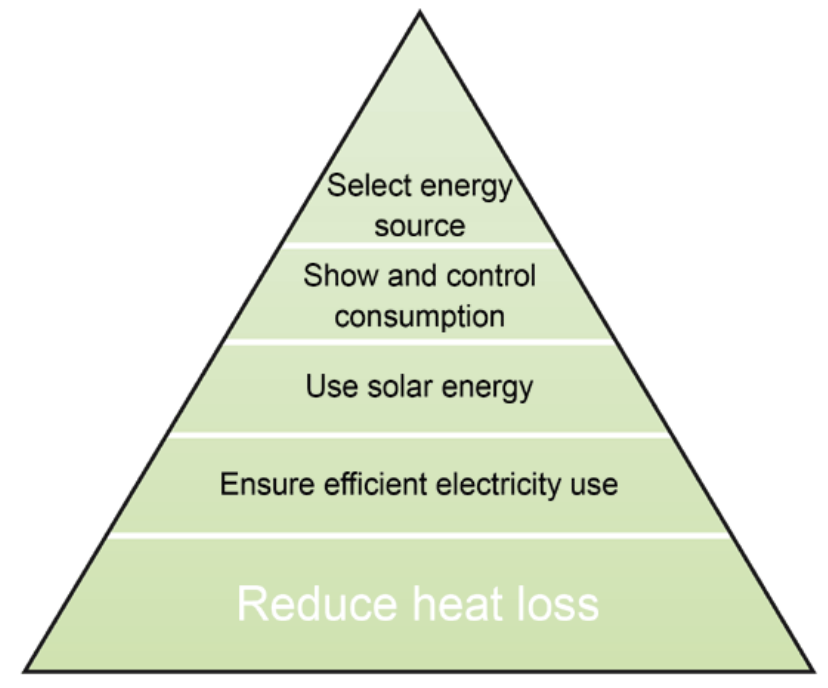

Fig. 85. Pirámide de Kioto sobre arquitectura pasiva. (http://www.paroc.com. 2015)

\section{Arquitectura Bioclimática}

Todos los estándares, normativas y estrategias necesariamente tienen que pasar por un concepto unificador que sirva para definir en líneas generales lo que supone realizar un proyecto de construcción (de nueva planta, rehabilitación o reforma) bajo criterios de eficiencia energética; este concepto tiene un nombre genérico: arquitectura bioclimática.

La Arquitectura Bioclimática o sostenible, es la que hace uso de materiales y técnicas de construcción de manera sostenible para la eficiente administración energética del organismo, mediante la captación, acumulación y distribución de recursos renovables con métodos pasivos y/o activos. Significando esto que no compromete con su uso actual, el aprovechamiento para las generaciones futuras. Es aquella que se relaciona directamente con su entorno; es decir, con las condiciones naturales, y sociales del mismo. Partiendo de lo anterior podríamos decir que Arquitectura Bioclimática no es otra cosa que las buenas prácticas dentro del quehacer arquitectónico, teniendo como objetivo el confort de los espacios interiores y la reducción de los efectos negativos sobre el entorno.

En el libro Arquitectura y Clima de Víctor Olgyay encontramos lo siguiente (Olgyay; 2004): 
aprovechando todos los recursos naturales que favorecen el confort pueden catalogarse como climáticamente equilibradas. La estabilidad perfecta rara vez puede alcanzarse, solamente es posible bajo circunstancias ambientales excepcionales. Pero puede conseguirse una casa muy confortable y con un bajo coste de mantenimiento reduciendo las necesidades de acondicionamiento mecánico..."

\section{Entorno}

La Interrelación del Organismo con el Entorno, el Confort en los Espacios Habitables y la Eficiencia o Aprovechamiento Energético, tanto en la captación como en el uso, son en resumen los aspectos fundamentales que definen la arquitectura bioclimática. El análisis del entorno ( $\mathrm{y}$ de los factores que forman parte del mismo), es la acción primaria que determina muchos de los pasos a dar posteriormente para conseguir el bienestar y el equilibrio energético deseado. Es a partir de un estudio de las condicionantes climáticas y medioambientales que se plantean las estrategias bioclimáticas de diseño; tomando en cuenta aspectos tales como la situación geográfica, el régimen de viento, los niveles de humedad, la incidencia del sol en las estaciones del año, la topografía, etc.

\section{Confort}

Cuando hablamos de Confort, nos referimos a 1) buena iluminación, 2) equilibrio acústico/sonoro, 3) kinestesia y ritmos biológicos del individuo favorecidos, 4) agradable sensación olfativa, 5) factores higrotérmicos adecuados.

\section{Aprovechamiento energético}

La arquitectura bioclimática, es lo opuesto a la práctica generalizada de exportación de modelos predeterminados, a lugares con características climáticas y ambientales distintas, siendo esto causante de gastos excesivos de energía, por compensar las deficiencias de diseño. Para que un organismo sea cómodo y a la vez con un consumo moderado, debe estar pensado y construido a favor de la naturaleza y no en contra. Como todo proceso bioclimático, las condicionantes climáticas han de tomarse en consideración para el planteamiento de una buena solución.

Los términos Ahorro, Aprovechamiento y Eficiencia, aun no siendo sinónimos, responden a un solo concepto de optimización de la energía y sobre todo al uso de renovables, que en lo concerniente a la arquitectura se podrían dividir en solar, eólica biomasa y R.S.U.

La Captación, la Acumulación y la Distribución son conceptos claves para alcanzar la eficiencia. 
La envolvente, cuya misión principal es la de proteger de los factores climáticos, garantizar el bienestar interior, permitir y graduar la entrada de luz natural y el contacto con el exterior; es uno de los elementos arquitectónicos más importantes a la hora de evaluar la eficiencia energética del edificio. Debe considerarse como una estructura dinámica, al ser el punto medio entre lo interno y lo externo; que reacciona ante las exigencias del usuario, las variaciones del tiempo y la radiación solar.

Además de su función protectora, con el aislamiento adecuado cuando hace falta para evitar las pérdidas de las condiciones imperantes en el interior; las fachadas, cubiertas, y elementos de cierre -por medios pasivos y activos- pueden captar, almacenar y distribuir energía solar; por ejemplo: Muros Trombe, Invernaderos, Cubiertas Ecológicas, etc.

En determinadas situaciones los cerramientos pueden ser parte de sistemas de transformación de energía: cubiertas fotovoltaicas, captadores solares.

\subsection{SOLAR DECATHLON. ENTRE EL ESTADO DE LA TÉCNICA Y LA INVESTIGACIÓN}

Al hacer referencia, en un solo concepto global, a la construcción modular, ligera y eficiencia energética, necesariamente se debe hacer referencia al concurso internacional de casas eficientes conocido como Solar Decathlon.

Solar Decathlon Europe es una competición universitaria de carácter internacional que fomenta la investigación sobre viviendas eficientes, desarrollando prototipos para la competición. El objetivo de los equipos participantes - equipos conformados por estudiantes universitarios- es el diseño y construcción de casas que consuman la menor cantidad de energía y que produzcan la menor cantidad residuos durante su ciclo de vida; implementando medidas pasivas y activas de captación solar y acondicionamiento interior.

El concurso tiene su origen en Estados Unidos y fue creado por el Departamento de Energía (DOE) de ese país en el año 2002 y fundamentalmente evalúa cada prototipo participante en base a 10 pruebas con una puntuación cada una, y que al sumar los puntos obtenidos en las mismas por los participantes- se puede determinar el ganador del concurso. Estas pruebas son realizadas por el jurado mediante sistemas de medición: 


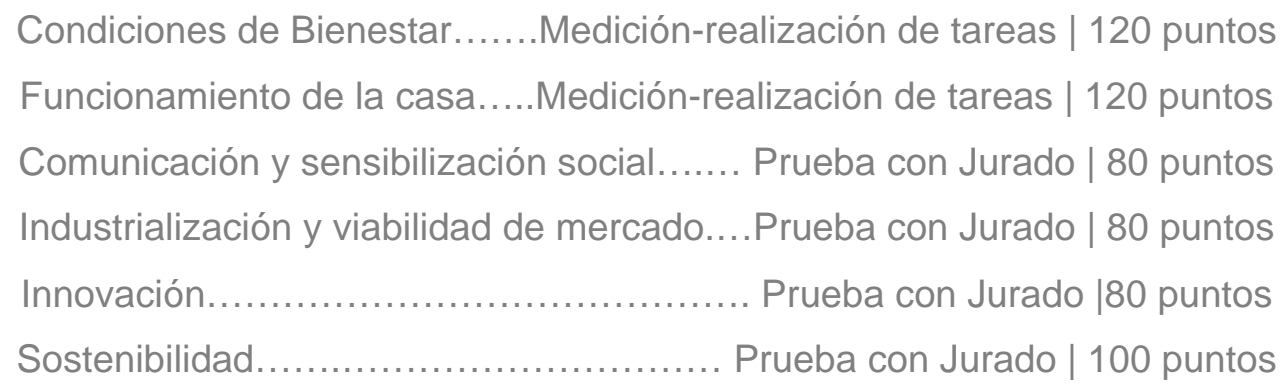

En el año 2010 y 2012 se celebraron en Madrid las primeras ediciones del concurso Solar Decathlon.

Ambos concursos han servido de material de estudio para esta tesis por las condicionantes de las viviendas diseñadas y pensadas para el clima de Madrid. Lo cierto es que dadas sus características y prestaciones, estos prototipos construidos permiten ser estudiados, como una gran base de datos, desde la perspectiva de este trabajo.

Estas casas son, sin duda, el conjunto de prototipos de CML y eficiencia energética más desarrollado actualmente a cualquier nivel.

Siendo prototipos hiperoptimizados, como modelos NZEB, el coste de producción es sensiblemente superior a lo que supondría el mismo modelo pero listo para su puesta en mercado de manera seriada y dentro de un contexto de comercialización.

Como parte de la metodología de trabajo para esta tesis se han tomado como referencia estos costes ( el de los prototipos), para analizar comparativamente lo que supone la producción de un prototipo optimizado y lo que supondría su precio de mercado si se ajustara a régimen de oferta y demanda real. En este caso se ha hecho este análisis con los proyectos de las ediciones madrileñas del concurso, siendo el resultado el que se muestra en el siguiente gráfico. Los costes han sido tomados de la propia documentación técnica de los prototipos.

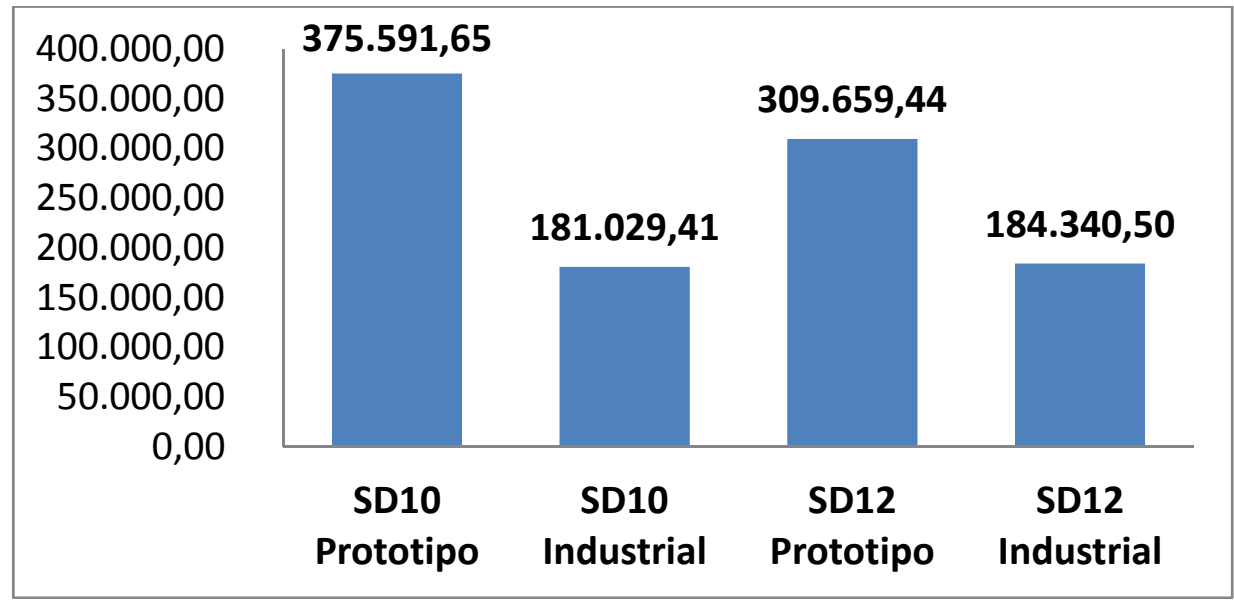

1. Fig. 86. Gráfico de coste medio de los prototipos para el concurso y coste medio del mismo modelo para comercialización. Elaboración propia. Datos tomados de web Solar Decathlon. (www.sdeurope.org. 2015) 
En los concursos de Madrid tanto en el del 2010 como en el del 2012 se presentaron un total de 35 viviendas de las cuales sólo dos no eran viviendas ligeras, pero todas sí pretendían aportar un plus energético a su balance.

Los modelos ganadores de las dos ediciones madrileñas, son la Lumenhaus de 2010 de la Universidad Virginia Tech y la Casa Canopea de 2012 de la Universidad de Rhone Alpes. Se da por supuesto que estos modelos se han desarrollado bajo los principios de NZEB toda vez que cumplen con las características de los correspondientes requisitos de la definición genérica.

La categoría de NZEB queda establecida de manera implícita en la propia documentación y publicaciones del concurso SOLAR DECATHLON

EUROPE 2010 Towards Energy Efficient Buildings ( Vega. 2011; Editor) y SOLAR DECATHLONEUROPE 2012 Improving Energy Efficient Buildings (Vega \& Serra, Editores. 2013) respectivamente

En el caso de la Lumenhaus (2010) la misma tiene un nivel de generación de energía, mediante captación solar fotovoltaica, que duplica su demanda con un ratio (balance de generación y demanda) de 2.12. Con fachadas dinámicas la casa capta pasivamente energía solar, o se protege, de acuerdo a sus necesidades. Al oeste la fachada cuenta con vidrios electrocrómicos que matizan la entrada del sol oscureciendo o transparentando el vidrio. Al sur, la fachada acristalada, se protege con paneles, con sensores, que producen un adecuado sombreamiento.

La casa Canopea del (2012) cuenta con un nivel de iluminación natural muy alto gracias a sus celosías de vidrio, que permiten además regular la ventilación natural. Con un concepto de smart grid (red inteligente) la vivienda, como los demás prototipos de concurso, contaba con un invernadero, de posible uso común, y espacios verdes propios para fomentar la interacción con elementos naturales. El prototipo recrea el último nivel de una nanotorre que interactúa con otras torres con las mismas características y conectadas a la red de suministro y servicios colectivos antes citada (Smart Grid).

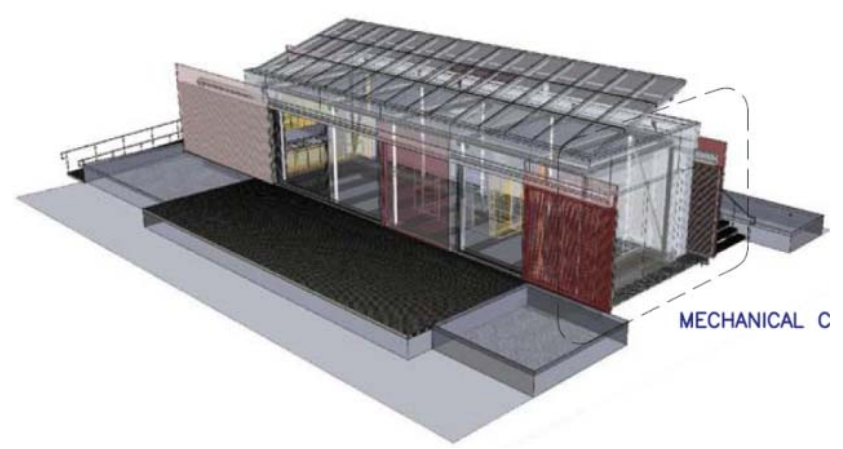

Fig. 87. Lumenhaus. Virginia Tech. 2010. (www.sdeurope.org. 2015) (www.sdeurope.org. 2015)

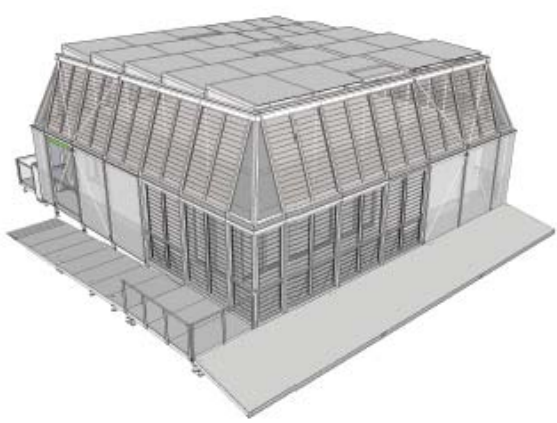

Canopea, Rhone Alpes. 2012. 
La Lumen House, es una vivienda modular y ligera de tipología unifamiliar; la casa Canopea, también ligera, es una recreación de vivienda individual en un bloque en altura.

Estudiadas sus características generales así como las puntuaciones finales obtenidas en el concurso se puede observar que aunque no son fruto de una evaluación rigurosamente científica sí que sirven como buen ejemplo, por sus prestaciones de CML.

\subsection{ESTADO DE LA INVESTIGACIÓN.}

\subsubsection{Artículos indexados JCR ( Journal Citation Reports)}

En artículos indexados (JCR) y otras publicaciones especializadas estos conceptos quedan definidos de manera individual.

La idea del edificio cero energía ha venido desarrollándose en los últimos años impulsada, sobre todo, por la reglamentación europea de que todos los edificios de nueva planta tendrán que ser NZEB antes del 2020. Aún así, y con este punto de inflexión, a cinco años vista no existe una definición unificada para el término; a partir de este punto - el de la unificación del criterio- se inicia el análisis del estado de la investigación. Lo cierto es que, objetivamente, resulta razonable que cada país tenga sus propios criterios para definir el término NZEB, tomando en cuenta sus condicionantes medioambientales, sociales, económicas y políticas, aunque sin embargo sigue siendo necesario realizar una unificación de criterios base, comunes en términos globales.

En el año 2010 se publicó el artículo "Zero Energy Building - A review of definitions and calculation methodologies" (A.J. Marszal et al. 2010) en el que un grupo de investigadores realizan una serie de planteamientos que sirven de antesala para la definición de los conceptos ZEB y NZEB de manera global. Con esta recopilación que parte de los conceptos establecidos en el documento "The IEA SHC Task 40/ECBCS Annex 52 'Towards Net Zero Energy Solar Buildings", se pretende alcanzar una unificación de criterios con relación a estos conceptos y la manera de realizar los cálculos que determinen si un edificio es o no cero energía.

Para ello se hace el enfoque tomando aspectos como la métrica de la balanza, el período de equilibrio, el tipo de energía tomado en cuenta para el balance energético, los niveles y tipos de aportaciones de energías renovables, las condiciones de confort interior, la conexión a la redes generales de suministro de energías y su interacción con las mismas.

Para el trabajo que nos ocupa y de acuerdo al artículo escrito por I.Sartori, "Net zero energy buildings: A consistent definition framework" (Satori et al. 2012), un criterio de definición común - a grandes rasgos, podría ser el equilibrio entre demanda / 
consumo, la oferta ponderada y el flujo de intercambios energéticos entre el edificio y la red de suministro, valorando la auto-generación energética, el auto-consumo y los balances netos anuales y/o mensuales.

De acuerdo a este artículo es común ver asociados los conceptos de NZEB y ZEB y que en muchos casos son utilizados indistintamente para definir lo mismo habiendo diferencia entre ambos. En el primer caso el término puede ser utilizado para referirse a los edificios que están conectados a la infraestructura energética (red eléctrica, red de gas ciudad, red de calefacción o refrigeración) con una generación (de origen renovable) de energía ponderada que sobrepase una demanda también ponderada, tomando como unidad de medida un período de tiempo base para calcular el balance de intercambio de energía. En el segundo caso el término se refiere a los edificios con generación de energía mediante fuentes renovables pero que son autónomos y que no están conectados a la red.

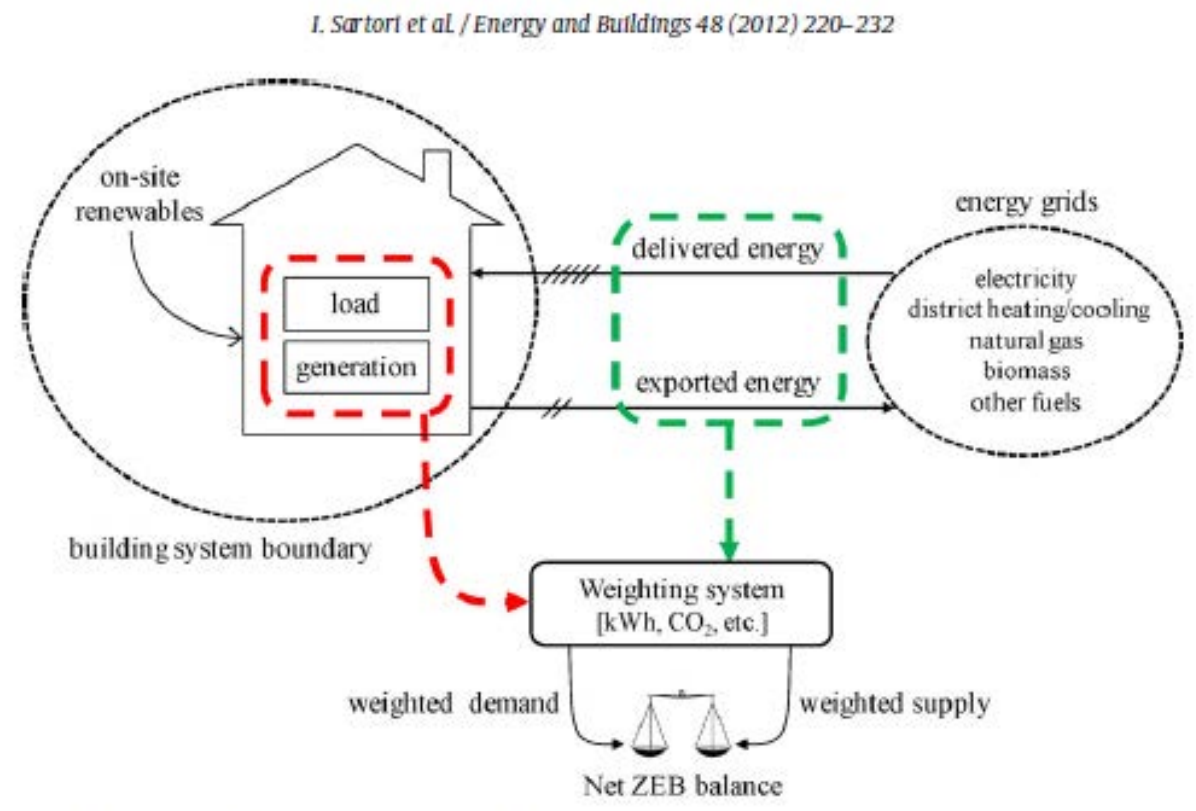

Fig. 1. Sketch of connection between buildings and energy grids showing relevant terminology.

Fig. 88. Esquema NZEB. (Satori et al. 2012)

En esta imagen figura 88, se hace una descripción gráfica de los términos más relevantes relacionados al NZEB de acuerdo a Sartori.

En términos generales lo que se dice es que como condición fundamental para que un edificio pueda entrar en la definición de cero energía es que la generación de energía ponderada - renovable en todo caso- exceda la demanda ponderada en un período de tiempo determinado, que se calcula generalmente como un año, dependiendo el criterio de ponderación de la métrica usada en la definición. Este balance de energía se puede determinar de dos posibles maneras: realizando un balance de importación/ exportación, es decir, entre la energía suministrada y exportada o haciendo un balance de demanda/ generación y según la definición, el balance de NZEB puede calcularse con la ecuación: 
Por otro lado y de manera gráfica se hace una representación del balance NZEB:

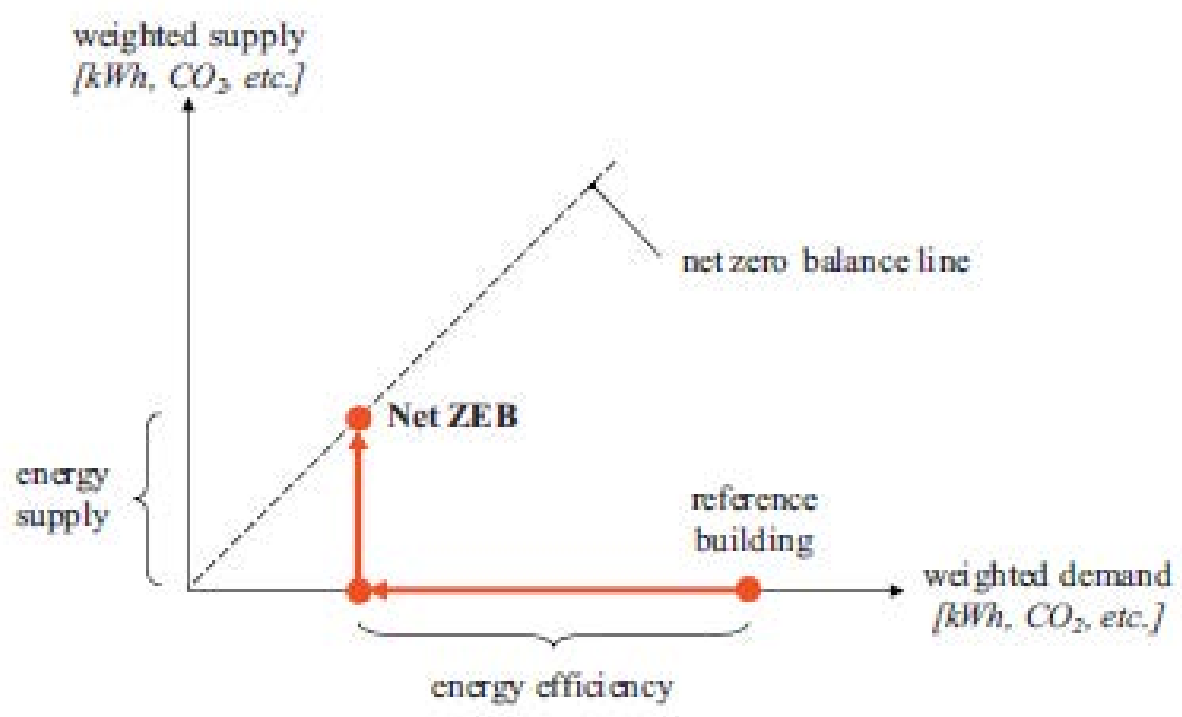

Fig. 2. Graph representing the net ZEB balance concept.

Fig. 89. Esquema NZEB. (Satori et al. 2012)

Como planteamiento fundamental en este artículo se describen cinco criterios que sirven para fijar una definición que pudiera servir para unificar el criterio de NZEB. Estos cinco criterios son:

- Limites constructivos y de sistemas del edificio.

- Sistema de ponderación.

- Balance energético.

- Características temporales de la energía.

- Medición y Verificación.

Cuando los autores se refieren a los Límites Constructivos y de Sistemas del edificio lo hacen en términos tanto físicos del edificio como de los sistemas de generación incorporados al mismo o a un conjunto al que pertenece. Se define en esta parte el límite en el balance referente a los usos energéticos comunes durante el uso del edificio, como calefacción, ACS, electricidad, etc.

Junto con estas dos se establecen también las condiciones de contorno que engloban desde la tipología del edificio hasta sus condiciones de uso y los utiliza como parámetros comparativos.

En cuanto al Sistema de Ponderación se plantea una posible unificación de las formas de medir la energía y las emisiones de Co2. Se parte de que siendo las fuentes de energía de distintos orígenes, el tipo de métrica para realizar el balance energético puede variar. Se valoran como formas de medir una ponderación simétrica (usando los mismos factores de ponderación para la energía importada y la exportada) o una 
ponderación asimétrica, utilizando factores distintos. También se toma en consideración, para la ponderación, los factores de conversión medios para períodos de tiempo determinados e incluso variaciones horarias.

El balance energético, de acuerdo a la ecuación, debe ser igual a cero luego de operar la resta entre suministro y demanda. Este balance puede ser calculado de diversas formas, siempre dependiendo directamente del periodo de tiempo (por ejemplo un año), relacionado con los flujos de energía en una u otra dirección (desde la fase de diseño o desde el funcionamiento del edificio), quedando siempre por definir en términos políticos y/o de legislación los niveles de eficiencia energética para el edificio y el uso - y tipo- de renovables.

Otro de los criterios para unificar el concepto de NZEB es el que tiene que ver con las Características Temporales de Energía y hace referencia, por un lado, al acoplamiento entre la generación de energía renovable, la demanda y el nivel de autoconsumo; y por otro lado se refiere a la interacción del edificio con las redes energéticas en el proceso de exportación e importación de la energía.

Por último se plantea la necesidad de establecer un método de medición y verificación. Las dos maneras de verificar y medir si un edificio es NZEB son mediante cálculo o mediante medición real del rendimiento, en cuanto a eficiencia energética.

Esto incluiría considerar el balance de importación/exportación de energía, el confort de los usuarios, el uso del edificio, las condiciones climáticas y las características de la igualación temporal.

Otro concepto que consideramos y que también está asociado al NZEB es el de edificios de cero $\mathrm{CO}_{2}$

Existe cierta unidad de criterio en cuanto a que un edificio con cero emisiones de $\mathrm{CO}_{2}$ debe englobar todo su ciclo de vida (ACV), desde la selección y procesamiento de la materia prima (para los materiales de construcción), pasando por el proceso de ejecución material de la obra, la vida útil del edificio y sus procesos energéticos, hasta la posible deposición y/o reutilización de estos materiales según lo escrito por F.Meggers en "Reduce $\mathrm{CO}_{2}$ from buildings with technology to zero emissions" (Meggers et al. 2012).

Se afirma, en este artículo, que los edificios son responsables de un tercio del consumo de energía total del planeta, y calculando lo que es su uso y mantenimiento puede llegar hasta un 50\%. Si se toma en consideración todo el proceso, haciendo un análisis de ciclo de vida, estaríamos hablando de casi la mitad del consumo de energía mundial.

Además como solución lógica y viable se plantea que la alternativa para solventar el problema de emisiones asociado al edificio - y su ciclo de vida- pasa por la implementación de sistemas de generación de energía de fuentes renovables y, desde 
luego, una selección de nuevos y mejores materiales de construcción cuya huella de carbono sea sustancialmente menor que la que corresponde a los materiales de uso más habitual.

Los autores tantean la posibilidad real de que el uso de los materiales ligeros no implican solamente baja densidad, sino que también tienen una mejor proporción (alta en todo caso) de fuerza/densidad o rigidez/densidad.

Al mismo tiempo favorecen el uso de sistemas ligeros con prestaciones estructurales. En términos generales se determina que, esencialmente, un edificio emitiría menos $\mathrm{CO}_{2}$ si se combinan: una selección de materiales cuya huella de carbono sea reducida (como es el caso de una buena parte de las soluciones con cerramientos ligeros, tal y como se plantea en este trabajo de tesis), implementación de renovables y unos hábitos de uso y consumo responsables por parte de los usuarios del edificio. Se hace la comparativa de que una residencia típica en Alemania contiene suficiente energía gris en los materiales como para operar el edificio durante 25 años y propone la construcción ligera, apoyada en un diseño arquitectónico optimizado, como alternativa que no comprometa la relación material/ emisiones/años más allá de unos $0,5 \mathrm{~kg} / \mathrm{m} 2$ de edificación. También se hace una aproximación a la conveniencia de la aplicación del principio de la segunda ley de la termodinámica y su relación directa en la reducción de emisiones de $\mathrm{CO}_{2}$. Actualmente, cualquier análisis de diseño de cualquier edificio propuesto se lleva a cabo utilizando equilibrios simples de energía basados en la primera ley de la termodinámica, donde la energía suministrada se equipara a la energía requerida por pérdidas (y consumo) de calor, ventilación, iluminación, etc.

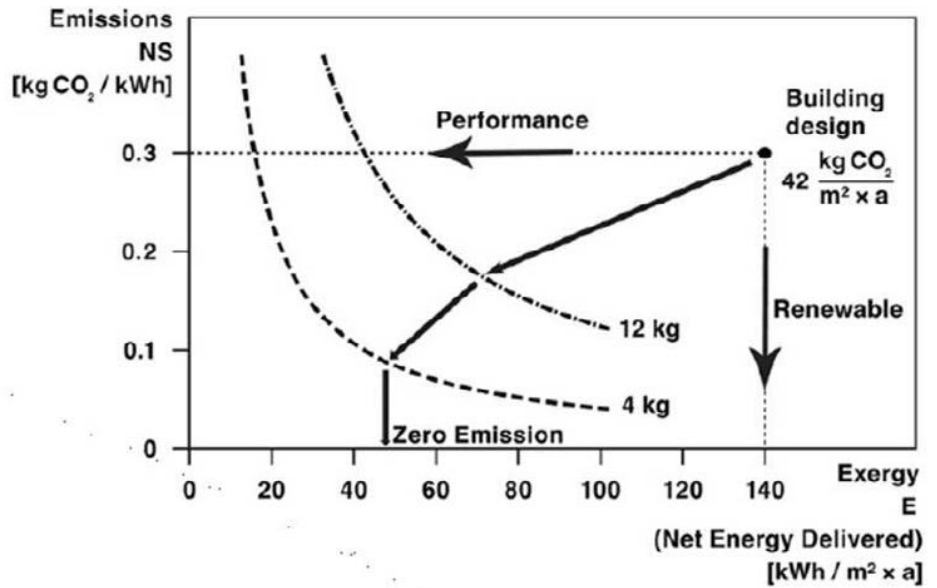

Fig. 3. NS-E diagram or Zero Emission Chart separating the non-sustainable (NS) level of exergy supply $\mathrm{CO}_{2}$ intensity and the actual net delivered exergy (E) of the building, allowing the designer to consider efficiency and supply improvements individually to move the building operation toward zero emissions. As designs increase building performance, the point moves to the left, which eventually facilitates the integration of more renewable energy in design steps, which in turn moves the point down and toward zero emissions at the $x$-axis.

Fig. 90. Esquema emisiones y energía entregada. (Meggers et al. 2012).

Con esta metodología, un tanto simple, ciertamente se ayuda a minimizar la cantidad de energía utilizada por un edificio, pero, según el artículo, si se aplican los conceptos 
de la segunda ley de la termodinámica, la optimización se podría extender para evaluar también la calidad de la fuente de energía que se está consumiendo.

Se propone el aprovechamiento de la energía dispersada libremente alrededor de un edificio como potenciales fuentes energéticas y se asocia directamente a la reducción del $\mathrm{CO}_{2}$. En este punto se considera el concepto de exergía como una variable a favor de la eficiencia energética de los edificios.

Según se va avanzando en la elaboración del estado de la investigación sobre la construcción modular eficiente y los factores independientes que pueden llegar a componer la idea global, se presenta la exergía como un posible hilo conductor que puede llegar a ser el denominador común de todos los conceptos que se relacionan con el trabajo.

Son varias las definiciones que se pueden encontrar para exergía; por ejemplo: la exergía es la capacidad de la energía para producir trabajo útil dentro de un sistema, basándose en el segundo principio de la termodinámica, o en otras palabras la exergía es la energía que se puede transformar totalmente en energía, interactuando con su entorno.

$$
\text { ENERGÍA = EXERGÍA + ANERGÍA }
$$

Mediante un análisis exergético del edificio y la aplicación de sus principios se pueden optimizar los consumos y tipos de energía hacia donde realmente son necesarios. Esto quiere decir que si para un sistema hace falta combustión de alta calidad se dirige hacia este área este tipo de consumo.

En el desarrollo del artículo se hace una propuesta concreta: utilizar la segunda ley de la termodinámica para mejorar los sistemas integrados de bomba de calor y maximizar la utilización de otras fuentes energéticas de bajo valor, o "fuentes anérgicas" procedentes del medioambiente o de los flujos de residuos térmicamente valiosos.

Con un análisis como el señalado (con un diseño de aumento de la baja temperatura) se plantea que en un local se puede lograr un rendimiento para las bombas de calor equivalente a siete unidades de calor por unidad de electricidad (COP>7). Al reconocer el potencial de bombas de calor de aumento de baja temperatura, la generación del agua caliente solar llega a hacerse obsoleta. Un panel PV con una eficacia del $20 \%$ conectado a una bomba de calor con una COP $>5$ dará un calor igual o más alto que el $100 \%$ de la energía solar entrante.

En términos generales se contrapone el concepto de aumento masivo del aislamiento, más propio del diseño pasivo, y se opta por la optimización de los cerramientos combinados con sistemas activos de baja exergía. Se aborda también el tema del 
almacenamiento de parte de la energía que pudiera necesitar el edificio para su funcionamiento.

Un buen ejemplo de almacenamiento de la energía se logra, de acuerdo a los autores, moviendo el calor espacialmente desde el suelo o los alrededores a un punto más valioso (es decir: bombas que sacan su calor del suelo), y/o moviendo el calor de manera temporal desde puntos estacionales o diarios a un punto diferente donde será más valioso (es decir: almacenaje de calor estacional o enfriamiento nocturno).

En "Low exergy building systems implementation" F.Meggers (Meggers et al. 2011), plantea que para obtener un edificio eficiente - en nuestro caso cero emisiones y cero energía,- no hace falta maximizar el espesor de los cerramientos (la barrera entre el edificio y el medio ambiente) y su aislamiento sino que se aproveche el intercambio de exergía del edificio con el medio ambiente, implementando fuentes de energía renovables de baja exergía (o Low Ex) y reduciendo el consumo energético.

Como planteamiento central la arquitectura pasiva hace énfasis - entre otras cosas en la mejora del aislamiento térmico de sus cerramientos, y en muchas ocasiones para conseguir este objetivo se incrementa considerablemente el espesor de los mismos.

En todo caso si se va hacia los espesores habituales de 25 o $30 \mathrm{~cm}$, esto, frente a una propuesta de arquitectura con cerramientos ligeros, siempre significaría una diferencia considerable por el aumento del volumen (y la superficie) de la piel del edificio.

En el artículo de referencia F. Meggers y su equipo plantean precisamente el cambio del espesor de los cerramientos exteriores (o aislamiento intensivo) por sistemas de aprovechamiento de la energía que se pierde, con tecnologías de baja exergía puestas a prueba como prototipos integrados a proyectos tales como los edificios B35, HPZ y HIB en Suiza. Ciertamente y según se puede observar el tema de la exergía en torno a la edificación está más desarrollado en torno a los sistemas de climatización y específicamente con el aprovechamiento de la anergía en las bombas de calor su rendimiento y COP.
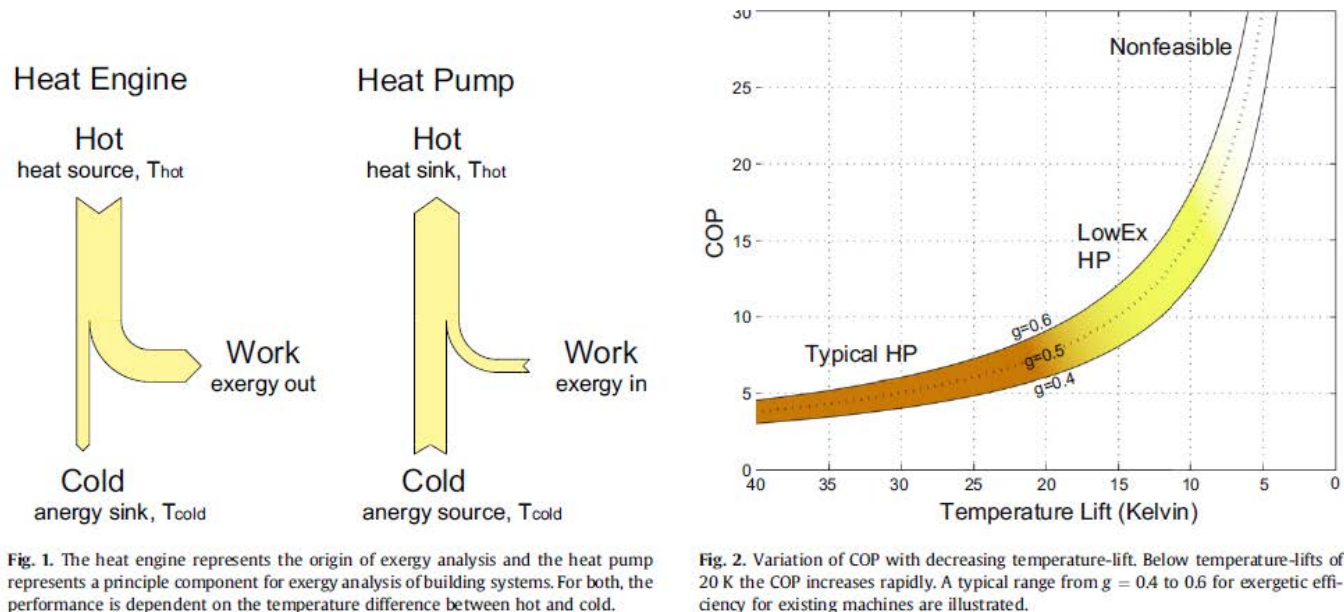

Fig. 2. Variation of COP with decreasing temperature-lift. Below temperature-lifts of $20 \mathrm{~K}$ the COP increases rapidly. A typical range from $g=0.4$ to 0.6 for exergetic efficiency for existing machines are illustrated.

Fig. 91. Esquema bomba de calor y principio de exergía. (Meggers et al. 2012). 
Los autores enfocan la cuestión del rendimiento de los sistemas de baja exergía (combinados) como una variante positiva para el diseño de los edificios sin depender de aspectos determinantes en la arquitectura pasiva como la orientación o el tipo de cerramiento.

El edificio B35 ha servido como gran laboratorio de ensayos donde se han implementado varios sistemas de baja exergía, integrados a la misma arquitectura del edificio y que se apoyan entre sí como los paneles térmicos/fotovoltaicos que alcanzan rendimientos de hasta un $40 \%$ y que se combinan con sistemas geotérmicos que completan el paquete implementado como se muestra en las siguientes figuras.
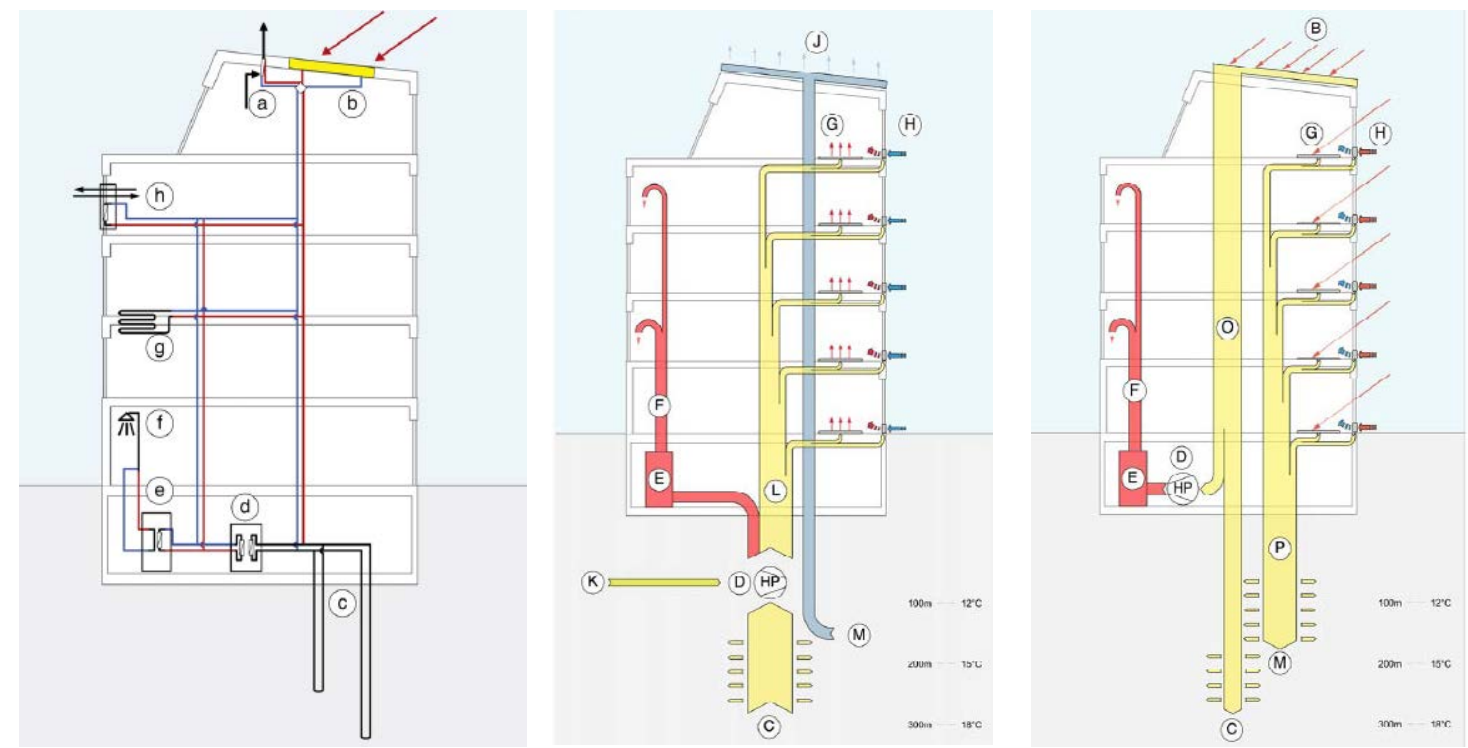

Fig. 91. Esquema de instalaciones edificio B35. (Meggers et al. 2011).

Las imágenes que se muestran, explican los conceptos de funcionamiento de los sistemas Low Ex integrados al B35. En ellas se muestra de manera explícita un ejemplo concreto de aplicación de las tecnologías de baja exergía.

En la imagen primera se pueden ver, a modo esquemático, como se combina la geotermia (c), con el modelo de panel híbrido de captación solar (b) - fotovoltaico con sistema hidrónico de circulación de agua- además de un sistema de recuperación del calor en la cubierta (a), una bomba de calor de alto rendimiento (d), un sistema de almacenamiento de agua caliente a baja temperatura y un sistema de recuperación del calor de las agua residuales (f). En las dos imágenes siguientes se especifica el funcionamiento de los sistemas tanto en verano como en invierno.

En la segunda figura, durante el invierno, se puede apreciar como el pozo más profundo ( $\mathrm{C}$ )) proporciona una mayor base de temperatura de funcionamiento para la bomba de calor ( $D$ ), que puede ser apoyada en gran medida, con energía renovable $(K)$ para producción de calefacción de baja temperatura $(L$ ) hacia la masa térmica $(G)$ y suministro de aire descentralizado $(H)$.

La tercera figura muestra los principios de funcionamiento en la temporada de invierno. En la misma se puede observar que el pozo de la derecha (M) absorbe calor para 
proporcionar un nivel de enfriamiento de $10^{\circ} \mathrm{C}(\mathrm{P})$ a la masa térmica $(\mathrm{G})$ y de suministro de aire $(\mathrm{H})$. Al mismo tiempo el pozo de la izquierda $(\mathrm{C})$ se regenera por el exceso de calor alrededor, unos $30^{\circ} \mathrm{C}(\mathrm{O})$ absorbido por los paneles PV / T (B), que también pueden ser utilizados por la bomba de calor (D) para generar la temperatura adecuada para el agua caliente (E) mediante recuperación de calor (F).

Siguiendo en el campo de la investigación concerniente a la arquitectura modular ligera y energéticamente eficiente, se construye el Bubble Zero como un prototipo que han llevado a cabo un grupo de investigadores del departamento de arquitectura del ETH de Zurich, la School of Computer Engineering, Nanyang Technological University, de Singapur y la School of Design and Environment, National University of Singapore y cuyo desarrollo queda recogido en el artículo "BubbleZERO-Design, Construction and Operation of a Transportable Research Laboratory for Low Exergy Building System Evaluation in the Tropics" ( M. Bruelisauer et. al. 2012)

El desarrollo de este modelo, y más aún su documentación en un artículo indexado, supone un caso excepcional de construcción modular y eficiencia energética combinados. Fuera de este caso, claramente referenciado, se podrían señalar las casas solares de los concursos del Solar Decathlon.

El equipo que ha llevado a cabo el Bubble Zero (a partir de un contenedor de transporte marítimo de mercancías enviado desde Suiza) lo ha tomado como un modelo experimental, diseñado en el ETH en Zurich, para un clima tropical como el de Singapur.

En este modelo se han puesto en marcha sistemas de baja exergía, y su correspondiente tecnología adaptada e integrada a los sistemas y soluciones constructivas concebidos con visión de conjunto y con las consideraciones espaciales y estéticas necesarias para completar un buen diseño a nivel arquitectónico. Para esto se han utilizando dos contenedores para transporte de mercancía en barco de unos 20 pies $\left(14,88 \mathrm{~m}^{2} / 32,6 \mathrm{~m}^{3}\right.$ aprox.) cada uno.

Los sistemas de baja exergía puestos en funcionamiento en este modelo, utilizan conceptos basados en la segunda ley de la termodinámica que definen el término exergía como una extensión del concepto de energía, que representa los cambios en la entropía.

El objetivo era diseñar un espacio para evaluar el desempeño de estos sistemas integrados a la construcción y usando un enfoque de diseño integrado. El modelo contiene paneles de refrigeración radiantes y suministro de aire descentralizados, además de un sistema de auto sombreado mediante burbujas inflables en la piel exterior; también se ha utilizado un acristalamiento de baja emisividad experimental e iluminación tipo LED. 


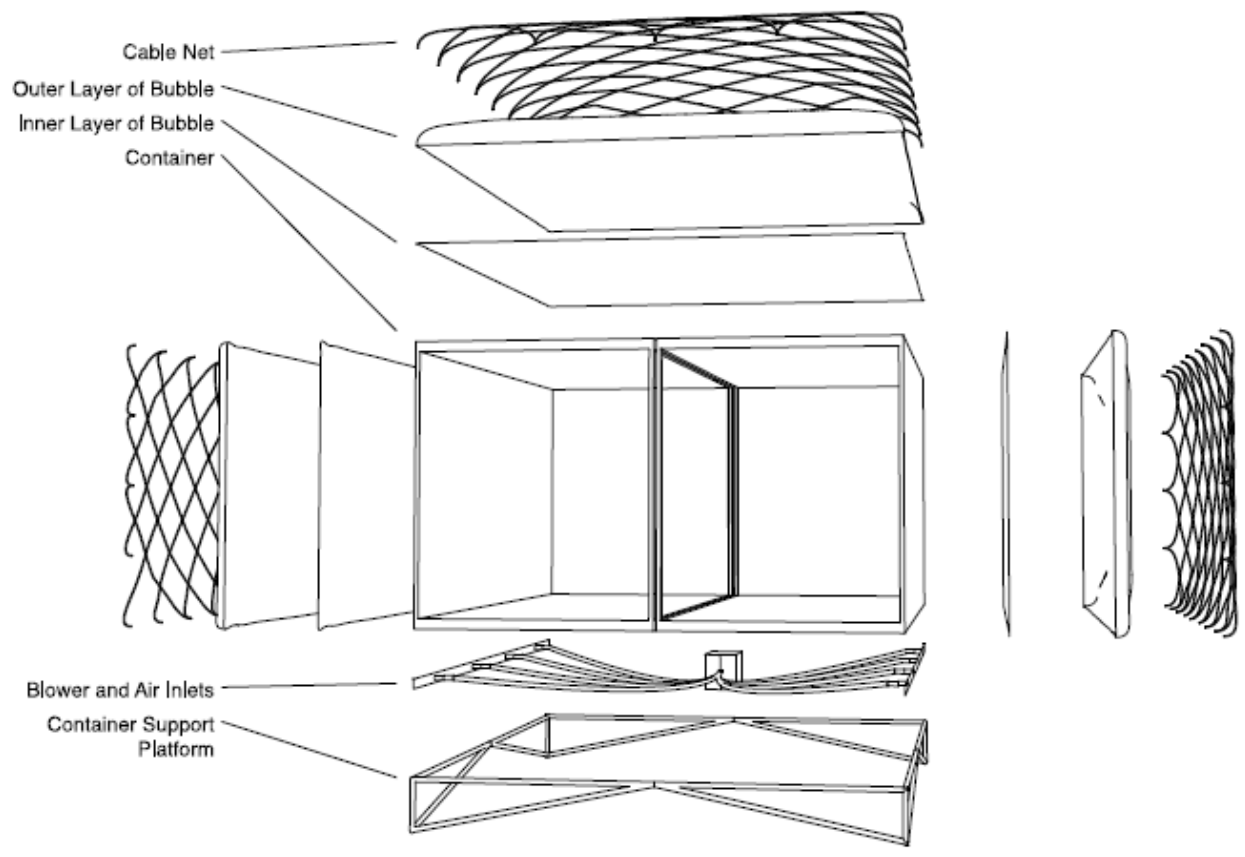

Fig. 92. Bubble Zero. ( Meggers et al. 2012).

Siendo la escala del Bubble Zero pequeña con relación a un edificio de oficinas convencional, se ha intentado recrear las condiciones propias (por ejemplo las cargas de enfriamiento sensible) de un edificio de mayor escala.

Este efecto se consigue al implementar la piel externa como una protección al soleamiento y al sobrecalentamiento produciendo ese aspecto "burbuja" del laboratorio.

Sobre las chapas de acero de los contenedores, se colocan, $5 \mathrm{~cm}$ de espuma aislante rígida XPS, una capa interior de material (poliéster blanco cubierto de PVC), una cámara de aire presurizada que hace que se expanda la burbuja, otra capa exterior de material (con un $75 \%$ de reflectancia), y una red de cables. Los sistemas de ventilación y de climatización para la creación de la zona de confort interior son los principales escenarios de ahorro del prototipo junto con una red hidrónica de circulación de agua compuesta por colectores, redes de circulación y las propias unidades de ventilación descentralizadas y máquinas enfriadoras.

En un clima tropical como el de Singapur los temas de la deshumidificación y la ventilación son fundamentales. Con los sistemas Low Ex se han conseguido temperaturas interiores dentro del rango de confort $\left(22,7^{\circ} / 23,7^{\circ}\right)$.

Las unidades descentralizadas cubren la demanda latente en el suministro de aire fresco en paralelo con los paneles radiantes de enfriamiento que cubren la demanda de enfriamiento sensible. La tasa de ventilación, por tanto, no depende de la demanda de enfriamiento, sino que se basa únicamente en la ocupación y en los criterios IAQ. Esto permite reducir la tasa de ventilación que resulta en la necesidad de menos energía para la deshumidificación y la operación del ventilador. 
Este modelo o prototipo Bubble Zero plantea un recorrido tecnológico por la reducción de las emisiones y la eficiencia mediante tecnología Low Ex. En el caso de los modelos de viviendas del concurso Solar Decathlon se plantean soluciones de eficiencia energética haciendo una combinación de sistemas de generación renovable de energía teniendo la energía solar como principal fuente energética.

\subsubsection{Otros artículos, tesis y publicaciones científicas.}

Además de los artículos indexados se han consultado otras fuentes documentales científicas, académicas y técnicas que quedan referenciadas en la bibliografía.

Entre estas publicaciones destaca el artículo de Pelli (Pelli, et al. 2007), en el cual se hace referencia al mapa de Koppen como herramienta válida para el estudio y calificación geográfica de las zonas climáticas del planeta. En este artículo se resalta el hecho de que, basándose en estudios botánicos sobre las especies de cada zona del planeta ha sido posible establecer un patrón climático de coincidencias análogo a las coincidencias de especies tipológicas en diferentes partes del mundo.

Este mapa de clasificación climática lleva el nombre de Wladimir Peter Koppen que fue el investigador y científico que hizo esta aportación en 1900. Esta clasificación, modificada posteriormente en 1918 y 1936, identifica los climas con un código de letras y colores que configuran un mapa mundial por zonas, con características climáticas parecidas por el tipo de vida vegetal que se reproduce allí, tomando en cuenta los factores de la naturaleza como la temperatura y fenómenos atmosféricos. El mapa que se reproduce en la parte de la metodología de la investigación resulta ser la evolución del mapa original y es parte de los estudios realizados por Pelli (Pelli et al, 2007) y que se incluyen en los anexos (Anexo 3), de esa tesis por su utilidad e interés para los análisis y estudios realizados en la misma.

\begin{tabular}{|c|c|c|c|c|c|c|c|}
\hline \multicolumn{8}{|c|}{ Clasificación climática de Köppen } \\
\hline & \multirow[b]{2}{*}{ Temperatura } & \multicolumn{6}{|c|}{ Humedad } \\
\hline & & $\mathrm{s}$ & w & $f$ & $\mathbf{m}$ & w & $\mathbf{s}$ \\
\hline A & Tropical & - & - & Ecuatorial $A f$ & Monzónico Am & $\begin{array}{l}\text { Tropical de } \\
\text { sabana Aw }\end{array}$ & $\begin{array}{l}\text { Tropical de } \\
\text { sabana As }\end{array}$ \\
\hline B & Seco & Estepario BS & Desértico $B W$ & - & - & - & - \\
\hline $\mathrm{C}$ & Templado & - & - & $\begin{array}{c}\text { Subtropical sin } \\
\text { estación seca } \\
\text { (pampeano o } \\
\text { chino) Cfa, } \\
\text { Oceánico Cfb }\end{array}$ & - & $\begin{array}{l}\text { Subtropical de } \\
\text { altura Cwa, Cwb }\end{array}$ & $\begin{array}{l}\text { Mediterráneo } \\
\text { Csa, Oceánico } \\
\text { de veranos } \\
\text { secos Csb }\end{array}$ \\
\hline \multirow[t]{2}{*}{ D } & Continental & - & - & $\begin{array}{c}\text { Continental Dfa, } \\
\text { Dfb, } \\
\text { Subártico } D f c, \\
\text { Dfd }\end{array}$ & , & $\begin{array}{c}\text { Manchuriano } \\
\text { Dwa, Dwb }\end{array}$ & - \\
\hline & & \multicolumn{3}{|c|}{$\mathrm{T}$} & \multicolumn{3}{|c|}{$\mathrm{F}$} \\
\hline $\mathrm{E}$ & Frío & \multicolumn{3}{|c|}{ Clima de Tundra ET } & \multicolumn{3}{|c|}{ Polar EF } \\
\hline
\end{tabular}

Fig. 93. Clasificación climática de Koppen. (Wikipedia, 2015) 
4. METOdOLOGÍA DE INVESTIGACIÓN 


\section{METODOLOGÍA DE INVESTIGACIÓN.}

El enfoque metodológico de trabajo, con el que se aborda la presente tesis doctoral, se fundamenta en un esquema con tres vertientes complementarias: una documental, una empírica y/o experimental y otra de simulación. De esta manera se pretende abordar el tema de la construcción modular ligera y la eficiencia energética de manera unificada, haciendo un análisis conjunto de estos dos aspectos que fundamentan el presente trabajo.

Con la primera vertiente, la Metodología de Análisis Documental y Teórico, se realiza una recopilación de los antecedentes, del estado actual del arte (técnica e investigación) y de sus posibles proyecciones futuras.

En una segunda vertiente de metodología de trabajo, la Metodología Experimental, se busca dar valor práctico y real al trabajo con respecto a la situación y comportamiento de un modelo existente y actualmente en uso que es el Taller de Prototipos de la Escuela Técnica Superior de Arquitectura de Madrid.

Con la Metodología de Simulación, como tercera vertiente, se representan a partir de los datos reales obtenidos empíricamente y de situaciones teóricas creadas, escenarios diferentes al estado actual, introduciendo modificaciones que mejorarían las prestaciones energéticas del Taller de Prototipos tanto en uso docente como para uso de vivienda. De esta manera se miden y cuantifican los efectos de las posibles mejoras aplicadas.

Como elemento central de la Metodología de Trabajo, en el Capítulo 1, se hace la introducción al tema y se plantean la hipótesis de partida, los objetivos del trabajo y la justificación de la investigación.

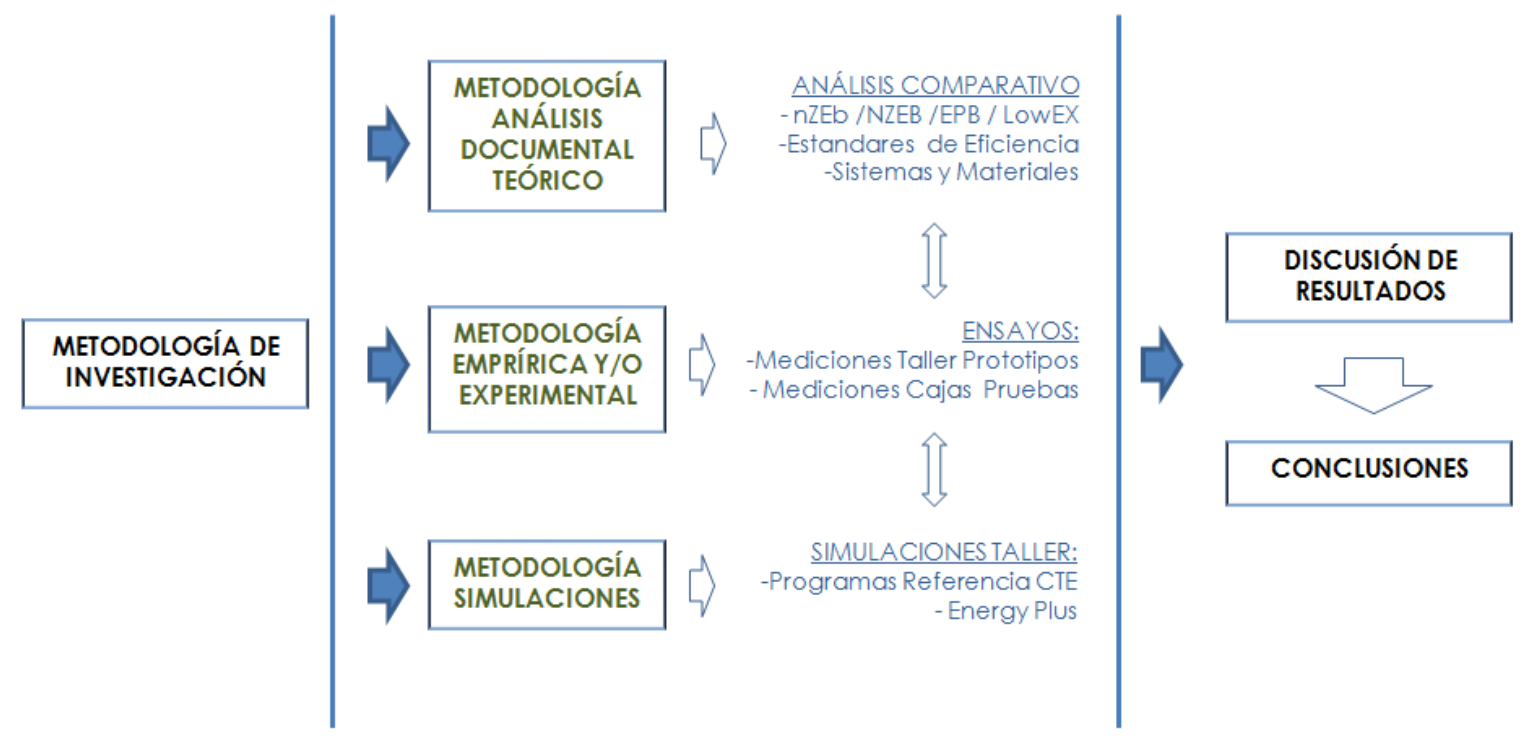

Fig. 1. Esquema general Metodología de Investigación adoptada. 


\subsection{METODOLOGÍA DE ANÁLISIS DOCUMENTAL Y TEÓRICO.}

\subsubsection{Objetivos y esquema de trabajo de la metodología documental.}

El objetivo concreto de realizar el análisis pormenorizado de la documentación disponible sobre el tema, es establecer puntos de referencia, tanto a nivel teórico como práctico, que puedan encontrarse en la documentación académica, técnica o comercial sobre la Construcción Modular Ligera y la Eficiencia Energética.

A partir de la información obtenida y procesada se ha podido establecer una línea de trabajo que ha definido las otras partes del análisis metodológico de la tesis.

El análisis documental y teórico está desarrollado y expuesto en los primeros epígrafes del presente documento, en la parte del Estado de la Técnica.

La metodología documental desarrollada consiste en recopilar la información concerniente al tema -Construcción Modular Ligera Energéticamente Eficiente-, analizar sus contenidos de acuerdo a los objetivos planteados y seleccionar la información considerada útil para la investigación. Siendo el caso que los dos conceptos centrales para esta tesis no son generalmente parte de un estado del arte unificado, la mayor parte de la información se encuentra dispersa en muy diversas fuentes de consulta tal como se relacionan a continuación en el siguiente esquema:

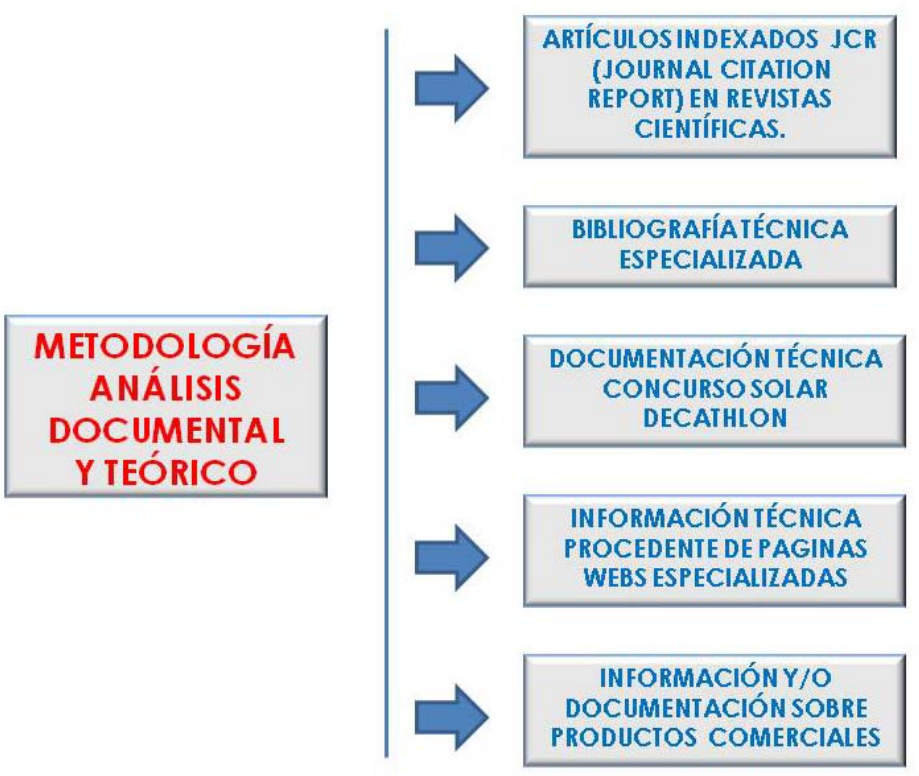

Fig 2 . Esquema Metodología de Análisis Documental y Teórico.

El orden jerárquico de este esquema se ha hecho de acuerdo al nivel de fiabilidad de las fuentes por lo que a un artículo indexado se le ha asignado un mayor nivel de fiabilidad que otro tipo de información técnica procedente de otras fuentes aún sean éstas contrastadas y de fiabilidad. 
Para el desarrollo del trabajo se ha partido de lo general para ir avanzando hacia lo particular, en este sentido, se ha realizado una organización de la documentación y la información obtenida, que partiendo de las generalidades del tema se va haciendo cada vez más específico, en un recorrido que deja evidencia de la progresión de la tecnología y el quehacer en torno a la arquitectura modular ligera y la eficiencia energética relacionada a ella.

En este sentido se ha realizado una clasificación de la información que parte desde los antecedentes del estado de la técnica hasta el estado actual tanto de ejemplos de construcción ligera e industrializada CLI, construcción modular ligera CML - y sus posibles soluciones de acondicionamiento interior, como concepto primario de eficiencia energética- pasando por sus materiales y sistemas de construcción, hasta sus aspectos normativos, sobre todo los relacionados a la eficiencia energética y a los conceptos de energía cero y energía casi nula.

\subsubsection{Antecedentes históricos del Estado de la Técnica}

En la primera parte de la tesis (Estado de la técnica), se hace un recorrido cronológico, a modo de antecedentes históricos, a través de los ejemplos más relevantes, que sirven como origen, de alguna manera, para el desarrollo de la trama argumental de la Tesis. Estos ejemplos - de varios de los más relevantes arquitectos, realizadores y/o promotores del siglo XIX y del siglo XX plantean una incursión en el terreno de la arquitectura industrializada y/o prefabricada, en serie y ligera, que permite hacer un diagnóstico, reflejando una mayor o menor integración de conceptos relativos a la optimización de recursos energéticos y los materiales utilizados.

Para poder obtener datos objetivos sobre los ejemplos seleccionados, se ha hecho un análisis de las características de sus cerramientos, haciendo especial énfasis en su composición de cara a su comportamiento térmico.

Terminando con la parte de los antecedentes históricos, se realiza un estudio, de manera más específica, de dos de los más claros prototipos de arquitectura modular ligera, asociada a principios básicos de eficiencia energética: Las Casas Tropicales de Jean Prouvé y La Casa Wichita de R. Buckminster Fuller. En ambos casos se hace una breve retrospectiva de la obra de ambos pioneros en el tema como antesala al desarrollo de los proyectos de análisis.

Se hace un estudio más detallado de estos ejemplos a modo de identificación de antecedentes de técnicas de acondicionamiento y/o arquitectura bioclimática en el campo de la CIL o CML; y dado que estos ejemplos sí incorporan mejoras en sus prestaciones, en cuanto al aprovechamiento energético, es posible hacer un análisis más amplio sobre las técnicas implementadas que sirven de antesala al análisis de la situación actual, tal y como se desarrolla en los siguientes epígrafes del capítulo 2. 
Esta información técnica, en sentido general, ha sido obtenida de diversas fuentes documentales, entre las que se pueden contar desde libros y/o monografías especializadas, hasta tesis e información disponible en páginas de internet de entidades relacionadas con los ejemplos y con el tema, y que han sido debidamente referenciadas en el cuerpo del texto y citadas en la bibliografía.

\subsubsection{Estado Actual de la Técnica}

Se realiza un enfoque global del estado actual de la arquitectura modular ligera, de la definición de la eficiencia energética en el contexto de la construcción y de la coexistencia de ambos conceptos en un mismo escenario cuando ha sido el caso.

Con relación a la CIL y a la CML se toman varios ejemplos representativos de la arquitectura modular ligera actual, destacando los que incorporan soluciones y/o sistemas de mejoras del rendimiento de los edificios y/o definen una línea de construcción ligera industrializada con vocación sostenible.

Se hace un orden cronológico de los distintos ejemplos estudiando su composición constructiva y sus prestaciones, de cara a la eficiencia energética de los modelos, proyectos o prototipos.

Para la elaboración de este epígrafe se han consultado, principalmente, las documentaciones técnicas disponibles de cada proyecto, procedentes, en muchos casos, de los propios autores y/o promotores de los mismos (páginas web, artículos, información comercial). En otros casos la fuente documental han sido artículos técnicos y trabajos científicos y/o académicos como tesis, tesinas y comunicaciones a congresos. Todas las fuentes documentales han sido debidamente referenciadas en el texto y relacionadas en la bibliografía de este trabajo.

\subsubsection{Materiales y sistemas constructivos. Análisis datos ACV}

A partir de de las conclusiones obtenidas por el estudio de los antecedentes históricos y ejemplos actuales y la documentación técnica y científica analizada al respecto, se realiza un análisis detallado de los principales materiales y sistemas constructivos utilizados en la CIL y la CML.

A partir de estudios previos de ACV elaborados por otros investigadores y que han sido contrastados con publicaciones especializadas en el tema, se presenta una relación pormenorizada de estos sistemas y/o materiales.

En la parte del Estado de la Técnica y de la Investigación se plantea el ACV (Análisis de Ciclo de Vida), como baremo para evaluar los parámetros objetivos, más evidentes, desde el punto de vista de la sostenibilidad asociada a la eficiencia energética en la edificación, junto con las técnicas activas o pasivas de acondicionamiento. 
En esta parte de la Metodología de la investigación se realiza un estudio de cada uno de ellos, desde el punto de vista de la sostenibilidad, con el objetivo de determinar el nivel de implicación medioambiental que conlleva la utilización de cada uno de ellos en el contexto de la construcción modular ligera.

El estudio de los distintos materiales de utilización habitual en la CIL (Construcción industrializada ligera) y CML (Construcción modular ligera), se realiza partiendo del hecho de que los mismos son comunes a ambos sistemas de construcción.

De acuerdo a la literatura consultada, como la referenciada en la bibliografía, la construcción ligera y modular ligera, tienen en común el uso predominante de materiales como la madera, el acero y el vidrio y de sistemas como el Balloon Frame, el Ligth Steel Frame, el Structural Insulate Panel o los paneles sándwich de chapa metálica. Otros materiales muy utilizados son los de tipo "compuestos" como el GRC, el PVC o el GRP.

\subsubsection{Conceptos de Eficiencia energética nZEB y NZEB. Contexto y comparaciones.}

A partir de las definiciones básicas y la introducción a los términos relacionados con la alta eficiencia energética que se establecen en el Estado de la Técnica y de la Investigación, se desarrolla un análisis más detallado de los mismos en la parte de la Metodología Documental. En esta parte de la Tesis se realiza un estudio comparativo entre los conceptos nZEB, NZEB y su posible transposición a las normativas locales en el ámbito de la UE con el concepto del Passivhaus como una alternativa de unificación de criterios, integrando el concepto de Low Ex a la ecuación de la CML.

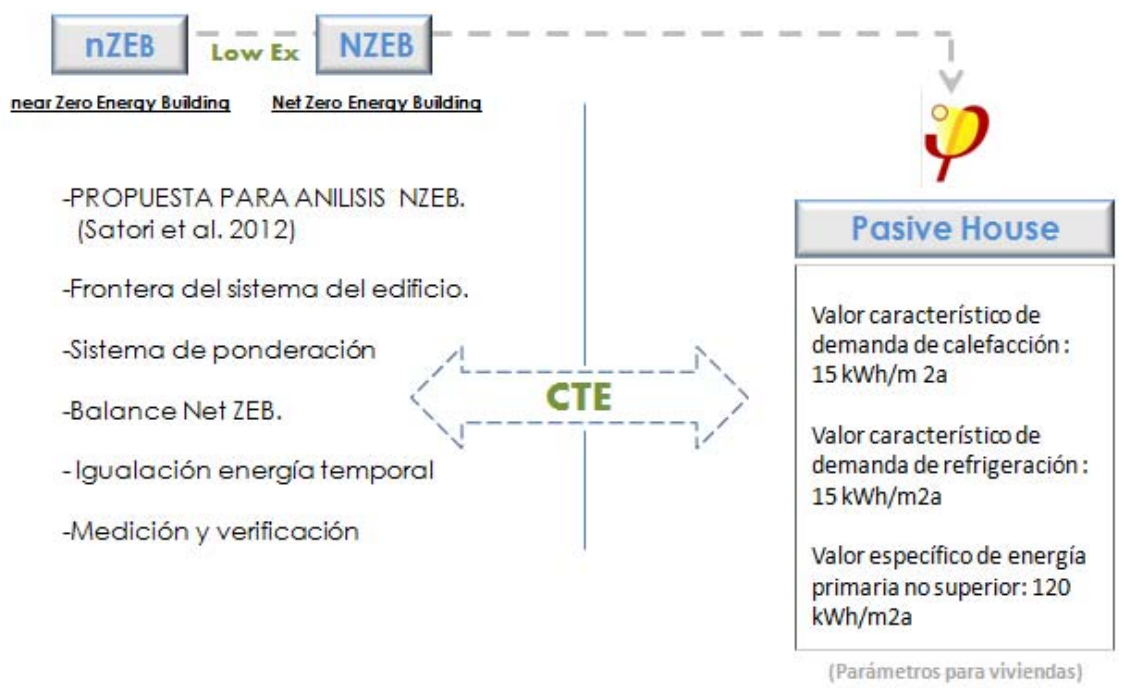

Fig 3. Esquema sobre relación nZEB, NZEB y estándar pasivo.

Para la parte de la definición de términos se utilizaron fuentes documentales indexadas como artículos de impacto JCR. Para acceder a estos artículos se utilizaron 
los portales Web of Sience, Sicence Direct e Ingenio (de búsqueda de artículos científicos y de impacto). La parte de la información sobre normativas europeas y nacionales fue obtenida mediante búsquedas en los portales relacionados a la Comisión Europea como Eurolex y IDAE, MINETUR, FENERCOM entre otros.

\subsubsection{Metodología Documental. Entre la Técnica y la Investigación: Concurso Solar Decathlon}

Parte importante de la elaboración del Estado de la Técnica y de la investigación ha sido el concurso Solar Decathlon (SD) promovido por el DOE de EE.UU desde el 2002.

Dadas sus características y prestaciones, estos prototipos construidos permiten ser estudiados, como una gran base de datos, desde la perspectiva de este trabajo.

Estas casas son, sin duda, el conjunto de prototipos de CML y eficiencia energética más desarrollado actualmente a cualquier nivel.

En este punto se hace un análisis de dos de las ediciones del concurso internacional de casas solares Solar Decathlon Europe (las del SD2010 y SD2012), y se toma como referente indispensable para el estudio de la construcción modular ligera energéticamente eficiente. Se han seleccionado estas dos ediciones por haber sido celebradas en Madrid y por ser de las más recientes al momento de elaboración de este trabajo. De cada una de estas ediciones, y sus prototipos participantes, se ha hecho un estudio general de las características técnicas y las características constructivas, desde el punto de vista de las prestaciones energéticas.

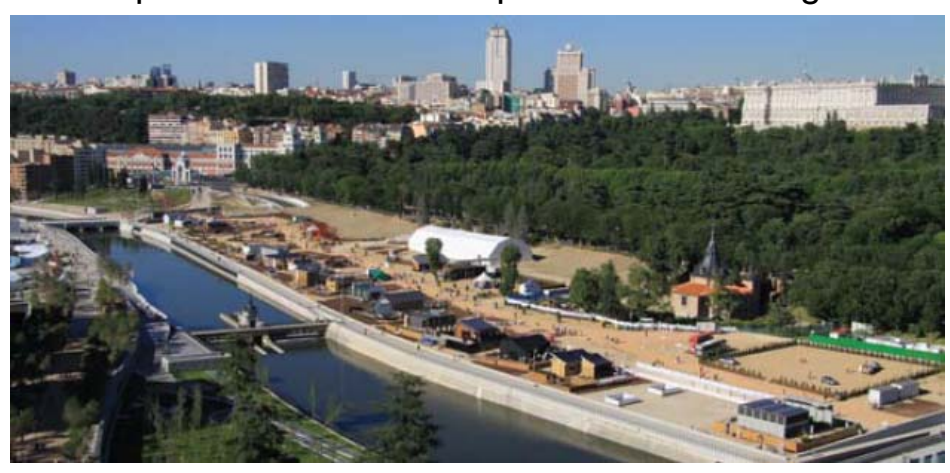

Fig. 4. Villa Solar SD10 ( Vega; 2011).

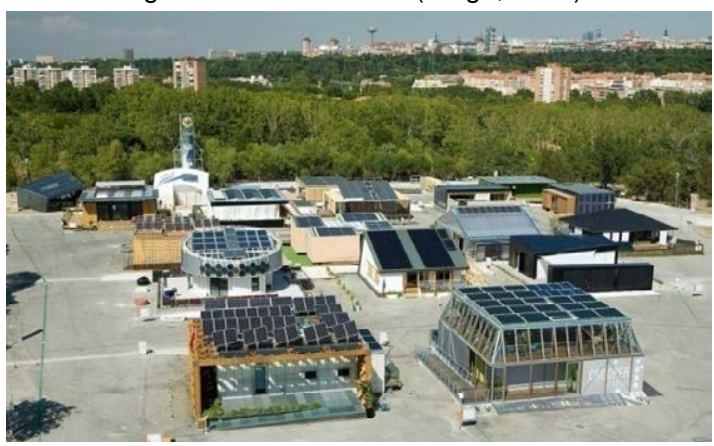

Fig. 5. Villa Solar SD12 (www.bustler.net) Consulta 2015. 
De manera específica se analizan los prototipos ganadores de ambas ediciones, la LumenHaus de la Universidad de Virginia, Solar Decathlon 2010 (SD10) y la Casa Canopea de École Nationale Supérieure D’Architecture de Grenoble Solar Decathlon 2012 (SD12).
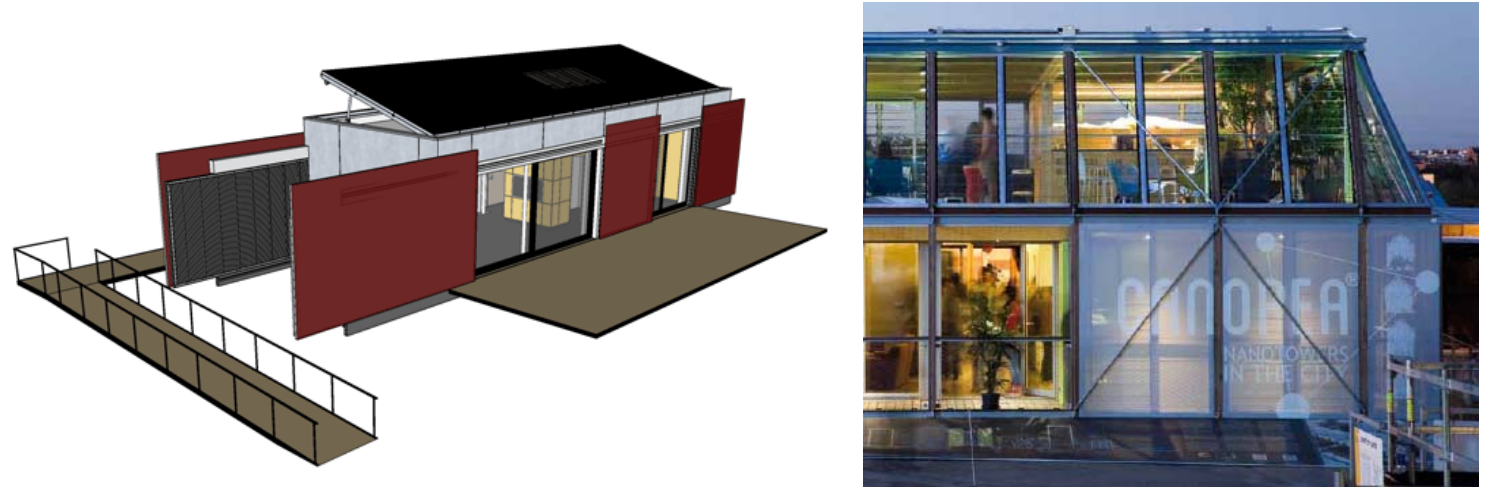

Fig. 6. LumenHaus SD10 (www.lumenhaus.com) Consulta 2015. Fig.7. Canopea SD12 (Vega \& Serra; 2013).

En esta parte de la metodología documental se hace un análisis comparativo entre los prototipos antes citados, tomando también en consideración los demás participantes en ambas ediciones del concurso y haciendo un estudio de los mismos. Para este análisis, que se hace desde la perspectiva de la construcción modular ligera energéticamente eficiente, tema central de esta tesis, se parte de los propios supuestos de competición del concurso, destacando los que son de interés para este trabajo.

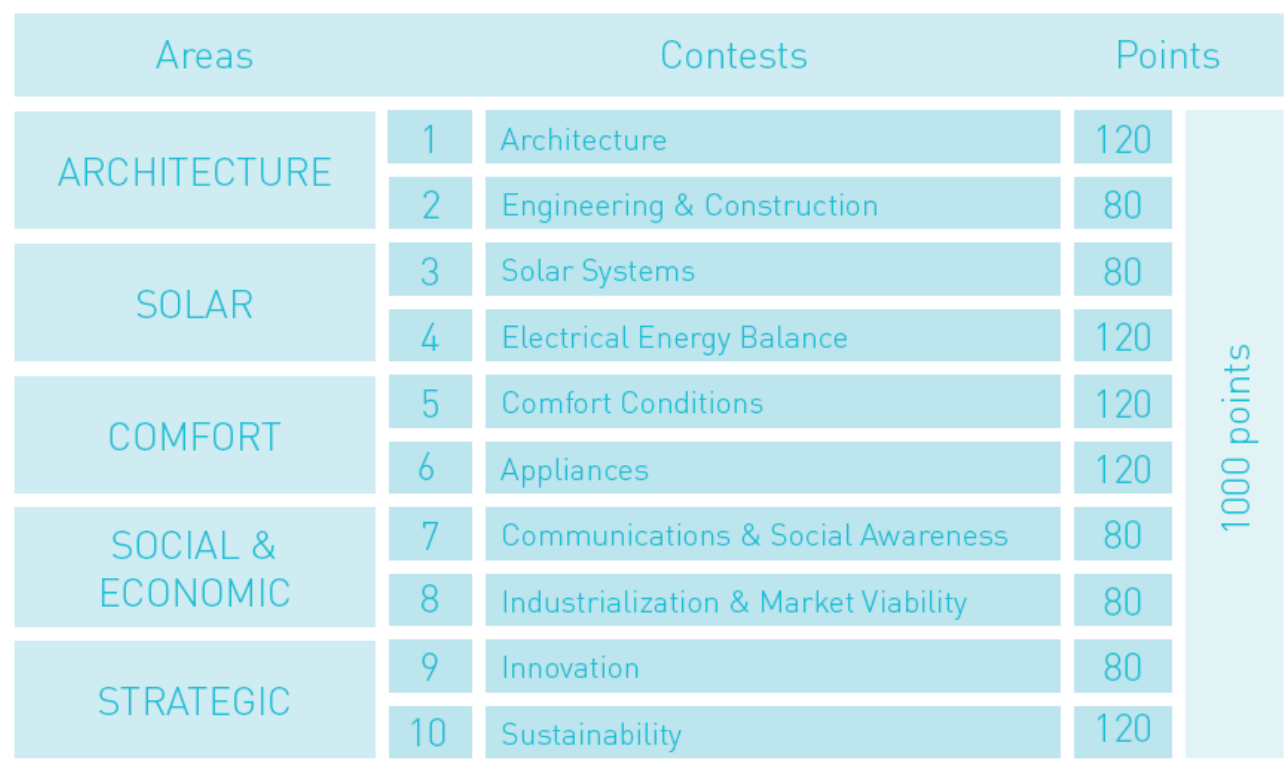

Fig. 8. Tipo de prueba y puntuación Concursos Solar Decathlon (Ed. Vega, 2011).

Como punto de partida se ha realizado una selección de los prototipos participantes del concurso y que son de construcción ligera. En un concurso de casas eficientes y que por la naturaleza itinerante del mismo, exige el fácil manejo y montaje de estas casas, no todas han resultado contar con estas condiciones. 
De un universo de 35 viviendas que suman ambas ediciones (SD10 $=17$ y SD $12=$ 18), sólo dos de ellas han resultado no ser ligeras. Ambos prototipos se han desarrollado para la edición SD12 (Solar Decathlon 2012).

\section{SD10 + SD12}

\begin{tabular}{|l|r|r|}
\hline \multicolumn{3}{|c|}{ CONSTRUCCIÓN LIGERA } \\
\hline \multicolumn{1}{|c|}{ Prototipo } & \multicolumn{1}{c|}{ Ligeras } & \multicolumn{1}{r|}{ No Ligeras } \\
\hline SD10 + SD12 & 33 & 2 \\
\hline TOTAL & \multicolumn{2}{|c}{} \\
\hline
\end{tabular}

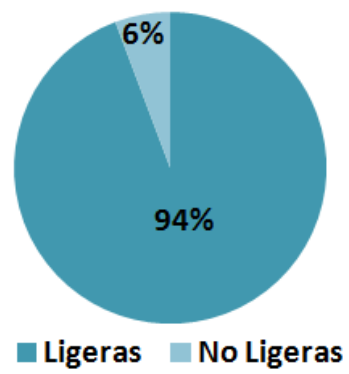

Fig 9. Relación prototipos ligeros y no ligeros SD 10 y SD 12. Elaboración propia.

Una vez determinados los prototipos ligeros en ambos concursos, se procede a su análisis en cuanto a sus prestaciones, tomando como punto de partida, las propias reglas del concurso, pruebas y resultados y los objetivos de este trabajo que son determinar la eficiencia energética de la construcción modular ligera:

- Superficie a acondicionar.

- Coste de inversión ( Prototipo y versión a producir en serie)

- Valores de Transmitancias U con respecto al CTE (Prestaciones cerramientos)

- Niveles de demanda por kWh m2 de acuerdo a lo establecido por estándares sobre nZEB y/o NZEB.

En cuando a los prototipos ganadores se hace el mismo tipo de estudio haciendo mayor énfasis en estos mismos aspectos de cara a formar un criterio de referencia en cuanto a la construcción modular ligera energéticamente eficiente.

Se hace un enfoque comparativo entre ambos abarcando aspectos tales como sus medidas pasivas y activas (sistemas de acondicionamiento y cerramiento).

Las Fuentes documentales para la elaboración de estos estudios, han sido los propios documentos técnicos de los proyectos del SD 10 y SD 12, disponible en las páginas oficiales del concurso tanto en Estados Unidos como en Europa (http://www.solardecathlon.gov) (http://www.sdeurope.org), así como los libros resumen de ambas ediciones: "Solar Decathlon Europe 2010 Towards Energy Efficient Buildings" y "Solar Decathlon Europe 2012 Improving Energy Efficient Buildings". (Vega, 2011); (Vega \& Serra; 2013).

También se han estudiado artículos de impacto (indexados en el Journal Citation Report) disponibles en las web de búsqueda científicas: Web of Science, Science Direct, Ingenio. 
Como referencia de base se ha utilizado la normativa europea, específicamente la Directiva 2010/31/UE y el propio Código Técnico de Edificación de España (CTE; 2013).

Para poder contextualizar el tema de la eficiencia energética dentro del estudio realizado sobre los prototipos, se han tomado también como referencia los conceptos que se manejan en los estándares relacionados con las exigencias de eficiencia, en este sentido y muy específicamente el estándar Passivhaus como herramienta comparativa.

\subsubsection{Conclusiones parciales Metodología Documental}

Parte de la metodología de la investigación ha servido para plantear el tema de investigación y sus posibles líneas de desarrollo.

La metodología de análisis documental, ha sido la base para fundamentar la parte de la metodología de investigación correspondiente a los ensayos y simulaciones.

En conjunto, con los otros métodos de investigación, con esta metodología documental, se ha podido, no solo establecer el estado de la técnica y la investigación, sino que la misma ha servido de referencia documental, con la precisión que pueden dar otros trabajos de investigación contrastados, teóricos empíricos y de simulaciones informáticas y que sirven para compara y/o comprobar, a su vez los (resultados) propios.

A partir de la información obtenida, se han podido estructurar las líneas de trabajo de campo y establecer los datos originales para las escenarios de mejoras planteados con las herramientas informáticas.

El estudio de los ejemplos históricos y actuales ha permitido determinar los sistemas constructivos y materiales de uso más común en este tipo de construcción.

Con este conocimiento previo de los sistemas y materiales se ha podido estudiar la implicación ambiental de cada uno de ellos. Quedando claro algunos conceptos de ideas: la carga medioambiental que pudiera tener un material de construcción está íntimamente ligada tanto a su peso propio como a la intensidad de uso en el ámbito de la construcción. Materiales como el aluminio y el acero, con una implicación medioambiental importante, pueden resultar rentables desde el punto de vista de la sostenibilidad si entran dentro de un ciclo cerrado del material. La madera, siempre que sea certificada se presenta como la mejor opción por su relación sostenibilidad / versatilidad de uso.

Por otro lado, y mediante el estudio de la documentación científica disponible, se han podido establecer con claridad los conceptos de nZEB y de NZEB - y sus diferenciasy aplicarlos en el contexto de la CML 
Se ha podido comprobar y observar que el concurso Solar Decathlon, no solo es un concurso de construcción eficiente, si no que por su propia naturaleza es un gran laboratorio de prototipos de CML, que aunque hiperoptimizados y sobre-valorados económicamente, pueden servir de referencia para el tema desarrollado en esta tesis.

También se ha comprobado que la utilización del Mapa de Koppen puede servir como herramienta, combinada, con otros medios informáticos, como el programa $\mathrm{CE}^{3} \mathrm{X}$, para desarrollar una metodología simplificada de análisis de la eficiencia energética de los edificios en diferentes latitudes.

\subsection{METODOLOGÍA EMPÍRICA O EXPERIMENTAL}

\subsubsection{Objetivos metodología empírica o experimental}

Esta parte de la metodología de investigación, se desarrolla como sistema de comprobación de varias hipótesis de partida que sirven para fundamentar y/o contrastar datos obtenidos tanto en el análisis documental como en la parte de las simulaciones informáticas. Por medio de la experimentación, sobre elementos físicos reales, se obtienen datos que luego pueden servir como herramienta de comprobación. Básicamente se ha querido estudiar el comportamiento de elementos ligeros de protección térmica como complemento a otras medidas activas y pasivas de mejora del acondicionamiento interior.

\subsubsection{Definición prototipos de ensayos y procedimientos empíricos}

Para la parte Experimental se han realizado una serie de mediciones y ensayos, evaluando las prestaciones y comportamiento (energético) del Taller de Prototipos de la ETSAM y el comportamiento dos cámaras de pruebas colocadas en la cubierta de la escuela. El taller de prototipos, de construcción ligera industrializada (equiparable a una $\mathrm{CML}$ ), se encuentra en el estacionamiento posterior de la ETSAM junto a otros edificios de características similares en cota $\pm 0,00$ y con las sombras arrojadas de los arboles de su entorno y el edificio de aulas del edificio antiguo.

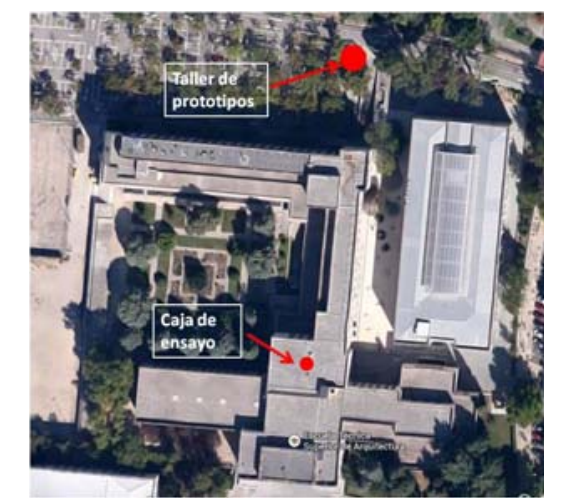

Ciudad Universitaria, Madrid.

TALLER

Latitud: $40^{\circ} 26^{\prime} 97^{\prime \prime} \mathrm{N}$

Longitud: $3^{\circ} 43^{\prime} 52^{\prime \prime} \mathrm{O}$

CAJAS DE ENSAYOS

Latitud: $40^{\circ} 26^{\prime} 23^{\prime \prime} \mathrm{N}$

Longitud: $3^{\circ} 43^{\prime} 52^{\prime \prime} \mathrm{O}$

Fig. 10. Localización de los prototipos de ensayo; arriba el taller y abajo las cajas o células de pruebas. 
Las dos cajas (cámaras o células) de ensayo se encuentran situadas en la planta de cubierta del edificio de aulas de la escuela hacia la parte sur del mismo y orientadas en esta dirección. No existe ningún tipo de sombra arrojada sobre la misma.
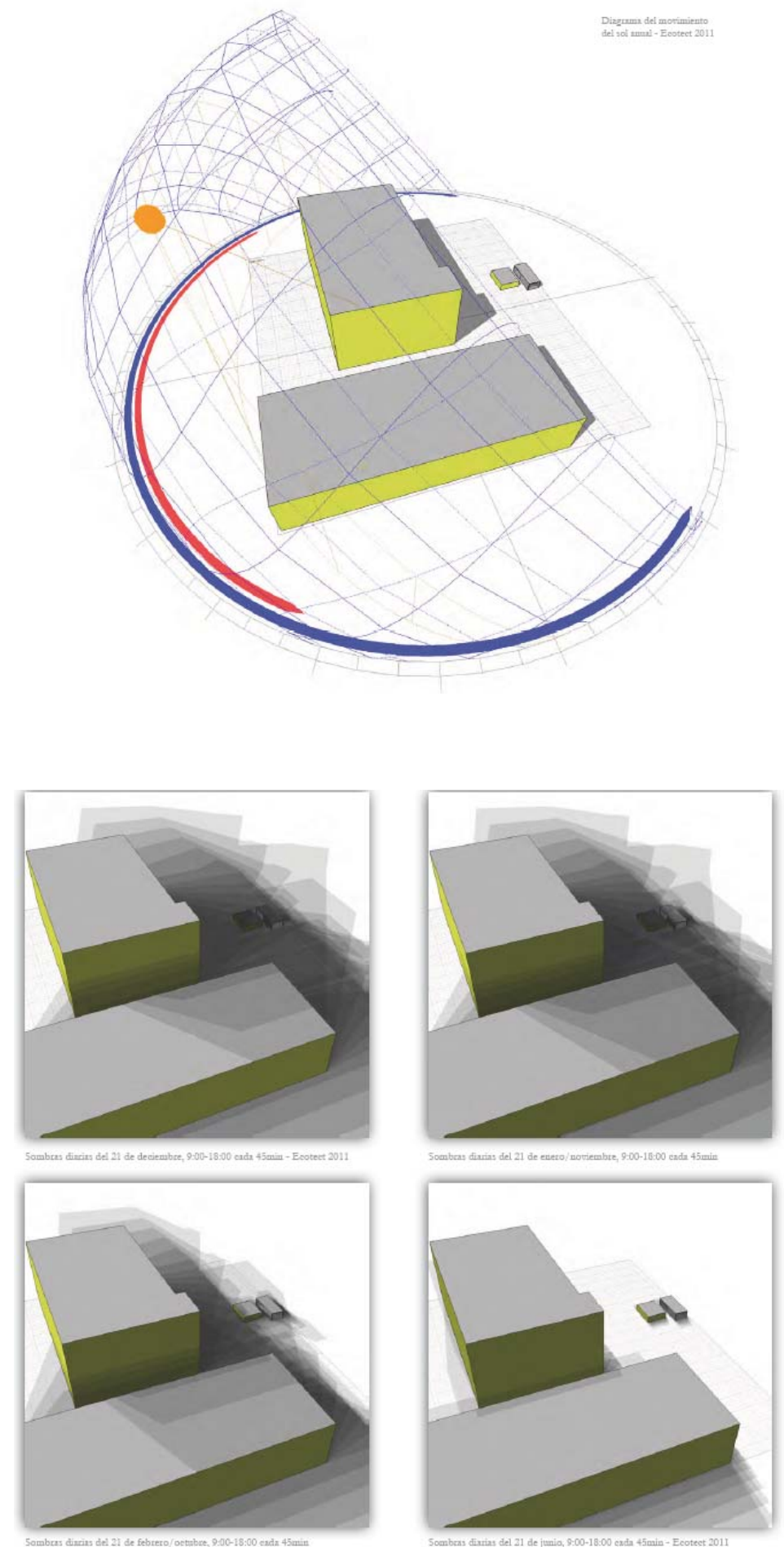

Diagrama de movimiento del sol (Fig. 11, arriba) y sombras arrojadas por edificio de aulas sobre Taller de Prototipo Etsam, en meses de diciembre, enero/noviembre, febrero/octubre, y junio (Fig.12, abajo). Simulación realizada con programa informático Ecotec (Rashevski; 2012). 
La selección del taller como célula de ensayos se ha debido a tres factores fundamentales:

1) La disponibilidad y acceso absolutos al mismo para realizar las pruebas.

2) Definición constructiva equiparable a la definición de un prototipo de CML.

3) Representa una unidad que integra varios elementos medibles de interés para este trabajo como sus tipos de cerramientos, equipos de climatización y régimen de uso.

La utilización de las cajas se ha debido, también a la disponibilidad de las mismas, pero sobre todo a la posibilidad que brindan de medir aspectos puntuales que complementan los datos obtenidos en las mediciones del taller.

Con estas comprobaciones experimentales se ha podido estudiar el comportamiento global de los elementos medidos (Taller y cámaras o células de ensayo) y además el comportamiento de sus componentes de cerramiento y sistemas de climatización.

Básicamente en el caso de los cerramientos se ha medido su comportamiento térmico y en cuanto a los equipos sus rendimientos.

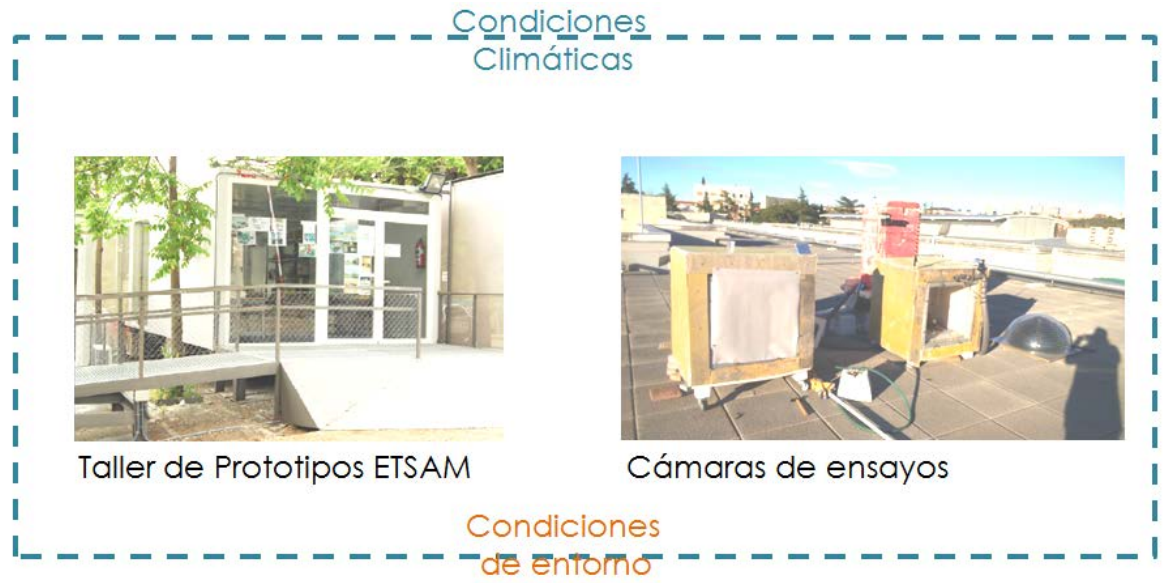

Fig. 13. Variables externas prototipos de ensayo (Taller y cajas o células).

El Taller de Prototipos que cuenta con una superficie de $38,90 \mathrm{~m}^{2}$ tiene una forma rectangular de 9,72 de largo por 4,00 de ancho. Tanto la superficie de la cubierta como la del suelo coinciden exactamente con la superficie del Taller, es decir que no cuenta con techos ni suelos en voladizo. La altura interior del mismo es de $2.50 \mathrm{~m}$ y cuenta con un volumen de 97,20.

Sus cerramientos verticales opacos están compuestos por paneles sándwich de chapa de aluminio pre-lacada y alma de poliuretano de aproximadamente $4 \mathrm{~cm}$ de espesor para una transmitancia total de $0,54 \mathrm{~W} / \mathrm{m}^{2} \mathrm{~K}$. El color de los paneles es blanco. 
Sus superficies acristaladas suman unos $29 \mathrm{~m}^{2}$ aproximadamente, repartidos de la siguiente manera: 5,35 m2 en la fachada norte, 10,70m2 en la fachada sur (la ventana más grande), $8,40 \mathrm{~m} 2$ en la fachada este y 5,35 en la fachada oeste. El tipo de vidrio es simple con una transmitancia de $5,70 \mathrm{~W} / \mathrm{m}^{2} \mathrm{~K}$. El marco de los mismos es de aluminio SRPT (sin rotura de puente térmico).

Hacia la fachada norte, cubriendo la totalidad de la misma, se ha dispuesto una protección de malla micro-perforada tipo Serge Ferrari, Soltis FT 381 de color gris. La misma también cubre la totalidad de la fachada oeste y se separa de la misma unos 25 $\mathrm{cm}$ dejando una cámara de aire ventilada entre medias.

El suelo del Taller está compuesto, simplemente, por un tablero de madera aglomerada de $2 \mathrm{~cm}$. de espesor y un acabado de PVC o linóleo de $0.05 \mathrm{~cm}$ de espesor en color azul mate. Su transmitancia es de $2,33 \mathrm{~W} / \mathrm{m}^{2} \mathrm{~K}$.

La superficie de la cubierta está compuesta por una chapa galvanizada, tipo minionda, sobre una cámara de aire ventilada de unos $5 \mathrm{~cm}$. Luego el cerramiento se compone por un aislamiento de lana mineral de $0,044 \mathrm{~W} / \mathrm{m}^{2} \mathrm{~K}$ y un tablero similar al del suelo. La transmitancia total de la cubierta es de $0,48 \mathrm{~W} / \mathrm{m}^{2} \mathrm{~K}$.

El equipo de climatización del taller consiste en dos bombas de calor marca Daitsu modelo DS18UP, con una potencia calorífica de $5.862 \mathrm{~W}$ y de refrigeración de 5.569 W, cada una. EI COP (ratio ahorro energético en calor) es de 3,61 y el EER (ratio de ahorro energético en frío).

Además cuenta con dos radiadores eléctricos de apoyo con una potencia nominal de $600 \mathrm{~W}$ y una potencia medida de entre 670 y $675 \mathrm{~W}$ cada uno. El suministro energético del Taller está suplido por el edificio principal de la escuela, igualmente el suministro energético de las cajas o células de ensayo de la cubierta de la escuela.

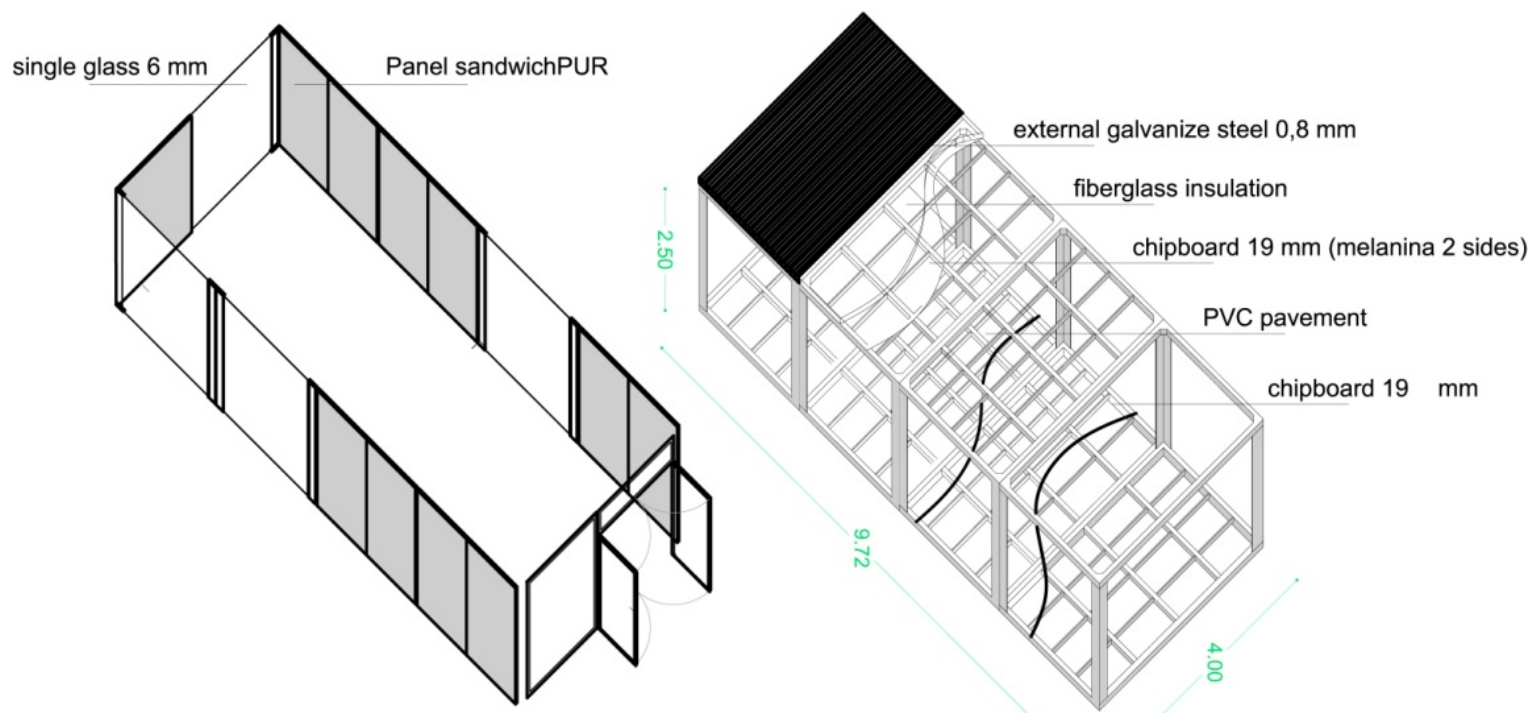

Fig 14. Vista en perspectiva de composición constructiva del Taller. (Acad: Lirola Pérez \& Mañanas ). 
Las dos cajas de ensayos están construidas, con cinco lados opacos y una cara acristalada (vidrio simple de $6 \mathrm{~mm}$ de $60 \times 60 \mathrm{~cm}$ ) orientada a sur, con una transmitancia de $5,7 \mathrm{~W} / \mathrm{m}^{2} \mathrm{~K}$. Los lados opacos están compuestos por paneles sándwich de madera y aislamiento interior con una transmitancia $U=0,19 \mathrm{~W} / \mathrm{m}^{2} \mathrm{~K}$. La composición del cerramiento opaco es: revestimiento exterior de madera, aislamiento de poliestireno extruido y tablero de madera hacia el interior, para un espesor total de $0,18 \mathrm{~cm}$.

Para recrear un espacio climatizado (calefacción), en el interior de una de las células, o en las dos según fuera el escenario de experimentación, se ha colocado un calentador tipo sonda eléctrica de $20 \mathrm{~kW}$ de potencia.

En ambos casos se han medido, en períodos determinados de tiempo, las temperaturas y consumos utilizando los sistemas de climatización antes descritos. Estos períodos de medición tanto del Taller como de las cajas han abarcado horarios nocturnos y diurnos de manera que los resultados obtenidos pudieran ser estudiados desde el punto de vista de uso de vivienda.

En el caso de las mediciones del Taller, las mismas se han realizado alternando el uso de estores de protección interior, tanto en uso diurno como nocturno, haciendo énfasis en la posible protección térmica nocturna.

En el caso de las mediciones de las cajas se han utilizado las mismas para puntualizar el posible comportamiento que pudiera tener una protección tipo malla Ferrari en la orientación sur. Para esto se ha colocado la malla en una de las células y se ha dejado la otra célula sin la protección para poder realizar la comparación.

Los períodos de medición han estado comprendidos en temporada de invierno y primavera.
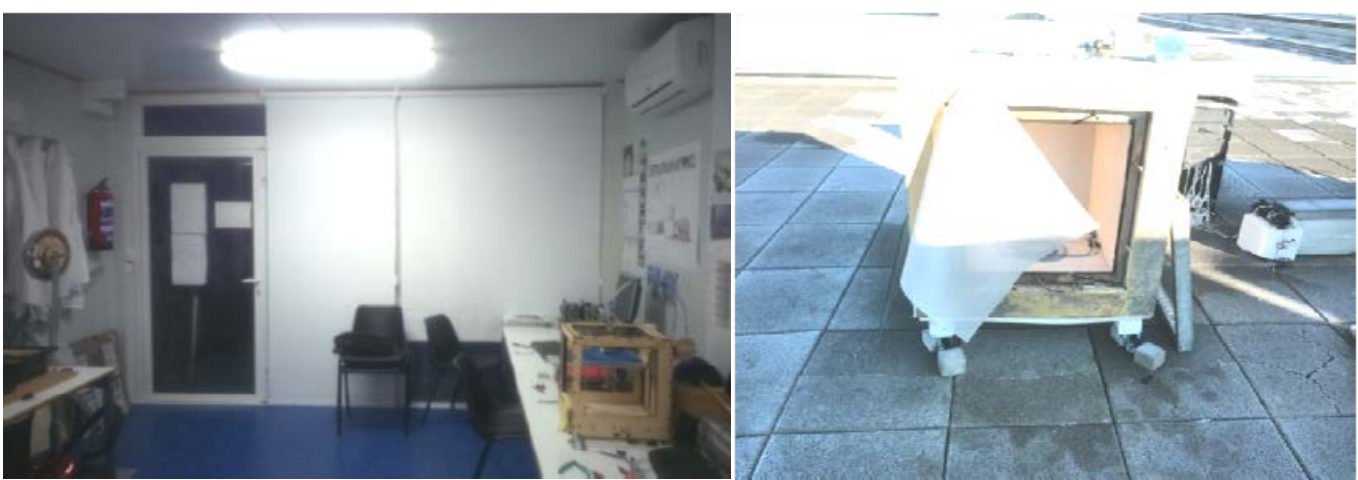

Fig. 15. Taller con estores bajados para posible protección térmica; Fig. 16. Malla tipo Ferrari colocado sobre acristalamiento caja de ensayos. 
Para los ensayos en el taller se han colocado unos medidores de temperaturas y humedades interiores y exteriores (Data Loggers), modelo Hobbo Anset H08-002-02, que han servido para poder comparar las condiciones fuera y dentro del taller. Para registrar las mediciones interiores se han colocado los medidores a una altura media de trabajo de $75 \mathrm{~cm}$ desde el nivel de suelo, sobre la mesa de trabajo principal y en otros casos a una distancia de $20 \mathrm{~cm}$ del interior del techo. También se han colocado junto (adheridos) a los cerramientos opacos y acristalados para comprobar su comportamiento. Las mediciones exteriores se han registrado mediante una sonda colocada desde el dispositivo de medición hasta el exterior. En los dos casos, los Data Loggers se han programado para que registren datos cada $10 \mathrm{~min}$.

Para los ensayos en las cajas de ensayos de $60 \mathrm{~cm} 3$, también se han colocado dos medidores de temperaturas y humedades. El primero de ellos se ha dispuesto en el interior de la misma y otro en el exterior. El medidor colocado en el interior ha sido un modelo Hobbo Anset H08-002-02 y en el exterior de la caja se ha puesto un medidor modelo Hobbo Anset Pro Series H08-032-08.
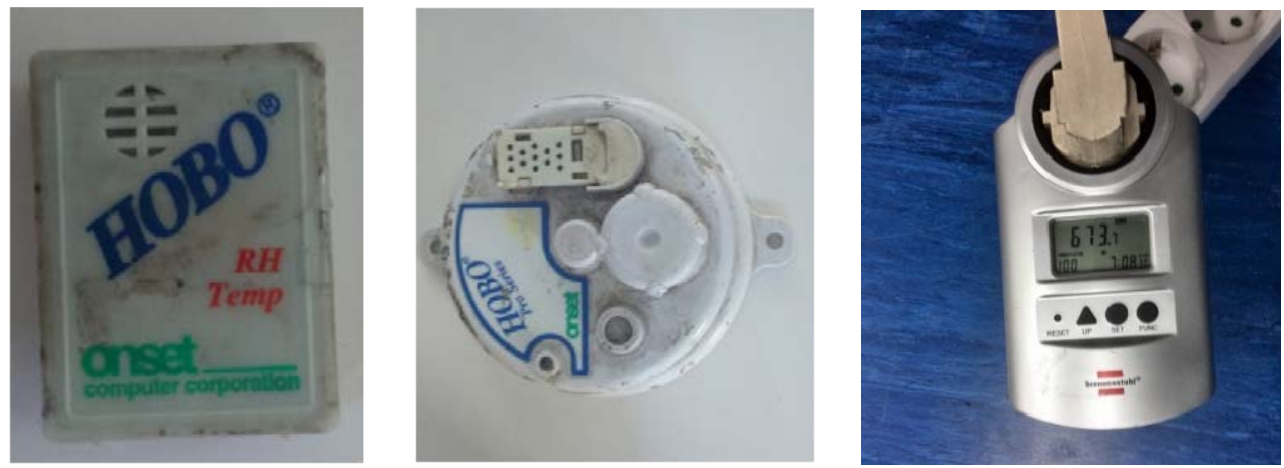

Fig. 17 Hobbo Anset H08-003-02. y Hobbo Anset Pro Series/H08-032-08. Fig. 18 Medidor de energía colocado en Taller.

\subsubsection{Conclusiones parciales Metodología Experimental}

Experimentalmente se confirma que pueden ser comprobadas las posibles situaciones y/o soluciones de diseño ensayadas, mediante las simulaciones energéticas y que los datos experimentales sirven para calibrar las simulaciones y confirmar resultados obtenidos en estas últimas.

Se ha podido comprobar experimentalmente que la piel (cerramiento) del edificio determina, y es el factor decisivo, de los niveles de confort de partida del prototipo.

También se ha comprobado, tanto en el taller como en las cajas de ensayos, que medidas pasivas, como la colocación de estores o la instalación de una malla microperforada benefician el balance térmico del interior del taller en el primer caso y de las cajas en el segundo. 


\subsection{METODOLOGÍA DE SIMULACIÓN}

\subsubsection{Objetivo de las simulaciones}

Los objetivos específicos de estas simulaciones informáticas son, obtener, mediante una metodología analítica, resultados de datos de consumos, demandas y generación de energía, habiendo recreado previamente el estado actual de un prototipo de CML y luego sus escenarios de mejoras y sus prestaciones energéticas, para determinar su nivel de eficiencia energética de cara al nZEB o NZEB, según la ubicación del modelo de simulación, de acuerdo al mapa de Koppen.

\subsubsection{Validación de las herramientas informáticas}

Para poder demostrar la hipótesis principal del trabajo, que es que la construcción modular ligera puede llegar a ser energéticamente eficiente, se han llevado a cabo, a parte de la recopilación experimental de variables y como segunda fase a este proceso de ensayos, unos análisis mediante simulaciones informáticas, sobre el mismo edificio objeto (Taller de Pototipos de la ETSAM) con las herramientas de referencia del Ministerio de Industria, Energía y Turismo (MINETUR) de España. Estos programas informáticos de referencia han sido el CALENER VyP y el $C E^{3} X$. También se han utilizado, para contrastar datos, otros programas promovidos por el MINETUR como el LIDER y la Herramienta Unificada de LIDER y CALENER (HULC). Además, como fuente de referencia, se ha utilizado el programa informático Energy Plus, desarrollado por el US Departament of Energy, DOE (Departamento de Energía de Estados Unidos).

El programa $C^{3} X$ es una herramienta promovida por el propio MINETUR y es la más utilizada de las herramientas disponibles (CALENER y CEEX) para la certificación de edificios existentes o parte de este mediante la Opción Simplificada establecida en el CTE. Resulta ser un programa eminentemente práctico, con una interface de usuario de manejo ágil.

Aún cuando, igual que los otros programas de referencia del MINETUR, éste realiza sus cálculos de manera interna, dejando espacio a que el usuario solo pueda introducir los datos sin poder alterar los algoritmos y/o esquemas de cálculo del programa, el margen de error es mínimo.

Previo a la preparación de esta tesis, y durante el proceso de redacción de la misma, el autor de ésta, ha realizado 131 certificados energéticos reales para inmuebles en uso y que han sido vendidos o alquilados, tomando en consideración la calificación obtenida por los mismos. Esto ha permitido realizar un ejercicio de comprobación real de la idoneidad - y las limitaciones- de la herramienta $C^{3} X$, pudiendo comprobar su nivel de fiabilidad como óptimo. 
La zona geográfica en la que se han realizado los certificados energéticos es la zona Nordeste de la ciudad de Madrid, España, en los años 2013, 2014 y 2015.

Aunque la mayoría de los inmuebles han sido viviendas en bloque, sus superficies y características de uso se asemejan a las asignadas al edificio objeto de análisis de esta tesis.

Por los años de construcción de la mayoría de los inmuebles, se ha podido establecer que la normativa de aplicación española es la NBE CT-79, y en todo caso anterior al 2006, en la que el nivel de aislamiento permitido en los edificios era inferior al actual y en el que muchos de los sistemas de acondicionamientos son hoy o muy antiguos o en buenas condiciones, pero con un desempeño precario con el consecuente nivel de emisiones de $\mathrm{CO}_{2}$ de los edificios.

La media en cuanto a calificación energética global de los mismos es una $\mathrm{F}$ (72 kg $\mathrm{CO}^{2} / \mathrm{m} 2$ ) y cuyo registro de los mismos consta en la Dirección General de Industria, Energía y Minas.

En estos certificados se determina la demanda energética del inmueble a certificar, entendiendo como demanda la necesidad de energía para calentar o refrigerar los espacios interiores. La misma se calcula a partir de los niveles de aislamiento y tipos de cerramientos, compacidad del edificio, tipos de huecos, renovaciones de aire, etc. También se determina el consumo de energía, que se refiere a lo que gasta realmente el edificio para suplir la demanda en un momento determinado. El consumo es la demanda por el rendimiento de las instalaciones.

La calificación global del edificio se expresa en términos del dióxido de carbono liberado a la atmósfera como consecuencia del consumo energético del mismo, y se expresa en $\mathrm{kgCO} 2 / \mathrm{m}^{2}$ año.

\subsubsection{Validación del método de simulación y el modelo de análisis.}

Tal como se ha expuesto en el epígrafe anterior de metodología de las simulaciones, el primer paso para realizar los análisis de comportamiento energético del edificio objeto, por medio de las simulaciones informáticas, ha sido la validación del procedimiento realizado con la herramienta $C E^{3} X$, promovido por el MINETUR.

Esta validación se ha hecho mediante una comparación con los resultados obtenidos en análisis similares previos, y específicamente en el realizado en la tesis de PérezPujazón de 2015. En dicha tesis se han utilizado otras herramientas informáticas, como el programa HULC (España- MINETUR) y el programa Energy Plus (Estados Unidos -DOE).

En dicha simulación han obtenido los siguientes resultados: 


\begin{tabular}{|c|c|c|c|c|c|c|}
\hline $\begin{array}{l}\text { DEMANDA-CONSUMO } \\
\text { CLIMATIZACIÖN ANUAL } \\
\text { CTE-HE (UDER-CALENER) }\end{array}$ & $\begin{array}{l}\text { DEMANDA } \\
\text { REFRIGERACION } \\
{\left[\mathrm{kWh} / \mathrm{m}^{2}\right]}\end{array}$ & $\begin{array}{l}\text { DEMANDA } \\
\text { CALEFACCIOON } \\
{\left[\mathrm{kWh} / \mathrm{m}^{2}\right]}\end{array}$ & $\begin{array}{c}\text { EFICIENCIA } \\
\text { REFRIGERACIÖN } \\
\text { EER }\end{array}$ & $\begin{array}{l}\text { RENDIMIENTO } \\
\text { CALEFACCIÖN } \\
\text { COP }\end{array}$ & $\begin{array}{l}\text { CONSUMO } \\
\text { REFRIGERACIÓN } \\
{\left[\mathrm{kWh} / \mathrm{m}^{2}\right]}\end{array}$ & $\begin{array}{l}\text { CONSUMO } \\
\text { CALEFACCIÓN } \\
\text { [kWh/m?] }\end{array}$ \\
\hline E. RFFFRFNCIA CUMPIIMIFNTO CTF-HF & 58.04 & 93.96 & & & & \\
\hline MODELO TALLER ETSAM (LIDER-CALENER) & 150.10 & 335.15 & 3.21 & 3.61 & 46.76 & 92.83 \\
\hline
\end{tabular}

Fig. 19. Resultados Demanda/Consumo Taller Prototipos con programa HULC (Pérez-Pujazón; 2015)

El programa HULC, de reciente introducción por el MINETUR, como herramienta incluye la unificación, en una única plataforma informática, de los programas generales oficiales empleados hasta la fecha para la evaluación de la demanda energética y del consumo energético (LIDER-CALENER), así como la adaptación de estas aplicaciones a los cambios introducidos por el CTE DB-HE en el año 2013 y en cumplimiento de la normativa europea. De acuerdo a la página web oficial del CTE:

Este programa permite la verificación de las exigencias 2.2.1 de la sección HEO, 2.2.1.1 y punto 2 del apartado 2.2.2.1 de la sección HE1 del Documento Básico de Ahorro de Energía DB-HE. La exigencia establecida para edificios de nueva construcción de uso distinto al residencial privado en el apartado 2.2.2 de la sección HEO debe verificarse, tal como establece el DB-HE, según el procedimiento básico para la certificación energética de edificios. Otras exigencias de las secciones HEO y HE1 que resulten de aplicación deben verificarse por otros medios.

Dado que el $\mathrm{CE}^{3} \mathrm{X}$ no permite realizar cálculos con edificios inferiores a $50 \mathrm{~m}^{2 \text {, }}$ para la comparación y validación de los resultados obtenido en este trabajo, se ha utilizado un factor de corrección que ha permitido confirmar los datos obtenidos.

Este valor numérico ha sido 1,33, en el caso de la superficie, y se ha aplicado dividiendo por el mismo los resultados obtenidos mediante el $\mathrm{CE}^{3} \mathrm{X}$ para contrastar los datos obtenidos por este programa. También se han aplicado otros factores de conversión para las demás variables (dimensionales y volumétricas) del Taller de Prototipos ETSA; tal como se muestra en la siguiente tabla:

\begin{tabular}{|l|r|r|r|}
\hline Variable & Valor actual & Factor de conversión & Nuevo valor \\
\hline Superficies m2 & 38,9 & 1,33 & 51,74 \\
\hline Longitud ( Ancho) ml & 4 & 1,155 & 4,62 \\
\hline Longitud (Largo) ml & 9,72 & 1,155 & 11,2266 \\
\hline Longitud (Alto) ml & 2,5 & 1,155 & 2,8875 \\
\hline Volumen m3 & 95,2 & 1,575 & 149,94 \\
\hline
\end{tabular}

Tabla 01. Factor de conversión.

El Taller de prototipos de la Etsam, con superficie de $38,9 \mathrm{~m}^{2}$ y altura libre de unos $2,50 \mathrm{~m}$, es de planta rectangular y eje este-oeste. 
En síntesis, se han realizado los cálculos de demandas y consumos del Taller de Prototipos ETSAM - aumentado en sus dimensiones proporcionalmente, pero sin alterar sus características técnico/constructivas, ni su uso- y los datos obtenidos mediante el CE3X se han contrastado con los datos obtenidos en simulaciones semejantes, realizadas por Pérez-Pujazón (en su tesis: "La implementación arquitectónica de los acristalamientos activos con agua circulante, y su contribución en edificios de consumo de energía casi nulo") , aplicando los factores de correcciones antes expuestos y confirmando que los valores obtenidos están en el mismo rango $u$ orden de magnitud que los de la tesis de referencia.

Los datos obtenidos en el proceso de comprobación del método de simulación seleccionado para el Taller de Prototipos (con programa $C^{3}{ }^{3} X$ v2.1), se presentan, íntegramente en el Anexo 6, y cuyo resumen sería el siguiente:

\begin{tabular}{|c|c|c|c|c|}
\hline \multicolumn{5}{|c|}{$\begin{array}{l}\text { 2. CALIFICACIÓN ENERGÉTICA DEL EDIFICIO EN CONSUMO DE ENERGÍA PRIMARIA NO RENOVABLE } \\
\text { Por energía primaria no renovable se entiende la energía consumida por el edificio procedente de fuentes no renovables que no } \\
\text { ha sufrido ningún proceso de conversión o transformación. }\end{array}$} \\
\hline INDICADOR GLOBAL & \multicolumn{4}{|c|}{ INDICADORES PARCIALES } \\
\hline \multirow{4}{*}{ 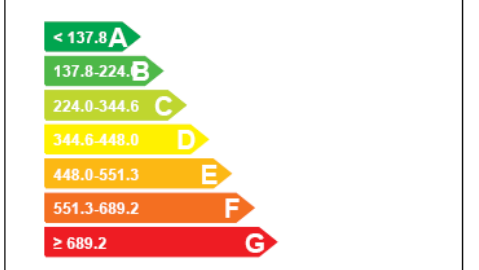 } & \multicolumn{2}{|c|}{ CALEFACCIÓN } & \multicolumn{2}{|l|}{ ACS } \\
\hline & \multirow{2}{*}{$\begin{array}{c}\text { Energía primaria } \\
\text { calefacción } \\
{\left[\mathrm{kWh} / \mathrm{m}^{2} \text { año] }\right.}\end{array}$} & \multirow[t]{2}{*}{ C } & $\begin{array}{l}\text { Energía primaria } \\
A C S \\
{\left[\mathrm{kWh} / \mathrm{m}^{2} \text { año] }\right.}\end{array}$ & \multirow[t]{2}{*}{ G } \\
\hline & & & 57.68 & \\
\hline & \multicolumn{2}{|c|}{ REFRIGERACIÓN } & \multicolumn{2}{|l|}{ ILUMINACIÓN } \\
\hline \multirow{2}{*}{$\begin{array}{l}\text { Consumo global de energía primaria no renovable } \\
\qquad\left[\mathrm{kWh} / \mathrm{m}^{2} \text { año }\right]^{1}\end{array}$} & $\begin{array}{c}\text { Energía primaria } \\
\text { refrigeración } \\
{\left[\mathrm{kWh} / \mathrm{m}^{2} \text { año] }\right.}\end{array}$ & \multirow[t]{2}{*}{ A } & $\begin{array}{c}\text { Energía primaria } \\
\text { iluminación } \\
{\left[\mathrm{kWh} / \mathrm{m}^{2} a n ̃ o\right]}\end{array}$ & \multirow[t]{2}{*}{ B } \\
\hline & 19.18 & & 60.32 & \\
\hline
\end{tabular}

Fig. 20. Datos de calificación energética para el consumo, de acuerdo al programa CE3X.

Equiparando los datos obtenidos con los planteados por Pérez-Pujazón, se ha manejando un margen que para los fines de este estudio, y como metodología simplificada de cálculo, resulta ser aceptable. En cualquier caso y aún existiendo una diferencia en los valores, la calificación energética absoluta del edificio, (e incluso las parciales), que se han obtenido, tanto con HULC como con $\mathrm{CE}^{3} \mathrm{X}$ equivaldría a la letra C como máximo, cumpliendo con el CTE, pero alejado de cualquier consideración de nZEB o NZEB.

A partir de esta validación, mediante este factor de corrección (aportación original de esta tesis) y habiendo confirmado que el método utilizado es fiable, es posible realizar los escenarios de simulaciones propuestos con las medidas de mejora correspondiente, cambiando el uso del Taller de Prototipos de uso terciario (edificio docente) a un uso residencial en un edificio de $52 \mathrm{~m}^{2}$ que dividido en 1,33 (aprox.). representa la superficie real actual. 


\subsubsection{Propuestas, medidas de mejoras y escenarios climáticos.}

Para la realización de las simulaciones se parte de un análisis y cálculo de la energía utilizada y las cargas térmicas que pueden actuar en el edificio objeto, con un uso definido y unos usuarios determinados. Mediante las herramientas de simulación se ponderan aspectos que van desde la constitución física del edificio y sus características constructivas, hasta la integración de sistemas activos y pasivos de acondicionamiento interior, tomando como referencia o ejemplos de eficiencia energética, algunas de las soluciones adoptadas por varios de los prototipos participantes en los concursos Solar Decathlon 2010 y 2012 de Madrid, así como estrategias y soluciones propuestas en los artículos científicos referenciados en el Estado de la Investigación de esta tesis y las soluciones planteadas en otros trabajos académicos. Tal como se expone en el epígrafe anterior, como escenario original para las simulaciones, y utilizando siempre el edificio objeto, se han seleccionado el emplazamiento actual y el uso actual como Taller de Prototipos y/o espacio de docencia. Una vez contrastados los datos con las fuentes de referencia, es decir los propios programas informáticos y la documentación técnica y científica disponible (artículos, tesis, ponencias) se han planteado cuatro propuestas alternativas para mejorar el Taller.

1. Instalación solar fotovoltaica al $100 \%$ en cubierta (inclinación 0\%5\%).

2. Bombas de calor de alto COP y EER, con Geotérmica y/o renovable. + vidrios activos.

3. Bombas de calor de alto COP y EER con Geotérmica y/o renovable, más vidrio activo (con cámara de agua) y mejora en los cerramientos.

En este caso y como referente principal se han considerado, como puntos de partida, los valores ya obtenidos y presentados en el trabajo "Células de Energía 0, ETSA Madrid", (Rashevski; 20129) en la tesis "La implementación Arquitectónica de los Acristalamientos Activos con Agua Circulante, y su Contribución en Edificios De Consumo de Energía Casi Nulo" (Pérez-Pujazón; 2015) .

Luego de validado el Taller, comparando las simulaciones propias de esta tesis con las simulaciones realizados en estos otros trabajos académicos, se replantea el uso del mismo, asignándole el uso característico de vivienda y aplicándole las mejoras en esa condición, pero con características constructivas y de sistemas iguales a los actuales.

Estas propuestas de mejora se van planteando en un escenario climático global, dividido a su vez en varios escenarios climáticos por zonas, en los que se va simulando el Taller de Prototipos (con uso característico de vivienda), aplicando las tres propuestas de mejoras y analizando su efectividad, por zona climática, de cara al NZEB o nZEB. 
En términos de simulación al Taller se le han hecho mejoras alternativas en cuanto a sus prestaciones energéticas y a medida que estas medidas se han ido incorporando, se ha ido ampliando el espacio geográfico en que el Taller, como construcción modular ligera energéticamente eficiente, puede ser emplazado. De acuerdo a esta metodología original, se ha podido determinar en qué lugares (por latitudes y/o zonas climáticas) el taller es más o menos eficiente al implementar estas medidas de mejoras, y según el tipo de medida.

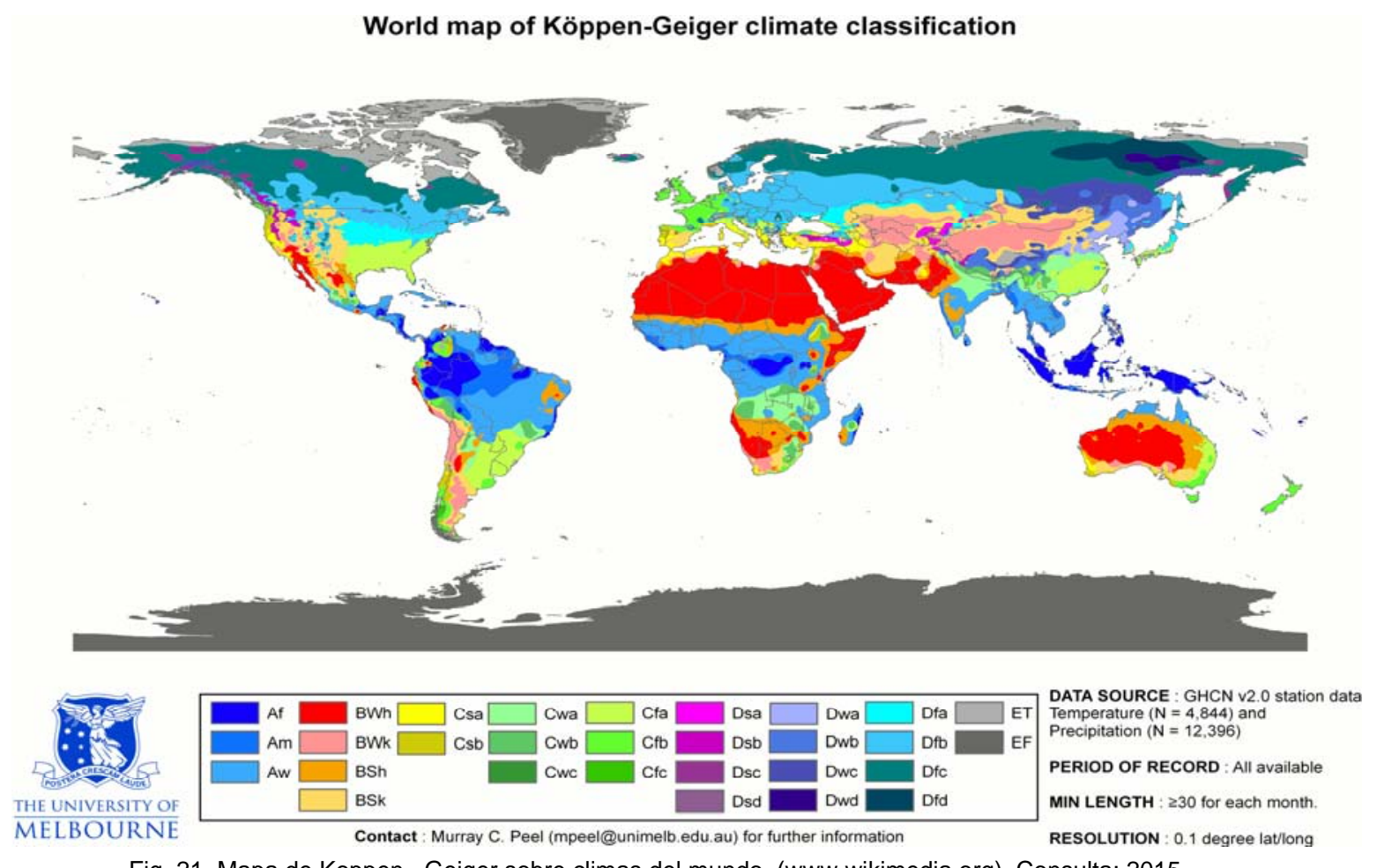

Fig. 21. Mapa de Koppen -Geiger sobre climas del mundo. (www.wikimedia.org). Consulta: 2015.

Para esto se ha utilizado el mapa Koppen-Geiger, que se describe en la parte del estado de la técnica y de la investigación, como guía de zonas climáticas.

En el caso de los trabajos académicos antes citados, su utilidad ha consistido en la aplicación de varios de sus datos de partida y/o resultados (de ensayos, simulaciones y conclusiones), como referencias técnicas y teóricas para los análisis y simulaciones propias de esta tesis. En la parte de la Discusión de Resultados se especifica, según sea el caso, el dato o resultado utilizado (sobre generación de renovables, características de medidas de mejora, rendimientos, etc) como punto de partida y, según sea el método de análisis, se describe si ha sido necesario algún procedimiento de validación para este trabajo.

Para el caso de la instalación de generación de energía solar fotovoltaica (FV), el fenómeno que convierte la energía solar (luz) en energía eléctrica; (ver definiciones de FV en trabajo tutelado para Diplomado de Estudios Avanzados DEA: "Arquitectura solar en países emergentes. Tecnología fotovoltaica; el escenario dominicano"; del autor de esta tesis en el Anexo 1), se ha realizado el cálculo propio de acuerdo a la latitud de emplazamiento del prototipo, según sea el caso, partiendo de una serie de 
pasos previos, tal como se describen en esta metodología y en la parte de análisis y discusión de resultados.

Para el caso de la geotermia - y partiendo de instalaciones geotérmicas someras, que son aquellas con profundidades de aplicación no mayores de $400 \mathrm{~m}$ de profundidad, con temperaturas por el orden de los $15^{\circ}$ y que va aumentado $15^{\circ}$ cada 100 metros de profundidad- se han tomado los datos y valores de simulación obtenidos en la tesis "La implementación arquitectónica de los acristalamientos activos con agua circulante, y su contribución en Edificios de consumo de Energía Casi Nulo" (Pérez- Pujazón; 2015) en su tesis y que son:

\begin{tabular}{|c|c|c|c|c|c|c|c|c|c|}
\hline $\begin{array}{l}\text { RENDIMIENTO COP } \\
\text { PERIODO DE CALEFACCIÓN }\end{array}$ & $\begin{array}{c}\text { VOLUMEN } \\
\text { AGUA } \\
\text { [m3] }\end{array}$ & $\begin{array}{c}\text { DENSIDAD } \\
\text { AGUA } \\
\text { [kg/m3] }\end{array}$ & $\begin{array}{c}\text { CALOR } \\
\text { ESPECíFICO } \\
\text { AGUA } \\
{\left[W h / \mathrm{kg}^{\circ} \mathrm{C}\right]}\end{array}$ & $\begin{array}{l}\text { SALTO } \\
\text { TÉRMICO } \\
{\left[{ }^{\circ} \mathrm{C}\right]}\end{array}$ & $\begin{array}{l}\text { TEMP. } \\
\text { DEPÓSITO } \\
(9: 00 \mathrm{~h}) \\
{\left[{ }^{\circ} \mathrm{C}\right]}\end{array}$ & $\begin{array}{c}\text { TEMP. } \\
\text { DEPÓSITO } \\
(18: 00 \mathrm{~h}) \\
{\left[{ }^{\circ} \mathrm{C}\right]}\end{array}$ & $\begin{array}{c}\text { COP } \\
\text { F. FRIO: TERRENO } \\
\text { (hasta las 18:00 h) }\end{array}$ & $\begin{array}{c}\text { COP } \\
\text { F. FRIOO: } \\
\text { DEPÓSITO } \\
\text { (hasta las 22:00 } \\
\text { h) }\end{array}$ & $\begin{array}{l}\text { COP } \\
\text { rendimiento } \\
\text { medio mensual }\end{array}$ \\
\hline Octubre & 6,4 & 1000,0 & 1,2 & 4,0 & 18,0 & 22,0 & 6,5 & 7,3 & 6,9 \\
\hline Noviembre & 6,4 & 1000,0 & 1,2 & 3,1 & 18,0 & 21,1 & 6,3 & 7,2 & 6,8 \\
\hline Diciembre & 6,4 & 1000,0 & 1,2 & 3,7 & 16,0 & 19,7 & 6,1 & 6,9 & 6,5 \\
\hline Enero & 6,4 & 1000,0 & 1,2 & 2,9 & 14,0 & 16,9 & 5,8 & 6,5 & 6,2 \\
\hline Febrero & 6,4 & 1000,0 & 1,2 & 3,5 & 12,0 & 15,5 & 5,8 & 6,4 & 6,1 \\
\hline Marzo & 6,4 & 1000,0 & 1,2 & 4,7 & 12,0 & 16,7 & 5,8 & 6,6 & 6,2 \\
\hline Abril & 6,4 & 1000,0 & 1,2 & 4,2 & 12,0 & 16,2 & 5,8 & 6,5 & 6,2 \\
\hline Mayo & 6,4 & 1000,0 & 1,2 & 3,8 & 12,0 & 15,8 & 5,8 & 6,7 & 6,3 \\
\hline
\end{tabular}

\begin{tabular}{|lcc|}
\hline $\begin{array}{l}\text { EFICIENCIA EER } \\
\text { PERIODO DE REFRIGERACIÓN }\end{array}$ & $\begin{array}{c}\text { TEMP. } \\
\text { TERRENO } \\
{\left[{ }^{\circ} \mathrm{C}\right]}\end{array}$ & $\begin{array}{c}\text { EER } \\
\text { eficiencia } \\
\text { media mensual }\end{array}$ \\
\hline Mayo & 12,0 & 8,5 \\
Junio & 14,0 & 7,5 \\
Julio & 16,0 & 7,0 \\
Agosto & 18,0 & 6,7 \\
Séptiembrè & 18,0 & 6,7 \\
Octubre & 18,0 & 6,7 \\
\hline
\end{tabular}

Fig. 22. Cálculo de rendimiento de bomba de calor, geotérmica, para calefacción por vidrios activos. ( Pérez Pujazón; 2015).

De acuerdo a estos valores, tomados de los cálculos realizados en esta tesis para el Taller de Prototipos de la ETSAM y en función de una bomba de calor tipo Vaillant Geotherm VWS 61/2, se obtiene de media para el EER un 7,18 y para el COP un 6,43.

Estas bombas de calor, se integran a un sistema de vidrios activos (con circulación de agua interior a una temperatura de entre 20 a $25^{\circ} \mathrm{C}$ ), que sustituyen, en la simulación, a los vidrios sencillos con que actualmente cuenta el taller. Estos vidrios activos cuentan con una $U$ (valor de transmitancia) de 1,123.

\subsubsection{Cálculo de consumos estimados zonas climáticas equiparables}

Utilizando una calculadora de consumos y asignando un uso medio a los equipos eléctricos de la vivienda se ha determinado un consumo global medio, para el cálculo de la generación fotovoltaica necesaria, y para poder dimensionar el sistema. Los consumos teóricos de los que se parte para estos fines se muestran en la parte de los anexos (Anexo 5). 
Estos consumos son el resultado de las sumas de los consumos individuales en cada caso tal como se muestra en la parte a continuación. Para el cálculo del consumo de energía eléctrica para calefacción y refrigeración se toman los valores que han resultado de la propia simulación del estado actual del taller como vivienda que se obtienen en $\mathrm{kWh} / \mathrm{m}^{2}$ años y se convierten a Wh/día. A partir de estos valores es posible determinar la capacidad de las instalaciones de generación de energía renovables de acuerdo a los cálculos realizados para cada una.

En el caso de la FV se calculan los niveles de radiación solar por zonas y a partir de éstos y de las necesidades energéticas mencionadas se dimensiona la instalación fotovoltaica. En la parte de la discusión de los resultados se exponen los valores de consumos calculados y los cálculos de generación renovable.

En sentido general y para la proyección de las instalaciones se ha tomado como referencia fundamental la normativa vigente y específicamente los epígrafes 2.2.1 y 2.2.2 de la Sección HE 5 del CTE (Contribución fotovoltaica mínima de energía eléctrica) y que se incluye en el citado anexo. Luego este consumo en Wh al día queda expresado de la siguiente manera: $(\mathrm{Cde})=\mathrm{Wh} /$ día .

El rendimiento de una instalación de estas características está por el orden del 80 al $75 \%$. Para este cálculo se ha asumido un rendimiento de la instalación del $75 \%$ y de esta manera poder calcular la energía total necesaria para suplir la demanda: Total energía necesaria $($ Ten $)=$ Cde $/$ 0,75 = Wh/día

Para poder determinar el nivel de radiación solar incidente en cada localidad se ha utilizado la aplicación PVGIS (Photovoltaic Geographical Information System European Commission, Joint Research Center). Esta plataforma on line permite calcular este valor para todas las localidades seleccionadas en este estudio.

Una vez seleccionado el mes más desfavorable en términos de radiación (que suele ser entre noviembre y enero), se dimensiona la instalación con la certeza de que aún en el mes con menor nivel de radiación la instalación podrá tener un rendimiento óptimo.

Luego se calcula la hora sol pico (HSP) en función de la radiación solar incidente obtenida de las tablas, dividida por la radiación solar incidente que se utiliza para calibrar los módulos y que sería $1000 \mathrm{~W} / \mathrm{m}^{2}\left(1 \mathrm{~kW} / \mathrm{m}^{2}\right)$. HSP = radiación solar tablas $/$ $1 \mathrm{~kW} / \mathrm{m} 2=\mathrm{HSP}$.

Para conocer el número de módulos necesarios se elige un tipo de módulo con su capacidad expresada en $\mathrm{W}$ de acuerdo a cada fabricante. Nmu= Módulos (número de unidades) = energía necesaria / HSP $\mathrm{x}$ rendimiento de la instalación $\mathrm{x}$ potencia pico del módulo. El rendimiento de la instalación se calcula entre un 0,7 y un 0,8. La potencia pico Wp se obtiene al determinar la cantidad de paneles (y su capacidad en $W$ ). $W P=N m u x$ tipo de módulo y su capacidad de generación en $W=W p$. 


\subsubsection{Conclusiones parciales Metodología de Simulaciones.}

La combinación de resultados de otras simulaciones de otros trabajos académicos, ha sido una buena herramienta para contrastar los datos propios y validar la herramienta principal de uso en esta tesis que ha sido el $\mathrm{CE}^{3} \times 2.1$, programa de referencia del Ministerio de Industria en España, para la certificación energética de edificios existentes.

Los datos de otras simulaciones realizadas al propio Taller, y que han sido contrastadas entre sí para confirmar sus respectivos datos, han servido de base para los escenarios de partida de simulaciones de esta tesis.

Mediante las simulaciones se ha demostrado que el Taller de prototipos, convertido a un uso característico de vivienda, puede llegar a ser nZEB e incluso NZEB con la implementación de sistemas renovables de energía.

La generación fotovoltaica, cuya instalación ocupa el 100\% de la cubierta en posición horizontal, ha resultado ser el sistema más eficiente en todos los casos.

Se ha confirmado que el uso del Mapa de Koppen, como mapa climático por zonas, puede ser útil al momento de equiparar los climas españoles con los definidos en dicho mapa y con los definidos en el CTE DB HE y mediante el $\mathrm{CE}^{3} \mathrm{X}$. Es posible utilizar un método de cálculo simplificado y obtener datos fiables como referencia inicial a datos más exactos, con el uso combinado del Mapa de Koppen y la herramienta $\mathrm{CE}^{3} \mathrm{X}$.

A continuación se presenta una tabla de equiparación entre las zonas climáticas españolas, según la definición del CTE, que quedan definidas a su vez en el Mapa de Koppen:

\begin{tabular}{|l|l|l|}
\hline \multicolumn{3}{|c|}{ TABLA DE EQUIPARACIÓN DE ZONAS CLIMÁTICAS } \\
\hline Localidad Española & \multicolumn{1}{|c|}{ Zonas Climáticas CTE } & Zonas Climáticas Mapa Koppen \\
\hline Santa Cruz de Tenerife & a3 & BWk, BWh, BSh, Aw y Am \\
\hline Almería & A4 & BWk \\
\hline Sevilla & B4 & Csa \\
\hline Madrid & D3 & BSk \\
\hline Ourense & D2 & Csb \\
\hline Santander & C1 & Cfb \\
\hline Burgos & E1 & Dsb \\
\hline
\end{tabular}

Tabla 02. Tabla de equiparación entre las zonas climáticas españolas y las definidas en el Mapa de Koppen. 
5. ANÁLISIS Y DISCUSIÓN DE RESULTADOS 


\section{ANÁLISIS Y DISCUSIÓN DE RESULTADOS}

\subsection{ANÁLISIS Y DISCUSIÓN DE RESULTADOS DE LA METODOLOGÍA DOCUMENTAL}

Los resultados de la metodología documental quedan expresados en el propio desarrollo de la metodología experimental y la metodología de simulaciones; es decir, los resultados obtenidos empíricamente y de manera teórica confirman lo planteado en artículos como los de Sartori, Voss o Meggers, en los que se establece la necesidad, (en los dos primeros), de unificar criterios en torno a los términos de nZEB o NZEB y la manera de establecer los parámetros para la puesta en práctica o (en el caso del segundo), establecer procedimientos empíricos para dotar de altos niveles de eficiencia a una construcción - y en el caso de la Bubble Zero- una construcción ligera como la que es objeto de esta tesis.

\subsubsection{Concurso Solar Decathlon}

Las casas del Solar Decathlon, de ambas ediciones, Solar Decathlon 2010 SD10 y Solar Decathlon SD12, resultaron ser en un 94\% de construcción ligera, el otro 6\% resultaron ser no ligeras, tal como se expresa en la parte de Metodología. Estas viviendas se han fabricado, a nivel de prototipos, para un concurso y han conllevado unos costes relativamente elevados (con relación a su superficie), que sólo se corresponden con su naturaleza de modelo hiper-optimizados para la competición en la cual debían tener un rendimiento tal que fueran fácilmente evaluables.

\subsubsection{Prototipos SD10 y SD12}

\section{Superficie a acondicionar (SD10 y SD 12)}

La media de superficie a acondicionar en este tipo de viviendas es de $49,80 \mathrm{~m}^{2}$ para el SD10 y 58,57m para el SD12; este dato está en correspondencia directa con la superficie del prototipo que se plantea como modelo de experimentación y simulación en este trabajo y que es de 38,90 m2 en el caso real existente y 50,61 en el modelo de simulación. 


\begin{tabular}{|l|r|r|r|r|}
\hline \multicolumn{5}{|c|}{ SUPERFICIES } \\
\hline Prototipo & Const./SD2010 & Útil/SD2010 & ronst./SD2012 & Útil/SD2012 \\
\hline H1 & 74,00 & 52,80 & 68,80 & 52,80 \\
\hline H2 & 73,20 & 55,00 & 107,10 & 69,60 \\
\hline H3 & 74,00 & 52,11 & 68,04 & 55,49 \\
\hline H4 & 74,00 & 44,67 & 78,40 & 67,60 \\
\hline H5 & 60,60 & 42,40 & 77,60 & 61,82 \\
\hline H6 & 73,80 & 48,55 & 67,00 & 45,10 \\
\hline H7 & 74,00 & 46,00 & 67,92 & 56,60 \\
\hline H9 & 70,00 & 46,00 & 144,95 & 46,36 \\
\hline H10 & 64,00 & 50,79 & 130,55 & 77,60 \\
\hline H11 & 74,00 & 52,82 & 76,80 & 66,50 \\
\hline H12 & 55,90 & 42,00 & 65,20 & 61,60 \\
\hline H13 & 67,74 & 51,71 & 89,13 & 54,60 \\
\hline H14 & 74,00 & 42,00 & 105,00 & 69,40 \\
\hline H15 & 57,52 & 46,36 & 55,62 & 55,62 \\
\hline H16 & 72,00 & 72,00 & 64,50 & 54,38 \\
\hline H17 & 68,05 & 44,00 & 83,82 & 49,17 \\
\hline H18 & 73,50 & 57,40 & 131,00 & 91,00 \\
\hline TOTAL & & & 78,70 & 62,40 \\
\hline PROMEDIO & $1.180,31$ & 846,61 & $1.322,03$ & 937,04 \\
\hline
\end{tabular}

Tabla 03. Superficies prototipos SD 10 y SD12. Elaboración propia.

(Los valores en rojo corresponden a los prototipos no ligeros. El promedio no los incluye)

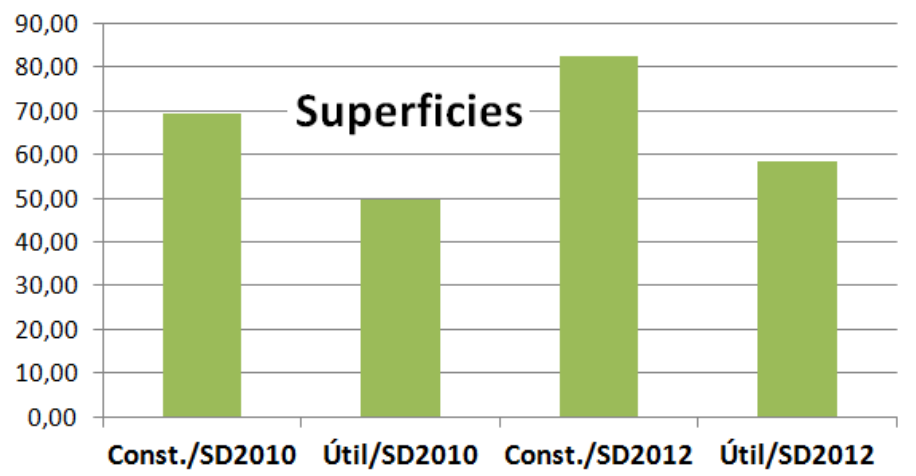

Fig. 23. Gráfico comparativo entre superficies medias SD 10 y SD12.

Al determinar la superficie de los prototipos del SD10 y SD12 es posible conocer el consumo que tiene cada uno por kWh m2.

Coste de inversión (Prototipo y versión a producir en serie SD10 y SD12).

Por otro lado se ha podido determinar que las casas del SD12 cuentan con mayor superficie que las casas del SD10 tal como se ve en el gráfico anterior. Fig. 23

El coste medio por vivienda ha resultado estar por encima de los 375 mil euros en el caso del SD 10 y de poco menos de 310 mil euros en el caso del SD12. La diferencia entre el coste de producción del modelo hiperoptimizado con relación a un prototipo fabricado en serie, para su comercialización.

En el caso del SD10 el porcentaje de reducción entre el prototipo de concurso y el prototipo comercial es de un $48 \%$ y en el caso del SD12 es de un $60 \%$. 


\begin{tabular}{|c|c|c|c|c|}
\hline \multicolumn{5}{|c|}{ COSTE PROTOTIPO / COSTE INDUSTRILAIZACIÓN } \\
\hline Prototipo & SD10 Prototipo & SD10 Industrial & SD12 Prototipo & SD12 Industrial \\
\hline $\mathrm{H} 1$ & $300.000,00$ & $233.000,00$ & $700.000,00$ & $140.000,00$ \\
\hline $\mathrm{H} 2$ & $626.712,00$ & $250.500,00$ & & \\
\hline $\mathrm{H} 3$ & $663.169,00$ & $220.000,00$ & $160.000,00$ & $124.000,00$ \\
\hline $\mathrm{H} 4$ & $240.650,00$ & $180.000,00$ & $360.000,00$ & $200.000,00$ \\
\hline $\mathrm{H} 5$ & $496.000,00$ & $180.000,00$ & $542.000,00$ & $241.000,00$ \\
\hline $\mathrm{H} 6$ & $817.800,00$ & $450.000,00$ & $360.000,00$ & $278.000,00$ \\
\hline $\mathrm{H} 7$ & $350.000,00$ & $100.000,00$ & $194.856,00$ & $108.860,00$ \\
\hline $\mathrm{H} 8$ & $313.000,00$ & $140.000,00$ & $150.000,00$ & $110.000,00$ \\
\hline H9 & $600.000,00$ & $120.000,00$ & $125.000,00$ & $70.000,00$ \\
\hline $\mathrm{H} 10$ & $276.727,00$ & $200.000,00$ & $319.225,00$ & $212.000,00$ \\
\hline $\mathrm{H} 11$ & $200.000,00$ & $200.000,00$ & $287.000,00$ & $240.000,00$ \\
\hline $\mathrm{H} 12$ & $250.000,00$ & $120.000,00$ & $234.020,00$ & $219.873,00$ \\
\hline $\mathrm{H} 13$ & $240.000,00$ & $163.000,00$ & $150.000,00$ & $70.000,00$ \\
\hline $\mathrm{H} 14$ & $170.000,00$ & $120.000,00$ & $450.000,00$ & $450.000,00$ \\
\hline $\mathrm{H} 15$ & $144.000,00$ & $156.000,00$ & $500.000,00$ & $250.000,00$ \\
\hline $\mathrm{H} 16$ & $247.000,00$ & $25.000,00$ & $300.000,00$ & $150.000,00$ \\
\hline $\mathrm{H} 17$ & $450.000,00$ & $220.000,00$ & & \\
\hline $\mathrm{H} 18$ & & & $122.450,00$ & $85.715,00$ \\
\hline TOTAL & $6.385 .058,00$ & $3.077 .500,00$ & $4.954 .551,00$ & $2.949 .448,00$ \\
\hline PROMEDRIO & $375.591,65$ & $181.029,41$ & $309.659,44$ & $184.340,50$ \\
\hline Ahorro en producción en serie & 48,0 & & & $\%$ \\
\hline
\end{tabular}

Tabla 04. Comparativa inversión prototipos SD 10 y SD 12 y posibles costes de producción en serie. Elaboración propia

Valores de Transmitancias U. Prestaciones cerramientos. (SD10 y SD12)

Los valores de transmitancia de los cerramientos de SD10 y SD12 son los que se han obtenido de la propia documentación técnica de cada participante.

\begin{tabular}{|c|r|r|r|}
\hline \hline \multicolumn{4}{|c|}{ PRESTACIÓN ENERGÉTICA U = Wm2k } \\
\hline Prototipo & SD2010 $\mathrm{m}$ & \multicolumn{1}{c|}{ SD2012 $\mathrm{m}$} & \multicolumn{1}{c|}{ CTE } \\
\hline $\mathrm{U}=\mathrm{W} / \mathrm{m} 2 \mathrm{~K}$ & 0,191 & 0,171 & 0,66 \\
\hline
\end{tabular}

Tabla 05. Comparativa U cerramientos SD 10 y SD 12 con relación al CTE. Elaboración propia.

En la tabla anterior y en el gráfico siguiente, se puede apreciar cómo las viviendas del SD cuentan con un nivel de aislamiento muy superior al límite permitido por el CTE de España. Este nivel de optimización de los cerramientos se ha obtenido con la utilización de materiales ligeros como los que se han descrito en la parte del Estado de la Técnica y que son los que se utilizan habitualmente en este tipo de construcción, históricamente y en la actualidad.

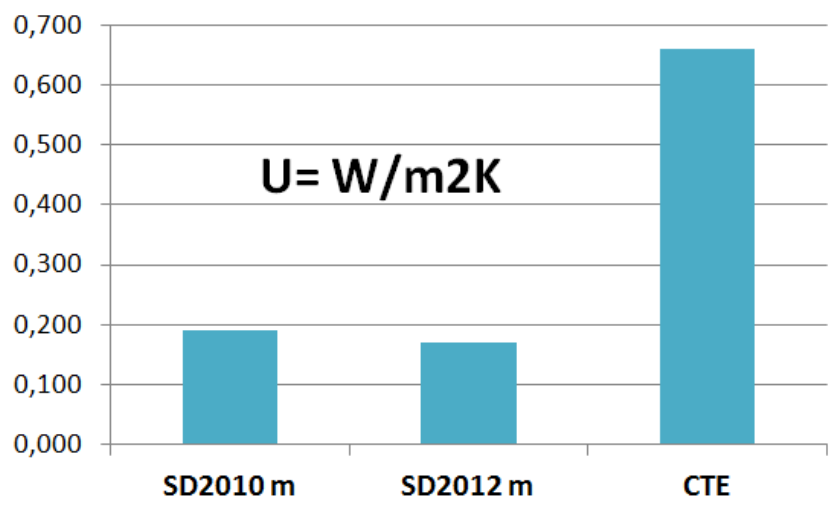

Fig. 24. Comparativa U cerramientos SD 10 y SD 12 con relación al CTE. Elaboración propia. 
Materiales como la madera y los de PCM se presentan como opciones con altos niveles de prestaciones, ambientales y energéticas, sobre todo en el caso de la madera certificada cuyo ACV resulta muy favorable en el balance final del edificio. Estos materiales ligeros, combinados de manera adecuada, demuestran que es posible (utilizando los factores de forma y de diseño, más allá de la composición del propio material) proporcionar un buen nivel de aislamiento a estos prototipos. La media de la $U$ de las casas del SD10 es 0,191 $\mathrm{Wm}^{2} \mathrm{ky}$ la media de la $U$ de las casas de SD12 es $0,171 \mathrm{~W} / \mathrm{m}^{2} \mathrm{k}$.

\section{Niveles de demanda por kWh $\mathrm{m}^{2}$ (SD10 y SD12)}

La demanda energética de las viviendas del SD10 y SD 12 es inferior a la demanda máxima establecida para viviendas en la zona climática D3 que es la que corresponde a Madrid, lugar de emplazamiento de las casas en ambas ediciones. La calificación B en Madrid, en cuanto a consumo de energía se sitúa entre los 54,2 y los $87,8 \mathrm{kWh} / \mathrm{m}^{2}$, de acuerdo a los resultados obtenidos en las certificaciones energéticas realizadas para el prototipo del Taller de la ETSAM de CML, es decir un edificio existente. La siguiente expresión establece el límite de consumo según CTE:

$$
C_{\text {ep }, \text { lim }}=C_{\text {ep,base }}+F_{\text {ep,sup }} / \mathrm{S}
$$

Los valores para desarrollar la fórmula anterior se encuentran en la tabla 2.1, en el epígrafe 2.2.1 del DB-HEO del CTE y son los siguientes (correspondientes a edificios nuevos y ampliaciones de envergadura):

\begin{tabular}{|l|c|c|c|c|c|c|}
\hline & \multicolumn{6}{|c|}{ Zona climática de invierno } \\
\cline { 2 - 7 } & $\mathbf{a}$ & $\mathbf{A}^{*}$ & $\mathbf{B}^{*}$ & $\mathbf{C}^{*}$ & $\mathbf{D}$ & $\mathbf{E}$ \\
\hline$C_{\text {ep, base }}\left[\mathrm{kW} \cdot \mathrm{h} / \mathrm{m}^{2} \cdot\right.$ año $]$ & 40 & 40 & 45 & 50 & 60 & 70 \\
\hline$F_{\text {ep,sup }}$ & 1000 & 1000 & 1000 & 1500 & 3000 & 4000 \\
\hline
\end{tabular}

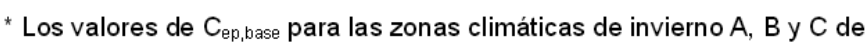
Canarias, Baleares, Ceuta y Melilla se obtendrán multiplicando los valores de $C_{e p, \text { base }}$ de esta tabla por 1,2 .

Fig. 25. Valor base y factor corrector por superficie del consumo energético. CTE2013

En el caso de las viviendas de SD10 y SD12 la demanda calculada por sus proyectistas no sobrepasa los 5.148,55 $\mathrm{kWh} \mathrm{m}^{2} \mathrm{a}$, en el primero y los 5.479,82 kWh $\mathrm{m}^{2}$ a en el segundo, lo que supone -y de acuerdo a la media de $49,80 \mathrm{~m}^{2}$ y $58,57 \mathrm{~m}^{2}$ respectivamente en cada concurso- un consumo inferior a los $120 \mathrm{kWh} \mathrm{m} \mathrm{m}^{2} \mathrm{a}$ establecidos en el estándar Passivhaus.

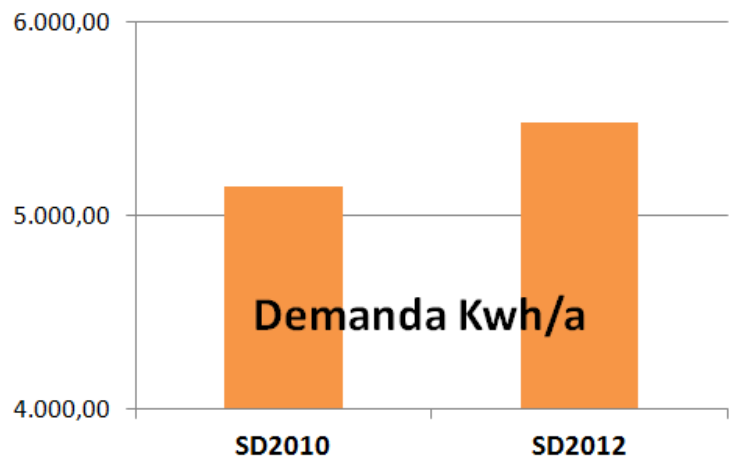

Fig. 26. Gráfico demanda energía casas del SD10 y SD12. Elaboración propia 


\subsubsection{Ganadores: LumenHaus 2010 y Canopea 2012.}

Como parte del proceso de evaluación de los prototipos ganadores en ambas ediciones del concurso, se ha hecho una comparativa de las puntuaciones totales de ambos. Con esto se ha podido establecer una argumentación sobre las mejores soluciones en el ámbito de la CML tomando el concurso como referente.

\begin{tabular}{|l|r|r|}
\hline \multicolumn{3}{|c|}{ CLASIFICACIÓN } \\
\hline Variable & LumenHAUS & Canopea \\
\hline Puntuación Total & 811,83 & 908,7 \\
\hline Puntuación Arquitectura & 120 & 120 \\
\hline Puntuación Cosntrucción & 51 & 71 \\
\hline
\end{tabular}

Tabla 06. Comparativa puntuaciones totales equipos ganadores SD10 y SD12. Elaboración propia

Emplazamiento y tipologías. Lumenhaus 2010 y Canopea 2012.

Las viviendas aunque en ambas ediciones del concurso estaban emplazadas en zonas próximas en Madrid (SD10 en Madrid Río y SD12 en Casa de Campo a aproximadamente 1,5 km del Manzanares), lo cierto es que la distancia del río y/o la arborización presente en toda la zona podría tener algún tipo de influencia en momentos puntuales del día. En el caso de la edición de 2010, es evidente que en horas del mediodía el nivel de humedad de la Villa Solar era mayor (favorablemente), que en el caso de la Villa Solar de 2012 emplazada en la Casa de Campo.

\begin{tabular}{|l|r|r|}
\hline \multicolumn{3}{|c|}{ EMPLAZAMIENTO } \\
\hline Ciudad & LumenHaus & Canopea \\
\hline Año & 2010 & 2012 \\
\hline Ciudad & Madrid & Madrid \\
\hline Localización & Madrid Río & Casa de Campo \\
\hline Coordenadas & $40^{\circ} 24^{\prime} 55.9728^{\prime \prime}(\mathrm{N}) 3^{\circ} 43^{\prime} 12^{\prime \prime}(\mathrm{W})$ & $40^{\circ} 24^{\prime} 59.3784^{\prime \prime}(\mathrm{N}) 3^{\circ} 43^{\prime} 39^{\prime \prime}(\mathrm{W})$ \\
\hline
\end{tabular}

\begin{tabular}{|l|r|r|}
\hline \multicolumn{3}{|c|}{ TIPOLOGÍA } \\
\hline Variable & LumenHaus & Canopea \\
\hline Tipología & Vivienda individual & Vivienda en altura \\
\hline Sistema & Construcción Modular Ligera 3D & Construcción Modular Ligera 2D \\
\hline Nivel producción/comercializ & Prototipo & Prototipo \\
\hline
\end{tabular}

Tabla 07 Datos de emplazamiento, tipología de edificación y de solución prefabricada. Elaboración propia.

\section{Superficies y sistemas constructivos. Lumenhaus 2010 y Canopea 2012.}

La tipología edificatoria en ambos casos es la de vivienda, pero en un caso individual (LumenHaus) y la otra en altura (Canopea). La composición de los cerramientos, en ambos casos ligeros, de los prototipos ganadores, queda definida de la siguiente tabla, así como las superficies a acondicionar. 


\begin{tabular}{|l|r|r|}
\hline \multicolumn{3}{|c|}{ CONSTRUCCIÓN } \\
\hline Variables & LumenHaus & Canopea \\
\hline Superficie a Acondicionar & 52,80 & 68,80 \\
\hline Superficie Construida & 74,00 & 195,90 \\
\hline Sistemas Constructivos & Acero & Combinación Acero/Madera \\
\hline Material/Sistema Muros & SIP y Vidrio & Vidrio y Panel tipo SIP \\
\hline Material/ Sistema Cubierta & SIP & Madera y Paneles FV \\
\hline Material Suelos & Hormigón & Madera \\
\hline
\end{tabular}

Tabla 08. Superficies y sistemas constructivos prototipos ganadores SD10 y SD12. Elaboración propia.

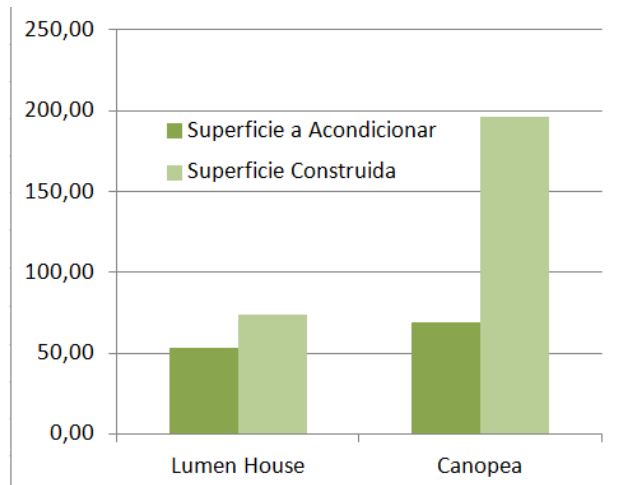

Fig. 27. Gráfico de superficies prototipos ganadores SD10 y SD12. Elaboración propia.

Costes de producción. Lumenhaus 2010 y Canopea 2012.

El coste de industrialización del prototipo de la LumenHaus (para su producción en serie) sería de unos 233 mil euros, lo que supondría un $23 \%$ menos del valor del prototipo para el concurso. En el caso de la vivienda Canopea determinar su valor conllevaría otros factores de ponderación más complicada dado que el proyecto en sí es la última planta de una vivienda en bloque. La inversión realizada por el equipo Canopea fue de unos 700 mil euros, estimando que para su producción en serie solo haría falta una inversión equivalente al $2 \%$ de esta cifra.

Valores de transmitancias U. Prestaciones cerramientos. Lumenhaus 2010 y Canopea 2012.

Los valores de transmitancia de los cerramientos de la LumenHaus y la Canopea, igual que el resto de documentación de los demás prototipos y en comparación con lo establecido en el CTE son los siguientes:

\begin{tabular}{|l|r|r|r|}
\hline \multicolumn{4}{|c|}{ PRESTACIONES ENERGÉTICAS CERRAMIENTOS U = Wm2K } \\
\hline Variables & LumenHaus & Canopea & CTE Zona D3 \\
\hline Muros & 0,021 & 0,08 & 0,66 \\
\hline Cubierta & 0,148 & 0,07 & 0,38 \\
\hline Suelo & 0,221 & 0,08 & 0,49 \\
\hline Superficie vidrio & 1,033 & 0,5 & 1,9 \\
\hline
\end{tabular}

Tabla 09. Transmitancias térmicas prototipos ganadores SD10 y SD12. Elaboración propia 
CTE. Uh $=1.90 \mathrm{~W} / \mathrm{m} 2 \mathrm{~K}$

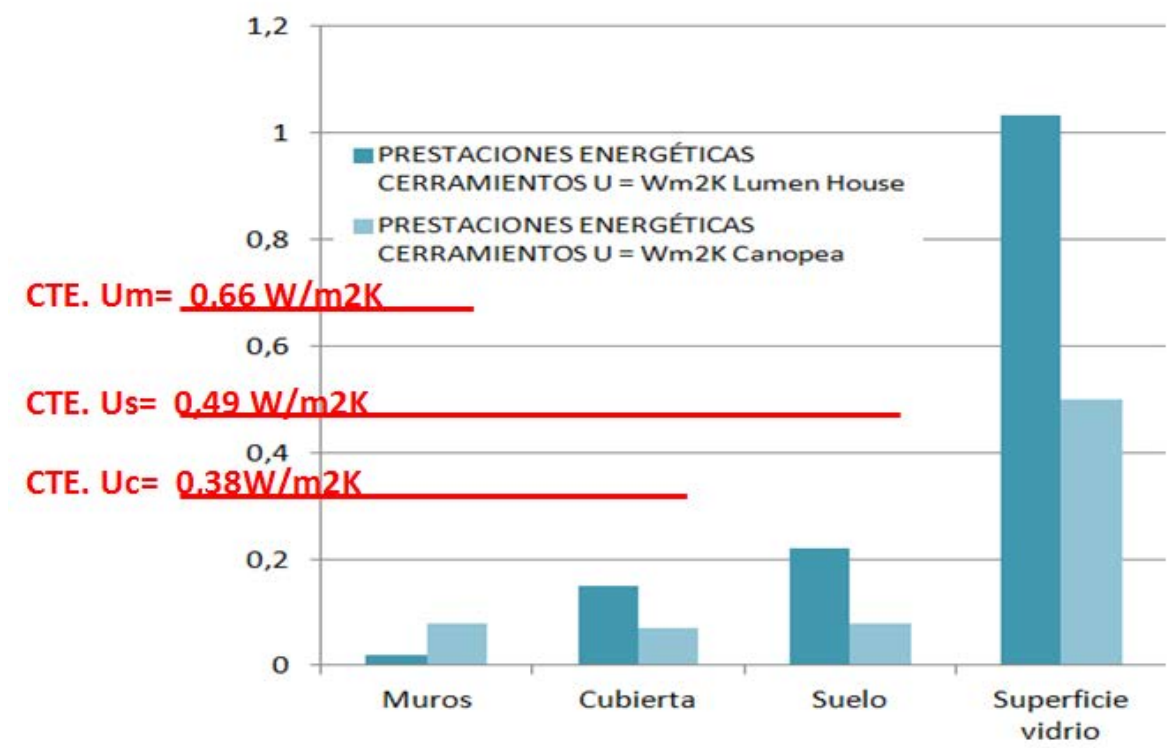

Fig. 28. Transmitancias térmicas prototipos ganadores SD10 y SD12. Elaboración propia.
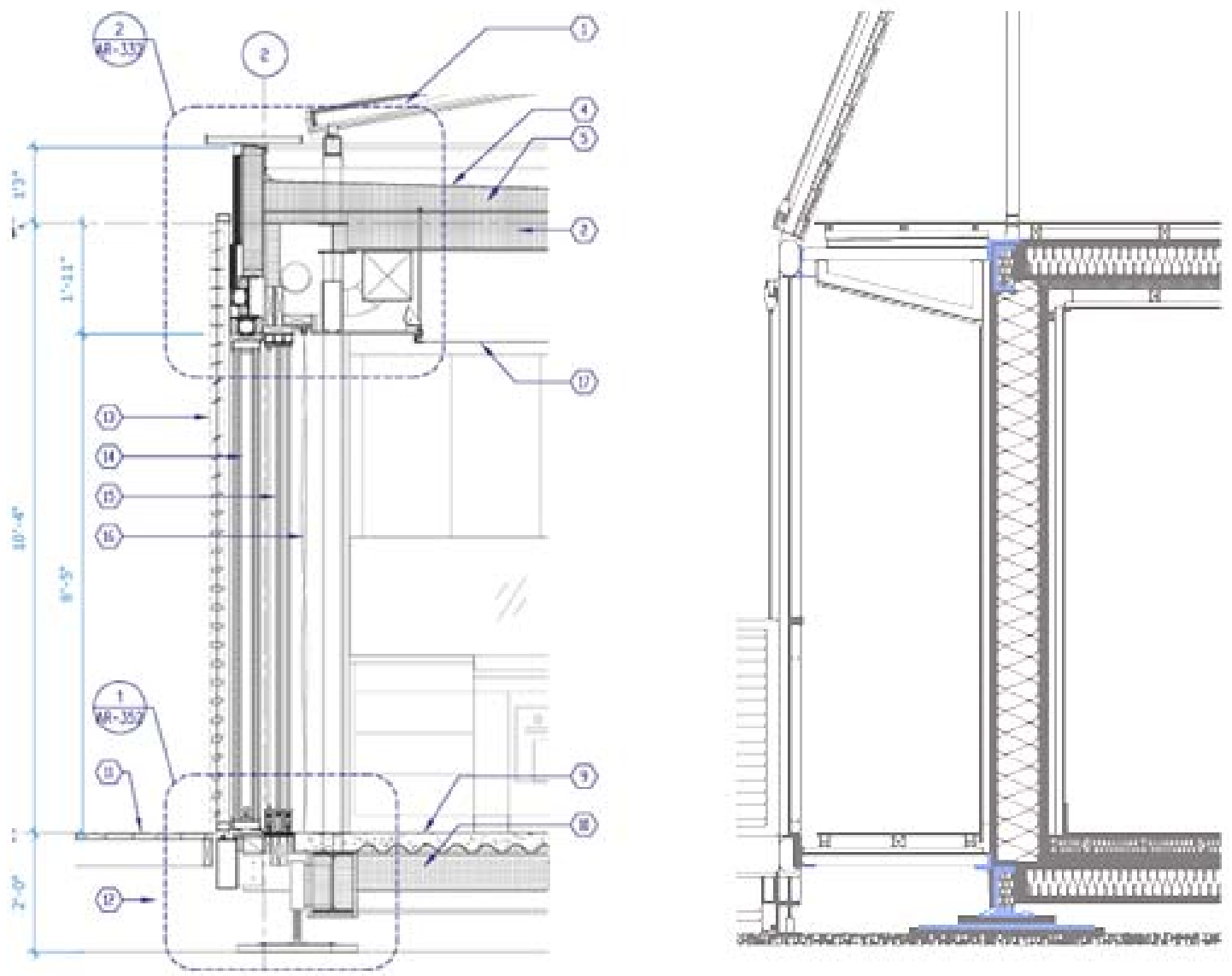

Fig. 29. Sección tipo LumenHaus (izq.) Sección tipo Canopea (Der). (www.lumenhaus.com) Consulta 2014 (Vega \& Serra; 2013). 
Niveles de demanda y producción (kWh m²). Lumenhaus 2010 y Canopea 2012.

La demanda energética de las viviendas ganadoras igual que las demás participantes del SD10 y SD12, resultan inferiores a la demanda máxima establecida para viviendas en la zona climática D3 que es la que corresponde a Madrid, lugar de emplazamiento de las casas en ambas ediciones.

En el siguiente gráfico se muestra la producción de energía frente al consumo/demanda y el vertido a la red:

\begin{tabular}{|l|r|r|}
\hline \multicolumn{3}{|c|}{ ENERGÍA } \\
\hline Variable & LumenHaus & Canopea \\
\hline Energía Producida Kwh/a & $17.813,20$ & 12.733 \\
\hline Energía Demandada Kwh/a & 8.395 & 7.023 \\
\hline Disponible para la RED Kwh/a & $9.418,20$ & 5.710 \\
\hline Ratio Producción/Consumo & 2,13 & 1,81 \\
\hline Consumo KWh/m2 & 159,00 & 86,7 \\
\hline
\end{tabular}

Tabla 10. Energía producida, demandada y consumida por los prototipos LumenHaus y Canopea Elaboración propia.

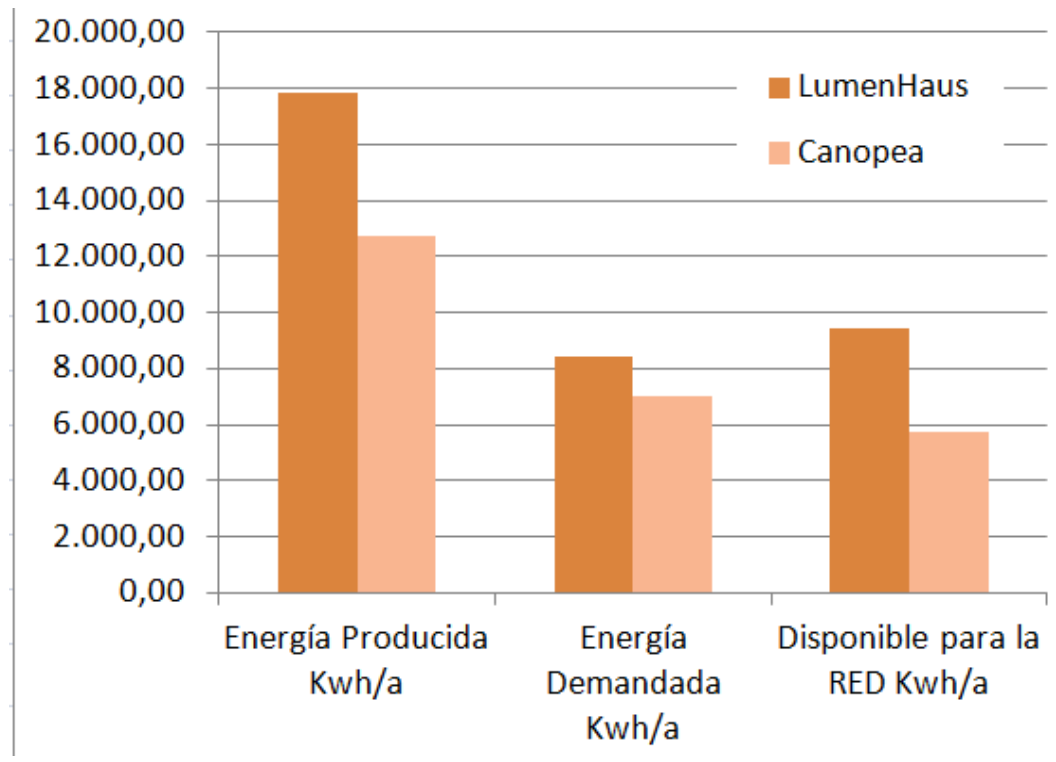

Fig30. Energía producida, demandada y consumida por los prototipos LumenHaus y Canopea Elaboración propia.

La generación de energía tanto de la LumenHaus como de la Canopea depende de la instalación fotovoltaica con la que cuentan y los consumos de cada prototipo quedan establecidos de la siguiente manera: 


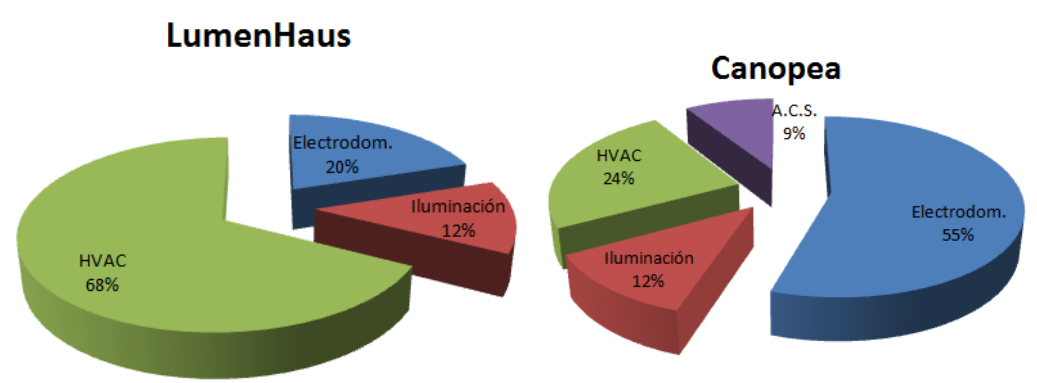

Fig. 31 Elaboración propia

A continuación se realiza una relación de soluciones tanto activas como pasivas implementadas en ambos proyectos. La combinación de este tipo de estrategias ha resultado ser una constante en los concursos del Solar Decathlon.

Dada la propia naturaleza del concurso el sistema de generación de energía es la solar fotovoltaica, pero es de resaltar la implementación de medidas combinadas, es decir que aprovechan activamente recursos mecanizando, en muchos casos, algunos de sus elementos para optimizar ese aprovechamiento.

\begin{tabular}{|l|l|l|}
\hline \multicolumn{3}{|c|}{ ESTRATEGIAS PASIVAS } \\
\hline Variables & LumenHaus & Canopea \\
\hline Captación Directa & & \\
\hline Ventilación Cruzada & & \\
\hline Efecto Invernadero & & \\
\hline Fachada Ventilada & & \\
\hline Protección Solar fachadas & & \\
\hline Vidrio de Altas Prestaciones & & \\
\hline Efecto Ventury & & \\
\hline Patio/Jardín & & \\
\hline Captación Agua de Lluvia & & \\
\hline Techo Verde & & \\
\hline Vegetación & & \\
\hline \multicolumn{2}{|c|}{ ESTRATEGIAS ACTIVAS } \\
\hline \multicolumn{2}{|c|}{ Canopea } \\
\hline Variables & LumenHaus & Canopea \\
\hline Protección solar móvil & LumenHaus & \\
\hline Enfriamiento Evaporativo & & \\
\hline Ventilación (Inter. Temp.PCM) & & \\
\hline Intercambiador de calor geoterm. & & \\
\hline Tratamiento Aguas Grises & & \\
\hline Sistema Hidropónico en red & & \\
\hline Desface nocturno de temperatura & & \\
\hline Superficie Radiante & & \\
\hline \multicolumn{2}{|c|}{ COMBINADAS } \\
\hline Variables & & \\
\hline FV & & \\
\hline Solar térmica & \\
\hline Hibrido FV y Solar térmica & \\
\hline Sistema Geotérmico Combinado & \\
\hline Eólica & & \\
\hline Bomba de calor de alta eficiencia & & \\
\hline \hline
\end{tabular}

Tabla 11. Energía producida, demandada y consumida por los prototipos LumenHaus y Canopea Elaboración propia. 


\subsection{ANÁLISIS Y DISCUSIÓN DE RESULTADOS DE LA METODOLOGÍA EMPÍRICA O EXPERIMENTAL.}

Con las pruebas experimentales, explicadas en la parte de la Metodología y en este epígrafe, se han podido comprobar y establecer los datos de temperaturas, (interiores y exteriores), humedades y consumos tanto del Taller como de la células de ensayo.

\section{Datos recogidos en Taller}

El Taller que cuenta con sistema de climatización de bomba de calor, tiene además, unos calentadores eléctricos como apoyo para la calefacción. Cada uno de ellos tiene una potencia de $600 \mathrm{~kW}$ nominales, pero habiéndolos comprobado con un medidor de potencias la misma oscilada entre los 670 y $675 \mathrm{~kW}$.

Para realizar los ensayos de temperaturas internas y externas y poder constatar in situ, el nivel de protección térmica con que cuenta esta construcción ligera industrializada, en lugar de utilizar las bombas de calor para la calefacción del local, se han utilizado estos calentadores eléctricos. Esto es así para tener una medición más focalizada hacia el consumo de unos elementos (los calentadores), cuyo rendimiento fuera 1 a 1, es decir 1 kW de consumo por 1 kW de calefacción.

En el caso de las bombas de calor, el COP (ratio de ahorro energético para calefacción) es de 3,61, cada una, o lo que es lo mismo, cuando una de las bombas de calor consume $1 \mathrm{~kW}$ de energía, devuelve $3,61 \mathrm{~kW}$ de unidades de calor al ambiente interior.

El Taller cuenta con unos estores de protección, dispuestos para su uso diurno y que evitan el deslumbramiento interior. Estos estores, de material sintético, opacos y de color blanco, protegen del exceso de luz en el espacio de trabajo del Taller.

La utilización nocturna de los mismos no es habitual dentro del régimen de uso del Taller, pero es de conocimiento, a nivel de cultura general, que pueden generar un efecto invernadero interior al ser utilizados de noche, sin la radiación solar exterior y con una fuente de calor interior, impidiendo que la energía calorífica se pierda por los acristalamientos.

Para cuantificar esto se realizaron mediciones en dos días consecutivos en horario nocturno, es decir desde las 21:00 hasta las 9:00. Los días seleccionados fueron en condiciones de primavera.

El primer ciclo de ensayo fue realizado con protecciones interiores en $45 \%$ de los acristalamientos, estores de suelo a techo el 21 de abril de 2014, y en el otro ciclo de ensayo sin estores fue realizado el día 22 de abril de 2015. 
Con esto se pudo comprobar que entre el ciclo con protección interior ligera (estores) y el ciclo sin protección, se produjo una diferencia de temperatura con el exterior de hasta $1,24^{\circ}$.

Esto quiere decir que en el período de medición con protección al 45\% se registró una diferencia de temperaturas del orden de $7,74{ }^{\circ} \mathrm{C}$, contando con un sistema de calefacción interior (calentadores eléctricos) con un consumo de unos $1.340 \mathrm{Wh}$ aproximadamente. En el período de medición sin protección la diferencia de temperatura entre el interior y el exterior fue de $6,50^{\circ} \mathrm{C}$, utilizando el mismo sistema de calefacción.

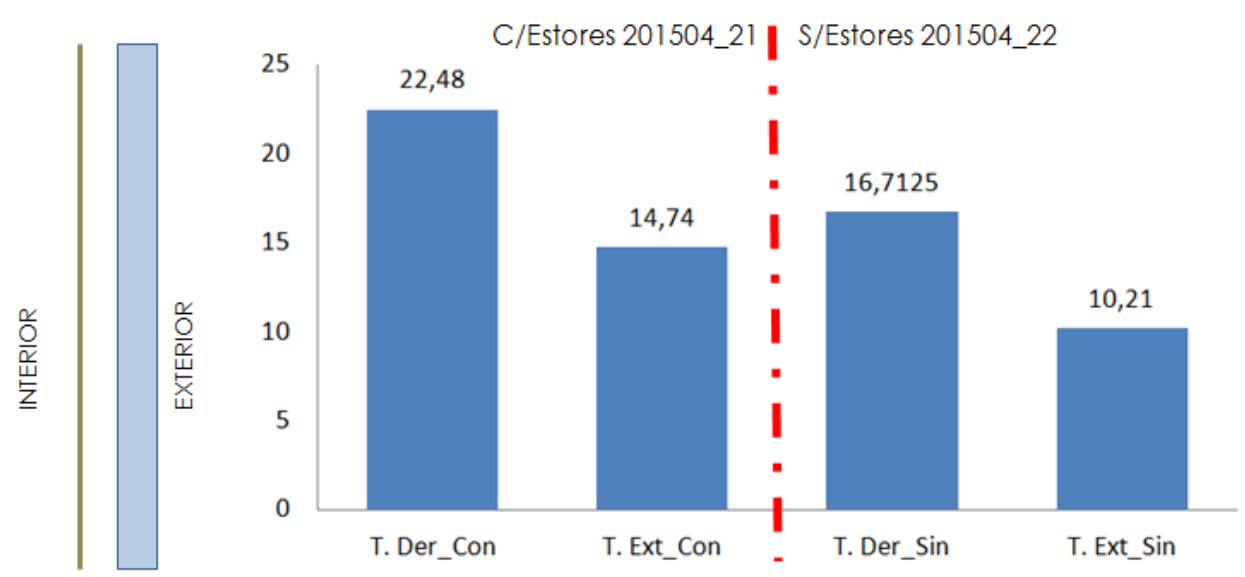

Diferencia entre mediciones con protección solar y sin protección en acristalamientos

Fig. 32

En la figura anterior se pueden ver las barras comparativas de temperaturas interior/ exterior "Con" estores (T.Der_Con y T. Ext_Con) y a la izquierda la misma comparativa "Sin" estores (T. Der_Sin y T.Ext_Sin). A la derecha del todo una representación del estor colocado junto al vidrio y con cámara de aire intermedia.

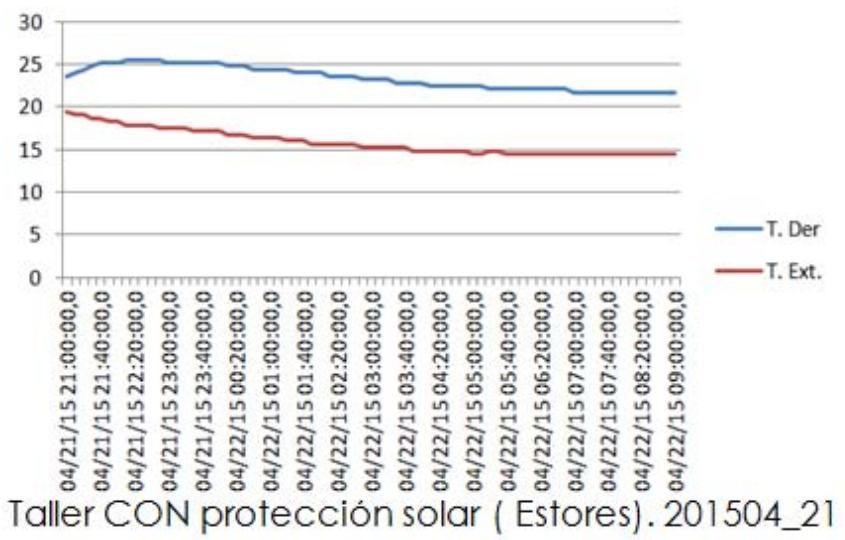

Fig. 33. Gráfico temperatura horarias períodos de mediciones con y sin estores. 


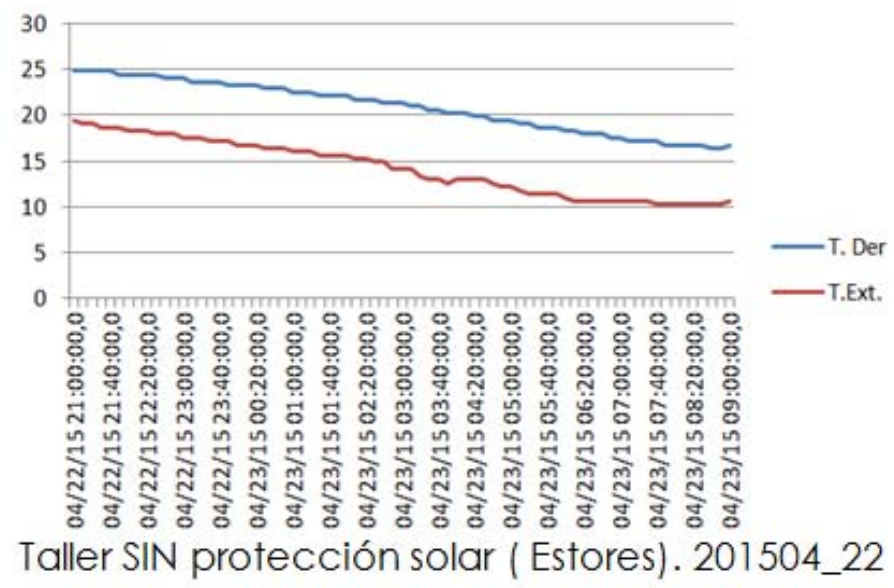

Fig 34. Gráfico temperaturas horarias períodos de mediciones con y sin estores.

Partiendo del hecho de que sólo con el $45 \%$ de protección interior de los acristalamientos ha sido posible reducir las pérdidas de temperaturas en $1,24{ }^{\circ} \mathrm{C}$ con una protección del $100 \%$ sería posible reducir las pérdidas de temperatura en un $2,75^{\circ} \mathrm{C}$, con el consiguiente ahorro energético que esto supone.

Para confirmar datos en cuanto a la diferencia entre temperaturas interiores y exteriores se realizó otro ciclo de ensayos de dos períodos consecutivos en el taller los días 28 y 29 de abril de 2015.

Con esto se confirmó que la media de diferencia entre el interior y el exterior podía variar según el lugar de ubicación de los medidores siendo la temperatura de las mesas de trabajo la media entre la temperatura del techo y la temperatura junto a los cerramientos. Esta conclusión obvia ha servido para confirmar no sólo que la temperatura interior está estratificada por altura y ubicación, sino también ha servido para confirmar que la mejor zona para realizar las mediciones anteriores había sido la altura $0,75 \mathrm{~m}$, en la zona de las mesas de trabajo centrales.

Con las mediciones en el taller y con la malla tipo Ferrari colocada solo a norte y a oeste no fue posible determinar la incidencia de la misma sobre el comportamiento térmico del Taller.

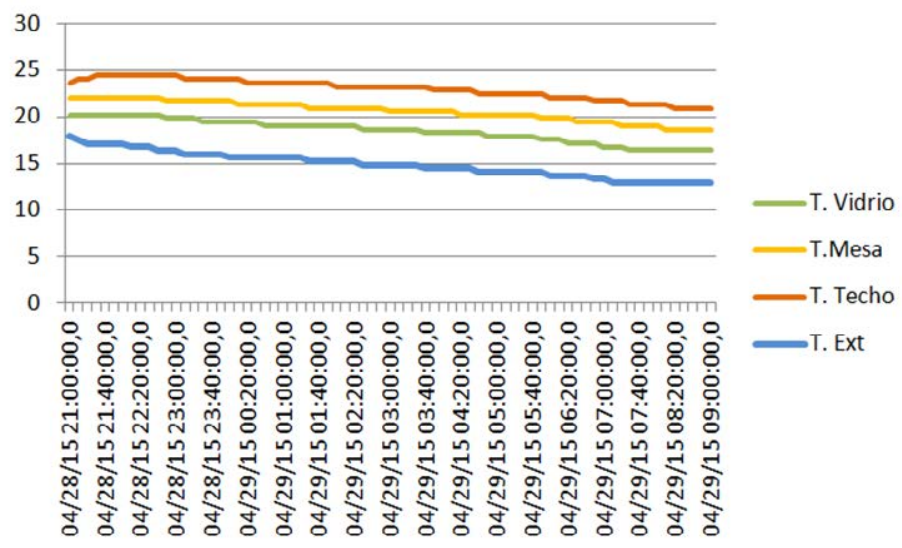

Fig. 35 Diferencia de temperaturas interiores y exteriores Taller. 201504_28/29 


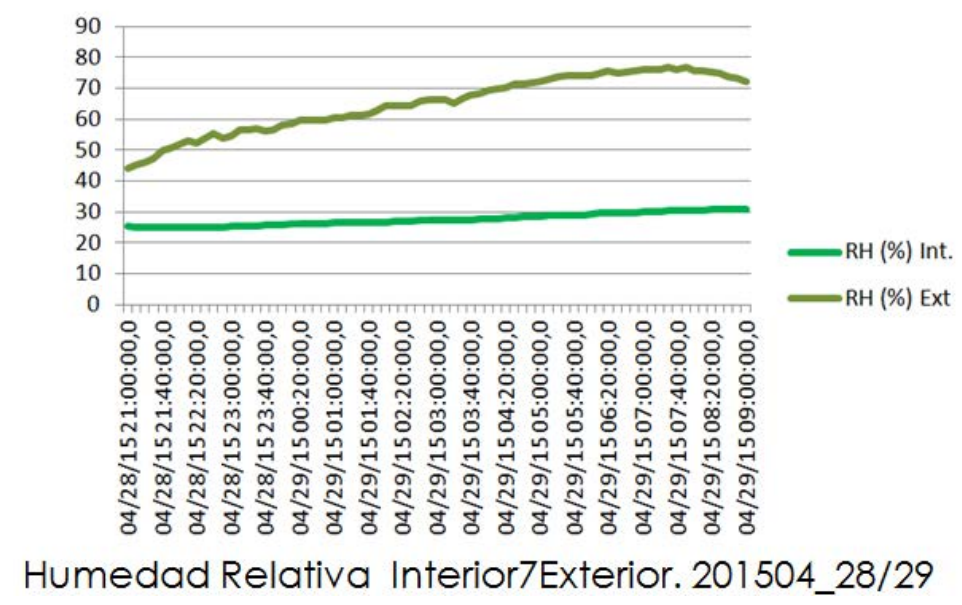

Fig. 36. Gráficos temperaturas y humedades horarias períodos de mediciones en condiciones normales (sin estores).

Datos recogidos con las células de ensayos.

Para poder determinar de una manera cuantificable las posibles características de la Malla micro-perforada Serge Ferrari, Soltis FT 381 (o similar) y confirmar o no si su utilización podría llegar a modificar las temperaturas interiores de algún espacio, se realizaron 6 ciclos de ensayos de 12 horas cada uno, utilizando las cámaras o células de ensayos (en la cubierta de la escuela), que sí permitían colocar la malla a sur para confirmar su comportamiento frente a la radiación solar en esta orientación.

Fue colocada una muestra de la malla, con dimensiones de $60 \times 60 \mathrm{~cm}$, en la cara acristalada de una de las cajas (a modo de protección), dejando la otra sin malla. En ambos casos se colocó una sonda eléctrica con potencia de 20 kW para calefacción.

La diferencia tanto en mediciones diurnas como nocturnas fue clara entre una caja y otra.

La caja con malla perdía menos calor por la noche que la caja sin malla, con una diferencia por el orden de los $4^{\circ} \mathrm{C}$ de media.

La caja sin malla, además se sobrecalentaba unos más $26^{\circ} \mathrm{C}$ más, al combinarse el efecto de captación solar pasiva con la generación interior de calor de la sonda.

Esto confirmó que la malla, un elemento ligero de protección exterior, impide la pérdida de calor de las superficies acristaladas.

En el siguiente gráfico se puede ver la relación entre las cajas con y sin malla. Las fechas de medición seleccionadas para estas pruebas fueron entre del 27 de febrero y el 3 de marzo de 2015. 


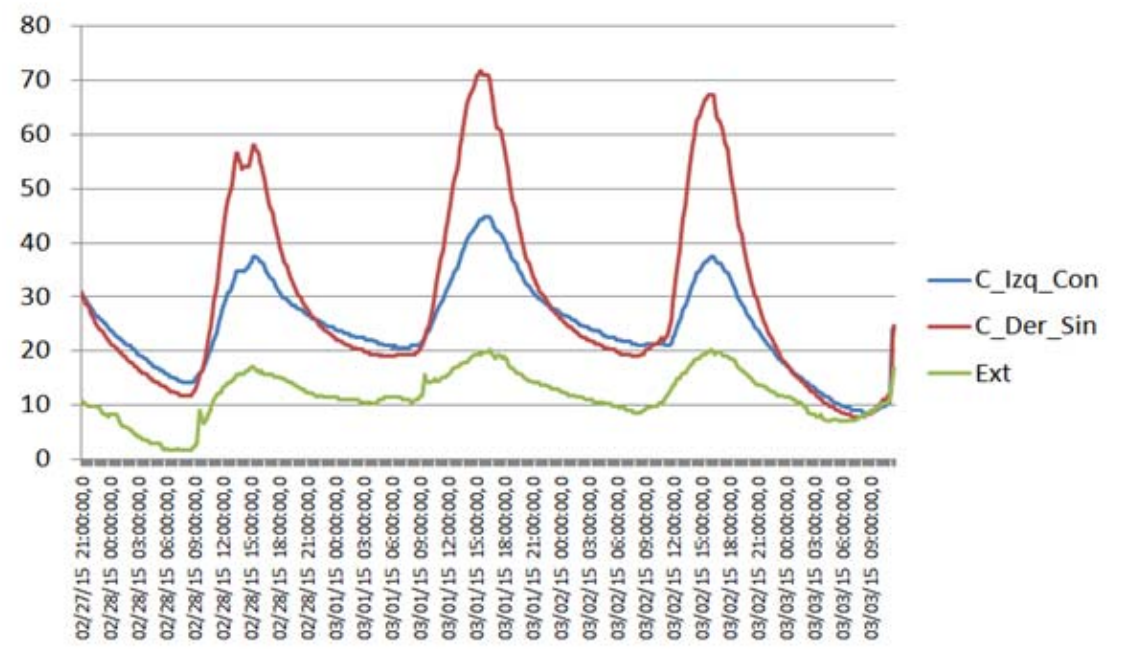

Cajas Derecha e izquierda con textil y calefacción 2015_02/27_03/03

Fig. 37. Gráficos temperaturas y horarios en caja con malla de protección y caja sin malla de protección.

\subsection{ANÁLISIS DISCUSIÓN DE RESULTADOS METODOLOGÍA DE SIMULACIONES}

Mediante la Metodología de Simulaciones y el análisis de sus resultados se ha podido determinar el nivel de eficiencia energética del Taller de Prototipos de la ETSAM, (modificado en su tamaño hasta una superficie de unos $52 \mathrm{~m}^{2}$ aproximadamente y con uso característico de vivienda), situando el mismo en diferentes escenarios climáticos de acuerdo al Mapa de Koppen (Bsh, BSk, BWk,BWh Csa, Csb, Cfb, Dsb, e incluso Am y Aw), adaptando el mismo a las zonas climáticas de españolas según el CTE.

En primer lugar se han obtenido los resultados de consumo energético (energía eléctrica), tanto para calefacción como para refrigeración (mediante el $\mathrm{CE}^{3} \mathrm{X}$ ) y de acuerdo a los requerimientos por zonas. El consumo de ACS (obtenido mediante $\mathrm{CE}^{3} \mathrm{X}$ también), se incluye en la parte del consumo global, asumiendo como combustible también la electricidad. El programa condiciona su funcionamiento a la implementación de A.C.S. También, con la herramienta on line de hmsistemas (www.hmsistemas.es), se han obtenido los consumos de los posibles equipos y electrodomésticos de uso en la vivienda (Taller-Vivienda modificada a $52 \mathrm{~m}^{2}$ ).

Luego, el procedimiento ha consistido en implementar las medidas de mejoras, descritas más adelante y comprobar el nivel de eficiencia, desde la medida más simple, como solo FV 100\%, o geotermia solamente, hasta la más compleja como geotermia + vidrios activos + mejoras de cerramientos, de acuerdo al clima; y comprobar con cuales medidas el Taller-Vivienda puede alcanzar los mejores niveles de cara al nZEB e incluso al NZEB. Para definir el nivel de nZEB se ha tomado como referencia el estándar PassivHaus en el cual se establecen $15 \mathrm{kWh} \mathrm{m}^{2}$ para calefacción y $15 \mathrm{kWh} \mathrm{m} \mathrm{m}^{2}$ para refrigeración, o $120 \mathrm{kWh} / \mathrm{m}^{2}$ año totales. 
En el caso del cálculo de la potencia fotovoltaica necesaria se ha utilizado las herramienta on line PVGIS (Photovoltaic Geographical Information System European Commission, Joint Research Center), para el cálculo del rendimiento de la instalación. Estos datos de generación se introducen en el $C^{3} X$ como "Incorporación/mejora de sistema fotovoltaico" (como primera medida de mejora) y aunque en la parte de "Generación de electricidad mediante renovables/cogeneración" se debe introducir una cifra en concepto de autoconsumo, como en efecto se ha hecho, para que el programa informático pueda hacer sus cálculos internos, esto no resulta de relevancia para la tesis, más allá de utilizar el dato para obtener la calificación energética por la mejora implementada.

La introducción de los datos concernientes al sistema geotérmico, obtenidos tal como se explica en la Metodología se simulaciones, se hace modificando los valores del rendimiento medio estacional de las bombas de calor, así como el dato de la $U$ del vidrio existente $\left(5,7 \mathrm{~W} / \mathrm{m}^{2} \mathrm{k}\right)$ por la del vidrio activo con circulación interior de agua $\left(1.123 \mathrm{~W} / \mathrm{m}^{2} \mathrm{k}\right)$. También se selecciona, en "Medidas de mejoras de las contribuciones energéticas", la opción de "Fuentes de energía renovable" al 100\% tanto el calefacción como en refrigeración.

Utilizando el Mapa Koppen como guía climática mundial, se equiparan los climas representados en este mapa a nivel global, representados por un código de colores, con los climas que se registran en España, representados con este mismo código de colores, extrapolándolos con las clasificaciones climáticas por zonas del apéndice $B$ del CTE DB-HE1.

El orden para establecer un análisis de los resultados obtenidos ha sido el siguiente, de acuerdo al nivel de mejoras y a la zona climática:

1. Resultado del cálculo de consumo energético del Taller-Vivienda de acuerdo a los resultados obtenidos en el $\mathrm{CE}^{3} \mathrm{X}$.

2. Definición de las zonas climáticas (Koppen/CTE equiparadas) en las que el prototipo (Taller-Vivienda $52 \mathrm{~m}^{2}$ ) en su estado actual, puede ser energéticamente eficiente de cara al NZEB o nZEB.

3. Definición de las zonas climáticas (Koppen/CTE equiparadas) en las cuales el Taller-Vivienda puede alcanzar un nZEB o NZEB, con implementación de FV $100 \%$, integrada en su cubierta y con mínima afección visual del edificio.

4. Definición de las zonas climáticas (Koppen/CTE equiparadas) en las cuales el Taller-Vivienda puede alcanzar un nZEB o NZEB, con implementación de bombas de calor geotérmicas (tierra/agua) de alto COP y EER integradas a un sistema de acristalamientos activos. 
5. Definición de las zonas climáticas (Koppen/CTE equiparadas) en las cuales el Taller-Vivienda puede alcanzar un nZEB o NZEB, con implementación de bombas de calor geotérmicas de alto COP y EER + vidrio activo+ mejora constructiva de los cerramientos.

A partir de estos supuestos se consiguen determinar las posibles opciones para un nZEB o NZEB de un prototipo de CML en diferentes zonas climáticas tal como se presentan a continuación. Antes se obtienen los datos de consumo energético por zona climática en el territorio de España.

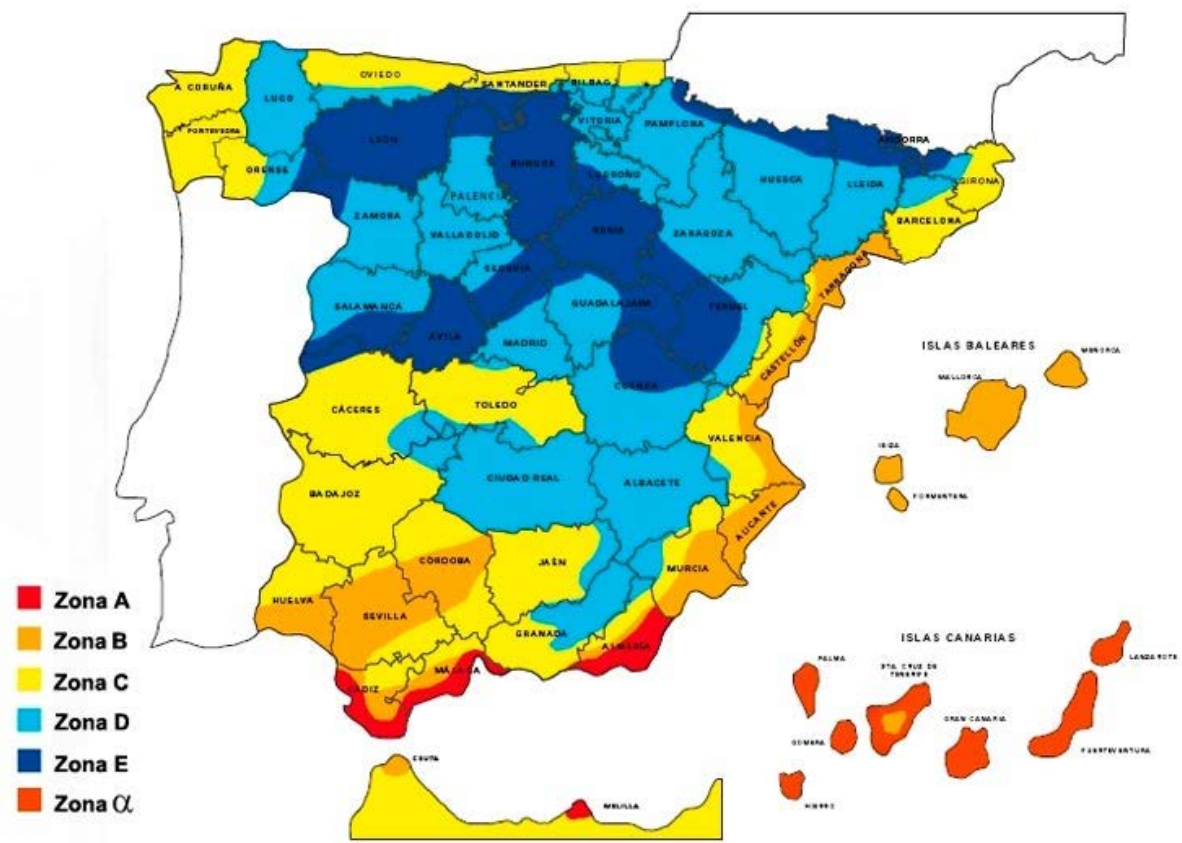

Fig. 38 Mapa zonas climáticas según CTE DB HE (www.aislaconpoliuretano.com. 2015)

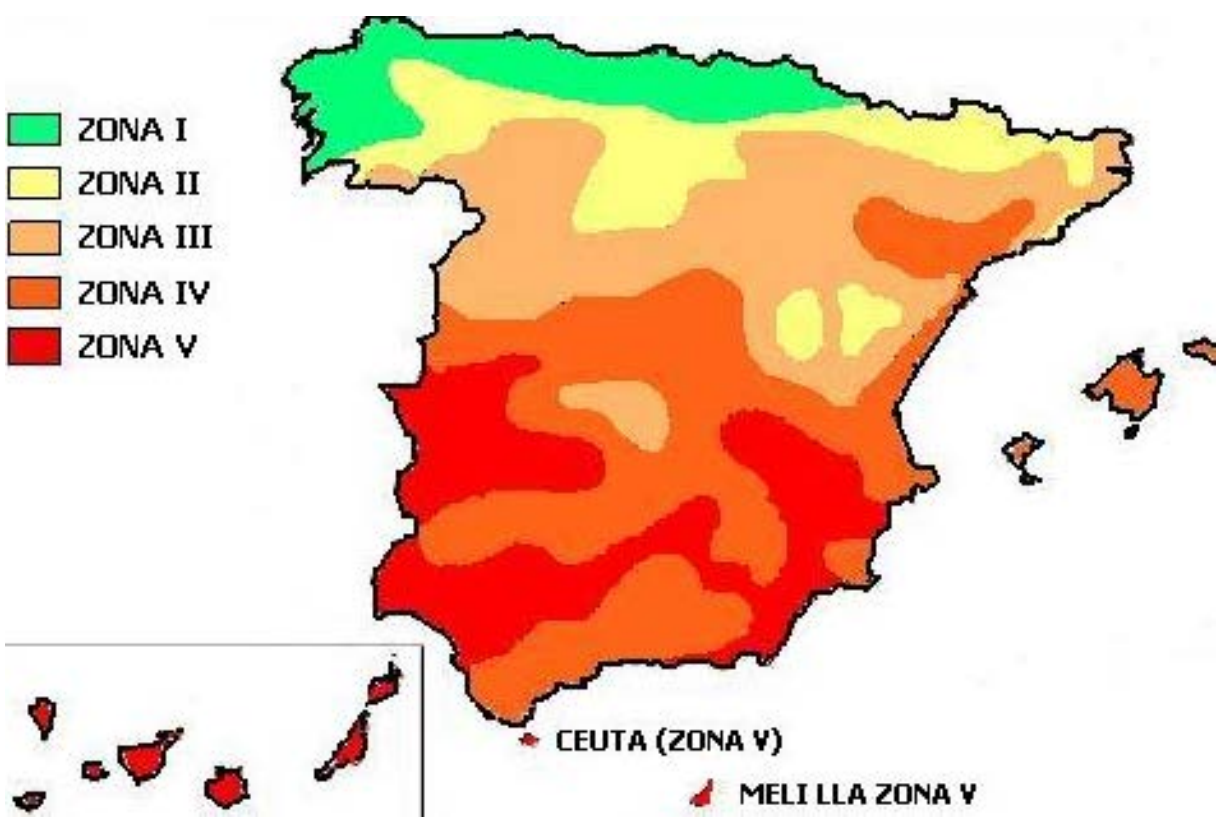

Fig. 39 Mapa zonas climáticas para producción FV según CTE DB HE 5 (www.sitiosolar.com. 2015) 


\subsubsection{Cálculos de consumo y de los sistemas de generación fotovoltaica (FV) por zonas climáticas Koppen/CTE para el Taller-Vivienda $52 \mathrm{~m}^{2}$.}

Los módulos fotovoltaicos seleccionados han sido de la marca Siliken S.L - SLK48P6L con 48 células de silicio policristalino, con dimensiones aproximadas de 1,32 x 0,99 m y una potencia pico de $190 \mathrm{Wp}$. Siendo la superficie de cubierta de $52 \mathrm{~m}^{2}$, se estaría hablando de 32 módulos en total para cubrir el 100\% de la superficie (y dejar espacio para la circulación y mantenimiento), lo que supondría una potencia pico nominal del orden de los $6.080 \mathrm{Wp}$. Este es un valor constante, que se repite para todas las proyecciones de instalaciones en este trabajo.

\section{Zona Climática BWk, BWh, A (Koppen) / a3 (CTE). Santa Cruz de Tenerife}

Originalmente, al momento de la puesta en funcionamiento del $\mathrm{CE}^{3} \mathrm{X}$, como herramienta para la certificación energética de edificios existentes en España, la zona climática de las Islas Canarias no estaba del todo bien definida. Se le asimilaba con un clima parecido a las zonas costeras de Andalucía. Luego esta definición, con la entrada en vigor de las modificaciones al DB HE del CTE, se mejoró en función de las verdaderas condiciones climáticas de esta zona. La calificación energética, para las Islas Canarias y mediante el $\mathrm{CE}^{3} \mathrm{X}$, sigue estando definida con limitaciones, aunque en la versión 2.1 del programa se reconoce mejor esta zona climática que con las versiones anteriores. En cualquier caso, las calificaciones parciales, tanto de $\mathrm{CO}^{2}$ como de $\mathrm{kWh} / \mathrm{m} 2$ año para las instalaciones, siguen siendo imprecisas en cuanto a sus resultados, por tomar en consideración valores de calefacción y ACS que no proceden.

En el caso de la calificación de Koppen y los estudios realizados recientemente por Peel (Peel, et al; 2007), existe cierta coincidencia con las definiciones con las que trabaja el programa, partiendo de un clima parecido al de Almería (zona A3/CTE) pero con la variación de que considera el clima de las islas como una combinación, hasta cierto punto complementaria de los climas BWh (árido cálido) y tipo A (tipo tropical). Esta combinación refleja las condiciones reales de acuerdo al tipo de vegetación de la zona y recrea de manera más o menos precisa las condiciones reales contando con el $100 \%$ de humedad propia de las islas.

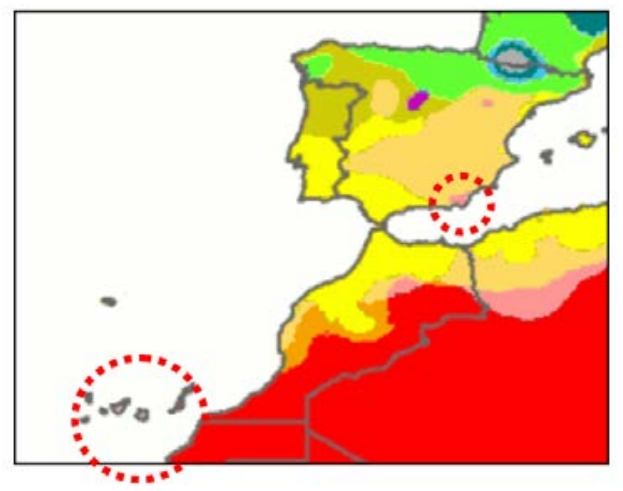

Fig. 40. Mapa Koppen España, Santa Cruz de Tenerife y Almería. (Peel et al. 2007). 
Por otro lado y por la imposibilidad de calcular la radiación con la herramienta "Photovoltaic Geographical Information System", promovida por la Comisión Europea, por estar diseñada para el ámbito Europeo; se ha utilizado en su lugar, para el realizar este cálculo, la herramienta web Onyx Solar, empresa norteamericana reconocida en el sector y ganadora del 1er. Premio sobre viabilidad industrial y de mercado dentro del concurso Solar Decathlon 2010, integrando el equipo SML House de la Universidad CEU-Cardenal Herrera.

Esta herramienta ha sido validada para esta tesis, comparando los resultados obtenidos para las otras zonas climáticas, con la herramienta homologada de la Comisión Europea (Photovoltaic Geographical Information System) y confirmando la coincidencia de sus datos $\pm 97 \%$.

\section{Datos obtenidos mediante $\mathrm{CE}^{3} \mathrm{X}$ :}

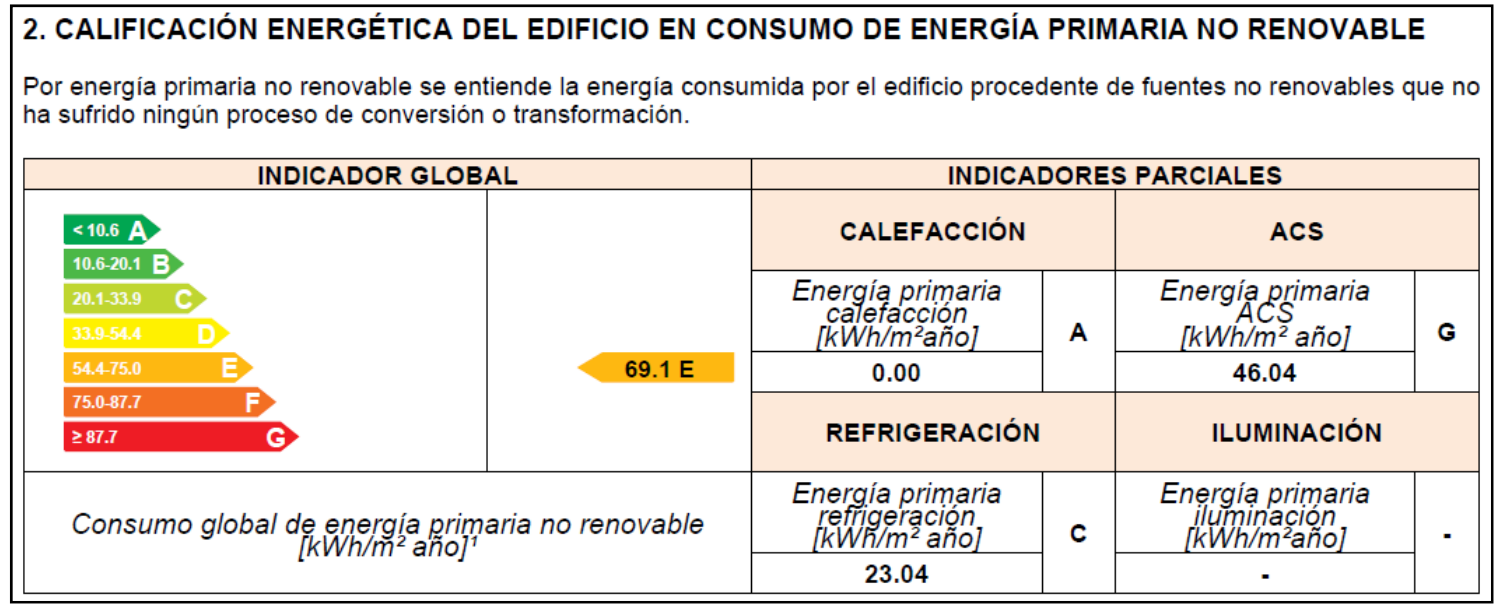

Fig. 41. Resultado consumos edificio objeto. Santa Cruz De Tenerife

El consumo energético calculado para el caso de Santa Cruz de Tenerife ha sido $4.940 \mathrm{Wh}$, calculados con la herramienta hmsistemas (www.hmsistemas.es. 2015) y tomando como datos válidos, los obtenidos en la certificación energética.

Cálculo FV 100\%, zona Climática BWk, BWh, A (Koppen) / a3 (CTE). Santa Cruz de Tenerife.

Se estima como rendimiento óptimo de la instalación fotovoltaica un 0,75 del cálculo original para cubrir las necesidades energéticas. Esto así de los $4.940 \mathrm{Wh}$ obtenidos mediante los cálculos de consumo se realiza la siguiente operación: 4.940 10,75= 6.586 Wh/día. Las horas sol pico, multiplicadas por $1 \mathrm{kWh} / \mathrm{m} 2$ son $1,88 \mathrm{HSP}$, en función del mes de diciembre. Para obtener el número de módulos se hace la siguiente operación: $6.586 \mathrm{Wh} /$ día / 1,88 HSP x 0,8 x $190 \mathrm{Wp}=24$ módulos. En función del tipo de módulo seleccionado, la instalación para el Taller-Vivienda de $52 \mathrm{~m}^{2}$ tendría que ser como mínimo de $4.560 \mathrm{Wp}$. Con la misma herramienta de Onyx (www.onyxsolar.com), se ha podido determinar que a partir de los datos de la siguiente tabla el ahorro en $\mathrm{CO}^{2}$ estaría por el orden de los $5.900 \mathrm{~kg}$ al año. 


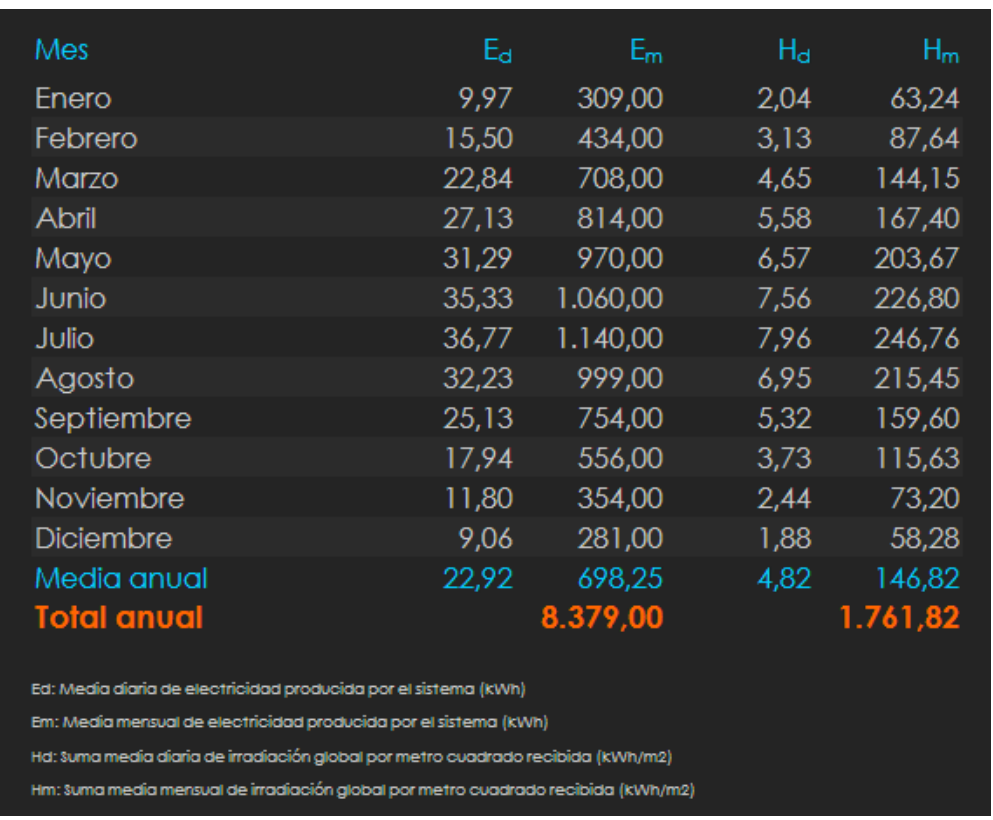

Fig. 42 Estimación de generación fotovoltaica. Santa Cruz de Tenerife. (Onyx Solar). Consulta 2015.

Zona Climática BWk (Koppen)/ A4. (CTE). Almería.

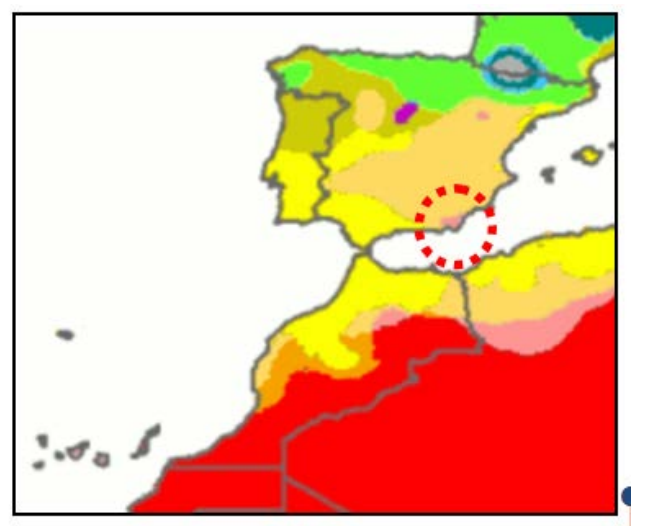

Fig.39 .Mapa Koppen España, Almería (Peel et al. 2007).

Datos obtenidos mediante $\mathrm{CE}^{3} \mathrm{X}$ :

\section{CALIFICACIÓN ENERGÉTICA DEL EDIFICIO EN CONSUMO DE ENERGÍA PRIMARIA NO RENOVABLE}

Por energía primaria no renovable se entiende la energía consumida por el edificio procedente de fuentes no renovables que no ha sufrido ningún proceso de conversión o transformación.

\begin{tabular}{|c|c|c|c|c|c|}
\hline \multicolumn{2}{|c|}{ INDICADOR GLOBAL } & \multicolumn{4}{|c|}{ INDICADORES PARCIALES } \\
\hline \multirow{2}{*}{ 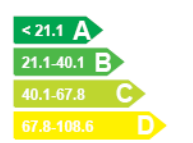 } & \multirow{4}{*}{ 194.3 E } & \multicolumn{2}{|c|}{ CALEFACCIÓN } & \multicolumn{2}{|l|}{ ACS } \\
\hline & & $\begin{array}{l}\text { Energía primaria } \\
\text { calefacción } \\
{\left[\mathrm{kWh} / \mathrm{m}^{2} \text { año] }\right.}\end{array}$ & \multirow[t]{2}{*}{ E } & $\begin{array}{c}\text { Energía primaria } \\
\text { ACS } \\
{\left[\mathrm{kWh} / \mathrm{m}^{2} \text { año] }\right.}\end{array}$ & \multirow[t]{2}{*}{ G } \\
\hline \multirow{2}{*}{\begin{tabular}{|l|l}
$108.6-196.1$ & F \\
$196.1-213.8$ & F \\
2213.8 & C
\end{tabular}} & & 56.56 & & 87.15 & \\
\hline & & \multicolumn{2}{|c|}{ REFRIGERACIÓN } & \multicolumn{2}{|l|}{ ILUMINACIÓN } \\
\hline \multirow{2}{*}{\multicolumn{2}{|c|}{$\begin{array}{c}\text { Consumo global de energía primaria no renovable } \\
\left.\qquad \mathrm{kWh} / \mathrm{m}^{2} \text { año }\right]^{1}\end{array}$}} & $\begin{array}{l}\text { Energía primaria } \\
\text { refrigeración } \\
{\left[\mathrm{kWh} / \mathrm{m}^{2} \text { año] }\right.}\end{array}$ & \multirow[t]{2}{*}{$\mathbf{E}$} & $\begin{array}{l}\text { Energía primaria } \\
\text { iluminación } \\
{\left[\mathrm{kWh} / \mathrm{m}^{2} a \text { año] }\right.}\end{array}$ & \multirow[t]{2}{*}{ - } \\
\hline & & 50.60 & & $\cdot$ & \\
\hline
\end{tabular}

Fig. 43. Resultado consumos edificio objeto. Almería. 
A partir de estos datos de consumo y con el cálculo de otros consumos eléctricos de la vivienda (luminarias y electrodomésticos) se ha determinado que el consumo sería del orden de los 5.799 Wh. En la parte de los anexos (Anexo 5), figuran los consumos de todos los escenarios de mejora planteados de acuerdo a la selección de las zonas climáticas.

Cálculo FV 100\%, zona BWk (Koppen)/ A4. (CTE). Almería.

El cálculo del rendimiento óptimo de la instalación fotovoltaica se ha proyectado para un $75 \%$ de rendimiento real. De este supuesto se parte del siguiente incremento para suplir todas la necesidades de consumo: $5.799 / 0,75=7.732 \mathrm{Wh} /$ día. Estos $5.799 \mathrm{Wh}$ se han calculado con la herramienta hmsistemas (www.hmsistemas.es. 2015). Las horas de sol pico se calcularon a razón de $1 \mathrm{kWh} / \mathrm{m} 2$, por el valor menos favorable de irradiación global diaria, obtenido de la herramienta on line Photovoltaic Geographical Information System, cuyos resultados puntuales se muestran más adelante y cuyos informes, para cada localidad, se han incluido en la parte de los anexos (Anexo 5) que se muestra más adelante, para Almería y que corresponde a $4,43 \mathrm{kWh} / \mathrm{m}^{2}$ día, en el mes de diciembre. Esto ha supuesto que la HSP equivale a 4,43 HSP.

Al realizar el cálculo para determinar el número de módulos, se ha considerado la energía necesaria entre el valor HSP, por el rendimiento de trabajo (considerado en 0,8) y la potencia pico de los módulos seleccionados: 7.732 Wh/día / 4,43 HSP x 0,8 x $190 \mathrm{Wp}=12$ módulos. De acuerdo al módulo seleccionado, la instalación para el Taller-Vivienda de $52 \mathrm{~m}^{2}$ sería de $2.280 \mathrm{Wp}$, pero se proyectará para $6.080 \mathrm{Wp}$.

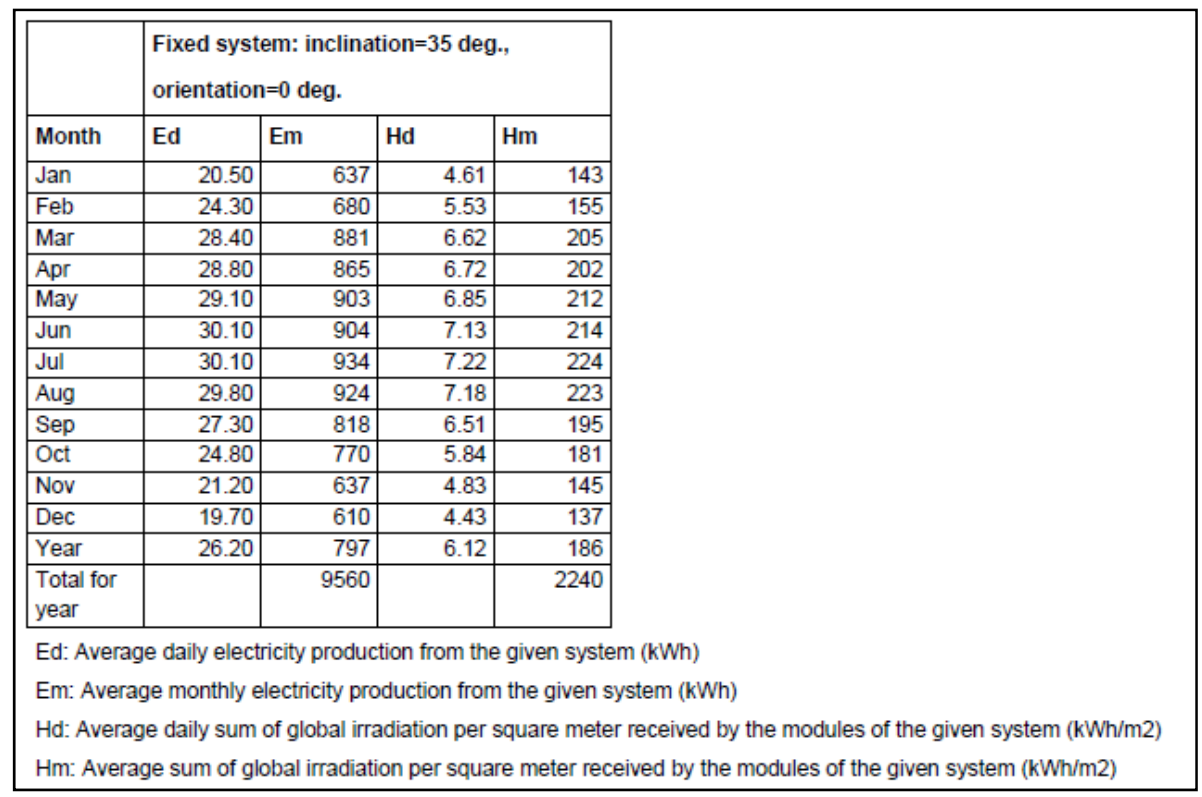

Fig. 44 de generación fotovoltaica. Almería.

(Photovoltaic Geographical Information System). Consulta 2015.

De acuerdo a la herramienta web de Onyx Solar (www.onyxsolar.com), de la compañía Onyx, referente del sector de la fotovoltaica integrada a la edificación y ganadora junto al equipo de la Universidad CEU-Cardenal Herrera Oria, del 1er. Premio sobre 
viabilidad industrial y de mercado dentro del concurso Solar Decathlon 2010, integrando el equipo SML House de la Universidad CEU-Cardenal Herrera; se ha podido determinar que con la integración de FV es posible llegar a ahorrar en emisiones de $\mathrm{CO}^{2} 6,537 \mathrm{Kg}$ en un año, (www.onyxsolar.com).

Zona Climática Csa (Koppen)/ B4 (CTE). Sevilla.

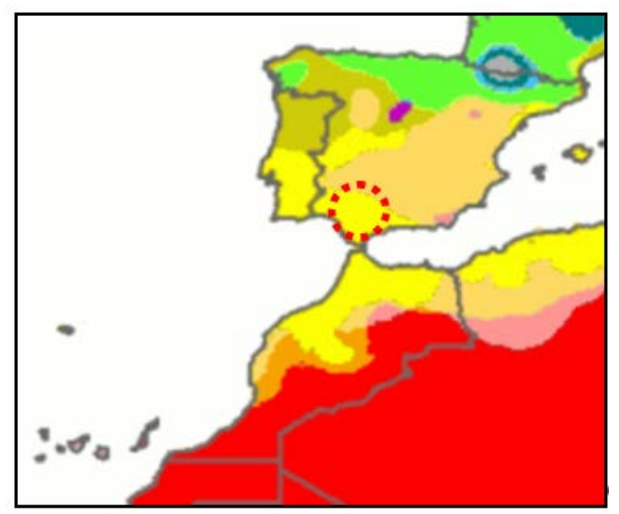

Fig. 45. Mapa Koppen España, Sevilla. (Peel et al. 2007).

Datos obtenidos mediante $\mathrm{CE}^{3} \mathrm{X}$ :

La suma total de los consumos ( $\mathrm{CE}^{3} \mathrm{X}$ y calculadora), es: $6.847 \mathrm{Wh}$.

\begin{tabular}{|c|c|c|c|c|c|}
\hline \multicolumn{6}{|c|}{$\begin{array}{l}\text { 2. CALIFICACIÓN ENERGÉTICA DEL EDIFICIO EN CONSUMO DE ENERGÍA PRIMARIA NO RENOVABLE } \\
\text { Por energía primaria no renovable se entiende la energia consumida por el edificio procedente de fuentes no renovables que no } \\
\text { ha sufrido ningún proceso de conversión o transformación. }\end{array}$} \\
\hline \multicolumn{2}{|c|}{ INDICADOR GLOBAL } & \multicolumn{4}{|c|}{ INDICADORES PARCIALES } \\
\hline \multirow{4}{*}{ 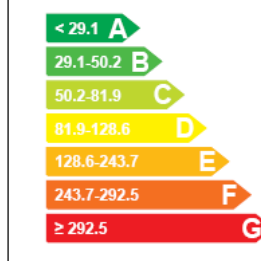 } & \multirow{4}{*}{$220.8 \mathrm{E}$} & \multicolumn{2}{|c|}{ CALEFACCIÓN } & \multicolumn{2}{|l|}{ ACS } \\
\hline & & $\begin{array}{c}\text { Energía primaria } \\
\text { calefacción } \\
{\left[\mathrm{kWh} / \mathrm{m}^{2} \text { añolo] }\right.}\end{array}$ & \multirow[t]{2}{*}{$\mathbf{E}$} & $\begin{array}{c}\text { Energía primaria } \\
A C S \\
{\left[\mathrm{kWh} / \mathrm{m}^{2} \text { año] }\right.}\end{array}$ & \multirow[t]{2}{*}{ G } \\
\hline & & 73.57 & & 87.37 & \\
\hline & & \multicolumn{2}{|c|}{ REFRIGERACIÓN } & \multicolumn{2}{|l|}{ ILUMINACIÓN } \\
\hline \multirow{2}{*}{\multicolumn{2}{|c|}{$\begin{array}{c}\text { Consumo global de energía primaria no renovable } \\
{\left[\mathrm{kWh} / \mathrm{m}^{2} \text { año }\right]^{1}}\end{array}$}} & $\begin{array}{c}\text { Energía primaria } \\
\text { refrigeración } \\
{\left[\mathrm{kWh} / \mathrm{m}^{2} \text { año] }\right.}\end{array}$ & $\mathbf{F}$ & $\begin{array}{c}\text { Energía primaria } \\
\text { iluminación } \\
{\left[\mathrm{kWh} / \mathrm{m}^{2} a n ̃ o\right]}\end{array}$ & \multirow[t]{2}{*}{$\cdot$} \\
\hline & & 59.89 & & - & \\
\hline
\end{tabular}

Fig. 46. Resultado consumos edificio objeto. Sevilla.

Cálculo FV 100\%, zona Climática Csa (Koppen)/ B4 (CTE). Sevilla.

Para obtener un rendimiento óptimo de la instalación fotovoltaica se estima un rendimiento de un $25 \%$ menos de instalado, en ese sentido se calcula, a partir de los 5.879 Wh el siguiente incremento: $5.879 / 0,75=7.838 \mathrm{Wh} /$ día. Las horas de sol pico equivalen a $1 \mathrm{kWh} / \mathrm{m} 2$ multiplicado por el valor menos favorable de irradiación global diaria, registrado en el mes de diciembre, y que se obtiene de la herramienta on-line Photovoltaic Geographical Information System; este valor es $4,11 \mathrm{kWh} / \mathrm{m}^{2}$ día. Esto supondría que la HSP equivaldría a 4,11 HSP. El cálculo para proyectar el número de módulos, se realiza, otra vez, considerando la energía necesaria entre el valor HSP por el rendimiento de trabajo $(0,8)$ y la potencia pico de los módulos seleccionados: 7.838 Wh/día / 4,11 HSP x 0,8 x $190 \mathrm{Wp}=13$ módulos. 


\begin{tabular}{|c|c|c|c|c|c|}
\hline \multirow[b]{2}{*}{ Month } & \multicolumn{4}{|c|}{$\begin{array}{l}\text { Fixed system: inclination }=35 \mathrm{deg} \text {., } \\
\text { orientation }=0 \text { deg. }\end{array}$} & \\
\hline & Ed & $\mathrm{Em}$ & $\mathrm{Hd}$ & $\mathrm{Hm}$ & \\
\hline Jan & 19.30 & 597 & 4.32 & 134 & \\
\hline Feb & 23.10 & 647 & 5.27 & 147 & \\
\hline Mar & 26.20 & 812 & 6.16 & 191 & \\
\hline $\mathrm{Apr}$ & 26.40 & 793 & 6.27 & 188 & \\
\hline May & 27.80 & 863 & 6.69 & 207 & \\
\hline Jun & 28.70 & 861 & 7.08 & 212 & \\
\hline Jul & 29.70 & 922 & 7.41 & 230 & \\
\hline Aug & 29.20 & 906 & 7.35 & 228 & \\
\hline Sep & 26.40 & 793 & 6.49 & 195 & \\
\hline Oct & 24.30 & 752 & 5.78 & 179 & \\
\hline Nov & 20.70 & 621 & 4.75 & 142 & \\
\hline $\mathrm{Dec}$ & 18.30 & 569 & \begin{tabular}{l|l|}
4.11 \\
\end{tabular} & 127 & \\
\hline Year & 25.00 & 761 & 5.98 & 182 & \\
\hline $\begin{array}{l}\text { Total for } \\
\text { year }\end{array}$ & & 9130 & & 2180 & \\
\hline \multicolumn{6}{|c|}{ Ed: Average daily electricity production from the given system (kWh) } \\
\hline \multicolumn{6}{|c|}{ Em: Average monthly electricity production from the given system (kWh) } \\
\hline \multicolumn{6}{|c|}{ Hd: Average daily sum of global irradiation per square meter received by the modules of the given system $(\mathrm{kWh} / \mathrm{m} 2)$} \\
\hline \multicolumn{6}{|c|}{$\mathrm{Hm}$ : Average sum of global irradiation per square meter received by the modules of the given system $(\mathrm{kWh} / \mathrm{m} 2)$} \\
\hline
\end{tabular}

Fig. 47. Estimación de generación fotovoltaica. Sevilla.

(Photovoltaic Geographical Information System). Consulta 2015.

De acuerdo al tipo de módulo seleccionado, la instalación para el Taller-Vivienda de $52 \mathrm{~m}^{2}$ sería de $2.470 \mathrm{Wp}$, pero se proyecta en función de $6.080 \mathrm{Wp}$. Con esta instalación, las emisiones de $\mathrm{CO}^{2}$ se reducen en $6.315 \mathrm{Kg} \mathrm{CO}^{2}$, de acuerdo a la herramienta Onyx Solar (www.onyxsolar.com) y tal como consta en el Anexo 5.

Zona Climática BSk (Koppen)/ D3 (CTE). Madrid.

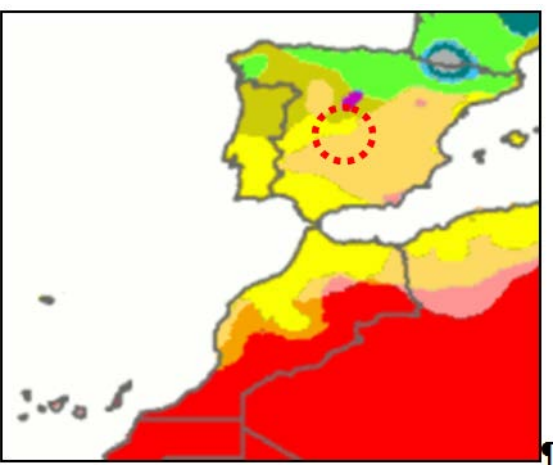

Fig.48. Mapa Koppen España, Madrid. (Peel et al. 2007).

Datos obtenidos mediante $\mathrm{CE}^{3} \mathrm{X}$ :

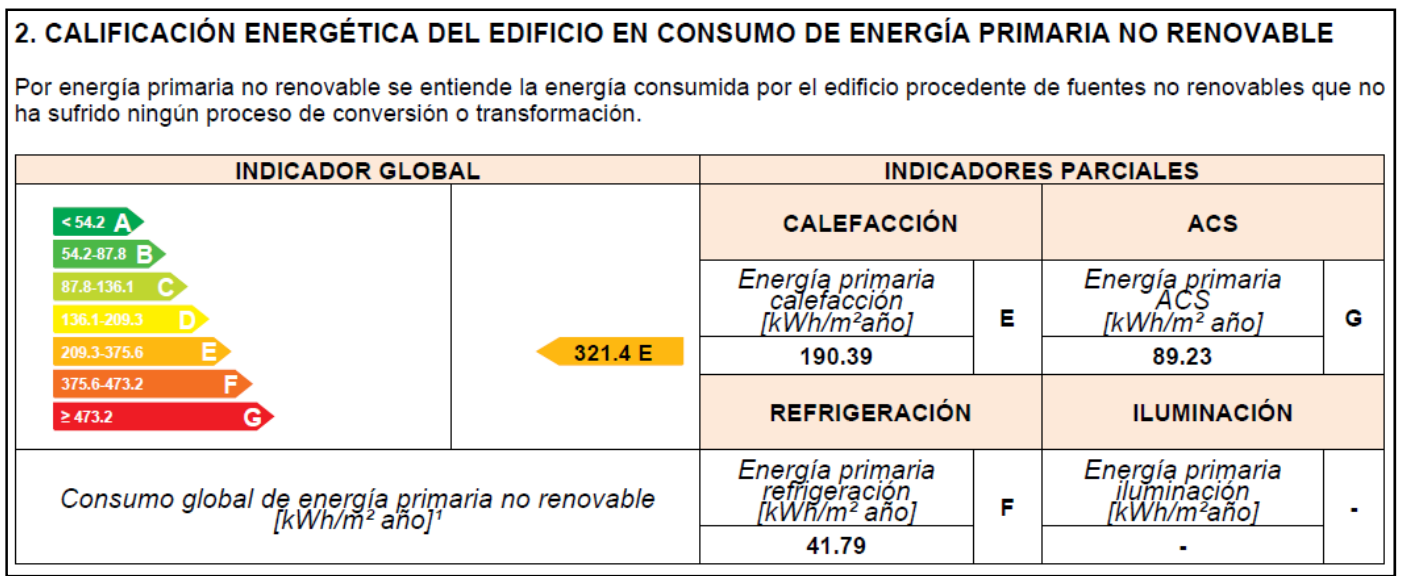

Fig. 49. Resultado consumos edificio objeto. Madrid 
A partir de los datos de consumo obtenido del $\mathrm{CE}^{3} \mathrm{X}$ y con el cálculo de otros consumos eléctricos de la vivienda (luminarias y electrodomésticos) se ha determinado que el consumo sería del orden de los 6.847 Wh. Ver Anexo 5.

\section{Cálculo FV 100\%, zona Climática BSk (Koppen)/ D3 (CTE). Madrid}

Para el cálculo de un rendimiento óptimo de la instalación fotovoltaica se ha estimado que a partir de los 6.847 Wh se debe cubrir una merma de la instalación expresado en el valor siguiente: $6.847 / 0,75=9.129 \mathrm{Wh} /$ día. Las horas de sol pico se calculan a $1 \mathrm{kWh} / \mathrm{m}^{2}$, multiplicado por el valor menos favorable de irradiación global diaria, que es de $3,48 \mathrm{kWh} / \mathrm{m}^{2}$ día, en el mes de diciembre. Suponiendo esto que la HSP sea 3,48. Este dato se ha obtenido de la herramienta on-line "Photovoltaic Geographical Information System" y que se muestra en el Anexo 5. Al realizar el cálculo para determinar el número de módulos, el mismo se realiza considerando la energía necesaria entre el valor HSP por el rendimiento de trabajo (considerado en 0,8 ) y la potencia pico de los módulos seleccionados: 9.129 Wh/día / 3,48 HSP $\times 0,8 \times 190$ $\mathrm{Wp}=18$ módulos. De acuerdo al modelo de módulo seleccionado, la instalación para el Taller-Vivienda de $52 \mathrm{~m}^{2}$ sería en principio de $3.420 \mathrm{Wp}$, pero se ha proyectado, para fines de este estudio para $6.080 \mathrm{Wp}$.

\begin{tabular}{|c|c|c|c|c|c|}
\hline \multirow[b]{2}{*}{ Month } & \multicolumn{4}{|c|}{$\begin{array}{l}\text { Fixed system: inclination }=35 \text { deg., } \\
\text { orientation }=0 \text { deg. }\end{array}$} & \\
\hline & Ed & Em & $\mathrm{Hd}$ & $\mathrm{Hm}$ & \\
\hline Jan & 16.90 & 524 & 3.60 & 112 & \\
\hline Feb & 21.80 & 610 & 4.76 & 133 & \\
\hline Mar & 26.20 & 811 & 5.96 & 185 & \\
\hline Apr & 26.30 & 788 & 6.07 & 182 & \\
\hline May & 27.20 & 843 & 6.43 & 199 & \\
\hline Jun & 29.10 & 873 & 7.05 & 211 & \\
\hline Jul & 30.80 & 954 & 7.55 & 234 & \\
\hline Aug & 30.10 & 933 & 7.35 & 228 & \\
\hline Sep & 27.60 & 827 & 6.56 & 197 & \\
\hline Oct & 23.30 & 721 & 5.29 & 164 & \\
\hline Nov & 18.30 & 548 & 3.96 & 119 & \\
\hline $\mathrm{Dec}$ & 16.40 & 509 & 3.48 & 108 & \\
\hline Year & 24.50 & 745 & 5.68 & 173 & \\
\hline $\begin{array}{l}\text { Total for } \\
\text { year }\end{array}$ & & 8940 & & 2070 & \\
\hline \multicolumn{6}{|c|}{ Ed: Average daily electricity production from the given system $(\mathrm{kWh})$} \\
\hline \multicolumn{6}{|c|}{ Em: Average monthly electricity production from the given system (kWh) } \\
\hline \multicolumn{6}{|c|}{ Hd: Average daily sum of global irradiation per square meter received by the modules of the given system ( $\mathrm{kWh} / \mathrm{m} 2)$} \\
\hline \multicolumn{6}{|c|}{$\mathrm{Hm}:$ Average sum of global irradiation per square meter received by the modules of the given system (kWh/m2) } \\
\hline
\end{tabular}

Fig.50 .Estimación de generación fotovoltaica. Madrid.

(Photovoltaic Geographical Information System). Consulta 2015.

Con esta estimación- y de acuerdo a la herramienta profesional Onyx Solar (www.onyxsolar.com) es posible ahorrar hasta $5.861 \mathrm{Kg} \mathrm{CO}^{2}$ al año. 
Zona Climática Csb (Koppen)/ D2 (CTE). Ourense.

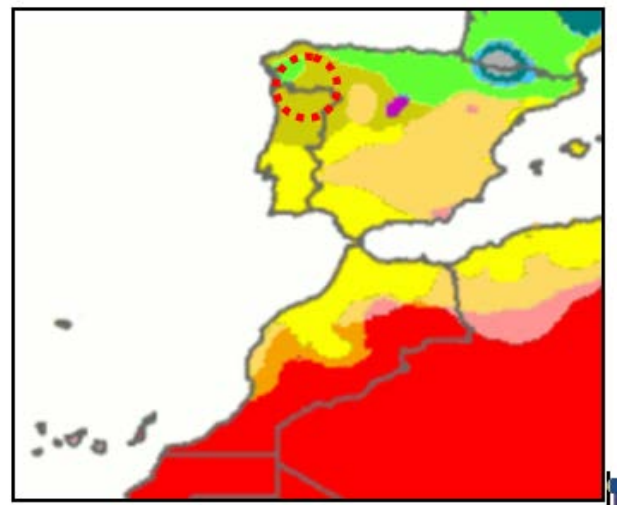

Fig. 51. Mapa Koppen España, Orense. (Peel et al. 2007).

Datos obtenidos mediante $\mathrm{CE}^{3} \mathrm{X}$ :

Igual que en los casos anteriores los datos de consumo se han obtenido de los cálculos del $\mathrm{CE}^{3} \mathrm{X}$ y la suma de los electrodomésticos de la vivienda. El resultado estimado es de $6.135 \mathrm{Wh}$.

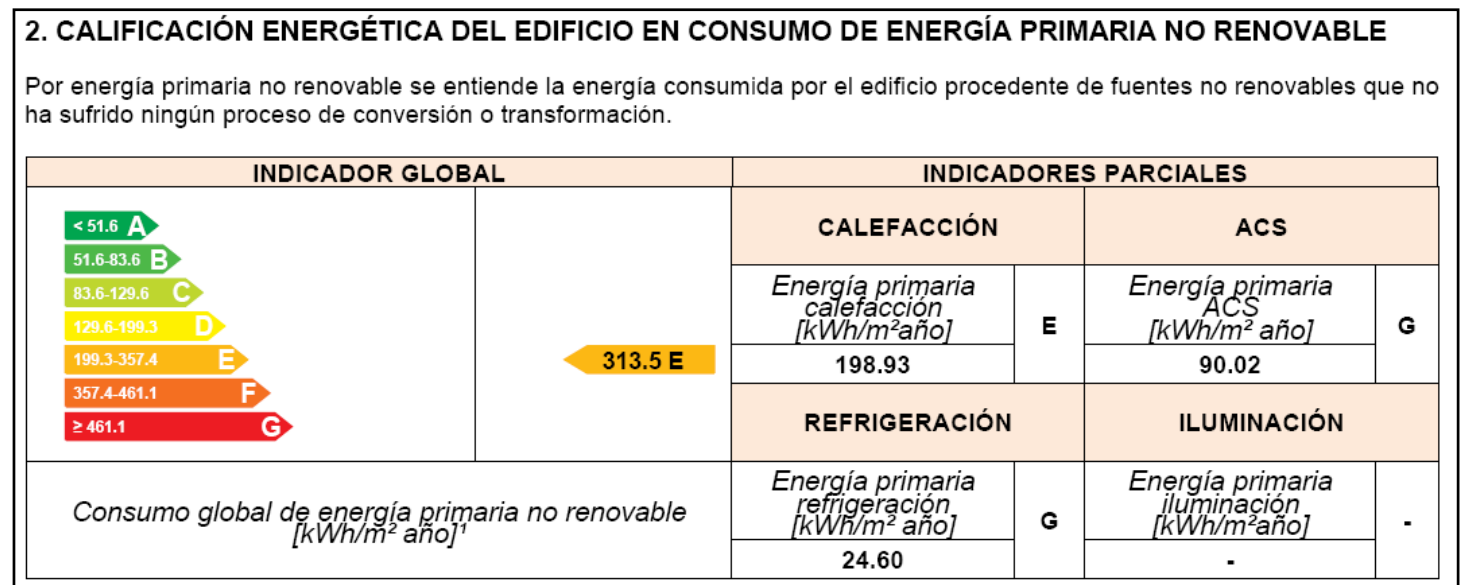

Fig. 52. Resultado consumos edificio objeto. Orense.

Cálculo FV 100 zona Climática Csb (Koppen)/ D2 (CTE). Ourense.

Como rendimiento óptimo se estima el $75 \%$ de merma para la instalación proyectada en función del consumo de 6.135 Wh. Este valor queda de la siguiente manera: $6.135 / 0,75=8.180$ Wh/día.

Las horas de sol pico a razón de $1 \mathrm{kWh} / \mathrm{m} 2$, se multiplican por el valor menos favorable de irradiación global diaria y que se registra en diciembre.

Con la ayuda de la herramienta on-line Photovoltaic Geographical Information System, se ha determinado que el dato es $2,55 \mathrm{kWh} / \mathrm{m}^{2}$ día Esto sería 2,55 HSP. 
En número de módulos se ha calculado dividiendo la energía necesaria entre HSP y multiplicando por el rendimiento de trabajo $(0,8)$ y la potencia pico de los módulos seleccionados, en este caso sigue siendo $190 \mathrm{Wp}$ : 8.180 Wh/día / 2,55 HSP x 0,8 $\times$ $190 \mathrm{Wp}=22$ módulos.

Según el tipo de módulo seleccionado, la instalación para el Taller-Vivienda de $52 \mathrm{~m}^{2}$ sería, en teoría, de $4.180 \mathrm{Wp}$, pero se asumen los $6.080 \mathrm{Wp}$ planteados con FV al $100 \%$.

El resultado del cálculo de la radiación con Photovoltaic Geographical Information System es el que se muestra a continuación.

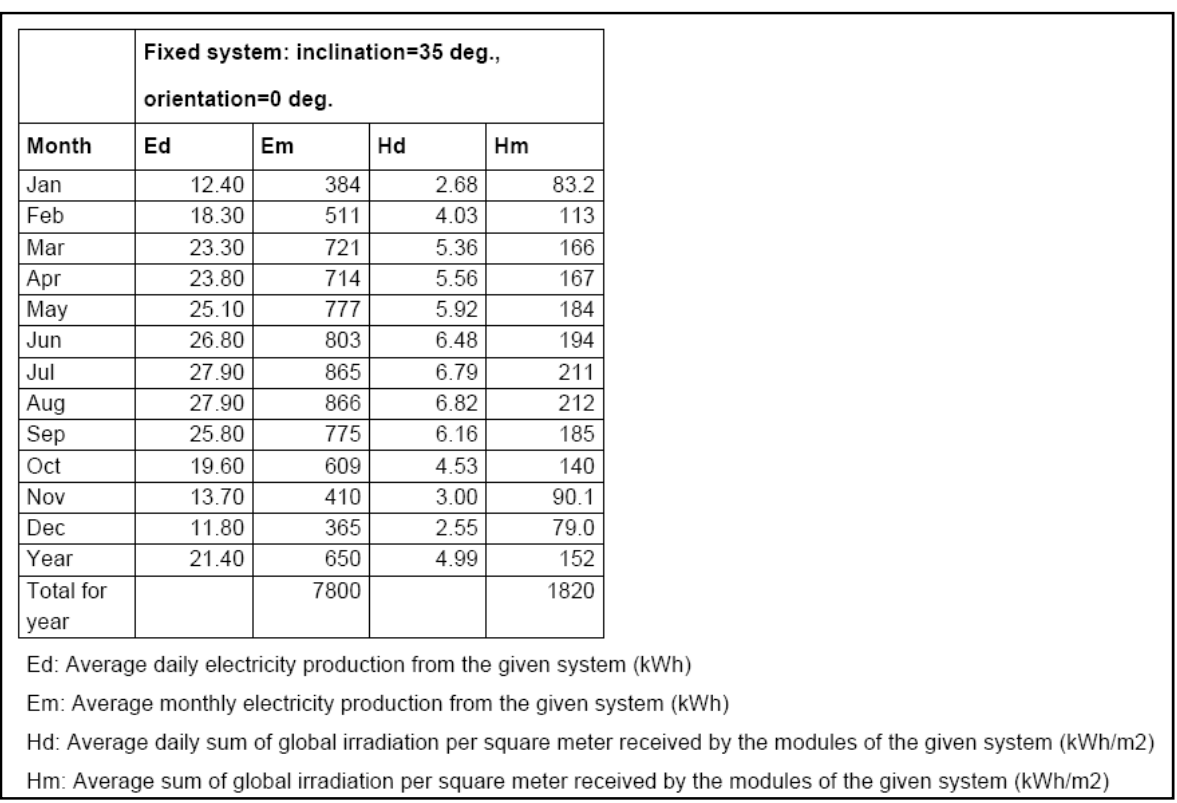

Fig. 53 .Estimación de generación fotovoltaica. Orense

(Photovoltaic Geographical Information System). Consulta 2015.

Esta instalación proyectada con esta potencia, significaría un ahorro de $5.229 \mathrm{Kg} \mathrm{CO}^{2}$, al año según Onyx Solar (www.onyxsolar.com).

Zona Climática Cfb (Koppen)/ C1 (CTE). Santander.

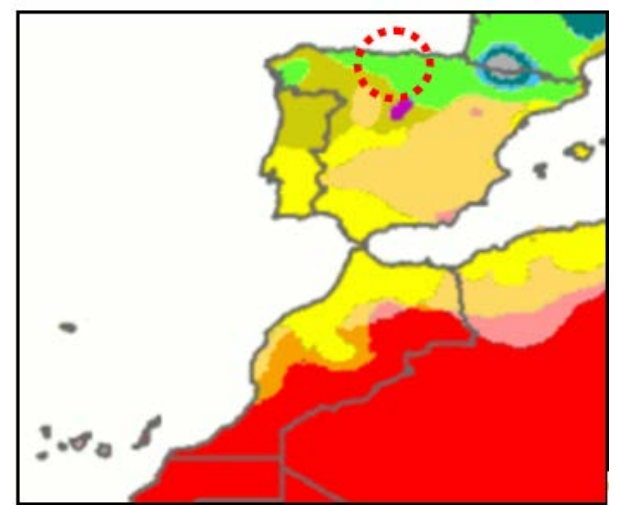

Fig.54 Mapa Koppen España, Santander. (Peel et al. 2007). 
Datos obtenidos mediante $\mathrm{CE}^{3} \mathrm{X}$ :

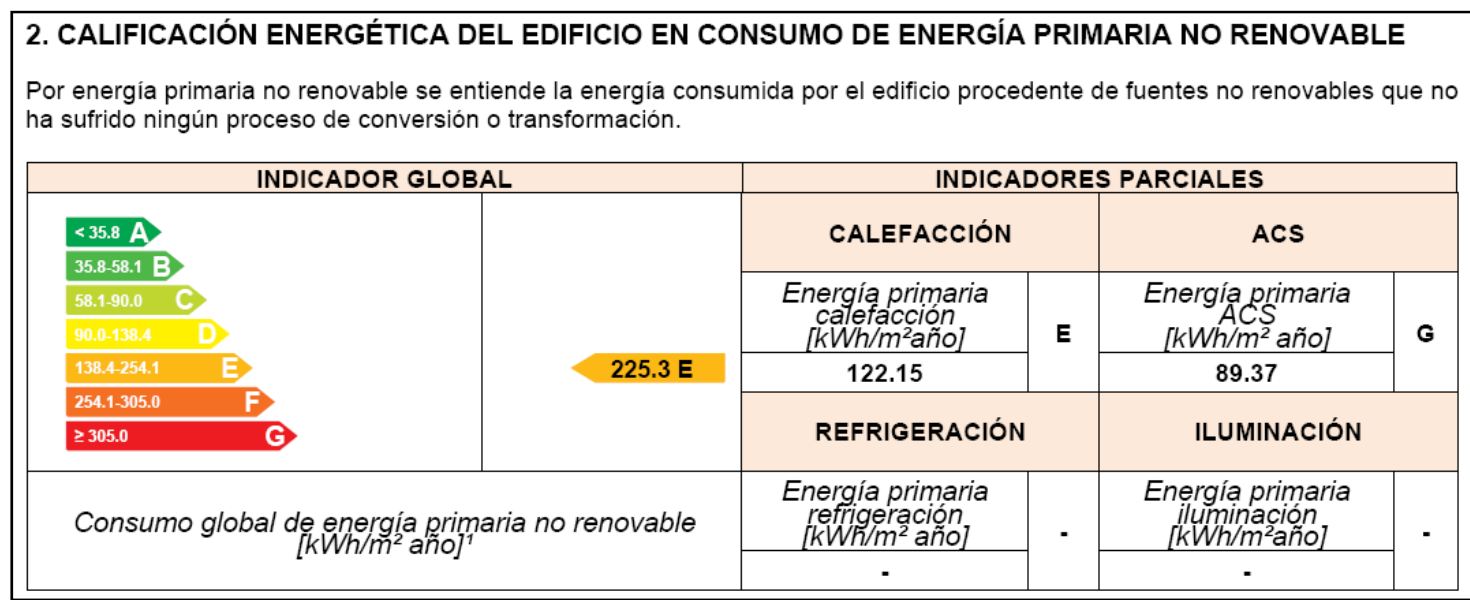

Fig. 52. Resultado consumos edificio objeto. Santander

Cálculo FV 100 zona Climática Cfb (Koppen)/ C1 (CTE). Santander.

El rendimiento óptimo de la instalación fotovoltaica tendría que calcularse para que los 6.057 Wh obtenidos en el cálculo de consumo queden cubiertos al 100\% y para esto se toma en consideración una merma de $25 \%$ del rendimiento de cualquier instalación que se proyecte: $6.057 / 0,75=8.076 \mathrm{Wh} /$ día.

Las horas sol pico, multiplicadas por $1 \mathrm{kWh} / \mathrm{m} 2$ son 2,31 HSP (Photovoltaic Geographical Information System; 2015). Calculadas en función del mes de diciembre. Para el cálculo de la cantidad de módulos, 8.076 Wh/día / 2,31 HSP x 0,8 $x \quad 190 \mathrm{Wp}=23$ módulos. De acuerdo al tipo de módulo seleccionado, la instalación para el Taller-Vivienda de $52 \mathrm{~m}^{2}$ sería como mínimo de $4.370 \mathrm{Wp}$.

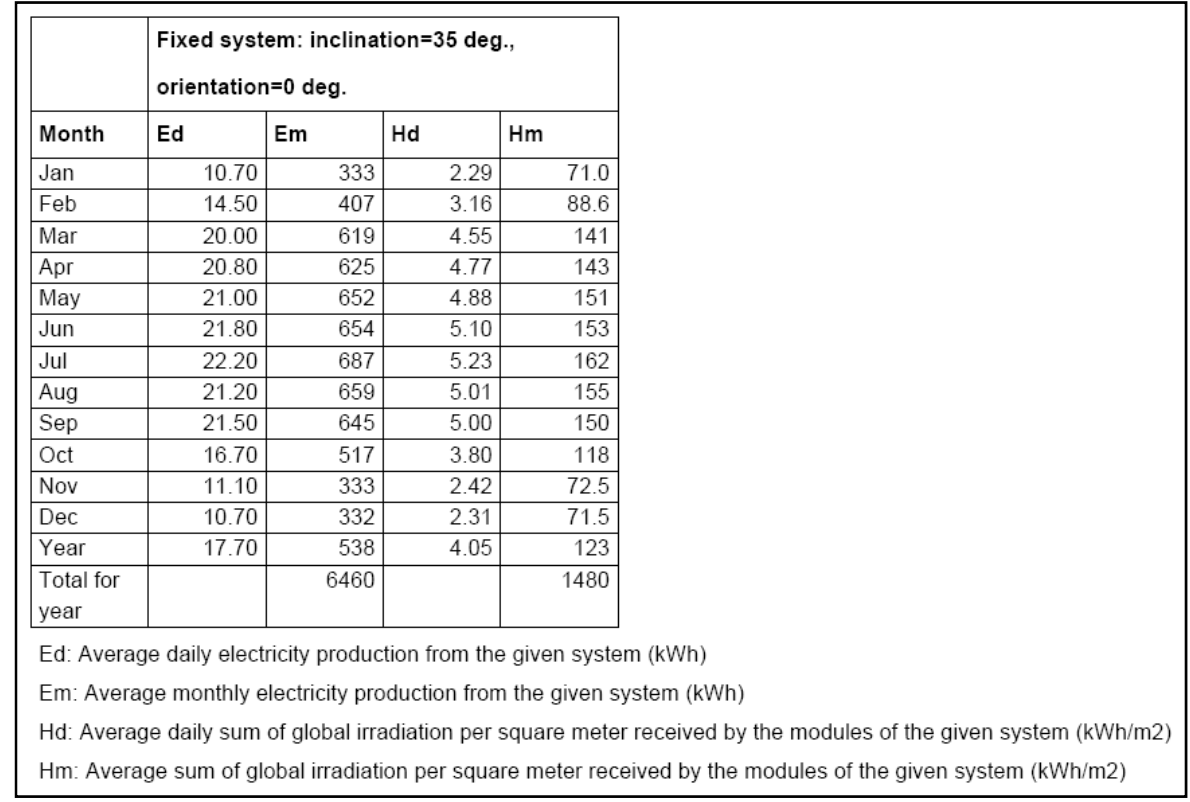

Fig. 56

Estimación de generación fotovoltaica. Santander.

(Photovoltaic Geographical Information System). Consulta 2015. 
La instalación significaría un ahorro de $4.285 \mathrm{Kg} \mathrm{CO} 2$, en un año, de acuerdo a herramienta Onyx Solar, como se muestra en la parte correspondiente del Anexo 5.

Zona Climática Dsb (Koppen)/ E1 (CTE). Burgos.

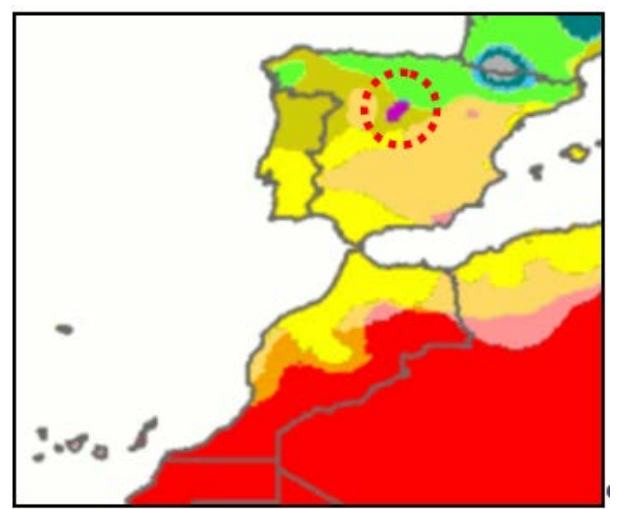

Fig. 57 Mapa Koppen España, Burgos. (Peel et al. 2007).

Datos obtenidos mediante $\mathrm{CE}^{3} \mathrm{X}$ :

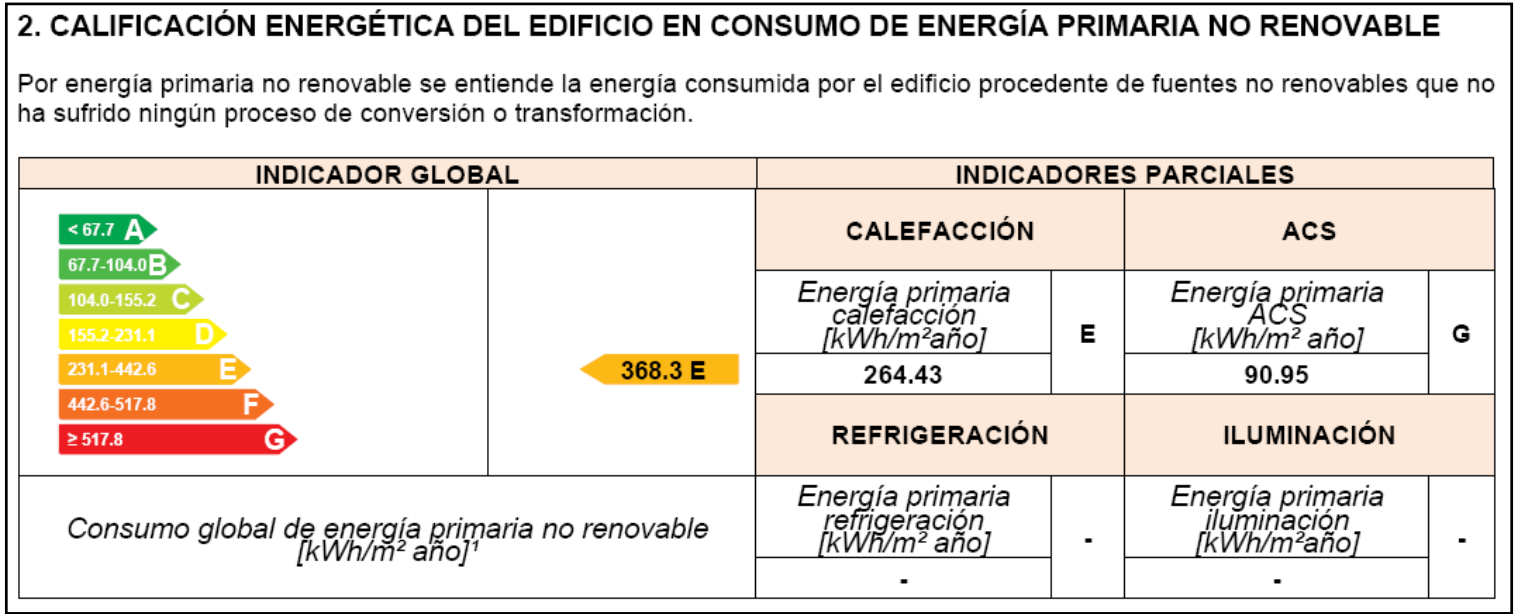

Fig. 58. Resultado consumos edificio objeto. Burgos.

Cálculo FV 100 \%, zona Climática Dsb (Koppen)/ E1 (CTE). Burgos.

Nuevamente se estima como rendimiento óptimo de la instalación fotovoltaica el $75 \%$ de los $6.091 \mathrm{Wh}$; siendo este el caso se proyecta para suplir esta merma del rendimiento: $6.091 / 0,75=8.121 \mathrm{Wh} /$ día .

Las horas sol pico, multiplicadas por $1 \mathrm{kWh} / \mathrm{m} 2$ son 2,47 HSP (Photovoltaic Geographical Information System; 2015) en función del mes de diciembre.

Para el cálculo de la cantidad de módulos, 8.121 Wh/día / 2,47 HSP x 0,8 x 190 Wp = 22 módulos. 
En función del tipo de módulo seleccionado, la instalación para el Taller-Vivienda de $52 \mathrm{~m}^{2}$ sería teóricamente de $4.180 \mathrm{Wp}$.

\begin{tabular}{|c|c|c|c|c|c|}
\hline \multirow[b]{2}{*}{ Month } & \multicolumn{4}{|c|}{$\begin{array}{l}\text { Fixed system: inclination }=35 \mathrm{deg} \text {., } \\
\text { orientation }=0 \text { deg. }\end{array}$} & \\
\hline & Ed & Em & $\mathrm{Hd}$ & $\mathrm{Hm}$ & \\
\hline Jan & 11.30 & 350 & 2.39 & 74.1 & \\
\hline Feb & 16.30 & 457 & 3.53 & 98.7 & \\
\hline Mar & 21.90 & 679 & 4.93 & 153 & \\
\hline Apr & 22.80 & 685 & 5.20 & 156 & \\
\hline May & 25.90 & 802 & 6.00 & 186 & \\
\hline Jun & 27.90 & 837 & 6.59 & 198 & \\
\hline Jul & 29.90 & 928 & 7.16 & 222 & \\
\hline Aug & 28.90 & 895 & 6.90 & 214 & \\
\hline Sep & 25.80 & 774 & 6.03 & 181 & \\
\hline Oct & 19.60 & 608 & 4.41 & 137 & \\
\hline Nov & 12.90 & 386 & 2.75 & 82.6 & \\
\hline Dec & 11.70 & 363 & 2.47 & 76.5 & \\
\hline Year & 21.30 & 647 & 4.87 & 148 & \\
\hline $\begin{array}{l}\text { Total for } \\
\text { year }\end{array}$ & & 7760 & & 1780 & \\
\hline \multicolumn{6}{|c|}{ Ed: Average daily electricity production from the given system (kWh) } \\
\hline \multicolumn{6}{|c|}{ Em: Average monthly electricity production from the given system (kWh) } \\
\hline \multicolumn{6}{|c|}{ Hd: Average daily sum of global irradiation per square meter received by the modules of the given system $(\mathrm{kWh} / \mathrm{m} 2)$} \\
\hline \multicolumn{6}{|c|}{$\mathrm{Hm}$ : Average sum of global irradiation per square meter received by the modules of the given system $(\mathrm{kWh} / \mathrm{m} 2)$} \\
\hline
\end{tabular}

Fig. 59. Estimación de generación fotovoltaica. Burgos.

(Photovoltaic Geographical Information System). Consulta 2015. 
5.3.2 Lugares, del mapa de Koppen, donde el Taller-Vivienda $52 \mathrm{~m}^{2}$, en estado actual, cumple nzEB o NZEB.

Luego de obtenidos los datos de consumo energético, a partir de las simulaciones con $\mathrm{CE}^{3} \mathrm{X}$, tal como se han mostrado en el epígrafe anterior, y la calculadora de consumos, y sin incorporar ningún tipo de medidas de mejoras, se establece que en ninguna zona climática del mapa de Koppen (como elemento comparativo o de equiparación con los climas que se registran en España, según CTE, para referencia con otros lugares indicados en el mapa), se cumplen los niveles de eficiencia nZEB o el NZEB tal y como se muestra la figura 60.

Los informes completos de las certificaciones por zonas climática se adjunta en el Anexo 6

Tipo de mejora: Ninguno

Cumplimiento NZEB: ..No

Cumplimiento nZEB: No

Cumplimiento CTE: . No

Zonas climáticas Koppen de cumplimiento NZEB o nZEB:.... Ninguna

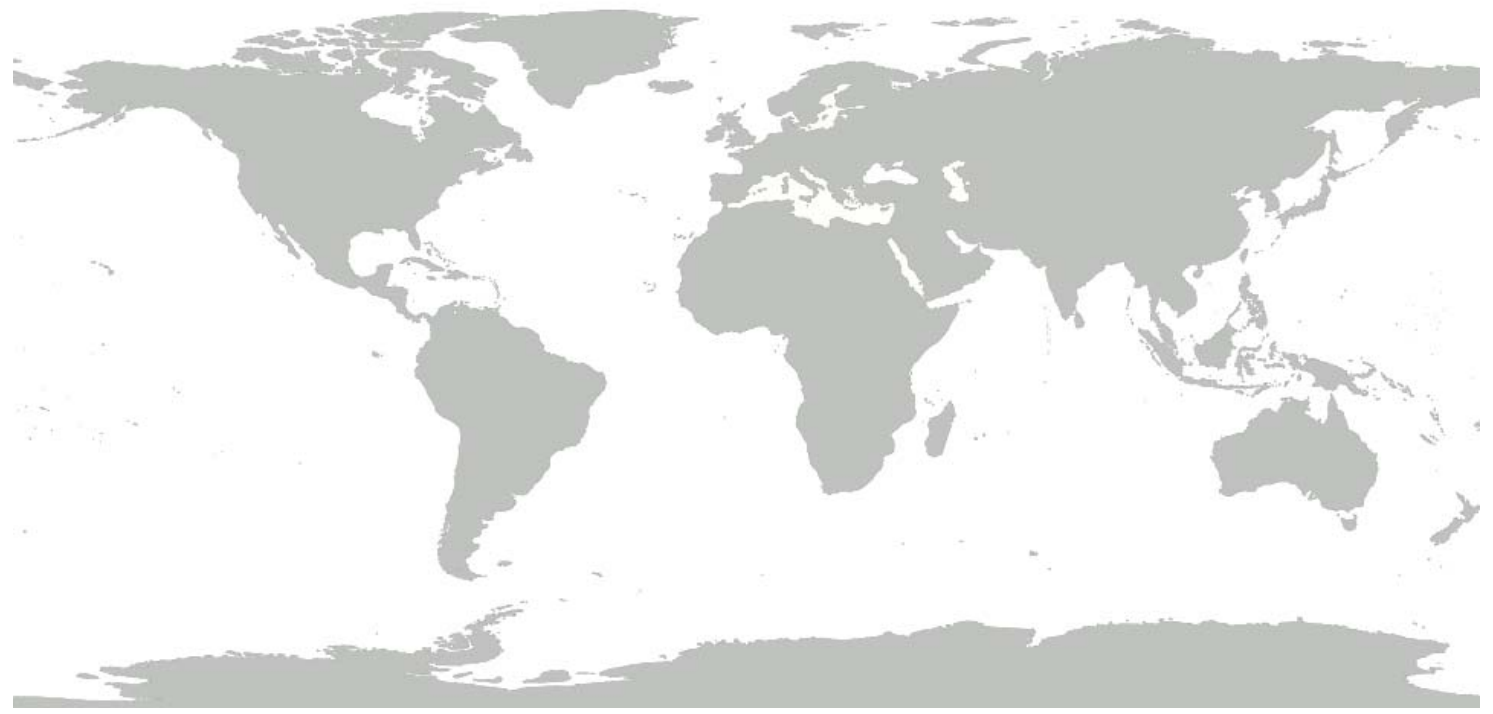

Fig. 60. Mapamundi sin zonas climáticas señaladas

Elaboración propia. (Colaboración de Pablo Fernández en dibujo mapas Koopen)*

El mapa gris refleja que no existe ningún lugar en el que el edificio objeto cumpla con los requisitos de nZEB o NZEB, tomando como consideración que para nZEB los parámetros más aceptados son los establecidos en el estándar Passivhaus : 15 $\mathrm{kWh} / \mathrm{m}^{2}$ año como máximo consumo para calefacción , $15 \mathrm{kWh} / \mathrm{m}^{2}$ año como máximo consumo para refrigeración o $120 \mathrm{kWh} / \mathrm{m}^{2}$ año en conjunto.

En este caso en que el Taller-Vivienda $52 \mathrm{~m}^{2}$ no cumple, en sus condiciones actuales, los niveles de NZEB o nZEB, tampoco cumple los niveles mínimos establecidos por la normativa española mediante la certificación energética. 
5.3.3 Lugares, del mapa de Koppen, donde el Taller-Vivienda $52 \mathrm{~m}^{2}$, cumple NZEB. Medida de mejora: Incorporación del 100 \% de generación fotovoltaica (paneles), en cubierta y a $0^{\circ}$ de inclinación..

Con los datos de consumo energético - como punto de partida- y proyectada la instalación fotovoltaica de acuerdo a la zona climática especificada en cada caso, se realizan los cálculos mediante $C E^{3} X$ y se obtiene la nueva calificación energética por zonas climáticas y de cara el nZEB o el NZEB. A continuación los valores obtenidos.

\section{Zona Climática BWk, BWh, $A^{(*)}$ (Koppen) / a3 (CTE). Santa Cruz de Tenerife}

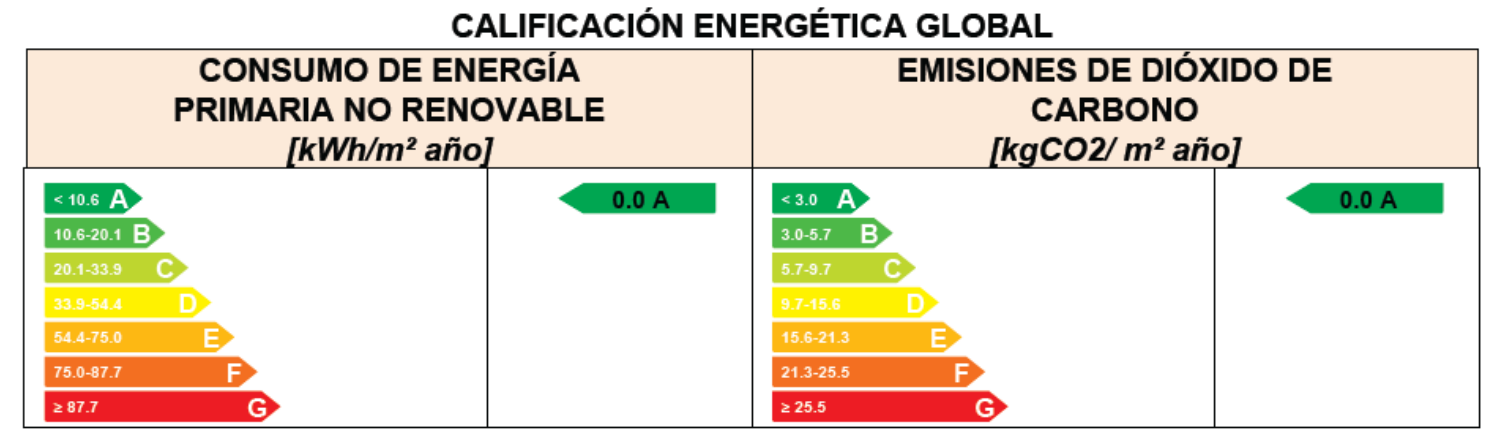

ANALISÍS TÉCNICO

\begin{tabular}{|c|c|c|c|c|c|c|c|c|c|c|c|c|c|c|c|}
\hline \multirow[b]{2}{*}{ Indicador } & \multicolumn{3}{|c|}{ Calefacción } & \multicolumn{3}{|c|}{ Refrigeración } & \multicolumn{3}{|c|}{ ACS } & \multicolumn{3}{|c|}{ Iluminación } & \multicolumn{3}{|c|}{ Total } \\
\hline & \multicolumn{2}{|c|}{ Valor } & $\begin{array}{c}\text { ahorro } \\
\text { respecto a } \\
\text { la situación } \\
\text { original }\end{array}$ & \multicolumn{2}{|c|}{ Valor } & $\begin{array}{c}\text { ahorro } \\
\text { respecto a } \\
\text { la situación } \\
\text { original }\end{array}$ & \multicolumn{2}{|c|}{ Valor } & $\begin{array}{c}\text { ahorro } \\
\text { respecto a } \\
\text { la situación } \\
\text { original }\end{array}$ & \multicolumn{2}{|c|}{ Valor } & $\begin{array}{c}\text { ahorro } \\
\text { respecto a } \\
\text { la situación } \\
\text { original }\end{array}$ & \multicolumn{2}{|c|}{ Valor } & $\begin{array}{c}\text { ahorro } \\
\text { respecto a } \\
\text { la situación } \\
\text { original }\end{array}$ \\
\hline $\begin{array}{l}\text { Consumo Energía } \\
\text { final }\left[\mathrm{kWh} / \mathrm{m}^{2} \text { año] }\right.\end{array}$ & \multicolumn{2}{|c|}{4.94} & $-\%$ & \multicolumn{2}{|c|}{11.12} & $-41.1 \%$ & \multicolumn{2}{|c|}{44.13} & $-180.3 \%$ & \multicolumn{2}{|c|}{-} & $-\%$ & \multicolumn{2}{|c|}{-66.76} & $382.6 \%$ \\
\hline $\begin{array}{c}\text { Consumo Energía } \\
\text { primaria no renovable } \\
{\left[\mathrm{kWh} / \mathrm{m}^{2} \text { año] }\right.}\end{array}$ & 14.44 & G & $-\%$ & 32.51 & D & $-41.1 \%$ & 129.03 & G & $-180.3 \%$ & - & - & $-\%$ & 0.00 & A & $100.0 \%$ \\
\hline $\begin{array}{c}\text { Emisiones de } \mathrm{CO} 2 \\
{\left[\mathrm{kgCO} 2 / \mathrm{m}^{2} \text { año] }\right.}\end{array}$ & 3.83 & G & $-\%$ & 8.63 & D & $-41.1 \%$ & 34.24 & G & $-180.3 \%$ & - & - & $-\%$ & 0.00 & A & $100.0 \%$ \\
\hline $\begin{array}{c}\text { Demanda [kWh/m² } \\
\text { año] }\end{array}$ & 16.52 & G & $0.0 \%$ & 28.44 & $D$ & $0.0 \%$ & & & & & & & & & \\
\hline
\end{tabular}

Fig. 61. Calificación energética Taller-Vivienda 52m2.Santa Cruz de Tenerife.

Aún con las limitaciones técnicas del programa, ha sido posible realizar, mediante opción simplificada, una análisis del nivel de eficiencia energética que supondría la implementación de $\mathrm{FV}$ en cubierta al $100 \%$ y con $0^{\circ}$ de inclinación ( $5^{\circ}$ grados para permitir la auto limpieza de los paneles), para no afectar la imagen del edificio más allá de su propia naturaleza constructiva. Los resultados obtenidos muestran la manera en que es posible alcanzar una calificación de NZEB tanto a nivel de consumo energético como a nivel de emisiones. En cuanto a los resultados de calefacción y ACS el programa no tiene la capacidad de anular este tipo de consumo, o por lo menos modificarlos, (en el caso del ACS), y llevarlos a un nivel que se corresponda con la zona climática. Para los objetivos de este tesis esos datos no se toman en cuenta tal y como se presentan.

${ }^{*}$ ) Algunas definiciones de la calificación A según Koppen, puede ser aplicable las Islas Canarias partiendo de la similitud de estas con los climas tropicales y a su nivel de humedad relativa del $100 \%$. 
En el caso específico de la calefacción, y dado que el programa no podía anular este consumo o modificarlo a un escenario más realista, para este análisis se ha alterado, deliberadamente, la fuente de energía que alimenta el sistema de calefacción, para que las emisiones asociadas a estos consumos no reales, resultaran cero.

En cualquier caso y partiendo de que el consumo calculado para este modelo de simulación corresponde a unos $4,940 \mathrm{Wh}$, la generación proyectada, 8,379 Wh, supera en casi el doble a este consumo. El Taller- Vivienda $52 \mathrm{~m}^{2}$, no solo es NZEB, sino que se plantea como una unidad de energía plus.

Tipo de mejora: Incorporación de generación fotovoltaica 100 \% en cubierta

Cumplimiento NZEB SI

Cumplimiento nZEB: SI

Cumplimiento CTE .SI

Zonas climáticas Koppen/CTE: BWk de Koppen y a3 del CTE

Zona Climática BWk (Koppen)/ A4 (CTE). Almería

\section{CALIFICACIÓN ENERGÉTICA GLOBAL}

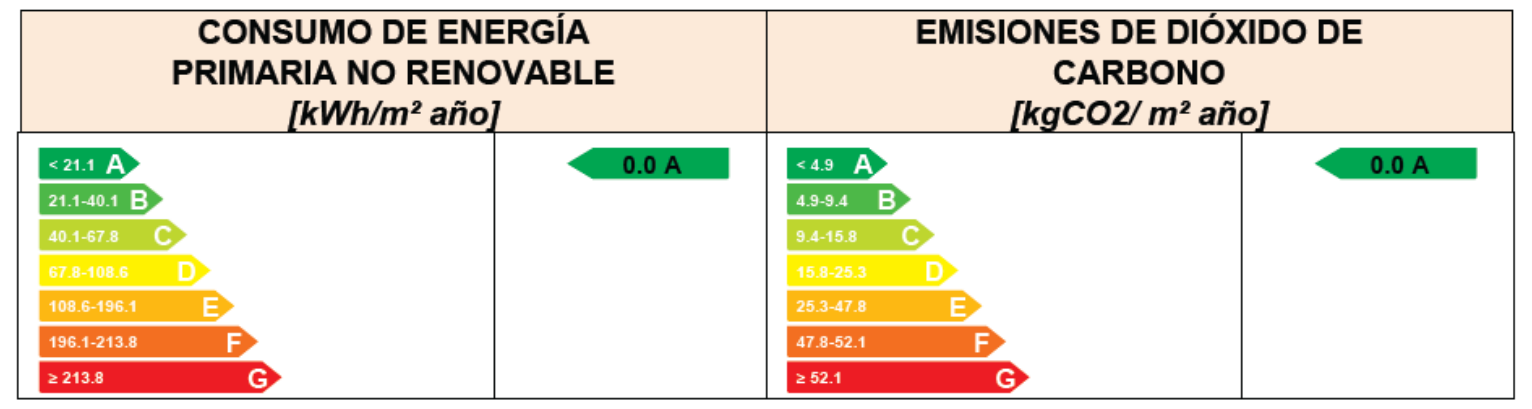

ANALISÍS TÉCNICO

\begin{tabular}{|c|c|c|c|c|c|c|c|c|c|c|c|c|c|c|}
\hline \multirow[b]{2}{*}{ Indicador } & \multicolumn{3}{|c|}{ Calefacción } & \multicolumn{3}{|c|}{ Refrigeración } & \multicolumn{3}{|c|}{ ACS } & \multicolumn{2}{|c|}{ Iluminación } & \multicolumn{3}{|c|}{ Total } \\
\hline & \multicolumn{2}{|c|}{ Valor } & $\begin{array}{c}\text { ahorro } \\
\text { respecto a } \\
\text { la situación } \\
\text { original }\end{array}$ & \multicolumn{2}{|c|}{ Valor } & $\begin{array}{c}\text { ahorro } \\
\text { respecto a } \\
\text { la situación } \\
\text { original }\end{array}$ & \multicolumn{2}{|c|}{ Valor } & $\begin{array}{c}\text { ahorro } \\
\text { respecto a } \\
\text { la situación } \\
\text { original }\end{array}$ & Valor & $\begin{array}{c}\text { ahorro } \\
\text { respecto a } \\
\text { la situación } \\
\text { original }\end{array}$ & \multicolumn{2}{|c|}{ Valor } & $\begin{array}{c}\text { ahorro } \\
\text { respecto a } \\
\text { la situación } \\
\text { original }\end{array}$ \\
\hline $\begin{array}{l}\text { Consumo Energia } \\
\text { final }\left[\mathrm{kWh} / \mathrm{m}^{2} \text { año] }\right.\end{array}$ & \multicolumn{2}{|c|}{32.54} & $-12.4 \%$ & \multicolumn{2}{|c|}{23.03} & $11.1 \%$ & \multicolumn{2}{|c|}{44.60} & $0.0 \%$ & - & $-\%$ & \multicolumn{2}{|c|}{77.16} & $22.4 \%$ \\
\hline $\begin{array}{l}\text { Consumo Energia } \\
\text { primaria no renovable } \\
{\left[\mathrm{kWh} / \mathrm{m}^{2} \text { año] }\right.}\end{array}$ & 63.59 & E & $-12.4 \%$ & 45.00 & $E$ & $11.1 \%$ & 87.15 & G & $0.0 \%$ & - & $-\%$ & 0.00 & A & $100.0 \%$ \\
\hline $\begin{array}{c}\text { Emisiones de CO2 } \\
{\left[\mathrm{kgCO} 2 / \mathrm{m}^{2} \text { año] }\right.}\end{array}$ & 10.77 & $\mathrm{D}$ & $-12.4 \%$ & 7.62 & D & $11.1 \%$ & 14.76 & G & $0.0 \%$ & - & $-\%$ & 0.00 & A & $100.0 \%$ \\
\hline $\begin{array}{c}\text { Demanda [kWh/m² } \\
\text { año] }\end{array}$ & 93.92 & G & $0.0 \%$ & 57.46 & $F$ & $0.0 \%$ & & & & & & & & \\
\hline
\end{tabular}

Fig. 62. Calificación energética Taller-Vivienda 52m2.Almería.

En el caso de Almería, definida en la zona climática A4 según el CTE y en la misma zona de Santa Cruz de Tenerife de acuerdo al mapa Koppen, tiene un nivel de eficiencia NZEB igual que en las Islas Canarias al implementar un $100 \%$ de fotovoltaica en la cubierta. 
Tipo de mejora: Incorporación de generación fotovoltaica 100 \% en cubierta

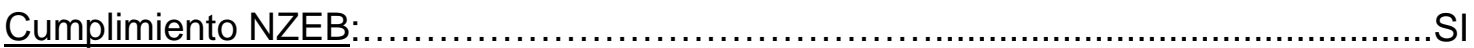

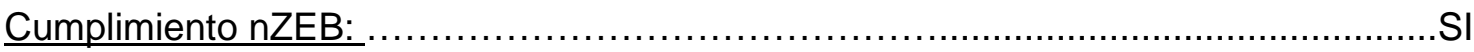

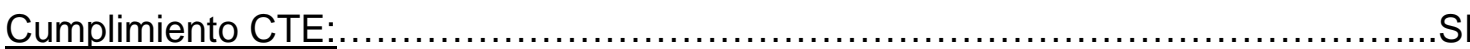

Zonas climáticas Koppen/CTE:............................BWk de Koppen y A4 del CTE

Vale hacer la aclaración de que el consumo energético del prototipo ha cambiado de acuerdo a la zona climática en el que se ha ido localizando, pero no ha variado, ni se ha visto disminuido con este tipo de medida de mejora (integración FV) al no ser intervenido ninguno de los elementos de cerramientos que le componen, y que son los que pueden mejorar el nivel de demanda energética de un edificio, tanto para calefacción como para refrigeración. En este caso la calificación mejora hasta niveles de NZEB porque la producción de energía renovable supera a la demanda.

En la parte de los anexos (Anexo 7), se presenta el mapa de zonas climáticas de Koppen en el que se muestra seleccionada la zona BWh en la que el Taller-Vivienda $52 \mathrm{~m}^{2}$, podría cumplir, por analogía de zonas, con los niveles de eficiencia de NZEB tanto en consumos energéticos como en emisiones.

Zonas Climáticas, BWh, BSh, Aw y Am (Koppen), aplicables complementariamente a las Islas Canarias.

Tal como se ha señalado, el territorio de las Islas Canarias tiene similitudes climáticas, en ciertas temporadas del año, con la zona del sur peninsular de España y además de estar incluidas esta zona climática, que abarca partes del norte África, Las Canarias podrían incluirse también dentro de las condiciones climáticas BWh y BSh (de acuerdo a la propia definición de Koppen).

Por otro lado y dadas las condiciones insulares de estos territorios, podrían ser asimilados, para algunos cálculos, parámetros como las temperaturas, los niveles de humedad y otros aspectos climáticos de las zonas Am y Aw de Koppen, cuya definición se encuentra en el Anexo 3. (Pelli, et al. 2007).

Aunque las zonas climáticas que pertenecen al grupo A, definidas por Koppen y ampliadas por Pelli (Pelli et al. 2007), responden a condicionantes botánicas muy particulares, también es cierto que realizando algunos ajustes en los rendimientos de la instalación FV podrían mantener su condición de de NZEB. 
CALIFICACIÓN ENERGÉTICA GLOBAL

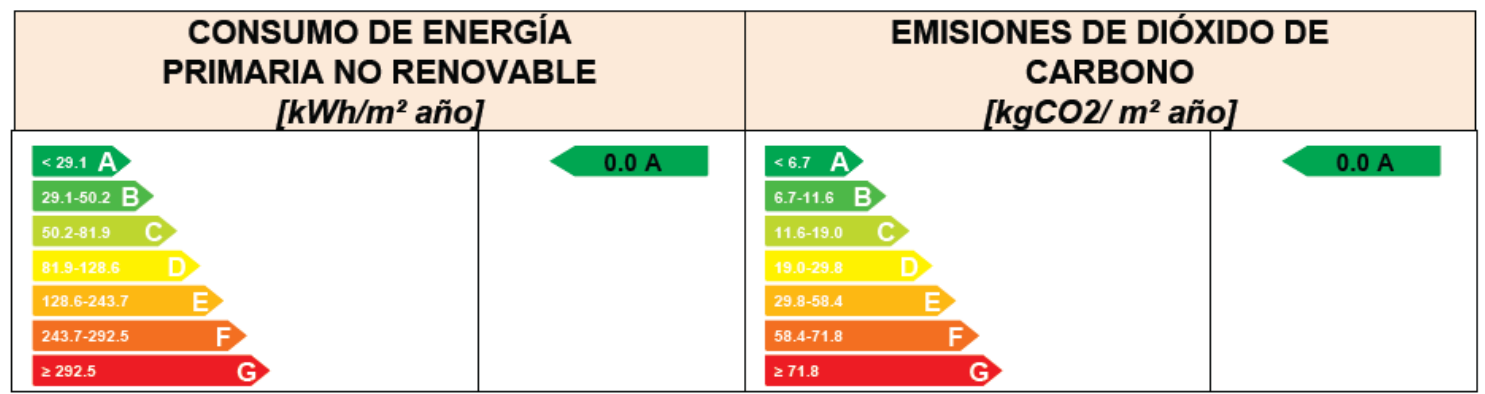

ANALISÍS TÉCNICO

\begin{tabular}{|c|c|c|c|c|c|c|c|c|c|c|c|c|c|c|c|}
\hline \multirow[b]{2}{*}{ Indicador } & \multicolumn{3}{|c|}{ Calefacción } & \multicolumn{3}{|c|}{ Refrigeración } & \multicolumn{3}{|c|}{ ACS } & \multicolumn{3}{|c|}{ Iluminación } & \multicolumn{3}{|c|}{ Total } \\
\hline & \multicolumn{2}{|c|}{ Valor } & $\begin{array}{c}\text { ahorro } \\
\text { respecto a } \\
\text { la situación } \\
\text { original }\end{array}$ & \multicolumn{2}{|c|}{ Valor } & $\begin{array}{c}\text { ahorro } \\
\text { respecto a } \\
\text { la situación } \\
\text { original }\end{array}$ & \multicolumn{2}{|c|}{ Valor } & $\begin{array}{c}\text { ahorro } \\
\text { respecto a } \\
\text { la situación } \\
\text { original }\end{array}$ & \multicolumn{2}{|c|}{ Valor } & $\begin{array}{c}\text { ahorro } \\
\text { respecto a } \\
\text { la situación } \\
\text { original }\end{array}$ & \multicolumn{2}{|c|}{ Valor } & $\begin{array}{c}\text { ahorro } \\
\text { respecto a } \\
\text { la situación } \\
\text { original }\end{array}$ \\
\hline $\begin{array}{l}\text { Consumo Energía } \\
\text { final }\left[\mathrm{kWh} / \mathrm{m}^{2} \text { año] }\right.\end{array}$ & \multicolumn{2}{|c|}{42.34} & $-12.5 \%$ & \multicolumn{2}{|c|}{27.26} & $11.1 \%$ & \multicolumn{2}{|c|}{44.71} & $0.0 \%$ & \multicolumn{2}{|c|}{-} & $-\%$ & \multicolumn{2}{|c|}{-20.57} & $118.2 \%$ \\
\hline $\begin{array}{c}\text { Consumo Energía } \\
\text { primaria no renovable } \\
{\left[\mathrm{kWh} / \mathrm{m}^{2} \text { año] }\right.}\end{array}$ & 82.73 & $E$ & $-12.5 \%$ & 53.27 & $\mathrm{~F}$ & $11.1 \%$ & 87.37 & G & $0.0 \%$ & - & - & $-\%$ & 0.00 & A & $100.0 \%$ \\
\hline $\begin{array}{c}\text { Emisiones de } \mathrm{CO} 2 \\
{\left[\mathrm{kgCO} 2 / \mathrm{m}^{2} \text { año] }\right.}\end{array}$ & 14.01 & $D$ & $-12.5 \%$ & 9.02 & D & $11.1 \%$ & 14.80 & G & $0.0 \%$ & - & - & $-\%$ & 0.00 & A & $100.0 \%$ \\
\hline $\begin{array}{l}\text { Demanda }\left[\mathrm{kWh} / \mathrm{m}^{2}\right. \\
\text { año] }\end{array}$ & 126.47 & G & $0.0 \%$ & 57.47 & $\mathrm{~F}$ & $0.0 \%$ & & & & & & & & & \\
\hline
\end{tabular}

Fig.63. Calificación energética Taller-Vivienda 52m2.Sevilla.

Para caracterizar el prototipo de simulación (Taller-Vivienda $52 \mathrm{~m}^{2}$ ) en la zona climática B4 de CTE y Csa de Koppen, se ha localizado el mismo, teóricamente, en Sevilla. En esta localización geográfica y climática, el prototipo ha alcanzado la definición de NZEB a partir de la implementación de FV 100\% en cubierta.

En los datos de consumo se puede ver como el valor de los consumos de energía del Taller- Vivienda $52 \mathrm{~m}^{2}$ se sitúa en un valor inferior al cero, en cuanto consumo final, y a cero el consumo de energía de fuentes no renovables de energía.

Tipo de mejora: Incorporación de generación fotovoltaica 100 \% en cubierta

Cumplimiento NZEB SI

Cumplimiento nZEB: SI

Cumplimiento CTE:

Zonas climáticas Koppen/CTE:

Csa de Koppen y B4 del CTE

Esta calificación de Koppen, que se basa en datos botánicos de varias zonas del mundo (especies comunes en lugares con climas parecidos), podría representar, para el caso de la instalación FV, un sistema de evaluación simplificada de alto interés proyectual, que combinado con herramientas, también simplificadas como el $\mathrm{CE}^{3} \mathrm{X}$ puedan servir como número inicial para unos cálculos más detallados.

En el mapa siguiente se representan, en una sola imagen, las zonas en las cuales el Taller-Vivienda cumple como NZEB con FV al 100\% en la cubierta. 


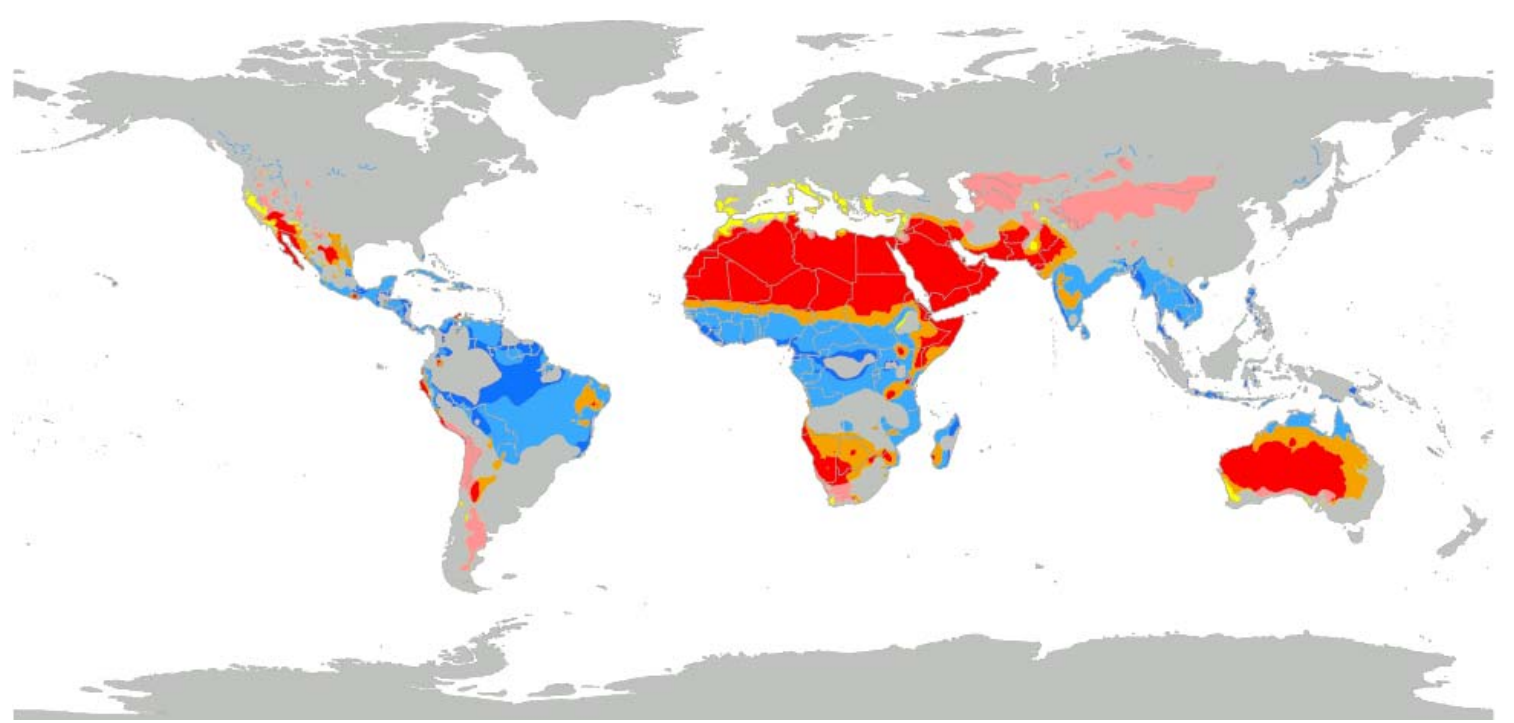

Fig.64 . Mapa zonas climáticas Koppen (BWk, BWh, BWk, BWh, BSh, Aw, Am, Csa). Taller Vivienda NZEB. Medida de mejora: Incorporación del 100 \% FV. Eloboración propia. *

5.3.4 Lugares del mapa de Koppen, donde el Taller-Vivienda $52 \mathrm{~m}^{2}$, cumple 0 se acerca a nZEB. Medidas de Mejoras: 1) Incorporación FV 100\% en cubierta; 2) Incorporación de geotermia.

1) Incorporación FV 100\% en cubierta

Zona Climática BSk (Koppen)/ D3 (CTE). Madrid.

CALIFICACIÓN ENERGÉTICA GLOBAL

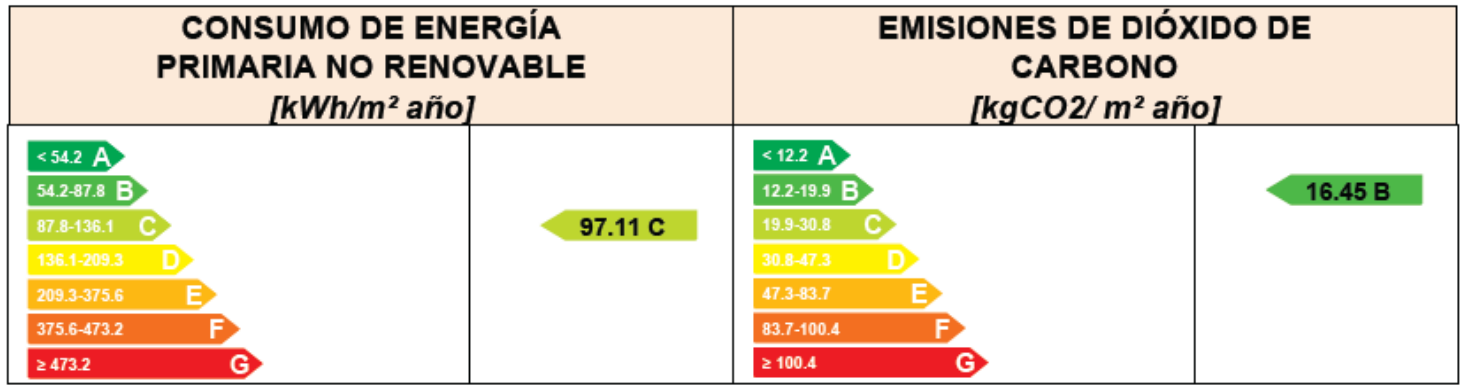

ANALISÍS TÉCNICO

\begin{tabular}{|c|c|c|c|c|c|c|c|c|c|c|c|c|c|c|c|}
\hline \multirow[b]{2}{*}{ Indicador } & \multicolumn{3}{|c|}{ Calefacción } & \multicolumn{3}{|c|}{ Refrigeración } & \multicolumn{3}{|c|}{ ACS } & \multicolumn{3}{|c|}{ Iluminación } & \multicolumn{3}{|c|}{ Total } \\
\hline & \multicolumn{2}{|c|}{ Valor } & $\begin{array}{l}\text { ahorro } \\
\text { respecto a } \\
\text { la situación } \\
\text { original }\end{array}$ & \multicolumn{2}{|c|}{ Valor } & $\begin{array}{c}\text { ahorro } \\
\text { respecto a } \\
\text { la situación } \\
\text { original }\end{array}$ & \multicolumn{2}{|c|}{ Valor } & $\begin{array}{c}\text { ahorro } \\
\text { respecto a } \\
\text { la situación } \\
\text { original }\end{array}$ & \multicolumn{2}{|c|}{ Valor } & $\begin{array}{c}\text { ahorro } \\
\text { respecto a } \\
\text { la situación } \\
\text { original }\end{array}$ & \multicolumn{2}{|c|}{ Valor } & $\begin{array}{c}\text { ahorro } \\
\text { respecto a } \\
\text { la situación } \\
\text { original }\end{array}$ \\
\hline $\begin{array}{l}\text { Consumo Energia } \\
\text { final }\left[\mathrm{kWh} / \mathrm{m}^{2} \text { año] }\right.\end{array}$ & \multicolumn{2}{|c|}{109.55} & $-12.4 \%$ & \multicolumn{2}{|c|}{19.02} & $11.1 \%$ & \multicolumn{2}{|c|}{45.66} & $0.0 \%$ & \multicolumn{2}{|c|}{-} & $-\%$ & \multicolumn{2}{|c|}{49.70} & $69.8 \%$ \\
\hline $\begin{array}{c}\text { Consumo Energia } \\
\text { primaria no renovable } \\
{\left[\mathrm{kWh} / \mathrm{m}^{2} \text { año] }\right.}\end{array}$ & 214.06 & $E$ & $-12.4 \%$ & 37.17 & E & $11.1 \%$ & 89.23 & G & $0.0 \%$ & - & - & $-\%$ & 97.11 & C & $69.8 \%$ \\
\hline $\begin{array}{c}\text { Emisiones de } \mathrm{CO} 2 \\
{\left[\mathrm{kgCO} 2 / \mathrm{m}^{2} \text { año] }\right.}\end{array}$ & 36.26 & E & $-12.4 \%$ & 6.30 & D & $11.1 \%$ & 15.12 & G & $0.0 \%$ & - & - & $-\%$ & 16.45 & B & $69.8 \%$ \\
\hline $\begin{array}{l}\text { Demanda [kWh/m² } \\
\text { año] }\end{array}$ & 266.10 & G & $0.0 \%$ & 44.85 & $F$ & $0.0 \%$ & & & & & & & & & \\
\hline
\end{tabular}

Fig.65. Calificación energética Taller-Vivienda 52m2.Madrid. 
El prototipo alcanza el nZEB dentro de la zona climática D3 definida por el CTE y equivalente a la zona BSk de Koppen, localizándolo en Madrid al incorporar 100\% de FV. De acuerdo a los resultados obtenidos mediante el $C E^{3} \mathrm{X}, \mathrm{y}$ que constan en los anexos (Anexo 6), el ahorro de consumo de energía primaria, con respecto al estado original, sin mejoras, es del $69,8 \%$, equivalente a $49,70 \mathrm{kWh} / \mathrm{m}^{2}$ año .

Tipo de mejora: Incorporación de generación fotovoltaica $100 \%$ en cubierta

Cumplimiento NZEB: NO

Cumplimiento nZEB: SI

Cumplimiento CTE: $\mathrm{SI}$

Zonas climáticas Koppen/CTE: BSk de Koppen y D3 del CTE

Zona Climática Csb (Koppen)/ D2 (CTE). Ourense.

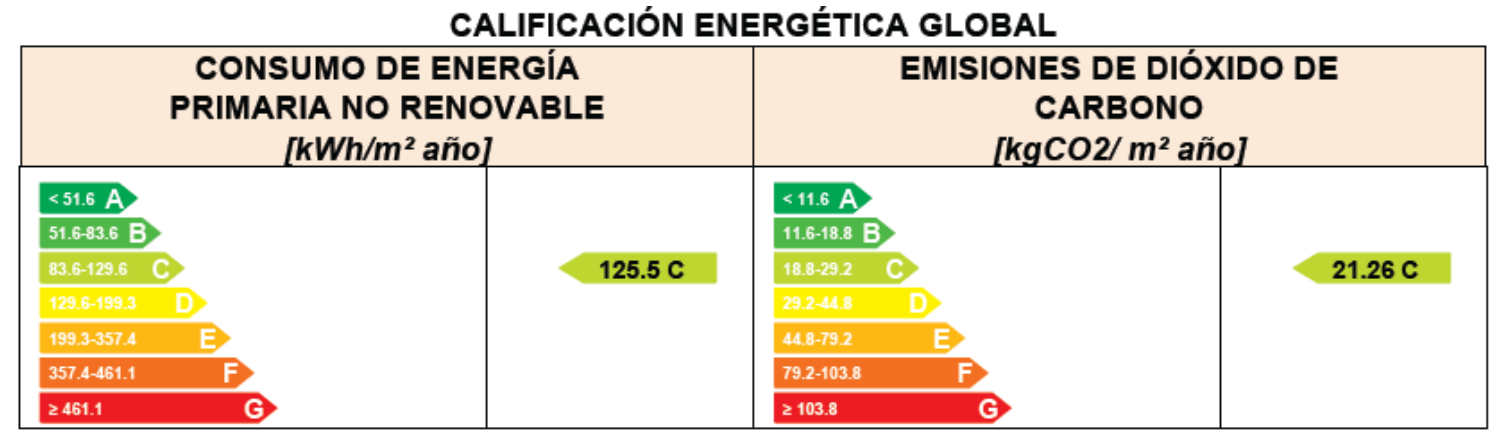

ANALISÍS TÉCNICO

\begin{tabular}{|c|c|c|c|c|c|c|c|c|c|c|c|c|c|c|c|}
\hline \multirow[b]{2}{*}{ Indicador } & \multicolumn{3}{|c|}{ Calefacción } & \multicolumn{3}{|c|}{ Refrigeración } & \multicolumn{3}{|c|}{ ACS } & \multicolumn{3}{|c|}{ Iluminación } & \multicolumn{3}{|c|}{ Total } \\
\hline & \multicolumn{2}{|c|}{ Valor } & $\begin{array}{c}\text { ahorro } \\
\text { respecto a } \\
\text { la situación } \\
\text { original }\end{array}$ & \multicolumn{2}{|c|}{ Valor } & $\begin{array}{c}\text { ahorro } \\
\text { respecto a } \\
\text { la situación } \\
\text { original }\end{array}$ & \multicolumn{2}{|c|}{ Valor } & $\begin{array}{c}\text { ahorro } \\
\text { respecto a } \\
\text { la situación } \\
\text { original }\end{array}$ & \multicolumn{2}{|c|}{ Valor } & $\begin{array}{c}\text { ahorro } \\
\text { respecto a } \\
\text { la situación } \\
\text { original }\end{array}$ & \multicolumn{2}{|c|}{ Valor } & $\begin{array}{c}\text { ahorro } \\
\text { respecto a } \\
\text { la situación } \\
\text { original }\end{array}$ \\
\hline $\begin{array}{l}\text { Consumo Energía } \\
\text { final }\left[\mathrm{kWh} / \mathrm{m}^{2} \text { año] }\right.\end{array}$ & \multicolumn{2}{|c|}{114.50} & $-12.5 \%$ & \multicolumn{2}{|c|}{11.20} & $11.1 \%$ & \multicolumn{2}{|c|}{46.07} & $0.0 \%$ & \multicolumn{2}{|c|}{-} & $-\%$ & \multicolumn{2}{|c|}{64.23} & $60.0 \%$ \\
\hline $\begin{array}{c}\text { Consumo Energía } \\
\text { primaria no renovable } \\
{\left[\mathrm{kWh} / \mathrm{m}^{2} \text { año] }\right.}\end{array}$ & 223.74 & $E$ & $-12.5 \%$ & 21.88 & $\mathrm{~F}$ & $11.1 \%$ & 90.02 & G & $0.0 \%$ & - & - & $-\%$ & 125.50 & C & $60.0 \%$ \\
\hline $\begin{array}{c}\text { Emisiones de } \mathrm{CO} 2 \\
{\left[\mathrm{kgCO} 2 / \mathrm{m}^{2} \text { año] }\right.}\end{array}$ & 37.90 & $E$ & $-12.5 \%$ & 3.71 & D & $11.1 \%$ & 15.25 & G & $0.0 \%$ & - & - & $-\%$ & 21.26 & C & $60.0 \%$ \\
\hline $\begin{array}{c}\text { Demanda [kWh } / \mathrm{m}^{2} \\
\text { año] }\end{array}$ & 266.22 & G & $0.0 \%$ & 28.59 & G & $0.0 \%$ & & & & & & & & & \\
\hline
\end{tabular}

Fig.66. Calificación energética Taller-Vivienda 52m2. Ourense.

De acuerdo al mapa Koppen, de referencia para este estudio, Ourense forma parte de la zona Csb, que de acuerdo a los cálculos con el $\mathrm{CE}^{3} \mathrm{X}$ entraría en la zona donde el prototipo puede cumplir el nZEB con FV 100\%.

A medida que se va realizando el estudio de zonificación se puede contrastar que según se va avanzando hacia el norte, la implementación de FV al 100\% en cubierta convierte al edificio en un en nZEB, dejando el NZEB hacia el sur. En cualquier caso, estos valores siguen siendo optimistas - desde el punto de vista del rendimiento de la instalación- pero en todo caso sirven de aproximación válida para un cálculo rápido y con un sistema de fácil manejo y con herramientas simplificadas. El ahorro que supone 
la incorporación de la FV con relación al estado original es del orden del 60 \%para un valor de $64,23 \mathrm{kWh} / \mathrm{m}^{2}$ año de consumo total de energía.

Tipo de mejora: Incorporación de generación fotovoltaica 100 \% en cubierta

Cumplimiento NZEB: NO

Cumplimiento nZEB: $\mathrm{SI}$

Cumplimiento CTE: $\mathrm{SI}$

Zonas climáticas Koppen/CTE: Csb de Koppen y D2 del CTE

Zona Climática Cfb (Koppen)/ C1 (CTE). Santander

CALIFICACIÓN ENERGÉTICA GLOBAL

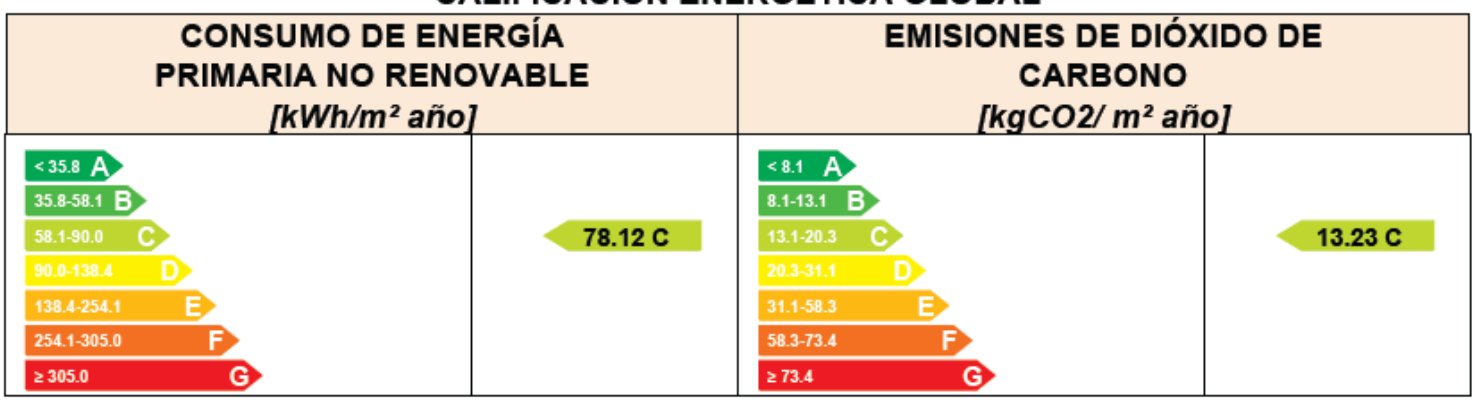

ANALISÍS TÉCNICO

\begin{tabular}{|c|c|c|c|c|c|c|c|c|c|c|c|c|c|c|c|}
\hline \multirow[b]{2}{*}{ Indicador } & \multicolumn{3}{|c|}{ Calefacción } & \multicolumn{3}{|c|}{ Refrigeración } & \multicolumn{3}{|c|}{ ACS } & \multicolumn{3}{|c|}{ Iluminación } & \multicolumn{3}{|c|}{ Total } \\
\hline & \multicolumn{2}{|c|}{ Valor } & $\begin{array}{c}\text { ahorro } \\
\text { respecto a } \\
\text { la situación } \\
\text { original }\end{array}$ & \multicolumn{2}{|c|}{ Valor } & $\begin{array}{l}\text { ahorro } \\
\text { respecto a } \\
\text { la situación } \\
\text { original }\end{array}$ & \multicolumn{2}{|c|}{ Valor } & $\begin{array}{l}\text { ahorro } \\
\text { respecto a } \\
\text { la situación } \\
\text { original }\end{array}$ & \multicolumn{2}{|c|}{ Valor } & $\begin{array}{c}\text { ahorro } \\
\text { respecto a } \\
\text { la situación } \\
\text { original }\end{array}$ & \multicolumn{2}{|c|}{ Valor } & $\begin{array}{l}\text { ahorro } \\
\text { respecto a } \\
\text { la situación } \\
\text { original }\end{array}$ \\
\hline $\begin{array}{l}\text { Consumo Energia } \\
\text { final }\left[\mathrm{kWh} / \mathrm{m}^{2} \text { año] }\right.\end{array}$ & \multicolumn{2}{|c|}{70.29} & $-12.4 \%$ & \multicolumn{2}{|c|}{ - } & $-\%$ & \multicolumn{2}{|c|}{45.74} & $0.0 \%$ & \multicolumn{2}{|l|}{ - } & $-\%$ & \multicolumn{2}{|c|}{39.98} & $65.3 \%$ \\
\hline $\begin{array}{c}\text { Consumo Energía } \\
\text { primaria no renovable } \\
{\left[\mathrm{kWh} / \mathrm{m}^{2} \text { año] }\right.}\end{array}$ & 137.35 & $E$ & $-12.4 \%$ & - & - & $-\%$ & 89.37 & G & $0.0 \%$ & - & - & $-\%$ & 78.12 & C & $65.3 \%$ \\
\hline $\begin{array}{c}\text { Emisiones de } \mathrm{CO} 2 \\
{\left[\mathrm{kgCO} 2 / \mathrm{m}^{2} \text { año] }\right.}\end{array}$ & 23.27 & $D$ & $-12.4 \%$ & - & - & $-\%$ & 15.14 & G & $0.0 \%$ & - & - & $-\%$ & 13.23 & C & $65.3 \%$ \\
\hline $\begin{array}{c}\text { Demanda [kWh/m² } \\
\text { año] }\end{array}$ & 198.23 & G & $0.0 \%$ & - & - & $-\%$ & & & & & & & & & \\
\hline
\end{tabular}

Fig.67. Calificación energética Taller-Vivienda 52m2. Santander.

En el caso de Santander - y las zonas climáticas equiparables de acuerdo al mapa de Koppen - la calificación energética se sitúa en una letra C, en ambos parámetros, igual que Ourense, al incorporar FV al $100 \%$ en cubierta, pudiendo ser considerada como un nZEB. La implementación del sistema fotovoltaico de generación de electricidad, representa un $65.3 \%$ de ahorro respecto a la situación original supuesta y presentada en la parte del cálculo de consumos.

Tipo de mejora: Incorporación de generación fotovoltaica 100 \% en cubierta

Cumplimiento NZEB NO

Cumplimiento nZEB: SI

Cumplimiento CTE: SI

Zonas climáticas Koppen/CTE: .Cfb (Koppen) y C1 del CTE 
Todos los supuestos anteriores corresponden a un nZEB con FV integrada en la cubierta al $100 \%$ de su superficie. En el siguiente mapa se representan las zonas en las cuales el Taller-Vivienda alcanza este nivel de eficiencia.

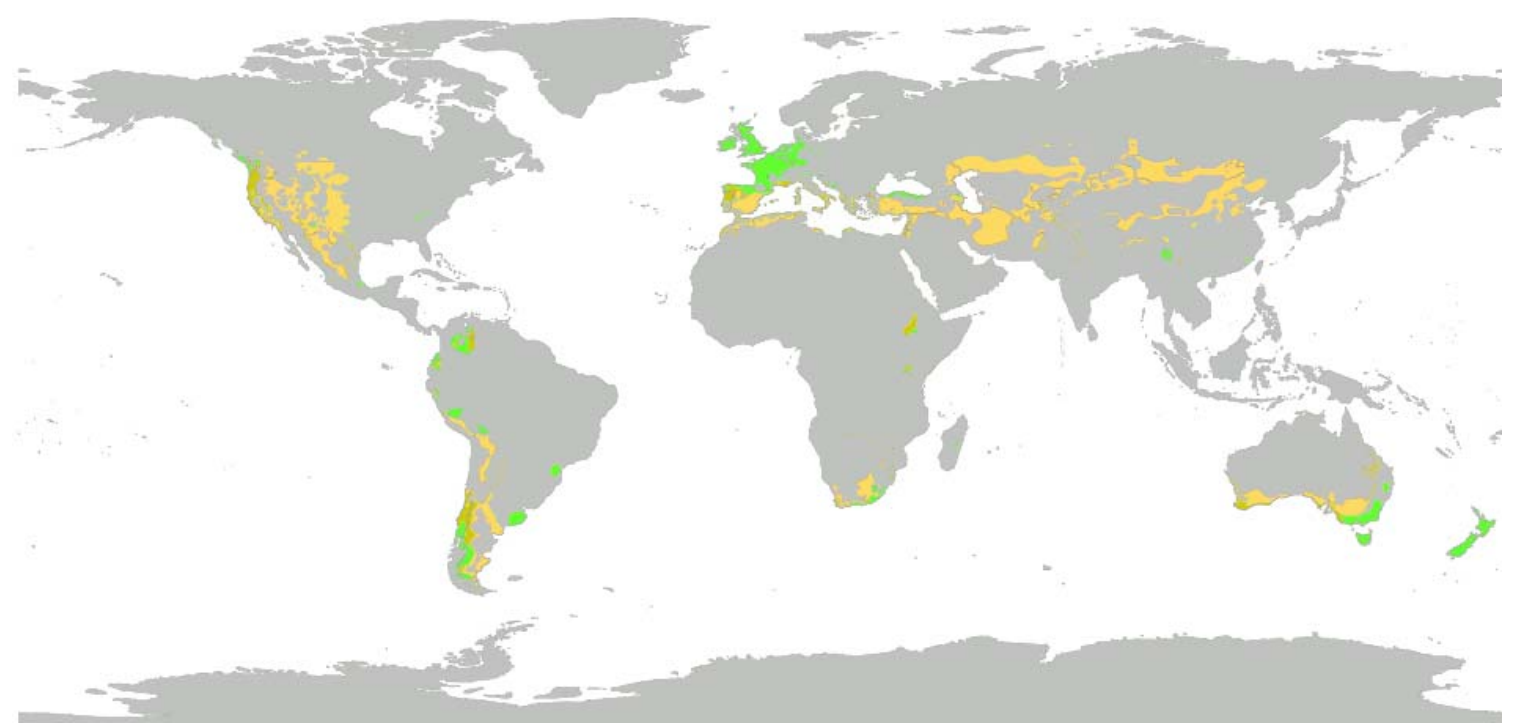

Fig.68. Mapa zonas climáticas Koppen (BSk, Csb, Cfb). Taller Vivienda nZEB. Medida de mejora: Incorporación del 100 \% FV. Eloboración propia.*

En los siguientes ejemplos también es posible alcanzar el nZEB para el Taller-Vivienda y sus ubicaciones teóricas, de acuerdo al mapa de Koppen y a la zonificación climática establecida en el CTE.

Para conseguir el nZEB se implementará, en este caso, un sistema de climatización basado en geotermia y bombas de calor (tierra/agua) de alto COP $(6,43)$ y $\operatorname{EER}(7,18$ de media), integradas a un sistema de vidrios activos con circulación de agua, desarrollados en las tesis tanto de Giménez (Giménez, 2011) como de Pérez-Pujazón (Pérez-Pujazón, 2015). Dichos valores de partida han sido introducidos en el programa de manera alternativa, dado que en su base de datos, no se define la geotermia propiamente dicha.

El programa plantea un tipo de mejora genérico, tal como se muestra a continuación, que permite introducir el concepto de "renovable", por un lado, y aumentar el rendimiento del COPy del EER de las bombas de calor, por el otro, y de acuerdo a los niveles equiparables a un sistema geotérmico. Se plantea entonces un sistema renovable con las características y prestaciones parecidas a la geotermia y dando al acristalamiento doble el valor de $U$ que tendría en caso de contar con circulación de agua en su cámara interior: $1,12 \mathrm{~W} / \mathrm{m}^{2} \mathrm{~K}$.

En cualquier caso, introduciendo lo valores, obtenidos en la parte de la investigación documental de esta tesis, tal como se explica en el epígrafe 4.3.4, es posible colocar al programa en condiciones de generar resultados equiparables a los de un sistema geotérmico como tal y con un nivel de orden de magnitudes parecidas. 

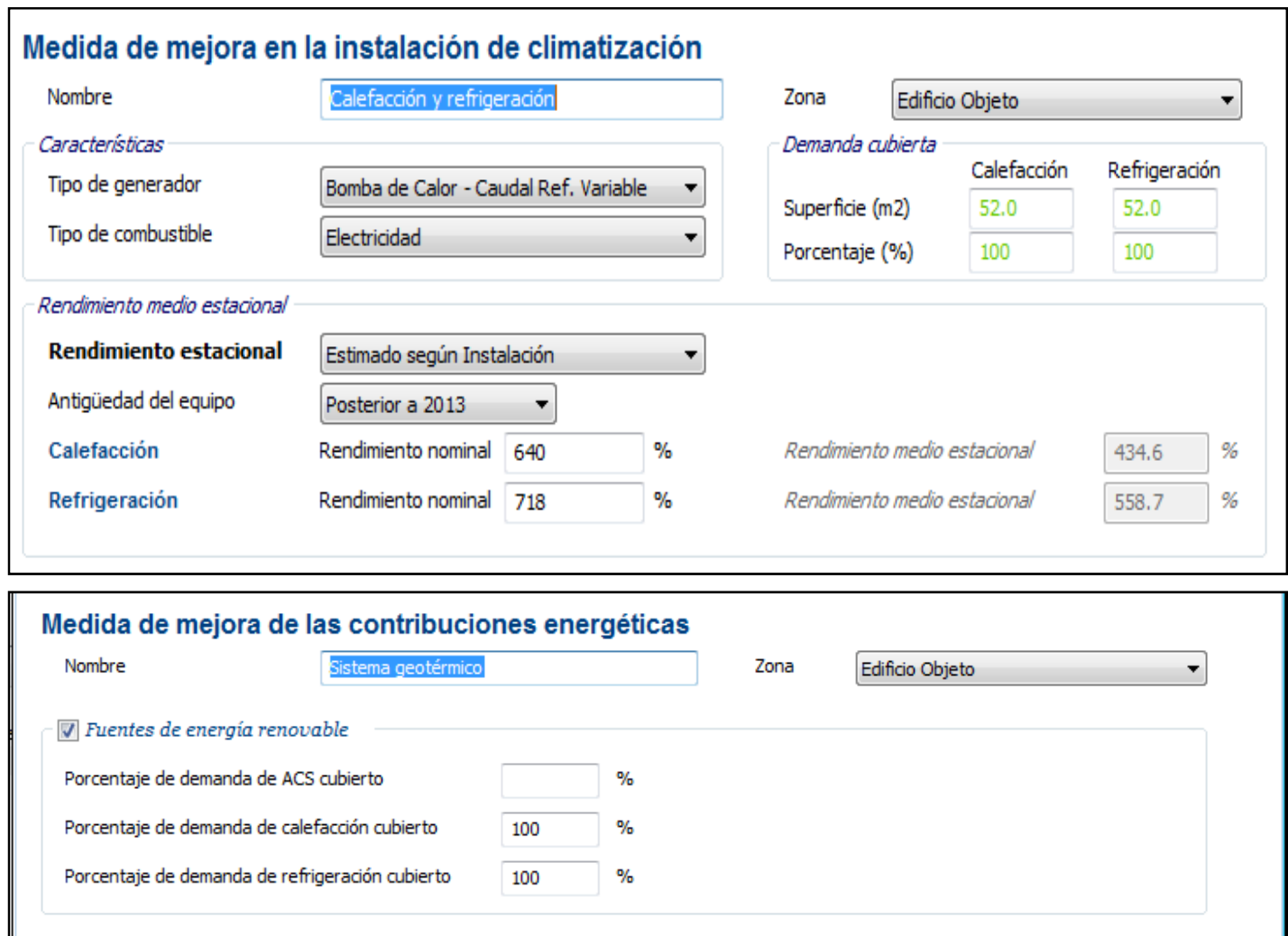

Fig.69. Introducción datos sistema geotérmico en CE3X

2) Incorporación de geotermia + vidrios activos

Zona Climática Dsb (Koppen)/ E1 (CTE). Burgos.

\section{CALIFICACIÓN ENERGÉTICA GLOBAL}

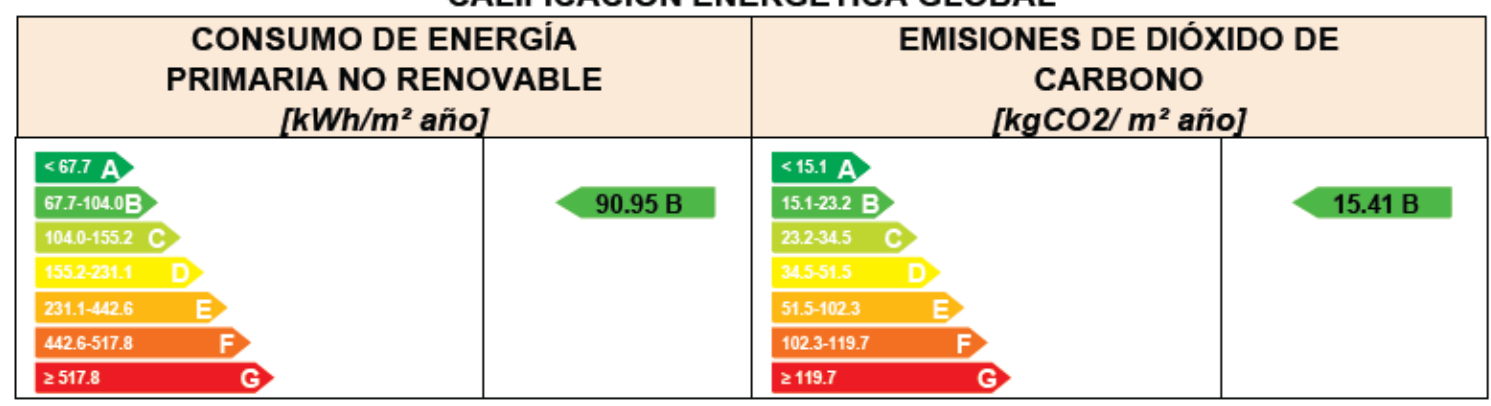

\section{ANALISÍS TÉCNICO}

\begin{tabular}{|c|c|c|c|c|c|c|c|c|c|c|c|c|c|c|c|}
\hline \multirow[b]{2}{*}{ Indicador } & \multicolumn{3}{|c|}{ Calefacción } & \multicolumn{3}{|c|}{ Refrigeración } & \multicolumn{3}{|c|}{ ACS } & \multicolumn{3}{|c|}{ Iluminación } & \multicolumn{3}{|c|}{ Total } \\
\hline & \multicolumn{2}{|c|}{ Valor } & $\begin{array}{c}\text { ahorro } \\
\text { respecto a } \\
\text { la situación } \\
\text { original }\end{array}$ & \multicolumn{2}{|c|}{ Valor } & $\begin{array}{c}\text { ahorro } \\
\text { respecto a } \\
\text { la situación } \\
\text { original }\end{array}$ & \multicolumn{2}{|c|}{ Valor } & $\begin{array}{c}\text { ahorro } \\
\text { respecto a } \\
\text { la situación } \\
\text { original }\end{array}$ & \multicolumn{2}{|c|}{ Valor } & $\begin{array}{c}\text { ahorro } \\
\text { respecto a } \\
\text { la situación } \\
\text { original }\end{array}$ & \multicolumn{2}{|c|}{ Valor } & $\begin{array}{c}\text { ahorro } \\
\text { respecto a } \\
\text { la situación } \\
\text { original }\end{array}$ \\
\hline $\begin{array}{l}\text { Consumo Energía } \\
\text { final }\left[\mathrm{kWh} / \mathrm{m}^{2} \text { año] }\right.\end{array}$ & \multicolumn{2}{|c|}{0.00} & $100.0 \%$ & \multicolumn{2}{|c|}{ - } & $-\%$ & \multicolumn{2}{|c|}{46.54} & $0.0 \%$ & \multicolumn{2}{|c|}{ - } & $-\%$ & \multicolumn{2}{|c|}{46.54} & $75.3 \%$ \\
\hline $\begin{array}{l}\text { Consumo Energía } \\
\text { primaria no renovable } \\
{\left[\mathrm{kWh} / \mathrm{m}^{2} \text { año] }\right.}\end{array}$ & 0.00 & A & $100.0 \%$ & - & - & $-\%$ & 90.95 & G & $0.0 \%$ & - & - & $-\%$ & 90.95 & B & $75.3 \%$ \\
\hline $\begin{array}{c}\text { Emisiones de } \mathrm{CO} 2 \\
{\left[\mathrm{kgCO} 2 / \mathrm{m}^{2} \text { año] }\right.}\end{array}$ & 0.00 & A & $100.0 \%$ & - & - & $-\%$ & 15.41 & G & $0.0 \%$ & - & - & $-\%$ & 15.41 & B & $75.3 \%$ \\
\hline $\begin{array}{c}\text { Demanda }\left[\mathrm{kWh} / \mathrm{m}^{2}\right. \\
\text { año] }\end{array}$ & 149.64 & $\mathrm{E}$ & $54.9 \%$ & - & - & $-\%$ & & & & & & & & & \\
\hline
\end{tabular}

Fig.70. Calificación energética Taller-Vivienda 52m2. Burgos. 
En este caso de Burgos - o la zona climática Dsb de Koppen o E1 del CTE- la calificación energética mejora en dos letras con relación al otro escenario de mejora (FV 100\%), es decir una D $\left(190,63 \mathrm{kWh} / \mathrm{m}^{2}\right.$ año) y que se incluye en el Anexo 6. Con relación al estado original teórico planteado, se obtiene hasta un 75,3\% de mejora. Un punto a destacar es la disminución de la demanda de calefacción con respecto al nZEB obtenido solo con la FV. Esto es debido a que el acristalamiento activo mejora globalmente las prestaciones en cuanto a aislamiento y climatización.

En el escenario de mejora con cerramientos opacos, no se registra un aumento significativo de la eficiencia del modelo al incorporar mejoras en los cerramientos más allá de las conseguidas con la incorporación del vidrio activo

Tipo de mejora: ....... Incorporación de geotermia y bombas de calor de alto COP y EER Cumplimiento NZEB NO

Cumplimiento nZEB: SI

Cumplimiento CTE SI

Zonas climáticas Koppen/CTE: Dsb (Koppen) y E1 del CTE

Zona Climática Cfb (Koppen)/ C1 (CTE). Santander.

CALIFICACIÓN ENERGÉTICA GLOBAL

\begin{tabular}{|c|c|c|c|}
\hline \multicolumn{2}{|c|}{$\begin{array}{l}\text { CONSUMO DE ENERGÍA } \\
\text { PRIMARIA NO RENOVABLE } \\
{\left[\mathrm{kWh} / \mathrm{m}^{2} \text { año] }\right.}\end{array}$} & \multicolumn{2}{|c|}{$\begin{array}{c}\text { EMISIONES DE DIÓXIDO DE } \\
\text { CARBONO } \\
{\left[\mathrm{kg} \mathrm{CO} 2 / \mathrm{m}^{2} \text { año] }\right.}\end{array}$} \\
\hline 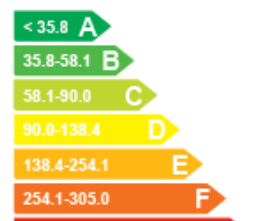 & $89.37 \mathrm{C}$ & 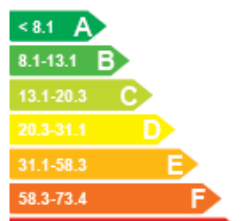 & $15.14 \mathrm{C}$ \\
\hline
\end{tabular}

\section{ANALISÍS TÉCNICO}

\begin{tabular}{|c|c|c|c|c|c|c|c|c|c|c|c|c|c|c|c|}
\hline \multirow[b]{2}{*}{ Indicador } & \multicolumn{3}{|c|}{ Calefacción } & \multicolumn{3}{|c|}{ Refrigeración } & \multicolumn{3}{|c|}{ ACS } & \multicolumn{3}{|c|}{ Iluminación } & \multicolumn{3}{|c|}{ Total } \\
\hline & \multicolumn{2}{|c|}{ Valor } & $\begin{array}{c}\text { ahorro } \\
\text { respecto a } \\
\text { la situación } \\
\text { original }\end{array}$ & \multicolumn{2}{|c|}{ Valor } & $\begin{array}{c}\text { ahorro } \\
\text { respecto a } \\
\text { la situación } \\
\text { original }\end{array}$ & \multicolumn{2}{|c|}{ Valor } & $\begin{array}{c}\text { ahorro } \\
\text { respecto a } \\
\text { la situación } \\
\text { original }\end{array}$ & \multicolumn{2}{|c|}{ Valor } & $\begin{array}{c}\text { ahorro } \\
\text { respecto a } \\
\text { la situación } \\
\text { original }\end{array}$ & \multicolumn{2}{|c|}{ Valor } & $\begin{array}{c}\text { ahorro } \\
\text { respecto a } \\
\text { la situación } \\
\text { original }\end{array}$ \\
\hline $\begin{array}{l}\text { Consumo Energía } \\
\text { final }\left[\mathrm{kWh} / \mathrm{m}^{2} \text { año] }\right.\end{array}$ & \multicolumn{2}{|c|}{0.00} & $100.0 \%$ & \multicolumn{2}{|c|}{ - } & $-\%$ & \multicolumn{2}{|c|}{45.74} & $0.0 \%$ & \multicolumn{2}{|c|}{ - } & $-\%$ & \multicolumn{2}{|c|}{45.74} & $60.3 \%$ \\
\hline $\begin{array}{c}\text { Consumo Energía } \\
\text { primaria no renovable } \\
{\left[\mathrm{kWh} / \mathrm{m}^{2} \text { año] }\right.}\end{array}$ & 0.00 & A & $100.0 \%$ & - & - & $-\%$ & 89.37 & G & $0.0 \%$ & - & - & $-\%$ & 89.37 & C & $60.3 \%$ \\
\hline $\begin{array}{c}\text { Emisiones de } \mathrm{CO} 2 \\
{\left[\mathrm{kgCO} 2 / \mathrm{m}^{2} \text { año] }\right.}\end{array}$ & 0.00 & A & $100.0 \%$ & - & - & $-\%$ & 15.14 & G & $0.0 \%$ & - & - & $-\%$ & 15.14 & C & $60.3 \%$ \\
\hline $\begin{array}{c}\text { Demanda [kWh/m² } \\
\text { año] }\end{array}$ & 154.85 & G & $21.9 \%$ & - & - & $-\%$ & & & & & & & & & \\
\hline
\end{tabular}

Fig.71. Calificación energética Taller-Vivienda 52m2. Santander.

En este escenario, de incorporación de geotermia, se obtiene una calificación C, igual que en el escenario supuesto de incorporación de FV. En el caso de la FV la calificación, aún siendo una $\mathrm{C}$, es mejor que en este caso. 
De cualquier modo queda claramente establecido que tanto una opción como la otra confieren al Taller-Vivienda unos niveles de eficiencia muy superiores a los que pudiera tener en sus condiciones actuales. El porcentaje de mejora con geotermia se sitúa en un $60,30 \%$.

Un dato que se repite es que el nivel de eficiencia no se incrementa, para alcanzar mejores valores que los actuales, con vidrio activo, al incorporar mejoras en los cerramientos opacos

Tipo de mejora: ......Incorporación de geotermia y bombas de calor de alto COP y EER Cumplimiento NZEB:

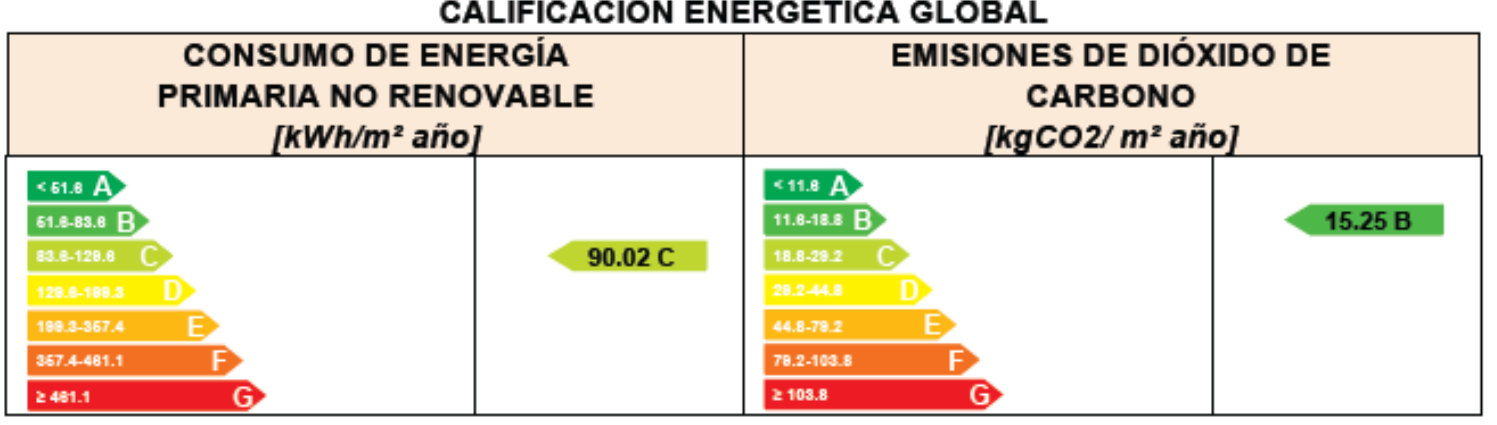

ANALISÍS TÉCNICO

\begin{tabular}{|c|c|c|c|c|c|c|c|c|c|c|c|c|c|c|c|}
\hline \multirow[b]{2}{*}{ Indicador } & \multicolumn{3}{|c|}{ Calefacción } & \multicolumn{3}{|c|}{ Refrigeración } & \multicolumn{3}{|c|}{ ACS } & \multicolumn{3}{|c|}{ Iluminación } & \multicolumn{3}{|c|}{ Total } \\
\hline & \multicolumn{2}{|c|}{ Valor } & $\begin{array}{l}\text { ahorro } \\
\text { respecto a } \\
\text { la situación } \\
\text { original }\end{array}$ & \multicolumn{2}{|c|}{ Valor } & $\begin{array}{c}\text { ahorro } \\
\text { respecto a } \\
\text { la situación } \\
\text { original }\end{array}$ & \multicolumn{2}{|c|}{ Valor } & $\begin{array}{l}\text { ahorro } \\
\text { respecto a } \\
\text { la situación } \\
\text { original }\end{array}$ & \multicolumn{2}{|c|}{ Valor } & $\begin{array}{l}\text { ahorro } \\
\text { respecto a } \\
\text { la situación } \\
\text { original }\end{array}$ & \multicolumn{2}{|c|}{ Valor } & $\begin{array}{c}\text { ahorro } \\
\text { respecto a } \\
\text { la situación } \\
\text { original }\end{array}$ \\
\hline $\begin{array}{l}\text { Consumo Energía } \\
\text { final }\left[\mathrm{kWh} / \mathrm{m}^{2} \text { año] }\right.\end{array}$ & \multicolumn{2}{|c|}{0.00} & $100.0 \%$ & \multicolumn{2}{|c|}{0.00} & $100.0 \%$ & \multicolumn{2}{|c|}{46.07} & $0.0 \%$ & \multicolumn{2}{|l|}{ - } & $-\%$ & \multicolumn{2}{|c|}{46.07} & $71.3 \%$ \\
\hline $\begin{array}{c}\text { Consumo Energía } \\
\text { primaria no renovable } \\
{\left[\mathrm{kWh} / \mathrm{m}^{2} \text { año] }\right.}\end{array}$ & 0.00 & A & $100.0 \%$ & 0.00 & A & $100.0 \%$ & 90.02 & G & $0.0 \%$ & - & - & $-\%$ & 90.02 & C & $71.3 \%$ \\
\hline $\begin{array}{c}\text { Emisiones de } \mathrm{CO} 2 \\
{\left[\mathrm{kgCO} 2 / \mathrm{m}^{2} \text { año] }\right.}\end{array}$ & 0.00 & A & $100.0 \%$ & 0.00 & A & $100.0 \%$ & 15.25 & G & $0.0 \%$ & - & - & $-\%$ & 15.25 & B & $71.3 \%$ \\
\hline $\begin{array}{c}\text { Demanda [kWh/m² } \\
\text { año] }\end{array}$ & 118.99 & $\mathrm{E}$ & $55.3 \%$ & 22.38 & $F$ & $21.7 \%$ & & & & & & & & & \\
\hline
\end{tabular}

Fig.72. Calificación energética Taller-Vivienda 52m2.Ourense.

Aún cuando los niveles de eficiencia energética de la calefacción y la refrigeración se mantenienen en una $A$, mejores que en el escenario de mejora con $\mathrm{FV} 100 \%$, el balance global desciende en la calificación a una letra $C$ en consumo y una $B$ en emisiones. La mejora en la calificación parcial de calefacción y refrigeración se debe a la optimización de los acristalamientos, es decir, al pasar de vidrios simples, a vidrios activos con circulación de agua interior. 
El nivel de mejora con relación al estado original teórico es de un 71,3 \%. Al incorporar mejoras en los cerramientos opacos, no se registra un incremento considerable que haga cambiar la calificación obtenida con la geotermia + vidrios activos.

Tipo de mejora: ...... Incorporación de geotermia y bombas de calor de alto COP y EER

Cumplimiento NZEB NO

Cumplimiento nZEB:

Cumplimiento CTE:

Zona Climática BSk (Koppen)/ D3 (CTE). Madrid.

CALIFICACIÓN ENERGÉTICA GLOBAL

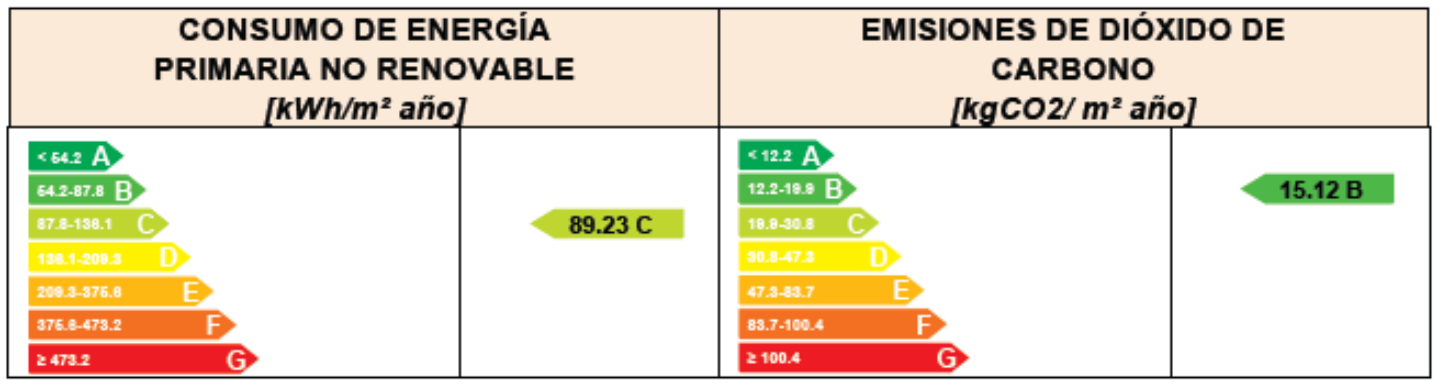

ANALISÍS TÉCNICO

\begin{tabular}{|c|c|c|c|c|c|c|c|c|c|c|c|c|c|c|}
\hline \multirow[b]{2}{*}{ Indicador } & \multicolumn{3}{|c|}{ Calefacción } & \multicolumn{3}{|c|}{ Refrigeración } & \multicolumn{3}{|c|}{ ACS } & \multicolumn{2}{|c|}{ Iluminación } & \multicolumn{3}{|c|}{ Total } \\
\hline & \multicolumn{2}{|c|}{ Valor } & $\begin{array}{c}\text { ahorro } \\
\text { respecto a } \\
\text { la situación } \\
\text { original }\end{array}$ & \multicolumn{2}{|c|}{ Valor } & $\begin{array}{c}\text { ahorro } \\
\text { respecto a } \\
\text { la situación } \\
\text { original }\end{array}$ & \multicolumn{2}{|c|}{ Valor } & $\begin{array}{c}\text { ahorro } \\
\text { respecto a } \\
\text { la situación } \\
\text { original }\end{array}$ & Valor & $\begin{array}{c}\text { ahorro } \\
\text { respecto a } \\
\text { la situación } \\
\text { original }\end{array}$ & \multicolumn{2}{|c|}{ Valor } & $\begin{array}{c}\text { ahorro } \\
\text { respecto a } \\
\text { la situación } \\
\text { original }\end{array}$ \\
\hline $\begin{array}{l}\text { Consumo Energía } \\
\text { final }\left[\mathrm{kWh} / \mathrm{m}^{2} \text { año] }\right.\end{array}$ & \multicolumn{2}{|c|}{0.00} & $100.0 \%$ & \multicolumn{2}{|c|}{0.00} & $100.0 \%$ & \multicolumn{2}{|c|}{45.66} & $0.0 \%$ & - & $-\%$ & \multicolumn{2}{|c|}{45.66} & $72.2 \%$ \\
\hline $\begin{array}{c}\text { primaria no renovable } \\
{\left[\mathrm{kWh} / \mathrm{m}^{2} \text { año] }\right.}\end{array}$ & 0.00 & A & $100.0 \%$ & 0.00 & A & $100.0 \%$ & 89.23 & G & $0.0 \%$ & - & - \% & 89.23 & C & $72.2 \%$ \\
\hline $\begin{array}{l}\text { Emisiones de } \mathrm{CO} 2 \\
{\left[\mathrm{kgCO} 2 / \mathrm{m}^{2} \text { año] }\right.}\end{array}$ & 0.00 & A & $100.0 \%$ & 0.00 & A & $100.0 \%$ & 15.12 & G & $0.0 \%$ & - & - \% & 15.12 & B & $72.2 \%$ \\
\hline $\begin{array}{l}\text { Demanda }\left[\mathrm{kWh} / \mathrm{m}^{2}\right. \\
\text { año] }\end{array}$ & 209.10 & G & $21.4 \%$ & 34.92 & $E$ & $22.2 \%$ & & & & & & & & \\
\hline
\end{tabular}

Fig.73. Calificación energética Taller-Vivienda 52m2. Madrid.

En el caso de la zona climática BSk, el Taller-Vivienda, al incorporar geotermia + vidrios activos como medida de mejora de la eficiencia energética, se mantiene en una calificación $\mathrm{C}$, con relación a la calificación obtenida al incorporar FV. Esta calificación C representa un nivel de eficiencia nZEB de acuerdo a los estándares establecidos y reconocidos internacionalmente, en especial el Passivhaus. Con relación al estado original, el incremento de la eficiencia, es del $72,2 \%$. La mejora obtenida al optimizar los cerramientos no cambia la evaluación global obtenida con las anteriores medidas.

Tipo de mejora: ......Incorporación de geotermia y bombas de calor de alto COP y EER

Cumplimiento NZEB: NO

Cumplimiento nZEB: SI

Cumplimiento CTE: . $\mathrm{SI}$ 
Las zonas climáticas en las cuales el Taller-Vivienda pasa a ser nZEB, al incorporar la geotermia, son las mismas que se representan en el mapa de Koppen siguiente:

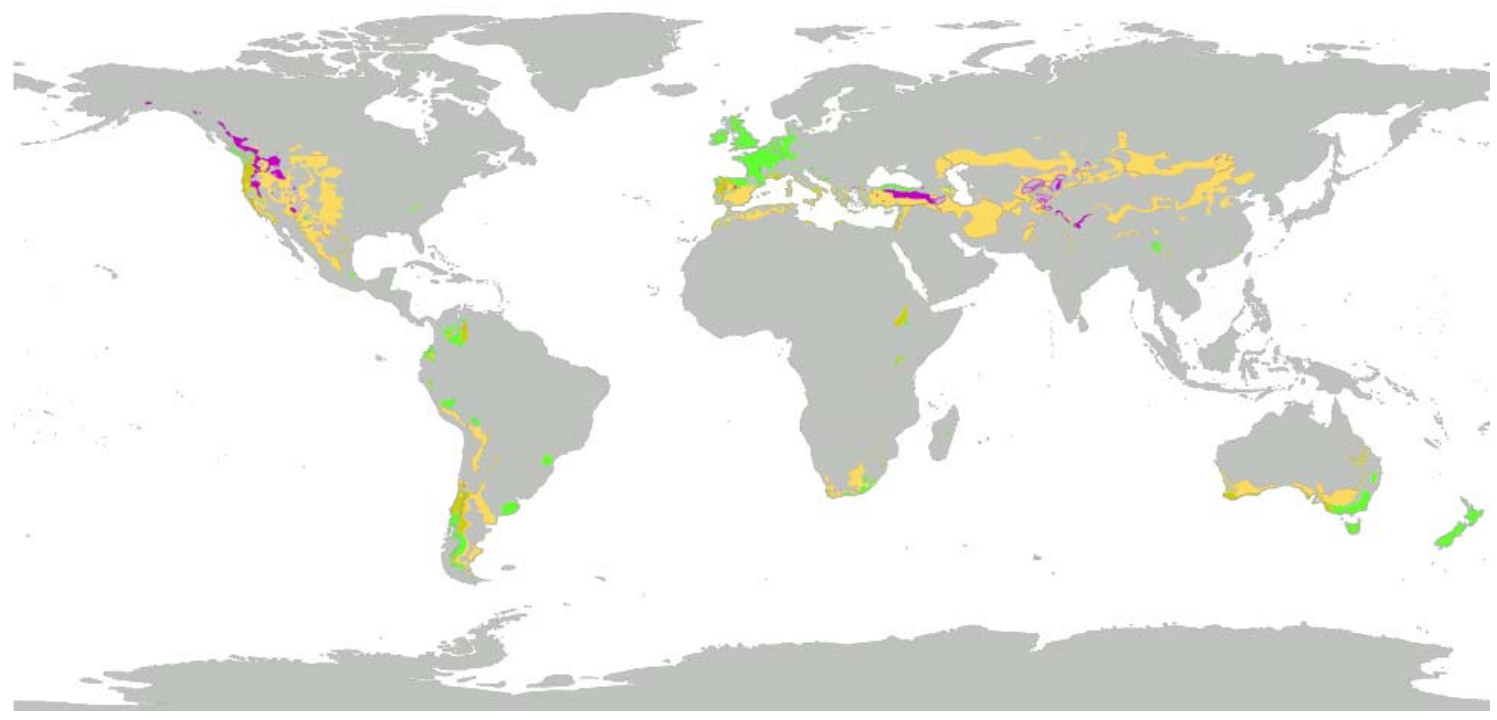

Fig.74. Mapa zonas climáticas Koppen (Dsb, Cfb, Csb, BSk). Taller Vivienda nZEB. Medida de mejora: Incorporación del 100 \% FV. Eloboración propia.*

Un dato interesante a reseñar es que para poder conseguir el NZEB en la zona Dsb (Koppen) que en la zonificación del CTE se equipara con la E1, Burgos, ha sido necesario introducir en el CE3X los dos tipos de medidas de mejora antes implementados, es decir la FV al $100 \%$ en la cubierta y la Geotermia con sistema de vidrios activos. El resultado obtenido es el siguiente:

CALIFICACIÓN ENERGÉTICA GLOBAL

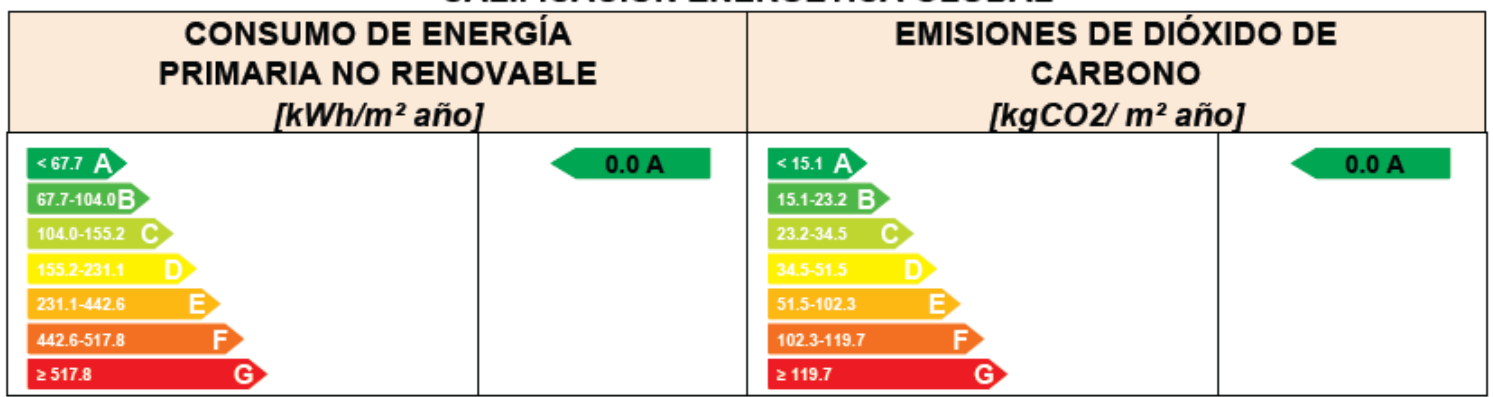

\section{ANALISÍS TÉCNICO}

\begin{tabular}{|c|c|c|c|c|c|c|c|c|c|c|c|c|c|c|c|}
\hline \multirow[b]{2}{*}{ Indicador } & \multicolumn{3}{|c|}{ Calefacción } & \multicolumn{3}{|c|}{ Refrigeración } & \multicolumn{3}{|c|}{ ACS } & \multicolumn{3}{|c|}{ Iluminación } & \multicolumn{3}{|c|}{ Total } \\
\hline & \multicolumn{2}{|c|}{ Valor } & $\begin{array}{c}\text { ahorro } \\
\text { respecto a } \\
\text { la situación } \\
\text { original }\end{array}$ & \multicolumn{2}{|c|}{ Valor } & $\begin{array}{c}\text { ahorro } \\
\text { respecto a } \\
\text { la situación } \\
\text { original }\end{array}$ & \multicolumn{2}{|c|}{ Valor } & $\begin{array}{c}\text { ahorro } \\
\text { respecto a } \\
\text { la situación } \\
\text { original }\end{array}$ & \multicolumn{2}{|c|}{ Valor } & $\begin{array}{c}\text { ahorro } \\
\text { respecto a } \\
\text { la situación } \\
\text { original }\end{array}$ & \multicolumn{2}{|c|}{ Valor } & $\begin{array}{c}\text { ahorro } \\
\text { respecto a } \\
\text { la situación } \\
\text { original }\end{array}$ \\
\hline $\begin{array}{l}\text { Consumo Energía } \\
\text { final }\left[\mathrm{kWh} / \mathrm{m}^{2} \text { año] }\right.\end{array}$ & \multicolumn{2}{|c|}{0.00} & $100.0 \%$ & \multicolumn{2}{|c|}{ - } & $-\%$ & \multicolumn{2}{|c|}{46.54} & $0.0 \%$ & \multicolumn{2}{|c|}{ - } & $-\%$ & \multicolumn{2}{|c|}{-60.51} & $132.1 \%$ \\
\hline $\begin{array}{c}\text { Consumo Energia } \\
\text { primaria no renovable } \\
{\left[\mathrm{kWh} / \mathrm{m}^{2} \text { año] }\right.}\end{array}$ & 0.00 & A & $100.0 \%$ & - & - & $-\%$ & 90.95 & G & $0.0 \%$ & - & - & $-\%$ & 0.00 & A & $100.0 \%$ \\
\hline $\begin{array}{c}\text { Emisiones de } \mathrm{CO} 2 \\
{\left[\mathrm{kgCO} 2 / \mathrm{m}^{2} \text { año] }\right.}\end{array}$ & 0.00 & A & $100.0 \%$ & - & - & $-\%$ & 15.41 & G & $0.0 \%$ & - & - & $-\%$ & 0.00 & A & $100.0 \%$ \\
\hline $\begin{array}{c}\text { Demanda [kWh/m² } \\
\text { año] }\end{array}$ & 261.26 & $F$ & $21.3 \%$ & - & - & $-\%$ & & & & & & & & & \\
\hline
\end{tabular}

Fig.75. Calificación energética Taller-Vivienda 52m2. Burgos.

En el caso del mapa de Koppen no hay una diferencia de color entre Madrid y Sevilla, sin embargo entre las zonas climáticas D3 y B4 sí que existe diferencia en cuanto a la 
calificación energética de acuerdo al $\mathrm{CE}^{3} \mathrm{X}$. Las zonas definidas como nZEB se corresponden, en consumo de $\mathrm{kWh} / \mathrm{m}^{2}$ año, a lo establecido por el estándar pasivo que sitúa esta definición de eficiencia en los $120 \mathrm{kWh} / \mathrm{m}^{2}$ años.

Se ha podido constatar, el último escenario, el de la mejora de los cerramientos, no supone un cambio significativo en la calificación del edificio cuando ya se ha incluido una medida de mejora superior como FV o geotermia, y no supone un ascenso a nZEB por sí sola. A continuación se muestran, a modo de ejemplo, la composición del cerramiento en estado actual y la composición del cerramiento propuesto:

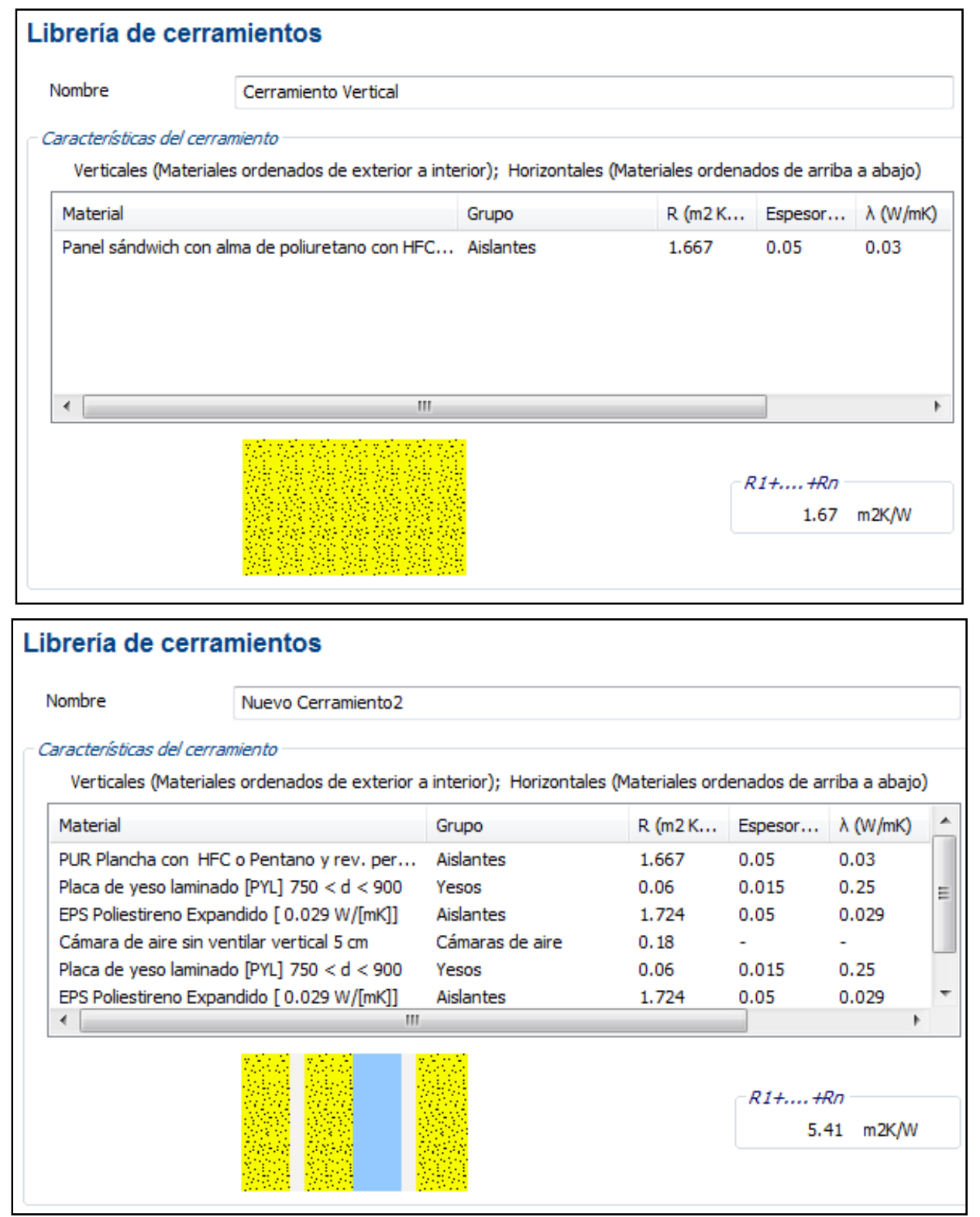

Fig.76. Composición cerramiento actual Taller de Prototipos y cerramiento propuesto Taller Vivienda $52 \mathrm{~m}^{2}$ Programa CE3X.

En la primera de las dos imágenes anteriores se puede ver una representación del tipo de cerramiento actual del Taller-Vivienda con una resistencia total aproximada de 1,67 $\mathrm{m}^{2} \mathrm{~K} / \mathrm{W}$ y un espesor de entre 4 y 5 centímetros del cerramiento. En la segunda imagen se puede observar la mejora en el tipo de cerramiento con la adición de 
diferentes capas interiores de aislamiento y cerramiento para un espesor total de entre 15 y $20 \mathrm{~cm}$, según el espacio de cámara de aire que se prevea dejar. Esta composición, con una resistencia total de $5,41 \mathrm{~m}^{2} \mathrm{~K} / \mathrm{W}$, representa un valor $\mathrm{U}=$ de 0,18 $\mathrm{W} / \mathrm{m}^{2} \mathrm{~K}$, bastante mejor que el valor original $\mathrm{deU}=0,53 \mathrm{~W} / \mathrm{m}^{2} \mathrm{~K}$.

Las mejoras en los cerramientos horizontales, suelo y techo, se expresa en valores con una diferencia similar o superior, en orden de magnitud, a la del cerramiento vertical opaco. En el caso del suelo, pasa de $\mathrm{U}=2,95 \mathrm{~W} / \mathrm{m}^{2} \mathrm{~K}$ a $\mathrm{U}=0,34 \mathrm{~W} / \mathrm{m}^{2} \mathrm{~K}$, y en el caso de la cubierta, pasa de 0,47 W/m2K de transmitancia a menos de la mitad.

En los casos de las calificaciones energéticas (certificados energéticos), realizadas por el autor de esta tesis, durante los años 2013 a 2015 con el programa $C^{3}{ }^{3} X$, se ha podido constatar que las mejoras en los cerramientos, representan un impacto positivo moderado y/o reducido, prácticamente testimonial, frente a las mejoras en los sistemas de calefacción, refrigeración, ACS y generación de renovables.

Dicho esto, también, es preciso señalar que aunque en la calificación global no se registran grandes mejoras al optimizar los cerramientos, sí que es cierto que los niveles de demanda energética por calefacción, e incluso por refrigeración, se reducen al intervenir los mismos, con el consiguiente beneficio en cuanto a la reducción de emisiones de $\mathrm{CO}^{2}$.

Es posible obtener otros resultados, tal como se muestra en la parte de los anexos ( Anexo 6), que optimizarían aún más el prototipo, al combinar la ventajas de la generación $\mathrm{FV}$ al $100 \%$ en la cubierta con las ventajas de la geotermia combinada con vidrios activos, sin embargo esta medida, que ya se ha planteado en otros trabajos académicos, ampliaría el tema hacia otro tipo de consideraciones de índole económico, que quedarían fuera de los objetivos planteados en este trabajo.

Vistos los anteriores resultados se plantea una alternativa - Pirámide Ligera- a la Pirámide de Kioto en la que las energías renovables y los principios de la exergía demuestran ser eficientes para obtener niveles de nZEB y NZEB.
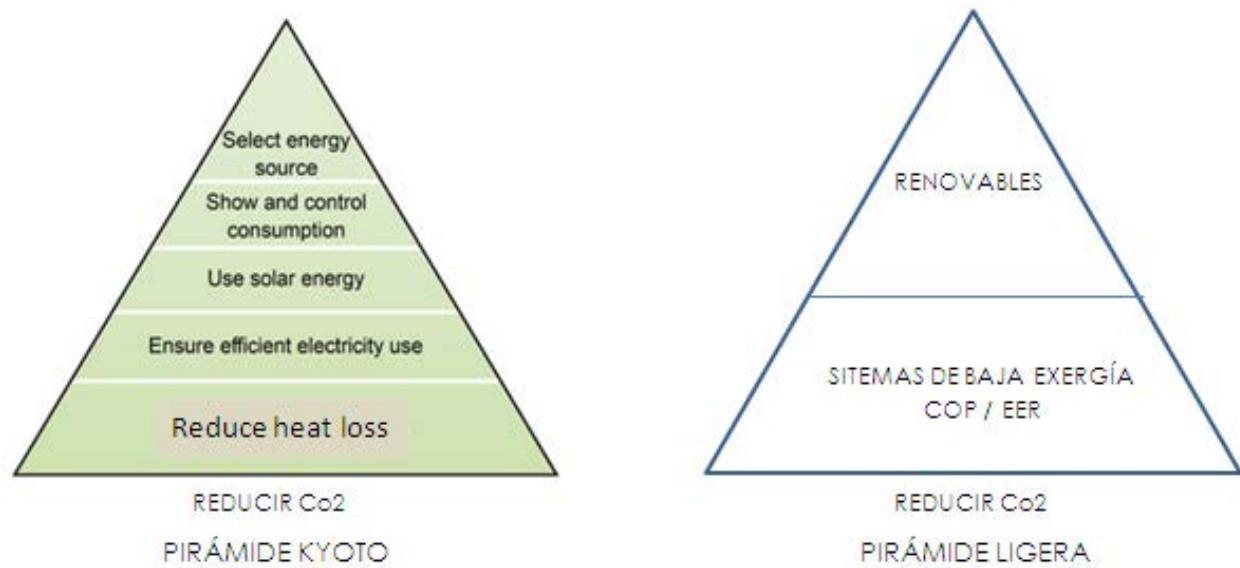

Fig.77. Comparativa Pirámide de Kyoto y Pirámide Ligera propuesta en esta tesis. 
6. CONCLUSIONES 


\section{CONCLUSIONES}

Las conclusiones de esta tesis se han planteado de acuerdo a la estructura empleada para desarrollar la metodología de investigación.

En una primera parte se plantean las conclusiones generales, para luego seguir con las conclusiones documentales, las conclusiones empíricas y las conclusiones de simulaciones. De esta manera se explican de manera detallada los objetivos alcanzados con cada una de las metodologías utilizadas y que han servido para demostrar la hipótesis inicial de trabajo.

\subsection{CONCLUSIONES GENERALES}

Se ha alcanzado el objetivo principal de la tesis, es decir, que se ha demostrado, experimentalmente y con las herramientas informáticas de simulación, que la CML puede ser energéticamente eficiente, llegando a cumplir los estándares de un edificio de consumo de energía casi cero (nZEB) e incluso de consumo cero (NZEB). Concretamente, con envolventes de transmitancia en torno a $0,54 \mathrm{~W} / \mathrm{m}^{2} \mathrm{~K}$ y para el uso de vivienda, se ha conseguido el consumo cero con un $100 \%$ de fotovoltaica en cubierta y en combinación para distintas localidades españolas y que a su vez son equiparables a las zonas definidas por Koppen en su mapa de clima. Además:

- Desde el punto de vista de un balance positivo de ACV, es posible establecer que la CML puede ser una opción más favorable, frente a la construcción tradicional masiva y pesada. Esto se ha comprobado con un prototipo de envolvente muy ligera ubicado en Madrid y extrapolado a otros climas.

- Esta tesis ha comprobado de manera experimental - y confirmado mediante las herramientas de simulación- que la aplicación de medidas pasivas (protecciones para enfriamiento y sobrecalentamiento), no relacionadas con la masividad de los materiales, han resultado ser útiles para la CML.

- Con este trabajo se ha demostrado que se puede desarrollar una CML, con características constructivas convencionales y con altas prestaciones energéticas, más allá de prototipos hiper-optimizados para concursos y/o competiciones y de acuerdo con la línea de investigación desarrollada por Meggers en sus trabajos y artículos.

- La construcción modular ligera y la construcción ligera industrializada han resultado ser equiparables, a la hora de realizar un análisis sobre la eficiencia energética asociada a las mismas. De este modo las investigaciones en este 
campo se pueden realizar indistintamente en construcción modular ligera o simplemente convencional ligera industrializada.

- Gracias a una metodología de investigación conjunta (documental, empírica y de simulaciones), se ha podido definir claramente a la CML como un tipo de construcción que puede llegar a ser altamente eficiente en términos energéticos; esto se ha conseguido discutiendo, comprobando y contrastando, mediante ensayos y simulaciones, los datos teóricos encontrados en la literatura técnica/científica concerniente al tema, como los propios artículos indexados de Meggers, Sartori, Voss Schmidt o Al-Beaini.

- Mediante esta investigación se ha podido profundizar en el conocimiento del comportamiento de los cerramientos ligeros -desde un punto de vista térmico- y de la aplicación de soluciones activas que promueven eficiencia energética, como las renovables y sistemas de baja exergía, como son las bombas de calor, las fachadas activas con agua en circulación y sistemas geotérmicos.

- Este estudio ha permitido evaluar los tipos de soluciones de eficiencia energética más adecuados para ser aplicados en la CML y sus posibles afecciones en cuanto a la naturaleza constructiva (peso, densidad y transmitancia de los materiales) e imagen del edificio, evaluando la contribución de aquellos que suponen una afección menor a la imagen del edificio, como captación en la fachada transparente, fotovoltaica horizontal en cubierta y geotermia.

- La metodología utilizada, combinando el mapa climático de Koppen y la herramienta informática de referencia, para certificaciones energéticas de edificios existentes, $C E^{3} X$, ha permitido estructurar la información de cara a futuras investigaciones sobre los nZEB y NZEB con un método simplificado.

Con este método de simplificación del cálculo de la eficiencia energética, equiparando zonas climáticas definidas en el CTE, con las zonas climáticas definidas en el mapa de Koppen se realiza un aporte para el cálculo inicial números gordos- de proyectos de eficiencia energética.

- Esta tesis favorece la generación del conocimiento en torno a aspectos como la construcción industrializada, la eficiencia energética (contemplada en los objetivos 20/20/20) y la aspectos relacionados a la baja exergía, que son promovidos en el contexto de la Unión Europea, pero que por su limitado volumen de publicaciones, falta de unanimidad de criterios y recientes hallazgos son pocos conocidos por los arquitectos y una gran masa de investigadores. 


\subsection{CONCLUSIONES DOCUMENTALES}

El análisis documental de la información disponible sobre los temas centrales de esta tesis, construcción modular ligera (o construcción ligera industrializada en general) y eficiencia energética, ha permitido elaborar un estado global del arte, que ha servido de base para - mediante las comprobaciones empíricas y de simulaciones- conseguir el objetivo principal de este trabajo: demostrar que la CML puede llegar a ser energéticamente eficiente.

- Aún cuando la construcción ligera industrializada (CLI), la CML y en sentido general la producción en serie de edificios, han sido siempre una aspiración para la arquitectura, los aspectos relacionados a la producción (en serie), los costes, la estandarización y la comercialización, no han podido ser resueltos a niveles equiparables con la industria del automóvil o la industria aeronáutica, para poder establecer una industria de la construcción modular ligera o industrial ligera.

- De acuerdo al estudio de los sistemas y tipos de materiales utilizados en la $\mathrm{CML}$, se ha podido establecer que el ACV de los mismos (contando con que éste sea un ciclo cerrado, desde la extracción de las materias primas y su procesamiento, hasta su reciclaje), resulta más favorable que el de la construcción tradicional pesada, tomando en cuenta que la relación entre kilogramo y metro cuadrado de construcción ligera es menor (en torno a los 175 y $200 \mathrm{~kg} / \mathrm{m} 2$ ) que en la construcción pesada (superior a $290 \mathrm{~kg} / \mathrm{m} 2$ en el caso de una muro de ladrillo : enlucido de yeso + ladrillo hueco doble + aislamiento de $6 \mathrm{~cm}+1 / 2$ pie de ladrillo perforado cara vista).

- La madera es, sin duda, el material con menor impacto ambiental y mejor balance de ACV. Sus prestaciones estructurales y de durabilidad quedan validadas con sistemas tan contrastados como el Balloon Frame. Otros materiales más comprometidos a nivel de emisiones como el acero, el aluminio o el vidrio compensan su balance de ACV por su relativa facilidad de reciclaje y/o reutilización (y su utilización en cantidades menores), frente a materiales cerámicos o derivados del cemento.

- En términos reales - a nivel histórico y en la actualidad- no se asocian los conceptos de construcción ligera y eficiencia energética (como un concepto global), más allá de reclamos comerciales y/o publicitarios. Sin embargo sí que existen ejemplos históricos, testimoniales, como la Casa Wichita o las Casas Tropicales, que incorporan soluciones pasivas de acondicionamiento que optimizan las prestaciones de las mismas. Esto indica que determinadas tendencias de investigación de eficiencia energética basadas en la 
construcción masiva y pasiva, ignoran deliberadamente estos antecedentes significativos.

- Aunque en sentido general, la literatura técnica especializada trata sobre la construcción ligera y la eficiencia energética de manera separada, existe material científico que aborda el tema de manera conjunta, como son los casos de los artículos indexados de Meggers y la tesis de Wadel, que han servido para colocar en contexto el tema de manera unificada. Las casas del concurso Solar Decathlon se pueden considerar como un ejemplo de combinación de estos criterios, como consecuencia de las exigencias (de alta eficiencia) y condicionantes (necesidad de fácil transporte y montaje) del concurso.

- El gran banco de datos conjunto, que sobre construcción modular ligera (o simplemente ligera) y eficiencia energética, significan los concursos del Solar Decathlon (SD), permite que los prototipos participantes en el mismo, puedan llegar a ser evaluados con criterios científicos, de cara a los estándares de nZEB y NZEB, y más allá, incluso, de las condiciones que permite el propio concurso. Tomando como escenario de estudio las ediciones del SD Europe 2010 y 2012, se ha podido determinar esta condición de alta eficiencia en el $100 \%$ de los casos estudiados (33 ligeras y 2 no ligeras).

- También se ha podido determinar que aunque las viviendas del SD Europe 2010 y 2012 son efectivamente EPB (Energy Plus Building) e incluso NZEB (por estar conectadas a la red del campus de la competición), la naturaleza de su diseño hiper-optimizado energéticamente (superproducción de EERR y sobredimensionado de las soluciones constructivas eficientes) y las condicionantes del concurso- sobre todo de tiempo- no permiten hacer una evaluación del todo objetiva de los prototipos. Esto sí es posible con el análisis (con ensayos y simulaciones) del Taller de Prototipos de la ETSAM, que es un modelo CML con soluciones constructivas convencionales. Por tanto sigue faltando un verdadero banco de resultados sistemáticos de experimentación y del cual esta tesis forma parte de una iniciativa en esa dirección, utilizando el mapa de Koppen como una herramienta de comparación de resultados en distintas zonas climáticas.

- Los conceptos de nZEB y NZEB pueden llegar a aplicarse en el contexto de la CML apoyados en la implementación de sistemas de baja exergía (Low Ex) considerando altos COP y EER, e incluso, con la combinación de las mismas en sistemas integrados.

- Estudiando los planteamientos de la Pirámide de Kioto, como fórmula para conseguir la eficiencia energética en la edificación convencional y dentro del contexto de los objetivos 20/20/20 y la Directiva 2010/31/UE, se ha podido plantear en esta tesis, de manera empírica, como alternativa de eficiencia 
energética en la CML la Pirámide Ligera, basada en los principios de NZEB y Low Ex estudiados por autores como Voss, Sartori y Meggers.

- Esta Pirámide Ligera, que se pretende desarrollar a partir de esta tesis, tiene como contexto los objetivos 20/20/20 y la Directiva 2010/31 y se fundamenta en el objetivo fundamental de reducción del $\mathrm{CO}_{2}$ sobre la base de los sistemas de baja exergía asociados a las EERR.

\subsection{CONCLUSIONES EXPERIMENTALES}

Mediante los ensayos se han podido comprobar, de manera experimental, varias situaciones teóricas de diseño que han permitido llegar a conclusiones sobre alternativas para la optimización de las prestaciones energéticas del taller de prototipos como una célula de ensayo y modelo de CML. De igual manera las cámaras de ensayo o cajas colocadas en la cubierta de la escuela han servido como complemento y apoyo para los ensayos en el taller.

Puntualmente, con los ensayos se ha podido demostrar que algunas soluciones pasivas - y a la vez ligeras- como la colocación de estores interiores y la protección tipo malla microperforada exterior, pueden resultar un complemento efectivo - dentro de las soluciones ligeras- para conseguir mejorar los niveles de eficiencia energética en la CML.

- Gracias a los ensayos se han podido calibrar los modelos de simulaciones, contrastando la información en ambos casos. Esto ha incluido desde el comportamiento de los cerramientos según tipo, composición, características y ubicación, hasta los equipos de climatización en cuanto a consumos y rendimientos.

- Las diferencias apreciables en las mediciones de temperatura interior del Taller de Prototipos, con el espacio acondicionado, entre tipos de cerramientos y su ubicación a cara interior --como por ejemplo el Vidrio Norte $\left(16,38^{\circ} \mathrm{C}\right)$ y el Techo $\left(20,95^{\circ} \mathrm{C}\right)--$ han servido para poder determinar mediante simulaciones las soluciones de diseño más viables en cuanto a confort térmico (aislamiento, utilización de sistemas de acondicionamiento).

- Con la colocación de protección interior nocturna (estores opacos de color blanco), en el $45 \%$ de los acristalamientos del Taller de Prototipos, se ha conseguido una diferencia de hasta $1,24{ }^{\circ} \mathrm{C}$ de temperatura interior con respecto a las mediciones sin estores. Esto quiere decir que mientras la diferencia de temperatura entre interior y exterior sin estores colocados es de $6,5^{\circ} \mathrm{C}$, con los estores colocados es de $7,74^{\circ} \mathrm{C}$. 
- Partiendo de estos datos y con un consumo promedio que oscila entre los 600 y los $726 \mathrm{~W} / \mathrm{hr}$, por cada calentador eléctrico colocado en el Taller de Prototipos, se ha podido calcular que los estores representan un ahorro de 88 W/h. por cada calentador, es decir $176 \mathrm{~W} / \mathrm{h}$ de ahorro total.

- Para poder determinar experimentalmente y de manera puntual, el nivel de protección exterior de la malla tipo Ferrari, se han utilizado las dos cámaras de ensayos colocadas en la cubierta de la escuela. Al colocar la malla en el acristalamiento de una de las cajas, y dejado la segunda caja sin malla, se ha determinado que efectivamente la malla puede llegar a tener un nivel de protección aproximada de hasta el $35 \%$ para evitar sobrecalentamientos y pérdidas de temperatura interiores de aproximadamente $11 \%$ para condiciones diurnas y nocturnas respectivamente y temperatura media de $11,8^{\circ} \mathrm{C}$ para el período de mediciones.

- Entre la caja con malla de protección y la caja sin malla de protección (ambas con sistema de calefacción de $20 \mathrm{~W} / \mathrm{hr}$ ), la diferencia de temperatura promedio fue de $2,8^{\circ} \mathrm{C}$ para condiciones de frío, es decir que la protección podría suponer un ahorro de $2,55 \mathrm{~W} / \mathrm{h}$ aproximadamente.

- En cuanto a la protección contra sobrecalentamiento, se comprobó que la caja con malla microperforada impidió el sobrecalentamiento con una diferencia de $23,66^{\circ} \mathrm{C}$ promedio, con relación a la caja no protegida. En ambos casos se mantuvo la aportación calorífica interior para acentuar las posibles diferencias y poder realizar los ejercicios de comparación.

\subsection{CONCLUSIONES DE SIMULACIONES}

La utilización combinada de resultados de diferentes programas de simulación (Energy Plus, CALENER Y Ce3x) ha permitido una mayor variedad de escenarios de diseño de CML y una mejor interpretación de los resultados obtenidos.

Gracias a esta combinación de resultados, y basándose en el análisis de la literatura técnica y científica y en los ensayos realizados en el taller de Prototipos y las cajas o cámara de pruebas, se ha podido determinar que la CML puede ser energéticamente eficiente y nZEB o NZEB con la implementación de renovables y sistemas de baja exergía, de acuerdo a lo establecido en la pirámide Ligera.

- El uso de Fotovoltaica en la cubierta del Taller (convertida a uso de vivienda de $52 \mathrm{~m}^{2}$ ), ha permitido que el mismo obtenga la calificación $A, N Z E B$, en las zonas climáticas de Koopen equiparables al sur de España y a las Islas Canarias. La FV ha permitido obtener niveles de nZEB en las zonas climáticas de Koppen equiparables al centro y norte de España. El uso de otros sistemas 
renovables o de baja exergía como las bobas de calor geotérmicas y vidrio dinámicos con cámara de agua, permiten obtener calificaciones $\mathrm{B}$ y $\mathrm{C}$ de nZEB en el centro y norte de España y en las zonas climáticas de Koppen equiparables.

Con este programa de calificación energética $C E^{3} X$, no se han obtenido resultados muy diferentes, en cuanto a mejora de las prestaciones energéticas (calificación energética global), entre el escenario de mejora con bomba geotérmica y vidrios activos y el escenario de mejora que además de esta medida incluía la mejora en los cerramientos opacos, hasta alcanzar una $\mathrm{U}=$ $0,18 \mathrm{~W} / \mathrm{m}^{2} \mathrm{~K}$ y espesores entre 15 y $20 \mathrm{~cm}$.

- Queda demostrado mediante las simulaciones realizadas, con el Taller como objeto de estudio, que un edificio de CML con características constructivas convencionales, puede llegar a ser altamente eficiente sin una hiperoptimización de sus prestaciones energéticas fuera de toda lógica de mercado, e incluso alcanzar niveles de nZEB y NZEB, basándose en los principios de la Pirámide Ligera que se plantean en esta tesis.

También se demuestra que, aún siendo el $\mathrm{CE}^{3} \mathrm{X}$ un programa ideado para un método simplificado de calificación energética de edificios existentes, con unos alcances de resultados no tan detallados como otros programas de simulación energética de edificios; es viable obtener una información técnica fiable para, en términos de prestaciones energéticas de edificios, hacer una primera aproximación y/o introducción hacia cálculos más detallados en un proyecto de eficiencia energética.

Al combinar este programa - el CE3X- diseñado para realizar la calificación energética, mediante opción simplificada y que es una de las herramientas informáticas promovidas por el Ministerio de Industria de España, para estos fines, con el mapa de zonas climáticas de Koppen, se ha podido realizar un estudio técnicamente solvente y confirmar su idoneidad como sistema de evaluación. 


\section{LÍNEAS FUTURAS DE INVESTIGACIÓN}

\section{LÍNEAS FUTURAS DE INVESTIGACIÓN}

Se plantean cinco líneas futuras de investigación paralelas y hasta cierto punto complementarias.

- Una primera línea sería la ampliación del estudio de los prototipos de los concursos Solar Decathlon, para la elaboración de una guía de buenas prácticas para la CML Energéticamente Eficiente.

- La segunda línea sería completar un análisis exhaustivo del ciclo de vida de los materiales para la CML e integrarlos a la guía.

- La tercera línea sería un estudio pormenorizado para la adaptación, bajo un criterio unificad, del concepto NZEB a la normativa española.

- La elaboración de un procedimiento, a partir de la experiencia de esta tesis, que permita evaluar de manera simplificada y a modo de primera aproximación de proyecto - y en cualquier zona climática del mundo a modo de números gordos- los niveles de eficiencia energética de un edificio.

- Por último y quizás la más ambiciosa está la posibilidad de desarrollar una célula cero energía en el Taller de Prototipos de la ETSAM. 


\section{OTROS TRABAJOS DE INVESTIGACIÓN Y/O DIFUSIÓN}

\section{OTROS TRABAJOS DE INVESTIGACIÓN YIO DIFUSIÓN}

Otros trabajos de investigación y/o publicaciones científicas o de divulgación, realizados por el autor de esta tesis, o en los que ha participado, son los que se relacionan a continuación:

\subsection{PATENTES}

1) “Cerramiento Dinámico para Edificaciones" (2015). Nº solicitud P201530064.

Fecha solicitud 20/01/2015.

Solicitante: Universidad Politécnica de Madrid (en proceso de tramitación)

Coinventores: B. Lauret Aguirregabiria, G. Ovando Vacarezza, B. Pérez-

Pujazón Millán, L. J. Claros Marfil, J.M. Lirola Pérez, E. Castañeda Vergara, J.C. Sánchez González.

2) "Panel Reforzado para Cerramientos Opacos en Construcciones" (2015). No solicitud P201530690.

Fecha solicitud 19/05/2015.

Solicitante: Universidad Politécnica de Madrid (en proceso de tramitación) Coinventores: Prefabricados Ponce, E. Castañeda Vergara, B. Lauret Aguirregabiria, J.M. Lirola Pérez, B. Pérez- Pujazón Millán, G. Ovando Vacarezza, L. J. Claros Marfil, J.C. Sánchez González.

\subsection{COMUNICACIONES A CONGRESOS}

1) “Active Transparent Façades Including Water-flow Glazing" (2015). Actas Congreso Internacional. VII International Congress on Architectural Envelopes. ISBN: 978-84-88734-10-5. B. Pérez - Pujazón Millán, B. Lauret Aguirregabiria, G. Ovando Vacarezza, J.C. Sánchez González, J.M. Lirola Pérez.

2) "Reducción de la demanda de refrigeración mediante acristalamientos activos con cámara de agua en circulación para su integración en Edificios de Energía Casi Nula". (2015). Actas XIII Congreso Ibero-americano de Climatización y Refrigeración. ISBN: 978-84-606-9212-6. B. Pérez Pujazón Millán; B. Lauret Aguirregabiria; J.M. Lirola Pérez; J.C. Sánchez González, G. Ovando Vacarezza, E. Castañeda Vergara, L. J. Claros Marfil.

\subsection{OTRAS PUBLICACIONES}


Desde el año 2012 (febrero) y hasta la redacción de esta tesis, el autor de la misma ha desarrollado una labor divulgativa, sobre temas relacionados con la arquitectura y la eficiencia energética, con la publicación semanal de la columna Arquitectura y Energía en el diario digital, de contenido generalista, Acento ( www.acento.com.do), para la Rep. Dominicana y el área del Caribe.

\subsection{CONCURSOS}

Durante el año 2014 el autor de esta tesis participó, como parte del equipo E-BOX, en el concurso ACTÚA-UPM XI, siendo seleccionado entre los 10 primeros equipos en la primera fase del concurso. En dicho certamen (de fomento para la creación de empresas de base tecnológica), promovido por de la Universidad Politécnica de Madrid, fue desarrollado, junto a Benito Lauret Aguirregabiria, Belén Pérez Pujazón y Luis Claros Marfil, un proyecto para la comercialización teórica de modelos de CML eficientes, para situaciones de emergencia y/o contingencia, así como para su utilización dentro del mercado habitual para este tipo de construcciones ( unidades móviles para obras, control de seguridad, kioscos, etc).

\subsection{TRABAJO DE INVESTIGACIÓN PARA DEA (Diplomado de Estudios Avanzados).}

En el año 2009 como trabajo previo de investigación a esta tesis, el autor de la misma presentó el trabajo (para la obtención del DEA / Suficiencia Investigadora), "Arquitectura Solar en Países Tropicales Emergentes. Tecnología Fotovoltaica; El Escenario Dominicano". En el mismo se llevó a cabo un estudio sobre la implementación de energías renovables en la edificación - especialmente la fotovoltaica - y su integración al argumento arquitectónico de esta. Se planteó un escenario tropical, a modo de ejemplo, como la República Dominicana y que posteriormente, en el desarrollo de esta tesis, se ha ampliado, tomando como referencia el mapa de zonas climáticas de Koppen y tomando la CML como vehículo para la implementación de las medidas de mejora de la eficiencia energética, mediante el uso de renovables, como la fotovoltaica y los principios de la exergía mediante bombas de calor y geotermia. 


\section{BIBLIOGRAFÍA}

\section{BIBLIOGRAFÍA}

\subsection{ARTÍCULOS INDEXADOS (JCR)}

- Serra, B. ; P. Verdejo; Díaz A. ; Merí, R. (2014). Assembling sustainable ideas: The construction process of the proposal SML system at the Solar Decathlon Europe 2012. Energy and Buildings 83; 186-194.

- Rodríguez, E. ; Rodríguez, S. ; Voss, K. ; Todorovic, M. (2014). Energy efficiency evaluation of zero energy houses. Energy and Buildings 83; 23-35.

- Rodríguez, E. ; Montero,C. ; Porteros, M. ; Vega,S. ; Navarro, I. ; CastilloCagigalc, M. ; Matallanasc, E. ; Gutiérrez, A. (2014). Passive design strategies and performance of Net Energy Plus Houses. Energy and Buildings 83; 10-22.

- Navarro, I. ; Gutiérrez, A. ; Montero, C. ; Rodríguez, E. ; Matallanasa, E. ; Castillo-Cagigala, M. ; Porteros, M. ; Solórzanod, J. ; Caamaño-Martín, E. ; Egidod, M.; Páeza, J. ; Vega, S. (2014). Experiences and methodology in a multidisciplinary energy and architecture competition: Solar Decathlon Europe 2012.

- Cerón, I. ; Caamaño-Martín, E. ; Neila, J. (2013). State-of-the-art' of building integrated photovoltaic products. Renewable Energy 58; 127-133.

- Bruelisauer, M. ; Chen, K.; lyengar, R. ; Leibundgut, H.; Li, C.; Li, M. ; Mast, M. ; Forrest Meggers ; Clayton Miller ; Dino Rossi; Esmail M. Saber ; Arno Schlueter ; Kwok Wai Tham. (2013). BubbleZERO—Design, Construction and Operation of a Transportable Research Laboratory for Low Exergy Building System Evaluation in the Tropics. Energies 6; 4551-4571.

- Meggers, F. ; Pantelic, J.; Baldini. L. ; Saber, E. ; Kim, M. (2013). Evaluating and adapting low exergy systems with decentralized ventilation for tropical climates. Energy and Buildings 67; 559-567.

- Sartori , I. ; Napolitano, A. ; Voss, K. (2012). Net zero energy buildings: A consistent definition framework. Energy and Buildings 48; 220-232.

- Meggers, F.; Leibundgut F. ; Kennedy, S. ; Qin M. ; Schlaich, M. ; Sobek, W. ; Shukuya, M. (2012). Reduce CO2 from buildings with technology to zero emissions. Sustainable Cities and Society 2; 29- 36. 
- Meggers, F. ; Ritter, V. ; Goffin, P; Baetschmann; M. ; Leibundgut, H. (2012). Low Exergy building systems implementation. Energy 41; 48-55.

- Rodríguez, E. ; Ruiz, L. ; Vega, S. ; Neila, J. (2012). Applications of Phase Change Material in highly energy-efficient houses. Energy and Buildings 50; 49-62

- Marszal, A. ; Heiselberg, P. ; Bourrelle, J. ; Musall, E. ; Voss, K. ; Sartori, I; Napolitano, A. (2011). Zero Energy Building - A review of definitions and calculation methodologies. Energy and Buildings 43; 971-979.

- $\quad$ Torio, H. ; Angelotti, A. ; Schmidt, D. (2009). Exergy analysis of renewable energy-based climatisation systems for buildings: A critical view. Energy and Buildings 41; 248-271.

- Zabalza, I. ; Valero, A. ; Aranda, A. (2011). Life cycle assessment of building materials: Comparative analysis of energy and environmental impacts and evaluation of the eco-efficiency improvement potential. Building and Environment 46 ; 1133-1140

- Dodoo, A.; Gustavsson, L. ; Sathres, R. (2014). Lifecycle carbon implications of conventional and low-energy multi-storey timber building systems. Energy and Buildings 82; 194-210.

- Visa, S. ; Moldovan, M. ; Comsit, M. ; Duta, A. (2014). Improving the renewable energy mix in a building toward the nearly zero energy status. Energy and Buildings 68; 72-78.

\subsection{OTROS ARTÍCULOS Y PUBLICACIONES CIENTÍFICAS}

- Rodriguez, E. (2015).From High Energy Efficiency to Zero Energy Buildings: Passive Strategies and Other Energy Efficient Solutions Used by Solar Decathlon Europe 2012 Houses. Solar Decathlon Europe 2012; Improving Energy Efficient Buildings.

- Lirola, J. ; Lauret, B. ; Khayet, M. ; Rashevski, M. ; Claros, L. ; Perez, B. ; Ovando, G. (2014). Energy Consumption And Thermal Behavior Of A Light Construction Room-Sized Test Cell. Construction And Building Research XIII; 193-200.

- Sarmirnto, J. ( 2013). Antecedentes de la vivienda industrializada como propuesta ecológica. HITO: Revista de Arquitectura 27; 28-41.

- Mercader, M; Ramírez, A; Olivares, M. (2012). Modelo de cuantificación de las emisiones de $\mathrm{Co} 2$ producidas en edificación derivadas de los recursos 
materiales consumidos en su ejecución. Informes de la Construcción (64) 527; 401-414.

- Cepeda, J. (2011). Prefabricación Ligera de Viviendas. Curso FIDAS Proyectar y Construir con Prefabricadas. FIDAS (Fundación para la Investigación y Difusión de la Arquitectura).

- Voss, K. Musall, E. ; Lichtme, M. (2011). From low-energy to net zeroenergy buildings: status and perspectives. Journal of Green Building; 6(1):4657.

- Queipo, J; Navarro, J. ; Izquierdo, M. ; Del Águila, A. ; Guinea, D. ; Villamor, M. ; Vega, S. ; Neila, J. ( 2009). Proyecto de investigación INVISO: Industrialización de viviendas sostenibles. Informes de la Construcción (61), 513; 73-86.

- Al-Beaini, S. ; Borgeson, S. ; Cofegory, B. ; Konis, K. ; Scown, C. ; Simjanovic, J.; Stanley, J. ; Strogen, B.; Walker, I. ( 2009). Feasibility of Achieving a Zero-Net-Energy, Zero-Net-Cost Homes. Lawrence Berkeley National Laboratory.

- Luengo, E. ( 2007). Una Aproximación a los Paneles Sándwich. Seguridad Laboral $n^{\circ}$ 108. Ed Mapfre Seguros.

Sarmanho, A. ; Moraes, R. (2012). Steel Framing: Arquitectura. Ed. Alacero. Brasil.

- Ala-Juusela, M. (2005).Heating and Cooling with Focus on Increased Energy Efficiency and Improved Comfort, Guidebook to IEA ECBCS Annex 37 Low Exergy, Systems for Heating and Cooling of Buildings.

- Schmidt, D. (2005). Designing Low-"Exergy" Buildings. IEA ECBCS Annex 37 Low Exergy, Systems for Heating and Cooling of Buildings.

Mateo, J. ; Bosch; C. ; Fernandez, F. ; Ramos, E; Royo, A.; Guillen, J. (1978). Caracola Edificaciones Modulares. Informes de la Construcción (30), nº 297.

\subsection{PONENCIAS Y COMUNICACIONES A CONGRESOS.}

- Pérez, B. ; Lauret B. ; Lirola, J. ; Sánchez, J. ; Ovando G. ; Castañeda, E. ; Claros, L. (2015). Reducción de la Demanda de Refrigeración mediante acristalamientos activos con cámara de agua en circulación para su integración en edificios de energía casi nula. XIII Congreso Ibero-americano De Climatización Y Refrigeración. 
- Díaz, N. (2015). Edificios de consumo de energía casi nulo. Passivhaus. Jornadas Técnicas Sobre nuevos Requisitos del CTE de la Edificación DB- HE.

- Pérez - Pujazón , B; Lauret Aguirregabiria, B; Ovando Vacarezza, G; Sánchez González, J; Lirola Pérez, J. (2015). Active Transparent Façades including Water-Flow Glazing. VII International Congress on Architectural Envelopes.

- Avellaneda, J; Mrkonjic, K. (2015). Retro-Innovación y Arquitectura Sostenible.

- Catalán, L. (2014). Avances en el ámbito reglamentario español: hacia los Edificios de Consumo de Energía Casi Nulo. Jornadas Edificación, rehabilitación y regeneración urbana. Los retos energéticos y el papel de la vivienda social.

- Galloa, A; Téllez, B; Prodanovica, M; González, J; Romero; M. (2014). Analysis of net Zero-Energy Building in Spain. Integration of PV, solar domestic hot water and air-conditioning systems. Energy Procedia $48 ; 828-836$.

- Musall,E. ; Voss, K. (2012). The Passive House Concept as Suitable Basis towards Net Zero Energy Buildings. 16 th. Passive House Conference.

- Wallpe J. ; Hutzel, W. ; Lasker, G.; Cory, C. (2012). Evaluating Net-Zero Energy Houses from the U.S. Department of Energy Solar Decathlon 2011. Construction Research Congress 2012. ASCE 2012.

- Ovando G. ; Lauret , B. ; Lirola, J. ; Castañeda, E. (2012). Technical evolution of 3D modular construction from the nineteenth century to World War II. 2d. International Conference on Construction and Building Research.

- Fernández, M. (2012) Aplicación del concepto de exergía a los edificios de energía casi nula. I Congreso de Edificios De Energía Casi Nula.

- Salom, J. ; Widén, J. ; Candanedo, J. ; Sartori. I. ; Voss, K. ; Marszal, A. (2011). Understanding net zero energy buildings: Evaluation of load matching and grid interaction indicators. 12th Conference of International Building Performance Simulation Association.

- Ovando, G.; Lauret, B. (2008). Industrialización y sostenibilidad en viviendas: Aplicación de la construcción modular ligera a casas solares. Il Jornadas de Investigación en la Edificación. 
- Torcellini, P. ; Pless, S. ; Deru, M. (2006). Zero Energy Buildings: A Critical Look at the Definition. ACEEE Summer Study.

\subsection{LIBROS Y GUÍAS}

- Wassouf, M. (2014). De la casa pasiva al estándar passivhaus. La Arquitectura en climas cálidos. Ed. GG. Barcelona.

- $\quad$ Catherine, C. (2014). Jean Prouvé: Maison demontable 8x8 =demountable house. Ed. Galerie Patrick Seguin. Londres.

- Kettenmann, A. (2014). Case Study Houses. The Complete CSH Program, 1944-1966. Ed. Taschen; Colonia.

- Smith, E. ; Gössel,P. (2013). Case Study Houses. The Complete CSH Program, 1944-1966. Ed. Taschen; Colonia.

- Vega, S; Serra, J. (2013). Solar Decathlon Europe 2012; Improving Energy Efficient Buildings. Ed. Solar Decathlon Europe + Universidad Politécnica de Madrid; Madrid

- $\quad$ AA VV. Fenercom.(2013).Guía Sobre Construcción Industrializada de Viviendas Eficientes. Ed. Fenercom y D.G. Industria Energía y minas De La Comunidad De Madrid.

- Cassinello, P. (2013). Eduardo Torroja 1949: strategy to industrialise housing in post-World War II. Ed. Fundación Eduardo Torroja. Madrid.

- Cepeda, J. (2013). Prefabricación ligera de viviendas. Nuevas premisas. Ed. Editorial Universidad de Sevilla-Secretariado de Publicaciones; Sevilla.

- Paredes, C. (Editora). (2012). Eco Arquitectura. Sostenibles, Bioclimáticas, Eficientes. Ed. Susaeta.

- Sánchez De León. (2012). Sistema constructivo. Casa Wichita 1946, R. Buckminster Fuller. Ed. Issu.

- AA. VV. DRAGADOS. (2012). Sistema de Edificación Modular Caracola. DIT 593/12. Ed. Instituto de Ciencias de la Construcción Eduardo Torroja.

- Zabalza, I. ; Aranda, A. ( 2011). Eficiencia Energética. Ecodiseño en la Edificación. Ed. Prensas Universitarias de Zaragoza. 
- Vega, S. (2011). Solar Decathlon Europe 2010; Towards Energy Efficient Buildings. Ed. 10ACTION Proiect; Madrid.

- AA VV. FENERCOM ( 2011). Guía del estándar passivhaus. Edificios de consumo energético casi nulo. Ed. Fenercom.

- $\quad$ AA VV. IDAE. (2011). Guía Práctica de la energía. Consumo Eficiente y Responsable. Ed. IDAE; Madrid.

- AA VV. IDAE. (2010). Informes Técnicos IDAE. Programa Solcasa. Ed. IDAE; Madrid.

- AA. VV. IDAE. (2010). Informes Técnicos IDAE. Programa Geotcasa. Ed. IDAE; Madrid.

- Cobbers, A. ; Jahn, O. (2010). Prefab Houses. Tachen. Colonia.

- Bergdoll,B. ; Christensen, P. (2009) Home Delivery: Fabricating the Modern Dwelling. Ed. Construction History Society. Cambridge.

- Cinqualbre, O. (2009). Jean Prouvé : La maison tropicale = The tropical house. Ed. Centre Pompidou. Paris.

- Ruano, M. (Editor) (2008). Un Vitruvio Ecológico; Principios y Prácticas del Proyecto Arquitectónico Sostenible. Ed. G.G. Barcelona.

- Eguaras, M.(Editor). (2008). Casas Ecológicas. Ed. Loft/Kolon. Barcelona.

- Federico, N. (2008). Fuller houses : R. Buckminster Fuller's, dymaxion dwellings and other domestic adventures. Ed. Lars Müller Publishers. Zürich.

- Federico, N. (2008). Buckminster Fuller. Ed. Infolio. Gollion.

- M. Hays. (2008). Buckminster Fuller: Starting with the universe. Ed. Whitney Museum of American Art.

- Martín, N.; Fernández, I. (2007). La Envolvente Fotovoltaica en la Arquitectura. Ed. Reverté; Barcelona.

- Schleifer, S. (Editor). (2007). Pequeñas Casas Ecológicas. Ed. Evergreen/Tachen. Colonia.

- Águila, A. (2006). La industrialización de la edificación de viviendas, Ed. Mairea; Madrid. 
- AA. VV. (2006). Les maisons tropicales. Catalogue Exhibition large Brazzaville Tropical House . Ed. galerie 54. Paris.

- $\quad$ Lupfer, G. ; Sigel, P. (2006). Walter Gropius 1883-1969. Propagandista del nuevo diseño. Ed. Tachen. Madrid.

- Hermannsdorfer, I. ; Rub, C. (2005). Solar Design; Photovoltaics for Old Buildings, Urban Space, Landscapes. Ed. Jovis; Berlin.

- Gorman, M. (2005). Buckmister Fuller: architettura in movimento. Ed. Skira 2005.

- $\quad$ Lavalou, A. (2005). Conversaciones con Jean Prouvé. Ed. GG. Barcelona

- Strike, J. (2004). De la construcción a los proyectos: La influencia de las nuevas técnicas en el diseño arquitectónico, 1700-2000. Ed. Reverté.

- Neila González, J. (2004). Arquitectura bioclimática en un entorno sostenible. Ed. Munilla-lería; Madrid.

- Olgyay, V. (2004). Arquitectura y Clima; Manual De Diseño Bioclimático para Arquitectos y Urbanistas. Ed. GG; Barcelona.

- Serrasolses, J. (2004). Tejados Fotovoltaicos. Energía Solar Conectada a la Red Eléctrica. Ed. Progensa; Sevilla.

- AA VV.Junta De Castilla y León. (2004). Energía Solar Fotovoltaica; Manual Del Arquitecto. Eren; Ed. Castilla y León.

- AA VV. Junta De Castilla y León. (2004). Energía Solar Fotovoltaica; Manual Del Proyectista. Eren; Ed. Castilla y León.

- Serra, R. (2004). Arquitectura y Climas. Ed. GG; Barcelona

- Schittich, C. (ed.). (2003) Arquitectura Solar; Estrategias, Visiones y Conceptos. Ed. Detail. Basilea.

- Shulman, J. ; Smith, E. ; Gössel; P. (2002). Case Study Houses. The Complete CSH Program (1945-1966). Ed. Tachen. Colonia.

- Sulzer, P. (2002). Jean Prouvé : highlights, 1917-1944. Ed. Princeton Architectural Press. Nueva York.

- Hawkes, D. ; Foster, W. ( 2002). Ingeniería, Arquitectura y Medioambiente. Ed. Cisspraxis. Valencia. 
- $\quad$ AA VV. (2001). Manual Del Vidrio. Ed. Saint Gobain Glass. Madrid.

- Baker, G. ; Castán, S. (2000). Le Corbusier. Análisis De La Forma. Ed. GG. Barcelona.

- Krausse, J. ; Lichtenstein, C. (1999). Your Private Sky. Ed. Lars Muller Publisher.

- Berdini, P. (1994). Walter Gropius. Obras y proyectos. Ed. GG. Barcelona.

- Gans, D. ; Castán, S. (1992). Guías de Arquitectura. Le Corbusier. Ed. GG. Barcelona.

- Ward, J. (1985). The artifacts of R. Buckminster Fuller. A Comprehensive Collection of His Designs and Drawings in Four Volumes. Ed. Garland Publishing. EE.UU.

\subsection{TESIS}

- Ovando Vacarezza, G. (2015). Criterios técnicos del proyecto con módulos tridimensionales ligeros: las casas del Solar Decathlon 2005 y 2007. Universidad Politécnica De Madrid. Madrid.

- Pérez- Pujazón, B. (2015) La implementación arquitectónica de los acristalamientos activos con agua circulante, y su contribución en edificios de consumo casi nulo. Universidad Politécnica De Madrid. Madrid.

- Ruiz, L. (2013). Optimización y propuesta de sistema opaco de cerramiento multicapa ligero con estructura de Light Steel Frame como alternativa competitiva a los sistemas de cerramientos tradicionales. Universidad Politécnica De Madrid. Madrid.

- Pastor, L. (2012). Sistema De Cerramiento Transparente De Alta Eficiencia Energética y Forma Libre $\left(\mathrm{F}^{2} \mathrm{TE}^{3}\right)$. Universidad Politécnica De Madrid. Madrid.

- Giménez, C. (2011). Alternativas para la mejora de la eficiencia energética de los acristalamientos: Ios vidrios dinámicos. Universidad Politécnica De Madrid. Madrid.

- Zabalza, I. (2010). Adaptación de la metodología del análisis del ciclo de vida para la evaluación y la mejora del impacto energético y ambiental de la edificación. Universidad de Zaragoza. Zaragoza. 
- Wadel, G. (2009). La sostenibilidad en la construcción industrializada. La construcción Modular Ligera aplicada a la vivienda. Universidad Politécnica de Cataluña.

\subsection{TRABAJOS DE INVESTIGACIÓN D.E.A. (Diplomado de Estudios} Avanzados)

- Sánchez, J. (2009). Arquitectura Solar en Países Tropicales Emergentes. Tecnología Fotovoltaica, El Escenario Dominicano. DCTA-ETSAM. Universidad Politécnica De Madrid. Madrid.

- Ovando, G. (2006). Módulos Tridimensionales Ligeros en Viviendas. DCTAETSAM. Universidad Politécnica De Madrid. Madrid.

\subsection{OTROS TRABAJOS ACADÉMICOS}

- Rashevski, M. (2012). Célula de Energía Cero. Trabajo Final de la Asignatura Vidrio Estructural ; DCTA-ETSAM. Universidad Politécnica De Madrid. Madrid.

- Pérez, B. (2011). Sistema de transferencia, disipación y acumulación térmica que optimice el funcionamiento de un cerramiento activo de vidrio con agua en circulación. Proyecto De Tesis Doctoral. DCTA-ETSAM. Universidad Politécnica De Madrid. Madrid.

- Zornoza, B. (2009). Reglas de Ejecución para Estructuras Metálicas Ligeras. Proyecto de Tesina de Especialidad sobre Estructuras Metálicas. Universidad Politécnica de Cataluña.

\subsection{REVISTAS TÉCNICAS}

- $\quad$ AA V. TECTÓNICA 38 (2012). Industrialización. Ed. ATC Ediciones. Madrid.

- $\quad$ AA W. El Croquis 136/164 (2012). Glenn Murcutt 1980-2012. Plumas de Metal. Ed. El Croquis Editorial. Madrid.

AA W. TECTÓNICA 36 (2011). Arquitectura Textil. Ed: ATC Ediciones. Madrid.

- AA VV. AV Monografías 149 (2011). Jean Prouvé 1901-1984. Ed. Arquitectura Viva. Madrid. 
- AA VV. DETAIL GREEN (02- 2011). Dossier: Acumuladores de calor latente. Ed. DETAIL. Bilbao.

- $\quad$ AA VV. DETAIL GREEN (07- 2010). Prefabricación Sostenible Ed. DETAIL. Bilbao.

- $\quad$ AA W. TECTÓNICA 31 (2010). Energía. Fundamentos. Ed. ATC Ediciones. Madrid.

- $\quad$ AA W. TECTÓNICA 32 (2010). Envolventes Metálicas. Ed. ATC Ediciones. Madrid.

- $\quad$ AA W. INFODOMUS 15 (2008). Ed. Informanews Iberia S.A. Madrid.

- $\quad$ AA W. INFODOMUS 16 (2008). Ed. Informanews Iberia S.A. Madrid.

- $\quad$ AA VV. DETAIL (02- 2007). Arquitecturas en Vidrio Ed. DETAIL. Bilbao.

- $\quad$ AA W. TECTÓNICA 22 (2006). Aluminio. Ed. ATC Ediciones. Madrid.

- $\quad$ AA W. TECTÓNICA 19 (2005). Plásticos. Ed. ATC Ediciones. Madrid.

- $\quad$ AA VV. DETAIL (04- 2005). Arquitectura Solar. Ed. DETAIL. Bilbao.

- $\quad$ AA W. TECTÓNICA 13 (2000). Madera (II). Estructuras. Ed. ATC Ediciones. Madrid.

- $\quad$ AA W. TECTÓNICA 9 (1998). Acero (I). Ed. ATC Ediciones. Madrid.

- $\quad$ AA W. TECTÓNICA 10 (1998). Vidrio (I). Ed. ATC Ediciones. Madrid.

- AA W. TECTÓNICA 1 (1996). Envolventes (I) Fachadas ligeras. Ed. ATC Ediciones. Madrid.

- AA W. TECTÓNICA 2 (1996). Envolventes (II) Fachadas ligeras. Ed. ATC Ediciones. Madrid.

\subsection{NORMATIVAS}

- R.D.900/2015 del 9 de octubre, por el que se regulan las condiciones administrativas, técnicas y económicas de las modalidades de suministro de energía eléctrica con autoconsumo y de producción con autoconsumo.

- Documento Básico sobre Ahorro de Energía del Código Técnico de la Edificación DB-HE CTE. (Versión diciembre 2014). 
- Reglamento de Instalaciones Térmicas en los Edificios (RITE); Versión Consolidada 2013

- Directiva 2012 / 27 / UE del Parlamento Europeo sobre Eficiencia Energética.

- Directiva 2010 / 31 / UE del Parlamento Europeo sobre Eficiencia Energética en los Edificios.

- Directiva 2002 / 91 / CE del Parlamento Europeo sobre Eficiencia Energética en los Edificios.

\subsection{PORTALES Y SITIOS DE INTERNET}

\subsubsection{Construcción Modular}

- $\quad$ www.fondationlecorbusier.fr

- http://www.ozetecture.org/glenn-murcutt-projects/

- https://proyectos4etsa.wordpress.com/

- $\quad$ http://www.urbipedia.org/index.php?title=Casa_Wichita

- http://www.plataformaarquitectura.cl/cl/02-288162/clasicos-de-arquitectura-lacasa-dymaxion-buckminster-fuller

- http://b2dymaxionhouse.blogspot.com.es/p/morphology.html

- https://en.wikipedia.org/wiki/Dymaxion_house

- https://es.wikipedia.org/wiki/Casa_Dymaxion\#La_casa_Dymaxion_real

- http://issuu.com/crueda_mpia/docs/michelle_sanchez_de_leon_metrobook_wic hita_house_

- $\quad$ https://proyectos4etsa.wordpress.com/2011/11/01/casa-wichita-buckminsterfuller-1944/

- http://es.wikiarquitectura.com/index.php/Casa_Wichita

- https://proyectos4etsa.wordpress.com/2011/11/03/la-maison-tropicale-jeanprouve-1949/ 
- http://es.wikiarquitectura.com/index.php/Maisons_Tropicales

- http://www.ppa-europe.eu/db/docs/081023_07_Pedreschi.pdf

- http://maison-tropicale.blogspot.com.es/p/morphology.html

- http://artdaily.com/news/20283/Jean-Prouv--s-Prototype-Maison-Tropicale-atChristie-s\#.Vd7LUfn5eDc

- http://www.arch.columbia.edu/files/gsapp/imceshared/gjb2011/V2N1_Rubin.pdf

- http://www.failedarchitecture.com/la-maison-tropicale-from-failure-in-niamey-tomasterpiece-in-new-york/

- $\quad$ http://www.vitruvius.com.br/revistas/read/arquitextos/10.122/3458

- http://jeanprouve.centrepompidou.fr/habitat-tropical.php

- https://proyectos4etsa.wordpress.com/tag/jean-prouve/

- http://www.lamaisontropicale.com/www/

- $\quad$ http://www.tdx.cat/handle/10803/6136

- $\quad$ http://www.tdx.cat/bitstream/handle/10803/6136/TGW07de13.pdf?sequence=7

- http://blog.arquitecturadecasas.info/2008/08/prefabricada-con-aglomerado-demadera.html

- https://proyectos4etsa.wordpress.com/tag/gropius/

- http://www.urbipedia.org/index.php?title=Dos_casas_prefabricadas_en_la_Colo nia_Weissenhof

- https://proyectos4etsa.wordpress.com/2011/12/26/the-packaged-house-systemkonrad-wachsmann-y-walter-gropius-general-panel-corporation-new-york-1942/

- http://es.wikiarquitectura.com/index.php/Case_Study_Houses

- http://www.selecta-home.eu/news/case-study-houses

- https://www.google.es/webhp?sourceid=chromeinstant\&rlz=1C1ASUT_esES613ES613\&ion=1\&espv=2\&ie=UTF-8\#q=CSH++ Case+Study+House+\%23+5+a+9+-+Parte+1 
- $\quad$ http://blog.modernica.net/inspire-me-monday-the-elusive-unbuilt-case-studyhomes/

- https://proyectos4etsa.wordpress.com/2011/11/03/case-study-house-4-casagreenbelt-ralph-rapson-1945-no-construida/

- http://wieler.com/homes/rapson-greenbelt/overview/

- $\quad$ http://ernst-arq.blogspot.com.es/2012/04/csh-case-study-house-5-9-parte2.html

- http://es.wikiarquitectura.com/index.php/Casa_Entenza_/_Case_Study_House_ n\%C2\%BA9

- http://enchinche.com/notas/csh-6-case-study-house-6-richard-neutra/

- http://es.wikiarquitectura.com/index.php?title=Case_Study_House_n\%C2\%BA_ 10

- http://itec.es/

- http://www.sistemamodulab.es/

- https://www.bluhomes.com/

- $\quad$ http://www.a-cero.com/index.php/es/industrializacion-acero-tech/a-cero-tech

- http://www.modultec.es/

- http://casasprefabricadascube.com/portfolio-items/cube-100/

- www. uh.edu/engines/epi779.htm

- https://collections.stanford.edu/bucky/bin/page?forward=home

- http://www.vitra.com.

- www.mercier\&Associés.com

- www.jousse-entreprise.com

- www.shelterpress.com.

- www.wikipedia.com 
www.searsarchives.com

www.architecture.about.com

www.automobiles-voisin.fr

www.plansofarchitecture.tumblr.com

www.nytimes.com

www.lib.ncsu.edu

www.ohiohistory.org

www.worksdifferent.com

http://www.artsandarchitecture.com/

www.docomomo-us.org

www. thehenryford.org

www.treehugger.com

http://www.frac-centre.fr

http://www.loftcube.net. 2015

www.microcompacthome.com

www.maderayconstruccion.com

\subsubsection{Eficiencia energética}

- http://www.enob.info/en/net-zero-energy-buildings/international-projects/

- http://www.lowex.net/

- https://ec.europa.eu/energy

- http://www.solardecathlon.gov/

- $\quad$ http://www.sdeurope.org 
- http://www.sdeurope.org/wp-content/uploads/downloads/2011/10/SOLARDECATHLON-EUROPE-2010.pdf

- http://www.sdeurope.org/wpcontent/uploads/downloads/2012/01/Folleto_SD_Largo_A4_singlepage_LR1.pdf

- http://www.sdeurope.org/downloads/sde2012/

- http://passiv.de/en

- $\quad$ http://task40.iea-shc.org

- $\quad$ http://shop.detail.de

- $\quad$ http://www.ecbcs.org/annexes/annex52.htm

- $\quad$ http://www.nrel.gov/

- http://living-future.org/netzero

- http://www.ietcc.csic.es/index.php/es/

- $\quad$ http://www.idae.es/

- http://icaen.gencat.cat/es/

- $\quad$ http://www.minetur.gob.es/es-ES/Paginas/index.aspx

- http://www.codigotecnico.org/

- www.boe.es

- www.aislaconpoliuretano.com

- www.wbdg.org

- www.tableroshuertas.es

- www.thermochip.com; 2015

http://www.scottsdalesteelframes.com

www.dovalbuilding.com 
www.eurobloc.com

http://www.kommerling.es. 20015

http://data.giss.nasa.gov

www.ipcc.ch. 2015

www.rockwool.es

http://passiv.de. 2015

http://www.paroc.com. 2015)

www.bustler.net

www.lumenhaus.com

www.sitiosolar.com 
ANEXOS 
ANEXO 1

ARQUITECTURA SOLAR EN PAISES TROPICALES EMERGENTES

TECNOLOGIA FOTOVOLTAICA: EL ESCENARIO DOMINICANO

Trabajo tutelado para la obtención del DEA/Suficiencia investigadora. 


\section{ARQUI TECTURA SOLAR}

\section{EN PAISES TROPI CALES EMERGENTES}

\section{TECNOLOGI A FOTOVOLTAI CA. EL ESCENARIO DOMI NI CANO}

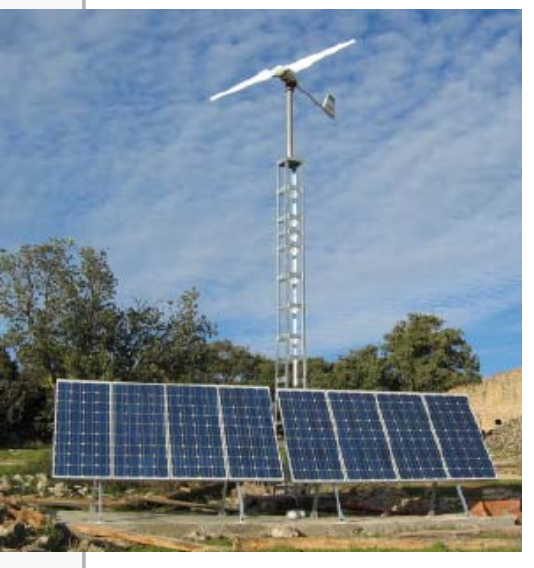

JUAN C. SÁNCHEZ G.
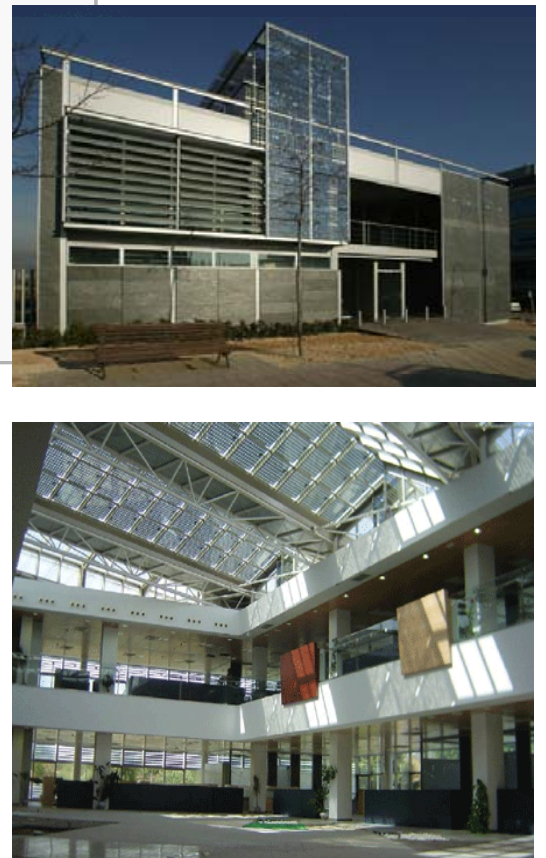


\section{INDICE}

1. INTRODUCCION. Arquitectura y Energía

2. JUSTIFICACION.

3. OBJETIVOS DEL TRABAJO.

4. HIPOTESIS.

5. TECNICAS BIOCLIMATICAS Y DE APROVECHAMIENTO ENERGETICO EN LA ARQUITECTURA. Aspectos Generales.

6. PANORAMA ENERGETICO MUNDIAL.

6.1 Energías Renovables. Características y situación actual en países industrializados y países en vías de desarrollo.

6.2 Las economías emergentes como entes de equilibrio medioambiental.

7. LA ALTERNATIVA FOTOVOLTAICA.

7.1 Energía solar y arquitectura.

7.2 Definición y Fundamentos de la Fotovoltaica. Tipologías y características técnicas.

7.3 Rendimientos, ciclo de vida de los sistemas fotovoltaicos e impacto ambiental.

7.4 Integración de la fotovoltaica al ente arquitectónico. Ejemplos

7.5 Costes y amortización.

8. ALTERNATIVAS RENOVABLES PARA PAISES TROPICALES DE ECONOMIAS EMERGENTES.

8.1 Realidades regionales, sociales y vinculaciones geopolíticas. Un perfil común.

8.2 Aspectos coincidentes: Climáticos; Ambientales; Económicos; Sociales. Arquitectónicos.

8.3 Soluciones Comunes y sus repercusiones a nivel local y global. La energía solar como alternativa de desarrollo en los trópicos.
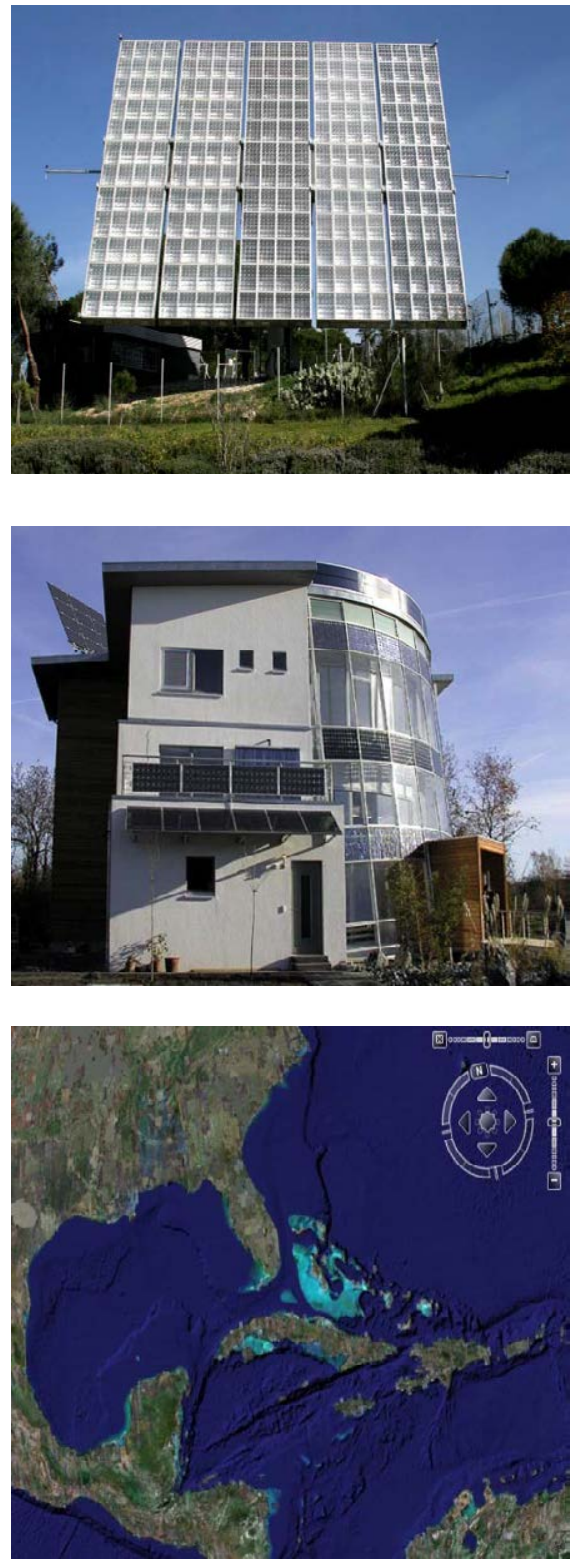


\section{EL ESCENARIO DOMINICANO COMO MODELO.}

9.1 ¿Porque la República Dominicana?

9.2 Ubicación geográfica.

9.3 Condiciones climáticas.

9.4 Aspectos realidad socioeconómica.

Problemática energética, de equipamientos y habitacional.

10. HACIA UNA ARQUITECTURA SOLAR EN LA REPUBLICA DOMINICANA.

10.1 Tecnología solar en la Arquitectura Dominicana. Estado actual, tendencias y posibilidades.

11. PROPUESTA PARA UNA ARQUITECTRURA SOLAR.

11.1 Técnicas y soluciones de integración. Contexto de la Arquitectura Tropical Dominicana como marco de referencia.

11.2 Análisis Climático del escenario modelo. La Isla de Santo Domingo

11.3 Integración en equipamientos y edificios habitacionales existentes y de nueva planta.

11.4 Propuestas de soluciones solares.

12. ANEXOS.

13. RECURSOS BIBLIOGRAFICOS. 


\section{INTRODUCCION}

\section{Arquitectura y Energía}

\section{"La tecnología debe ser social antes que técnica" Michel Foucault}

Ciertamente desde que el Hombre ha poblado el planeta ha venido alterando sus condiciones climática generales, agotando los recursos naturales de que dispone y encaminándose aceleradamente a una situación de crisis de escasez de los mismos. Conceptos tales como "cambio climático", "calentamiento Global" y los antes citados están presentes en nuestro día a día.

La casi totalidad de Naciones ha tomado conciencia real de la situación actual en que se encuentra el planeta. Muestra de ello son los distintos marcos operativos que se han creado para afrontar este nuevo desafío; destacándose el Protocolo de Kioto (Kioto 1997-2004) que establece un acuerdo internacional para reducir las emisiones de seis gases provocadores del calentamiento global- dióxido de carbono $\left(\mathrm{CO}_{2}\right)$, gas metano $\left(\mathrm{CH}_{4}\right)$, óxido nitroso $\left(\mathrm{N}_{2} \mathrm{O}\right)$, Hidrofluorocarbonos (HFC), Perfluorocarbonos (PFC) y Hexafluoruro de azufre $\left(\mathrm{SF}_{6}\right)$ - en un porcentaje aproximado de un $5 \%$, dentro del periodo que va desde el año 2008 al 2012, tomando como referencia las emisiones de 1990.

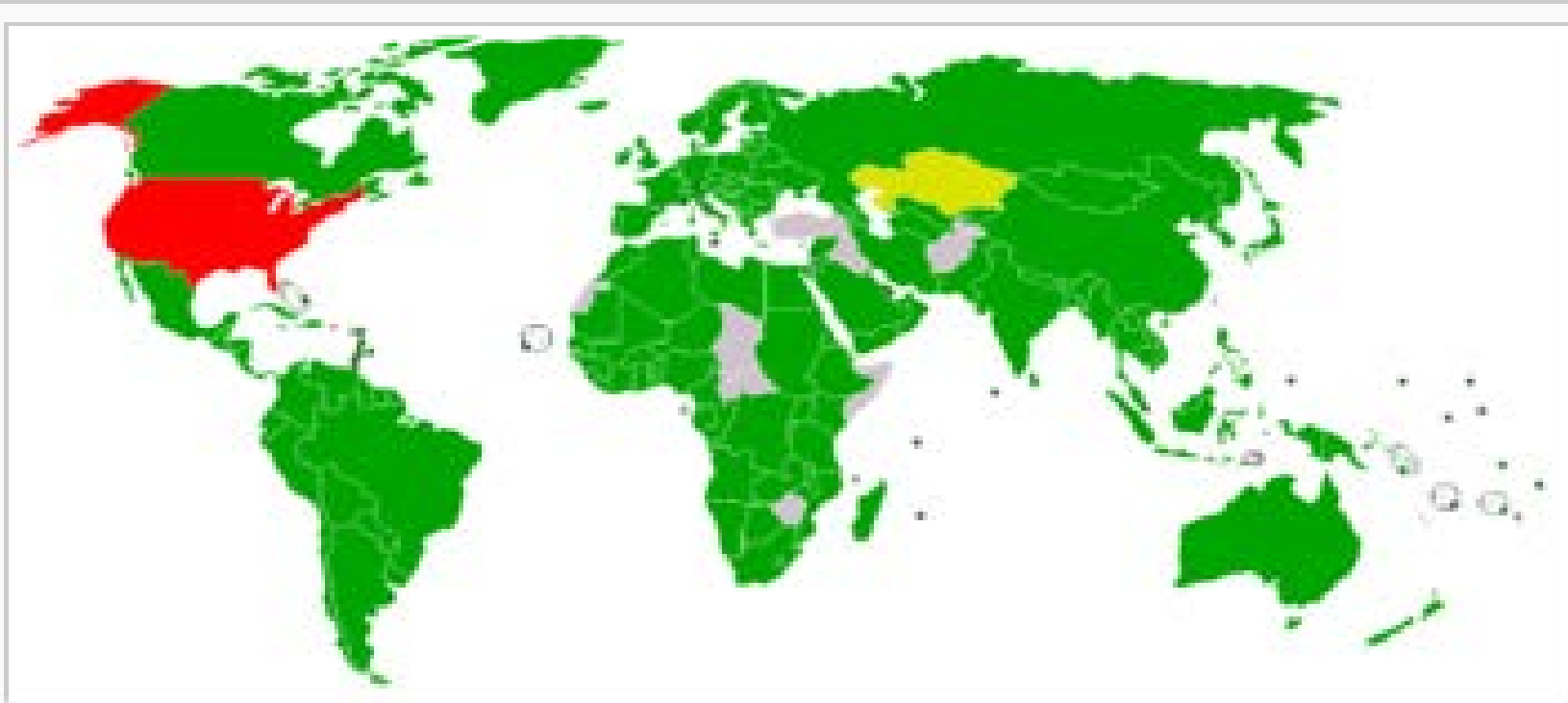

Hosicion de los dversos paises en 2 ub respecto del Hotocolo de Kioto.

Firmado y ratificado.

Firmado pero con ratificación pendiente.

Firmado pero con ratificación rechazada.

No posicionado. 
Muchos de los signatarios de este protocolo, pertenecen al grupo de países industrializados, que son los responsables de la mayor cantidad de emisiones de gases de efecto invernadero. Otro grupo de países, son los llamados emergentes o en vías de desarrollo cuyo patrón de crecimiento corresponde también al modelo contaminante de los mas ricos. Sin embargo, Lo que se plantea es que los primeros implementen políticas de reducción de emisiones y los segundos, asuman modelos de desarrollo sostenible, en materias tales como industria, transporte, energía e infraestructuras en general, cuyo papel en el crecimiento de estas sociedades es fundamental.

La naturaleza de la arquitectura como técnica, ha hecho que sea protagonista, y a la vez escenario de los grandes acontecimientos sociales de la historia de la humanidad.

El momento actual en que vivimos no es diferente en cuanto al papel social , tecnológico, económico, etc.; que debe asumir la arquitectura; aunque si diferente en los desafíos que se presentan en las ultimas décadas, relacionados con el tema del consumo y la optimización de los fuentes energéticas.

Los edificios como organismos vivos, que consumen una cuota importante de la energía que produce el planeta ( un $40 \%$ se le asigna a la industria de la construcción en países como Alemania), también aportan un alto porcentaje de emisiones de $\mathrm{CO} 2$, por ser consecuencia la misma, de la explotación de recursos fósiles.

Desde la extracción de las materias primas para la fabricación de los materiales constructivos, su comercialización, transporte y puesta en obra, hasta su ciclo de vida y el consumo propio del edificio, van sumando valores negativos a la hora de pasar balance a la salud de nuestro medio ambiente

En este contexto global la arquitectura bioclimática -la que emplea materiales y técnicas sostenibles, que no comprometen el futuro de las próximas generaciones- presenta alternativas de desarrollo sostenible y eficiencia energética apropiadas.

Lo que enfocaremos en este trabajo a partir de este punto, es la relación existente entre la arquitectura solar/bioclimática -que hace énfasis en las técnicas fotovoltaicas- y entornos sociales (de países no industrializados), donde la implementación de esta, seria fundamental para su avance socioeconómico y necesariamente sostenible.

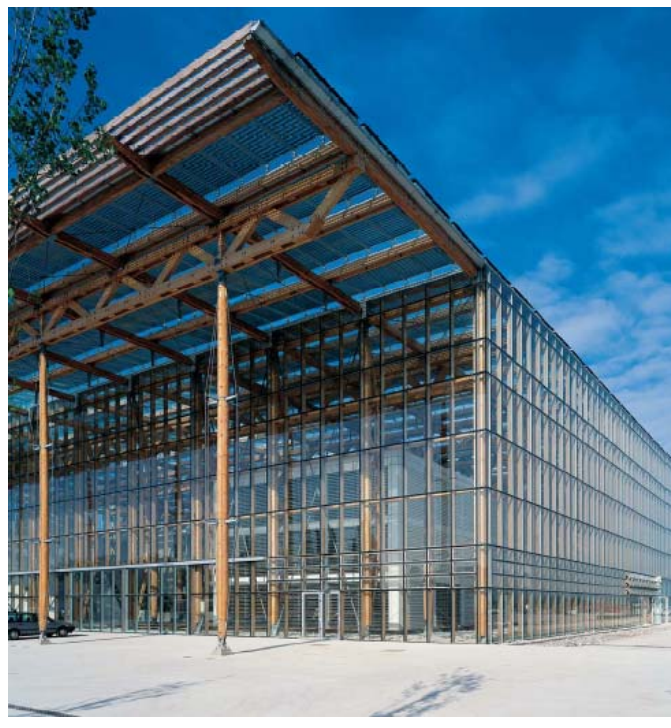

ACADEMIA MONT CENIS (Herne)

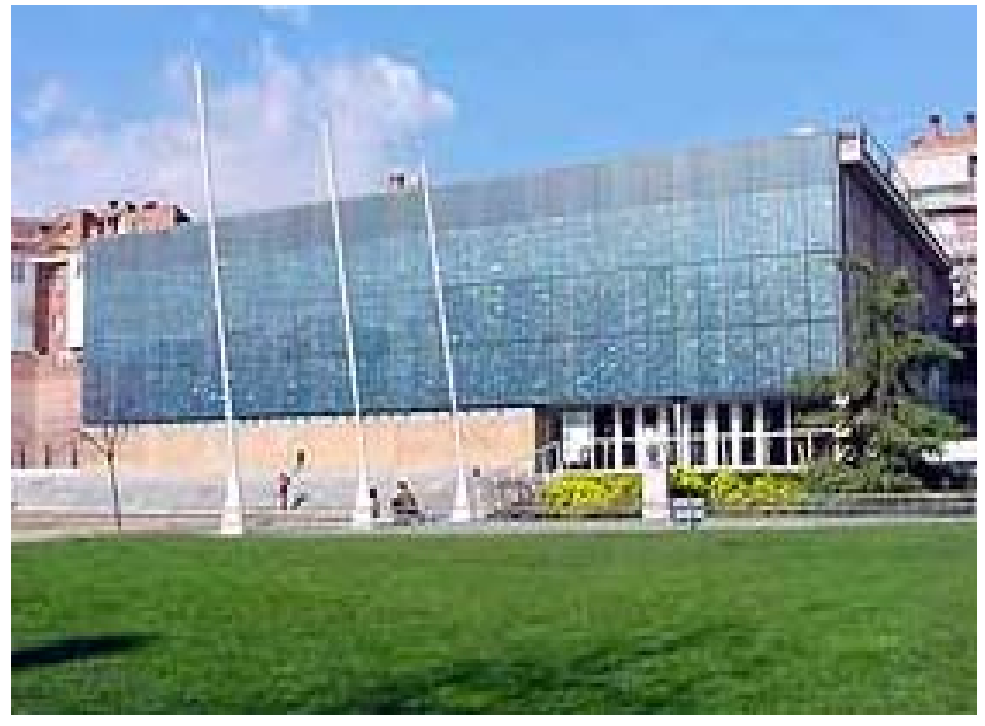

BIBLIOTECA POMPEU ( Barcelona) 


\section{JUSTIFICACION}

Diversas razones motivan un trabajo de investigación de esta naturaleza; entre ellas:

- La realidad de que la acción del hombre ha ido deteriorando el lugar donde vive, produciendo acelerados cambios en las condiciones climáticas

-Que el modelo de desarrollo actual de la sociedad, es contrario a la preservación de los recursos naturales, al equilibrio biológico del planeta y el bienestar de la raza humana.

- El rápido deterioro de nuestro medio ambiente, el agotamiento de las reservas energéticas fósiles, y los conflictos relacionados a esta situación.

-La perspectiva real de que el uso de renovables y un cambio de mentalidad de cara a la conservación de los recursos naturales, puede frenar este proceso de destrucción.

La problemática actual, que afecta especialmente a las sociedades en vías de desarrollo, va sumada a otras circunstancias propias, que impiden su avance; como es la falta de servicios básicos (agua, electricidad), infraestructuras, viviendas, equipamientos, etc.

-El convencimiento y el compromiso de que a través de la arquitectura bioclimática se puedan alcanzar objetivos de desarrollo, acordes con un modelo mas sostenible en países y sociedades desarrolladas y emergentes.

-Poder contar entre las técnicas bioclimáticas, con el aprovechamiento de los rayos solares y su transformación en electricidad por medio de tecnología fotovoltaica; lo cual repercute directamente en el mejoramiento de las condiciones socioeconómicas de sociedades cuya generación eléctrica presenta deficiencias.

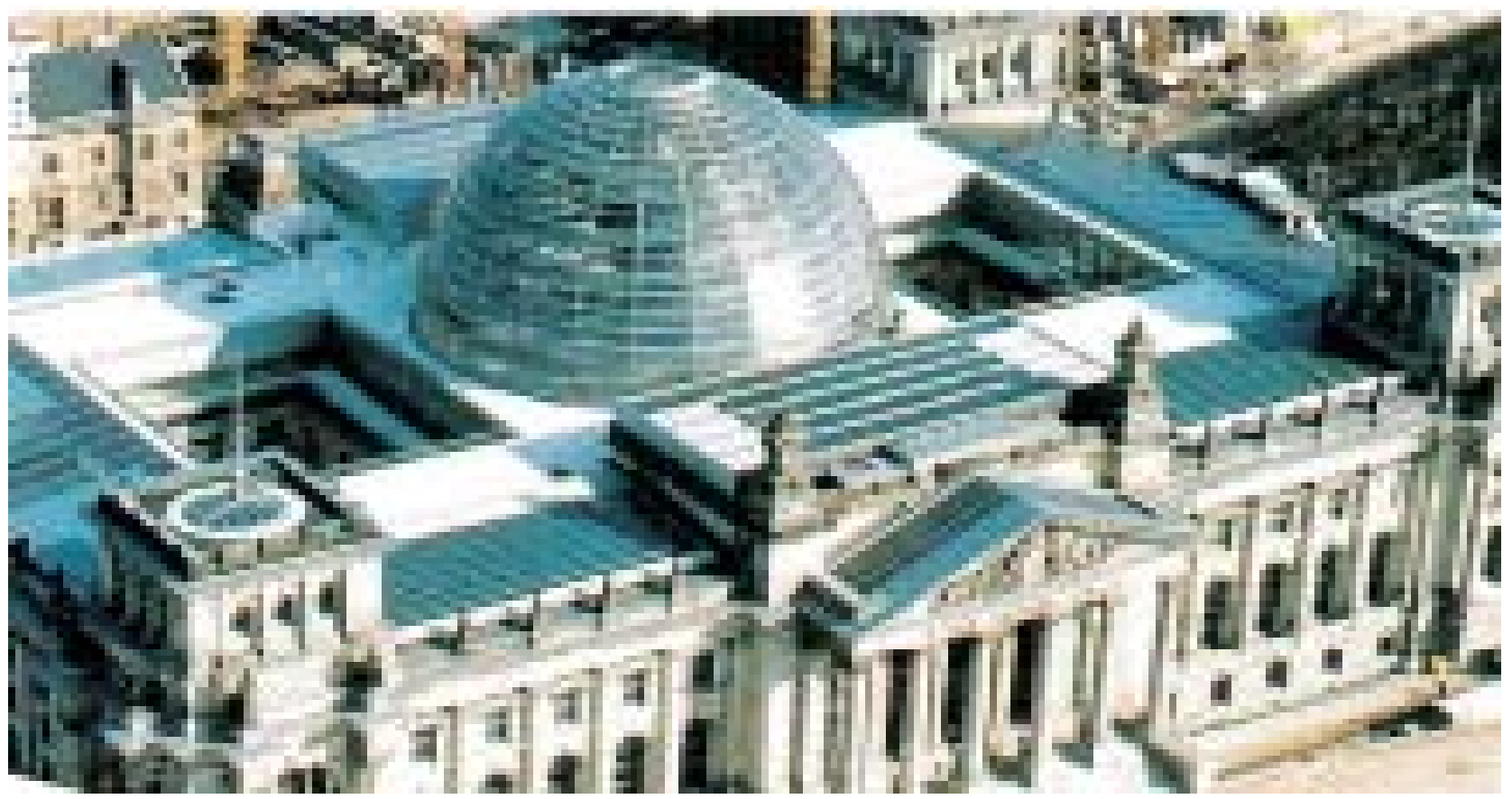

CUPULA REICHSTAG (Parlamento Alemán).N. Foster. Ejemplo de aprovechamiento y eficiencia energética. 
-La posibilidad de que planteamientos de esta naturaleza, puedan motivar a las naciones industrializados y sus empresas, a crear infraestructuras con criterios bioclimáticos en países menos avanzados; sirviendo esto para que los primeros puedan compensar su exceso de emisiones de CO2 gracias los Mecanismos de Desarrollo limpio.

-Que el Desarrollo sostenible entendido como un modelo “...en que sean compatibles un crecimiento elevado y sostenido de la producción de bienes y servicios con un progreso social extendido, una protección del medio ambiente y un uso prudente de los recursos naturales...con un enfoque integral que incluye cohesión social, capacidad de crecimiento de los recursos materiales y gestión responsable de recursos naturales.. * es la alternativa idónea a un sistema actual, que no solo perjudica a los estados emergentes, sino que atenta contra la salud del planeta.

-La generación de energía con el uso de fuentes renovables (Solar), y la integración de estos mecanismos al quehacer arquitectónico no solo genera bienestar y desarrollo a las sociedades que lo implementen, sino que desacelera el proceso de calentamiento global causado por la liberación de dióxido de carbono y otros gases que atrapan el calor en la atmósfera de la Tierra; gases que son creados con la quema de combustibles fósiles para la producción de energía.

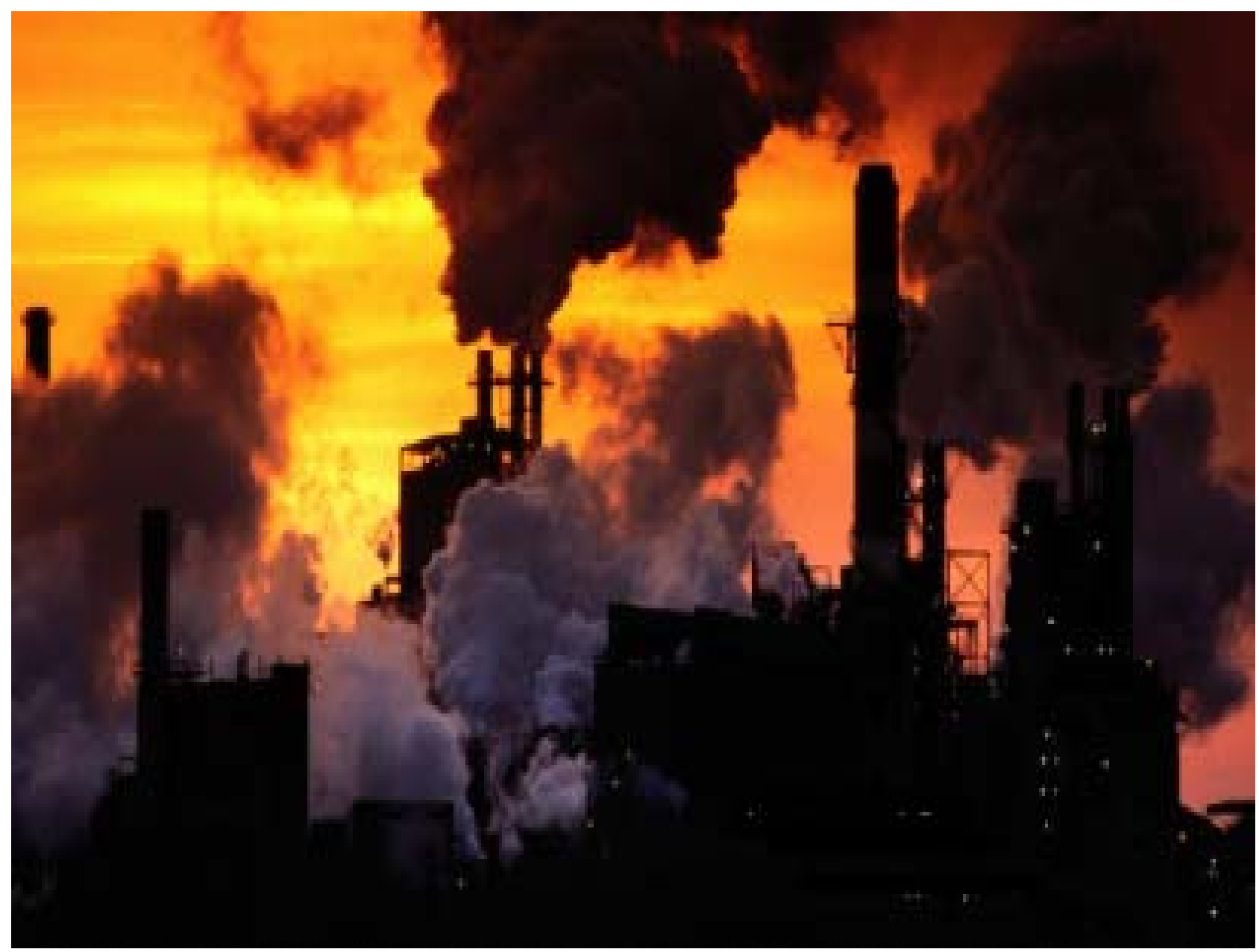

Emisión de CO2 por la combustión de recursos fósiles. Fuente: An Inconvenient Truth. 


\section{OBJETIVOS}

1.-. Hacer un análisis general del estado actual de la tecnología fotovoltaica en la arquitectura y su integración con la misma como elemento compositivo de la piel del edificio y de su entorno. Sus Niveles de rendimiento y mantenimiento así como las repercusiones y el impacto que estas producen en el medio ambiente.

2.- Plantear como la arquitectura bioclimática -específicamente la implementación de tecnologías fotovoltaicas- puede contribuir a la mejora de la calidad de vida de sociedades en vías de desarrollo.

\section{3.- Proponer técnicas solares de} aprovechamiento energético en edificaciones habitacionales, de equipamiento, mobiliario urbano, etc. ya existentes y de nueva planta.

4.- Contribuir con soluciones alternativas al problema socioeconómico que representa el deficiente sistema de energía eléctrica en los países emergentes cuya ubicación geografía favorece especialmente el uso de tecnología solar.

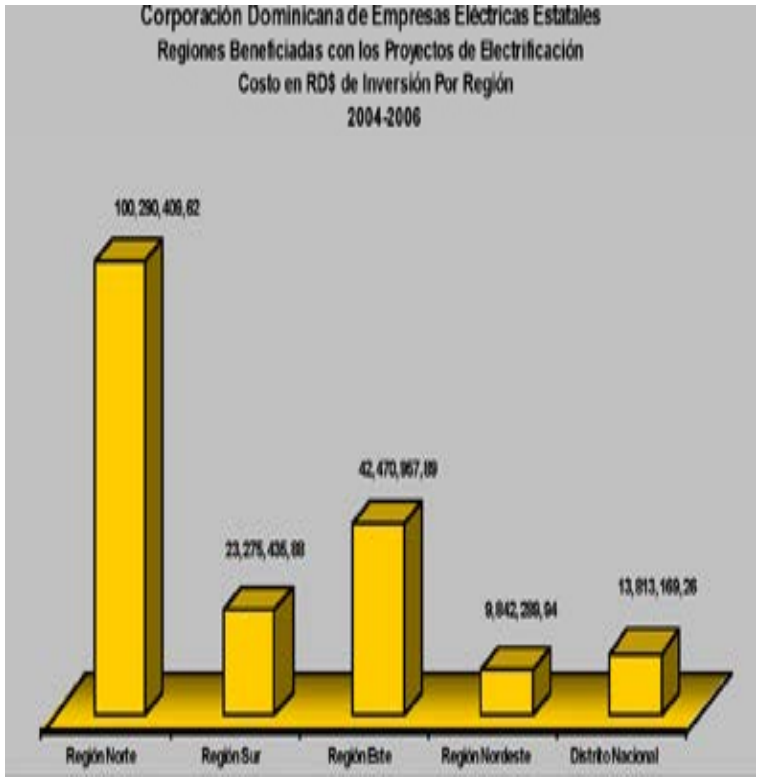

Inversión energética en Rep. Dominicana.

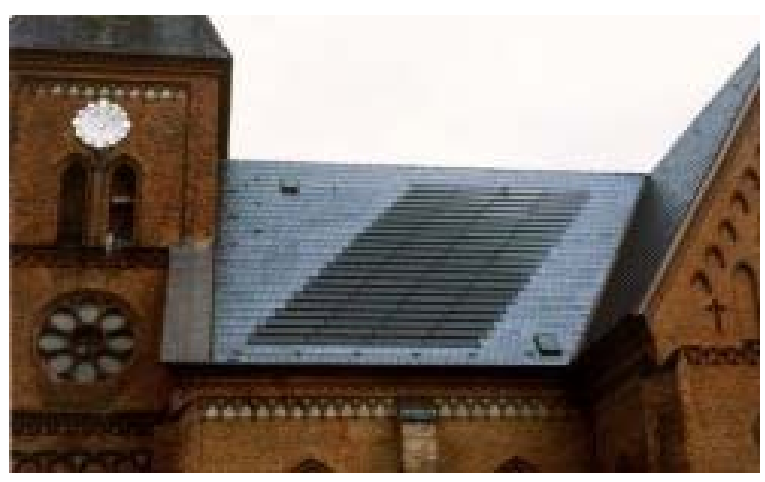

Iglesia de Carlow- Alemania. Restauración fotovoltaica.

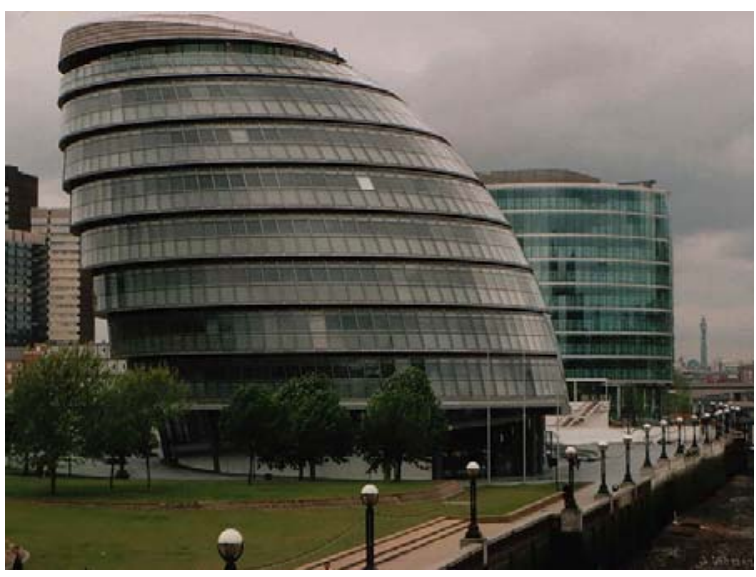

CITY HALL LODON. (Ayuntamiento Londres). N. Foster. Ejemplo de aprovechamiento y eficiencia energética. 


\section{HIPOTESIS}

1.- Una arquitectura comprometida con el medio ambiente, repercute directamente en el mejoramiento de las condiciones socioeconómicas de los países menos industrializados.

2.-Las Naciones Insulares en vías de desarrollo son un campo fértil para la implementación de tecnología de aprovechamiento solar en su arquitectura.

3.-Mediante la creación y restauración de infraestructuras y equipamientos con criterios bioclimáticos -tecnología fotovoltaica- en las sociedades de economías emergentes, se puede optimizar el rendimiento energético y salvar el déficit existente.

4.- Una adecuada proyección de sistemas solares fotovoltaicos en el proyecto arquitectónico desde la concepción del mismo, garantiza su integración favoreciendo un equilibrio entre los aspectos estéticos y funcionales de Balance energética positivo.
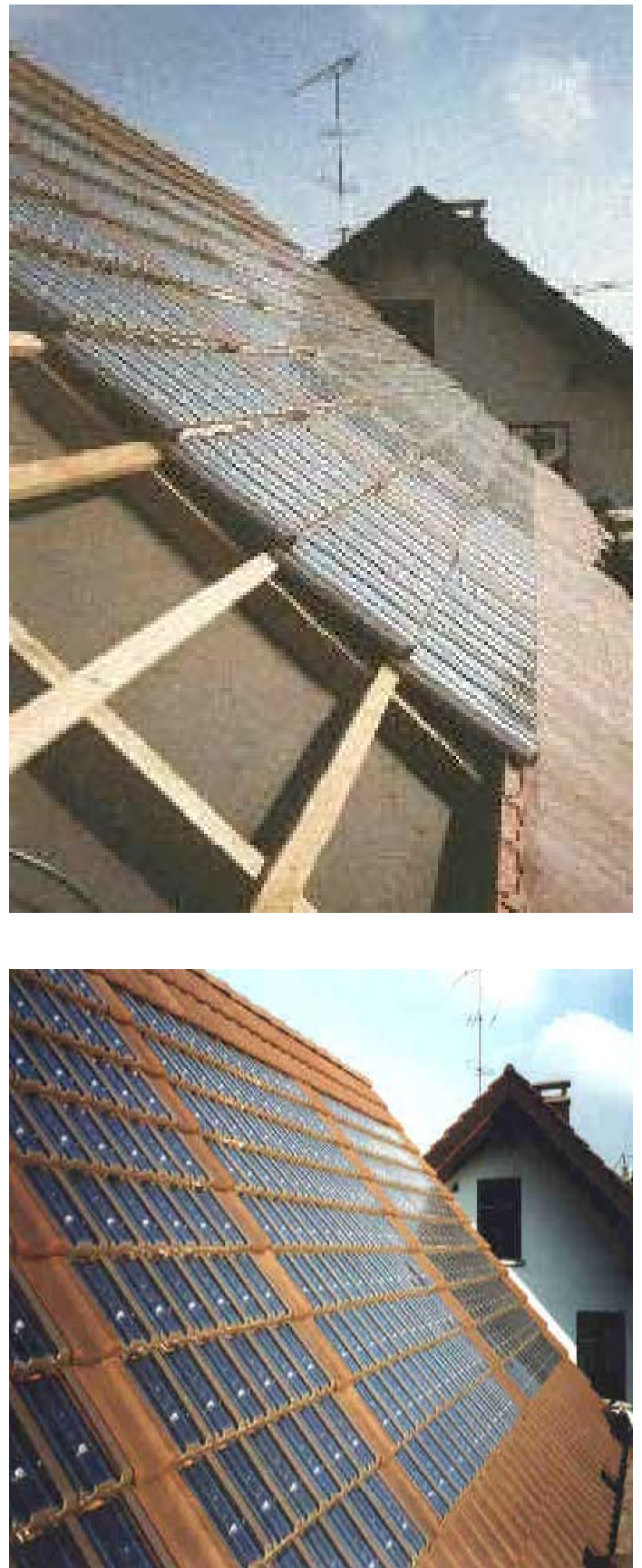

Tejas Fotovoltaicas. 


\section{TECNICAS BIOCLIMATICAS Y DE APROVECHAMIENTO ENERGETICO EN LA ARQUITECTURA}

Este tema, sirve de introducción y resumen de los conceptos generales de bioclimática, eficiencia energética, y las técnicas para combinar estas en un organismo arquitectónico.

\section{Arquitectura Bioclimática y optimización de recursos}

La Arquitectura Bioclimática o sostenible, es la que hace uso materiales y técnicas de construcción de manera sostenible para la eficiente administración energética del organismo, mediante la captación, acumulación y distribución de recursos renovables con métodos pasivos y/o activos. Significando esto que no compromete con su uso actual, el aprovechamiento para las generaciones futuras. Es aquella que se relaciona directamente con su entorno; es decir, con las condiciones naturales, y sociales del mismo.

Partiendo de lo anterior podríamos decir que Arquitectura Bioclimática no es otra cosa que las buenas prácticas dentro del quehacer arquitectónico; teniendo como objetivo el confort de los espacios interiores reducción de los efectos negativos sobre el entorno.
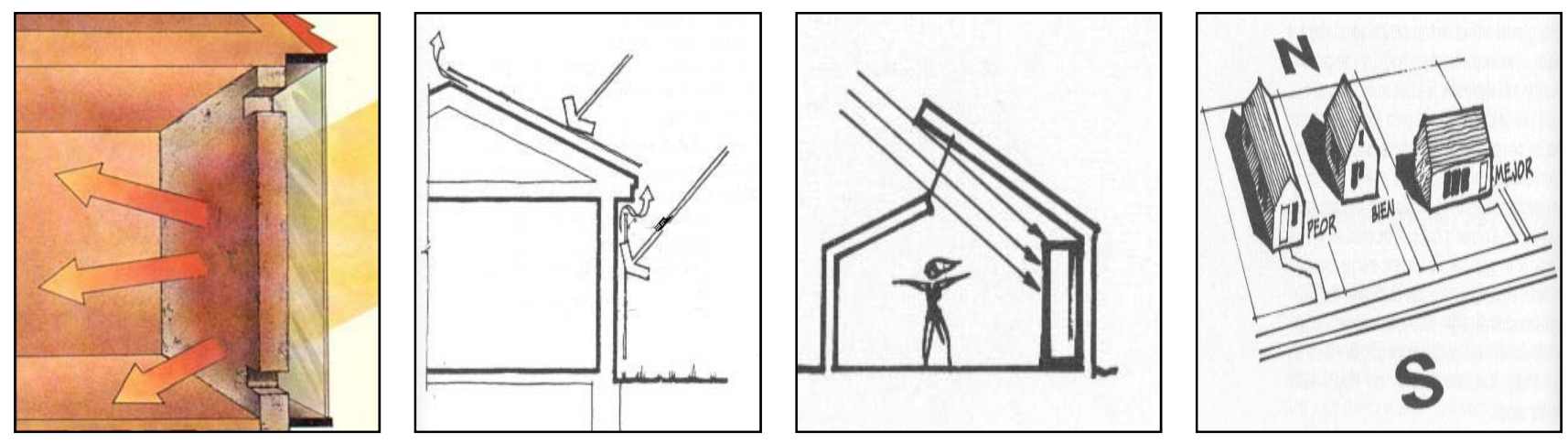

En el libro Arquitectura y Clima de Víctor Olgyay encontramos lo siguiente:

"El proceso lógico seria trabajar con las fuerzas de la naturaleza y no contra ellas, aprovechando sus potencialidades para crear unas condiciones de vida adecuadas. Aquellas estructuras que un entorno determinado reducen tensiones innecesarias aprovechando todos los recursos naturales que favorecen el confort pueden catalogarse como climáticamente equilibradas. La estabilidad perfecta rara vez puede alcanzarse, solamente es posible bajo circunstancias ambientales excepcionales. Pero puede conseguirse una casa muy confortable y con un bajo coste de mantenimiento reduciendo las necesidades de acondicionamiento mecánico...". Fin de la cita

La Interrelación del Organismo con el Entorno; el Confort en los Espacios Habitables y la Eficiencia o Aprovechamiento Energético, tanto en la captación como en el uso; son en resumen los aspectos fundamentales que definen la arquitectura bioclimática. 


\section{- RELACION EDIFICO Y ENTORNO.}

El análisis del entorno ( $y$ de los factores que forman parte del mismo), es la acción primaria que determina mucho de los pasos a dar posteriormente para conseguir el bienestar y el equilibrio energético deseado.

Es a partir de un estudio de las condicionantes climáticas y medioambientales que se plantean las estrategias bioclimáticas de diseño; tomando en cuenta aspectos tales como la situación geográfica, el régimen de viento, los niveles de humedad, la incidencia del sol en las estaciones del año, la topografía, etc..

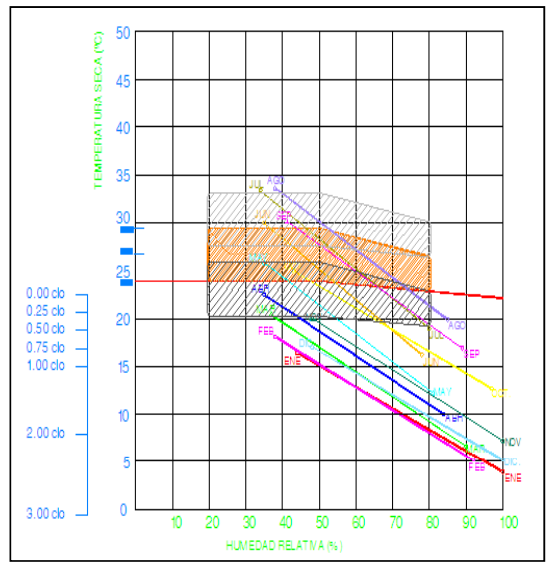

Diagrama de Olgyay

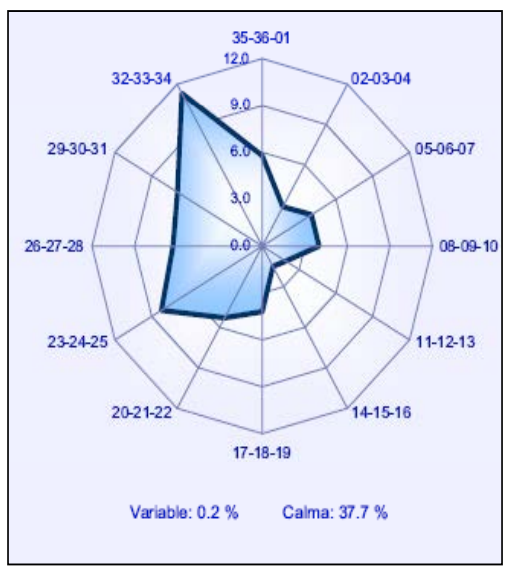

Rosa de Vientos

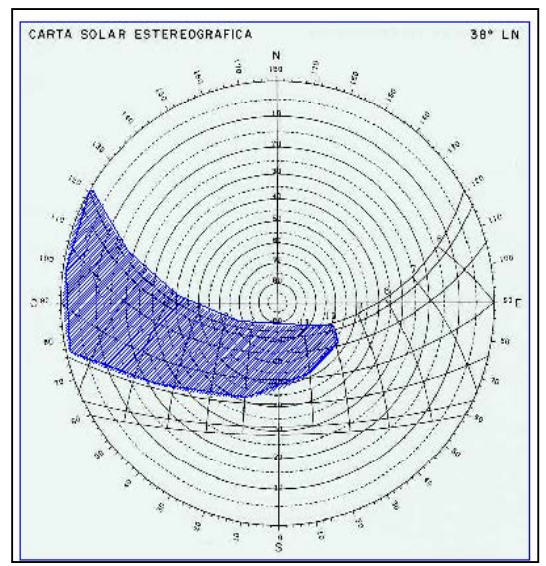

Carta solar estereográfica

Otro punto importante en la relación entre el entorno y el organismo arquitectónico, es el de la no agresión al medio; con :

1) Materiales de construcción sostenibles, que en su colocación y vida útil no desprendan sustancias nocivas, siendo preferiblemente reciclables o reciclados, para reducir la utilización de materia prima nueva y el consecuente consumo de energía para su fabricación y descarte, al final de su vida útil.

2) Adecuado manejo de las emisiones de gases y desechos sólidos. Teniendo en cuenta que la contaminación gaseosa producida por un edificio esta relacionada con los combustibles fósiles empleados para acondicionamiento ( frío/calor en los espacios interiores) o agua caliente sanitaria; la reducción de fósiles y el empleo sistemas que aprovechen las energías naturales, disminuye la contaminación. Igual disminución se produce al clasificar los desechos sólidos y al controlar su deposición.

3) Consumo moderado y reciclaje de las aguas. La implementación de sistemas de consumo de agua eficaces y la depuración primaria para su reutilización ( usos de aguas grises para riego y cisternas de inodoros), reducen sustancialmente los desperdicios; y las emisiones de aguas negras. 


\section{- CONFORT Y BIENESTAR EN ESPACIOS HABITABLES.}

Cuando hablamos de Confort, nos referimos a 1) buena de iluminación, 2) equilibrio acústico/sonoro, 3) kinestesia favorecida y los ritmos biológicos del individuo, 4) agradable sensación olfativa, 5) factores higrotérmicos adecuados.

1) Iluminación. Conseguir espacios bien iluminados, adecuados a la función a realizar en ellos en el día y la noche.

2) Equilibrio Acústico. Antes de disponer de aislamientos o barreras acústicas, estudiar las posibilidades de ubicación de los espacios de manera que por sus usos no se vean afectados por emisiones sonoras contradictorias con la naturaleza de este.

3) Factores Kinestesicos y Biológicos. Coordinar de tal manera los ambientes y espacios de recorridos para que resulten cómodos los movimientos realizados por el usuario.

4) Sensación Olfativa. Para una agradable sensación olfativa, es preciso el uso de materiales sanos que no desprendan olores ni sustancias nocivas para la salud y tomar en cuenta el régimen de vientos predominantes en localidad para evitar la penetración de los mismos desde el exterior si no se desea, por medio de barreras o elemento de cierre.

5) Factores Higrotérmicos. Aun cuando todos son importantes, lo que caracteriza el confort y el bienestar de un espacio interior o exterior, es la calidad del aire; es decir , sus condiciones higrotérmicas (humedad, ventilación, temperatura).

La Bioarquitectura y sus técnicas ha de emplearse para satisfacer estas necesidades (sean en condiciones de verano o invierno), con una buena orientación y aislamiento para los espacios, un correcto dimensionado y disposición de los planos de cerramiento y de los huecos para la entrada de luz y aire, así como de la radiación solar en los casos que haga falta.

Siendo el objetivo primordial de esta manera de proyectar, el bienestar del usuario y una eficiente gestión de los recursos; la correcta consecución de pasos en el proceso de diseño ( y previo a este ) es fundamental:

\section{1.- Análisis del lugar, su entorno y datos climáticos.}

Orografía. Topografía. Geobiología. Recursos Hidráulicos. Vegetación. Aspectos Urbanos.

Temperatura. Niveles de Humedad. Régimen de Vientos. Soleamiento. Régimen de lluvias

\section{2.- Elaboración del programa de necesidades de diseño.}

Arquitectura y pre-estudio del consumo de energía.

3.-Zonificación y pre diseño.

A partir de los datos de análisis del lugar.

\section{4.-Selección de materiales sostenibles.}

Autóctonos; Reciclado y reciclables; No tóxicos.

5.- Estudio de necesidades energéticas, consumos y factibilidad del uso de renovables Ver posibilidad en el uso Solar/Fotovoltaica, Eólica, Biomasa, etc.; según el caso.

\section{6.- Evaluación de Impacto ambiental.}

\section{7.- Propuesta de Diseño.}




\section{- APROVECHAMIENTO ENERGETICO.}

La arquitectura bioclimática, es lo opuesto a la practica generalizada de exportación de modelos predeterminados, a lugares con características climáticas y ambientales distintas, siendo esto causante de gastos excesivos de energía, por compensar las deficiencias de diseño. Para que un organismo sea cómodo y a la vez con un consumo moderado, debe estar pensado y construido a favor de la naturaleza y no en contra. Como todo proceso bioclimático, las condicionantes climáticas han de tomarse en consideración para el planteamiento de una buena solución.

Los términos Ahorro, Aprovechamiento y Eficiencia, aun no siendo sinónimos, responden a un solo concepto de optimización de la energía y sobre todo al uso de renovables, que en lo concerniente a la arquitectura se podrían dividir en solar, eólica biomasa y R.S.U.

La Captación, la Acumulación y la Distribución son conceptos claves para alcanzar la eficiencia.

Gran parte del consumo de una vivienda va ligado al objetivo de proporcionar confort térmico en su interior, y en la medida de lo posible este debería conseguirse de manera natural o auxiliándose de una producción electricidad y térmica sostenible.

Los términos energéticos que influyen en el balance higrotérmico - principalmente en la regiones frías y/o templadas- son:

1.- Conducción a través de lo cerramientos.

Esto es proporcional al valor medio de $U$ de la piel, representando perdidas en invierno y ganancias en verano. La incidencia de la radiación solar en los planos de cerramiento, disminuye la perdidas en invierno y aumentando las ganancias en periodos estivales. De ahí lo beneficioso de un buen aislamiento.

\section{2.- Intercambio de Aire.}

Se realiza mediante ventilación e infiltración. Un buen sistema de intercambio de volúmenes de aire entre el exterior y el interior, impide perdidas no deseadas en invierno y movimiento en verano, que evita el empleo de métodos mecánicos.

\section{3.- Ganancias solares a través de cristales.}

Es la cantidad de energía calorífica que entra por las superficies acristaladas. Representa ganancias en cualquier época del año.

\section{Ganancia de calor internas.}

Son todas las producidas por los propios ocupantes, electrodomésticos, iluminación y demás aparatos eléctricos.

\section{5.- Fuentes auxiliares de energía.}

Representa la cantidad de carga aportada por los elementos de climatización, instalados, para el confort interno del edificio; sea para calor o frío.

En latitudes con temperaturas no extremas -frío o calor- o donde no hay grandes diferencias entre estaciones, y no deben existir grandes consumos por climatización mecánica; sigue siendo necesaria una buena gestión de la energía. Hay variantes en los términos anteriores, y algunos de ellos no han de tomarse en consideración según el lugar, pero el aprovechamiento energético sigue siendo fundamental para obtener confort de manera sostenible. 
En determinados lugares (como en las zonas tropicales) solo es necesario procurar una adecuada ventilación o iluminación natural, que garantizaría un nivel higrotérmico adecuado con el consiguiente confort que ello implica.

Cualquiera que sea el caso la piel del edificio juega un papel preponderante para la aplicación de técnicas y sistemas bioclimáticos de aprovechamiento energético.

\section{LA PIEL DEL EDIFICIO:}

La envolvente, cuya misión principal es la de proteger de los actores climáticos, garantizar el bienestar interior, permitir y graduar la entrada de luz natural y el contacto con el exterior; es uno de los elementos arquitectónico mas importante a la hora de evaluar la eficiencia energética del edificio. Debe de considerarse como una estructura dinámica, al ser el punto medio entre lo interno y lo externo; que reacciona ante las exigencias del usuario, las variaciones del tiempo y la radiación solar.

\section{Cerramiento Eficientes:}

Además de su función protectora, con el aislamiento adecuado cuando hace falta para evitar las perdidas de las condiciones imperantes en el interior; las fachadas, cubiertas, y elementos de cierre -por medios pasivos y activos- pueden captador, almacenar y distribuir energía solar; por ejemplo: Muros Trombe, Invernaderos,Cubiertas Ecológicas, etc..

En determinadas situaciones los cerramientos pueden ser parte de sistemas de transformación de energía: Cubiertas Fotovoltaicas, Captadores solares.

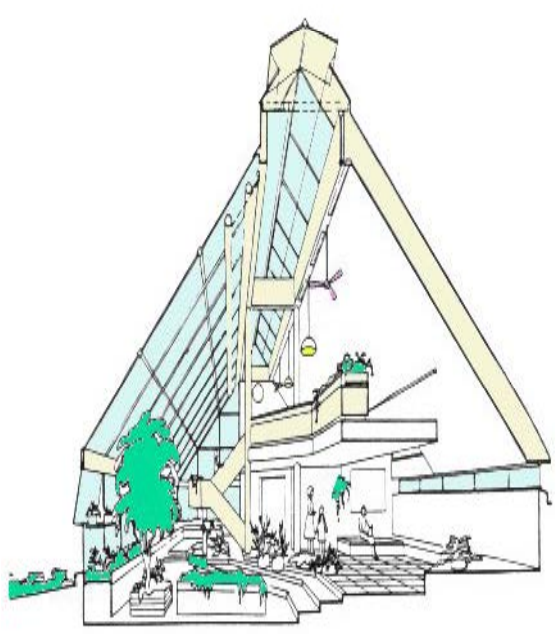

Invernadero. Centro Comercial.

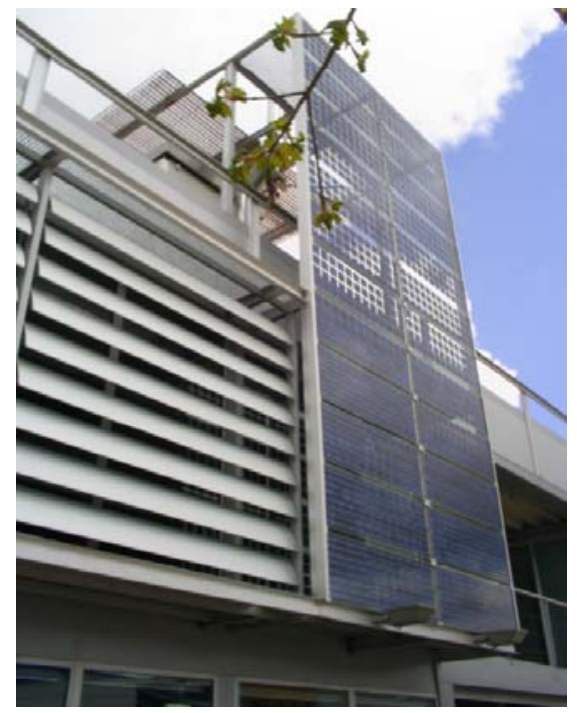

Lamas orientables de protección solar Paneles fotovoltaicos. Edif. Fund. Metrópoli.

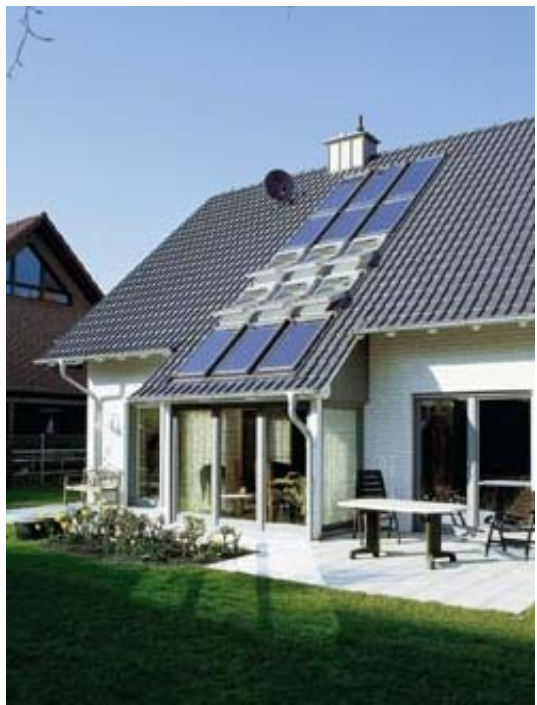

Captadores solares en tejado Vivienda Unifamiliar. 


\section{PANORAMA ENERGETICO MUNDIAL}

Según datos obtenidos del informe "International Energy Outlook 2007" elaborado por la Energy Information Administration de los EE.UU; desde el 2004 y hasta el 2030 el consumo de energía en el mundo se incrementará en un $57 \%$ aproximadamente. Esto a pesar de las alzas previstas del petróleo y del gas Natural. Un porcentaje importante de este incremento será producido por los países en vías de desarrollo.

Se estima que el consumo de energía en el mercado experimente un incremento medio de un 2,5\% por año hasta 2030 en los países ajenos a la OCDE, y en los países miembros será del 0,6\%; así, durante este periodo, los países OCDE incrementarán su demanda energética en un $24 \%$, mientras que el resto de países lo harán al 95\%.

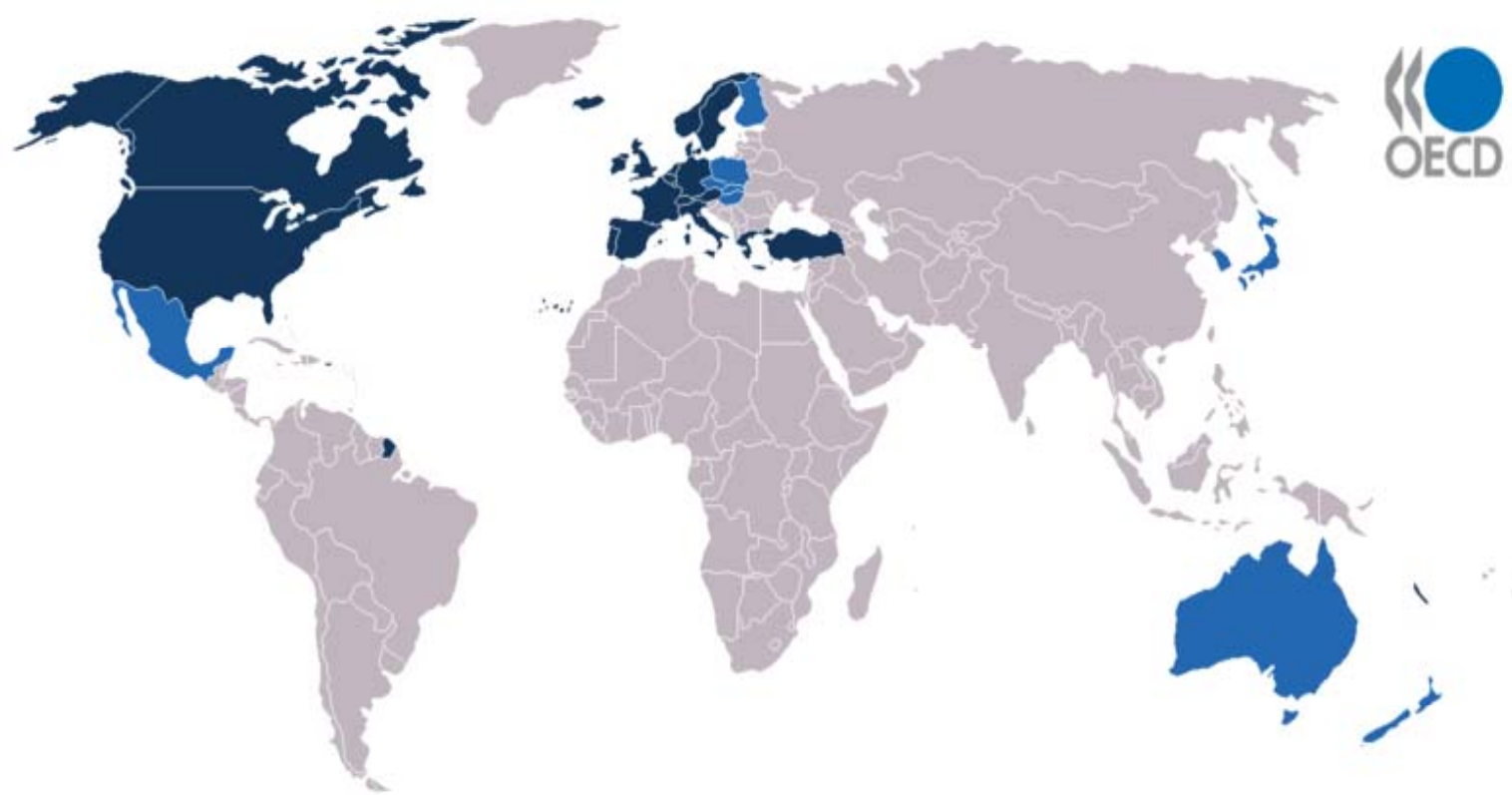

Mapa de países miembros de la OCDE. Organización para la Cooperación y el Desarrollo Económico. Fuente OCDE.

Globalmente, la industria y el transporte crecerán un 2,1\% por año. Los ámbitos residencial y comercial, tendrán un promedio anual de 1,5 y 1,9\% entre 2002 y 2025.

En los mercados consolidados, donde el crecimiento de la población no se proyecta muy grande; el sector comercial crece a un ritmo más rápido que en el resto de los sectores, y este incremento se basa en el desarrollo de las telecomunicaciones o lo que es lo mismo, la transformación de una sociedad industrial a una sociedad de servicios.

Los países de la OCDE, tendrían un consumo de energía en el sector transporte del $0.9 \%$ entre 2004 y 2030 , frente al $2,9 \%$ del resto de economías. Vemos otras cifras parecidas al comparar los consumos en industrial y residencial $(0,6 \%$ frente a $2,4 \%$ ) y comercial $(1,2 \%$ frente a $3,7 \%)$. Esta diferencia viene por las proyecciones del lento crecimiento poblacional de las economías más avanzadas, y la mejora progresiva de las instalaciones ya existentes para mejorar su eficiencia. 
Las economías emergentes serán, con mucho, las responsables del crecimiento proyectado en el consumo de energía dentro del mercado en las dos próximas décadas. La actividad económica medida por el producto interior bruto como medida del poder adquisitivo, se espera que se incremente en un 5,3\% por año en los mercados de los países fuera de la OCDE, frente al 2,5\% de los países miembros.

\section{Cuadrillones Btu.}

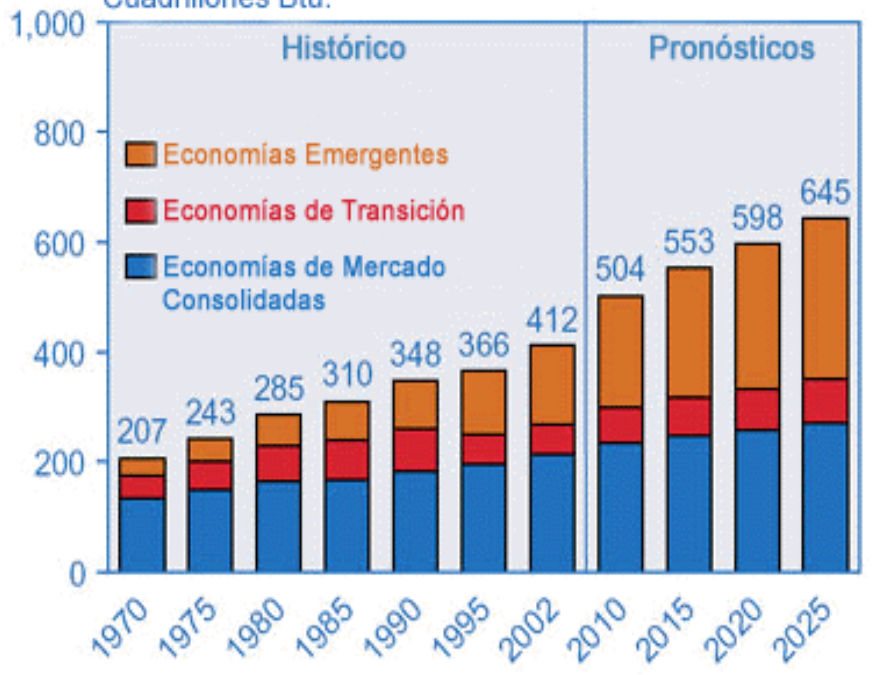

Mercado mundial consumo energético.1970-2025. Fuente EIA.

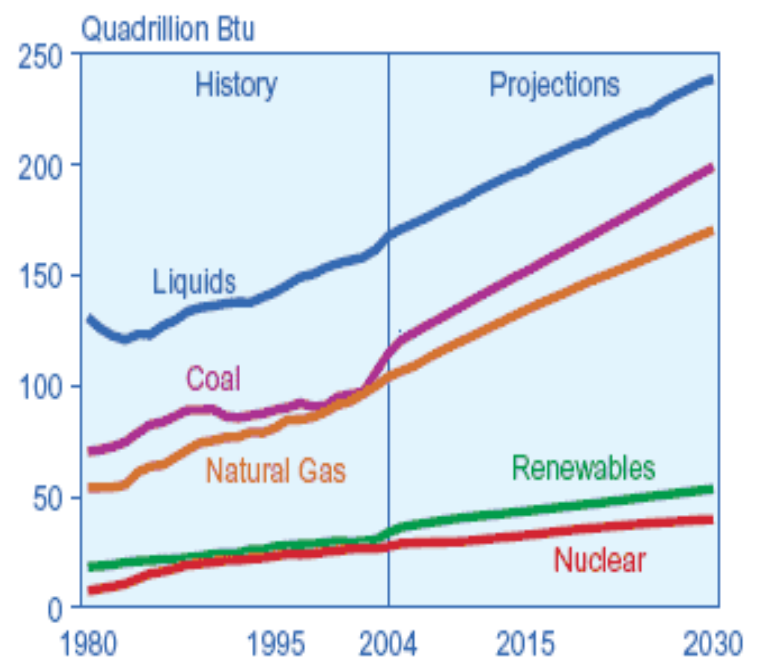

Tendencia del uso de combustibles según su tipo. Fuente EIA

En el caso del petróleo, su aumento es mas marcado porque los derivados de este son los combustibles mas utilizados para el transporte y en algunos países para la generación de electricidad; aunque como fuente de producción de electricidad, se espera que el carbón siga siendo el mas usado. La generación de eléctrica a partir del petróleo crecerá a un ritmo menor en los países de la OCDE debido al incremento de precios del crudo, mientras que en las economías menos desarrolladas podría llegar a descender a un ritmo del $0,3 \%$ anual. Solo en Oriente Medio, donde hay reservas abundantes, se seguirá usando esta materia prima como fuente fundamental de provisión.

De acuerdo a estudios realizados en 2007, la demanda de electricidad crecerá en los próximos 20 años. La capacidad productiva crecerá un 2,4\% anual, a escala mundial en este periodo, es decir de los 16.424 billones de kWh. a los 30.364 billones. La mayor parte de este crecimiento, se dará para cubrir las necesidades de las economías emergentes. De hecho, para el año 2030 se prevé que las economías en desarrollo ya generen más electricidad que los países OCDE, mientras que la demanda crecerá a una tasa tres veces mayor en las primeras que en los segundos.

Estas diferencias se establecen teniendo en cuenta la mayor madurez de las infraestructuras eléctricas en los países OCDE, y por otro lado, las progresivas mejoras en la condiciones de vida de muchos países en desarrollo conllevarán mayores demandas de electricidad.

Como hemos visto, la generación de energía depende en gran medida de los combustibles fósiles y aunque se hacen investigaciones e inversiones para la explotación de fuentes renovables, es la tendencia antes mencionada la que prevalece y se proyecta al futuro.

El problema de estas fuentes es su gran responsabilidad como emisores de $\mathrm{CO} 2$ y las consecuencias que acarrea en cuanto al cambio climático. El "Internacional Energy Outlook 2007", declara que las emisiones de CO2 aumentaran de 26,9 billones de toneladas en 2004 a 33,9 en 2015 y 42,9 en 2030. 


\section{World Wind Energy - Total Installed Capacity [MW] 1997-2007}

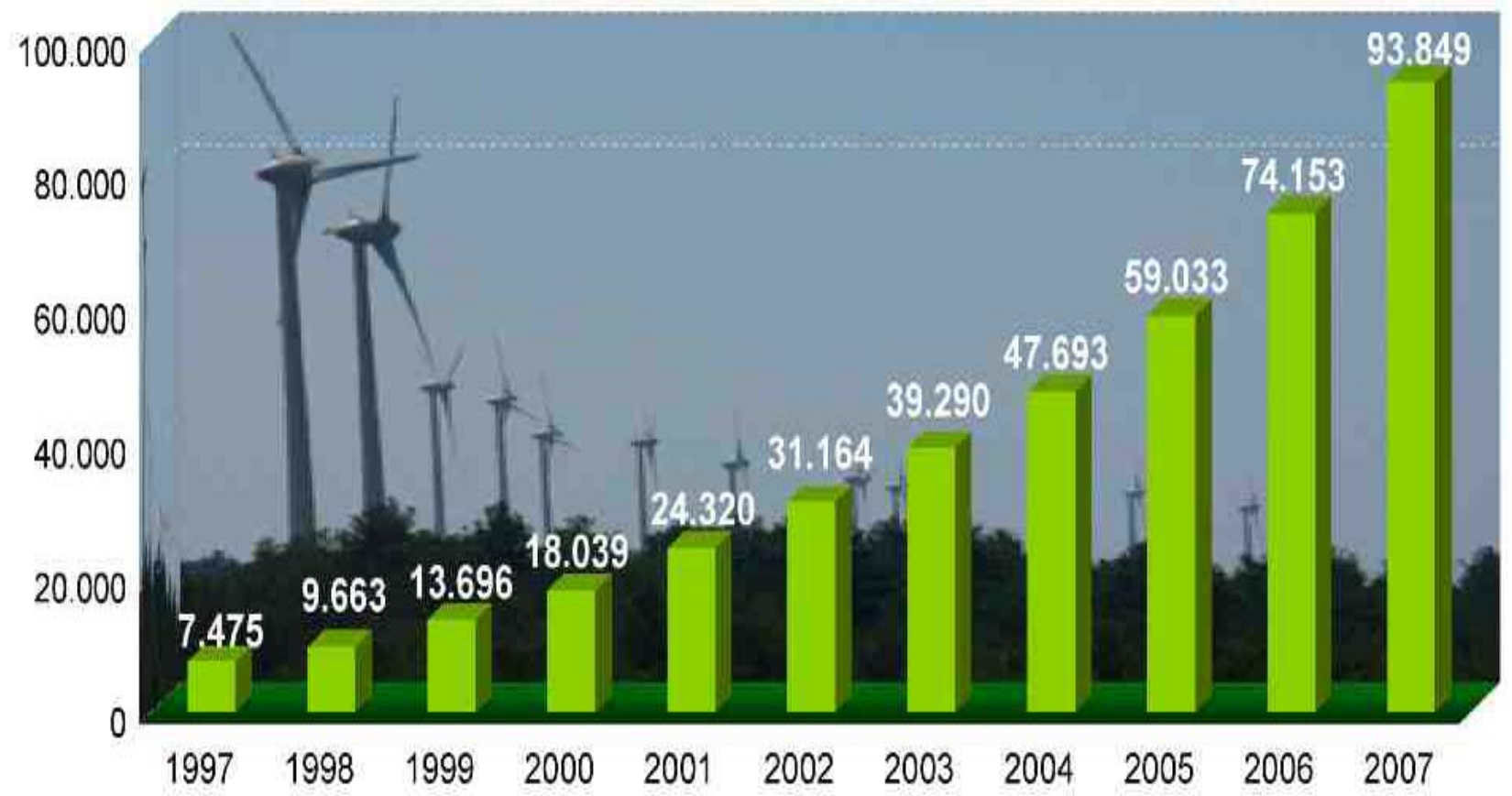

Capacidad mundial de Eólica instalada. Fuente WWEA.

En Europa, Alemania España y Dinamarca; en América, EE.UU.; y en Asia, India; son los que han realizado las mayores inversiones en generación de energía a través de la eólica. Dinamarca es, de los primeros y mas importantes fabricantes y consumidores de turbinas eólicas desde 1970; y en la actualidad se genera aproximadamente $20 \%$ de su electricidad mediante aerogeneradores.

Al 2006, los mayores productores de energía eólica en el mundo son: Alemania: $21.000 \mathrm{MW}$; España: 11.730 MW; EE.UU. : 11.603 MW; India : 6.270 MW; Dinamarca: 3.136 MW; China 2.405 MW; Italia: 2.123 MW; Reino Unido: 1.963 MW; Portugal: 1.716 MW; Francia 1.577 MW.

Dentro de las economías emergentes de América Latina, la generación de energía eólica representa alrededor de 473 MW.Brasil: 256 MW; México: 88 MW; Costa Rica: 74 MW; Argentina: 27 MW; Chile 20 MW;Colombia: 20 MW; Perú: 1 MW; Cuba 5 MW; y otras islas del Caribe: 57 MW.

\section{Biomasa:}

La Biomasa (masa biológica), es el tipo de combustible que se obtiene de recursos biológicos tales como la madera ( biomasa sólida), aceites vegetales (biomasa liquida), y biomasa húmeda, de la cual se pueden obtener gases para combustión. La Biomasa natural (leña), es la que se produce de forma espontánea en la naturaleza, en los montes y bosques. La Biomasa residual es la generada por las actividades agrícolas, forestales, etc..

Alguno de los aportes fundamental de este recurso renovable, son: aun cuan es combustible y el resultado sea la emisión $\mathrm{CO} 2$, es la misma cantidad captada en su momento por las plantas durante su crecimiento; no significando esto un aumento de emisiones, sino un ciclo cerrado. Otro valor agregado es la posibilidad de reciclaje de residuos de otras actividades. 
Estas previsiones marcan un crecimiento promedio del 1,8\% entre 2004 y 2030 . Este crecimiento será menor en los OCDE $(0,8 \%)$ y mayor en los emergentes $(2,6 \%)$. A la cabeza de los primeros, México $(2,3 \%)$, y a nivel mundial China (3,4\%), superando, en 2010 a EE.UU. como principal emisor, y en el 2030 superará el volumen emitido por los norteamericanos en un $41 \%$.

Según pronósticos, los signatarios del protocolo deberían de reducir sus emisiones en un total de 593 millones de toneladas respecto a los no firmantes de este acuerdo.

Las economías emergentes son las que se perfilan como mas dependientes de los combustibles fósiles en el presente y el futuro inmediato; aun estando estos países comprometidos con Kioto y redujeran sus emisiones, el incremento de la contaminación por la producción de energía sería realmente muy significativo.

Incluso asumiendo plenamente los compromisos del protocolo, las emisiones de dióxido de carbono en el mundo seguirían aumentando de 29,8 millones de toneladas en 2010 a 38,2 millones de toneladas en 2030.

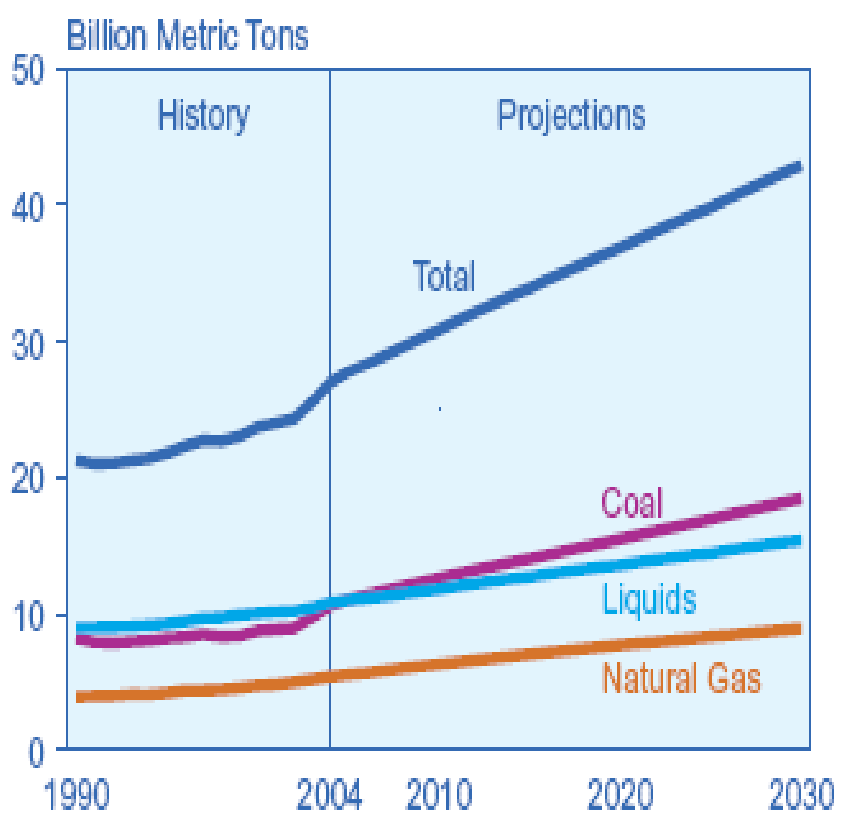

Mercado mundial del consumo energético.1970-2025. Fuente EIA.

\subsection{Energías Renovables. Características y situación actual en países industrializados y países en vías de desarrollo.}

Haciendo una breve descripción del termino Energías Renovables, podríamos decir que son aquellas fuentes energéticas que teóricamente son inagotables y que su impacto al medio ambiente es mínimo o nulo; partiendo de las mínimas emisiones de $\mathrm{CO} 2$ que producen al ser utilizadas.

Con relación a la arquitectura podemos hablar de tres fuentes renovables de energías fundamentales: Eólica, Biomasa, y Solar.

\section{Eólica:}

El viento que conocemos como tal, no es mas que el aire atmosférico que se mueve debido a la diferencia de temperatura existente entre sus puntos. La energía eólica es la transformación de la energía mecánica que posee el viento en energía eléctrica.

Precisamente en la generación de electricidad es donde la eólica ha tenido mayor utilidad en los últimos años; siendo los aerogeneradores de eje horizontal los mas comunes. Desarrollan velocidades 10 veces mayores a las del aire. Para el arranque de una de estas maquinas hacen falta por lo menos $5 \mathrm{~m} / \mathrm{s}$, y su calculo de hace para velocidades no mayores de $16 \mathrm{~m} / \mathrm{s}$. 


\section{Producción de energía primaria con biomasa en la UE}

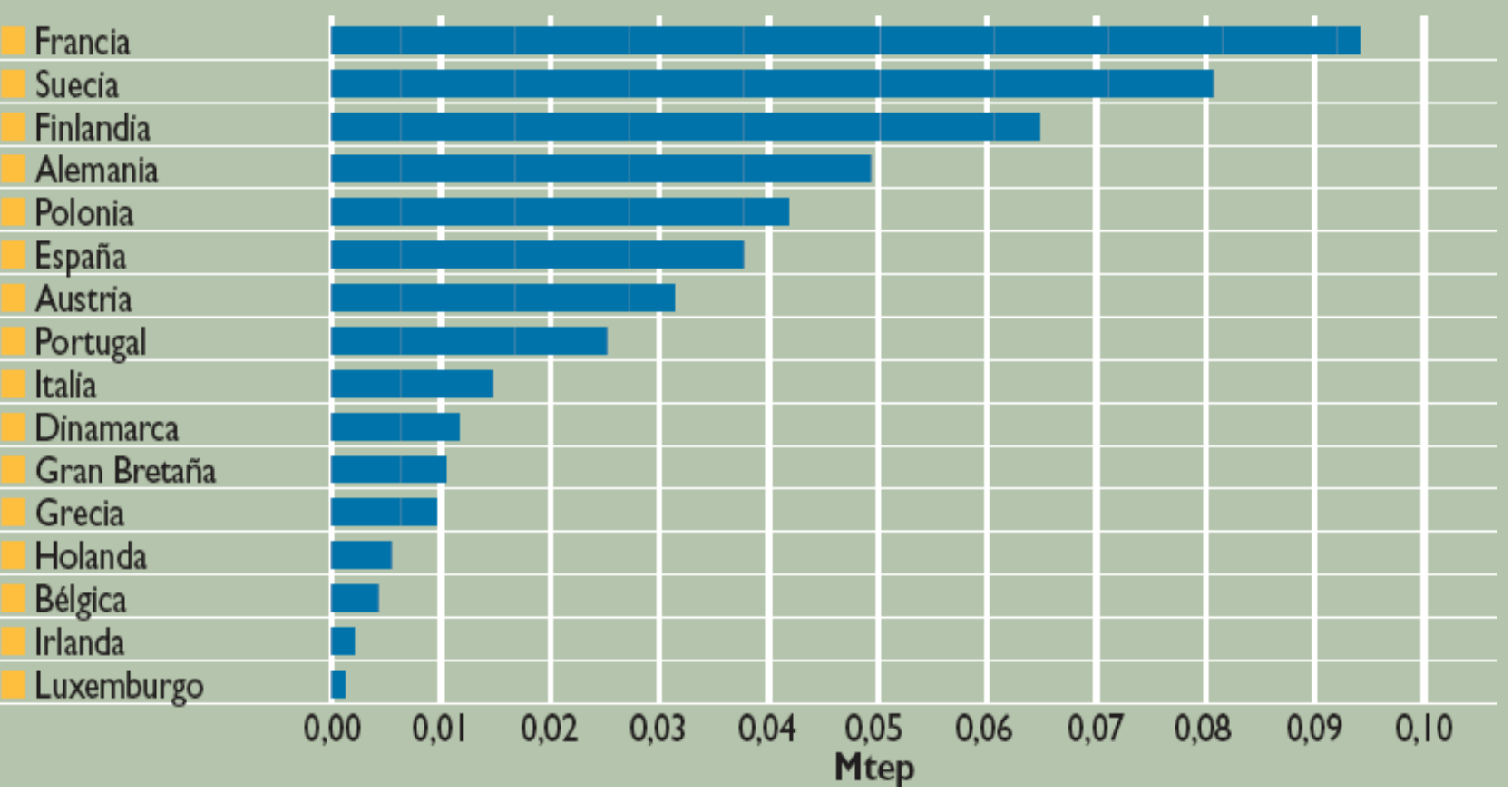

Fuente: F.O. Light

Dentro de las posibles aplicaciones de la biomasa tenemos: Térmica, Eléctrica Biocombustibles, Gases combustibles.

En el caso de la producción de electricidad esta se obtiene en menor medida de la biomasa residual y mayormente de los cultivos leñosos de rápido crecimiento, así como de la cosecha de herbáceos. El biogás, obtenido de la fermentación de lodos, etc.. también puede ser una buena fuente de generación.

Aun hoy en día la producción de electricidad por medio de Biomasa tiene un bajo rendimiento; aproximadamente un $20 \%$ de su poder calorífico interno, esto cuando un $8 \%$ se asume como consumo propio de la instalación de combustión.

\begin{tabular}{|c|c|}
\hline Country & $\begin{array}{l}\text { Millions of } \\
\text { Gallons }\end{array}$ \\
\hline USA & 6498.6 \\
\hline Erazil & 5019.2 \\
\hline European Union & 570.3 \\
\hline China & 486.0 \\
\hline Canada & 211.3 \\
\hline Thailand & 79.2 \\
\hline Columbia & 74.9 \\
\hline India & 52.8 \\
\hline Central Arnerica & 39.6 \\
\hline Australia & 26.4 \\
\hline Turkey & 15.8 \\
\hline Pakistan & 9.2 \\
\hline Peru & 7.9 \\
\hline Argentina & 5.2 \\
\hline Paraguay & 4.7 \\
\hline Total & $13,101.7$ \\
\hline
\end{tabular}

Producción Mundial de Etanol. Fuente: F.O. Light

El mercado de la producción energética mundial por biomasa esta muy desarrollado en los países de la UE; siendo Francia en principal productor. Si además consideramos la producción y el consumo de Biocombustibles, se debe tomar en cuenta a Brasil y a EE.UU. Como dos de los principales patrocinadores de estas iniciativas. 


\begin{tabular}{l|r|r|r|r|r|r} 
& & & & & & \\
Country & 2002 & 2003 & 2004 & 2005 & 2006 & 2007 \\
\hline Brazil & 0 & 0 & 90.3 & 31.2 & 433.7 & 188.8 \\
\hline Costa Rica & 12 & 14.7 & 25.4 & 33.4 & 35.9 & 39.3 \\
\hline El Salvador & 4.5 & 6.9 & 5.7 & 23.7 & 38.5 & 73.3 \\
\hline Jamaica & 29 & 39.3 & 36.6 & 36.3 & 66.8 & 75.2 \\
\hline Trinadad B Tobago & 0 & 0 & 0 & 10.0 & 24.8 & 42.7 \\
\hline Canada & & & & & & 5.4 \\
\hline China & & & & & & 4.5 \\
\hline
\end{tabular}

Total

$\begin{array}{llllll}45.5 & 60.9 & 159.9 & 135.0 & 653.3 & 426.2\end{array}$

Mayores Importadores de Etanol. Fuente: F.O. Light

\section{Uso mundial de biomasa}

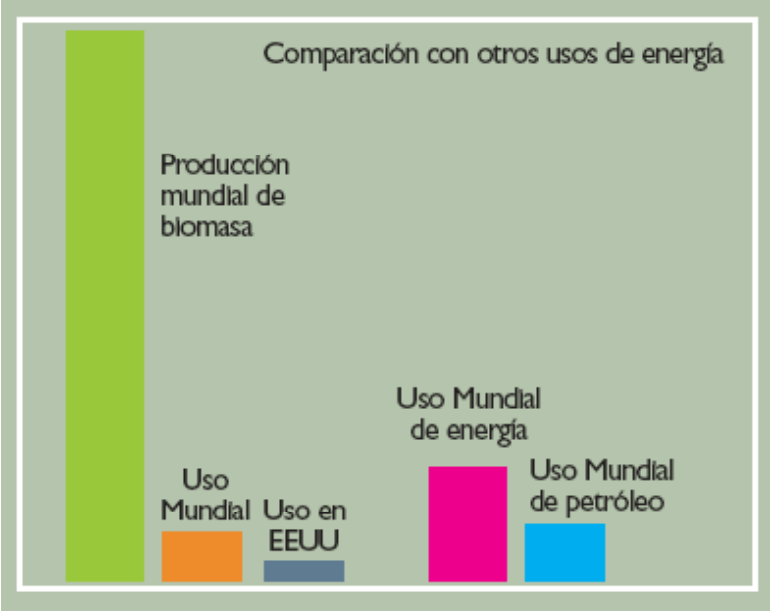

Parámetros uso Biomasa. Fuente: F.O. Light

\section{SOLAR}

El sol es la fuente de energía por excelencia, y el aprovechamiento de su radiación esta prácticamente presente, directa o indirectamente en todos los aspectos de la vida. Se caracteriza por su elevada calidad, su impacto cero al medio ambiente.

Siendo un recurso inagotable ( le restan 5 mil millones de años de vida); su aprovechamiento esta supeditado a condiciones geográficas y climáticas.

La radiación y su potencia, varían según la hora, las condiciones de la atmósfera y del lugar. En buenas condiciones de irradiación se estima que $1000 \mathrm{~W} / \mathrm{m} 2$ (Irradiancia) inciden en la superficie de la tierra.

Dada la gran capacidad del sol, se han desarrollado varias tecnologías de aprovechamiento su energía:

\section{Solar Pasiva.}

Aprovechamiento del calor del sol sin necesidad sistemas mecánicos.

\section{Solar Térmica.}

Calentamiento del agua a temperaturas moderadas para uso sanitario y calefacción.

\section{Solar Termoeléctrica.}

Producción de electricidad con un ciclo termodinámico convencional mediante un fluido calentado a alta temperatura.

\section{Solar Híbrida.}

Combinación de la energía solar con la combustión de biomasa, combustibles eólica, etc..

\section{Solar Eólica.}

Calentamiento de aire que posteriormente sube por una chimenea con generadores.

\section{Solar Fotovoltaica.}

Para producir electricidad mediante placas de semiconductores que se excitan con la radiación solar. 
En lo referente a la arquitectura, las formas mas comunes de aprovechamiento solar son: 1)luz natural, calor, y electricidad.

1) Permitiendo la entrada de Luz natural ( aportado por el sol), a los espacios interiores del la edificación, se ahorra la aportación eléctrica necesaria para iluminar estos ambientes.

2) El calor captado por sistemas de aprovechamiento térmico (colectores) se puede usar de varias maneras. Para obtener agua caliente de consumo doméstico o industrial; para calefacción de la edificaciones; climatización de piscinas en épocas de frió; etc..

3) La electricidad a partir de la captación solar, y su transformación por paneles fotovoltaicos, representa un aporte importante para el ahorro energético de la edificación. Esto se refleja positivamente en los aspectos económicos y ambientales.

\section{Solar Térmica.}

En la Unión Europea, Alemania ha crecido desde el 2005, 25,6 \% en su mercado nacional. Unos 980.000 m2 de solar termal fueron instalados en este país a partir de ese año. (equivalente a $686 \mathrm{MWTH}$ ). El crecimiento austriaco de mercado ha sido similar (+ el 25,1 \% a partir de 2004), con una superficie recién instalada de $239.540 \mathrm{~m} 2$ (167,7 MWTH de capacidad). Grecia ha mantenido el nivel de su mercado solar termal (más el $3 \%$ de crecimiento); es decir que 220,500m2 de superficie instalada, equivalente a 154.4 MWTH. Ya para el 2007 se añadieron $250.000 \mathrm{~m} 2$ de captadores solares en España, lo que eleva a 1.220.000 m2 (854 MWTH) el total acumulado hasta finales del pasado año. Con todo esto, Europa representa aprox. el $10 \%$ del total mundial de solar térmica.

Se calcula que solamente en China, se encuentra el $40 \%$ de los captadores solares instalados a nivel mundial; y en Israel el $80 \%$ de las vivienda llevan esta tecnología.

En los Estados Unidos y Canadá, el calentamiento de piscinas es el campo de mayor aplicación de la solar térmica, con una capacidad instalada de 13 GW desde 2005.

Si bien en Países emergentes de Centro América y el Caribe ( Panamá, Cuba, Rep. Dominicana), los sistemas de captadores solares térmicos representan una opción alternativa a los sistemas eléctricos, para ACS; aun no superan el $1 \%$ en sus mercados locales.

\section{Solar Fotovoltaica.}

Japón es el mayor productor mundial de energía solar fotovoltaica, seguido de Alemania (5 millones de metros cuadrados de paneles; esto es el 0,03\% del total de producción energética local).

La Unión Europea ha venido desarrollando esta tecnología a nivel de un 30\% de media anual desde finales de los noventa ( $20 \%$ a nivel mundial). Alemania tiene el $80 \%$ de la potencia instalada. En el caso de España, la producción sobrepasa los 400 MWP por año.

Dentro de las economía emergentes, México mantiene un mercado ligeramente encima de 1 MWP .La capacidad Fotovoltaica instalada en México hacia el final de 2007 es de 20,8 MWP. 


\subsection{Las economías emergentes como entes de equilibrio medioambiental}

Los naciones no industrializados, en vías de desarrollo o de economías emergentes, que hemos venido mencionando; son el grupo de países que no han alcanzado aun un nivel de avance y desarrollo que permita el bienestar al grueso de sus poblaciones.

Algunos indicadores trazan la pauta para la ubicación de un país en esta franja: Alta tasa de desempleo; grandes desigualdades económicas entre sus habitantes; poco aporte estatal al desarrollo de la ciencia y tecnología; bajo ingreso per cápita; elevada deuda externa; dependencia tecnológica de otros países; exportadores de materia prima, e importadores de productos industrializados.

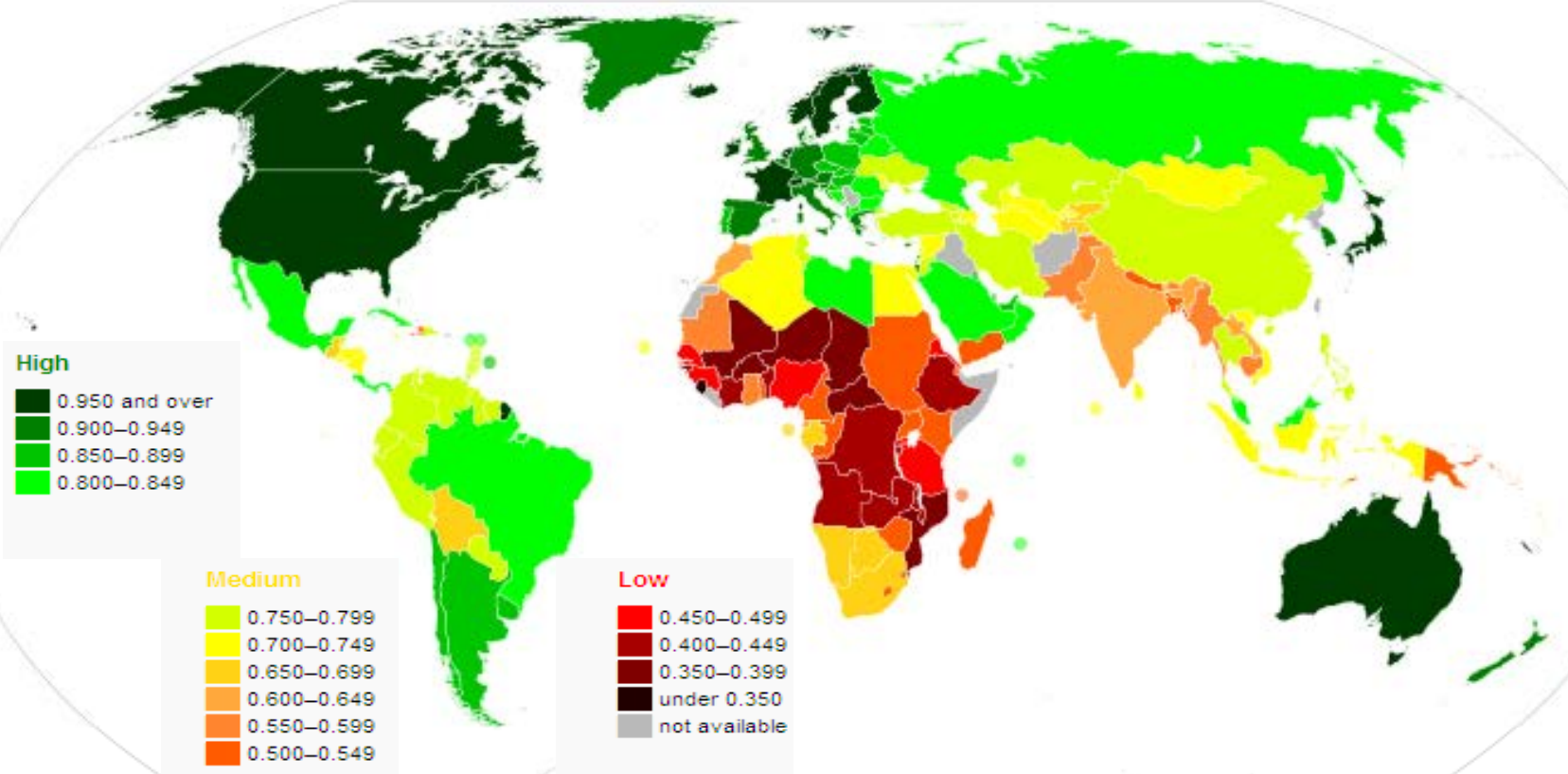

Mapa del índice de desarrollo Humano. Actualmente máximo indicador del nivel de desarrollo de los pueblos. Fuete: HDR 2008

Gran parte del territorio de estos estados poseen grandes recursos naturales que ayudan al equilibrio de todo el planeta.

Tal es el caso de los territorios selváticos del amazonas en América del sur. En este basta extensión de tierra - que es compartida por, Brasil, Perú, Bolivia, Colombia, Ecuador, Surinam, Guyana, Guyana Francesa y Venezuela- se encuentra uno de los pulmones naturales y captadores de $\mathrm{CO} 2$ mas grandes de todo el planeta.

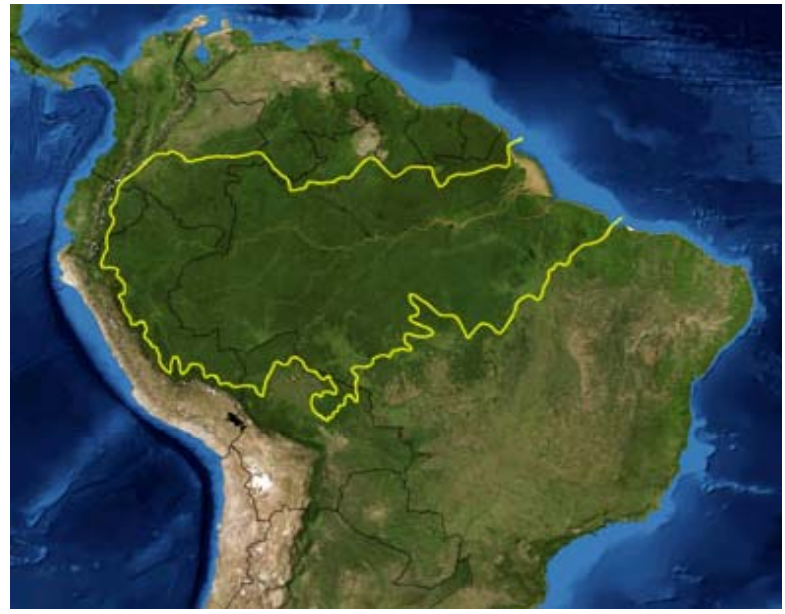

Mapa de la Selva Amazónica. Fuente: G. Earth 
La mayor extensión de selva amazónica pertenece al Brasil, que posee mas del $50 \%$ de la misma. Este filtro en la región tropical, ocupa una extensión de aproximadamente los 6.000 .000 de $\mathrm{km}^{2}$; se desarrolla entorno al río Amazonas y sus fluviales. EI balance entre $\mathrm{CO} 2$ y $\mathrm{O} 2$ esta perfectamente equilibrado aquí, y las condiciones están dadas para la presencia de la mas grande reserva de la biodiversidad global amenazada por la deforestación y el cambio climático.

Se podrían citar varios ejemplos mas de reservas y puntos clave de equilibrio medioambiental en los países emergentes pero de igual manera se podrían citar muchos en países industrializados. Lo que hace especial el escenario de un país emergente, es que combinado con sus reservas ecológicas y riquezas naturales, están sus condiciones sociales propias; que si en principio pueden ser obstáculos para su desarrollo, luego pueden convertirse en estímulos para el avance de iniciativas amigables con el medio ambiente.

Basándose en estas condiciones socioeconómicas y tomando el tema del cambio climático como punto de partida central, se plantean los MDL (Mecanismos de Desarrollo Limpio).

Los Mecanismos de Desarrollo Limpio, forman parte de un acuerdo del Protocolo de Kioto, que permite a los gobiernos de los países industrializados y sus empresas, suscribir convenios para cumplir con metas de reducción de gases de efecto invernadero. Esto seria, invirtiendo en proyectos de reducción de emisiones en países no industrializados como una alternativa para adquirir reducciones certificadas de emisiones a menores costos que en sus mercados de origen.

La particularidad de los escenarios emergentes es la posibilidad de combinar la conservación de sus reservas ecológicas y recursos naturales, con mecanismos de desarrollo que fomenten la inversión en tecnologías de generación de renovables y que esto se refleje también en avance y mejora de las condiciones de vida.

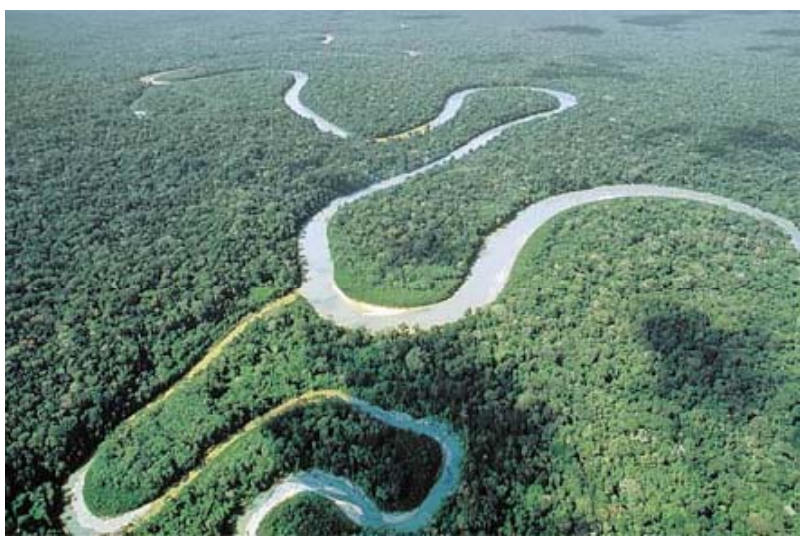

Río Amazonas y sus fluviales.

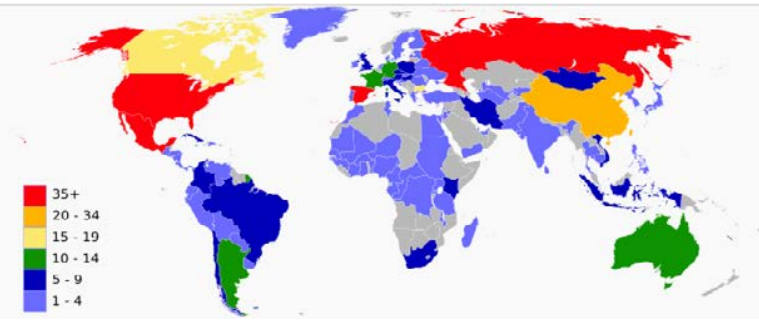

Mapa de las reservas de la biodiversidad del planeta.

CANTIDAD PREDICHA DE CALENTAMIENTO GLOBAL EVITADO

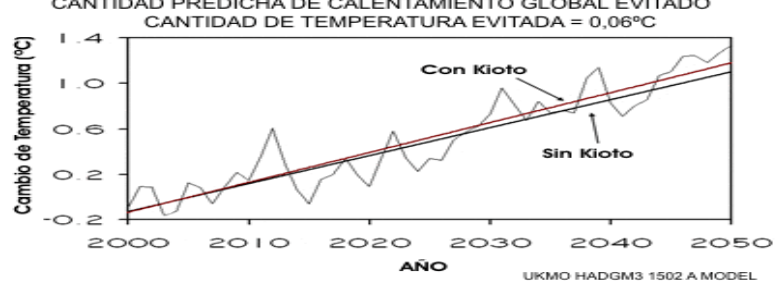

Todo esto solo funcionaria, aplicando los controles necesarios (leyes y normativas locales), para evitar caer en prácticas insostenibles como la implementación de proyectos, que mas que ayudar, comprometerían mucho el desarrollo sostenible que hace falta para establecer las bases necesarias de una perspectiva mas allá de Kioto.

Los países en vías de desarrollo se convierten en receptores de cooperación por parte de las naciones poderosas, pero a su vez y como parte del mismo proceso, serian vehículos idóneos para canalizar indicativas en pro del medioambiente.

A la vez que entran a formar parte - de alguna manera- en la toma de decisiones en materia de prevención del cambio climático; reciben una inyección de capital económico y tecnológico importante. 


\section{LA ALTERNATIVA FOTOVOLTAICA.}

\subsection{Energía solar y arquitectura.}

El sol es una estrella con una temperatura media de $5.500^{\circ} \mathrm{C}$. En su interior se producen una seria de reacciones que representan una perdida de masa que se convierte luego en energía. Esta energía es la radiación solar.

El sol emite una radiación de 63.450 .720 W/m2; y la atmósfera terrestre esta a una distancia de 149,6 millones de $\mathrm{Km}$. La constante solar es el valor de la radiación recibida perpendicularmente sobre la atmósfera y equivale a $1.353 \mathrm{w} / \mathrm{m} 2$, que varían mas o menos $3 \%$ a causa de la elipticidad de la orbita del globo terráqueo.

Se calcula que a la tierra solo llega el 33\% de la energía total interceptada por la atmósfera, y que el 70\% de ella cae en la masa marina. Sin embargo esto representa muchas veces mas de lo que consume el nuestro mundo.

Irradiación solar en superficie

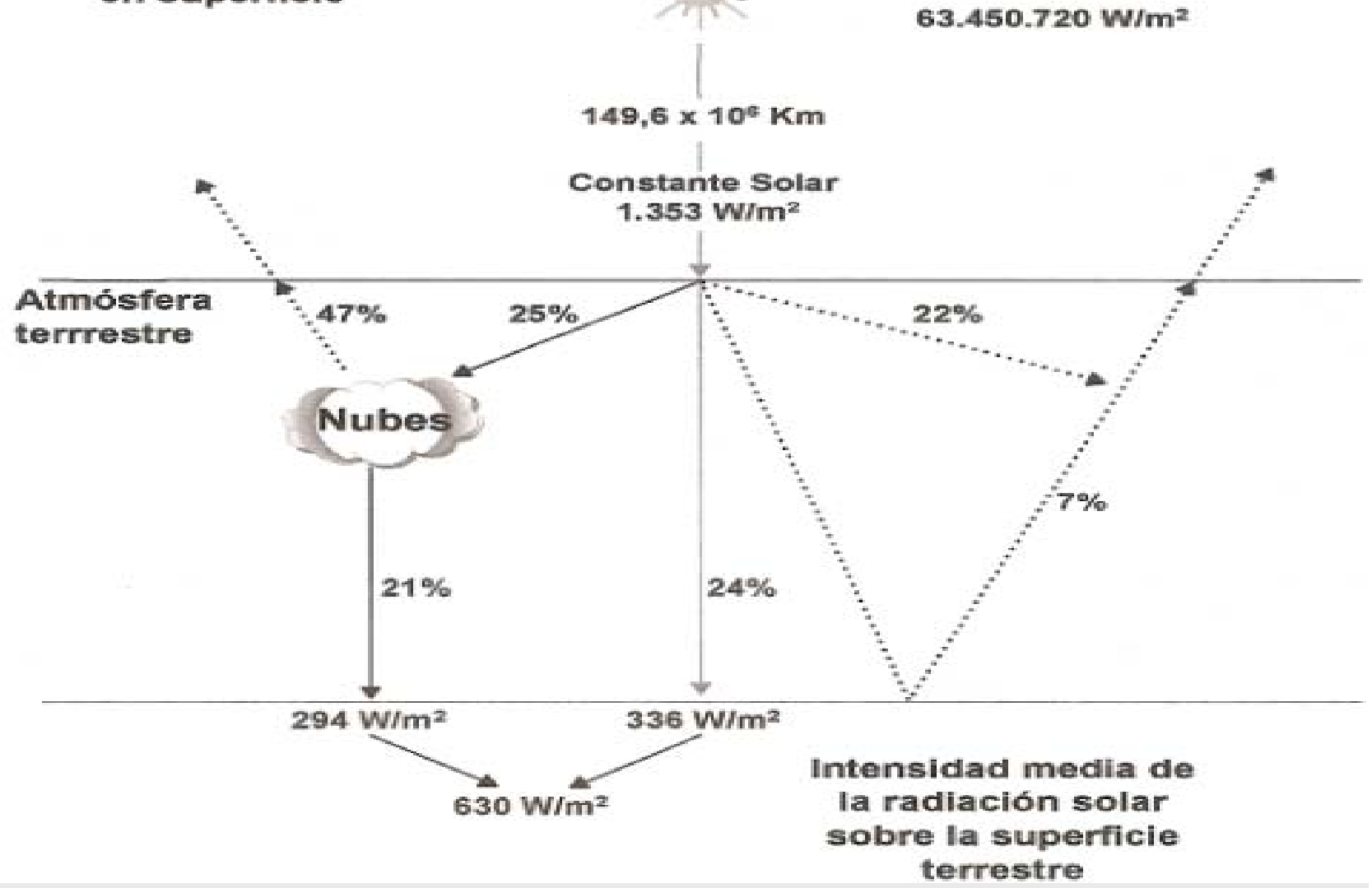

Partiendo de cómo inciden los rayos solares en la tierra, podemos hablar de tres tipos de radiación solar:

Radiación directa:

Es la recibida desde el Sol, sin que sea desviada por la atmósfera.

Radiación difusa:

Es la que cambia su dirección debido a la reflexión y difusión de la atmósfera, principalmente.

Radiación albedo:

Es la radiación directa y difusa que se recibe por reflexión en el suelo u otras superficies. 
Las proporciones de radiación que recibe una superficie depende de algunas variables:

\section{Condiciones meteorológicas:}

En un día con nubes, la radiación recibida es difusa mientras en un día despejado es directa.

Inclinación de la superficie respecto a la horizontal:

Una superficie horizontal recibe la radiación difusa en su máxima expresión y la mínima reflejada.

Presencia de superficies reflectantes:

Las superficies claras suelen ser las mas reflectantes por lo que la radiación reflejada aumenta en invierno a causa de la blancura de la nieve.

La trayectoria del sol es diferente según la época del año. Subiendo mucho en verano y no tanto en invierno; de ahí la diferencia en la sombras.
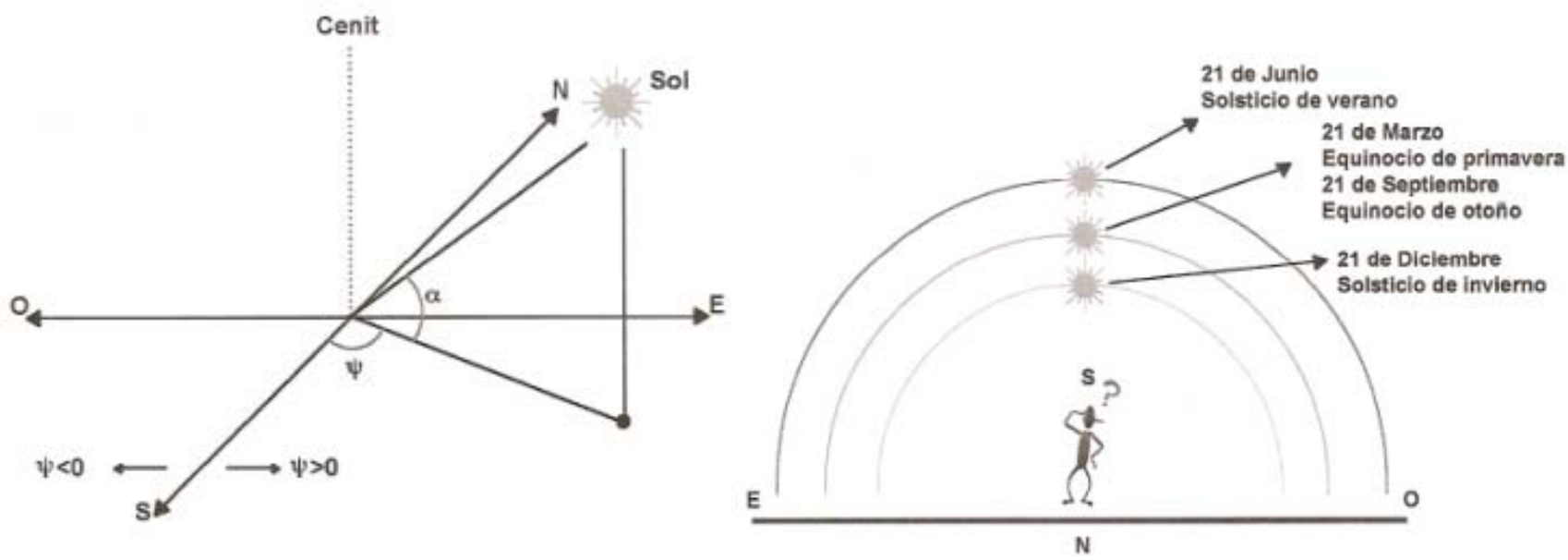

Altura solar. Fuente: Energía Solar FV.J.M. Méndez

Para un observador que este sobre la superficie de la tierra, el Sol describe una trayectoria aparente que depende de la latitud y de la longitud del lugar donde esta.

La latitud es la distancia angular de un punto cualquiera del globo terráqueo con relación al ecuador; esto es desde 0 a $90^{\circ}$ en el hemisferio norte.

La longitud es también un ángulo que viene referenciado al meridiano de Greenwich, desplazándose hacia el este.

La posición del Sol se define por dos ángulos:

-La Altura Solar $h$, que es el ángulo formado por la posición aparente del Sol, con la horizontal.

-El Azimut Solar, es el ángulo entre el meridiano del lugar y el plano vertical que pasa por el sol, contando de forma negativa hacia el este.

Tenemos también que cuanto mas bajo esta el Sol respecto a la línea de horizonte, mayor es el espesor de capa atmosférica que tiene que pasar sus rayos, y mayor también las transformaciones que sufrirán.

La masa de aire es el cociente entre el espesor de la atmósfera atravesad por los rayos del sol (OM), y el espesor atravesado en la línea vertical del lugar en cuestión (OA). 
El tema del asoleamiento ha influenciado la elección del emplazamiento de la edificación desde los principios de la historia; así como de la selección de materiales, formas constructivas, etc..

Si nos remontamos aproximadamente 400 años antes de Cristo encontramos el Megaron de Sócrates como ejemplo de construcción solar. Este modelo de vivienda deja ver principios básicos y aun vigentes de arquitectura solar pasiva. El factor de forma favorable, aberturas hacia el sol, protecciones solares bien proyectadas, zonificación solar, aprovechamiento de la inercia térmica , etc.; favorecen el uso inteligente de la energía del sol.

El tema del asoleamiento ha influenciado la elección del emplazamiento de la edificación desde los principios de la historia; así como de la selección de materiales, formas constructivas, etc..

Si nos remontamos aproximadamente 400 años antes de Cristo encontramos el Megaron de Sócrates como ejemplo de construcción solar. Este modelo de vivienda deja ver principios básicos y aun vigentes de arquitectura solar pasiva.

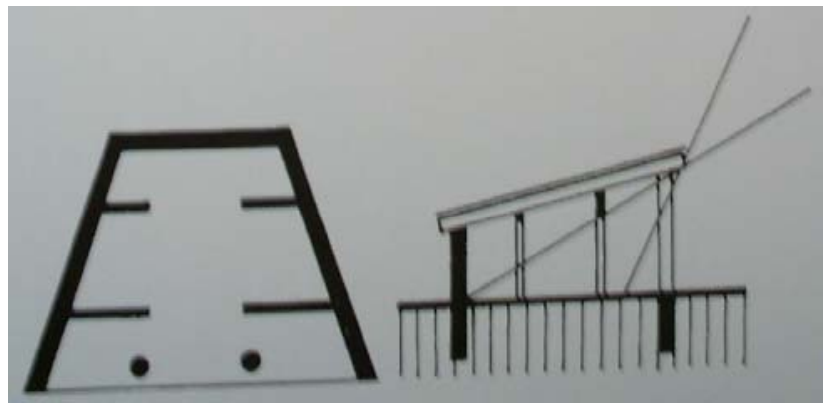

Megaron (Sócrates) . Fuente: Arq. Solar. Detail

Junto con el desarrollo de la economía mundial, durante el siglo XIX, vino un desarrollo tecnológico que abarco aspectos de la construcción como los cerramientos en vidrio de gran formato, y con esto nuevas posibilidades para las técnicas solares. Con los invernaderos que surgieron con las nuevas técnicas del vidrio, se pudo captar la radiación ultravioleta y transformar en radiación de calor infrarroja.

En los comienzos del siglo XX los postulados de la modernidad plantean un protagonismo para el sol, la transparencia, la luz, el aires. Los problemas higrotérmicos, aun quedaban pendientes de resolver.

Tipologías de casa pasivas autosuficientes en, se abren paso tímidamente en la Alemania de principios de los años 30 , y en cierta medida trazan la pauta a la llamada arquitectura ecológica de la década de los 70, surgida a raíz de la crisis del petróleo de 1973.

El aprovechamiento inteligente de la radiación solar, siempre ha sido un objetivo a alcanzar por la arquitectura; y por esto varios factores se han tenido en cuanta con mayor o menor importancia según la situación y la vocación del proyectista por llevar a cabo un buen proyecto. Algunos de estos son:

-Situación y microclima del lugar de emplazamiento.

-Topografía y su influencia en las condiciones térmicas del edificio.

-Protección contra el viento y/o soterramiento (en los casos de necesidad de ganancias térmicas).

-Consideración de las tipologías arquitectónicas locales para aplicación de soluciones al nuevo edificio.

-Factor de forma del organismo.

-Orientación y asoleamiento y protección solar.

-Zonificación.

-Diseño de la envolvente de manera eficiente. 


\subsection{Definición y Fundamentos de Fotovoltaica. Tipologías y características técnicas.}

la

El fenómeno fotovoltaico fue dado a conocer por el francés, Henri Becquerel en 1839. Las primeras celdas solares que en este caso eran de selenio se desarrollaron a partir del 1880.

Solo hasta el 1950 que se empieza a utilizar el silicio monocristalino; pero con una eficiencia entre el $1 \%$ y $6 \%$. En laboratorio se podía alcanzar un eficiencia de casi $15 \%$. Al día de hoy este rango sigue siendo el promedio.

La electricidad se produce basándose en el "efecto fotovoltaico"; un fenómeno físico que consiste en convertir los rayos de luz solar en energía eléctrica mediante unos semiconductores (células fotovoltaicas). Estas células son elaboradas con silicio puro e impurezas de ciertos elementos químicos (boro y fósforo), y que son capaces de generar cada de ellas una corriente de 2 a 4 Amperios, a un voltaje de 0,46 a 0,48 Voltios, usando la radiación luminosa como fuente de energía.

Estas células se montan en serie sobre paneles o módulos, para conseguir un voltaje adecuado. Aunque los niveles de eficiencia aun no impiden que parte de la radiación incidente se pierde por reflexión y otra parte por transmisión; si se ha podido conseguir que la captada haga saltar electrones de una capa a la otra creando una corriente proporcional a la radiación incidente.

El común de las células fotovoltaicas tienes un grosor que varía entre los 0,25 y los $0,35 \mathrm{~mm}$ Los materiales para la fabricación de los paneles solares son: Silicio Monocristalino: de rendimiento energético hasta 15 - 17\%; Silicio Poli-cristalino: de rendimiento energético hasta 12 - 14 \%; Silicio Amorfo: con rendimiento energético menor del $10 \%$. También hay otros materiales como Arseniuro de galio, Seleniuro de indio y cobre, y Telurio de cadmio. La presencia de estos componentes en la fabricación de células aun no resulta ser frecuente.

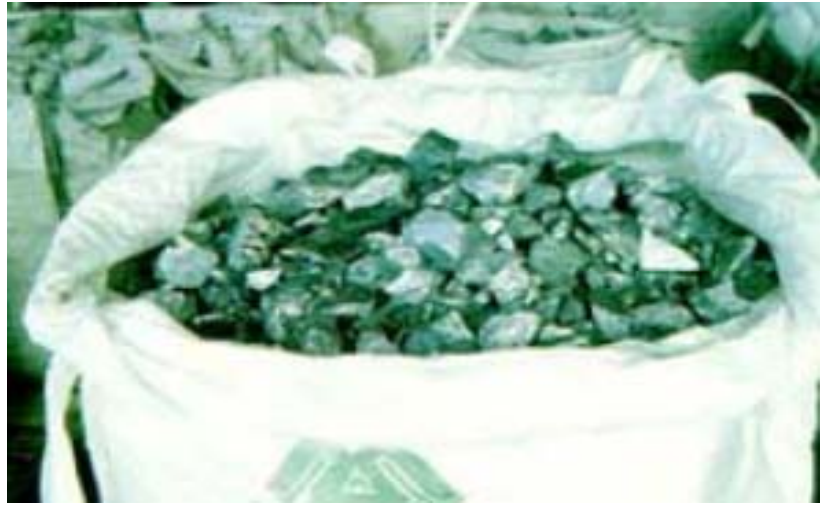

Silicio en estado puro. Fuente: Archivo particular.

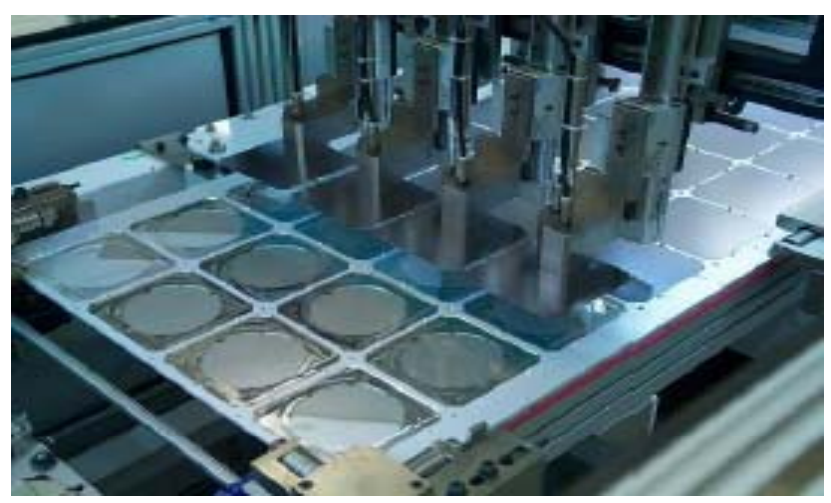

Fabricación de células de silicio. Fuente: Archivo particular.

Actualmente, el material más utilizado para la fabricación de la células que se comercializan, es el silicio monocristalino o multicristalino. La razón para que su uso sea el mas extendido, aparte de su relativo mayor rendimiento, es el conocimiento de su tecnología, y la fiabilidad demostrada en el tiempo.

El Silicio amorfo, es la tecnología mas consolidada dentro de las conocidas como "Laminas Delgadas". Su ventaja esta en el ahorro de tiempo y material en su proceso de fabricación, con respecto a los cristalinos. Su desventaja fundamental es su rendimiento entorno al $50 \%$ de las anteriores. Su uso ha estado muy extendido en el mercado de la electrónica domestica ( linternas, relojes, calculadoras, etc.). Su posibilidades en el manejo y aplicación, permiten que cada vez su integración en la arquitectura vaya en aumento. 
Las limitantes en cuanto a rendimiento que presenta el silicio amorfo han servido de motivación para la búsqueda de materiales policristalinos con los que se pueda desarrollar la tecnología de lamina delgada.

En el mercado existe una reducida producción de módulos de teleruro de cadmio (CdTe). Este componente resulta altamente toxico para el medio ambiente al momento de ser usado en la fabricación de obleas.

Otra tecnología que presenta grandes posibilidades futuras, es que usa para la fabricación el seleniuro de cobre e indio (CIS). Con este se han conseguido laminas delgadas con un rendimiento próximo al $11 \%$.

También presentes en el mercado, encontraos módulos que en ocasiones no alcanzan los valores antes mencionados, en otras los igualan o los superan. El modulo de estructura piramidal y contactos enterrados de fabricación española, consigue rangos próximos al 16\%; con contactos en la cara posterior llegan al $17 \%$ de rendimiento.

En Japón, se desarrolla una tecnología que combina el silicio amorfo y el silicio monocristalino, conocida como "hetero junction with intrinsic thin layer" (HIT), con valores próximos al $17 \%$.
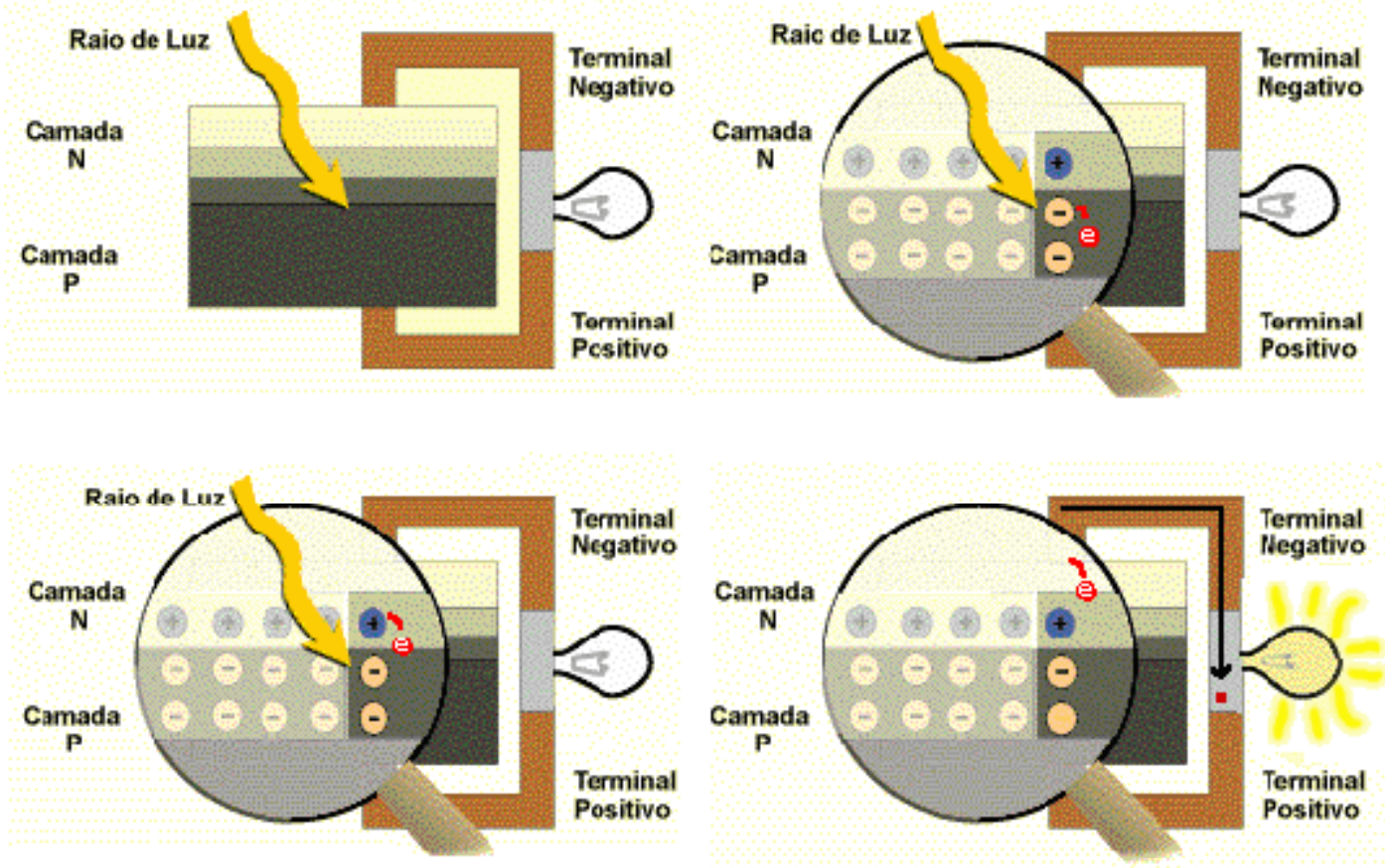

Grafico del fenómeno fotovoltaico. Fuente: Igenfor

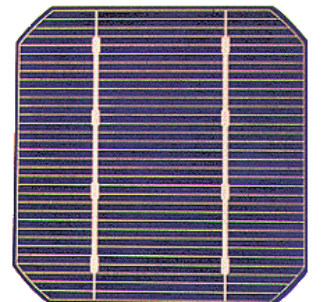

Célula de silicio monocristalino

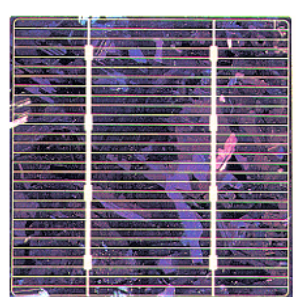

Célula de silicio multicristalino

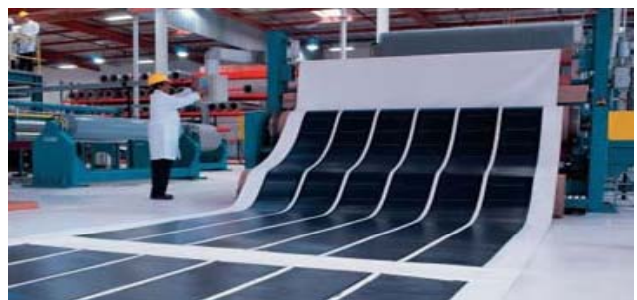

Célula de silicio amorfo 
Forma y características técnicas.

\section{La célula fotovoltaica:}

La parte o superficie activa de la célula es la que interviene en el proceso fotovoltaico. Al principio era normal que el material semiconductor que servía de conexión fueran pequeños trazos de metal en cara expuesta al sol, lo que suponía una merma en el rendimiento. Ya en la actualidad las conexiones del semiconductor, se hacen por la parte de atrás, incrementando así el área de captación sin que para ello sea mas grande la célula.

Al ser tratada con un compuesto antirreflectante, la superficie expuesta a la luz del materia semiconductor, no refleja los rayos ni disminuye la cantidad de energía captada.

La forma va determinada por el método de fabricación. Los modelos iniciales que se fabricaron tenían forma de circulo. Hoy pueden ser de cualquier forma, aunque casi siempre su corte es cuadrado con o sin redondeados.

El grosor de una célula común del mercado varia entre 0,25 y $0,35 \mathrm{~mm}$, de geometría cuadrada, y superficie aproximada de $12 \times 12 \mathrm{~cm} 2$.

Luego de numerosos ensayos mecánicos y eléctricos sujeto a normas de diseño y fabricación, las células que forman los módulos fotovoltaicos, están aptas para soportar incidencias técnicas, como producidas por las condicionantes climático-ambientales.

Las células solares forman un producto intermedio ya que proporcionan valores de corriente y de tensión limitados, si se comparan a los necesarios generalmente por los aparatos; no estando aisladas eléctricamente.

La relación entre la energía eléctrica generada y la luminosa usad para producirla es lo que se conoce como eficiencia de conversión. Como antes se ha mencionado, los productos disponibles en el mercado tiene una eficiencia de conversión de entre $12 \%$ y $18 \%$.

\section{El panel fotovoltaico:}

Es la estructura única que contiene las células fotovoltaicas. El numero y su voltaje de salida depende de la composición cristalina de las mismas.

El tamaño de los paneles puede variar según el dato anterior. Los mas comunes están formados por 40 u 80 células conectadas en serie. Su superficie varia entre 0,80m2 y 2,0 m2.

El panel que encapsula las células esta compuesto por un lamina superior de vidrio y un estrato inferior de fluoruro de polivinilo. Preparado de esta forma, se lleva a un horno de alta temperatura con alto grado de vacío. Al añadir un marco metálico se le confiere la resistencia mecánica que necesita el panel para ser posteriormente instalado, no si antes colocar en la parte trasera del mismo una caja de unión donde se colocan los diodos y contactos eléctricos.

Aun cuando cada fabricante ensambla el panel de manera un tanto distintas, hay puntos en común a cada método, como el hecho de adherir a las células dos capas plásticas ( una en la parte superior, traslucida, con protección ultravioleta; la otra una capa dieléctrica posterior), que le sirven de soporte y forman un sándwich. El frente del panel tiene un vidrio templado con bajo contenido de plomo que le protege de los agentes atmosféricos y golpes. 


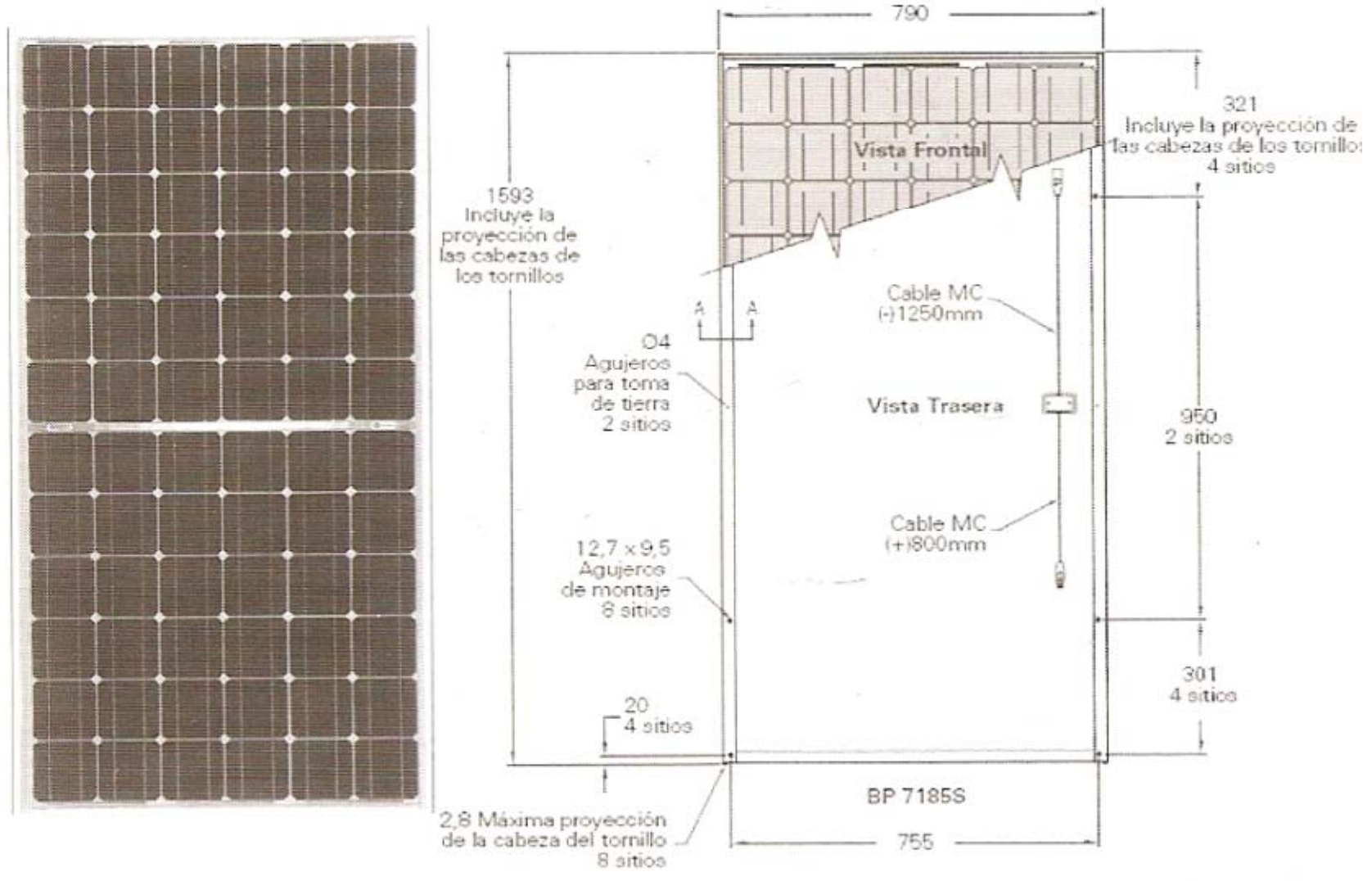

Grafico del fenómeno fotovoltaico. Fuente: Guía Completa de la Energía FV. J.M. Fernández.

A menos que sean diseñados por encargo, los paneles que se comercializan al publico suelen tener potencias de salida mayores de entre a los $50 \mathrm{Wp}$ y $220 \mathrm{Wp}$.

Contando con que los valores de luminosidad y la orientación de los paneles se mantengan en el punto adecuado, la corriente de salida varia con el valor del voltaje de la carga y su temperatura de trabajo.

En la grafica se muestra la relación entre voltaje de salida y corriente para un panel FV para cuatro temperaturas de trabajo y un nivel constante de radiación. El valor máximo para voltaje de salida es un voltaje de circuito abierto, y el valor máximo para la corriente corresponde a un voltaje de salida nulo.

La corriente generada y su intensidad aumenta con la radiación, manteniéndose el voltaje mas o menos constante.

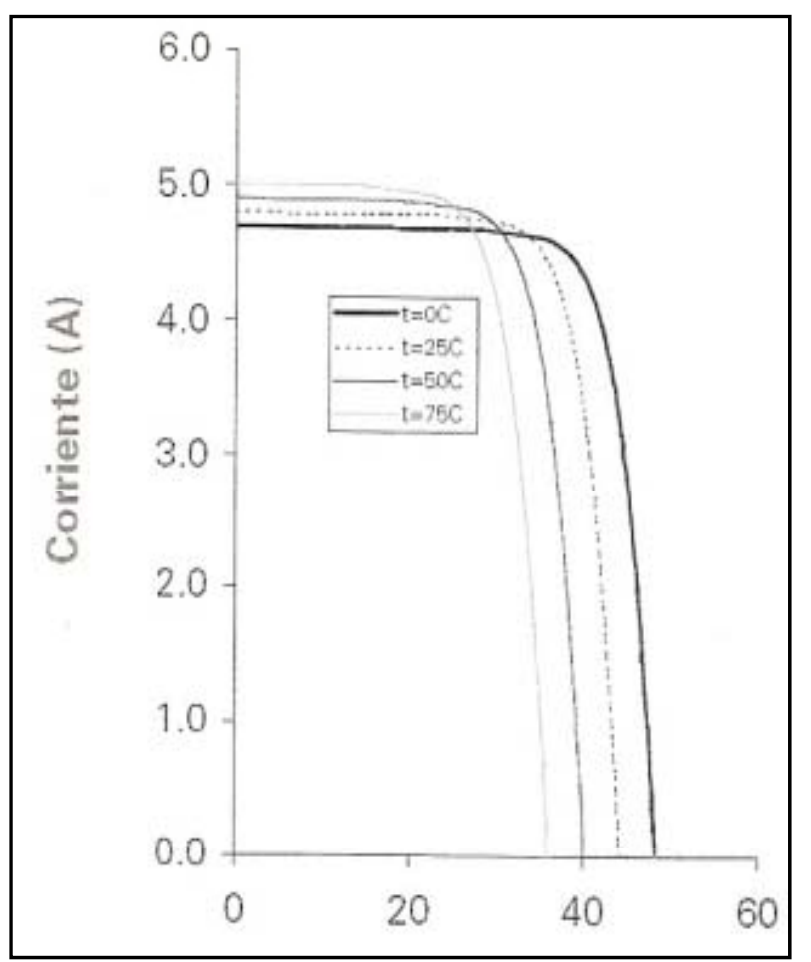

Curva de potencia panel BP 3155. Fuente:J.M. Fernández. 
Para el optimo funcionamiento de un panel FV, debe de tomarse como importante punto de análisis las temperaturas del lugar para su instalación.

Las temperaturas altas incrementan la corriente en las células, pero a la vez una disminución mayor en proporción de la tensión. Esto implica que tanto la corriente de cortocircuito como el voltaje a circuito abierto se afectan por el aumento de temperatura.

Tomando como referencia los $25^{\circ} \mathrm{C}$, la corriente de cortocircuito comienza a aumentar un $1 \%$ por cada $50^{\circ}$ y a partir de un $3 \%$ a $75^{\circ} \mathrm{C}$; y el voltaje de circuito abierto disminuye considerablemente, aproximadamente $8 \%$ cada $50^{\circ} \mathrm{C}$ y cerca de un $15 \%$ a los $75 \%$.

En otras palabras, la potencia del panel disminuye al aumentar la temperatura de trabajo del mismo. $1000 \mathrm{w} / \mathrm{m} 2$ de radiación, calienta un panel $25^{\circ}$ por encima de la temperatura del aire; reduciendo la tensión y por ende la potencia en un factor superior al $12 \%$.

Existe una relación lineal que expresa la temperatura de trabajo de un panel FV:

$$
T_{t}=T_{a}+k * R
$$

Donde $T t$ es la temperatura de trabajo del panel; Ta es la máxima temperatura ambiente; $R$ es el valor de la radiación solar $\mathrm{W} / \mathrm{m} 2$; y $k$ es un coeficiente que varia entre 0,02 y $0,04{ }^{\circ} \mathrm{C} . \mathrm{m} 2 / \mathrm{W}$, dependiendo de la velocidad promedio del viento.

Si esta relación es baja o no existe, el enfriamiento del panel es nulo, y $k$ toma valores muy parecidos 0,04 . Cuando la velocidad promedio del viento enfría bien el panel, el valor de $k$ será de 0,02 . Es bueno apuntar que el valor medio de R varia entre $800 \mathrm{~W} / \mathrm{m} 2$ y $1000 \mathrm{~W} / \mathrm{m} 2$.

En los lugares con altos niveles de insolación como las tierras tropicales, se parte del valor máximo, y si aumenta el índice de nubosidad el valor de R se reduciría a 800 W/m2.

El producto de los valores de voltaje y la corriente es la potencia máxima de salida. El valor mas alto correspondiente a una temperatura de $25^{\circ}$ se llama valor pico ( Wp) del panel, y se determina usando los valores STC: Radiación solar de 1000 w/m2; Temperatura 25; y Espectro de luz de 1,5 de la masa del aire.

El Wp es el valor o unidad de medida de referencia de los módulos FV y expresa la potencia eléctrica suministrada por el modulo en las condiciones estándar de STC.

En el uso diario, para la casi totalidad de los paneles, la relación entre el aumento de la temperatura de trabajo y el valor de potencia de salida es inversamente proporcional. A causa de la disipación del calor dentro de las células, la temperatura de trabajo siempre será superior a $25^{\circ} \mathrm{C}$, y cuando esto pasa la potencia de salida no es alcanzada.

Al diseñar un sistema de esta naturaleza se debe tomar en consideración esta degradación del panel y/o modulo para que los requerimientos eléctricos puedan alcanzarse también en los cálidos días del verano. De igual manera para días con temperaturas inferiores a $25^{\circ}$ no hay que considerar esta degradación.

Es costumbre de los fabricantes del producto especificar el factor de degradación o perdidas porcentuales de potencia máxima en ${ }^{\circ} \mathrm{C}$. 
Esta claro que la necesidad de energía no siempre coincide con el momento de la captación por lo cual es necesario disponer de un sistema de acumulación que libere la carga en momento que haga falta.

Para los sistemas solares fotovoltaicos se hace necesaria la utilización de acumuladores eléctricos o baterías donde almacena la energía; debiendo estar las mismas en lugares con buena ventilación, conservando siempre el nivel de electrolito indicado por los fabricantes y un mantenimiento adecuado.

Otro componente del equipo FV es el Regulador, el cual controla los procesos de carga y descarga de los acumuladores. Al regular el proceso de descarga, evita que el estado de carga de la batería llegue a un punta muy bajo al momento de consumir la energía guardada. La manera de conseguir esto es desconectando la batería de los circuitos de consumo. Este dispositivo también informa de los parámetros eléctricos de la instalación: tensión, intensidad, carga, etc..

El Convertidor, Rectificador o Inversor, es el que adapta la corriente que se genera en los paneles FV a las condiciones de consumo deseadas.

Dependiendo del tipo de corriente que transforme puede ser propiamente un Inversor que transforma corriente continua en alterna; un Convertidor que transforma corriente alterna (CA), en corriente continua (CC); y Rectificador que transforma la continua en continua.

Por lo general el inversor se conecta a la salida del regulador o bien a los bornes de batería si tiene control de descarga de los acumuladores.

Los módulos FV y las baterías trabajan en corriente continua por lo cual cuando los elementos de consumo trabajan en continua, es necesario un convertidor CC para adecuar la tensión proporcionada por el acumulador a la que le hacen falta según las cargas de consumo. Si en lugar de esto, los elementos de consumo trabajan en alterna, hace falta un inversor CA.

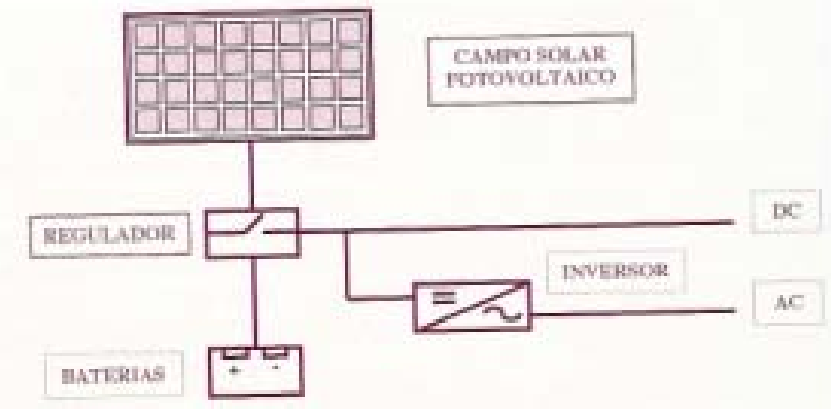

Sistema Solar FV. Fuente: E. solar FV. M. Arquitectos

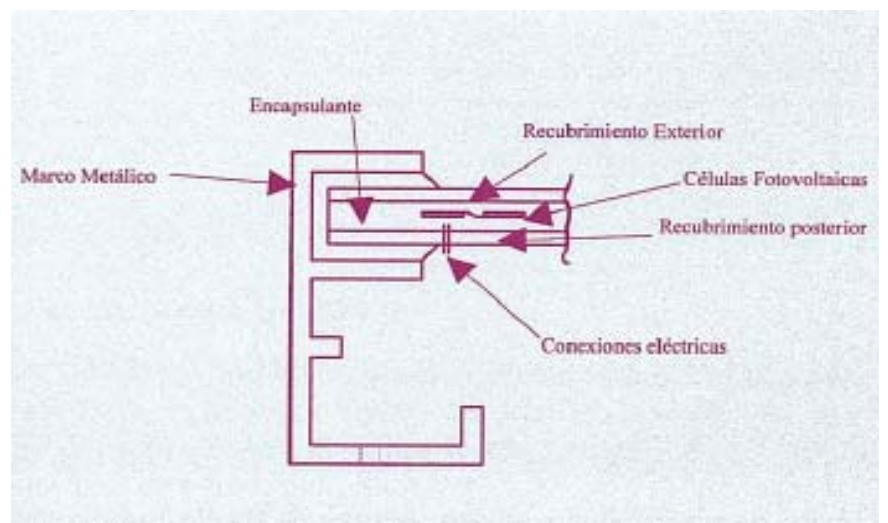

Esquema de un modulo FV. Fuente: E. solar FV. M. Arq.
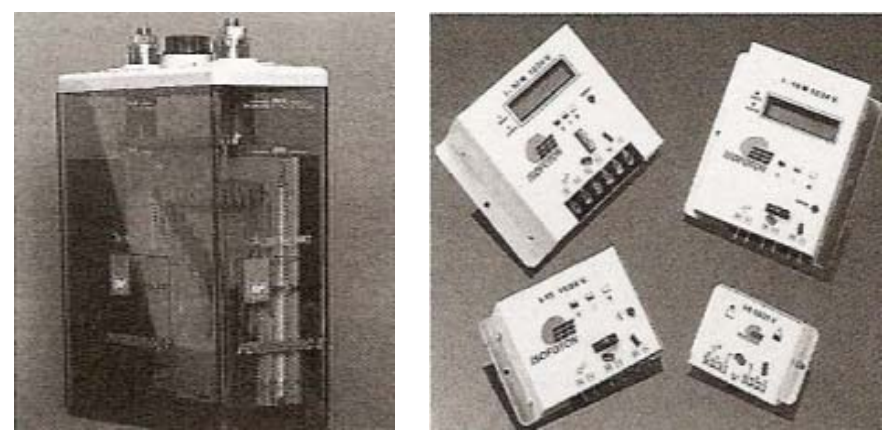

Acumulador eléctrico y reguladores. Fuente: E. solar FV. M. Arq.

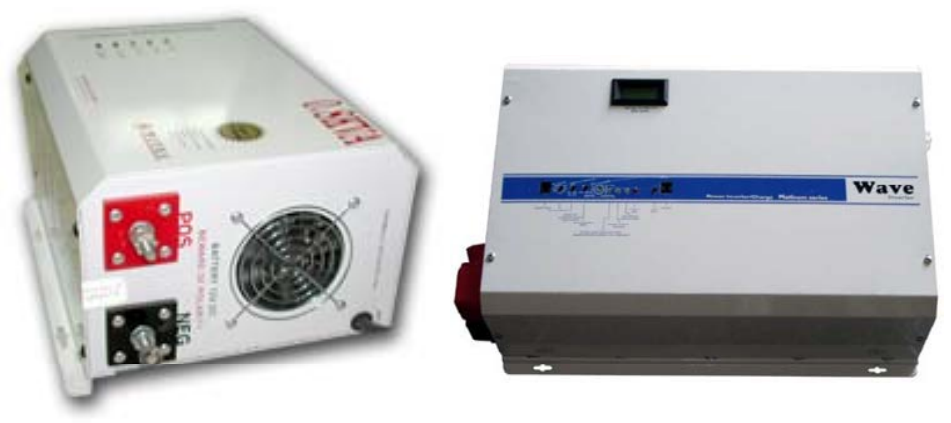

Inversores. Fuente: Archivo particular. 
Junto con los elementos habituales en la instalaciones FV, hay otros accesorios que son necesarios el control y la seguridad misma de las instalaciones.

Igual que en instalaciones eléctricas, en las FV se hace uso de distintos equipos comunes a ambas; sin embargo para las segundas, hay que prestar atención especial a lo concerniente a la corriente continua ya que en las instalaciones eléctricas generalmente los sistemas están alimentados por corriente alterna lo cual puede conducir a errores en las conexiones FV. Por ejemplo el cableado usado en instalaciones FV debe ser de secciones superiores a los de los convencionales debido al uso de bajas tensiones continuas del orden de los $48 \mathrm{~V}, 24 \mathrm{~V}$ y en el menor de los casos de $12 \mathrm{~V}$; siempre con requerimientos de potencias importantes. En el caso de las conexiones, muchas veces a la intemperie; estas deben ser estancas y con un nivel de protección IP acorde, así como contra la humedad, y demás fenómenos atmosféricos.

Los elementos de protección deben ser los adecuados para el tipo de corriente de una instalación FV. Los Magnetotérmicos, fusibles, diodos e interruptores han de estar diseñados para corriente continua o alterna según sea el caso.

Los fusibles se usan para no permitir las sobreinstalaciones; los magnetotérmicos limitan la intensidad en el circuito de consumo instalándose en las salidas del inversor y acumulador; los diodos, dispositivos de protección, evitan los que los módulos se comporten como receptores. De estos últimos tenemos los de bloqueo que evitan que la potencia se disipe de los módulos a las baterías; los de paso evitan los efectos del sombreado impidiendo que las células actúen como receptores.

Otro factor importante es la conexión de la estructura soporte a una toma de tierra para evitar desbalances en el sistema.

Informaciones tales como la tensión del campo FV y de las baterías, la intensidad del FV y la de consumo, la carga de batería, regulación de la carga, energía eléctrica generada y consumida, etc..; pueden ser visualizados a través de indicadores previamente instalados para tales fines en los mismos aparatos de control.

Puede darse el caso con los inversores, que estén preparados para ser conectados a un grupo electrógeno, produciéndose el control de entrada del grupo atendiendo a la energía generada por los paneles, la carga de las baterías y el consumo existente.

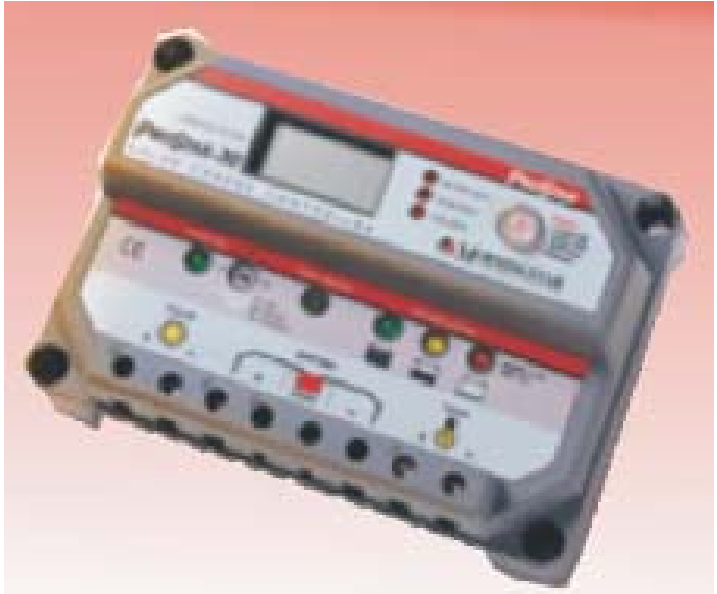

Indicador eléctrico FV. Fuente: Archivo particular.

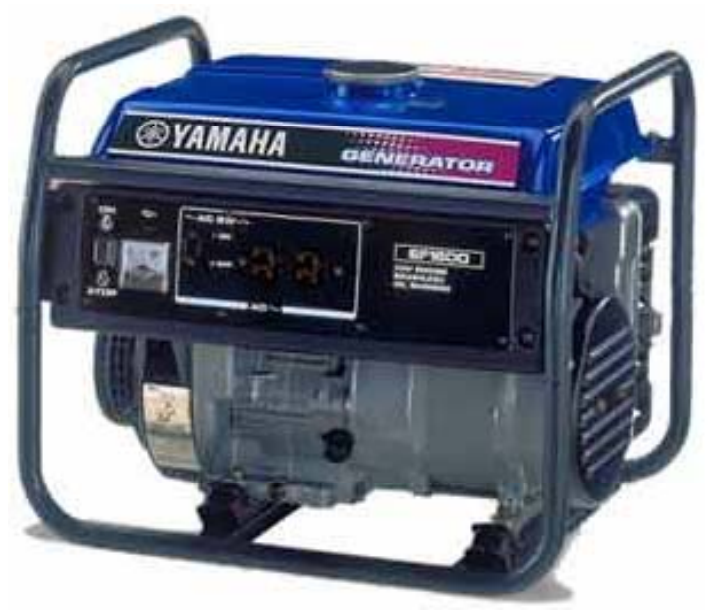

Generador eléctrico. Fuente: Archivo particular. 
Existen dos tipos de instalaciones fotovoltaicas: Aisladas de la red, o Conectadas a la red de distribución.

Las instalaciones aisladas de red son las que no tienen conexión con la red eléctrica convencional. Este tipo de instalación suele ser la mas extendida tanto para uso domestico como para la agricultura o telecomunicaciones. Dentro de las instalaciones aisladas, las hay con sistema de acumulación que son los que están conectados a baterías y que permiten el suministro eléctrico diferido al periodo de captación; pudiendo ser a su vez de CC o CA.

Los sistemas directos no cuentan con baterías, de forma que únicamente se dispondrá de electricidad en los momentos de radiación solar. Estos sistemas se utilizan en instalaciones donde la continuidad no es un requisito para el servicio, como por ejemplo el sector agrícola.

Las instalaciones conectadas a la red, son las que sirven toda la energía que se genera en su sistema FV, a la red general de distribución. Este tipo de instalación no tiene baterías ni reguladores, y cuentan solamente con los paneles de captación y el o los inversores. Deben contar además con un medidor de energía consumida y servida; sistema de interrupción del suministro dependiendo del estado de los paneles; y adaptador de la corriente alterna producida para darla a la red.

Otro tipo de instalación fotovoltaica es la instalación mixta (aislada-conectada).

Con esta modalidad, se inyecta una parte de la energía generada a la red de distribución; la otra parte se consume en el propio lugar de generación.

Legislaciones de algunos países no permiten este tipo de sistema, obligando a que toda la generación fotovoltaica sea inyectada ( vendida) a la red general. Tal es el ejemplo de España, donde toda la energía debe ser servida a la red, siendo la naturaleza del sistema fotovoltaico meramente generador y no abastecedor.

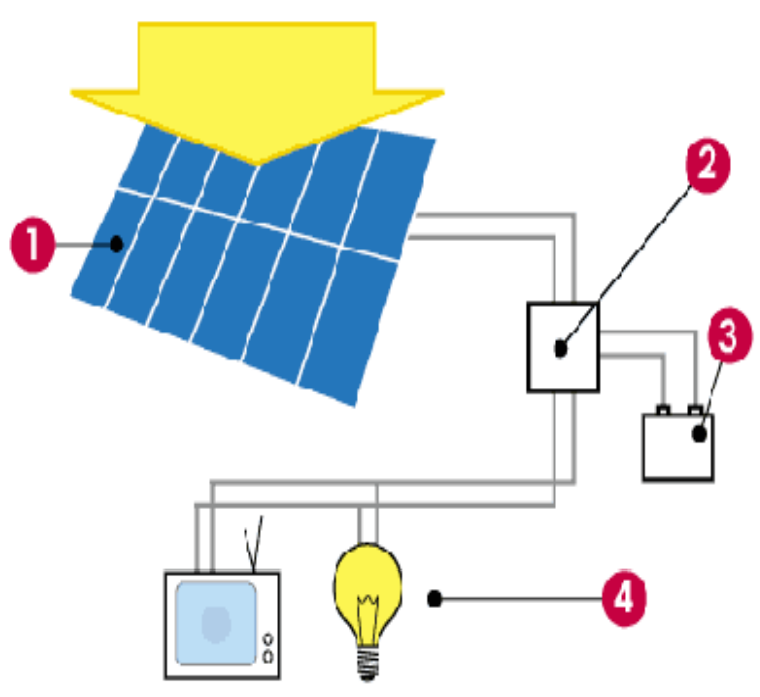

1. Paneles Solares 3. Batería 2. Controlador de Carga 4. Artefactos Eléctricos

Sistema aislado con acumulación y consumo (CC). Fuente: Vilco

\section{ESQUEMA DE UN SISTEMA FOTOVOLTAICO CONECTADO A RED}

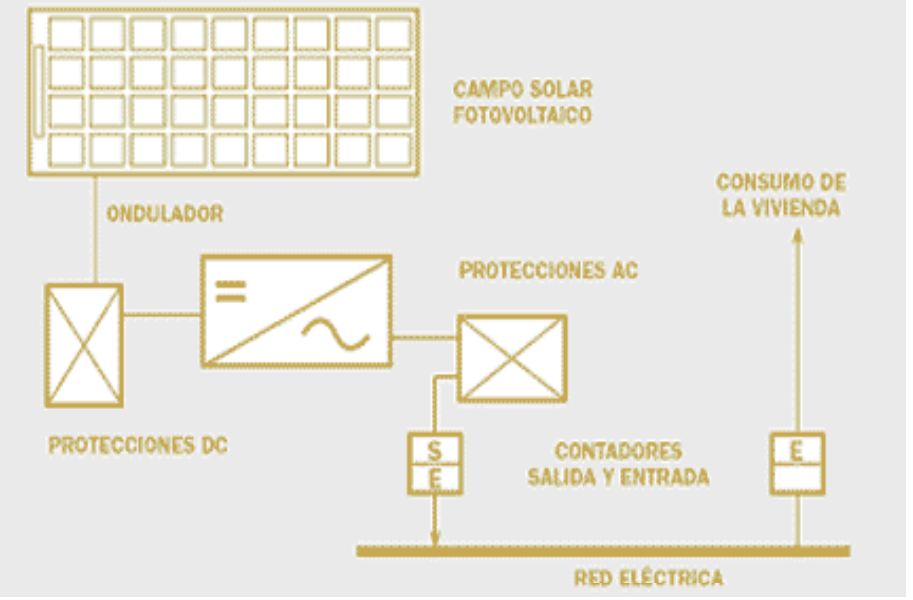

Sistema conectado a la red (CC). Fuente: Omega Solar 


\subsection{Rendimientos, ciclo de vida de los sistemas fotovoltaicos y huella ecológica.}

El rendimiento de una instalación fotovoltaica depende básicamente de la intensidad de la radiación luminosa y de la temperatura de las células solares.

La intensidad de la corriente generada por el panel se ve aumentada con la radiación, mientras que el voltaje permanece mas o menos constante.

Visto esto, es de gran importancia la orientación e inclinación de los paneles y/o módulos fotovoltaicos con respecto a la horizontal, ya que los valores de la radiación van variando a lo largo del día en función de la inclinación del sol respecto al horizonte.

El incremento de la temperatura en las células representa un incremento en la corriente, y a la vez una disminución mucho mayor, en proporción de la tensión.

El efecto global resultante, es que la potencia del panel disminuye al aumentar la temperatura de trabajo del mismo; es decir que existe una relación inversamente proporcional entre el aumento de temperatura y la potencia.

Una radiación de $1.000 \mathrm{~W} / \mathrm{m} 2$ es capaz de calentar un panel unos 30 grados por encima de la temperatura del aire circundante, lo que reduce la tensión en $2 \mathrm{mV} /$ (célula*grado) * 36 células * 30 grados $=2,16$ Voltios y por tanto la potencia en un 15\%. Es por esto que se deben colocar los paneles en un lugar en el que estén bien ventilados.

Los paneles FV como cualquier elemento expuesto a la intemperie, podría llegar a presentar algún tipo de deterioro; sin embargo al carecer de partes móviles, y al estar las celdas y contactos encapsulados con resina sintética, le permite al conjunto una vida útil de 30 años o más.

Otra ventaja que tiene es que si una de las celdas falla no afecta al funcionamiento de las demás y la intensidad y voltaje producidos pueden ser fácilmente ajustados añadiendo o suprimiendo celdas.
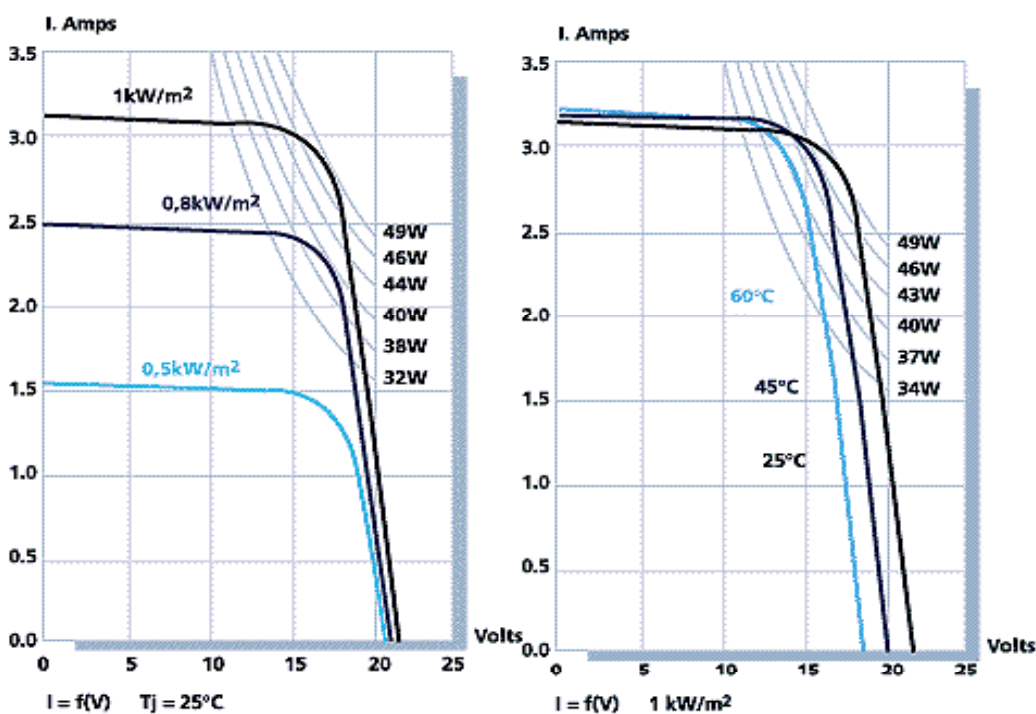

Grafico de variación de intensidad Fuente: IIE

El peligro de rotura de los paneles es mínimo, ya que como hemos dicho antes van protegidos en su cara exterior con vidrio templado, que permite aguantar condiciones meteorológicas muy duras tales como el hielo, la abrasión, cambios bruscos de temperatura, o los impactos producidos por el granizo.

Una prueba común para la homologación en el mercado, es lanzar con una especia cañón neumático una bola de hielo de dimensiones y consistencia preestablecidas al centro del cristal del panel. 
Las sistemas fotovoltaicos no requieren mucho mantenimiento; las partes de este y la formas de hacerlo son las siguientes:

Paneles: de mantenimiento nulo o poco. No tienen partes móviles y las células y sus conexiones internas están encapsuladas en varias capas de material protector. Una revisión general 1 ó 2 veces al año es lo recomendable, asegurándose de que las conexiones entre panel y regulador estén bien ajustadas y sin corrosión. En la mayoría de las veces, la lluvia elimina la necesidad de limpieza de los paneles y en caso de ser necesario, simplemente utilizar agua y algún detergente no abrasivo.

Regulador: su simplicidad reduce sustancialmente el mantenimiento igual que sus averías. Las operaciones que se pueden realizar son las siguientes: observación del estado y funcionamiento del regulador; comprobación de conexiones y cables; observación de los valores instantáneos del voltímetro y amperímetro.

Esta claro que la energía solar fotovoltaica captada a través de las células y paneles, constituye frente a los combustibles fósiles, una fuente inagotable de energía, con un impacto comparativamente mucho menor.

Los efectos de la energía solar fotovoltaica sobre los principales factores ambientales son como siguen:

Clima: la generación de energía eléctrica a partir de la radiación solar no requiere ningún tipo de combustión, y es por esta razón que no se produce polución, ni emisiones de CO2.

Ruidos: Es totalmente silencioso, representando una clara ventaja en pro del bienestar del entorno.

Geología: Las células fotovoltaicas se fabrican con silicio, proveniente de la arena, abundante en la naturaleza. Por lo tanto, en la fabricación de los paneles fotovoltaicos no se producen alteraciones en las características litológicas, topográficas o estructurales del terreno.

Suelo: al no ser producidos ni contaminantes, ni vertidos, ni movimientos de tierra, la incidencia sobre las características físicas y químicas del suelo es prácticamente nula.

Aguas superficiales y subterráneas: No hay alteración de los acuíferos o de las aguas superficiales ni por consumo, ni por contaminación por residuos o vertidos de sustancias.

Flora y fauna: No se produce repercusión sobre la vegetación, y al eliminarse los tendidos eléctricos, evitándose los posibles efectos perjudiciales para las aves.

Paisaje: los paneles solares tienen distintas posibilidades de integración, lo que hace que sean un elemento fácil de integrar y armonizar en diferentes tipos de estructuras, minimizando su impacto visual. Su presencia es notoria al ser insertados en paisajes abiertos y naturales; pero representa la mejor solución para aquellos lugares a los que se quiere dotar de energía eléctrica preservando las condiciones del entorno; como es el caso de los espacios naturales protegidos.

Medio social: El suelo necesario para instalar un sistema fotovoltaico depende de la energía que se quiera generar, pero en ningún caso se platea hostil al medio que le rodea ni produce grave impacto. Además muchas veces, se pueden integrar en los tejados de las viviendas. 


\subsection{Integración de la fotovoltaica al ente arquitectónico. Ejemplos}

Siendo desde siempre, la única función de los paneles fotovoltaicos la generación de electricidad a partir del sol; nunca antes como ahora, se había tratado de hacer de este medio de producción de energía parte del concepto del edificio.

Al constatar de que todos los edificios, usan sus ventanas como fuente de energía solar pasiva, proporcionando luz ( y calor donde hace falta), al interior; vemos que tratar de convertir las demás superficies del edificio, sobre todo las opacas, en captadores de energía solar; forma parte del mismo principio.

En este sentido, la fachada fotovoltaica ( o superficie o cubierta), viene a desempeñar un papel compositivo del organismo. Igual que una fachada convencional, debe procurar cumplir las funciones de cerramiento y protección, impermeabilidad, estabilidad, resistencia a cargas de viento, resistencia al fuego, resistencia a los fenómenos atmosféricos; y por ultimo que su costo se ajuste a las posibilidades del proyecto.

A estos nuevos requerimientos de cerramiento que se le van atribuyendo a los sistemas fotovoltaicos, se suman la adecuada orientación e inclinación del panel, la buena ventilación, y la captación de irradiancia sin que medien sombras.

Para cumplir con todo esto de maneta efectiva, la integración debe ser proyectada desde el principio del proceso de diseño. Decidiendo que papel jugara el panel en la fachada, que tipos de sistemas se usaran y el nivel de exposición deseado para los mismos.

Según las especificaciones de diseño del organismo, se barajan varios conceptos de implementación de los sistemas fotovoltaicos:

-Situados de manera invisible (por ejemplo en cubiertas).

-Superpuestos sobre el diseño.

-Integrados al edifico pero sin resaltar.

-Integrados al edificio de manera protagónica.

-Consustanciales al edificio trazando la pauta del diseño.

Básicamente, podemos hablar de cinco formas de integración de los paneles a la piel del edificio:

Fachadas ventiladas; Muros cortinas; Sistemas de ventanas; Protecciones solares; Cubiertas y Lucernarios.

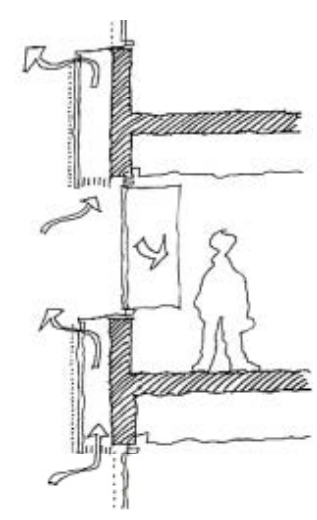

Fachada ventilada.

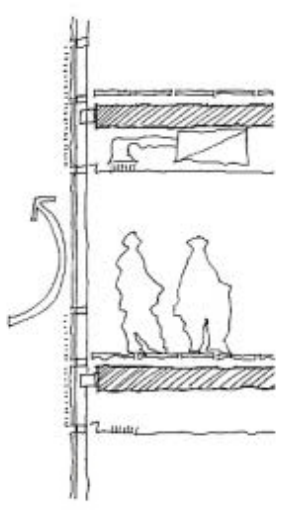

Muro cortina.

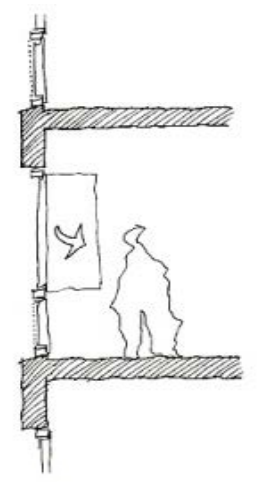

Ventana con antepecho.

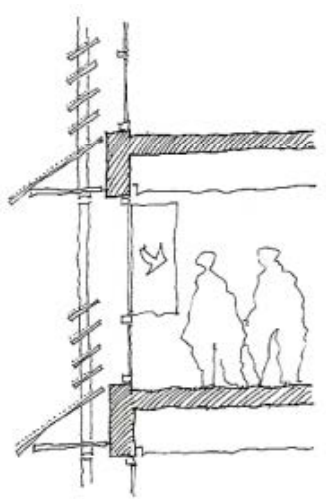

Lamas y parasoles.

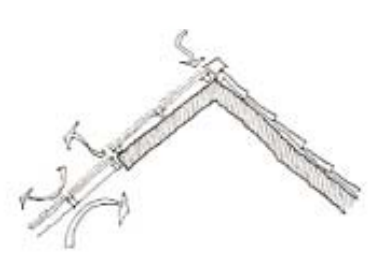

Cubiertas y lucernarios. 
Como cualquier elemento que conforma el cerramiento de un edificio, los paneles fotovoltaicos están sujetos a una evaluación de su vida útil, mas aun dada su doble función.

Existen elementos reemplazables, otros sujetos a mantenimiento( juntas interiores y herrajes), y otros mas duraderos que solo necesitan limpieza (perfiles, anclajes). Aun a las partes que se cuentan para ser reemplazadas ( juntas de goma, sellados de silicona, vidrios, etc.), se les calcula una vida útil de entre 20 y 25 años.

La estructura de un cerramiento están diseñados mediante el criterio doble de estados limites, es decir tensión máxima, y los de servicio o deformación máxima. Casi siempre, los cerramientos y sus partes se diseñan para soportar cargas de viento, nieve, cargas de impacto, etc.. Las cargas sísmicas y sus efectos se deben tomar igualmente en consideración. Otro aspecto de vital importancia a tomar en consideración por los proyectistas, es el relacionado a la interacción entre la estructura de la edificación propiamente dicha, con sus deformaciones y movimientos previstos, y el cerramiento eficiente.

Permeabilidad al aire, estanqueidad al agua y ciertas prestaciones térmicas; son parte de las condicionantes a tomar en cuenta también.

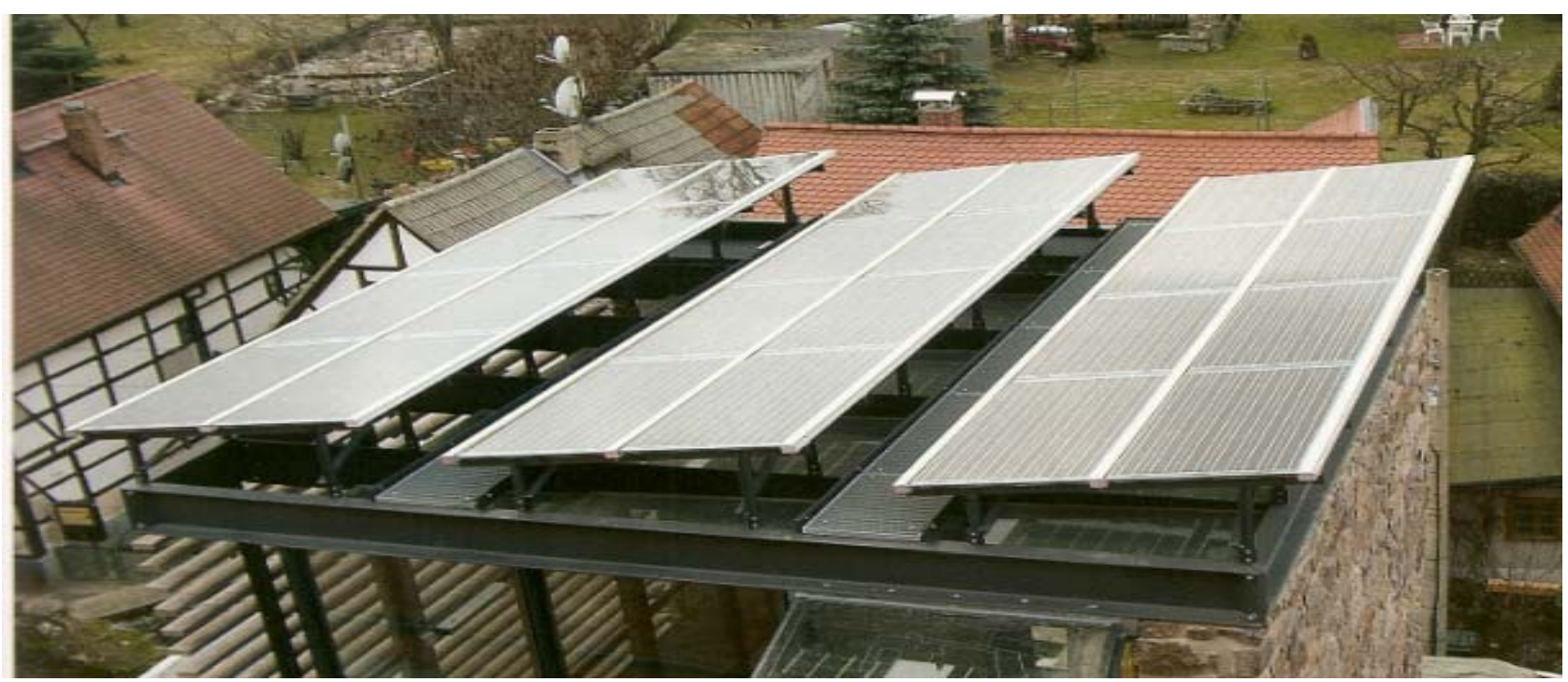

Superposición paneles FV en cubierta. Academy Building en Meiben, Alemania. Fuente: Solar Desing

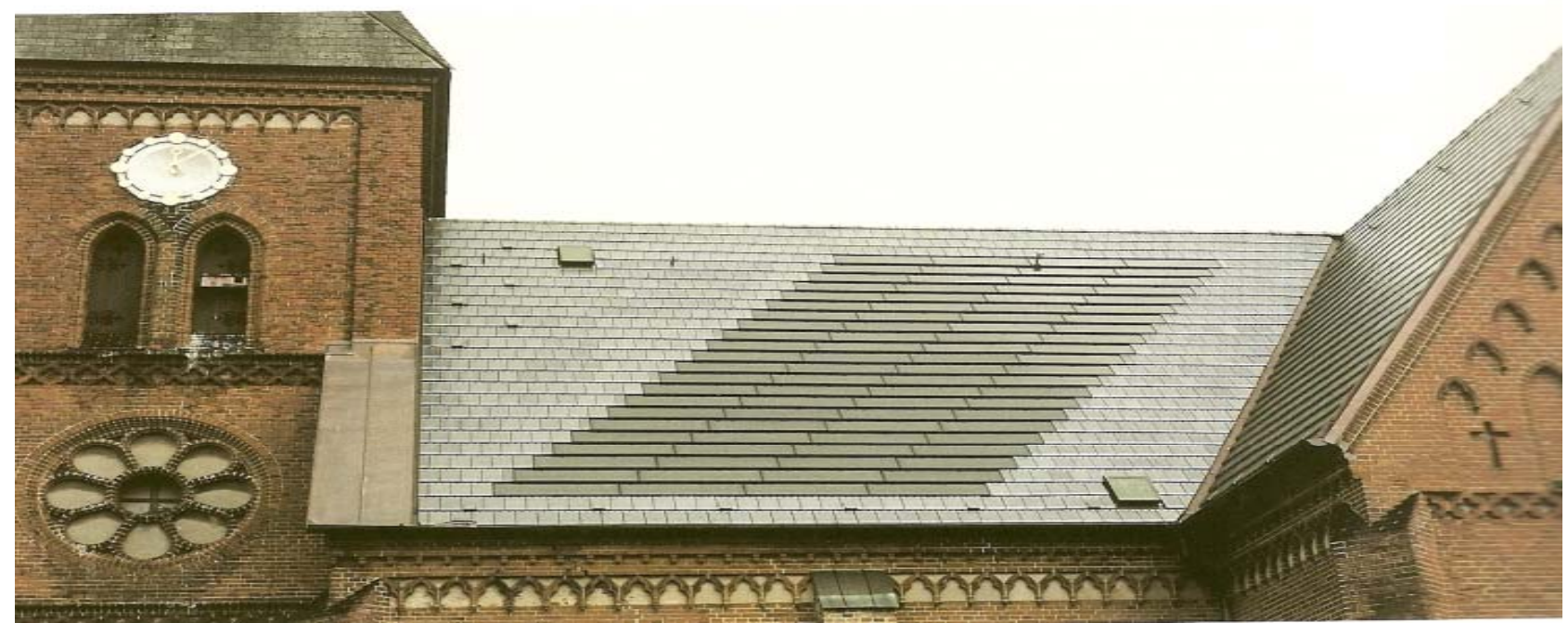

Integración de paneles FV en tejado. Iglesia en Carlow, Barwalde. Alemania. Fuente: Solar Desing 


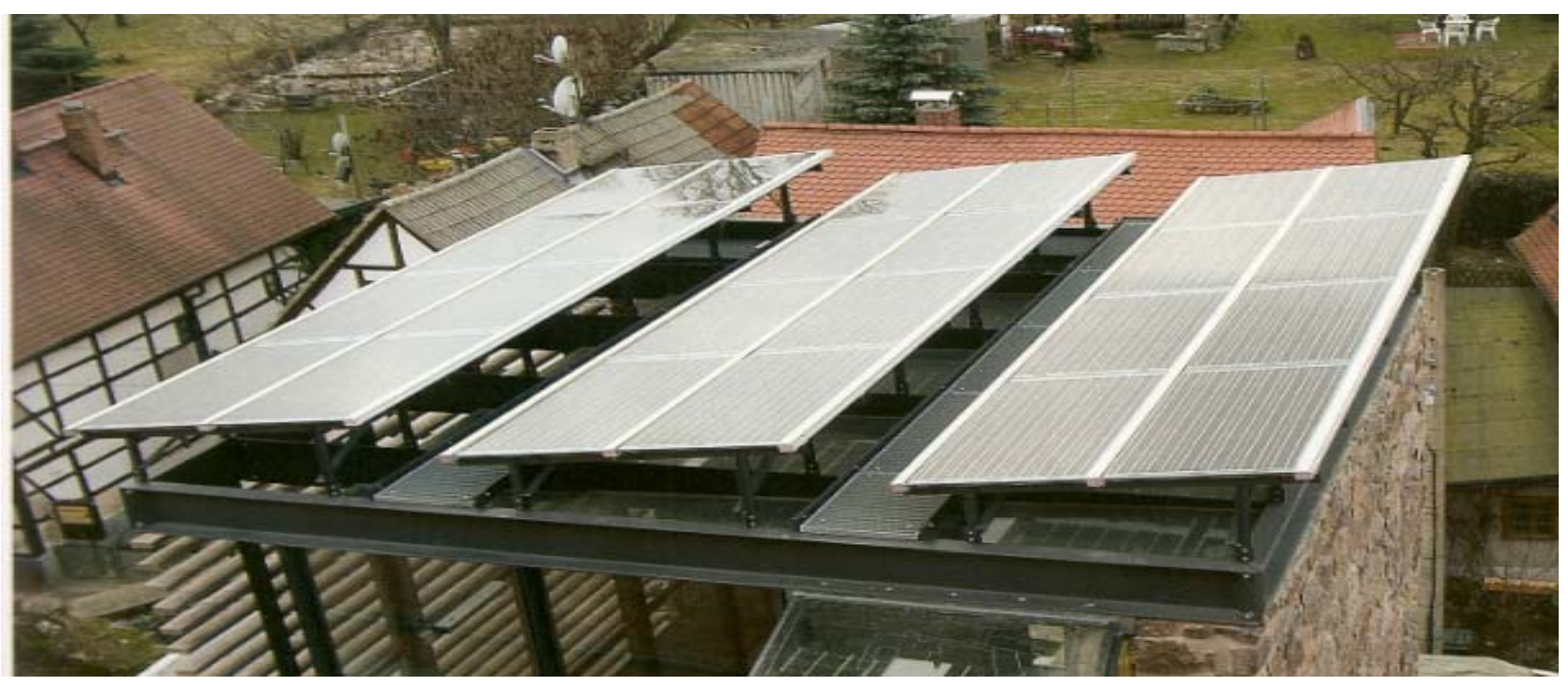




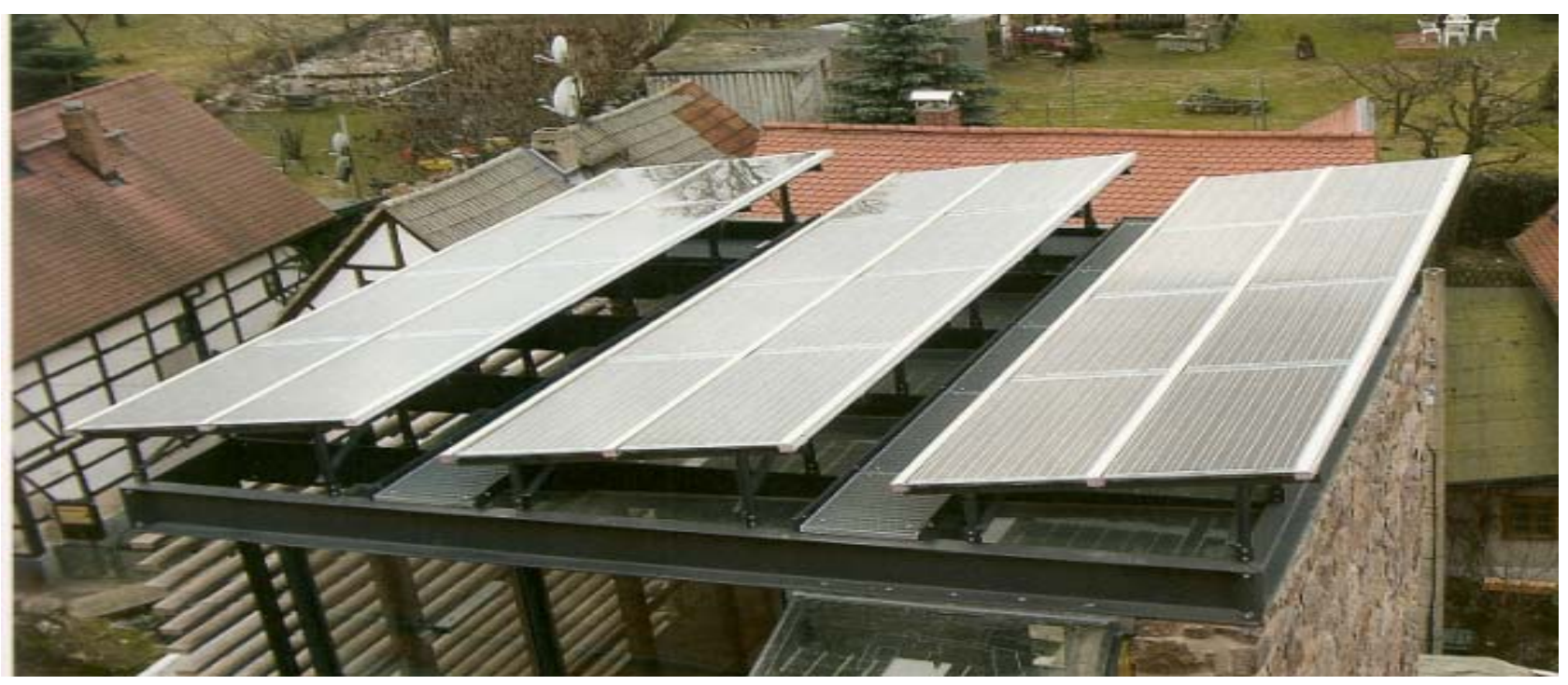




\subsection{Costes y amortización.}

Una instalación Fotovoltaica, igual que cualquier otro producto en el mercado que se rija por la ley de la oferta y la demanda, esta sujeto a precios variables; precios que como es normal llevan sumados lo costos de fabricación, e instalación cuando es el caso.

Al día de hoy, una instalación de esta naturaleza resulta tener aun precios elevados. Es por esta razón que en muchos países que quieren incentivar el uso de renovables para la generación de energía eléctrica, aportan parte del capital de inversión a cualquier persona o entidad interesada en tener una de estas.

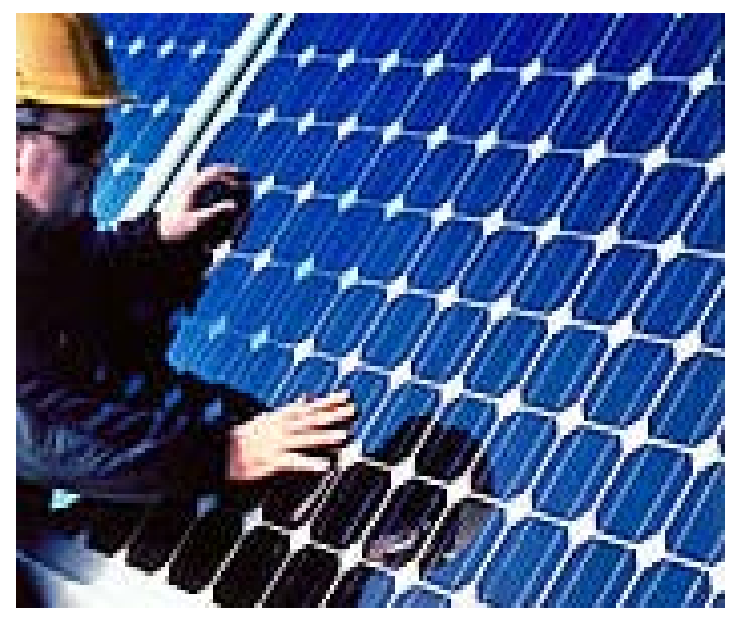

Instalador FV. Fuente: Archivo particular

Ya sea con la reducción de impuestos al momento de comprar o instalar los equipos, o ya sea disponiendo que las grandes empresas generadoras compren a precio preferencial la producción que pueda obtenerse por estos medios en una vivienda unifamiliar o edificios de equipamientos.

Por ejemplo en España, el coste de una instalación fotovoltaica conectada a la red puede esta entre los de 6.000 y 7000 euros por Kwp instalado. En este precio están incluidos todos los elementos que conforman el sistema es decir, paneles, inversores, protecciones.

Con $1 \mathrm{Kw}$. de potencia pueden generarse en un día soleado sin seguidor solar de hasta 3,8 kWh. Si se cuenta con seguidor solar podrían generarse unos 5,6 kWh. aproximadamente por día. El precio de compra por parte de las compañías distribuidoras y generadoras seria de 0,44 euros $/ \mathrm{kWh}$.

En países como la República Dominicana el costo del vatio instalado asciende a aproximadamente US $\$ 6.00$ Obteniendo del estado ayuda en forma de recortes tributarios.

La vida útil de un sistema FV es algo menor a los 30 años, pero partiendo de los costos de fabricación, compra e instalación su amortización puede ocurrir al cabo de 7 u 8 años.

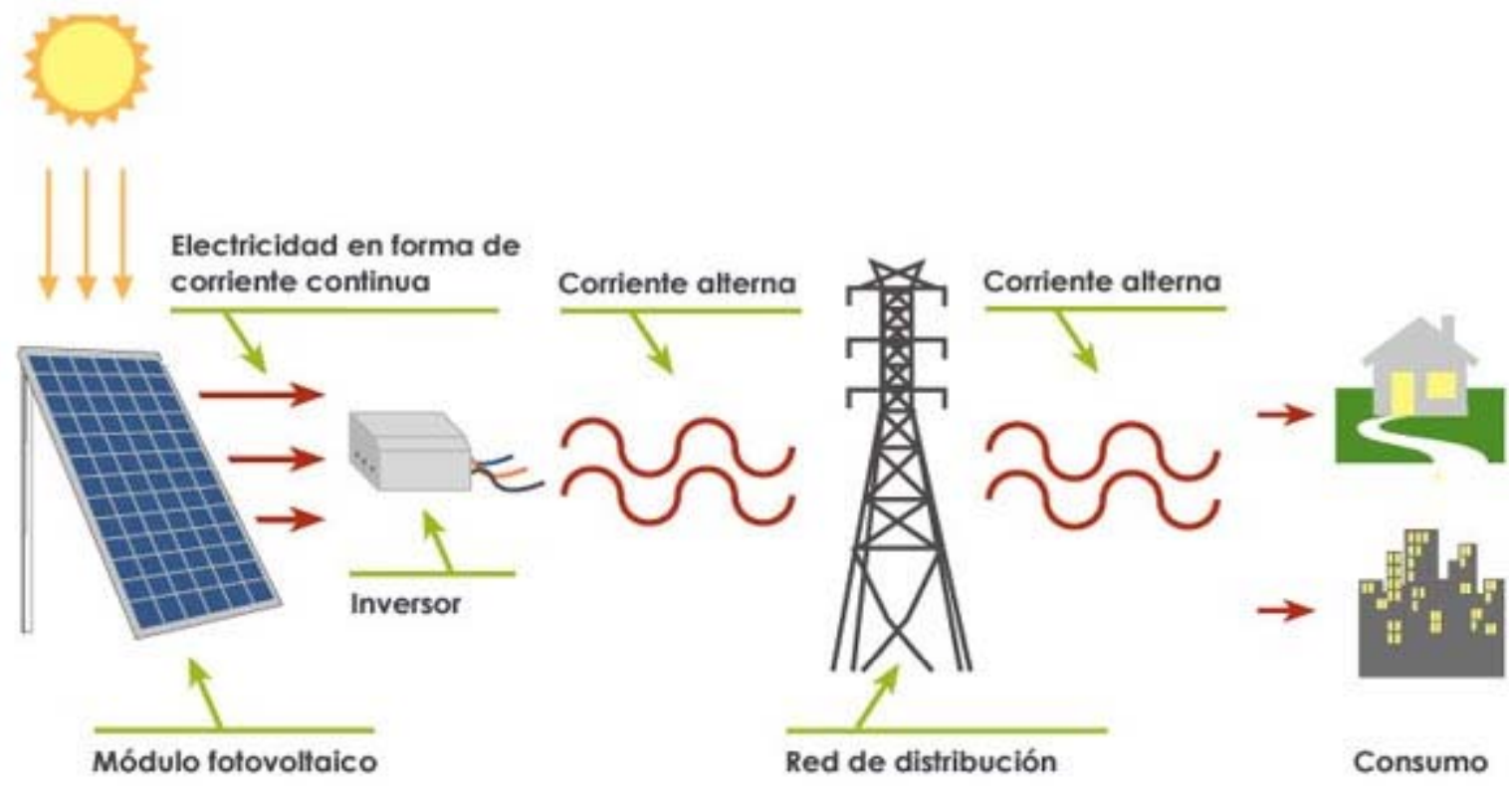

Energía FV servida a la Red. Fuente: Archivo particular 


\section{ALTERNATIVAS RENOVABLES PARA PAISES TROPICALES DE ECONOMIAS EMERGENTES}

\subsection{Realidades regionales, sociales y vinculaciones geopolíticas. Un perfil común.}

Los distintos países del mundo, han ido transitando de diferentes maneras -unos mas y otros menossus propios caminos y creando su propia historia a través del tiempo. Sin embargo, el sistema globalizado en que vivimos hoy en día, hace que lo que pasa en un extremo del mundo tenga repercusiones al otro lado del mismo y en la cotidianidad de todos. La diferencia esta en la forma en que cada cual asume la cuestión, cualquiera que fuera, de acuerdo a sus posibilidades como nación.

Un ejemplo de esto lo tenemos en el tipo de cambio de las monedas fuertes (euro, dólar), o divisas. Cuando estas monedas adquieren o pierden valor en los mercados mundiales, los sistemas económicos locales de cada país sufren alteraciones muchas veces importantes, teniendo que comprar, pagar o vender bienes y servicios a precios no proyectados en sus presupuestos iniciales.

De igual manera sucede con los precios de cotización del barril de petróleo. Cuando este sube de precio, los combustibles derivados del mismo -los que sirven para generar gran parte de la energía mundial y mover la mayoría de los medios de transporte de carga y de pasajeros- aumentan tanto en el norte de Europa como en el cono sur de América.

Donde radica la diferencia es en la capacidad que tienen los países de cada una de estas regiones, de afrontar situaciones de esta naturaleza.

Esta diferencia depende básicamente de las condiciones sociales, económicas y en algunos casos culturales de cada nación. Los estados desarrollados o industrializados, tienen como denominador común el tener resueltos casi cualquier situación en torno a estos temas, combinando metodologías y recursos que traen como consecuencia un nivel de vida optimo para la mayoría de sus ciudadanos.

Inversamente proporcionales se plantean las cosas en los llamados países en vías de desarrollo o emergentes. Los acuciantes problemas sociales, económicos y a veces culturales, se conjugan causando un empobrecimiento agudo de la población y sus condiciones de vida.

En medio de este escenario global, esta el aspecto energético; la asignatura pendiente que toca a todos afrontar.

La generación y distribución de la energía para consumos distintos (domésticos, agrícolas, industriales), esta asociada a dos grandes desafíos para estas sociedades: la economía y el medio ambiente.

En países cuya ubicación geográfica y clima son parecidos, se presentan contextos y necesidades socioeconómicas comunes. La mayoría de las veces encuentran soluciones muy parecidas. Este es el caso de los países tropicales, algunos de ellos en territorios insulares con características semejantes entre si, y otros socialmente parecidos en territorios continentales que también comparten condicionantes climáticas.

Por estas y otras similitudes, muchos de estos estados se encuentran agrupados en organismos regionales que procuran velar por los intereses comunes y alcanzar mejores cotas de desarrollo. También se da el caso de afiliaciones a organismos transcontinentales como la A.C.P. ( Asia, Caribe, Pacifico), que es una alianza de naciones con necesidades e intereses comunes, de cara a las relaciones de cooperación con la Unión Europea y el otros países industrializados.

El Acuerdo de Cotonú, que fue firmado en 2000 y sustituye a los Convenios anteriores (de Yaundé y de Lomé), ofrece el marco general actual de las relaciones entre la Unión y los 79 países ACP. A este Acuerdo se añaden unos componentes regionales y nacionales, así como un componente financiero, representado sobre todo por el Fondo Europeo de Desarrollo (FED). 
Por ejemplo en el caso del Caribe y a través de la ACP la UE (Unión Europea), impulsa iniciativas de cooperación para aprovechar mejor el proceso de globalización; siendo importante elaborar un modelo económico viable para la región. Por eso, la Unión dará apoyo a los esfuerzos de integración regional en el Caribe y contribuyendo a mejorar su competitividad, a diversificar sus exportaciones y a instaurar de alguna manera mercados regionales. El proceso de los Acuerdos de Cooperación Económica (ACE) desempeñará un papel determinante para alcanzar estos objetivos.

En este tenor, el medio ambiente y los recursos naturales representan un activo importante para el Caribe, en particular para las capas más pobres de la población local. Efectivamente, los Estados del Caribe deben actualmente hacer frente a varios problemas relativos al medio ambiente que tienen efectos importantes sobre el desarrollo económico y social de la región. Se enfrentan, así, a problemas derivados de la erosión del suelo, la deforestación, la escasez de recursos hidráulicos, la gestión de recursos pesqueros, la pérdida de biodiversidad, y la gestión de los residuos y los productos químicos tóxicos, así como los generados por el cambio climático

La UE contribuirá a aumentar la capacidad de la región para administrar las catástrofes naturales a todos los niveles, haciendo hincapié en la reducción de los riesgos, el nivel de preparación, la alerta rápida, la prevención de las catástrofes y la atenuación de sus efectos.

Para la región del pacifico la ACP procura que se encaminen esfuerzos principalmente en las siguientes direcciones:

- consolidar las relaciones políticas sobre temas de interés común como la seguridad política mundial, el comercio, el desarrollo económico y social, y el medio ambiente;

- concentrar las medidas de desarrollo orientadas principalmente hacia la cooperación regional para alcanzar una masa crítica, mejorar la gobernabilidad a escala regional y facilitar el enriquecimiento mutuo.

-aumentar la eficacia en el suministro de la ayuda, en particular recurriendo con más frecuencia a la ayuda presupuestaria directa y trabajando más estrechamente con otros socios, en particular Australia y Nueva Zelanda.

La estrategia de la UE para África define un marco de acción para el conjunto de los Estados miembros con el fin de apoyar los esfuerzos desplegados por África para alcanzar los Objetivos de Desarrollo del Milenio (ODM) de las Naciones Unidas. Desde hace algunos años, se vienen registrando numerosos progresos en África: la gobernabilidad ha mejorado mucho, y el crecimiento económico ha alcanzado niveles nunca antes registrados. La Unión Africana (UA), la Nueva Asociación para el Desarrollo de África (NEPAD) y las organizaciones internacionales han dotado a África de una hoja de ruta política y económica y de una visión para el futuro.

No obstante, para África, el camino que queda por recorrer para lograr el desarrollo sostenible es aún largo. En la actualidad, un $40 \%$ de los africanos vive aún con menos de un dólar al día, las tres cuartas partes de las víctimas del SIDA son africanos y un africano de cada cinco vive en un país desgarrado por la guerra o los conflictos violentos. Por lo que se refiere a la renta per cápita, dieciocho de los veinte países más pobres del planeta son africanos.
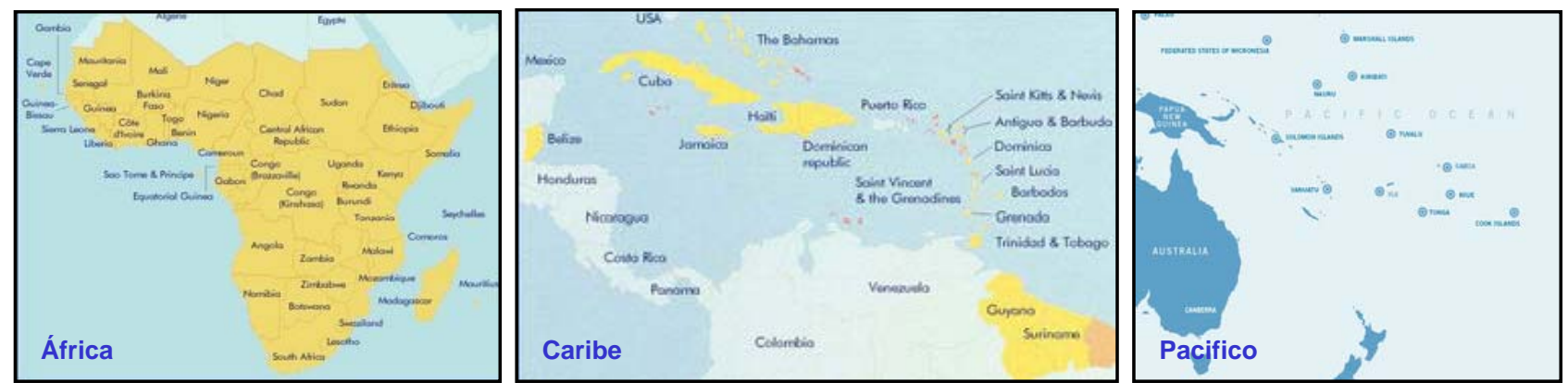

Mapa de países de la ACP.Fuente: Archivo particular. 
La realidad y el denominador común a todos estos países, es el bajo nivel de desarrollo de infraestructuras, la prestación por parte del estado de los servicios básicos a la población; y en sentido general los estándares que completan el Índice de Desarrollo Humano en estos países, no siempre están presentes de forma adecuada. También es cierto que no siempre unos niveles altos de PIB garantizan calidad de vida integral, sobre todo si se tomo en cuenta en el balance el tema medioambiental. Los ricos no siempre hacen las cosas bien y a veces quieren obligar a los pobres a que las hagan aun cuando ni siquiera cuentan con su apoyo.

\subsection{Aspectos coincidentes: Climáticos, Ambientales, Económicos, Sociales. \\ Arquitectónicas.}

Es franja comprendida entre los Trópicos de Cáncer( paralelo situado a los $23^{\circ} 27^{\prime}$ de latitud al norte del ecuador), y Trópico de Capricornio ( paralelo situado a los $23^{\circ} 27^{\prime}$ de latitud al sur del ecuador), alberga territorios con gran variedad climática, y algunos factores comunes. Partiendo de esto y para fines de nuestro estudio, podemos hablar de dos grandes divisiones : Clima tropical templado húmedo, próximo al ecuador; y Clima tropical cálido seco, próximo a los trópicos.

En la cuenca del Caribe no solo existe un perfil general común a todos los territorios que la componen, sino que lo hace también con territorios situados en las antípoda como Vietnam, Laos, Malasia, etc.; y que tienen también algunas semejanzas sociales y medioambientales. De igual modo pasa con algunas zonas del África tropical

\begin{tabular}{|c|c|c|c|}
\hline \multicolumn{4}{|c|}{ ALGUNAS CARACTERISTICAS COMUNES DE PAISES TROPICALES EN VIAS DE DESARROLLO } \\
\hline SOCIALES & ECONOMICAS & GEOPOLITICAS & CLIMATICAS \\
\hline $\begin{array}{l}\text { Población } \\
\text { mayoritariamente joven. } \\
\text { Acceso limitado a la } \\
\text { educación y a los } \\
\text { servicios básicos de salud } \\
\text { con menos del } 8 \% \text { de sus } \\
\text { presupuestos nacionales. }\end{array}$ & $\begin{array}{l}\text { Medios de producción } \\
\text { limitados. Poco desarrollo } \\
\text { industrial. Bajo nivel de } \\
\text { renta per. capita. Altos } \\
\text { niveles de deuda publica. } \\
\text { Economía dependiente de } \\
\text { factores externos. }\end{array}$ & $\begin{array}{c}\text { Recursos naturales y } \\
\text { ubicación geográfica } \\
\text { estratégicas para las } \\
\text { antiguas potencias } \\
\text { colonizadoras, hoy países } \\
\text { industrializados. }\end{array}$ & $\begin{array}{l}\text { Condiciones climáticas } \\
\text { parecidas. Altos niveles de } \\
\text { humedad, y temperaturas } \\
\text { entre } 20 \text { y } 35^{\circ} \text { C durante } \\
\text { todo el año. Pluviometría } \\
\text { alta y ciclones durante } \\
\text { seis meses al año. }\end{array}$ \\
\hline
\end{tabular}

Fuente: Archivo particular.

Como se muestra en el cuadro de arriba, es posible hacer un perfil de indicadores que resultan comunes a cualquiera de estos países en las áreas sociales, económicas, geopolíticas, culturales y climáticas.

Al elaborar estos parámetros, podría estarse hablando indistintamente de alguna de las nación que forman esta banda central del globo; definiendo a grandes rasgos las variables determinantes de su nivel de desarrollo; y hacerlo a la vez como punto de partida para la presentación de soluciones comunes que luego se irían matizando según la situación propia de cada caso.

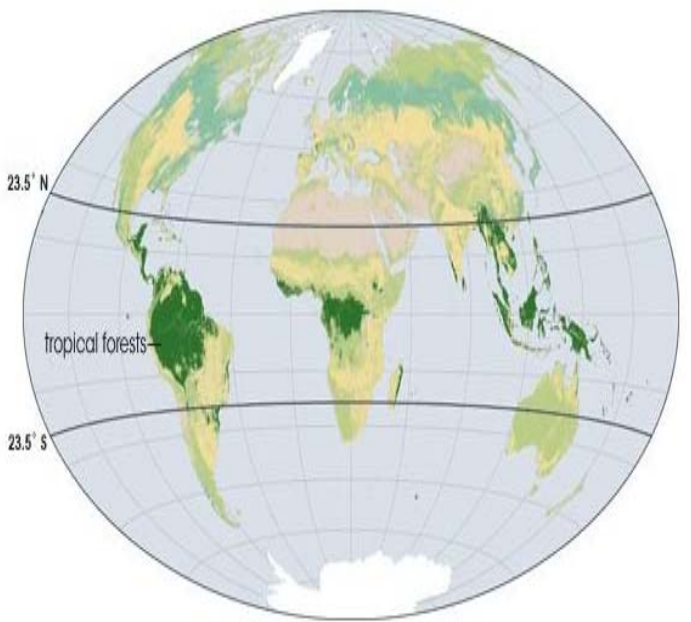

Zonas Tropicales. Fuente: Archivo particular. 
Es normal que en muchas de estos lugares se hayan dado soluciones arquitectónicas parecidas tratando de satisfacer demandas de confort comunes; desarrollando un tipo de arquitectura que a través del tiempo ha sabido interpretar y aprovechar de manera sostenible, con métodos pasivos las condicionantes climáticas de un tipo de región. Al combinar estas soluciones autóctonas con técnicas de captación solar, puede conseguirse una tipología común a toda una región del mundo que se presenta con grandes proyecciones hacia el futuro.
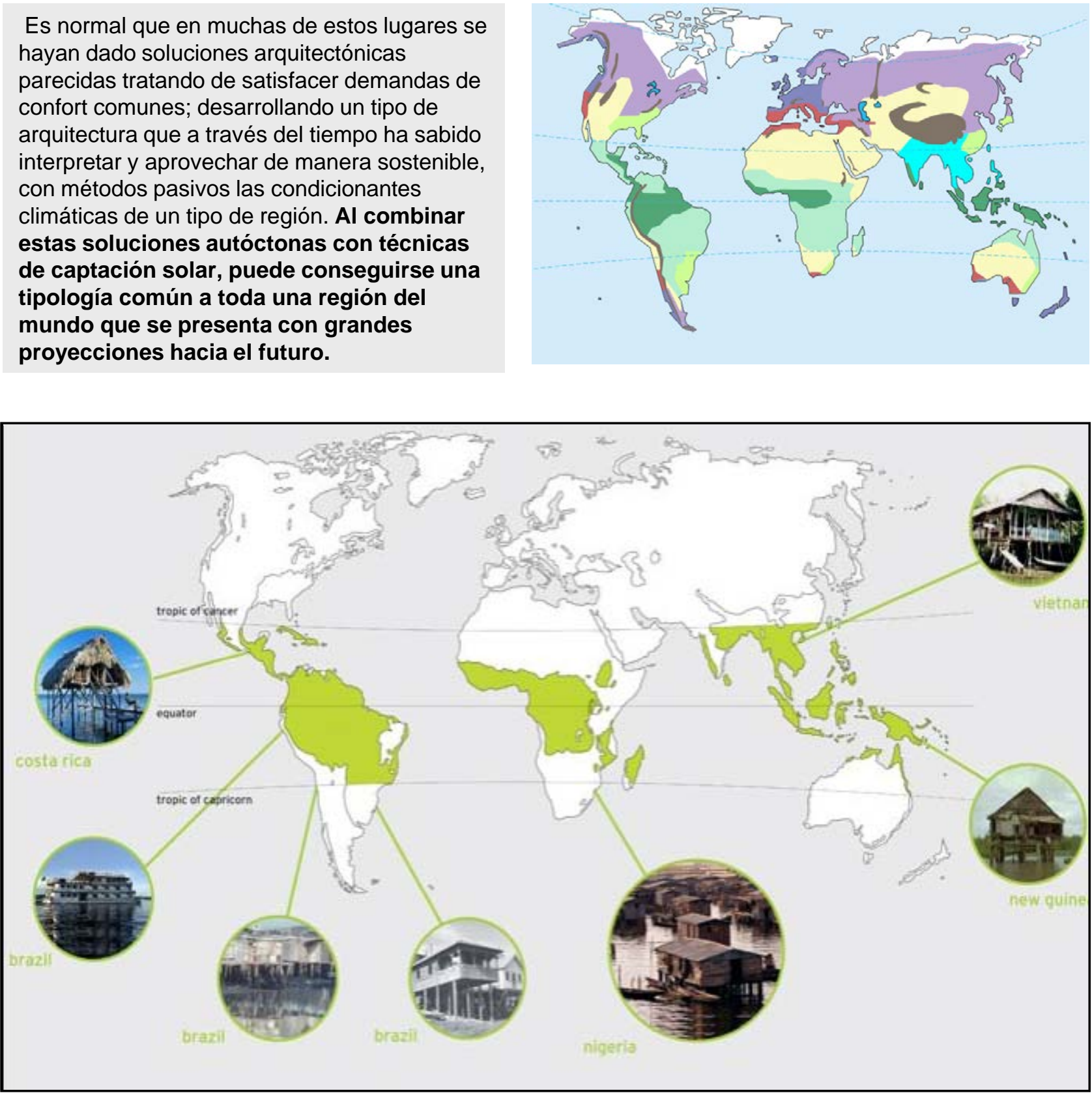

Mapa de algunas tipologías arquitectónicas semejantes en zonas tropicales del mundo. Fuente: Mod. Arq. Tropical. E. Rodríguez.

Como se observa en el mapa, se presentan tipologías muy parecidas que buscan la mayor eficiencia posible manejando recursos limitados y muy condicionados a las circunstancias del lugar como es el caso de estos palafitos.

El trópico responde a una realidad climática, y es normal que su arquitectura vernácula presente soluciones comunes. Los altos índices de humedad relativa, las temperaturas medianamente altas y por consiguiente la necesidad de ventilación constante; marcan un sello distintivo singular, una forma particular de construir parecida, tanto en el Caribe como en las islas del pacifico y territorios africanos que comprenden las zonas tropicales.
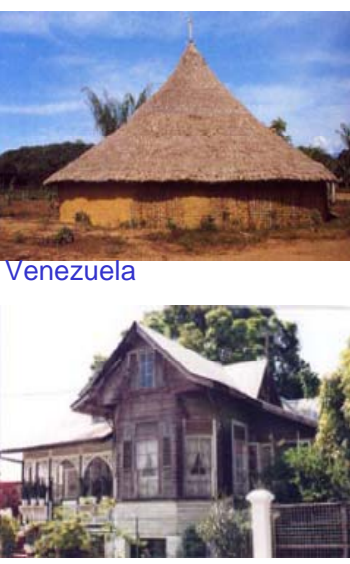

Trinidad y Tobago

Fuente: Archivo particular
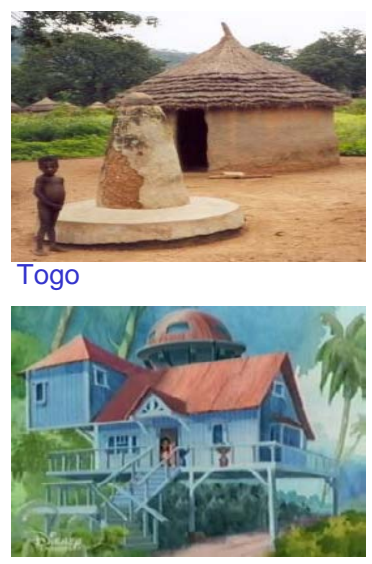

Hawai 


\subsection{Soluciones Comunes y sus repercusiones a nivel local y global. La energía solar como alternativa de desarrollo en los trópicos.}

Sabiendo que hay semejanzas entre los puntos mas meridionales donde los rayos del Sol inciden verticalmente sobre la Tierra, y los puntos más septentrionales en los que el Sol puede ocupar el cenit o la vertical del lugar a mediodía; observamos que también puede haber una importante variación climática:

- En zonas tropicales secas las radiación solar es muy intensa y trae consigo temperaturas altas en verano, siendo las noches de invierno muy frías.

- En zonas tropicales húmedas las constantes temperaturas altas con una pequeña diferencia entre la noche y el día, se combinan con una humedad relativa por encima del $80 \%$ y en muchos casos poco movimiento de aire.

- Próximo al Ecuador, se desarrollan las tormentas tropicales desde donde se dirigen hacía el Norte o Sur con fuertes vientos y lluvias.

\section{ALGUNAS SOLUCIONES COMUNES}

Con todo esto hay objetivos claros que hay que cumplir como condicionantes de diseño en gran parte de estas zonas:

-Controlar las altas temperaturas

- Protegerse de la radiación solar.

- Ventilar, dado los altos niveles de humedad del aire.

- Protegerse de los también altos niveles de precipitaciones torrenciales que en ocasiones pueden convertirse en tormentas.

-Desarrollar métodos de construcción que ofrezcan a los usuarios espacios confortables que no requieran sistemas de enfriamiento con el consiguiente gasto de combustible fósil. (*)

Casi siempre un denominador común en las zonas tropicales es el factor calor. La incidencia del Sol, ha de tenerse en cuenta al proyectar los sombreamientos que eviten la captación directa por las aberturas y las superficies vidriadas de la edificación; y el calentamiento de los cerramientos opacos exteriores, con la posterior transmisión de esta energía calórica a lo interno. La adecuada ventilación, completa el "Tandem" básico para zonas tropicales. Otros puntos importantes serian además de propiciar la ventilación natural:

-Factor Forma y Orientación (Orientación optima perpendicular al eje norte-sur).

-Mejorar el microclima con elementos del paisaje (Árboles como elementos de sombra pérgolas, paisajismo y reguladores térmicos).

-Aprovechar la inercia del terreno.

Ciertamente gran parte de nuestro enfoque de solución, va dirigido mas bien hacia algunas de las zonas tropicales principales: Regiones Húmedas con Selva Tropical y Húmedos de Sabana cerca al Ecuador. Sin embargo, muchas de las soluciones que se plantean pueden servir gran parte del año para las regiones Cálidas y Secas, Desértico, Seco Estepario y Sabanas Secas, cerca de los dos Trópicos. 


\section{LA ENERGIA SOLAR COMO ALTERNATIVA DE DESARROLLO EN LOS TROPICOS.}

El "arquitecto" vernáculo de las zonas tropicales, sabe aprovechar su medio natural en beneficio de la edificación y los que en ella vivirán, garantizando la comodidad, utilizando poco o ningún método mecanizado consumidor en exceso de energía.

Recobrando las técnicas de construcción propias del lugar y tomando su lenguaje arquitectónico como interpretación fiel de un contexto regional; proponemos soluciones de integración Fotovoltaica y/o ACS en el quehacer constructivo; fusionando soluciones tropicales con soluciones de tecnología de aprovechamiento solar.

Podemos señalar, haciendo un ejercicio de comparación, como el concepto de VENTILACION predominante en esta tipología; se mantiene y cobra importancia en la FV, dado que en gran medida determina el rendimiento optimo de los paneles integrados a la piel del edificio, que necesitan trabajar a temperaturas medias-bajas para conseguirlo.

Lo ideal y lo que se propone, es conseguir conjugar las técnicas y crear una tipología de arquitectura tropical eficiente. Poniendo en practica esta fusión: lo vernáculo y eficiencia energética se planteamos algunos ejemplos propios de soluciones de diseño que pudieran llevarse a cabo.

\section{En edificaciones:}

- Cubierta ventilada con integración de paneles FV Policristalinos en superficies horizontales inclinadas y verticales (por donde entra el aire).

- Cubierta mixta de Cana Paneles FV de Silicio Amorfo y/o policristalino.

- Cerramientos verticales y cerrajería (puertas y ventanas), con celosías Fotovoltaicas Monoclistalinas fijas/ móviles, y Captadores Solares ACS.

-Terrazas y Porches y Balcones fotovoltaicos.

En zonas costeras y de playa, donde también se ha desarrollado este lenguaje constructivo, pueden surgir soluciones de integración fotovoltaica en los espacios y las facilidades que se emplacen en el; integrándolas de manera que sean parte de la naturaleza misma del sitio.

\section{Mobiliario de Playa:}

-Sombrillas de playa fotovoltaicas orientables.

-Bosque Tropical Multicristalino.

-Duchas Solares.

-Tumbonas con cubierta energética.

Naturalmente, cada uno de estas propuestas implica un diseño bien pensado y mejor acabado aun; pero no dejan de ser perfectamente realizables en el tiempo y en el espacio que habitamos. Y aunque en este trabajo no pensamos desarrollarlas del todo, si nos proponemos demostrar que con estas y tantas otras soluciones practicas parecidas, es posible mejorar la situación energética actual de la mayoría de las zonas comprendidas entre el Trópico de Cáncer y el de Capricornio. 
El impacto positivo de una obra arquitectónica eficiente, integrada a su entorno y que se aproveche de las posibilidades que le brinda las condiciones climáticas en una región tropical; no solo repercute a nivel económico -a mediano plazo- a los propietarios de la misma, toda vez que un buen diseño implica un ahorro de energía en materia de climatización; sino que también tiene una repercusión a nivel de su localidad.

Este impacto local se da en diferentes ámbitos; y estos son, como hemos venido mencionando ya, y se seguirán planteando en lo adelante: el Social, el Económico y el Ecológico o Medioambiental.

\section{REPERCUCIONES:}

\section{SOCIALES:}

- La sociedad adquiere nuevamente una conciencia sobre las implicaciones de una arquitectura vernácula, y los beneficios que se obtienen implantado sus técnicas.

- Se mantiene un contacto muy cercano con el entorno y se afianza la identidad local.

- La población internaliza mejor las tecnologías de eficiencia energética y sostenibilidad a través de sus propias maneras de construir.

\section{ECONOMICAS:}

-Como cualquier actividad productiva de esta naturaleza ( construcción, industria, comercio), se generan movimientos económicos a escalas altas, medias y básicas. Desde el diseño y fabricación de los materiales constructivos, pasando por su venta y posterior instalación, como es natural se va creando una cadena que deriva en beneficios tanto para la macro como para la microeconomía.

- Esto es aplicable especialmente con el tema de la fabricación, venta e instalación de dispositivos de captación energética.

\section{ECOLOGICAS:}

-Al utilizar técnicas bioclimáticas se reducen sustancialmente las emisiones causadas por el uso de combustibles fósiles para climatización.

-Los principios de eficiencia energética combinados con la arquitectura vernácula, en cierta medida evita la importación de muchos materiales cuya industrialización y traslado conllevan y una huella ecológica desproporcionada

-Esta arquitectura adaptada al lugar y que integra dispositivos de eficientización y captación energética conduce aun camino de reutilización de recursos materiales y principios de sostenibilidad.

De esta misma manera, pero en escala multiplicada, se produce el impacto a nivel global.

Necesariamente estos impactos positivos se proyectan mas allá de las fronteras locales, llegando a trascender sus consecuencias a ámbitos que benefician a la colectividad mundial.

Un kilogramo de $\mathrm{CO} 2$ que se deja de emitir en uno de estos países, redunda positivamente en el balance de emisiones del planeta. De ahí la importancia de crear una nivel de conciencia a toda la humanidad y sus clases dirigenciales sobre como sus actos positivos tienen eco en lugares mas allá de sus dominios. 


\section{Integración de paneles FV en cubiertas ventiladas y balcones}

Siendo soluciones probadas favorablemente en contextos climáticos y ambientales distintos y con otros modelos constructivos diferentes a la región tropical; las lamas y paneles integrados en balcones ( esta ultima no tan optimas por estar a $90^{\circ}$ ), y otros elementos de las fachadas tropicales, optimizan aun mas este tipología, pudiendo guardar a las vez relación con el lenguaje compositivo de la edificación y su entorno natural y social.

\section{Integración en Cubierta Cana/FV}

La cana u hoja de palmeras, como elemento vegetal, aporta a la cubierta frescura no solo visual, sino también funcionalmente hablando. Por su naturaleza y las técnicas de colocación utilizadas, es posible el intercambio de aire interior/exterior disipando rápidamente el calor, pero sin dejar pasar el agua de las lluvias frecuentes. Aunque su vida útil es relativamente corta (5 a 10 años), su mantenimiento y recambio es fácil y rápido.

Al integrar paneles y o captadores solares, es necesario un diseño mas consistente en la estructura de cubierta y sus fijaciones, pero que a la vez no obstaculice la función de disipador de calor de la cana.

\section{Integración en Carpinterías}

Las puertas y las ventanas en la arquitectura tropical, adaptan a las necesidades locales, técnicas y elementos como los dispositivos de ventilación interiores y exteriores.

Se plantea la incorporación de sistemas de capitación solar en sustitución de las simples lamas de madera o metal; que cumplan la doble función de permitir la entrada de aire y recibir los rayos solares para su transformación fotovoltaica.

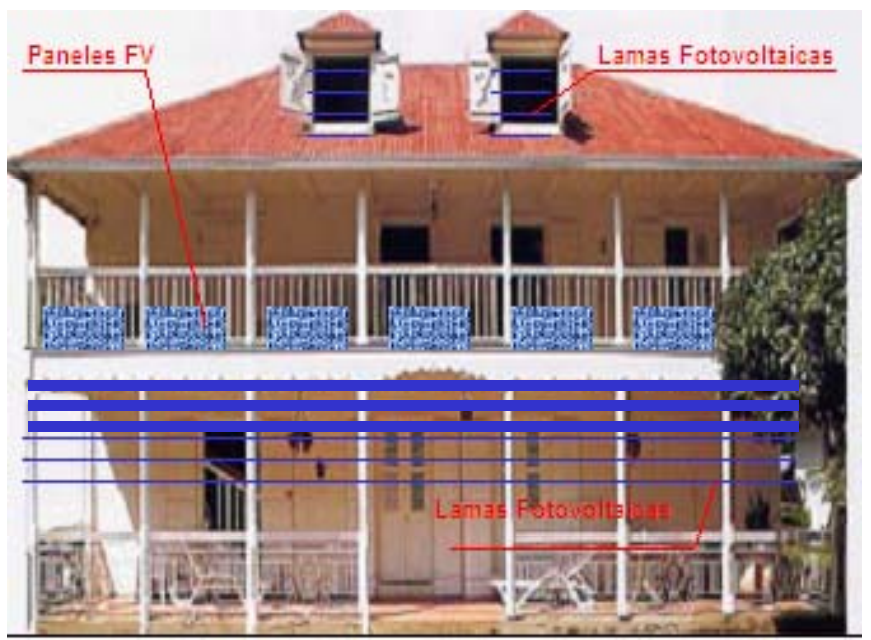

Integración Fotovoltaica Casa Antillana. Fuente: Archivo particular
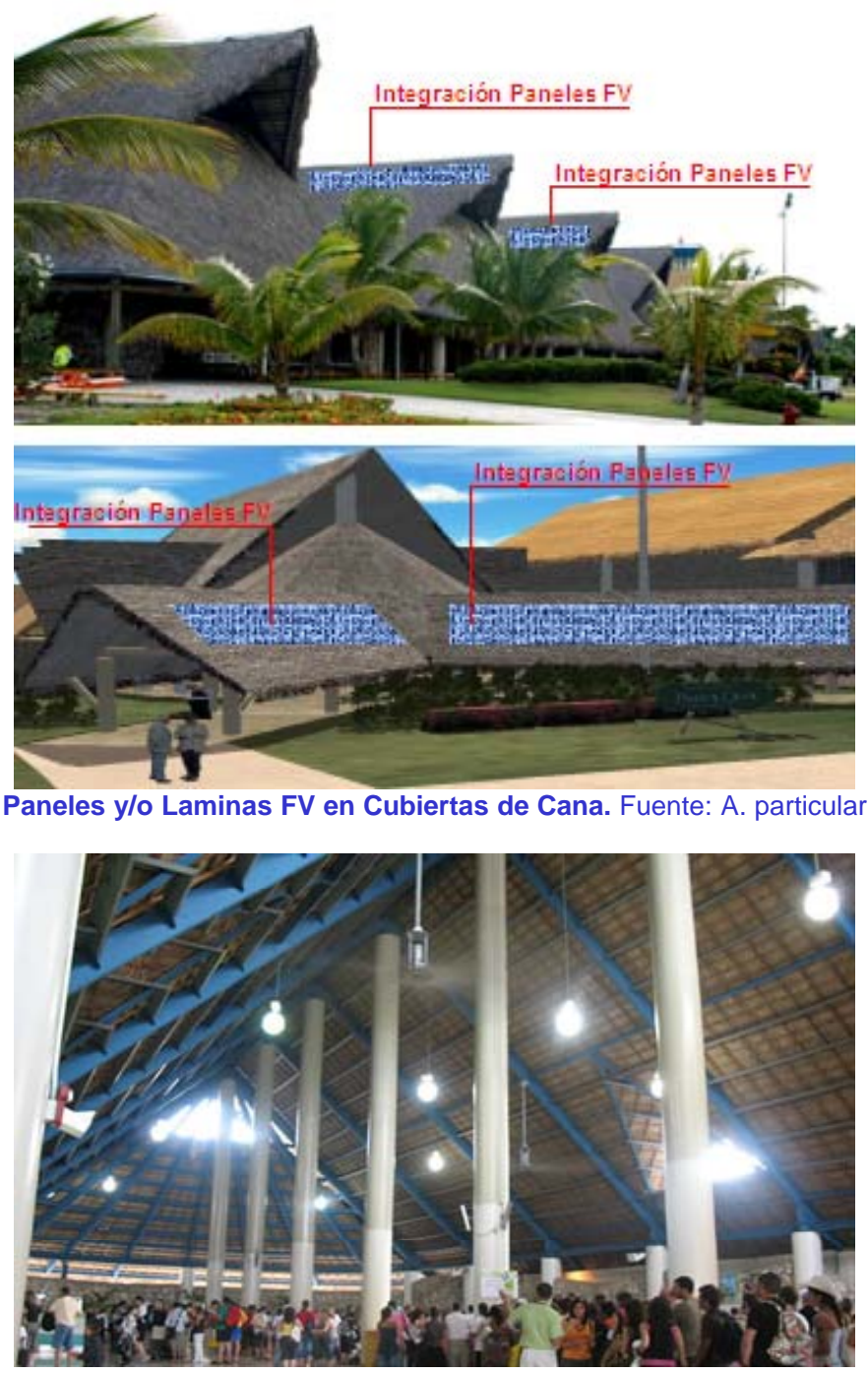

Estructura de refuerzo para techos de Cana. Fuente Archivo Particular 


\section{EL ESCENARIO DOMINICANO}

\section{ARQUITECTURA SOLAR EN PAISES TROPICALES EMERGENTES \\ TECNOLOGIA FOTOVOLTAICA.}
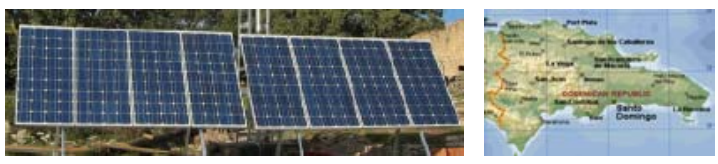

\section{1 ¿Por qué la República Dominicana?}

Es fácil enumerar las razones por las cuales puede elegirse la República Dominicana como escenario de ensayo para el tema del nuestro estudio; a continuación citamos algunas de ellas :

1. País tropical situado en los $18^{\circ} \mathrm{N}$ aproximadamente, con las condiciones climáticas tipológicas regionales propicias para el estudio actual.

2. País en vías de desarrollo con poco nivel industrial; pero con grandes posibilidades de crecimiento, y un clima de inversión apto para la instalación en el país de la industria de captadores solares y fotovoltaicos

3. Condiciones sociales y económicas actuales propias de este tipo de países tropicales, que representan grandes posibilidades para el fomento de nuevas tecnologías; todo esto combinado con la necesidad de inversiones que eleven el nivel y la calidad de vida de las personas de estas latitudes.

4. Buena ubicación geográfica para la comercialización y exportación en toda el área del Caribe y Centroamérica.

5. Existencia de una tipología de arquitectura vernácula-antillana común a la mayor parte de las islas del Caribe y a varias zonas similares alrededor del mundo.

6. Es un vivo ejemplo del profundo déficit energético que afecta a los países de su rango de desarrollo y ubicación geográfica. 


\section{EL ESCENARIO DOMINICANO}

\subsection{Ubicación geográfica.}

La República Dominicana forma parte del continente Americano; situado en la sub-región de América Central conocida como El Caribe.

Forma parte del archipiélago de las Antillas; una cadena de isla que enmarca y separa el Mar Caribe, del océano Atlántico.

Las Islas de las Antillas están divididas en Mayores:, y son: Cuba, Sto. Domingo, Jamaica, Puerto. Rico; y Menores: Islas Bahamas, Islas Barlovento, Islas Sotavento.

El territorio de la Rep. Dom. esta constituido por el 75\% (48.442 Km²), de la Isla de Sto. Domingo, en su parte oriental. También son parte de su territorio las islas Saona, Alto Velo, Alto Velito, Beata, Catalina, y Catalinita.
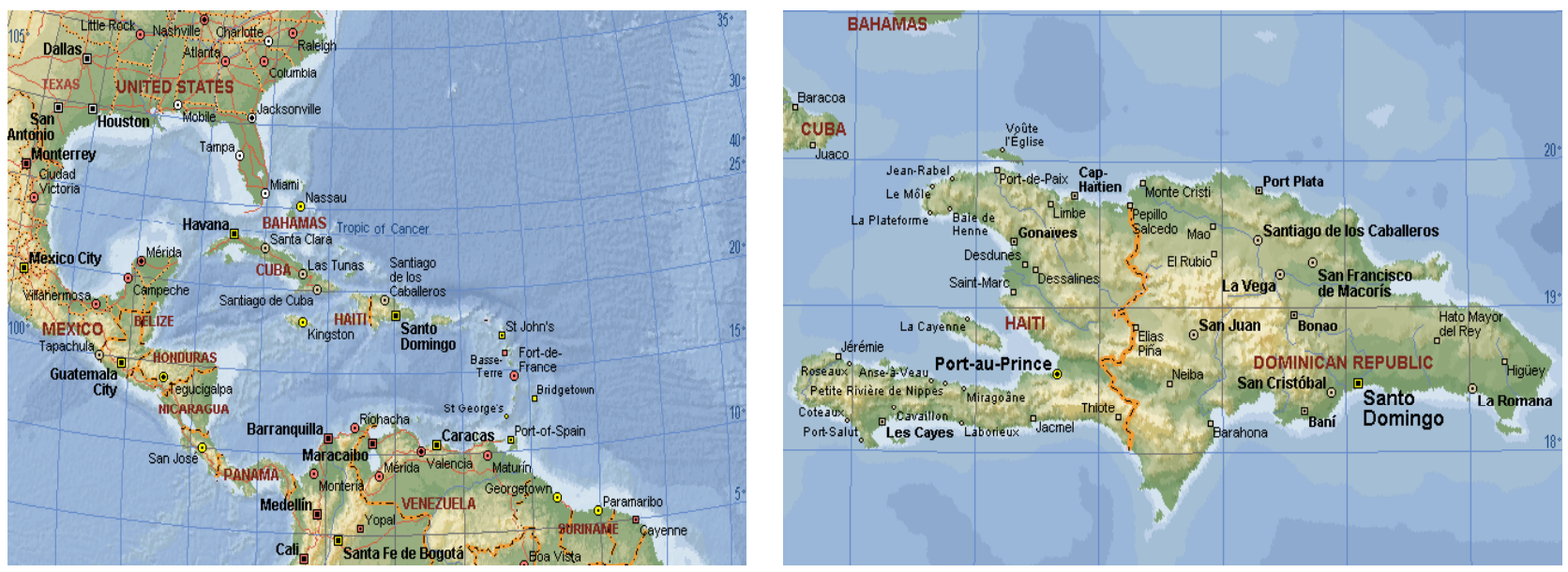

América Central y El Caribe. Fuente: Archivo particular.

\section{Sus Coordenadas son:}

$1736^{\prime} 22^{\prime \prime}$ y 1956 ' 09" de latitud Norte.

68 19' 24" y 72 01' 00" de latitud Oeste.

Según el meridiano de Greenwich.

Los limites del territorio dominicano son : Al Norte con el Océano Atlántico; al Sur con el Mar Caribe al Este con el Canal de La Mona, que le separa de Puerto Rico.(102 Km de ancho); al oeste esta la República de Haití. 


\subsection{Condiciones climáticas.}

Las características climáticas de la isla de Santo Domingo corresponden por su latitud a la categoría de Tropical Húmedo. El relieve y la acción de los vientos alisios son factores moderados que dan origen a cuatro tipos de Microclimas:

a) Clima Tropical Húmedo de Sabana.

b) Clima Tropical Húmedo de Bosque.

c) Clima Tropical Húmedo de Selva.

d) Clima Seco Estepario.

Las temp. más altas registradas en verano( de $34^{\circ}$ a $36^{\circ} \mathrm{C}$ ) tienen lugar en la franja suroeste de la nación. Los niveles de pluviometría mas altos se registran entre mayo y junio, y de septiembre a noviembre. Aunque en muchas zonas y principalmente al Noreste las lluvias pueden estar presentes durante todos los meses del año.

La presencia de depresiones y tormentas tropicales, así como de huracanes es común dentro de la temporada comprendida entre el 1 de junio y el 30 de noviembre. En muchas ocasiones los huracanes pueden alcanzar velocidades superiores a los $200 \mathrm{Km} / \mathrm{h}$.

Nota: Datos y análisis climáticos en capitulo 11

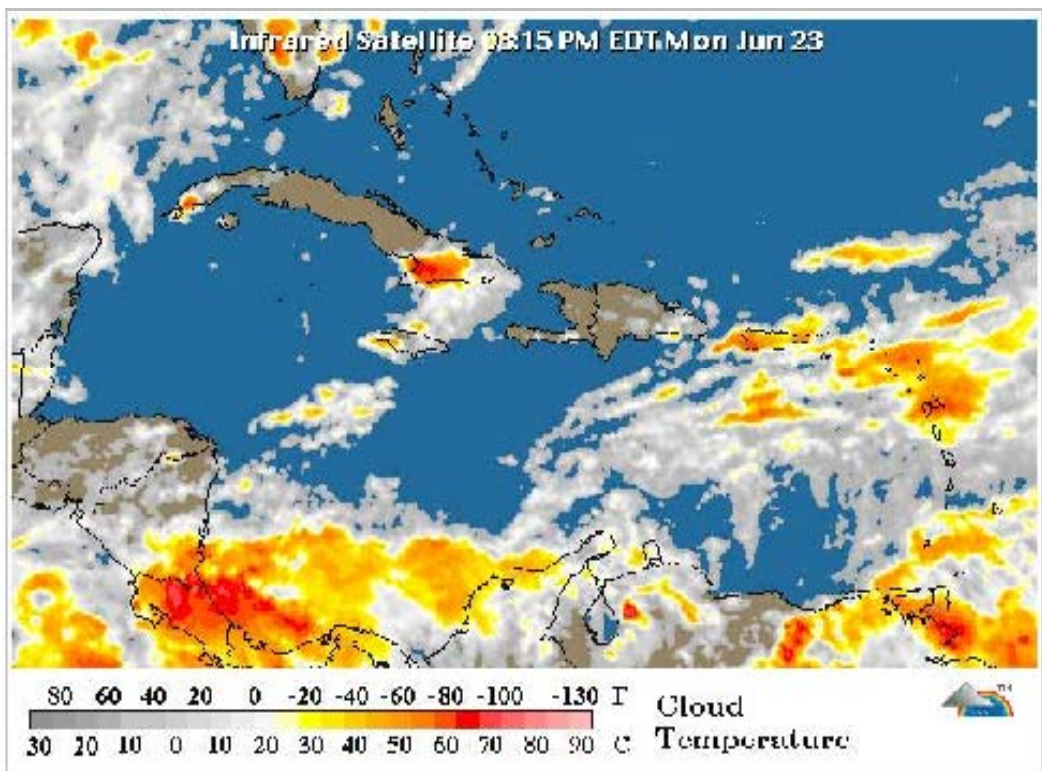

Imagen en infrarrojo de temperatura área del Caribe. Fuente NOAA

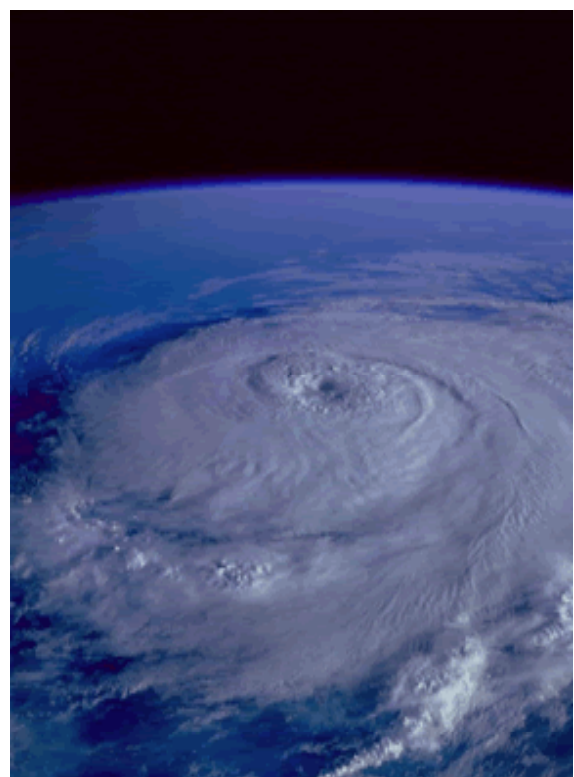

Huracán. Vista satélite. Fuente NOAA 


\subsection{Aspectos realidad socioeconómica. Problemática energética, equipamientos y habitacional.}

Dentro de los países denominados en vías de desarrollo, la República Dominicana entra en el rango de los de ingresos medios de acuerdo a su nivel económico. Igualmente su perfil es parecido al de muchos dentro de su categoría

Los principales renglones de la economía nacional son la agricultura, comercio, servicios. El turismo y las zonas francas, como partes del sector servicios, han sido durante los últimos años los mayores generadores de empleo del país. El turismo representa mas de 1000 millones de dólares de ingresos al año, sin embargo este modelo se perfila como insostenibles con tendencia a agotarse en los próximos años si no se modifican algunos patrones de gestión por parte del estada y el sector privado

La agricultura que todavía se mantiene puntera en las estructuras de producción, es junto a la minería la de mayores índices de exportación y comercio exterior.

El Programa de Naciones Unidas para el Desarrollo (PNUD) presenta en sus informes desde el 2005 al 2008, que la República Dominicana se ha insertado en la economía mundial de manera social y políticamente excluyente; conociendo tasas de crecimiento macroeconómico promedio anual en los últimos años de entre el $4 \%$ y $6 \%$, pero que no repercuten en la mejoría de los servicios y la calidad de vida de los Dominicanos. Estos datos sitúan a la República Dominicana entre uno de los países con mayor potencial, pero con menor desarrollo humano en la actualidad.

Gráfico I.2

Diferencia de posiciones entre clasificación de países según su ingreso y clasificación según su IDH, 2002

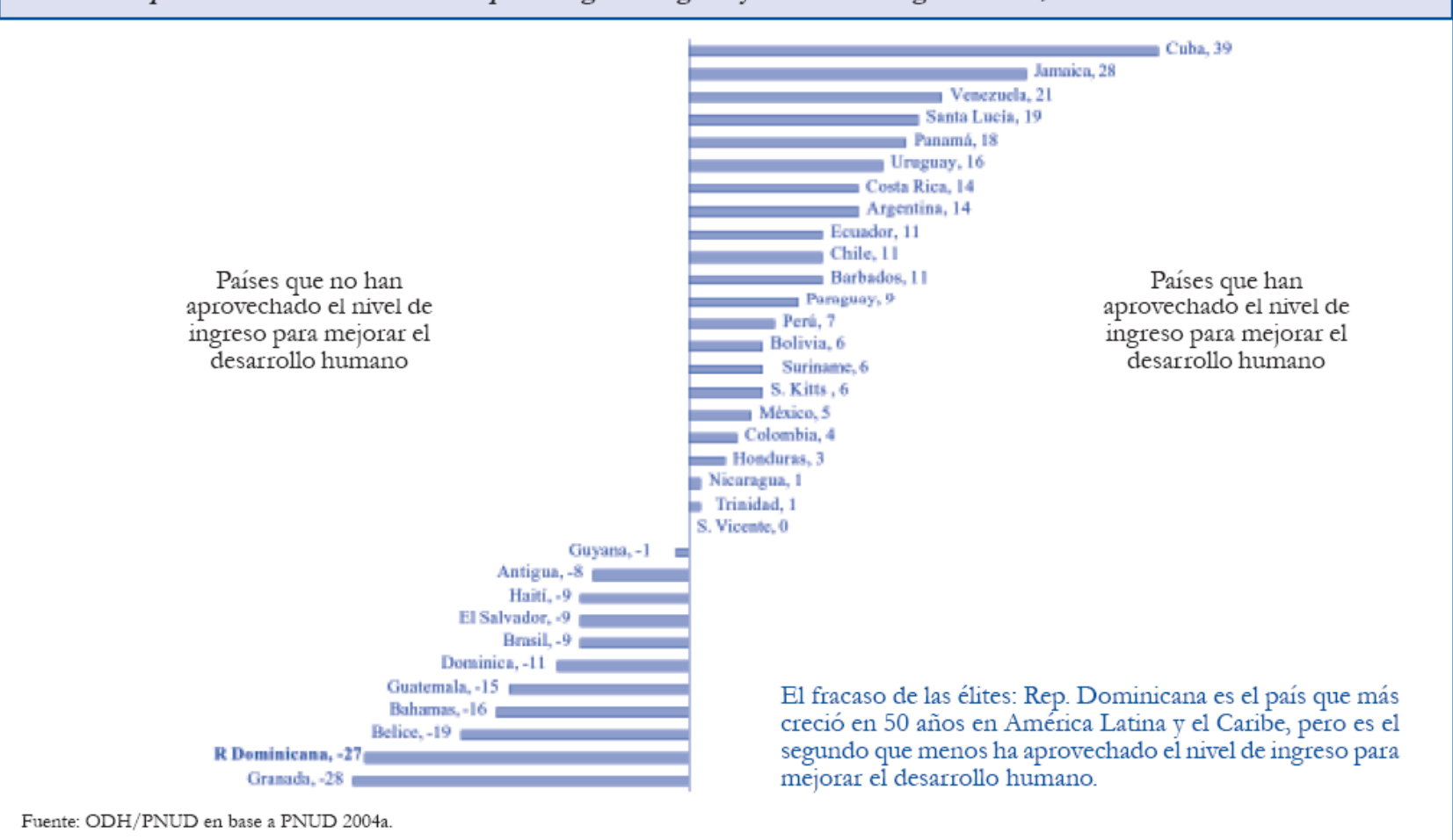

En resumidas cuentas, el Índice de Desarrollo Humano ha mejorado a lo largo del tiempo, pero en forma volátil y no sostenida. Este crecimiento no ha avanzado a la misma velocidad en que ha mejorado el PIB por habitante. Según el IDH calculado a nivel mundial, República Dominicana ocupa el lugar número 98 de 177 países en el mundo. No obstante, al estimar la posición de acuerdo a su PIB per cápita (en dólares PPA33 ) se sitúa en el puesto 71, es decir, 27 posiciones por encima. A nivel mundial el país está en mejor posición por PIB per cápita que por IDH, tendencia que se ha agudizado en el tiempo. 
Dada esta situación, el estado no puede hacer una sólida inversión en prestaciones y servicios que demanda la población .

Salud, educación y energía son de los mas afectados en este contexto económico imperante. Falta de centros sanitarios y desabastecimiento de los existentes; precario sistema educativo manifiesto en la ausencia de centros e inversión en el área. Sumado a esto, el deficiente servicio eléctrico, agravado por las sucesivas crisis mundiales del petróleo.

El país tiene que disponer de más de 2 mil quinientos millones de dólares para satisfacer sus necesidades de combustibles, lo que equivale a más de $35 \%$ del total de las divisas anuales y aproximadamente la tercera parte del actual presupuesto general de la nación. Un con esta elevada disposición de los recursos domésticos para la importación de combustibles, la eficiencia del servicio energético apenas logra alcanzar alrededor de un $50 \%$ de la población dominicana.

El consumo energético nacional esta repartido de la siguiente manera: residencias $49 \%$; industrias $32 \%$; comercios $7 \%$; gobierno $4 \%$ y ayuntamientos $8 \%$.

La energía servida equivale al $70 \%$ u $80 \%$ de la demanda, en el mejor de los casos. El sistema consiste en que las generadoras tanto públicas como privadas (o mixtas), venden la producción de energía, medidas en megavatios, a la empresa de transmisión ETED, que es administrada por el CDEEE (Corporación de empresas eléctricas estatales).

Hogares, escuelas, hospitales, etc.; sufren las consecuencias de un sistema energético ineficiente, costos, contaminante del medio ambiente; $y$ que hoy por hoy se mantiene vigente, a la espera de una eficientización que pudiera venir de la mano de las energías renovables. Para esto ya se van creando las facilidades y bases legales, dentro del marco de los Objetivos de Desarrollo del Milenio planteado por las Naciones Unidas; y del cual es país es uno de los escenarios piloto. Queda ejecutar los planes y proyectos conjuntos, que integren la generación de energía limpia a los edificios que hacen falta para cubrir la demanda social.

\begin{tabular}{|l|}
\hline ZONA \\
\hline NORTE \\
SUR \\
ESTE \\
\hline
\end{tabular}

Total

\begin{tabular}{|c|c|c|c|c|c|c|c|c|c|c|}
\hline AYER & 0 & HOY & 0 & HOY & $\%$ & \multirow{2}{*}{\multicolumn{2}{|c|}{$\begin{array}{c}\text { POTENCIA (MW) } \\
\text { NO SERVIDA }\end{array}$}} & \multicolumn{3}{|c|}{ CANTIDAD DE CIRCUITOS } \\
\hline $9.00 \mathrm{pm}$ & $\%$ & $4.00 \mathrm{pm}$ & $\%$ & $9.00 \mathrm{pm}$ & $\%$ & & & POR ZONA & ABIER' & \\
\hline 505 & $30 \%$ & 415 & $29 \%$ & 510 & $31 \%$ & 86 & $25 \%$ & $182 \quad 35 \%$ & 19 & $10 \%$ \\
\hline 449 & $27 \%$ & 382 & $26 \%$ & 465 & $29 \%$ & 120 & $35 \%$ & $16231 \%$ & 27 & $17 \%$ \\
\hline 702 & $42 \%$ & 652 & $45 \%$ & 653 & $40 \%$ & 135 & $40 \%$ & $18134 \%$ & 30 & $17 \%$ \\
\hline 1,656 & & 1,449 & & 1,628 & & 341 & $21 \%$ & 525 & 76 & $14 \%$ \\
\hline
\end{tabular}

Energía servida en 24 horas por zona en día tipo mes de julio. Fuente: SIE

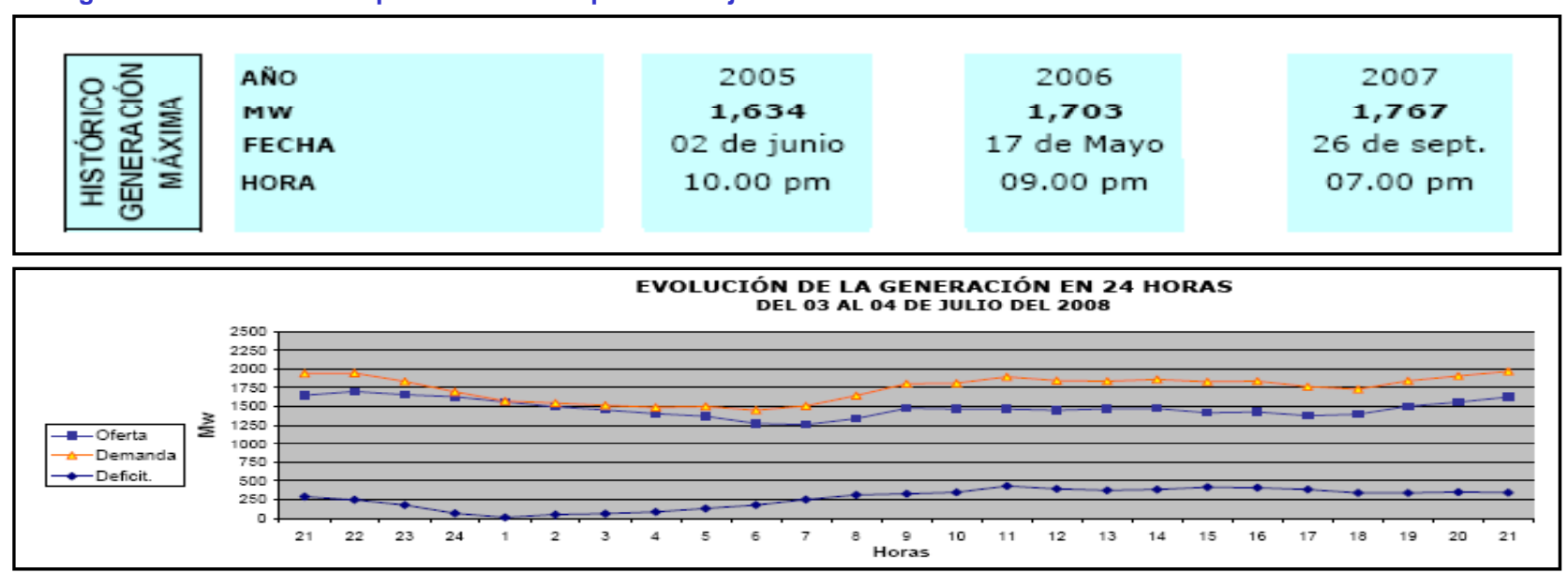

Fuente: Superintendencia de Electricidad R.D. 


\title{
10. HACIA UNA ARQUITECTURA SOLAR EN LA REP. DOM.
}

\author{
10.1 Tecnología fotovoltaica en la arquitectura Dominicana. \\ Estado actual, Tendencias y Posibilidades.
}

Por su ubicación geográfica, la República Dominicana disfruta de muchas horas de sol durante los doce meses del año, contrario a lo que pasa en otras latitudes donde la incidencia solar es mucho menor en otoño e invierno. (Ver grafico Pág. 21)

Sin embargo, es precisamente en estos países de latitudes altas, donde el aprovechamiento solar esta mas avanzada, dado su alto desarrollo económico y tecnológico.

Por otro lado vemos que países de nivel socioeconómico menor, y con gran incidencia solar, han podido desarrollar técnicas de aprovechamiento, mas allá del grado experimental. Ejemplo de ello son Costa Rica; Puerto Rico, Panamá.

La potencia estimada instalada en la República Dominicana para el año 2007 era de $0,01 \mathrm{KW}$. Esto equivale a menos del $0,1 \%$ de la potencia instalada en España y al $0,02 \%$ de Alemania.

Se ha podido observar que es en el área de los equipamientos; y dentro de ésta, básicamente en los sectores turístico y de telecomunicaciones, donde se ha producido una mayor penetración de las tecnologías solares ( $78 \%$ del mercado total), en la arquitectura dominicana.

Aun cuando en otros tipos de equipamientos (institucionales, etc.), y en desarrollos habitacionales ha habido cierta aplicación de estos sistemas, no ha sido tan significativa en comparación con los sectores antes mencionados.

Actual mente esta vigencia la Ley 57-07 y su reglamento de aplicación de reciente aprobación, que aunque no obliga a la utilización de fotovoltaica, y renovables en sentido general, en los proyectos de reforma y nueva planta; si impulsa su uso con incentivos fiscales y recortes de impuestos.

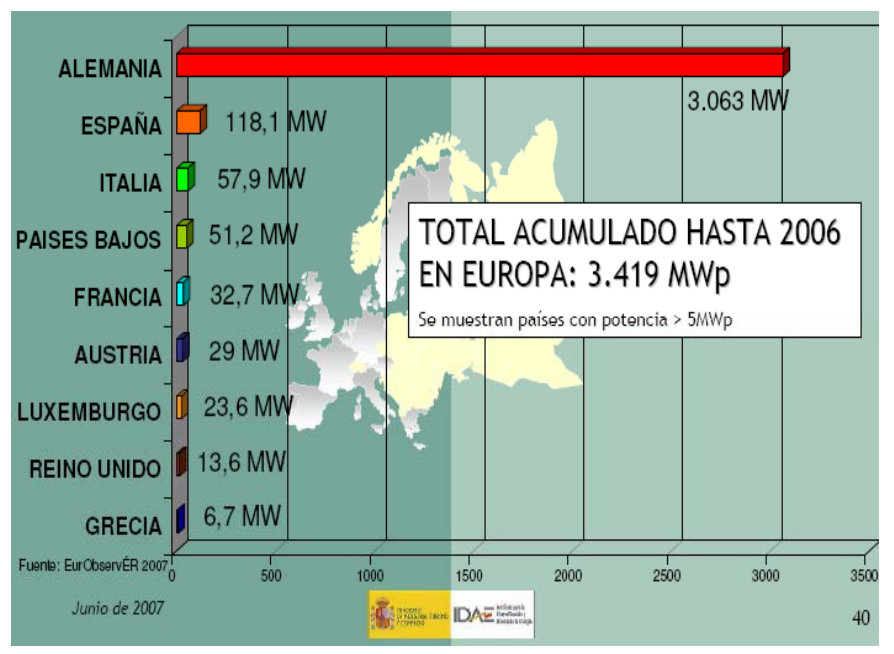

Potencia Instalada en Europa 2006. Fuente IDAE

\section{Implementacion de Fotovoltaica}

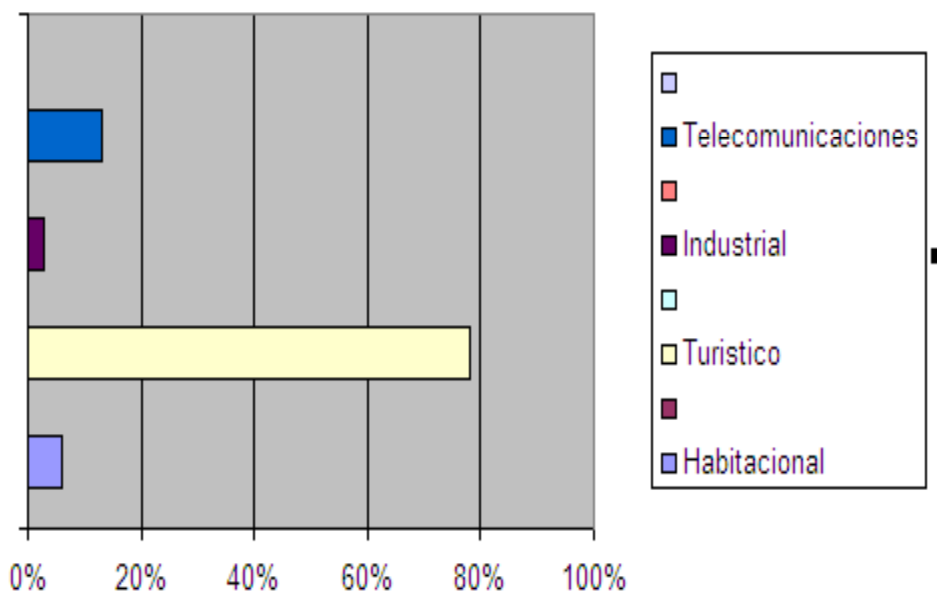

Grafico comparativo porcentaje instalación sectores RD. Fuente: E.Propia. 


\begin{tabular}{|c|c|c|c|c|c|c|}
\hline \multirow{3}{*}{ Año } & \multicolumn{6}{|c|}{$\begin{array}{l}\text { Indicadores del sector turismo, } \\
\text { según año, 2002-2006 }\end{array}$} \\
\hline & \multirow{2}{*}{$\begin{array}{c}\text { Habitaciones } \\
\text { hoteleras }^{1} \\
\end{array}$} & \multirow{2}{*}{$\begin{array}{c}\text { Tasa ocupación } \\
\text { hotelera }(\%)^{2}\end{array}$} & \multirow{2}{*}{$\begin{array}{c}\text { Ingresos } \\
\text { p/turismo } \\
(\text { Millones USS) } \\
\end{array}$} & \multicolumn{3}{|c|}{ Empleos generados por la actividad ${ }^{2}$} \\
\hline & & & & Total & Directos & Indirectos \\
\hline 2002 & 54,730 & 62.8 & 2730.4 & 157,388 & 44,968 & 112,420 \\
\hline 2003 & 56,393 & 72.7 & 3127.9 & 164,694 & 47,055 & 117,639 \\
\hline 2004 & 58,932 & 74.2 & 3151.6 & 171,478 & 48,994 & 122,484 \\
\hline 2005 & 59,870 & 73.9 & 3518.3 & 172,116 & 49,176 & 122,940 \\
\hline $2006^{\mathrm{p}}$ & 63,277 & 73.0 & $3,792.2$ & 188,289 & 53,797 & 134,492 \\
\hline
\end{tabular}

El sector turístico, también llamado la industria sin chimenea, es uno de los principales usuarios de las tecnologías de aprovechamiento solar, sobretodo a nivel de Agua Caliente Sanitaria ( ACS).

\begin{tabular}{|c|c|c|c|}
\hline \multicolumn{2}{|c|}{2005} & \multicolumn{2}{c|}{$2006^{\mathrm{p}}$} \\
\hline Establecimientos & Habitaciones & Establecimientos & Habitaciones \\
\hline $\mathbf{6 5 3}$ & $\mathbf{5 9 , 8 7 0}$ & $\mathbf{6 7 4}$ & $\mathbf{6 3 , 2 7 7}$ \\
\hline
\end{tabular}

La mayoría de estas infraestructuras están ubicadas y asociadas a las costas del país, especialmente las del Este y al Noreste de la isla. El criterio adoptado por estos complejos vacacionales responde al concepto de turismo de sol y playa.

El gran volumen de agua potable utilizado en este tipos de instalaciones, hace que también aumenten las necesidades de ACS; y la energía para calentarla representa un coste elevado que pretende reducirse con el aprovechamiento solar.

Los captadores solares utilizados para estos fines, se encuentran insertados - no tanto integrados- en los tejados de los edificios donde dan servicios, y en algunos casos en las zonas de maquinas. No siempre su ubicación con respecto al ángulo de radiación solar es el óptimo, y muchas veces se encuentran parcialmente sombreados por vegetación u otros edificios. Como cualquier tipo de estructura expuesta al salitre de las playas, la vida útil de estas instalaciones se puede ver reducida considerablemente cuando no se les da el mantenimiento adecuado ( limpieza, sustitución de piezas oxidadas, etc.).

Como bien es sabido, la isla de Santo Domingo esta en plena zona de huracanes, los cuales pueden incidir sobre su geografía durante la temporada ciclónica que dura unos 6 meses cada año. Visto esto, se da el caso con mucha frecuencia de que cualquier elemento colocado sobre la piel del edificio y no integrado (como suele pasar), es susceptible de ser desprendido por los fuertes vientos de estos fenómenos atmosféricos. Los lugares de costa, donde están situados la mayoría de los establecimientos hoteleros, son de los mas afectados, y las instalaciones de los mismos se ven seriamente dañadas con el paso de tormentas, huracanes o su influencia en zonas próximas.

La inclusión de estas variables propias de zonas tropicales costeras, en el quehacer arquitectónico (que procura el aprovechamiento energético solar), seria de gran beneficio para los organismos y para la eficientización y prolongación de la vida útil de las instalaciones sean estas de ACS o FV. 
En materia de telecomunicaciones la República Dominicana es posiblemente el país del área de Centro América y el Caribe con mayor desarrollo.

La infraestructura de medios y recursos tecnológicos sirve de manera eficiente a todo el territorio nacional dando cobertura tanto de telefonía residencial y móvil, como televisión y radio.

Como en muchas otras partes del mundo las señales transmitidas desde los puntos origen, son repetidas por antenas retransmisoras situadas en lugares estratégicos, y que en muchas ocasiones se encuentran apartados de las red eléctrica general.

Estos equipos de retransmisión aislados de la red general de electricidad, se sirven en su mayoría de grupos electrógenos de combustión fósil (plantas eléctricas diesel); y en menor medida pero cada vez mas, son alimentados por energía proveniente de paneles fotovoltaicos. Este es el otro escenario importante de aplicación de la FV en Dominicana.

En este tipo de usos, el tema de integración arquitectónica de los paneles no esta tan comprometido con la estética como con la funcionabilidad; con el hecho de que funcionen de manera adecuada condicionados por su buena colocación y orientación.

Muchas de las montañas dominicanas donde son emplazadas estas antenas están densamente pobladas de árboles, de los cuales varios deben ser podados y mantenidos a una altura que no proyecten sombra sobre las placas y no mengüen así el rendimiento de estas.

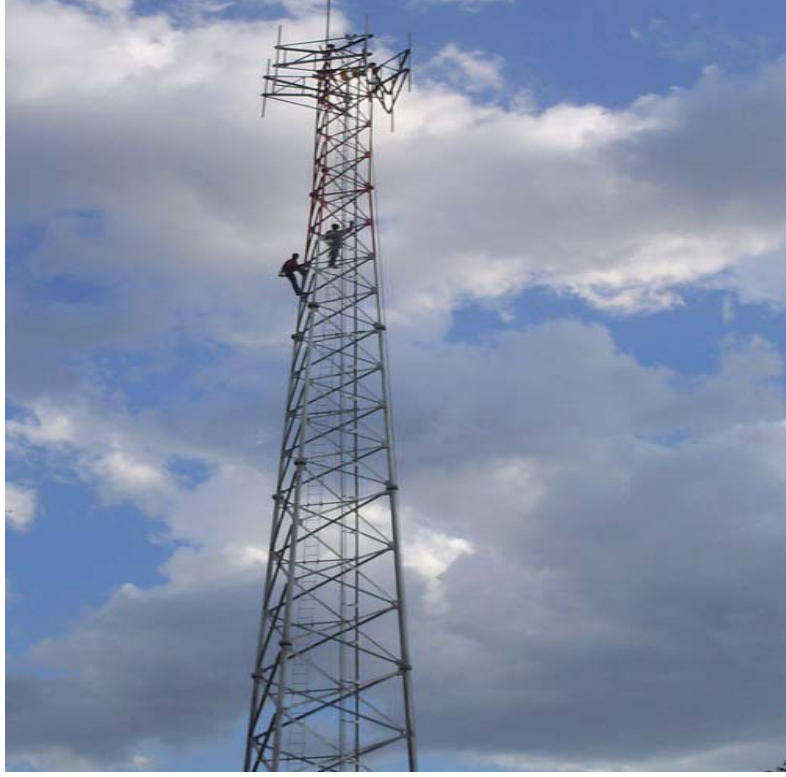

Antena de transmisión.

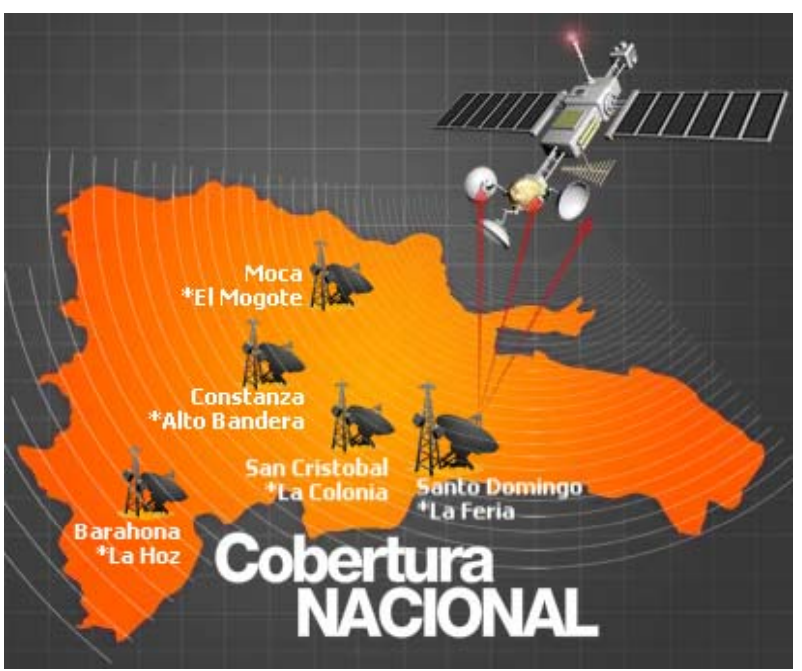

Mapa Inst. Canal Televisión Local. Fuente: Antena Latina.

\begin{tabular}{|c|c|c|c|c|c|}
\hline Indicador & $2002^{*}$ & 2003 & 2004 & 2005 & 2006 \\
\hline Radiodifusoras & 325 & 330 & 313 & 369 & 367 \\
\hline AM & 138 & 136 & 133 & 148 & 148 \\
\hline FM & 187 & 194 & 180 & 221 & 219 \\
\hline Televisoras & 44 & 45 & 41 & 42 & 42 \\
\hline UHF & 32 & 38 & 34 & 34 & 37 \\
\hline VHF & 12 & 7 & 7 & 8 & 8 \\
\hline $\begin{array}{l}\text { Teléfonos en servicio }{ }^{1} \\
\text { Líneas alámbrica. }\end{array}$ & $\begin{array}{r}2,609,566 \\
908,957\end{array}$ & $\begin{array}{r}3,000,723 \\
908,809\end{array}$ & $\begin{array}{r}3,436,321 \\
902,258\end{array}$ & $\begin{array}{r}4,519,541 \\
896,252\end{array}$ & $\begin{array}{r}5,502,685 \\
897,026\end{array}$ \\
\hline Línens inalímbrica & $1,700,609$ & $2,091,914$ & $2,534,063$ & 3.623 .289 & $4,605,659$ \\
\hline $\begin{array}{l}\text { Población estimada } \\
\text { Teledensidad }(\boldsymbol{\varphi})\end{array}$ & $\begin{array}{r}8,562,541^{b} \\
30.5\end{array}$ & $\begin{array}{r}8.930 .267 \\
33.6\end{array}$ & $\begin{array}{r}9.085,326 \\
37.8\end{array}$ & $\begin{array}{r}9.249 .970 \\
48.9\end{array}$ & $\begin{array}{r}9.406 .286 \\
\mathbf{5 8 . 5}\end{array}$ \\
\hline Teledensidad alámbrica & 10.6 & 10.2 & 9.9 & 9.7 & 9.5 \\
\hline Teledensidad inalámbrica & 19.9 & 23.4 & 27.9 & 39.2 & 49.0 \\
\hline Cuentas de Intemet & 82,518 & 96,391 & 106,296 & 134,545 & 183,876 \\
\hline Usuarios de Internet & 330,072 & 385,564 & 426,184 & 672,725 & $1,405,400$ \\
\hline Compañias de Internet & 7 & 7 & 7 & 6 & $14^{\circ}$ \\
\hline Compañias de telecable & 56 & 58 & 59 & $\ldots$ & 73 \\
\hline Compañias de telefonia & 12 & 16 & 21 & 23 & $28^{d}$ \\
\hline
\end{tabular}

Indicadores Telecomunicaciones en Rep. Dom.Fuente: ONE 
Es muy normal, que en países en vías de desarrollo como la República Dominicana, el tema habitacional y de equipamientos ( hospitales, escuelas, centro culturales y deportivos), sea mas preocupante que en las naciones poderosas. La ausencia de soluciones y de medios económicos que ayuden a enfrentar el déficit que en estos renglones del desarrollo se presenta, y la necesidad de buscarle salida a estas situaciones, domina gran parte de las agendas de sus gobiernos.

\begin{tabular}{|l|lr|}
\hline Tipo de Vivienda & Alquilada & 617,731 \\
& Propia, pagándola & 234,519 \\
Propia, pagada totalmente & $1,132,138$ \\
& Cedida o prestada & $196,15$. \\
Otro & 13,305 & Total 2,193,848 \\
\hline
\end{tabular}

Tipo de vivienda en la República Dominicana. Fuente: Elaboración propia/ONE

\begin{tabular}{|c|c|c|c|c|c|c|}
\hline \multirow{2}{*}{ Centros y camas } & \multicolumn{6}{|c|}{ Número de centros } \\
\hline & 2001 & 2002 & 2003 & 2004 & 2005 & 2006 \\
\hline Centros & $\mathbf{0}$ & 1,007 & 1,219 & 1,219 & 171 & 135 \\
\hline Hospitales provinciales & $90^{a}$ & $30^{\mathrm{d}}$ & 40 & 40 & 28 & $31^{\mathrm{d}}$ \\
\hline Hospitales municipales & $\cdots$ & 107 & 87 & 87 & 123 & 105 \\
\hline Sub-centros & & & 5 & 5 & 9 & 16 \\
\hline Consultorios & $722^{b}$ & 159 & 216 & 216 & $608^{f}$ & $472^{f}$ \\
\hline Clínicas rurales & & 615 & 702 & 702 & .. & ... \\
\hline Clínicas urbanas & $\cdots$ & $\cdots$ & 37 & 37 & $730^{e}$ & $801^{e}$ \\
\hline Dispensarios & $\cdots$ & 90 & 108 & 108 & $\cdots$ & $\cdots$ \\
\hline Hospitales especializados & $\cdots$ & 6 & $\cdots$ & 12 & & .... \\
\hline Otros & $215^{\mathrm{c}}$ & 30 & 24 & 12 & 11 & 14 \\
\hline Camas & 9,585 & 9,291 & 9,395 & 9,209 & 9,640 & 9,517 \\
\hline
\end{tabular}

Tipos y número de centros de atención sanitaria y número de camas. Fuente ONE.

\begin{tabular}{|c|c|c|c|c|c|}
\hline \multirow[t]{2}{*}{ Grados } & \multicolumn{2}{|c|}{ Rural: Secciones } & \multicolumn{2}{|c|}{ Urbana: Secciones } & \multirow{2}{*}{$\begin{array}{r}\text { Totales } \\
\text { Secciones }\end{array}$} \\
\hline & NoMultigrado & Multigrado & NoMultigrado & Multigrado & \\
\hline Primero & 3,301 & 1,595 & 3,146 & 207 & 8,249 \\
\hline Segundo & 2,889 & 1,317 & 3,187 & 37 & 7,430 \\
\hline Tercero & 4,554 & 1.233 & 4,714 & 24 & 10,525 \\
\hline Cuarto & 2,526 & 1,063 & 3,125 & 21 & 6,735 \\
\hline Quinto & 2,191 & 432 & 2,866 & 14 & 5,503 \\
\hline Sexto & 1,660 & 0 & 1,950 & 0 & 3,610 \\
\hline Séptimo & 1,284 & 0 & 1,605 & 0 & 2,889 \\
\hline Octavo & 10,71 & 0 & 1,388 & 0 & 2,459 \\
\hline Total Secciones & 19,476 & 5,640 & 21,981 & 303 & 47,400 \\
\hline Total por zona & & 16 & & & 47,400 \\
\hline
\end{tabular}

Numero y tipos de aulas según zona rural o urbana. Fuente ONE 
Si comparamos las cifras de las tablas anteriores con las estándares establecidos por los organismos internacionales, tales como la Organización Mundial de la Salud (OMS), la Organización de la Naciones Unidas para la Educación, la Ciencia y la Cultura (UNESCO), o el Banco Mundial, podremos comprobar que en la República Dominicana existe un déficit importante en vivienda, salud y educación.

Por citar un ejemplo, el del sector salud, la OMS plantea que el numero adecuado de camas por cada mil habitantes es entre ocho y diez. El dato para Dominicana es de 9,7 camas por cada mil habitantes; esto es contando con que el sector privado aportar mas del $60 \%$ de estas camas, con el consiguiente coste para el ciudadano. En datos reales esto supone que el estado dispone de 3,8 camas por cada mil habitantes, significando esto menos de la mitad de lo recomendado por la OMS.

Partiendo de escenarios parecidos en vivienda y educación, el tema de tener que construir las casas, las escuelas y los hospitales que necesita la población, da la oportunidad de proyectar junto con estos, las soluciones de aprovechamiento energético que precisen estos organismos para su funcionamiento.

Esto viene dado, porque la otra gran deficiencia nacional, es el inconstante servicio de electricidad para la población. En la actualidad, los "apagones" ( cortes en el servicio eléctrico), dificultan el desenvolvimiento de las actividades cotidianas y las diferentes facetas de la vida, incluido la operatividad de los equipamientos con los malestares que esta situación conlleva.

Es decir, junto la con la necesidad intrínseca que cubre el organismo; resolver además el gran problema de abastecimiento eléctrico que sufre los mismo una vez construidos; integrando sistemas de captación solar a la piel de los mismos, haciendo la solución energética parte integral de la composición constructiva.

Se pueden encontrar varios ejemplos de integración fotovoltaica en edificios de equipamientos, sobre todo en países de Europa como Alemania o España. Esta practica se va llevando a cabo cada día mas en otros lugares como Estados Unidos y Australia; y en países emergentes es aun algo muy incipiente.

En países como los del grupo ACP ( Asia, Caribe, Pacifico), donde las infraestructuras aun están por construirse, resulta ser el momento idóneo para la implementación de estos sistemas de aprovechamiento; y resulta además que en muchos de ellos las condicionantes climáticas son sumamente favorables durante casi todo el año, sin contar que las condiciones social también se prestan para llevar a cabo proyectos de esta naturaleza.

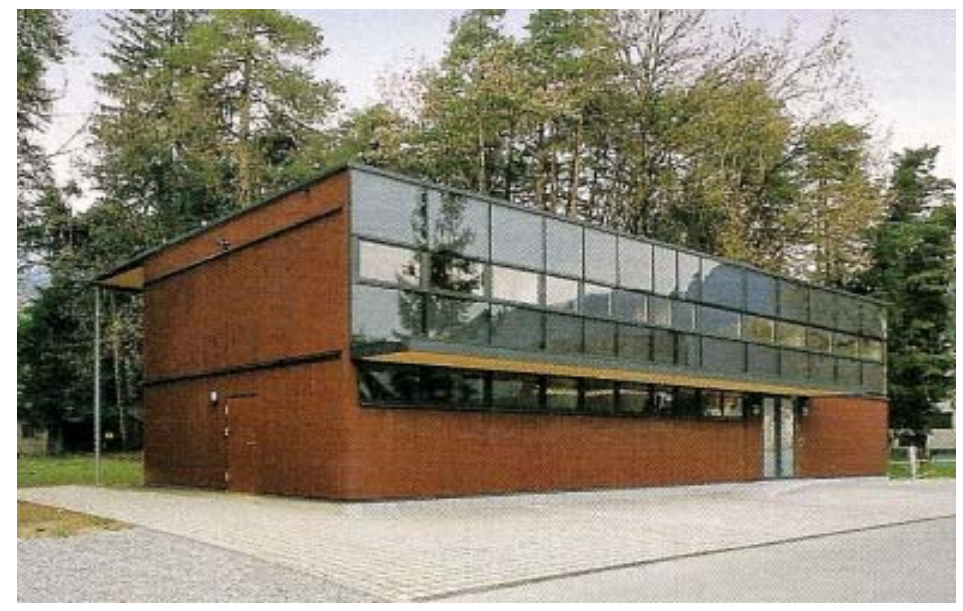

Ejemplo equipo. Casa BoyScouts-Ludesch, Alemania . Fuente: Detail 4, 2005

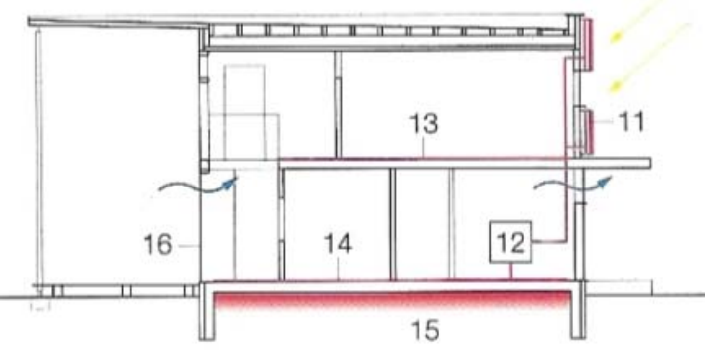

\section{Colectores solares}

Bomba de calor

Suelo radiante (no aplicable en el trópico)

14 Activación de elementos constructivos Solera de hormigón sin aislamiento

15 Terreno como acumulador estacional

16 Fachada norte con acristalamiento de suelo a techo 
Viendo el caso Dominicano, analizando las factibilidades y dificultades que allí se presentan se concluye que están dadas las circunstancias para encaminar un gran plan de eficiencia energética nacional.

\begin{tabular}{|c|c|c|c|}
\hline \multicolumn{4}{|c|}{ Condiciones Favorables Captacion Solar en Rep. Dominicana } \\
\hline Cliamaticas & Económicas & Sociales & Ambientales \\
\hline $\begin{array}{c}\text { Altos niveles de } \\
\text { soleamiento durante todo } \\
\text { el año que permiten un } \\
\text { excelente promedio de } \\
\text { captación radiación por los } \\
\text { colectores y sistemas } \\
\text { fotovoltaicos. }\end{array}$ & $\begin{array}{l}\text { Condiciones aptas para } \\
\text { inversión en energías } \\
\text { renovables como } \\
\text { alternativa para reducción } \\
\text { factura petrolera. Mano de } \\
\text { obra disponible para toda } \\
\text { la estructura de } \\
\text { fabricación e instalación. }\end{array}$ & $\begin{array}{l}\text { Coincidencia de dos } \\
\text { necesidades básicas a } \\
\text { resolver en un mismo } \\
\text { escenario: Falta de } \\
\text { infraestructuras y } \\
\text { equipamientos, y } \\
\text { deficiencia en el servicio } \\
\text { eléctrico. }\end{array}$ & $\begin{array}{c}\text { Voluntad política reflejada } \\
\text { en la reciente creación del } \\
\text { marco legal y } \\
\text { administrativo para la } \\
\text { protección del medio } \\
\text { ambiente. }\end{array}$ \\
\hline
\end{tabular}

Fuente: Elaboración propia

La conjugación de los factores señalados en este cuadro, hace real la posibilidad de llevar a cabo un proyecto conjunto en el orden social y en el de la eficiencia energética tomando como fuente de alimentación la radiación solar.

Los modelos arquitectónicos importados predominan en toda la geografía nacional Dominicana; la mayoría de las veces no respondiendo a las necesidades propias de la zona climática a la que pertenecen; sin embargo existe un lenguaje propio de la región, una manera de hacer arquitectura que representa unas condiciones medioambientales y una cultura propia de las Antillas; y que se presta perfectamente para la creación de una tipología eficiente que incluya elementos propios y técnicas de aprovechamiento solar integrados; como se desarrollara en los capítulos siguientes.

Se estaría planteando la real solución a gran parte de la problemática de suministro de electricidad que ha venido castigando a la población dominicana desde principios del siglo pasado; un mal endémico que ha persistido durante generaciones. También se estarían cumpliendo parte de los objetivos del milenio en materia de medio ambiente; rompiendo con la ruta negativa que nos va llevando al agotamiento de los recursos de nuestro planeta.
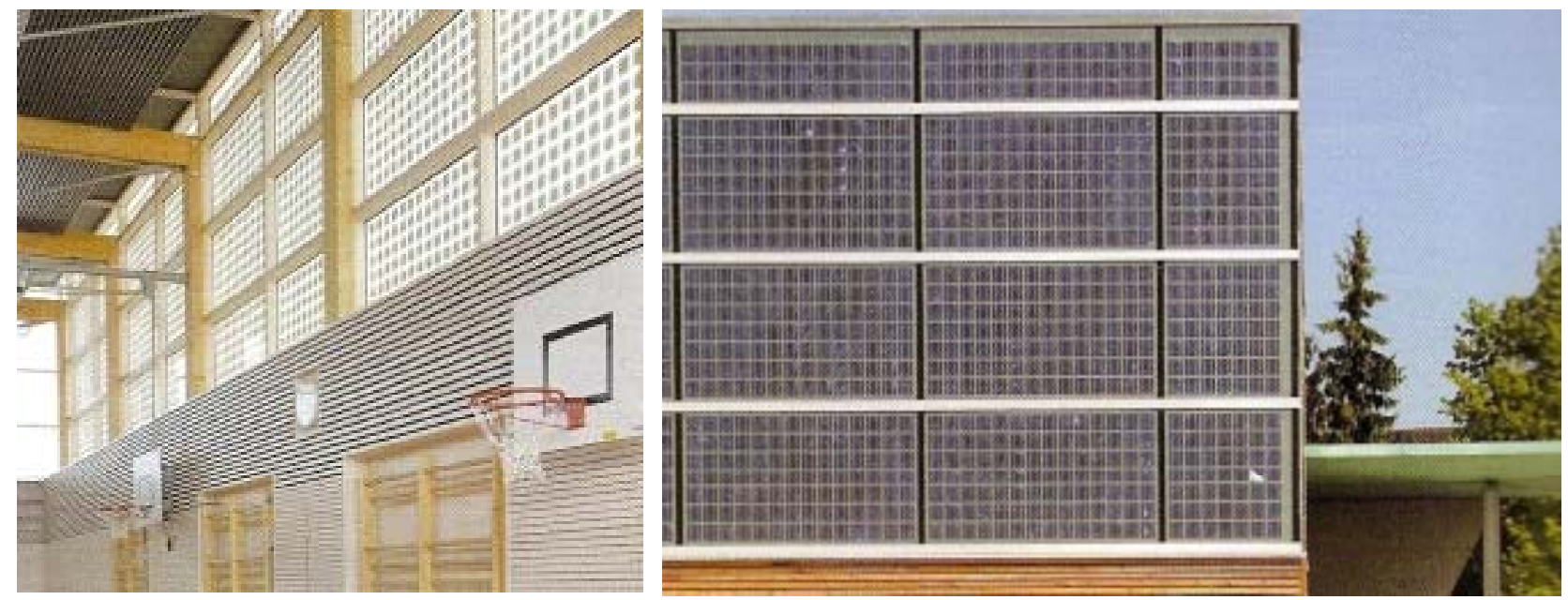

Ejemplo de equipamiento con paneles FV integrados. Polideportivo de Burgweinting, Alemania . Fuente: Detail 4, 2005 
Con estos grandes temas aun por resolver, puede parecer un asunto no tan necesario el implementar técnicas de aprovechamiento de energía para estos edificios cuando la gran mayoría de ellos están en condiciones de uso y de funcionamiento mínimas, y en muchos casos ni siquiera existen. Es decir cuando hay que resolver el problema básico de su propia existencia. Un Hospital no puede tener paneles fotovoltaicos en su fachada o cubierta, si antes no tiene camas para sus pacientes; una vivienda no puede calentar su agua caliente con energía solar, si no tiene servicio de agua corriente, o sus paredes se están cayendo; una escuela no pude pretender ser autosuficiente energéticamente cuando alguno de sus alumnos toman clases bajo una árbol todos los días.

Sin embargo las perspectivas de desarrollo deben trazarse de forma integral, incluyendo en un mismo plan los servicios básicos ( vivienda, salud, educación); es decir, la construcción o readecuación de los edificios que los alberguen y además tomar en cuenta su consumo, la manera de cubrirlo y de ser eficientes; puesto que el otro gran problema que acosa a estas sociedades emergentes - en gran medida al mundo entero en la actualidad- y que se combina con sus otras precariedades, es el del suministro de energía.

La tendencia a seguir, es que todo organismo arquitectónico que cumpla su función social, no solo genere de manera sostenible la energía que consume, sino que pueda aportar algo al sistema energético general, y por demás al medio ambiente que se beneficiaria con el ahorro y aprovechamiento consecuente. Por ejemplo, La luz que haría falta para iluminar un aula de clases podría ser suplida por paneles fotovoltaicos integrados a la piel de la misma escuela; el ACS necesaria en el hospital o centro de salud primario, podría ser calentada por colectores colocados para tales fines en un área de la planta física del edificio.

Se pueden plantear varias soluciones de diseño que a la vez de solventar las deficiencias que en materia de servicios elementales persisten, incluyan sistemas de aprovechamiento solar con las aspiraciones de reducción de las emisiones de CO2. Soluciones que ayuden a afrontar la crisis energética -a escala social y económica- que siempre a mermado las posibilidades de desarrollo de los países menos ricos, y que ahora se ha generalizado a todo el mundo con la posible escasez futura y aumento actual del precio del crudo a niveles históricos; situación esta ultima que debilita las economías de los estados nos productores.

Las posibilidades de llevar a acabo estas soluciones, aumentan en países como la República Dominicana, dada sus excelentes condiciones climáticas, y el buen ambiente para la inversión del tipo de MDL por parte de los países industrializados que han superado sus respectivas cuotas de emisiones de toneladas de $\mathrm{CO} 2$ al año.

También es favorable el ambiente socioeconómico para la instalación de fabricas de paneles y colectores solares bajo la modalidad de Zonas Francas Tecnológicas por el bajo costo de la mano de obra y la ubicación geográfica de la isla en términos estratégicos para la exportación hacia otros países de Norte América, Centro América y el Caribe. Esto comienza a llevarse a cabo de manera tímida, pero con buenas proyecciones por algunas compañías europeas, lo que repercutiría en el bienestar de las poblaciones donde se lleve a cabo y para la economía nacional, tal y como ocurrió a mediados de los años 80 con el "Boom" las factorías de textiles internacionales afincadas en Dominicana.

En conclusión, los beneficios que representaría un plan de aplicación de las tecnologías de generación energética por medios sostenibles ( con énfasis en la solar), están fuera de dudas y van mas allá de los aspectos meramente técnicos, entrando en los de índole ambiental, social, y económicos de una nación con grandes posibilidades y proyecciones de desarrollo y el perfil de muchas otras de su tipo en el área o en zonas climáticas parecidas. 
Como se ha citado antes la ley 57-07, es el marco normativo y regulatorio básico de aplicación nacional, que busca fomentar y establecer los controles para el desarrollo y la inversión en proyectos que aprovechen cualquier fuente de energía renovable y que procuren acogerse a dichos incentivos.

Dentro de los objetivos de esta Ley están, diversificar y aumentar la capacidad energética no convencional del país, reduciendo a su vez la dependencia de combustibles fósiles importados, con los beneficios ecológicos y económicos que esta supone.

Demostrando antes viabilidad física, técnica, medioambiental y financiera; todos los proyectos públicos, privados, mixtos, corporativos con instalaciones de producción de energías renovables, estarían dentro del ámbito de aplicación de la ley ( ver Art. 5 ).

Quien traza la política del Estado Dominicano en el sector energía, y es responsable de dar seguimiento al cumplimiento de la presente ley es La Comisión Nacional de Energía (CNE) que fue creada conforme al Artículo 7 de la ley General de Electricidad No.12501,del 26 de julio del 2001. También es esta comisión quien recomienda a las autoridades fiscales la exención del $100 \%$ de todos los impuestos de importación y del Impuesto de Transferencia a los Bienes Industrializados y Servicios (ITBIS), además de los impuestos a la venta final.

Otro de los incentivos importantes que legalmente se concede a la producción de energía limpia es la liberalización por un período de diez años años y hasta el 2020, del pago del impuesto sobre la renta sobre los ingresos derivados de la generación y venta de electricidad, agua caliente, generados a base de fuentes renovables.

Una Instalación fotovoltaica en República Dominicana, integrada a algún edificio determinado; necesariamente tendría como función primaria el suministro propio de la energía que las grandes compañías generadoras dejan de servirle a causa de los constantes cortes en el servicio; pero a su vez, las empresas distribuidoras están obligadas a comprar los excedentes de estas instalaciones, a precios regulados por la Superintendencia de Electricidad previo estudio y recomendación del CNE, y según establece la Ley General de Electricidad.

Como se ha mencionado antes, la demanda eléctrica nacional asciende aproximadamente a $2000 \mathrm{MW}$ diarios, de los cuales se cubre - de acuerdo a estadísticas de la Superintendencia de Electricidad- poco menos del 85\%; y casi todos ellos teniendo como fuente de energía los derivados del petróleo, y en el mejor de los casos la generación de hidroeléctricas.

Según datos recogidos, entre las empresas que ofertan el servicio de venta e instalación de sistemas solares para edificaciones; la captación solar para el calentamiento de agua, ha sido la de mayor expansión desde mediados de la década de los 80 hasta la actualidad, frente a la FV de relativa reciente introducción.

Esta oferta/demanda de captadores solares sigue superando por mucha a la de paneles fotovoltaicos, como lo demuestran los planes y proyectos de instalación que tienen los principales proveedores del mercado local con el Estado Dominicano. Tal es el caso de la empresa líder del sector que proyecta el cambio de 15,000 calentadores eléctricos por solares, con una capacidad de instalación superior a 2000 unidades (de fabricación criolla), por mes a un costo de US\$200 el m².

Recientemente en el 2008 ha entrado en funcionamiento una planta de fabricación de captadores solares -de capital español- a unos $25 \mathrm{Km}$. del centro de la ciudad de Sto.Dgo.. Con esta iniciativa se espera abastecer no solo el mercado local, sino también cubrir la demanda de esta tecnología y en un futuro de fotovoltaica, en toda el área del Caribe. 


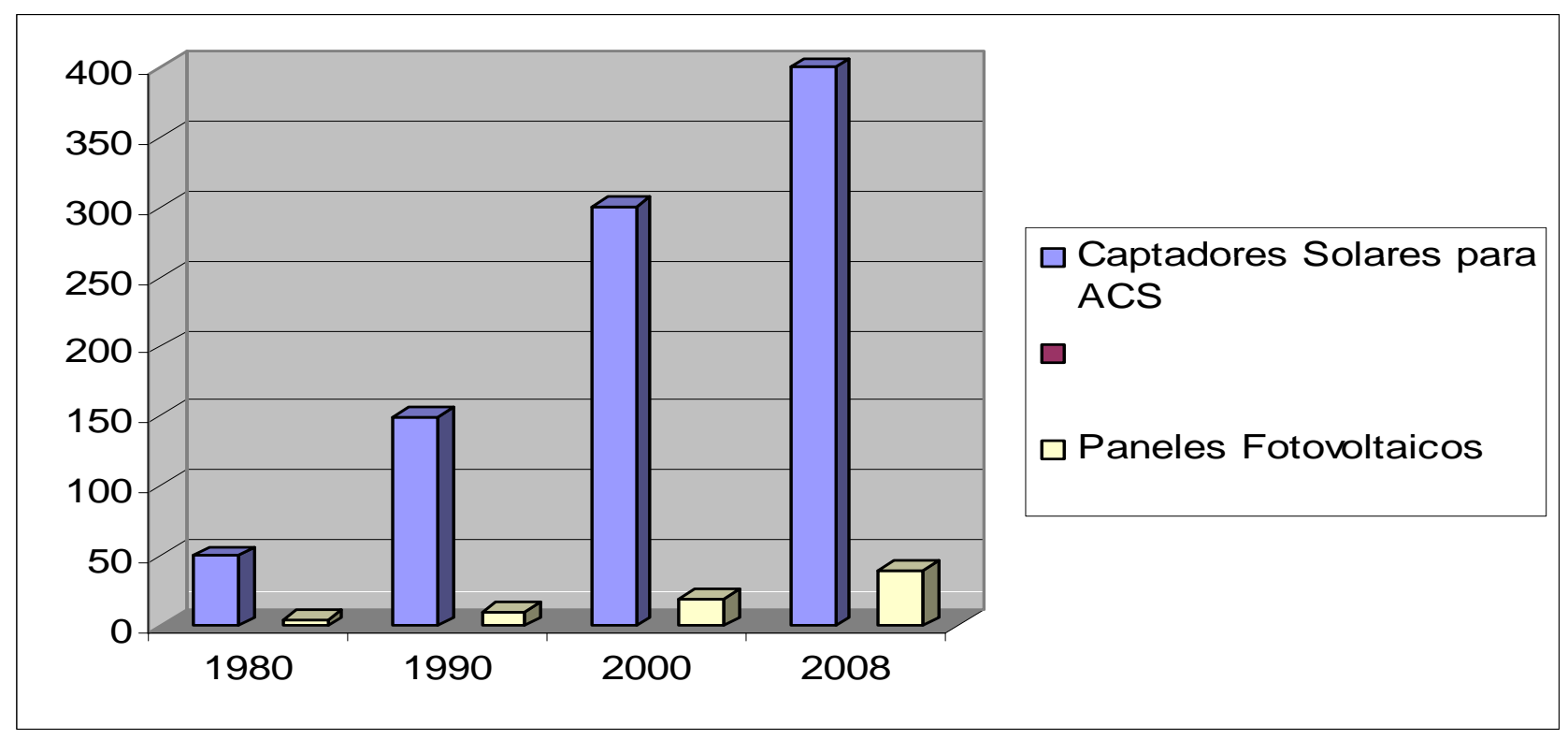

Comparativa por año de Instalación Solar para ACS y Paneles Fotovoltaicos . Fuente: Elaboración Propia

Al día de hoy, el reducido mercado local de paneles fotovoltaicos es abastecido en su totalidad por la importación de células desde el extranjero, principalmente desde España; y estas en su mayoría son del tipo monocristalinas por ser - a juicio de los importadores que las comercializan- las que mejor relación presentan entre rendimiento y precio. Esto, sujeto experimentaciones de campo podría ser comprobado o no, y ver cual tipo de célula se adapta mejor al medio, de acuerdo a datos climáticos y de temperaturas locales. Partiendo siempre de la experiencia de que con una temperatura de ideal del $25^{\circ} \mathrm{C}$, la tecnología de silicio monocristalino tiene un rendimiento de $15 \%$, la de silicio multicristalino de $11 \%$, y la de silicio amorfo un 7\%, para 1000 vatios por metro cuadrado de irradiancia solar.

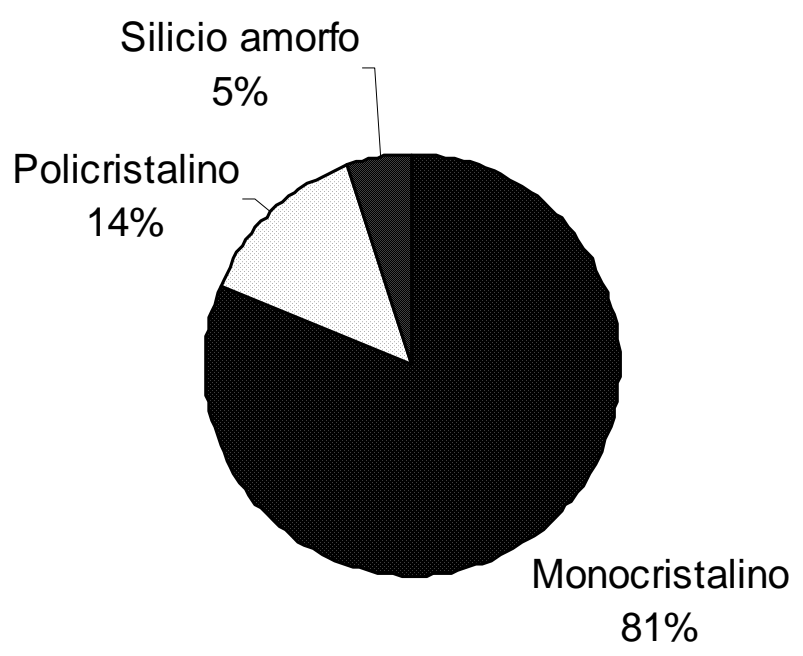

Presencia en el mercado local del tipo de célula. Fuente: E. Propia

Existen instalaciones de paneles fotovoltaicos policristalinos y amorfos, pero en una relación aproximada de 1 a 8 ; es decir que por cada 8 paneles de células monocristalinas instalados, se pone en funcionamiento uno con células policristalinos o de silicio amorfo.

Parte de este trabajo seria determinar, que tipo de célula se adapta realmente al clima local, y de que manera se integraría armónicamente con el ente arquitectónico; es decir como parte de la fachada y/o de la cubierta y con que sistema (fachada ventilada, muro cortina, superpuesto, inclinado, plano, etc. ), en cada caso; tratando de dar a cada situación una solución donde el rendimiento sea el mas alto según los criterios de temperatura, colocación con respecto su automantenimiento (limpieza), de vida útil con respecto a los fenómenos atmosféricos presentes en el área del Caribe, etc.. 
El Estado Dominicano se ha abocado a la puesta en marcha de iniciativas de producción energética mediante el uso de fuentes renovables y para ello ha ido creando un marco normativo que adecue el medio para tales fines.

La sociedad empieza a conocer los beneficios de una forma de producción de energía, y los perjuicios de otras de cara no solo al medio ambiente y todo lo que ello implica, sino también de cara a los indicadores económicos que apuntan como insostenible desde todos los puntos de vista la generación de energía a partir de los recursos fósiles actuales.

En el caso del aprovechamiento solar, la tecnología esta servida en el mundo y ya es posible pensar en muchas y múltiples maneras de utilizarlas de manera efectiva en latitudes medias como la de la región centro americana donde funciona el DR- CAFTA ( Tratado de Libre Comercio entre República Dominicana, Centro América y Estados Unidos), que permite un flujo constante en el intercambio económico y tecnológico de la zona.

Estos factores normativos, sociales, económicos y tecnológicos; que en principio se presentan favorables, son precisamente los que aun quedan pendientes de fortalecer para un desarrollo aceptable de las renovables y en especial de la fotovoltaica, tal y como se muestra en las siguientes tablas:

\begin{tabular}{|l|l|}
\hline Aspectos Normativos & \multicolumn{1}{c|}{ Estado de la Cuestion } \\
\cline { 2 - 3 } & $\begin{array}{l}\text { 1. Marco normativo ( Ley 57-07) definido en rasgos muy generales. } \\
\text { 2. Necesaria aclaración del reglamento de la Ley para su aplicación. }\end{array}$ \\
& 3. Falta de normativa completa sobre instalaciones de aprovechamiento solar, sobretodo en edificaciones. \\
& 4. Cierto grado de desconocimiento por parte de instituciones implicadas al momento de tramitación de los proyectos. \\
\hline
\end{tabular}

\begin{tabular}{|l|l|}
\hline Aspectos Sociales & \multicolumn{1}{c|}{ Estado de la Cuestión } \\
\cline { 2 - 3 } & 1. Desconocimiento por parte de los beneficiarios de las facilidades que les otorga la Ley. \\
& 2. Falta de información para la ciudadanía que podría acceder a la fotovoltaica y renovables en general. \\
& 3. Reducida participación de las instancias municipales. \\
& 4. Necesidad de promoción a nivel de los medios de comunicación de las tecnolocias solares. \\
\hline
\end{tabular}

\begin{tabular}{|l|l|}
\hline Aspectos Económicos & \multicolumn{1}{c|}{ Estado de la Cuestion } \\
\cline { 2 - 3 } & $\begin{array}{l}\text { 1. Aun con las reducciones fiscales los costos de las instalaciones son muy elevados. } \\
\text { 2. Los protocolos de compra de energia por parte de las grandes generadoras no estan del todo definidos. } \\
\text { 3. Necesidad de aumento de insentivos fiscales para la produccion de energia limpia } \\
\text { 4. Limitada financiación privada. }\end{array}$ \\
\hline
\end{tabular}

\begin{tabular}{|l|l|}
\hline Aspectos Tecnológicos & \multicolumn{1}{c|}{ Estado de la Cuestión } \\
\cline { 2 - 3 } & $\begin{array}{l}\text { 1. Dificultades para la conexión de los pequeños productores a la red general. } \\
\text { 2. Gran dependencia de las importaciones de las materias primas. } \\
\text { 3. Timido desarrollo investigacion de renovables por parte de las universidades ylo centros de formación. } \\
\text { 4. Necesidad de formacion sobre las nuevas tecnologias para los tecricos superiores. (ingenieros, arguitecos, etc). }\end{array}$ \\
\hline \hline
\end{tabular}




\title{
11. PROPUESTA PARA UNA ARQUITECTURA SOLAR
}

\author{
11.1 Técnicas y soluciones de integración en el contexto de la Arquitectura Tropical \\ Dominicana como marco de referencia.
}

\section{Arquitectura Antillana en Dominicana}

En la República Dominicana tienen presencia varios modelos arquitectónicos, fruto de las diferentes necesidades, posibilidades, y perfiles campesinos o metropolitanos de los usuario. También la importación de soluciones constructivas y espaciales y su adaptación al medio ha ido creando una forma particular de hacer las cosas.

De los modelos arquitectónicos aborígenes (unos de planta circular y techo cónico llamada caney, y otros rectangulares, con techo a dos aguas llamada bohío, algunas con galerías frontales) queda como herencia en muchos campos Dominicanos, el uso de materiales vegetales tales como yagua, cana, yarey, guano, palma, bejuco, etc. ; y en parte algunas técnicas como la fijación de postes de madera en el suelo y cañas sujetadas por cintas de bejucos, techos de palma o paja, con respiradero en lo alto, recubierto por un caballete, para la salida del aire caliente y del humo de las brasas que siempre mantenían dentro de las casas.

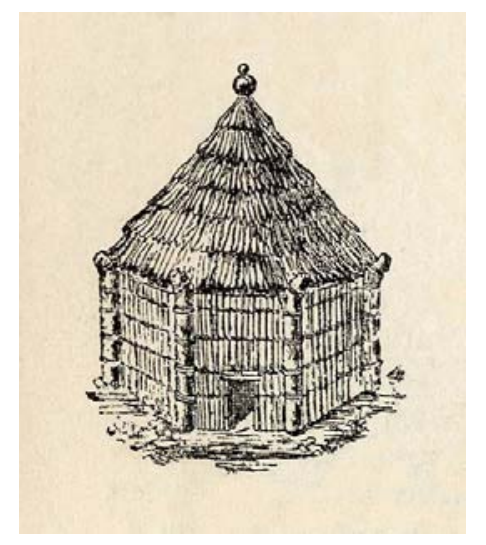

Caney Taino. Fuente: F. De Oviedo

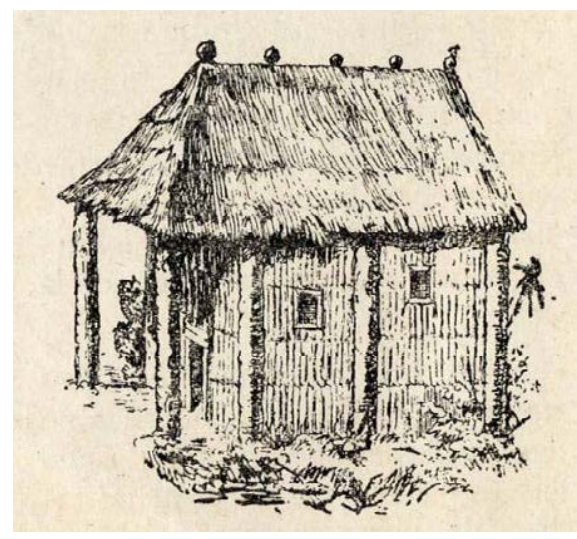

Bohío Taino. Fuente: F. De Oviedo

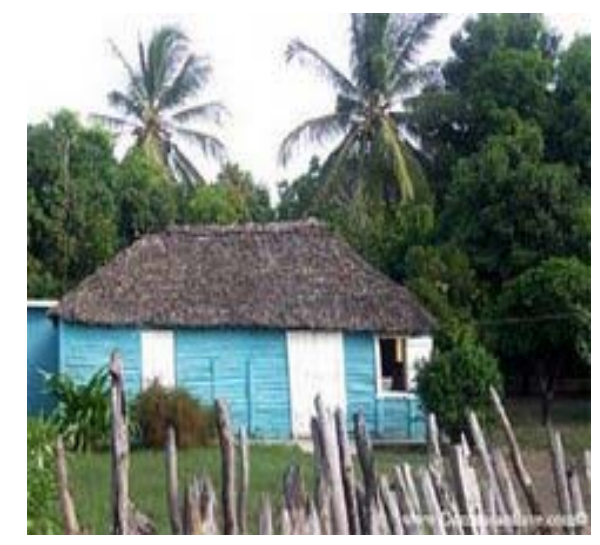

Casa rural actual. Fuente: Archivo Particular

En las localidades rurales estas casas autóctonas cuentan con un único cuerpo simple la mayoría de las veces en forma de rectángulo con pavimentos de tierra, y alguna vez de cemento pulido que se extienden al exterior de la casa a haciendo las veces de solado.

Los muros de materiales vegetales (horcones, tejamanil o tablas de palma), son pintados con pigmentos minerales en colores variados que resaltan con la luminosidad propia de esas tierras, aunque cada vez más utilizan pintura industrial.

Con el tiempo, la evolución propia de las sociedades y el incipiente desarrollo económico vienen los materiales industrializados, las formas más complejas, se comienzan a usar tragaluces de madera sobre puertas y ventanas y cresterías caladas en los aleros con motivos decorativos; y de ser construidas por los mismo usuarios, pasan a ser construidas por maestros constructores. Estos factores hacen que surja una categoría de arquitectura urbana y suburbana llamada Popular.

Este conjunto de innovaciones junto con las influencias constructivas francesas, inglesas, holandesas y de otras naciones europeas establecidas en Caribe vienen a resumirse en un nombre: Arquitectura Antillana. 
El termino Arquitectura Tropical Caribeña o Antillana comprende toda una tipología vernácula tanto en el diseño como en la ejecución, acorde con las condicionantes geográficas y culturales de la región del Gran Caribe donde esta situada la Isla de Santo Domingo.

Las corrientes o estilos predominantes que engloba y a la vez definen esta tipología son:

Victoriano: inspirado en arquitectura vernácula inglesa. Llega por el norte a Rep. Dom. a finales del siglo 19. Se caracteriza por:

- Edificaciones construidas principalmente en madera (debido al costo), y también en ladrillo.

- Estancias poliédricas con ventanas salientes.

-Abundancia en fachadas de saledizos, cornisas, aquilones, ventiladores, pórticos, balaustres.

- Calado diverso de festones de aleros, llegando hasta los topes de galerías y a fachadas laterales.

-Elementos rústicos en madera, finamente trabajados.

- Piezas de forja importadas y ensambladas aquí.

-Variantes de estilo "angloantillano" y "gingerbread" (pan de jengibre)

-Puertas y ventanas francesas, inglesas y americanas.

-Balcones con tendencias victorianas.

Vernáculo (*): Inspirado en gran medida por el victoriano y "gingerbread".

-Adornos exteriores de madera torneada (balaustres, ménsulas) o taladrada (ventiladores, tímpano de frontones, festones variados, parte superior de los tabiques separando las piezas de las casas).

-Paredes y techos forrados de tabloncillos muy trabajados.

-Puertas de persianas francesas de madera.

- Ventiladores de diseños geométricos en madera, motivo abanico, sobre las puertas.

- Introducción de planchuelas de cinc en techo y paredes.

- Las otras vertientes de techo vernáculo, era en yagua y tablitas.

Aun cuando la influencia europea es marcada, y se importan modelos desde otras latitudes, con la inclusión de soluciones "tropicalizadas" se logra le conferirle un carácter de eficiencia bastante optimo, haciendo de esta una arquitectura netamente criollo, propia de su medio.

La conjunción de factores tales como porcentaje de Humedad Relativa entorno al $100 \%$, altos niveles de pluviometría constantes, salinidad en el ambiente (sobre todo en las costas), temperaturas medias del orden de los $26^{\circ}-27^{\circ}$, presencia de tormentas durante varios meses del años; hacen que unos objetivos ( como hemos dicho antes), sean fundamentales entre muchos varios importantes a la hora de proyectar: La Ventilación y la seguridad en la edificación y los elementos que la componen; o dicho con otras palabras lo que trata de conseguirse con la aplicación de estas técnicas es favorecer la renovación constante del aire, de manera que el aire caliente y húmedo de las estancias habitadas salga rápidamente, y que a la vez ofrezcan un refugio seguro contra los frecuentes fenómenos atmosféricos.

Como todas las técnicas vernáculas, también la arquitectura Tropical Caribeña aprovecha el medio natural en beneficio de la edificación y sus habitantes, con el consecuente confort que ello implica , y sin la utilización de métodos mecánicos que ameriten un gasto de energía proveniente comúnmente de fuentes fósiles.

(*) Aquí el termino es asumido -en las Antillas- como un estilo arquitectónico. 


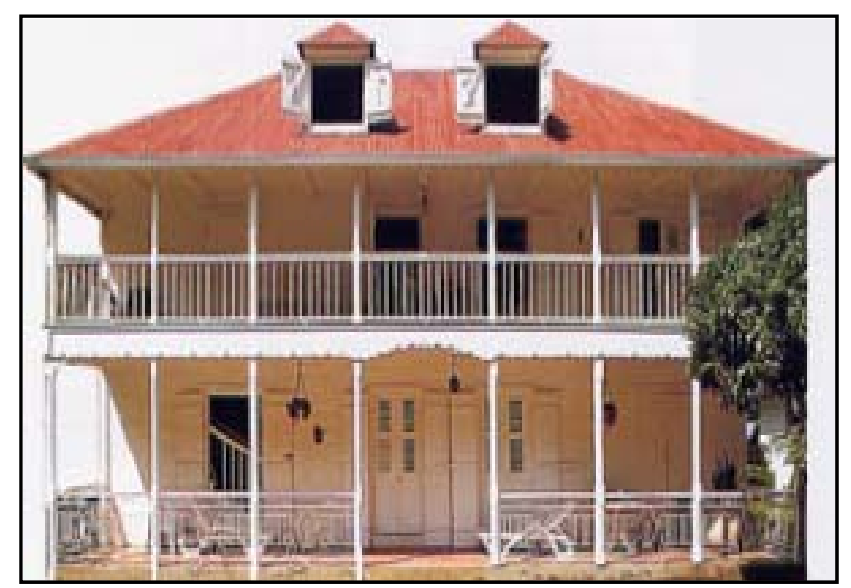

Tipología Antillana Terrazas y Ventilación en Techos y Puertas

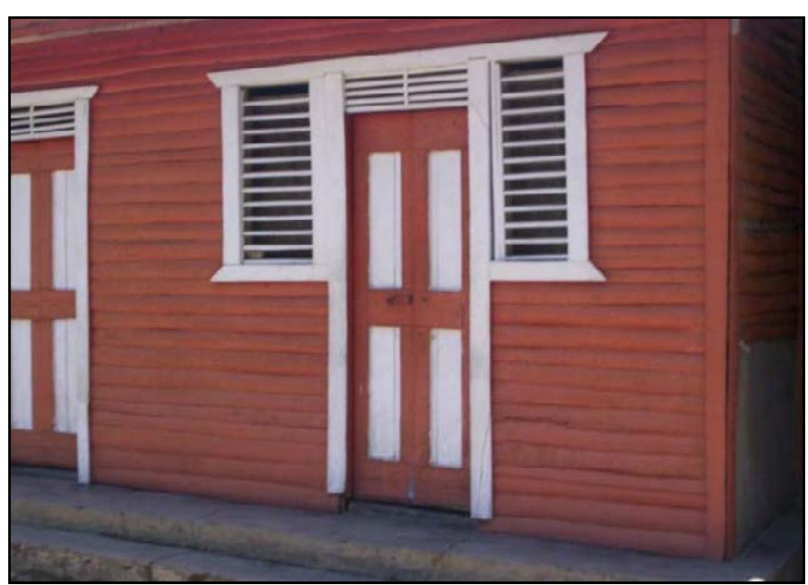

Puertas con romanillas propio de los modelos tropicales.

Partiendo de este marco, y tomando este lenguaje arquitectónico como interpretación fiel de un contexto regional, proponemos soluciones de integración Fotovoltaica y de ACS en el quehacer constructivo; fusionando soluciones tropicales con soluciones de tecnología de aprovechamiento solar.

Como hemos señalado en el Capitulo 8, la Ventilación es un objetivo de diseño primordial en estas latitudes. Con respecto a la FV es sabido que el rendimiento de los paneles va asociado en gran medida a este concepto dada la necesidad de que trabajen a temperaturas moderadas.

Con una conjugación de las técnicas constructivas vernáculas y los criterios de FV , se conseguiría una tipología de arquitectura caribeña eficiente.

\section{EJEMPLO DE INTEGRACION EN LA ENVOLVENTE (La Cubierta).}

La envolvente ligera de la Arquitectura Antillana, permite una integración de dispositivos de captación. Esto si se toman las medidas estructurales y de instalaciones adecuadas. De ahí que mencionáramos antes la Cana u hoja de palmeras, como elemento de cubierta vegetal. (*)

\section{A Favor:}

- Claramente a favor, están las prestaciones de ventilación necesarias para el buen funcionamiento de los captadores; o lo que es lo mimo, el optimo intercambio de aire interior/exterior que disipa rápidamente el calor que pudieran aportar las mismas placas fotovoltaicas.

- La rápida colocación de este tipo de cubierta; la facilidad con que sus partes pudieran ser moduladas, y hasta cierto punto industrializadas.

-Los bajos costos del material; que incluyen la recolección, su traslado ( muchas veces nulo por estar en el mimo lugar), y su colocación.

\section{En Contra:}

-Quizás el mas importante desafío para la factibilidad o rentabilidad de una instalación solar sobre este soporte, es la corta vida útil del mismo con relación a la de los paneles FV. La Cana se puede deteriorar, a causa del tiempo y los agentes climáticos, en un plazo de entre cinco a diez años. Esto no quiere decir que no pueda durar mucho mas, pero en comparación con los 25 o 30 años de vida útil de los paneles FV, sigue siendo una vida corta.

-Partiendo del contexto nacional y falta de institucionalidad imperante; puede producirse una ausencia de controles que eviten el maltrato y Deforestación por el abuso en el uso del material.

(*) Para nuestra propuesta, planteamos esta solución este combinada con otra soluciones de cerramiento de cubiertas. 


\section{EJEMPLO DE INTEGRACION EN CARPINTERIA Y CERRAJERIA}

Muchos de los modelos de carpinterías (puertas y ventanas), que se utilizan en la arquitectura tropical caribeña, adaptadas a las necesidades climáticas locales, son factibles para la adaptación de técnicas y elementos para la generación de energía solar.

En el caso de las ventanas tipo persianas o puertas con estas incorporadas ( tipo romanillas), planteamos un cambio de las simples lamas de madera o metal a unas lamas fotovoltaicas que a la vez de hacer su función primaria de regular la ventilación puedan captar la energía del sol para su posterior conversión en electricidad.

Como también se ha mencionado antes, puede darse el caso de una integración de lamas y paneles en los frontales de los balcones.

\section{A Favor:}

\section{Puertas y Ventanas}

-Al sustituir los elementos fijos o regulables de las ventanas tipo persianas y de las puertas; se aprovecha una superficie que antes tenia la única función de permitir la entrada de aire.

-Por lo naturaleza y el objetivo mismo de las lamas, la ventilación para los paneles esta garantizada no habiendo problemas de sobrecalentamiento de las mismas.

- La posibilidad de ser regulables con relación a la orientación del sol y la latitud de la isla: $18^{\circ} \mathrm{N}$.

\section{Balcones}

-Se aprovecha un espacio mas para la captación en la fachada.

-Le confiere una vistosidad al balcón mas allá de un simple panel opaco o transparente.

-Se plantea la posibilidad de paneles no fijo, sino orientables en los cerramiento de los balcones para mejor captación solar.

\section{En Contra:}

\section{Puertas y Ventanas}

-La presencia de sombras en algunas ventanas y puertas de la fachada.

-Con la falta de controles debidos, la movilidad de estos elementos puede ser perjudicial para su operatividad.

-Podría verse condicionado por el objetivo de captación el uso básico de la puerta o la ventana, que es : Abrir y Cerrar.

\section{Balcones}

-La practica común de colocar los paños fijos de los balcones a $90^{\circ}$, perjudicando la captación solar adecuada.

- La posibilidad de sobras arrojas por toldos o parasoles, ropa colgada y objetos propios o vecinos.

-El fácil acceso o contacto con los componentes del sistema captador, por parte de las personas.

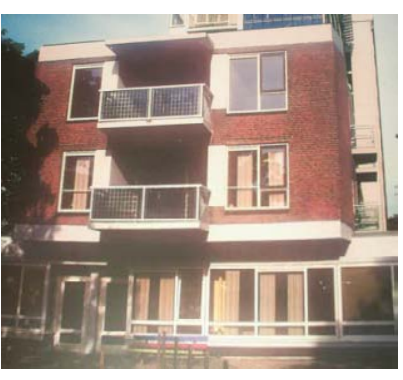

Balcones con paneles FV.
Son múltiples las soluciones factibles combinando los aspectos vernáculos de la arquitectura tropical caribeña y las tecnologías de captación solar, específicamente la fotovoltaica. Muchas de ellas se quedarían en simple ejemplos como parte de un trabajo teórico; otro podrían pasar a ser realidad, fruto de un análisis que permita comprobar lo que es posible o no. Lo cierto para cualquiera que fuera el caso- es que son un ejercicio de esperanza para un lugar como La Isla de Santo Domingo donde aun quedan muchas cosas por hacer. 


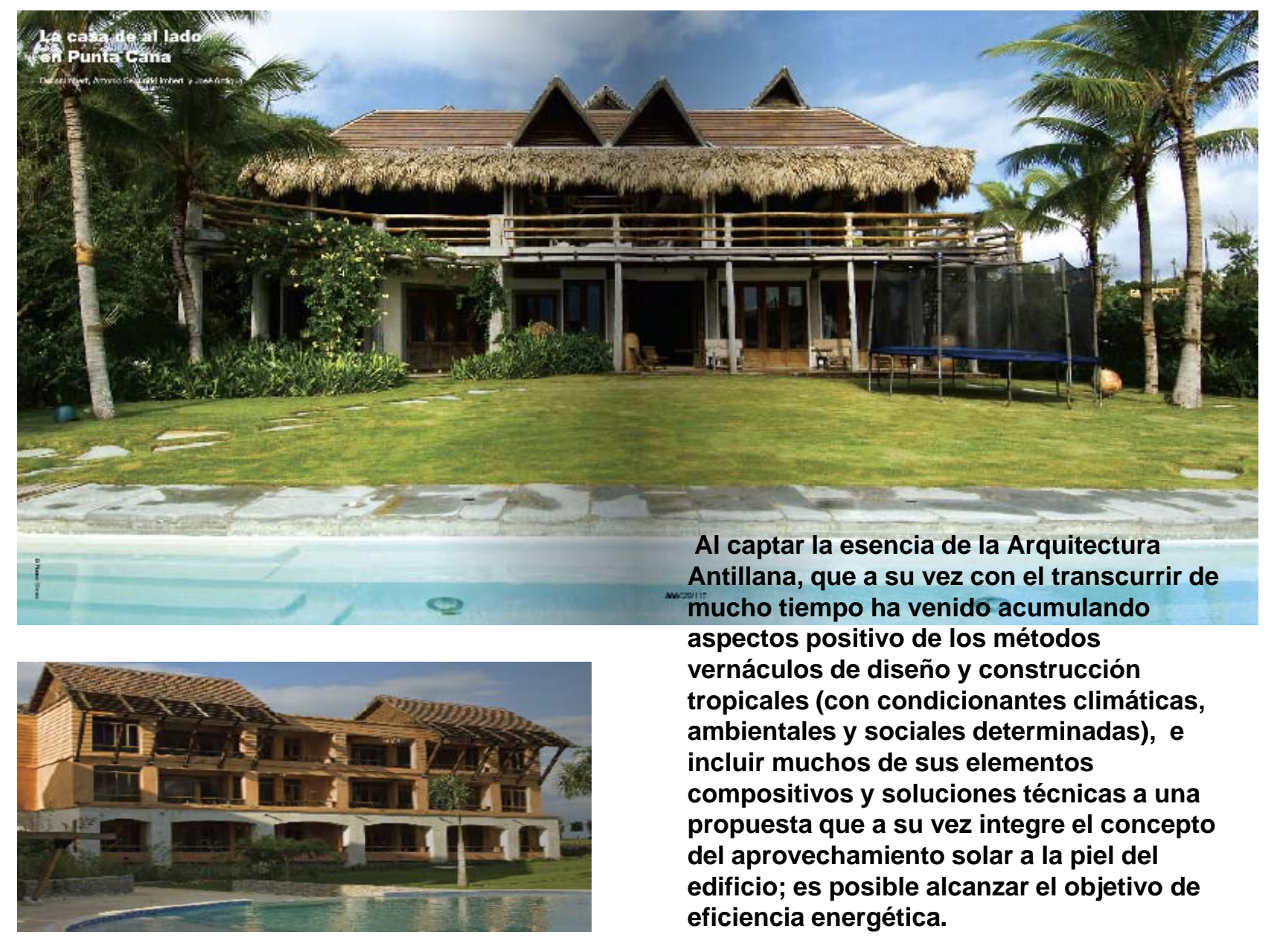

\section{Resumen PORPUESTA GENERALES:}

\section{Posibles escenarios de Actuación:}

\begin{tabular}{l|l} 
1.- Equipamientos & $\begin{array}{l}\text { De nueva planta y } \\
\text { 2.- Habitacional }\end{array}$ \\
Rehabilitaciones
\end{tabular}

Se crea una tipología fusionada que este acorde e interprete las necesidades del usuario y las realidades medioambientales de su entorno y las realidades socioeconómicas del medio.

El vehículo de expresión de esta tendencia seria según sea el caso, edificios habitacionales y/o de equipamientos, además de mobiliario urbano que estaría en torno a estos.

\title{
DESARROLLO PROPUESTA GENERALES (Diseño)
}

\author{
1.- Equipamientos \\ 2.- Habitacional \\ Integración a la piel del edificio según \\ condicionantes, lugar y tipologías. \\ Propuestas para fachada y techos
}

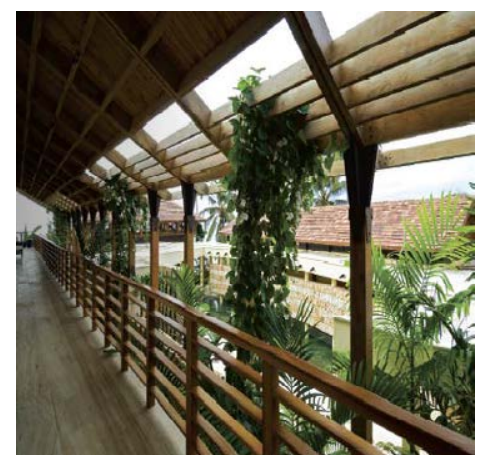




\subsection{Análisis Climático del escenario modelo. La Isla de Santo Domingo.}

Al momento de planificar y hacer una propuesta de aprovechamiento energético en el ente arquitectónico, es preciso partir tomar lo datos climatológicos y medio ambientales, para poder realizar el análisis bioclimático que conducirá a la solución optima.

Tomando la isla de Santo Domingo como escenario experimental de este trabajo, hemos realizado los estudio y análisis climáticos que nos muestran las estrategias a llevar a cabo para un diseño bioclimático y de aprovechamiento solar, que es el objeto de este trabajo.

A partir de los datos de temperaturas, humedades relativas, índices de nubosidad, nivel de precipitaciones pluviométricas, hemos podido elaborar los siguientes gráficos y tablas, como herramientas de trabajo para trazar estrategias de diseño:

\section{CUADRO DATOS ANALISIS CLIMATICO. Ver Anexo 01}

\begin{tabular}{|c|c|c|c|c|c|c|c|c|c|c|c|c|c|}
\hline \multirow[t]{4}{*}{ REP. DOMINICANA } & \multirow{2}{*}{\multicolumn{2}{|c|}{$\begin{array}{l}\text { LATITUD } \\
\text { LONGITUD }\end{array}$}} & \multicolumn{2}{|c|}{$18^{\circ} 29^{\prime} 00^{\prime \prime} \mathrm{N}$} & & & & \multirow{3}{*}{\multicolumn{3}{|c|}{ SANTO DOMINGO }} & & & \\
\hline & & & $69^{\circ} 94^{\prime} 0$ & " O & & & & & & & & & \\
\hline & \multicolumn{2}{|c|}{ ALTITUD } & \multicolumn{2}{|l|}{$14,0 \mathrm{~m}$} & & & & & & & & & \\
\hline & & ENE & FEB & MAR & ABR & MAY & JUN & JUL & AGO & SEP & OCT & NOV & DIC \\
\hline Humedad relativa media & Hrmed & 82 & 80 & 79 & 79 & 83 & 84 & 84 & 84 & 85 & 86 & 85 & 84 \\
\hline & & & & & & & & & & & & & \\
\hline Temperatura media & $\mathrm{T}$ & 24,2 & 24,1 & 24,7 & 25,4 & 26,1 & 26,7 & 26,7 & 26,9 & 27 & 26,5 & 25,8 & 24,8 \\
\hline Temperatura máxima & $\mathrm{T}_{\mathrm{M}}$ & 29,3 & 29,3 & 29,7 & 30,3 & 30,4 & 30,9 & 31,4 & 31,6 & 31,5 & 31,2 & 30,7 & 29,7 \\
\hline Temperatura mínima & $\mathrm{T}_{\mathrm{m}}$ & 19,7 & 19,8 & 20,3 & 21,2 & 22,3 & 23,0 & 22,9 & 22,8 & 22,8 & 22,4 & 21,5 & 20,4 \\
\hline Hora máxima & $\mathrm{h}_{\mathrm{M}}$ & 15,00 & 15,00 & 15,00 & 15,00 & 15,00 & 15,00 & 15,00 & 15,00 & 15,00 & 15,00 & 15,00 & 15,00 \\
\hline Hora mínima: amanecer & $\mathrm{h}_{\mathrm{m}}$ & 6,46 & 6,25 & 6,01 & 5,54 & 5,45 & 5,53 & 5,74 & 6,01 & 6,25 & 6,55 & 6,47 & 6,55 \\
\hline
\end{tabular}

Cuadro Temperaturas y Humedades. Fuente: Elaboración Propia.

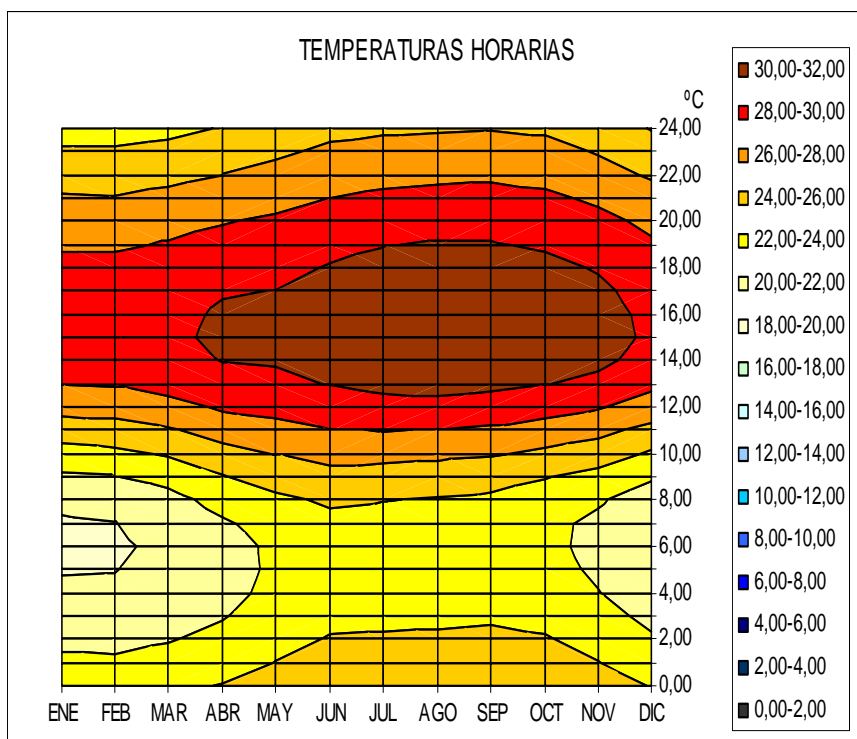

Grafico Temperaturas. Fuente: Elaboración Propia.
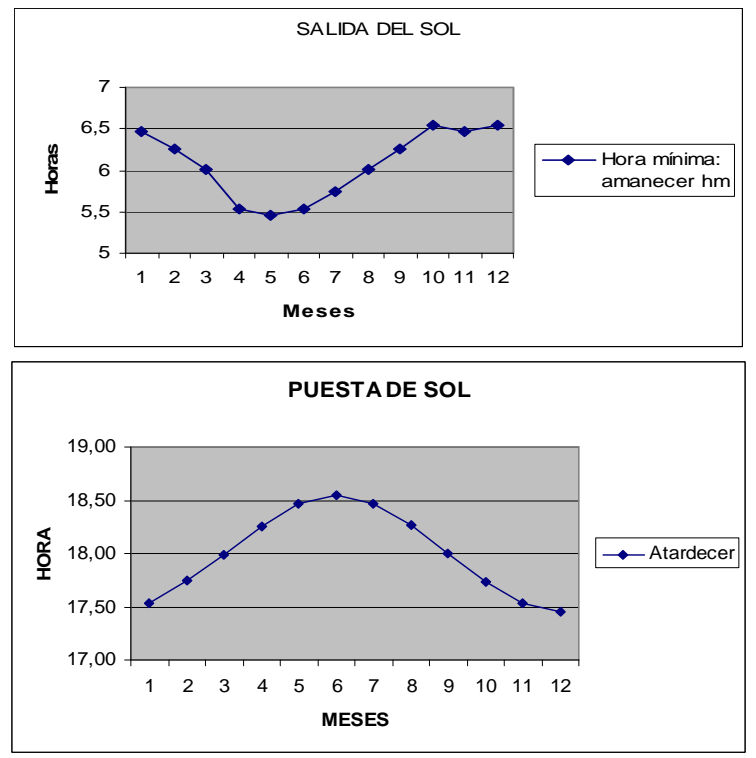

Grafico Salida y Puesta del Sol. Fuente: Elaboración Propia. 


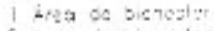

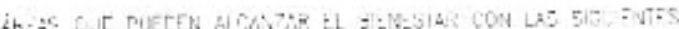

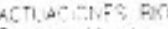

Strats leat iics

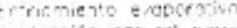

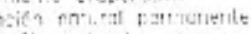

Cumber dos icternas

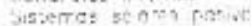

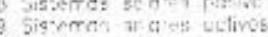

in $\mathrm{HL}_{2}+\mathrm{riv}$ ticiog

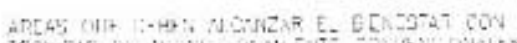

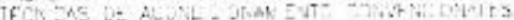

1 be nyerc:ser

$2 \operatorname{coc} \times=x$

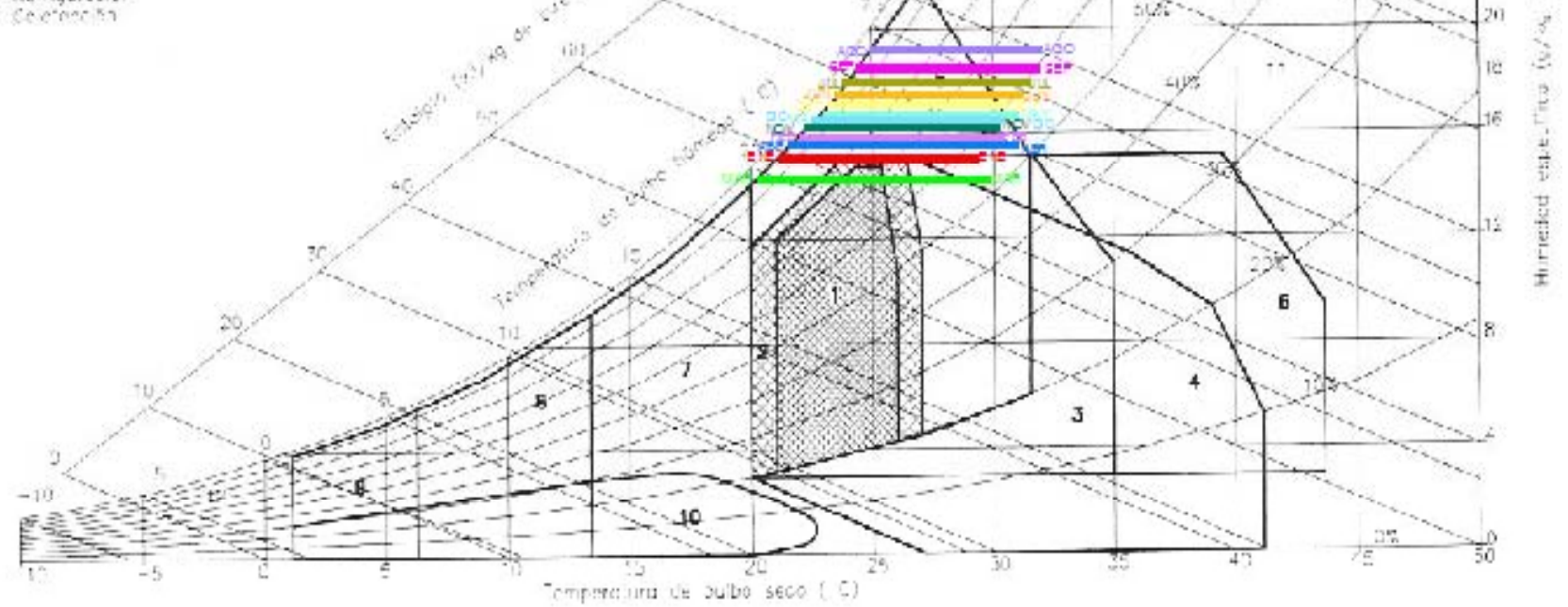

Climogramo de bienesta de Givon 


\section{CARTA SOLAR $18^{\circ} 29^{\prime}$.}
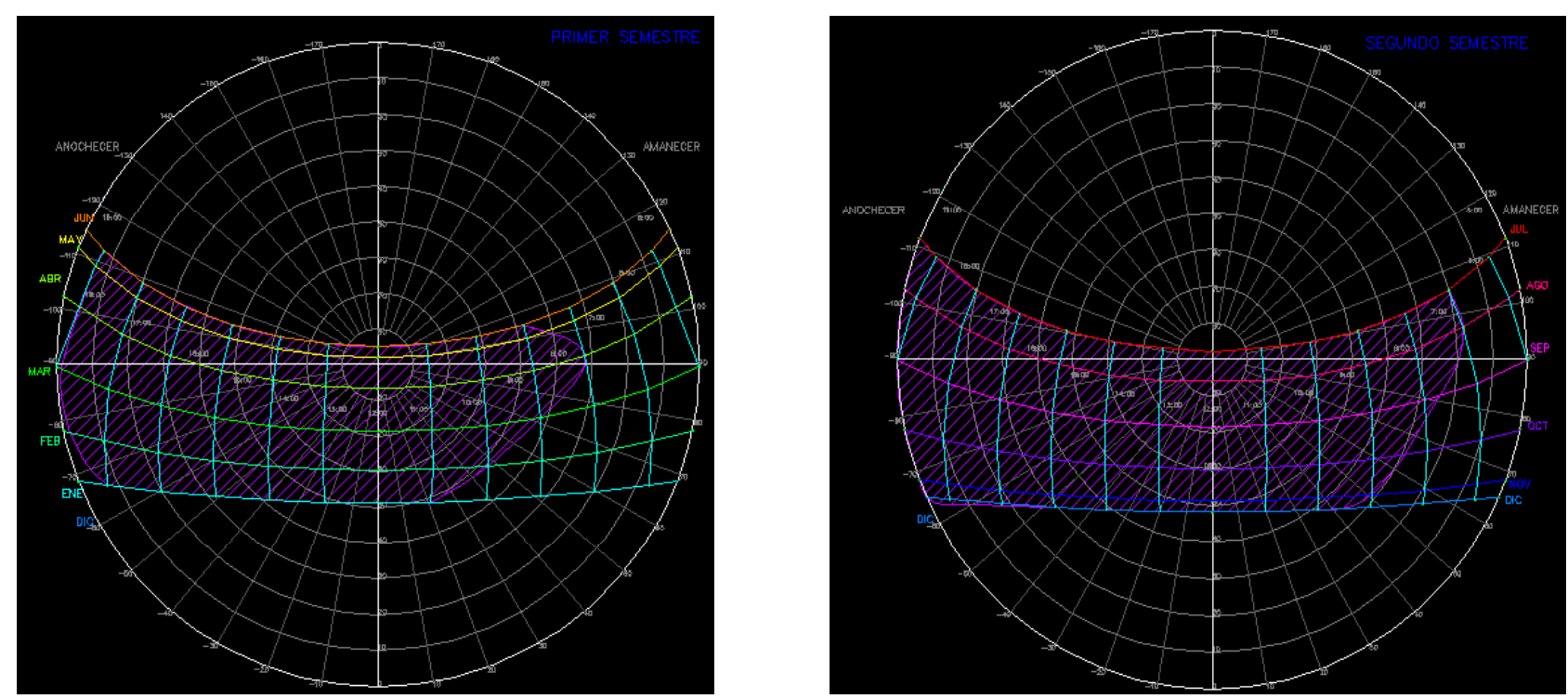

Carta Solar Estereográfica $18^{\circ} 29^{\prime}$ norte. Fuente: Elaboración Propia.

\begin{tabular}{|c|c|c|c|c|c|c|c|c|c|c|c|c|c|c|c|c|}
\hline ALTURA & & & & & & & & & & & & & & & & \\
\hline & 5,00 & 6,00 & 7,00 & 8,00 & 9,00 & 10,00 & 11,00 & 12,00 & 13,00 & 14,00 & 15,00 & 16,00 & 17,00 & 18,00 & 19,00 & \\
\hline ENE & $-19,8017$ & $-6,2026$ & 7,0465 & 19,7351 & 31,4863 & 41,6026 & 48,8522 & 51,5720 & 48,8522 & 41,6026 & 31,4863 & 19,7351 & 7,0465 & $-6,2026$ & $-19,8017$ & 6,46 \\
\hline 21-ene & 74,5509 & 70,8032 & 66,0326 & 59,7482 & 51,1235 & 38,8864 & 21,6720 & 0,0000 & $-21,6720$ & $-38,8864$ & $-51,1235$ & $-59,7482$ & $-66,0326$ & $-70,8032$ & $-74,5509$ & 68,7400 \\
\hline FEB & $-17,5861$ & $-3,5028$ & 10,3665 & 23,8635 & 36,6868 & 48,1972 & 56,9801 & 60,4837 & 56,9801 & 48,1972 & 36,6868 & 23,8635 & 10,3665 & $-3,5028$ & $-17,5861$ & 6,25 \\
\hline 21-feb & 83,6653 & 79,3275 & 74,4006 & 68,2580 & 59,8716 & 47,3712 & 27,7666 & 0,0000 & $-27,7666$ & $-47,3712$ & $-59,8716$ & $-68,2580$ & $-74,4006$ & $-79,3275$ & $-83,6653$ & 78,1680 \\
\hline MAR & $-14,3561$ & $-0,1267$ & 14,0948 & 28,1978 & 42,0020 & 55,0891 & 66,1907 & 71,3063 & 66,1907 & 55,0891 & 42,0020 & 28,1978 & 14,0948 & $-0,1267$ & $-14,3561$ & 6,01 \\
\hline 21-mar & 94,4124 & 89,6167 & 84,7996 & 79,3022 & 72,0847 & 60,8847 & 39,8746 & 0,0000 & $-39,8746$ & $-60,8847$ & $-72,0847$ & $-79,3022$ & $-84,7996$ & $-89,6167$ & $-94,4124$ & 89,5749 \\
\hline$A B R$ & $-10,2388$ & 3,6115 & 17,6820 & 31,8751 & 46,1133 & 60,2884 & 74,0400 & 83,2890 & 74,0400 & 60,2884 & 46,1133 & 31,8751 & 17,6820 & 3,6115 & $-10,2388$ & 5,74 \\
\hline $21-a b r$ & 105,9335 & 101,0087 & 96,6909 & 92,4877 & 87,7833 & 81,2180 & 67,2381 & 0,0000 & $-67,2381$ & $-81,2180$ & $-87,7833$ & $-92,4877$ & $-96,6909$ & $-101,0087$ & $-105,9335$ & 102,2044 \\
\hline MAY & $-7,0465$ & 6,2026 & 19,8017 & 33,6255 & 47,5940 & 61,6484 & 75,7207 & 88,1520 & 75,7207 & 61,6484 & 47,5940 & 33,6255 & 19,8017 & 6,2026 & $-7,0465$ & 5,54 \\
\hline 21-may & 113,9674 & 109,1968 & 105,4491 & 102,4539 & 100,1244 & 98,6868 & 99,8722 & 0,0000 & $-99,8722$ & $-98,6868$ & $-100,1244$ & $-102,4539$ & $-105,4491$ & $-109,1968$ & $-113,9674$ & 111,2600 \\
\hline JUN & $-5,7715$ & 7,1742 & 20,5077 & 34,0846 & 47,8013 & 61,5517 & 75,0757 & 84.8402 & 75,0757 & 61,5517 & 47,8013 & 34,0846 & 20,5077 & 7,1742 & $-5,7715$ & 5,45 \\
\hline 21-jun & 117,0432 & 112,3846 & 108,8959 & 106,4035 & 105,0362 & 105,6502 & 112,7860 & 0,0000 & $-112,7860$ & $-105,6502$ & $-105,0362$ & $-106,4035$ & $-108,8959$ & $-112,3846$ & $-117,0432$ & 114,7790 \\
\hline JUL & $-6,9305$ & 6,2925 & 19,8692 & 33,6728 & 47,6217 & 61,6543 & 75,6916 & 87,8485 & 75,6916 & 61,6543 & 47,6217 & 33,6728 & 19,8692 & 6,2925 & $-6,9305$ & 5,53 \\
\hline 21-jul & 114,2499 & 109,4885 & 105,7636 & 102,8140 & 100,57 & 99,3259 & 101,0958 & 0,0000 & $-101,0958$ & 259 & -100, & $-102,8140$ & $-105,7636$ & $-109,4885$ & $-114,2499$ & 111,5821 \\
\hline$A G O$ & $-10,1753$ & 3,6654 & 17,7293 & 31,9187 & 46,1566 & 60,3382 & 74,1178 & 83,4641 & 74,1178 & 60,3382 & 46,1566 & \begin{tabular}{|l|}
31,9187 \\
\end{tabular} & 17,7293 & 3,6654 & $-10,1753$ & 5,74 \\
\hline 21-ago & 106,0993 & 101,1756 & 96,8678 & 92,6874 & 88,0281 & 81,5568 & 67,8099 & 0,0000 & $-67,8099$ & $-81,5568$ & $-88,0281$ & $-92,6874$ & $-96,8678$ & $-101,1756$ & $-106,0993$ & 102,3892 \\
\hline SEP & $-14,2910$ & $-0,0633$ & 14,1604 & 28,2703 & 42,0882 & 55,2014 & 66,3505 & 71,5082 & 66,3505 & 55,2014 & 42,0882 & 28,2703 & 14,1604 & $-0,0633$ & $-14,2910$ & 6,00 \\
\hline 21-sep & 94,6096 & 89,8084 & 84,9964 & 79,5160 & 72,3304 & 61,1781 & 40,1809 & 0,0000 & $-40,1809$ & $-61,1781$ & $-72,3304$ & $-79,5160$ & $-84,9964$ & $-89,8084$ & $-94,6096$ & 89,7874 \\
\hline OCT & $-17,7293$ & $-3,6654$ & 10,1753 & 23, & & & & 59,9559 & 5083 & & & & 1753 & & & \\
\hline 21-oct & 83,1322 & 78,8244 & 73,9007 & 67,7400 & 3226 & 46,8113 & 27,3352 & 0,0000 & $-27,3352$ & $-46,8113$ & $-59,3226$ & $-67,7400$ & $-73,9007$ & $-78,8244$ & $-83,1322$ & 77,6108 \\
\hline Nov & $-19,8692$ & $-6,2925$ & 6,9305 & 19,5872 & 31,2989 & 41,3678 & 48,5705 & 51,2685 & 48,5705 & 41,3678 & 31,2989 & 19,5872 & 6,9305 & $-6,2925$ & $-19,8692$ & 6,47 \\
\hline 21-nov & 74,2364 & 70,5115 & 65,7501 & 59,4667 & 50,8439 & 38,6297 & 21,5008 & 0,0000 & $-21,5008$ & $-38,6297$ & $-50,8439$ & $-59,4667$ & $-65,7501$ & $-70,5115$ & $-74,2364$ & 68,4179 \\
\hline DIC & $-20,5077$ & $-7,1742$ & 5,7715 & 18,0981 & 29,4095 & 39,0115 & 45,7659 & 48,2602 & 45,7659 & 39,0115 & 29,4095 & 18,0981 & 5,7715 & $-7,1742$ & $-20,5077$ & 6,55 \\
\hline 21-dic & 71,1041 & 67,6154 & 62,9568 & 56,7047 & 48,1308 & 36,1810 & 19,8997 & 0,0000 & $-19,8997$ & $-36,1810$ & $-48,1308$ & $-56,7047$ & $-62,9568$ & $-67,6154$ & $-71,1041$ & 65,2210 \\
\hline
\end{tabular}

Cuadro de Altura Solar y Acimut. Fuente: Elaboración Propia.

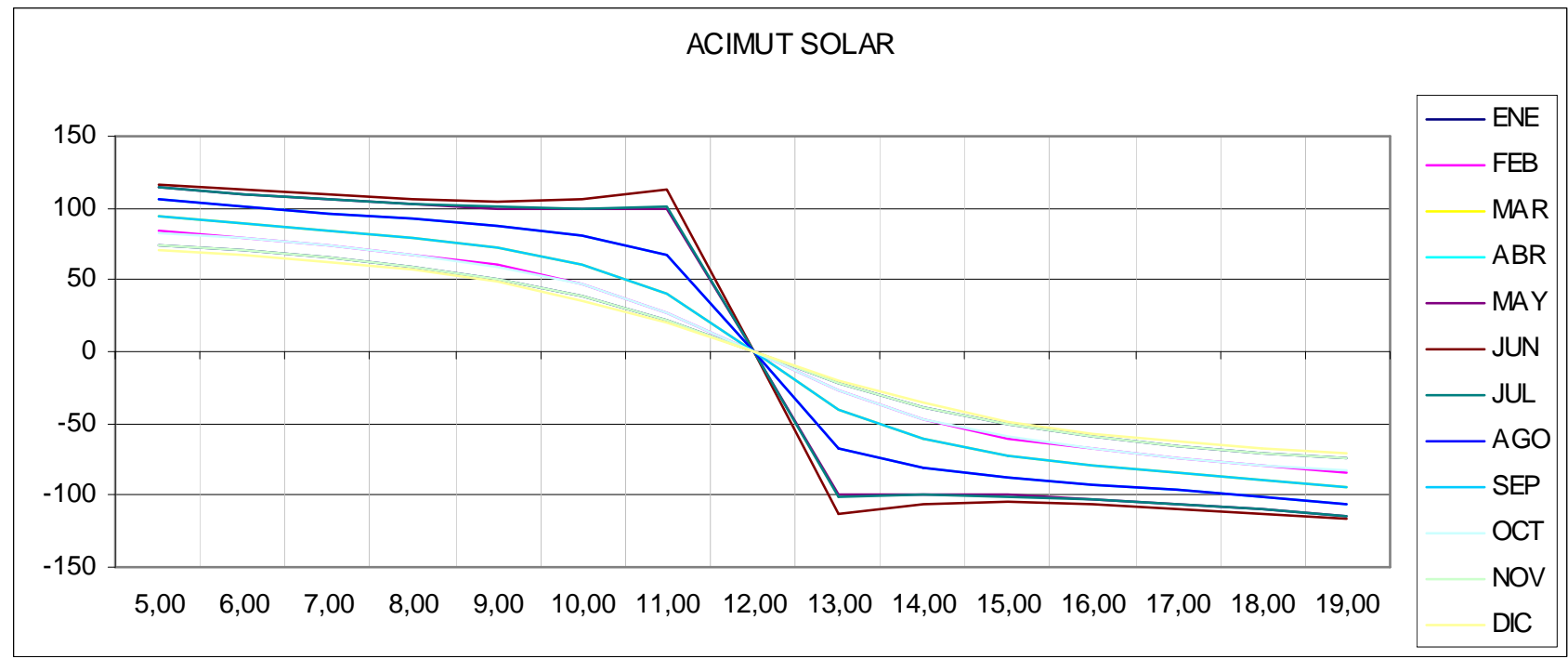

Grafico Acimut Solar. Fuente: Elaboración Propia. 
Por medio de las cartas solares y los cuadros anteriores, podemos determinar la altura solar y acimut, y diseñar los tipos y disposiciones de protecciones de sombra correspondientes a la latitud del lugar. La altura solar en el Solsticio de verano ( 21 de junio), es $84,84^{\circ}$ y la altura en el Solsticio de Invierno ( 21 de enero), es $51,57^{\circ}$.

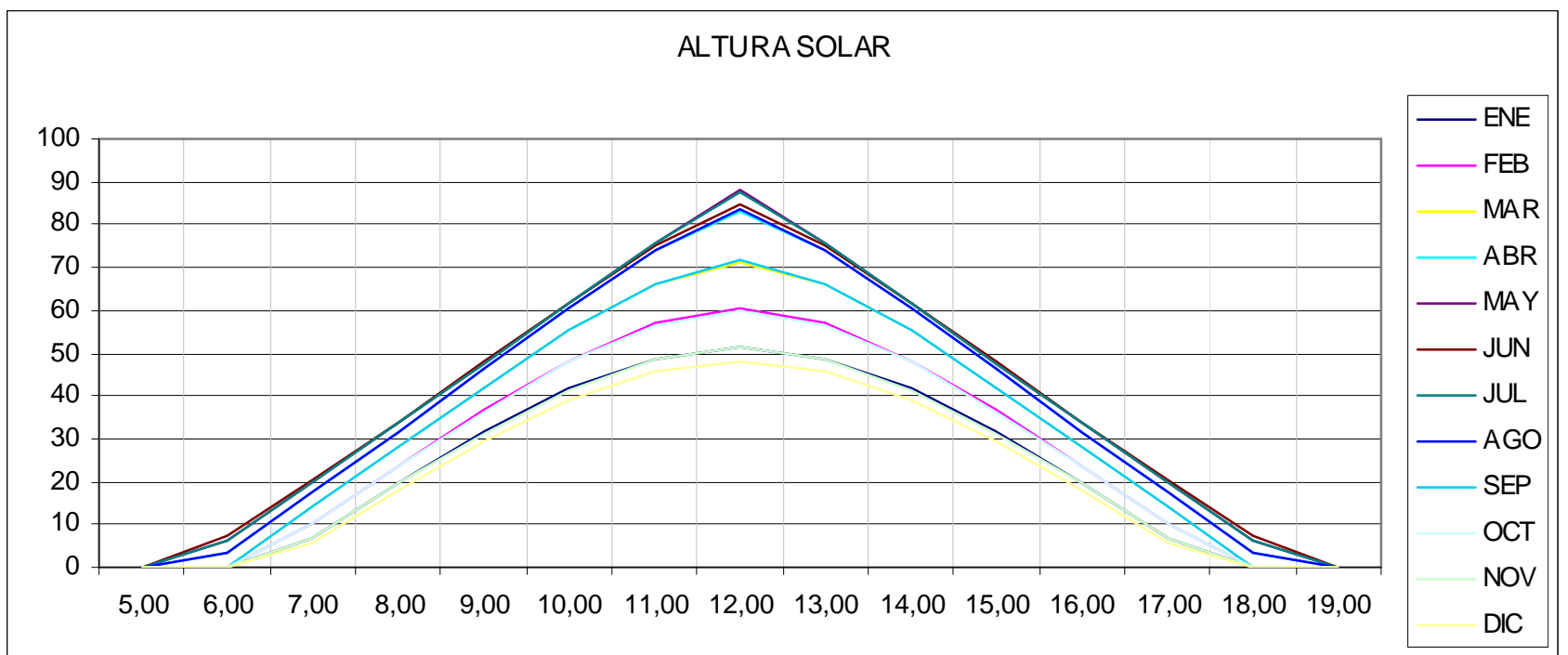

Grafico de Altura Solar. Fuente: Elaboración Propia.

\section{CALCULO DE LA IRRADIANCIA SOLAR A PARTIR DEL INDICE DE NUBOSIDAD}

\begin{tabular}{|c|c|c|c|c|c|c|c|c|c|c|c|c|}
\hline Localidad: & \multicolumn{5}{|c|}{ SANTO DOMINGO } & & & & & & & \\
\hline Latitud: & 18,29 & $\circ$ & & & & & & & & & & \\
\hline Altitud: & 14 & $\mathbf{m}$ & & & & & & & & & & \\
\hline Día de cálculo del mes: & 15 & & & & & & & & & & & \\
\hline & ENE & FEB & MAR & ABR & MAY & JUN & JUL & AGO & SEP & OCT & NOV & DIC \\
\hline Índice de nubosidad & 0,48 & 0,49 & 0,49 & 0,52 & 0,61 & 0,62 & 0,60 & 0,57 & 0,60 & 0,57 & 0,51 & 0.55 \\
\hline
\end{tabular}

\begin{tabular}{|c|c|c|c|c|c|c|c|c|c|c|c|c|c|c|c|c|c|c|}
\hline LATITUD: & 18,29 & ${ }^{0} \mathrm{NO}$ & RTE & & SAN & O DC & MIN & & & & & & & & & & & \\
\hline ALTITUD: & 14 & & & & & & & & & & & & & & & & & \\
\hline DÍA 15 DEL MES & CON EL IINDIC & EDEN & UBOSID & AD MED & & & & & & & & & & & & & & \\
\hline INCLINADA: IGU & LALALATIT & $\mathrm{JD}(\mathrm{AS}$ & JR) & & IRRADIA & NCIA M & EDIA HC & RARIAS & OBRE S & UPERF & $\mathrm{CIE}(\mathrm{W}$ & & & & & & & \\
\hline ENERO & hora sola & $05: 00$ & $06: 00$ & 07:00 & 08:00 & 09:00 & $10: 00$ & $11: 00$ & $12: 00$ & $13: 00$ & $14: 00$ & $15: 00$ & $16: 00$ & $17: 00$ & 18:00 & $19: 00$ & & \\
\hline & \begin{tabular}{|l|} 
NORTE \\
\end{tabular} & 0 & 0 & 59 & 80 & 100 & 117 & 129 & 133 & 129 & 117 & 100 & 80 & 59 & 0 & 0 & 1102 & Wh \\
\hline & SUR & 0 & 0 & 127 & 240 & 325 & 387 & 427 & 440 & 427 & 387 & 325 & 240 & 127 & 0 & 0 & 3452 & Wh \\
\hline & ESTE & 0 & 0 & 205 & 343 & 369 & 328 & 243 & 133 & 129 & 117 & 100 & 80 & 59 & 0 & 0 & 2106 & Wh \\
\hline & OESTE & 0 & 0 & 59 & 80 & 100 & 117 & 129 & 133 & 243 & 328 & 369 & 343 & 205 & 0 & 0 & 2106 & Wh \\
\hline & CUBIERTA & 0 & 0 & 137 & 268 & 409 & 529 & 609 & 638 & 609 & 529 & 409 & 268 & 137 & 0 & 0 & 4541 & Wh \\
\hline & INCLINADA & 0 & 0 & 154 & 308 & 464 & 593 & 679 & 709 & 679 & 593 & 464 & 308 & 154 & 0 & 0 & 5105 & Wh \\
\hline FEBRERO & hora solat & 05:00 & $06: 00$ & 07:00 & $08: 00$ & 09:00 & $10: 00$ & 11:00 & 12:00 & 13:00 & 14:00 & $15: 00$ & 16:00 & $17: 00$ & 18:00 & $19: 00$ & & \\
\hline & \begin{tabular}{|l|} 
NORTE \\
\end{tabular} & 0 & 0 & 65 & 88 & 109 & 128 & 142 & 147 & 142 & 128 & 109 & 88 & 65 & 0 & 0 & 1210 & Wh \\
\hline & SUR & 0 & 0 & 127 & 216 & 291 & 350 & 388 & 402 & 388 & 350 & 291 & 216 & 127 & 0 & 0 & 3147 & Wh \\
\hline & ESTE & 0 & 0 & 262 & 380 & 398 & 351 & 263 & 147 & 142 & 128 & 109 & 88 & 65 & 0 & 0 & 2333 & Wh \\
\hline & OESTE & 0 & 0 & 65 & 88 & & 128 & 142 & 147 & 263 & 351 & 398 & 380 & 262 & 0 & 0 & 2333 & Wh \\
\hline & CUBIERTA & 0 & 0 & 165 & 311 & 462 & 590 & 677 & 709 & 677 & 590 & 462 & 311 & 165 & 0 & 0 & 5118 & Wh \\
\hline & INCLINADA & 0 & 0 & 180 & 340 & 501 & 636 & 727 & 760 & 727 & 636 & 501 & 340 & 180 & 0 & 0 & 5529 & Wh \\
\hline MARZO & hora solat & 05:00 & $06: 00$ & 07:00 & $08: 00$ & 09:00 & $10: 00$ & 11:00 & $12: 00$ & 13:00 & $14: 00$ & 15:00 & 16:00 & 17:00 & 18:00 & 19:00 & & \\
\hline & \begin{tabular}{|l|} 
NORTE \\
\end{tabular} & 0 & 0 & 71 & 95 & 118 & 139 & 157 & 165 & 157 & 139 & 118 & 95 & 71 & 0 & 0 & 1327 & \\
\hline & SUR & 0 & 0 & 104 & 171 & 235 & 289 & 328 & 343 & 328 & 289 & 235 & 171 & 104 & 0 & 0 & 2595 & Wh \\
\hline & ESTE & 0 & 0 & 316 & 417 & 425 & 374 & 283 & 165 & 157 & 139 & 118 & 95 & 71 & 0 & 0 & 2562 & \\
\hline & OESTE & 0 & 0 & 71 & 95 & 118 & 139 & 157 & 165 & 283 & 374 & 425 & 417 & 316 & 0 & 0 & 2562 & Wh \\
\hline & CUBIERTA & 0 & 0 & 201 & 361 & 521 & 658 & 754 & 791 & 754 & 658 & 521 & 361 & 201 & 0 & 0 & 5780 & \\
\hline & INCLINADA & 0 & 0 & 205 & 371 & 537 & 679 & 777 & 815 & 777 & 679 & 537 & 371 & 205 & 0 & 0 & 5953 & \\
\hline
\end{tabular}




\begin{tabular}{|c|c|c|c|c|c|c|c|c|c|c|c|c|c|c|c|c|c|c|}
\hline \multirow[t]{7}{*}{ ABRIL } & hora solal & $05: 00$ & $06: 00$ & $07: 00$ & $08: 00$ & 09:00 & $10: 00$ & 11:00 & $12: 00$ & $13: 00$ & $14: 00$ & $15: 00$ & $16: 00$ & $17: 00$ & $18: 00$ & $19: 00$ & & \\
\hline & \begin{tabular}{|l|} 
NORTE \\
\end{tabular} & 0 & 65 & 101 & 105 & 129 & 152 & 175 & 189 & 175 & 152 & 129 & 105 & 101 & 65 & 0 & 1642 & Wh \\
\hline & SUR & 0 & 57 & 81 & 105 & 155 & 203 & 241 & 260 & 241 & 203 & 155 & 105 & 81 & 57 & 0 & 1942 & Wh \\
\hline & ESTE & 0 & 108 & 339 & 416 & 419 & 372 & 292 & 189 & 175 & 152 & 129 & 105 & 81 & 57 & 0 & 2833 & Wh \\
\hline & \begin{tabular}{|l|} 
OESTE \\
\end{tabular} & 0 & 57 & 81 & 105 & 129 & 152 & 175 & 189 & 292 & 372 & 419 & 416 & 339 & 108 & 0 & 2833 & Wh \\
\hline & CUBIERTA & 0 & 116 & 241 & 399 & 554 & 689 & 789 & 836 & 789 & 689 & 554 & 399 & 241 & 116 & 0 & 6414 & Wh \\
\hline & INCLINADA & 0 & 111 & 227 & 384 & 541 & 677 & 779 & 826 & 779 & 677 & 541 & 384 & 227 & 111 & 0 & 6264 & Wh \\
\hline \multirow[t]{7}{*}{ MAYO } & hora sola & 05:00 & $06: 00$ & 07:00 & 08:00 & 09:00 & $10: 00$ & $11: 00$ & $12: 00$ & $13: 00$ & $14: 00$ & $15: 00$ & $16: 00$ & $17: 00$ & $18: 00$ & 19:00 & & \\
\hline & \begin{tabular}{|l|} 
NORTE \\
\end{tabular} & 0 & 102 & 147 & 164 & 173 & 182 & 195 & 212 & 195 & 182 & 173 & 164 & 147 & 102 & 0 & 2138 & Wh \\
\hline & SUR & 0 & 70 & 94 & 117 & 141 & 164 & 188 & 215 & 188 & 164 & 141 & 117 & 94 & 70 & 0 & 1764 & Wh \\
\hline & ESTE & 0 & 167 & 307 & 363 & 366 & 334 & 279 & 212 & 188 & 164 & 141 & 117 & 94 & 70 & 0 & 2802 & Wh \\
\hline & OESTE & 0 & 70 & 94 & 117 & 141 & 164 & 188 & 212 & 279 & 334 & 366 & 363 & 307 & 167 & 0 & 2802 & Wh \\
\hline & CUBIERTA & 0 & 151 & 265 & 399 & 530 & 644 & 735 & 796 & 735 & 644 & 530 & 399 & 265 & 151 & 0 & 6244 & Wh \\
\hline & INCLINADA & 0 & 137 & 240 & 370 & 500 & 615 & 705 & 768 & 705 & 615 & 500 & 370 & 240 & 137 & 0 & 5901 & Wh \\
\hline \multirow[t]{7}{*}{ JUNIO } & hora sola & 05:00 & 06:00 & 07:00 & 08:00 & 09:00 & $10: 00$ & $11: 00$ & $12: 00$ & $13: 00$ & $14: 00$ & $15: 00$ & $16: 00$ & $17: 00$ & $18: 00$ & 19:00 & & \\
\hline & \begin{tabular}{|l|} 
NORTE \\
\end{tabular} & 0 & 118 & 166 & 187 & 198 & 165 & 188 & 205 & 188 & 165 & 198 & 187 & 166 & 118 & 0 & 2250 & Wh \\
\hline & SUR & 0 & 74 & 96 & 119 & 142 & 209 & 223 & 236 & 223 & 209 & 142 & 119 & 96 & 74 & 0 & 1963 & Wh \\
\hline & ESTE & 0 & 183 & 301 & 351 & 354 & 324 & 273 & 205 & 188 & 165 & 142 & 119 & 96 & 74 & 0 & 2775 & Wh \\
\hline & OESTE & 0 & 74 & 96 & 119 & 142 & 165 & 188 & 205 & 273 & 324 & 354 & 351 & 301 & 183 & 0 & 2775 & Wh \\
\hline & CUBIERTA & 0 & 162 & 273 & 401 & 526 & 635 & 721 & 768 & 721 & 635 & 526 & 401 & 273 & 162 & 0 & 6206 & Wh \\
\hline & INCLINADA & 0 & 144 & 242 & 366 & 489 & 625 & 705 & 750 & 705 & 625 & 489 & 366 & 242 & 144 & 0 & 5892 & Wh \\
\hline
\end{tabular}

\begin{tabular}{|c|c|c|c|c|c|c|c|c|c|c|c|c|c|c|c|c|c|c|}
\hline \multirow[t]{7}{*}{ JULIO } & hora solat & 05:00 & $06: 00$ & $07: 00$ & $08: 00$ & 09:00 & $10: 00$ & $11: 00$ & $12: 00$ & $13: 00$ & $14: 00$ & $15: 00$ & $16: 00$ & $17: 00$ & $18: 00$ & $19: 00$ & & \\
\hline & \begin{tabular}{|l|} 
NORTE \\
\end{tabular} & 0 & 112 & 159 & 179 & 189 & 164 & 187 & 206 & 187 & 164 & 189 & 179 & 159 & 112 & 0 & 2184 & Wh \\
\hline & SUR & 0 & 71 & 94 & 117 & 140 & 198 & 212 & 227 & 212 & 198 & 140 & 117 & 94 & 71 & 0 & 1890 & Wh \\
\hline & ESTE & 0 & 180 & 310 & 363 & 366 & 333 & 277 & 206 & 187 & 164 & 140 & 117 & 94 & 71 & 0 & 2807 & Wh \\
\hline & OESTE & 0 & 71 & 94 & 117 & 140 & 164 & 187 & 206 & 277 & 333 & 366 & 363 & 310 & 180 & 0 & 2807 & Wh \\
\hline & CUBIERTA & 0 & 155 & 270 & 404 & 534 & 648 & 737 & 790 & 737 & 648 & 534 & 404 & 270 & 155 & 0 & 6286 & Wh \\
\hline & INCLINADA & 0 & 138 & 240 & 370 & 499 & 634 & 717 & 767 & 717 & 634 & 499 & 370 & 240 & 138 & 0 & 5965 & Wh \\
\hline \multirow[t]{7}{*}{ AGOSTO } & hora sola & 05:00 & $06: 00$ & $07: 00$ & 08:00 & 09:00 & $10: 00$ & $11: 00$ & $12: 00$ & $13: 00$ & $14: 00$ & $15: 00$ & $16: 00$ & $17: 00$ & $18: 00$ & $19: 00$ & & \\
\hline & \begin{tabular}{|l|} 
NORTE \\
\end{tabular} & 0 & 82 & 124 & 135 & 139 & 159 & 183 & 201 & 183 & 159 & 139 & 135 & 124 & 82 & 0 & 1848 & Wh \\
\hline & SUR & 0 & 64 & 88 & 111 & 135 & 174 & 211 & 233 & 211 & 174 & 135 & 111 & 88 & 64 & 0 & 1800 & Wh \\
\hline & ESTE & 0 & 142 & 320 & 385 & 389 & 351 & 285 & 201 & 183 & 159 & 135 & 111 & 88 & 64 & 0 & 2815 & Wh \\
\hline & OESTE & 0 & 64 & 88 & 111 & 135 & 159 & 183 & 201 & 285 & 351 & 389 & 385 & 320 & 142 & 0 & 2815 & Wh \\
\hline & CUBIERTA & 0 & 134 & 253 & 397 & 539 & 663 & 759 & 811 & 759 & 663 & 539 & 397 & 253 & 134 & 0 & 6301 & Wh \\
\hline & INCLINADA & 0 & 125 & 233 & 375 & 517 & 642 & 738 & 790 & 738 & 642 & 517 & 375 & 233 & 125 & 0 & 6052 & Wh \\
\hline \multirow[t]{7}{*}{ SEPTIEMBRE } & hora solat & 05:00 & 06:00 & 07:00 & 08:00 & 09:00 & $10: 00$ & $11: 00$ & $12: 00$ & $13: 00$ & $14: 00$ & $15: 00$ & $16: 00$ & $17: 00$ & $18: 00$ & $19: 00$ & & \\
\hline & \begin{tabular}{|l|} 
NORTE \\
\end{tabular} & 0 & 61 & 85 & 109 & 132 & 155 & 175 & 184 & 175 & 155 & 132 & 109 & 85 & 61 & 0 & 1617 & Wh \\
\hline & SUR & 0 & 61 & 94 & 144 & 195 & 241 & 276 & 290 & 276 & 241 & 195 & 144 & 94 & 61 & 0 & 2313 & Wh \\
\hline & ESTE & 0 & 61 & 287 & 364 & 373 & 338 & 273 & 184 & 175 & 155 & 132 & 109 & 85 & 61 & 0 & 2596 & Wh \\
\hline & \begin{tabular}{|l|} 
OESTE \\
\end{tabular} & 0 & 61 & 85 & 109 & 132 & 155 & 175 & 184 & 273 & 338 & 373 & 364 & 287 & 61 & 0 & 2596 & Wh \\
\hline & CUBIERTA & 0 & 122 & 224 & 361 & 497 & 615 & 702 & 737 & 702 & 615 & 497 & 361 & 224 & 122 & 0 & 5778 & Wh \\
\hline & INCLINADA & 0 & 119 & 220 & 359 & 499 & 619 & 707 & 742 & 707 & 619 & 499 & 359 & 220 & 119 & 0 & 5786 & Wh \\
\hline
\end{tabular}

\begin{tabular}{|c|c|c|c|c|c|c|c|c|c|c|c|c|c|c|c|c|c|c|}
\hline \multirow[t]{7}{*}{ OCTUBRE } & hora sola & $05: 00$ & $06: 00$ & $0 /: 00$ & $08: 00$ & $09: 00$ & 70:00 & $11: 00$ & 12:00 & 13:00 & 14:00 & 75:00 & $16: 00$ & 11:00 & 18:00 & 19:00 & & \\
\hline & NORTE & 0 & 0 & 75 & 98 & 120 & 140 & 155 & 161 & 155 & 140 & 120 & 98 & 75 & 0 & 0 & 1339 & Wh \\
\hline & SUR & 0 & 0 & 120 & 191 & 254 & 305 & 340 & 352 & 340 & 305 & 254 & 191 & 120 & 0 & 0 & 2774 & Wh \\
\hline & ESTE & 0 & 0 & 256 & 353 & 368 & 331 & 258 & 161 & 155 & 140 & 120 & 98 & 75 & 0 & 0 & 2316 & Wh \\
\hline & OESTE & 0 & 0 & 75 & 98 & 120 & 140 & 155 & 161 & 258 & 331 & 368 & 353 & 256 & 0 & 0 & 2316 & Wh \\
\hline & CUBIERTA & 0 & 0 & 187 & 320 & 457 & 574 & 654 & 684 & 654 & 574 & 457 & 320 & 187 & 0 & 0 & 5067 & Wh \\
\hline & INCLINADA & 0 & 0 & 195 & 338 & 482 & 604 & 687 & 717 & 687 & 604 & 482 & 338 & 195 & 0 & 0 & 5329 & Wh \\
\hline \multirow[t]{7}{*}{ NOVIEMBRE } & hora sola & $05: 00$ & $06: 00$ & $07: 00$ & 08:00 & 09:00 & $10: 00$ & $11: 00$ & $12: 00$ & $13: 00$ & $14: 00$ & 15:00 & $16: 00$ & $17: 00$ & $18: 00$ & $19: 00$ & & \\
\hline & \begin{tabular}{|l|} 
NORTE \\
\end{tabular} & 0 & 0 & 63 & 85 & 105 & 122 & 135 & 140 & 135 & 122 & 105 & 85 & 63 & 0 & 0 & 1161 & \\
\hline & SUR & 0 & 0 & 128 & 229 & 307 & 366 & 403 & 416 & 403 & 366 & 307 & 229 & 128 & 0 & 0 & 3283 & Wh \\
\hline & ESTE & 0 & 0 & 216 & 341 & 364 & 325 & 245 & 140 & 135 & 122 & 105 & 85 & 63 & 0 & 0 & 2140 & Wh \\
\hline & OESTE & 0 & 0 & 63 & 85 & 105 & 122 & 135 & 140 & 245 & 325 & 364 & 341 & 216 & 0 & 0 & 2140 & Wh \\
\hline & CUBIERTA & 0 & 0 & 148 & 278 & 416 & 533 & 613 & 641 & 613 & 533 & 416 & 278 & 148 & 0 & 0 & 4618 & Wh \\
\hline & INCLINADA & 0 & 0 & 164 & 313 & 464 & 589 & 673 & 702 & 673 & 589 & 464 & 313 & 164 & 0 & 0 & 5109 & Wh \\
\hline \multirow[t]{7}{*}{ DICIEMBRE } & hora sola & 05:00 & $06: 00$ & $07: 00$ & 08:00 & 09:00 & 10:00 & $11: 00$ & $12: 00$ & $13: 00$ & $14: 00$ & 15:00 & $16: 00$ & $17: 00$ & $18: 00$ & $19: 00$ & & \\
\hline & NORTE & 0 & 0 & 65 & 85 & 105 & 121 & 132 & 136 & 132 & 121 & 105 & 85 & 65 & 0 & 0 & 1151 & Wh \\
\hline & SUR & 0 & 0 & 121 & 228 & 306 & 363 & 398 & 411 & 398 & 363 & 306 & 228 & 121 & 0 & 0 & 3241 & Wh \\
\hline & ESTE & 0 & 0 & 176 & 303 & 330 & 298 & 229 & 136 & 132 & 121 & 105 & 85 & 65 & 0 & 0 & 1979 & \\
\hline & OESTE & 0 & 0 & 65 & 85 & 105 & 121 & 132 & 136 & 229 & 298 & 330 & 303 & 176 & 0 & 0 & 1979 & \\
\hline & CUBIERTA & 0 & 0 & 142 & 256 & 380 & 485 & 556 & 581 & 556 & 485 & 380 & 256 & 142 & 0 & 0 & 4219 & \\
\hline & INCLINADA & 0 & 0 & 156 & 292 & 429 & 543 & 618 & 645 & 618 & 543 & 429 & 292 & 156 & 0 & 0 & 4720 & Wh \\
\hline
\end{tabular}

Fuente: Programa F.Javier Neila. 


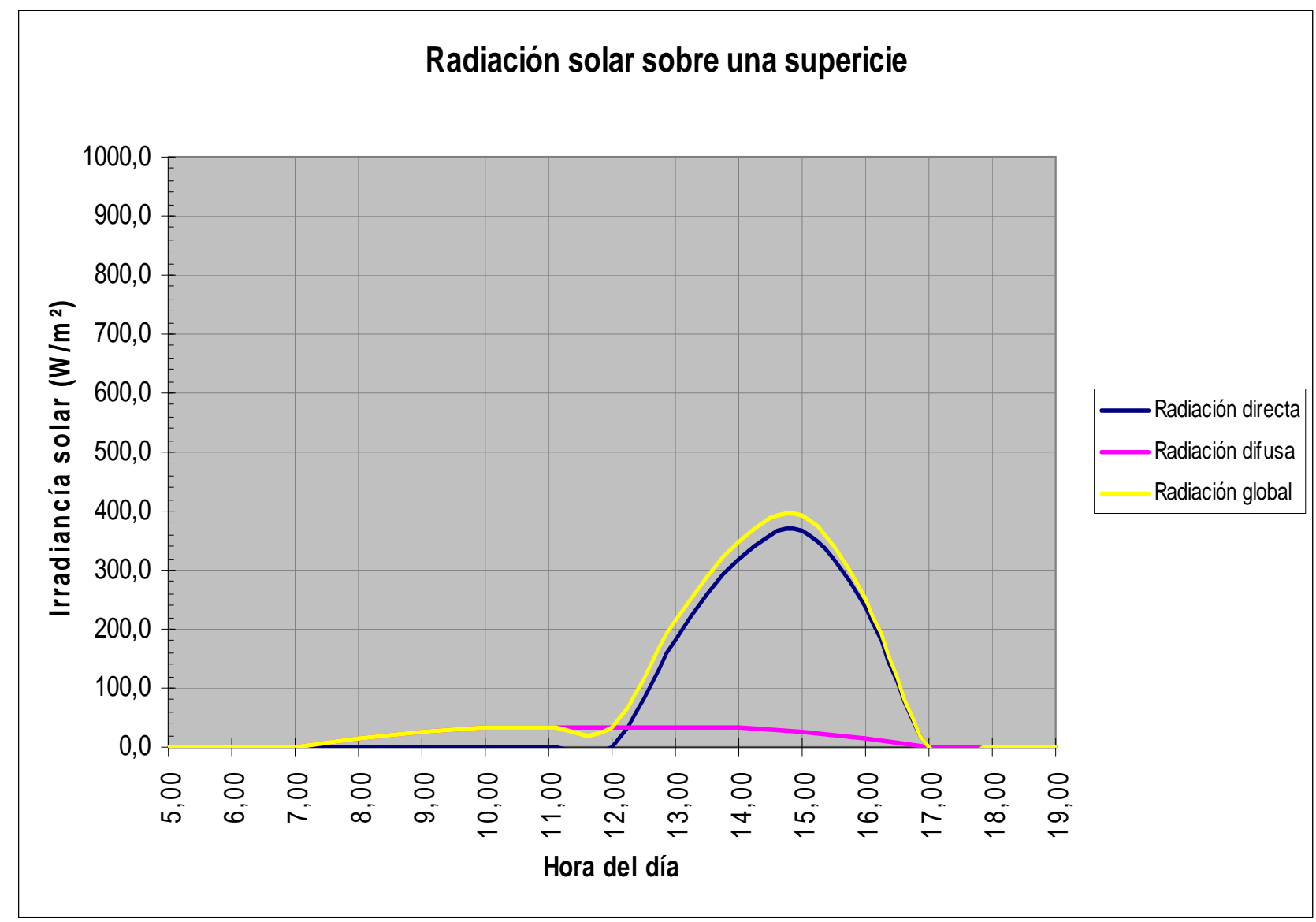

Grafico Radiación Solar. Fuente: Programa F.Javier Neila.

El calculo de la irradiancia media horaria sobre las superficies de la edificación (norte, sur, este, oeste, cubierta plana, cubierta inclinada), se hace tomando los datos de nubosidad media de cada mes en la localidad de estudio; con esto se inicia la proyección del tipo de solución fotovoltaica necesaria para cubrir la necesidad energética de un organismo determinado.

\section{Conclusiones Generales Análisis Bioclimático}

Lugo de realizados los estudios para la zona climática en cuestión ( $18^{\circ} 29^{\prime}$ latitud Norte), se llega a las conclusiones generales de estrategia de diseño siguiente:

1. Durante todo el año se mantiene una media de temperatura constante, sin grandes saltos; lo que facilita la vida y el contacto en los espacios exteriores.

2. El punto resaltante del estudio bioclimático, es la necesidad constante de ventilación tanto para los espacios interiores y exteriores, como en nuestro, caso para los paneles fotovoltaicos instalados la piel del edificio.

3. Los días se presentan bastante despejados gran parte del año, lo que facilita un nivel de irradiancia aceptable para los sistemas de captación.

4. La necesidad de sombra gran parte del año, permite integrar en los elementos constructivos que la producen sistemas de captación solar regulable. 


\subsection{Integración en equipamientos y edificios habitacionales existentes y de nueva planta.}

Para nuestra alternativa de integración fotovoltaica a la edificación, la situación de déficit actual que sufre la República Dominicana en materia habitacional y de equipamientos, resulta una brillante oportunidad; dado además, que las condiciones sociales, económicas, culturales y energéticas son imperantes en esta nación caribeña, son semejantes a las de otros países de la región, aun mas allá; en muchos estados de la franja tropical hasta llegar a las antípoda.

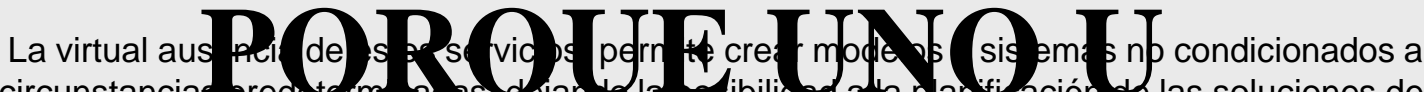

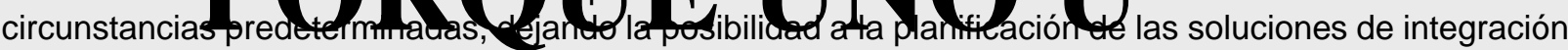 desde el principio mismo de la concepción del proyecto. La otra cara, el precario estado de muchas de las edificaciones existentes, tamb en da spa lo er crorta medida- a crear modelos y sistemas adaptables a esa realidad.}

\section{????????????}

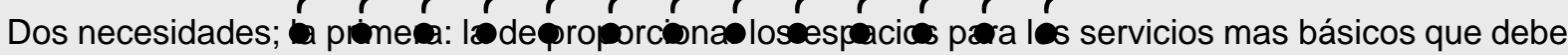
brindar una sociedad a sus ciudadanos ( vivienda, educación, salud), procurando desempeñar el papel social para el cual se proyecta; la segunda: la de reducir el gasto energético potenciando el ahorro y los métodos alternativos de generación de energía en un país donde el suministro a veces cubre poco mas de la mitad de la demanda ( $60-80 \%)$.

\section{PROPUESTA:}

Desde nuestro enfoque la conjunción de ambas necesidades ( espacio y energía), deriva en una solución combinada, siendo el mismo organismo arquitectónico ( por medio de su piel u otro elemento compositivo), un ente generador, de por lo menos, su propia energía.

Planteamos una serie de ejemplos de posibles aplicaciones en algunas edificaciones de diversos usos y ya existentes. Se parte de su naturaleza, y se analizan sus necesidades energéticas, así como las posibilidades de cubrirlas por medios del aprovechamiento solar como parte integral de su propia arquitectura.

Con una relación de datos, se muestra el estado actual, lo que existe al día de hoy; como es el edificio y las cifras correspondientes a su consumo medido en valores ponderables tanto económicamente como a nivel medioambiental pudiendo determinarse así , en cierta medida, también su impacto social.

Un posible modelo de aplicación de soluciones, se muestra igualmente con datos de valores de consumo y ahorro, a partir de la implementación de las técnicas fotovoltaicas. Se refleja la reducción de emisiones de $\mathrm{CO} 2$, y el impacto en los aspectos económicos.

Se plantean escenarios de emplazamiento socio-ambientalmente distintos para organismo tipológicos diferentes, tratando de abarcar siempre los tres renglones antes citados ( vivienda, salud y educación), y las implicaciones energéticas de los mismos:

1. Un pequeño centro educativo semi-privado, existente y operativo en la actualidad. Ejemplo de un modelo común en la zona del Caribe para asumir el problemática educativa.

2. Un centro de asistencia primaria ( sub-centro de salud). Puerta de entrada -igual que en países desarrollados- de la población; pero en estos casos al deficitario sistema de salubridad de estas naciones en vías de desarrollo. 
3. Un bloque de viviendas ( edificio residencial en altura media) bien planificado y dirigido a los sectores sociales de nivel económico medio. Insertado en la realidad de un medio donde no se garantizan al $100 \%$ los servicios básicos de suministro de agua y electricidad, teniendo que ser asumidos por la comunidad de propietarios.

4. Vivienda unifamiliar media, cuyas condiciones y problemática de déficit de servicio prestado por el estado, las asume ya no una comunidad de propietarios, sino una familia de manera individual; poniendo en practica el modelo mas básico de autogestión.

5. Conjunto de infraviviendas, ya sea periférico o enclavado en los centro metropolitanos. La propia naturaleza de estos asentamiento de familias, hace que cualquier solución habitacional propuesta deba de hacerse a una escala colectiva y urbana.
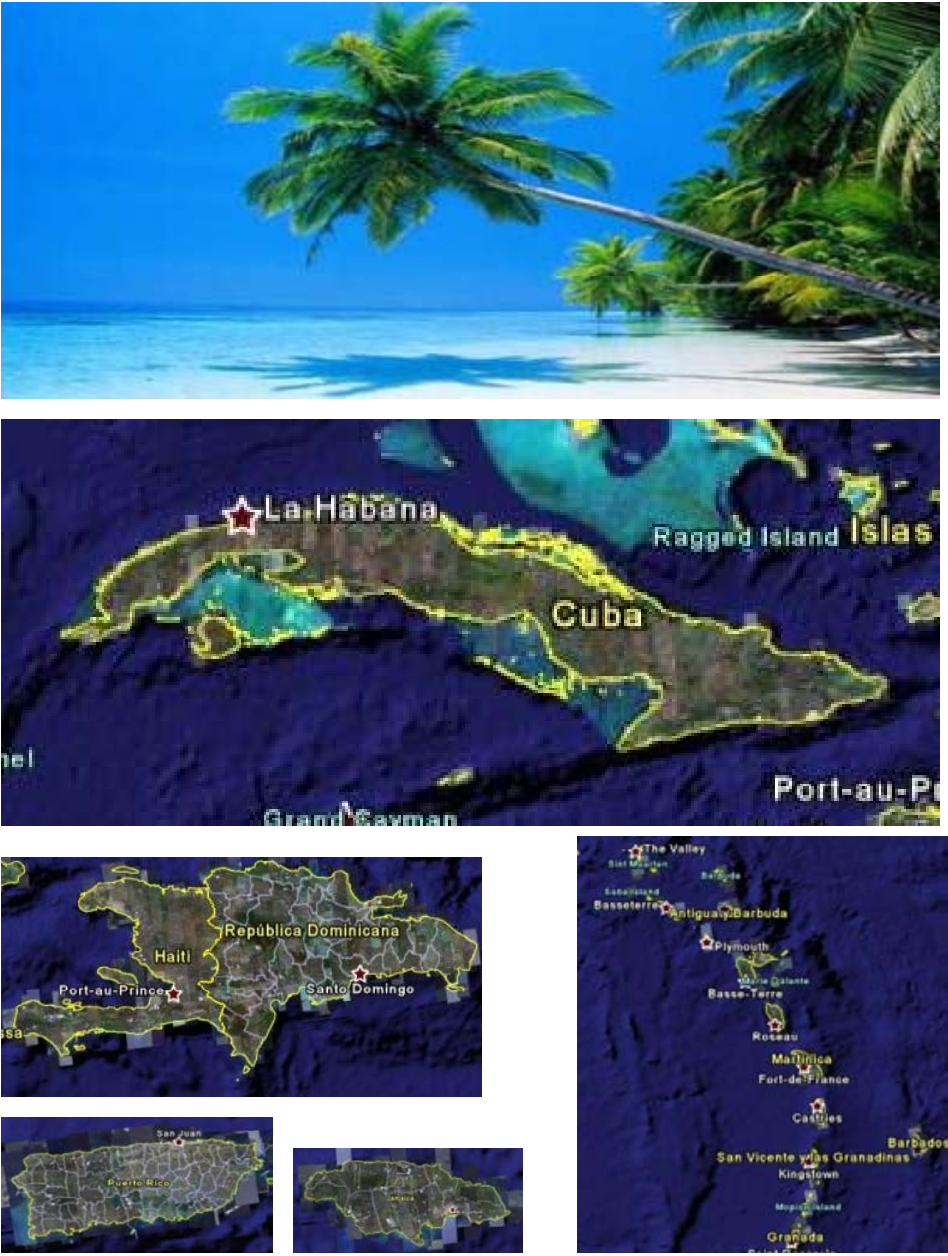

Antillas Mayores y Antillas Menores. Fuente: Archivo Particular.

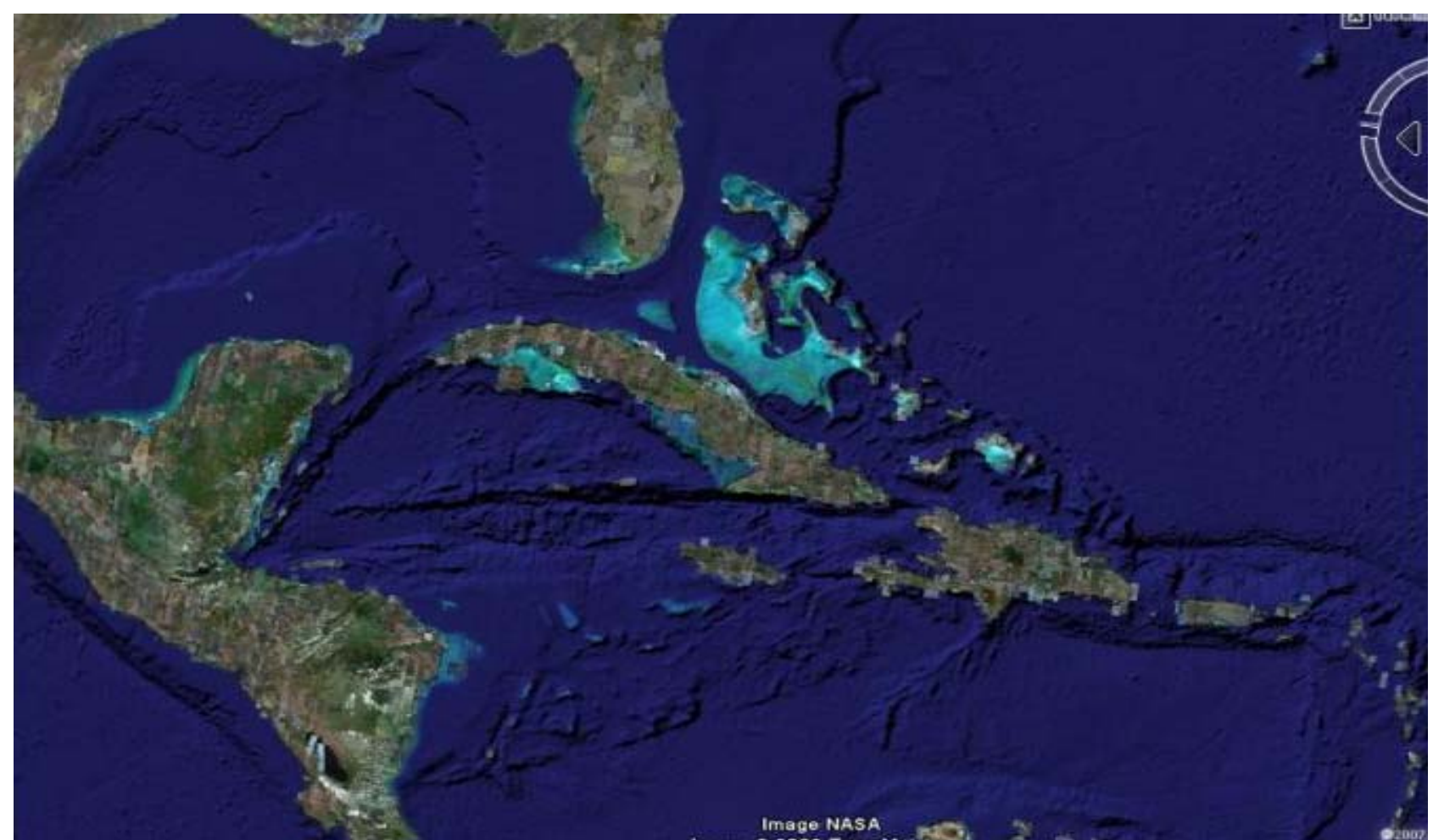

Cuenca del Caribe. Fuente: Archivo Particular. 


\section{PROPUESTAS DE INTEGRACION 1. Escuela Inicial J.Peña(Organismo existente)}

\section{Antecedentes y características del organismo:}

La Escuela Inicial Juana Peña, funciona desde mediados de los 90 en una localidad residencial de la provincia de Santo Domingo (Hainamosa), a $15 \mathrm{Km}$. hacia el del centro del Distrito Nacional. La construcción del edificio con capacidad para 40 alumnos y de $164 \mathrm{~m} 2$ construidos; fue promovida por misioneros protestantes con el propósito de instalar un centro de servicios comunitarios y templo congregacional.

En la actualidad el trabajo en la localidad sigue siendo sostenido económicamente en un 80 \% por los misioneros; dado que la limitaciones económicas en el presupuesto nacional, impiden que el Estado Dominicano asuma la responsabilidad educativa en esta zona, este incentiva y apoya (en este caso con el $20 \%$ de los gastos operativos), las iniciativas encamonadas por instituciones como las iglesia o los Organismos no gubernamentales.

Su planta rectangular, y la composición de la fachada, guardan mayor relación con un templo, que con un centro educativo. En su interior se han adaptado las facilidades propias de una escuela inicial, aunque las limitaciones de espacio impiden el desarrollo y la ampliación de las actividades relacionadas con los usos actuales.

Como en cualquier lugar de la República Dominicana, el déficit energético dificulta y encarece el desenvolvimiento de actividades, toda vez que para suplir este carencia en el servicio se recurre al uso de generadores de emergencia con el consecuente gasto en combustible y emisiones de CO2.

\begin{tabular}{|l|c|}
\hline \multicolumn{2}{|c|}{ ESCha Técnica } \\
\hline \multicolumn{2}{|c|}{ ESCUELA INICIAL JUANA PEÑA } \\
\hline \multicolumn{2}{|c|}{} \\
\hline Tipo de edificio & Equip/Educativo \\
\hline Localidad & Sto. Dgo. Este \\
\hline Numero de estudiantes & 40 \\
\hline M2 Superficie Construida & $164 \mathrm{~m} 2$ \\
\hline Necesidades energéticas al mes & $600 \mathrm{Kw} / \mathrm{h}$ \\
\hline Promedio energía servida al mes & $420 \mathrm{Kw} / \mathrm{h}(70 \%)$ \\
\hline Déficit energético estimado al mes & $180 \mathrm{Kw} / \mathrm{h}(30 \%)$ \\
\hline Consumo medio de combustible de grupo electrógeno alternativo al mes (20 dias de 8 Hr) & $221 \mathrm{lt}$. \\
\hline Costo funcionamiento grupo electrógeno al mes(20 dias de 8 Hr)/precio gasolina & US\$ 330 \\
\hline Cantidad en de CO2 emitido al mes por equipo alternativo & $0.52 \mathrm{t}$ \\
\hline
\end{tabular}

Fuente: Elaboración Propia.
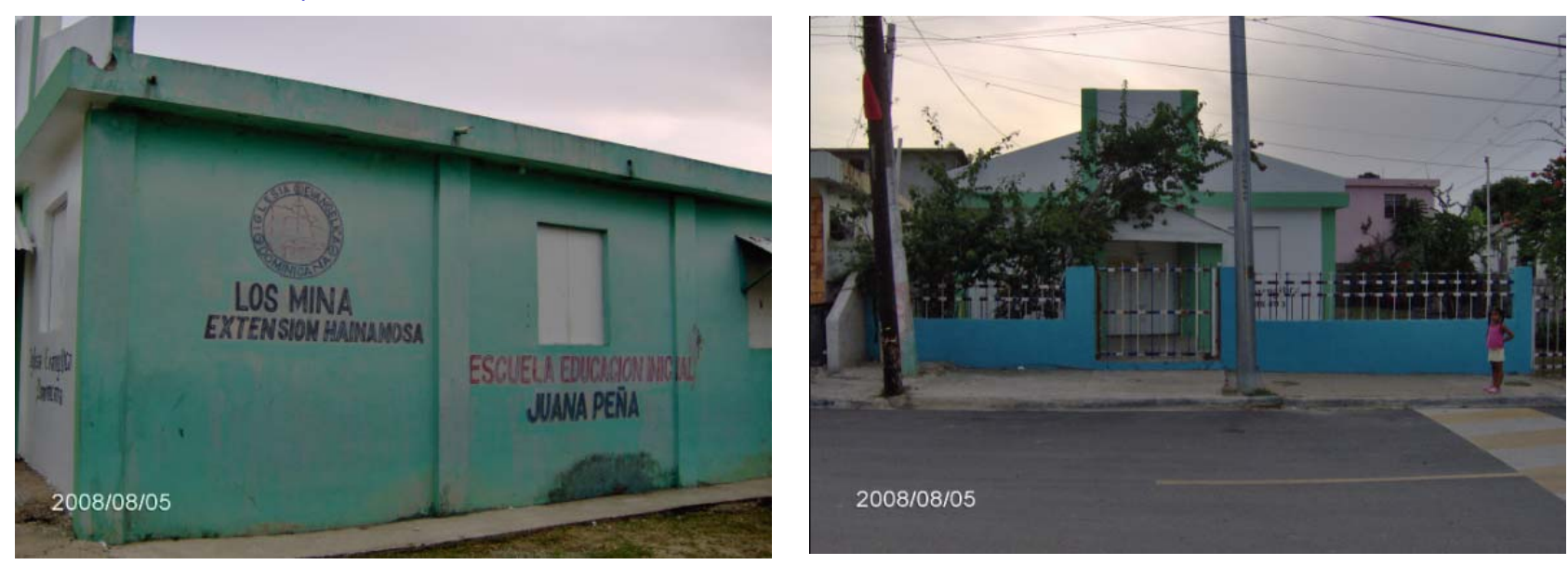

Fuente: Archivo particular. 


\section{Comentario de propuesta:}

La propuesta consiste en la implementación e integración en la arquitectura del edificio, de un sistema de generación renovable, y alternativo al de plantas eléctricas de emergencia.

Un sistemas de paneles fotovoltaicos instalados como parte de la cubierta de una nueva terraza para actividades relacionadas al centro educativo. La disposición de $60 \mathrm{~m} 2$ de paneles policristalinos, con un rendimiento del $15 \%$, con una inclinación de $18^{\circ}$ (según latitud del lugar), y paralelos al eje horizontal, permitirán generar la energía no servida por la red eléctrica general, y posiblemente aportar un Plus de generación, que seria consumido por el propio edificio, dado que en el sistema nacional no se contempla aun la venta del mismo a las compañías eléctricas.

La repercusión de este sistema no solo seria apreciable en el orden económico, sino también en lo concerniente al medio ambiente. Su repercusión social es tangible, además, toda vez que la compra, instalación, mantenimiento, etc., precisa de mano de obra local.

\begin{tabular}{|l|c|}
\hline \multicolumn{2}{|c|}{ Propuesta de Integración } \\
\hline \multicolumn{2}{|c|}{ ESCUELA INICIAL JUANA PEÑA } \\
\hline \multicolumn{2}{|c|}{} \\
\hline Superficie captadora necesarios para suplir demanda déficit (51 placas de 1.05m2 c/u) & $54 \mathrm{~m} 2$ \\
\hline Superficie captadora proyectada en edificio & $60 \mathrm{~m} 2$ \\
\hline Costo watts panel fotovoltaico instalado & US\$5.91 \\
\hline Costo de la instalacion fotovoltaica & US\$59,100.00 \\
\hline Potencia fotovoltaica instalada ( con placas de 175w y tamaño de150x70 cm) & $10 \mathrm{KW}$ \\
\hline Ahorro estimado de combustible para grupo electrógeno alternativo & $100 \%$ \\
\hline Reducción de gasto en US\$ al día & $100 \%$ \\
\hline Plazas de trabajo creadas en proceso de instalación y mantenimiento & 10 \\
\hline Cantidad de CO2 no emitido al mes por equipo alterno (gasolina). & $0.52 \mathrm{t}$ \\
\hline Período de amortizacion & 7 años \\
\hline
\end{tabular}

Fuente: Elaboración Propia.
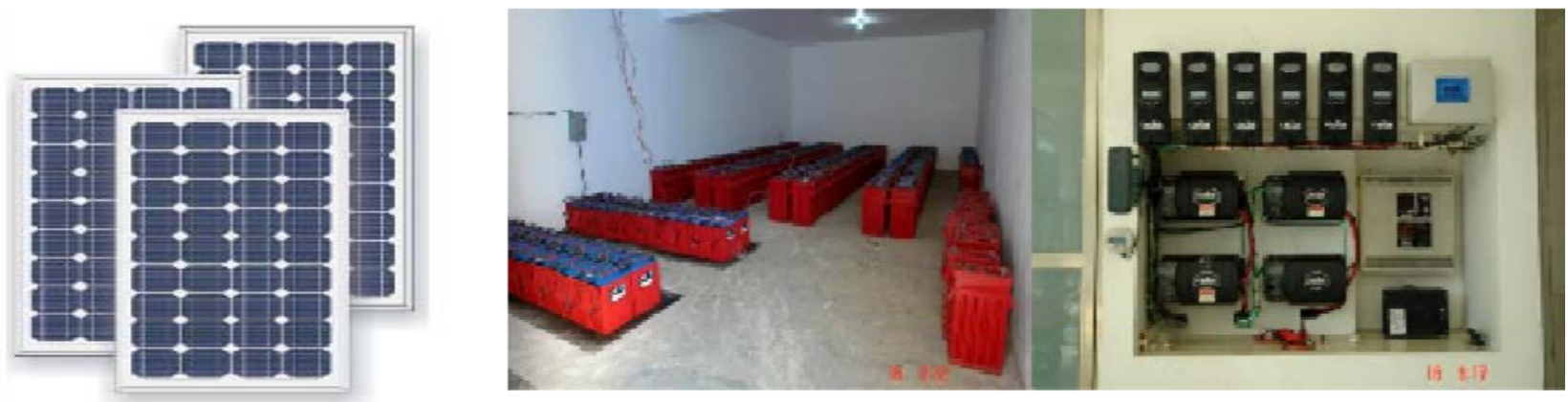

Sistema de generación fotovoltaico Fuente: Archivo particular

La integración de sistema de generación fotovoltaico se hace partiendo de principios compositivos propios de la tipología de arquitectura antillana, sus soluciones estructurales y de ventilación.

Los cálculos y estimaciones realizadas expresan las proyecciones de ahorros tanto para la red general de suministro de energía (Edeste-CDEEE), como el ahorro en combustible para los grupos electrógenos alternativos,que sirven para suplir el déficit de la compañía generadora.

Esto implica no solo un beneficio económico para la institución ( apoyada por el dependiente del estado), y la sociedad, sino también un importante reducción en las emisiones de CO2 a la atmósfera, y lo que esto significa para el medio ambiente. 


\section{PROPUESTAS DE INTEGRACION 2. Centro de Atención Primaria de Salud}

\section{Antecedentes y características tipológicas:}

Los Centros de Atención Primaria, o SubCentros de Salud, son la antesala o puerta de entrada que encuentra la población de zonas alejadas de los centros urbanos o de centros médicos de mayor capacidad. Tienen como función suplir el mayor numero de necesidades básicas de salud. En muchas ocasiones, por la lejanía del asentamiento, se equipan estos, con capacidad para atender casos de cierta importancia medica.

Es muy común que sus facilidades se vean desbordadas por la demanda de servicios; mucho de los cuales no pueden ser atendidos ya sea por falta equipos y materiales, infraestructura o simple personal sanitario. Si a esto se le suma algunas precariedades comunes a toda la sociedad en cuanto a suministro de agua potable, recogida de desechos, energía eléctrica, etc.; la situación puede tornase poco manejable.

La capacidad en planta física varia según el lugar donde esta ubicado y al nivel demográfico del mismo. Lo que si es coincidente en varias de zonas del Caribe, es la versatilidad y capacidad de adaptación que se desarrolla para sortear la adversidad que se presenta día a día.

\begin{tabular}{|l|c|}
\hline \multicolumn{2}{|c|}{ Ficha Técnica } \\
\hline \multicolumn{2}{|c|}{ SUBCENTRO DE SALUD } \\
\hline \multicolumn{2}{|c|}{} \\
\hline Tipo de edificio & Equipamiento Salud \\
\hline Localidad & Indeterminado (Caribe) \\
\hline M2 Superficie Construida por nivel (1 niveles) & $600 \mathrm{~m} 2$ \\
\hline Necesidades energéticas al mes & $1200 \mathrm{Kw} / \mathrm{h}$ \\
\hline Promedio energía servida al mes & $720 \mathrm{Kw} / \mathrm{h}(60 \%)$ \\
\hline Déficit energético estimado al mes & $480 \mathrm{Kw} / \mathrm{h}(40 \%)$ \\
\hline Consumo medio de combustible de grupo electrógeno alternativo al mes (20 dias de $12 \mathrm{Hr})$ & $455 \mathrm{It}$. \\
\hline Costo funcionamiento grupo electrógeno al mes(20 dias de 12 Hr)/precio gasoleo & US\$ 590 \\
\hline Cantidad en de CO2 emitido al mes por equipo alternativo (gasoleo) & $1,21 \mathrm{t}$ \\
\hline
\end{tabular}

Fuente: Elaboración Propia.

\begin{tabular}{|c|c|c|c|}
\hline & $\begin{array}{l}\text { Potencia } \\
\text { (vatios) }\end{array}$ & $\begin{array}{l}\text { periodo } \\
\text { (horas/día) }\end{array}$ & $\begin{array}{l}\text { Energía/día } \\
\text { (vatios-horas) }\end{array}$ \\
\hline Refrigerador devacunas & 60 & $5-10$ & $300-600$ \\
\hline Refrigerador/congelador de vacunas & 60 & $6-12$ & $410-720$ \\
\hline Luces $(c / u)$ & 20 & $2-12$ & $40-240$ \\
\hline \multicolumn{4}{|l|}{ Comunicaciones radio VHF } \\
\hline Stand by & 2 & 12 & 24 \\
\hline Transmisión & 30 & 1 & 30 \\
\hline Microscopio & 15 & 1.0 & 30 \\
\hline Nebulizador centrífugo & 150 & $0.3-2.0$ & $50-300$ \\
\hline Vaporizador & 40 & $1.0-4-0$ & $40-160$ \\
\hline Concentrador de oxígeno & 300 & $1.0-4-0$ & $300-1200$ \\
\hline Ventilador de techo & 40 & $4-12$ & $160-480$ \\
\hline $\begin{array}{l}\text { Bomba de agua (1500 litros/día } \\
\text { a } 40 \text { metros) }\end{array}$ & 100 & 6 & 600 \\
\hline \multicolumn{4}{|l|}{$T V$} \\
\hline 12 " Blancoy negro & 15 & $1.0-4-0$ & $15-60$ \\
\hline $19 "$ Color & 60 & $1.0-4.0$ & $60-240$ \\
\hline 25 "Color & 130 & $1.0-4-0$ & $130-520$ \\
\hline VCR & 30 & $1.0-4-0$ & $30-120$ \\
\hline AM/FM estéreo & 15 & $1.0-12$ & $15-180$ \\
\hline Esteriliza dor eléctrico* & 1500 & $0.5-2.0$ & $750-3000$ \\
\hline
\end{tabular}

Un modelo de consumo de un Centro de Atención Primaria. Fuente: Energías Renovables para Centros de Salud. LNER-USA. 


\section{Comentario de Propuesta:}

Proveer al Centro de Atención Medica Primaria o Sub-Centro de Salud, de un sistema de generación energética como alternativa a un grupo electrógeno convencional utilizado para cubrir la falta de suministro.

Este sistema compuesto por células fotovoltaicas, se integraría tanto en la cubierta como en la piel del edificio, siempre formando parte de la estructura compositiva, y procurando una correcta ventilación que garantice un funcionamiento en condiciones optimas.

Se fusionaría en cubierta y fachadas las practicas comunes a la arquitectura tropical antillana, con técnicas de integración fotovoltaica, procurando conservar el lenguaje característico de estas zona y haciendo eficiente sus cerramientos.

El objetivo final será, conseguir una generación energética sostenible de apoyo al sistema general de la red publica; reducir la emisiones de $\mathrm{CO} 2$; e integrar estas tecnologías al ente social que es el edificio.

\begin{tabular}{|c|c|}
\hline \multicolumn{2}{|l|}{ Propuesta de Integración } \\
\hline \multicolumn{2}{|l|}{ SUBCENTRO DE SALUD } \\
\hline Superficie captadora necesarios para suplir demanda déficit (137 placas de $1.05 \mathrm{~m} 2$ aprox) & $144 \mathrm{~m} 2$ \\
\hline Superficie captadora proyectada en edificio $\left(a 18^{\circ}=100 \%\right)$ & $7.35 \mathrm{~m} 2$ \\
\hline Costo watts panel fotovoltaico instalado & US\$ 5.91 \\
\hline Costo de la instalacion fotovoltaica & US\$ $141,840.00$ \\
\hline Potencia fotovoltaica instalada ( con placas de 175w y tamaño de150x70 cm) & $23,97 \mathrm{Kw}$ \\
\hline Ahorro estimado de combustible para grupo electrógeno alternativo & $100 \%$ \\
\hline Reducción de gasto en US\$ al día & $100 \%$ \\
\hline Plazas de trabajo creadas en proceso de instalación y mantenimiento & 12 \\
\hline Cantidad de $\mathrm{CO} 2$ no emitido al mes por equipo alterno & $1,21 \mathrm{t}$ \\
\hline Período de amortizacion & 6 años \\
\hline
\end{tabular}

Fuente: Elaboración Propia.

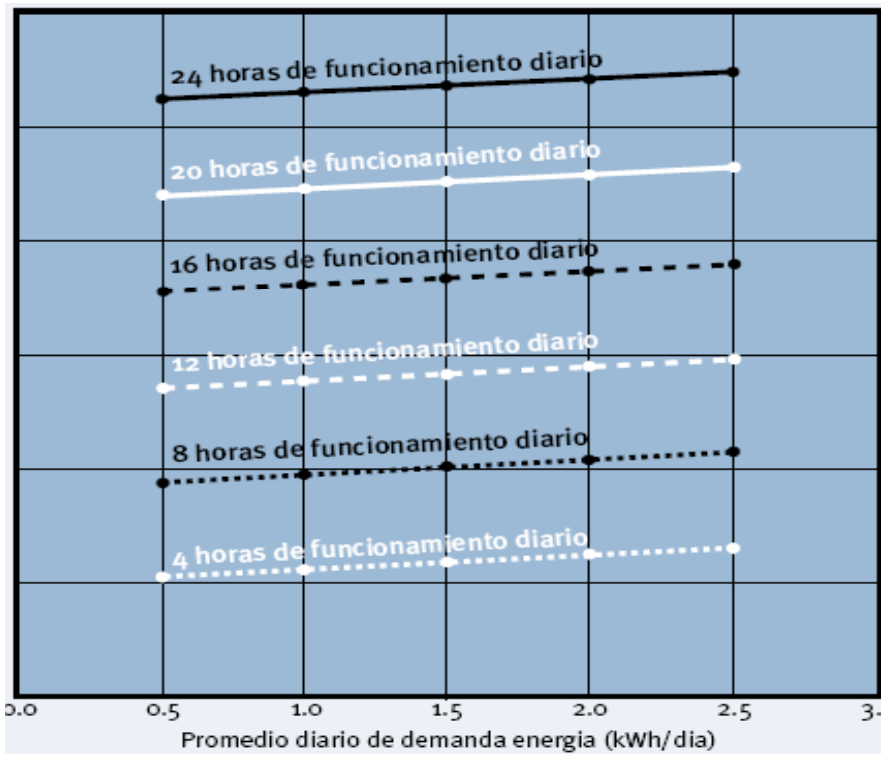

Relación horas Igeneración grupo electrógeno SubCentro Salud. Fuente: LNER-USA.
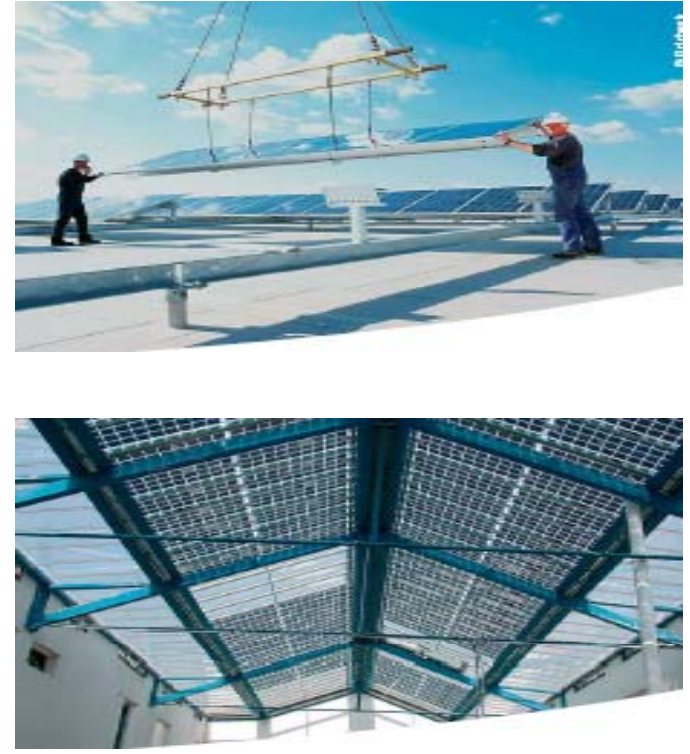

Integración paneles a la arquitectura del edifico. Fuente: A. Particular. 


\section{Antecedentes y características del organismo:}

El edificio residencial de la calle Ana Josefa Puello, del Distrito Nacional de Santo Domingo, fue construido en el año 2003 y cuenta con 7 viviendas de 70 y 110 m2 construidos. Es de promoción privada, y es característico de una tipología propia de vivienda de clase media en la República Dominicana.

El tema habitacional y su solución ocupa un punto importante en la agenda del gobierno y sus planes de desarrollo, sin embargo el centro de la ciudad capital, a sido copado con edificios residenciales de altura emplazados en parcelas donde antes existía una vivienda unifamiliar; promovidos por constructores privados.

De planta cuadrada, respondiendo a la geometría de la parcela, no presenta grandes aportes de diseño arquitectónico, mas allá del objetivo de cumplir su función habitacional.

Los servicios básicos como agua potable y energía eléctrica, se sirven con limitaciones, razón por la cual este tipo de proyectos debe prever desde su concepción, la autogestión de lo que en condiciones normales debería suplir el estado.

\begin{tabular}{|l|c|}
\hline \multicolumn{2}{|c|}{ Ficha Técnica } \\
\hline \multicolumn{2}{|c|}{ EDIFICIO RESIDENCIAL CIANA JOSEFA PUELLO } \\
\hline Tipo de edificio & Residencial \\
\hline Localidad & Sto. Dgo. D.N. \\
\hline Numero de viviendas & 7 \\
\hline M2 Superficie Construida por nivel (3 niveles) & $180 \mathrm{~m} 2$ \\
\hline Necesidades energéticas al mes en area comun & $149.94 \mathrm{Kw} / \mathrm{h}$ \\
\hline Promedio energía servida al mes & $104.3 \mathrm{Kw} / \mathrm{h}(70 \%)$ \\
\hline Déficit energético estimado al mes & $45.64 \mathrm{Kw} / \mathrm{h}(30 \%)$ \\
\hline Consumo medio de combustible de grupo electrógeno alternativo al mes (30 dias de 8 Hr) & $554 \mathrm{It}$. \\
\hline Costo funcionamiento grupo electrógeno al mes( 30 dias de 8 Hr)/precio gasoleo & US\$ 825 \\
\hline Cantidad en de CO2 emitido al mes por equipo alternativo & $1.47 \mathrm{t}$ \\
\hline
\end{tabular}

Fuente: Elaboración Propia.

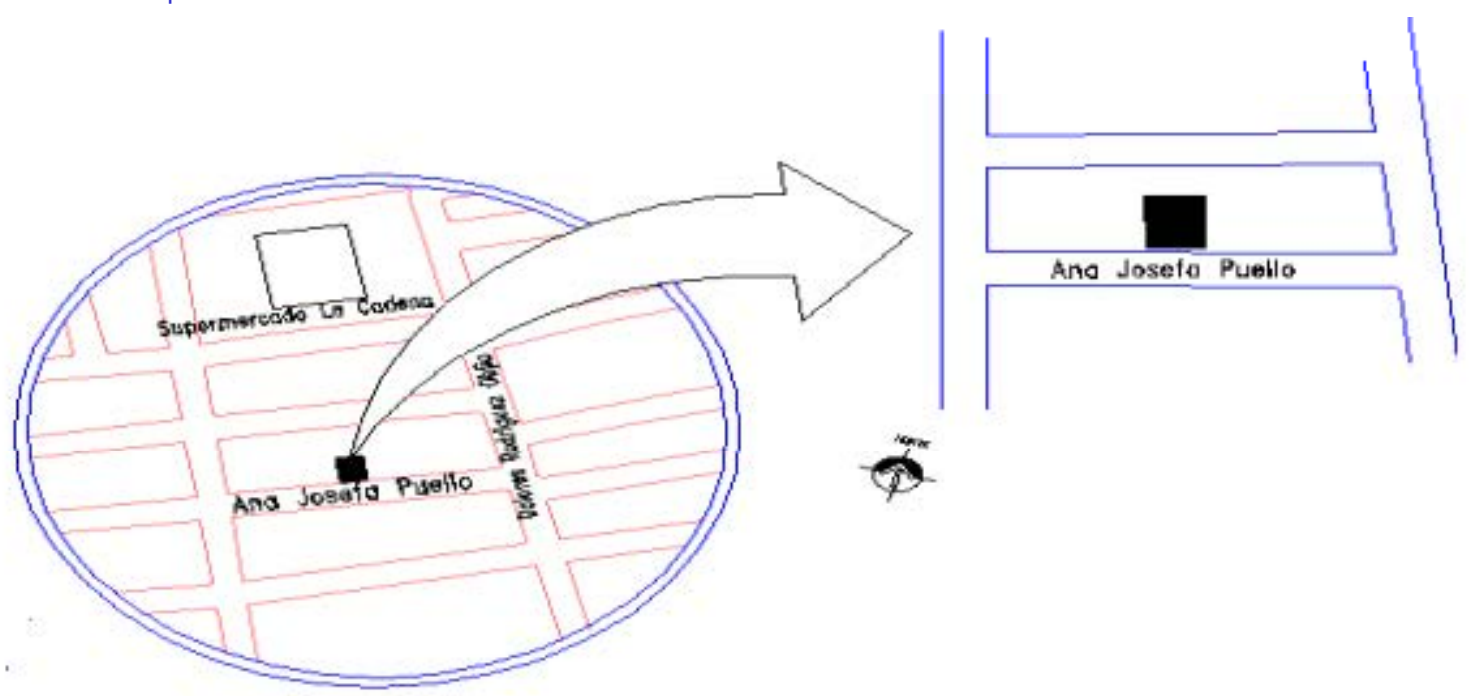




\section{Comentario de Propuesta:}

Para este organismo, la propuesta es sustituir el sistema de generación de emergencias para zonas comunes, por un sistema fotovoltaico de paneles policristalinos, inversor y acumuladores.

Los paneles serian integrados como parte de la piel del edificio en su fachada frontal, como parte de la carpintería en las ventanas de las escalera y entrada al estacionamiento en planta baja, y como cubierta de acceso a la entrada principal peatonal del edificio.

La disposición de $25 \mathrm{~m} 2$ de paneles policristalinos, en la piel de la fachada tendrían una eficiencia del $60-70 \%$ con respecto a la inclinación adecuada, según la latitud del lugar ( $18^{\circ}$ norte). Los paneles restante ocuparían un área de $8 \mathrm{~m} 2$ de fachada dispuestos en lamas orientables en la carpintería. Estas lamas fotovoltaicas tendrían un rendimiento teórico del $100 \%$ a partir del rendimiento establecido para las células multicristalinas.

La implementación de esta técnica de generación renovable, favorece el ahorro económico, ya que no es necesaria la compra de combustible fósil para la producción de energía en momentos de déficit. Además del ahorro que supone en emisiones de CO2 a al medio ambiente, evita la contaminación sónica producida por los grupos electrógenos.

\begin{tabular}{|c|c|}
\hline \multicolumn{2}{|l|}{ Propuesta de Integración } \\
\hline \multicolumn{2}{|l|}{ EDIFICIO RESIDENCIAL CIANA JOSEFA PUELLO } \\
\hline Superficie captadora necesarios para suplir demanda déficit (30 placas de $1.05 \mathrm{~m} 2$ ) & $32 \mathrm{~m} 2$ \\
\hline Superficie captadora proyectada en edificio $\left(a 18^{\circ}=100 \%\right.$ y a $90^{\circ}=60 \%$ deefectividad $)$ & $25 \mathrm{~m} 2\left(90^{\circ}\right) / 8 \mathrm{~m} 2\left(18^{\circ}\right)$ \\
\hline Costo watts panel fotovoltaico instalado & US\$5.91 \\
\hline Costo de la instalacion fotovoltaica & US\$ 31,027.50 \\
\hline Potencia fotovoltaica instalada ( con placas de $175 \mathrm{w}$ y tamaño de150x70 cm) & $5,25 \mathrm{Kw}$ \\
\hline Ahorro estimado de combustible para grupo electrógeno alternativo & $100 \%$ \\
\hline Reducción de gasto en US\$ al día & $100 \%$ \\
\hline Plazas de trabajo creadas en proceso de instalación y mantenimiento & 12 \\
\hline Cantidad de CO2 no emitido al mes por equipo alterno (gasoleo) & $1.47 \mathrm{t}$ \\
\hline Período de amortizacion & 6 años \\
\hline
\end{tabular}

Fuente: Elaboración Propia.

Al momento de integrar las células fotovoltaicas, se ha hecho tomando en consideración las soluciones de ventilación planteadas en los modelos tipológicos antillanos.

Las celosías en ventanales para la regulación de la entrada de aire, han sido sustituidas por lamas orientables de silicio policristalino. Estas lamas hacen las veces de celosías regulables y a la vez de captadores energéticos. La combinación de estas con paneles fijos en las ventanas conforman un elemento unitario.

La piel fotovoltaica, integrada en el plano vertical de frontal del edificio, funciona como fachada ventilada; siendo al mismo tiempo captadora de energía y pantalla protectora a los rayos solares incidentes en esta cara. 


\section{PROPUESTAS DE INTEGRACION 4. Vivienda Unifamiliar}

\section{Antecedentes y características tipológicas:}

Las viviendas unifamiliares caribeñas, generalmente pertenecen a una tipología mas propia de una arquitectura de estilo internacional, por las formas y suerte de soluciones empleadas para dar solución a los temas de diseño propios de este modelo de edificación. No obstante estas "contaminaciones" conservan un espíritu tropical, sobre todo en el hecho de procurarle cierta seguridad frente a los fenómenos atmosféricos frecuentes en la zona.

Este tipo de vivienda, es común en un grupo de la población de nivel social, cultural y económico medio. Son casas en solares de 150 m2 aprox.; de tres dormitorios, uno o dos baños, salón-comedor, cocina, u plaza de aparcamiento. La altura del edifico puede variar según las especificaciones urbanísticas del lugar, de entre uno o dos niveles. Ha sido una solución de diseño aplicada en la década de los 80 que se ha sido sustituida por edificios residenciales en altura, que buscan aprovechar al máximo los metros de parcela.

\begin{tabular}{|l|c|}
\hline \multicolumn{1}{|c|}{ Ficha Técnica } \\
\hline \multicolumn{1}{|c|}{ VIVIENDA UNIFAMILIAR NIVEL MEDIO } \\
\hline \multicolumn{1}{|c|}{ Residencial } \\
\hline Tipo de edificio & Indeterminado (Caribe) \\
\hline Localidad & 1 \\
\hline Numero de viviendas & $120 \mathrm{~m} 2$ \\
\hline M2 Superficie Construida por nivel (2 niveles) & $371 \mathrm{Kw} / \mathrm{h}$ \\
\hline Necesidades energéticas al mes & $296.8 \mathrm{Kw} / \mathrm{h}(80 \%)$ \\
\hline Promedio energía servida al mes & $74.20 \mathrm{Kw} / \mathrm{h}(20 \%)$ \\
\hline Déficit energético estimado al mes & $180 \mathrm{It}$. \\
\hline Consumo medio de combustible de grupo electrógeno alternativo al mes (30 dias de 6 Hr) & $\mathrm{US} \$ 261$ \\
\hline Costo funcionamiento grupo electrógeno al mes( 30 dias de 6 Hr)/precio gasoleo & $0.43 \mathrm{t}$ \\
\hline Cantidad en de CO2 emitido al mes por equipo alternativo & \\
\hline
\end{tabular}
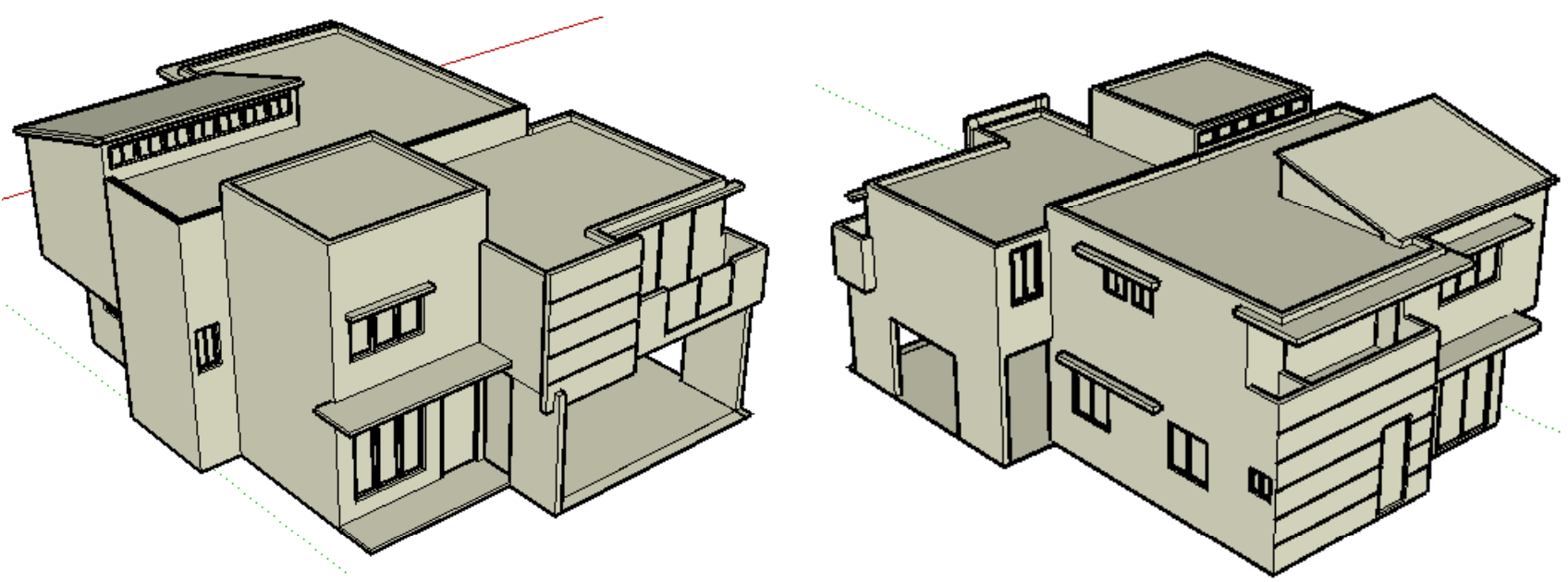

Modelo de casa de nivel medio en el Caribe. Fuente: Archivo Particular 


\section{Comentario de Propuesta:}

La propuesta consistes en colocar un sistema de generación de paneles fotovoltaicos, para suplir el déficit de energía no servida por la red general a una vivienda de nivel medio.

Los paneles serian integrados en la cubierta del edificio con la orientación he inclinación convenientes para su mejor desempeño.

La instalación de $7.35 \mathrm{~m} 2$ de paneles policristalinos, en cubierta, representaría un $100 \%$ dada la inclinación a la que serian puestos ( $18^{\circ}$ norte). Los del tipo policristalino o multicistalino, que serian los utilizados en este caso, tienen un rendimiento del 15 a17\%, trabajando bajo condiciones estándares de temperatura $\left(25^{\circ}\right)$, ventilación y limpieza.

Con este sistema renovable, se favorece el ahorro económico, no siendo necesaria la compra de gasolina para la ningún grupo electrógeno. Igualmente, supone un ahorro de emisiones de $\mathrm{CO} 2$ a al medio ambiente, con los beneficios que esto da a nuestras vidas en el planeta.

\begin{tabular}{|c|c|}
\hline \multicolumn{2}{|l|}{ Propuesta de Integración } \\
\hline \multicolumn{2}{|l|}{ VIVIENDA UNIFAMILIAR NIVEL MEDIO } \\
\hline Superficie captadora necesarios para suplir demanda déficit (7 placas de $1.05 \mathrm{~m} 2$ aprox) & $7.35 \mathrm{~m} 2$ \\
\hline Superficie captadora proyectada en edificio (a 18=100\% ) & $7.35 \mathrm{~m} 2$ \\
\hline Costo watts panel fotovoltaico instalado & US\$5.91 \\
\hline Costo de la instalacion fotovoltaica & US $\$ 14,617.40$ \\
\hline Potencia fotovoltaica instalada ( con placas de 175w y tamaño de150x70 cm) & $1,22 \mathrm{Kw}$ \\
\hline Ahorro estimado de combustible para grupo electrógeno alternativo & $100 \%$ \\
\hline Reducción de gasto en US\$ al día & $100 \%$ \\
\hline Plazas de trabajo creadas en proceso de instalación y mantenimiento & 6 \\
\hline Cantidad de CO2 no emitido al mes por equipo alterno (gasolina) & $0.43 \mathrm{t}$ \\
\hline Período de amortizacion & 8 años \\
\hline
\end{tabular}

Fuente: Elaboración Propia.

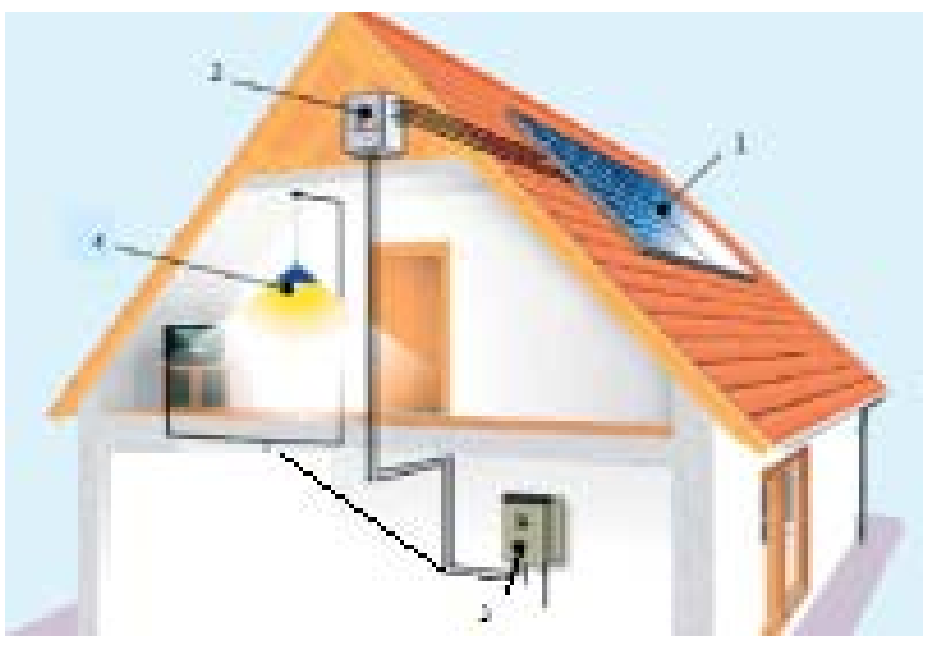

\section{ESQUEMA SISTEMA FOTOVOLTAICO}

1. Paneles Fotovoltaicos.

2. Caja de conexión.

3. Inversor.

4. Carga eléctrica.

Modelo esquemático sistema domestico

Fuente: Archivo Particular. 


\section{ANEXOS}

\section{Anexo 1}

TEMPERATURA MEDIA MENSUAL -

\section{(Grados Centigrados)}

Estaciones
Aeropuerto Arroyo Barril
Aeropuerto Herrera
Aeropuerto La Unión
Aeropuerto Punta Cana
Altamira
Azua
Bani
Barahona
Bayaguana
Bonao
Cabral
Cabrera
Cevicos
Constanza
Cotui
Dajabón
Duvergé
El Cercado
Elias Piña
El Seibo
Enriquillo
San Pedro de Macorís
San Rafael Yuma
Santiago
Santiago Rodriguez
Santo Domingo
Tamayo
Villa Altagracia
Villa Riva
Villa Vásquez
Yamasá
Yásica
A

Ene Feb Mar Abr May Jun Jul Ago Sep Oct Nov Dic Año 24.624 .925 .626 .126 .427 .127 .126 .826 .826 .625 .725 .026 .1 24.624 .424 .825 .826 .427 .127 .427 .427 .126 .926 .125 .126 .1 23.323 .323 .824 .725 .727 .027 .027 .126 .926 .325 .023 .725 .3 24.824 .825 .225 .826 .627 .327 .627 .827 .627 .126 .425 .326 .4 22.222 .623 .524 .425 .626 .526 .626 .926 .726 .124 .422 .824 .9 25.225 .526 .226 .827 .327 .728 .428 .528 .127 .426 .625 .526 .9 25.926 .026 .727 .427 .627 .928 .628 .528 .127 .627 .025 .927 .3 24.624 .825 .426 .226 .727 .327 .927 .927 .526 .726 .225 .226 .4 $24.624 .925 .626 .327 .027 .627 .727 .627 .5 \quad 272 \quad 26.325 .026 .4$ 23.423 .824 .625 .425 .926 .826 .927 .026 .826 .425 .223 .825 .5 25.225 .526 .427 .127 .027 .127 .427 .727 .527 .226 .425 .526 .7 24.724 .825 .225 .626 .026 .626 .826 .826 .726 .525 .724 .925 .9 $23.023 .424 .325 .226 .026 .626 .626 .626 .626 .1 \quad 24.723 .325 .2$ $16.1 \quad 16.517 .418 .1 \quad 18.819 .219 .319 .519 .419 .018 .016 .718 .2$ $23.824 .325 .726 .226 .927 .427 .427 .527 .527 .1 \quad 25.724 .226 .1$ 23.624 .124 .825 .426 .027 .027 .427 .427 .126 .625 .223 .725 .7 26.426 .927 .828 .728 .829 .229 .829 .929 .728 .927 .926 .728 .4 20.421 .322 .323 .223 .524 .324 .424 .224 .023 .321 .920 .422 .8 $24.324 .825 .626 .026 .126 .326 .5 \quad 26.526 .326 .025 .324 .425 .7$ $24.224 .425 .225 .926 .627 .227 .6 \quad 27.727 .326 .8 \quad 25.724 .626 .1$ 26.026 .226 .426 .526 .626 .927 .227 .527 .527 .126 .826 .326 .8 24.224 .525 .225 .926 .627 .327 .527 .627 .326 .925 .924 .826 .1 24.224 .525 .626 .127 .227 .728 .328 .428 .227 .426 .024 .826 .5 23.524 .025 .025 .826 .527 .527 .627 .927 .727 .025 .423 .926 .0

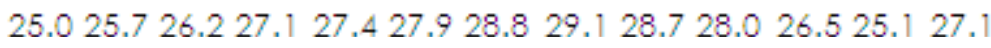
$24.224 .124 .725 .426 .126 .726 .927 .026 .926 .525 .8 \quad 24825.8$ $25.325 .525 .926 .527 .027 .427 .8 \quad 27.927 .827 .5 \quad 26.925 .8 \quad 26.8$ 24.024 .024 .525 .125 .325 .726 .026 .126 .225 .925 .424 .225 .9 24.424 .925 .325 .926 .827 .027 .227 .427 .227 .026 .024 .926 .2 24.625 .426 .226 .827 .828 .528 .829 .028 .728 .226 .624 .927 .1 24.124 .525 .325 .926 .526 .927 .026 .826 .726 .425 .624 .625 .9 22.822 .823 .424 .125 .026 .026 .326 .326 .625 .924 .523 .324 .8 


Estaciones
Altamira
Azua
Baní
Barahona
Bayaguana
Bonao
Cabo Engaño
Cabral
Cabrera
Cevicos
Constanza
Cotuí
Dajabón
Divergé
El Cercado
Elías Piña
El Seibo
Enriquillo
San Pedro de Macorís
San Rafael Yuma
Santiago
Santiago Rodriguez
Santo Domingo
Tamayo
Villa Altagracia
Villa Riva
Villa Vásquez
Yamasá
Yásica
Salo

Ene Feb Mar Abr May Jun Jul Ago Sep Oct Nov Dic Año 27.228 .029 .129 .730 .932 .332 .232 .432 .331 .629 .427 .630 .2 31.231 .531 .932 .232 .432 .834 .034 .033 .432 .632 .131 .432 .5 31.331 .632 .132 .632 .732 .933 .633 .633 .432 .932 .431 .432 .5 29.429 .329 .630 .130 .430 .831 .832 .031 .630 .830 .729 .930 .6 30.230 .731 .632 .132 .432 .732 .832 .832 .832 .531 .630 .231 .8 29.630 .030 .931 .431 .833 .033 .133 .133 .232 .731 .329 .631 .6 27.727 .728 .028 .729 .730 .330 .430 .630 .830 .629 .428 .129 .3 31.431 .832 .833 .433 .132 .933 .533 .933 .833 .332 .731 .832 .9 28.328 .529 .029 .529 .930 .730 .630 .931 .030 .429 .528 .629 .7 28.329 .330 .431 .231 .532 .132 .032 .132 .231 .629 .828 .330 .7 $23.323 .924 .825 .125 .526 .226 .426 .526 .425 .924 .623 .3 \quad 25.2$ 29.730 .531 .632 .132 .533 .233 .033 .133 .433 .131 .429 .731 .9 $29.429 .930 .730 .831 .232 .333 .3 \quad 33.433 .032 .1 \quad 30.529 .3 \quad 31.3$ 32.132 .934 .034 .934 .735 .035 .936 .035 .834 .833 .632 .334 .3 28.029 .130 .230 .930 .231 .131 .831 .531 .130 .228 .827 .730 .0 31.031 .632 .632 .732 .532 .833 .233 .232 .932 .331 .530 .832 .3 30.230 .631 .532 .032 .333 .033 .533 .733 .532 .931 .630 .532 .1 31.031 .131 .331 .531 .531 .732 .032 .232 .232 .131 .931 .331 .6 29.629 .730 .230 .630 .931 .632 .032 .132 .031 .530 .829 .930 .9 29.430 .031 .332 .132 .733 .334 .034 .033 .932 .731 .130 .032 .0 28.929 .430 .531 .331 .933 .033 .133 .333 .432 .530 .428 .831 .4 31.432 .232 .732 .833 .133 .634 .334 .434 .033 .632 .231 .233 .0 $29.329 .329 .730 .3 \quad 30.430 .931 .431 .631 .531 .230 .729 .730 .5$ 31.131 .131 .231 .531 .832 .233 .033 .133 .032 .632 .231 .532 .0 29.429 .730 .530 .931 .031 .431 .631 .631 .931 .630 .629 .830 .8 $29.630 .230 .531 .132 .032 .132 .232 .532 .532 .2 \quad 31.029 .931 .3$ $30.531 .532 .633 .033 .834 .735 .1 \quad 35.335 .334 .532 .530 .833 .3$ 29.630 .431 .332 .532 .733 .233 .233 .032 .832 .629 .830 .031 .8 $27.727 .828 .829 .530 .131 .531 .7 \quad 31.732 .131 .329 .327 .729 .9$ 


Estaciones
Altamira
Azua
Baní
Barahona
Bayaguana
Bonao
Cabo Engaño
Cabral
Cabrera
Cevicos
Constanza
Cotuí
Dajabón
Duvergé
El Cercado
Elías Piña
El Seibo
Enriquillo
San Pedro de Macorís
San Rafael Yuma
Santiago
Santiago Rodriguez
Santo Domingo
Tamayo
Villa Altagracia
Villa Riva
Villa Vásquez
Yamasá
Yasica
Cuna

Ene Feb Mar Abr May Jun Jul Ago Sep Oct Nov Dic Año 17.217 .417 .918 .720 .020 .720 .720 .920 .820 .418 .917 .719 .3 19.319 .720 .621 .522 .422 .823 .223 .222 .922 .421 .319 .821 .6 20.620 .821 .622 .222 .823 .323 .823 .623 .122 .621 .820 .722 .2 $\begin{array}{lllllllllllll}20.4 & 20.9 & 21.7 & 22.7 & 23.4 & 24.2 & 24.4 & 24.1 & 23.6 & 22.9 & 22.1 & 20.9 & 22.6\end{array}$ 19.419 .419 .820 .721 .922 .622 .722 .622 .522 .221 .420 .021 .3 18.218 .218 .919 .620 .221 .021 .221 .120 .720 .419 .718 .819 .8 $\begin{array}{lllllllllllll}22.0 & 21.9 & 22.2 & 22.6 & 23.3 & 24.3 & 24.8 & 24.9 & 24.5 & 23.8 & 23.4 & 21.7 & 23.3\end{array}$ 19.119 .520 .421 .221 .321 .421 .521 .921 .621 .220 .319 .320 .7 21.221 .221 .722 .022 .523 .023 .223 .122 .922 .922 .421 .622 .3 17.617 .718 .119 .220 .421 .021 .221 .120 .920 .619 .818 .419 .7 $09.509 .810 .711 .812 .813 .013 .213 .213 .012 .7 \quad 11.810 .7 \quad 11.8$ 18.618 .920 .020 .621 .622 .122 .122 .121 .821 .520 .719 .220 .8 $17.718 .018 .919 .921 .121 .821 .621 .821 .721 .320 .1 \quad 18.420 .2$ 21.021 .221 .822 .723 .123 .623 .923 .923 .823 .322 .321 .322 .6 13.114 .114 .916 .017 .118 .017 .817 .317 .216 .915 .413 .515 .9 $18.118 .519 .019 .419 .920 .120 .2 \quad 20.220 .220 .019 .518 .419 .5$ $18.518 .218 .619 .320 .421 .221 .621 .621 .020 .7 \quad 19.918 .820 .0$ 21.221 .621 .821 .821 .922 .322 .723 .122 .922 .422 .021 .622 .1 $19.519 .620 .121 .021 .822 .722 .822 .922 .822 .5 \quad 21.520 .221 .5$ $19.219 .220 .020 .422 .122 .422 .923 .022 .822 .221 .1 \quad 19.921 .3$ $18.318 .419 .120 .021 .322 .222 .322 .322 .021 .620 .3 \quad 18.820 .5$ 17.217 .818 .619 .620 .620 .821 .021 .020 .720 .519 .117 .819 .5 19.719 .820 .321 .222 .323 .022 .922 .822 .822 .421 .520 .421 .6 $19.419 .920 .521 .722 .522 .923 .022 .923 .022 .7 \quad 21.720 .121 .7$ 19.319 .119 .219 .620 .220 .620 .821 .020 .820 .720 .419 .620 .1 19.419 .820 .220 .821 .721 .922 .222 .321 .921 .820 .819 .921 .0 19.419 .720 .220 .721 .722 .622 .823 .022 .522 .120 .619 .321 .2 19.019 .119 .820 .321 .021 .421 .521 .421 .220 .920 .219 .320 .4 18.518 .218 .118 .719 .820 .520 .820 .920 .920 .720 .119 .519 .7 


\section{VELOCIDAD PROMEDIO DEL VIENTO (Kms $\mathrm{x}$ Hora)}

\section{DIRECCION DEL VIENTO PREDOMINANTE}

\begin{tabular}{|c|c|c|c|c|c|c|c|c|c|c|c|c|c|}
\hline Estaciones & Ene & Feb & Mar & Abr & May. & Jun & Jul & Ago & Sep & oct & Nov & Dic & Año \\
\hline Aeropuerto Arroyo Barril & $E$ & $E$ & NE & E & $E$ & $E$ & NE & $E$ & NE & NE & NE & NE & $E$ \\
\hline Aeropuerto La Unión & E & $E$ & $E$ & $E$ & $E$ & $E$ & $E$ & $E$ & $E$ & $E$ & $E$ & $E$ & $E$ \\
\hline Aeropuerto Herrera & $N$ & SE & SE & SE & SE & SE & SE & SE & SE & $N$ & $N$ & $\mathrm{~N}$ & SE \\
\hline Aeropuerto Punta Cana & $E$ & $E$ & $E$ & $E$ & $E$ & $E$ & $E$ & $E$ & $E$ & $E$ & $E$ & $E$ & $E$ \\
\hline Barahona & SE & SE & SE & SE & SE & SE & SE & SE & SE & SE & SE & SE & SE \\
\hline Bayaguana & $E$ & $E$ & $E$ & $E$ & SE & SE & E & SE & SE & SE & $E$ & E & $E$ \\
\hline Jimani & E & E & $E$ & E & E & $\mathrm{E}$ & $E$ & $E$ & $\mathrm{E}$ & $\mathrm{E}$ & $E$ & $E$ & $E$ \\
\hline La Vega & SE & SE & SE & SE & SE & SE & SE & SE & SE & SE & SE & SE & SE \\
\hline Sabana de la Mar & $E$ & $E$ & $E$ & $E$ & $E$ & $E$ & $E$ & $E$ & $E$ & $E$ & E & $E$ & E \\
\hline San Cristóbal & $\mathrm{N}$ & $N$ & SE & SE & SE & SE & $N$ & $\mathrm{~N}$ & SE & SE & $N$ & $N$ & SE \\
\hline San Juan de la Maguana & $\mathrm{E}$ & $E$ & $E$ & $E$ & $E$ & $E$ & $E$ & $E$ & $E$ & $E$ & $E$ & $E$ & $E$ \\
\hline Santiago & $E$ & $E$ & $E$ & $E$ & $E$ & $E$ & $E$ & $E$ & $E$ & $E$ & $E$ & $E$ & E \\
\hline Santo Domingo & $\mathrm{N}$ & $N$ & $N$ & $N$ & $N$ & $N$ & $N$ & $\mathrm{~N}$ & $N$ & $N$ & $N$ & $N$ & $N$ \\
\hline
\end{tabular}

\section{VELOCIDAD PROMEDIO DEL VIENTO (Kms $\mathrm{x}$ Hora)}

Estaciones

Aeropuerto La Unión

Aeropuerto Herrera

Aeropuerto Las Américas

Aeropuerto Punta Cana

Barahona

Constanza
Ene Feb Mar Abr May Jun Jul Ago Sep Oct Nor Dic Año

$\begin{array}{lllllllllllll}7.8 & 8.7 & 10.0 & 9.9 & 9.1 & 12.5 & 12.9 & 12.4 & 11.4 & 8.8 & 7.8 & 7.6 & 9.9\end{array}$

$\begin{array}{llllllllllllll}13.7 & 14.5 & 14.9 & 14.4 & 14.1 & 13.5 & 14.0 & 12.8 & 13.0 & 11.7 & 12.6 & 13.1 & 13.5\end{array}$

$\begin{array}{lllllllllllll}11.8 & 12.3 & 12.9 & 13.1 & 12.3 & 12.7 & 12.6 & 11.9 & 11.2 & 10.9 & 11.2 & 12.2 & 12.1\end{array}$

$\begin{array}{lllllllllllll}16.3 & 16.9 & 15.7 & 15.7 & 13.8 & 14.1 & 16.8 & 15.7 & 13.5 & 12.3 & 15.7 & 17.0 & 15.3\end{array}$

$\begin{array}{lllllllllllll}12.8 & 14.2 & 15.6 & 15.3 & 14.2 & 14.6 & 15.3 & 14.4 & 13.1 & 11.5 & 11.4 & 11.7 & 13.7\end{array}$

$\begin{array}{llllllllllll}10.4 & 10.3 & 11.3 & 10.7 & 9.1 & 10.2 & 12.7 & 11.8 & 9.8 & 8.9 & 9.6 & 10.6\end{array}$

10.4 


\section{DIRECCION DEL VIENTO PREDOMINANTE}

\begin{tabular}{|c|c|c|c|c|c|c|c|c|c|c|c|c|c|}
\hline Estaciones & Ene & Feb & Mar & Abr & May & Jun & Jul & Ago & Sep & Oct & Nor & Dic & Año \\
\hline Aeropuerto Arroyo Barril & $E$ & $E$ & NE & $E$ & $E$ & $E$ & NE & $E$ & NE & NE & NE & NE & $E$ \\
\hline Aeropuerto La Unión & E & E & $E$ & E & E & E & $E$ & $E$ & $E$ & $E$ & $E$ & $E$ & E \\
\hline Aeropuerto Herrera & $N$ & SE & SE & SE & SE & SE & SE & SE & SE & N & $\mathrm{N}$ & N & SE \\
\hline Aeropuerto Punta Cana & $E$ & $E$ & $E$ & $E$ & $E$ & $E$ & $E$ & $E$ & $E$ & $E$ & $E$ & $E$ & $E$ \\
\hline Barahona & SE & SE & SE & SE & SE & SE & SE & SE & SE & SE & SE & SE & SE \\
\hline Bayaguana & $E$ & $E$ & E & $E$ & SE & SE & $E$ & SE & SE & SE & E & $E$ & $E$ \\
\hline Jimani & $E$ & $E$ & $E$ & $E$ & $E$ & E & $E$ & $E$ & $E$ & $E$ & $E$ & $E$ & $E$ \\
\hline La Vega & SE & SE & SE & SE & SE & SE & SE & SE & SE & SE & SE & SE & SE \\
\hline Sabana de la Mar & $E$ & $E$ & $E$ & $E$ & $E$ & $E$ & $E$ & $E$ & $E$ & $E$ & $E$ & $E$ & $E$ \\
\hline San Cristóbal & $N$ & $N$ & SE & SE & SE & SE & $N$ & $N$ & SE & SE & $N$ & $N$ & SE \\
\hline San Juan de la Maguana & E & E & E & E & E & E & E & E & E & E & $E$ & E & $E$ \\
\hline Santiago & $E$ & $E$ & E & E & $E$ & $E$ & $E$ & $E$ & $E$ & $E$ & $E$ & $E$ & $E$ \\
\hline Santo Domingo & $N$ & $N$ & $\mathrm{~N}$ & $N$ & $N$ & $N$ & $N$ & $N$ & $N$ & $N$ & $N$ & $N$ & $N$ \\
\hline
\end{tabular}

\section{VELOCIDAD PROMEDIO DEL VIENTO (Kms $\mathrm{x}$ Hora)}

$\begin{array}{lcccccccccccccc}\text { Estaciones } & \text { Ene } & \text { Feb } & \text { Mar } & \text { Abr } & \text { May } & \text { Jun } & \text { Jul } & \text { Ago } & \text { Sep } & \text { Oct Nov Dic } & \text { Año } \\ \text { Aeropuerto La Unión } & 7.8 & 8.7 & 10.0 & 9.9 & 9.1 & 12.5 & 12.9 & 12.4 & 11.4 & 8.8 & 7.8 & 7.6 & 9.9 \\ \text { Aeropuerto Herrera } & 13.7 & 14.5 & 14.9 & 14.4 & 14.1 & 13.5 & 14.0 & 12.8 & 13.0 & 11.7 & 12.6 & 13.1 & 13.5 \\ \text { Aeropuerto Las Américas } & 11.8 & 12.3 & 12.9 & 13.1 & 12.3 & 12.7 & 12.6 & 11.9 & 11.2 & 10.9 & 11.2 & 12.2 & 12.1 \\ \text { Aeropuerto Punta Cana } & 16.3 & 16.9 & 15.7 & 15.7 & 13.8 & 14.1 & 16.8 & 15.7 & 13.5 & 12.3 & 15.7 & 17.0 & 15.3 \\ \text { Barahona } & 12.8 & 14.2 & 15.6 & 15.3 & 14.2 & 14.6 & 15.3 & 14.4 & 13.1 & 11.5 & 11.4 & 11.7 & 13.7 \\ \text { Constanza } & 10.4 & 10.3 & 11.3 & 10.7 & 9.1 & 10.2 & 12.7 & 11.8 & 9.8 & 8.9 & 9.6 & 10.6 & 10.4\end{array}$




\section{HUMEDAD RELATIVA MEDIA MENSUAL (Porciento)}

Estaciones
Aeropuerto Arroyo Barril
Aeropuerto La Unión
Aeropuerto Herrera
Aeropuerto Las Américas
Aeropuerto Punta Cana
Barahona
Bayaguana
Cabrera
Constanza
Jimani
La Vega
Monte Cristi
Sabana de la Mar
San Cristóbal
San Juan de la Maguana
Santiago
Santo Domingo

\begin{tabular}{|c|c|c|c|c|c|c|c|c|c|c|c|}
\hline 79 & 77 & 75 & 76 & 77 & 75 & 75 & 76 & 77 & 76 & 79 & 79 \\
\hline 83 & 83 & 81 & 81 & 80 & 76 & 76 & 76 & 77 & 79 & 82 & 83 \\
\hline 75 & 75 & 74 & 74 & 76 & 76 & 76 & 76 & 76 & 77 & 77 & 75 \\
\hline 82 & 80 & 79 & 78 & 82 & 82 & 81 & 82 & 84 & 84 & 84 & 83 \\
\hline 84 & 82 & 82 & 82 & 83 & 82 & 82 & 83 & 83 & 83 & 83 & 83 \\
\hline 73 & 73 & 72 & 72 & 76 & 76 & 72 & 73 & 76 & 78 & 75 & 73 \\
\hline 74 & 71 & 69 & 71 & 75 & 75 & 75 & 77 & 78 & 78 & 77 & 75 \\
\hline 78 & 78 & 76 & 77 & 77 & 76 & 75 & 75 & 75 & 75 & 75 & 76 \\
\hline 77 & 76 & 73 & 75 & 78 & 76 & 74 & 76 & 77 & 78 & 79 & 79 \\
\hline 64 & 62 & 61 & 63 & 67 & 63 & 60 & 61 & 64 & 67 & 68 & 65 \\
\hline 75 & 73 & 69 & 71 & 73 & 71 & 71 & 70 & 71 & 74 & 78 & 78 \\
\hline 79 & 78 & 77 & 77 & 79 & 75 & 73 & 74 & 75 & 77 & 77 & 79 \\
\hline 84 & 82 & 81 & 80 & 83 & 84 & 83 & 84 & 85 & 85 & 85 & 84 \\
\hline 76 & 74 & 72 & 72 & 77 & 79 & 77 & 77 & 78 & 79 & 77 & 77 \\
\hline 70 & 69 & 68 & 70 & 73 & 71 & 69 & 70 & 72 & 74 & 73 & 71 \\
\hline 77 & 75 & 72 & 72 & 74 & 71 & 71 & 71 & 73 & 75 & 78 & 79 \\
\hline 82 & 80 & 79 & 79 & 83 & 84 & 84 & 84 & 85 & 86 & 85 & 84 \\
\hline
\end{tabular}

\section{NUBOSIDAD PROMEDIO MENSUAL (Octavos)}

Estaciones

Aeropuerto Arroyo Barril

Aeropuerto La Unión

Aeropuerto Herrera

Aeropuerto Las Américas

Aeropuerto Punta Cana

Barahona

Bayaguana

Jimani

Monte Cristi

Puerto Plata

Sabana de la Mar

San Cristóbal

San Juan de la Maguana

Santiago

Santo Domingo
Ene Feb Mar Abr May Jun Jul Ago Sep Oct Nov Dic Año $\begin{array}{lllllllllllll}4.0 & 3.6 & 3.4 & 3.8 & 4.6 & 4.2 & 4.2 & 4.3 & 4.4 & 4.5 & 4.6 & 4.0 & 4.1\end{array}$

$\begin{array}{lllllllllllll}3.9 & 3.8 & 3.7 & 4.1 & 4.7 & 3.9 & 3.9 & 3.8 & 3.9 & 3.9 & 4.3 & 3.9 & 4.0\end{array}$

$\begin{array}{lllllllllllll}4.1 & 4.2 & 4.1 & 4.4 & 5.1 & 4.9 & 4.9 & 4.8 & 4.8 & 4.6 & 4.4 & 4.0 & 4.5\end{array}$

$\begin{array}{lllllllllllll}3.7 & 3.8 & 3.7 & 4.1 & 4.9 & 4.8 & 4.7 & 4.6 & 4.8 & 4.7 & 4.2 & 4.0 & 4.3\end{array}$

$\begin{array}{lllllllllllll}3.6 & 3.6 & 3.6 & 3.6 & 4.5 & 4.3 & 4.2 & 4.0 & 4.1 & 4.0 & 4.0 & 3.8 & 3.9\end{array}$

$\begin{array}{lllllllllllll}2.7 & 2.8 & 3.0 & 3.3 & 4.3 & 4.4 & 3.9 & 3.9 & 4.1 & 3.9 & 3.2 & 2.8 & 3.5\end{array}$

$\begin{array}{lllllllllllll}4.4 & 4.5 & 4.7 & 5.0 & 5.5 & 5.3 & 5.0 & 4.9 & 5.1 & 4.9 & 4.8 & 4.6 & 4.9\end{array}$

$\begin{array}{lllllllllllll}2.7 & 2.9 & 3.2 & 3.6 & 4.2 & 3.8 & 3.4 & 3.6 & 3.9 & 3.8 & 3.3 & 2.8 & 3.4\end{array}$

$\begin{array}{lllllllllllll}3.3 & 3.5 & 3.3 & 3.8 & 4.4 & 3.9 & 3.8 & 3.7 & 4.0 & 4.0 & 3.8 & 3.6 & 3.8\end{array}$

$\begin{array}{lllllllllllll}3.8 & 3.6 & 3.5 & 3.7 & 4.1 & 4.0 & 3.7 & 3.7 & 3.9 & 3.9 & 4.4 & 4.3 & 3.9\end{array}$

$\begin{array}{lllllllllllll}3.6 & 3.6 & 3.5 & 3.9 & 4.7 & 4.3 & 4.3 & 4.2 & 4.3 & 4.1 & 4.1 & 3.8 & 4.0\end{array}$

$\begin{array}{lllllllllllll}3.8 & 4.0 & 4.0 & 4.2 & 4.3 & 4.4 & 4.1 & 4.1 & 4.0 & 4.1 & 4.0 & 4.0 & 4.1\end{array}$

$\begin{array}{lllllllllllll}2.5 & 3.0 & 3.1 & 3.8 & 4.4 & 3.9 & 3.6 & 3.9 & 4.0 & 4.0 & 3.4 & 2.5 & 3.5\end{array}$

$\begin{array}{lllllllllllll}3.9 & 3.9 & 3.9 & 4.2 & 4.8 & 4.6 & 4.3 & 4.3 & 4.4 & 4.3 & 4.4 & 4.2 & 4.3\end{array}$

$\begin{array}{lllllllllllll}3.8 & 3.9 & 3.9 & 4.2 & 4.9 & 5.0 & 4.8 & 4.6 & 4.8 & 4.6 & 4.2 & 4.1 & 4.4\end{array}$ 


\section{PRECIPITACION PROMEDIO HISTORICO MENSUAL Y ANUAL}

(Milimetros enteros)

\begin{tabular}{|c|c|c|c|c|c|c|c|c|c|c|c|c|c|c|}
\hline Estación & Operador & $\mathbf{E}$ & $\mathbf{F}$ & $M$ & A & M & $\mathrm{J}$ & J & A & $s$ & 0 & $\mathrm{~N}$ & D & AÑO \\
\hline Aeropuerto AILA & ONAMET & 45 & 41 & 41 & 67 & 140 & 1101 & 102 & 144 & 150 & 142 & 103 & 62 & 21148 \\
\hline Aeropuerto.Arroyo.Barril & ONAMET & 123 & 78 & 103 & 158 & 309 & 158 & 151 & 180 & 211 & 249 & 254 & 189 & 92162 \\
\hline Aeropuerto Herrera & ONAMET & 101 & 107 & 78 & 92 & 198 & 1411 & 131 & 164 & 228 & 209 & 168 & 78 & 81694 \\
\hline Aeropuerto La Unión & ONAMET & 181 & 138 & 118 & 127 & 155 & 51 & 66 & 74 & 66 & 107 & 240 & 219 & 91540 \\
\hline Abadesa & ONAMET & 66 & 60 & 89 & 121 & 247 & 2061 & 184 & 232 & 201 & 161 & 118 & & 61770 \\
\hline Altamira & ONAMET & 145 & 125 & 117 & 183 & 236 & 130 & 72 & 85 & 145 & 187 & 251 & 203 & 31878 \\
\hline Azua & ONAMET & 20 & 14 & 19 & 39 & 96 & 64 & 43 & 78 & 116 & 128 & 45 & 17 & 679 \\
\hline Baní & ONAMET & 29 & 27 & 30 & 46 & 140 & 137 & 87 & 122 & 131 & 143 & 59 & 26 & 6978 \\
\hline Bánica & ONAMET & 16 & 23 & 40 & 137 & 258 & 1621 & 151 & 190 & 208 & 188 & 57 & 29 & 91453 \\
\hline Barahona & ONAMET & 30 & 31 & 40 & 70 & 186 & 151 & 39 & 77 & 133 & 183 & 70 & & 01049 \\
\hline Bayaguana & ONAMET & 44 & 59 & 76 & 132 & 257 & 2212 & 219 & 254 & 213 & 185 & 105 & & 71820 \\
\hline Bonao & ONAMET & 123 & 115 & 114 & 221 & 347 & 1611 & 178 & 194 & 183 & 227 & 222 & 143 & 32227 \\
\hline Cabo Engaño & ONAMET & 65 & 48 & 48 & 65 & 129 & 100 & 78 & 92 & 95 & 134 & 115 & & 81054 \\
\hline Cabral & ONAMET & 22 & 18 & 23 & 33 & 132 & 123 & 44 & 111 & 104 & 136 & 55 & 21 & 1821 \\
\hline Cabrera & ONAMET & 151 & 109 & 93 & 128 & 210 & 1161 & 152 & 167 & 154 & 210 & 276 & 198 & 81965 \\
\hline Cacheo & ONAMET & 14 & 20 & 39 & 64 & 114 & 78 & 75 & 117 & 145 & 123 & 62 & 15 & 5866 \\
\hline Cacique & ONAMET & 67 & 72 & 89 & 124 & 232 & 1951 & 195 & 257 & 209 & 182 & 109 & & 41803 \\
\hline Cevicos & ONAMET & 81 & 85 & 95 & 144 & 303 & 2442 & 240 & 254 & $194^{\circ}$ & 181 & 152 & 114 & 42088 \\
\hline Comendador & ONAMET & 15 & 35 & 74 & 170 & 330 & 200 & 160 & 230 & 2672 & 230 & 85 & 28 & 81823 \\
\hline Constanza & ONAMET & 37 & 36 & 33 & 68 & 186 & 111 & 71 & 107 & 121 & 110 & 68 & 53 & 3999 \\
\hline Cotuí & ONAMET & 86 & 91 & 88 & 130 & 235 & 1501 & 181 & 184 & 152 & 143 & 148 & 127 & 71714 \\
\hline Dajabón & ONAMET & 37 & 46 & 51 & 89 & 198 & 181 & 98 & 125 & 142 & 148 & 88 & & 11273 \\
\hline Duveraé & ONAMET & 8 & 14 & 21 & 28 & 87 & 52 & 20 & 70 & 70 & 77 & 37 & 11 & 1494 \\
\hline San Pedro de Macorís & ONAMET & 32 & 32 & 31 & 59 & 140 & 971 & 102 & 113 & 146 & 148 & 99 & 52 & 21050 \\
\hline San Rafael del Yuma & ONAMET & 73 & 51 & 67 & 72 & 179 & 102 & 92 & 122 & 147 & 162 & 134 & 89 & 91290 \\
\hline San José de Ocoa & ONAMET & 27 & 30 & 35 & 84 & 196 & 123 & 85 & 111 & 152 & 149 & 66 & 29 & 91085 \\
\hline Santiago & ONAMET & 52 & 50 & 57 & 91 & 164 & 67 & 53 & 63 & 91 & 108 & 106 & 77 & $7 \quad 979$ \\
\hline Santo Domingo & ONAMET & 59 & 53 & 51 & 73 & 188 & 1521 & 145 & 161 & 173 & 171 & 109 & 74 & 41410 \\
\hline Tamayo & ONAMET & 9 & 9 & 16 & 37 & 61 & 59 & 23 & 58 & 59 & 57 & 32 & 18 & $8 \quad 437$ \\
\hline Villa Altagracia & ONAMET & 97 & 90 & 102 & 164 & 285 & 2562 & 2442 & $261:$ & 234 & 250 & 175 & 175 & 52261 \\
\hline Villa Riva & ONAMET & 136 & 118 & 117 & 146 & 270 & 2412 & 2142 & 228 & $209^{\prime}$ & 187 & 214 & 187 & 72267 \\
\hline Villa vásquez & ONAMET & 37 & 32 & 39 & 56 & 84 & 73 & 37 & 40 & 53 & 71 & 83 & 63 & $\begin{array}{ll}3 \quad 667\end{array}$ \\
\hline Yamasá & ONAMET & 94 & 81 & 81 & 159 & 289 & 2302 & 2422 & 269 & 227 & 207 & 145 & 107 & 72131 \\
\hline
\end{tabular}




\section{RECURSOS BIBLIOGRAFICOS}

\section{LIBROS}

1. MARTIN, NURIA; FERNANDEZ, IGNACIO.

2007. La Envolvente Fotovoltaica en la Arquitectura.

Ed. Reverte. Barcelona.

2. HERNANDEZ PEZZI, CARLOS.

2007. Un Vitruvio Ecológico: Principios y Practica del Proyecto Arquitectónico Sostenible.

Ed. Gustavo Gili. Barcelona.

3. GORE, ALBERT.

2006. An Inconvenient Truth: The Planetary Emergency of Global Warming and What We Can Do About it.

Ed. Gedisa. Barcelona

4. E. BREA; M. DOMINGUEZ; L. ROCA; R. SILVESTRE; J. DEL MONTE. 2006. Santo Domingo. Guía de Arquitectura.

Ed. Dirección General de Arquitectura y Vivienda. Junta de Andalucía. Sevilla- Santo Domingo.

5. HERMANNSDORFER, INGRID; RUB, CHRISTINE.

2005. Solar Desing. Photovoltaics for Old Buildings, Urban Space, Landscapes.

Ed. GCC Grafisches Centrun Cuno, Calbe. Berling.

6. MENDEZ, MUÑIZ; CUERVO, RAFAEL.

2005. Energía Solar Fotovoltaica.

Ed. Fundación Confemetal. Madrid.

7. Energía Solar Fotovoltaica: Manual del Proyectista.

2004.

Ed. Junta de Castilla y León.

8. Energía Solar Fotovoltaica: Manual del Arquitecto.

2004.

Ed. Junta de Castilla y León.

9. NEILA, JAVIER.

2004. Arquitectura Bioclimática.

Ed. Munilla-Lería. Madrid.

10. SERRASOLSES, JAUME.

2004. Tejados Fotovoltaicos. Energía solar conectada a la red eléctrica.

Ed. Progensa. Sevilla.

11.SERRA, RAFAEL.

2004. Arquitectura y Climas.

Ed. Gustavo Gili. Barcelona.

12. NEILA, JAVIER.

2003. 11 Propuestas de Arquitectura Medioambiental. Mayab 2003

Ed. Mairea Libros. Madrid. 
13. OLGYAY, VICTOR.

2003. Arquitectura y Clima. Manual de Diseño Bioclimático para Arquitectura y Urbanismo.

Ed. Gustavo Gili. Barcelona.

14. SCHITTICH, CHRISTIAN.

2003. Arquitectura Solar. Estrategias, Visiones, Conceptos.

Ed. Detail. Munich.

15. GARCIA, JOSE.

2003. Cálculo de la Energía Solar.

Ed. Bellisco. Madrid.

16. HAWKES, DEAN; FORSTER WAYNE.

2002. Ingeniería, Arquitectura y Medioambiente.

Ed. Cisspraxis. Valencia.

17. RUANO, MIGUEL.

2002. Eco-Urbanismo.

Ed. Gustavo Gili. Barcelona.

18. NEUFERT, ERNEST.

2000. Arte de Proyectar en Arquitectura.

Ed. Gustavo Gili. Barcelona.

19. ARMANDO, DELFIS.

2000. Arquitectura Ecológica Tropical.

Ed. Árbol. México.

20. BOSCH, JUAN.

2000. El Caribe, Frontera Imperial.

Ed. Alfa y Omega. Santo Domingo.

21. CUITO, AURORA.

1999. Eco-Tecture.

Ed. Loft Publications, S.L.Barcelona.

22. CATHERINE, SLESSOR.

1997. Eco- Tech.

Ed. Gustavo Gili. Barcelona.

23. SENSONIAN; JAVIER.

1997. Bioarquitectura.

Ed. Noriega. México.

\section{PUBLICACIONES}

1. AA.VV.

2008. Informe sobe desarrollo humano. República Dominicana.

Ed. Pnud. Santo Domingo.

2. AA.VV.

2007. El Sol puede ser suyo. Respuestas a preguntas sobre FV.

Ed. Idae. Madrid. 
3. AA. VV.

2007. Procedimiento Básico Para La Certificación De Eficiencia

Energética De Los Edificios De nueva construcción.

Ed. Legran. Madrid.

4. WOLFSEGGER, CHRISTOPH; STIERSTORFER, JOHANNES; AUBREY, CRISPIN. 2007. Solar Generation IV.

Ed. Greenpeace- EPIA. Amsterdam.

5. RODRIGUEZ, EDWIN.

2007. Seminario de Arquitectura Bioclimática Tropical.

Ed. Mayab. Madrid.

6. CAAMAÑO, ESTEFANIA; EGIDO, MIGUEL. 2005. Módulo Fotovoltaica Mayab.

Ed. Mayab. Madrid

7. AA.VV.

2005. Water, Electricity and the Poor: Who benefist from utility subsidies?

The World Bank. Washington.

8. JIMENEZ, ANTONIO; OLSON KEN.

1998. Energía Renovable para centros de salud rurales.

Ed. Laboratorio Nacional de Energía Renovable de EE.UU. Colorado.

9. AA. VV..

The History of Solar.

Ed. U.S. Department of Energy.

10. GATON, DOMINGO.

Apuntes de Arquitectura y Clima. República Dominicana.

11. BEDOLLA, CESAR; NEILA, JAVIER.

Acondicionamiento y Energía Solar en Arquitectura.

\section{REVISTAS}

1. AA. VV.

2008. Archivos de Arquitectura Antillana ${ }^{\circ} 29$.

Ed. AAA. Santo Domingo.

2. AA. VV.

2006. Archivos de Arquitectura Antillana ${ }^{\circ} 24$.

Ed. AAA. Santo Domingo.

3. AA. VV.

2006. Archivos de Arquitectura Antillana ${ }^{\circ} 23$.

Ed. AAA. Santo Domingo.

4. AA.VV.

2005. DETAIL n6. Solar Architecture.

Ed. Detail. Germany. 


\section{PAGINAS Y ENLACES WEB}

1.www.listin.com.do

2. www.hoy.com.do

3. www.elnacional.com.do

4. www.elcaribecdn.com

5. www3.diariolibre.com

6. www.diariohorizonte.com

7. www.granma.cubaweb.cu

8. www.endi.com

9. www.primerahora.com

10. www. thesanjuanstar.com

11. www. eluniversal.com

12. www.jamaicanobserver.com

13. www.lanouvelliste.com

14. www.idea.es

15. www.aesol.es
16. www.bancentral.gov.do

17. www.sie.gov.do

18. www.cde.gov.do

19. www.energia.info.cu

20. www.aeepr.com

21. www.climatecrisis.net

22. www.bp.com

23. www.agenciaandaluzadelaenergia.es

24. www.wikipedia.org

25. www.worldenergy.org

26. www.solarpowerconference.com

27. www1.eere.energy.gov

28. www.sidsnet.org

29. www.isofoton.com

30. www.iea.org

31. www.ipcc.ch 
ANEXO 2

DOCUMENTACIÓN GRÁFICA SOBRE LA CASA WICHITA DE RICHARD BUCKMINSTER FULLER.

DOCUMENTACIÓN GRÁFICA SOBRE LAS CASAS TROPICALES

DE JEAN PROUVÉ 
ANEXO 2.1

Documentación Gráfica sobre la Casa Wichita de Richard Buckminster Fuller. 
Las siguientes imágenes que se han incluido en este Anexo, son del libro "The artifacts of R. Buckminster Fuller. A Comprehensive Collection of His Designs and Drawings in Four Volumes" (Dymaxion deployment, 1927-1946), editado por James Ward para Garland Publishing. Este libro es una recopilación de varios dibujos e información gráfica de interés, sobre la Casa Wichita (y el concepto Dymaxion).
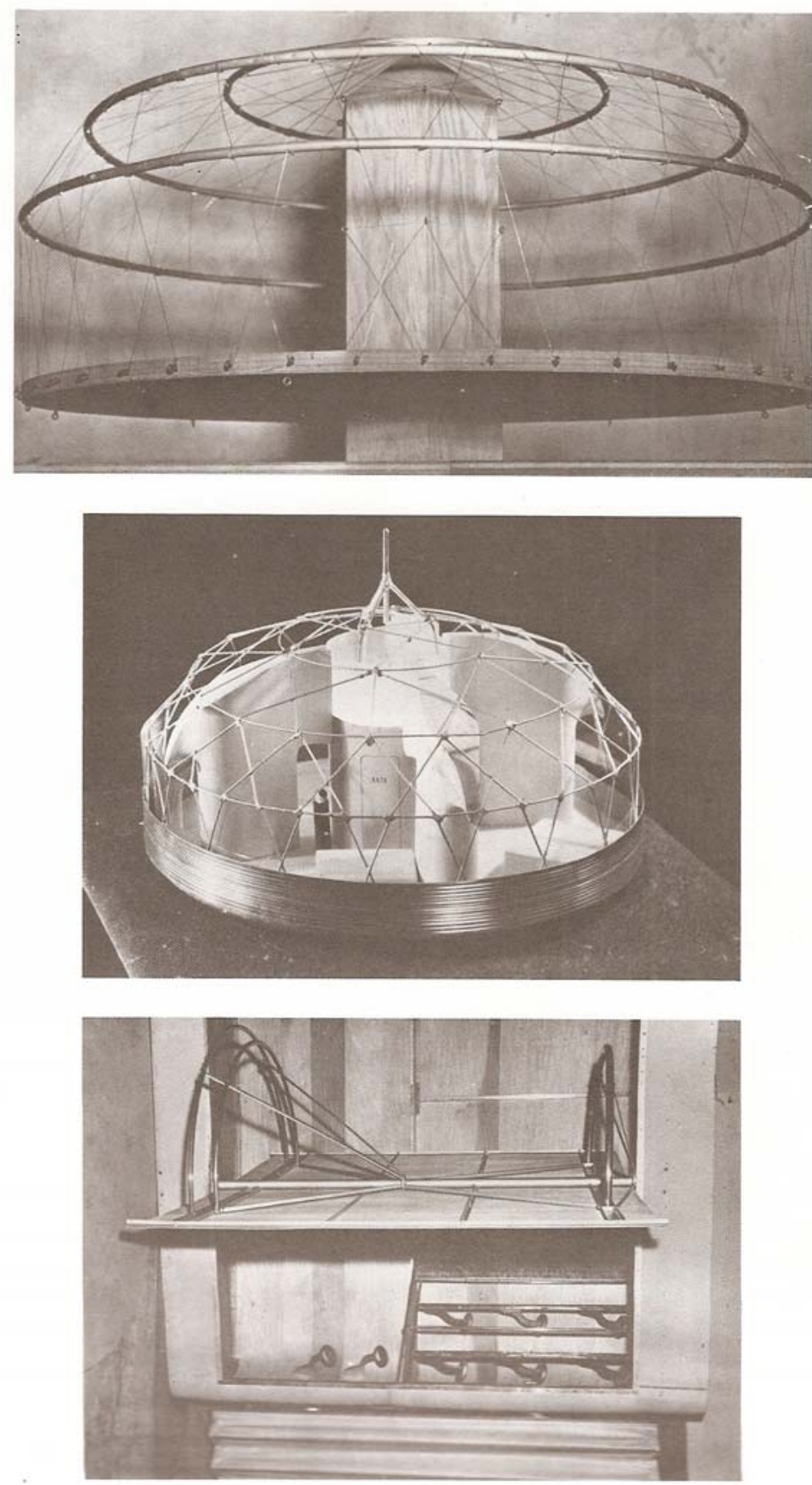

Modelo a escala sistema constructivo y estructural Casa Wichita. Fig. 1 

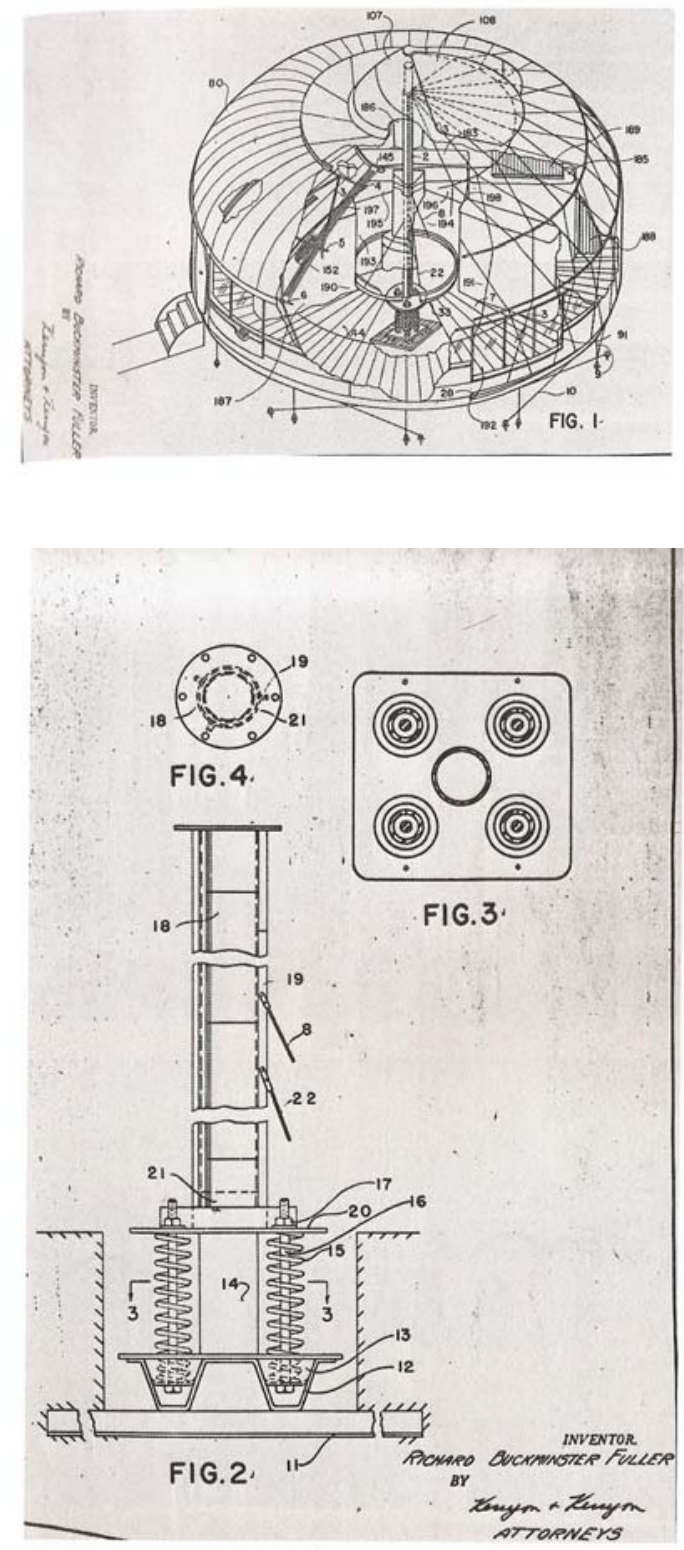

Sistema constructivo y estructural y cimentación mástil Casa Wichita. Fig. 2 

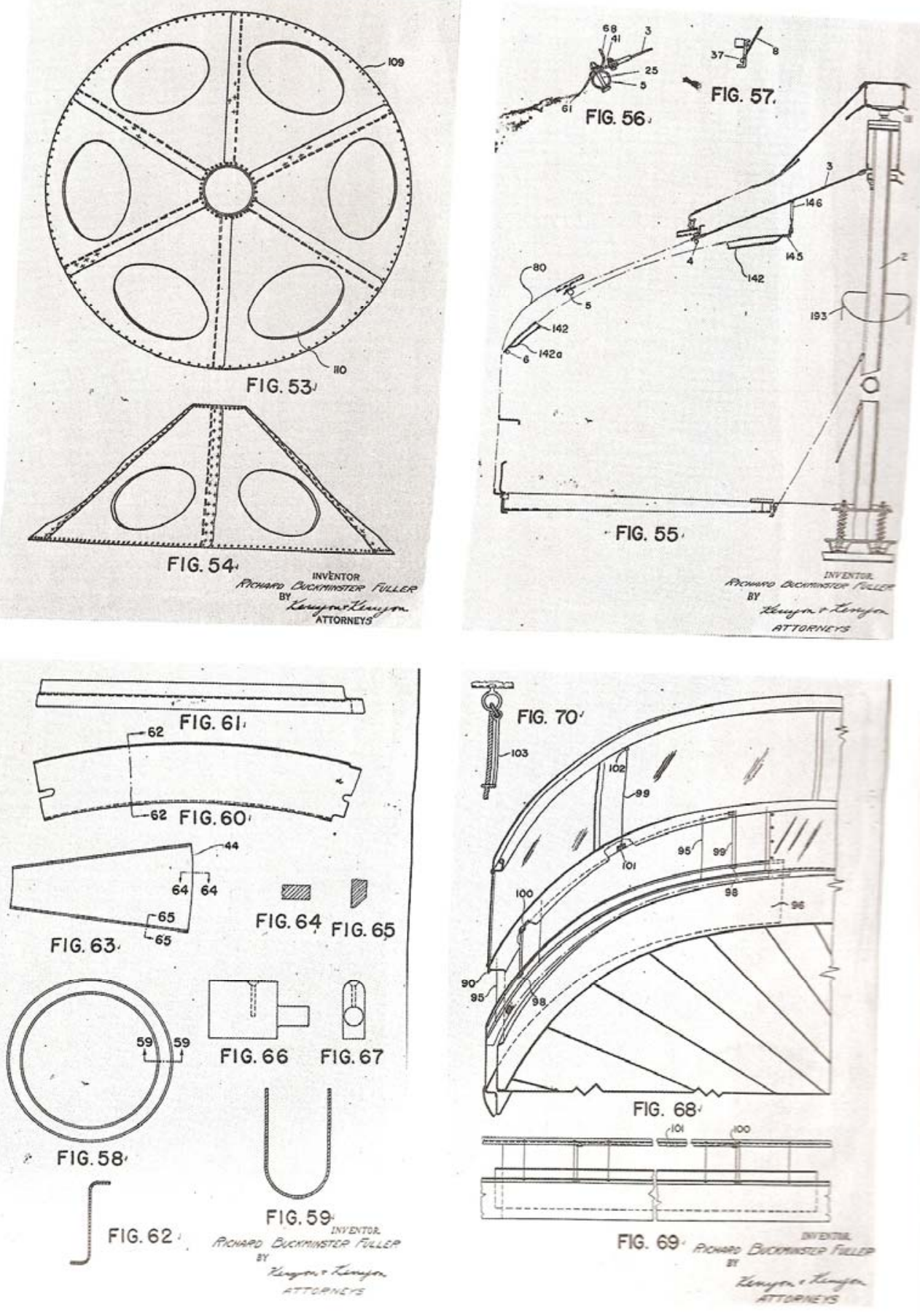

Despiece constructivo Casa Wichita. Fig. 3 

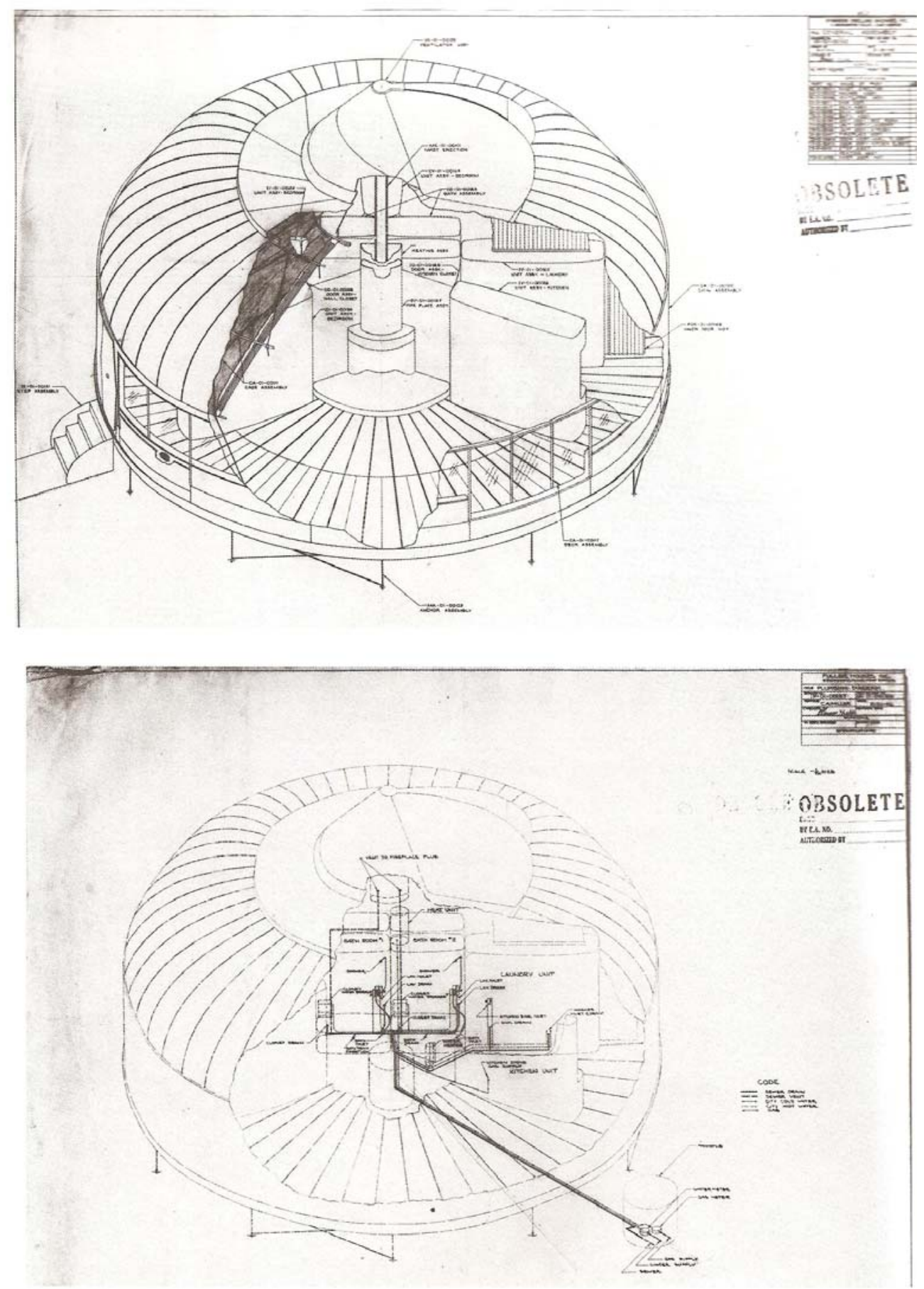

Vista tridimensional sistema constructivo Casa Wichita. Fig. 4 

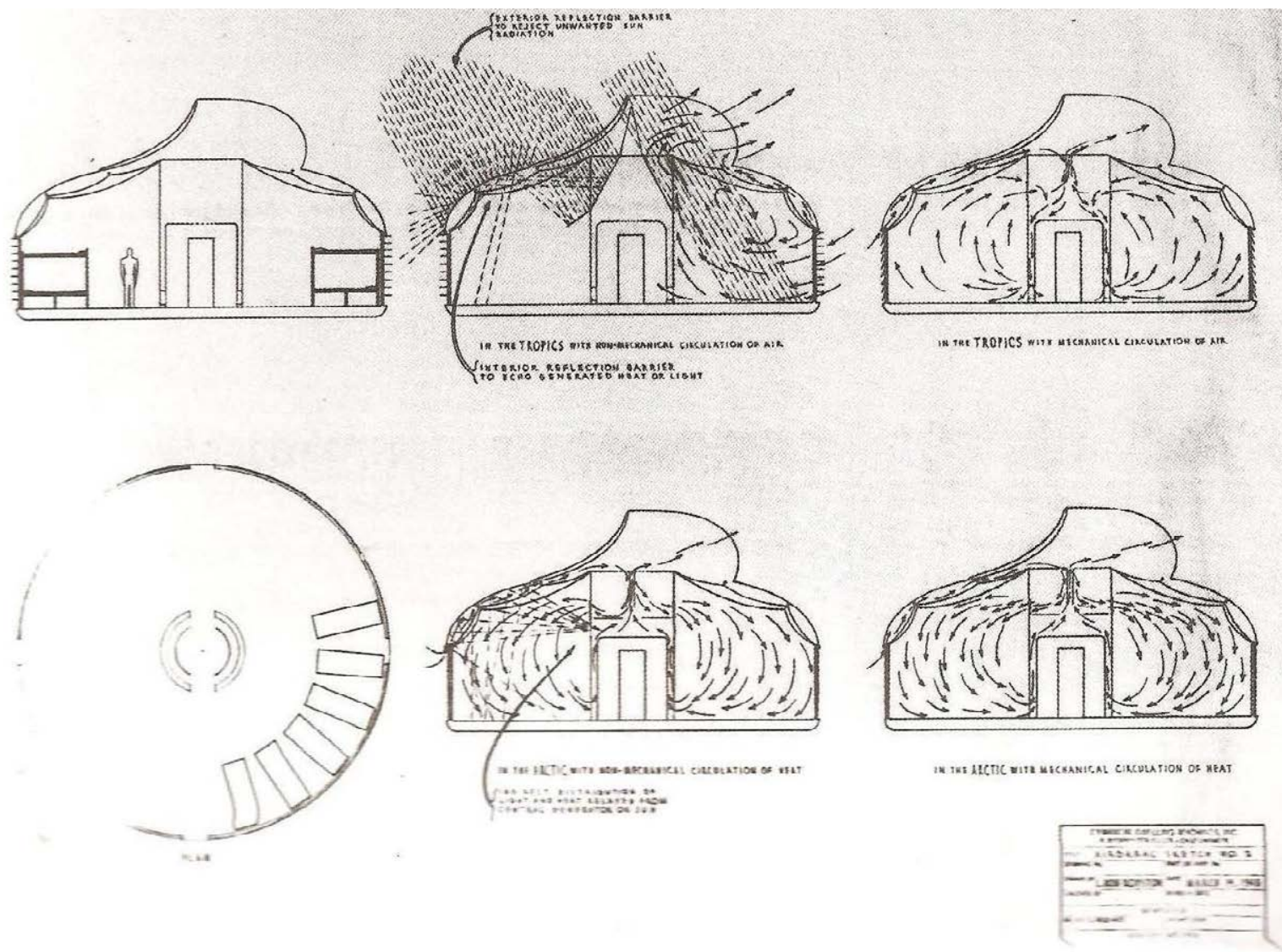

Principio de funcionamiento sistema de ventilación natural por cubierta Casa Wichita. Fig. 5

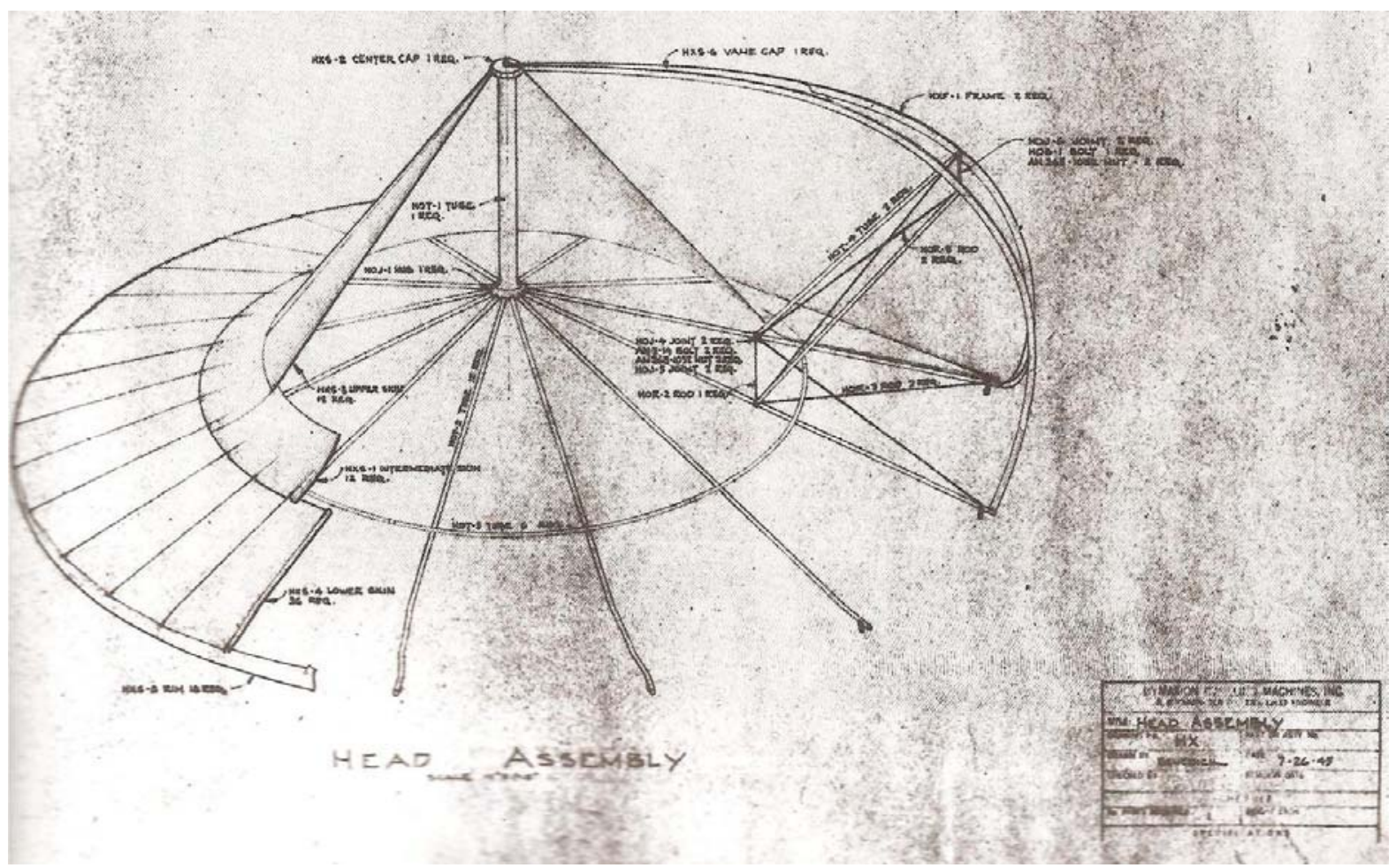

Pieza de coronación sistema de ventilación natural por cubierta Casa Wichita. Fig. 6 


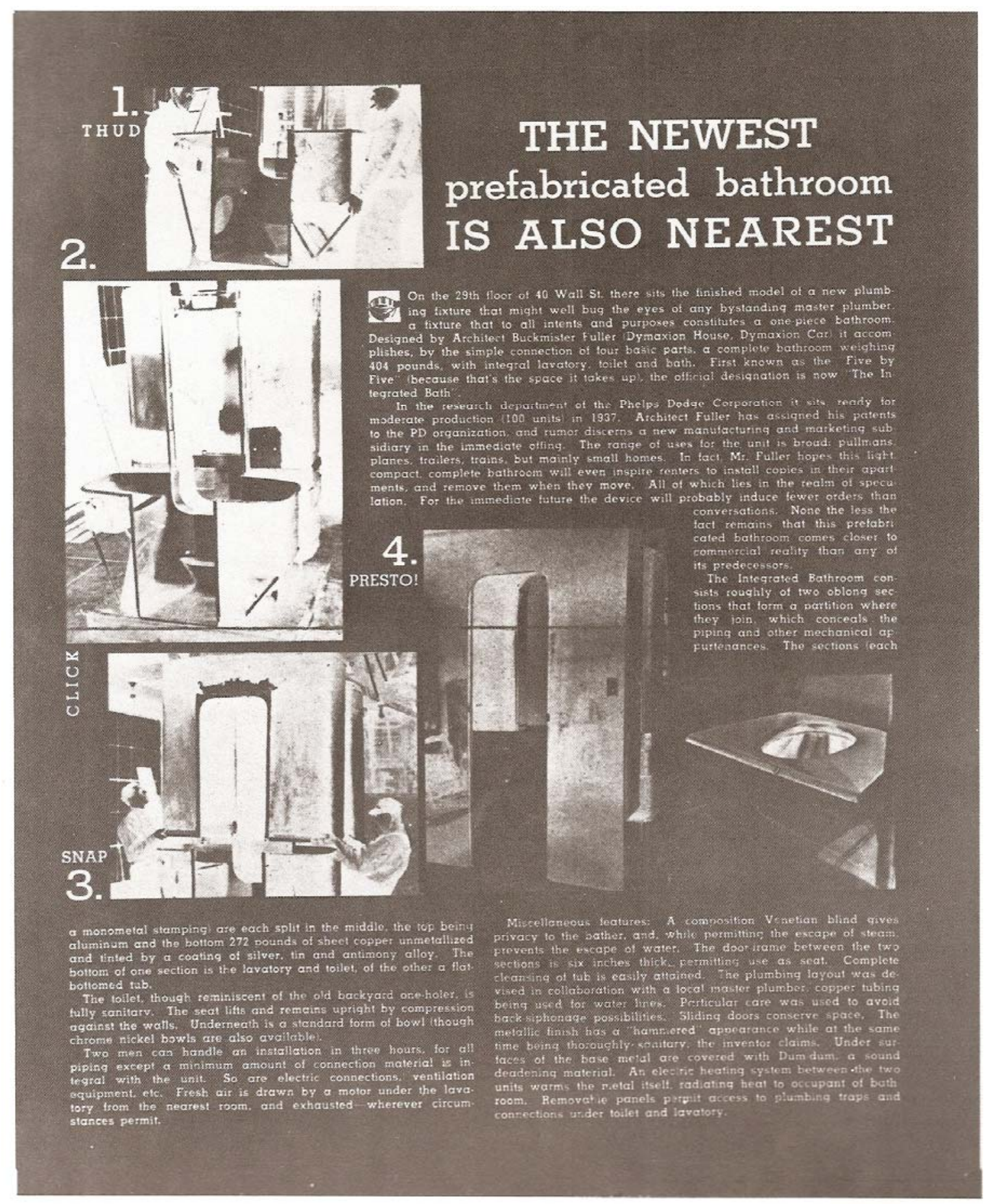

Hoja de publicidad técnico-comercial Baño Dymaxion. Fig. 7 

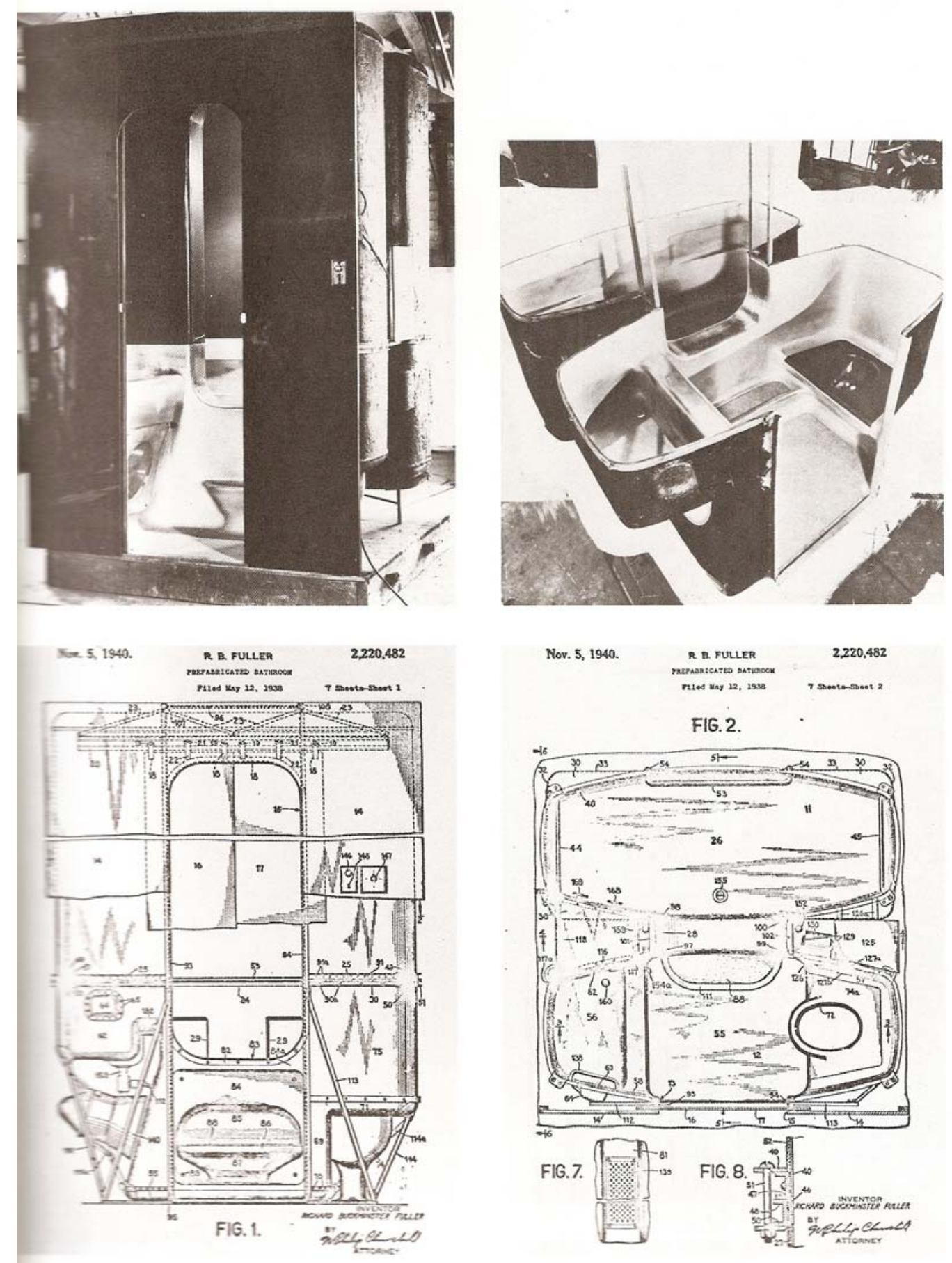

FIG. 2.

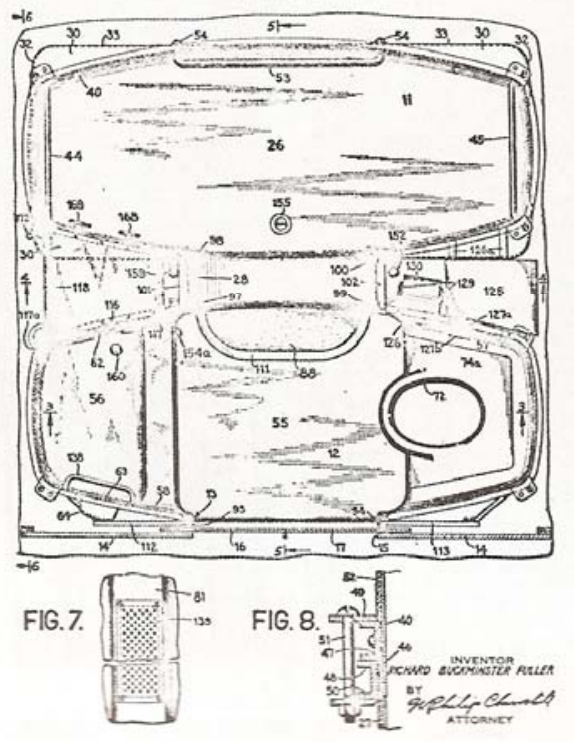

Imágenes Baño Dymaxion. Fig. 8 

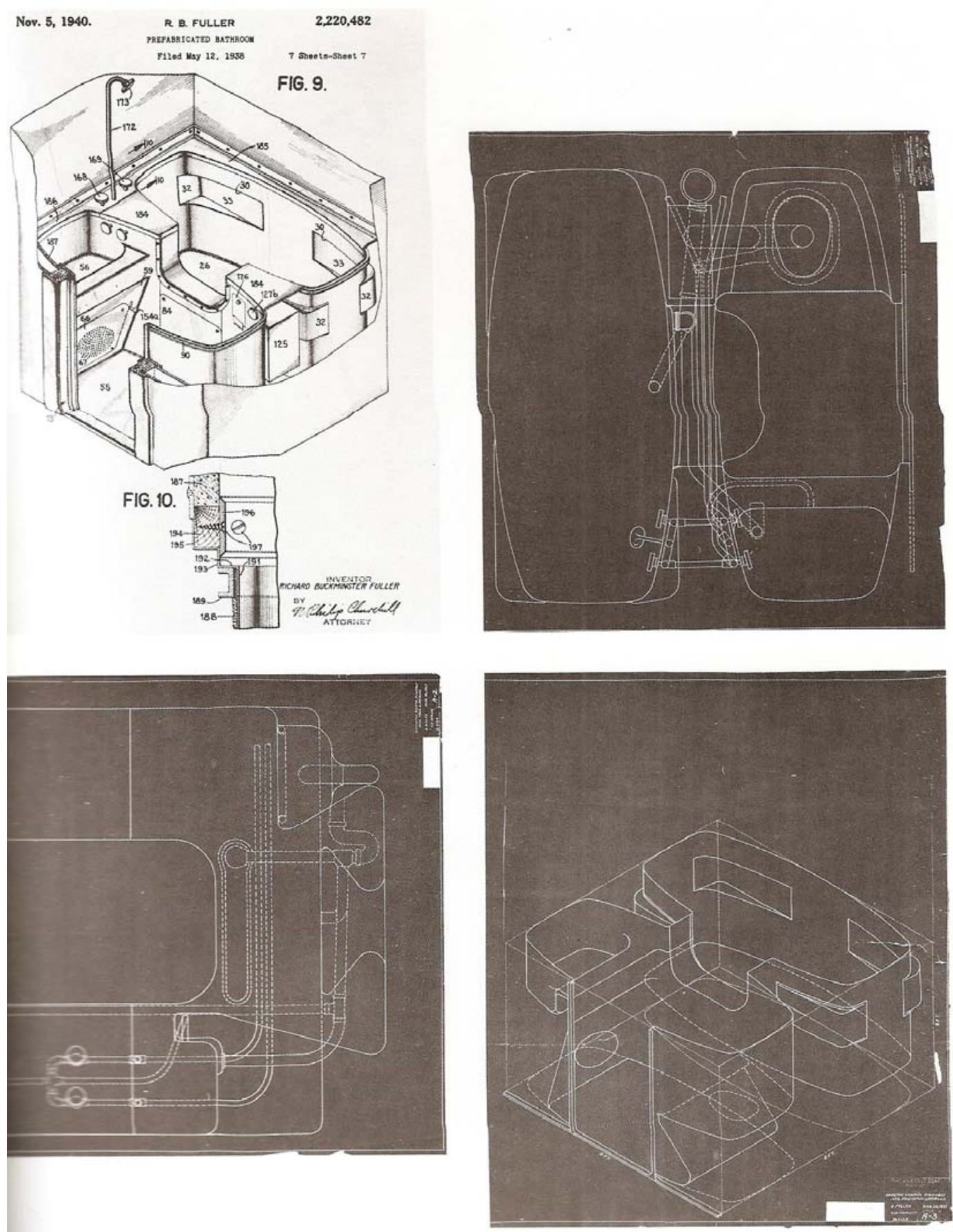

Imágenes Baño Dymaxion. Fig. 9 
ANEXO 2.2

Documentación Gráfica sobre las Casas Tropicales de Jean Prouvé 
Las siguientes imágenes han sido recopiladas del libro "Jean Prouve: La Maison Tropicale / The Tropical House", editado por el Centro Pompidou de Paris bajo la dirección de Olivier Cinqualbre en el año 2009. Se incluye en esta parte de los anexos por ser un material de considerable valor gráfico para la redacción de esta tesis, en la parte concerniente a las Casas Tropicales de Jean Prouvé, ejemplos de prototipos de CIL con soluciones de acondicionamiento pasivo.

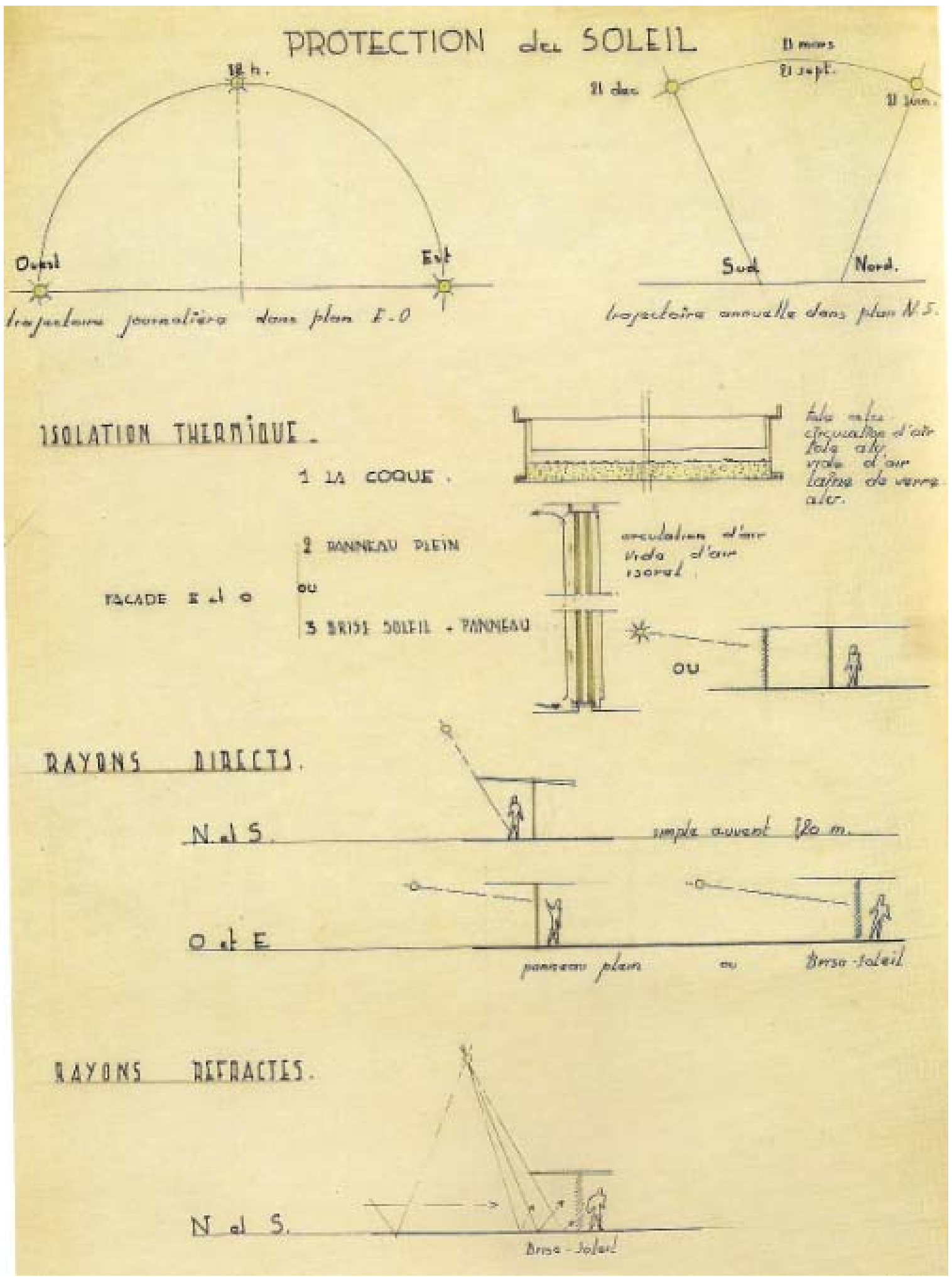

Estudio de soleamiento para los proyectos de las Casas Tropicales. Fig.10 


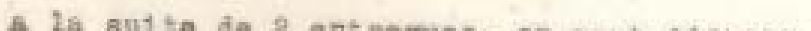

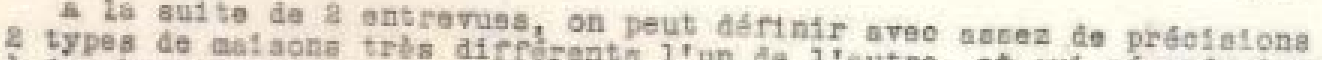
i dos beosino réls.

4) - I type entiàrenent mosalifque evee rez-de-ohausab́e ot I b́tage, ne oomportent pas de coursives, ot oorpronint ou non une cul sing toge, buanderie et $I$ góchoir.

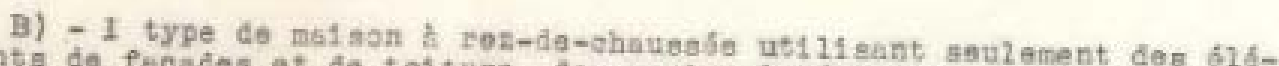
ments do feqades es do toisure, des portas intorieuroa ot des instruments on męoaneris.

\section{Ier Trig}

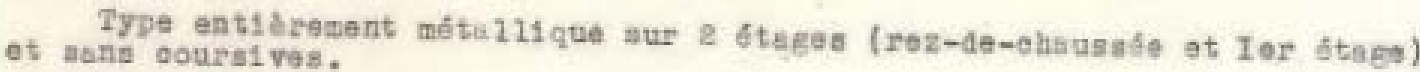

I0) - avee ouleine, busnderte at stotiolx.

ge) - acha ouisine, busncerie et eb́choir.

- Ces a sypes eomyortant toujoure un orfice (eau), une rifarve de vivros, ettenent au sflour.

- Dens le type $I$ aveo aufaino, la eufalne eat 2 l'stege.

- Une hauteur de $3 \mathrm{~m}$, sous D1ufond, en.96 exeotenent.

- z typea de pannesux de fapade :

I) I type à aliattes nobilas (I)

8) I type d dilettes firea an 2 purtien (B)

- a - une aliege rixe

- b - un ouvrunt aolt avee projeotion

aे 2*1telienne, goit à axe horizontel

SHEMC

DES DIMrgISL ONS

(2)

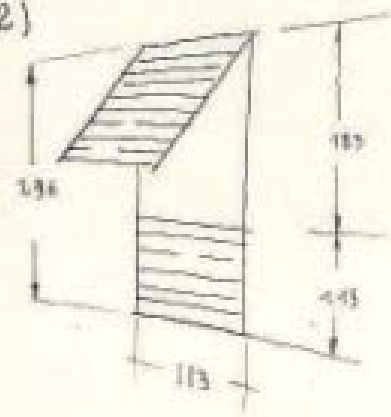

(1)

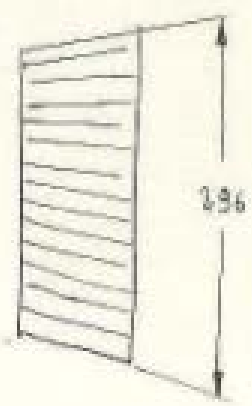

Estudio elementos de cerramiento y protección solar Casas Tropicales. Fig.11 


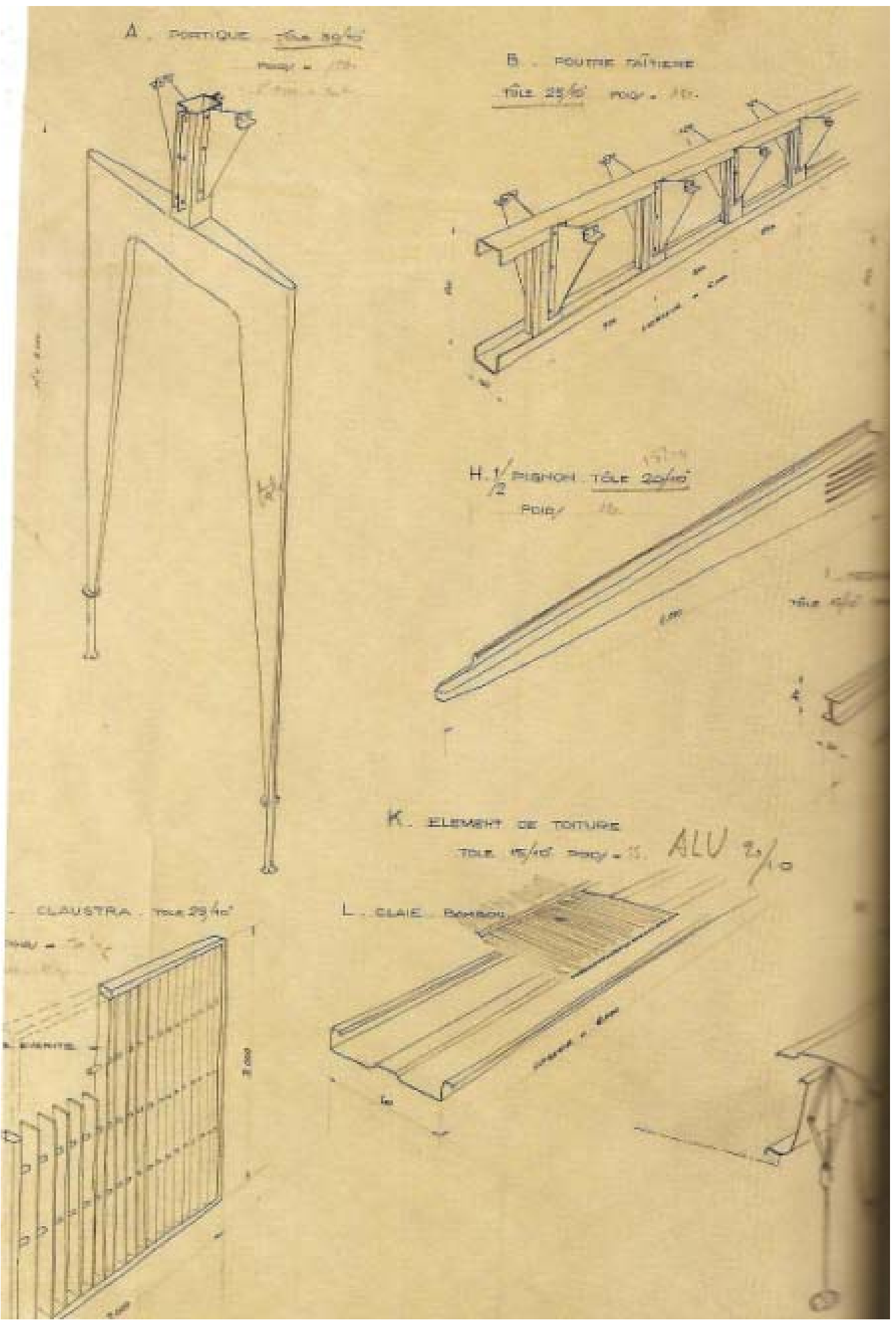

Detalles de elementos constructivos y estructurales Casas Tropicales. Fig.12 


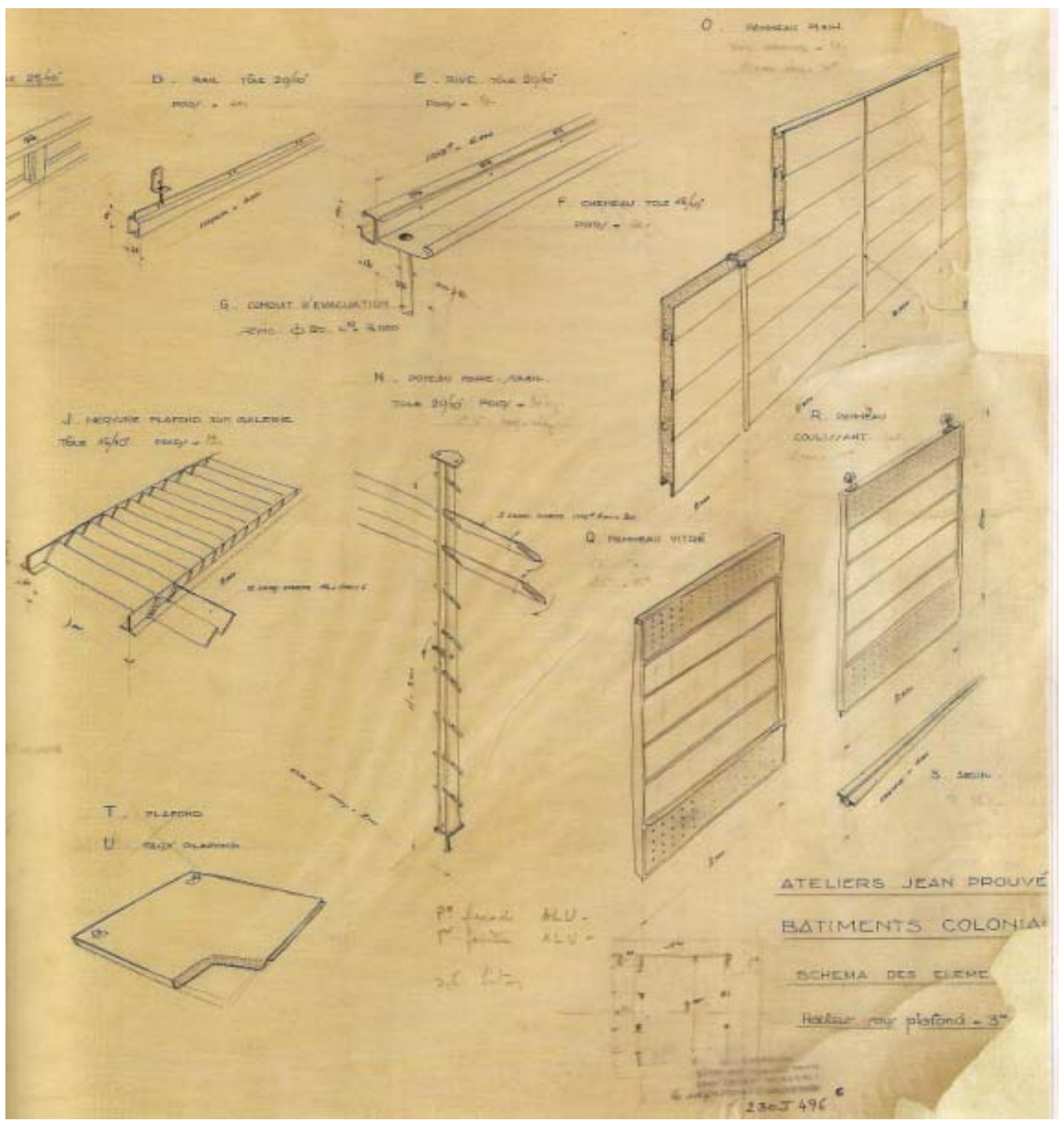

Detalles de elementos constructivos y de protección solar Casas Tropicales. Fig. 13 


\section{TECH N I Q UES}

MAISON COLONIALE PREFABRIQUEE EN ALUMINIUM

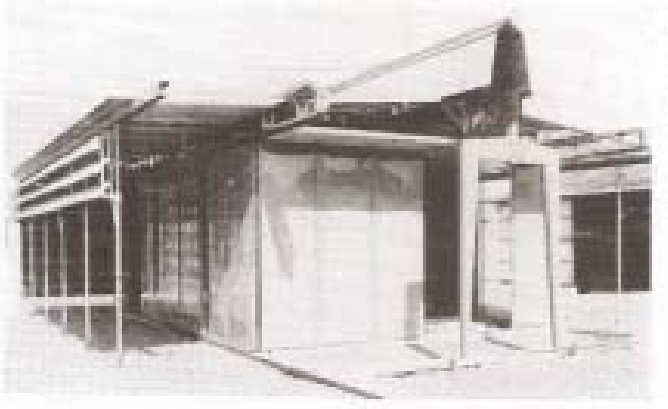

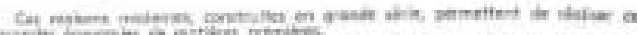

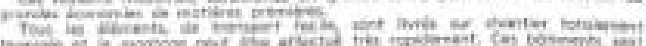

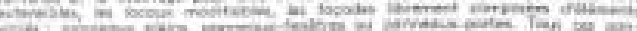

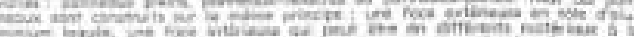

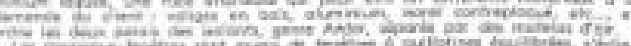

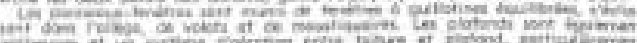

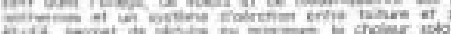
Jem hasurk, Conatiute-
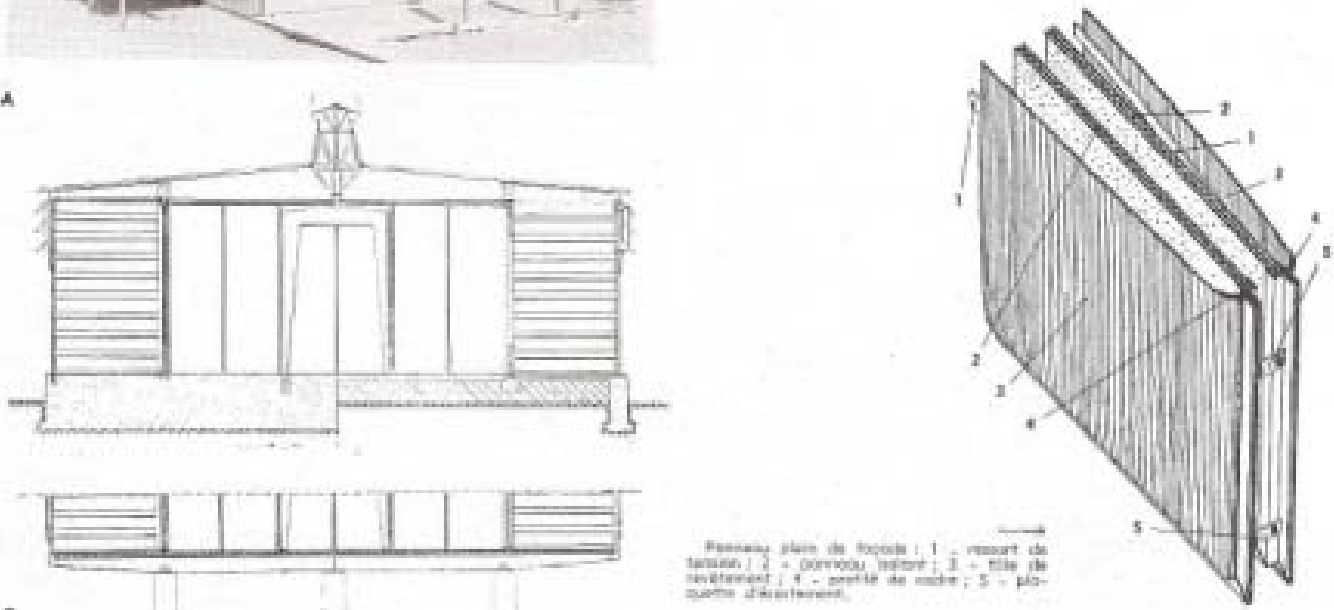

thenction

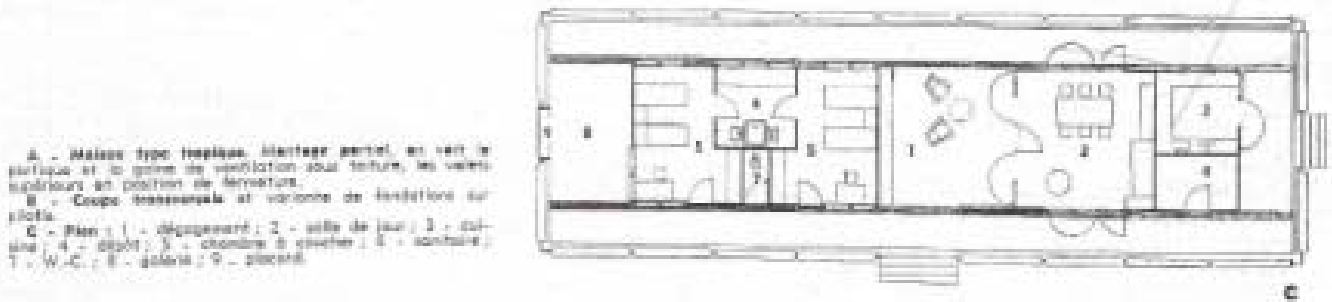

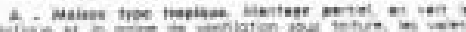

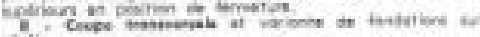

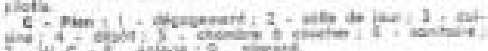
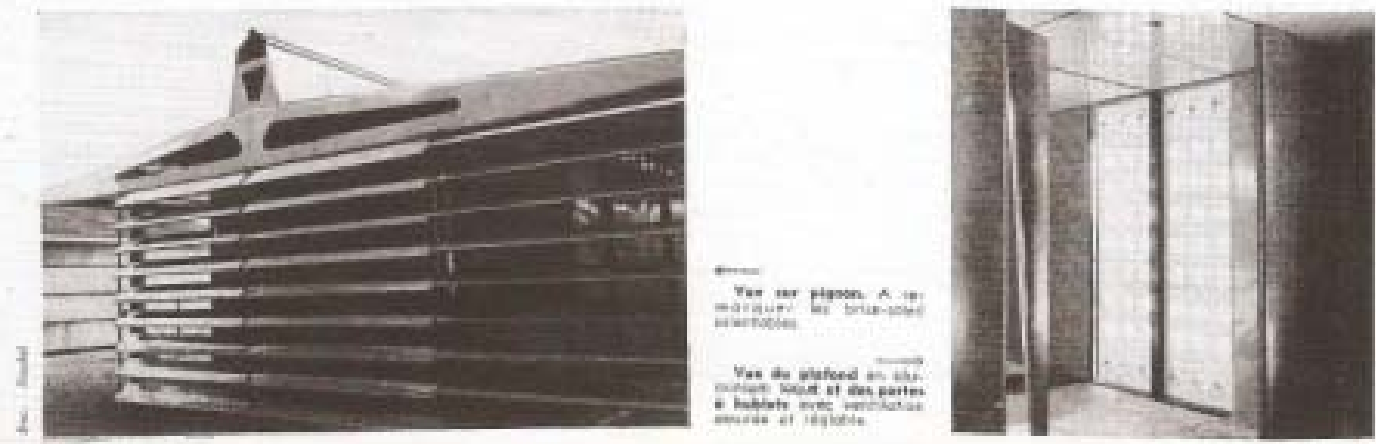

Hoja de publicidad técnico-comercial de Casa Niamey. Fig. 14 


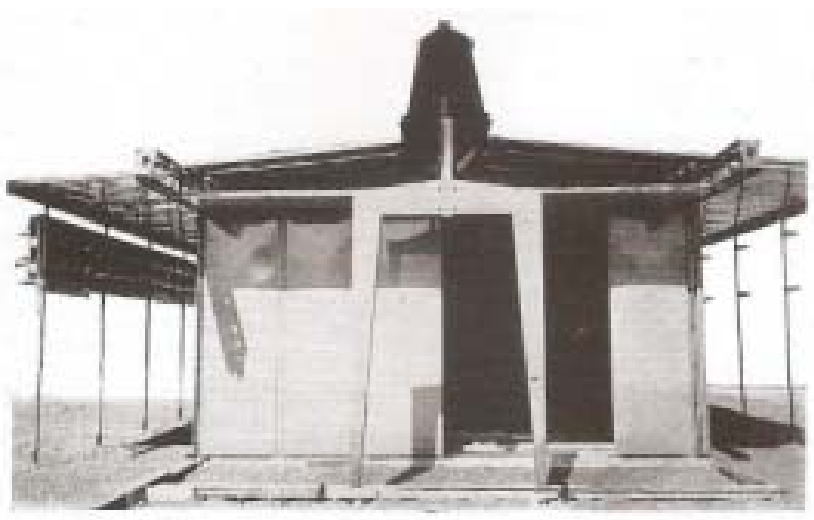

maison préfabriquée type "tropique"

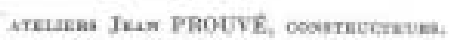

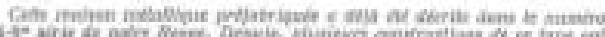
of

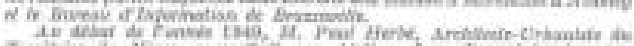

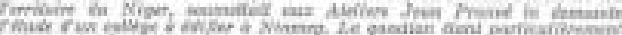

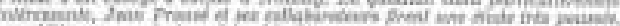

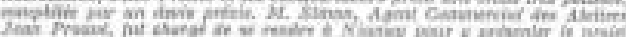
ons ontofis.

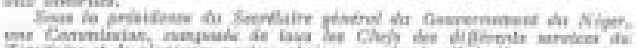

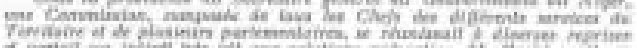

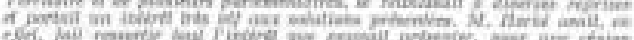

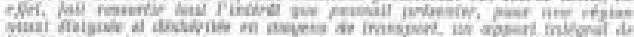

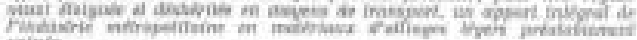

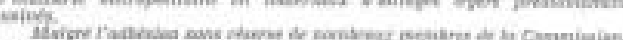

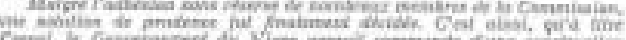

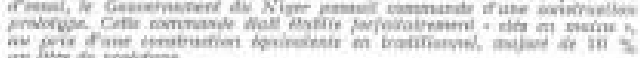

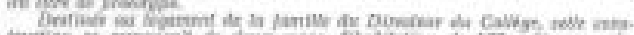

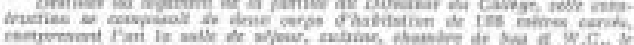

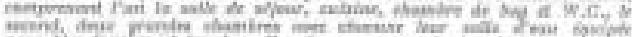

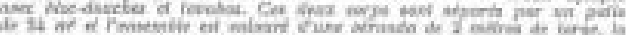

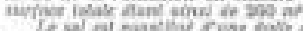

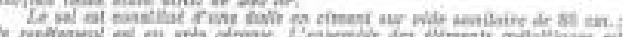

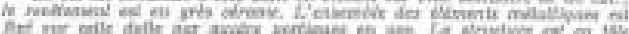

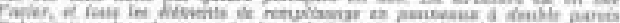

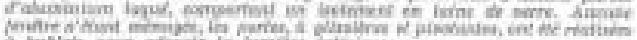

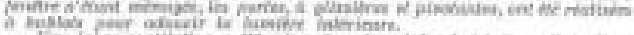

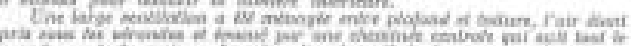

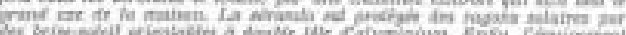

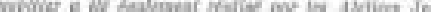

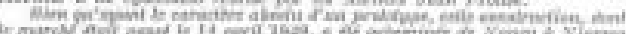

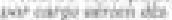

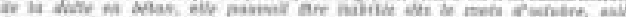

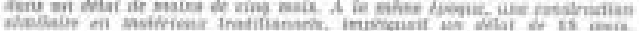

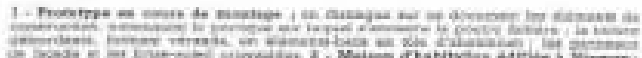
ar. ne
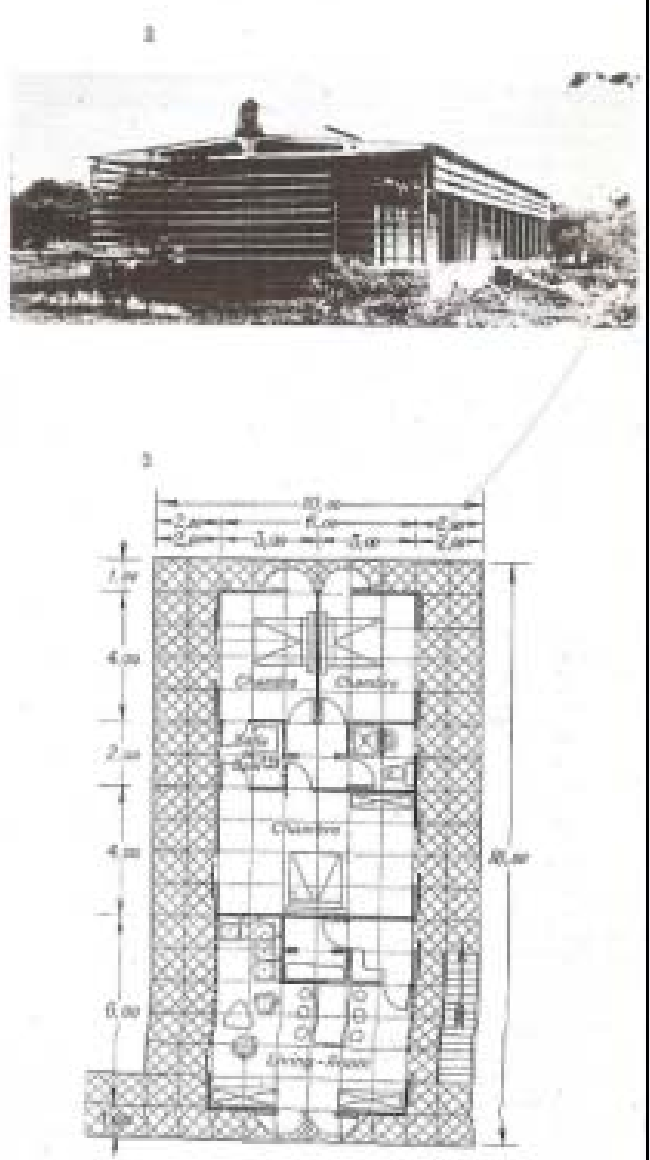

Hoja de publicidad técnico-comercial de Casa Niamey. Fig. 15 


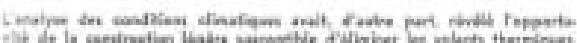
ii.

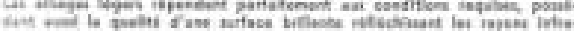

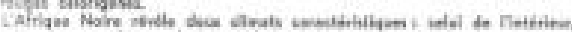

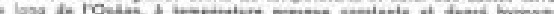

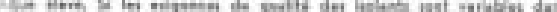

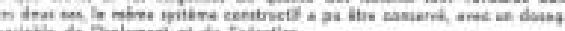

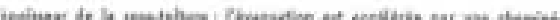

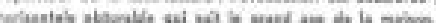

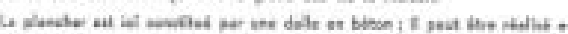

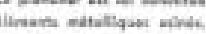

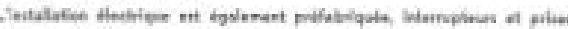

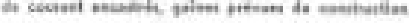

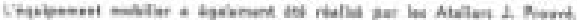

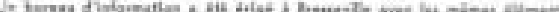

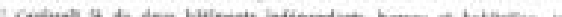

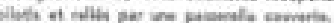

\section{Afrique}
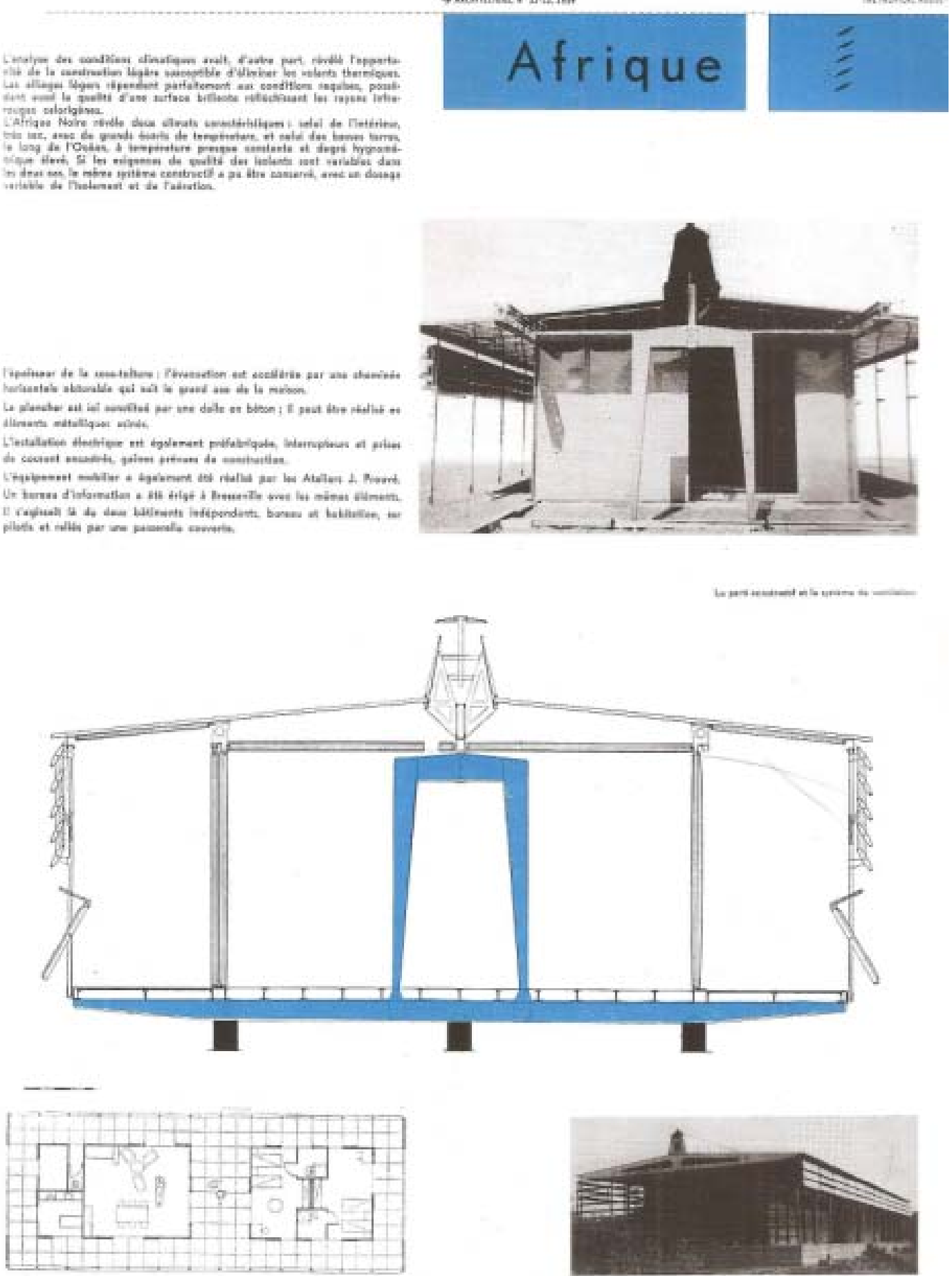

Hoja de publicidad técnico-comercial de Casa Niamey. Fig. 16 


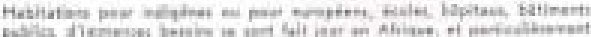
of atian heis

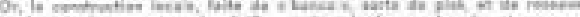

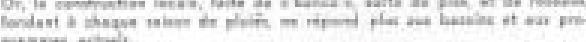

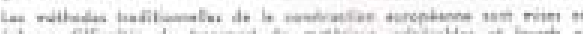

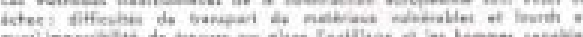

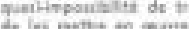

Une habitation a Niamey Henti fround, archituste

1951

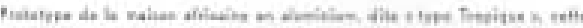

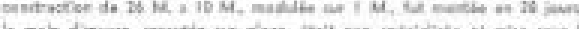

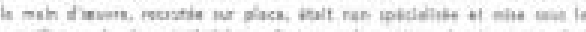

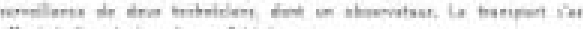

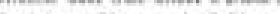

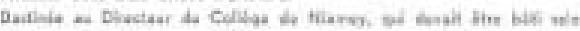

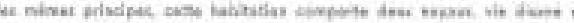

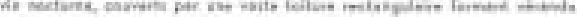

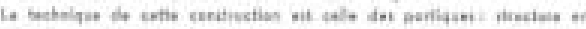

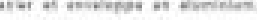

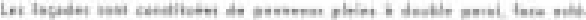

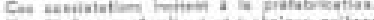

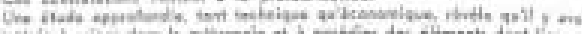

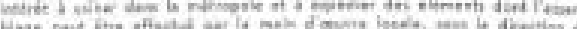

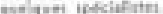

(a)

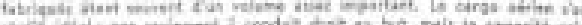

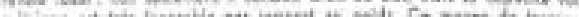
noing

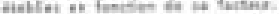

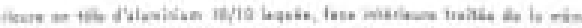

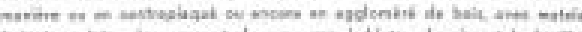

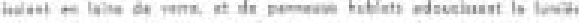

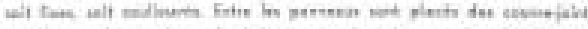

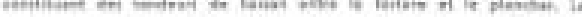

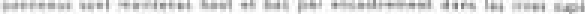

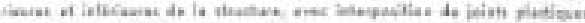

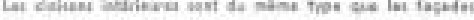

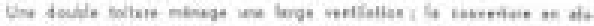

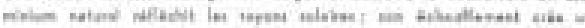

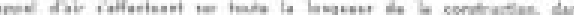

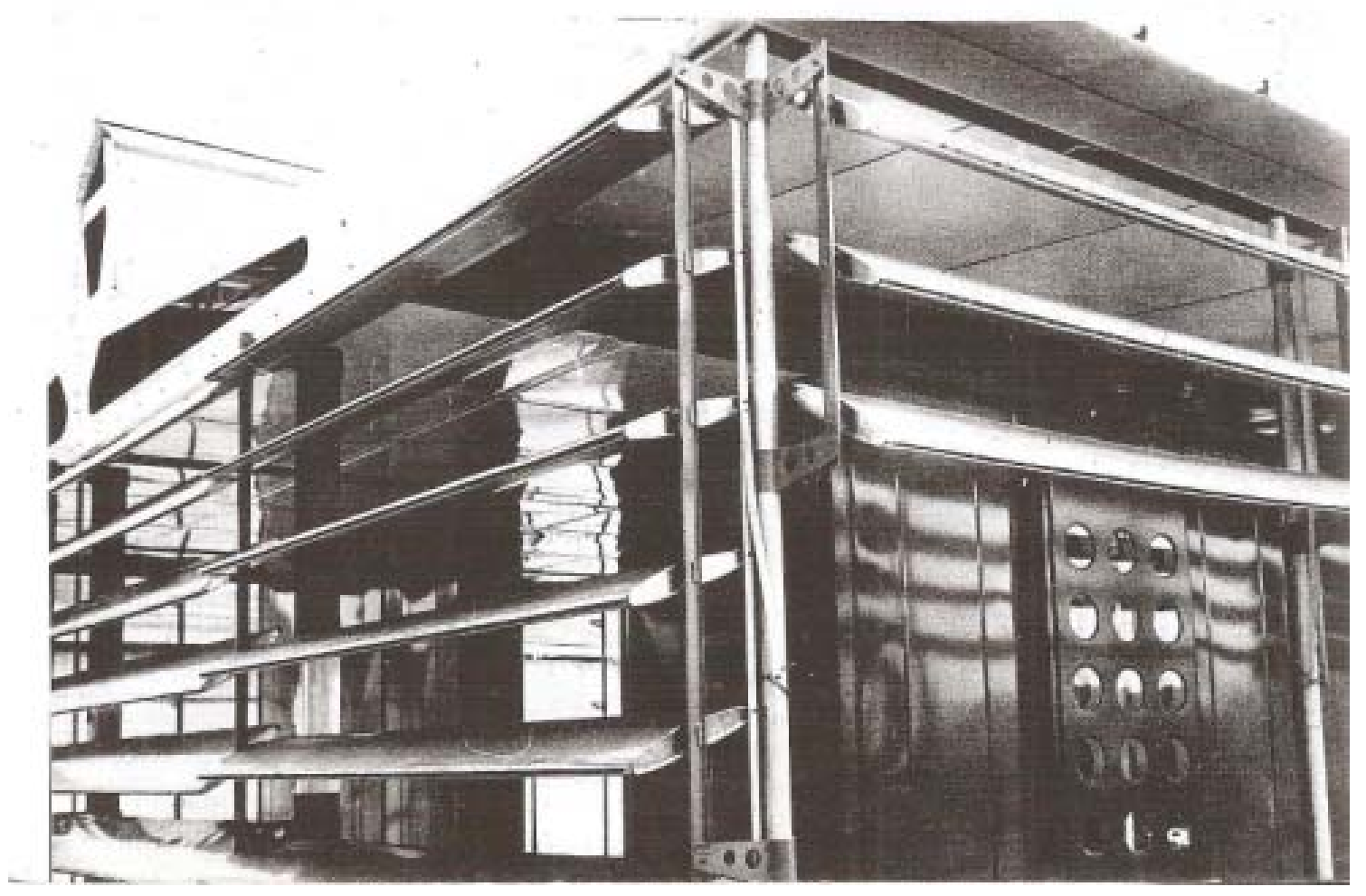

Hoja de publicidad técnico-comercial de Casa Niamey. Fig. 17 


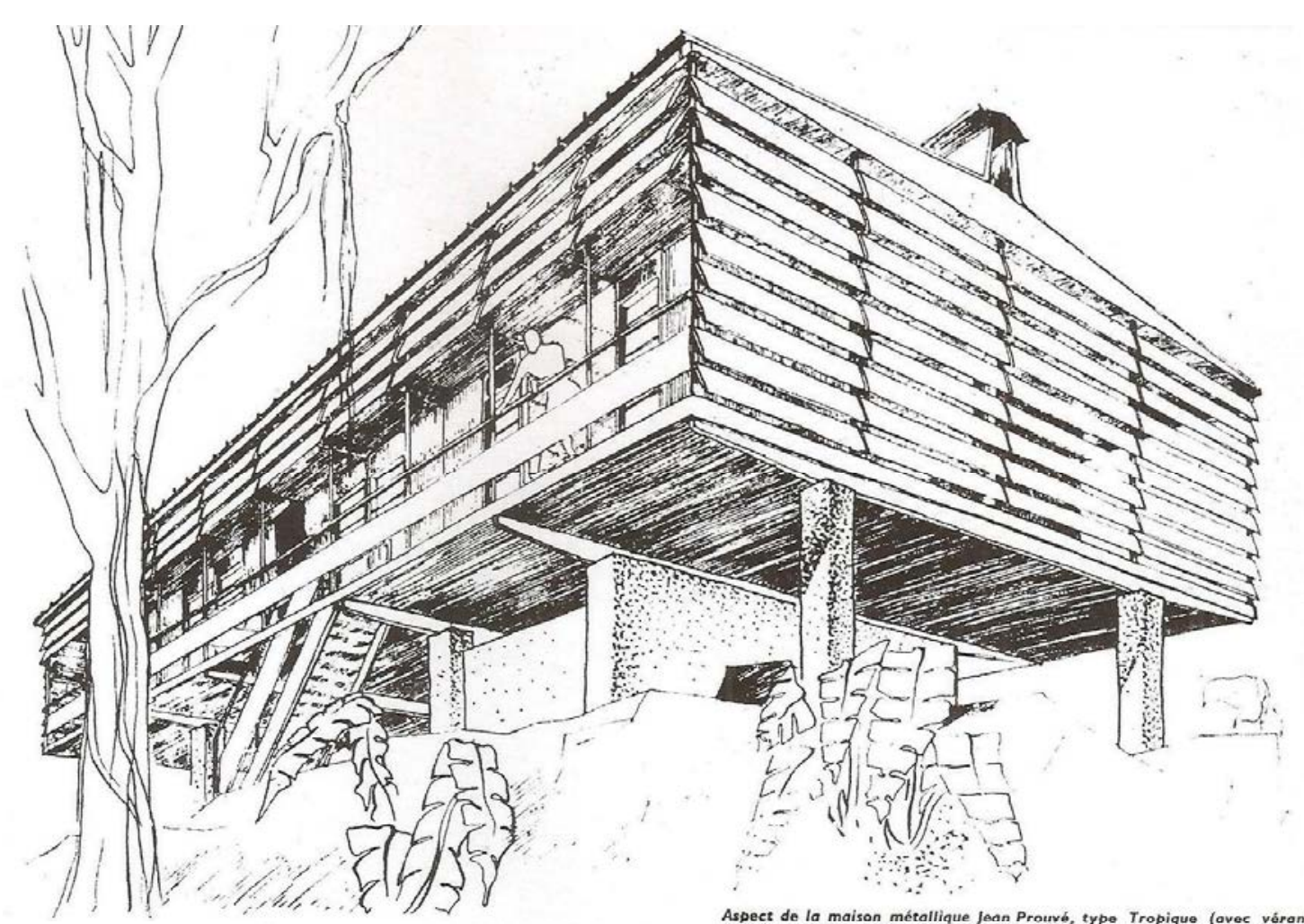

Aspect de la maison métallique Jjan Prourb, type Tropique (avec vérando
et brise-soleil). - View of the Tropique type of metal house, by et brise-soleil). . View of the ropique type of metal house, by
Jean Pro uvé. - Aspecto de la casa metalica jean Prouve, tipo Trópico.

\title{
LES MAISONS PRÉFABRIQUÉES A L'EXPOSITION POUR L'ÉQUIPEMENT DE L'UNION FRANÇAISE
}

\begin{abstract}
A Société des Ingénieurs pour la France d'Outre-Mar et les Pays Extéricurs a organisé du 28 septembre au 17 octobre une Exposition pour l'Equipement de I'Union Française qui s'est tenue sur les berges de la Seine entre le Pont de l'Alma et le Pont Alexandre-III. Les buts étaient et le Pont

- Présenter aux utilisateurs les matériels et produits spécialement adaptés aux conditions particulières d'emploi dans les pays de la France d'Outre-Mer et que l'industrie métropolitaine est capable de produire.

- Fournir aux industriels et exportateurs
- ropolitaine est capable de produire. des indications sur les besoins de ces territoires:

- Favoriser les prises de contact entre producteurs et utilisateurs et développer les transactions de la Métropole vers l'extérieur. Parmi les six cents exposants, qui embras saient, en fait, une très grande partie de
\end{abstract}

l'activité industrielle française, nous avons particulièrement remarqué la présentation des bâtiments préfabriqués démontables qui apportent une solution de choix au problème universel du logement, et plus particulièremant dans les Colonies où le manque de mnt dans les Colonies où le manque de
matériaux convenables, les difficultés de matériaux convenables, les difficultés de transport et l'absence de main-d'œurre qualifiée rendent encore plus difficile la construction des habitations.

La Socićté Technique pour I'Utilisation des Alliages Légers (S.T.U.D.A.L.) présentait les maisons préfabriquées Jan Prouvé, de les OPEC, toutes faisant intervenir très largement les alliages légers.
ment

\section{LA MAISON JEAN PROUVÉ}

Les Ateliers de construction métallique Jean Prouvé à Nancy, construisent en série et intégralement en usine des éléments qui permettent d'édifier en quelques jours des constructions définitives présentant un très grand confort et, du fait de la souplesse de composition permise pour le procédé, répondant le mieux à chaque utilisation prévue.

Ces constructions sont légères $(50 \mathrm{~kg} / \mathrm{m}$ ") et durables comme celles établies avec les matériaux traditionnels : elles sont métal liques, forment un tout par elles-mêmes. et sont constituées par des éléments modulés standard permettant d'obtenir $3 \mathrm{~m}$ ou $4 \mathrm{~m}$ en longueur ( ou des multiples de ces deux chiffres; $3 \mathrm{~m}, 4 \mathrm{~m}, 6 \mathrm{~m}, 7 \mathrm{~m}$ ou $8 \mathrm{~m}$ en largeur; elles sont livrées avec ou sans plancher. Pour le montage au sol, on prévoit soit des piliers de ciment ou de maçonnoit soit des piliers de ciment ou de maçonnerie dont le nombre varie avec la superficie: dans ce cas, le plancher est fourni; soit une
dalle ou un plancher en ciment. 


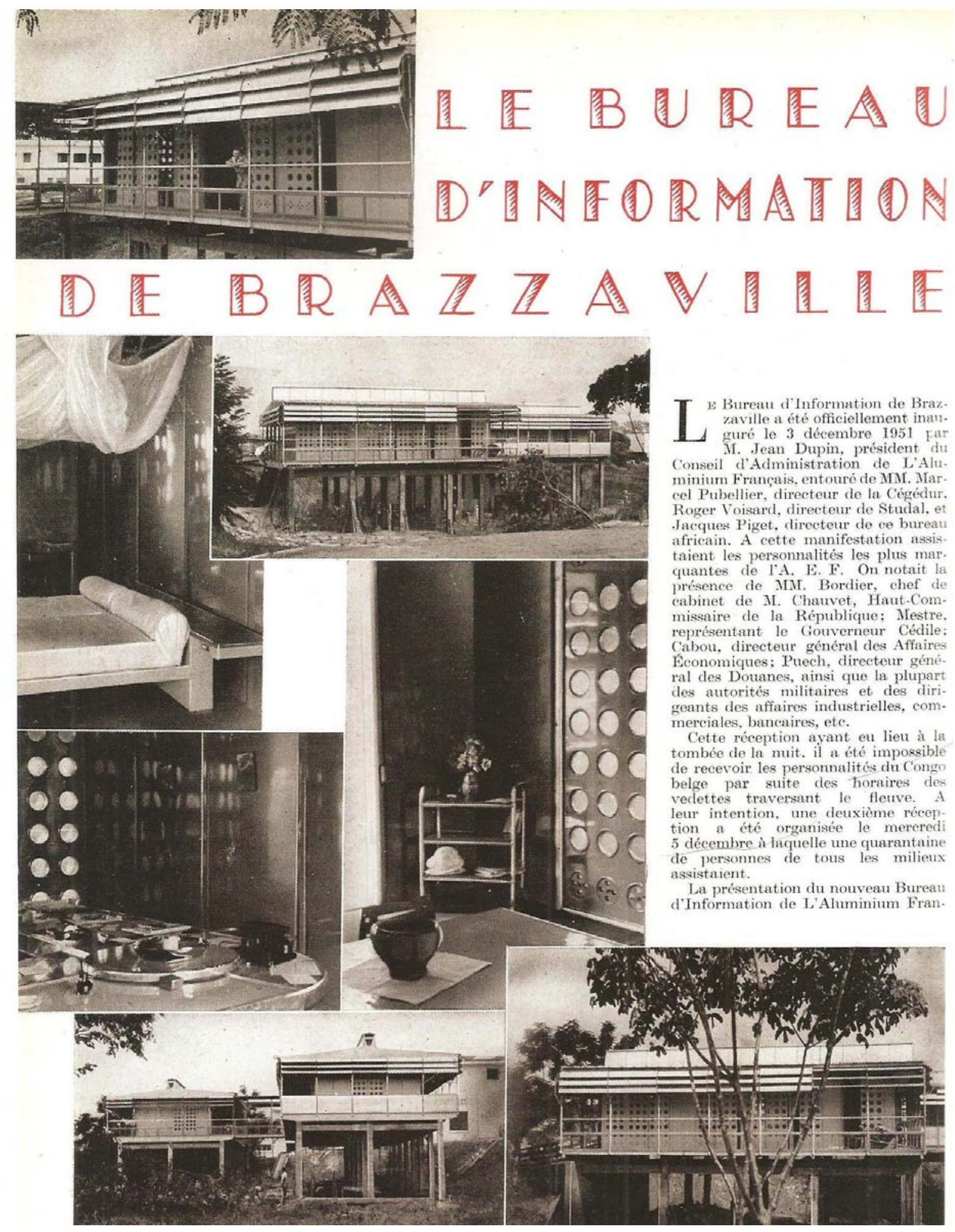

Hoja de publicidad técnico-comercial de Casa Brazzaville. Fig. 19 
çais a remporté un frano succès. Les visiteurs ont été surpris de l'aspect net, sobre des bureaux contrastant avec le earactère plus intime des pièces d'habitation, obtenu par la recherche des couleurs du mobilier - intégralement métallique lui aussi - et par des voilages, des rideaux, des appareils d'éclairage exécutés avec les moyens locaux Le Bureau de L'Aluminium Français était déjà bion connu de la plupart des Brazzavillois qui, toutefois, ne savaient pas, bien souvent, de quoi il s'agissait. Sa situation le met parfaitement en vue, il mi-chemin de la situaet de la Mairie, à la limite du quartier résidentiel et du quartier commercial. D'autre part, son aspect est tout fait inhabituel a Brazzaville par ne compect est tout : présent, aucune construction préfabriquée. En jusqu à publicité faite au cours du montage avait attiré gure, la chantier un grand nombre de visiteurs, et non des mur le puisque les plus hautes personnalités eiviles de la Fédé ration s'y sont rendues.

L'ensemble comporte deux bâtiments en alliage léger lu type Tropique on des Ateliers Jean Prouvé L' léger titue la partie bureaus Aroliers Jean Prouve. L un constitue la partie bureaux proprement dite. Ses dimensions par une passerelle, est Thabitation de M. Jacques Piget. par une passerelle, est Thabitation de M. Jac

Les bureaux comprennent une salle d'attente et d'oxpoLes bureaux comprennent une salle d'attente et d'exposition de $6 \times 4 \mathrm{~m}$, le bureau du directeur de $6 \times 4 \mathrm{~m}$, un secretariat de $4 \times 4 \mathrm{~m}$, tun cabinet de toilette, un vestiaire. Le logement du directeur comprend une salle de séjour de $6 \times 4 \mathrm{~m}$ completée par un renfoncement dans lequel un bar a ete installé, une chambre à coucher principale de $6 \times 4 \mathrm{~m}$, deux chambres a coucher de $4 \times 3 \mathrm{~m}$, une cuisine de $4 \mathrm{~m} \times 2 \mathrm{~m}$, deux cabinets de toilette dont l'un comporte un bloc-douche Sécip.

Le type de maison "Tropique "a été déjà décrit dans le $n^{\circ} 161$ de décembre 1949 de cette revue. Rappelons qu'elle est entièrement préfabriquée et se compose d'une partie inférieure formée de rives délimitant le contour de la construction avec des poutres principales supportant
les deux portiques sur lesquels s'encastre la poutre faitière;

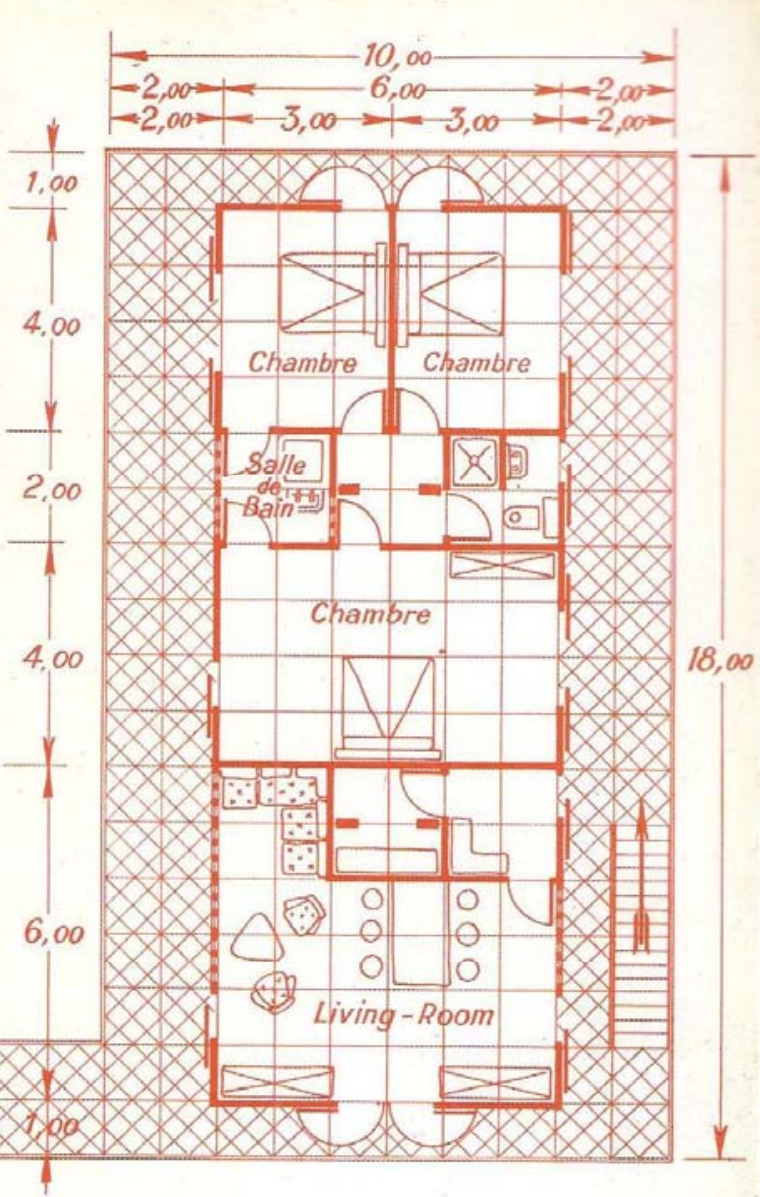

4,00

d'une toiture débordante formant vérandah en éléments. bacs en tôle d'aluminium de $15 / 10 \mathrm{~mm}$ d'épaisseur:- de panneaux pleins, panneaux-fenêtres, panneaux-portes cons. panneaux pleins, panneaux-fenétres, panneaux-portes conscadre en profilés d'alliage léger qui recoit une face exté. rieure et une face intérieure en oluminium $10 / 10 \mathrm{~mm}$ laqué avec, entre les deux, un isolement par laine de verre; les panneaux sont raceordés entre eux par des couvreles panneaux sont raceordes entre eux par des couvrejoints avec interposition de matière isolante stivant la deux panneaux, relient sou tens, la toiture deux panneaux, relient sous tension, la toiture au plancher. Les cloisons interieures sont algalement composées de pannoux a dotable paroi en altaminim, aveo isolation. Le plafond est constitué de panneatux de $1 \mathrm{~m} \times 1 \mathrm{~m}$, en tole dealuminium. Le plancher est reatise au moyen de panneaux de memes dimensions, en acier, recouverts de linoléum. Installation électrique préfabriquée. Ventilation assurée par des prises dair aménagees dans les longs-pans du toit avee bvactation naturelle par la poutre faitière formant cheminée et dotée, à cet effet, de volets de réglage. La défense contre le soleil, déjà assurée en partie par la toiture largement débordante, est complétée par des brisesoleil constitués par la superposition de trois lames horizontales orientables. Cette construction est légère et ne pèse que $50 \mathrm{~kg}$ au $\mathrm{m}^{2}$; elle est durable et n'a rien ì redouter de l'attaque des termites.

Hoja de publicidad técnico-comercial de Casa Brazzaville. Fig. 20 


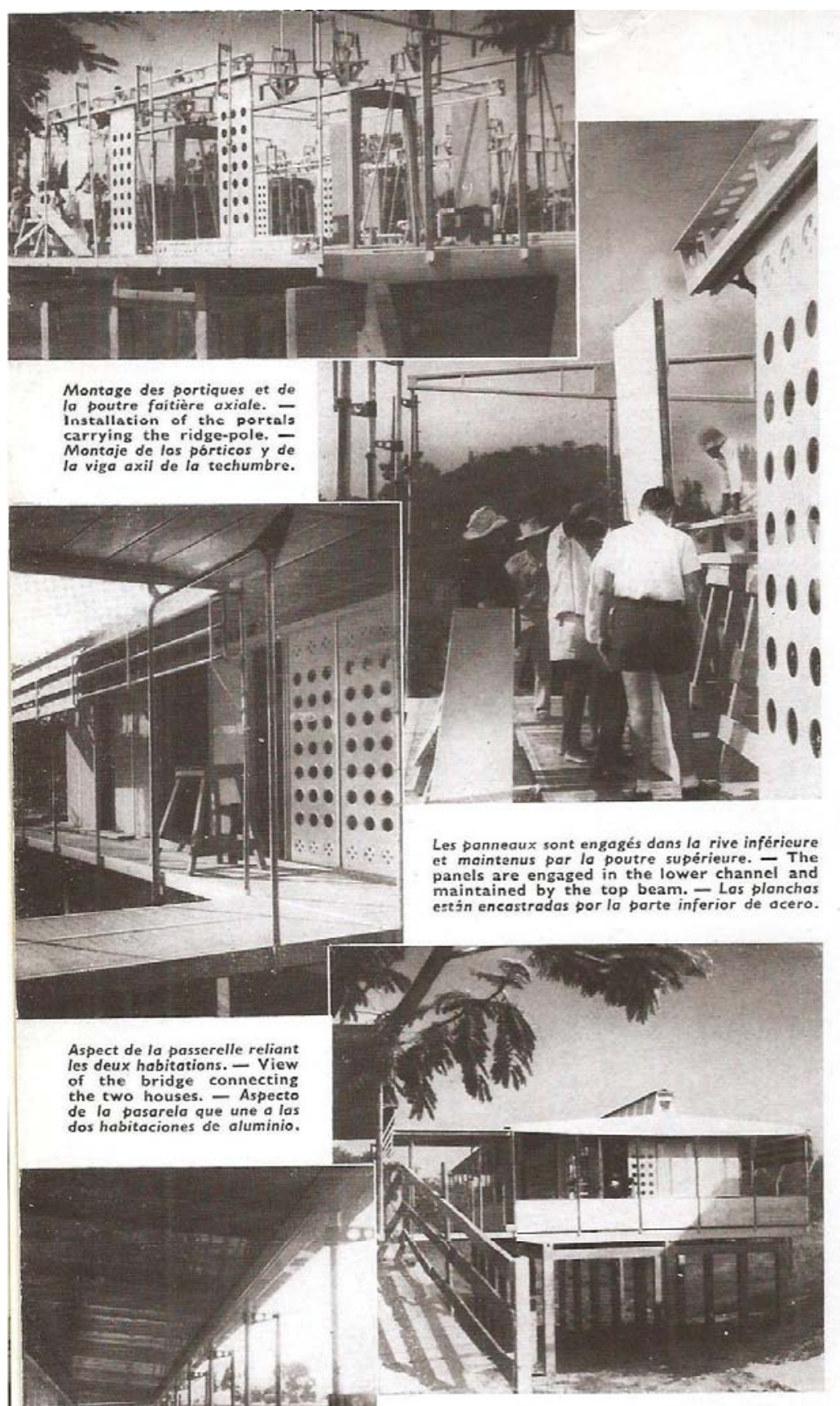

Vue d'ensemble de l'habitation entourée sur toutes ses faces par unc galerie couverte. On reconnait lo forme particulière de la poutre faitière assurant
l'évacuation de l'air de ventilation qui circule dans l'́́pacisseur du toit. - General view of the house surrounded by a covered gallery. Note the particular shape of the ridge-pole which provides an exaust for the ventilation air, flowing inside
of the roof structure. - Vista de conjunto de la construccion que sirve de habitación rodeada por formas particular de la viga de la techumbre asegura la evacuación del aire de ventilación.
Le terrain sur lequel les battiments ont étédifiés, en bordure de lavenue Paul-Doumer, présentait un relief trì inégal et sa cote générale était de 4 in inégal et sa cote gúvesu de l'avene. en dessots du niveau de favenue. II etait done lupssible de monter le maisons directement sur lo sol; de lavenue, on n'en aurait vu que le toits, ce qui n'était pas le but recher ché; en outre, la ventilation aurai été insuffisante. On a done construit les maisons sur des poteaux en béton dont la tête se trouve à la cote do l'avenue. Comme l'exécution d'une dalle de béton aurait obligé à réalise IIn coffrage considérable et délicat. le Ateliers Jean Prouvé ont livré um plancher métallique préfabriqué.

Les différents éléments de la cons. truction ont été acheminés par avion. Les dernières caisses étant arrivée le 31 mai, le premier boulon de lia charpente du plancher a été posé lé 1er juin. Le montage a été fait par II. Jacques Piget - qui n'avait aucuns expérience en la matière - assist d'ume main-d'ouvre locale de charpentiers et de magons y eompre penticess no nant deux equipes do hinit inges. On imagine les dincertes inevitables auxquelles il eut à faire face. Néan2 juillet.

Cette inauguration officielle montre que le nouveau B.R.I.A. de Brazzaville, dont l'activité est obligatoirement différente de celle d'un burean métropolitain, a démarré d'excellent facon Son but est de porter it la facon. Son but est do porter connaissance des inclistricls une documentation technique et commerciale constamment mise a jour, les faisant profiter ainsi de l'expérience des Services Centraux; il étudie su place les applications qui paraissen utiles et les signale au siège de Paris, servant ainsi de trait d'union entre les utilisateurs et les technicien. de l'aluminium.

Un des premiers résultats de ce nouveau B.R.I.A a été de prouver par le fait qu'il était parfaitement possible d'aménatur maison métal. lique aussi confortablement quime maison de construction classique, et de lui donner le même air personnel et intime. La maison en aluminium n'est pas une gageure futuriste, mais une solution raisonnable apportée au probleme de l'habitation qui est, partout, préoeeupent. Pour leur part, les

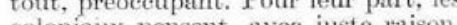
colonian pensent, avec juste raison. que les régions éloignees des ports, qui manquent de ciment et de pierres, tireront d'abord le maximum de profit de cette technique nouvelle, plus économique en l'espèce que les pro. cédés classiques en raison surtout des difficultés de transport. Et c'est pourquoi le Tehad sintéresse, dès mainte. nant, in ime importante fourniture de maisons en aluminium.

Nous souhaitons bonne chance it Jacques Piget pour les tâches impor. tantes qui s'ouvrent devant lui.

Hoja de publicidad técnico-comercial de Casa Brazzaville. Fig. 21 

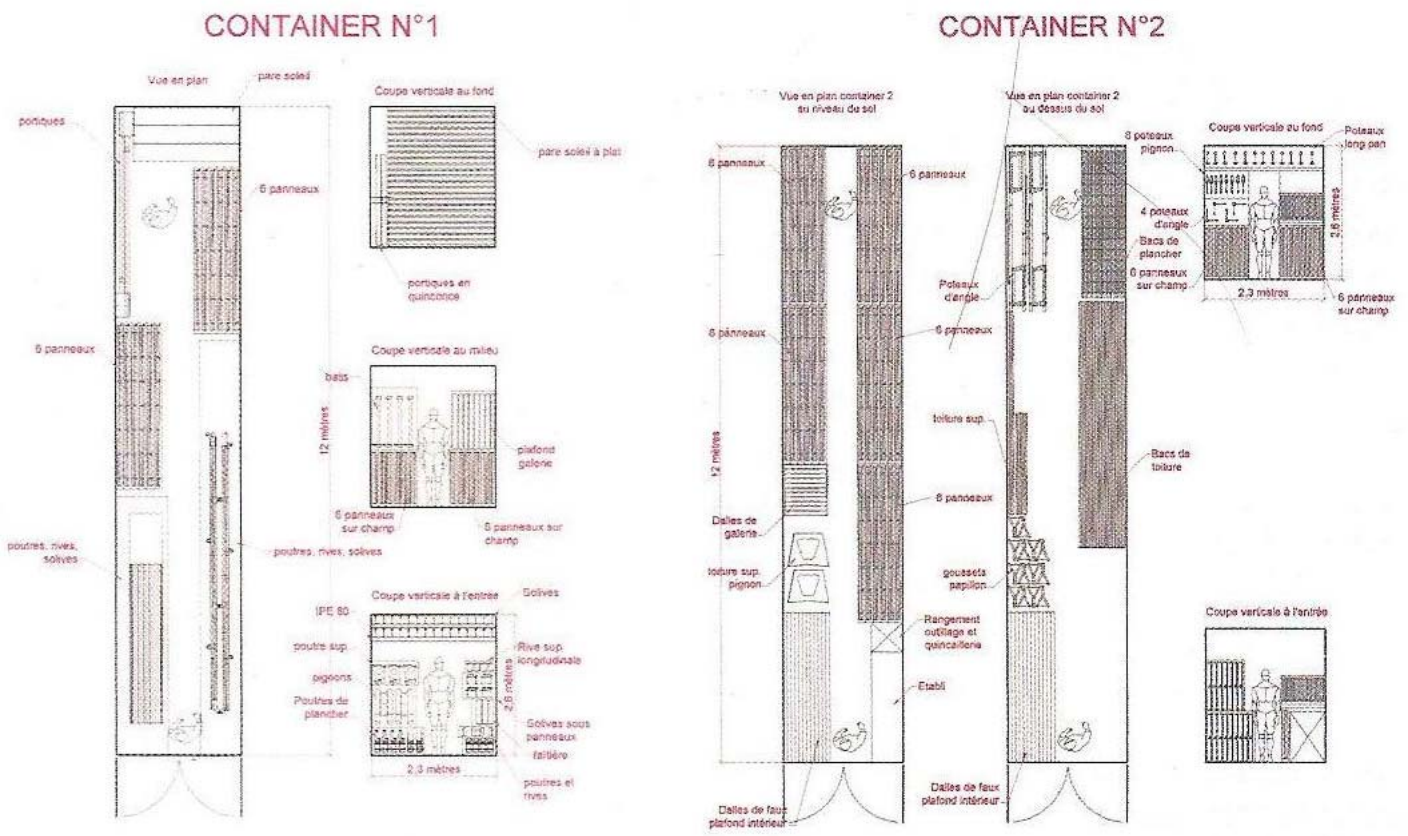

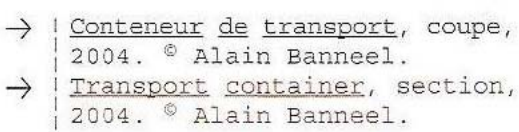

Esquema que almacenamiento elementos constructivos Casas Tropicales para su restauración y reconstrucción en Paris. Fig. 22 

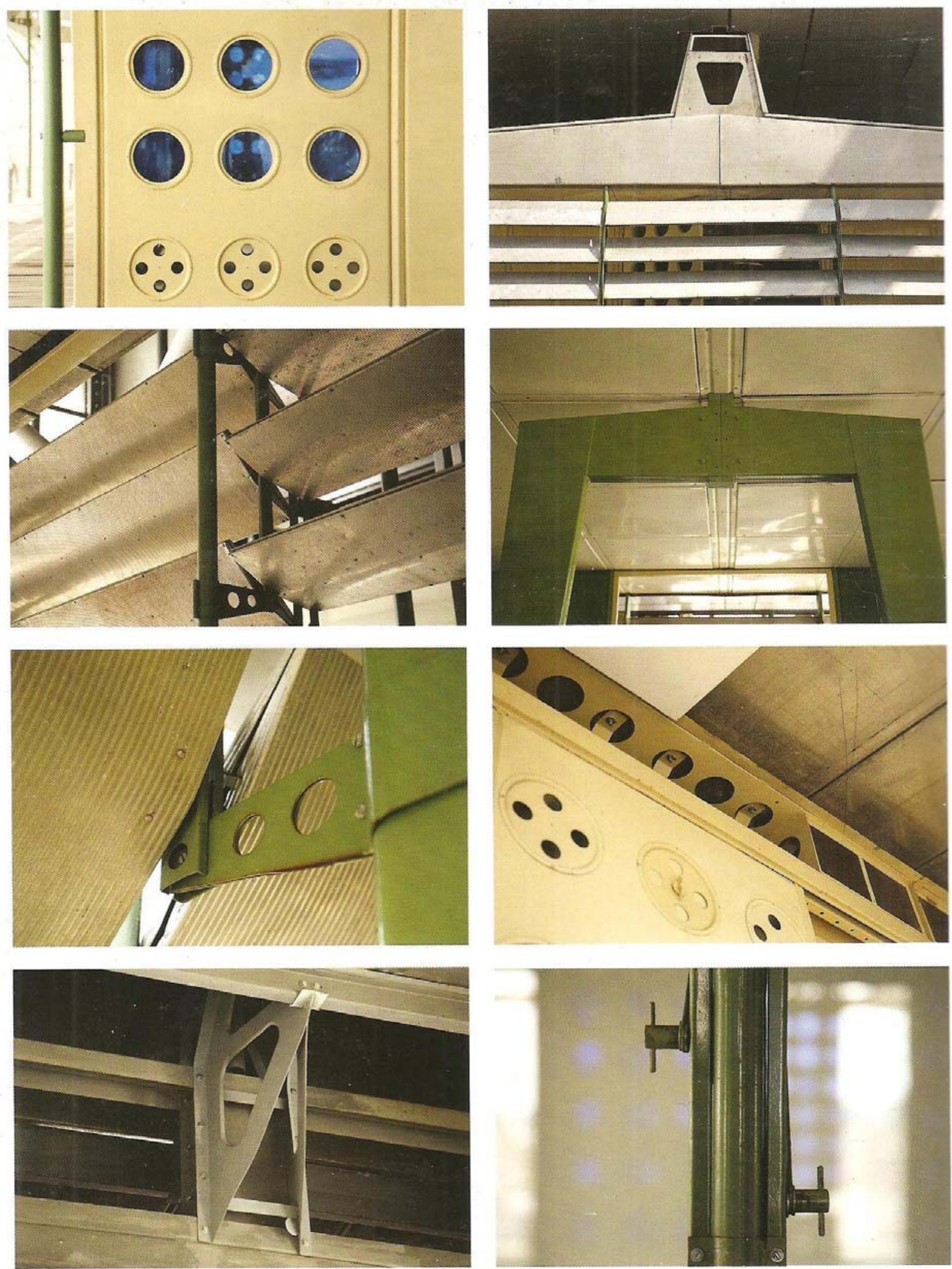

Modelo restaurado y reconstruido de Casa Tropical. Centro Pompidou en Paris. Fig. 23 
ANEXO 3

UPDATED WORLD MAP

OF THE KOPPEN-GEIGER CLIMATE CLASSIFICATION.

Artículo sobre zonificación climática según el mapa de Koppen-Geiger.

Peel, M. C.; Finlayson B. L. ; McMahon T. A. 


\title{
Updated world map of the Köppen-Geiger climate classification
}

\author{
M. C. Peel ${ }^{1}$, B. L. Finlayson ${ }^{2}$, and T. A. McMahon ${ }^{1}$ \\ ${ }^{1}$ Department of Civil and Environmental Engineering, The University of Melbourne, Victoria, Australia \\ ${ }^{2}$ School of Anthropology, Geography and Environmental Studies, The University of Melbourne, Victoria, Australia
}

Received: 15 February 2007 - Published in Hydrol. Earth Syst. Sci. Discuss.: 1 March 2007

Revised: 28 September 2007 - Accepted: 4 October 2007 - Published: 11 October 2007

\begin{abstract}
Although now over 100 years old, the classification of climate originally formulated by Wladimir Köppen and modified by his collaborators and successors, is still in widespread use. It is widely used in teaching school and undergraduate courses on climate. It is also still in regular use by researchers across a range of disciplines as a basis for climatic regionalisation of variables and for assessing the output of global climate models. Here we have produced a new global map of climate using the Köppen-Geiger system based on a large global data set of long-term monthly precipitation and temperature station time series. Climatic variables used in the Köppen-Geiger system were calculated at each station and interpolated between stations using a twodimensional (latitude and longitude) thin-plate spline with tension onto a $0.1^{\circ} \times 0.1^{\circ}$ grid for each continent. We discuss some problems in dealing with sites that are not uniquely classified into one climate type by the Köppen-Geiger system and assess the outcomes on a continent by continent basis. Globally the most common climate type by land area is BWh (14.2\%, Hot desert) followed by Aw (11.5\%, Tropical savannah). The updated world Köppen-Geiger climate map is freely available electronically in the Supplementary Material Section (http://www.hydrol-earth-syst-sci.net/ 11/1633/2007/hess-11-1633-2007-supplement.zip).
\end{abstract}

\section{Introduction}

The climate classification based on the work of Wladimir Köppen, and dating from 1900, continues to be the most widely used climate classification over a century later. Essenwanger (2001) has provided a comprehensive review of the classification of climate from prior to Köppen through to the present. The period of greatest activity was from the

Correspondence to: M. C. Peel

(mpeel@unimelb.edu.au) mid-nineteenth century through to the 1950s. What is somewhat surprising about this time profile of activity is that as both the availability of data and computing power to process them has become increasingly widely available post-1960, the level of activity in the development of new climate classifications has markedly declined. The continued popularity and widespread use of the Köppen classification is remarkable. There is no doubt an element of historical inertia in this as each generation of students is taught global climate using this system and it is the basis of most common global climate maps. To replace it with a new system would be a significant task. Arthur Wilcock (1968) was probably correct in surmising: "If ...... one is convinced that there are in principle strict limits to what can be achieved by any simple classification, one may consider it profitless to seek minor improvements at the cost of confusion." (p. 13).

Köppen's inspiration for developing a world map of climate classification in 1900 owed much to the global vegetation map of Grisebach published in 1866 and Köppen's own background in plant sciences (Wilcock, 1968). Thornthwaite (1943) claims that Köppen's use of the first five letters of the alphabet to label his climate zones is taken from the five vegetation groups delineated by the late nineteenth century French/Swiss botanist Alphonse De Candolle who in turn based these on the climate zones of the ancient Greeks. It is inconceivable that Köppen could have produced his original classification and map without using other landscape signals of climate (particularly vegetation) since there would have been so little observed climate data available at that time. In Fig. 3 of this paper we show the relative number of stations with temperature and precipitation data starting from 1800 . Compared with what is available now, there would have been data from few stations available to Köppen and the global distribution would have been much more inconsistent than is the case now. In the light of this, the persistence of his scheme of classification is even more remarkable. 
While Sanderson (1999) has argued that it is time for modern atmospheric scientists to develop a new classification of climates, the Köppen classification continues to be the one most widely used in teaching. If we take as an example the textbooks of Arthur Strahler that are in very wide use in the English speaking world, it is the case that despite Strahler's own attempt to produce a new climate classification (see, for example, Strahler, 1971) the latest edition of this series of texts still uses the Köppen system (Strahler and Strahler, 2005).

The use of Köppen's classification is not confined to teaching. Many researchers routinely use it for their own particular research purposes. The present authors have used it as the basis for grouping rivers by climate type around the world in order to facilitate comparisons of runoff characteristics (McMahon et al., 1992; Peel et al., 2004). Lohmann et al. (1993) have applied the Köppen classification to the output from both atmosphere general circulation models and coupled atmosphere-ocean circulation models and compared these to maps of the Köppen classification using modern data sets and to Köppen's 1923 map. They modelled both present conditions and enhanced greenhouse scenarios and concluded: "However, the Köppen classification is easier to apply and is still a useful tool for estimating the ability of climate models to reproduce the present climate as well as indicate the impact of climate changes on the biosphere." (p. 191) No doubt Köppen would have been pleased with this assessment.

In a similar study to that of Lohmann et al. (1993), Kalvova et al. (2003) compared global climate model outputs to maps of Köppen's classification drawn from gridded observed data and to Köppen's 1923 map. They were attracted to the Köppen system because of its known links to natural vegetation patterns as they have attempted to assess the impact of global warming on major biomes. They also compare the map they produced of Köppen's climate zones based on modern data with his 1923 map and show that the differences are only around $0.5 \%$ of the area distribution. Similar uses of the Köppen classification have been made by Wang and Overland (2004), Gnanadesikan and Stouffer (2006) and Kleidon et al. (2000) where it is the relation between the Köppen zones and natural vegetation systems that has made it useful to their purposes. It is noteworthy that Kleidon et al. (2000) also used the Köppen 1923 map as a basis for comparison.

A more critical approach to the Köppen classification has been taken by Triantafyllou and Tsonis (1994) who claim to be the first to evaluate the Köppen classification using modern temperature and precipitation data (for the northern hemisphere). They classified climate stations on a year by year basis and then analysed the frequency with which they shifted between the major Köppen climate types (e.g. A to B) in order to assess the adequacy of the Köppen system. In North American and North Africa they found low variability within a climate type and narrow regions of high variability between climate types, indicating the Köppen system performed adequately. For Europe and Asia they found the pattern of variability less defined, indicating either high within climate type variability or wide regions between climate types resulting in an inadequate performance of the Köppen system. It is the case however that the Köppen classification was intended to represent long term mean climate conditions and not year-toyear variability though it can be put to good use as the basis for assessing climate variability on a year-to-year (Dick, 1964) or multi-decadal basis (Gentilli, 1971). Triantafyllou and Tsonis (1994) conclude, with Sanderson (1999), that there is a need for a new scheme to represent the world's climates.

That may be so, but when Fovell and Fovell (1993) used cluster analysis to objectively determine climate zones for the conterminous United States based on modern climate data they returned to the Köppen classification to assess the outcomes. Similarly Stern et al. (2000), with all the data resources of the Australian Bureau of Meteorology at their disposal, used a modification of the Köppen classification to draw a new map of the climates of Australia. Their assessment that " $\ldots$ the telling evidence that the Köppen classification's merits outweigh its deficiencies lies in its wide acceptance." (p. 2).

It is against this background that we have chosen to redraw the Köppen-Geiger world map using global long-term monthly precipitation and temperature station data. Recently, four Köppen world maps based on gridded data have been produced for various resolutions, periods and levels of complexity. Kalvova et al. (2003) using Climate Research Unit (CRU, the University of East Anglia) gridded data for the period 1961-1990 presented a map of the 5 major Köppen climate types (with E divided into 2 types) at a resolution of $2.5^{\circ}$ latitude by $2.5^{\circ}$ longitude. Gnanadesikan and Stouffer (2006) presented a Köppen map of 14 climate types based on the same CRU data and period as Kalvova et al. (2003), but at a resolution of $0.5^{\circ}$ latitude by $0.5^{\circ}$ longitude. Fraedrich et al. (2001) using CRU data for the period 1901-1995 presented a Köppen map of 16 climate types at a resolution of $0.5^{\circ}$ latitude by $0.5^{\circ}$ longitude and investigated the change in climate types over the period 1981-1995 relative to the complete period of record. The most comprehensive Köppen world map drawn from gridded data to date is that of Kottek et al. (2006) who presented a map with 31 climate types at a resolution of $0.5^{\circ}$ latitude by $0.5^{\circ}$ longitude based on both the CRU and Global Precipitation Climatology Centre (GPCC) VASClimO v1.1 data sets for the period 1951-2000.

All four maps based on gridded data are for restricted periods (1901-1995, 1961-1990 or 1951-2000) and any subgrid resolution climate type variability has been obscured. So here we present an updated world map of the KöppenGeiger climate classification based on station data for the whole period of record. The data and methodology used to construct this map are described in the next section. Individual continental Köppen-Geiger climate maps are presented 


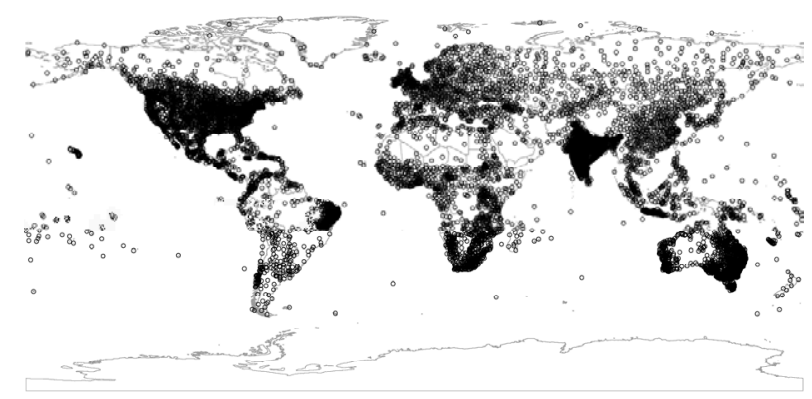

Fig. 1. Location of precipitation stations with 30 or more values for each month.

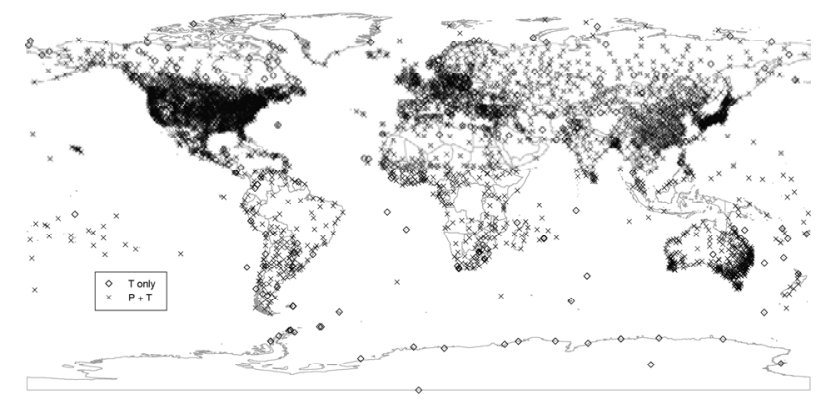

Fig. 2. Location of temperature stations with 30 or more values for each month. Symbols are "T only" = temperature data only and "P $+\mathrm{T} "=$ both temperature and precipitation data.

and discussed. The continental maps are then combined to form the new world Köppen-Geiger map, which is followed by a discussion, a link to the map for free download and a conclusion.

\section{Data and methodology}

The philosophy behind the construction of this updated version of the Köppen-Geiger climate map is to rely on observed data, rather than experience, wherever possible and minimise the number of subjective decisions. To this end, a large, globally extensive, climatic dataset was used to describe the observed climate and the methodology used to interpolate the observations was chosen to be simple and flexible, but not beyond what the data could support. There have been many modifications proposed to the Köppen system but here we have used criteria that follow Köppen's last publication about his classification system in the Köppen-Geiger Handbook (Köppen, 1936), with the exception of the boundary between the temperate (C) and cold (D) climates. We have followed Russell (1931) and used the temperature of the coldest month $>0^{\circ} \mathrm{C}$, rather than $>-3^{\circ} \mathrm{C}$ as used by Köppen in defining the temperate - cold climate boundary (see Wilcox, 1968 and Essenwanger, 2001 for a history of this modification).

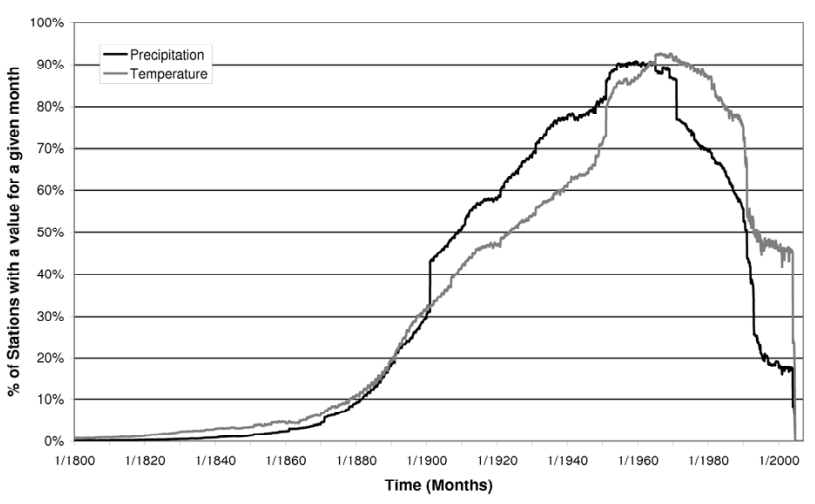

Fig. 3. Percentage of precipitation and temperature stations with a monthly value.

The quality of the final map depends on the quality of the input data and to this end long-term station records of monthly precipitation and monthly temperature were obtained from the Global Historical Climatology Network $(\mathrm{GHCN})$ version 2.0 dataset (Peterson and Vose, 1997). Stations from this dataset with at least 30 observations for each month were used in the analysis (12396 precipitation and 4844 temperature stations). Figures 1 and 2 show the global spatial distribution of precipitation and temperature stations respectively. In Fig. 2 temperature stations that also have precipitation data are denoted separately from the temperature only stations. Regions of high station density are the USA, southern Canada, northeast Brazil (precipitation only), Europe, India (precipitation only), Japan and eastern Australia. Desert, polar and some tropical regions, like Saharan Africa, Saudi Arabia, central Australia, northern Canada, northern Russia and the Amazon region of Brazil have sparse station density.

In the following analysis the complete period of record at each precipitation and temperature station is used. The stations exhibit a wide range of record lengths from a minimum of 30 values for each month up to 299 for precipitation and 297 for temperature. In Fig. 3, the percentage of stations with a monthly value is plotted over time and shows that the historical period that the data are most representative of are from 1909 to 1991 for precipitation and 1923 to 1993 for temperature. Spatially there is variation in the period of record covered, with Australia, Europe, Japan and the USA generally having the longest records.

The whole-of-record approach assumes that data from one period is comparable with data from any other period. This assumption can be violated by global or local trends, like the recent observed warming of global surface temperature, largely attributable to increasing concentrations of greenhouse gases (Barnett et al., 2005). However, at the level of broad climate types (1st letter, see Table 1) the KöppenGeiger climate classification has been found to be relatively insensitive to temperature trends (Triantafyllou and Tsonis, 
Table 1. Description of Köppen climate symbols and defining criteria.

\begin{tabular}{|c|c|c|c|c|}
\hline $1 \mathrm{st}$ & 2nd & $3 \mathrm{rd}$ & Description & Criteria* \\
\hline \multirow[t]{4}{*}{ A } & & & Tropical & $\mathrm{T}_{\text {cold }} \geq 18$ \\
\hline & $\mathrm{f}$ & & - Rainforest & $P_{\text {dry }} \geq 60$ \\
\hline & $\mathrm{m}$ & & - Monsoon & Not (Af) \& $P_{d r y} \geq 100-M A P / 25$ \\
\hline & $\mathrm{w}$ & & - Savannah & Not (Af) \& $\mathrm{P}_{\mathrm{dry}}<100-\mathrm{MAP} / 25$ \\
\hline \multirow[t]{5}{*}{ B } & & & Arid & $\mathrm{MAP}<10 \times \mathrm{P}_{\text {threshold }}$ \\
\hline & $\mathrm{W}$ & & - Desert & $\mathrm{MAP}<5 \times \mathrm{P}_{\text {threshold }}$ \\
\hline & $\mathrm{S}$ & & - Steppe & $\mathrm{MAP} \geq 5 \times \mathrm{P}_{\text {threshold }}$ \\
\hline & & $\mathrm{h}$ & - Hot & $\mathrm{MAT} \geq 18$ \\
\hline & & $\mathrm{k}$ & - Cold & MAT $<18$ \\
\hline \multirow[t]{7}{*}{$\mathrm{C}$} & & & Temperate & $\mathrm{T}_{\text {hot }}>10 \& 0<\mathrm{T}_{\text {cold }}<18$ \\
\hline & $\mathrm{s}$ & & - Dry Summer & $\mathrm{P}_{\text {sdry }}<40 \& \mathrm{P}_{\text {sdry }}<\mathrm{P}_{\text {wwet }} / 3$ \\
\hline & $\mathrm{w}$ & & - Dry Winter & $\mathrm{P}_{\mathrm{wdry}}<\mathrm{P}_{\text {swet }} / 10$ \\
\hline & $\mathrm{f}$ & & - Without dry season & Not $(\mathrm{Cs})$ or $(\mathrm{Cw})$ \\
\hline & & $\mathrm{a}$ & - Hot Summer & $\mathrm{T}_{\mathrm{hot}} \geq 22$ \\
\hline & & $\mathrm{b}$ & - Warm Summer & Not (a) \& $\mathrm{T}_{\operatorname{mon} 10} \geq 4$ \\
\hline & & $\mathrm{c}$ & - Cold Summer & $\operatorname{Not}(\mathrm{a}$ or $\mathrm{b}) \& 1 \leq \mathrm{T}_{\operatorname{mon} 10}<4$ \\
\hline \multirow[t]{8}{*}{$\mathrm{D}$} & & & Cold & $\mathrm{T}_{\text {hot }}>10 \& \mathrm{~T}_{\text {cold }} \leq 0$ \\
\hline & $\mathrm{s}$ & & - Dry Summer & $\mathrm{P}_{\text {sdry }}<40 \& \mathrm{P}_{\text {sdry }}<\mathrm{P}_{\text {wwet }} / 3$ \\
\hline & $\mathrm{w}$ & & - Dry Winter & $\mathrm{P}_{\mathrm{wdry}}<\mathrm{P}_{\text {swet }} / 10$ \\
\hline & $\mathrm{f}$ & & - Without dry season & Not $(D s)$ or $(D w)$ \\
\hline & & $\mathrm{a}$ & - Hot Summer & $\mathrm{T}_{\mathrm{hot}} \geq 22$ \\
\hline & & $\mathrm{b}$ & - Warm Summer & Not (a) \& $\mathrm{T}_{\operatorname{mon} 10} \geq 4$ \\
\hline & & $\mathrm{c}$ & - Cold Summer & Not $(a, b$ or $d)$ \\
\hline & & $\mathrm{d}$ & - Very Cold Winter & $\operatorname{Not}(\mathrm{a}$ or $\mathrm{b}) \& \mathrm{~T}_{\text {cold }}<-38$ \\
\hline \multirow[t]{3}{*}{$\mathrm{E}$} & & & Polar & $\mathrm{T}_{\mathrm{hot}}<10$ \\
\hline & $\mathrm{T}$ & & - Tundra & $\mathrm{T}_{\text {hot }}>0$ \\
\hline & $\mathrm{F}$ & & - Frost & $\mathrm{T}_{\text {hot }} \leq 0$ \\
\hline
\end{tabular}

$* \mathrm{MAP}=$ mean annual precipitation, MAT $=$ mean annual temperature, $\mathrm{T}_{\text {hot }}=$ temperature of the hottest month, $\mathrm{T}_{\text {cold }}=$ temperature of the coldest month, $\mathrm{T}_{\text {mon } 10}=$ number of months where the temperature is above $10, \mathrm{P}_{\mathrm{dry}}=$ precipitation of the driest month, $\mathrm{P}_{\text {sdry }}=$ precipitation of the driest month in summer, $\mathrm{P}_{\text {wdry }}=$ precipitation of the driest month in winter, $\mathrm{P}_{\text {swet }}=$ precipitation of the wettest month in summer, $\mathrm{P}_{\mathrm{wwet}}=$ precipitation of the wettest month in winter, $\mathrm{P}_{\text {threshold }}=$ varies according to the following rules (if $70 \%$ of MAP occurs in winter then $P_{\text {threshold }}=2 \times$ MAT, if $70 \%$ of MAP occurs in summer then $P_{\text {threshold }}=2 \times$ MAT +28 , otherwise $P_{\text {threshold }}=2 \times$ MAT +14 ). Summer $($ winter) is defined as the warmer (cooler) six month period of ONDJFM and AMJJAS.

1994). The greatest sensitivity of the resultant map to climatic trends is likely to be in the transition zones between climate types, rather than within a climate type (as seen in Fraedrich et al., 2001). Any benefits of restricting the data to a common period would be achieved at the expense of spatial representativeness, since stations with data that did not sufficiently overlap the common period would have been excluded from the analysis. In using the complete period of record the resultant Köppen-Geiger climate type map presents the long-term climate type for the maximum number of locations around the world.

A total of 4279 locations have data for both precipitation and temperature (indicated with an " $x$ " in Fig. 2). At these locations the Köppen-Geiger climate type can be determined from the raw station data. Although an updated Köppen-Geiger map based on 4279 locations would be a significant improvement over earlier maps, considerable information would be lost if locations with only precipitation or temperature were ignored. To avoid this loss of informa- tion the precipitation and temperature based variables used in the criteria to determine the Köppen-Geiger climate type (see Table 1) were calculated at each precipitation and temperature station. Then each variable was interpolated using a two-dimensional (latitude and longitude) thin-plate spline with tension (Mitas and Mitasova, 1988) onto a $0.1 \times 0.1$ degree of latitude and longitude grid for each continent. The Köppen-Geiger criteria were then applied to the splined variables. The tension spline interpolations were performed in ESRI ArcMap version 9.1 using settings of "weight" = 1 and "points" $=10$ for all interpolations. The chosen tension spline settings provided flexible and smooth interpolations of the climatic variables across the wide range of station densities and variable values experienced within and between continents. Although optimisation of the spline settings for each variable and continent may have improved the interpolation of individual climatic variables, it was not expected to significantly alter the final Köppen-Geiger climate type maps (which is a combination of the variables) and so was not 
Table 2. Average monthly and annual precipitation $(\mathrm{P})$ and temperature $(\mathrm{T})$ for Herberton Post Office, Australia.

\begin{tabular}{llllllllllllll}
\hline & $\mathrm{J}$ & $\mathrm{F}$ & $\mathrm{M}$ & $\mathrm{A}$ & $\mathrm{M}$ & $\mathrm{J}$ & $\mathrm{J}$ & $\mathrm{A}$ & $\mathrm{S}$ & $\mathrm{O}$ & $\mathrm{N}$ & $\mathrm{D}$ & Ann \\
\hline $\mathrm{P}(\mathrm{mm})$ & 238.4 & 229.7 & 214.4 & 86.0 & 46.9 & 33.3 & 22.0 & 18.2 & 16.5 & 25.3 & 77.3 & 137.9 & 1146 \\
$\mathrm{~T}\left({ }^{\circ} \mathrm{C}\right)$ & 23.2 & 22.8 & 21.9 & 20.0 & 17.9 & 16.0 & 15.5 & 16.5 & 18.6 & 21.0 & 22.4 & 23.3 & 19.9 \\
\hline
\end{tabular}

pursued in this paper. However, in continental sub-regions with high station density more flexible spline settings would have provided better local results.

A potential improvement to the above methodology would be to apply a three-dimensional spline, using elevation as the third dimension (based on a digital elevation model like HYDRO1k, USGS, 2000). Elevation plays a key role in the observed spatial pattern of precipitation and temperature and is an important variable in the interpolation of precipitation and temperature fields (Daly, 2006). In this analysis longterm average climatic variables are interpolated, which display considerably less spatial variability than is typically observed in daily, monthly or even annual fields to which 3$\mathrm{D}$ interpolation is usually applied. However, due to sparse station density, particularly in high elevation regions, a more complex 3-D interpolation procedure was not used in this paper.

Another potential improvement would be to conduct crossvalidation on the individual splined variables to investigate the sensitivity of each spline to the underlying data as well as cross-validation of the final Köppen-Geiger climate type map to assess the sensitivity of the map to each individual station. Such a sensitivity analysis would probably indicate that the Köppen-Geiger climate type map is most sensitive in regions of low station density, transition zones between climate types and also in regions where there are large elevation differences. A cross-validation exercise was not conducted as part of this paper due to the considerable amount of time required for such an exercise.

A description of the symbols and the criteria used to define the Köppen-Geiger climate types is provided in Table 1. The 30 possible climate types in Table 1 are divided into 3 tropical (Af, Am and Aw), 4 arid (BWh, BWk, BSh and BSk), 9 temperate (Csa, Csb, Csc, Cfa, Cfb, Cfc, Cwa, Cwb and Cwc), 12 cold (Dsa, Dsb, Dsc, Dsd, Dfa, Dfb, Dfc, Dfd, Dwa, Dwb, Dwc and Dwd) and 2 polar (ET and EF). All precipitation variables are in units of millimetres $(\mathrm{mm})$ and all temperature variables are in units of degrees Celsius $\left({ }^{\circ} \mathrm{C}\right)$. Since all locations that satisfy the $\mathrm{B}$ climate criteria will also satisfy one of the other (A, C, D or E) climate criteria, the B climates must be identified first. The set of locations defined as having a B climate is based on a combination of mean annual precipitation and mean annual temperature. The sets of A, C, D and E climate locations are mutually exclusive and are based on temperature criteria only.

In applying the criteria to the global dataset it became ap- parent that in some $\mathrm{C}$ climate locations it is possible to satisfy both the $\mathrm{Cs}$ and $\mathrm{Cw}$ criteria simultaneously. An example of this is Herberton Post Office (17.38 S, 145.38 E, elevation $900 \mathrm{~m}$ ) in North Queensland, Australia. Table 2 shows the monthly averages of precipitation and temperature for the Herberton Post Office record. Each average is based on about 105 monthly values for precipitation and 78 monthly values for temperature, so these averages are from a long-term station. Following the Köppen-Geiger criteria in Table 1, summer is the period ONDJFM and over $70 \%$ of the mean annual precipitation falls during summer. Since the mean annual precipitation $(1146 \mathrm{~mm})$ is larger than the B climate type precipitation threshold of $678 \mathrm{~mm}(10 *(2 * 19.9+28))$ (see Table 1$)$ the station is not a B climate. With the coldest monthly temperature $15.5^{\circ} \mathrm{C}$, the station is not an A climate, but does satisfy the criteria for a $\mathrm{C}$ climate. When the second letter is allocated, the driest summer month is $25.3 \mathrm{~mm}$, which is below $40 \mathrm{~mm}$ and is less than one third of the wettest winter month $(86.0 \mathrm{~mm})$, so the station satisfies a Cs climate type. However, the driest winter month $(16.5 \mathrm{~mm})$ is less than one tenth of the wettest summer month $(238.4 \mathrm{~mm})$, so this station also satisfies the $\mathrm{Cw}$ climate type. Considering that over $70 \%$ of the precipitation falls during summer a classification of $\mathrm{Cw}$ is appropriate, while a classification of $\mathrm{Cs}$ is not.

For cases such as Herberton Post Office an additional test was developed and applied to determine whether to use Cs or $\mathrm{Cw}$ at a given location. When a location satisfied both $\mathrm{Cs}$ and $\mathrm{Cw}$ criteria, the precipitation for the six months containing summer and the six months containing winter were compared, with $\mathrm{Cw}$ assigned if the summer precipitation was greater than the winter precipitation. This additional rule was also applied to locations that satisfied both the Ds and Dw climate criteria as well.

In the presence of steep gradients of a variable, splines are known to over- or under-estimate, particularly if there is limited station density. Initially, these spline artefacts were ignored at the individual variable level. However, once a continental map of Köppen-Geiger climate type was produced, the map was checked for locations where over or under-estimation in a splined variable had caused an aberrant climate type to be defined. These aberrant areas were generally found to be small and were patched by hand based on surrounding observations. Conversely, in some low station density regions, a climate type would extend further than expected due to a lack of observations to inform the spline. In these situations, discussed later, the climate type was left 


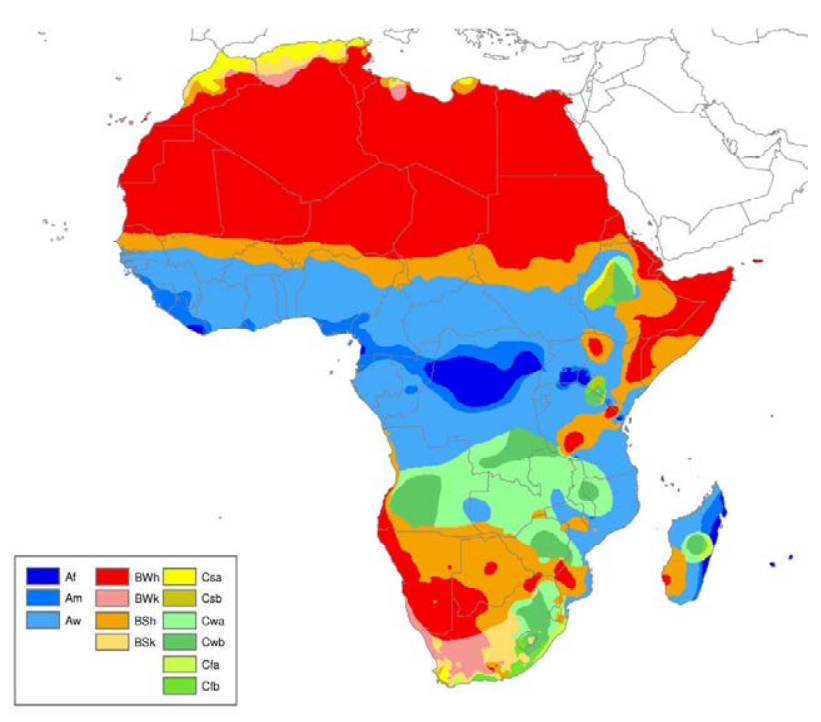

Fig. 4. Köppen-Geiger climate type map of Africa.

unmodified, due to a lack of information on which to base any corrections.

Contrary to some earlier forms of the Köppen-Geiger climate type map the concept of a high altitude climate type is not used in this paper. Designated as a separate 1st letter climate type $\mathrm{H}$ (Highland) or as a sub category of the E climate type (ETH or EFH) the highland climate type requires elevation information to be defined. Although global elevation data are available, defining all locations above a specified elevation as an $\mathrm{H}$ climate provides little information about the climate at those locations relative to using the full suite of A, B, C, D and E climate types. Therefore no highland climate type is used in this paper.

Once the Köppen-Geiger climate type map for each continent was constructed, the percentage of land area covered by the major climate types was calculated. Since the area of a $0.1 \times 0.1$ degree pixel changes with latitude, a map of $0.1 \times 0.1$ degree pixel area was constructed and then projected onto a Cylindrical Equal Area projection of the world to determine the area $\left(\right.$ in $\left.\mathrm{km}^{2}\right)$ of each $0.1 \times 0.1$ degree pixel. These pixel areas were then summed for each climate type to provide an estimate of the land area covered by each climate type.

\section{Continental maps}

The Köppen-Geiger climate type map was determined using the methodology described in the previous section for each continent. Continental definitions used in this paper follow those used in the HYDRO1k DEM of the world (USGS, 2000). These maps are presented and discussed in this section.

\subsection{Africa}

The map of Köppen-Geiger climate type for Africa (Fig. 4) shows that only three (A, B and C) of the main climate types are present in Africa. Of these three the dominant climate type by land area is the arid B $(57.2 \%)$, followed by tropical A $(31.0 \%)$ and temperate $\mathrm{C}(11.8 \%)$.

Figure 4 is based on 1436 precipitation and 331 temperature stations. Of these stations a total of 313 had both precipitation and temperature data for the same location, from which the climate type could be independently calculated and checked against the map. The climate type at 309 of these locations matched the map exactly and in the remaining 4 locations the correct climate type was present in a neighbouring cell.

The thin-plate spline with tension settings used to interpolate individual variables does not force the spline through the exact station values. Therefore, slight differences in climate type between station and spline-based estimates are expected. If the station and map climate types do not match exactly, then the station-based climate type usually appears in a neighbouring cell of the spline-based map. However, if the station-based climate type is not present in a neighbouring cell, then the spline-based estimate is incorrect, indicating that at least one of the splines has not successfully interpolated the observed data. For Africa, all of the station estimates match the map exactly or are in a neighbouring cell.

The low density of temperature stations in Africa resulted in some climate types extending further than expected, which could not be corrected due to lack of data. The two regions where this is most evident are the temperate regions in the Eastern Rift Valley south of Nairobi, Kenya and around Antananarivo, Madagascar. In both of these cases the temperature stations are in high elevation locations (Nairobi and Antananarivo) and experience a temperate climate type. However, due to the lack of nearby lower elevation temperature stations, the temperate influence of both these high elevation stations extends well beyond their immediate location and large regions of temperate climate type result in regions that are more likely to be tropical.

Another interesting feature in Fig. 4 is the division of the temperate region in the Ethiopian highlands into $\mathrm{Cs}$ and $\mathrm{Cw}$ climate types. This region experiences a strong seasonal precipitation regime (most precipitation occurs during AprilSeptember) but a very even monthly temperature regime (the hottest month is $\sim 5^{\circ} \mathrm{C}$ hotter than the coldest month). On the western side of the highlands, the six months from OctoberMarch are warmer than April-September, so summer is defined as October-March, thus the precipitation falls in winter. Whereas on the eastern side of the highlands the six months from April-September are warmer, so summer is defined as April-September, thus the precipitation falls in summer. Therefore, in Fig. 4 the western side of the highlands have a Cs climate and the eastern side have a $\mathrm{Cw}$ climate. 


\subsection{Asia}

In this paper Asia is defined as the region east of a northsouth line through the Urals Mountains down to the Arabian Sea. The map of Köppen-Geiger climate type for Asia (Fig. 5) shows that all five of the main climate types are present in Asia. The dominant climate type by land area is the cold D (43.8\%), followed by arid B (23.9\%), tropical A (16.3\%), temperate $\mathrm{C}(12.3 \%)$ and polar E $(3.8 \%)$.

Figure 5 is based on 3650 precipitation and 944 temperature stations. Of these stations a total of 748 had both precipitation and temperature data for the same location, from which the climate type could be independently calculated and checked against the map. The climate type at 732 of these locations matched the map exactly and in 14 of the remaining 16 locations the correct climate type was present in a neighbouring cell. However, at 2 locations (Kodaikanal, India and Pune, India) the observed climate type differs from the map, indicating that at least one of the splines has not successfully interpolated the observed data.

In the case of Kodaikanal $(10.2 \mathrm{~N}, 77.5 \mathrm{E})$, located at $2343 \mathrm{~m}$ elevation on the eastern side of the Western Ghats in Tamil Nadu State, the seasonality of precipitation is much less distinct than that observed in the surrounding lowlands ( $\sim 100 \mathrm{~m}$ elevation). So although the observations indicate a $\mathrm{Cfb}$ climate type at Kodaikanal, the map indicates a Cwb climate type. The disparity is due to the high density of precipitation stations in the surrounding lowlands, which influence the precipitation splines, particularly the winter dry month spline, to underestimate the precipitation at Kodaikanal. This under-estimation, particularly the winter dry month precipitation, leads to a $\mathrm{Cw}$ rather than a $\mathrm{Cf}$ climate type. The universal spline settings used for the analysis are not flexible enough to fully capture the local variation in precipitation, resulting in the misallocation of this site. Correcting the final climate type map around Kodaikanal would be speculative and has not been attempted.

At Pune (18.5 N, 73.9E), in Maharashtra State, there is a very strong orographic gradient in mean annual precipitation. The thin coastal strip to the west $(25 \mathrm{~km})$ of Pune receives mean annual precipitation of between 3000-6000 mm. At Pune the mean annual precipitation is $700 \mathrm{~mm}$. The observations at Pune indicate a BSh climate, whereas the map indicates an Aw climate. This difference is due to the mean annual precipitation spline overestimating the precipitation at Pune, due to the very steep precipitation gradient, and thus placing Pune in an A rather than a B climate type. Again, the universal spline settings used are not flexible enough to fully capture the local variation in precipitation, resulting in the misallocation of this site. Likewise, correcting the final climate type map around Pune would be speculative and has not been attempted.

The low density of temperature stations in southern India resulted in a region of temperate climate type extending further south than expected. As mentioned above, Kodaikanal in

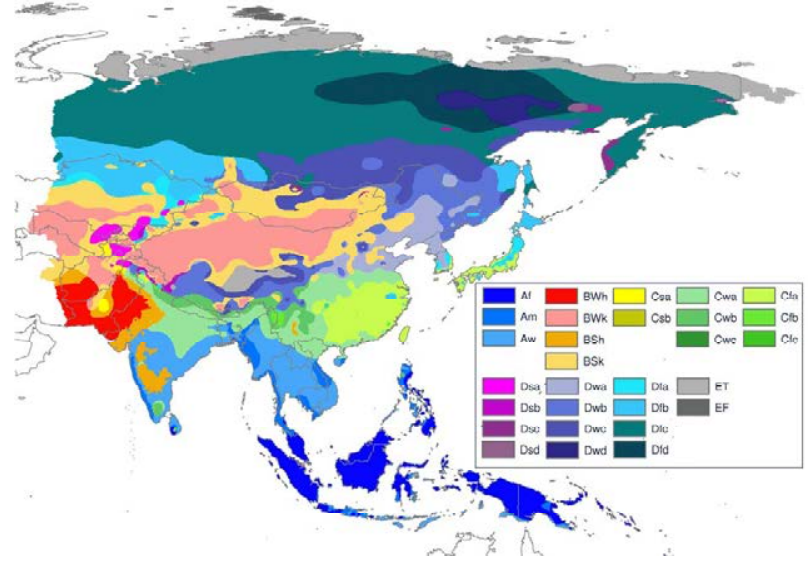

Fig. 5. Köppen-Geiger climate type map of Asia.

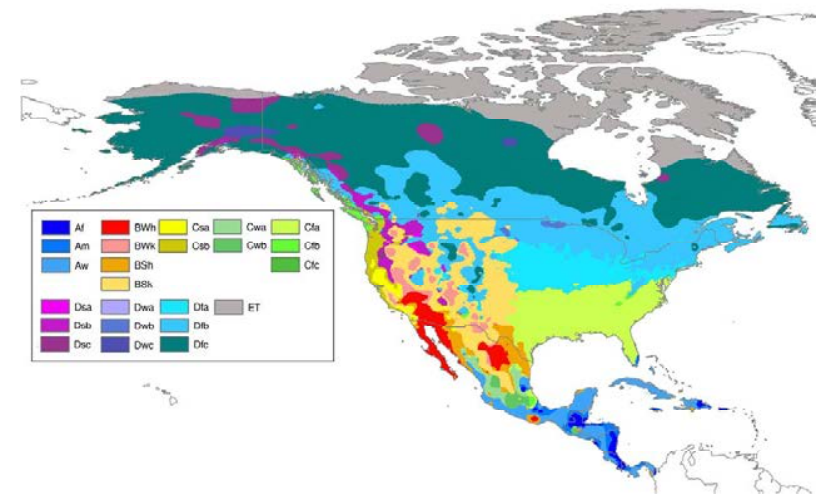

Fig. 6. Köppen-Geiger climate type map of North America.

Tamil Nadu is a high elevation station in a temperate climate type. However, it is up to $140 \mathrm{~km}$ from its nearest neighbour to the west and over $400 \mathrm{~km}$ away from the nearest station to the northeast. All the surrounding temperature stations are in a tropical climate type. The large area of temperate, rather than tropical climate in southern India is due to this single station and the lack of temperature stations in the surrounding lowland areas, which could not be corrected due to lack of data.

\subsection{North America}

North America is defined in this paper as Canada, the USA, the countries of Central America and the Caribbean Islands. The map of Köppen-Geiger climate type for North America (Fig. 6) shows that all five of the main climate types are present in North America. The dominant climate type by land area is cold D (54.5\%), followed by arid B $(15.3 \%)$, temperate C (13.4\%), polar E (11.0\%) and tropical A $(5.9 \%)$.

Figure 6 is based on 3034 precipitation and 2236 temperature stations. Of these stations a total of 2078 had both 


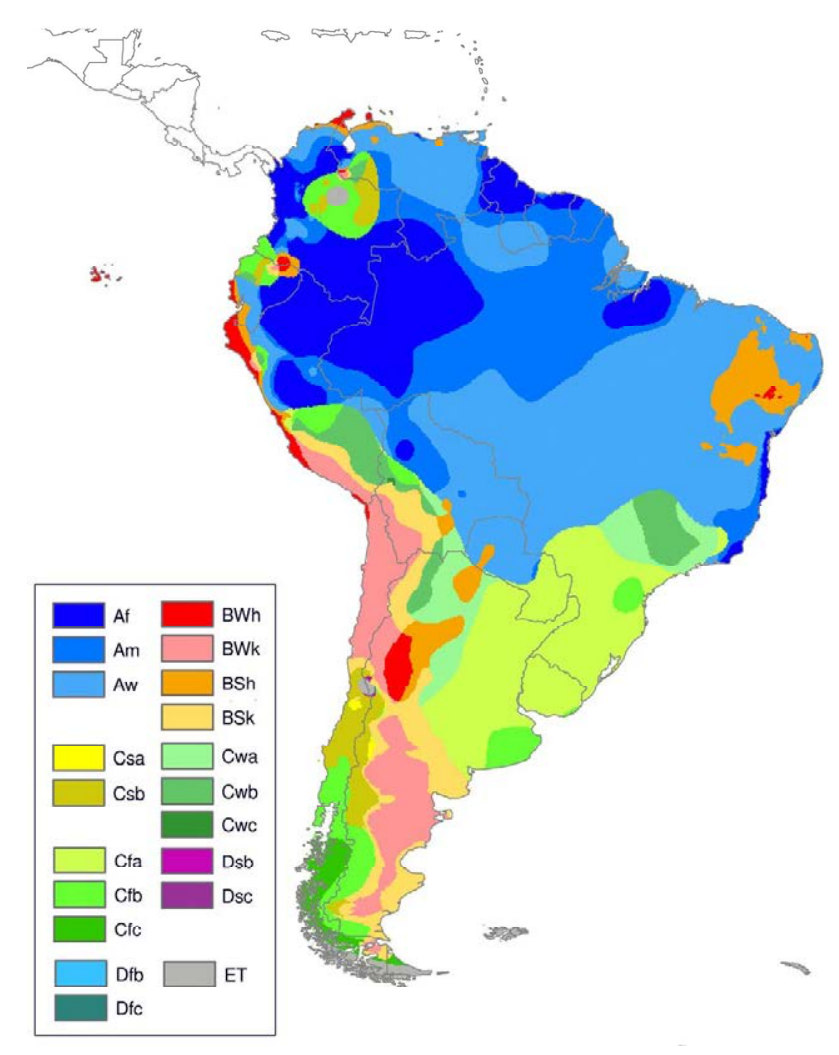

Fig. 7. Köppen-Geiger climate type map of South America.

precipitation and temperature data for the same location, from which the climate type could be independently calculated and checked against the map. The climate type at 2020 of these locations matched the map exactly and in all the remaining 58 locations the correct climate type was present in a neighbouring cell.

In Guatemala, there is a low density of temperature stations, which results in a region of temperate climate type extending further than expected around Guatemala City $(14.5 \mathrm{~N},-90.6 \mathrm{~W})$. At an elevation of $1500 \mathrm{~m}$, Guatemala City has a temperate Cwb climate. However, it is up to $175 \mathrm{~km}$ from its nearest neighbour to the southeast in El Salvador. All the surrounding temperature stations are in tropical climate types. Although much of the area around Guatemala City is likely to be temperate due to the high elevation, the temperate region on the map extends into what are likely to be tropical areas near the coast where there are no temperature stations to define the boundary more closely.

A region of BWh south of Oaxaca, Mexico (17.1 N, -96.7 W) may be an artefact of the spline process, but since there are no precipitation or temperature stations in this arid region it is impossible to be certain. At an elevation of $1550 \mathrm{~m}$, Oaxaca experiences an arid BSh climate type, but whether the region to the south is as arid as BWh remains uncertain.
In the methodology section, an additional criterion to deal with locations that satisfy both $\mathrm{Cs}$ and $\mathrm{Cw}$ or Ds and Dw criteria was described. In North America this criterion was successfully applied at 11 temperate locations (mainly in Mexico) with observed precipitation and temperature data. However, other locations in North America show that the criteria for selecting the second letter of the C and D climate types are not always providing an appropriate outcome. For example, at Batopilas in the state of Chihuahua, Mexico $(27.0 \mathrm{~N}$, $107.7 \mathrm{~W}$ ), where only precipitation data are available, the climate type in Fig. 6 is given as Csa. Nearby temperature stations confirm that summer is in the six-month period from April through to September. At Batopilas the average summer rainfall is $441 \mathrm{~mm}$ and the average winter rainfall is $191 \mathrm{~mm}$. Nearby temperate locations are all $\mathrm{Cw}$, which is consistent with the summer dominant rainfall at Batopilas. Following the temperate second letter criteria in Table 1, the driest month in summer $(5.3 \mathrm{~mm})$ is below $40 \mathrm{~mm}$ and is less than one third of the wettest month in winter $(49.3 \mathrm{~mm})$, so a Cs climate type is satisfied. When the $\mathrm{Cw}$ climate criterion is applied, the driest month in winter $(18.4 \mathrm{~mm})$ is not one tenth of the wettest month in summer $(154.6 \mathrm{~mm})$, so a $\mathrm{Cw}$ climate type is not satisfied. Since this site only satisfies the Cs criteria, the additional check of the summer and winter precipitation, described in the methodology section, is not applied. So at Batopilas, the summer rainfall is greater than the winter rainfall, by a factor of 2 , yet it is defined by the Köppen-Geiger criteria as a temperate climate with a dry summer (Csa).

A slightly different concern with the temperate second letter criteria is observed at White River, in the state of Arizona, USA (33.84 N, 109.97 W) where the Köppen-Geiger criteria suggest a Csa climate type. However, a Cs climate appears inappropriate since summer precipitation $(228 \mathrm{~mm})$ is greater than the winter precipitation $(201 \mathrm{~mm})$. A more appropriate climate type would be Cfa since the precipitation is evenly distributed throughout the two six month periods. Other locations where concerns about the second letter criteria for the $\mathrm{C}$ or D climate types were observed are Prescott (Cs $-34.57 \mathrm{~N}$, 112.44 W), USA and the Ds regions in northern Canada and Alaska centred on Fort Yukon (66.6 N, 145.3 W), Anchorage (61.2, 149.9 W), Yellowknife (62.47 N, 114.45 W), Carcross $(60.18 \mathrm{~N}, 134.7 \mathrm{~W})$, Mayo $(63.62 \mathrm{~N}, 135.87 \mathrm{~W})$ and west of Fairbanks (64.9 N, 147.7 W).

\subsection{South America}

The map of Köppen-Geiger climate type for South America (Fig. 7) shows that three main climate types A, B and C dominate the climate of South America. Of these three the dominant climate type by land area is tropical A $(60.1 \%)$, followed by temperate C $(24.1 \%)$ and arid B (15.0\%). The Polar E $(0.8 \%)$ climate type occurs in four places in South America, twice in the Andes, due to the high elevation, along the 
southern edge of Chile (Strait of Magellan)/Argentina (Tierra del Fuego) and in the Falkland Islands and South Georgia.

Figure 7 is based on 1115 precipitation and 192 temperature stations. Of these stations a total of 171 had both precipitation and temperature data for the same location for which the climate type is known and can be checked against the map. The climate type at 165 of these locations matched the map exactly and in 5 of the remaining 6 locations the correct climate type was present in a neighbouring cell. In the case of Aracaju (10.9 S, 37.1 W), in the state of Sergipe, Brazil, the observed precipitation and temperature satisfy the Am climate type (borderline Aw), whereas the map shows this site in a region of Aw climate type. The splined variables indicate that this station is clearly Aw, which is not consistent with the observations. The reason the splined variables are inconsistent with the observations is that this region has a very high density of precipitation stations (Fig. 1). The universal spline settings used for the analysis are not flexible enough to fully capture the local variation in precipitation, resulting in the misallocation of this site.

The misallocation of Aracaju due to the spline settings not being flexible enough to adequately represent the local variation in precipitation is indicative of neighbouring parts of the Nordeste region of Brazil. The climate types represented in this region BWh, BSh, Aw, Am and Af are consistent with the observations. However, the spatial distribution of these climate types would be more in line with the precipitation observations had a more flexible spline setting been used for the precipitation data in this region. The sparse distribution of temperature stations in this region would make any corrections to the final climate type map speculative.

The generally low density of temperature stations in South America resulted in some climate types extending further than expected, which could not be corrected due to the lack of data. Two regions where this is most evident are the temperate regions northeast of Bogota, Colombia and around Quito, Ecuador. In both of these cases the temperature stations are in high elevation locations and experience a temperate climate type. However, due to the lack of nearby lower elevation temperature stations, the temperate influence of both these high elevation stations extends well beyond their immediate location and large regions of temperate climate type result in regions that are more likely to be tropical. In the case of Bogota, a region of ET climate type is observed within the temperate region. This region is largely coincident with the higher sections of the Cordillera Oriental, which is likely to have a climate type of ET.

\subsection{Europe}

In this paper, Europe is defined as the region west of a northsouth line through the Urals Mountains down to the Arabian Sea and includes the Arabian Peninsula and the countries of the Middle East. The Köppen-Geiger climate type map of Europe (Fig. 8) shows that only four main climate types are

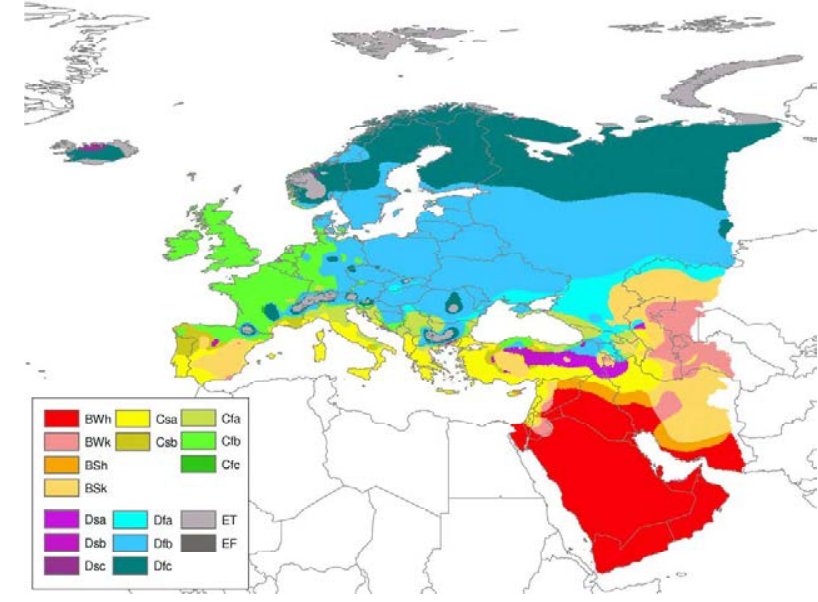

Fig. 8. Köppen-Geiger climate type map of Europe.

found in Europe. The dominant climate type by land area is cold D (44.4\%), followed by arid B (36.3\%), temperate C (17.0\%) and polar E (2.3\%).

Figure 8 is based on 1209 precipitation and 684 temperature stations. Of these stations a total of 496 had both precipitation and temperature data for the same location for which the climate type is known and can be checked against the map. The climate type at 488 of these locations matched the map exactly and in the remaining 8 locations the correct climate type was present in a neighbouring cell.

As is the case for other continents, in Europe there are some climate types extending further than expected due to a low density of temperature stations. For example, around Mussala (42.18 N, 23.58 E), Bulgaria there is a region of ET climate type. There are three temperature stations within this ET region, which are all located at over $2000 \mathrm{~m}$ in elevation, and their observations confirm an ET climate type. However, rather than being part of a single range of mountains, these three stations are located on top of three separate peaks with extensive lowlands in between. As there are no temperature stations located in the lowlands the splines ignore them and the entire region is set to ET, rather than a mixture of ET and Df. A similar situation occurs in the Central Massif of France around Le Puy de Dome (45.8 N, 2.9 E) and Mont Aigoual $(44.12 \mathrm{~N}, 3.58 \mathrm{E})$ where two temperature stations atop isolated peaks extend a region of Df climate between them. This region should be a mixture of $\mathrm{Df}$ (on the mountains) and $\mathrm{Cf}$ in the lowlands, but there are no temperature stations in the lowlands.

In Iceland the temperature stations are all located in coastal areas. Without any inland temperature data to inform the splines, the coastal climate type of Dfc extends inland where a climate type of ET is more likely to be appropriate. The region of ET climate type in southern Norway extends to the coast at the northwestern edge, an area that would be expected to be $\mathrm{Cfb}$ if temperature data were available. 


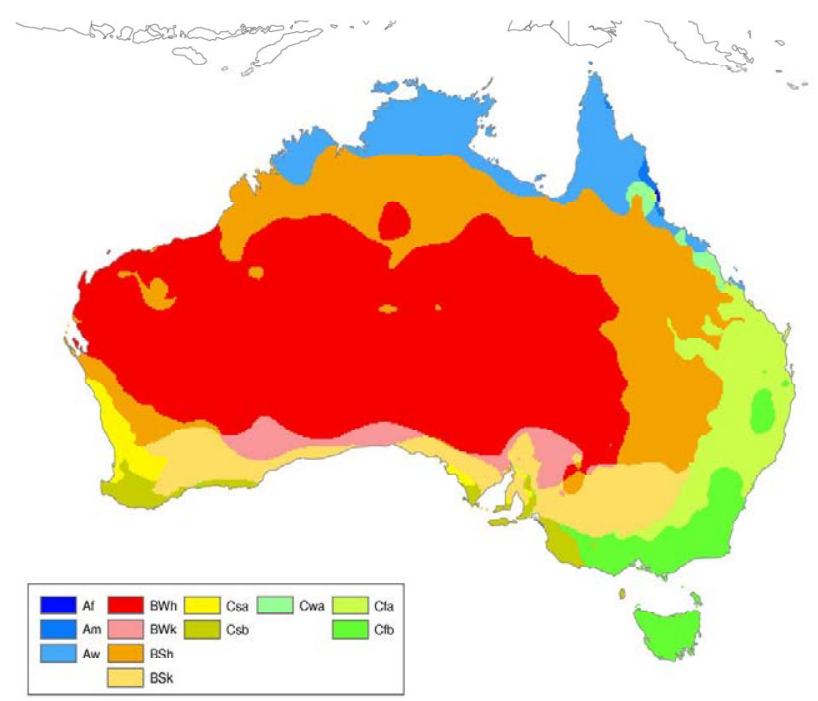

Fig. 9. Köppen-Geiger climate type map of Australia.

Along the French-Italian border the low density of temperature stations effectively reduces the area of ET climate type. At St Bernard (45.7 N, 6.9 E) in Switzerland the climate type is ET, while the nearest station in a direct line to the south, Nice (43.65 N, 7.2 E) in France, experiences a Csa climate. Despite the Alps stretching almost to the coast, the region of ET climate mapped does not, due to the lack of temperature stations in the region.

\subsection{Australia}

The Köppen-Geiger climate type map of Australia (Fig. 9) shows that only three main climate types are found in Australia. The dominant climate type by land area is arid B (77.8\%), followed by temperate C (13.9\%) and tropical A $(8.3 \%)$.

Figure 9 is based on 1807 precipitation and 351 temperature stations. Of these stations a total of 345 had both precipitation and temperature data for the same location for which the climate type is known and can be checked against the map. The climate type at 340 of these locations matched the map exactly and in the remaining 5 locations the correct climate type was present in a neighbouring cell.

The spatial distribution of precipitation and temperature stations in the arid western central region of Australia is sparse, so boundaries between the different arid climate types are less reliable than in the more data rich eastern and south western regions (Fig. 2).

\subsection{Islands, Greenland and Antarctica}

In the spline analyses used to estimate the Köppen-Geiger climate type for each continent, data from small offshore islands were generally removed prior to analysis, since they

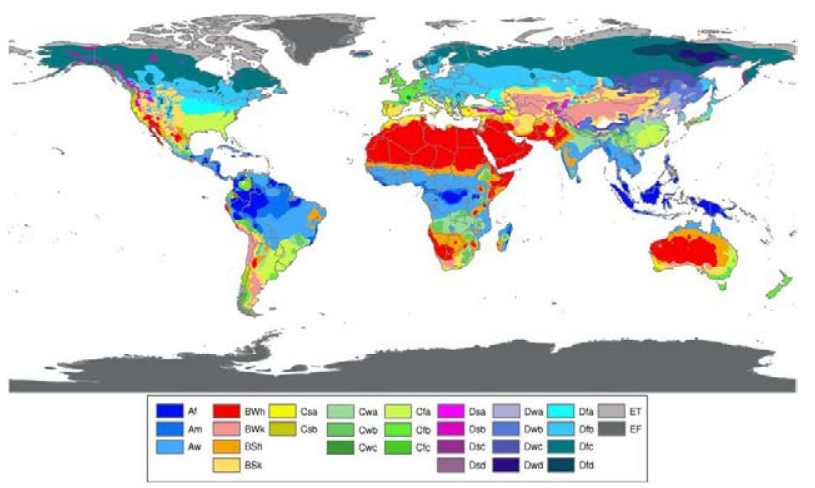

Fig. 10. Köppen-Geiger climate type map of the World.

tended to influence the splines over the mainland in low station density regions. Therefore, islands like the Canary Islands, Cape Verde, Hawaii and the islands of the South Pacific were allocated a Köppen-Geiger climate type by hand based on observations from the islands.

In Greenland there were 10 precipitation and 9 temperature stations, 8 of which have both variables at the same location. All of these stations are in coastal locations, so there was no climatic information about the interior of Greenland on which to base a spline analysis. In Antarctica, there were 21 temperature stations and no precipitation stations with all but 2 stations being in coastal locations. Like Greenland there was little interior climatic information on which to base a spline analysis. The climate type at all the Greenland stations was ET, while in Antarctica they were a mixture of ET and EF.

In order to interpolate the climate type over the whole of Greenland and Antarctica an alternate method was required. In the case of Greenland, elevation data was used, with any location $<1000 \mathrm{~m}$ given a climate type of ET and a location $\geq 1000 \mathrm{~m}$ given a climate type of EF. In Antarctica the whole continent was set to a climate type of EF, except around stations that were known to be ET. In Table 1 the criterion that divides ET from EF is the hottest month being greater than $0^{\circ} \mathrm{C}$. Of the Antarctic stations the hottest month at any station was $1.6^{\circ} \mathrm{C}$, so most of the ET stations are borderline EF. Based on this observation, any location near an ET station with an elevation of $<100 \mathrm{~m}$ was set to ET.

\section{The world map: discussion and conclusion}

The continental and island maps are combined together to form the world Köppen-Geiger climate type map (Fig. 10). Globally the dominant climate class by land area is arid B (30.2\%) followed by cold D (24.6\%), tropical A (19.0\%), temperate $\mathrm{C}(13.4 \%)$ and polar $\mathrm{E}(12.8 \%)$. The most common individual climate type by land area is BWh (14.2\%), followed by Aw (11.5\%). Of the 30 possible climate types 
the Csc climate type never occurs and the Cwc climate type occurs in only 25 pixels (representing $0.002 \%$ of total land area).

In the methodology, a new criterion for locations that satisfy both $\mathrm{Cs}$ and $\mathrm{Cw}$ (or Ds and Dw) criteria simultaneously was described and it was applied successfully in several locations. However, the criteria for the second letter of the $\mathrm{C}$ and D climates was still found to produce inappropriate results, particularly in the high latitudes of North America, and needs to be further revised. Future revisions based on mutually exclusive total seasonal precipitation thresholds, similar to the $70 \%$ criteria used for the B climate, may prove more robust than criteria based on the wettest and driest months of summer and winter.

The updated world Köppen-Geiger climate type map is based on the climatology at stations over their entire period of record, with each variable individually interpolated and differs from the recent work of Kottek et al. (2006), which is based on $0.5 \times 0.5$ degree gridded temperature and precipitation data for the period 1951 to 2000 . Although broadly similar to the map of Kottek et al. (2006), the present map also deals with locations that satisfy both $\mathrm{Cs}$ and $\mathrm{Cw}$ (or Ds and Dw) and has a finer resolution.

The single setting used for the 2-D thin-plate spline with tension was able to successfully interpolate the observed data in the vast majority of cases. For a total of 4279 stations with both precipitation and temperature data, the map differs significantly at only 3 stations (Kodaikanal, Pune and Aracaju) and in each case a more flexible spline setting may have improved the map. However, in mountainous regions and in regions of low station density the addition of elevation into the interpolation procedure may improve the extrapolation of Köppen-Geiger climate type. In addition to improved estimates of precipitation and temperate in mountainous regions, elevation information would limit the influence of isolated high elevation stations extending their climate type into lowland regions.

The electronic form (in ESRI Arc Grid (raster) and JPG formats) of the world Köppen-Geiger climate type map is available in the Supplementary Material section (http://www.hydrol-earth-syst-sci.net/11/1633/2007/ hess-11-1633-2007-supplement.zip). Also available at this site are files containing the precipitation and temperature variables for all stations used in the construction of the map.

Acknowledgements. Australian Research Council Discovery grants DP0449685 and DP0773016 financially supported this work. F. Peel assisted with the colour scheme used for the maps.

Edited by: R. T. Clarke

\section{References}

Barnett, T., Zwiers, F., Hegerl, G., Allen, M., Crowley, T., Gillett, N., Hasselmann, K., Jones, P., Santer, B., Schnur, R., Stott, P.,
Taylor, K., and Tett. S.: Detecting and attributing external influences on the climate system: a review of recent advances, J. Climate, 18, 1291-1314, 2005.

Daly, C.: Guidelines for assessing the suitability of spatial climate data sets, Int. J. Climatol., 26, 707-721, 2006.

Dick, R. S.: Frequency patterns of arid, semi-arid and humid climates in Queensland, Capricornia, 1, 21-30, 1964.

Essenwanger, O. M.: Classification of climates. In World Survey of Climatology 1C, General Climatology, Elsevier, Amsterdam, pp. 102, 2001.

Fovell, R. G. and Fovell, M.-Y. C.: Climate zones of the conterminous United States defined using cluster analysis, J. Climate, 6, 2103-2135, 1993.

Fraedrich, K., Gerstengarbe, F. -W. and Werner, P. C.: Climate shifts during the last century, Climatic Change, 50, 405-417, 2001.

Gentilli, J. (Ed.): Climates of Australia and New Zealand, World Survey of Climatology, Vol. 13. Elsevier, Amsterdam, 405p, 1971.

Gnandesikan, A. and Stouffer, R. J.: Diagnosing atmosphere-ocean general circulation model errors relevant to the terrestrial biosphere using the Köppen climate classification, Geophys. Res. Lett., 33, L22701, doi:10.1029/2006GL028098, 2006.

Kalvova, J., Halenka, T., Bezpalcova, K., and Nemesova, I.: Köppen Climate types in observed and simulated climates, Stud. Geophys. Geod., 47, 185-202, 2003.

Kleidon, A., Fraedrich, K., and Heimann, M.: A green planet versus a desert world: estimating the maximum effect of vegetation on the land surface climate, Climatic Change, 44, 471-493, 2000.

Köppen, W.: Das geographisca System der Klimate, in: Handbuch der Klimatologie, edited by: Köppen, W. and Geiger, G., 1. C. Gebr, Borntraeger, 1-44, 1936.

Kottek, M., Grieser, J., Beck, C., Rudolf, B., and Rubel, F.: World map of the Köppen-Geiger climate classification updated, Meteorol. Zeitschr., 15(3), 259-263, 2006.

Lohmann, U., Sausen, R., Bengtsson, L., Cubasch, U., Perlwitz, J., and Roeckner, E.: The Köppen climate classification as a diagnostic tool for general circulation models, Clim. Res., 3, 177193, 1993.

McMahon, T. A., Finlayson, B. L., Haines, A. T., and Srikanthan, R.: Global Runoff - Continental Comparisons of Annual Flows and Peak Discharges, Catena Verlag, Cremlingen, 166pp, 1992.

Mitas, L. and Mitasova, H.: General variational approach to the interpolation problem, Comput. Math. Applic., 16, 983-992, 1988.

Peel, M. C., McMahon, T. A., and Finlayson, B. L.: Continental differences in the variability of annual runoff - update and reassessment, J. Hydrol., 295, 185-197, 2004.

Peterson, T. C. and Vose, R. S.: An overview of the Global Historical Climatology Network temperature database, Bull. Am. Meteorol. Soc., 78(12), 2837-2849, 1997.

Russell, R. J.: Dry climates of the United States: I climatic map, University of California, Publications in Geography, 5, 1-41, 1931.

Sanderson, M.: The classification of climates from Pythagoras to Koeppen, Bull. Am. Meteorol. Soc., 80, 669-673, 1999.

Stern, H., De Hoedt, G., and Ernst, J.: Objective classification of Australian climates, Aust. Meteorol. Mag., 49, 87-96, 2000.

Strahler, A. N.: The Earth Sciences. Harper and Row, New York, 824pp, 1971. 
Strahler, A. H. and Strahler, A. N.: Physical Geography : Science and Systems of the Human Environment. Wiley, New York, 794pp, 2005.

Thornthwaite, C. W.: Problems in the classification of climates, Geogr. Rev., 33(2), 233-255, 1943.

Triantafyllou, G. N. and Tsonis, A. A.: Assessing the ability of the Köppen system to delineate the general world pattern of climates, Geophys. Res. Lett., 21(25), 2809-2812, 1994.
USGS (2000), HYDRO1k, http://edc.usgs.gov/products/elevation/ gtopo30/hydro/ (accessed 16/10/2006).

Wang, M. and Overland, J. E.: Detecting Arctic climate change using Köppen climate classification, Climatic Change, 67, 4362, 2004.

Wilcock, A. A.: Köppen after fifty years, Ann. Assoc. Am. Geog., 58(1), 12-28, 1968. 
ANEXO 4 RESULTADOS DE 131 CERTIFICACIONES ENERGÉTICAS DE VIVIENDAS EN MADRID, A MODO DE VALIDACIÓN DEL USO DE LA HERRAMIENTA INFORMÁTICA CE $^{3} X$. UTILIZADA EN LA TESIS 
ANEXO 4.1

RESULTADOS DE 131 CERTIFICACIONES ENERGÉTICAS. CALIFICACIÓN ESTADO ACTUAL 
CALIFICACIÓN ENERGÉTICA ACTUAL

\begin{tabular}{|c|c|c|c|c|c|c|c|c|c|}
\hline \multicolumn{10}{|c|}{ CALIFICACIÓN ENERGÉTICA ACTUAL } \\
\hline № Proyecto & & Letra & $\mathrm{kgCO} 2 \mathrm{~m} 2$ año & Sup & Calef. kWhm2 año & Letra Cale. & Refri.kWhm2 año & Letra Refri. & Global kWh m2 año \\
\hline № Proyecto & Año & Calificación Global (Letra) & Emisiones Globales & Superficie & Dem. Calefacción & Calificación Calef. & Dem. Refrigeración & Calificación Refri. & Consumo Global \\
\hline 11 & 1952 & G & $\begin{array}{r}168,05 \\
\end{array}$ & 30 & 173,46 & $G$ & $\begin{array}{r}6,86 \\
\end{array}$ & C & $\begin{array}{r}675,81 \\
\end{array}$ \\
\hline 12 & 1959 & G & 119,25 & 48 & 160,98 & G & 10,71 & $\mathrm{D}$ & 481,68 \\
\hline 13 & 1970 & G & 117,83 & 64 & 126,39 & $\mathrm{~F}$ & 6,29 & $B$ & 473,86 \\
\hline 14 & 1965 & $\mathrm{~F}$ & 67,11 & 49 & 173,25 & G & 12,68 & $\mathrm{D}$ & 327,78 \\
\hline 15 & 1968 & E & 49,73 & 71 & 137,27 & G & 23,9 & G & 237,75 \\
\hline 16 & 1958 & G & 125,92 & 50 & 150,31 & G & 8,35 & C & 501,18 \\
\hline 17 & 1961 & E & 43,95 & 27 & 115,31 & $\mathrm{E}$ & 10,46 & $\mathrm{D}$ & 210,12 \\
\hline 18 & 1984 & E & 43,31 & 85 & 97,33 & $\mathrm{E}$ & 16,82 & $E$ & 208,45 \\
\hline 19 & 1966 & $G$ & 125,57 & 60 & 153,48 & $G$ & 26,81 & $\mathrm{G}$ & 509,3 \\
\hline 20 & 2005 & $D$ & 33,03 & 569 & 73,63 & D & 8,4 & $\bar{B}$ & 156,52 \\
\hline 21 & 1973 & $E$ & 36,03 & 96 & 78,15 & $E$ & 13,95 & D & 168,4 \\
\hline 22 & 1960 & $D$ & 25,35 & 44 & 69,76 & $E$ & 9,07 & C & 122,31 \\
\hline 23 & 1974 & $\mathrm{E}$ & 52,56 & 59 & 136,77 & $G$ & 7,89 & $\bar{C}$ & 201,11 \\
\hline 24 & 1978 & $\mathrm{E}$ & 56,29 & 36 & 92,71 & $E$ & 14,78 & D & 168,65 \\
\hline 25 & 1960 & $F$ & 61,73 & 43 & 130,37 & $F$ & 19,33 & $F$ & 298,76 \\
\hline 26 & 1960 & $\mathrm{~F}$ & 70,29 & 42,82 & 92,28 & $E$ & 16,93 & $E$ & 284,29 \\
\hline 27 & 1940 & $E$ & 48 & 67 & 90,18 & $E$ & 26,87 & G & 219,89 \\
\hline 28 & 2008 & $E$ & 66,14 & 123 & 271,21 & $F$ & & & 311,72 \\
\hline 29 & 1870 & $G$ & 147,87 & 28,5 & 143,85 & $G$ & 19,82 & $F$ & 594,66 \\
\hline 30 & 1900 & $\bar{G}$ & 115,71 & 31,4 & 94,9 & $E$ & 21,91 & $F$ & 465,34 \\
\hline 31 & 1929 & $E$ & 42,88 & 36 & 108,08 & $E$ & 22,74 & $\mathrm{~F}$ & 204,23 \\
\hline 32 & 1940 & $E$ & 41,41 & 28 & 108,62 & $E$ & 18,5 & $E$ & 198,48 \\
\hline 33 & 1975 & $E$ & 40,75 & 60 & 120,51 & $E$ & 7,94 & C & 198,92 \\
\hline 34 & 1969 & G & 96,15 & 33,32 & 83,48 & $E$ & 12,59 & D & 386,67 \\
\hline 35 & 1980 & $E$ & 29,35 & 98,12 & 83,09 & $E$ & 17,46 & $\bar{E}$ & 139,14 \\
\hline 36 & 1979 & $G$ & 171,47 & 60 & 209,55 & $G$ & 21,22 & $\mathrm{~F}$ & 693,29 \\
\hline 37 & 1989 & $E$ & 45,98 & 57,25 & 127,54 & $F$ & 8,32 & C & 221,49 \\
\hline 38 & 1967 & G & 86,38 & 48,5 & 118,26 & $E$ & 7,5 & C & 350,1 \\
\hline 39 & 1962 & $G$ & 114,41 & 53 & 122,59 & $F$ & 21,89 & $\mathrm{~F}$ & 460,09 \\
\hline 40 & 1950 & $\mathrm{E}$ & 40,64 & 40,41 & 122,86 & $F$ & 10,06 & D & 197,63 \\
\hline 41 & 1961 & $E$ & 39,23 & 65,05 & 97,72 & $E$ & 20,83 & $\mathrm{~F}$ & 186,83 \\
\hline 42 & 1960 & $G$ & 84,11 & 53,3 & 142,35 & $G$ & \begin{tabular}{|c|}
6,11 \\
\end{tabular} & B & 324,19 \\
\hline 43 & 1979 & $E$ & 30,75 & 110,17 & 76,57 & $E$ & 13,19 & $D$ & 147,54 \\
\hline 44 & 1990 & $E$ & 32,34 & 86,14 & 59,21 & D & 15,85 & $E$ & 154,51 \\
\hline 45 & 1973 & $E$ & 34,54 & 86,3 & 92,67 & $E$ & 17,64 & $\mathrm{E}$ & 164,76 \\
\hline 46 & 2005 & $E$ & 34,12 & 78,91 & 55,25 & $D$ & 19,75 & $\mathrm{~F}$ & 154,85 \\
\hline 47 & 1983 & $F$ & 107,48 & 78,81 & 310,36 & $G$ & & & 410,74 \\
\hline 48 & & & & & & & & & \\
\hline 49 & 1979 & $E$ & 36,41 & 35,43 & 77,09 & $\mathrm{E}$ & 16,49 & $E$ & 174,43 \\
\hline 50 & 1950 & G & 153,05 & 26,35 & 151,29 & $G$ & 6,74 & C & 615,49 \\
\hline 51 & 1987 & G & 82,45 & 36,05 & 52,98 & D & 19,42 & $\mathrm{~F}$ & 331,57 \\
\hline 52 & 1987 & G & 106,81 & 20,27 & 42,29 & $D$ & 23,23 & $\mathrm{~F}$ & 429,54 \\
\hline \begin{tabular}{|l|}
53 \\
\end{tabular} & 2000 & G & 94,44 & 37,85 & 63,64 & D & 20,68 & $\mathrm{~F}$ & 379,8 \\
\hline 54 & 1964 & G & 82,24 & 51,3 & 105,31 & $E$ & 17,99 & $E$ & 333,92 \\
\hline 55 & 2008 & $D$ & 25,68 & 91,9 & 56,62 & D & 15,77 & $\mathrm{E}$ & 121,56 \\
\hline 56 & 1964 & $\bar{G}$ & 83,32 & 56,77 & 215,95 & $\mathrm{G}$ & 17,72 & $E$ & 406,23 \\
\hline 57 & 1940 & $G$ & 96,5 & 41,61 & 71,18 & $E$ & 17,28 & $\mathrm{E}$ & 388,1 \\
\hline
\end{tabular}




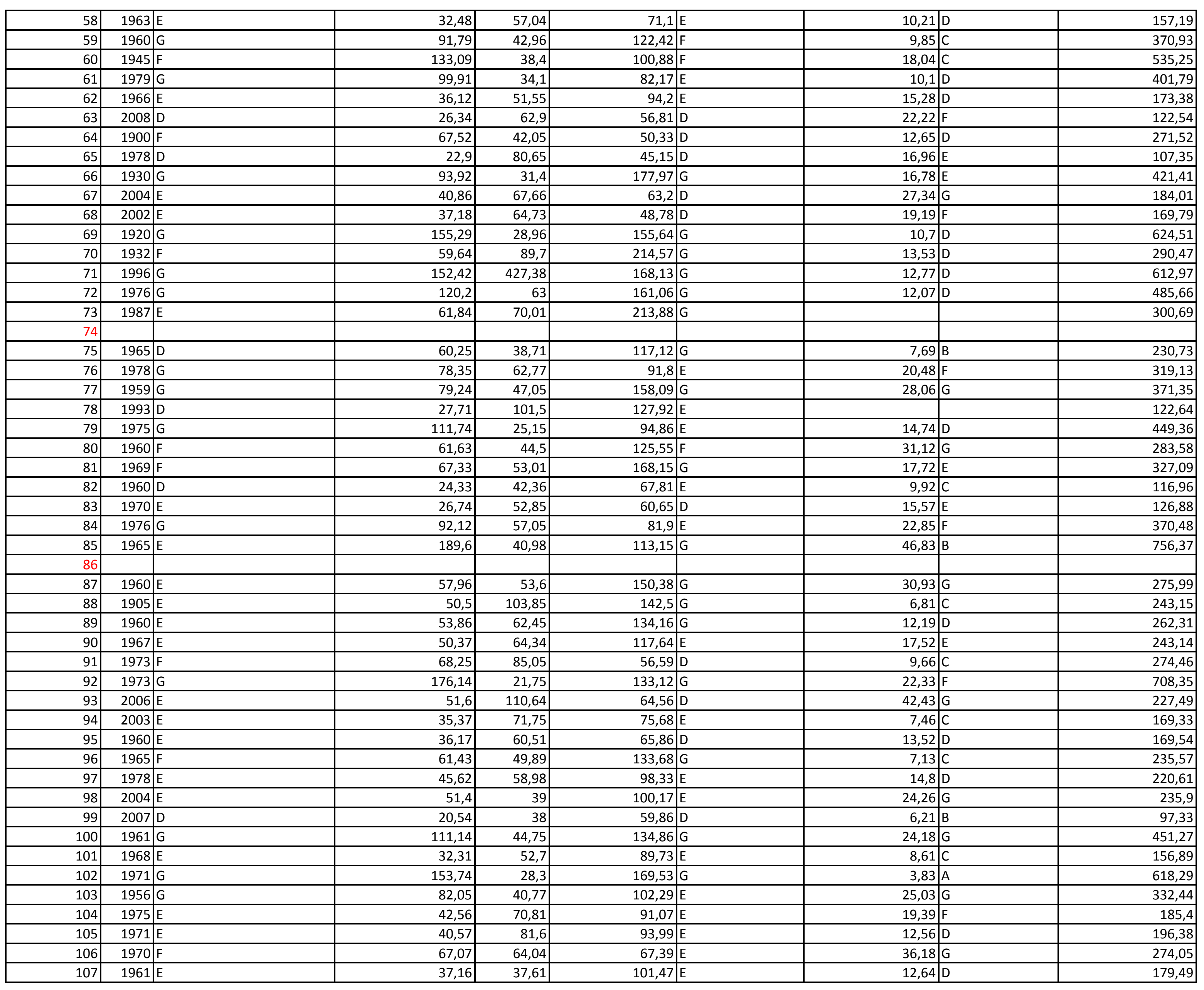




\begin{tabular}{|c|c|c|c|c|c|c|c|c|}
\hline 108 & 1995|E & $E$ & 49,05 & 42,66 & 102,46 & $\mathrm{E}$ & \begin{tabular}{l|l|}
27,36 & $\mathrm{G}$
\end{tabular} & 233,12 \\
\hline 109 & $1970 \mid \mathrm{C}$ & G & 99,96 & \begin{tabular}{|c|}
48,67 \\
\end{tabular} & 89,78 & $E$ & \begin{tabular}{|l|l|}
30,33 & \\
\end{tabular} & 402 \\
\hline 110 & $1965 \mathrm{E}_{\mathrm{E}}$ & $E$ & 58,08 & 38,41 & 107,44 & $E$ & \begin{tabular}{l|l|}
33,62 & $\mathrm{P}$ \\
\end{tabular} & 264,62 \\
\hline 111 & $1961 \mid \mathrm{E}$ & $\mathrm{E}$ & 47,02 & 48,32 & 104,96 & $\mathrm{E}$ & \begin{tabular}{l|l|}
12,22 & $\mathrm{D}$ \\
\end{tabular} & 228,44 \\
\hline 112 & $2002 \mid \mathrm{E}$ & $\mathrm{E}$ & 33,96 & 70 & 52,38 & $D$ & \begin{tabular}{|l|l|}
22,49 & \\
\end{tabular} & 153,55 \\
\hline 113 & $1964 \mathrm{E}$ & $\mathrm{E}$ & 43,85 & 51,85 & 116,63 & E & \begin{tabular}{l|l|l}
12,47 & $\mathrm{P}$ \\
\end{tabular} & 207,88 \\
\hline 114 & 2006 & $\mathrm{E}$ & 43,32 & 69,2 & \begin{tabular}{|l|}
85,71 \\
\end{tabular} & $E$ & \begin{tabular}{|l|l|}
20,63 & $F$ \\
\end{tabular} & 207,14 \\
\hline 115 & $1962 \mathrm{E}$ & $\mathrm{E}$ & 33,85 & 303,53 & 79,92 & $E$ & \begin{tabular}{l|l|l}
16,11 & $E$ \\
\end{tabular} & 128,99 \\
\hline 116 & $1960 \mathrm{E}_{\mathrm{E}}$ & $\mathrm{E}$ & 37,04 & 31,14 & 106,24 & $E$ & \begin{tabular}{|l|l|}
10,67 & $D$ \\
\end{tabular} & 176,24 \\
\hline 117 & $1961 \mathrm{E}$ & $\mathrm{E}$ & 53,84 & 57,65 & 161,88 & G & \begin{tabular}{l|l|}
11,61 & $D$ \\
\end{tabular} & 262,42 \\
\hline 118 & & & & & & & & \\
\hline 119 & $1969 \mathrm{E}$ & $\mathrm{E}$ & 54,86 & 187,92 & 196,86 & $G$ & $\begin{array}{l}7,6 \mid C \\
\end{array}$ & 266,23 \\
\hline 120 & 2000 & $\mathrm{E}$ & 58,1 & 56,8 & 177,86 & $F$ & & 287,67 \\
\hline 121 & $1965 \mathrm{E}_{\mathrm{E}}$ & $E$ & 56,36 & 50,88 & 156,29 & G & $\begin{array}{l}9,19 \\
\end{array}$ & 270,26 \\
\hline 122 & $1964 \mid \mathrm{E}$ & $\mathrm{E}$ & 55,47 & 60,93 & 89,73 & E & \begin{tabular}{l|l}
16,82 & $\mathrm{E}$ \\
\end{tabular} & 259,99 \\
\hline 123 & $2008 / \mathrm{E}$ & $\mathrm{E}$ & 29,22 & 63,99 & 70,65 & $E$ & $14,65 \mid D$ & 139,46 \\
\hline 124 & $1978 \mathrm{E}$ & $\mathrm{E}$ & 42,67 & 93,14 & 79,04 & $\mathrm{E}$ & \begin{tabular}{|l|l|}
15,39 & $\mathrm{D}$ \\
\end{tabular} & 163,44 \\
\hline 125 & $1984 \mathrm{E}_{\mathrm{E}}$ & $E$ & 57,18 & 76,65 & 69,72 & $\mathrm{E}$ & \begin{tabular}{|l|l|}
14,97 & \\
\end{tabular} & 277,78 \\
\hline 126 & $1970 \mathrm{C}$ & G & 155,34 & 63,94 & 201,54 & G & 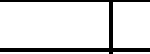 & 624,71 \\
\hline 127 & $1968 \mathrm{C}$ & G & 106,4 & 54,96 & 140,17 & G & $4,67 \mid \mathrm{B}$ & 427,88 \\
\hline 128 & $1923 \mathrm{C}$ & G & 78,21 & 52,34 & 73,54 & E & $\begin{array}{l}7,44 \mid C \\
\end{array}$ & 314,53 \\
\hline 129 & $1960 \mathrm{C}$ & $\mathrm{G}$ & 127,07 & 46,66 & 131,57 & $\mathrm{~F}$ & \begin{tabular}{|l|l|}
11,28 & \\
\end{tabular} & 511,02 \\
\hline 130 & $1975 \mathrm{E}$ & $\mathrm{E}$ & 28,73 & 61,25 & 81,84 & E & \begin{tabular}{l|l}
12,53 & $\mathrm{P}$ \\
\end{tabular} & 137,78 \\
\hline 131 & 2003[ & $D$ & 25,89 & 80,4 & 51,69 & D & \begin{tabular}{ll|l|}
10,65 & $D$ \\
\end{tabular} & 121,02 \\
\hline 132 & $2004 \mathrm{E}$ & $\mathrm{E}$ & 27,72 & 96,41 & 47,17 & D & \begin{tabular}{r|r|r|} 
& $\mathrm{D}$ \\
\end{tabular} & 126,7 \\
\hline 133 & $1987 \mid \mathrm{F}$ & $\mathrm{F}$ & 60,68 & 53,33 & 95,07 & $E$ & \begin{tabular}{|l|l|l}
19,08 & $E$ \\
\end{tabular} & 230,22 \\
\hline 134 & $1956 \mathrm{C}$ & G & 122,87 & 39,92 & 121,63 & $\mathrm{~F}$ & \begin{tabular}{|l|l|}
10,43 & $D$ \\
\end{tabular} & 494,12 \\
\hline 135 & 2008[ & D & 23,57 & 39,77 & 26,74 & C & \begin{tabular}{l|l|}
35,05 & $G$ \\
\end{tabular} & 104,9 \\
\hline 136 & $2001 \mathrm{E}$ & $E$ & 39,88 & 132,35 & 93,43 & $E$ & \begin{tabular}{|l|l|}
18,73 & \\
\end{tabular} & 184,86 \\
\hline 137 & & & & & & & & \\
\hline 138 & $1985 \mathrm{EE}$ & $\mathrm{E}$ & 45,1 & 57,98 & 106,23 & $E$ & \begin{tabular}{|l|l}
13,73 & $\mathrm{D}$ \\
\end{tabular} & 218,44 \\
\hline 139 & $2004 \mathrm{E}$ & $\mathrm{E}$ & 27,96 & 38,53 & 39,46 & C & \begin{tabular}{l|l}
26,78 & $G$ \\
\end{tabular} & 128,93 \\
\hline 140 & $\left.1969\right|_{E}$ & $E$ & 28,3 & 66,01 & 64,08 & $D$ & \begin{tabular}{|l|l|}
17,11 & \\
\end{tabular} & 134,05 \\
\hline 141 & $1978 \mathrm{E}$ & $\mathrm{E}$ & 40,24 & 59,71 & 69,13 & E & \begin{tabular}{l|l|l}
14,55 & $D$ \\
\end{tabular} & 152,87 \\
\hline 142 & $1985 \mathrm{E}$ & $\mathrm{E}$ & 26,48 & 71,97 & 55,68 & D & \begin{tabular}{r|c}
7,53 & $\mathrm{C}$ \\
\end{tabular} & 123,8 \\
\hline 143 & $1961 \mathrm{E}$ & $\mathrm{E}$ & 50,82 & 56,57 & 131,04 & $\mathrm{~F}$ & $\begin{array}{l}6,97 \mid C \\
\end{array}$ & 249,15 \\
\hline 144 & $1960 / \mathrm{F}$ & $\mathrm{F}$ & 68,37 & 62,85 & 89,35 & $E$ & \begin{tabular}{|l|l|}
15,83 & $\mathrm{E}$ \\
\end{tabular} & 278,98 \\
\hline 145 & 2002 & D & 23,87 & 75,34 & 46,94 & D & \begin{tabular}{c|c|c}
10,55 & $D$ \\
\end{tabular} & 114,43 \\
\hline 146 & 2002[ & $D$ & 22,15 & 75,05 & 29,56 & C & \begin{tabular}{|l|l|}
21,13 & $F$ \\
\end{tabular} & 102,17 \\
\hline 147 & $2005 \mathrm{E}$ & $\mathrm{E}$ & 40,31 & 39,13 & 89,38 & $E$ & \begin{tabular}{l|l|}
15,93 & $E$ \\
\end{tabular} & 193,92 \\
\hline 148 & $1960 \mathrm{C}$ & G & 71,41 & 41,34 & 203,33 & G & \begin{tabular}{l|l|l}
26,97 & $\mathrm{G}$ \\
\end{tabular} & 343,99 \\
\hline 149 & $1960 \mathrm{C}$ & G & 107,44 & 45,64 & 150,73 & G & \begin{tabular}{|l|l}
13,83 & $\mathrm{P}$ \\
\end{tabular} & 436,1 \\
\hline 150 & $1957 \mathrm{C}$ & C & 55,2 & 55,35 & 81,18 & G & 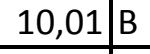 & 213,95 \\
\hline 151 & $1964 \mid \mathrm{E}$ & $\mathrm{E}$ & 63,38 & 70,12 & 32,07 & $F$ & \begin{tabular}{l|l|l}
39,56 & $\mathrm{E}$ \\
\end{tabular} & 254,9 \\
\hline 152 & $1961 \mathrm{C}$ & G & 117,77 & 37,28 & 162,08 & G & \begin{tabular}{l|l|l|}
8,47 & \\
\end{tabular} & 473,63 \\
\hline 153 & $1960 \mathrm{C}$ & G & 77,8 & 47,6 & 89 & $E$ & \begin{tabular}{|l|l}
12,09 & $\mathrm{D}$ \\
\end{tabular} & 316,91 \\
\hline 154 & $1963 \mathrm{E}$ & $\mathrm{E}$ & 46,76 & 46,47 & 128,62 & $F$ & \begin{tabular}{l|l|l|}
10,07 & $D$ \\
\end{tabular} & 227,93 \\
\hline 155 & $1988 \mathrm{E}$ & $\mathrm{E}$ & 87,69 & 40,98 & \begin{tabular}{|c|}
95,54 \\
\end{tabular} & G & \begin{tabular}{l|l|}
12,69 & $\mathrm{C}$
\end{tabular} & 352,64 \\
\hline
\end{tabular}


ANEXO 4.2

RESULTADOS DE 131 CERTIFICACIONES ENERGÉTICAS. CALIFICACIÓN AL INCLUIR POSIBLES MEDIDAS DE MEJORAS. 
CALIFICACIÓN CON MEDIDAS DE MEJORA

\begin{tabular}{|c|c|c|c|c|c|c|c|c|c|}
\hline \multicolumn{10}{|c|}{ CALIFICACIÓN CON MEDIDAS DE MEJORA } \\
\hline № Proyecto & Letra & CO2 letra & kgCO2 m2 año & Calef. letra & kWh m2 año & Refri. Letra & kWh m2 año & C & 1 \\
\hline № Proyecto & Calificación & Calificación Global ( Letra) & Emisiones Globales & Calificación Calef. & Dem. Calefacción & & Dem. Refri. & & \\
\hline 11 & G & $\mathrm{E}$ & 51,5 & G & 173,46 & C & 6,86 & & \\
\hline 12 & G & E & 46,95 & G & 160,98 & $\mathrm{D}$ & 10,71 & & $\mathrm{x}$ \\
\hline 13 & G & $\mathrm{E}$ & 36,74 & $\mathrm{~F}$ & 126,39 & B & 6,29 & & $\mathrm{x}$ \\
\hline 14 & G & $\mathrm{E}$ & 42,83 & G & 173,25 & $\mathrm{D}$ & 12,68 & & $\mathrm{x}$ \\
\hline 15 & $\mathrm{E}$ & $\mathrm{E}$ & 38,85 & E & 107,88 & $\mathrm{E}$ & $15,73 \mid x$ & $\mathrm{x}$ & $x$ \\
\hline 16 & G & E & 39,08 & G & 150,31 & C & 8,35 & & $\mathrm{x}$ \\
\hline 17 & E & $\mathrm{D}$ & 24,33 & $\mathrm{D}$ & 49,92 & $\mathrm{E}$ & $18,86 \mid \times$ & $x$ & $x$ \\
\hline 18 & $\mathrm{E}$ & D & 24,65 & D & 57,33 & A & $2,98 \mid x$ & $\mathrm{x}$ & $x$ \\
\hline 19 & G & $\mathrm{E}$ & 53,88 & G & 153,48 & G & 26,81 & & $x$ \\
\hline 20 & $D$ & $A$ & \begin{tabular}{|l|}
5,81 \\
\end{tabular} & D & 76,63 & $B$ & \begin{tabular}{|l|}
8,4 \\
\end{tabular} & & $x$ \\
\hline 21 & $E$ & $C$ & 16,7 & $\mathrm{D}$ & 49,26 & $B$ & $4,3 \times$ & $x$ & $x$ \\
\hline 22 & $\mathrm{E}$ & $C$ & 13,48 & C & 29,59 & B & $\begin{array}{l}5,83 \times \mathrm{x} \\
5\end{array}$ & $\mathrm{x}$ & $x$ \\
\hline 23 & $\mathrm{E}$ & D & 26,09 & D & 56,89 & A & $3,85 \times$ & $x$ & $x$ \\
\hline 24 & E & D & 26,08 & C & 35,54 & C & $7,42 \times$ & $x$ & $x$ \\
\hline 25 & $G$ & D & 20,12 & $\mathrm{E}$ & 68 & $B$ & 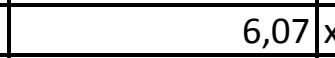 & $\mathrm{x}$ & $x$ \\
\hline 26 & $F$ & D & 24,36 & $E$ & 69,91 & D & $10,34 \mid x$ & $\mathrm{x}$ & $x$ \\
\hline 27 & $\mathrm{E}$ & D & 26,24 & D & 65,97 & $\mathrm{~F}$ & $20,44 \times$ & $x$ & $x$ \\
\hline 28 & $\mathrm{E}$ & $A$ & 12,79 & $F$ & 262,16 & & & $\mathrm{x}$ & $x$ \\
\hline 29 & $G$ & $E$ & 39,74 & $G$ & 138,72 & D & $11,77 \times x$ & $x$ & $x$ \\
\hline 30 & G & $\mathrm{E}$ & 33,42 & $\mathrm{E}$ & 94,9 & $\mathrm{~F}$ & 21,91 & & $x$ \\
\hline 31 & $\mathrm{E}$ & D & 22,81 & D & 64,61 & D & $12,68 \times$ & $x$ & $x$ \\
\hline 32 & $\mathrm{E}$ & D & 24,73 & D & 42,83 & $\mathrm{~F}$ & $23,49 \times \mathrm{x}$ & $\mathrm{x}$ & $x$ \\
\hline 33 & $E$ & $D$ & 26,38 & $E$ & 77,81 & D & $|12,57| x$ & $x$ & $x$ \\
\hline 34 & $G$ & $D$ & 22,81 & D & 61,31 & $D$ & $11,8 \times$ & $x$ & $x$ \\
\hline 35 & $\mathrm{E}$ & $D$ & 19,47 & D & 44,13 & $E$ & $|15,67| x$ & $\mathrm{x}$ & $x$ \\
\hline 36 & $G$ & $E$ & 51,41 & $G$ & 165,59 & $\mathrm{D}$ & $14,13 \mid x$ & $x$ & $x$ \\
\hline 37 & $\mathrm{E}$ & D & 26,02 & $\mathrm{E}$ & 67,7 & $D$ & $12,53 \times x$ & $\mathrm{x}$ & $x$ \\
\hline 38 & $G$ & D & 25,04 & D & 65,54 & $D$ & $11,24 \times$ & $x$ & $x$ \\
\hline 39 & G & $\mathrm{E}$ & 31,3 & $\mathrm{E}$ & 73,32 & G & $29,47 \mid x$ & $x$ & $x$ \\
\hline 40 & $\mathrm{E}$ & D & 25,58 & $\mathrm{E}$ & 70,83 & C & $9,45 \mid x$ & $x$ & $x$ \\
\hline 41 & $\mathrm{E}$ & $D$ & 26,19 & $\mathrm{E}$ & 68,06 & $\mathrm{~F}$ & $\begin{array}{l}19,3 \times \times \\
\end{array}$ & $x$ & $x$ \\
\hline 42 & $G$ & $\mathrm{E}$ & 38,42 & $G$ & 142,35 & $\bar{B}$ & \begin{tabular}{|l|}
6,11 \\
\end{tabular} & & $x$ \\
\hline 43 & $\mathrm{E}$ & $D$ & 24,4 & D & 51,56 & $D$ & $11,35 \times x$ & $\mathrm{x}$ & $x$ \\
\hline 44 & $\mathrm{E}$ & $D$ & 19,19 & D & 42,34 & $\mathrm{D}$ & \begin{tabular}{|c|}
$14,58 \times x$ \\
\end{tabular} & $x$ & $x$ \\
\hline 45 & $\mathrm{E}$ & $D$ & 24,49 & D & 56,35 & $E$ & $16,36 \times x$ & $\mathrm{x}$ & $x$ \\
\hline 46 & $\mathrm{E}$ & $D$ & 23,55 & $D$ & 55,25 & $\mathrm{~F}$ & 19,75 & & $x$ \\
\hline 47 & $E$ & D & 50,36 & G & 285,55 & & & & $x$ \\
\hline 48 & & & & & & & & & \\
\hline 49 & $E$ & D & 26,02 & $\mathrm{E}$ & 69,19 & $D$ & $15,15 \times x$ & $x$ & $x$ \\
\hline 50 & G & $E$ & 42,17 & G & 147,28 & C & $7,05 \mid x$ & $x$ & $x$ \\
\hline 51 & $G$ & D & 21,69 & $D$ & 46,22 & $E$ & $|16,16| x$ & $x$ & $x$ \\
\hline 52 & G & $D$ & 25,77 & $D$ & 40,87 & $E$ & $|18,47| x$ & $x$ & $x$ \\
\hline 53 & G & $\mathrm{E}$ & 35,28 & D & 63,64 & $\mathrm{~F}$ & 20,68 & & $x$ \\
\hline 54 & G & $\mathrm{E}$ & 37,88 & $\mathrm{E}$ & 105,31 & $\mathrm{E}$ & 17,99 & & $x$ \\
\hline 55 & $\mathrm{E}$ & $C$ & \begin{tabular}{|c|}
15,97 \\
\end{tabular} & $C$ & 33,64 & $\mathrm{D}$ & $|13,46| x$ & $x$ & $x$ \\
\hline 56 & G & $\mathrm{E}$ & 59,07 & G & 197,58 & $\mathrm{E}$ & \begin{tabular}{|c|}
$18,86 \times x$ \\
\end{tabular} & $\mathrm{x}$ & $x$ \\
\hline 57 & $G$ & D & 26,15 & $E$ & 71,18 & $\mathrm{E}$ & 17,28 & & $x$ \\
\hline
\end{tabular}




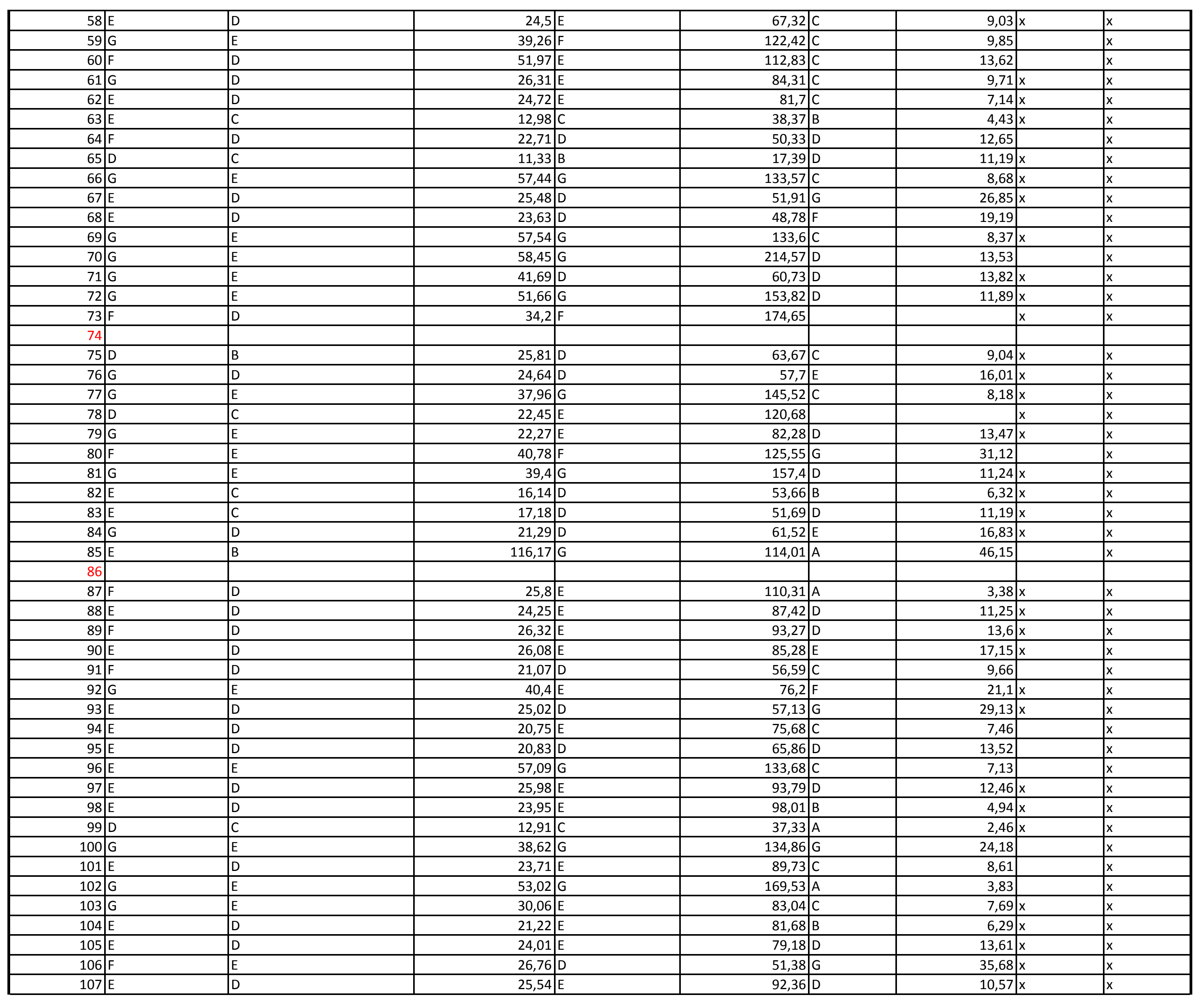




\begin{tabular}{|c|c|c|c|c|c|c|c|c|}
\hline 108 & & $D$ & $\begin{array}{l}26,2 \\
\end{array}$ & \begin{tabular}{|c|}
79,86 \\
\end{tabular} & & \begin{tabular}{l|l|l|}
20,29 \\
\end{tabular} & $x$ & $x$ \\
\hline 109 & $\bar{G}$ & $\mathrm{E}$ & \begin{tabular}{l|l}
40,61 & $\mathrm{E}$ \\
\end{tabular} & $89,78 \mid$ & $\mathrm{G}$ & \begin{tabular}{|l|}
30,33 \\
\end{tabular} & & $x$ \\
\hline 110 & $F$ & D & $\begin{array}{l}24,6 \mid E \\
\end{array}$ & $80,67 \mid$ & C & \begin{tabular}{l|l|l|}
6,74 & \\
\end{tabular} & $x$ & $x$ \\
\hline 111 & $\bar{E}$ & $D$ & \begin{tabular}{l|l|}
24,93 & $\mathrm{E}$ \\
\end{tabular} & 102,45 & $\mathrm{~A}$ & $\begin{array}{l}3,56 \\
3\end{array}$ & $x$ & $x$ \\
\hline 112 & $E$ & $D$ & \begin{tabular}{|l|l|}
21,68 & $D$ \\
\end{tabular} & 52,38 & $\mathrm{~F}$ & 22,49 & & $x$ \\
\hline 113 & $\bar{E}$ & D & \begin{tabular}{l|l|}
24,17 & $\mathrm{E}$ \\
\end{tabular} & 102,65 & $\mathrm{~A}$ & $2,61 \mid x$ & $x$ & $x$ \\
\hline 114 & $\bar{E}$ & $D$ & \begin{tabular}{l|l|}
23,65 & $\mathrm{E}$ \\
\end{tabular} & 83,79 & $\mathrm{D}$ & $11,55 \times x$ & $x$ & $x$ \\
\hline 115 & $\bar{E}$ & $D$ & \begin{tabular}{l|l}
25,32 & $\mathrm{P}$ \\
\end{tabular} & $62,44 \mid$ & C & $\begin{array}{ll}6,94 \mid x \\
\end{array}$ & $x$ & $x$ \\
\hline 116 & $E$ & $D$ & \begin{tabular}{|l|l|}
24,22 & $\mathrm{E}$ \\
\end{tabular} & $92,97 \mid$ & C & \begin{tabular}{l|l|}
8,28 & $x$ \\
\end{tabular} & $x$ & $x$ \\
\hline 117 & $\mathrm{~F}$ & D & \begin{tabular}{l|l|}
26,16 & $\mathrm{E}$ \\
\end{tabular} & 102,09 & C & \begin{tabular}{l|l|}
8,62 & $x$ \\
\end{tabular} & $x$ & $x$ \\
\hline 118 & & & & & & & & \\
\hline 119 & $\mathrm{~F}$ & $D$ & \begin{tabular}{l|c}
18,13 & $C$ \\
\end{tabular} & \begin{tabular}{ll|}
34,33 \\
\end{tabular} & C & $\begin{array}{l}9,29 \\
9\end{array}$ & $x$ & $x$ \\
\hline 120 & $\bar{E}$ & $D$ & \begin{tabular}{l|l}
28,06 & $\mathrm{E}$ \\
\end{tabular} & $|120,7|$ & & \begin{tabular}{l|l} 
& $x$
\end{tabular} & $x$ & $x$ \\
\hline 121 & $\mathrm{~F}$ & $D$ & \begin{tabular}{l|l|}
25,55 & $\mathrm{E}$ \\
\end{tabular} & 98,78| & C & $\begin{array}{l}7,78 \\
\end{array}$ & $x$ & $x$ \\
\hline 122 & $F$ & D & \begin{tabular}{|l|l|}
23,38 & $\mathrm{E}$ \\
\end{tabular} & 88,03 & C & \begin{tabular}{ll|l}
7,79 & \\
\end{tabular} & $x$ & $x$ \\
\hline 123 & $E$ & $D$ & \begin{tabular}{l|l|}
22,22 & $\mathrm{E}$ \\
\end{tabular} & $70,65 \mid$ & $\mathrm{D}$ & \begin{tabular}{|l|}
14,65 \\
\end{tabular} & & $x$ \\
\hline 124 & $\bar{E}$ & D & $26,34 \mid \mathrm{D}$ & $|46,57|$ & B & \begin{tabular}{c|c|c|}
5,15 & $x$ \\
\end{tabular} & $x$ & $x$ \\
\hline 125 & $\mathrm{~F}$ & D & \begin{tabular}{|l||}
24,47 \\
\end{tabular} & 59,02 & $B$ & \begin{tabular}{l|l|}
4,95 & $x$ \\
\end{tabular} & $x$ & $x$ \\
\hline 126 & $\bar{G}$ & $\mathrm{E}$ & \begin{tabular}{l|l|l}
60,77 & $G$
\end{tabular} & 201,54 & & & & $x$ \\
\hline 127 & $\bar{G}$ & $\mathrm{E}$ & \begin{tabular}{l|l|}
41,98 & $F$ \\
\end{tabular} & 129,94 & $B$ & \begin{tabular}{l|l}
4,19 & $x$ \\
\end{tabular} & $x$ & $x$ \\
\hline 128 & $\bar{G}$ & $E$ & \begin{tabular}{l|l|}
27,29 & $\mathrm{E}$ \\
\end{tabular} & 73,54 & C & \begin{tabular}{|l|l|}
7,44 \\
\end{tabular} & & $x$ \\
\hline 129 & $\bar{G}$ & $\mathrm{E}$ & \begin{tabular}{l|l|}
45,14 & $F$ \\
\end{tabular} & 131,57 & $\mathrm{D}$ & $\begin{array}{ll}11,28 \\
\end{array}$ & & $x$ \\
\hline 130 & $\bar{E}$ & $D$ & \begin{tabular}{l|l|}
24,56 & \\
\end{tabular} & 76,95 & $B$ & $\begin{array}{l}4,84 \mid x \\
\end{array}$ & $x$ & $x$ \\
\hline 131 & $E$ & C & \begin{tabular}{|l|l|}
13,73 & $\mathrm{P}$ \\
\end{tabular} & 48,84 & A & \begin{tabular}{|l|l|}
3,77 & $\mathrm{x}$ \\
\end{tabular} & $x$ & $x$ \\
\hline 132 & $\bar{E}$ & $D$ & \begin{tabular}{l||}
22,81 \\
\end{tabular} & $47,17 \mid$ & $\mathrm{D}$ & $\begin{array}{l}12,5 \\
\end{array}$ & & $x$ \\
\hline 133 & $\bar{E}$ & $E$ & \begin{tabular}{|l|l|}
57,26 & $\mathrm{P}$ \\
\end{tabular} & $87,63 \mid$ & $E$ & \begin{tabular}{l|l|}
18,06 & $x$
\end{tabular} & $x$ & $x$ \\
\hline 134 & $\bar{G}$ & $E$ & \begin{tabular}{l|l|}
42,01 & $F$ \\
\end{tabular} & 121,63 & $\mathrm{D}$ & \begin{tabular}{|l|}
10,43 \\
\end{tabular} & & $x$ \\
\hline 135 & $\bar{D}$ & $C$ & \begin{tabular}{l|l}
13,38 & $C$ \\
\end{tabular} & 26,74 & $\bar{G}$ & \begin{tabular}{|l|}
35,05 \\
\end{tabular} & & $x$ \\
\hline 136 & $\bar{E}$ & D & \begin{tabular}{l|l|}
25,43 & \\
\end{tabular} & $92,18 \mid$ & $\bar{D}$ & \begin{tabular}{ll|}
11,85 & $x$
\end{tabular} & $x$ & $x$ \\
\hline 137 & & & & & & & & \\
\hline 138 & $\bar{E}$ & $D$ & \begin{tabular}{l|l|}
26,01 & $\mathrm{E}$ \\
\end{tabular} & $81,25 \mid$ & $E$ & \begin{tabular}{l|l|}
19,05 & $x$ \\
\end{tabular} & $x$ & $x$ \\
\hline 139 & $\bar{E}$ & $D$ & \begin{tabular}{l|l|}
20,65 & \\
\end{tabular} & 39,46 & $\bar{G}$ & 26,77 & & $x$ \\
\hline 140 & $E$ & $D$ & \begin{tabular}{|l||}
22,27 \\
\end{tabular} & 64,08 & $E$ & 17,11 & & $x$ \\
\hline 141 & $\bar{E}$ & $D$ & \begin{tabular}{l|c}
25,72 & $\mathrm{C}$
\end{tabular} & \begin{tabular}{|c||}
33,3 \\
\end{tabular} & B & $\begin{array}{c}5,24 \mid x \\
\end{array}$ & $\bar{x}$ & $x$ \\
\hline 142 & $E$ & D & \begin{tabular}{|l|l|}
19,68 & $D$ \\
\end{tabular} & 55,68 & C & \begin{tabular}{|l|l|}
7,53 \\
\end{tabular} & & $x$ \\
\hline 143 & $\bar{E}$ & $D$ & \begin{tabular}{l|l|}
26,16 & $\mathrm{E}$ \\
\end{tabular} & 106,58 & B & $\begin{array}{l}5,96 \\
\end{array}$ & $x$ & $x$ \\
\hline 144 & $\mathrm{~F}$ & $E$ & \begin{tabular}{|l|l|}
31,33 & $E$
\end{tabular} & 89,35 & $E$ & \begin{tabular}{|l|}
15,83 \\
\end{tabular} & & $x$ \\
\hline 145 & $\bar{D}$ & $C$ & \begin{tabular}{|l||}
17,17 \\
\end{tabular} & $46,94 \mid$ & $\mathrm{D}$ & \begin{tabular}{|l|}
10,55 \\
\end{tabular} & & $x$ \\
\hline 146 & $\bar{D}$ & C & \begin{tabular}{l|c|}
16,75 & \\
\end{tabular} & 29,56 & $F$ & 21,13 & & $x$ \\
\hline 147 & $\bar{E}$ & $D$ & \begin{tabular}{|l|l|}
26,03 & \\
\end{tabular} & 86,99 & $\mathrm{D}$ & 13,68 & & \\
\hline 148 & $\mathrm{G}$ & $\mathrm{E}$ & \begin{tabular}{|l|l}
58,26 & $\mathrm{G}$ \\
\end{tabular} & 203,33 & $\mathrm{G}$ & 26,97 & & $x$ \\
\hline 149 & $\bar{G}$ & $E$ & \begin{tabular}{l|l|}
$43,23 \mid G$ \\
\end{tabular} & 150,73 & $\mathrm{D}$ & 13,83 & & $x$ \\
\hline 150 & $\bar{c}$ & C & \begin{tabular}{l|l|l}
47,44 &
\end{tabular} & 59,33 & $B$ & \begin{tabular}{l|l}
11,58 & $x$
\end{tabular} & $x$ & $x$ \\
\hline 151 & $\bar{E}$ & $D$ & \begin{tabular}{|l|l|}
52,94 \\
\end{tabular} & 21,78 & $\mathrm{G}$ & \begin{tabular}{|l|l|}
53,43 & $x$ \\
\end{tabular} & $x$ & $x$ \\
\hline 152 & $\bar{G}$ & $\mathrm{E}$ & \begin{tabular}{l|l}
52,69 & $G$ \\
\end{tabular} & 162,08 & C & \begin{tabular}{|l|}
8,47 \\
\end{tabular} & & $x$ \\
\hline 153 & $\bar{G}$ & $\mathrm{E}$ & \begin{tabular}{l|l|}
33,43 & $\mathrm{P}$ \\
\end{tabular} & 89 & $\bar{D}$ & 12,09 & & $x$ \\
\hline 154 & & $D$ & \begin{tabular}{|l|l|}
26,36 & $\mathrm{E}$ \\
\end{tabular} & $92,88 \mid$ & $\mathrm{D}$ & 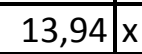 & $x$ & $x$ \\
\hline 155 & & D & 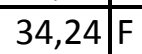 & 107,92 & $\bar{D}$ & 9,81 & & $x$ \\
\hline
\end{tabular}


ANEXO 5

CÁLCULOS DE CONSUMOS GENERALES, PARÁMETROS PARA INSTALACIÓN FOTOVOLTAICA Y PARA SISTEMA DE BOMBA DE CALOR GEOTÉRMICA 
A.5.1.

CÁLCULO DE CONSUMOS ESTIMADOS POR ZONAS CLIMÁTICAS KOPPEN/CTE. PROTOTIPO TALLER- VIVIENDA $52 \mathrm{M}^{2}$ 
Zona climática a3/España o su equivalente. Ejemplo Santa Cruz de Tenerife.

\begin{tabular}{|c|c|c|c|c|}
\hline Equipo & Ud & $\begin{array}{l}\text { Potencia } \\
\text { (W) }\end{array}$ & $\begin{array}{l}\text { Horas al } \\
\text { dia* }\end{array}$ & Total (Wh) \\
\hline Bombillas de $30 \mathrm{w}$ & $\mathbf{0}$ & 30 & 3 & $\mathbf{0}$ \\
\hline Bombillas de $20 \mathrm{w}$ & 16 & 20 & 4 & 1280 \\
\hline Bombillas de $15 \mathrm{w}$ & $\mathbf{0}$ & 15 & 3 & $\mathbf{0}$ \\
\hline Bombillas de $11 \mathrm{~W}$ & $\mathbf{0}$ & 11 & 1 & $\mathbf{0}$ \\
\hline Televisor & 2 & 80 & 4 & 640 \\
\hline Lavadora en frio (lavado) & 1 & 500 & 1 & 500 \\
\hline Microondas & 1 & 750 & 0.25 & 187.5 \\
\hline Nevera & 1 & 80 & 12 & 960 \\
\hline Bomba de Calor & 1 & 5720 & .0128 & $73.216 c$ \\
\hline Bomba de Calor & $\mathbf{0}$ & 5720 & 1 & $\mathbf{0}$ \\
\hline Calentador & 1 & 1200 & 1 & 1200 \\
\hline Otros... & 1 & 100 & 1 & 100 \\
\hline Calcular & & & Total w & 4940 \\
\hline
\end{tabular}

Calculadora de consumos energéticos (electricidad). (www.hmsistemas.es) Consulta 2015. Fig. 1

\section{CALIFICACIÓN ENERGÉTICA DEL EDIFICIO EN CONSUMO DE ENERGÍA PRIMARIA NO RENOVABLE}

Por energía primaria no renovable se entiende la energía consumida por el edificio procedente de fuentes no renovables que no ha sufrido ningún proceso de conversión o transformación.

\begin{tabular}{|c|c|c|c|c|}
\hline INDICADOR GLOBAL & \multicolumn{4}{|c|}{ INDICADORES PARCIALES } \\
\hline$<10.6 \mathrm{~A}$ & \multicolumn{2}{|c|}{ CALEFACCIÓN } & \multicolumn{2}{|l|}{ ACS } \\
\hline \begin{tabular}{|ll}
20.1 .33 .9 & C \\
33.9 .54 .4 & D \\
\end{tabular} & $\begin{array}{l}\text { Energía primaria } \\
\text { calefacción } \\
{\left[\mathrm{kWh} / \mathrm{m}^{2} \text { año] }\right.}\end{array}$ & \multirow[t]{2}{*}{ A } & $\begin{array}{c}\text { Energía primaria } \\
\text { ACS } \\
{\left[\mathrm{kWh} / \mathrm{m}^{2} \text { año] }\right.}\end{array}$ & \multirow[t]{2}{*}{ G } \\
\hline 54.4-75.0 $\quad$ B & 0.00 & & 47.30 & \\
\hline 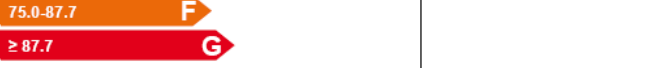 & \multicolumn{2}{|c|}{ REFRIGERACIÓN } & \multicolumn{2}{|l|}{ ILUMINACIÓN } \\
\hline \multirow{2}{*}{$\begin{array}{l}\text { Consumo global de energía primaria no renovable } \\
\qquad\left[\mathrm{kWh} / \mathrm{m}^{2} \text { año }\right]^{1}\end{array}$} & $\begin{array}{l}\text { Energía primaria } \\
\text { refrigeración } \\
\text { [kWh//m² año] }\end{array}$ & \multirow[t]{2}{*}{ C } & $\begin{array}{c}\text { Energia primaria } \\
\text { iluminación } \\
\text { [kWh/m²año] }\end{array}$ & \multirow[t]{2}{*}{-} \\
\hline & 26.34 & & - & \\
\hline
\end{tabular}

Resultado consumos edificio objeto (Taller con uso de vivienda) Elaboración propia. Fig. 2 
Zona Climática BWk (Koppen)/ A4 . Almería (CTE)

\begin{tabular}{|c|c|c|c|c|}
\hline Equipo & Ud & $\begin{array}{l}\text { Potencia } \\
\text { (W) }\end{array}$ & $\begin{array}{l}\text { Horas al } \\
\text { dia* }\end{array}$ & Total (Wh) \\
\hline Bombillas de $30 \mathrm{w}$ & $\mathbf{0}$ & 30 & 3 & $\mathbf{0}$ \\
\hline Bombillas de $20 \mathrm{w}$ & 16 & 20 & 6 & 1920 \\
\hline Bombillas de 15 w & $\mathbf{0}$ & 15 & 3 & $\mathbf{0}$ \\
\hline Bombillas de $11 \mathrm{w}$ & $\mathbf{0}$ & 11 & 1 & $\mathbf{0}$ \\
\hline Televisor & 2 & 80 & 4 & 640 \\
\hline Lavadora en frio (lavado) & 1 & 500 & 1 & 500 \\
\hline Microondas & 1 & 750 & 0.25 & 187.5 \\
\hline Nevera & 1 & 80 & 24 & 1920 \\
\hline Bomba de Calor & 1 & 5720 & 0.0263 & 150.436 \\
\hline Bomba de Calor & 1 & 5720 & 0.0245 & 140.14 \\
\hline Calentador & 1 & 1200 & 0.202 & 242.4 \\
\hline Otros... & 1 & 100 & 1 & 100 \\
\hline Calcular & & & Total w & 5799 \\
\hline
\end{tabular}

Calculadora de consumos energéticos (electricidad), edificio objeto. Almería. (www.hmsistemas.es) Consulta 2015. Fig. .3

\section{CALIFICACIÓN ENERGÉTICA DEL EDIFICIO EN CONSUMO DE ENERGÍA PRIMARIA NO RENOVABLE}

Por energía primaria no renovable se entiende la energía consumida por el edificio procedente de fuentes no renovables que no ha sufrido ningún proceso de conversión o transformación.

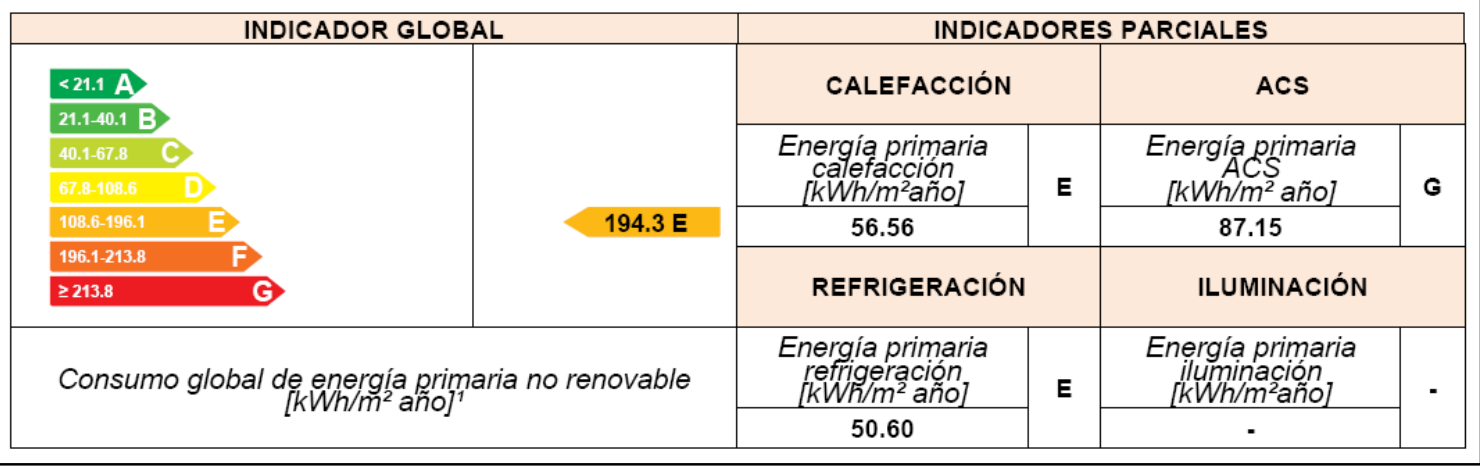

Resultado consumos edificio objeto. Almería. Fig. 4 
Zona Climática Csa (Koppen)/ B4 Sevilla (CTE)

\begin{tabular}{|c|c|c|c|c|}
\hline Equipo & Ud & $\begin{array}{l}\text { Potencia } \\
\text { (W) }\end{array}$ & $\begin{array}{l}\text { Horas al } \\
\text { dia* }\end{array}$ & Total (Wh) \\
\hline Bombillas de $30 \mathrm{w}$ & $\mathbf{0}$ & 30 & 3 & $\mathbf{0}$ \\
\hline Bombillas de $20 \mathrm{w}$ & 16 & 20 & 6 & 1920 \\
\hline Bombillas de 15 w & 0 & 15 & 3 & 0 \\
\hline Bombillas de $11 \mathrm{~W}$ & $\mathbf{0}$ & 11 & 1 & $\mathbf{0}$ \\
\hline Televisor & 2 & 80 & 4 & 640 \\
\hline Lavadora en frio (lavado) & 1 & 500 & 1 & 500 \\
\hline Microondas & 1 & 750 & 0.25 & 187.5 \\
\hline Nevera & 1 & 80 & 24 & 1920 \\
\hline Bomba de Calor & 1 & 5720 & 0.0358 & 204.77! \\
\hline Bomba de Calor & 1 & 5720 & 0.0291 & 166.45 \\
\hline Calentador & 1 & 1200 & 0.202 & 242.4 \\
\hline Otros... & 1 & 100 & 1 & 100 \\
\hline Calcular & & & Total w & 5879 \\
\hline
\end{tabular}

Calculadora de consumos energéticos (electricidad), edificio objeto. Sevilla (www.hmsistemas.es) Consulta 2015. Fig. 5

\section{CALIFICACIÓN ENERGÉTICA DEL EDIFICIO EN CONSUMO DE ENERGÍA PRIMARIA NO RENOVABLE}

Por energía primaria no renovable se entiende la energía consumida por el edificio procedente de fuentes no renovables que no ha sufrido ningún proceso de conversión o transformación.

\begin{tabular}{|c|c|c|c|c|}
\hline INDICADOR GLOBAL & \multicolumn{4}{|c|}{ INDICADORES PARCIALES } \\
\hline$<29.1 \mathrm{~A}$ & \multicolumn{2}{|c|}{ CALEFACCIÓN } & \multicolumn{2}{|l|}{ ACS } \\
\hline $\begin{array}{ll}50.2-81.9 \quad \text { C } \\
81.9-128.6 & \text { D }\end{array}$ & $\begin{array}{l}\text { Energía primaria } \\
\text { calefacción } \\
{\left[\mathrm{kWh} / \mathrm{m}^{2} a \tilde{a} \text { o] }\right.}\end{array}$ & \multirow[t]{2}{*}{$\mathbf{E}$} & $\begin{array}{c}\text { Energía primaria } \\
A C S \\
{\left[\mathrm{kWh} / \mathrm{m}^{2} \text { año] }\right.}\end{array}$ & \multirow[t]{2}{*}{ G } \\
\hline 128.6-243.7 $\quad$ B & 73.57 & & 87.37 & \\
\hline $\begin{array}{ll}243.7-292.5 & \text { F } \\
\geq 292.5 & \text { G }\end{array}$ & \multicolumn{2}{|c|}{ REFRIGERACIÓN } & \multicolumn{2}{|l|}{ ILUMINACIÓN } \\
\hline \multirow{2}{*}{$\begin{array}{l}\text { Consumo global de energía primaria no renovable } \\
\qquad\left[\mathrm{kWh} / \mathrm{m}^{2} \text { año }\right]^{1}\end{array}$} & $\begin{array}{l}\text { Energía primaria } \\
\text { refrigeración } \\
\text { [kWh/m² año] }\end{array}$ & \multirow[t]{2}{*}{$\mathbf{F}$} & $\begin{array}{l}\text { Energia primaria } \\
\text { iluminación } \\
{\left[\mathrm{kWh} / \mathrm{m}^{2} \text { año] }\right.}\end{array}$ & \multirow[t]{2}{*}{-} \\
\hline & 59.89 & & $\cdot$ & \\
\hline
\end{tabular}

Resultado consumos edificio objeto. Sevilla. Fig. 6 
Zona climática D3 /España o su equivalente. Ejemplo: Madrid.

\begin{tabular}{|c|c|c|c|c|}
\hline Equipo & Ud & $\begin{array}{l}\text { Potencia } \\
\text { (W) }\end{array}$ & $\begin{array}{l}\text { Horas al } \\
\text { dia* }\end{array}$ & Total (Wh) \\
\hline Bombillas de $30 \mathrm{w}$ & $\mathbf{0}$ & 30 & 3 & 0 \\
\hline Bombillas de $20 \mathrm{w}$ & 16 & 20 & 6 & 1920 \\
\hline Bombillas de 15 w & $\mathbf{0}$ & 15 & 3 & 0 \\
\hline Bombillas de 11 w & o & 11 & 1 & 0 \\
\hline Televisor & 2 & 80 & 4 & 640 \\
\hline Lavadora en frio (lavado) & $\mathbf{1}$ & 500 & $\mathbf{1}$ & 500 \\
\hline Microondas & 1 & 750 & 0.25 & 187.5 \\
\hline Nevera & $\mathbf{1}$ & 80 & 24 & 1920 \\
\hline Bomba de Calor & 1 & 5720 & 0.0923 & 527.956 \\
\hline Bomba de Calor & 1 & 5720 & 0.0205 & 117.26 \\
\hline Calentador & 1 & 1200 & 0.78 & 936 \\
\hline Otros... & 1 & 100 & 1 & 100 \\
\hline Calcular & & & Total w & 6847 \\
\hline
\end{tabular}

Calculadora de consumos energéticos ( electricidad). (www.hmsistemas.es) Consulta 2015. Fig. 7

\section{CALIFICACIÓN ENERGÉTICA DEL EDIFICIO EN CONSUMO DE ENERGÍA PRIMARIA NO RENOVABLE}

Por energía primaria no renovable se entiende la energía consumida por el edificio procedente de fuentes no renovables que no ha sufrido ningún proceso de conversión o transformación.

\begin{tabular}{|c|c|c|c|c|}
\hline INDICADOR GLOBAL & \multicolumn{4}{|c|}{ INDICADORES PARCIALES } \\
\hline$<54.2 \mathrm{~A}$ & \multicolumn{2}{|l|}{ CALEFACCIÓN } & \multicolumn{2}{|l|}{ ACS } \\
\hline $\begin{array}{ll}87.8-136.1 & \text { C } \\
136.1-209.3 & \text { D } \\
\end{array}$ & $\begin{array}{c}\text { Energía primaria } \\
\text { calefacción } \\
\text { [kWh/mªño] }\end{array}$ & \multirow[t]{2}{*}{$\mathbf{E}$} & $\begin{array}{c}\text { Energía primaria } \\
A C S \\
{\left[\mathrm{kWh} / \mathrm{m}^{2} \text { año] }\right.}\end{array}$ & \multirow[t]{2}{*}{ G } \\
\hline 209.3.375.6 $\quad$ E & 190.97 & & 91.68 & \\
\hline $\begin{array}{ll}375.6-473.2 & \text { F } \\
2473.2 & \text { G }\end{array}$ & \multicolumn{2}{|c|}{ REFRIGERACIÓN } & \multicolumn{2}{|l|}{ ILUMINACIÓN } \\
\hline \multirow{2}{*}{$\begin{array}{l}\text { Consumo global de energía primaria no renovable } \\
\qquad\left[\mathrm{kWh} / \mathrm{m}^{2} \text { año }\right]^{1}\end{array}$} & $\begin{array}{c}\text { Energía primaria } \\
\text { refrigeración } \\
\text { [kWh/m² año] }\end{array}$ & \multirow[t]{2}{*}{$\mathbf{F}$} & $\begin{array}{c}\text { Energía primaria } \\
\text { iluminación } \\
{\left[\mathrm{kWh} / \mathrm{m}^{2} a \tilde{n} o\right]}\end{array}$ & \multirow[t]{2}{*}{-} \\
\hline & 42.42 & & - & \\
\hline
\end{tabular}

Resultado consumos edificio objeto ( Taller con uso de vivienda) Elaboración propia. Fig. 8 
Zona Climática Csb (Koppen)/ D2 Orense (CTE)

\begin{tabular}{|c|c|c|c|c|}
\hline Equipo & Ud & $\begin{array}{l}\text { Potencia } \\
\text { (W) }\end{array}$ & $\begin{array}{l}\text { Horas al } \\
\text { dia* }\end{array}$ & Total (Wh) \\
\hline Bombillas de $30 \mathrm{w}$ & $\mathbf{0}$ & 30 & 3 & $\mathbf{0}$ \\
\hline Bombillas de 20 w & 16 & 20 & 6 & 1920 \\
\hline Bombillas de 15 w & $\mathbf{0}$ & 15 & 3 & $\mathbf{0}$ \\
\hline Bombillas de $11 \mathrm{w}$ & $\mathbf{0}$ & 11 & 1 & o \\
\hline Televisor & 2 & 80 & 4 & 640 \\
\hline Lavadora en frio (lavado) & 1 & 500 & 1 & 500 \\
\hline Microondas & 1 & 750 & 0.25 & 187.5 \\
\hline Nevera & 1 & 80 & 24 & 1920 \\
\hline Bomba de Calor & 1 & 5720 & 0.0965 & 551.98 \\
\hline Bomba de Calor & 1 & 5720 & 0.012 & 68.64 \\
\hline Calentador & 1 & 1200 & 0.208 & 249.6 \\
\hline Otros... & 1 & 100 & 1 & 100 \\
\hline Calcular & & & Total W & 6135 \\
\hline
\end{tabular}

Calculadora de consumos energéticos (electricidad), edificio objeto. Orense (www.hmsistemas.es) Consulta 2015. Fig. 9

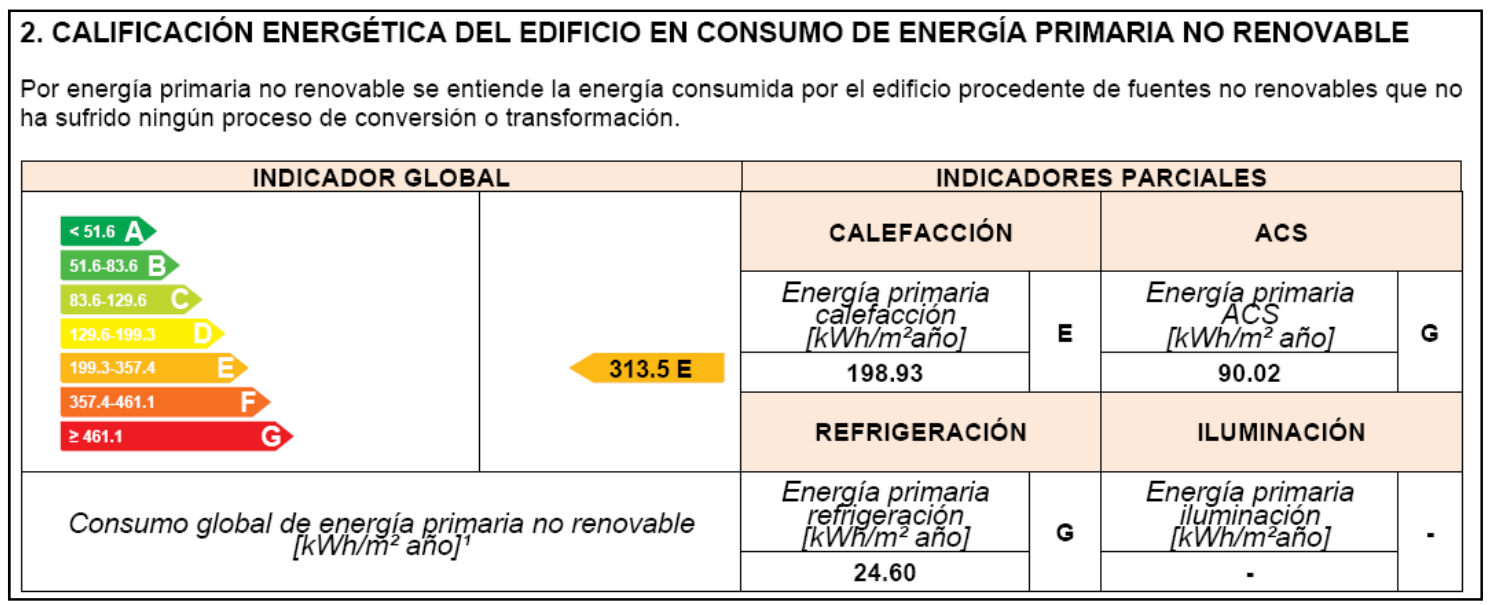

Resultado consumos edificio objeto. Orense. Fig. 10 
Zona Climática Cfb (Koppen)/ C1 Santander (CTE)

\begin{tabular}{|c|c|c|c|c|}
\hline Equipo & Ud & $\begin{array}{l}\text { Potencia } \\
\text { (W) }\end{array}$ & $\begin{array}{l}\text { Horas al } \\
\text { dia* }\end{array}$ & Total (Wh) \\
\hline Bombillas de $30 \mathrm{w}$ & $\mathbf{0}$ & 30 & 3 & $\mathbf{0}$ \\
\hline Bombillas de $20 \mathrm{w}$ & 16 & 20 & 6 & 1920 \\
\hline Bombillas de $15 \mathrm{w}$ & $\mathbf{0}$ & 15 & 3 & $\mathbf{0}$ \\
\hline Bombillas de $11 \mathrm{~W}$ & $\mathbf{0}$ & 11 & 1 & $\mathbf{0}$ \\
\hline Televisor & 2 & 80 & 4 & 640 \\
\hline Lavadora en frio (lavado) & 1 & 500 & 1 & 500 \\
\hline Microondas & 1 & 750 & 0.25 & 187.5 \\
\hline Nevera & 1 & 80 & 24 & 1920 \\
\hline Bomba de Calor & 1 & 5720 & 0.0358 & 204.77! \\
\hline Bomba de Calor & 1 & 5720 & 0.0592 & 338.62 \\
\hline Calentador & 1 & 1200 & 0.2067 & 248.04 \\
\hline Otros... & 1 & 100 & 1 & 100 \\
\hline Calcular & & & Total w & 6057 \\
\hline
\end{tabular}

Calculadora de consumos energéticos (electricidad), edificio objeto. Santander. (www.hmsistemas.es) Consulta 2015. Fig. 11

\begin{tabular}{|c|c|c|c|c|}
\hline \multicolumn{5}{|c|}{$\begin{array}{l}\text { 2. CALIFICACIÓN ENERGÉTICA DEL EDIFICIO EN CONSUMO DE ENERGÍA PRIMARIA NO RENOVABLE } \\
\text { Por energía primaria no renovable se entiende la energía consumida por el edificio procedente de fuentes no renovables que no } \\
\text { ha sufrido ningún proceso de conversión o transformación. }\end{array}$} \\
\hline INDICADOR GLOBAL & \multicolumn{4}{|c|}{ INDICADORES PARCIALES } \\
\hline$<35.8 \mathrm{~A}$ & \multicolumn{2}{|c|}{ CALEFACCIÓN } & \multicolumn{2}{|l|}{ ACS } \\
\hline $\begin{array}{lll}58.1-90.0 & C \\
90.0-138.4 & D\end{array}$ & $\begin{array}{l}\text { Energía primaria } \\
\text { calefacción } \\
{\left[\mathrm{kWh} / \mathrm{m}^{2} \text { año] }\right.}\end{array}$ & \multirow[t]{2}{*}{$\mathbf{E}$} & $\begin{array}{l}\text { Energía primaria } \\
A C S \text { S } \\
{\left[\mathrm{kWh} / \mathrm{m}^{2} \text { año] }\right.}\end{array}$ & \multirow[t]{2}{*}{ G } \\
\hline 138.4.254.1 $\quad$ 的 & 122.15 & & 89.37 & \\
\hline $\begin{array}{ll}254.1 .305 .0 & \text { F } \\
2305.0 & \text { G }\end{array}$ & \multicolumn{2}{|c|}{ REFRIGERACIÓN } & \multicolumn{2}{|l|}{ ILUMINACIÓN } \\
\hline \multirow{2}{*}{$\begin{array}{c}\text { Consumo global de energía primaria no renovable } \\
\qquad\left[\mathrm{kWh} / \mathrm{m}^{2} \text { año }\right]^{1}\end{array}$} & $\begin{array}{c}\text { Energía primaria } \\
\text { refrigeración } \\
{\left[\mathrm{kWh} / \mathrm{m}^{2} \text { año] }\right.}\end{array}$ & \multirow[t]{2}{*}{ - } & $\begin{array}{c}\text { Energía primaria } \\
\text { iluminación } \\
{\left[\mathrm{kWh} / \mathrm{m}^{2} \text { año] }\right.}\end{array}$ & \\
\hline & . & & . & \\
\hline
\end{tabular}

Resultado consumos edificio objeto. Santander Fig. 12 
Zona Climática Bsb (Koppen)/ E1 Burgos (CTE)

\begin{tabular}{|c|c|c|c|c|}
\hline Equipo & Ud & $\begin{array}{l}\text { Potencia } \\
\text { (W) }\end{array}$ & $\begin{array}{l}\text { Horas al } \\
\text { dia* }\end{array}$ & Total (Wh) \\
\hline Bombillas de $30 \mathrm{w}$ & $\mathbf{0}$ & 30 & 3 & $\mathbf{0}$ \\
\hline Bombillas de 20 w & 16 & 20 & 6 & 1920 \\
\hline Bombillas de 15 w & $\mathbf{0}$ & 15 & 3 & $\mathbf{0}$ \\
\hline Bombillas de $11 \mathrm{w}$ & $\mathbf{0}$ & 11 & 1 & $\mathbf{0}$ \\
\hline Televisor & 2 & 80 & 4 & 640 \\
\hline Lavadora en frio (lavado) & 1 & 500 & 1 & 500 \\
\hline Microondas & 1 & 750 & 0.25 & 187.5 \\
\hline Nevera & 1 & 80 & 24 & 1920 \\
\hline Bomba de Calor & 1 & 5720 & 0.1284 & 734.44 \\
\hline Bomba de Calor & $\mathbf{0}$ & 5720 & 0.0592 & $\mathbf{0}$ \\
\hline Calentador & 1 & 1200 & 0.075 & 90 \\
\hline Otros... & 1 & 100 & 1 & 100 \\
\hline Calcular & & & Total W & 6091 \\
\hline
\end{tabular}

Calculadora de consumos energéticos (electricidad), edificio objeto. Burgos (www.hmsistemas.es). Consulta 2015. Fig. 13

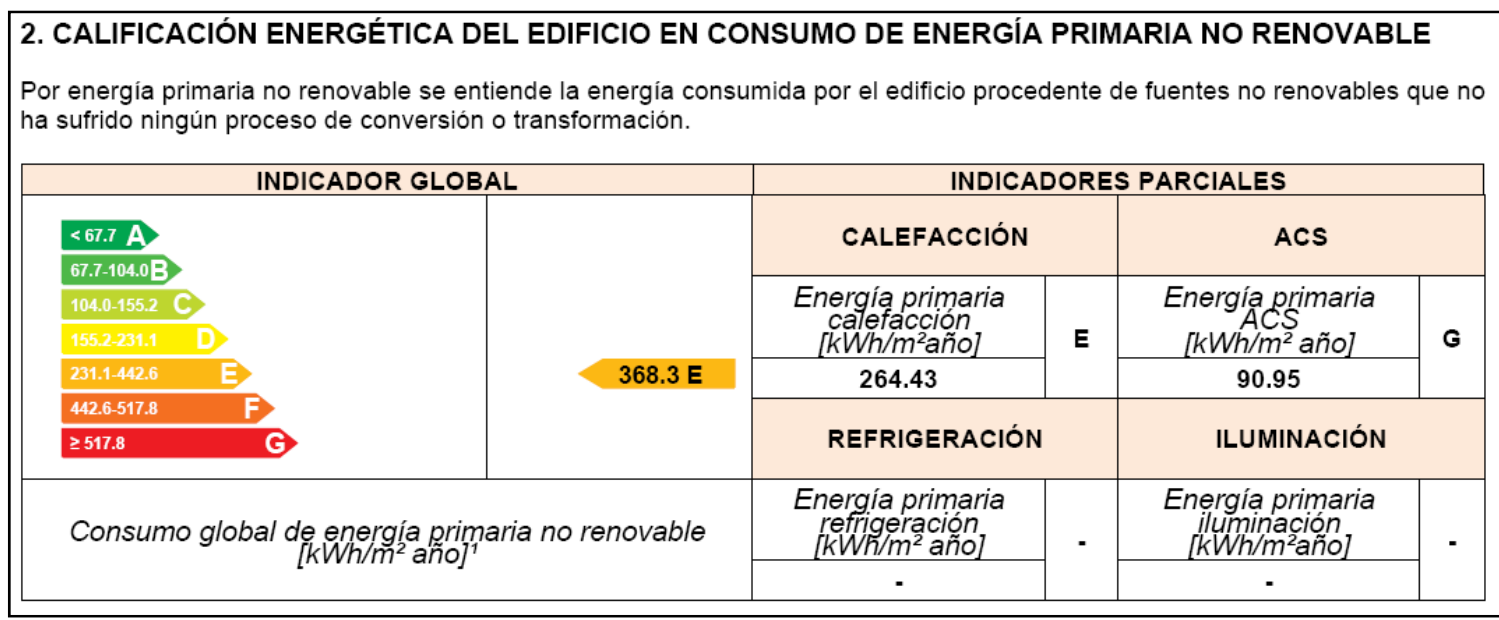

Resultado consumos edificio objeto. Burgos. Fig. 14 
A.5.2.

REFERENCIA PARA CÁLCULOS DE POTENCIA MÍNIMA: CTE DB-HE5 EPÍGRAFES 2.2.1 Y 2.2.2 


\subsection{Cuantificación de la exigencia}

\subsubsection{Potencia eléctrica mínima}

1 La potencia nominal mínima a instalar se calculará mediante la siguiente fórmula:

$\mathrm{P}=\mathrm{C} \cdot(0,002 \cdot \mathrm{S}-5)$

Siendo

$P \quad$ la potencia nominal a instalar [KW];

C el coeficiente definido en la tabla 2.1 en función de la zona climática establecida en el apartado 4.1;

8 la superficie construida del edificio $\left[\mathrm{m}^{2}\right]$ :

Tabla 2.1 Coeficiente climítico

\begin{tabular}{|c|c|}
\hline Zona climítica & C \\
\hline I & 1 \\
II & 1,1 \\
III & 1,2 \\
IV & 1,3 \\
V & 1,4 \\
\hline
\end{tabular}

2 La superficie $\mathrm{S}$ a considerar para el caso de edificios destinados a cualquiera de los usos recogidos en la tabla 1.1 ejecutados dentro de una misma parcela catastral, será la suma de todas ellas.

3 En todos los casos, la potencia pico mínima del generador será al menos igual a la potencia nominal del imersor. La potencia nominal máxima obligatoria a instalar en todos los casos será de $100 \mathrm{~kW}$.

4 La potencia eléctric a mínima de la instalación solar fotovoltaica determinada en aplicación de la exigencia básica que se desarrolla en esta sección, podrá sustituirse parcial o totalmente cuando se cubra la producción eléctrica estimada que correspondería a la potencia mínima mediante el aprovechamiento de otras fuentes de energías renovables.

5 Para estimar la producción de la instalación fotovoltaica se considerarán los ratios de producción siguientes por zonas climáticas, en kWhikW:

Tabla 2.2 Ratios de producción por zona climática

\begin{tabular}{|l|ccccc|}
\hline & Zona I & Zona II & Zona III & Zona IV & Zona V \\
\hline $\begin{array}{l}\text { Horas equival entes de referencia anuales } \\
\text { (WWhNWW) }\end{array}$ & 1.232 & 1.362 & 1.492 & 1.632 & 1.753 \\
\hline
\end{tabular}

Fig. 15

\subsubsection{Pérdidas por orientación, inclinación y sombras}

1 La disposición de los módulos se hará de tal manera que las pérdidas debidas a la orientación e inclinación del sistema y a las sombras sobre el mismo sean inferiores a los límites de la tabla 2.3 .

2 Las pérdidas se expresan como porcentaje de la radiación solar que incidiría sobre la superficie de captación orientada al sur, a la inclinación óptima y sin sombras.

Tabla 2.3 Pérdidas límite

\begin{tabular}{|l|ccc|}
\hline Caso & Orientación e inclinación & Sombras & Total \\
\hline General & $10 \%$ & $10 \%$ & $15 \%$ \\
Superposición de módulos fotovoltaicos & $20 \%$ & $15 \%$ & $30 \%$ \\
Integración arquifectónica de módulos fotovoltaicos & $40 \%$ & $20 \%$ & $50 \%$ \\
\hline
\end{tabular}

Fig. 16 
A.5.3.

DATOS OBTENIDOS DE LA HERRAMIENTA ONLINE PHOTOVOLTAIC GEOGRAPHICAL INFORMATION SYSTEM (PVGIS), SOBRE RADIACIÓN SOLAR Y POSIBLE DESEMPEÑO DE INSTALACIÓN FV, A PARTIR DE LOS VALORES MENOS FAVORABLES DE IRRADIACIÓN GLOBAL DIARIA. 
A.5.3.1.

Zona Climática BWk, BWh, A (Koppen) / a3 (CTE). Santa Cruz de Tenerife 


$\begin{array}{lrrrr} & & & & \\ \text { Mes } & E_{d} & E_{m} & H_{d} & H_{m} \\ \text { Enero } & 9,97 & 309,00 & 2,04 & 63,24 \\ \text { Febrero } & 15,50 & 434,00 & 3,13 & 87,64 \\ \text { Marzo } & 22,84 & 708,00 & 4,65 & 144,15 \\ \text { Abril } & 27,13 & 814,00 & 5,58 & 167,40 \\ \text { Mayo } & 31,29 & 970,00 & 6,57 & 203,67 \\ \text { Junio } & 35,33 & 1.060,00 & 7,56 & 226,80 \\ \text { Julio } & 36,77 & 1.140,00 & 7,96 & 246,76 \\ \text { Agosto } & 32,23 & 999,00 & 6,95 & 215,45 \\ \text { Septiembre } & 25,13 & 754,00 & 5,32 & 159,60 \\ \text { Octubre } & 17,94 & 556,00 & 3,73 & 115,63 \\ \text { Noviembre } & 11,80 & 354,00 & 2,44 & 73,20 \\ \text { Diciembre } & 9,06 & 281,00 & 1,88 & 58,28 \\ \text { Media anual } & 22,92 & 698,25 & 4,82 & 146,82 \\ \text { Total anual } & & \mathbf{8 . 3 7 9 , 0 0} & & 1.761,82\end{array}$

Ed: Media diaria de electricidad producida por el sistema [kWh]

Em: Media mensual de electricidad producida por el sistema ( $\mathrm{kWh}$ )

Hd: suma media diaria de irradiación global por metro cuadrado recibida ( $\mathrm{kWh} / \mathrm{m} 2$ )

Hm: suma media mensual de irradiación global por metro cuadrado recibida ( $\mathrm{kWh} / \mathrm{m} 2$ ) 
A.5.3.2.

Zona Climática BWk (Koppen)/ A4 . (CTE). Almería 


\section{Performance of Grid-connected PV}

\section{PVGIS estimates of solar electricity generation}

Location: 365' 2 " North, $2^{\circ} 27^{\prime} 49^{\prime \prime}$ West, Elevation: 2 m a.s.I., Solar radiation database used: PVGIS-CMSAF

Nominal power of the PV system: $6.1 \mathrm{~kW}$ (crystalline silicon)

Estimated losses due to temperature and low irradiance: 15.7\% (using local ambient temperature)

Estimated loss due to angular reflectance effects: $2.5 \%$

Other losses (cables, inverter etc.): $14.0 \%$

Combined PV system losses: 29.3\%

\begin{tabular}{|l|r|r|r|r|}
\hline \multicolumn{5}{|l|}{ Fixed system: inclination=35 deg., } \\
orientation=0 deg. \\
\hline Month & \multicolumn{1}{|l|}{ Ed } & \multicolumn{1}{l|}{ Em } & \multicolumn{1}{l|}{ Hd } & \multicolumn{1}{l|}{ Hm } \\
\hline Jan & 20.50 & 637 & 4.61 & 143 \\
\hline Feb & 24.30 & 680 & 5.53 & 155 \\
\hline Mar & 28.40 & 881 & 6.62 & 205 \\
\hline Apr & 28.80 & 865 & 6.72 & 202 \\
\hline May & 29.10 & 903 & 6.85 & 212 \\
\hline Jun & 30.10 & 904 & 7.13 & 214 \\
\hline Jul & 30.10 & 934 & 7.22 & 224 \\
\hline Aug & 29.80 & 924 & 7.18 & 223 \\
\hline Sep & 27.30 & 818 & 6.51 & 195 \\
\hline Oct & 24.80 & 770 & 5.84 & 181 \\
\hline Nov & 21.20 & 637 & 4.83 & 145 \\
\hline Dec & 19.70 & 610 & 4.43 & 137 \\
\hline Year & 26.20 & 797 & 6.12 & 186 \\
\hline Total for & & 9560 & & 2240 \\
year & & & & \\
\hline
\end{tabular}

Ed: Average daily electricity production from the given system (kWh)

Em: Average monthly electricity production from the given system ( $\mathrm{kWh}$ )

$\mathrm{Hd}$ : Average daily sum of global irradiation per square meter received by the modules of the given system $(\mathrm{kWh} / \mathrm{m} 2)$

$\mathrm{Hm}$ : Average sum of global irradiation per square meter received by the modules of the given system $(\mathrm{kWh} / \mathrm{m} 2)$

PVGIS (c) European Communities, 2001-2012

Reproduction is authorised, provided the source is acknowledged.

http://re.jrc.ec.europa.eu/pvgis/

Disclaimer:

The European Commission maintains this website to enhance public access to information about its initiatives and European Union policies in general. However the Commission accepts no responsibility or liability whatsoever with regard to the information on this site.

This information is:

- of a general nature only and is not intended to address the specific circumstances of any particular individual or entity;

- not necessarily comprehensive, complete, accurate or up to date

- not professional or legal advice (if you need specific advice, you should always consult a suitably qualified professional).

Some data or information on this site may have been created or structured in files or formats that are not error-free and we cannot guarantee that our service will not be interrupted or otherwise affected by such problems. The Commission accepts no responsibility with regard to such problems incurred as a result of using this site or any linked external sites. 
A.5.3.3.

Zona Climática Csa (Koppen)/ B4 (CTE). Sevilla. 


\section{Performance of Grid-connected PV}

\section{PVGIS estimates of solar electricity generation}

Location: 37²3'20" North, 559'4" West, Elevation: 21 m a.s.I., Solar radiation database used: PVGIS-CMSAF

Nominal power of the PV system: $6.1 \mathrm{~kW}$ (crystalline silicon)

Estimated losses due to temperature and low irradiance: 17.3\% (using local ambient temperature)

Estimated loss due to angular reflectance effects: $2.6 \%$

Other losses (cables, inverter etc.): $14.0 \%$

Combined PV system losses: $30.7 \%$

\begin{tabular}{|l|r|r|r|r|}
\hline \multicolumn{5}{|l|}{ Fixed system: inclination=35 deg., } \\
orientation=0 deg. \\
\hline Month & \multicolumn{1}{|l|}{ Ed } & \multicolumn{1}{l|}{ Em } & \multicolumn{1}{l|}{ Hd } & \multicolumn{1}{l|}{ Hm } \\
\hline Jan & 19.30 & 597 & 4.32 & 134 \\
\hline Feb & 23.10 & 647 & 5.27 & 147 \\
\hline Mar & 26.20 & 812 & 6.16 & 191 \\
\hline Apr & 26.40 & 793 & 6.27 & 188 \\
\hline May & 27.80 & 863 & 6.69 & 207 \\
\hline Jun & 28.70 & 861 & 7.08 & 212 \\
\hline Jul & 29.70 & 922 & 7.41 & 230 \\
\hline Aug & 29.20 & 906 & 7.35 & 228 \\
\hline Sep & 26.40 & 793 & 6.49 & 195 \\
\hline Oct & 24.30 & 752 & 5.78 & 179 \\
\hline Nov & 20.70 & 621 & 4.75 & 142 \\
\hline Dec & 18.30 & 569 & 4.11 & 127 \\
\hline Year & 25.00 & 761 & 5.98 & 182 \\
\hline Total for & & 9130 & & 2180 \\
year & & & & \\
\hline
\end{tabular}

Ed: Average daily electricity production from the given system (kWh)

Em: Average monthly electricity production from the given system ( $\mathrm{kWh}$ )

$\mathrm{Hd}$ : Average daily sum of global irradiation per square meter received by the modules of the given system $(\mathrm{kWh} / \mathrm{m} 2)$

$\mathrm{Hm}$ : Average sum of global irradiation per square meter received by the modules of the given system $(\mathrm{kWh} / \mathrm{m} 2)$

PVGIS (c) European Communities, 2001-2012

Reproduction is authorised, provided the source is acknowledged.

http://re.jrc.ec.europa.eu/pvgis/

Disclaimer:

The European Commission maintains this website to enhance public access to information about its initiatives and European Union policies in general. However the Commission accepts no responsibility or liability whatsoever with regard to the information on this site.

This information is:

- of a general nature only and is not intended to address the specific circumstances of any particular individual or entity;

- not necessarily comprehensive, complete, accurate or up to date

- not professional or legal advice (if you need specific advice, you should always consult a suitably qualified professional).

Some data or information on this site may have been created or structured in files or formats that are not error-free and we cannot guarantee that our service will not be interrupted or otherwise affected by such problems. The Commission accepts no responsibility with regard to such problems incurred as a result of using this site or any linked external sites. 
A.5.3.4.

Zona Climática BSk (Koppen)/ D3 (CTE). Madrid 


\section{Performance of Grid-connected PV}

\section{PVGIS estimates of solar electricity generation}

Location: 40²5'0" North, 342'13" West, Elevation: 665 m a.s.l., Solar radiation database used: PVGIS-CMSAF

Nominal power of the PV system: $6.1 \mathrm{~kW}$ (crystalline silicon)

Estimated losses due to temperature and low irradiance: 14.9\% (using local ambient temperature)

Estimated loss due to angular reflectance effects: $2.5 \%$

Other losses (cables, inverter etc.): $14.0 \%$

Combined PV system losses: $28.7 \%$

\begin{tabular}{|l|r|r|r|r|}
\hline \multicolumn{5}{|l|}{} \\
\multicolumn{5}{|l|}{ Fixed system: inclination=35 deg., } \\
\hline Month & \multicolumn{1}{|l|}{ Ed } & \multicolumn{1}{l|}{ Em } & \multicolumn{1}{l|}{ Hd } & \multicolumn{1}{l|}{ Hm } \\
\hline Jan & 16.90 & 524 & 3.60 & 112 \\
\hline Feb & 21.80 & 610 & 4.76 & 133 \\
\hline Mar & 26.20 & 811 & 5.96 & 185 \\
\hline Apr & 26.30 & 788 & 6.07 & 182 \\
\hline May & 27.20 & 843 & 6.43 & 199 \\
\hline Jun & 29.10 & 873 & 7.05 & 211 \\
\hline Jul & 30.80 & 954 & 7.55 & 234 \\
\hline Aug & 30.10 & 933 & 7.35 & 228 \\
\hline Sep & 27.60 & 827 & 6.56 & 197 \\
\hline Oct & 23.30 & 721 & 5.29 & 164 \\
\hline Nov & 18.30 & 548 & 3.96 & 119 \\
\hline Dec & 16.40 & 509 & 3.48 & 108 \\
\hline Year & 24.50 & 745 & 5.68 & 173 \\
\hline $\begin{array}{l}\text { Total for } \\
\text { year }\end{array}$ & & 8940 & & 2070 \\
\hline
\end{tabular}

Ed: Average daily electricity production from the given system (kWh)

Em: Average monthly electricity production from the given system ( $\mathrm{kWh}$ )

$\mathrm{Hd}$ : Average daily sum of global irradiation per square meter received by the modules of the given system $(\mathrm{kWh} / \mathrm{m} 2)$

$\mathrm{Hm}$ : Average sum of global irradiation per square meter received by the modules of the given system $(\mathrm{kWh} / \mathrm{m} 2)$

PVGIS (c) European Communities, 2001-2012

Reproduction is authorised, provided the source is acknowledged.

http://re.jrc.ec.europa.eu/pvgis/

Disclaimer:

The European Commission maintains this website to enhance public access to information about its initiatives and European Union policies in general. However the Commission accepts no responsibility or liability whatsoever with regard to the information on this site.

This information is:

- of a general nature only and is not intended to address the specific circumstances of any particular individual or entity;

- not necessarily comprehensive, complete, accurate or up to date;

- not professional or legal advice (if you need specific advice, you should always consult a suitably qualified professional).

Some data or information on this site may have been created or structured in files or formats that are not error-free and we cannot guarantee that our service will not be interrupted or otherwise affected by such problems. The Commission accepts no responsibility with regard to such problems incurred as a result of using this site or any linked external sites. 
A.5.3.5.

Zona Climática Csb (Koppen)/ D2 (CTE). Ourense. 


\section{Performance of Grid-connected PV}

\section{PVGIS estimates of solar electricity generation}

Location: 42²0'8" North, 751'49" West, Elevation: 136 m a.s.l., Solar radiation database used: PVGIS-CMSAF

Nominal power of the PV system: $6.1 \mathrm{~kW}$ (crystalline silicon)

Estimated losses due to temperature and low irradiance: 15.5\% (using local ambient temperature)

Estimated loss due to angular reflectance effects: $2.6 \%$

Other losses (cables, inverter etc.): $14.0 \%$

Combined PV system losses: 29.3\%

\begin{tabular}{|l|r|r|r|r|}
\hline \multicolumn{5}{|l|}{} \\
\multicolumn{5}{|l|}{ Fixed system: inclination=35 deg., } \\
\hline Month & \multicolumn{1}{|l|}{ Ed } & \multicolumn{1}{l|}{ Em } & \multicolumn{1}{l|}{ Hd } & \multicolumn{1}{l|}{ Hm } \\
\hline Jan & 12.40 & 384 & 2.68 & 83.2 \\
\hline Feb & 18.30 & 511 & 4.03 & 113 \\
\hline Mar & 23.30 & 721 & 5.36 & 166 \\
\hline Apr & 23.80 & 714 & 5.56 & 167 \\
\hline May & 25.10 & 777 & 5.92 & 184 \\
\hline Jun & 26.80 & 803 & 6.48 & 194 \\
\hline Jul & 27.90 & 865 & 6.79 & 211 \\
\hline Aug & 27.90 & 866 & 6.82 & 212 \\
\hline Sep & 25.80 & 775 & 6.16 & 185 \\
\hline Oct & 19.60 & 609 & 4.53 & 140 \\
\hline Nov & 13.70 & 410 & 3.00 & 90.1 \\
\hline Dec & 11.80 & 365 & 2.55 & 79.0 \\
\hline Year & 21.40 & 650 & 4.99 & 152 \\
\hline $\begin{array}{l}\text { Total for } \\
\text { year }\end{array}$ & & 7800 & & 1820 \\
\hline
\end{tabular}

Ed: Average daily electricity production from the given system (kWh)

Em: Average monthly electricity production from the given system ( $\mathrm{kWh}$ )

$\mathrm{Hd}$ : Average daily sum of global irradiation per square meter received by the modules of the given system $(\mathrm{kWh} / \mathrm{m} 2)$

$\mathrm{Hm}$ : Average sum of global irradiation per square meter received by the modules of the given system $(\mathrm{kWh} / \mathrm{m} 2)$

PVGIS (c) European Communities, 2001-2012

Reproduction is authorised, provided the source is acknowledged.

http://re.jrc.ec.europa.eu/pvgis/

Disclaimer:

The European Commission maintains this website to enhance public access to information about its initiatives and European Union policies in general. However the Commission accepts no responsibility or liability whatsoever with regard to the information on this site.

This information is:

- of a general nature only and is not intended to address the specific circumstances of any particular individual or entity;

- not necessarily comprehensive, complete, accurate or up to date

- not professional or legal advice (if you need specific advice, you should always consult a suitably qualified professional).

Some data or information on this site may have been created or structured in files or formats that are not error-free and we cannot guarantee that our service will not be interrupted or otherwise affected by such problems. The Commission accepts no responsibility with regard to such problems incurred as a result of using this site or any linked external sites. 
A.5.3.6.

Zona Climática Cfb (Koppen)/ C1 (CTE). Santander. 


\section{Performance of Grid-connected PV}

\section{PVGIS estimates of solar electricity generation}

Location: $43^{\circ} 27^{\prime} 44^{\prime \prime}$ North, $3^{\circ} 48^{\prime} 35^{\prime \prime}$ West, Elevation: 16 m a.s.I., Solar radiation database used: PVGIS-CMSAF

Nominal power of the PV system: $6.1 \mathrm{~kW}$ (crystalline silicon)

Estimated losses due to temperature and low irradiance: 13.6\% (using local ambient temperature)

Estimated loss due to angular reflectance effects: $2.8 \%$

Other losses (cables, inverter etc.): $14.0 \%$

Combined PV system losses: $27.7 \%$

\begin{tabular}{|l|r|r|r|r|}
\hline \multicolumn{5}{|l|}{ Fixed system: inclination=35 deg., } \\
orientation=0 deg. \\
\hline Month & \multicolumn{1}{|l|}{ Ed } & \multicolumn{1}{l|}{ Em } & \multicolumn{1}{l|}{ Hd } & \multicolumn{1}{l|}{ Hm } \\
\hline Jan & 10.70 & 333 & 2.29 & 71.0 \\
\hline Feb & 14.50 & 407 & 3.16 & 88.6 \\
\hline Mar & 20.00 & 619 & 4.55 & 141 \\
\hline Apr & 20.80 & 625 & 4.77 & 143 \\
\hline May & 21.00 & 652 & 4.88 & 151 \\
\hline Jun & 21.80 & 654 & 5.10 & 153 \\
\hline Jul & 22.20 & 687 & 5.23 & 162 \\
\hline Aug & 21.20 & 659 & 5.01 & 155 \\
\hline Sep & 21.50 & 645 & 5.00 & 150 \\
\hline Oct & 16.70 & 517 & 3.80 & 118 \\
\hline Nov & 11.10 & 333 & 2.42 & 72.5 \\
\hline Dec & 10.70 & 332 & 2.31 & 71.5 \\
\hline Year & 17.70 & 538 & 4.05 & 123 \\
\hline Total for & & 6460 & & 1480 \\
year & & & & \\
\hline
\end{tabular}

Ed: Average daily electricity production from the given system (kWh)

Em: Average monthly electricity production from the given system ( $\mathrm{kWh}$ )

$\mathrm{Hd}$ : Average daily sum of global irradiation per square meter received by the modules of the given system $(\mathrm{kWh} / \mathrm{m} 2)$

$\mathrm{Hm}$ : Average sum of global irradiation per square meter received by the modules of the given system $(\mathrm{kWh} / \mathrm{m} 2)$

PVGIS (c) European Communities, 2001-2012

Reproduction is authorised, provided the source is acknowledged.

http://re.jrc.ec.europa.eu/pvgis/

Disclaimer:

The European Commission maintains this website to enhance public access to information about its initiatives and European Union policies in general. However the Commission accepts no responsibility or liability whatsoever with regard to the information on this site.

This information is:

- of a general nature only and is not intended to address the specific circumstances of any particular individual or entity;

- not necessarily comprehensive, complete, accurate or up to date

- not professional or legal advice (if you need specific advice, you should always consult a suitably qualified professional).

Some data or information on this site may have been created or structured in files or formats that are not error-free and we cannot guarantee that our service will not be interrupted or otherwise affected by such problems. The Commission accepts no responsibility with regard to such problems incurred as a result of using this site or any linked external sites. 
A.5.3.7.

Zona Climática Dsb (Koppen)/ E1 (CTE). Burgos. 


\section{Performance of Grid-connected PV}

\section{PVGIS estimates of solar electricity generation}

Location: 42 $20^{\prime} 38^{\prime \prime}$ North, $3^{\circ} 41^{\prime} 48^{\prime \prime}$ West, Elevation: 866 m a.s.I., Solar radiation database used: PVGIS-CMSAF

Nominal power of the PV system: $6.1 \mathrm{~kW}$ (crystalline silicon)

Estimated losses due to temperature and low irradiance: 13.8\% (using local ambient temperature)

Estimated loss due to angular reflectance effects: $2.7 \%$

Other losses (cables, inverter etc.): $14.0 \%$

Combined PV system losses: $27.8 \%$

\begin{tabular}{|l|r|r|r|r|}
\hline \multicolumn{5}{|l|}{} \\
\multicolumn{5}{|l|}{ Fixed system: inclination=35 deg., } \\
\hline Month & \multicolumn{1}{|l|}{ Ed } & \multicolumn{1}{l|}{ Em } & \multicolumn{1}{l|}{ Hd } & \multicolumn{1}{l|}{ Hm } \\
\hline Jan & 11.30 & 350 & 2.39 & 74.1 \\
\hline Feb & 16.30 & 457 & 3.53 & 98.7 \\
\hline Mar & 21.90 & 679 & 4.93 & 153 \\
\hline Apr & 22.80 & 685 & 5.20 & 156 \\
\hline May & 25.90 & 802 & 6.00 & 186 \\
\hline Jun & 27.90 & 837 & 6.59 & 198 \\
\hline Jul & 29.90 & 928 & 7.16 & 222 \\
\hline Aug & 28.90 & 895 & 6.90 & 214 \\
\hline Sep & 25.80 & 774 & 6.03 & 181 \\
\hline Oct & 19.60 & 608 & 4.41 & 137 \\
\hline Nov & 12.90 & 386 & 2.75 & 82.6 \\
\hline Dec & 11.70 & 363 & 2.47 & 76.5 \\
\hline Year & 21.30 & 647 & 4.87 & 148 \\
\hline $\begin{array}{l}\text { Total for } \\
\text { year }\end{array}$ & & 7760 & & 1780 \\
\hline
\end{tabular}

Ed: Average daily electricity production from the given system (kWh)

Em: Average monthly electricity production from the given system ( $\mathrm{kWh}$ )

$\mathrm{Hd}$ : Average daily sum of global irradiation per square meter received by the modules of the given system $(\mathrm{kWh} / \mathrm{m} 2)$

$\mathrm{Hm}$ : Average sum of global irradiation per square meter received by the modules of the given system $(\mathrm{kWh} / \mathrm{m} 2)$

PVGIS (c) European Communities, 2001-2012

Reproduction is authorised, provided the source is acknowledged.

http://re.jrc.ec.europa.eu/pvgis/

Disclaimer:

The European Commission maintains this website to enhance public access to information about its initiatives and European Union policies in general. However the Commission accepts no responsibility or liability whatsoever with regard to the information on this site.

This information is:

- of a general nature only and is not intended to address the specific circumstances of any particular individual or entity;

- not necessarily comprehensive, complete, accurate or up to date

- not professional or legal advice (if you need specific advice, you should always consult a suitably qualified professional).

Some data or information on this site may have been created or structured in files or formats that are not error-free and we cannot guarantee that our service will not be interrupted or otherwise affected by such problems. The Commission accepts no responsibility with regard to such problems incurred as a result of using this site or any linked external sites. 
A. 5.4

HERRAMIENTA WEB DE ONYX SOLAR (www.onyxsolar.com), SOBRE AHORRO ASOCIADOS A LA INSTALACIÓN FOTOVOLTÁICA. CÁLCULO REALIZADO SEGÚN ZONAS CLIMÁTICAS. 
La herramienta Onyx sirve como un método de cuantificación, desde una perspectiva comercial, de los ahorros que puede suponer una instalación FV con las características de las proyectadas en esta tesis. Los datos obtenidos mediante la misma podrían enfocarse como unos valores de primera aproximación o números iniciales para cálculos más elaborados. Los datos de generación FV calculados con esta herramienta, han sido comparados con los datos obtenidos mediante la herramienta Photovoltaic Geographical Information System, promovida por la Comisión Europea, obteniendo un margen de error de menos del 5\%.

Zona Climática BWk, BWh, A (Koppen) / a3 (CTE). Santa Cruz de Tenerife

Electricidad generada por año:

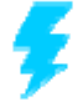

8.379 kWh

Puntos totales de luz funcionando 4 horas por día:

506 horas *

Emisiones de $\mathrm{CO}_{2}$ evitadas al año:

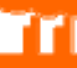

$5.948 \mathrm{Kg} \mathrm{CO} 2$

Barriles de petróleo ahorrados:

5 barriles

Distancia recorrida con un coche eléctrico gracias a la energía generada:

\section{$65.763 \mathrm{~km}$}

* Cálculo realizado con bombillas de bajo consumo LED de 12W (intensidad de luz equivalente a una bombilla incandescente tradicional de $100 \mathrm{~W}$ ). 
Zona Climática BWk (Koppen)/ A4 . (CTE). Almería .

\section{Electricidad generada por año:}

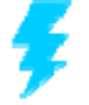

$9.810 \mathrm{kWh}$

Puntos totales de luz funcionando 4 horas por día:

559 horas *

Emisiones de $\mathrm{CO}_{2} \underline{\text { evitadas al año: }}$

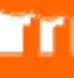

$6.573 \mathrm{~kg} \mathrm{co} 2$

Barriles de petróleo ahorrados:

0

6 barriles

Distancia recorrida con un coche eléctrico gracias a la energía generada:

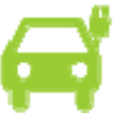

$72.667 \mathrm{~km}$

* Cálculo realizado con bombillas de bajo consumo led de 12w (intensidad de luz equivalente a una bombilla incandescente tradicional de 100w) 
Zona Climática Csa (Koppen)/ B4 (CTE). Sevilla.

Electricidad generada por año:

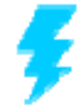

$9.426 \mathrm{kWh}$

Puntos totales de luz funcionando 4 horas por día:

537 horas *

Emisiones de $\mathrm{CO}_{2}$ evitadas al año

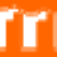

$6.315 \mathrm{~kg} \mathrm{co} 2$

Barriles de petróleo ahorrados:

0

6 barriles

Distancia recorrida con un coche eléctrico gracias a la energía generada:

$69.822 \mathrm{~km}$

* Cálculo realizado con bombillas de bajo consumo led de 12w (intensidad de luz equivalente a una bombilla incandescente tradicional de 100w). 
Zona Climática BSk (Koppen)/ D3 (CTE). Madrid .:

Electricidad generada por año:

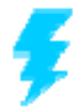

$8.748 \mathrm{kWh}$

Puntos totales de luz funcionando 4 horas por día:

499 horas *

Emisiones de $\mathrm{CO}_{2} \underline{\text { evitadas al año: }}$

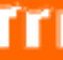

$5.861 \mathrm{~kg} \mathrm{co} 2$

Barriles de petróleo ahorrados:

0

5 barriles

Distancia recorrida con un coche eléctrico gracias a la energía generada:

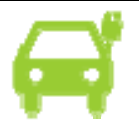

$64.800 \mathrm{~km}$

* Cálculo realizado con bombillas de bajo consumo led de 12w (intensidad de luz equivalente a una bombilla incandescente tradicional de $100 \mathrm{w}$ ) 
Zona Climática Csb (Koppen)/ D2 (CTE). Ourense.

Electricidad generada por año:

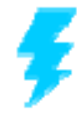

$7.804 \mathrm{kWh}$

Puntos totales de luz funcionando 4 horas por día:

445 horas *

Emisiones de $\mathrm{CO}_{2}$ evitadas al año:

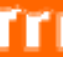

$5.229 \mathrm{~kg} \mathrm{co} 2$

Barriles de petróleo ahorrados:

0

5 barriles

Distancia recorrida con un coche eléctrico gracias a la energía generada:

$57.807 \mathrm{~km}$

* Cálculo realizado con bombillas de bajo consumo led de 12w (intensidad de luz equivalente a una bombilla incandescente tradicional de 100w) 
Zona Climática Cfb (Koppen)/ C1 (CTE). Santander.

Electricidad generada por año:

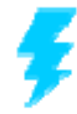

$6.396 \mathrm{kWh}$

Puntos totales de luz funcionando 4 horas por día:

365 horas *

Emisiones de $\mathrm{CO}_{2}$ evitadas al año:

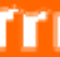

$4.285 \mathrm{~kg} \mathrm{co} 2$

Barriles de petróleo ahorrados:

0

4 barriles

Distancia recorrida con un coche eléctrico gracias a la energía generada:

$47.378 \mathrm{~km}$

* Cálculo realizado con bombillas de bajo consumo led de $12 w$ (intensidad de luz equivalente a una bombilla incandescente tradicional de 100w) 
Zona Climática Dsb (Koppen)/ E1 (CTE). Burgos.

Electricidad generada por año:

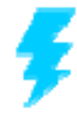

$7.835 \mathrm{kWh}$

Puntos totales de luz funcionando 4 horas por día:

447 horas *

Emisiones de $\mathrm{CO}_{2}$ evitadas al año:

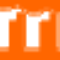

$5.249 \mathrm{~kg} \mathrm{co} 2$

Barriles de petróleo ahorrados:

0

5 barriles

Distancia recorrida con un coche eléctrico gracias a la energía generada:

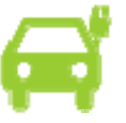

$58.037 \mathrm{~km}$

* Cálculo realizado con bombillas de bajo consumo led de 12w (intensidad de luz equivalente a una bombilla incandescente tradicional de 100w) 
A. 5.5

VALORES DE CÁLCULOS RENDIMIENTOS EER Y COP SISTEMA BOMBA DE CALOR+VIDRIOS ACTIVOS CON CIRCULACIÓN DE AGUA 
Los valores de referencia para el rendimiento de la bomba de calor, del sistema de circulación de agua en vidrios activos, que se han utilizado para ser introducidos en la herramienta simplificada $C E^{3} X$ han sido obtenidos de los cálculos realizados para la tesis "La implementación arquitectónica de los acristalamientos activos con agua circulante, y su contribución en Edificios de consumo de Energía Casi Nulo" (PérezPujazón, 2015). A partir de estos cálculos se han estructurado los escenarios de mejoras por zonas climáticas de acuerdo a las definiciones de Koppen extrapoladas a las zonas climáticas establecidas en el CTE.

\begin{tabular}{|c|c|c|c|c|c|c|c|c|c|}
\hline & & & & & & \multicolumn{2}{|c|}{$\begin{array}{l}\text { EFICIENCIA EER } \\
\text { PERIODO DE REFRIGERACIÓN }\end{array}$} & $\begin{array}{l}\text { TEMP. } \\
\text { TERRENO } \\
{\left[{ }^{\circ} \mathrm{C}\right]}\end{array}$ & $\begin{array}{c}\text { EER } \\
\text { eficiencia } \\
\text { media mensual }\end{array}$ \\
\hline $\begin{array}{l}\text { BOMBA DE CALOR GEOTÉRMICA } \\
\text { AGUA/AGUA VAILLANT GEOTHERM } \\
\text { MODELO VWS } 61 / 2\end{array}$ & $\begin{array}{l}\text { POTENCIA } \\
\text { CALORIFICA } \\
\text { (calefacción } \\
\left.35^{\circ}\right) \\
{[W]} \\
6900\end{array}$ & $\begin{array}{c}\text { POTENCIA } \\
\text { FRIGORIFICA } \\
\text { (refrigeración } \\
18^{\circ} \text { ) } \\
{[W]} \\
8800 \\
\end{array}$ & $\begin{array}{c}\text { COP } \\
\text { NOMINAL } \\
\text { (UNE EN } \\
14511 \text { ) } \\
4,7 \\
\end{array}$ & $\begin{array}{c}\text { EER } \\
\text { NOMMINAL } \\
\text { (UNE EN } \\
14511) \\
5,7 \\
\end{array}$ & & $\begin{array}{l}\text { Mayo } \\
\text { Junio } \\
\text { Julio } \\
\text { Agosto } \\
\text { Septiembre } \\
\text { Octubre }\end{array}$ & & $\begin{array}{l}12,0 \\
14,0 \\
16,0 \\
18,0 \\
18,0 \\
18,0 \\
\end{array}$ & $\begin{array}{l}8,5 \\
7,5 \\
7,0 \\
6,7 \\
6,7 \\
6,7 \\
6,7 \\
\end{array}$ \\
\hline $\begin{array}{l}\text { CAPTACIÓN DE ENERGIÁA } \\
\text { ACRISTALAMIENTOS ACTIVOS } \\
\text { PERIODO DE CALEFACCIÓN } \\
\text { (media diaria mensual) }\end{array}$ & $\begin{array}{c}\text { RAD. SOLAR } \\
\text { (DIRECTA + } \\
\text { DIFUSA) ESTE } \\
{\left[\mathrm{kWh} / \mathrm{m}^{2}\right]}\end{array}$ & $\begin{array}{l}\text { SUPERFICIE } \\
\text { V. ACTIVOS } \\
\text { A ESTE } \\
{\left[\mathrm{m}^{2}\right]}\end{array}$ & $\begin{array}{l}\text { RAD. SOLAR } \\
\text { (DIRECTA + } \\
\text { DIFUSA) SUR } \\
{\left[\mathrm{kWh} / \mathrm{m}^{2}\right]}\end{array}$ & $\begin{array}{l}\text { SUPERFICIE } \\
\text { V. ACTIVOS } \\
\text { A SUR } \\
{\left[\mathrm{m}^{2}\right]}\end{array}$ & $\begin{array}{l}\text { RAD. SOLAR } \\
\text { (DIRECTA+ } \\
\text { DIFUSA) OESTE } \\
{\left[\mathrm{kWh} / \mathrm{m}^{2}\right]}\end{array}$ & $\begin{array}{l}\text { SUPERFICIE } \\
\text { V. ACTINOS } \\
\text { A ESTE } \\
{\left[\mathrm{m}^{2}\right]}\end{array}$ & $\begin{array}{l}\text { ENERGIA } \\
\text { SOBRE } \\
\text { V. ACTIVOS } \\
\text { [kWh] }\end{array}$ & $\begin{array}{c}\text { EFICIENCIA } \\
\text { CAPTACIÓN } \\
\%\end{array}$ & $\begin{array}{l}\text { CAPTACIÓN } \\
\text { ENERGÍA } \\
\text { [kWh] }\end{array}$ \\
\hline Octubre & 2,0 & 6,0 & 3,6 & 21,4 & 2,0 & 4,3 & 97,8 & 30,0 & 29,4 \\
\hline Noviembre & 1,4 & 6,0 & 3,0 & 21,4 & 1,4 & 4,3 & 77,9 & 30,0 & 23,4 \\
\hline Diciembre & 1,5 & 6,0 & 3,6 & 21,4 & 1,5 & 4,3 & 91,3 & 30,0 & 27,4 \\
\hline Enero & 1,3 & 6,0 & 2,7 & 21,4 & 1,3 & 4,3 & 71,6 & 30,0 & 21,5 \\
\hline Febrero & 1,7 & 6,0 & 3,2 & 21,4 & 1,7 & 4,3 & 86,3 & 30,0 & 25,9 \\
\hline Marzo & 3,0 & 6,0 & 4,0 & 21,4 & 3,0 & 4,3 & 116,0 & 30,0 & 34,8 \\
\hline Abril & 3,5 & 6,0 & 3,2 & 21,4 & 3,5 & 4,3 & 104,5 & 30,0 & 31,4 \\
\hline Mayo & 3,6 & 6,0 & 2,6 & 21,4 & 3,6 & 4,3 & 92,9 & 30,0 & 27,9 \\
\hline $\begin{array}{l}\text { RENDIMIENTO COP } \\
\text { PERIODO DE CALEFACCIÓN }\end{array}$ & $\begin{array}{l}\text { VOLUMEN } \\
\text { AGUA } \\
\text { [m3] }\end{array}$ & $\begin{array}{l}\text { DENSIDAD } \\
\text { AGUA } \\
{[\mathrm{kg} / \mathrm{m} 3]}\end{array}$ & $\begin{array}{l}\text { CALOR } \\
\text { ESPECIFICO } \\
\text { AGUA } \\
{\left[\text { Wh/ } / \mathrm{kg}^{\circ} \mathrm{C}\right]}\end{array}$ & $\begin{array}{l}\text { SALTO } \\
\text { TÉRMICO } \\
{\left[{ }^{\circ} \mathrm{C}\right]}\end{array}$ & $\begin{array}{l}\text { TEMP. } \\
\text { DEPÓSITO } \\
(9: 00 \mathrm{~h}) \\
{\left[{ }^{\circ} \mathrm{C}\right]}\end{array}$ & $\begin{array}{c}\text { TEMP. } \\
\text { DEPÓsITO } \\
\text { (18:00 h) } \\
{\left[{ }^{\circ} \mathrm{C}\right]}\end{array}$ & $\begin{array}{c}\text { COP } \\
\text { F. FRiO: TERRENO } \\
\text { (hasta las } 18: 00 \mathrm{~h} \text { ) }\end{array}$ & $\begin{array}{c}\text { COP } \\
\text { F. FRiO: } \\
\text { DEPOSITO } \\
\text { (hasta las } 22: 00 \\
\text { h) }\end{array}$ & $\begin{array}{l}\text { Cop } \\
\text { rendimiento } \\
\text { medio mensual }\end{array}$ \\
\hline Octubre & 6,4 & 1000,0 & 1,2 & 4,0 & 18,0 & 22,0 & 6,5 & 7,3 & 6,9 \\
\hline Noviembre & 6,4 & 1000,0 & 1,2 & 3,1 & 18,0 & 21,1 & 6,3 & 7,2 & 6,8 \\
\hline Diciembre & 6,4 & 1000,0 & 1,2 & 3,7 & 16,0 & 19,7 & 6,1 & 6,9 & 6,5 \\
\hline Enero & 6,4 & 1000,0 & 1,2 & 2,9 & 14,0 & 16,9 & 5,8 & 6,5 & 6,2 \\
\hline Febrero & 6,4 & 1000,0 & 1,2 & 3,5 & 12,0 & 15,5 & 5,8 & 6,4 & 6,1 \\
\hline Marzo & 6,4 & 1000,0 & 1,2 & 4,7 & 12,0 & 16,7 & 5,8 & 6,6 & 6,2 \\
\hline Abril & 6,4 & 1000,0 & 1,2 & 4,2 & 12,0 & 16,2 & 5,8 & 6,5 & 6,2 \\
\hline Mayo & 6,4 & 1000,0 & 1,2 & 3,8 & 12,0 & 15,8 & 5,8 & 6,7 & 6,3 \\
\hline
\end{tabular}

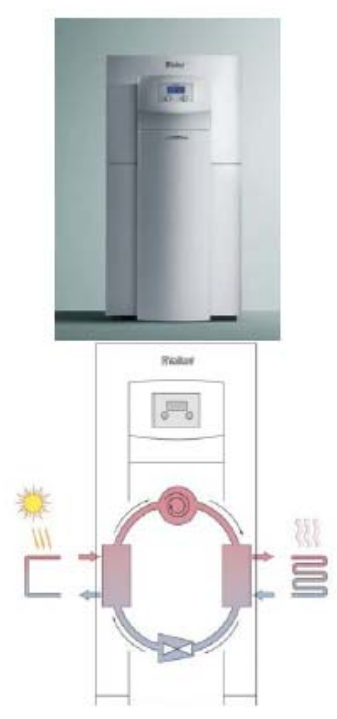



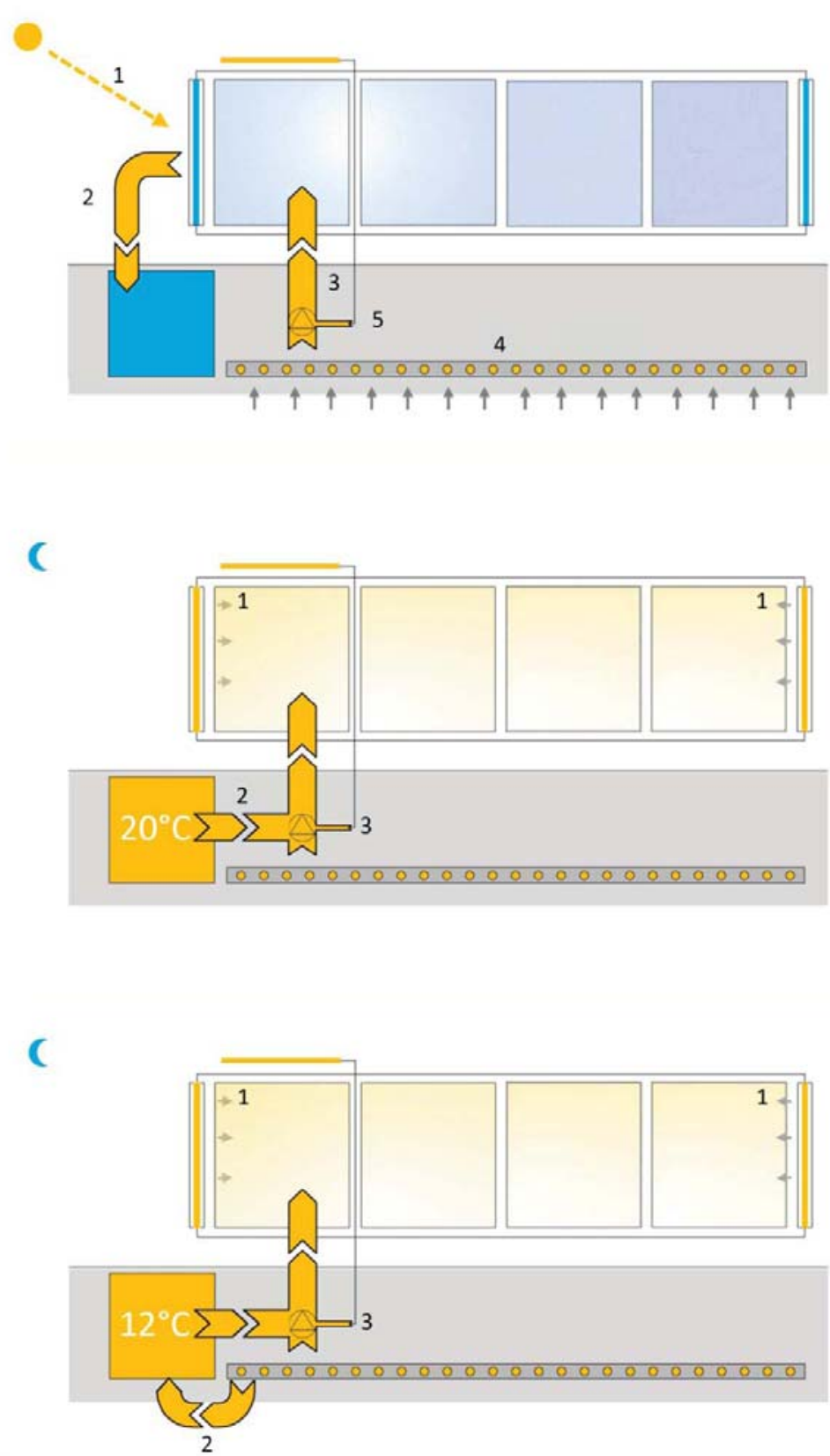

Esquemas de funcionamiento sistema de bomba de calor geotérmica + vidrios activos. 1) El sistema descrito capta calor solar (día de invierno) por los vidrios activos y acumula el calor solar en un depósito estacional. El tipo de calefacción es de baja temperatura $\left(35^{\mathrm{a}} \mathrm{C}\right)$ y utiliza una bomba de calor tierra/agua. Extrae el calor del terreno que es el foco frio a razón de $12^{\circ} \mathrm{C}$ a 1,5m. La potencia eléctrica absorbida por la bomba es COP=5,8. 2) En día de invierno con elevada radiación solar la temperatura del depósito es mayor que la temperatura del terreno, actuando el primero como fuente y el segundo como foco frio; la potencia absorbida por la bomba de calor es COP 7 (foco frio $20^{\circ} \mathrm{C}$, calefacción $35^{\circ} \mathrm{C}$ ). 3) En día de invierno con reducida radiación la potencia eléctrica absorbida por la bomba de calor es $\mathrm{COP}=5,8$ (foco frio $12^{\circ} \mathrm{C}$, calefacción $35^{\circ} \mathrm{C}$ ). (Pérez-Pujazón, 2015). Fig. 2 


\section{ANEXO 6}

CERTIFICADOS DE CALIFICACIÓN ENERGÉTICA DEL TALLER-VIVIENDA $52 \mathrm{M}^{2}$. POR ZONAS CLIMÁTICAS DE ACUERDO AL CÓDIGO TÉCNICO DE EDIFICACIÓN (CTE). RESULTADOS ESTADO ACTUAL Y ESTADO CON MEDIDAS DE MEJORAS.

Resultados Validación Taller $\mathrm{CE}^{3} \mathrm{X}$ Santa Cruz de Tenerife Almería Sevilla Madrid Ourense Santander Burgos 
A.6.1

Resultados Validación Taller de Prototipos ETSAM en $\mathrm{CE}^{3} \mathrm{X}$ 


\section{CERTIFICADO DE EFICIENCIA ENERGÉTICA DE EDIFICIOS}

IDENTIFICACIÓN DEL EDIFICIO O DE LA PARTE QUE SE CERTIFICA:

\begin{tabular}{|l|l|l|l|}
\hline Nombre del edificio & \multicolumn{4}{l|}{ Vivienda Taller Modificado } \\
\hline Dirección & Avda. Juan De Herrera n 4 & \multicolumn{2}{l|}{} \\
\hline Municipio & Madrid & Código Postal & 28040 \\
\hline Provincia & Madrid & Comunidad Autónoma & $\begin{array}{l}\text { Comunidad } \\
\text { Madrid }\end{array}$ \\
\hline Zona climática & D3 & Año construcción & 2007 \\
\hline $\begin{array}{l}\text { Normativa vigente (construcción } \\
\text { rehabilitación) }\end{array}$ & C.T.E. & \\
\hline Referencia/s catastral/es & 8071702 VK3787A0001PY \\
\hline
\end{tabular}

\begin{tabular}{|c|c|}
\hline \multicolumn{2}{|c|}{ Tipo de edificio o parte del edificio que se certifica: } \\
\hline o Edificio de nueva construcción & - Edificio Existente \\
\hline $\begin{array}{l}\text { Vivienda } \\
\circ \text { Unifamiliar } \\
\circ \text { Bloque } \\
\circ \text { Bloque completo } \\
\circ \text { Vivienda individual }\end{array}$ & $\begin{array}{l}\text { - Terciario } \\
\text { - Edificio completo } \\
\text { ○ Local }\end{array}$ \\
\hline
\end{tabular}

DATOS DEL TÉCNICO CERTIFICADOR:

\begin{tabular}{|c|c|c|c|c|c|}
\hline Nombre y Apellidos & \multicolumn{3}{|c|}{ Juan Carlos Sánchez } & NIF(NIE) & 000000000 \\
\hline Razón social & \multicolumn{2}{|c|}{ Juan Carlos Sánchez } & & NIF & 000000000 \\
\hline \multicolumn{2}{|l|}{ Domicilio } & \multicolumn{4}{|l|}{ Calle Pinar Del Rey } \\
\hline \multicolumn{2}{|l|}{ Municipio } & Madrid & \multicolumn{2}{|c|}{ Código Postal } & 28033 \\
\hline \multicolumn{2}{|l|}{ Provincia } & Madrid & \multicolumn{2}{|c|}{ Comunidad Autónoma } & $\begin{array}{l}\text { Comunidad de } \\
\text { Madrid }\end{array}$ \\
\hline \multicolumn{2}{|c|}{ e-mail: } & \multicolumn{2}{|c|}{ juancsanchezg@hotmail.com } & Teléfono & 000000000000 \\
\hline \multicolumn{2}{|c|}{ Titulación habilitante según normativa vigente } & \multicolumn{4}{|c|}{ Arquitecto } \\
\hline \multicolumn{3}{|c|}{$\begin{array}{l}\text { Procedimiento reconocido de calificación energética utilizado y } \\
\text { versión: }\end{array}$} & \multicolumn{3}{|c|}{ CEXv2.1 } \\
\hline
\end{tabular}

CALIFICACIÓN ENERGÉTICA OBTENIDA:

\begin{tabular}{|c|c|c|c|}
\hline \multicolumn{2}{|c|}{$\begin{array}{l}\text { CONSUMO DE ENERGÍA } \\
\text { PRIMARIA NO RENOVABLE } \\
{\left[\mathrm{kWh} / \mathrm{m}^{2} \text { año] }\right.}\end{array}$} & \multicolumn{2}{|c|}{$\begin{array}{c}\text { EMISIONES DE DIÓXIDO DE } \\
\text { CARBONO } \\
{\left[\mathrm{kgCO} 2 / \mathrm{m}^{2} \text { año] }\right.} \\
\end{array}$} \\
\hline 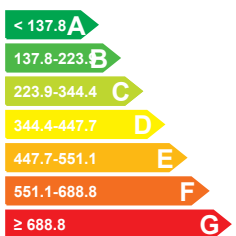 & $271.0 \mathrm{C}$ & 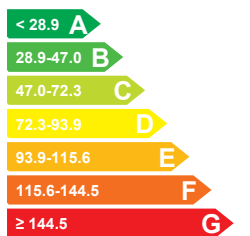 & $45.9 \mathrm{~B}$ \\
\hline
\end{tabular}

El técnico abajo firmante declara responsablemente que ha realizado la certificación energética del edificio o de la parte que se certifica de acuerdo con el procedimiento establecido por la normativa vigente y que son ciertos los datos que figuran en el presente documento, y sus anexos:

Fecha: $26 / 10 / 2015$

Firma del técnico certificador

Anexo I. Descripción de las características energéticas del edificio.

Anexo II. Calificación energética del edificio.

Anexo III. Recomendaciones para la mejora de la eficiencia energética.

Anexo IV. Pruebas, comprobaciones e inspecciones realizadas por el técnico certificador.

Registro del Órgano Territorial Competente: 


\section{DESCRIPCIÓN DE LAS CARACTERÍSTICAS ENERGÉTICAS DEL EDIFICIO}

En este apartado se describen las características energéticas del edificio, envolvente térmica, instalaciones, condiciones de funcionamiento y ocupación y demás datos utilizados para obtener la calificación energética del edificio.

\section{SUPERFICIE, IMAGEN Y SITUACIÓN}

\begin{tabular}{|l|l}
\hline Superficie habitable $\left[\mathrm{m}^{2}\right]$ & 52.0
\end{tabular}

\begin{tabular}{|c|c|c|}
\hline Imagen del edificio & Plano de situación \\
\hline & &
\end{tabular}

\section{ENVOLVENTE TÉRMICA}

\section{Cerramientos opacos}

\begin{tabular}{|l|c|c|c|c|}
\hline \multicolumn{1}{|c|}{ Nombre } & Tipo & $\begin{array}{c}\text { Superficie } \\
{\left[\mathrm{m}^{2}\right]}\end{array}$ & $\begin{array}{c}\text { Transmitancia } \\
{\left[\mathbf{W} / \mathbf{m}^{2} \cdot \mathrm{K}\right]}\end{array}$ & Modo de obtención \\
\hline Cubierta con aire & Cubierta & 52.0 & 0.47 & Conocidas \\
\hline Muro de fachada Norte & Fachada & 27.18 & 0.54 & Conocidas \\
\hline Muro de fachada Sur & Fachada & 21.88 & 0.54 & Conocidas \\
\hline Muro de fachada este & Fachada & 3.28 & 0.54 & Conocidas \\
\hline Muro de fachada oeste & Fachada & 8.04 & 0.54 & Conocidas \\
\hline Suelo con aire & Suelo & 52.0 & 2.95 & Conocidas \\
\hline
\end{tabular}

Huecos y lucernarios

\begin{tabular}{|l|c|c|c|c|c|c|}
\hline Nombre & Tipo & $\begin{array}{c}\text { Superficie } \\
{\left[\mathbf{m}^{2}\right]}\end{array}$ & $\begin{array}{c}\text { Transmitancia } \\
{\left[\mathbf{W} / \mathbf{m}^{2} \cdot \mathbf{K}\right]}\end{array}$ & $\begin{array}{c}\text { Factor } \\
\text { solar }\end{array}$ & $\begin{array}{c}\text { Modo de } \\
\text { obtención. } \\
\text { Transmitancia }\end{array}$ & $\begin{array}{c}\text { Modo de } \\
\text { obtención. } \\
\text { Factor solar }\end{array}$ \\
\hline V1 & Hueco & 5.3 & 5.70 & 0.67 & Estimado & Estimado \\
\hline V2 & Hueco & 5.3 & 5.70 & 0.16 & Estimado & Estimado \\
\hline V3 & Hueco & 5.3 & 5.70 & 0.67 & Estimado & Estimado \\
\hline V4 & Hueco & 5.3 & 5.70 & 0.67 & Estimado & Estimado \\
\hline V5 & Hueco & 5.03 & 5.70 & 0.16 & Estimado & Estimado \\
\hline Pta. & Hueco & 5.03 & 5.70 & 0.16 & Estimado & Estimado \\
\hline
\end{tabular}




\section{INSTALACIONES TÉRMICAS}

Generadores de calefacción

\begin{tabular}{|c|c|c|c|c|c|}
\hline Nombre & Tipo & $\begin{array}{c}\text { Potencia } \\
\text { nominal [kW] }\end{array}$ & $\begin{array}{l}\text { Rendimiento } \\
\text { Estacional[\%] }\end{array}$ & $\begin{array}{l}\text { Tipo de } \\
\text { Energía }\end{array}$ & $\begin{array}{c}\text { Modo de } \\
\text { obtención }\end{array}$ \\
\hline $\begin{array}{l}\text { Calefacción } \\
\text { refrigeración }\end{array}$ & $\begin{array}{l}\text { Bomba de Calor - } \\
\text { Caudal Ref. Variable }\end{array}$ & & 268.3 & Electricidad & Estimado \\
\hline TOTALES & Calefacción & & & & \\
\hline
\end{tabular}

Generadores de refrigeración

\begin{tabular}{|c|c|c|c|c|c|}
\hline Nombre & Tipo & $\begin{array}{c}\text { Potencia } \\
\text { nominal }[k W]\end{array}$ & $\begin{array}{c}\text { Rendimiento } \\
\text { Estacional[\%] }\end{array}$ & $\begin{array}{l}\text { Tipo de } \\
\text { Energía }\end{array}$ & $\begin{array}{c}\text { Modo de } \\
\text { obtención }\end{array}$ \\
\hline $\begin{array}{l}\text { Calefacción } \\
\text { refrigeración }\end{array}$ & $\begin{array}{l}\text { Bomba de Calor - } \\
\text { Caudal Ref. Variable }\end{array}$ & & 280.0 & Electricidad & Estimado \\
\hline TOTALES & Refrigeración & & & & \\
\hline
\end{tabular}

Instalaciones de Agua Caliente Sanitaria

Demanda diario de ACS a $60^{\circ}$ (litros/día) 3.0

\begin{tabular}{|c|c|c|c|c|c|}
\hline Nombre & Tipo & $\begin{array}{c}\text { Potencia } \\
\text { nominal [kW] }\end{array}$ & $\begin{array}{c}\text { Rendimiento } \\
\text { Estacional[\%] }\end{array}$ & $\begin{array}{c}\text { Tipo de } \\
\text { Energía }\end{array}$ & $\begin{array}{c}\text { Modo de } \\
\text { obtención }\end{array}$ \\
\hline Equipo ACS & Efecto Joule & & 100.0 & Electricidad & Estimado \\
\hline TOTALES & ACS & & & & \\
\hline
\end{tabular}

4. INSTALACIÓN DE ILUMINACIÓN (sólo edificios terciarios)

\begin{tabular}{|c|c|c|c|c|}
\hline Espacio & $\begin{array}{c}\text { Potencia instalada } \\
{\left[\mathrm{W} / \mathrm{m}^{2}\right]}\end{array}$ & VEEI [W/m².100lux] & $\begin{array}{c}\text { Iluminación media } \\
\text { [lux] }\end{array}$ & Modo de obtención \\
\hline Edificio Objeto & 12.33 & 2.56 & 500.00 & Estimado \\
\hline TOTALES & 12.33 & & & \\
\hline
\end{tabular}

\section{CONDICIONES DE FUNCIONAMIENTO Y OCUPACIÓN (sólo edificios terciarios)}

\begin{tabular}{|c|c|c|}
\hline Espacio & Superficie $\left[\mathrm{m}^{2}\right]$ & Perfil de uso \\
\hline Edificio & 52.0 & Intensidad Alta $-8 \mathrm{~h}$ \\
\hline
\end{tabular}




\section{ANEXO II
CALIFICACIÓN ENERGÉTICA DEL EDIFICIO}

\begin{tabular}{|l|l|l|l|}
\hline Zona climática & D3 & Uso & Intensidad Alta - 8h \\
\hline
\end{tabular}

\section{CALIFICACIÓN ENERGÉTICA DEL EDIFICIO EN EMISIONES}

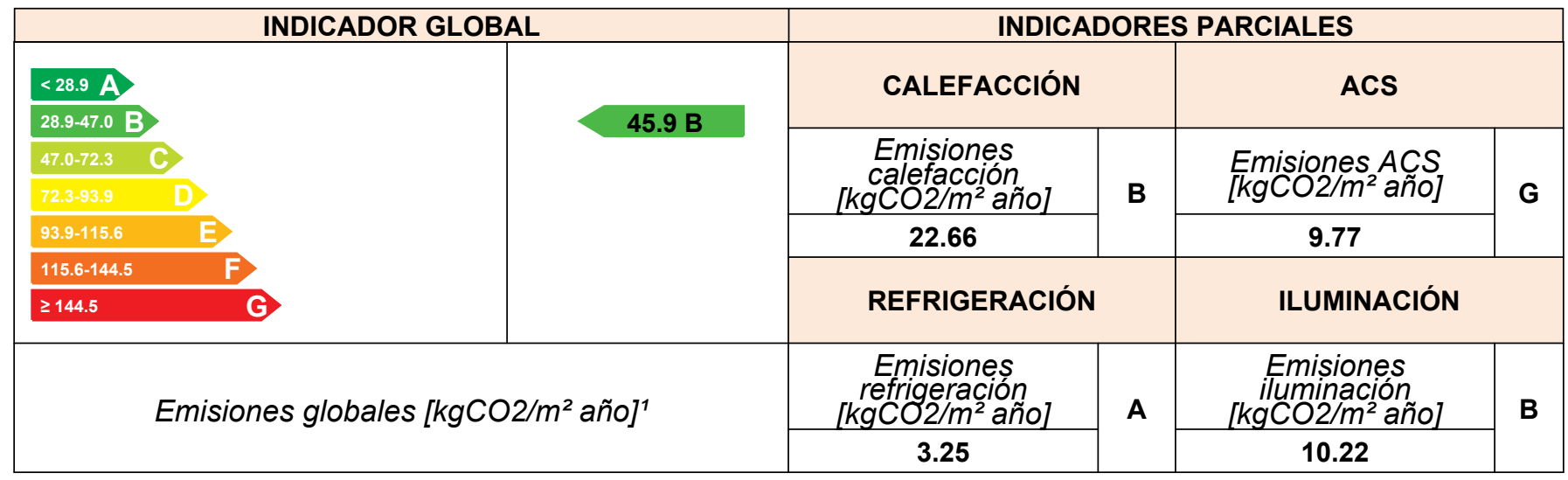

La calificación global del edificio se expresa en términos de dióxido de carbono liberado a la atmósfera como consecuencia del consumo energético del mismo.

\begin{tabular}{|l|c|c|}
\cline { 2 - 3 } \multicolumn{1}{c|}{} & $\mathbf{k g C O} 2 / \mathbf{m}^{\mathbf{2}}$ año & $\mathbf{~} \mathbf{k g C O 2 / a n ̃ o ~}$ \\
\hline Emisiones CO2 por consumo eléctrico & 45.90 & 2386.97 \\
\hline Emisiones CO2 por otros combustibles & 0.00 & 0.00 \\
\hline
\end{tabular}

\section{CALIFICACIÓN ENERGÉTICA DEL EDIFICIO EN CONSUMO DE ENERGÍA PRIMARIA NO RENOVABLE}

Por energía primaria no renovable se entiende la energía consumida por el edificio procedente de fuentes no renovables que no ha sufrido ningún proceso de conversión o transformación.

\begin{tabular}{|c|c|c|c|c|c|}
\hline \multicolumn{2}{|c|}{ INDICADOR GLOBAL } & \multicolumn{4}{|c|}{ INDICADORES PARCIALES } \\
\hline \multirow{4}{*}{ 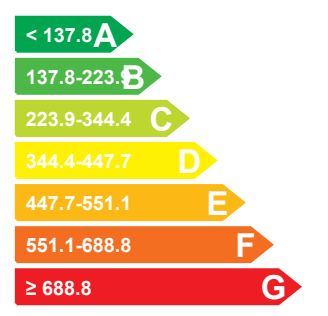 } & \multirow{4}{*}{$271.0 \mathrm{C}$} & \multicolumn{2}{|c|}{ CALEFACCIÓN } & \multicolumn{2}{|l|}{ ACS } \\
\hline & & $\begin{array}{l}\text { Energía primaria } \\
\text { calefacción } \\
{\left[\mathrm{kWh} / \mathrm{m}^{2} \text { añol }\right.}\end{array}$ & \multirow[t]{2}{*}{ C } & $\begin{array}{l}\text { Energía primaria } \\
A C S \\
{\left[\mathrm{kWh} / \mathrm{m}^{2} \text { añol }\right.}\end{array}$ & \multirow[t]{2}{*}{ G } \\
\hline & & 133.78 & & 57.68 & \\
\hline & & \multicolumn{2}{|c|}{ REFRIGERACIÓN } & \multicolumn{2}{|l|}{ ILUMINACIÓN } \\
\hline \multirow{2}{*}{\multicolumn{2}{|c|}{$\begin{array}{c}\text { Consumo global de energía primaria no renovable } \\
\qquad\left[\mathrm{kWh} / \mathrm{m}^{2} \text { año }\right]^{1}\end{array}$}} & $\begin{array}{l}\text { Energía primaria } \\
\text { refrigeración } \\
{\left[\mathrm{kWh} / \mathrm{m}^{2} \text { añol }\right.}\end{array}$ & \multirow[t]{2}{*}{ A } & $\begin{array}{l}\text { Energía primaria } \\
\text { iluminación } \\
{\left[\mathrm{kWh} / \mathrm{m}^{2} \mathrm{año} \mathrm{o}\right]}\end{array}$ & \multirow[t]{2}{*}{ B } \\
\hline & & 19.21 & & 60.32 & \\
\hline
\end{tabular}

\section{CALIFICACIÓN PARCIAL DE LA DEMANDA ENERGÉTICA DE CALEFACCIÓN Y REFRIGERACIÓN}

La demanda energética de calefacción y refrigeración es la energía necesaria para mantener las condiciones internas de confort del edificio.

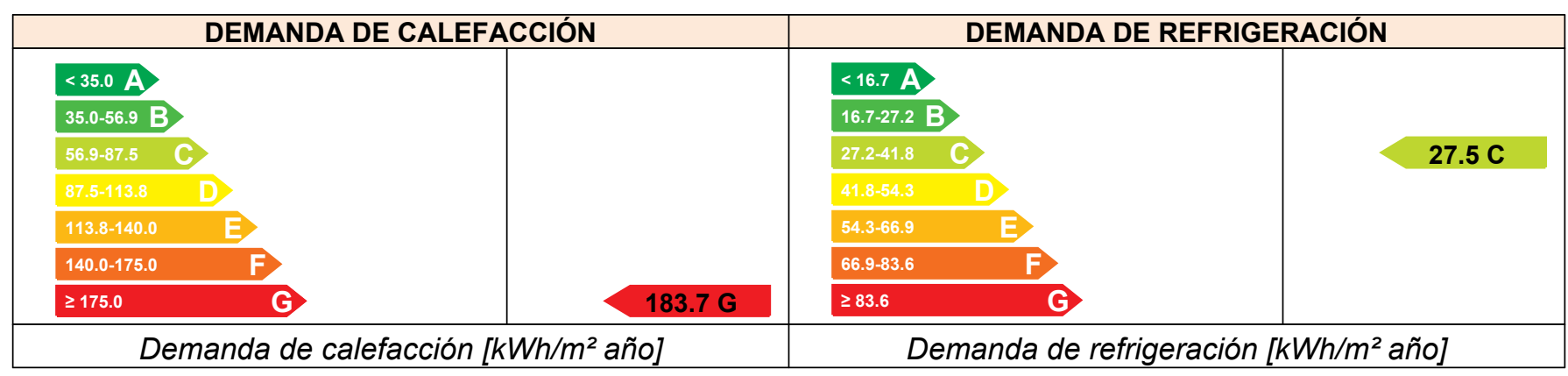

${ }^{1}$ El indicador global es resultado de la suma de los indicadores parciales más el valor del indicador para consumos auxiliares, si los hubiera (sólo ed. terciarios, ventilación, bombeo, etc...). La energía eléctrica autoconsumida se descuenta únicamente del indicador global, no así de los valores parciales 


\section{ANEXO III \\ RECOMENDACIONES PARA LA MEJORA DE LA EFICIENCIA ENERGÉTICA}

FV $100 \%$

CALIFICACIÓN ENERGÉTICA GLOBAL

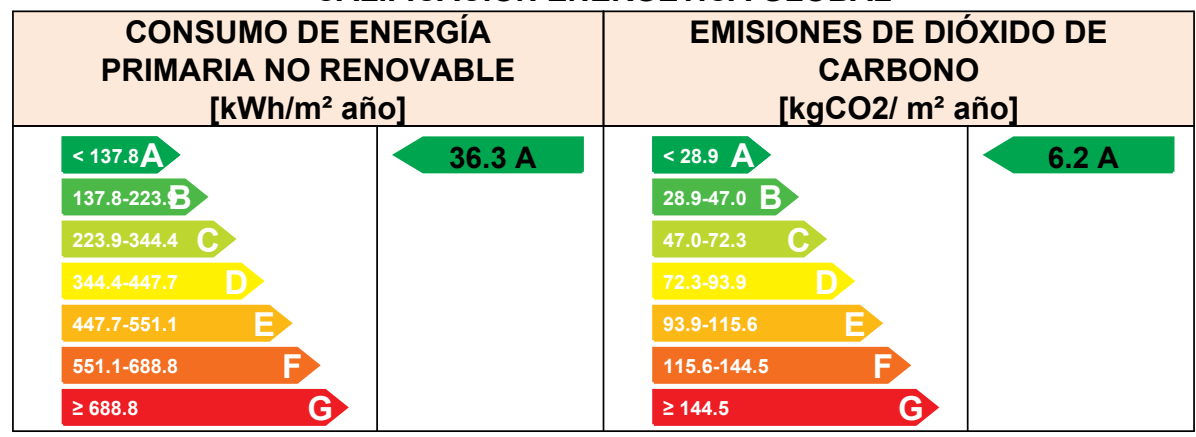

CALIFICACIONES ENERGÉTICAS PARCIALES

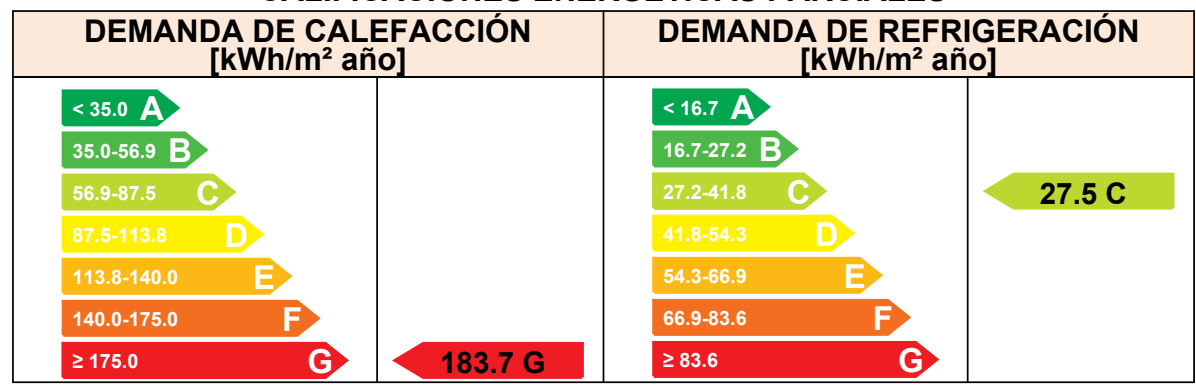

\section{ANÁLISIS TÉCNICO}

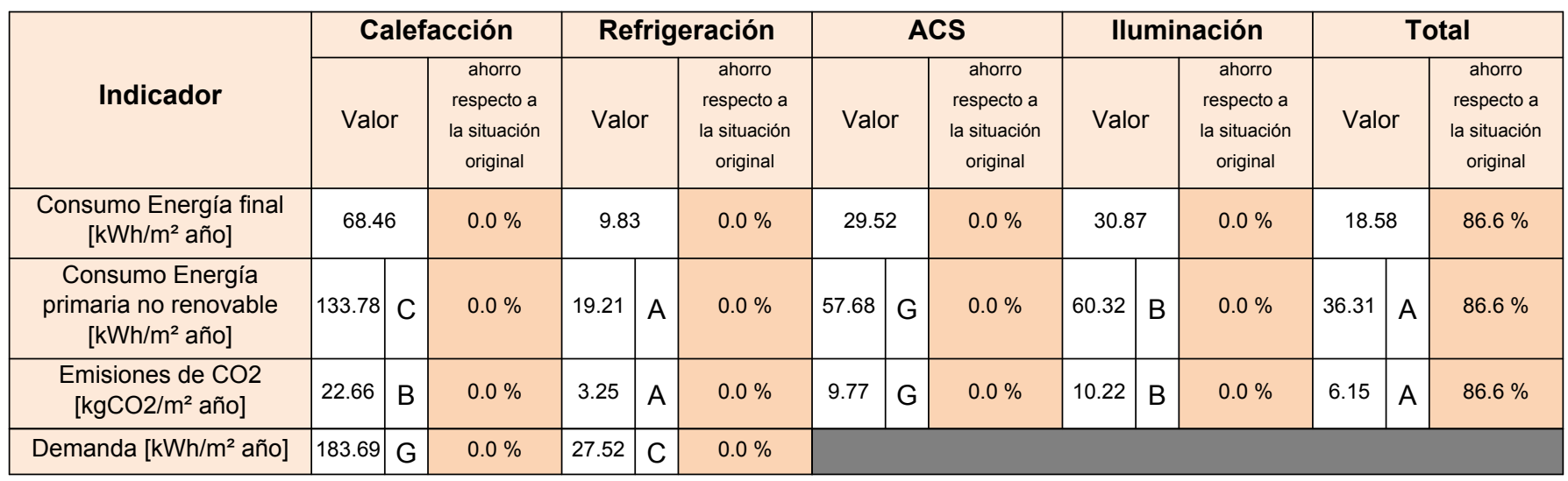

Nota: Los indicadores energéticos anteriores están calculados en base a coeficientes estándar de operación y funcionamiento del edificio, por lo que solo son válidos a efectos de su calificación energética. Para el análisis económico de las medidas de ahorro y eficiencia energética, el técnico certificador deberá utilizar las condiciones reales y datos históricos de consumo del edificio.

\section{DESCRIPCIÓN DE LA MEDIDA DE MEJORA}

Características de la medida (modelo de equipos, materiales, parámetros característicos )

Coste estimado de la medida

Otros datos de interés 


\section{ANEXO IV \\ PRUEBAS, COMPROBACJONES E INSPECCIONES REALIZADAS POR EL TECNICO CERTIFICADOR}

Se describen a continuación las pruebas, comprobaciones e inspecciones llevadas a cabo por el técnico certificador durante el proceso de toma de datos y de calificación de la eficiencia energética del edificio, con la finalidad de establecer la conformidad de la información de partida contenida en el certificado de eficiencia energética.

Fecha de realización de la visita del técnico certificador 
A.6.2

Zona Climática BWk, BWh, Aw, Am (Koppen) / a3 (CTE). Santa Cruz de Tenerife 


\section{CERTIFICADO DE EFICIENCIA ENERGÉTICA DE EDIFICIOS}

IDENTIFICACIÓN DEL EDIFICIO O DE LA PARTE QUE SE CERTIFICA:

\begin{tabular}{|l|l|l|l|}
\hline Nombre del edificio & \multicolumn{4}{l|}{ Vivienda Taller Modificado } \\
\hline Dirección & \multicolumn{3}{|l|}{ Tesis } \\
\hline Municipio & $\begin{array}{l}\text { Santa Cruz de } \\
\text { Tenerife }\end{array}$ & Código Postal & 38004 \\
\hline Provincia & $\begin{array}{l}\text { Santa Cruz de } \\
\text { Tenerife }\end{array}$ & Comunidad Autónoma & Canarias \\
\hline Zona climática & alpha3 & Año construcción & 2007 \\
\hline $\begin{array}{l}\text { Normativa vigente (construcción } \\
\text { rehabilitación) }\end{array}$ & \multicolumn{4}{l|}{} \\
\hline Referencia/s catastral/es & C.T.E. & \\
\hline
\end{tabular}

\begin{tabular}{|l|l|}
\hline \multicolumn{2}{|c|}{ Tipo de edificio o parte del edificio que se certifica: } \\
\hline$\circ$ Edificio de nueva construcción & $\bullet$ Edificio Existente \\
\hline \multicolumn{2}{|c|}{} \\
\hline \begin{tabular}{l|l} 
Vivienda \\
Unifamiliar
\end{tabular} & $\circ$ Terciario \\
$\begin{array}{l}\text { Bloque } \\
\text { Bloque completo } \\
\circ \text { Vivienda individual }\end{array}$ & $\circ$ Local \\
\hline
\end{tabular}

DATOS DEL TÉCNICO CERTIFICADOR:

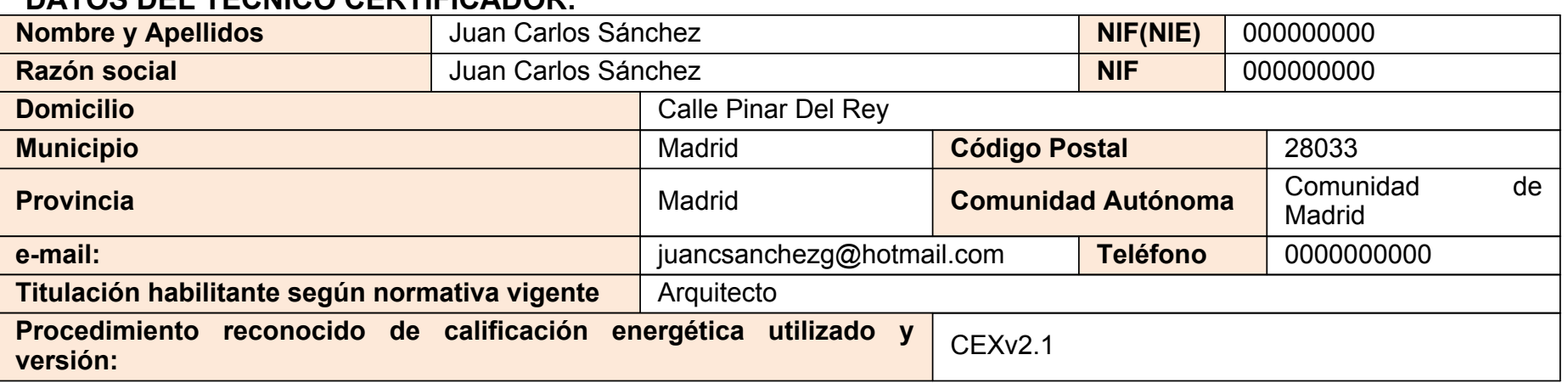

CALIFICACIÓN ENERGÉTICA OBTENIDA:

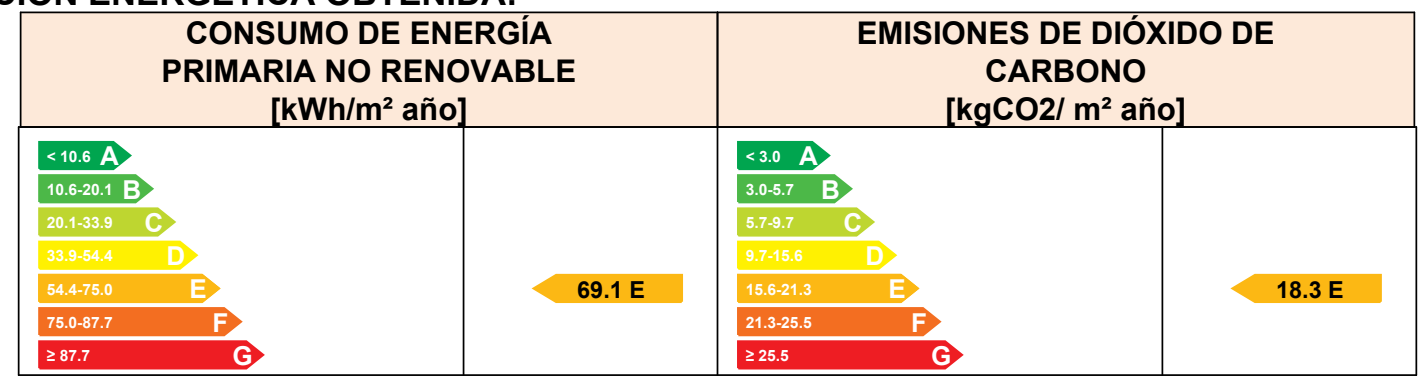

El técnico abajo firmante declara responsablemente que ha realizado la certificación energética del edificio o de la parte que se certifica de acuerdo con el procedimiento establecido por la normativa vigente y que son ciertos los datos que figuran en el presente documento, y sus anexos:

Fecha: 01/12/2015

Firma del técnico certificador

Anexo I. Descripción de las características energéticas del edificio.

Anexo II. Calificación energética del edificio.

Anexo III. Recomendaciones para la mejora de la eficiencia energética.

Anexo IV. Pruebas, comprobaciones e inspecciones realizadas por el técnico certificador.

Registro del Órgano Territorial Competente: 


\section{DESCRIPCIÓN DE LAS CARACTERÍSTICAS ENERGÉTICAS DEL EDIFICIO}

En este apartado se describen las características energéticas del edificio, envolvente térmica, instalaciones, condiciones de funcionamiento y ocupación y demás datos utilizados para obtener la calificación energética del edificio.

\section{SUPERFICIE, IMAGEN Y SITUACIÓN}

\begin{tabular}{|l|l}
\hline Superficie habitable $\left[\mathrm{m}^{2}\right]$ & 52.0
\end{tabular}

\begin{tabular}{|c|c|c|}
\hline Imagen del edificio & Plano de situación \\
\hline & &
\end{tabular}

\section{ENVOLVENTE TÉRMICA}

\section{Cerramientos opacos}

\begin{tabular}{|l|c|c|c|c|}
\hline \multicolumn{1}{|c|}{ Nombre } & Tipo & $\begin{array}{c}\text { Superficie } \\
{\left[\mathrm{m}^{2}\right]}\end{array}$ & $\begin{array}{c}\text { Transmitancia } \\
{\left[\mathbf{W} / \mathbf{m}^{2} \cdot \mathrm{K}\right]}\end{array}$ & Modo de obtención \\
\hline Cubierta con aire & Cubierta & 52.0 & 0.47 & Conocidas \\
\hline Muro de fachada Norte & Fachada & 27.18 & 0.54 & Conocidas \\
\hline Suelo con aire & Suelo & 52.0 & 2.95 & Conocidas \\
\hline Muro de fachada Sur & Fachada & 21.88 & 0.54 & Conocidas \\
\hline Muro de fachada Oeste & Fachada & 8.04 & 0.54 & Conocidas \\
\hline Muro de fachada Este & Fachada & 3.28 & 0.54 & Conocidas \\
\hline
\end{tabular}

Huecos y lucernarios

\begin{tabular}{|l|c|c|c|c|c|c|}
\hline Nombre & Tipo & $\begin{array}{c}\text { Superficie } \\
{\left[\mathbf{m}^{2}\right]}\end{array}$ & $\begin{array}{c}\text { Transmitancia } \\
{\left[\mathbf{W} / \mathbf{m}^{2} \cdot \mathbf{K}\right]}\end{array}$ & $\begin{array}{c}\text { Factor } \\
\text { solar }\end{array}$ & $\begin{array}{c}\text { Modo de } \\
\text { obtención. } \\
\text { Transmitancia }\end{array}$ & $\begin{array}{c}\text { Modo de } \\
\text { obtención. } \\
\text { Factor solar }\end{array}$ \\
\hline V1 & Hueco & 5.3 & 5.70 & 0.67 & Estimado & Estimado \\
\hline V3 & Hueco & 5.3 & 5.70 & 0.67 & Estimado & Estimado \\
\hline V4 & Hueco & 5.3 & 5.70 & 0.67 & Estimado & Estimado \\
\hline V2 & Hueco & 5.3 & 5.70 & 0.67 & Estimado & Estimado \\
\hline V5 & Hueco & 5.03 & 5.70 & 0.67 & Estimado & Estimado \\
\hline Pta & Hueco & 5.03 & 5.70 & 0.67 & Estimado & Estimado \\
\hline
\end{tabular}




\section{INSTALACIONES TÉRMICAS}

Generadores de calefacción

\begin{tabular}{|c|c|c|c|c|c|}
\hline Nombre & Tipo & $\begin{array}{c}\text { Potencia } \\
\text { nominal [kW] }\end{array}$ & $\begin{array}{c}\text { Rendimiento } \\
\text { Estacional[\%] }\end{array}$ & $\begin{array}{c}\text { Tipo de } \\
\text { Energía }\end{array}$ & $\begin{array}{c}\text { Modo de } \\
\text { obtención }\end{array}$ \\
\hline Sólo calefacción & $\begin{array}{c}\text { Bomba de Calor }- \\
\text { Caudal Ref. Variable }\end{array}$ & & 361.0 & $\begin{array}{l}\text { Biomasa } \\
\text { densificada } \\
\text { (pelets) }\end{array}$ & Conocido \\
\hline TOTALES & Calefacción & & & \\
\hline
\end{tabular}

\section{Generadores de refrigeración}

\begin{tabular}{|c|c|c|c|c|c|}
\hline Nombre & Tipo & $\begin{array}{c}\text { Potencia } \\
\text { nominal [kW] }\end{array}$ & $\begin{array}{c}\text { Rendimiento } \\
\text { Estacional[\%] }\end{array}$ & $\begin{array}{c}\text { Tipo de } \\
\text { Energía }\end{array}$ & $\begin{array}{c}\text { Modo de } \\
\text { obtención }\end{array}$ \\
\hline Sólo refrigeración & $\begin{array}{c}\text { Máquina frigorífica } \\
\text { Caudal Ref. Variable }\end{array}$ & & 361.0 & Electricidad & Conocido \\
\hline TOTALES & Refrigeración & & & & \\
\hline
\end{tabular}

Instalaciones de Agua Caliente Sanitaria

Demanda diario de ACS a $60^{\circ}$ (litros/día) 45.55

\begin{tabular}{|c|c|c|c|c|c|}
\hline Nombre & Tipo & $\begin{array}{c}\text { Potencia } \\
\text { nominal [kW] }\end{array}$ & $\begin{array}{c}\text { Rendimiento } \\
\text { Estacional[\%] }\end{array}$ & $\begin{array}{c}\text { Tipo de } \\
\text { Energía }\end{array}$ & $\begin{array}{c}\text { Modo de } \\
\text { obtención }\end{array}$ \\
\hline Equipo ACS & Efecto Joule & & 100.0 & Electricidad & Estimado \\
\hline TOTALES & ACS & & & & \\
\hline
\end{tabular}

\section{ENERGÍAS RENOVABLES}

\section{Térmica}

\begin{tabular}{|c|c|c|c|c|}
\hline \multirow{2}{*}{ Nombre } & \multicolumn{2}{|c|}{$\begin{array}{c}\text { Consumo de Energía Final, cubierto en función del servicio } \\
\text { asociado [\%] }\end{array}$} & $\begin{array}{c}\text { Demanda de } \\
\text { ACS cubierta } \\
\text { [\%] }\end{array}$ \\
\cline { 2 - 5 } & Calefacción & Refrigeración & ACS & \\
\hline Contribuciones energéticas & 100.0 & - & - & - \\
\hline TOTAL & 100.0 & - & - & - \\
\hline
\end{tabular}




\section{ANEXO II
CALIFICACIÓN ENERGÉTICA DEL EDIFICIO}

\begin{tabular}{|l|l|l|l|}
\hline Zona climática & alpha3 & Uso & Residencial \\
\hline
\end{tabular}

\section{CALIFICACIÓN ENERGÉTICA DEL EDIFICIO EN EMISIONES}

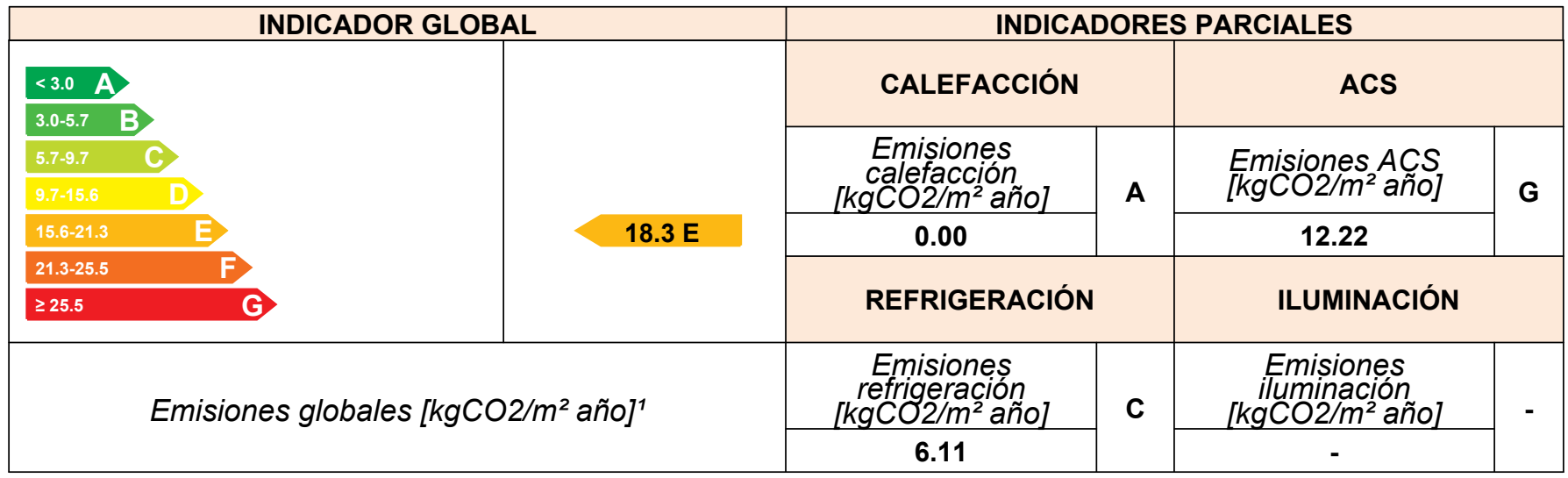

La calificación global del edificio se expresa en términos de dióxido de carbono liberado a la atmósfera como consecuencia del consumo energético del mismo.

\begin{tabular}{|l|c|c|}
\cline { 2 - 3 } \multicolumn{1}{c|}{} & $\mathbf{k g C O} 2 / \mathbf{m}^{\mathbf{2}}$ año & $\mathbf{~} \mathbf{k g C O 2 / a n ̃ o ~}$ \\
\hline Emisiones CO2 por consumo eléctrico & 18.33 & 953.25 \\
\hline Emisiones CO2 por otros combustibles & 0.00 & 0.00 \\
\hline
\end{tabular}

\section{CALIFICACIÓN ENERGÉTICA DEL EDIFICIO EN CONSUMO DE ENERGÍA PRIMARIA NO RENOVABLE}

Por energía primaria no renovable se entiende la energía consumida por el edificio procedente de fuentes no renovables que no ha sufrido ningún proceso de conversión o transformación.

\begin{tabular}{|c|c|c|c|c|c|}
\hline \multicolumn{2}{|c|}{ INDICADOR GLOBAL } & \multicolumn{4}{|c|}{ INDICADORES PARCIALES } \\
\hline \multirow{4}{*}{ 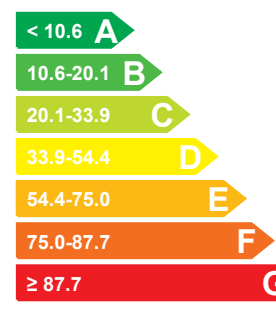 } & & \multicolumn{2}{|c|}{ CALEFACCIÓN } & \multicolumn{2}{|l|}{ ACS } \\
\hline & & $\begin{array}{l}\text { Energía primaria } \\
\text { calefacción } \\
{\left[\mathrm{kWh} / \mathrm{m}^{2} \text { año] }\right.}\end{array}$ & \multirow[t]{2}{*}{ A } & $\begin{array}{l}\text { Energía primaria } \\
A C S \\
{\left[\mathrm{kWh} / \mathrm{m}^{2} \text { año] }\right.}\end{array}$ & \multirow[t]{2}{*}{ G } \\
\hline & \multirow[t]{2}{*}{$69.1 \mathrm{E}$} & 0.00 & & 46.04 & \\
\hline & & \multicolumn{2}{|c|}{ REFRIGERACIÓN } & \multicolumn{2}{|l|}{ ILUMINACIÓN } \\
\hline \multirow{2}{*}{\multicolumn{2}{|c|}{$\begin{array}{l}\text { Consumo global de energía primaria no renovable } \\
\qquad\left[\mathrm{kWh} / \mathrm{m}^{2} \text { año }\right]^{1}\end{array}$}} & $\begin{array}{l}\text { Energía primaria } \\
\text { refrigeración } \\
{\left[\mathrm{kWh} / \mathrm{m}^{2} \text { añol }\right.}\end{array}$ & \multirow[t]{2}{*}{ C } & $\begin{array}{l}\text { Energía primaria } \\
\text { iluminación } \\
{\left[\mathrm{kWh} / \mathrm{m}^{2} a \tilde{n} o\right]}\end{array}$ & \\
\hline & & 23.04 & & - & \\
\hline
\end{tabular}

\section{CALIFICACIÓN PARCIAL DE LA DEMANDA ENERGÉTICA DE CALEFACCIÓN Y REFRIGERACIÓN}

La demanda energética de calefacción y refrigeración es la energía necesaria para mantener las condiciones internas de confort del edificio.

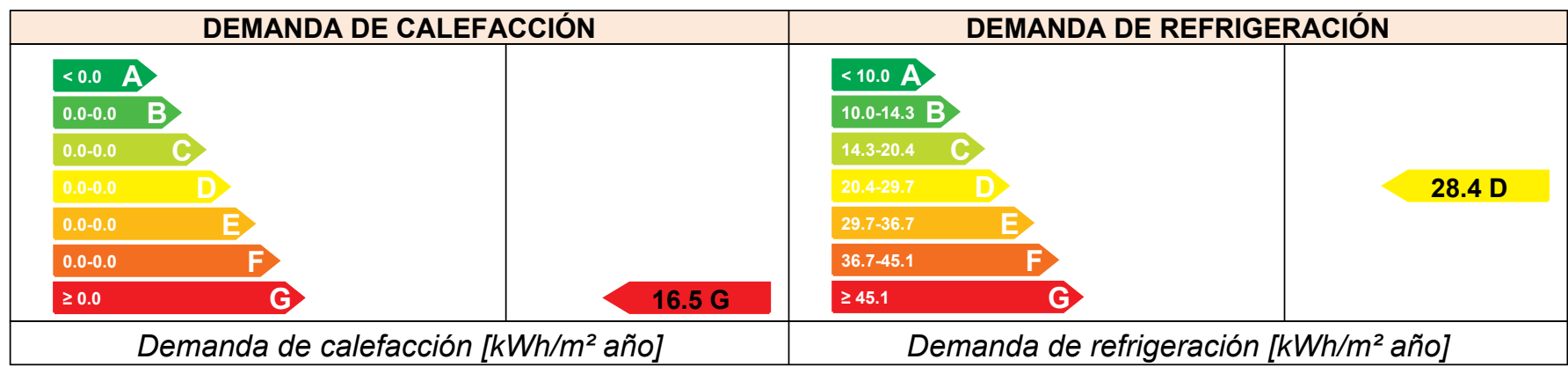

${ }^{1}$ El indicador global es resultado de la suma de los indicadores parciales más el valor del indicador para consumos auxiliares, si los hubiera (sólo ed. terciarios, ventilación, bombeo, etc...). La energía eléctrica autoconsumida se descuenta únicamente del indicador global, no así de los valores parciales 


\section{ANEXO III \\ RECOMENDACIONES PARA LA MEJORA DE LA EFICIENCIA ENERGÉTICA}

FV $100 \%$

CALIFICACIÓN ENERGÉTICA GLOBAL

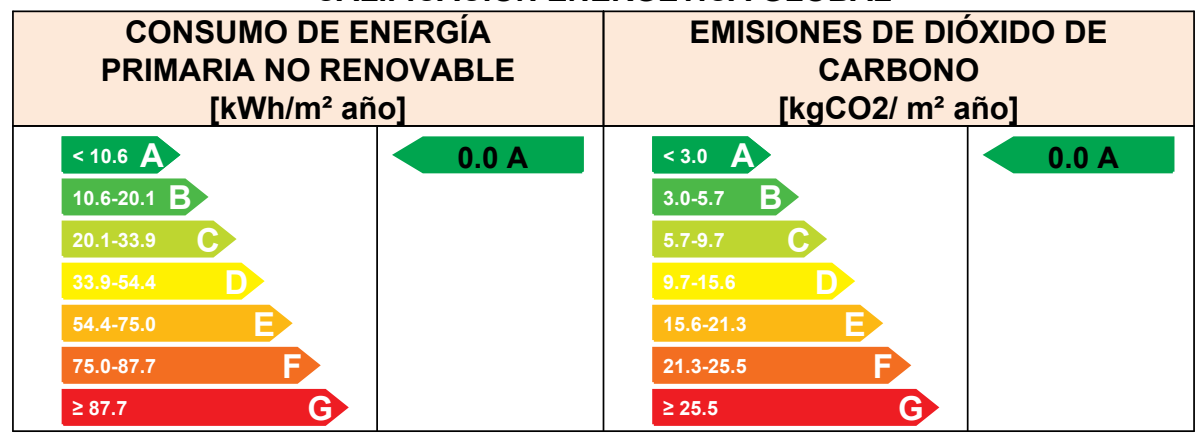

CALIFICACIONES ENERGÉTICAS PARCIALES

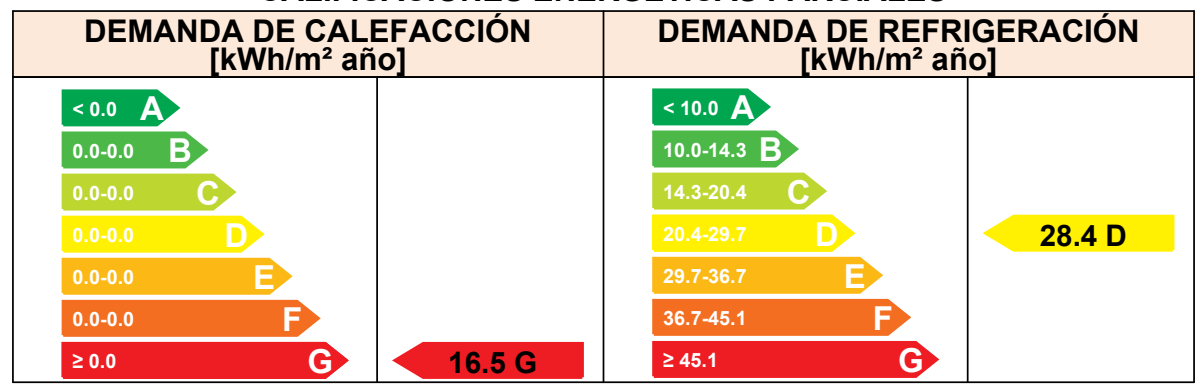

\section{ANÁLISIS TÉCNICO}

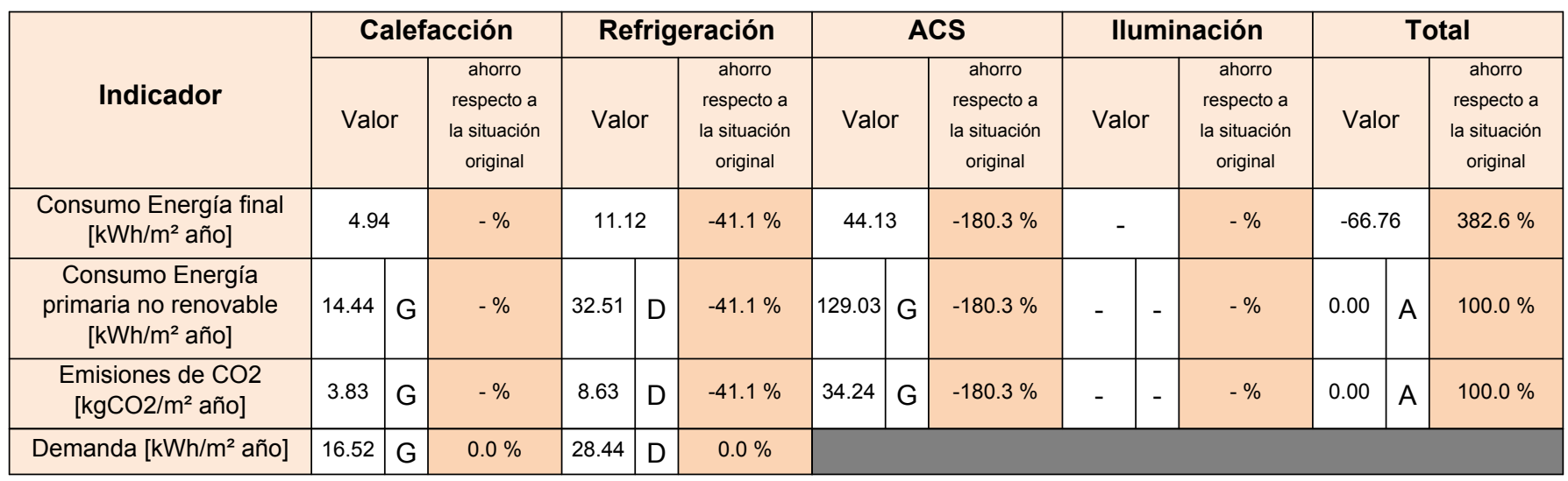

Nota: Los indicadores energéticos anteriores están calculados en base a coeficientes estándar de operación y funcionamiento del edificio, por lo que solo son válidos a efectos de su calificación energética. Para el análisis económico de las medidas de ahorro y eficiencia energética, el técnico certificador deberá utilizar las condiciones reales y datos históricos de consumo del edificio.

\section{DESCRIPCIÓN DE LA MEDIDA DE MEJORA}

Características de la medida (modelo de equipos, materiales, parámetros característicos )

Coste estimado de la medida

Otros datos de interés 


\section{ANEXO IV \\ PRUEBAS, COMPROBACJONES E INSPECCIONES REALIZADAS POR EL TECNICO CERTIFICADOR}

Se describen a continuación las pruebas, comprobaciones e inspecciones llevadas a cabo por el técnico certificador durante el proceso de toma de datos y de calificación de la eficiencia energética del edificio, con la finalidad de establecer la conformidad de la información de partida contenida en el certificado de eficiencia energética.

Fecha de realización de la visita del técnico certificador 


\begin{tabular}{|c|c|c|c|c|c|}
\hline & DEN & $\begin{array}{c}\text { Ref. } \\
\text { Catastral }\end{array}$ & 000000000 & $\begin{array}{c}\text { Versión } \\
\text { informe } \\
\text { asociado }\end{array}$ & $01 / 12 / 2015$ \\
\hline $\begin{array}{c}\text { Certificación } \\
\text { Energetica } \\
\text { de Edificios }\end{array}$ & $\begin{array}{c}\text { Id. } \\
\text { Mejora }\end{array}$ & $\begin{array}{l}\text { Programa } \\
\text { y versión }\end{array}$ & CEXv2.1 & Fecha & $2 / 1 / 2004$ \\
\hline
\end{tabular}

\section{Informe descriptivo de la medida de mejora}

\section{DENOMINACIÓN DE LA MEDIDA DE MEJORA}

FV $100 \%$

\section{DESCRIPCIÓN DE LA MEDIDA DE MEJORA}

Características de la medida (modelo de equipos, materiales, parámetros característicos )

Coste estimado de la medida

Otros datos de interés

CALIFICACIÓN ENERGÉTICA GLOBAL

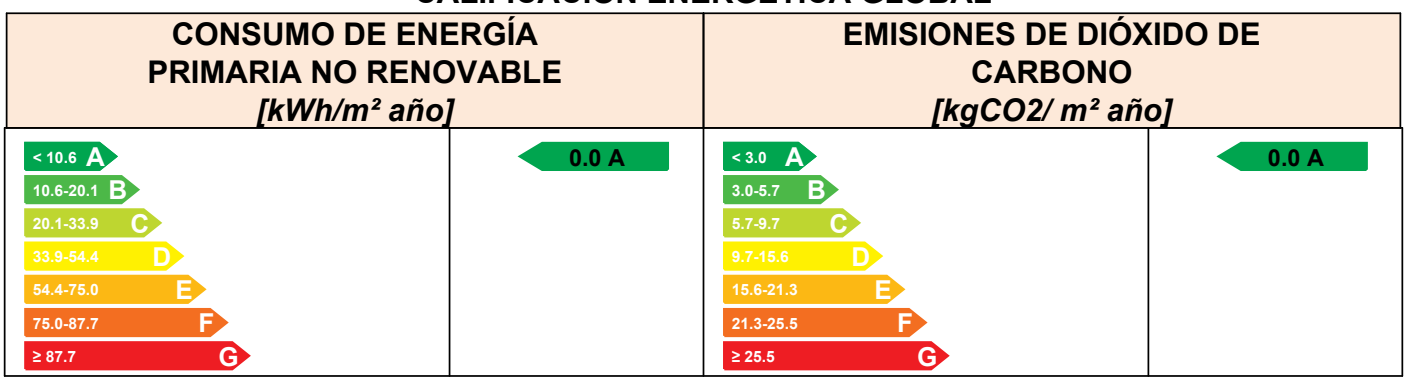

CALIFICACIONES ENERGÉTICAS PARCIALES

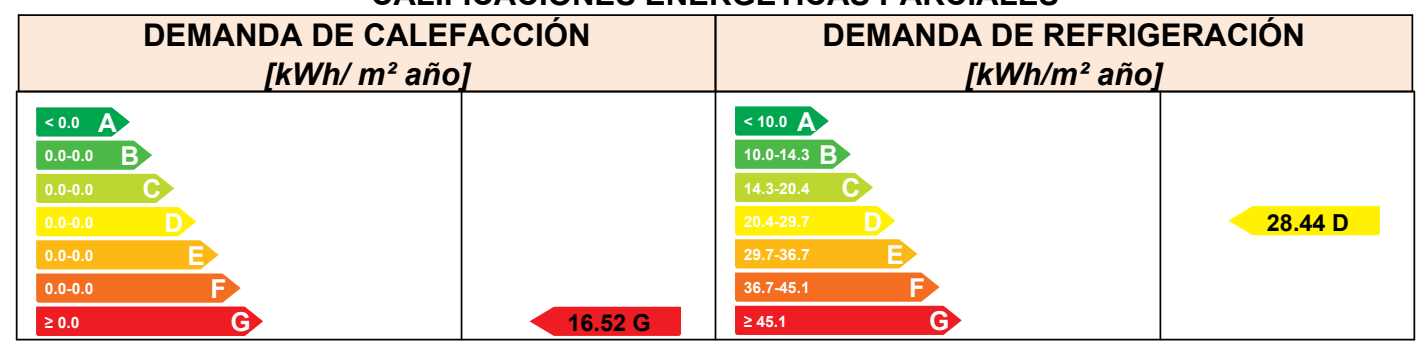




\begin{tabular}{|c|c|c|c|c|c|}
\hline & & $\begin{array}{c}\text { Ref. } \\
\text { Catastral }\end{array}$ & 000000000 & $\begin{array}{c}\text { Versión } \\
\text { informe } \\
\text { asociado }\end{array}$ & $01 / 12 / 2015$ \\
\hline $\begin{array}{l}\text { Certificación } \\
\text { Energética } \\
\text { de Edificios }\end{array}$ & $\begin{array}{c}\text { Id. } \\
\text { Mejora }\end{array}$ & $\begin{array}{l}\text { Programa } \\
\text { y versión }\end{array}$ & CEXv2.1 & Fecha & $2 / 1 / 2004$ \\
\hline
\end{tabular}

\section{ANALISÍS TÉCNICO}

\begin{tabular}{|c|c|c|c|c|c|c|c|c|c|c|c|c|c|c|c|}
\hline \multirow[b]{2}{*}{ Indicador } & \multicolumn{3}{|c|}{ Calefacción } & \multicolumn{3}{|c|}{ Refrigeración } & \multicolumn{3}{|c|}{ ACS } & \multicolumn{3}{|c|}{ Iluminación } & \multicolumn{3}{|c|}{ Total } \\
\hline & \multicolumn{2}{|c|}{ Valor } & $\begin{array}{c}\text { ahorro } \\
\text { respecto a } \\
\text { la situación } \\
\text { original }\end{array}$ & \multicolumn{2}{|c|}{ Valor } & $\begin{array}{c}\text { ahorro } \\
\text { respecto a } \\
\text { la situación } \\
\text { original }\end{array}$ & \multicolumn{2}{|c|}{ Valor } & $\begin{array}{c}\text { ahorro } \\
\text { respecto a } \\
\text { la situación } \\
\text { original }\end{array}$ & \multicolumn{2}{|c|}{ Valor } & $\begin{array}{c}\text { ahorro } \\
\text { respecto a } \\
\text { la situación } \\
\text { original }\end{array}$ & \multicolumn{2}{|c|}{ Valor } & $\begin{array}{c}\text { ahorro } \\
\text { respecto a } \\
\text { la situación } \\
\text { original }\end{array}$ \\
\hline $\begin{array}{l}\text { Consumo Energía } \\
\text { final }\left[\mathrm{kWh} / \mathrm{m}^{2} \text { año] }\right.\end{array}$ & \multicolumn{2}{|c|}{4.94} & $-\%$ & \multicolumn{2}{|c|}{11.12} & $-41.1 \%$ & \multicolumn{2}{|c|}{44.13} & $-180.3 \%$ & \multicolumn{2}{|l|}{-} & $-\%$ & \multicolumn{2}{|c|}{-66.76} & $382.6 \%$ \\
\hline $\begin{array}{c}\text { Consumo Energía } \\
\text { primaria no renovable } \\
{\left[\mathrm{kWh} / \mathrm{m}^{2} \text { año] }\right.}\end{array}$ & 14.44 & G & $-\%$ & 32.51 & D & $-41.1 \%$ & 129.03 & G & $-180.3 \%$ & - & - & $-\%$ & 0.00 & A & $100.0 \%$ \\
\hline $\begin{array}{c}\text { Emisiones de CO2 } \\
{\left[\mathrm{kgCO} 2 / \mathrm{m}^{2} \text { año] }\right.}\end{array}$ & 3.83 & G & $-\%$ & 8.63 & D & $-41.1 \%$ & 34.24 & G & $-180.3 \%$ & - & - & $-\%$ & 0.00 & A & $100.0 \%$ \\
\hline $\begin{array}{c}\text { Demanda }\left[\mathrm{kWh} / \mathrm{m}^{2}\right. \\
\text { año] }\end{array}$ & 16.52 & G & $0.0 \%$ & 28.44 & D & $0.0 \%$ & & & & & & & & & \\
\hline
\end{tabular}

\section{ENVOLVENTE TÉRMICA}

\section{Cerramientos opacos}

\begin{tabular}{|c|c|c|c|c|c|}
\hline Nombre & Tipo & $\begin{array}{c}\text { Superficie } \\
\text { actual } \\
{\left[\mathbf{m}^{2}\right]}\end{array}$ & $\begin{array}{c}\text { Transmitancia } \\
\text { actual } \\
{\left[\mathbf{W} / \mathbf{m}^{\mathbf{2}} \mathbf{~ K}\right]}\end{array}$ & $\begin{array}{c}\text { Superficie } \\
\text { post } \\
\text { mejora } \\
{\left[\mathbf{m}^{2}\right]}\end{array}$ & $\begin{array}{c}\text { Transmitancia } \\
\text { post mejora } \\
{\left[\mathbf{W} / \mathbf{m}^{\mathbf{2}} \mathbf{K}\right]}\end{array}$ \\
\hline Cubierta con aire & Cubierta & 52.00 & 0.47 & 52.00 & 0.47 \\
\hline Muro de fachada Norte & Fachada & 27.18 & 0.54 & 27.18 & 0.54 \\
\hline Suelo con aire & Suelo & 52.00 & 2.95 & 52.00 & 2.95 \\
\hline Muro de fachada Sur & Fachada & 21.88 & 0.54 & 21.88 & 0.54 \\
\hline Muro de fachada Oeste & Fachada & 8.04 & 0.54 & 8.04 & 0.54 \\
\hline Muro de fachada Este & Fachada & 3.28 & 0.54 & 3.28 & 0.54 \\
\hline
\end{tabular}

Huecos y lucernarios

\begin{tabular}{|c|c|c|c|c|c|c|c|}
\hline Nombre & Tipo & $\begin{array}{c}\text { Superficie } \\
\text { actual } \\
{\left[\mathrm{m}^{2}\right]}\end{array}$ & $\begin{array}{c}\text { Transmitancia } \\
\text { actual del } \\
\text { hueco[W/m² } \\
\mathrm{K}]\end{array}$ & $\begin{array}{c}\text { Transmitancia } \\
\text { actual del } \\
\text { vidrio[W/m² } \\
\mathrm{K}]\end{array}$ & $\begin{array}{l}\text { Superficie } \\
\text { post } \\
\text { mejora } \\
{\left[\mathrm{m}^{2}\right]}\end{array}$ & $\begin{array}{c}\text { Transmitancia } \\
\text { post mejora } \\
{\left[\mathrm{W} / \mathrm{m}^{2} \mathrm{~K}\right]}\end{array}$ & $\begin{array}{c}\text { Transmitancia } \\
\text { post mejora } \\
\text { del vidrio } \\
{\left[\mathrm{W} / \mathrm{m}^{2} \mathrm{~K}\right]}\end{array}$ \\
\hline V1 & Hueco & 5.3 & 5.70 & 5.70 & 5.3 & 5.70 & 5.70 \\
\hline V3 & Hueco & 5.3 & 5.70 & 5.70 & 5.3 & 5.70 & 5.70 \\
\hline V4 & Hueco & 5.3 & 5.70 & 5.70 & 5.3 & 5.70 & 5.70 \\
\hline V2 & Hueco & 5.3 & 5.70 & 5.70 & 5.3 & 5.70 & 5.70 \\
\hline V5 & Hueco & 5.03 & 5.70 & 5.70 & 5.03 & 5.70 & 5.70 \\
\hline Pta & Hueco & 5.03 & 5.70 & 5.70 & 5.03 & 5.70 & 5.70 \\
\hline
\end{tabular}




\begin{tabular}{|c|c|c|c|c|c|}
\hline & & $\begin{array}{c}\text { Ref. } \\
\text { Catastral }\end{array}$ & 000000000 & $\begin{array}{c}\text { Versión } \\
\text { informe } \\
\text { asociado }\end{array}$ & $01 / 12 / 2015$ \\
\hline $\begin{array}{l}\text { Certificación } \\
\text { Energética } \\
\text { de Edificios }\end{array}$ & $\begin{array}{c}\text { Id. } \\
\text { Mejora }\end{array}$ & $\begin{array}{l}\text { Programa } \\
\text { y versión }\end{array}$ & CEXv2.1 & Fecha & $2 / 1 / 2004$ \\
\hline
\end{tabular}

\section{INSTALACIONES TÉRMICAS}

\section{Generadores de calefacción}

\begin{tabular}{|c|c|c|c|c|c|c|c|c|c|}
\hline \multirow[t]{2}{*}{ Nombre } & \multirow[t]{2}{*}{ Tipo } & $\begin{array}{c}\text { Potencia } \\
\text { nominal }\end{array}$ & $\begin{array}{l}\text { Rendi- } \\
\text { miento } \\
\text { Estacional }\end{array}$ & $\begin{array}{c}\text { Estimación } \\
\text { Energía } \\
\text { Consumida } \\
\text { anual }\end{array}$ & \multirow[t]{2}{*}{$\begin{array}{l}\text { Tipo post } \\
\text { mejora }\end{array}$} & $\begin{array}{c}\text { Potencia } \\
\text { nominal } \\
\text { post } \\
\text { mejora }\end{array}$ & $\begin{array}{c}\text { Rendimiento } \\
\text { estacional } \\
\text { post mejora }\end{array}$ & $\begin{array}{l}\text { Estimación } \\
\text { Energía } \\
\text { Consumida } \\
\text { anual Post } \\
\text { mejora }\end{array}$ & $\begin{array}{l}\text { Energía } \\
\text { anual } \\
\text { ahorrada }\end{array}$ \\
\hline & & {$[\mathrm{kW}]$} & [\%] & [kWh/mªño] & & {$[\mathbf{k W}]$} & [\%] & [kWh/m²año] & {$\left[\mathrm{kWh} / \mathrm{m}^{2} \mathbf{a n ̃ o}\right]$} \\
\hline Sólo calefacción & $\begin{array}{c}\text { Bomba de } \\
\text { Calor - } \\
\text { Caudal Ref. } \\
\text { Variable }\end{array}$ & & $361.0 \%$ & - & - & - & - & - & - \\
\hline $\begin{array}{l}\text { Calefacción y } \\
\text { refrigeración }\end{array}$ & - & - & - & - & $\begin{array}{c}\text { Bomba de } \\
\text { Calor - } \\
\text { Caudal Ref. } \\
\text { Variable }\end{array}$ & & $334.4 \%$ & - & - \\
\hline TOTALES & & & & & & & & & \\
\hline
\end{tabular}

\section{Generadores de refrigeración}

\begin{tabular}{|c|c|c|c|c|c|c|c|c|c|}
\hline \multirow[t]{2}{*}{ Nombre } & \multirow[t]{2}{*}{ Tipo } & $\begin{array}{l}\text { Potencia } \\
\text { nominal }\end{array}$ & $\begin{array}{l}\text { Rendi- } \\
\text { miento } \\
\text { Estacional }\end{array}$ & $\begin{array}{c}\text { Estimación } \\
\text { Energía } \\
\text { Consumida } \\
\text { anual }\end{array}$ & \multirow[t]{2}{*}{$\begin{array}{c}\text { Tipo post } \\
\text { mejora }\end{array}$} & $\begin{array}{c}\text { Potencia } \\
\text { nominal } \\
\text { post } \\
\text { mejora }\end{array}$ & $\begin{array}{c}\text { Rendimiento } \\
\text { estacional } \\
\text { post mejora }\end{array}$ & $\begin{array}{c}\text { Estimación } \\
\text { Energía } \\
\text { Consumida } \\
\text { anual Post } \\
\text { mejora }\end{array}$ & $\begin{array}{c}\text { Energía } \\
\text { anual } \\
\text { ahorrada }\end{array}$ \\
\hline & & {$[\mathrm{kW}]$} & [\%] & {$\left[\mathrm{kWh} / \mathrm{m}^{2} \mathrm{año}\right]$} & & {$[\mathrm{kW}]$} & {$[\%]$} & {$\left[\mathrm{kWh} / \mathrm{m}^{2} \mathrm{año}\right]$} & [kWh/mªño] \\
\hline Sólo refrigeración & $\begin{array}{c}\text { Máquina } \\
\text { frigorífica - } \\
\text { Caudal Ref. } \\
\text { Variable }\end{array}$ & & $361.0 \%$ & - & - & - & - & - & - \\
\hline $\begin{array}{l}\text { Calefacción y } \\
\text { refrigeración }\end{array}$ & - & - & - & - & $\begin{array}{c}\text { Bomba de } \\
\text { Calor - } \\
\text { Caudal Ref. } \\
\text { Variable }\end{array}$ & & $255.8 \%$ & - & - \\
\hline TOTALES & & - & & - & & - & & - & - \\
\hline
\end{tabular}

\section{Instalaciones de Agua Caliente Sanitaria}

\begin{tabular}{|c|c|c|c|c|c|c|c|c|c|}
\hline Nombre & Tipo & $\begin{array}{l}\text { Potencia } \\
\text { nominal }\end{array}$ & $\begin{array}{l}\text { Rendi- } \\
\text { miento } \\
\text { Estacional }\end{array}$ & $\begin{array}{c}\text { Estimación } \\
\text { Energía } \\
\text { Consumida } \\
\text { anual }\end{array}$ & $\begin{array}{c}\text { Tipo post } \\
\text { mejora }\end{array}$ & $\begin{array}{c}\text { Potencia } \\
\text { nominal } \\
\text { post } \\
\text { mejora }\end{array}$ & $\begin{array}{c}\text { Rendimiento } \\
\text { estacional } \\
\text { post mejora }\end{array}$ & $\begin{array}{c}\text { Estimación } \\
\text { Energía } \\
\text { Consumida } \\
\text { anual Post } \\
\text { mejora }\end{array}$ & $\begin{array}{l}\text { Energía } \\
\text { anual } \\
\text { ahorrada }\end{array}$ \\
\hline & & {$[\mathrm{kW}]$} & [\%] & {$\left[\mathrm{kWh} / \mathrm{m}^{2} \mathrm{año}\right]$} & & {$[\mathrm{kW}]$} & [\%] & [kWh/m²año] & [kWh/m²año] \\
\hline Equipo ACS & Efecto Joule & & $100.0 \%$ & - & Efecto Joule & & $100.0 \%$ & - & - \\
\hline TOTALES & & - & & - & & - & & - & - \\
\hline
\end{tabular}




\begin{tabular}{|c|c|c|c|c|c|}
\hline & & $\begin{array}{c}\text { Ref. } \\
\text { Catastral }\end{array}$ & 000000000 & $\begin{array}{l}\text { Versión } \\
\text { informe } \\
\text { asociado }\end{array}$ & $01 / 12 / 2015$ \\
\hline $\begin{array}{l}\text { Certificación } \\
\text { Energética } \\
\text { de Edificios }\end{array}$ & $\begin{array}{c}\text { Id. } \\
\text { Mejora }\end{array}$ & $\begin{array}{l}\text { Programa } \\
\text { y versión }\end{array}$ & CEXv2.1 & Fecha & $2 / 1 / 2004$ \\
\hline
\end{tabular}

\section{ENERGÍAS RENOVABLES}

\section{Térmica}

\begin{tabular}{|c|c|c|c|c|}
\hline \multirow{2}{*}{ Nombre } & \multicolumn{2}{|c|}{$\begin{array}{c}\text { Consumo de Energía Final, cubierto en función } \\
\text { del servicio asociado [\%] }\end{array}$} & $\begin{array}{c}\text { Demanda de ACS } \\
\text { cubierta [\%] }\end{array}$ \\
\cline { 2 - 5 } & Calefacción & Refrigeración & ACS & \\
\hline Contribuciones energéticas & 100 & - & - & - \\
\hline TOTALES & 100.0 & - & - & - \\
\hline
\end{tabular}

Post mejora

\begin{tabular}{|c|c|c|c|c|}
\hline \multirow{2}{*}{ Nombre } & \multicolumn{3}{|c|}{$\begin{array}{c}\text { Consumo de Energía Final, cubierto en función } \\
\text { del servicio asociado [\%] }\end{array}$} & $\begin{array}{c}\text { Demanda de ACS } \\
\text { cubierta [\%] }\end{array}$ \\
\cline { 2 - 5 } & Calefacción & Refrigeración & ACS & \\
\hline- & - & - & - & - \\
\hline TOTALES & - & - & - & - \\
\hline
\end{tabular}

\section{Eléctrica}

\begin{tabular}{|c|c|c|}
\hline Nombre & $\begin{array}{c}\text { Energía eléctrica generada y } \\
\text { autoconsumida [kWh/año] }\end{array}$ & $\begin{array}{c}\text { Energía eléctrica generada y } \\
\text { autoconsumida post mejora } \\
\text { [kWh/año] }\end{array}$ \\
\hline Incorporación/mejora de sistema fotovoltaico & - & 8379 \\
\hline TOTALES & 0.0 & 8379.0 \\
\hline
\end{tabular}


A.6.3

Zona Climática BWk (Koppen)/ A4 (CTE). Almería 


\section{CERTIFICADO DE EFICIENCIA ENERGÉTICA DE EDIFICIOS}

IDENTIFICACIÓN DEL EDIFICIO O DE LA PARTE QUE SE CERTIFICA:

\begin{tabular}{|l|l|l|l|}
\hline Nombre del edificio & \multicolumn{3}{l|}{ Vivienda Taller Modificado } \\
\hline Dirección & Tesis & Código Postal & 04071 \\
\hline Municipio & Almería & Comunidad Autónoma & Andalucía \\
\hline Provincia & Almería & Año construcción & 2007 \\
\hline Zona climática & A4 & & \\
\hline $\begin{array}{l}\text { Normativa vigente (construcción } \\
\text { rehabilitación) }\end{array}$ & C.T.E. & \\
\hline Referencia/s catastral/es & 000000000 & \\
\hline
\end{tabular}

\begin{tabular}{|l|l|}
\hline \multicolumn{2}{|c|}{ Tipo de edificio o parte del edificio que se certifica: } \\
\hline$\circ$ Edificio de nueva construcción & $\bullet$ Edificio Existente \\
\hline \multicolumn{2}{|c|}{} \\
\hline$\bullet$ Vivienda & $\circ$ Terciario \\
$\bullet$ Unifamiliar & $\circ$ Edificio completo \\
$\circ$ Bloque & $\circ$ Local \\
$\circ$ Bloque completo & \\
\hline Vivienda individual & \\
\hline
\end{tabular}

DATOS DEL TÉCNICO CERTIFICADOR:

\begin{tabular}{|c|c|c|c|c|c|}
\hline Nombre y Apellidos & \multicolumn{3}{|c|}{ Juan Carlos Sánchez } & NIF(NIE) & 000000000 \\
\hline Razón social & \multicolumn{3}{|c|}{ Juan Carlos Sánchez } & NIF & 000000000 \\
\hline \multicolumn{2}{|l|}{ Domicilio } & \multicolumn{4}{|l|}{ Calle Pinar Del Rey } \\
\hline \multicolumn{2}{|l|}{ Municipio } & Madrid & \multicolumn{2}{|c|}{ Código Postal } & 28033 \\
\hline \multicolumn{2}{|l|}{ Provincia } & Madrid & \multicolumn{2}{|c|}{ Comunidad Autónoma } & $\begin{array}{l}\text { Comunidad } \\
\text { Madrid }\end{array}$ \\
\hline \multicolumn{2}{|l|}{ e-mail: } & \multicolumn{2}{|c|}{ juancsanchezg@hotmail.com } & Teléfono & 0000000000 \\
\hline \multicolumn{2}{|c|}{ Titulación habilitante según normativa vigente } & \multicolumn{4}{|l|}{ Arquitecto } \\
\hline $\begin{array}{l}\text { Procedimiento reconocido de } \\
\text { versión: }\end{array}$ & calificación & ergética utilizado y & CEX & & \\
\hline
\end{tabular}

\section{CALIFICACIÓN ENERGÉTICA OBTENIDA:}

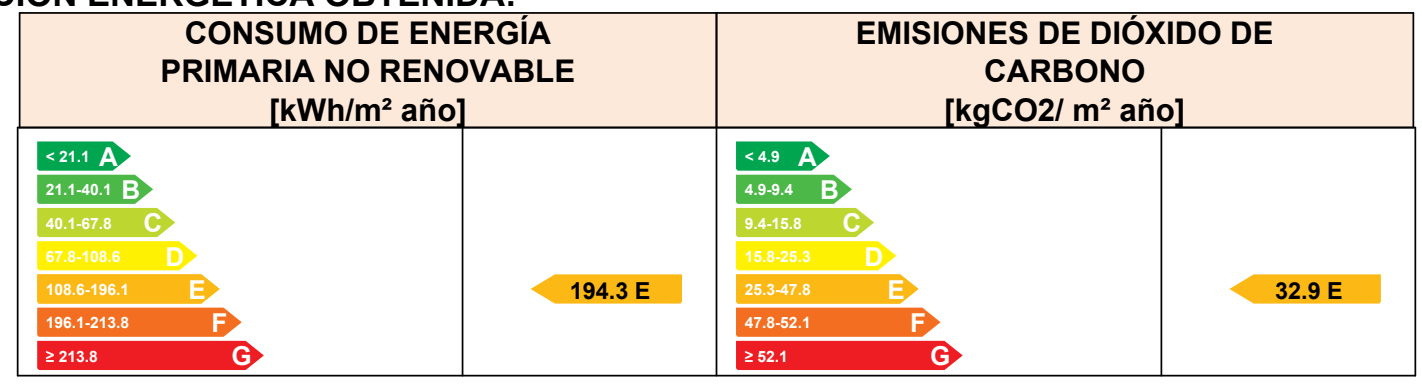

El técnico abajo firmante declara responsablemente que ha realizado la certificación energética del edificio o de la parte que se certifica de acuerdo con el procedimiento establecido por la normativa vigente y que son ciertos los datos que figuran en el presente documento, y sus anexos:

Fecha: 01/12/2015

\section{Firma del técnico certificador}

Anexo I. Descripción de las características energéticas del edificio.

Anexo II. Calificación energética del edificio.

Anexo III. Recomendaciones para la mejora de la eficiencia energética.

Anexo IV. Pruebas, comprobaciones e inspecciones realizadas por el técnico certificador.

Registro del Órgano Territorial Competente: 


\section{DESCRIPCIÓN DE LAS CARACTERÍSTICAS ENERGÉTICAS DEL EDIFICIO}

En este apartado se describen las características energéticas del edificio, envolvente térmica, instalaciones, condiciones de funcionamiento y ocupación y demás datos utilizados para obtener la calificación energética del edificio.

\section{SUPERFICIE, IMAGEN Y SITUACIÓN}

\begin{tabular}{|l|l}
\hline Superficie habitable $\left[\mathrm{m}^{2}\right]$ & 52.0
\end{tabular}

\begin{tabular}{|c|c|c|}
\hline Imagen del edificio & Plano de situación \\
\hline & &
\end{tabular}

\section{ENVOLVENTE TÉRMICA}

\section{Cerramientos opacos}

\begin{tabular}{|l|c|c|c|c|}
\hline \multicolumn{1}{|c|}{ Nombre } & Tipo & $\begin{array}{c}\text { Superficie } \\
{\left[\mathrm{m}^{2}\right]}\end{array}$ & $\begin{array}{c}\text { Transmitancia } \\
{\left[\mathbf{W} / \mathbf{m}^{2} \cdot \mathrm{K}\right]}\end{array}$ & Modo de obtención \\
\hline Cubierta con aire & Cubierta & 52.0 & 0.47 & Conocidas \\
\hline Muro de fachada Norte & Fachada & 27.18 & 0.54 & Conocidas \\
\hline Suelo con aire & Suelo & 52.0 & 2.95 & Conocidas \\
\hline Muro de fachada Sur & Fachada & 21.88 & 0.54 & Conocidas \\
\hline Muro de fachada Oeste & Fachada & 8.04 & 0.54 & Conocidas \\
\hline Muro de fachada Este & Fachada & 3.28 & 0.54 & Conocidas \\
\hline
\end{tabular}

Huecos y lucernarios

\begin{tabular}{|l|c|c|c|c|c|c|}
\hline Nombre & Tipo & $\begin{array}{c}\text { Superficie } \\
{\left[\mathbf{m}^{2}\right]}\end{array}$ & $\begin{array}{c}\text { Transmitancia } \\
{\left[\mathbf{W} / \mathbf{m}^{2} \cdot \mathbf{K}\right]}\end{array}$ & $\begin{array}{c}\text { Factor } \\
\text { solar }\end{array}$ & $\begin{array}{c}\text { Modo de } \\
\text { obtención. } \\
\text { Transmitancia }\end{array}$ & $\begin{array}{c}\text { Modo de } \\
\text { obtención. } \\
\text { Factor solar }\end{array}$ \\
\hline V1 & Hueco & 5.3 & 5.70 & 0.67 & Estimado & Estimado \\
\hline V3 & Hueco & 5.3 & 5.70 & 0.67 & Estimado & Estimado \\
\hline V4 & Hueco & 5.3 & 5.70 & 0.67 & Estimado & Estimado \\
\hline V2 & Hueco & 5.3 & 5.70 & 0.67 & Estimado & Estimado \\
\hline V5 & Hueco & 5.03 & 5.70 & 0.67 & Estimado & Estimado \\
\hline Pta & Hueco & 5.03 & 5.70 & 0.67 & Estimado & Estimado \\
\hline
\end{tabular}




\section{INSTALACIONES TÉRMICAS}

Generadores de calefacción

\begin{tabular}{|c|c|c|c|c|c|}
\hline Nombre & Tipo & $\begin{array}{c}\text { Potencia } \\
\text { nominal [kW] }\end{array}$ & $\begin{array}{l}\text { Rendimiento } \\
\text { Estacional[\%] }\end{array}$ & $\begin{array}{l}\text { Tipo de } \\
\text { Energía }\end{array}$ & $\begin{array}{c}\text { Modo de } \\
\text { obtención }\end{array}$ \\
\hline $\begin{array}{l}\text { Calefacción } \\
\text { refrigeración }\end{array}$ & $\begin{array}{l}\text { Bomba de Calor - } \\
\text { Caudal Ref. Variable }\end{array}$ & & 324.5 & Electricidad & Estimado \\
\hline TOTALES & Calefacción & & & & \\
\hline
\end{tabular}

\section{Generadores de refrigeración}

\begin{tabular}{|c|c|c|c|c|c|}
\hline Nombre & Tipo & $\begin{array}{c}\text { Potencia } \\
\text { nominal [kW] }\end{array}$ & $\begin{array}{c}\text { Rendimiento } \\
\text { Estacional[\%] }\end{array}$ & $\begin{array}{c}\text { Tipo de } \\
\text { Energía }\end{array}$ & $\begin{array}{c}\text { Modo de } \\
\text { obtención }\end{array}$ \\
\hline $\begin{array}{l}\text { Calefacción } \\
\text { refrigeración }\end{array}$ & y & $\begin{array}{c}\text { Bomba de Calor } \\
\text { Caudal Ref. Variable }\end{array}$ & 221.9 & Electricidad & Estimado \\
\hline TOTALES & Refrigeración & & & \\
\hline
\end{tabular}

Instalaciones de Agua Caliente Sanitaria

Demanda diario de ACS a $60^{\circ}$ (litros/día) 45.55

\begin{tabular}{|c|c|c|c|c|c|}
\hline Nombre & Tipo & $\begin{array}{c}\text { Potencia } \\
\text { nominal [kW] }\end{array}$ & $\begin{array}{c}\text { Rendimiento } \\
\text { Estacional[\%] }\end{array}$ & $\begin{array}{c}\text { Tipo de } \\
\text { Energía }\end{array}$ & $\begin{array}{c}\text { Modo de } \\
\text { obtención }\end{array}$ \\
\hline Equipo ACS & Efecto Joule & & 100.0 & Electricidad & Estimado \\
\hline TOTALES & ACS & & & & \\
\hline
\end{tabular}




\section{ANEXO II
CALIFICACIÓN ENERGÉTICA DEL EDIFICIO}

\begin{tabular}{|l|l|l|l|}
\hline Zona climática & A4 & Uso & Residencial \\
\hline
\end{tabular}

\section{CALIFICACIÓN ENERGÉTICA DEL EDIFICIO EN EMISIONES}

\begin{tabular}{|c|c|c|c|c|c|}
\hline \multicolumn{2}{|c|}{ INDICADOR GLOBAL } & \multicolumn{4}{|c|}{ INDICADORES PARCIALES } \\
\hline $\begin{array}{l}<.9 \quad \text { A } \\
4.9-9.4 \quad \text { B }\end{array}$ & & \multicolumn{2}{|c|}{ CALEFACCIÓN } & \multicolumn{2}{|l|}{ ACS } \\
\hline $\begin{array}{ll}9.4-15.8 & C \\
15.8 \cdot 25.3 & D\end{array}$ & & $\begin{array}{c}\text { Emisiones } \\
\text { calefacción } \\
{\left[\mathrm{kaCO} 2 \mathrm{~m}^{2} \text { añol }\right.}\end{array}$ & \multirow{2}{*}{ D } & $\begin{array}{l}\text { Emisiones ACS } \\
{\left[\mathrm{kgCO} 2 / \mathrm{m}^{2} \text { año] }\right.}\end{array}$ & \multirow{2}{*}{ G } \\
\hline $25.3-47.8$ & \multirow[t]{2}{*}{$32.9 \mathrm{E}$} & 9.58 & & 14.76 & \\
\hline $\begin{array}{ll}477.8-52.1 & F \\
\geq 52.1 & C\end{array}$ & & \multicolumn{2}{|c|}{ REFRIGERACIÓN } & \multicolumn{2}{|l|}{ ILUMINACIÓN } \\
\hline \multirow{2}{*}{\multicolumn{2}{|c|}{ Emisiones globales $\left[\mathrm{kgCO} 2 / \mathrm{m}^{2}\right.$ año] ${ }^{1}$}} & $\begin{array}{c}\text { Emisiones } \\
\text { refrigeración } \\
{\left[\mathrm{kgCO} 2 / \mathrm{m}^{2} \text { año] }\right.}\end{array}$ & \multirow[t]{2}{*}{ D } & $\begin{array}{c}\text { Emisiones } \\
\text { iluminación } \\
{\left[\mathrm{kgCO} 2 / \mathrm{m}^{2} \text { año] }\right.}\end{array}$ & \multirow[t]{2}{*}{-} \\
\hline & & 8.57 & & - & \\
\hline
\end{tabular}

La calificación global del edificio se expresa en términos de dióxido de carbono liberado a la atmósfera como consecuencia del consumo energético del mismo.

\begin{tabular}{|l|c|c|}
\cline { 2 - 3 } \multicolumn{1}{c|}{} & $\mathbf{k g C O} 2 / \mathbf{m}^{\mathbf{2}}$ año & $\mathbf{~} \mathbf{k g C O 2 / a n ̃ o ~}$ \\
\hline Emisiones CO2 por consumo eléctrico & 32.92 & 1711.62 \\
\hline Emisiones CO2 por otros combustibles & 0.00 & 0.00 \\
\hline
\end{tabular}

\section{CALIFICACIÓN ENERGÉTICA DEL EDIFICIO EN CONSUMO DE ENERGÍA PRIMARIA NO RENOVABLE}

Por energía primaria no renovable se entiende la energía consumida por el edificio procedente de fuentes no renovables que no ha sufrido ningún proceso de conversión o transformación.

\begin{tabular}{|c|c|c|c|c|c|}
\hline \multicolumn{2}{|c|}{ INDICADOR GLOBAL } & \multicolumn{4}{|c|}{ INDICADORES PARCIALES } \\
\hline \multirow{4}{*}{ 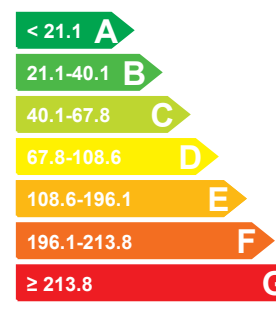 } & & \multicolumn{2}{|c|}{ CALEFACCIÓN } & \multicolumn{2}{|l|}{ ACS } \\
\hline & & $\begin{array}{l}\text { Energía primaria } \\
\text { calefacción } \\
{\left[\mathrm{kWh} / \mathrm{m}^{2} \text { año] }\right.}\end{array}$ & \multirow[t]{2}{*}{$\mathrm{E}$} & $\begin{array}{l}\text { Energía primaria } \\
A C S \\
{\left[\mathrm{kWh} / \mathrm{m}^{2} \text { año] }\right.}\end{array}$ & \multirow[t]{2}{*}{ G } \\
\hline & \multirow[t]{2}{*}{ 194.3 E } & 56.56 & & 87.15 & \\
\hline & & \multicolumn{2}{|c|}{ REFRIGERACIÓN } & \multicolumn{2}{|l|}{ ILUMINACIÓN } \\
\hline \multirow{2}{*}{\multicolumn{2}{|c|}{$\begin{array}{l}\text { Consumo global de energía primaria no renovable } \\
\qquad\left[\mathrm{kWh} / \mathrm{m}^{2} \text { año }\right]^{1}\end{array}$}} & $\begin{array}{l}\text { Energía primaria } \\
\text { refrigeración } \\
{\left[\mathrm{kWh} / \mathrm{m}^{2} \text { añol }\right.}\end{array}$ & \multirow[t]{2}{*}{ E } & $\begin{array}{l}\text { Energía primaria } \\
\text { iluminación } \\
{\left[\mathrm{kWh} / \mathrm{m}^{2} a \tilde{n o}\right.}\end{array}$ & \multirow[t]{2}{*}{ - } \\
\hline & & 50.60 & & & \\
\hline
\end{tabular}

\section{CALIFICACIÓN PARCIAL DE LA DEMANDA ENERGÉTICA DE CALEFACCIÓN Y REFRIGERACIÓN}

La demanda energética de calefacción y refrigeración es la energía necesaria para mantener las condiciones internas de confort del edificio.

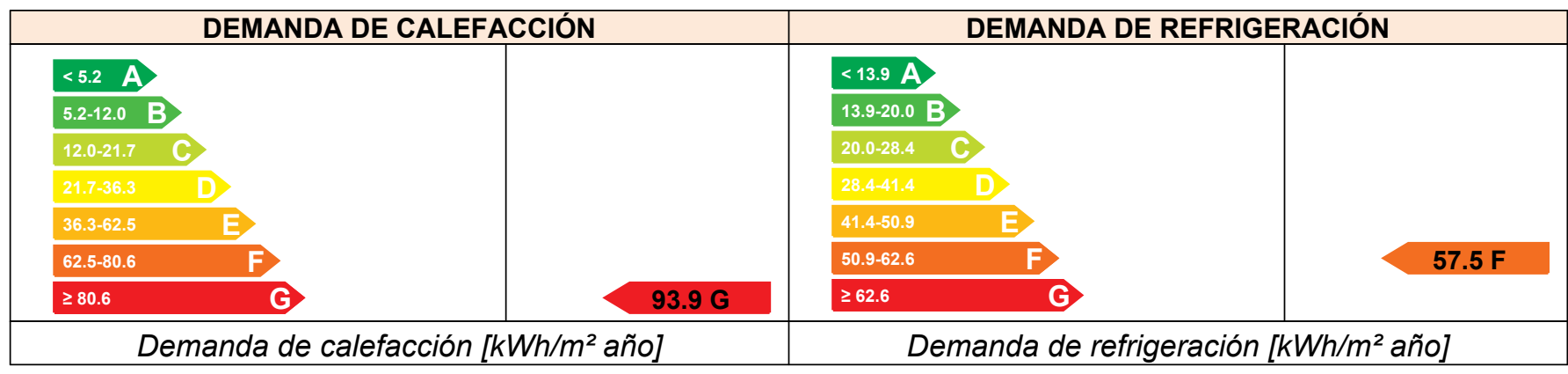

${ }^{1}$ El indicador global es resultado de la suma de los indicadores parciales más el valor del indicador para consumos auxiliares, si los hubiera (sólo ed. terciarios, ventilación, bombeo, etc...). La energía eléctrica autoconsumida se descuenta únicamente del indicador global, no así de los valores parciales 


\section{ANEXO III \\ RECOMENDACIONES PARA LA MEJORA DE LA EFICIENCIA ENERGÉTICA}

FV $100 \%$

\section{CALIFICACIÓN ENERGÉTICA GLOBAL}

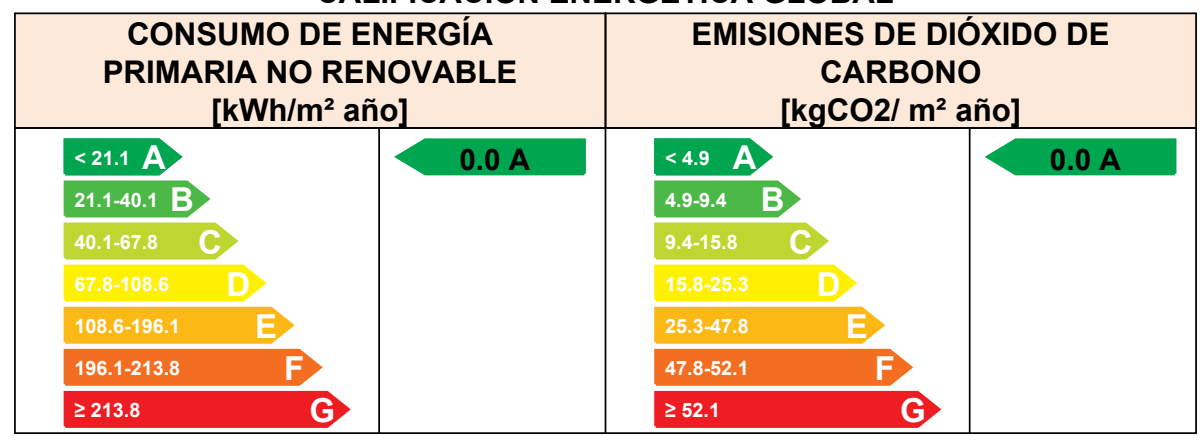

CALIFICACIONES ENERGÉTICAS PARCIALES

\begin{tabular}{|c|c|c|c|}
\hline \multicolumn{2}{|c|}{$\begin{array}{l}\text { DEMANDA DE CALEFACCIÓN } \\
{\left[\mathrm{kWh} / \mathrm{m}^{2} \text { año] }\right.}\end{array}$} & \multicolumn{2}{|c|}{$\begin{array}{l}\text { DEMANDA DE REFRIGERACIÓN } \\
{\left[\mathrm{kWh} / \mathrm{m}^{2} \text { año] }\right.}\end{array}$} \\
\hline$<5.2$ A & & $<13.9 \mathrm{~A}$ & \\
\hline $5.2-12.0 \quad B$ & & 13.9-20.0 B & \\
\hline 12.0-21.7 C & & $20.0-28.4 \quad \mathrm{C}$ & \\
\hline $21.7-36.3$ & & $28.4-41.4$ & \\
\hline $36.3-62.5$ & & $41.4-50.9$ & \\
\hline $62.5-80.6$ & & $50.9-62.6$ & $57.5 \mathrm{~F}$ \\
\hline$\geq 80.6$ & $93.9 \mathrm{G}$ & $\geq 62.6$ & \\
\hline
\end{tabular}

\section{ANÁLISIS TÉCNICO}

\begin{tabular}{|c|c|c|c|c|c|c|c|c|c|c|c|c|c|c|c|}
\hline \multirow[b]{2}{*}{ Indicador } & \multicolumn{3}{|c|}{ Calefacción } & \multicolumn{3}{|c|}{ Refrigeración } & \multicolumn{3}{|c|}{ ACS } & \multicolumn{3}{|c|}{ Iluminación } & \multicolumn{3}{|c|}{ Total } \\
\hline & \multicolumn{2}{|c|}{ Valor } & $\begin{array}{c}\text { ahorro } \\
\text { respecto a } \\
\text { la situación } \\
\text { original }\end{array}$ & \multicolumn{2}{|c|}{ Valor } & $\begin{array}{c}\text { ahorro } \\
\text { respecto a } \\
\text { la situación } \\
\text { original }\end{array}$ & \multicolumn{2}{|c|}{ Valor } & $\begin{array}{c}\text { ahorro } \\
\text { respecto a } \\
\text { la situación } \\
\text { original }\end{array}$ & \multicolumn{2}{|c|}{ Valor } & $\begin{array}{c}\text { ahorro } \\
\text { respecto a } \\
\text { la situación } \\
\text { original }\end{array}$ & \multicolumn{2}{|c|}{ Valor } & $\begin{array}{c}\text { ahorro } \\
\text { respecto a } \\
\text { la situación } \\
\text { original }\end{array}$ \\
\hline $\begin{array}{l}\text { Consumo Energía final } \\
{\left[\mathrm{kWh} / \mathrm{m}^{2} \text { año] }\right.}\end{array}$ & \multicolumn{2}{|c|}{32.54} & $-12.4 \%$ & \multicolumn{2}{|c|}{23.03} & $11.1 \%$ & \multicolumn{2}{|c|}{44.60} & $0.0 \%$ & \multicolumn{2}{|c|}{-} & $-\%$ & \multicolumn{2}{|c|}{77.16} & $22.4 \%$ \\
\hline $\begin{array}{c}\text { Emisiones de } \mathrm{CO} 2 \\
{\left[\mathrm{kgCO} 2 / \mathrm{m}^{2} \text { año] }\right.}\end{array}$ & 10.77 & $\mathrm{D}$ & $-12.4 \%$ & 7.62 & $\mathrm{D}$ & $11.1 \%$ & 14.76 & G & $0.0 \%$ & - & - & $-\%$ & 0.00 & $A$ & $100.0 \%$ \\
\hline Demanda [kWh $/ \mathrm{m}^{2}$ año] & 93.92 & $\mathrm{G}$ & $0.0 \%$ & 57.46 & $\mathrm{~F}$ & $0.0 \%$ & & & & & & & & & \\
\hline
\end{tabular}

Nota: Los indicadores energéticos anteriores están calculados en base a coeficientes estándar de operación y funcionamiento del edificio, por lo que solo son válidos a efectos de su calificación energética. Para el análisis económico de las medidas de ahorro y eficiencia energética, el técnico certificador deberá utilizar las condiciones reales y datos históricos de consumo del edificio.

\section{DESCRIPCIÓN DE LA MEDIDA DE MEJORA}

Características de la medida (modelo de equipos, materiales, parámetros característicos )

Coste estimado de la medida

Otros datos de interés 


\section{ANEXO IV \\ PRUEBAS, COMPROBACJONES E INSPECCIONES REALIZADAS POR EL TECNICO CERTIFICADOR}

Se describen a continuación las pruebas, comprobaciones e inspecciones llevadas a cabo por el técnico certificador durante el proceso de toma de datos y de calificación de la eficiencia energética del edificio, con la finalidad de establecer la conformidad de la información de partida contenida en el certificado de eficiencia energética.

Fecha de realización de la visita del técnico certificador 


\begin{tabular}{|c|c|c|c|c|c|}
\hline & DEN & $\begin{array}{c}\text { Ref. } \\
\text { Catastral }\end{array}$ & 000000000 & $\begin{array}{c}\text { Versión } \\
\text { informe } \\
\text { asociado }\end{array}$ & $01 / 12 / 2015$ \\
\hline $\begin{array}{c}\text { Certificación } \\
\text { Energetica } \\
\text { de Edificios }\end{array}$ & $\begin{array}{c}\text { Id. } \\
\text { Mejora }\end{array}$ & $\begin{array}{l}\text { Programa } \\
\text { y versión }\end{array}$ & CEXv2.1 & Fecha & $4 / 1 / 2004$ \\
\hline
\end{tabular}

\section{Informe descriptivo de la medida de mejora}

\section{DENOMINACIÓN DE LA MEDIDA DE MEJORA}

FV $100 \%$

\section{DESCRIPCIÓN DE LA MEDIDA DE MEJORA}

Características de la medida (modelo de equipos, materiales, parámetros característicos )

Coste estimado de la medida

Otros datos de interés

CALIFICACIÓN ENERGÉTICA GLOBAL

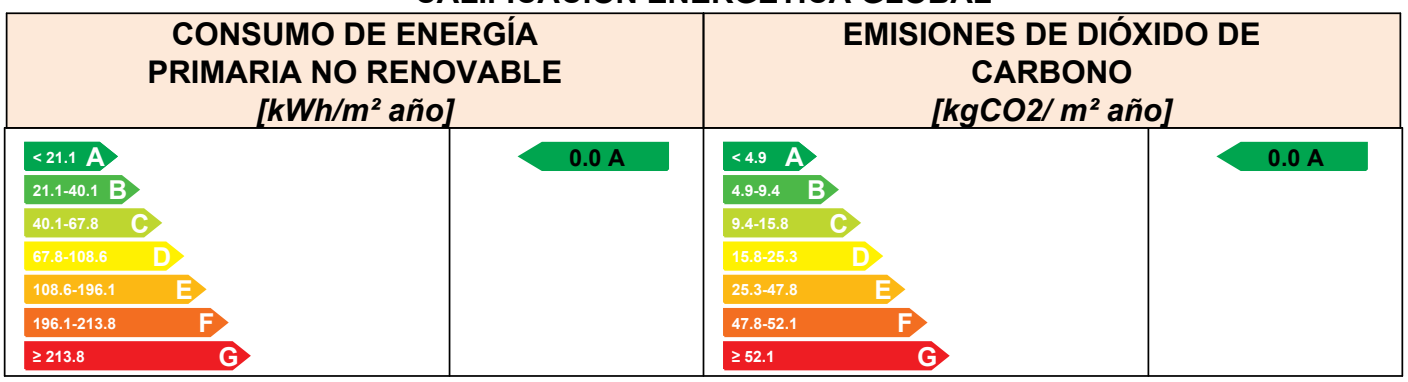

CALIFICACIONES ENERGÉTICAS PARCIALES

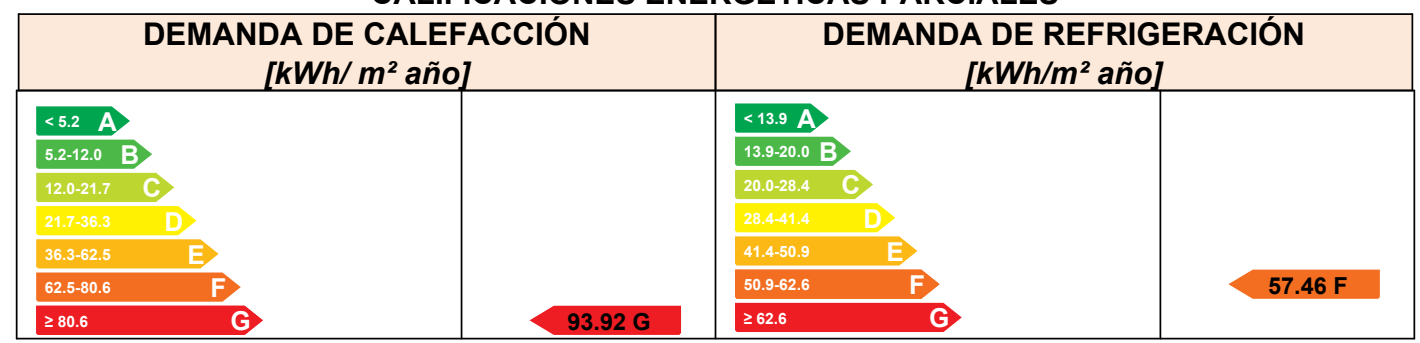




\begin{tabular}{|c|c|c|c|c|c|}
\hline & & $\begin{array}{c}\text { Ref. } \\
\text { Catastral }\end{array}$ & 000000000 & $\begin{array}{c}\text { Versión } \\
\text { informe } \\
\text { asociado }\end{array}$ & $01 / 12 / 2015$ \\
\hline $\begin{array}{l}\text { Certificación } \\
\text { Energética } \\
\text { de Edificios }\end{array}$ & $\begin{array}{c}\text { Id. } \\
\text { Mejora }\end{array}$ & $\begin{array}{l}\text { Programa } \\
\text { y versión }\end{array}$ & CEXv2.1 & Fecha & $4 / 1 / 2004$ \\
\hline
\end{tabular}

\section{ANALISÍS TÉCNICO}

\begin{tabular}{|c|c|c|c|c|c|c|c|c|c|c|c|c|c|c|c|}
\hline \multirow[b]{2}{*}{ Indicador } & \multicolumn{3}{|c|}{ Calefacción } & \multicolumn{3}{|c|}{ Refrigeración } & \multicolumn{3}{|c|}{ ACS } & \multicolumn{3}{|c|}{ Iluminación } & \multicolumn{3}{|c|}{ Total } \\
\hline & \multicolumn{2}{|c|}{ Valor } & $\begin{array}{c}\text { ahorro } \\
\text { respecto a } \\
\text { la situación } \\
\text { original }\end{array}$ & \multicolumn{2}{|c|}{ Valor } & $\begin{array}{c}\text { ahorro } \\
\text { respecto a } \\
\text { la situación } \\
\text { original }\end{array}$ & \multicolumn{2}{|c|}{ Valor } & $\begin{array}{c}\text { ahorro } \\
\text { respecto a } \\
\text { la situación } \\
\text { original }\end{array}$ & \multicolumn{2}{|c|}{ Valor } & $\begin{array}{c}\text { ahorro } \\
\text { respecto a } \\
\text { la situación } \\
\text { original }\end{array}$ & \multicolumn{2}{|c|}{ Valor } & $\begin{array}{c}\text { ahorro } \\
\text { respecto a } \\
\text { la situación } \\
\text { original }\end{array}$ \\
\hline $\begin{array}{l}\text { Consumo Energía } \\
\text { final }\left[\mathrm{kWh} / \mathrm{m}^{2} \text { año] }\right.\end{array}$ & \multicolumn{2}{|c|}{32.54} & $-12.4 \%$ & \multicolumn{2}{|c|}{23.03} & $11.1 \%$ & \multicolumn{2}{|c|}{44.60} & $0.0 \%$ & \multicolumn{2}{|l|}{-} & $-\%$ & \multicolumn{2}{|c|}{77.16} & $22.4 \%$ \\
\hline $\begin{array}{l}\text { Consumo Energía } \\
\text { primaria no renovable } \\
{\left[\mathrm{kWh} / \mathrm{m}^{2} \text { año] }\right.}\end{array}$ & 63.59 & $E$ & $-12.4 \%$ & 45.00 & $E$ & $11.1 \%$ & 87.15 & G & $0.0 \%$ & - & - & $-\%$ & 0.00 & A & $100.0 \%$ \\
\hline $\begin{array}{c}\text { Emisiones de CO2 } \\
{\left[\mathrm{kgCO} 2 / \mathrm{m}^{2} \text { año] }\right.}\end{array}$ & 10.77 & D & $-12.4 \%$ & 7.62 & D & $11.1 \%$ & 14.76 & G & $0.0 \%$ & - & - & $-\%$ & 0.00 & A & $100.0 \%$ \\
\hline $\begin{array}{c}\text { Demanda }\left[\mathrm{kWh} / \mathrm{m}^{2}\right. \\
\text { año] }\end{array}$ & 93.92 & G & $0.0 \%$ & 57.46 & $F$ & $0.0 \%$ & & & & & & & & & \\
\hline
\end{tabular}

\section{ENVOLVENTE TÉRMICA}

\section{Cerramientos opacos}

\begin{tabular}{|c|c|c|c|c|c|}
\hline Nombre & Tipo & $\begin{array}{c}\text { Superficie } \\
\text { actual } \\
{\left[\mathbf{m}^{2}\right]}\end{array}$ & $\begin{array}{c}\text { Transmitancia } \\
\text { actual } \\
{\left[\mathbf{W} / \mathbf{m}^{\mathbf{2}} \mathbf{~ K}\right]}\end{array}$ & $\begin{array}{c}\text { Superficie } \\
\text { post } \\
\text { mejora } \\
{\left[\mathbf{m}^{2}\right]}\end{array}$ & $\begin{array}{c}\text { Transmitancia } \\
\text { post mejora } \\
{\left[\mathbf{W} / \mathbf{m}^{\mathbf{2}} \mathbf{K}\right]}\end{array}$ \\
\hline Cubierta con aire & Cubierta & 52.00 & 0.47 & 52.00 & 0.47 \\
\hline Muro de fachada Norte & Fachada & 27.18 & 0.54 & 27.18 & 0.54 \\
\hline Suelo con aire & Suelo & 52.00 & 2.95 & 52.00 & 2.95 \\
\hline Muro de fachada Sur & Fachada & 21.88 & 0.54 & 21.88 & 0.54 \\
\hline Muro de fachada Oeste & Fachada & 8.04 & 0.54 & 8.04 & 0.54 \\
\hline Muro de fachada Este & Fachada & 3.28 & 0.54 & 3.28 & 0.54 \\
\hline
\end{tabular}

Huecos y lucernarios

\begin{tabular}{|c|c|c|c|c|c|c|c|}
\hline Nombre & Tipo & $\begin{array}{c}\text { Superficie } \\
\text { actual } \\
{\left[\mathrm{m}^{2}\right]}\end{array}$ & $\begin{array}{c}\text { Transmitancia } \\
\text { actual del } \\
\text { hueco[W/m² } \\
\mathrm{K}]\end{array}$ & $\begin{array}{c}\text { Transmitancia } \\
\text { actual del } \\
\text { vidrio[W/m² } \\
\mathrm{K}]\end{array}$ & $\begin{array}{c}\text { Superficie } \\
\text { post } \\
\text { mejora } \\
{\left[\mathrm{m}^{2}\right]}\end{array}$ & $\begin{array}{c}\text { Transmitancia } \\
\text { post mejora } \\
{\left[\mathrm{W} / \mathrm{m}^{2} \mathrm{~K}\right]}\end{array}$ & $\begin{array}{c}\text { Transmitancia } \\
\text { post mejora } \\
\text { del vidrio } \\
{\left[\mathrm{W} / \mathrm{m}^{2} \mathrm{~K}\right]}\end{array}$ \\
\hline V1 & Hueco & 5.3 & 5.70 & 5.70 & 5.3 & 5.70 & 5.70 \\
\hline V3 & Hueco & 5.3 & 5.70 & 5.70 & 5.3 & 5.70 & 5.70 \\
\hline V4 & Hueco & 5.3 & 5.70 & 5.70 & 5.3 & 5.70 & 5.70 \\
\hline V2 & Hueco & 5.3 & 5.70 & 5.70 & 5.3 & 5.70 & 5.70 \\
\hline V5 & Hueco & 5.03 & 5.70 & 5.70 & 5.03 & 5.70 & 5.70 \\
\hline Pta & Hueco & 5.03 & 5.70 & 5.70 & 5.03 & 5.70 & 5.70 \\
\hline
\end{tabular}




\begin{tabular}{|c|c|c|c|c|c|}
\hline & & $\begin{array}{c}\text { Ref. } \\
\text { Catastral }\end{array}$ & 000000000 & $\begin{array}{c}\text { Versión } \\
\text { informe } \\
\text { asociado }\end{array}$ & $01 / 12 / 2015$ \\
\hline $\begin{array}{l}\text { Certificación } \\
\text { Energética } \\
\text { de Edificios }\end{array}$ & $\begin{array}{c}\text { Id. } \\
\text { Mejora }\end{array}$ & $\begin{array}{l}\text { Programa } \\
\text { y versión }\end{array}$ & CEXv2.1 & Fecha & $4 / 1 / 2004$ \\
\hline
\end{tabular}

\section{INSTALACIONES TÉRMICAS}

\section{Generadores de calefacción}

\begin{tabular}{|c|c|c|c|c|c|c|c|c|c|}
\hline \multirow[t]{2}{*}{ Nombre } & \multirow[t]{2}{*}{ Tipo } & $\begin{array}{l}\text { Potencia } \\
\text { nominal }\end{array}$ & $\begin{array}{l}\text { Rendi- } \\
\text { miento } \\
\text { Estacional }\end{array}$ & $\begin{array}{c}\text { Estimación } \\
\text { Energía } \\
\text { Consumida } \\
\text { anual }\end{array}$ & \multirow[t]{2}{*}{$\begin{array}{c}\text { Tipo post } \\
\text { mejora }\end{array}$} & $\begin{array}{c}\text { Potencia } \\
\text { nominal } \\
\text { post } \\
\text { mejora }\end{array}$ & $\begin{array}{c}\text { Rendimiento } \\
\text { estacional } \\
\text { post mejora }\end{array}$ & $\begin{array}{c}\text { Estimación } \\
\text { Energía } \\
\text { Consumida } \\
\text { anual Post } \\
\text { mejora }\end{array}$ & $\begin{array}{c}\text { Energía } \\
\text { anual } \\
\text { ahorrada }\end{array}$ \\
\hline & & {$[k W]$} & [\%] & {$\left[\mathrm{kWh} / \mathrm{m}^{2} \mathrm{año}\right]$} & & {$[k W]$} & [\%] & [kWh/m²año] & [kWh/m²año] \\
\hline $\begin{array}{l}\text { Calefacción y } \\
\text { refrigeración }\end{array}$ & $\begin{array}{c}\text { Bomba de } \\
\text { Calor - } \\
\text { Caudal Ref. } \\
\text { Variable }\end{array}$ & & $324.5 \%$ & - & $\begin{array}{c}\text { Bomba de } \\
\text { Calor - } \\
\text { Caudal Ref. } \\
\text { Variable }\end{array}$ & & $288.6 \%$ & - & - \\
\hline TOTALES & & & & & & & & & \\
\hline
\end{tabular}

\section{Generadores de refrigeración}

\begin{tabular}{|c|c|c|c|c|c|c|c|c|c|}
\hline \multirow[t]{2}{*}{ Nombre } & \multirow[t]{2}{*}{ Tipo } & $\begin{array}{r}\text { Potencia } \\
\text { nominal }\end{array}$ & $\begin{array}{c}\text { Rendi- } \\
\text { miento } \\
\text { Estacional }\end{array}$ & $\begin{array}{c}\text { Estimación } \\
\text { Energía } \\
\text { Consumida } \\
\text { anual }\end{array}$ & \multirow[t]{2}{*}{$\begin{array}{l}\text { Tipo post } \\
\text { mejora }\end{array}$} & $\begin{array}{c}\text { Potencia } \\
\text { nominal } \\
\text { post } \\
\text { mejora }\end{array}$ & $\begin{array}{c}\text { Rendimiento } \\
\text { estacional } \\
\text { post mejora }\end{array}$ & $\begin{array}{c}\text { Estimación } \\
\text { Energía } \\
\text { Consumida } \\
\text { anual Post } \\
\text { mejora }\end{array}$ & $\begin{array}{c}\text { Energía } \\
\text { anual } \\
\text { ahorrada }\end{array}$ \\
\hline & & {$[\mathrm{kW}]$} & {$[\%]$} & {$\left[\mathrm{kWh} / \mathrm{m}^{2} \mathrm{año}\right]$} & & {$[\mathrm{kW}]$} & {$[\%]$} & [kWh/m²año] & {$\left[\mathrm{kWh} / \mathrm{m}^{2} \mathrm{año}\right.$} \\
\hline $\begin{array}{l}\text { Calefacción y } \\
\text { refrigeración }\end{array}$ & $\begin{array}{c}\text { Bomba de } \\
\text { Calor - } \\
\text { Caudal Ref. } \\
\text { Variable }\end{array}$ & & $221.9 \%$ & - & $\begin{array}{c}\text { Bomba de } \\
\text { Calor - } \\
\text { Caudal Ref. } \\
\text { Variable }\end{array}$ & & $249.5 \%$ & - & - \\
\hline TOTALES & & - & & - & & - & & - & - \\
\hline
\end{tabular}

\section{Instalaciones de Agua Caliente Sanitaria}

\begin{tabular}{|c|c|c|c|c|c|c|c|c|c|}
\hline Nombre & Tipo & $\begin{array}{l}\text { Potencia } \\
\text { nominal }\end{array}$ & $\begin{array}{c}\text { Rendi- } \\
\text { miento } \\
\text { Estacional }\end{array}$ & $\begin{array}{c}\text { Estimación } \\
\text { Energía } \\
\text { Consumida } \\
\text { anual }\end{array}$ & $\begin{array}{c}\text { Tipo post } \\
\text { mejora }\end{array}$ & $\begin{array}{l}\text { Potencia } \\
\text { nominal } \\
\text { post } \\
\text { mejora }\end{array}$ & $\begin{array}{c}\text { Rendimiento } \\
\text { estacional } \\
\text { post mejora }\end{array}$ & $\begin{array}{c}\text { Estimación } \\
\text { Energía } \\
\text { Consumida } \\
\text { anual Post } \\
\text { mejora }\end{array}$ & $\begin{array}{l}\text { Energía } \\
\text { anual } \\
\text { ahorrada }\end{array}$ \\
\hline & & {$[\mathrm{kW}]$} & [\%] & {$\left[\mathrm{kWh} / \mathrm{m}^{2} \mathrm{año}\right]$} & & {$[\mathrm{kW}]$} & [\%] & [kWh/m²año] & [kWh/m²año] \\
\hline Equipo ACS & Efecto Joule & & $100.0 \%$ & - & Efecto Joule & & $100.0 \%$ & - & - \\
\hline TOTALES & & - & & - & & - & & - & - \\
\hline
\end{tabular}




\begin{tabular}{|c|c|c|c|c|c|}
\hline & $D E$ & $\begin{array}{c}\text { Ref. } \\
\text { Catastral }\end{array}$ & 000000000 & $\begin{array}{l}\text { Versión } \\
\text { informe } \\
\text { asociado }\end{array}$ & $01 / 12 / 2015$ \\
\hline $\begin{array}{c}\text { Certificación } \\
\text { Energética } \\
\text { de Edificioios }\end{array}$ & $\begin{array}{c}\text { Id. } \\
\text { Mejora }\end{array}$ & $\begin{array}{l}\text { Programa } \\
\text { y versión }\end{array}$ & CEXv2.1 & Fecha & $4 / 1 / 2004$ \\
\hline
\end{tabular}

\section{ENERGÍAS RENOVABLES}

\section{Eléctrica}

\begin{tabular}{|c|c|c|}
\hline Nombre & $\begin{array}{c}\text { Energía eléctrica generada y } \\
\text { autoconsumida [kWh/año] }\end{array}$ & $\begin{array}{c}\text { Energía eléctrica generada y } \\
\text { autoconsumida post mejora } \\
\text { [kWh/año] }\end{array}$ \\
\hline Incorporación/mejora de sistema fotovoltaico & - & 6245 \\
\hline TOTALES & - & 6245.0 \\
\hline
\end{tabular}


A.6.4

Zona Climática Csa (Koppen)/ B4 (CTE). Sevilla. 


\section{CERTIFICADO DE EFICIENCIA ENERGÉTICA DE EDIFICIOS}

IDENTIFICACIÓN DEL EDIFICIO O DE LA PARTE QUE SE CERTIFICA:

\begin{tabular}{|l|l|l|l|}
\hline Nombre del edificio & Vivienda Taller Modificado \\
\hline Dirección & Tesis & Código Postal & 41001 \\
\hline Municipio & Sevilla & Comunidad Autónoma & Andalucía \\
\hline Provincia & Sevilla & Año construcción & 2007 \\
\hline Zona climática & B4 & & \\
\hline $\begin{array}{l}\text { Normativa vigente (construcción } \\
\text { rehabilitación) }\end{array}$ & C.T.E. & \\
\hline Referencia/s catastral/es & 000000000 & \\
\hline
\end{tabular}

\begin{tabular}{|l|l|}
\hline \multicolumn{2}{|c|}{ Tipo de edificio o parte del edificio que se certifica: } \\
\hline$\circ$ Edificio de nueva construcción & $\bullet$ Edificio Existente \\
\hline \multicolumn{2}{|c|}{} \\
\hline$\bullet$ Vivienda & $\circ$ Terciario \\
$\bullet$ Unifamiliar & $\circ$ Edificio completo \\
$\circ$ Bloque & $\circ$ Local \\
$\circ$ Bloque completo & \\
\hline Vivienda individual & \\
\hline
\end{tabular}

DATOS DEL TÉCNICO CERTIFICADOR:

\begin{tabular}{|c|c|c|c|c|c|}
\hline Nombre y Apellidos & \multicolumn{3}{|c|}{ Juan Carlos Sánchez } & NIF(NIE) & 000000000 \\
\hline Razón social & \multicolumn{3}{|c|}{ Juan Carlos Sánchez } & NIF & 000000000 \\
\hline \multicolumn{2}{|l|}{ Domicilio } & \multicolumn{4}{|l|}{ Calle Pinar Del Rey } \\
\hline \multicolumn{2}{|l|}{ Municipio } & Madrid & \multicolumn{2}{|c|}{ Código Postal } & 28033 \\
\hline \multicolumn{2}{|l|}{ Provincia } & Madrid & \multicolumn{2}{|c|}{ Comunidad Autónoma } & $\begin{array}{l}\text { Comunidad } \\
\text { Madrid }\end{array}$ \\
\hline \multicolumn{2}{|l|}{ e-mail: } & \multicolumn{2}{|c|}{ juancsanchezg@hotmail.com } & Teléfono & 0000000000 \\
\hline \multicolumn{2}{|c|}{ Titulación habilitante según normativa vigente } & \multicolumn{4}{|l|}{ Arquitecto } \\
\hline $\begin{array}{l}\text { Procedimiento reconocido de } \\
\text { versión: }\end{array}$ & calificación & ergética utilizado y & CEX & & \\
\hline
\end{tabular}

\section{CALIFICACIÓN ENERGÉTICA OBTENIDA:}

\begin{tabular}{|c|c|c|c|}
\hline \multicolumn{2}{|c|}{$\begin{array}{c}\text { CONSUMO DE ENERGÍA } \\
\text { PRIMARIA NO RENOVABLE } \\
{\left[\mathrm{kWh} / \mathrm{m}^{2} \text { año] }\right.}\end{array}$} & \multicolumn{2}{|c|}{$\begin{array}{c}\text { EMISIONES DE DIÓXIDO DE } \\
\text { CARBONO } \\
{\left[\mathrm{kgCO} 2 / \mathrm{m}^{2} \text { año] }\right.}\end{array}$} \\
\hline 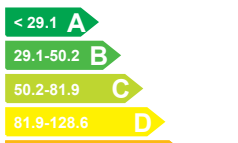 & & 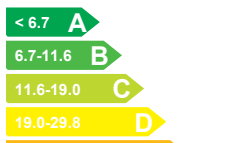 & \\
\hline $\begin{array}{ll}128.6-243.7 & E \\
243.7-292.5 & \text { F } \\
2292.5 & \text { G }\end{array}$ & $220.8 \mathrm{E}$ & $\begin{array}{ll}29.8-58.4 & E \\
58.4-71.8 & F \\
271.8 & \text { G }\end{array}$ & $37.4 \mathrm{E}$ \\
\hline
\end{tabular}

El técnico abajo firmante declara responsablemente que ha realizado la certificación energética del edificio o de la parte que se certifica de acuerdo con el procedimiento establecido por la normativa vigente y que son ciertos los datos que figuran en el presente documento, y sus anexos:

Fecha: 01/12/2015

\section{Firma del técnico certificador}

Anexo I. Descripción de las características energéticas del edificio.

Anexo II. Calificación energética del edificio.

Anexo III. Recomendaciones para la mejora de la eficiencia energética.

Anexo IV. Pruebas, comprobaciones e inspecciones realizadas por el técnico certificador.

Registro del Órgano Territorial Competente: 


\section{DESCRIPCIÓN DE LAS CARACTERÍSTICAS ENERGÉTICAS DEL EDIFICIO}

En este apartado se describen las características energéticas del edificio, envolvente térmica, instalaciones, condiciones de funcionamiento y ocupación y demás datos utilizados para obtener la calificación energética del edificio.

\section{SUPERFICIE, IMAGEN Y SITUACIÓN}

\begin{tabular}{|l|l}
\hline Superficie habitable $\left[\mathrm{m}^{2}\right]$ & 52.0
\end{tabular}

\begin{tabular}{|c|c|c|}
\hline Imagen del edificio & Plano de situación \\
\hline & &
\end{tabular}

\section{ENVOLVENTE TÉRMICA}

\section{Cerramientos opacos}

\begin{tabular}{|l|c|c|c|c|}
\hline \multicolumn{1}{|c|}{ Nombre } & Tipo & $\begin{array}{c}\text { Superficie } \\
{\left[\mathrm{m}^{2}\right]}\end{array}$ & $\begin{array}{c}\text { Transmitancia } \\
{\left[\mathbf{W} / \mathbf{m}^{2} \cdot \mathrm{K}\right]}\end{array}$ & Modo de obtención \\
\hline Cubierta con aire & Cubierta & 52.0 & 0.47 & Conocidas \\
\hline Muro de fachada Norte & Fachada & 27.18 & 0.54 & Conocidas \\
\hline Suelo con aire & Suelo & 52.0 & 2.95 & Conocidas \\
\hline Muro de fachada Sur & Fachada & 21.88 & 0.54 & Conocidas \\
\hline Muro de fachada Oeste & Fachada & 8.04 & 0.54 & Conocidas \\
\hline Muro de fachada Este & Fachada & 3.28 & 0.54 & Conocidas \\
\hline
\end{tabular}

Huecos y lucernarios

\begin{tabular}{|l|c|c|c|c|c|c|}
\hline Nombre & Tipo & $\begin{array}{c}\text { Superficie } \\
{\left[\mathbf{m}^{2}\right]}\end{array}$ & $\begin{array}{c}\text { Transmitancia } \\
{\left[\mathbf{W} / \mathbf{m}^{2} \cdot \mathbf{K}\right]}\end{array}$ & $\begin{array}{c}\text { Factor } \\
\text { solar }\end{array}$ & $\begin{array}{c}\text { Modo de } \\
\text { obtención. } \\
\text { Transmitancia }\end{array}$ & $\begin{array}{c}\text { Modo de } \\
\text { obtención. } \\
\text { Factor solar }\end{array}$ \\
\hline V1 & Hueco & 5.3 & 5.70 & 0.67 & Estimado & Estimado \\
\hline V3 & Hueco & 5.3 & 5.70 & 0.67 & Estimado & Estimado \\
\hline V4 & Hueco & 5.3 & 5.70 & 0.67 & Estimado & Estimado \\
\hline V2 & Hueco & 5.3 & 5.70 & 0.67 & Estimado & Estimado \\
\hline V5 & Hueco & 5.03 & 5.70 & 0.67 & Estimado & Estimado \\
\hline Pta & Hueco & 5.03 & 5.70 & 0.67 & Estimado & Estimado \\
\hline
\end{tabular}




\section{INSTALACIONES TÉRMICAS}

Generadores de calefacción

\begin{tabular}{|c|c|c|c|c|c|}
\hline Nombre & Tipo & $\begin{array}{c}\text { Potencia } \\
\text { nominal [kW] }\end{array}$ & $\begin{array}{c}\text { Rendimiento } \\
\text { Estacional[\%] }\end{array}$ & $\begin{array}{l}\text { Tipo de } \\
\text { Energía }\end{array}$ & $\begin{array}{c}\text { Modo de } \\
\text { obtención }\end{array}$ \\
\hline $\begin{array}{l}\text { Calefacción } \\
\text { refrigeración }\end{array}$ & $\begin{array}{l}\text { Bomba de Calor - } \\
\text { Caudal Ref. Variable }\end{array}$ & & 335.9 & Electricidad & Estimado \\
\hline TOTALES & Calefacción & & & & \\
\hline
\end{tabular}

\section{Generadores de refrigeración}

\begin{tabular}{|c|c|c|c|c|c|}
\hline Nombre & Tipo & $\begin{array}{c}\text { Potencia } \\
\text { nominal [kW] }\end{array}$ & $\begin{array}{c}\text { Rendimiento } \\
\text { Estacional[\%] }\end{array}$ & $\begin{array}{c}\text { Tipo de } \\
\text { Energía }\end{array}$ & $\begin{array}{c}\text { Modo de } \\
\text { obtención }\end{array}$ \\
\hline $\begin{array}{l}\text { Calefacción } \\
\text { refrigeración }\end{array}$ & $y$ & $\begin{array}{c}\text { Bomba de Calor } \\
\text { Caudal Ref. Variable }\end{array}$ & & 187.5 & Electricidad \\
\hline TOTALES & Refrigeración & & & \\
\hline
\end{tabular}

Instalaciones de Agua Caliente Sanitaria

Demanda diario de ACS a $60^{\circ}$ (litros/día) 45.55

\begin{tabular}{|c|c|c|c|c|c|}
\hline Nombre & Tipo & $\begin{array}{c}\text { Potencia } \\
\text { nominal [kW] }\end{array}$ & $\begin{array}{c}\text { Rendimiento } \\
\text { Estacional[\%] }\end{array}$ & $\begin{array}{c}\text { Tipo de } \\
\text { Energía }\end{array}$ & $\begin{array}{c}\text { Modo de } \\
\text { obtención }\end{array}$ \\
\hline Equipo ACS & Efecto Joule & & 100.0 & Electricidad & Estimado \\
\hline TOTALES & ACS & & & & \\
\hline
\end{tabular}




\section{ANEXO II
CALIFICACIÓN ENERGÉTICA DEL EDIFICIO}

\begin{tabular}{|l|l|l|l|}
\hline Zona climática & B4 & Uso & Residencial \\
\hline
\end{tabular}

\section{CALIFICACIÓN ENERGÉTICA DEL EDIFICIO EN EMISIONES}

\begin{tabular}{|c|c|c|c|c|c|}
\hline \multicolumn{2}{|c|}{ INDICADOR GLOBAL } & \multicolumn{4}{|c|}{ INDICADORES PARCIALES } \\
\hline $\begin{array}{l}<6.7 \text { A } \\
6.7-11.6 \quad \mathrm{~B}\end{array}$ & & \multicolumn{2}{|c|}{ CALEFACCIÓN } & \multicolumn{2}{|l|}{ ACS } \\
\hline $\begin{array}{ll}11.6-19.0 & \text { C } \\
19.0-29.8 & D\end{array}$ & & $\begin{array}{c}\text { Emisiones } \\
\text { calefacción } \\
{\left[\mathrm{kgCO} 2 / \mathrm{m}^{2} \text { añol }\right.}\end{array}$ & \multirow{2}{*}{ D } & $\begin{array}{l}\text { Emisiones ACS } \\
{\left[\mathrm{kgCO} 2 / \mathrm{m}^{2} \text { año] }\right.}\end{array}$ & \multirow{2}{*}{ G } \\
\hline 29.8-58.4 $\quad$ E & \multirow[t]{2}{*}{$37.4 \mathrm{E}$} & 12.46 & & 14.80 & \\
\hline $\begin{array}{ll}58.4-71.8 & F \\
\geq 71.8 & C\end{array}$ & & \multicolumn{2}{|c|}{ REFRIGERACIÓN } & \multicolumn{2}{|l|}{ ILUMINACIÓN } \\
\hline \multirow{2}{*}{\multicolumn{2}{|c|}{ Emisiones globales $\left[\mathrm{kgCO} 2 / \mathrm{m}^{2}\right.$ año] ${ }^{1}$}} & $\begin{array}{c}\text { Emisiones } \\
\text { refrigeración } \\
{\left[\mathrm{kgCO} 2 / \mathrm{m}^{2} \text { año] }\right.}\end{array}$ & \multirow[t]{2}{*}{ D } & $\begin{array}{c}\text { Emisiones } \\
\text { iluminación } \\
{\left[\mathrm{kgCO} 2 / \mathrm{m}^{2} \text { año] }\right.}\end{array}$ & \multirow[t]{2}{*}{-} \\
\hline & & 10.14 & & - & \\
\hline
\end{tabular}

La calificación global del edificio se expresa en términos de dióxido de carbono liberado a la atmósfera como consecuencia del consumo energético del mismo.

\begin{tabular}{|l|c|c|}
\cline { 2 - 3 } \multicolumn{1}{c|}{} & $\mathbf{k g C O} 2 / \mathbf{m}^{\mathbf{2}}$ año & $\mathbf{~} \mathbf{k g C O 2 / a n ̃ o ~}$ \\
\hline Emisiones CO2 por consumo eléctrico & 37.41 & 1945.16 \\
\hline Emisiones CO2 por otros combustibles & 0.00 & 0.00 \\
\hline
\end{tabular}

\section{CALIFICACIÓN ENERGÉTICA DEL EDIFICIO EN CONSUMO DE ENERGÍA PRIMARIA NO RENOVABLE}

Por energía primaria no renovable se entiende la energía consumida por el edificio procedente de fuentes no renovables que no ha sufrido ningún proceso de conversión o transformación.

\begin{tabular}{|c|c|c|c|c|c|}
\hline \multicolumn{2}{|c|}{ INDICADOR GLOBAL } & \multicolumn{4}{|c|}{ INDICADORES PARCIALES } \\
\hline \multirow{4}{*}{ 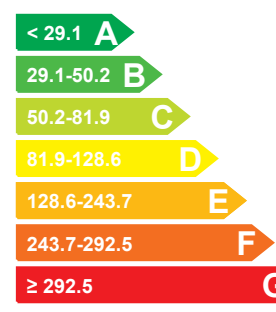 } & \multirow{4}{*}{$220.8 \mathrm{E}$} & \multicolumn{2}{|c|}{ CALEFACCIÓN } & \multicolumn{2}{|l|}{ ACS } \\
\hline & & $\begin{array}{l}\text { Energía primaria } \\
\text { calefacción } \\
{\left[\mathrm{kWh} / \mathrm{m}^{2} \text { año] }\right.}\end{array}$ & \multirow[t]{2}{*}{$\mathrm{E}$} & $\begin{array}{l}\text { Energía primaria } \\
A C S \\
{\left[\mathrm{kWh} / \mathrm{m}^{2} \text { añol }\right.}\end{array}$ & \multirow[t]{2}{*}{ G } \\
\hline & & 73.57 & & 87.37 & \\
\hline & & \multicolumn{2}{|c|}{ REFRIGERACIÓN } & \multicolumn{2}{|l|}{ ILUMINACIÓN } \\
\hline \multirow{2}{*}{\multicolumn{2}{|c|}{$\begin{array}{l}\text { Consumo global de energía primaria no renovable } \\
\qquad\left[\mathrm{kWh} / \mathrm{m}^{2} \text { año }\right]^{1}\end{array}$}} & $\begin{array}{l}\text { Energía primaria } \\
\text { refrigeración } \\
{\left[\mathrm{kWh} / \mathrm{m}^{2} \text { añol }\right.}\end{array}$ & \multirow[t]{2}{*}{$\mathbf{F}$} & $\begin{array}{l}\text { Energía primaria } \\
\text { iluminación } \\
{\left[\mathrm{kWh} / \mathrm{m}^{2} a n ̃ o\right]}\end{array}$ & \\
\hline & & 59.89 & & - & \\
\hline
\end{tabular}

\section{CALIFICACIÓN PARCIAL DE LA DEMANDA ENERGÉTICA DE CALEFACCIÓN Y REFRIGERACIÓN}

La demanda energética de calefacción y refrigeración es la energía necesaria para mantener las condiciones internas de confort del edificio.

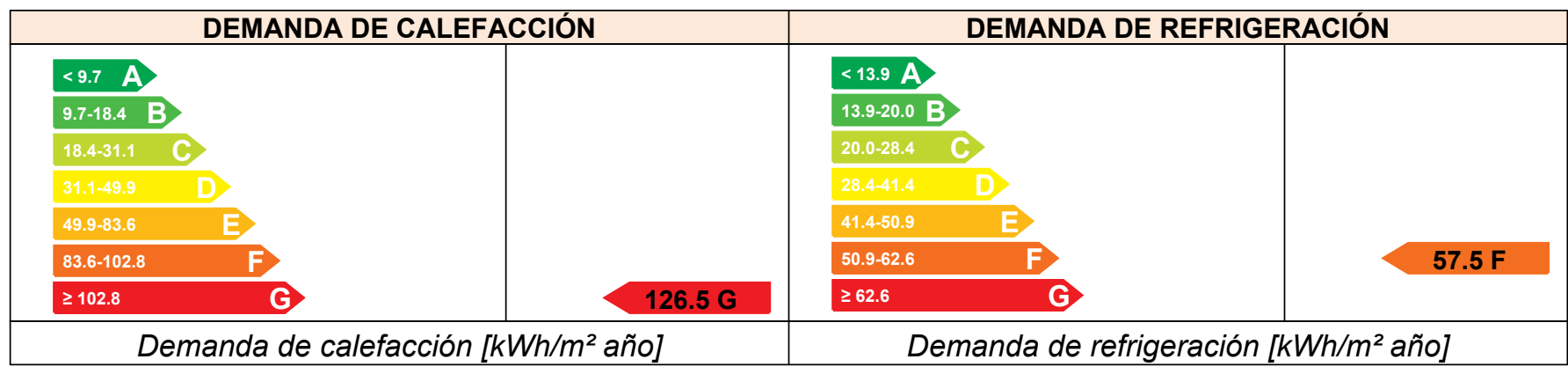

${ }^{1}$ El indicador global es resultado de la suma de los indicadores parciales más el valor del indicador para consumos auxiliares, si los hubiera (sólo ed. terciarios, ventilación, bombeo, etc...). La energía eléctrica autoconsumida se descuenta únicamente del indicador global, no así de los valores parciales 


\section{ANEXO III \\ RECOMENDACIONES PARA LA MEJORA DE LA EFICIENCIA ENERGÉTICA}

FV $100 \%$

\section{CALIFICACIÓN ENERGÉTICA GLOBAL}

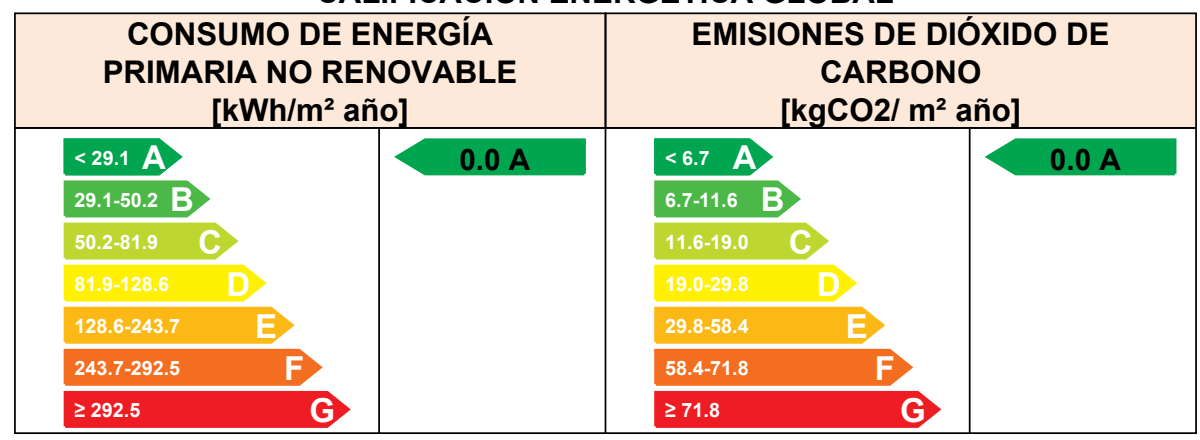

CALIFICACIONES ENERGÉTICAS PARCIALES

\begin{tabular}{|c|c|c|c|}
\hline \multicolumn{2}{|c|}{$\begin{array}{l}\text { DEMANDA DE CALEFACCIÓN } \\
{\left[\mathrm{kWh} / \mathrm{m}^{2} \text { año] }\right.}\end{array}$} & \multicolumn{2}{|c|}{$\begin{array}{l}\text { DEMANDA DE REFRIGERACIÓN } \\
{\left[\mathrm{kWh} / \mathrm{m}^{2} \text { año] }\right.}\end{array}$} \\
\hline$<9.7$ A & & $<13.9 \mathrm{~A}$ & \\
\hline $9.7-18.4 \quad \mathrm{~B}$ & & 13.9-20.0 B & \\
\hline 18.4-31.1 C & & $20.0-28.4 \quad \mathrm{C}$ & \\
\hline $31.1-49.9$ & & $28.4-41.4$ & \\
\hline $49.9-83.6$ & & $41.4-50.9$ & \\
\hline $83.6-102.8$ & & $50.9-62.6$ & $57.5 \mathrm{~F}$ \\
\hline$\geq 102.8$ & $126.5 \mathrm{G}$ & $\geq 62.6$ & \\
\hline
\end{tabular}

\section{ANÁLISIS TÉCNICO}

\begin{tabular}{|c|c|c|c|c|c|c|c|c|c|c|c|c|c|c|c|}
\hline \multirow[b]{2}{*}{ Indicador } & \multicolumn{3}{|c|}{ Calefacción } & \multicolumn{3}{|c|}{ Refrigeración } & \multicolumn{3}{|c|}{ ACS } & \multicolumn{3}{|c|}{ Iluminación } & \multicolumn{3}{|c|}{ Total } \\
\hline & \multicolumn{2}{|c|}{ Valor } & $\begin{array}{c}\text { ahorro } \\
\text { respecto a } \\
\text { la situación } \\
\text { original }\end{array}$ & \multicolumn{2}{|c|}{ Valor } & $\begin{array}{c}\text { ahorro } \\
\text { respecto a } \\
\text { la situación } \\
\text { original }\end{array}$ & \multicolumn{2}{|c|}{ Valor } & $\begin{array}{c}\text { ahorro } \\
\text { respecto a } \\
\text { la situación } \\
\text { original }\end{array}$ & \multicolumn{2}{|c|}{ Valor } & $\begin{array}{c}\text { ahorro } \\
\text { respecto a } \\
\text { la situación } \\
\text { original }\end{array}$ & \multicolumn{2}{|c|}{ Valor } & $\begin{array}{c}\text { ahorro } \\
\text { respecto a } \\
\text { la situación } \\
\text { original }\end{array}$ \\
\hline $\begin{array}{l}\text { Consumo Energía final } \\
{\left[\mathrm{kWh} / \mathrm{m}^{2} \text { año] }\right.}\end{array}$ & \multicolumn{2}{|c|}{42.34} & $-12.5 \%$ & \multicolumn{2}{|c|}{27.26} & $11.1 \%$ & \multicolumn{2}{|c|}{44.71} & $0.0 \%$ & \multicolumn{2}{|c|}{-} & $-\%$ & \multicolumn{2}{|c|}{-20.57} & $118.2 \%$ \\
\hline $\begin{array}{c}\text { Emisiones de } \mathrm{CO} 2 \\
{\left[\mathrm{kgCO} 2 / \mathrm{m}^{2} \text { año] }\right.}\end{array}$ & 14.01 & $\mathrm{D}$ & $-12.5 \%$ & 9.02 & $\mathrm{D}$ & $11.1 \%$ & 14.80 & G & $0.0 \%$ & - & - & $-\%$ & 0.00 & $A$ & $100.0 \%$ \\
\hline Demanda [kWh $/ \mathrm{m}^{2}$ año] & 126.47 & G & $0.0 \%$ & 57.47 & $\mathrm{~F}$ & $0.0 \%$ & & & & & & & & & \\
\hline
\end{tabular}

Nota: Los indicadores energéticos anteriores están calculados en base a coeficientes estándar de operación y funcionamiento del edificio, por lo que solo son válidos a efectos de su calificación energética. Para el análisis económico de las medidas de ahorro y eficiencia energética, el técnico certificador deberá utilizar las condiciones reales y datos históricos de consumo del edificio.

\section{DESCRIPCIÓN DE LA MEDIDA DE MEJORA}

Características de la medida (modelo de equipos, materiales, parámetros característicos )

Coste estimado de la medida

Otros datos de interés 
CALIFICACIÓN ENERGÉTICA GLOBAL

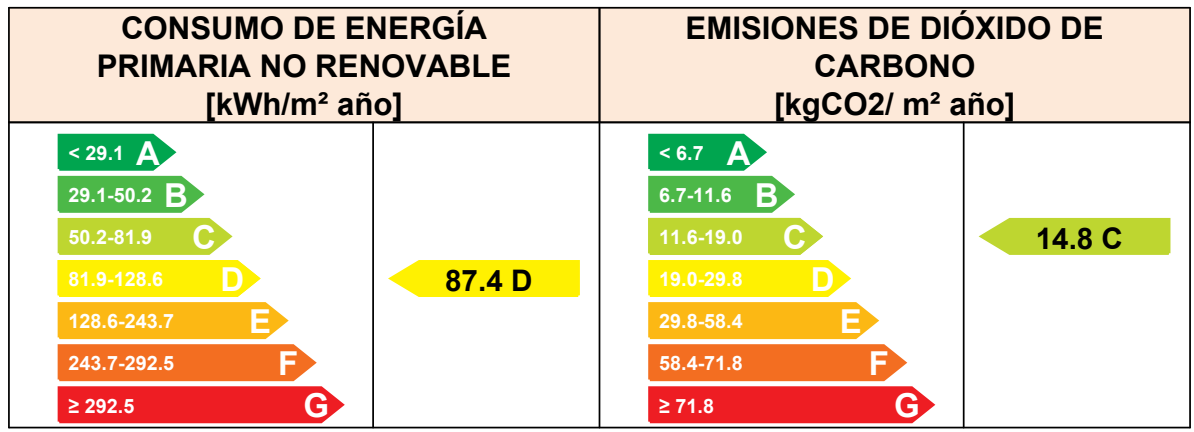

CALIFICACIONES ENERGÉTICAS PARCIALES

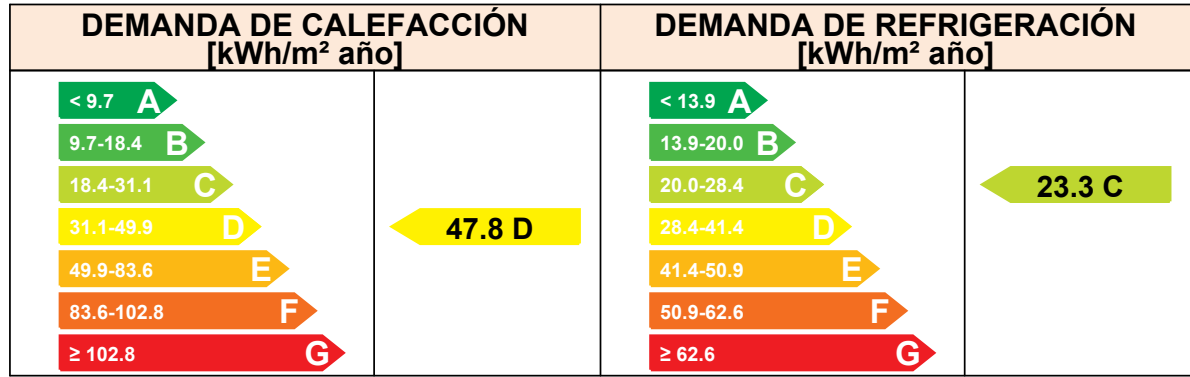

\section{ANÁLISIS TÉCNICO}

\begin{tabular}{|c|c|c|c|c|c|c|c|c|c|c|c|c|c|c|}
\hline \multirow[b]{2}{*}{ Indicador } & \multicolumn{3}{|c|}{ Calefacción } & \multicolumn{3}{|c|}{ Refrigeración } & \multicolumn{3}{|c|}{ ACS } & \multicolumn{2}{|c|}{ Iluminación } & \multicolumn{3}{|c|}{ Total } \\
\hline & \multicolumn{2}{|c|}{ Valor } & $\begin{array}{c}\text { ahorro } \\
\text { respecto a } \\
\text { la situación } \\
\text { original }\end{array}$ & \multicolumn{2}{|c|}{ Valor } & $\begin{array}{c}\text { ahorro } \\
\text { respecto a } \\
\text { la situación } \\
\text { original }\end{array}$ & \multicolumn{2}{|c|}{ Valor } & $\begin{array}{c}\text { ahorro } \\
\text { respecto a } \\
\text { la situación } \\
\text { original }\end{array}$ & Valor & $\begin{array}{c}\text { ahorro } \\
\text { respecto a } \\
\text { la situación } \\
\text { original }\end{array}$ & \multicolumn{2}{|c|}{ Valor } & $\begin{array}{c}\text { ahorro } \\
\text { respecto a } \\
\text { la situación } \\
\text { original }\end{array}$ \\
\hline $\begin{array}{c}\text { Consumo Energía final } \\
{\left[\mathrm{kWh} / \mathrm{m}^{2} \text { año] }\right.}\end{array}$ & \multicolumn{2}{|c|}{0.00} & $100.0 \%$ & \multicolumn{2}{|c|}{0.00} & $100.0 \%$ & \multicolumn{2}{|c|}{44.71} & $0.0 \%$ & - & $-\%$ & \multicolumn{2}{|c|}{44.71} & $60.4 \%$ \\
\hline $\begin{array}{c}\text { Consumo Energía } \\
\text { primaria no renovable } \\
{\left[\mathrm{kWh} / \mathrm{m}^{2} \text { año] }\right.}\end{array}$ & 0.00 & $A$ & $100.0 \%$ & 0.00 & $A$ & $100.0 \%$ & 87.37 & G & $0.0 \%$ & - & $-\%$ & 87.37 & $\mathrm{D}$ & $60.4 \%$ \\
\hline $\begin{array}{l}\text { Emisiones de } \mathrm{CO} 2 \\
{\left[\mathrm{kgCO} 2 / \mathrm{m}^{2} \text { año] }\right.}\end{array}$ & 0.00 & $A$ & $100.0 \%$ & 0.00 & $A$ & $100.0 \%$ & 14.80 & G & $0.0 \%$ & - & $-\%$ & 14.80 & $\mathrm{C}$ & $60.4 \%$ \\
\hline Demanda $\left[\mathrm{kWh} / \mathrm{m}^{2}\right.$ año] & 47.79 & $\mathrm{D}$ & $62.2 \%$ & 23.27 & C & $59.5 \%$ & & & & & & & & \\
\hline
\end{tabular}

Nota: Los indicadores energéticos anteriores están calculados en base a coeficientes estándar de operación y funcionamiento del edificio, por lo que solo son válidos a efectos de su calificación energética. Para el análisis económico de las medidas de ahorro y eficiencia energética, el técnico certificador deberá utilizar las condiciones reales y datos históricos de consumo del edificio.

\section{DESCRIPCIÓN DE LA MEDIDA DE MEJORA}

Características de la medida (modelo de equipos, materiales, parámetros característicos )

Coste estimado de la medida

\section{Otros datos de interés}


CALIFICACIÓN ENERGÉTICA GLOBAL

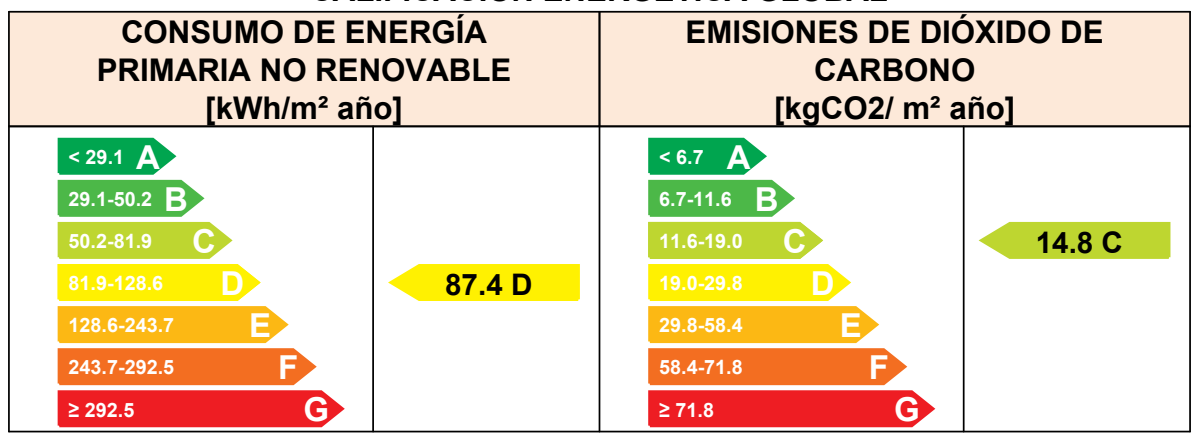

CALIFICACIONES ENERGÉTICAS PARCIALES

\begin{tabular}{|c|c|c|c|}
\hline \multicolumn{2}{|c|}{$\begin{array}{l}\text { DEMANDA DE CALEFACCIÓN } \\
{\left[\mathrm{kWh} / \mathrm{m}^{2} \text { año] }\right.}\end{array}$} & \multicolumn{2}{|c|}{$\begin{array}{l}\text { DEMANDA DE REFRIGERACIÓN } \\
{\left[\mathrm{kWh} / \mathrm{m}^{2} \text { año] }\right.}\end{array}$} \\
\hline$<9.7$ A & & $<13.9 \mathrm{~A}$ & \\
\hline $9.7-18.4 \quad$ B & & 13.9-20.0 B & \\
\hline 18.4-31.1 C & & $20.0-28.4 \quad C$ & $28.1 \mathrm{C}$ \\
\hline $31.1-49.9 \quad$ D & & $28.4-41.4$ & \\
\hline 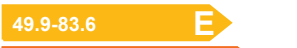 & & $41.4-50.9$ & \\
\hline $83.6-102.8$ & $97.7 \mathrm{~F}$ & $50.9-62.6$ & \\
\hline$\geq 102.8 \quad$ G & & G & \\
\hline
\end{tabular}

\section{ANÁLISIS TÉCNICO}

\begin{tabular}{|c|c|c|c|c|c|c|c|c|c|c|c|c|c|c|}
\hline \multirow[b]{2}{*}{ Indicador } & \multicolumn{3}{|c|}{ Calefacción } & \multicolumn{3}{|c|}{ Refrigeración } & \multicolumn{3}{|c|}{ ACS } & \multicolumn{2}{|c|}{ Iluminación } & \multicolumn{3}{|c|}{ Total } \\
\hline & \multicolumn{2}{|c|}{ Valor } & $\begin{array}{c}\text { ahorro } \\
\text { respecto a } \\
\text { la situación } \\
\text { original }\end{array}$ & \multicolumn{2}{|c|}{ Valor } & $\begin{array}{c}\text { ahorro } \\
\text { respecto a } \\
\text { la situación } \\
\text { original }\end{array}$ & \multicolumn{2}{|c|}{ Valor } & $\begin{array}{c}\text { ahorro } \\
\text { respecto a } \\
\text { la situación } \\
\text { original }\end{array}$ & Valor & $\begin{array}{c}\text { ahorro } \\
\text { respecto a } \\
\text { la situación } \\
\text { original }\end{array}$ & \multicolumn{2}{|c|}{ Valor } & $\begin{array}{c}\text { ahorro } \\
\text { respecto a } \\
\text { la situación } \\
\text { original }\end{array}$ \\
\hline $\begin{array}{c}\text { Consumo Energía final } \\
{\left[\mathrm{kWh} / \mathrm{m}^{2} \text { año] }\right.}\end{array}$ & \multicolumn{2}{|c|}{0.00} & $100.0 \%$ & \multicolumn{2}{|c|}{0.00} & $100.0 \%$ & \multicolumn{2}{|c|}{44.71} & $0.0 \%$ & - & $-\%$ & \multicolumn{2}{|c|}{44.71} & $60.4 \%$ \\
\hline $\begin{array}{c}\text { Consumo Energía } \\
\text { primaria no renovable } \\
{\left[\mathrm{kWh} / \mathrm{m}^{2} \text { año] }\right.}\end{array}$ & 0.00 & $A$ & $100.0 \%$ & 0.00 & $A$ & $100.0 \%$ & 87.37 & G & $0.0 \%$ & - & $-\%$ & 87.37 & $\mathrm{D}$ & $60.4 \%$ \\
\hline $\begin{array}{l}\text { Emisiones de } \mathrm{CO} 2 \\
{\left[\mathrm{kgCO} 2 / \mathrm{m}^{2} \text { año }\right]}\end{array}$ & 0.00 & $A$ & $100.0 \%$ & 0.00 & $A$ & $100.0 \%$ & 14.80 & G & $0.0 \%$ & - & $-\%$ & 14.80 & $\mathrm{C}$ & $60.4 \%$ \\
\hline Demanda $\left[\mathrm{kWh} / \mathrm{m}^{2}\right.$ año] & 97.74 & $\mathrm{~F}$ & $22.7 \%$ & 28.09 & C & $51.1 \%$ & & & & & & & & \\
\hline
\end{tabular}

Nota: Los indicadores energéticos anteriores están calculados en base a coeficientes estándar de operación y funcionamiento del edificio, por lo que solo son válidos a efectos de su calificación energética. Para el análisis económico de las medidas de ahorro y eficiencia energética, el técnico certificador deberá utilizar las condiciones reales y datos históricos de consumo del edificio.

\section{DESCRIPCIÓN DE LA MEDIDA DE MEJORA}

Características de la medida (modelo de equipos, materiales, parámetros característicos )

Coste estimado de la medida

\section{Otros datos de interés}




\section{ANEXO IV \\ PRUEBAS, COMPROBACJONES E INSPECCIONES REALIZADAS POR EL TECNICO CERTIFICADOR}

Se describen a continuación las pruebas, comprobaciones e inspecciones llevadas a cabo por el técnico certificador durante el proceso de toma de datos y de calificación de la eficiencia energética del edificio, con la finalidad de establecer la conformidad de la información de partida contenida en el certificado de eficiencia energética.

Fecha de realización de la visita del técnico certificador 


\begin{tabular}{|c|c|c|c|c|c|}
\hline & DEN & $\begin{array}{c}\text { Ref. } \\
\text { Catastral }\end{array}$ & 000000000 & $\begin{array}{c}\text { Versión } \\
\text { informe } \\
\text { asociado }\end{array}$ & $01 / 12 / 2015$ \\
\hline $\begin{array}{c}\text { Certificación } \\
\text { Energetica } \\
\text { de Edificios }\end{array}$ & $\begin{array}{c}\text { Id. } \\
\text { Mejora }\end{array}$ & $\begin{array}{l}\text { Programa } \\
\text { y versión }\end{array}$ & CEXv2.1 & Fecha & $3 / 1 / 2004$ \\
\hline
\end{tabular}

\section{Informe descriptivo de la medida de mejora}

\section{DENOMINACIÓN DE LA MEDIDA DE MEJORA}

FV $100 \%$

\section{DESCRIPCIÓN DE LA MEDIDA DE MEJORA}

Características de la medida (modelo de equipos, materiales, parámetros característicos )

Coste estimado de la medida

Otros datos de interés

CALIFICACIÓN ENERGÉTICA GLOBAL

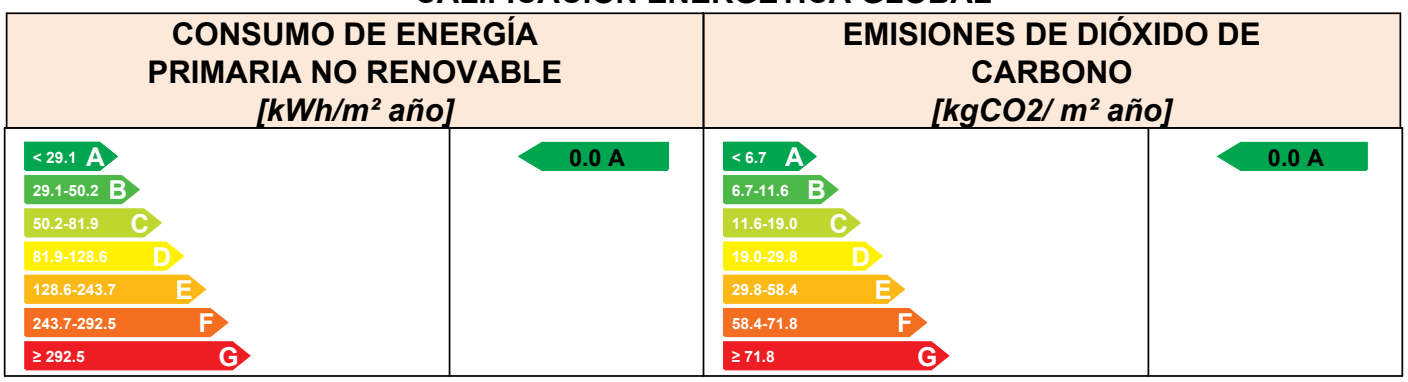

CALIFICACIONES ENERGÉTICAS PARCIALES

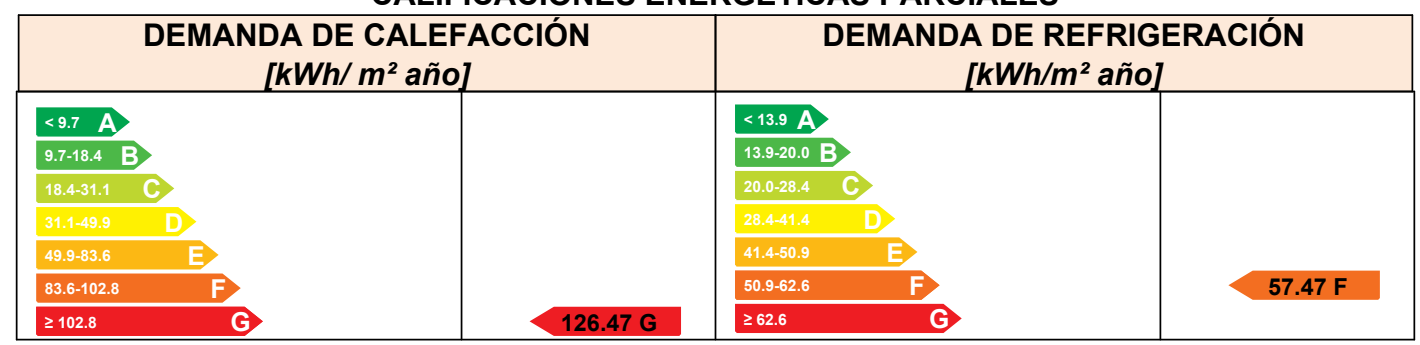




\begin{tabular}{|c|c|c|c|c|c|}
\hline & & $\begin{array}{c}\text { Ref. } \\
\text { Catastral }\end{array}$ & 000000000 & $\begin{array}{c}\text { Versión } \\
\text { informe } \\
\text { asociado }\end{array}$ & $01 / 12 / 2015$ \\
\hline $\begin{array}{l}\text { Certificación } \\
\text { Energética } \\
\text { de Edificios }\end{array}$ & $\begin{array}{c}\text { Id. } \\
\text { Mejora }\end{array}$ & $\begin{array}{l}\text { Programa } \\
\text { y versión }\end{array}$ & CEXv2.1 & Fecha & $3 / 1 / 2004$ \\
\hline
\end{tabular}

\section{ANALISÍS TÉCNICO}

\begin{tabular}{|c|c|c|c|c|c|c|c|c|c|c|c|c|c|c|c|}
\hline \multirow[b]{2}{*}{ Indicador } & \multicolumn{3}{|c|}{ Calefacción } & \multicolumn{3}{|c|}{ Refrigeración } & \multicolumn{3}{|c|}{ ACS } & \multicolumn{3}{|c|}{ Iluminación } & \multicolumn{3}{|c|}{ Total } \\
\hline & \multicolumn{2}{|c|}{ Valor } & $\begin{array}{c}\text { ahorro } \\
\text { respecto a } \\
\text { la situación } \\
\text { original }\end{array}$ & \multicolumn{2}{|c|}{ Valor } & $\begin{array}{c}\text { ahorro } \\
\text { respecto a } \\
\text { la situación } \\
\text { original }\end{array}$ & \multicolumn{2}{|c|}{ Valor } & $\begin{array}{c}\text { ahorro } \\
\text { respecto a } \\
\text { la situación } \\
\text { original }\end{array}$ & \multicolumn{2}{|c|}{ Valor } & $\begin{array}{c}\text { ahorro } \\
\text { respecto a } \\
\text { la situación } \\
\text { original }\end{array}$ & \multicolumn{2}{|c|}{ Valor } & $\begin{array}{c}\text { ahorro } \\
\text { respecto a } \\
\text { la situación } \\
\text { original }\end{array}$ \\
\hline $\begin{array}{l}\text { Consumo Energía } \\
\text { final }\left[\mathrm{kWh} / \mathrm{m}^{2} \text { año] }\right.\end{array}$ & \multicolumn{2}{|c|}{42.34} & $-12.5 \%$ & \multicolumn{2}{|c|}{27.26} & $11.1 \%$ & \multicolumn{2}{|c|}{44.71} & $0.0 \%$ & \multicolumn{2}{|l|}{-} & $-\%$ & \multicolumn{2}{|c|}{-20.57} & $118.2 \%$ \\
\hline $\begin{array}{l}\text { Consumo Energía } \\
\text { primaria no renovable } \\
{\left[\mathrm{kWh} / \mathrm{m}^{2} \text { año] }\right.}\end{array}$ & 82.73 & $E$ & $-12.5 \%$ & 53.27 & $F$ & $11.1 \%$ & 87.37 & G & $0.0 \%$ & - & - & $-\%$ & 0.00 & A & $100.0 \%$ \\
\hline $\begin{array}{c}\text { Emisiones de CO2 } \\
{\left[\mathrm{kgCO} 2 / \mathrm{m}^{2} \text { año] }\right.}\end{array}$ & 14.01 & D & $-12.5 \%$ & 9.02 & D & $11.1 \%$ & 14.80 & G & $0.0 \%$ & - & - & $-\%$ & 0.00 & A & $100.0 \%$ \\
\hline $\begin{array}{l}\text { Demanda }\left[\mathrm{kWh} / \mathrm{m}^{2}\right. \\
\text { año] }\end{array}$ & 126.47 & G & $0.0 \%$ & 57.47 & $F$ & $0.0 \%$ & & & & & & & & & \\
\hline
\end{tabular}

\section{ENVOLVENTE TÉRMICA}

\section{Cerramientos opacos}

\begin{tabular}{|c|c|c|c|c|c|}
\hline Nombre & Tipo & $\begin{array}{c}\text { Superficie } \\
\text { actual } \\
{\left[\mathbf{m}^{2}\right]}\end{array}$ & $\begin{array}{c}\text { Transmitancia } \\
\text { actual } \\
{\left[\mathbf{W} / \mathbf{m}^{\mathbf{2}} \mathbf{~ K}\right]}\end{array}$ & $\begin{array}{c}\text { Superficie } \\
\text { post } \\
\text { mejora } \\
{\left[\mathbf{m}^{2}\right]}\end{array}$ & $\begin{array}{c}\text { Transmitancia } \\
\text { post mejora } \\
{\left[\mathbf{W} / \mathbf{m}^{\mathbf{2}} \mathbf{K}\right]}\end{array}$ \\
\hline Cubierta con aire & Cubierta & 52.00 & 0.47 & 52.00 & 0.47 \\
\hline Muro de fachada Norte & Fachada & 27.18 & 0.54 & 27.18 & 0.54 \\
\hline Suelo con aire & Suelo & 52.00 & 2.95 & 52.00 & 2.95 \\
\hline Muro de fachada Sur & Fachada & 21.88 & 0.54 & 21.88 & 0.54 \\
\hline Muro de fachada Oeste & Fachada & 8.04 & 0.54 & 8.04 & 0.54 \\
\hline Muro de fachada Este & Fachada & 3.28 & 0.54 & 3.28 & 0.54 \\
\hline
\end{tabular}

Huecos y lucernarios

\begin{tabular}{|c|c|c|c|c|c|c|c|}
\hline Nombre & Tipo & $\begin{array}{c}\text { Superficie } \\
\text { actual } \\
{\left[\mathrm{m}^{2}\right]}\end{array}$ & $\begin{array}{c}\text { Transmitancia } \\
\text { actual del } \\
\text { hueco[W/m² } \\
\mathrm{K}]\end{array}$ & $\begin{array}{c}\text { Transmitancia } \\
\text { actual del } \\
\text { vidrio[W/m² } \\
\mathrm{K}]\end{array}$ & $\begin{array}{l}\text { Superficie } \\
\text { post } \\
\text { mejora } \\
{\left[\mathrm{m}^{2}\right]}\end{array}$ & $\begin{array}{c}\text { Transmitancia } \\
\text { post mejora } \\
{\left[\mathrm{W} / \mathrm{m}^{2} \mathrm{~K}\right]}\end{array}$ & $\begin{array}{c}\text { Transmitancia } \\
\text { post mejora } \\
\text { del vidrio } \\
{\left[\mathrm{W} / \mathrm{m}^{2} \mathrm{~K}\right]}\end{array}$ \\
\hline V1 & Hueco & 5.3 & 5.70 & 5.70 & 5.3 & 5.70 & 5.70 \\
\hline V3 & Hueco & 5.3 & 5.70 & 5.70 & 5.3 & 5.70 & 5.70 \\
\hline V4 & Hueco & 5.3 & 5.70 & 5.70 & 5.3 & 5.70 & 5.70 \\
\hline V2 & Hueco & 5.3 & 5.70 & 5.70 & 5.3 & 5.70 & 5.70 \\
\hline V5 & Hueco & 5.03 & 5.70 & 5.70 & 5.03 & 5.70 & 5.70 \\
\hline Pta & Hueco & 5.03 & 5.70 & 5.70 & 5.03 & 5.70 & 5.70 \\
\hline
\end{tabular}




\begin{tabular}{|c|c|c|c|c|c|}
\hline & & $\begin{array}{c}\text { Ref. } \\
\text { Catastral }\end{array}$ & 000000000 & $\begin{array}{c}\text { Versión } \\
\text { informe } \\
\text { asociado }\end{array}$ & $01 / 12 / 2015$ \\
\hline $\begin{array}{l}\text { Certificación } \\
\text { Energética } \\
\text { de Edificios }\end{array}$ & $\begin{array}{c}\text { Id. } \\
\text { Mejora }\end{array}$ & $\begin{array}{l}\text { Programa } \\
\text { y versión }\end{array}$ & CEXv2.1 & Fecha & $3 / 1 / 2004$ \\
\hline
\end{tabular}

\section{INSTALACIONES TÉRMICAS}

\section{Generadores de calefacción}

\begin{tabular}{|c|c|c|c|c|c|c|c|c|c|}
\hline \multirow[t]{2}{*}{ Nombre } & \multirow[t]{2}{*}{ Tipo } & $\begin{array}{l}\text { Potencia } \\
\text { nominal }\end{array}$ & $\begin{array}{l}\text { Rendi- } \\
\text { miento } \\
\text { Estacional }\end{array}$ & $\begin{array}{c}\text { Estimación } \\
\text { Energía } \\
\text { Consumida } \\
\text { anual }\end{array}$ & \multirow[t]{2}{*}{$\begin{array}{c}\text { Tipo post } \\
\text { mejora }\end{array}$} & $\begin{array}{c}\text { Potencia } \\
\text { nominal } \\
\text { post } \\
\text { mejora }\end{array}$ & $\begin{array}{c}\text { Rendimiento } \\
\text { estacional } \\
\text { post mejora }\end{array}$ & $\begin{array}{c}\text { Estimación } \\
\text { Energía } \\
\text { Consumida } \\
\text { anual Post } \\
\text { mejora }\end{array}$ & $\begin{array}{c}\text { Energía } \\
\text { anual } \\
\text { ahorrada }\end{array}$ \\
\hline & & {$[k W]$} & [\%] & {$\left[\mathrm{kWh} / \mathrm{m}^{2} \mathrm{año]}\right.$} & & {$[k W]$} & [\%] & [kWh/m²año] & [kWh/m²año] \\
\hline $\begin{array}{l}\text { Calefacción y } \\
\text { refrigeración }\end{array}$ & $\begin{array}{c}\text { Bomba de } \\
\text { Calor - } \\
\text { Caudal Ref. } \\
\text { Variable }\end{array}$ & & $335.9 \%$ & - & $\begin{array}{c}\text { Bomba de } \\
\text { Calor - } \\
\text { Caudal Ref. } \\
\text { Variable }\end{array}$ & & $298.7 \%$ & - & - \\
\hline TOTALES & & & & & & & & & \\
\hline
\end{tabular}

\section{Generadores de refrigeración}

\begin{tabular}{|c|c|c|c|c|c|c|c|c|c|}
\hline \multirow[t]{2}{*}{ Nombre } & \multirow[t]{2}{*}{ Tipo } & $\begin{array}{r}\text { Potencia } \\
\text { nominal }\end{array}$ & $\begin{array}{c}\text { Rendi- } \\
\text { miento } \\
\text { Estacional }\end{array}$ & $\begin{array}{c}\text { Estimación } \\
\text { Energía } \\
\text { Consumida } \\
\text { anual }\end{array}$ & \multirow[t]{2}{*}{$\begin{array}{l}\text { Tipo post } \\
\text { mejora }\end{array}$} & $\begin{array}{c}\text { Potencia } \\
\text { nominal } \\
\text { post } \\
\text { mejora }\end{array}$ & $\begin{array}{c}\text { Rendimiento } \\
\text { estacional } \\
\text { post mejora }\end{array}$ & $\begin{array}{c}\text { Estimación } \\
\text { Energía } \\
\text { Consumida } \\
\text { anual Post } \\
\text { mejora }\end{array}$ & $\begin{array}{c}\text { Energía } \\
\text { anual } \\
\text { ahorrada }\end{array}$ \\
\hline & & {$[\mathrm{kW}]$} & {$[\%]$} & {$\left[\mathrm{kWh} / \mathrm{m}^{2} \mathrm{año}\right]$} & & {$[\mathrm{kW}]$} & {$[\%]$} & [kWh/m²año] & {$\left[\mathrm{kWh} / \mathrm{m}^{2} \mathrm{año}\right.$} \\
\hline $\begin{array}{l}\text { Calefacción y } \\
\text { refrigeración }\end{array}$ & $\begin{array}{c}\text { Bomba de } \\
\text { Calor - } \\
\text { Caudal Ref. } \\
\text { Variable }\end{array}$ & & $187.5 \%$ & - & $\begin{array}{c}\text { Bomba de } \\
\text { Calor - } \\
\text { Caudal Ref. } \\
\text { Variable }\end{array}$ & & $210.8 \%$ & - & - \\
\hline TOTALES & & - & & - & & - & & - & - \\
\hline
\end{tabular}

\section{Instalaciones de Agua Caliente Sanitaria}

\begin{tabular}{|c|c|c|c|c|c|c|c|c|c|}
\hline Nombre & Tipo & $\begin{array}{l}\text { Potencia } \\
\text { nominal }\end{array}$ & $\begin{array}{c}\text { Rendi- } \\
\text { miento } \\
\text { Estacional }\end{array}$ & $\begin{array}{c}\text { Estimación } \\
\text { Energía } \\
\text { Consumida } \\
\text { anual }\end{array}$ & $\begin{array}{c}\text { Tipo post } \\
\text { mejora }\end{array}$ & $\begin{array}{l}\text { Potencia } \\
\text { nominal } \\
\text { post } \\
\text { mejora }\end{array}$ & $\begin{array}{c}\text { Rendimiento } \\
\text { estacional } \\
\text { post mejora }\end{array}$ & $\begin{array}{c}\text { Estimación } \\
\text { Energía } \\
\text { Consumida } \\
\text { anual Post } \\
\text { mejora }\end{array}$ & $\begin{array}{l}\text { Energía } \\
\text { anual } \\
\text { ahorrada }\end{array}$ \\
\hline & & {$[\mathrm{kW}]$} & [\%] & {$\left[\mathrm{kWh} / \mathrm{m}^{2} \mathrm{año}\right]$} & & {$[\mathrm{kW}]$} & [\%] & [kWh/m²año] & [kWh/m²año] \\
\hline Equipo ACS & Efecto Joule & & $100.0 \%$ & - & Efecto Joule & & $100.0 \%$ & - & - \\
\hline TOTALES & & - & & - & & - & & - & - \\
\hline
\end{tabular}




\begin{tabular}{|c|c|c|c|c|c|}
\hline & $D E$ & $\begin{array}{c}\text { Ref. } \\
\text { Catastral }\end{array}$ & 000000000 & $\begin{array}{l}\text { Versión } \\
\text { informe } \\
\text { asociado }\end{array}$ & $01 / 12 / 2015$ \\
\hline $\begin{array}{c}\text { Certificación } \\
\text { Energética } \\
\text { de Edificioios }\end{array}$ & $\begin{array}{c}\text { Id. } \\
\text { Mejora }\end{array}$ & $\begin{array}{l}\text { Programa } \\
\text { y versión }\end{array}$ & CEXv2.1 & Fecha & $3 / 1 / 2004$ \\
\hline
\end{tabular}

\section{ENERGÍAS RENOVABLES}

\section{Eléctrica}

\begin{tabular}{|c|c|c|}
\hline Nombre & $\begin{array}{c}\text { Energía eléctrica generada y } \\
\text { autoconsumida [kWh/año] }\end{array}$ & $\begin{array}{c}\text { Energía eléctrica generada y } \\
\text { autoconsumida post mejora } \\
\text { [kWh/año] }\end{array}$ \\
\hline Incorporación/mejora de sistema fotovoltaico & - & 9130 \\
\hline TOTALES & - & 9130.0 \\
\hline
\end{tabular}




\begin{tabular}{|c|c|c|c|c|c|}
\hline & & $\begin{array}{c}\text { Ref. } \\
\text { Catastral }\end{array}$ & 000000000 & $\begin{array}{c}\text { Versión } \\
\text { informe } \\
\text { asociado }\end{array}$ & $01 / 12 / 2015$ \\
\hline $\begin{array}{l}\text { Certificación } \\
\text { Energética } \\
\text { de Edificios }\end{array}$ & $\begin{array}{c}\text { Id. } \\
\text { Mejora }\end{array}$ & $\begin{array}{l}\text { Programa } \\
\text { y versión }\end{array}$ & CEXv2.1 & Fecha & $3 / 1 / 2004$ \\
\hline
\end{tabular}

\section{Informe descriptivo de la medida de mejora}

\section{DENOMINACIÓN DE LA MEDIDA DE MEJORA}

Bomba de calor alto cop y eer con geotermia y vidrios activos + mejora aislamientos

\section{DESCRIPCIÓN DE LA MEDIDA DE MEJORA}

Características de la medida (modelo de equipos, materiales, parámetros característicos )

Coste estimado de la medida

Otros datos de interés

CALIFICACIÓN ENERGÉTICA GLOBAL

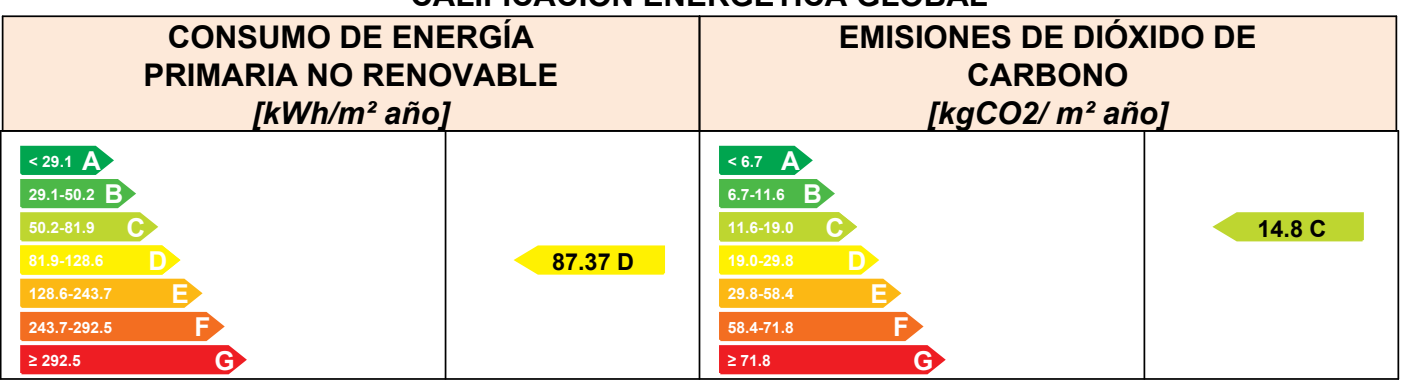

CALIFICACIONES ENERGÉTICAS PARCIALES

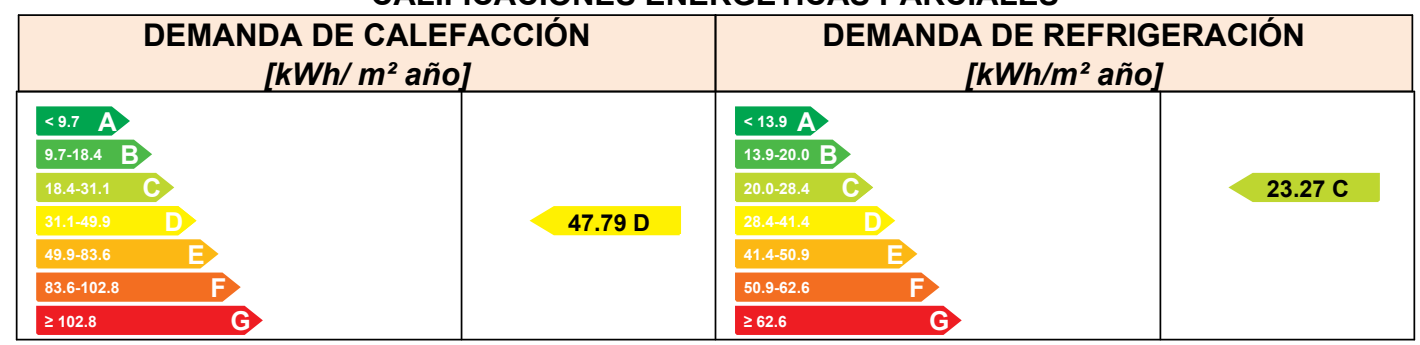




\begin{tabular}{|c|c|c|c|c|c|}
\hline & & $\begin{array}{c}\text { Ref. } \\
\text { Catastral }\end{array}$ & 000000000 & $\begin{array}{c}\text { Versión } \\
\text { informe } \\
\text { asociado }\end{array}$ & $01 / 12 / 2015$ \\
\hline $\begin{array}{l}\text { Certificación } \\
\text { Energética } \\
\text { de Edificios }\end{array}$ & $\begin{array}{c}\text { Id. } \\
\text { Mejora }\end{array}$ & $\begin{array}{l}\text { Programa } \\
\text { y versión }\end{array}$ & CEXv2.1 & Fecha & $3 / 1 / 2004$ \\
\hline
\end{tabular}

\section{ANALISÍS TÉCNICO}

\begin{tabular}{|c|c|c|c|c|c|c|c|c|c|c|c|c|c|c|c|}
\hline \multirow[b]{2}{*}{ Indicador } & \multicolumn{3}{|c|}{ Calefacción } & \multicolumn{3}{|c|}{ Refrigeración } & \multicolumn{3}{|c|}{ ACS } & \multicolumn{3}{|c|}{ Iluminación } & \multicolumn{3}{|c|}{ Total } \\
\hline & \multicolumn{2}{|c|}{ Valor } & $\begin{array}{c}\text { ahorro } \\
\text { respecto a } \\
\text { la situación } \\
\text { original }\end{array}$ & \multicolumn{2}{|c|}{ Valor } & $\begin{array}{c}\text { ahorro } \\
\text { respecto a } \\
\text { la situación } \\
\text { original }\end{array}$ & \multicolumn{2}{|c|}{ Valor } & $\begin{array}{c}\text { ahorro } \\
\text { respecto a } \\
\text { la situación } \\
\text { original }\end{array}$ & \multicolumn{2}{|c|}{ Valor } & $\begin{array}{c}\text { ahorro } \\
\text { respecto a } \\
\text { la situación } \\
\text { original }\end{array}$ & \multicolumn{2}{|c|}{ Valor } & $\begin{array}{c}\text { ahorro } \\
\text { respecto a } \\
\text { la situación } \\
\text { original }\end{array}$ \\
\hline $\begin{array}{l}\text { Consumo Energía } \\
\text { final }\left[\mathrm{kWh} / \mathrm{m}^{2} \text { año] }\right.\end{array}$ & \multicolumn{2}{|c|}{0.00} & $100.0 \%$ & \multicolumn{2}{|c|}{0.00} & $100.0 \%$ & \multicolumn{2}{|c|}{44.71} & $0.0 \%$ & \multicolumn{2}{|c|}{-} & $-\%$ & \multicolumn{2}{|c|}{44.71} & $60.4 \%$ \\
\hline $\begin{array}{c}\text { Consumo Energía } \\
\text { primaria no renovable } \\
{\left[\mathrm{kWh} / \mathrm{m}^{2} \text { año] }\right.}\end{array}$ & 0.00 & A & $100.0 \%$ & 0.00 & A & $100.0 \%$ & 87.37 & G & $0.0 \%$ & - & - & $-\%$ & 87.37 & $\mathrm{D}$ & $60.4 \%$ \\
\hline $\begin{array}{c}\text { Emisiones de CO2 } \\
{\left[\mathrm{kgCO} 2 / \mathrm{m}^{2} \text { año] }\right.}\end{array}$ & 0.00 & A & $100.0 \%$ & 0.00 & A & $100.0 \%$ & 14.80 & G & $0.0 \%$ & - & - & $-\%$ & 14.80 & C & $60.4 \%$ \\
\hline $\begin{array}{l}\text { Demanda }\left[\mathrm{kWh} / \mathrm{m}^{2}\right. \\
\text { año] }\end{array}$ & 47.79 & D & $62.2 \%$ & 23.27 & C & $59.5 \%$ & & & & & & & & & \\
\hline
\end{tabular}

\section{ENVOLVENTE TÉRMICA}

\section{Cerramientos opacos}

\begin{tabular}{|c|c|c|c|c|c|}
\hline Nombre & Tipo & $\begin{array}{c}\text { Superficie } \\
\text { actual } \\
{\left[\mathbf{m}^{2}\right]}\end{array}$ & $\begin{array}{c}\text { Transmitancia } \\
\text { actual } \\
{\left[\mathbf{W} / \mathbf{m}^{\mathbf{2}} \mathbf{~ K}\right]}\end{array}$ & $\begin{array}{c}\text { Superficie } \\
\text { post } \\
\text { mejora } \\
{\left[\mathbf{m}^{2}\right]}\end{array}$ & $\begin{array}{c}\text { Transmitancia } \\
\text { post mejora } \\
{\left[\mathbf{W} / \mathbf{m}^{\mathbf{2}} \mathbf{K}\right]}\end{array}$ \\
\hline Cubierta con aire & Cubierta & 52.00 & 0.47 & 52.00 & 0.22 \\
\hline Muro de fachada Norte & Fachada & 27.18 & 0.54 & 27.18 & 0.27 \\
\hline Suelo con aire & Suelo & 52.00 & 2.95 & 52.00 & 0.34 \\
\hline Muro de fachada Sur & Fachada & 21.88 & 0.54 & 21.88 & 0.27 \\
\hline Muro de fachada Oeste & Fachada & 8.04 & 0.54 & 8.04 & 0.27 \\
\hline Muro de fachada Este & Fachada & 3.28 & 0.54 & 3.28 & 0.27 \\
\hline
\end{tabular}

Huecos y lucernarios

\begin{tabular}{|c|c|c|c|c|c|c|c|}
\hline Nombre & Tipo & $\begin{array}{c}\text { Superficie } \\
\text { actual } \\
{\left[\mathrm{m}^{2}\right]}\end{array}$ & $\begin{array}{c}\text { Transmitancia } \\
\text { actual del } \\
\text { hueco[W/m² } \\
\mathrm{K}]\end{array}$ & $\begin{array}{c}\text { Transmitancia } \\
\text { actual del } \\
\text { vidrio[W/m² } \\
\mathrm{K}]\end{array}$ & $\begin{array}{l}\text { Superficie } \\
\text { post } \\
\text { mejora } \\
{\left[\mathrm{m}^{2}\right]}\end{array}$ & $\begin{array}{c}\text { Transmitancia } \\
\text { post mejora } \\
{\left[\mathrm{W} / \mathrm{m}^{2} \mathrm{~K}\right]}\end{array}$ & $\begin{array}{c}\text { Transmitancia } \\
\text { post mejora } \\
\text { del vidrio } \\
{\left[\mathrm{W} / \mathrm{m}^{2} \mathrm{~K}\right]}\end{array}$ \\
\hline V1 & Hueco & 5.3 & 5.70 & 5.70 & 5.3 & 1.27 & 1.12 \\
\hline V3 & Hueco & 5.3 & 5.70 & 5.70 & 5.3 & 1.27 & 1.12 \\
\hline V4 & Hueco & 5.3 & 5.70 & 5.70 & 5.3 & 1.27 & 1.12 \\
\hline V2 & Hueco & 5.3 & 5.70 & 5.70 & 5.3 & 1.27 & 1.12 \\
\hline V5 & Hueco & 5.03 & 5.70 & 5.70 & 5.03 & 1.27 & 1.12 \\
\hline Pta & Hueco & 5.03 & 5.70 & 5.70 & 5.03 & 1.27 & 1.12 \\
\hline
\end{tabular}




\begin{tabular}{|c|c|c|c|c|c|}
\hline & & $\begin{array}{c}\text { Ref. } \\
\text { Catastral }\end{array}$ & 000000000 & $\begin{array}{c}\text { Versión } \\
\text { informe } \\
\text { asociado }\end{array}$ & $01 / 12 / 2015$ \\
\hline $\begin{array}{l}\text { Certificación } \\
\text { Energética } \\
\text { de Edificios }\end{array}$ & $\begin{array}{c}\text { Id. } \\
\text { Mejora }\end{array}$ & $\begin{array}{l}\text { Programa } \\
\text { y versión }\end{array}$ & CEXv2.1 & Fecha & $3 / 1 / 2004$ \\
\hline
\end{tabular}

\section{INSTALACIONES TÉRMICAS}

\section{Generadores de calefacción}

\begin{tabular}{|c|c|c|c|c|c|c|c|c|c|}
\hline \multirow[t]{2}{*}{ Nombre } & \multirow[t]{2}{*}{ Tipo } & $\begin{array}{r}\text { Potencia } \\
\text { nominal }\end{array}$ & $\begin{array}{c}\text { Rendi- } \\
\text { miento } \\
\text { Estacional }\end{array}$ & $\begin{array}{c}\text { Estimación } \\
\text { Energía } \\
\text { Consumida } \\
\text { anual }\end{array}$ & \multirow[t]{2}{*}{$\begin{array}{l}\text { Tipo post } \\
\text { mejora }\end{array}$} & $\begin{array}{c}\text { Potencia } \\
\text { nominal } \\
\text { post } \\
\text { mejora }\end{array}$ & $\begin{array}{c}\text { Rendimiento } \\
\text { estacional } \\
\text { post mejora }\end{array}$ & $\begin{array}{c}\text { Estimación } \\
\text { Energía } \\
\text { Consumida } \\
\text { anual Post } \\
\text { mejora }\end{array}$ & $\begin{array}{l}\text { Energía } \\
\text { anual } \\
\text { ahorrada }\end{array}$ \\
\hline & & {$[\mathrm{kW}]$} & [\%] & {$\left[\mathrm{kWh} / \mathrm{m}^{2} \mathrm{año}\right]$} & & {$[\mathrm{kW}]$} & [\%] & [kWh/m²año] & [kWh/m²año] \\
\hline $\begin{array}{l}\text { Calefacción y } \\
\text { refrigeración }\end{array}$ & $\begin{array}{c}\text { Bomba de } \\
\text { Calor - } \\
\text { Caudal Ref. } \\
\text { Variable }\end{array}$ & & $335.9 \%$ & - & $\begin{array}{c}\text { Bomba de } \\
\text { Calor - } \\
\text { Caudal Ref. } \\
\text { Variable }\end{array}$ & & $595.4 \%$ & - & - \\
\hline TOTALES & & & & & & & & & \\
\hline
\end{tabular}

\section{Generadores de refrigeración}

\begin{tabular}{|c|c|c|c|c|c|c|c|c|c|}
\hline \multirow[t]{2}{*}{ Nombre } & \multirow[t]{2}{*}{ Tipo } & $\begin{array}{r}\text { Potencia } \\
\text { nominal }\end{array}$ & $\begin{array}{c}\text { Rendi- } \\
\text { miento } \\
\text { Estacional }\end{array}$ & $\begin{array}{c}\text { Estimación } \\
\text { Energía } \\
\text { Consumida } \\
\text { anual }\end{array}$ & \multirow[t]{2}{*}{$\begin{array}{l}\text { Tipo post } \\
\text { mejora }\end{array}$} & $\begin{array}{c}\text { Potencia } \\
\text { nominal } \\
\text { post } \\
\text { mejora }\end{array}$ & $\begin{array}{c}\text { Rendimiento } \\
\text { estacional } \\
\text { post mejora }\end{array}$ & $\begin{array}{c}\text { Estimación } \\
\text { Energía } \\
\text { Consumida } \\
\text { anual Post } \\
\text { mejora }\end{array}$ & $\begin{array}{c}\text { Energía } \\
\text { anual } \\
\text { ahorrada }\end{array}$ \\
\hline & & {$[\mathrm{kW}]$} & {$[\%]$} & {$\left[\mathrm{kWh} / \mathrm{m}^{2} \mathrm{año}\right]$} & & {$[\mathrm{kW}]$} & {$[\%]$} & [kWh/m²año] & {$\left[\mathrm{kWh} / \mathrm{m}^{2} \mathrm{año}\right.$} \\
\hline $\begin{array}{l}\text { Calefacción y } \\
\text { refrigeración }\end{array}$ & $\begin{array}{c}\text { Bomba de } \\
\text { Calor - } \\
\text { Caudal Ref. } \\
\text { Variable }\end{array}$ & & $187.5 \%$ & - & $\begin{array}{c}\text { Bomba de } \\
\text { Calor - } \\
\text { Caudal Ref. } \\
\text { Variable }\end{array}$ & & $419.4 \%$ & - & - \\
\hline TOTALES & & - & & - & & - & & - & - \\
\hline
\end{tabular}

\section{Instalaciones de Agua Caliente Sanitaria}

\begin{tabular}{|c|c|c|c|c|c|c|c|c|c|}
\hline Nombre & Tipo & $\begin{array}{l}\text { Potencia } \\
\text { nominal }\end{array}$ & $\begin{array}{c}\text { Rendi- } \\
\text { miento } \\
\text { Estacional }\end{array}$ & $\begin{array}{c}\text { Estimación } \\
\text { Energía } \\
\text { Consumida } \\
\text { anual }\end{array}$ & $\begin{array}{c}\text { Tipo post } \\
\text { mejora }\end{array}$ & $\begin{array}{l}\text { Potencia } \\
\text { nominal } \\
\text { post } \\
\text { mejora }\end{array}$ & $\begin{array}{c}\text { Rendimiento } \\
\text { estacional } \\
\text { post mejora }\end{array}$ & $\begin{array}{c}\text { Estimación } \\
\text { Energía } \\
\text { Consumida } \\
\text { anual Post } \\
\text { mejora }\end{array}$ & $\begin{array}{l}\text { Energía } \\
\text { anual } \\
\text { ahorrada }\end{array}$ \\
\hline & & {$[\mathrm{kW}]$} & [\%] & {$\left[\mathrm{kWh} / \mathrm{m}^{2} \mathrm{año}\right]$} & & {$[\mathrm{kW}]$} & [\%] & [kWh/m²año] & [kWh/m²año] \\
\hline Equipo ACS & Efecto Joule & & $100.0 \%$ & - & Efecto Joule & & $100.0 \%$ & - & - \\
\hline TOTALES & & - & & - & & - & & - & - \\
\hline
\end{tabular}




\begin{tabular}{|c|c|c|c|c|c|}
\hline & DEN & $\begin{array}{c}\text { Ref. } \\
\text { Catastral }\end{array}$ & 000000000 & $\begin{array}{c}\text { Versión } \\
\text { informe } \\
\text { asociado }\end{array}$ & $01 / 12 / 2015$ \\
\hline $\begin{array}{c}\text { Certificación } \\
\text { Energatica } \\
\text { de Edificios } \\
\text { de Editios }\end{array}$ & $\begin{array}{c}\text { Id. } \\
\text { Mejora }\end{array}$ & $\begin{array}{l}\text { Programa } \\
\text { y versión }\end{array}$ & CEXv2.1 & Fecha & $3 / 1 / 2004$ \\
\hline
\end{tabular}

\section{ENERGÍAS RENOVABLES}

\section{Térmica}

\begin{tabular}{|c|c|c|c|c|}
\hline \multirow{2}{*}{ Nombre } & \multicolumn{3}{|c|}{$\begin{array}{c}\text { Consumo de Energía Final, cubierto en función } \\
\text { del servicio asociado [\%] }\end{array}$} & $\begin{array}{c}\text { Demanda de ACS } \\
\text { cubierta [\%] }\end{array}$ \\
\cline { 2 - 5 } & Calefacción & Refrigeración & ACS & \\
\hline- & - & - & - & - \\
\hline TOTALES & - & - & - & - \\
\hline
\end{tabular}

\section{Post mejora}

\begin{tabular}{|c|c|c|c|c|}
\hline \multirow{2}{*}{ Nombre } & \multicolumn{2}{|c|}{$\begin{array}{c}\text { Consumo de Energía Final, cubierto en función } \\
\text { del servicio asociado [\%] }\end{array}$} & $\begin{array}{c}\text { Demanda de ACS } \\
\text { cubierta [\%] }\end{array}$ \\
\cline { 2 - 5 } & Calefacción & Refrigeración & ACS & \\
\hline Sistema geotérmico & 100 & 100 & - & - \\
\hline TOTALES & 100.0 & 100.0 & - & - \\
\hline
\end{tabular}




\begin{tabular}{|c|c|c|c|c|c|}
\hline & & $\begin{array}{c}\text { Ref. } \\
\text { Catastral }\end{array}$ & 000000000 & $\begin{array}{c}\text { Versión } \\
\text { informe } \\
\text { asociado }\end{array}$ & $01 / 12 / 2015$ \\
\hline $\begin{array}{l}\text { Certificación } \\
\text { Energética } \\
\text { de Edificios }\end{array}$ & $\begin{array}{c}\text { Id. } \\
\text { Mejora }\end{array}$ & $\begin{array}{l}\text { Programa } \\
\text { y versión }\end{array}$ & CEXv2.1 & Fecha & $3 / 1 / 2004$ \\
\hline
\end{tabular}

\section{Informe descriptivo de la medida de mejora}

\section{DENOMINACIÓN DE LA MEDIDA DE MEJORA}

Bomba de calor alto cop y eer con geotermia y vidrios activos

\section{DESCRIPCIÓN DE LA MEDIDA DE MEJORA}

Características de la medida (modelo de equipos, materiales, parámetros característicos )

Coste estimado de la medida

Otros datos de interés

CALIFICACIÓN ENERGÉTICA GLOBAL

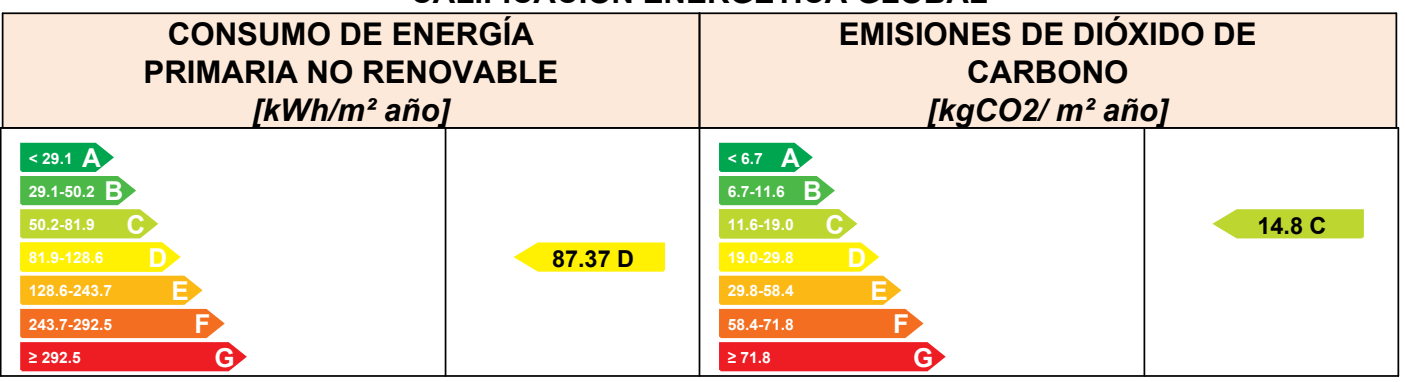

CALIFICACIONES ENERGÉTICAS PARCIALES

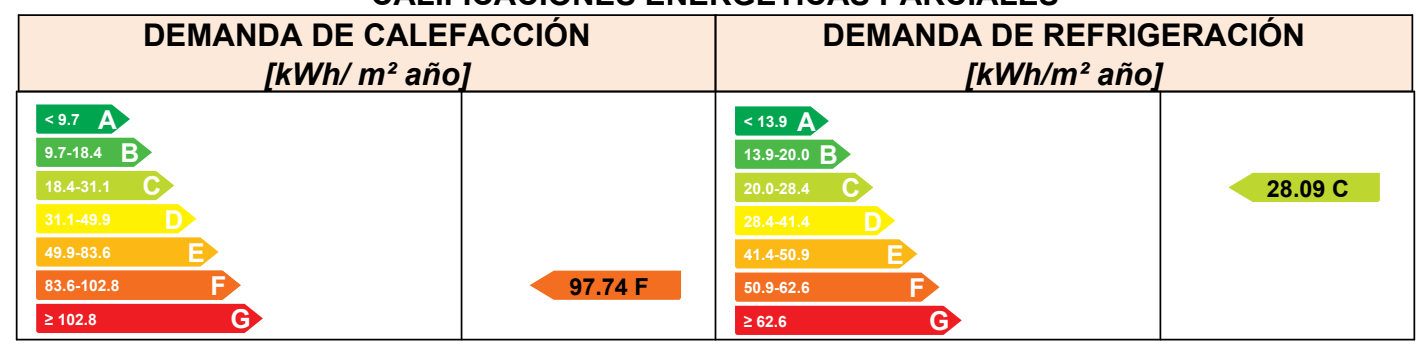




\begin{tabular}{|c|c|c|c|c|c|}
\hline & & $\begin{array}{c}\text { Ref. } \\
\text { Catastral }\end{array}$ & 000000000 & $\begin{array}{c}\text { Versión } \\
\text { informe } \\
\text { asociado }\end{array}$ & $01 / 12 / 2015$ \\
\hline $\begin{array}{l}\text { Certificación } \\
\text { Energética } \\
\text { de Edificios }\end{array}$ & $\begin{array}{c}\text { Id. } \\
\text { Mejora }\end{array}$ & $\begin{array}{l}\text { Programa } \\
\text { y versión }\end{array}$ & CEXv2.1 & Fecha & $3 / 1 / 2004$ \\
\hline
\end{tabular}

\section{ANALISÍS TÉCNICO}

\begin{tabular}{|c|c|c|c|c|c|c|c|c|c|c|c|c|c|c|c|}
\hline \multirow[b]{2}{*}{ Indicador } & \multicolumn{3}{|c|}{ Calefacción } & \multicolumn{3}{|c|}{ Refrigeración } & \multicolumn{3}{|c|}{ ACS } & \multicolumn{3}{|c|}{ Iluminación } & \multicolumn{3}{|c|}{ Total } \\
\hline & \multicolumn{2}{|c|}{ Valor } & $\begin{array}{c}\text { ahorro } \\
\text { respecto a } \\
\text { la situación } \\
\text { original }\end{array}$ & \multicolumn{2}{|c|}{ Valor } & $\begin{array}{c}\text { ahorro } \\
\text { respecto a } \\
\text { la situación } \\
\text { original }\end{array}$ & \multicolumn{2}{|c|}{ Valor } & $\begin{array}{c}\text { ahorro } \\
\text { respecto a } \\
\text { la situación } \\
\text { original }\end{array}$ & \multicolumn{2}{|c|}{ Valor } & $\begin{array}{c}\text { ahorro } \\
\text { respecto a } \\
\text { la situación } \\
\text { original }\end{array}$ & \multicolumn{2}{|c|}{ Valor } & $\begin{array}{c}\text { ahorro } \\
\text { respecto a } \\
\text { la situación } \\
\text { original }\end{array}$ \\
\hline $\begin{array}{l}\text { Consumo Energía } \\
\text { final }\left[\mathrm{kWh} / \mathrm{m}^{2} \text { año] }\right.\end{array}$ & \multicolumn{2}{|c|}{0.00} & $100.0 \%$ & \multicolumn{2}{|c|}{0.00} & $100.0 \%$ & \multicolumn{2}{|c|}{44.71} & $0.0 \%$ & \multicolumn{2}{|c|}{-} & $-\%$ & \multicolumn{2}{|c|}{44.71} & $60.4 \%$ \\
\hline $\begin{array}{c}\text { Consumo Energía } \\
\text { primaria no renovable } \\
{\left[\mathrm{kWh} / \mathrm{m}^{2} \text { año] }\right.}\end{array}$ & 0.00 & A & $100.0 \%$ & 0.00 & A & $100.0 \%$ & 87.37 & G & $0.0 \%$ & - & - & $-\%$ & 87.37 & $\mathrm{D}$ & $60.4 \%$ \\
\hline $\begin{array}{c}\text { Emisiones de CO2 } \\
{\left[\mathrm{kgCO} 2 / \mathrm{m}^{2} \text { año] }\right.}\end{array}$ & 0.00 & A & $100.0 \%$ & 0.00 & A & $100.0 \%$ & 14.80 & G & $0.0 \%$ & - & - & $-\%$ & 14.80 & C & $60.4 \%$ \\
\hline $\begin{array}{l}\text { Demanda }\left[\mathrm{kWh} / \mathrm{m}^{2}\right. \\
\text { año] }\end{array}$ & 97.74 & $\mathrm{~F}$ & $22.7 \%$ & 28.09 & C & $51.1 \%$ & & & & & & & & & \\
\hline
\end{tabular}

\section{ENVOLVENTE TÉRMICA}

\section{Cerramientos opacos}

\begin{tabular}{|c|c|c|c|c|c|}
\hline Nombre & Tipo & $\begin{array}{c}\text { Superficie } \\
\text { actual } \\
{\left[\mathbf{m}^{2}\right]}\end{array}$ & $\begin{array}{c}\text { Transmitancia } \\
\text { actual } \\
{\left[\mathbf{W} / \mathbf{m}^{\mathbf{2}} \mathbf{~ K}\right]}\end{array}$ & $\begin{array}{c}\text { Superficie } \\
\text { post } \\
\text { mejora } \\
{\left[\mathbf{m}^{2}\right]}\end{array}$ & $\begin{array}{c}\text { Transmitancia } \\
\text { post mejora } \\
{\left[\mathbf{W} / \mathbf{m}^{\mathbf{2}} \mathbf{K}\right]}\end{array}$ \\
\hline Cubierta con aire & Cubierta & 52.00 & 0.47 & 52.00 & 0.47 \\
\hline Muro de fachada Norte & Fachada & 27.18 & 0.54 & 27.18 & 0.54 \\
\hline Suelo con aire & Suelo & 52.00 & 2.95 & 52.00 & 2.95 \\
\hline Muro de fachada Sur & Fachada & 21.88 & 0.54 & 21.88 & 0.54 \\
\hline Muro de fachada Oeste & Fachada & 8.04 & 0.54 & 8.04 & 0.54 \\
\hline Muro de fachada Este & Fachada & 3.28 & 0.54 & 3.28 & 0.54 \\
\hline
\end{tabular}

Huecos y lucernarios

\begin{tabular}{|c|c|c|c|c|c|c|c|}
\hline Nombre & Tipo & $\begin{array}{c}\text { Superficie } \\
\text { actual } \\
{\left[\mathrm{m}^{2}\right]}\end{array}$ & $\begin{array}{c}\text { Transmitancia } \\
\text { actual del } \\
\text { hueco[W/m² } \\
\mathrm{K}]\end{array}$ & $\begin{array}{c}\text { Transmitancia } \\
\text { actual del } \\
\text { vidrio[W/m² } \\
\mathrm{K}]\end{array}$ & $\begin{array}{c}\text { Superficie } \\
\text { post } \\
\text { mejora } \\
{\left[\mathrm{m}^{2}\right]}\end{array}$ & $\begin{array}{c}\text { Transmitancia } \\
\text { post mejora } \\
{\left[\mathrm{W} / \mathrm{m}^{2} \mathrm{~K}\right]}\end{array}$ & $\begin{array}{c}\text { Transmitancia } \\
\text { post mejora } \\
\text { del vidrio } \\
{\left[\mathrm{W} / \mathrm{m}^{2} \mathrm{~K}\right]}\end{array}$ \\
\hline V1 & Hueco & 5.3 & 5.70 & 5.70 & 5.3 & 1.27 & 1.12 \\
\hline V3 & Hueco & 5.3 & 5.70 & 5.70 & 5.3 & 1.27 & 1.12 \\
\hline V4 & Hueco & 5.3 & 5.70 & 5.70 & 5.3 & 1.27 & 1.12 \\
\hline V2 & Hueco & 5.3 & 5.70 & 5.70 & 5.3 & 1.27 & 1.12 \\
\hline V5 & Hueco & 5.03 & 5.70 & 5.70 & 5.03 & 1.27 & 1.12 \\
\hline Pta & Hueco & 5.03 & 5.70 & 5.70 & 5.03 & 1.27 & 1.12 \\
\hline
\end{tabular}




\begin{tabular}{|c|c|c|c|c|c|}
\hline & & $\begin{array}{c}\text { Ref. } \\
\text { Catastral }\end{array}$ & 000000000 & $\begin{array}{c}\text { Versión } \\
\text { informe } \\
\text { asociado }\end{array}$ & $01 / 12 / 2015$ \\
\hline $\begin{array}{l}\text { Certificación } \\
\text { Energética } \\
\text { de Edificios }\end{array}$ & $\begin{array}{c}\text { Id. } \\
\text { Mejora }\end{array}$ & $\begin{array}{l}\text { Programa } \\
\text { y versión }\end{array}$ & CEXv2.1 & Fecha & $3 / 1 / 2004$ \\
\hline
\end{tabular}

\section{INSTALACIONES TÉRMICAS}

\section{Generadores de calefacción}

\begin{tabular}{|c|c|c|c|c|c|c|c|c|c|}
\hline \multirow[t]{2}{*}{ Nombre } & \multirow[t]{2}{*}{ Tipo } & $\begin{array}{r}\text { Potencia } \\
\text { nominal }\end{array}$ & $\begin{array}{c}\text { Rendi- } \\
\text { miento } \\
\text { Estacional }\end{array}$ & $\begin{array}{c}\text { Estimación } \\
\text { Energía } \\
\text { Consumida } \\
\text { anual }\end{array}$ & \multirow[t]{2}{*}{$\begin{array}{l}\text { Tipo post } \\
\text { mejora }\end{array}$} & $\begin{array}{c}\text { Potencia } \\
\text { nominal } \\
\text { post } \\
\text { mejora }\end{array}$ & $\begin{array}{c}\text { Rendimiento } \\
\text { estacional } \\
\text { post mejora }\end{array}$ & $\begin{array}{c}\text { Estimación } \\
\text { Energía } \\
\text { Consumida } \\
\text { anual Post } \\
\text { mejora }\end{array}$ & $\begin{array}{l}\text { Energía } \\
\text { anual } \\
\text { ahorrada }\end{array}$ \\
\hline & & {$[\mathrm{kW}]$} & [\%] & {$\left[\mathrm{kWh} / \mathrm{m}^{2} \mathrm{año}\right]$} & & {$[\mathrm{kW}]$} & [\%] & [kWh/m²año] & [kWh/m²año] \\
\hline $\begin{array}{l}\text { Calefacción y } \\
\text { refrigeración }\end{array}$ & $\begin{array}{c}\text { Bomba de } \\
\text { Calor - } \\
\text { Caudal Ref. } \\
\text { Variable }\end{array}$ & & $335.9 \%$ & - & $\begin{array}{c}\text { Bomba de } \\
\text { Calor - } \\
\text { Caudal Ref. } \\
\text { Variable }\end{array}$ & & $595.4 \%$ & - & - \\
\hline TOTALES & & & & & & & & & \\
\hline
\end{tabular}

\section{Generadores de refrigeración}

\begin{tabular}{|c|c|c|c|c|c|c|c|c|c|}
\hline \multirow[t]{2}{*}{ Nombre } & \multirow[t]{2}{*}{ Tipo } & $\begin{array}{r}\text { Potencia } \\
\text { nominal }\end{array}$ & $\begin{array}{c}\text { Rendi- } \\
\text { miento } \\
\text { Estacional }\end{array}$ & $\begin{array}{c}\text { Estimación } \\
\text { Energía } \\
\text { Consumida } \\
\text { anual }\end{array}$ & \multirow[t]{2}{*}{$\begin{array}{l}\text { Tipo post } \\
\text { mejora }\end{array}$} & $\begin{array}{c}\text { Potencia } \\
\text { nominal } \\
\text { post } \\
\text { mejora }\end{array}$ & $\begin{array}{c}\text { Rendimiento } \\
\text { estacional } \\
\text { post mejora }\end{array}$ & $\begin{array}{c}\text { Estimación } \\
\text { Energía } \\
\text { Consumida } \\
\text { anual Post } \\
\text { mejora }\end{array}$ & $\begin{array}{c}\text { Energía } \\
\text { anual } \\
\text { ahorrada }\end{array}$ \\
\hline & & {$[\mathrm{kW}]$} & {$[\%]$} & {$\left[\mathrm{kWh} / \mathrm{m}^{2} \mathrm{año}\right]$} & & {$[\mathrm{kW}]$} & {$[\%]$} & [kWh/m²año] & {$\left[\mathrm{kWh} / \mathrm{m}^{2} \mathrm{año}\right.$} \\
\hline $\begin{array}{l}\text { Calefacción y } \\
\text { refrigeración }\end{array}$ & $\begin{array}{c}\text { Bomba de } \\
\text { Calor - } \\
\text { Caudal Ref. } \\
\text { Variable }\end{array}$ & & $187.5 \%$ & - & $\begin{array}{c}\text { Bomba de } \\
\text { Calor - } \\
\text { Caudal Ref. } \\
\text { Variable }\end{array}$ & & $419.4 \%$ & - & - \\
\hline TOTALES & & - & & - & & - & & - & - \\
\hline
\end{tabular}

\section{Instalaciones de Agua Caliente Sanitaria}

\begin{tabular}{|c|c|c|c|c|c|c|c|c|c|}
\hline Nombre & Tipo & $\begin{array}{l}\text { Potencia } \\
\text { nominal }\end{array}$ & $\begin{array}{c}\text { Rendi- } \\
\text { miento } \\
\text { Estacional }\end{array}$ & $\begin{array}{c}\text { Estimación } \\
\text { Energía } \\
\text { Consumida } \\
\text { anual }\end{array}$ & $\begin{array}{c}\text { Tipo post } \\
\text { mejora }\end{array}$ & $\begin{array}{l}\text { Potencia } \\
\text { nominal } \\
\text { post } \\
\text { mejora }\end{array}$ & $\begin{array}{c}\text { Rendimiento } \\
\text { estacional } \\
\text { post mejora }\end{array}$ & $\begin{array}{c}\text { Estimación } \\
\text { Energía } \\
\text { Consumida } \\
\text { anual Post } \\
\text { mejora }\end{array}$ & $\begin{array}{l}\text { Energía } \\
\text { anual } \\
\text { ahorrada }\end{array}$ \\
\hline & & {$[\mathrm{kW}]$} & [\%] & {$\left[\mathrm{kWh} / \mathrm{m}^{2} \mathrm{año}\right]$} & & {$[\mathrm{kW}]$} & [\%] & [kWh/m²año] & [kWh/m²año] \\
\hline Equipo ACS & Efecto Joule & & $100.0 \%$ & - & Efecto Joule & & $100.0 \%$ & - & - \\
\hline TOTALES & & - & & - & & - & & - & - \\
\hline
\end{tabular}




\begin{tabular}{|c|c|c|c|c|c|}
\hline & DEN & $\begin{array}{c}\text { Ref. } \\
\text { Catastral }\end{array}$ & 000000000 & $\begin{array}{c}\text { Versión } \\
\text { informe } \\
\text { asociado }\end{array}$ & $01 / 12 / 2015$ \\
\hline $\begin{array}{c}\text { Certificación } \\
\text { Energatica } \\
\text { de Edificios } \\
\text { de Editios }\end{array}$ & $\begin{array}{c}\text { Id. } \\
\text { Mejora }\end{array}$ & $\begin{array}{l}\text { Programa } \\
\text { y versión }\end{array}$ & CEXv2.1 & Fecha & $3 / 1 / 2004$ \\
\hline
\end{tabular}

\section{ENERGÍAS RENOVABLES}

\section{Térmica}

\begin{tabular}{|c|c|c|c|c|}
\hline \multirow{2}{*}{ Nombre } & \multicolumn{3}{|c|}{$\begin{array}{c}\text { Consumo de Energía Final, cubierto en función } \\
\text { del servicio asociado [\%] }\end{array}$} & $\begin{array}{c}\text { Demanda de ACS } \\
\text { cubierta [\%] }\end{array}$ \\
\cline { 2 - 5 } & Calefacción & Refrigeración & ACS & \\
\hline- & - & - & - & - \\
\hline TOTALES & - & - & - & - \\
\hline
\end{tabular}

\section{Post mejora}

\begin{tabular}{|c|c|c|c|c|}
\hline \multirow{2}{*}{ Nombre } & \multicolumn{2}{|c|}{$\begin{array}{c}\text { Consumo de Energía Final, cubierto en función } \\
\text { del servicio asociado [\%] }\end{array}$} & $\begin{array}{c}\text { Demanda de ACS } \\
\text { cubierta [\%] }\end{array}$ \\
\cline { 2 - 5 } & Calefacción & Refrigeración & ACS & \\
\hline Sistema geotérmico & 100 & 100 & - & - \\
\hline TOTALES & 100.0 & 100.0 & - & - \\
\hline
\end{tabular}


A.6.5

Zona Climática BSk (Koppen)/ D3 (CTE). Madrid. 


\section{CERTIFICADO DE EFICIENCIA ENERGÉTICA DE EDIFICIOS}

IDENTIFICACIÓN DEL EDIFICIO O DE LA PARTE QUE SE CERTIFICA:

\begin{tabular}{|l|l|l|l|}
\hline Nombre del edificio & Vivienda Taller Modificado \\
\hline Dirección & Tesis & \multicolumn{3}{|l|}{} \\
\hline Municipio & Madrid & Código Postal & 28040 \\
\hline Provincia & Madrid & Comunidad Autónoma & $\begin{array}{l}\text { Comunidad } \\
\text { Madrid }\end{array}$ \\
\hline Zona climática & D3 & Año construcción & 2007 \\
\hline $\begin{array}{l}\text { Normativa vigente (construcción } \\
\text { rehabilitación) }\end{array}$ & C.T.E. & \\
\hline Referencia/s catastral/es & 000000000 & \\
\hline
\end{tabular}

\begin{tabular}{|l|l|}
\hline \multicolumn{2}{|c|}{ Tipo de edificio o parte del edificio que se certifica: } \\
\hline$\circ$ Edificio de nueva construcción & $\bullet$ Edificio Existente \\
\hline & \\
\hline & $\circ$ Terciario \\
Vivienda & $\circ$ Edificio completo \\
$\begin{array}{l}\text { Unifamiliar } \\
\text { Bloque } \\
\circ \text { Bloque completo } \\
\circ \text { Vivienda individual }\end{array}$ & $\circ$ Local \\
\hline
\end{tabular}

DATOS DEL TÉCNICO CERTIFICADOR:

\begin{tabular}{|c|c|c|c|c|c|}
\hline Nombre y Apellidos & \multicolumn{3}{|c|}{ Juan Carlos Sánchez } & NIF(NIE) & 000000000 \\
\hline Razón social & \multicolumn{2}{|c|}{ Juan Carlos Sánchez } & & NIF & 000000000 \\
\hline \multicolumn{2}{|l|}{ Domicilio } & \multicolumn{4}{|l|}{ Calle Pinar Del Rey } \\
\hline \multicolumn{2}{|l|}{ Municipio } & Madrid & \multicolumn{2}{|c|}{ Código Postal } & 28033 \\
\hline \multicolumn{2}{|l|}{ Provincia } & Madrid & \multicolumn{2}{|c|}{ Comunidad Autónoma } & $\begin{array}{l}\text { Comunidad de } \\
\text { Madrid }\end{array}$ \\
\hline \multicolumn{2}{|c|}{ e-mail: } & \multicolumn{2}{|c|}{ juancsanchezg@hotmail.com } & Teléfono & 0000000000 \\
\hline \multicolumn{2}{|c|}{ Titulación habilitante según normativa vigente } & \multicolumn{4}{|c|}{ Arquitecto } \\
\hline \multicolumn{3}{|c|}{$\begin{array}{l}\text { Procedimiento reconocido de calificación energética utilizado y } \\
\text { versión: }\end{array}$} & \multicolumn{3}{|c|}{ CEXv2.1 } \\
\hline
\end{tabular}

CALIFICACIÓN ENERGÉTICA OBTENIDA:

\begin{tabular}{|c|c|c|c|}
\hline \multicolumn{2}{|c|}{$\begin{array}{l}\text { CONSUMO DE ENERGÍA } \\
\text { PRIMARIA NO RENOVABLE } \\
\text { [kWh/m² año] }\end{array}$} & \multicolumn{2}{|c|}{$\begin{array}{l}\text { EMISIONES DE DIÓXIDO DE } \\
\text { CARBONO } \\
{\left[\mathrm{kgCO} 2 / \mathrm{m}^{2} \text { año] }\right.}\end{array}$} \\
\hline 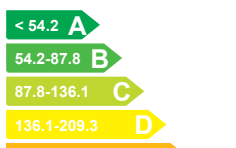 & & 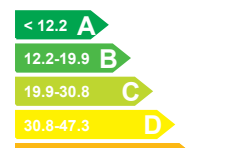 & \\
\hline $\begin{array}{lr}2009.3756 .6 & B \\
375.6473 .2 & F \\
2473.2 & G\end{array}$ & $321.4 \mathrm{E}$ & 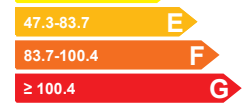 & $54.4 \mathrm{E}$ \\
\hline
\end{tabular}

El técnico abajo firmante declara responsablemente que ha realizado la certificación energética del edificio o de la parte que se certifica de acuerdo con el procedimiento establecido por la normativa vigente y que son ciertos los datos que figuran en el presente documento, y sus anexos:

Fecha: 01/12/2015

Firma del técnico certificador

Anexo I. Descripción de las características energéticas del edificio.

Anexo II. Calificación energética del edificio.

Anexo III. Recomendaciones para la mejora de la eficiencia energética.

Anexo IV. Pruebas, comprobaciones e inspecciones realizadas por el técnico certificador.

Registro del Órgano Territorial Competente: 


\section{DESCRIPCIÓN DE LAS CARACTERÍSTICAS ENERGÉTICAS DEL EDIFICIO}

En este apartado se describen las características energéticas del edificio, envolvente térmica, instalaciones, condiciones de funcionamiento y ocupación y demás datos utilizados para obtener la calificación energética del edificio.

\section{SUPERFICIE, IMAGEN Y SITUACIÓN}

\begin{tabular}{|l|l}
\hline Superficie habitable $\left[\mathrm{m}^{2}\right]$ & 52.0
\end{tabular}

\begin{tabular}{|c|c|c|}
\hline Imagen del edificio & Plano de situación \\
\hline & &
\end{tabular}

\section{ENVOLVENTE TÉRMICA}

\section{Cerramientos opacos}

\begin{tabular}{|l|c|c|c|c|}
\hline \multicolumn{1}{|c|}{ Nombre } & Tipo & $\begin{array}{c}\text { Superficie } \\
{\left[\mathrm{m}^{2}\right]}\end{array}$ & $\begin{array}{c}\text { Transmitancia } \\
{\left[\mathbf{W} / \mathbf{m}^{2} \cdot \mathrm{K}\right]}\end{array}$ & Modo de obtención \\
\hline Cubierta con aire & Cubierta & 52.0 & 0.47 & Conocidas \\
\hline Muro de fachada Norte & Fachada & 27.18 & 0.54 & Conocidas \\
\hline Suelo con aire & Suelo & 52.0 & 2.95 & Conocidas \\
\hline Muro de fachada Sur & Fachada & 21.88 & 0.54 & Conocidas \\
\hline Muro de fachada Oeste & Fachada & 8.04 & 0.54 & Conocidas \\
\hline Muro de fachada Este & Fachada & 3.28 & 0.54 & Conocidas \\
\hline
\end{tabular}

Huecos y lucernarios

\begin{tabular}{|l|c|c|c|c|c|c|}
\hline Nombre & Tipo & $\begin{array}{c}\text { Superficie } \\
{\left[\mathbf{m}^{2}\right]}\end{array}$ & $\begin{array}{c}\text { Transmitancia } \\
{\left[\mathbf{W} / \mathbf{m}^{2} \cdot \mathbf{K}\right]}\end{array}$ & $\begin{array}{c}\text { Factor } \\
\text { solar }\end{array}$ & $\begin{array}{c}\text { Modo de } \\
\text { obtención. } \\
\text { Transmitancia }\end{array}$ & $\begin{array}{c}\text { Modo de } \\
\text { obtención. } \\
\text { Factor solar }\end{array}$ \\
\hline V1 & Hueco & 5.3 & 5.70 & 0.67 & Estimado & Estimado \\
\hline V3 & Hueco & 5.3 & 5.70 & 0.67 & Estimado & Estimado \\
\hline V4 & Hueco & 5.3 & 5.70 & 0.67 & Estimado & Estimado \\
\hline V2 & Hueco & 5.3 & 5.70 & 0.67 & Estimado & Estimado \\
\hline V5 & Hueco & 5.03 & 5.70 & 0.67 & Estimado & Estimado \\
\hline Pta & Hueco & 5.03 & 5.70 & 0.67 & Estimado & Estimado \\
\hline
\end{tabular}




\section{INSTALACIONES TÉRMICAS}

Generadores de calefacción

\begin{tabular}{|c|c|c|c|c|c|}
\hline Nombre & Tipo & $\begin{array}{c}\text { Potencia } \\
\text { nominal [kW] }\end{array}$ & $\begin{array}{l}\text { Rendimiento } \\
\text { Estacional[\%] }\end{array}$ & $\begin{array}{l}\text { Tipo de } \\
\text { Energía }\end{array}$ & $\begin{array}{c}\text { Modo de } \\
\text { obtención }\end{array}$ \\
\hline $\begin{array}{l}\text { Calefacción } \\
\text { refrigeración }\end{array}$ & $\begin{array}{l}\text { Bomba de Calor - } \\
\text { Caudal Ref. Variable }\end{array}$ & & 273.1 & Electricidad & Estimado \\
\hline TOTALES & Calefacción & & & & \\
\hline
\end{tabular}

\section{Generadores de refrigeración}

\begin{tabular}{|c|c|c|c|c|c|}
\hline Nombre & Tipo & $\begin{array}{c}\text { Potencia } \\
\text { nominal [kW] }\end{array}$ & $\begin{array}{c}\text { Rendimiento } \\
\text { Estacional[\%] }\end{array}$ & $\begin{array}{c}\text { Tipo de } \\
\text { Energía }\end{array}$ & $\begin{array}{c}\text { Modo de } \\
\text { obtención }\end{array}$ \\
\hline $\begin{array}{l}\text { Calefacción } \\
\text { refrigeración }\end{array}$ & $y$ & $\begin{array}{c}\text { Bomba de Calor } \\
\text { Caudal Ref. Variable }\end{array}$ & & 209.7 & Electricidad \\
\hline TOTALES & Refrigeración & & & \\
\hline
\end{tabular}

Instalaciones de Agua Caliente Sanitaria

Demanda diario de ACS a $60^{\circ}$ (litros/día) 45.55

\begin{tabular}{|c|c|c|c|c|c|}
\hline Nombre & Tipo & $\begin{array}{c}\text { Potencia } \\
\text { nominal [kW] }\end{array}$ & $\begin{array}{c}\text { Rendimiento } \\
\text { Estacional[\%] }\end{array}$ & $\begin{array}{c}\text { Tipo de } \\
\text { Energía }\end{array}$ & $\begin{array}{c}\text { Modo de } \\
\text { obtención }\end{array}$ \\
\hline Equipo ACS & Efecto Joule & & 100.0 & Electricidad & Estimado \\
\hline TOTALES & ACS & & & & \\
\hline
\end{tabular}




\section{ANEXO II
CALIFICACIÓN ENERGÉTICA DEL EDIFICIO}

\begin{tabular}{|l|l|l|l|}
\hline Zona climática & D3 & Uso & Residencial \\
\hline
\end{tabular}

\section{CALIFICACIÓN ENERGÉTICA DEL EDIFICIO EN EMISIONES}

\begin{tabular}{|c|c|c|c|c|c|}
\hline \multicolumn{2}{|c|}{ INDICADOR GLOBAL } & \multicolumn{4}{|c|}{ INDICADORES PARCIALES } \\
\hline \begin{tabular}{|l|}
$<12.2 \mathrm{~A}$ \\
$12.2-19.9 \mathrm{~B}$ \\
\end{tabular} & & \multicolumn{2}{|c|}{ CALEFACCIÓN } & \multicolumn{2}{|l|}{ ACS } \\
\hline 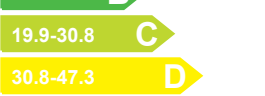 & & $\begin{array}{c}\text { Emisiones } \\
\text { calefacción } \\
{\left[\mathrm{kgCO} 2 / \mathrm{m}^{2} \text { añol }\right.}\end{array}$ & \multirow{2}{*}{ D } & $\begin{array}{l}\text { Emisiones ACS } \\
{\left[\mathrm{kgCO} 2 / \mathrm{m}^{2} \text { año] }\right.}\end{array}$ & \multirow{2}{*}{ G } \\
\hline $47.3-83.7$ & \multirow[t]{2}{*}{$54.4 \mathrm{E}$} & 32.25 & & 15.12 & \\
\hline $\begin{array}{ll}83.7-100.4 & F \\
\geq 100.4 & C\end{array}$ & & \multicolumn{2}{|c|}{ REFRIGERACIÓN } & \multicolumn{2}{|l|}{ ILUMINACIÓN } \\
\hline \multirow{2}{*}{\multicolumn{2}{|c|}{ Emisiones globales $\left[\mathrm{kgCO} 2 / \mathrm{m}^{2}\right.$ año] ${ }^{1}$}} & $\begin{array}{c}\text { Emisiones } \\
\text { refrigeración } \\
{\left[\mathrm{kgCO} 2 / \mathrm{m}^{2} \text { año] }\right.}\end{array}$ & \multirow[t]{2}{*}{ D } & $\begin{array}{c}\text { Emisiones } \\
\text { iluminación } \\
{\left[\mathrm{kgCO} 2 / \mathrm{m}^{2} \text { año] }\right.}\end{array}$ & \multirow[t]{2}{*}{-} \\
\hline & & 7.08 & & - & \\
\hline
\end{tabular}

La calificación global del edificio se expresa en términos de dióxido de carbono liberado a la atmósfera como consecuencia del consumo energético del mismo.

\begin{tabular}{|l|c|c|}
\cline { 2 - 3 } \multicolumn{1}{c|}{} & $\mathbf{k g C O} 2 / \mathbf{m}^{\mathbf{2}}$ año & $\mathbf{~} \mathbf{k g C O 2 / a n ̃ o ~}$ \\
\hline Emisiones CO2 por consumo eléctrico & 54.45 & 2831.22 \\
\hline Emisiones CO2 por otros combustibles & 0.00 & 0.00 \\
\hline
\end{tabular}

\section{CALIFICACIÓN ENERGÉTICA DEL EDIFICIO EN CONSUMO DE ENERGÍA PRIMARIA NO RENOVABLE}

Por energía primaria no renovable se entiende la energía consumida por el edificio procedente de fuentes no renovables que no ha sufrido ningún proceso de conversión o transformación.

\begin{tabular}{|c|c|c|c|c|c|}
\hline \multicolumn{2}{|c|}{ INDICADOR GLOBAL } & \multicolumn{4}{|c|}{ INDICADORES PARCIALES } \\
\hline \multirow{4}{*}{ 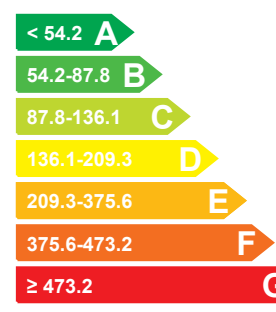 } & & \multicolumn{2}{|c|}{ CALEFACCIÓN } & \multicolumn{2}{|l|}{ ACS } \\
\hline & & $\begin{array}{l}\text { Energía primaria } \\
\text { calefacción } \\
{\left[\mathrm{kWh} / \mathrm{m}^{2} \text { año] }\right.}\end{array}$ & \multirow[t]{2}{*}{$\mathrm{E}$} & $\begin{array}{l}\text { Energía primaria } \\
A C S \\
{\left[\mathrm{kWh} / \mathrm{m}^{2} \text { año] }\right.}\end{array}$ & \multirow[t]{2}{*}{ G } \\
\hline & \multirow[t]{2}{*}{$321.4 \mathrm{E}$} & 190.39 & & 89.23 & \\
\hline & & \multicolumn{2}{|c|}{ REFRIGERACIÓN } & \multicolumn{2}{|l|}{ ILUMINACIÓN } \\
\hline \multirow{2}{*}{\multicolumn{2}{|c|}{$\begin{array}{l}\text { Consumo global de energía primaria no renovable } \\
\qquad\left[\mathrm{kWh} / \mathrm{m}^{2} \text { año }\right]^{1}\end{array}$}} & $\begin{array}{l}\text { Energía primaria } \\
\text { refrigeración } \\
{\left[\mathrm{kWh} / \mathrm{m}^{2} \text { añol }\right.}\end{array}$ & \multirow[t]{2}{*}{$\mathbf{F}$} & $\begin{array}{l}\text { Energía primaria } \\
\text { iluminación } \\
{\left[\mathrm{kWh} / \mathrm{m}^{2} a \tilde{n} o\right]}\end{array}$ & \\
\hline & & 41.79 & & - & \\
\hline
\end{tabular}

\section{CALIFICACIÓN PARCIAL DE LA DEMANDA ENERGÉTICA DE CALEFACCIÓN Y REFRIGERACIÓN}

La demanda energética de calefacción y refrigeración es la energía necesaria para mantener las condiciones internas de confort del edificio.

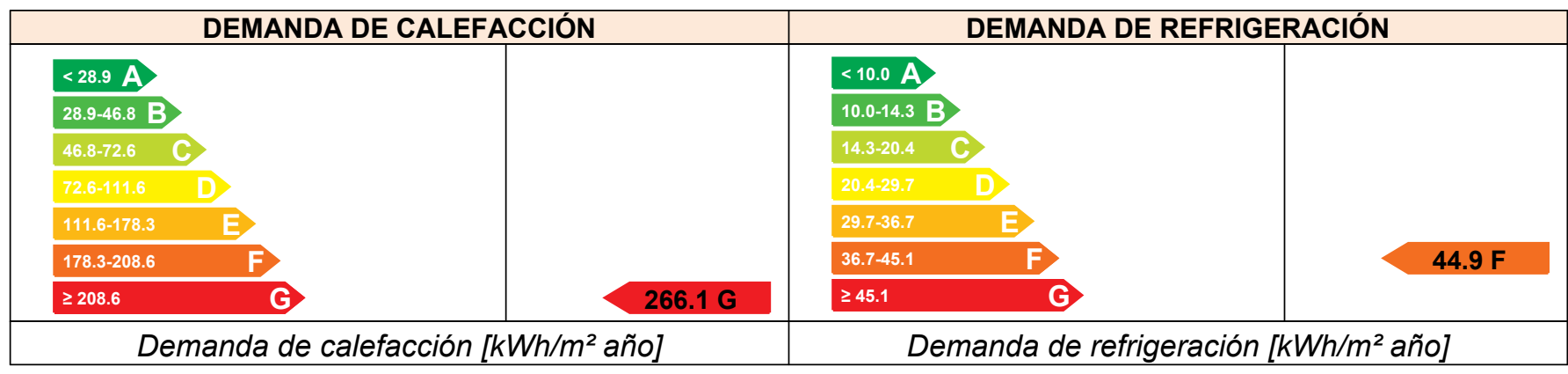

${ }^{1}$ El indicador global es resultado de la suma de los indicadores parciales más el valor del indicador para consumos auxiliares, si los hubiera (sólo ed. terciarios, ventilación, bombeo, etc...). La energía eléctrica autoconsumida se descuenta únicamente del indicador global, no así de los valores parciales 


\section{ANEXO III \\ RECOMENDACIONES PARA LA MEJORA DE LA EFICIENCIA ENERGÉTICA}

FV $100 \%$

CALIFICACIÓN ENERGÉTICA GLOBAL

\begin{tabular}{|c|c|c|c|}
\hline \multicolumn{2}{|c|}{$\begin{array}{l}\text { CONSUMO DE ENERGÍA } \\
\text { PRIMARIA NO RENOVABLE } \\
\text { [kWh/m² año] }\end{array}$} & \multicolumn{2}{|c|}{$\begin{array}{c}\text { EMISIONES DE DIÓXIDO DE } \\
\text { CARBONO } \\
{\left[\mathrm{kgCO} 2 / \mathrm{m}^{2} \text { año] }\right.}\end{array}$} \\
\hline$<54.2 \mathrm{~A}$ & & $<12.2$ A & \\
\hline $54.2-87.8 \mathrm{~B}$ & & 12.2-19.9 B & $16.5 \mathrm{~B}$ \\
\hline $87.8-136.1 \quad C$ & $97.1 \mathrm{C}$ & $19.9-30.8 \quad \mathrm{C}$ & \\
\hline $136.1-209.3$ D & & $30.8-47.3$ & \\
\hline 209.3-375.6 E & & $47.3-83.7$ & \\
\hline $375.6-473.2$ & & $83.7-100.4$ & \\
\hline$\geq 473.2 \quad$ G & & $\geq 100.4 \quad$ G & \\
\hline
\end{tabular}

CALIFICACIONES ENERGÉTICAS PARCIALES

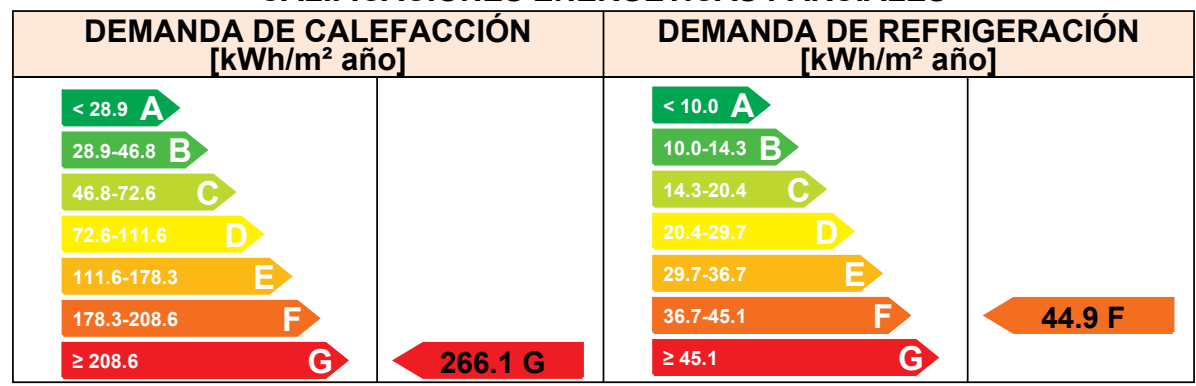

\section{ANÁLISIS TÉCNICO}

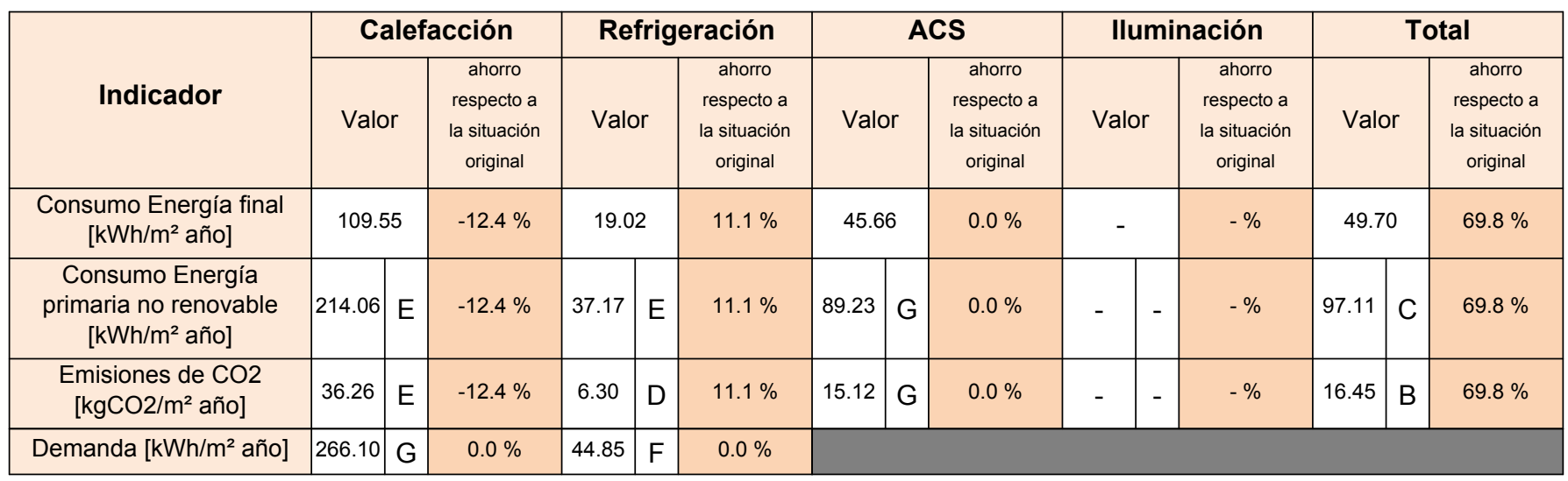

Nota: Los indicadores energéticos anteriores están calculados en base a coeficientes estándar de operación y funcionamiento del edificio, por lo que solo son válidos a efectos de su calificación energética. Para el análisis económico de las medidas de ahorro y eficiencia energética, el técnico certificador deberá utilizar las condiciones reales y datos históricos de consumo del edificio.

\section{DESCRIPCIÓN DE LA MEDIDA DE MEJORA}

Características de la medida (modelo de equipos, materiales, parámetros característicos )

Coste estimado de la medida

Otros datos de interés 
CALIFICACIÓN ENERGÉTICA GLOBAL

\begin{tabular}{|c|c|c|c|}
\hline \multicolumn{2}{|c|}{$\begin{array}{l}\text { CONSUMO DE ENERGÍA } \\
\text { PRIMARIA NO RENOVABLE } \\
{\left[\mathrm{kWh} / \mathrm{m}^{2} \text { año] }\right.}\end{array}$} & \multicolumn{2}{|c|}{$\begin{array}{c}\text { EMISIONES DE DIÓXIDO DE } \\
\text { CARBONO } \\
{\left[\mathrm{kgCO} 2 / \mathrm{m}^{2} \text { año }\right]}\end{array}$} \\
\hline$<54.2 \mathrm{~A}$ & & $<12.2 \mathrm{~A}$ & \\
\hline 54.2-87.8 B & & $12.2-19.9$ B & $15.1 \mathrm{~B}$ \\
\hline 87.8-136.1 C & $89.2 \mathrm{C}$ & 19.9-30.8 C & \\
\hline $136.1-209.3 \quad$ D & & $30.8-47.3$ & \\
\hline 209.3-375.6 E & & $47.3-83.7$ & \\
\hline $375.6-473.2$ & & $83.7-100.4$ & \\
\hline$\geq 473.2 \quad$ G & & $\geq 100.4$ & \\
\hline
\end{tabular}

CALIFICACIONES ENERGÉTICAS PARCIALES

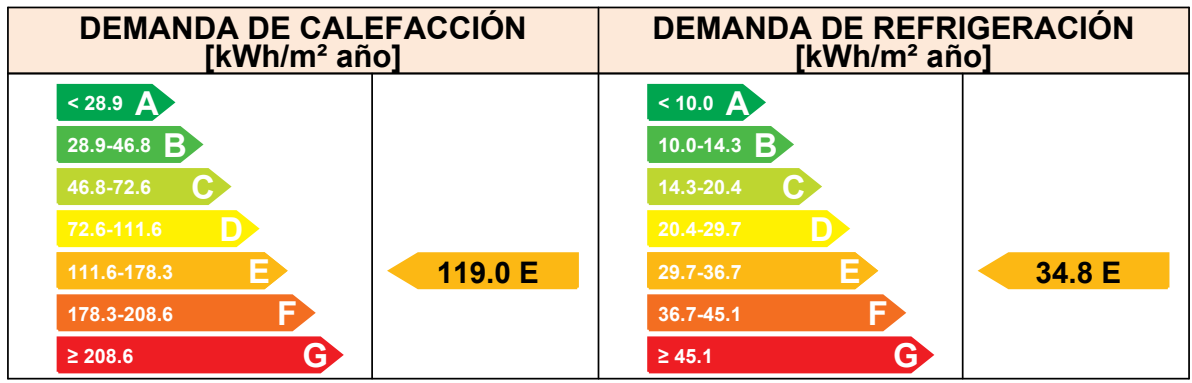

\section{ANÁLISIS TÉCNICO}

\begin{tabular}{|c|c|c|c|c|c|c|c|c|c|c|c|c|c|c|c|}
\hline \multirow[b]{2}{*}{ Indicador } & \multicolumn{3}{|c|}{ Calefacción } & \multicolumn{3}{|c|}{ Refrigeración } & \multicolumn{3}{|c|}{ ACS } & \multicolumn{3}{|c|}{ Iluminación } & \multicolumn{3}{|c|}{ Total } \\
\hline & \multicolumn{2}{|c|}{ Valor } & $\begin{array}{c}\text { ahorro } \\
\text { respecto a } \\
\text { la situación } \\
\text { original }\end{array}$ & \multicolumn{2}{|c|}{ Valor } & $\begin{array}{c}\text { ahorro } \\
\text { respecto a } \\
\text { la situación } \\
\text { original }\end{array}$ & \multicolumn{2}{|c|}{ Valor } & $\begin{array}{c}\text { ahorro } \\
\text { respecto a } \\
\text { la situación } \\
\text { original }\end{array}$ & \multicolumn{2}{|c|}{ Valor } & $\begin{array}{c}\text { ahorro } \\
\text { respecto a } \\
\text { la situación } \\
\text { original }\end{array}$ & \multicolumn{2}{|c|}{ Valor } & $\begin{array}{c}\text { ahorro } \\
\text { respecto a } \\
\text { la situación } \\
\text { original }\end{array}$ \\
\hline $\begin{array}{c}\text { Consumo Energía final } \\
{\left[\mathrm{kWh} / \mathrm{m}^{2} \text { año] }\right.}\end{array}$ & \multicolumn{2}{|c|}{0.00} & $100.0 \%$ & \multicolumn{2}{|c|}{0.00} & $100.0 \%$ & \multicolumn{2}{|c|}{45.66} & $0.0 \%$ & \multicolumn{2}{|l|}{ - } & $-\%$ & \multicolumn{2}{|c|}{45.66} & $72.2 \%$ \\
\hline $\begin{array}{c}\text { Consumo Energía } \\
\text { primaria no renovable } \\
{\left[\mathrm{kWh} / \mathrm{m}^{2} \text { año] }\right.}\end{array}$ & 0.00 & $A$ & $100.0 \%$ & 0.00 & A & $100.0 \%$ & 89.23 & G & $0.0 \%$ & - & - & $-\%$ & 89.23 & $\mathrm{C}$ & $72.2 \%$ \\
\hline $\begin{array}{c}\text { Emisiones de } \mathrm{CO} 2 \\
{\left[\mathrm{kgCO} 2 / \mathrm{m}^{2} \text { año] }\right.}\end{array}$ & 0.00 & $A$ & $100.0 \%$ & 0.00 & A & $100.0 \%$ & 15.12 & G & $0.0 \%$ & - & - & $-\%$ & 15.12 & $\mathrm{~B}$ & $72.2 \%$ \\
\hline Demanda $\left[\mathrm{kWh} / \mathrm{m}^{2}\right.$ año] & 118.99 & $E$ & $55.3 \%$ & 34.83 & E & $22.3 \%$ & & & & & & & & & \\
\hline
\end{tabular}

Nota: Los indicadores energéticos anteriores están calculados en base a coeficientes estándar de operación y funcionamiento del edificio, por lo que solo son válidos a efectos de su calificación energética. Para el análisis económico de las medidas de ahorro y eficiencia energética, el técnico certificador deberá utilizar las condiciones reales y datos históricos de consumo del edificio.

\section{DESCRIPCIÓN DE LA MEDIDA DE MEJORA}

Características de la medida (modelo de equipos, materiales, parámetros característicos )

Coste estimado de la medida

\section{Otros datos de interés}


CALIFICACIÓN ENERGÉTICA GLOBAL

\begin{tabular}{|c|c|c|c|}
\hline \multicolumn{2}{|c|}{$\begin{array}{l}\text { CONSUMO DE ENERGÍA } \\
\text { PRIMARIA NO RENOVABLE } \\
{\left[\mathrm{kWh} / \mathrm{m}^{2} \text { año] }\right.}\end{array}$} & \multicolumn{2}{|c|}{$\begin{array}{c}\text { EMISIONES DE DIÓXIDO DE } \\
\text { CARBONO } \\
{\left[\mathrm{kgCO} 2 / \mathrm{m}^{2} \text { año }\right]}\end{array}$} \\
\hline$<54.2 \mathrm{~A}$ & & $<12.2 \mathrm{~A}$ & \\
\hline 54.2-87.8 B & & $12.2-19.9$ B & $15.1 \mathrm{~B}$ \\
\hline 87.8-136.1 C & $89.2 \mathrm{C}$ & 19.9-30.8 C & \\
\hline $136.1-209.3 \quad$ D & & $30.8-47.3$ & \\
\hline 209.3-375.6 E & & $47.3-83.7$ & \\
\hline $375.6-473.2$ & & $83.7-100.4$ & \\
\hline$\geq 473.2 \quad$ G & & $\geq 100.4$ & \\
\hline
\end{tabular}

CALIFICACIONES ENERGÉTICAS PARCIALES

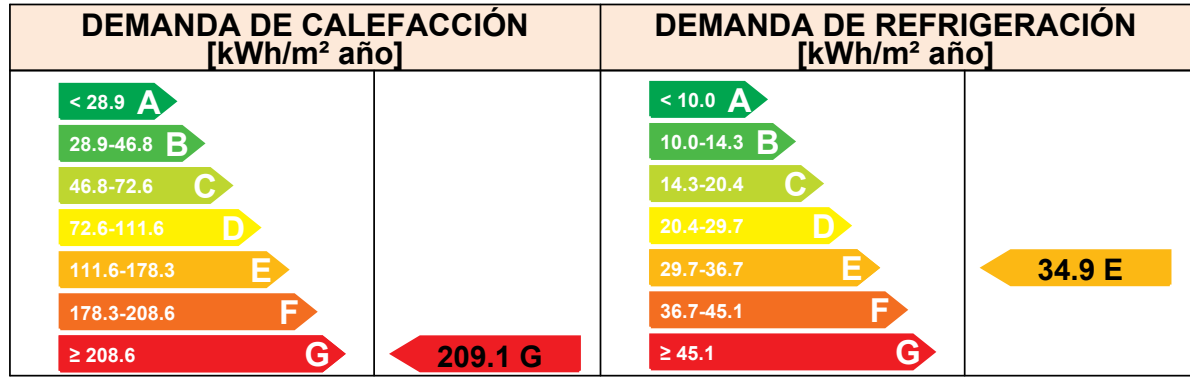

\section{ANÁLISIS TÉCNICO}

\begin{tabular}{|c|c|c|c|c|c|c|c|c|c|c|c|c|c|c|c|}
\hline \multirow[b]{2}{*}{ Indicador } & \multicolumn{3}{|c|}{ Calefacción } & \multicolumn{3}{|c|}{ Refrigeración } & \multicolumn{3}{|c|}{ ACS } & \multicolumn{3}{|c|}{ Iluminación } & \multicolumn{3}{|c|}{ Total } \\
\hline & \multicolumn{2}{|c|}{ Valor } & $\begin{array}{c}\text { ahorro } \\
\text { respecto a } \\
\text { la situación } \\
\text { original }\end{array}$ & \multicolumn{2}{|c|}{ Valor } & $\begin{array}{c}\text { ahorro } \\
\text { respecto a } \\
\text { la situación } \\
\text { original }\end{array}$ & \multicolumn{2}{|c|}{ Valor } & $\begin{array}{c}\text { ahorro } \\
\text { respecto a } \\
\text { la situación } \\
\text { original }\end{array}$ & \multicolumn{2}{|c|}{ Valor } & $\begin{array}{c}\text { ahorro } \\
\text { respecto a } \\
\text { la situación } \\
\text { original }\end{array}$ & \multicolumn{2}{|c|}{ Valor } & $\begin{array}{c}\text { ahorro } \\
\text { respecto a } \\
\text { la situación } \\
\text { original }\end{array}$ \\
\hline $\begin{array}{c}\text { Consumo Energía final } \\
{\left[\mathrm{kWh} / \mathrm{m}^{2} \text { año] }\right.}\end{array}$ & \multicolumn{2}{|c|}{0.00} & $100.0 \%$ & \multicolumn{2}{|c|}{0.00} & $100.0 \%$ & \multicolumn{2}{|c|}{45.66} & $0.0 \%$ & \multicolumn{2}{|l|}{ - } & $-\%$ & \multicolumn{2}{|c|}{45.66} & $72.2 \%$ \\
\hline $\begin{array}{c}\text { Consumo Energía } \\
\text { primaria no renovable } \\
{\left[\mathrm{kWh} / \mathrm{m}^{2} \text { año] }\right.}\end{array}$ & 0.00 & $A$ & $100.0 \%$ & 0.00 & A & $100.0 \%$ & 89.23 & G & $0.0 \%$ & - & - & $-\%$ & 89.23 & $\mathrm{C}$ & $72.2 \%$ \\
\hline $\begin{array}{c}\text { Emisiones de } \mathrm{CO} 2 \\
{\left[\mathrm{kgCO} 2 / \mathrm{m}^{2} \text { año] }\right.}\end{array}$ & 0.00 & $A$ & $100.0 \%$ & 0.00 & A & $100.0 \%$ & 15.12 & G & $0.0 \%$ & - & - & $-\%$ & 15.12 & $\mathrm{~B}$ & $72.2 \%$ \\
\hline Demanda $\left[\mathrm{kWh} / \mathrm{m}^{2}\right.$ año] & 209.10 & G & $21.4 \%$ & 34.92 & E & $22.2 \%$ & & & & & & & & & \\
\hline
\end{tabular}

Nota: Los indicadores energéticos anteriores están calculados en base a coeficientes estándar de operación y funcionamiento del edificio, por lo que solo son válidos a efectos de su calificación energética. Para el análisis económico de las medidas de ahorro y eficiencia energética, el técnico certificador deberá utilizar las condiciones reales y datos históricos de consumo del edificio.

\section{DESCRIPCIÓN DE LA MEDIDA DE MEJORA}

Características de la medida (modelo de equipos, materiales, parámetros característicos )

Coste estimado de la medida

\section{Otros datos de interés}




\section{ANEXO IV \\ PRUEBAS, COMPROBACJONES E INSPECCIONES REALIZADAS POR EL TECNICO CERTIFICADOR}

Se describen a continuación las pruebas, comprobaciones e inspecciones llevadas a cabo por el técnico certificador durante el proceso de toma de datos y de calificación de la eficiencia energética del edificio, con la finalidad de establecer la conformidad de la información de partida contenida en el certificado de eficiencia energética.

Fecha de realización de la visita del técnico certificador 


\begin{tabular}{|c|c|c|c|c|c|}
\hline & DEN & $\begin{array}{c}\text { Ref. } \\
\text { Catastral }\end{array}$ & 000000000 & $\begin{array}{c}\text { Versión } \\
\text { informe } \\
\text { asociado }\end{array}$ & $01 / 12 / 2015$ \\
\hline $\begin{array}{c}\text { Certificación } \\
\text { Energetica } \\
\text { de Edificios }\end{array}$ & $\begin{array}{c}\text { Id. } \\
\text { Mejora }\end{array}$ & $\begin{array}{l}\text { Programa } \\
\text { y versión }\end{array}$ & CEXv2.1 & Fecha & $3 / 1 / 2004$ \\
\hline
\end{tabular}

\section{Informe descriptivo de la medida de mejora}

\section{DENOMINACIÓN DE LA MEDIDA DE MEJORA}

FV $100 \%$

\section{DESCRIPCIÓN DE LA MEDIDA DE MEJORA}

Características de la medida (modelo de equipos, materiales, parámetros característicos )

Coste estimado de la medida

Otros datos de interés

CALIFICACIÓN ENERGÉTICA GLOBAL

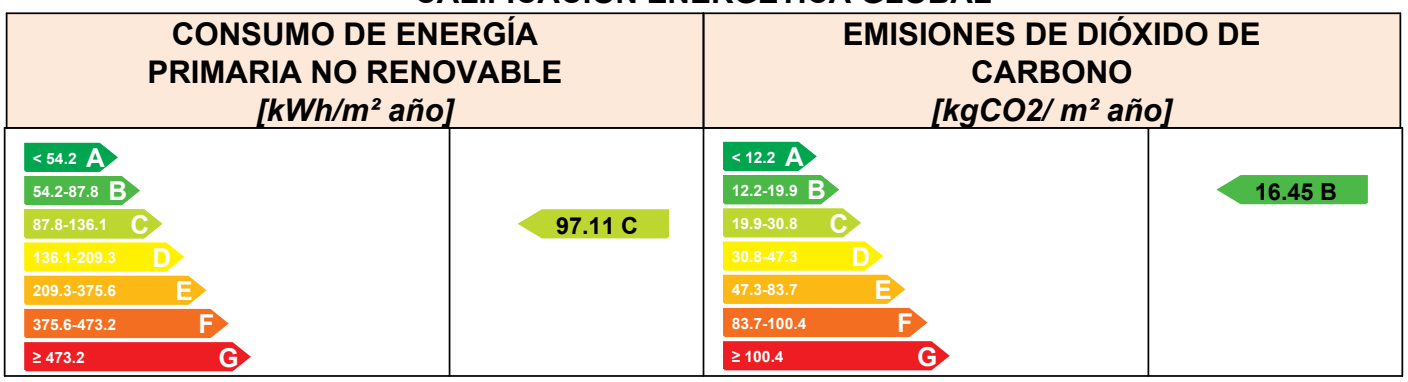

CALIFICACIONES ENERGÉTICAS PARCIALES

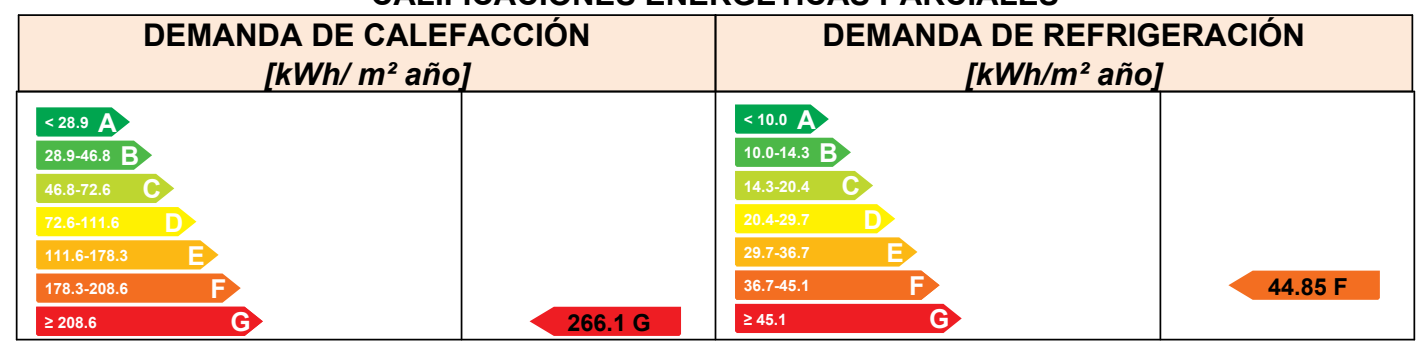




\begin{tabular}{|c|c|c|c|c|c|}
\hline & & $\begin{array}{c}\text { Ref. } \\
\text { Catastral }\end{array}$ & 000000000 & $\begin{array}{c}\text { Versión } \\
\text { informe } \\
\text { asociado }\end{array}$ & $01 / 12 / 2015$ \\
\hline $\begin{array}{l}\text { Certificación } \\
\text { Energética } \\
\text { de Edificios }\end{array}$ & $\begin{array}{c}\text { Id. } \\
\text { Mejora }\end{array}$ & $\begin{array}{l}\text { Programa } \\
\text { y versión }\end{array}$ & CEXv2.1 & Fecha & $3 / 1 / 2004$ \\
\hline
\end{tabular}

\section{ANALISÍS TÉCNICO}

\begin{tabular}{|c|c|c|c|c|c|c|c|c|c|c|c|c|c|c|c|}
\hline \multirow[b]{2}{*}{ Indicador } & \multicolumn{3}{|c|}{ Calefacción } & \multicolumn{3}{|c|}{ Refrigeración } & \multicolumn{3}{|c|}{ ACS } & \multicolumn{3}{|c|}{ Iluminación } & \multicolumn{3}{|c|}{ Total } \\
\hline & \multicolumn{2}{|c|}{ Valor } & $\begin{array}{c}\text { ahorro } \\
\text { respecto a } \\
\text { la situación } \\
\text { original }\end{array}$ & \multicolumn{2}{|c|}{ Valor } & $\begin{array}{c}\text { ahorro } \\
\text { respecto a } \\
\text { la situación } \\
\text { original }\end{array}$ & \multicolumn{2}{|c|}{ Valor } & $\begin{array}{c}\text { ahorro } \\
\text { respecto a } \\
\text { la situación } \\
\text { original }\end{array}$ & \multicolumn{2}{|c|}{ Valor } & $\begin{array}{c}\text { ahorro } \\
\text { respecto a } \\
\text { la situación } \\
\text { original }\end{array}$ & \multicolumn{2}{|c|}{ Valor } & $\begin{array}{c}\text { ahorro } \\
\text { respecto a } \\
\text { la situación } \\
\text { original }\end{array}$ \\
\hline $\begin{array}{l}\text { Consumo Energía } \\
\text { final }\left[\mathrm{kWh} / \mathrm{m}^{2} \text { año] }\right.\end{array}$ & \multicolumn{2}{|c|}{109.55} & $-12.4 \%$ & \multicolumn{2}{|c|}{19.02} & $11.1 \%$ & \multicolumn{2}{|c|}{45.66} & $0.0 \%$ & \multicolumn{2}{|l|}{-} & $-\%$ & \multicolumn{2}{|c|}{49.70} & $69.8 \%$ \\
\hline $\begin{array}{c}\text { Consumo Energía } \\
\text { primaria no renovable } \\
{\left[\mathrm{kWh} / \mathrm{m}^{2} \text { año] }\right.}\end{array}$ & 214.06 & $E$ & $-12.4 \%$ & 37.17 & $E$ & $11.1 \%$ & 89.23 & G & $0.0 \%$ & - & - & $-\%$ & 97.11 & C & $69.8 \%$ \\
\hline $\begin{array}{c}\text { Emisiones de CO2 } \\
{\left[\mathrm{kgCO} 2 / \mathrm{m}^{2} \text { año] }\right.}\end{array}$ & 36.26 & $E$ & $-12.4 \%$ & 6.30 & D & $11.1 \%$ & 15.12 & G & $0.0 \%$ & - & - & $-\%$ & 16.45 & $B$ & $69.8 \%$ \\
\hline $\begin{array}{l}\text { Demanda }\left[\mathrm{kWh} / \mathrm{m}^{2}\right. \\
\text { año] }\end{array}$ & 266.10 & G & $0.0 \%$ & 44.85 & $F$ & $0.0 \%$ & & & & & & & & & \\
\hline
\end{tabular}

\section{ENVOLVENTE TÉRMICA}

\section{Cerramientos opacos}

\begin{tabular}{|c|c|c|c|c|c|}
\hline Nombre & Tipo & $\begin{array}{c}\text { Superficie } \\
\text { actual } \\
{\left[\mathbf{m}^{2}\right]}\end{array}$ & $\begin{array}{c}\text { Transmitancia } \\
\text { actual } \\
{\left[\mathbf{W} / \mathbf{m}^{\mathbf{2}} \mathbf{~ K}\right]}\end{array}$ & $\begin{array}{c}\text { Superficie } \\
\text { post } \\
\text { mejora } \\
{\left[\mathbf{m}^{2}\right]}\end{array}$ & $\begin{array}{c}\text { Transmitancia } \\
\text { post mejora } \\
{\left[\mathbf{W} / \mathbf{m}^{\mathbf{2}} \mathbf{K}\right]}\end{array}$ \\
\hline Cubierta con aire & Cubierta & 52.00 & 0.47 & 52.00 & 0.47 \\
\hline Muro de fachada Norte & Fachada & 27.18 & 0.54 & 27.18 & 0.54 \\
\hline Suelo con aire & Suelo & 52.00 & 2.95 & 52.00 & 2.95 \\
\hline Muro de fachada Sur & Fachada & 21.88 & 0.54 & 21.88 & 0.54 \\
\hline Muro de fachada Oeste & Fachada & 8.04 & 0.54 & 8.04 & 0.54 \\
\hline Muro de fachada Este & Fachada & 3.28 & 0.54 & 3.28 & 0.54 \\
\hline
\end{tabular}

Huecos y lucernarios

\begin{tabular}{|c|c|c|c|c|c|c|c|}
\hline Nombre & Tipo & $\begin{array}{c}\text { Superficie } \\
\text { actual } \\
{\left[\mathrm{m}^{2}\right]}\end{array}$ & 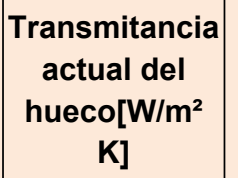 & $\begin{array}{c}\text { Transmitancia } \\
\text { actual del } \\
\text { vidrio[W/m² } \\
\mathrm{K}]\end{array}$ & $\begin{array}{c}\text { Superficie } \\
\text { post } \\
\text { mejora } \\
{\left[\mathrm{m}^{2}\right]}\end{array}$ & $\begin{array}{c}\text { Transmitancia } \\
\text { post mejora } \\
{\left[\mathrm{W} / \mathrm{m}^{2} \mathrm{~K}\right]}\end{array}$ & $\begin{array}{c}\text { Transmitancia } \\
\text { post mejora } \\
\text { del vidrio } \\
{\left[\mathrm{W} / \mathrm{m}^{2} \mathrm{~K}\right]}\end{array}$ \\
\hline V1 & Hueco & 5.3 & 5.70 & 5.70 & 5.3 & 5.70 & 5.70 \\
\hline V3 & Hueco & 5.3 & 5.70 & 5.70 & 5.3 & 5.70 & 5.70 \\
\hline V4 & Hueco & 5.3 & 5.70 & 5.70 & 5.3 & 5.70 & 5.70 \\
\hline V2 & Hueco & 5.3 & 5.70 & 5.70 & 5.3 & 5.70 & 5.70 \\
\hline V5 & Hueco & 5.03 & 5.70 & 5.70 & 5.03 & 5.70 & 5.70 \\
\hline Pta & Hueco & 5.03 & 5.70 & 5.70 & 5.03 & 5.70 & 5.70 \\
\hline
\end{tabular}




\begin{tabular}{|c|c|c|c|c|c|}
\hline & & $\begin{array}{c}\text { Ref. } \\
\text { Catastral }\end{array}$ & 000000000 & $\begin{array}{c}\text { Versión } \\
\text { informe } \\
\text { asociado }\end{array}$ & $01 / 12 / 2015$ \\
\hline $\begin{array}{l}\text { Certificación } \\
\text { Energética } \\
\text { de Edificios }\end{array}$ & $\begin{array}{c}\text { Id. } \\
\text { Mejora }\end{array}$ & $\begin{array}{l}\text { Programa } \\
\text { y versión }\end{array}$ & CEXv2.1 & Fecha & $3 / 1 / 2004$ \\
\hline
\end{tabular}

\section{INSTALACIONES TÉRMICAS}

\section{Generadores de calefacción}

\begin{tabular}{|c|c|c|c|c|c|c|c|c|c|}
\hline \multirow[t]{2}{*}{ Nombre } & \multirow[t]{2}{*}{ Tipo } & $\begin{array}{r}\text { Potencia } \\
\text { nominal }\end{array}$ & $\begin{array}{c}\text { Rendi- } \\
\text { miento } \\
\text { Estacional }\end{array}$ & $\begin{array}{c}\text { Estimación } \\
\text { Energía } \\
\text { Consumida } \\
\text { anual }\end{array}$ & \multirow[t]{2}{*}{$\begin{array}{l}\text { Tipo post } \\
\text { mejora }\end{array}$} & $\begin{array}{c}\text { Potencia } \\
\text { nominal } \\
\text { post } \\
\text { mejora }\end{array}$ & $\begin{array}{c}\text { Rendimiento } \\
\text { estacional } \\
\text { post mejora }\end{array}$ & $\begin{array}{c}\text { Estimación } \\
\text { Energía } \\
\text { Consumida } \\
\text { anual Post } \\
\text { mejora }\end{array}$ & $\begin{array}{l}\text { Energía } \\
\text { anual } \\
\text { ahorrada }\end{array}$ \\
\hline & & {$[\mathrm{kW}]$} & [\%] & {$\left[\mathrm{kWh} / \mathrm{m}^{2} \mathrm{año}\right]$} & & {$[\mathrm{kW}]$} & [\%] & [kWh/m²año] & [kWh/m²año] \\
\hline $\begin{array}{l}\text { Calefacción y } \\
\text { refrigeración }\end{array}$ & $\begin{array}{c}\text { Bomba de } \\
\text { Calor - } \\
\text { Caudal Ref. } \\
\text { Variable }\end{array}$ & & $273.1 \%$ & - & $\begin{array}{c}\text { Bomba de } \\
\text { Calor - } \\
\text { Caudal Ref. } \\
\text { Variable }\end{array}$ & & $242.9 \%$ & - & - \\
\hline TOTALES & & & & & & & & & \\
\hline
\end{tabular}

\section{Generadores de refrigeración}

\begin{tabular}{|c|c|c|c|c|c|c|c|c|c|}
\hline \multirow[t]{2}{*}{ Nombre } & \multirow[t]{2}{*}{ Tipo } & $\begin{array}{r}\text { Potencia } \\
\text { nominal }\end{array}$ & $\begin{array}{c}\text { Rendi- } \\
\text { miento } \\
\text { Estacional }\end{array}$ & $\begin{array}{c}\text { Estimación } \\
\text { Energía } \\
\text { Consumida } \\
\text { anual }\end{array}$ & \multirow[t]{2}{*}{$\begin{array}{l}\text { Tipo post } \\
\text { mejora }\end{array}$} & $\begin{array}{c}\text { Potencia } \\
\text { nominal } \\
\text { post } \\
\text { mejora }\end{array}$ & $\begin{array}{c}\text { Rendimiento } \\
\text { estacional } \\
\text { post mejora }\end{array}$ & $\begin{array}{c}\text { Estimación } \\
\text { Energía } \\
\text { Consumida } \\
\text { anual Post } \\
\text { mejora }\end{array}$ & $\begin{array}{c}\text { Energía } \\
\text { anual } \\
\text { ahorrada }\end{array}$ \\
\hline & & {$[\mathrm{kW}]$} & {$[\%]$} & {$\left[\mathrm{kWh} / \mathrm{m}^{2} \mathrm{año}\right]$} & & {$[\mathrm{kW}]$} & {$[\%]$} & [kWh/m²año] & {$\left[\mathrm{kWh} / \mathrm{m}^{2} \mathrm{año}\right.$} \\
\hline $\begin{array}{l}\text { Calefacción y } \\
\text { refrigeración }\end{array}$ & $\begin{array}{c}\text { Bomba de } \\
\text { Calor - } \\
\text { Caudal Ref. } \\
\text { Variable }\end{array}$ & & $209.7 \%$ & - & $\begin{array}{c}\text { Bomba de } \\
\text { Calor - } \\
\text { Caudal Ref. } \\
\text { Variable }\end{array}$ & & $235.8 \%$ & - & - \\
\hline TOTALES & & - & & - & & - & & - & - \\
\hline
\end{tabular}

\section{Instalaciones de Agua Caliente Sanitaria}

\begin{tabular}{|c|c|c|c|c|c|c|c|c|c|}
\hline Nombre & Tipo & $\begin{array}{l}\text { Potencia } \\
\text { nominal }\end{array}$ & $\begin{array}{c}\text { Rendi- } \\
\text { miento } \\
\text { Estacional }\end{array}$ & $\begin{array}{c}\text { Estimación } \\
\text { Energía } \\
\text { Consumida } \\
\text { anual }\end{array}$ & $\begin{array}{c}\text { Tipo post } \\
\text { mejora }\end{array}$ & $\begin{array}{l}\text { Potencia } \\
\text { nominal } \\
\text { post } \\
\text { mejora }\end{array}$ & $\begin{array}{c}\text { Rendimiento } \\
\text { estacional } \\
\text { post mejora }\end{array}$ & $\begin{array}{c}\text { Estimación } \\
\text { Energía } \\
\text { Consumida } \\
\text { anual Post } \\
\text { mejora }\end{array}$ & $\begin{array}{l}\text { Energía } \\
\text { anual } \\
\text { ahorrada }\end{array}$ \\
\hline & & {$[\mathrm{kW}]$} & [\%] & {$\left[\mathrm{kWh} / \mathrm{m}^{2} \mathrm{año}\right]$} & & {$[\mathrm{kW}]$} & [\%] & [kWh/m²año] & [kWh/m²año] \\
\hline Equipo ACS & Efecto Joule & & $100.0 \%$ & - & Efecto Joule & & $100.0 \%$ & - & - \\
\hline TOTALES & & - & & - & & - & & - & - \\
\hline
\end{tabular}




\begin{tabular}{|c|c|c|c|c|c|}
\hline & $D E$ & $\begin{array}{c}\text { Ref. } \\
\text { Catastral }\end{array}$ & 000000000 & $\begin{array}{l}\text { Versión } \\
\text { informe } \\
\text { asociado }\end{array}$ & $01 / 12 / 2015$ \\
\hline $\begin{array}{c}\text { Certificación } \\
\text { Energética } \\
\text { de Edificioios }\end{array}$ & $\begin{array}{c}\text { Id. } \\
\text { Mejora }\end{array}$ & $\begin{array}{l}\text { Programa } \\
\text { y versión }\end{array}$ & CEXv2.1 & Fecha & $3 / 1 / 2004$ \\
\hline
\end{tabular}

\section{ENERGÍAS RENOVABLES}

\section{Eléctrica}

\begin{tabular}{|c|c|c|}
\hline Nombre & $\begin{array}{c}\text { Energía eléctrica generada y } \\
\text { autoconsumida [kWh/año] }\end{array}$ & $\begin{array}{c}\text { Energía eléctrica generada y } \\
\text { autoconsumida post mejora } \\
\text { [kWh/año] }\end{array}$ \\
\hline Incorporación/mejora de sistema fotovoltaico & - & 8940 \\
\hline TOTALES & - & 8940.0 \\
\hline
\end{tabular}




\begin{tabular}{|c|c|c|c|c|c|}
\hline & & $\begin{array}{c}\text { Ref. } \\
\text { Catastral }\end{array}$ & 000000000 & $\begin{array}{c}\text { Versión } \\
\text { informe } \\
\text { asociado }\end{array}$ & $01 / 12 / 2015$ \\
\hline $\begin{array}{l}\text { Certificación } \\
\text { Energética } \\
\text { de Edificios }\end{array}$ & $\begin{array}{c}\text { Id. } \\
\text { Mejora }\end{array}$ & $\begin{array}{l}\text { Programa } \\
\text { y versión }\end{array}$ & CEXv2.1 & Fecha & $3 / 1 / 2004$ \\
\hline
\end{tabular}

\section{Informe descriptivo de la medida de mejora}

\section{DENOMINACIÓN DE LA MEDIDA DE MEJORA}

Bomba de calor alto cop y eer con geotermia y vidrios activos + mejora aislamientos

\section{DESCRIPCIÓN DE LA MEDIDA DE MEJORA}

Características de la medida (modelo de equipos, materiales, parámetros característicos )

Coste estimado de la medida

Otros datos de interés

CALIFICACIÓN ENERGÉTICA GLOBAL

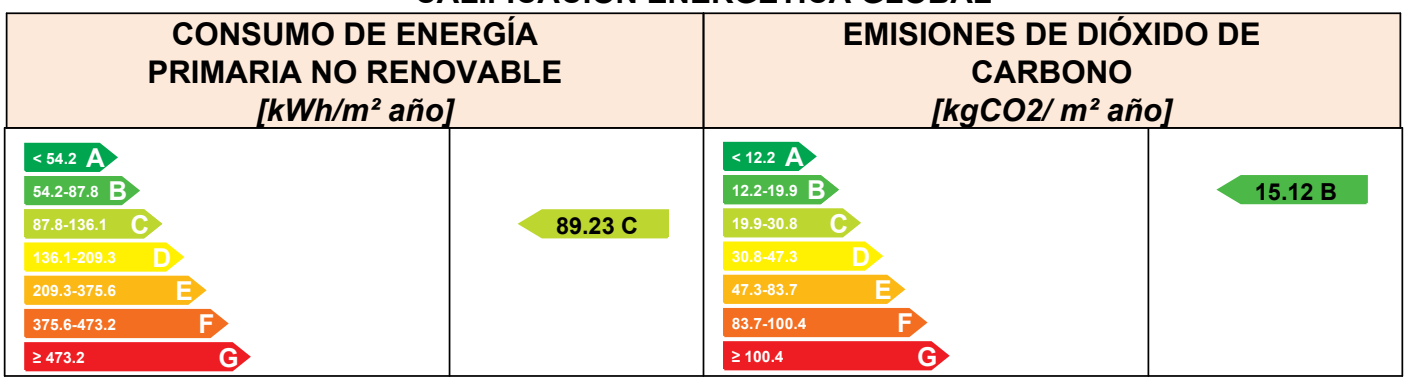

CALIFICACIONES ENERGÉTICAS PARCIALES

\begin{tabular}{|c|c|c|c|}
\hline \multicolumn{2}{|c|}{$\begin{array}{l}\text { DEMANDA DE CALEFACCIÓN } \\
{\left[\mathrm{kWh} / \mathrm{m}^{2} \text { año] }\right.}\end{array}$} & \multicolumn{2}{|c|}{$\begin{array}{l}\text { DEMANDA DE REFRIGERACIÓN } \\
{\left[\mathrm{kWh} / \mathrm{m}^{2} \mathrm{año}\right]}\end{array}$} \\
\hline 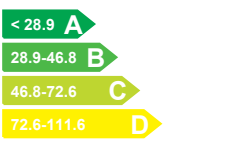 & & 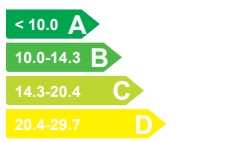 & \\
\hline $\begin{array}{ll}111.6-178.3 & E \\
178.3-208.6 & F \\
208.6 & \text { G }\end{array}$ & $118.99 \mathrm{E}$ & \begin{tabular}{|ll}
$29.7-36.7$ & E \\
$36.7-45.1$ & F \\
245.1 & G
\end{tabular} & $34.83 \mathrm{E}$ \\
\hline
\end{tabular}




\begin{tabular}{|c|c|c|c|c|c|}
\hline & & $\begin{array}{c}\text { Ref. } \\
\text { Catastral }\end{array}$ & 000000000 & $\begin{array}{c}\text { Versión } \\
\text { informe } \\
\text { asociado }\end{array}$ & $01 / 12 / 2015$ \\
\hline $\begin{array}{l}\text { Certificación } \\
\text { Energética } \\
\text { de Edificios }\end{array}$ & $\begin{array}{c}\text { Id. } \\
\text { Mejora }\end{array}$ & $\begin{array}{l}\text { Programa } \\
\text { y versión }\end{array}$ & CEXv2.1 & Fecha & $3 / 1 / 2004$ \\
\hline
\end{tabular}

\section{ANALISÍS TÉCNICO}

\begin{tabular}{|c|c|c|c|c|c|c|c|c|c|c|c|c|c|c|c|}
\hline \multirow[b]{2}{*}{ Indicador } & \multicolumn{3}{|c|}{ Calefacción } & \multicolumn{3}{|c|}{ Refrigeración } & \multicolumn{3}{|c|}{ ACS } & \multicolumn{3}{|c|}{ Iluminación } & \multicolumn{3}{|c|}{ Total } \\
\hline & \multicolumn{2}{|c|}{ Valor } & $\begin{array}{c}\text { ahorro } \\
\text { respecto a } \\
\text { la situación } \\
\text { original }\end{array}$ & \multicolumn{2}{|c|}{ Valor } & $\begin{array}{c}\text { ahorro } \\
\text { respecto a } \\
\text { la situación } \\
\text { original }\end{array}$ & \multicolumn{2}{|c|}{ Valor } & $\begin{array}{c}\text { ahorro } \\
\text { respecto a } \\
\text { la situación } \\
\text { original }\end{array}$ & \multicolumn{2}{|c|}{ Valor } & $\begin{array}{c}\text { ahorro } \\
\text { respecto a } \\
\text { la situación } \\
\text { original }\end{array}$ & \multicolumn{2}{|c|}{ Valor } & $\begin{array}{c}\text { ahorro } \\
\text { respecto a } \\
\text { la situación } \\
\text { original }\end{array}$ \\
\hline $\begin{array}{l}\text { Consumo Energía } \\
\text { final }\left[\mathrm{kWh} / \mathrm{m}^{2} \text { año] }\right.\end{array}$ & \multicolumn{2}{|c|}{0.00} & $100.0 \%$ & \multicolumn{2}{|c|}{0.00} & $100.0 \%$ & \multicolumn{2}{|c|}{45.66} & $0.0 \%$ & \multicolumn{2}{|l|}{-} & $-\%$ & \multicolumn{2}{|c|}{45.66} & $72.2 \%$ \\
\hline $\begin{array}{c}\text { Consumo Energía } \\
\text { primaria no renovable } \\
{\left[\mathrm{kWh} / \mathrm{m}^{2} \text { año] }\right.}\end{array}$ & 0.00 & A & $100.0 \%$ & 0.00 & A & $100.0 \%$ & 89.23 & G & $0.0 \%$ & - & - & $-\%$ & 89.23 & C & $72.2 \%$ \\
\hline $\begin{array}{c}\text { Emisiones de CO2 } \\
{\left[\mathrm{kgCO} 2 / \mathrm{m}^{2} \text { año] }\right.}\end{array}$ & 0.00 & A & $100.0 \%$ & 0.00 & A & $100.0 \%$ & 15.12 & G & $0.0 \%$ & - & - & $-\%$ & 15.12 & B & $72.2 \%$ \\
\hline $\begin{array}{c}\text { Demanda }\left[\mathrm{kWh} / \mathrm{m}^{2}\right. \\
\text { año] }\end{array}$ & 118.99 & $E$ & $55.3 \%$ & 34.83 & $E$ & $22.3 \%$ & & & & & & & & & \\
\hline
\end{tabular}

\section{ENVOLVENTE TÉRMICA}

\section{Cerramientos opacos}

\begin{tabular}{|c|c|c|c|c|c|}
\hline Nombre & Tipo & $\begin{array}{c}\text { Superficie } \\
\text { actual } \\
{\left[\mathbf{m}^{2}\right]}\end{array}$ & $\begin{array}{c}\text { Transmitancia } \\
\text { actual } \\
{\left[\mathbf{W} / \mathbf{m}^{\mathbf{2}} \mathbf{~ K}\right]}\end{array}$ & $\begin{array}{c}\text { Superficie } \\
\text { post } \\
\text { mejora } \\
{\left[\mathbf{m}^{2}\right]}\end{array}$ & $\begin{array}{c}\text { Transmitancia } \\
\text { post mejora } \\
{\left[\mathbf{W} / \mathbf{m}^{\mathbf{2}} \mathbf{K}\right]}\end{array}$ \\
\hline Cubierta con aire & Cubierta & 52.00 & 0.47 & 52.00 & 0.22 \\
\hline Muro de fachada Norte & Fachada & 27.18 & 0.54 & 27.18 & 0.27 \\
\hline Suelo con aire & Suelo & 52.00 & 2.95 & 52.00 & 0.34 \\
\hline Muro de fachada Sur & Fachada & 21.88 & 0.54 & 21.88 & 0.27 \\
\hline Muro de fachada Oeste & Fachada & 8.04 & 0.54 & 8.04 & 0.27 \\
\hline Muro de fachada Este & Fachada & 3.28 & 0.54 & 3.28 & 0.27 \\
\hline
\end{tabular}

Huecos y lucernarios

\begin{tabular}{|c|c|c|c|c|c|c|c|}
\hline Nombre & Tipo & $\begin{array}{c}\text { Superficie } \\
\text { actual } \\
{\left[\mathrm{m}^{2}\right]}\end{array}$ & $\begin{array}{c}\text { Transmitancia } \\
\text { actual del } \\
\text { hueco[W/m² } \\
\mathrm{K}]\end{array}$ & $\begin{array}{c}\text { Transmitancia } \\
\text { actual del } \\
\text { vidrio[W/m² } \\
\mathrm{K}]\end{array}$ & $\begin{array}{l}\text { Superficie } \\
\text { post } \\
\text { mejora } \\
{\left[\mathrm{m}^{2}\right]}\end{array}$ & $\begin{array}{c}\text { Transmitancia } \\
\text { post mejora } \\
{\left[\mathrm{W} / \mathrm{m}^{2} \mathrm{~K}\right]}\end{array}$ & $\begin{array}{c}\text { Transmitancia } \\
\text { post mejora } \\
\text { del vidrio } \\
{\left[\mathrm{W} / \mathrm{m}^{2} \mathrm{~K}\right]}\end{array}$ \\
\hline V1 & Hueco & 5.3 & 5.70 & 5.70 & 5.3 & 1.27 & 1.12 \\
\hline V3 & Hueco & 5.3 & 5.70 & 5.70 & 5.3 & 1.27 & 1.12 \\
\hline V4 & Hueco & 5.3 & 5.70 & 5.70 & 5.3 & 1.27 & 1.12 \\
\hline V2 & Hueco & 5.3 & 5.70 & 5.70 & 5.3 & 1.27 & 1.12 \\
\hline V5 & Hueco & 5.03 & 5.70 & 5.70 & 5.03 & 1.27 & 1.12 \\
\hline Pta & Hueco & 5.03 & 5.70 & 5.70 & 5.03 & 1.27 & 1.12 \\
\hline
\end{tabular}




\begin{tabular}{|c|c|c|c|c|c|}
\hline & & $\begin{array}{c}\text { Ref. } \\
\text { Catastral }\end{array}$ & 000000000 & $\begin{array}{c}\text { Versión } \\
\text { informe } \\
\text { asociado }\end{array}$ & $01 / 12 / 2015$ \\
\hline $\begin{array}{l}\text { Certificación } \\
\text { Energética } \\
\text { de Edificios }\end{array}$ & $\begin{array}{c}\text { Id. } \\
\text { Mejora }\end{array}$ & $\begin{array}{l}\text { Programa } \\
\text { y versión }\end{array}$ & CEXv2.1 & Fecha & $3 / 1 / 2004$ \\
\hline
\end{tabular}

\section{INSTALACIONES TÉRMICAS}

\section{Generadores de calefacción}

\begin{tabular}{|c|c|c|c|c|c|c|c|c|c|}
\hline \multirow[t]{2}{*}{ Nombre } & \multirow[t]{2}{*}{ Tipo } & $\begin{array}{r}\text { Potencia } \\
\text { nominal }\end{array}$ & $\begin{array}{c}\text { Rendi- } \\
\text { miento } \\
\text { Estacional }\end{array}$ & $\begin{array}{c}\text { Estimación } \\
\text { Energía } \\
\text { Consumida } \\
\text { anual }\end{array}$ & \multirow[t]{2}{*}{$\begin{array}{l}\text { Tipo post } \\
\text { mejora }\end{array}$} & $\begin{array}{c}\text { Potencia } \\
\text { nominal } \\
\text { post } \\
\text { mejora }\end{array}$ & $\begin{array}{c}\text { Rendimiento } \\
\text { estacional } \\
\text { post mejora }\end{array}$ & $\begin{array}{c}\text { Estimación } \\
\text { Energía } \\
\text { Consumida } \\
\text { anual Post } \\
\text { mejora }\end{array}$ & $\begin{array}{l}\text { Energía } \\
\text { anual } \\
\text { ahorrada }\end{array}$ \\
\hline & & {$[\mathrm{kW}]$} & [\%] & {$\left[\mathrm{kWh} / \mathrm{m}^{2} \mathrm{año}\right]$} & & {$[\mathrm{kW}]$} & [\%] & [kWh/m²año] & [kWh/m²año] \\
\hline $\begin{array}{l}\text { Calefacción y } \\
\text { refrigeración }\end{array}$ & $\begin{array}{c}\text { Bomba de } \\
\text { Calor - } \\
\text { Caudal Ref. } \\
\text { Variable }\end{array}$ & & $273.1 \%$ & - & $\begin{array}{c}\text { Bomba de } \\
\text { Calor - } \\
\text { Caudal Ref. } \\
\text { Variable }\end{array}$ & & $484.2 \%$ & - & - \\
\hline TOTALES & & & & & & & & & \\
\hline
\end{tabular}

\section{Generadores de refrigeración}

\begin{tabular}{|c|c|c|c|c|c|c|c|c|c|}
\hline \multirow[t]{2}{*}{ Nombre } & \multirow[t]{2}{*}{ Tipo } & $\begin{array}{r}\text { Potencia } \\
\text { nominal }\end{array}$ & $\begin{array}{c}\text { Rendi- } \\
\text { miento } \\
\text { Estacional }\end{array}$ & $\begin{array}{c}\text { Estimación } \\
\text { Energía } \\
\text { Consumida } \\
\text { anual }\end{array}$ & \multirow[t]{2}{*}{$\begin{array}{l}\text { Tipo post } \\
\text { mejora }\end{array}$} & $\begin{array}{c}\text { Potencia } \\
\text { nominal } \\
\text { post } \\
\text { mejora }\end{array}$ & $\begin{array}{c}\text { Rendimiento } \\
\text { estacional } \\
\text { post mejora }\end{array}$ & $\begin{array}{c}\text { Estimación } \\
\text { Energía } \\
\text { Consumida } \\
\text { anual Post } \\
\text { mejora }\end{array}$ & $\begin{array}{c}\text { Energía } \\
\text { anual } \\
\text { ahorrada }\end{array}$ \\
\hline & & {$[\mathrm{kW}]$} & {$[\%]$} & {$\left[\mathrm{kWh} / \mathrm{m}^{2} \mathrm{año}\right]$} & & {$[\mathrm{kW}]$} & {$[\%]$} & [kWh/m²año] & {$\left[\mathrm{kWh} / \mathrm{m}^{2} \mathrm{año}\right.$} \\
\hline $\begin{array}{l}\text { Calefacción y } \\
\text { refrigeración }\end{array}$ & $\begin{array}{c}\text { Bomba de } \\
\text { Calor - } \\
\text { Caudal Ref. } \\
\text { Variable }\end{array}$ & & $209.7 \%$ & - & $\begin{array}{c}\text { Bomba de } \\
\text { Calor - } \\
\text { Caudal Ref. } \\
\text { Variable }\end{array}$ & & $469.1 \%$ & - & - \\
\hline TOTALES & & - & & - & & - & & - & - \\
\hline
\end{tabular}

\section{Instalaciones de Agua Caliente Sanitaria}

\begin{tabular}{|c|c|c|c|c|c|c|c|c|c|}
\hline Nombre & Tipo & $\begin{array}{l}\text { Potencia } \\
\text { nominal }\end{array}$ & $\begin{array}{c}\text { Rendi- } \\
\text { miento } \\
\text { Estacional }\end{array}$ & $\begin{array}{c}\text { Estimación } \\
\text { Energía } \\
\text { Consumida } \\
\text { anual }\end{array}$ & $\begin{array}{c}\text { Tipo post } \\
\text { mejora }\end{array}$ & $\begin{array}{l}\text { Potencia } \\
\text { nominal } \\
\text { post } \\
\text { mejora }\end{array}$ & $\begin{array}{c}\text { Rendimiento } \\
\text { estacional } \\
\text { post mejora }\end{array}$ & $\begin{array}{c}\text { Estimación } \\
\text { Energía } \\
\text { Consumida } \\
\text { anual Post } \\
\text { mejora }\end{array}$ & $\begin{array}{l}\text { Energía } \\
\text { anual } \\
\text { ahorrada }\end{array}$ \\
\hline & & {$[\mathrm{kW}]$} & [\%] & {$\left[\mathrm{kWh} / \mathrm{m}^{2} \mathrm{año}\right]$} & & {$[\mathrm{kW}]$} & [\%] & [kWh/m²año] & [kWh/m²año] \\
\hline Equipo ACS & Efecto Joule & & $100.0 \%$ & - & Efecto Joule & & $100.0 \%$ & - & - \\
\hline TOTALES & & - & & - & & - & & - & - \\
\hline
\end{tabular}




\begin{tabular}{|c|c|c|c|c|c|}
\hline & DEN & $\begin{array}{c}\text { Ref. } \\
\text { Catastral }\end{array}$ & 000000000 & $\begin{array}{c}\text { Versión } \\
\text { informe } \\
\text { asociado }\end{array}$ & $01 / 12 / 2015$ \\
\hline $\begin{array}{c}\text { Certificación } \\
\text { Energatica } \\
\text { de Edificios } \\
\text { de Editios }\end{array}$ & $\begin{array}{c}\text { Id. } \\
\text { Mejora }\end{array}$ & $\begin{array}{l}\text { Programa } \\
\text { y versión }\end{array}$ & CEXv2.1 & Fecha & $3 / 1 / 2004$ \\
\hline
\end{tabular}

\section{ENERGÍAS RENOVABLES}

\section{Térmica}

\begin{tabular}{|c|c|c|c|c|}
\hline \multirow{2}{*}{ Nombre } & \multicolumn{3}{|c|}{$\begin{array}{c}\text { Consumo de Energía Final, cubierto en función } \\
\text { del servicio asociado [\%] }\end{array}$} & $\begin{array}{c}\text { Demanda de ACS } \\
\text { cubierta [\%] }\end{array}$ \\
\cline { 2 - 5 } & Calefacción & Refrigeración & ACS & \\
\hline- & - & - & - & - \\
\hline TOTALES & - & - & - & - \\
\hline
\end{tabular}

\section{Post mejora}

\begin{tabular}{|c|c|c|c|c|}
\hline \multirow{2}{*}{ Nombre } & \multicolumn{2}{|c|}{$\begin{array}{c}\text { Consumo de Energía Final, cubierto en función } \\
\text { del servicio asociado [\%] }\end{array}$} & $\begin{array}{c}\text { Demanda de ACS } \\
\text { cubierta [\%] }\end{array}$ \\
\cline { 2 - 5 } & Calefacción & Refrigeración & ACS & \\
\hline Sistema Geotérmico & 100 & 100 & - & - \\
\hline TOTALES & 100.0 & 100.0 & - & - \\
\hline
\end{tabular}




\begin{tabular}{|c|c|c|c|c|c|}
\hline & & $\begin{array}{c}\text { Ref. } \\
\text { Catastral }\end{array}$ & 000000000 & $\begin{array}{c}\text { Versión } \\
\text { informe } \\
\text { asociado }\end{array}$ & $01 / 12 / 2015$ \\
\hline $\begin{array}{l}\text { Certificación } \\
\text { Energética } \\
\text { de Edificios }\end{array}$ & $\begin{array}{c}\text { Id. } \\
\text { Mejora }\end{array}$ & $\begin{array}{l}\text { Programa } \\
\text { y versión }\end{array}$ & CEXv2.1 & Fecha & $3 / 1 / 2004$ \\
\hline
\end{tabular}

\section{Informe descriptivo de la medida de mejora}

\section{DENOMINACIÓN DE LA MEDIDA DE MEJORA}

Bomba de calor alto cop y eer con geotermia y vidrios activos

\section{DESCRIPCIÓN DE LA MEDIDA DE MEJORA}

Características de la medida (modelo de equipos, materiales, parámetros característicos )

Coste estimado de la medida

Otros datos de interés

CALIFICACIÓN ENERGÉTICA GLOBAL

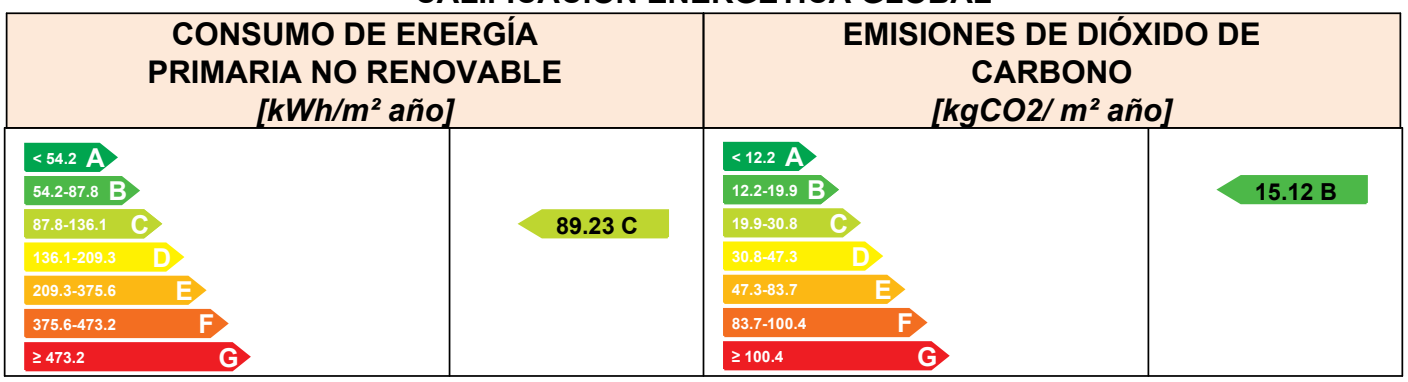

CALIFICACIONES ENERGÉTICAS PARCIALES

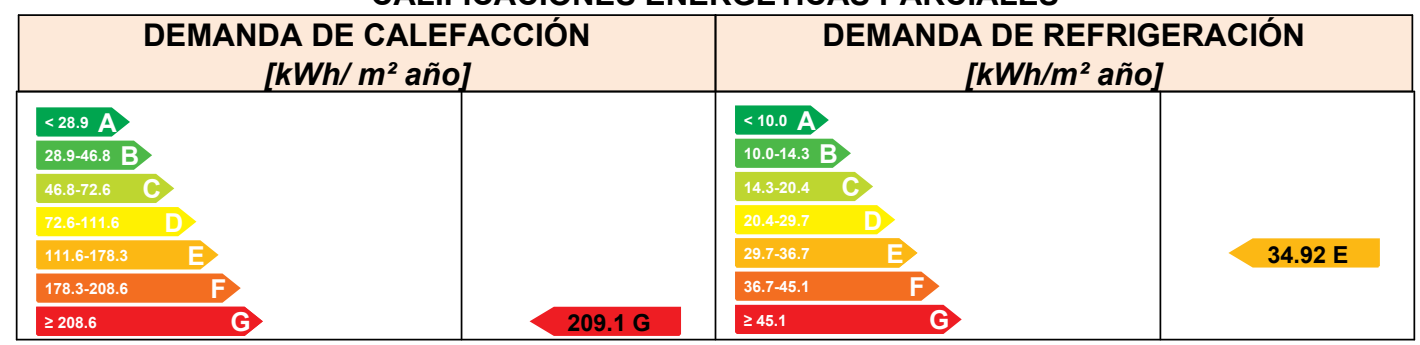




\begin{tabular}{|c|c|c|c|c|c|}
\hline & & $\begin{array}{c}\text { Ref. } \\
\text { Catastral }\end{array}$ & 000000000 & $\begin{array}{c}\text { Versión } \\
\text { informe } \\
\text { asociado }\end{array}$ & $01 / 12 / 2015$ \\
\hline $\begin{array}{l}\text { Certificación } \\
\text { Energética } \\
\text { de Edificios }\end{array}$ & $\begin{array}{c}\text { Id. } \\
\text { Mejora }\end{array}$ & $\begin{array}{l}\text { Programa } \\
\text { y versión }\end{array}$ & CEXv2.1 & Fecha & $3 / 1 / 2004$ \\
\hline
\end{tabular}

\section{ANALISÍS TÉCNICO}

\begin{tabular}{|c|c|c|c|c|c|c|c|c|c|c|c|c|c|c|c|}
\hline \multirow[b]{2}{*}{ Indicador } & \multicolumn{3}{|c|}{ Calefacción } & \multicolumn{3}{|c|}{ Refrigeración } & \multicolumn{3}{|c|}{ ACS } & \multicolumn{3}{|c|}{ Iluminación } & \multicolumn{3}{|c|}{ Total } \\
\hline & \multicolumn{2}{|c|}{ Valor } & $\begin{array}{c}\text { ahorro } \\
\text { respecto a } \\
\text { la situación } \\
\text { original }\end{array}$ & \multicolumn{2}{|c|}{ Valor } & $\begin{array}{c}\text { ahorro } \\
\text { respecto a } \\
\text { la situación } \\
\text { original }\end{array}$ & \multicolumn{2}{|c|}{ Valor } & $\begin{array}{c}\text { ahorro } \\
\text { respecto a } \\
\text { la situación } \\
\text { original }\end{array}$ & \multicolumn{2}{|c|}{ Valor } & $\begin{array}{c}\text { ahorro } \\
\text { respecto a } \\
\text { la situación } \\
\text { original }\end{array}$ & \multicolumn{2}{|c|}{ Valor } & $\begin{array}{c}\text { ahorro } \\
\text { respecto a } \\
\text { la situación } \\
\text { original }\end{array}$ \\
\hline $\begin{array}{l}\text { Consumo Energía } \\
\text { final }\left[\mathrm{kWh} / \mathrm{m}^{2} \text { año] }\right.\end{array}$ & \multicolumn{2}{|c|}{0.00} & $100.0 \%$ & \multicolumn{2}{|c|}{0.00} & $100.0 \%$ & \multicolumn{2}{|c|}{45.66} & $0.0 \%$ & \multicolumn{2}{|l|}{-} & $-\%$ & \multicolumn{2}{|c|}{45.66} & $72.2 \%$ \\
\hline $\begin{array}{c}\text { Consumo Energía } \\
\text { primaria no renovable } \\
{\left[\mathrm{kWh} / \mathrm{m}^{2} \text { año] }\right.}\end{array}$ & 0.00 & A & $100.0 \%$ & 0.00 & A & $100.0 \%$ & 89.23 & G & $0.0 \%$ & - & - & $-\%$ & 89.23 & C & $72.2 \%$ \\
\hline $\begin{array}{c}\text { Emisiones de CO2 } \\
{\left[\mathrm{kgCO} 2 / \mathrm{m}^{2} \text { año] }\right.}\end{array}$ & 0.00 & A & $100.0 \%$ & 0.00 & A & $100.0 \%$ & 15.12 & G & $0.0 \%$ & - & - & $-\%$ & 15.12 & B & $72.2 \%$ \\
\hline $\begin{array}{l}\text { Demanda }\left[\mathrm{kWh} / \mathrm{m}^{2}\right. \\
\text { año] }\end{array}$ & 209.10 & $G$ & $21.4 \%$ & 34.92 & $E$ & $22.2 \%$ & & & & & & & & & \\
\hline
\end{tabular}

\section{ENVOLVENTE TÉRMICA}

\section{Cerramientos opacos}

\begin{tabular}{|c|c|c|c|c|c|}
\hline Nombre & Tipo & $\begin{array}{c}\text { Superficie } \\
\text { actual } \\
{\left[\mathbf{m}^{2}\right]}\end{array}$ & $\begin{array}{c}\text { Transmitancia } \\
\text { actual } \\
{\left[\mathbf{W} / \mathbf{m}^{\mathbf{2}} \mathbf{~ K}\right]}\end{array}$ & $\begin{array}{c}\text { Superficie } \\
\text { post } \\
\text { mejora } \\
{\left[\mathbf{m}^{2}\right]}\end{array}$ & $\begin{array}{c}\text { Transmitancia } \\
\text { post mejora } \\
{\left[\mathbf{W} / \mathbf{m}^{\mathbf{2}} \mathbf{K}\right]}\end{array}$ \\
\hline Cubierta con aire & Cubierta & 52.00 & 0.47 & 52.00 & 0.47 \\
\hline Muro de fachada Norte & Fachada & 27.18 & 0.54 & 27.18 & 0.54 \\
\hline Suelo con aire & Suelo & 52.00 & 2.95 & 52.00 & 2.95 \\
\hline Muro de fachada Sur & Fachada & 21.88 & 0.54 & 21.88 & 0.54 \\
\hline Muro de fachada Oeste & Fachada & 8.04 & 0.54 & 8.04 & 0.54 \\
\hline Muro de fachada Este & Fachada & 3.28 & 0.54 & 3.28 & 0.54 \\
\hline
\end{tabular}

Huecos y lucernarios

\begin{tabular}{|c|c|c|c|c|c|c|c|}
\hline Nombre & Tipo & $\begin{array}{c}\text { Superficie } \\
\text { actual } \\
{\left[\mathrm{m}^{2}\right]}\end{array}$ & $\begin{array}{c}\text { Transmitancia } \\
\text { actual del } \\
\text { hueco[W/m² } \\
\mathrm{K}]\end{array}$ & $\begin{array}{c}\text { Transmitancia } \\
\text { actual del } \\
\text { vidrio[W/m² } \\
\mathrm{K}]\end{array}$ & $\begin{array}{c}\text { Superficie } \\
\text { post } \\
\text { mejora } \\
{\left[\mathrm{m}^{2}\right]}\end{array}$ & $\begin{array}{c}\text { Transmitancia } \\
\text { post mejora } \\
{\left[\mathrm{W} / \mathrm{m}^{2} \mathrm{~K}\right]}\end{array}$ & $\begin{array}{c}\text { Transmitancia } \\
\text { post mejora } \\
\text { del vidrio } \\
{\left[\mathrm{W} / \mathrm{m}^{2} \mathrm{~K}\right]}\end{array}$ \\
\hline V1 & Hueco & 5.3 & 5.70 & 5.70 & 5.3 & 1.27 & 1.12 \\
\hline V3 & Hueco & 5.3 & 5.70 & 5.70 & 5.3 & 1.27 & 1.12 \\
\hline V4 & Hueco & 5.3 & 5.70 & 5.70 & 5.3 & 1.27 & 1.12 \\
\hline V2 & Hueco & 5.3 & 5.70 & 5.70 & 5.3 & 1.27 & 1.12 \\
\hline V5 & Hueco & 5.03 & 5.70 & 5.70 & 5.03 & 1.27 & 1.12 \\
\hline Pta & Hueco & 5.03 & 5.70 & 5.70 & 5.03 & 1.27 & 1.12 \\
\hline
\end{tabular}




\begin{tabular}{|c|c|c|c|c|c|}
\hline & & $\begin{array}{c}\text { Ref. } \\
\text { Catastral }\end{array}$ & 000000000 & $\begin{array}{c}\text { Versión } \\
\text { informe } \\
\text { asociado }\end{array}$ & $01 / 12 / 2015$ \\
\hline $\begin{array}{l}\text { Certificación } \\
\text { Energética } \\
\text { de Edificios }\end{array}$ & $\begin{array}{c}\text { Id. } \\
\text { Mejora }\end{array}$ & $\begin{array}{l}\text { Programa } \\
\text { y versión }\end{array}$ & CEXv2.1 & Fecha & $3 / 1 / 2004$ \\
\hline
\end{tabular}

\section{INSTALACIONES TÉRMICAS}

\section{Generadores de calefacción}

\begin{tabular}{|c|c|c|c|c|c|c|c|c|c|}
\hline \multirow[t]{2}{*}{ Nombre } & \multirow[t]{2}{*}{ Tipo } & $\begin{array}{r}\text { Potencia } \\
\text { nominal }\end{array}$ & $\begin{array}{c}\text { Rendi- } \\
\text { miento } \\
\text { Estacional }\end{array}$ & $\begin{array}{c}\text { Estimación } \\
\text { Energía } \\
\text { Consumida } \\
\text { anual }\end{array}$ & \multirow[t]{2}{*}{$\begin{array}{l}\text { Tipo post } \\
\text { mejora }\end{array}$} & $\begin{array}{c}\text { Potencia } \\
\text { nominal } \\
\text { post } \\
\text { mejora }\end{array}$ & $\begin{array}{c}\text { Rendimiento } \\
\text { estacional } \\
\text { post mejora }\end{array}$ & $\begin{array}{c}\text { Estimación } \\
\text { Energía } \\
\text { Consumida } \\
\text { anual Post } \\
\text { mejora }\end{array}$ & $\begin{array}{l}\text { Energía } \\
\text { anual } \\
\text { ahorrada }\end{array}$ \\
\hline & & {$[\mathrm{kW}]$} & [\%] & {$\left[\mathrm{kWh} / \mathrm{m}^{2} \mathrm{año}\right]$} & & {$[\mathrm{kW}]$} & [\%] & [kWh/m²año] & [kWh/m²año] \\
\hline $\begin{array}{l}\text { Calefacción y } \\
\text { refrigeración }\end{array}$ & $\begin{array}{c}\text { Bomba de } \\
\text { Calor - } \\
\text { Caudal Ref. } \\
\text { Variable }\end{array}$ & & $273.1 \%$ & - & $\begin{array}{c}\text { Bomba de } \\
\text { Calor - } \\
\text { Caudal Ref. } \\
\text { Variable }\end{array}$ & & $484.2 \%$ & - & - \\
\hline TOTALES & & & & & & & & & \\
\hline
\end{tabular}

\section{Generadores de refrigeración}

\begin{tabular}{|c|c|c|c|c|c|c|c|c|c|}
\hline \multirow[t]{2}{*}{ Nombre } & \multirow[t]{2}{*}{ Tipo } & $\begin{array}{r}\text { Potencia } \\
\text { nominal }\end{array}$ & $\begin{array}{c}\text { Rendi- } \\
\text { miento } \\
\text { Estacional }\end{array}$ & $\begin{array}{c}\text { Estimación } \\
\text { Energía } \\
\text { Consumida } \\
\text { anual }\end{array}$ & \multirow[t]{2}{*}{$\begin{array}{l}\text { Tipo post } \\
\text { mejora }\end{array}$} & $\begin{array}{c}\text { Potencia } \\
\text { nominal } \\
\text { post } \\
\text { mejora }\end{array}$ & $\begin{array}{c}\text { Rendimiento } \\
\text { estacional } \\
\text { post mejora }\end{array}$ & $\begin{array}{c}\text { Estimación } \\
\text { Energía } \\
\text { Consumida } \\
\text { anual Post } \\
\text { mejora }\end{array}$ & $\begin{array}{c}\text { Energía } \\
\text { anual } \\
\text { ahorrada }\end{array}$ \\
\hline & & {$[\mathrm{kW}]$} & {$[\%]$} & {$\left[\mathrm{kWh} / \mathrm{m}^{2} \mathrm{año}\right]$} & & {$[\mathrm{kW}]$} & {$[\%]$} & [kWh/m²año] & {$\left[\mathrm{kWh} / \mathrm{m}^{2} \mathrm{año}\right.$} \\
\hline $\begin{array}{l}\text { Calefacción y } \\
\text { refrigeración }\end{array}$ & $\begin{array}{c}\text { Bomba de } \\
\text { Calor - } \\
\text { Caudal Ref. } \\
\text { Variable }\end{array}$ & & $209.7 \%$ & - & $\begin{array}{c}\text { Bomba de } \\
\text { Calor - } \\
\text { Caudal Ref. } \\
\text { Variable }\end{array}$ & & $469.1 \%$ & - & - \\
\hline TOTALES & & - & & - & & - & & - & - \\
\hline
\end{tabular}

\section{Instalaciones de Agua Caliente Sanitaria}

\begin{tabular}{|c|c|c|c|c|c|c|c|c|c|}
\hline Nombre & Tipo & $\begin{array}{l}\text { Potencia } \\
\text { nominal }\end{array}$ & $\begin{array}{c}\text { Rendi- } \\
\text { miento } \\
\text { Estacional }\end{array}$ & $\begin{array}{c}\text { Estimación } \\
\text { Energía } \\
\text { Consumida } \\
\text { anual }\end{array}$ & $\begin{array}{c}\text { Tipo post } \\
\text { mejora }\end{array}$ & $\begin{array}{l}\text { Potencia } \\
\text { nominal } \\
\text { post } \\
\text { mejora }\end{array}$ & $\begin{array}{c}\text { Rendimiento } \\
\text { estacional } \\
\text { post mejora }\end{array}$ & $\begin{array}{c}\text { Estimación } \\
\text { Energía } \\
\text { Consumida } \\
\text { anual Post } \\
\text { mejora }\end{array}$ & $\begin{array}{l}\text { Energía } \\
\text { anual } \\
\text { ahorrada }\end{array}$ \\
\hline & & {$[\mathrm{kW}]$} & [\%] & {$\left[\mathrm{kWh} / \mathrm{m}^{2} \mathrm{año}\right]$} & & {$[\mathrm{kW}]$} & [\%] & [kWh/m²año] & [kWh/m²año] \\
\hline Equipo ACS & Efecto Joule & & $100.0 \%$ & - & Efecto Joule & & $100.0 \%$ & - & - \\
\hline TOTALES & & - & & - & & - & & - & - \\
\hline
\end{tabular}




\begin{tabular}{|c|c|c|c|c|c|}
\hline & DEN & $\begin{array}{c}\text { Ref. } \\
\text { Catastral }\end{array}$ & 000000000 & $\begin{array}{c}\text { Versión } \\
\text { informe } \\
\text { asociado }\end{array}$ & $01 / 12 / 2015$ \\
\hline $\begin{array}{c}\text { Certificación } \\
\text { Energatica } \\
\text { de Edificios } \\
\text { de Editios }\end{array}$ & $\begin{array}{c}\text { Id. } \\
\text { Mejora }\end{array}$ & $\begin{array}{l}\text { Programa } \\
\text { y versión }\end{array}$ & CEXv2.1 & Fecha & $3 / 1 / 2004$ \\
\hline
\end{tabular}

\section{ENERGÍAS RENOVABLES}

\section{Térmica}

\begin{tabular}{|c|c|c|c|c|}
\hline \multirow{2}{*}{ Nombre } & \multicolumn{3}{|c|}{$\begin{array}{c}\text { Consumo de Energía Final, cubierto en función } \\
\text { del servicio asociado [\%] }\end{array}$} & $\begin{array}{c}\text { Demanda de ACS } \\
\text { cubierta [\%] }\end{array}$ \\
\cline { 2 - 5 } & Calefacción & Refrigeración & ACS & \\
\hline- & - & - & - & - \\
\hline TOTALES & - & - & - & - \\
\hline
\end{tabular}

\section{Post mejora}

\begin{tabular}{|c|c|c|c|c|}
\hline \multirow{2}{*}{ Nombre } & \multicolumn{2}{|c|}{$\begin{array}{c}\text { Consumo de Energía Final, cubierto en función } \\
\text { del servicio asociado [\%] }\end{array}$} & $\begin{array}{c}\text { Demanda de ACS } \\
\text { cubierta [\%] }\end{array}$ \\
\cline { 2 - 5 } & Calefacción & Refrigeración & ACS & \\
\hline Sistema Geotérmico & 100 & 100 & - & - \\
\hline TOTALES & 100.0 & 100.0 & - & - \\
\hline
\end{tabular}




\begin{tabular}{|c|c|c|c|c|c|}
\hline & & $\begin{array}{c}\text { Ref. } \\
\text { Catastral }\end{array}$ & 000000000 & $\begin{array}{c}\text { Versión } \\
\text { informe } \\
\text { asociado }\end{array}$ & $01 / 12 / 2015$ \\
\hline $\begin{array}{l}\text { Certificación } \\
\text { Energética } \\
\text { de Edificios }\end{array}$ & $\begin{array}{c}\text { Id. } \\
\text { Mejora }\end{array}$ & $\begin{array}{l}\text { Programa } \\
\text { y versión }\end{array}$ & CEXv2.1 & Fecha & $4 / 1 / 2004$ \\
\hline
\end{tabular}

\section{Informe descriptivo de la medida de mejora}

\section{DENOMINACIÓN DE LA MEDIDA DE MEJORA}

FV+ Bomba de calor alto cop y eer con geotermia y vidrios activos

\section{DESCRIPCIÓN DE LA MEDIDA DE MEJORA}

Características de la medida (modelo de equipos, materiales, parámetros característicos )

Coste estimado de la medida

Otros datos de interés

CALIFICACIÓN ENERGÉTICA GLOBAL

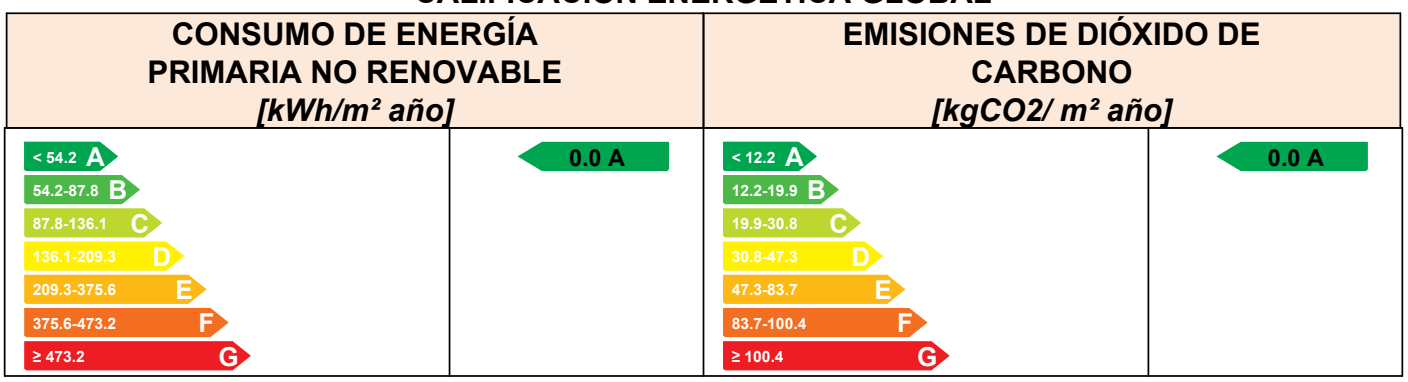

CALIFICACIONES ENERGÉTICAS PARCIALES

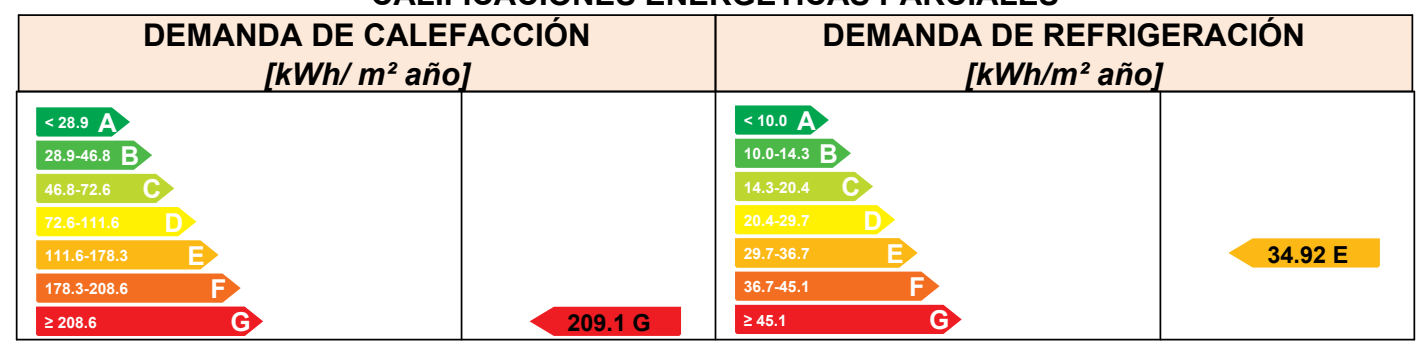




\begin{tabular}{|c|c|c|c|c|c|}
\hline & & $\begin{array}{c}\text { Ref. } \\
\text { Catastral }\end{array}$ & 000000000 & $\begin{array}{c}\text { Versión } \\
\text { informe } \\
\text { asociado }\end{array}$ & $01 / 12 / 2015$ \\
\hline $\begin{array}{l}\text { Certificación } \\
\text { Energética } \\
\text { de Edificios }\end{array}$ & $\begin{array}{c}\text { Id. } \\
\text { Mejora }\end{array}$ & $\begin{array}{l}\text { Programa } \\
\text { y versión }\end{array}$ & CEXv2.1 & Fecha & $4 / 1 / 2004$ \\
\hline
\end{tabular}

\section{ANALISÍS TÉCNICO}

\begin{tabular}{|c|c|c|c|c|c|c|c|c|c|c|c|c|c|c|c|}
\hline \multirow[b]{2}{*}{ Indicador } & \multicolumn{3}{|c|}{ Calefacción } & \multicolumn{3}{|c|}{ Refrigeración } & \multicolumn{3}{|c|}{ ACS } & \multicolumn{3}{|c|}{ Iluminación } & \multicolumn{3}{|c|}{ Total } \\
\hline & \multicolumn{2}{|c|}{ Valor } & $\begin{array}{c}\text { ahorro } \\
\text { respecto a } \\
\text { la situación } \\
\text { original }\end{array}$ & \multicolumn{2}{|c|}{ Valor } & $\begin{array}{c}\text { ahorro } \\
\text { respecto a } \\
\text { la situación } \\
\text { original }\end{array}$ & \multicolumn{2}{|c|}{ Valor } & $\begin{array}{c}\text { ahorro } \\
\text { respecto a } \\
\text { la situación } \\
\text { original }\end{array}$ & \multicolumn{2}{|c|}{ Valor } & $\begin{array}{c}\text { ahorro } \\
\text { respecto a } \\
\text { la situación } \\
\text { original }\end{array}$ & \multicolumn{2}{|c|}{ Valor } & $\begin{array}{c}\text { ahorro } \\
\text { respecto a } \\
\text { la situación } \\
\text { original }\end{array}$ \\
\hline $\begin{array}{l}\text { Consumo Energía } \\
\text { final }\left[\mathrm{kWh} / \mathrm{m}^{2} \text { año] }\right.\end{array}$ & \multicolumn{2}{|c|}{0.00} & $100.0 \%$ & \multicolumn{2}{|c|}{0.00} & $100.0 \%$ & \multicolumn{2}{|c|}{45.66} & $0.0 \%$ & \multicolumn{2}{|l|}{-} & $-\%$ & \multicolumn{2}{|c|}{-78.87} & $148.0 \%$ \\
\hline $\begin{array}{c}\text { Consumo Energía } \\
\text { primaria no renovable } \\
{\left[\mathrm{kWh} / \mathrm{m}^{2} \text { año] }\right.}\end{array}$ & 0.00 & A & $100.0 \%$ & 0.00 & A & $100.0 \%$ & 89.23 & G & $0.0 \%$ & - & - & $-\%$ & 0.00 & A & $100.0 \%$ \\
\hline $\begin{array}{c}\text { Emisiones de CO2 } \\
{\left[\mathrm{kgCO} 2 / \mathrm{m}^{2} \text { año] }\right.}\end{array}$ & 0.00 & A & $100.0 \%$ & 0.00 & A & $100.0 \%$ & 15.12 & G & $0.0 \%$ & - & - & $-\%$ & 0.00 & A & $100.0 \%$ \\
\hline $\begin{array}{l}\text { Demanda }\left[\mathrm{kWh} / \mathrm{m}^{2}\right. \\
\text { año] }\end{array}$ & 209.10 & $G$ & $21.4 \%$ & 34.92 & $E$ & $22.2 \%$ & & & & & & & & & \\
\hline
\end{tabular}

\section{ENVOLVENTE TÉRMICA}

\section{Cerramientos opacos}

\begin{tabular}{|c|c|c|c|c|c|}
\hline Nombre & Tipo & $\begin{array}{c}\text { Superficie } \\
\text { actual } \\
{\left[\mathbf{m}^{2}\right]}\end{array}$ & $\begin{array}{c}\text { Transmitancia } \\
\text { actual } \\
{\left[\mathbf{W} / \mathbf{m}^{\mathbf{2}} \mathbf{~ K}\right]}\end{array}$ & $\begin{array}{c}\text { Superficie } \\
\text { post } \\
\text { mejora } \\
{\left[\mathbf{m}^{2}\right]}\end{array}$ & $\begin{array}{c}\text { Transmitancia } \\
\text { post mejora } \\
{\left[\mathbf{W} / \mathbf{m}^{\mathbf{2}} \mathbf{K}\right]}\end{array}$ \\
\hline Cubierta con aire & Cubierta & 52.00 & 0.47 & 52.00 & 0.47 \\
\hline Muro de fachada Norte & Fachada & 27.18 & 0.54 & 27.18 & 0.54 \\
\hline Suelo con aire & Suelo & 52.00 & 2.95 & 52.00 & 2.95 \\
\hline Muro de fachada Sur & Fachada & 21.88 & 0.54 & 21.88 & 0.54 \\
\hline Muro de fachada Oeste & Fachada & 8.04 & 0.54 & 8.04 & 0.54 \\
\hline Muro de fachada Este & Fachada & 3.28 & 0.54 & 3.28 & 0.54 \\
\hline
\end{tabular}

Huecos y lucernarios

\begin{tabular}{|c|c|c|c|c|c|c|c|}
\hline Nombre & Tipo & $\begin{array}{c}\text { Superficie } \\
\text { actual } \\
{\left[\mathrm{m}^{2}\right]}\end{array}$ & $\begin{array}{c}\text { Transmitancia } \\
\text { actual del } \\
\text { hueco[W/m² } \\
\mathrm{K}]\end{array}$ & $\begin{array}{c}\text { Transmitancia } \\
\text { actual del } \\
\text { vidrio[W/m² } \\
\mathrm{K}]\end{array}$ & $\begin{array}{c}\text { Superficie } \\
\text { post } \\
\text { mejora } \\
{\left[\mathrm{m}^{2}\right]}\end{array}$ & $\begin{array}{c}\text { Transmitancia } \\
\text { post mejora } \\
{\left[\mathrm{W} / \mathrm{m}^{2} \mathrm{~K}\right]}\end{array}$ & $\begin{array}{c}\text { Transmitancia } \\
\text { post mejora } \\
\text { del vidrio } \\
{\left[\mathrm{W} / \mathrm{m}^{2} \mathrm{~K}\right]}\end{array}$ \\
\hline V1 & Hueco & 5.3 & 5.70 & 5.70 & 5.3 & 1.27 & 1.12 \\
\hline V3 & Hueco & 5.3 & 5.70 & 5.70 & 5.3 & 1.27 & 1.12 \\
\hline V4 & Hueco & 5.3 & 5.70 & 5.70 & 5.3 & 1.27 & 1.12 \\
\hline V2 & Hueco & 5.3 & 5.70 & 5.70 & 5.3 & 1.27 & 1.12 \\
\hline V5 & Hueco & 5.03 & 5.70 & 5.70 & 5.03 & 1.27 & 1.12 \\
\hline Pta & Hueco & 5.03 & 5.70 & 5.70 & 5.03 & 1.27 & 1.12 \\
\hline
\end{tabular}




\begin{tabular}{|c|c|c|c|c|c|}
\hline & & $\begin{array}{c}\text { Ref. } \\
\text { Catastral }\end{array}$ & 000000000 & $\begin{array}{c}\text { Versión } \\
\text { informe } \\
\text { asociado }\end{array}$ & $01 / 12 / 2015$ \\
\hline $\begin{array}{l}\text { Certificación } \\
\text { Energética } \\
\text { de Edificios }\end{array}$ & $\begin{array}{c}\text { Id. } \\
\text { Mejora }\end{array}$ & $\begin{array}{l}\text { Programa } \\
\text { y versión }\end{array}$ & CEXv2.1 & Fecha & $4 / 1 / 2004$ \\
\hline
\end{tabular}

\section{INSTALACIONES TÉRMICAS}

\section{Generadores de calefacción}

\begin{tabular}{|c|c|c|c|c|c|c|c|c|c|}
\hline \multirow[t]{2}{*}{ Nombre } & \multirow[t]{2}{*}{ Tipo } & $\begin{array}{r}\text { Potencia } \\
\text { nominal }\end{array}$ & $\begin{array}{c}\text { Rendi- } \\
\text { miento } \\
\text { Estacional }\end{array}$ & $\begin{array}{c}\text { Estimación } \\
\text { Energía } \\
\text { Consumida } \\
\text { anual }\end{array}$ & \multirow[t]{2}{*}{$\begin{array}{l}\text { Tipo post } \\
\text { mejora }\end{array}$} & $\begin{array}{c}\text { Potencia } \\
\text { nominal } \\
\text { post } \\
\text { mejora }\end{array}$ & $\begin{array}{c}\text { Rendimiento } \\
\text { estacional } \\
\text { post mejora }\end{array}$ & $\begin{array}{c}\text { Estimación } \\
\text { Energía } \\
\text { Consumida } \\
\text { anual Post } \\
\text { mejora }\end{array}$ & $\begin{array}{l}\text { Energía } \\
\text { anual } \\
\text { ahorrada }\end{array}$ \\
\hline & & {$[\mathrm{kW}]$} & [\%] & {$\left[\mathrm{kWh} / \mathrm{m}^{2} \mathrm{año}\right]$} & & {$[\mathrm{kW}]$} & [\%] & [kWh/m²año] & [kWh/m²año] \\
\hline $\begin{array}{l}\text { Calefacción y } \\
\text { refrigeración }\end{array}$ & $\begin{array}{c}\text { Bomba de } \\
\text { Calor - } \\
\text { Caudal Ref. } \\
\text { Variable }\end{array}$ & & $273.1 \%$ & - & $\begin{array}{c}\text { Bomba de } \\
\text { Calor - } \\
\text { Caudal Ref. } \\
\text { Variable }\end{array}$ & & $484.2 \%$ & - & - \\
\hline TOTALES & & & & & & & & & \\
\hline
\end{tabular}

\section{Generadores de refrigeración}

\begin{tabular}{|c|c|c|c|c|c|c|c|c|c|}
\hline \multirow[t]{2}{*}{ Nombre } & \multirow[t]{2}{*}{ Tipo } & $\begin{array}{r}\text { Potencia } \\
\text { nominal }\end{array}$ & $\begin{array}{c}\text { Rendi- } \\
\text { miento } \\
\text { Estacional }\end{array}$ & $\begin{array}{c}\text { Estimación } \\
\text { Energía } \\
\text { Consumida } \\
\text { anual }\end{array}$ & \multirow[t]{2}{*}{$\begin{array}{l}\text { Tipo post } \\
\text { mejora }\end{array}$} & $\begin{array}{c}\text { Potencia } \\
\text { nominal } \\
\text { post } \\
\text { mejora }\end{array}$ & $\begin{array}{c}\text { Rendimiento } \\
\text { estacional } \\
\text { post mejora }\end{array}$ & $\begin{array}{c}\text { Estimación } \\
\text { Energía } \\
\text { Consumida } \\
\text { anual Post } \\
\text { mejora }\end{array}$ & $\begin{array}{c}\text { Energía } \\
\text { anual } \\
\text { ahorrada }\end{array}$ \\
\hline & & {$[\mathrm{kW}]$} & {$[\%]$} & {$\left[\mathrm{kWh} / \mathrm{m}^{2} \mathrm{año}\right]$} & & {$[\mathrm{kW}]$} & {$[\%]$} & [kWh/m²año] & {$\left[\mathrm{kWh} / \mathrm{m}^{2} \mathrm{año}\right.$} \\
\hline $\begin{array}{l}\text { Calefacción y } \\
\text { refrigeración }\end{array}$ & $\begin{array}{c}\text { Bomba de } \\
\text { Calor - } \\
\text { Caudal Ref. } \\
\text { Variable }\end{array}$ & & $209.7 \%$ & - & $\begin{array}{c}\text { Bomba de } \\
\text { Calor - } \\
\text { Caudal Ref. } \\
\text { Variable }\end{array}$ & & $469.1 \%$ & - & - \\
\hline TOTALES & & - & & - & & - & & - & - \\
\hline
\end{tabular}

\section{Instalaciones de Agua Caliente Sanitaria}

\begin{tabular}{|c|c|c|c|c|c|c|c|c|c|}
\hline Nombre & Tipo & $\begin{array}{l}\text { Potencia } \\
\text { nominal }\end{array}$ & $\begin{array}{c}\text { Rendi- } \\
\text { miento } \\
\text { Estacional }\end{array}$ & $\begin{array}{c}\text { Estimación } \\
\text { Energía } \\
\text { Consumida } \\
\text { anual }\end{array}$ & $\begin{array}{c}\text { Tipo post } \\
\text { mejora }\end{array}$ & $\begin{array}{l}\text { Potencia } \\
\text { nominal } \\
\text { post } \\
\text { mejora }\end{array}$ & $\begin{array}{c}\text { Rendimiento } \\
\text { estacional } \\
\text { post mejora }\end{array}$ & $\begin{array}{c}\text { Estimación } \\
\text { Energía } \\
\text { Consumida } \\
\text { anual Post } \\
\text { mejora }\end{array}$ & $\begin{array}{l}\text { Energía } \\
\text { anual } \\
\text { ahorrada }\end{array}$ \\
\hline & & {$[\mathrm{kW}]$} & [\%] & {$\left[\mathrm{kWh} / \mathrm{m}^{2} \mathrm{año}\right]$} & & {$[\mathrm{kW}]$} & [\%] & [kWh/m²año] & [kWh/m²año] \\
\hline Equipo ACS & Efecto Joule & & $100.0 \%$ & - & Efecto Joule & & $100.0 \%$ & - & - \\
\hline TOTALES & & - & & - & & - & & - & - \\
\hline
\end{tabular}




\begin{tabular}{|c|c|c|c|c|c|}
\hline & & $\begin{array}{c}\text { Ref. } \\
\text { Catastral }\end{array}$ & 000000000 & $\begin{array}{c}\text { Versión } \\
\text { informe } \\
\text { asociado }\end{array}$ & $01 / 12 / 2015$ \\
\hline $\begin{array}{l}\text { Certificación } \\
\text { Energética } \\
\text { de Edificios }\end{array}$ & $\begin{array}{c}\text { Id. } \\
\text { Mejora }\end{array}$ & $\begin{array}{l}\text { Programa } \\
\text { y versión }\end{array}$ & CEXv2.1 & Fecha & $4 / 1 / 2004$ \\
\hline
\end{tabular}

\section{ENERGÍAS RENOVABLES}

\section{Térmica}

\begin{tabular}{|c|c|c|c|c|}
\hline \multirow{2}{*}{ Nombre } & \multicolumn{3}{|c|}{$\begin{array}{c}\text { Consumo de Energía Final, cubierto en función } \\
\text { del servicio asociado [\%] }\end{array}$} & $\begin{array}{c}\text { Demanda de ACS } \\
\text { cubierta [\%] }\end{array}$ \\
\cline { 2 - 5 } & Calefacción & Refrigeración & ACS & \\
\hline- & - & - & - & - \\
\hline TOTALES & - & - & - & - \\
\hline
\end{tabular}

Post mejora

\begin{tabular}{|c|c|c|c|c|}
\hline \multirow{2}{*}{ Nombre } & \multicolumn{2}{|c|}{$\begin{array}{c}\text { Consumo de Energía Final, cubierto en función } \\
\text { del servicio asociado [\%] }\end{array}$} & $\begin{array}{c}\text { Demanda de ACS } \\
\text { cubierta [\%] }\end{array}$ \\
\cline { 2 - 5 } & Calefacción & Refrigeración & ACS & \\
\hline FV+ Sistema Geotérmico & 100 & 100 & - & - \\
\hline TOTALES & 100.0 & 100.0 & - & - \\
\hline
\end{tabular}

\section{Eléctrica}

\begin{tabular}{|c|c|c|}
\hline Nombre & $\begin{array}{c}\text { Energía eléctrica generada y } \\
\text { autoconsumida [kWh/año] }\end{array}$ & $\begin{array}{c}\text { Energía eléctrica generada y } \\
\text { autoconsumida post mejora } \\
\text { [kWh/año] }\end{array}$ \\
\hline FV+ Sistema Geotérmico & - & 8940 \\
\hline TOTALES & - & 8940.0 \\
\hline
\end{tabular}


A.6.6

Zona Climática Csb (Koppen)/ D2 (CTE). Ourense. 


\section{CERTIFICADO DE EFICIENCIA ENERGÉTICA DE EDIFICIOS}

IDENTIFICACIÓN DEL EDIFICIO O DE LA PARTE QUE SE CERTIFICA:

\begin{tabular}{|l|l|l|l|}
\hline Nombre del edificio & Vivienda Taller Modificado \\
\hline Dirección & Tesis & Código Postal & 32005 \\
\hline Municipio & Ourense & Comunidad Autónoma & Galicia \\
\hline Provincia & Ourense & Año construcción & 2007 \\
\hline Zona climática & D2 & & \\
\hline $\begin{array}{l}\text { Normativa vigente (construcción } \\
\text { rehabilitación) }\end{array}$ & C.T.E. & \\
\hline Referencia/s catastral/es & 000000000 & \\
\hline
\end{tabular}

\begin{tabular}{|l|l|}
\hline \multicolumn{2}{|c|}{ Tipo de edificio o parte del edificio que se certifica: } \\
\hline$\circ$ Edificio de nueva construcción & $\bullet$ Edificio Existente \\
\hline \multicolumn{2}{|c|}{} \\
\hline$\bullet$ Vivienda & $\circ$ Terciario \\
$\bullet$ Unifamiliar & $\circ$ Edificio completo \\
$\circ$ Bloque & $\circ$ Local \\
$\circ$ Bloque completo & \\
\hline Vivienda individual & \\
\hline
\end{tabular}

DATOS DEL TÉCNICO CERTIFICADOR:

\begin{tabular}{|c|c|c|c|c|c|}
\hline Nombre y Apellidos & \multicolumn{3}{|c|}{ Juan Carlos Sánchez } & NIF(NIE) & 000000000 \\
\hline Razón social & \multicolumn{3}{|c|}{ Juan Carlos Sánchez } & NIF & 000000000 \\
\hline \multicolumn{2}{|l|}{ Domicilio } & \multicolumn{4}{|l|}{ Calle Pinar Del Rey } \\
\hline \multicolumn{2}{|l|}{ Municipio } & Madrid & \multicolumn{2}{|c|}{ Código Postal } & 28033 \\
\hline \multicolumn{2}{|l|}{ Provincia } & Madrid & \multicolumn{2}{|c|}{ Comunidad Autónoma } & $\begin{array}{l}\text { Comunidad } \\
\text { Madrid }\end{array}$ \\
\hline \multicolumn{2}{|l|}{ e-mail: } & \multicolumn{2}{|c|}{ juancsanchezg@hotmail.com } & Teléfono & 0000000000 \\
\hline \multicolumn{2}{|c|}{ Titulación habilitante según normativa vigente } & \multicolumn{4}{|l|}{ Arquitecto } \\
\hline $\begin{array}{l}\text { Procedimiento reconocido de } \\
\text { versión: }\end{array}$ & calificación & ergética utilizado y & CEX & & \\
\hline
\end{tabular}

\section{CALIFICACIÓN ENERGÉTICA OBTENIDA:}

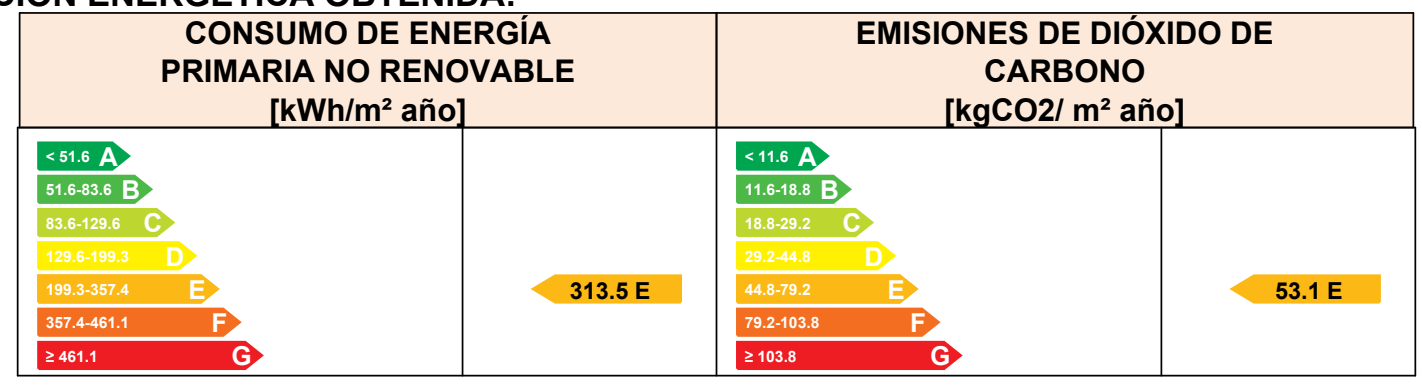

El técnico abajo firmante declara responsablemente que ha realizado la certificación energética del edificio o de la parte que se certifica de acuerdo con el procedimiento establecido por la normativa vigente y que son ciertos los datos que figuran en el presente documento, y sus anexos:

Fecha: 01/12/2015

Firma del técnico certificador

Anexo I. Descripción de las características energéticas del edificio.

Anexo II. Calificación energética del edificio.

Anexo III. Recomendaciones para la mejora de la eficiencia energética.

Anexo IV. Pruebas, comprobaciones e inspecciones realizadas por el técnico certificador.

Registro del Órgano Territorial Competente: 


\section{DESCRIPCIÓN DE LAS CARACTERÍSTICAS ENERGÉTICAS DEL EDIFICIO}

En este apartado se describen las características energéticas del edificio, envolvente térmica, instalaciones, condiciones de funcionamiento y ocupación y demás datos utilizados para obtener la calificación energética del edificio.

\section{SUPERFICIE, IMAGEN Y SITUACIÓN}

\begin{tabular}{|l|l}
\hline Superficie habitable $\left[\mathrm{m}^{2}\right]$ & 52.0
\end{tabular}

\begin{tabular}{|c|c|c|}
\hline Imagen del edificio & Plano de situación \\
\hline & &
\end{tabular}

\section{ENVOLVENTE TÉRMICA}

\section{Cerramientos opacos}

\begin{tabular}{|l|c|c|c|c|}
\hline \multicolumn{1}{|c|}{ Nombre } & Tipo & $\begin{array}{c}\text { Superficie } \\
{\left[\mathrm{m}^{2}\right]}\end{array}$ & $\begin{array}{c}\text { Transmitancia } \\
{\left[\mathbf{W} / \mathbf{m}^{2} \cdot \mathrm{K}\right]}\end{array}$ & Modo de obtención \\
\hline Cubierta con aire & Cubierta & 52.0 & 0.47 & Conocidas \\
\hline Muro de fachada Norte & Fachada & 27.18 & 0.54 & Conocidas \\
\hline Suelo con aire & Suelo & 52.0 & 2.95 & Conocidas \\
\hline Muro de fachada Sur & Fachada & 21.88 & 0.54 & Conocidas \\
\hline Muro de fachada Oeste & Fachada & 8.04 & 0.54 & Conocidas \\
\hline Muro de fachada Este & Fachada & 3.28 & 0.54 & Conocidas \\
\hline
\end{tabular}

Huecos y lucernarios

\begin{tabular}{|l|c|c|c|c|c|c|}
\hline Nombre & Tipo & $\begin{array}{c}\text { Superficie } \\
{\left[\mathbf{m}^{2}\right]}\end{array}$ & $\begin{array}{c}\text { Transmitancia } \\
{\left[\mathbf{W} / \mathbf{m}^{2} \cdot \mathbf{K}\right]}\end{array}$ & $\begin{array}{c}\text { Factor } \\
\text { solar }\end{array}$ & $\begin{array}{c}\text { Modo de } \\
\text { obtención. } \\
\text { Transmitancia }\end{array}$ & $\begin{array}{c}\text { Modo de } \\
\text { obtención. } \\
\text { Factor solar }\end{array}$ \\
\hline V1 & Hueco & 5.3 & 5.70 & 0.67 & Estimado & Estimado \\
\hline V3 & Hueco & 5.3 & 5.70 & 0.67 & Estimado & Estimado \\
\hline V4 & Hueco & 5.3 & 5.70 & 0.67 & Estimado & Estimado \\
\hline V2 & Hueco & 5.3 & 5.70 & 0.67 & Estimado & Estimado \\
\hline V5 & Hueco & 5.03 & 5.70 & 0.67 & Estimado & Estimado \\
\hline Pta & Hueco & 5.03 & 5.70 & 0.67 & Estimado & Estimado \\
\hline
\end{tabular}




\section{INSTALACIONES TÉRMICAS}

Generadores de calefacción

\begin{tabular}{|c|c|c|c|c|c|}
\hline Nombre & Tipo & $\begin{array}{c}\text { Potencia } \\
\text { nominal [kW] }\end{array}$ & $\begin{array}{l}\text { Rendimiento } \\
\text { Estacional[\%] }\end{array}$ & $\begin{array}{l}\text { Tipo de } \\
\text { Energía }\end{array}$ & $\begin{array}{c}\text { Modo de } \\
\text { obtención }\end{array}$ \\
\hline $\begin{array}{l}\text { Calefacción } \\
\text { refrigeración }\end{array}$ & $\begin{array}{l}\text { Bomba de Calor - } \\
\text { Caudal Ref. Variable }\end{array}$ & & 261.5 & Electricidad & Estimado \\
\hline TOTALES & Calefacción & & & & \\
\hline
\end{tabular}

\section{Generadores de refrigeración}

\begin{tabular}{|c|c|c|c|c|c|}
\hline Nombre & Tipo & $\begin{array}{c}\text { Potencia } \\
\text { nominal [kW] }\end{array}$ & $\begin{array}{c}\text { Rendimiento } \\
\text { Estacional[\%] }\end{array}$ & $\begin{array}{c}\text { Tipo de } \\
\text { Energía }\end{array}$ & $\begin{array}{c}\text { Modo de } \\
\text { obtención }\end{array}$ \\
\hline $\begin{array}{l}\text { Calefacción } \\
\text { refrigeración }\end{array}$ & y & $\begin{array}{c}\text { Bomba de Calor } \\
\text { Caudal Ref. Variable }\end{array}$ & 227.1 & Electricidad & Estimado \\
\hline TOTALES & Refrigeración & & & \\
\hline
\end{tabular}

Instalaciones de Agua Caliente Sanitaria

Demanda diario de ACS a $60^{\circ}$ (litros/día) 45.55

\begin{tabular}{|c|c|c|c|c|c|}
\hline Nombre & Tipo & $\begin{array}{c}\text { Potencia } \\
\text { nominal [kW] }\end{array}$ & $\begin{array}{c}\text { Rendimiento } \\
\text { Estacional[\%] }\end{array}$ & $\begin{array}{c}\text { Tipo de } \\
\text { Energía }\end{array}$ & $\begin{array}{c}\text { Modo de } \\
\text { obtención }\end{array}$ \\
\hline Equipo ACS & Efecto Joule & & 100.0 & Electricidad & Estimado \\
\hline TOTALES & ACS & & & & \\
\hline
\end{tabular}




\section{ANEXO II
CALIFICACIÓN ENERGÉTICA DEL EDIFICIO}

\begin{tabular}{|l|l|l|l|}
\hline Zona climática & D2 & Uso & Residencial \\
\hline
\end{tabular}

\section{CALIFICACIÓN ENERGÉTICA DEL EDIFICIO EN EMISIONES}

\begin{tabular}{|c|c|c|c|c|c|}
\hline \multicolumn{2}{|c|}{ INDICADOR GLOBAL } & \multicolumn{4}{|c|}{ INDICADORES PARCIALES } \\
\hline $\begin{array}{l}<11.6 \mathrm{~A} \\
11.6-18.8 \mathrm{~B}\end{array}$ & & \multicolumn{2}{|c|}{ CALEFACCIÓN } & \multicolumn{2}{|l|}{ ACS } \\
\hline $\begin{array}{|ll|}18.829 .2 & \text { C } \\
29.2-44.8 & \text { D }\end{array}$ & & $\begin{array}{c}\text { Emisiones } \\
\text { calefacción } \\
{\left[\mathrm{kgCO} 2 / \mathrm{m}^{2} \text { añol }\right.}\end{array}$ & \multirow{2}{*}{ D } & $\begin{array}{l}\text { Emisiones ACS } \\
{\left[\mathrm{kgCO} 2 / \mathrm{m}^{2} \text { año] }\right.}\end{array}$ & \multirow{2}{*}{ G } \\
\hline $44.8-79.2$ & \multirow[t]{2}{*}{$53.1 \mathrm{E}$} & 33.70 & & 15.25 & \\
\hline $\begin{array}{ll}79.2-103.8 & F \\
\geq 103.8 & C\end{array}$ & & \multicolumn{2}{|c|}{ REFRIGERACIÓN } & \multicolumn{2}{|l|}{ ILUMINACIÓN } \\
\hline \multirow{2}{*}{\multicolumn{2}{|c|}{ Emisiones globales $\left[\mathrm{kgCO} 2 / \mathrm{m}^{2}\right.$ año] ${ }^{1}$}} & $\begin{array}{c}\text { Emisiones } \\
\text { refrigeración } \\
{\left[\mathrm{kgCO} 2 / \mathrm{m}^{2} \text { año] }\right.}\end{array}$ & \multirow[t]{2}{*}{ E } & $\begin{array}{c}\text { Emisiones } \\
\text { iluminación } \\
{\left[\mathrm{kgCO} 2 / \mathrm{m}^{2} \text { año] }\right.}\end{array}$ & \multirow[t]{2}{*}{-} \\
\hline & & 4.17 & & - & \\
\hline
\end{tabular}

La calificación global del edificio se expresa en términos de dióxido de carbono liberado a la atmósfera como consecuencia del consumo energético del mismo.

\begin{tabular}{|l|c|c|}
\cline { 2 - 3 } \multicolumn{1}{c|}{} & $\mathbf{k g C O} 2 / \mathbf{m}^{\mathbf{2}}$ año & $\mathbf{~} \mathbf{k g C O 2 / a n ̃ o ~}$ \\
\hline Emisiones CO2 por consumo eléctrico & 53.11 & 2761.90 \\
\hline Emisiones CO2 por otros combustibles & 0.00 & 0.00 \\
\hline
\end{tabular}

\section{CALIFICACIÓN ENERGÉTICA DEL EDIFICIO EN CONSUMO DE ENERGÍA PRIMARIA NO RENOVABLE}

Por energía primaria no renovable se entiende la energía consumida por el edificio procedente de fuentes no renovables que no ha sufrido ningún proceso de conversión o transformación.

\begin{tabular}{|c|c|c|c|c|c|}
\hline \multicolumn{2}{|c|}{ INDICADOR GLOBAL } & \multicolumn{4}{|c|}{ INDICADORES PARCIALES } \\
\hline \multirow{4}{*}{ 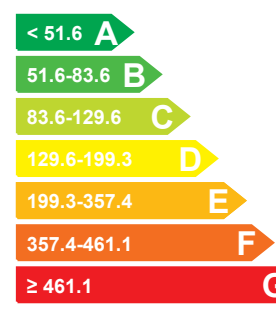 } & & \multicolumn{2}{|c|}{ CALEFACCIÓN } & \multicolumn{2}{|l|}{ ACS } \\
\hline & & $\begin{array}{l}\text { Energía primaria } \\
\text { calefacción } \\
{\left[\mathrm{kWh} / \mathrm{m}^{2} \text { año] }\right.}\end{array}$ & \multirow[t]{2}{*}{$\mathrm{E}$} & $\begin{array}{l}\text { Energía primaria } \\
A C S \\
{\left[\mathrm{kWh} / \mathrm{m}^{2} \text { año] }\right.}\end{array}$ & \multirow[t]{2}{*}{ G } \\
\hline & \multirow[t]{2}{*}{$313.5 \mathrm{E}$} & 198.93 & & 90.02 & \\
\hline & & \multicolumn{2}{|c|}{ REFRIGERACIÓN } & \multicolumn{2}{|l|}{ ILUMINACIÓN } \\
\hline \multirow{2}{*}{\multicolumn{2}{|c|}{$\begin{array}{l}\text { Consumo global de energía primaria no renovable } \\
\qquad\left[\mathrm{kWh} / \mathrm{m}^{2} \text { año }\right]^{1}\end{array}$}} & $\begin{array}{l}\text { Energía primaria } \\
\text { refrigeración } \\
{\left[\mathrm{kWh} / \mathrm{m}^{2} \text { añol }\right.}\end{array}$ & \multirow[t]{2}{*}{ G } & $\begin{array}{l}\text { Energía primaria } \\
\text { iluminación } \\
{\left[\mathrm{kWh} / \mathrm{m}^{2} a \tilde{n} o\right]}\end{array}$ & \\
\hline & & 24.60 & & - & \\
\hline
\end{tabular}

\section{CALIFICACIÓN PARCIAL DE LA DEMANDA ENERGÉTICA DE CALEFACCIÓN Y REFRIGERACIÓN}

La demanda energética de calefacción y refrigeración es la energía necesaria para mantener las condiciones internas de confort del edificio.

\begin{tabular}{|c|c|c|c|}
\hline \multicolumn{2}{|c|}{ DEMANDA DE CALEFACCIÓN } & \multicolumn{2}{|c|}{ DEMANDA DE REFRIGERACIÓN } \\
\hline$<28.9$ A & & $<3.9$ A & \\
\hline $28.9-46.8 \mathrm{~B}$ & & $3.9-6.4 \quad B$ & \\
\hline 46.8-72.6 C & & 6.4-9.9 C & \\
\hline 72.6-111.6 D & & 9.9-15.2 D & \\
\hline 111.6-178.3 $\quad$ E & & 15.2-18.3 $\quad$ E & \\
\hline 178.3-208.6 $\quad$ F & & 18.3-22.5 $\quad \mathrm{F}$ & \\
\hline$\geq 208.6$ & $266.2 \mathrm{G}$ & $\geq 22.5$ & $28.6 \mathrm{G}$ \\
\hline \multicolumn{2}{|c|}{ Demanda de calefacción [kWh/m² año] } & \multicolumn{2}{|c|}{ Demanda de refrigeración $\left[\mathrm{kWh} / \mathrm{m}^{2}\right.$ año] } \\
\hline
\end{tabular}

${ }^{1}$ El indicador global es resultado de la suma de los indicadores parciales más el valor del indicador para consumos auxiliares, si los hubiera (sólo ed. terciarios, ventilación, bombeo, etc...). La energía eléctrica autoconsumida se descuenta únicamente del indicador global, no así de los valores parciales 


\section{ANEXO III \\ RECOMENDACIONES PARA LA MEJORA DE LA EFICIENCIA ENERGÉTICA}

FV $100 \%$

CALIFICACIÓN ENERGÉTICA GLOBAL

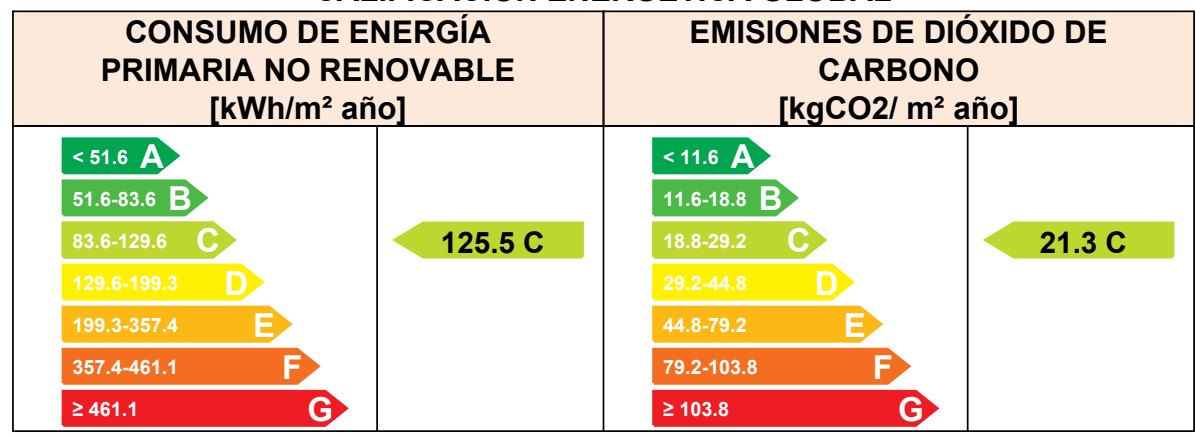

CALIFICACIONES ENERGÉTICAS PARCIALES

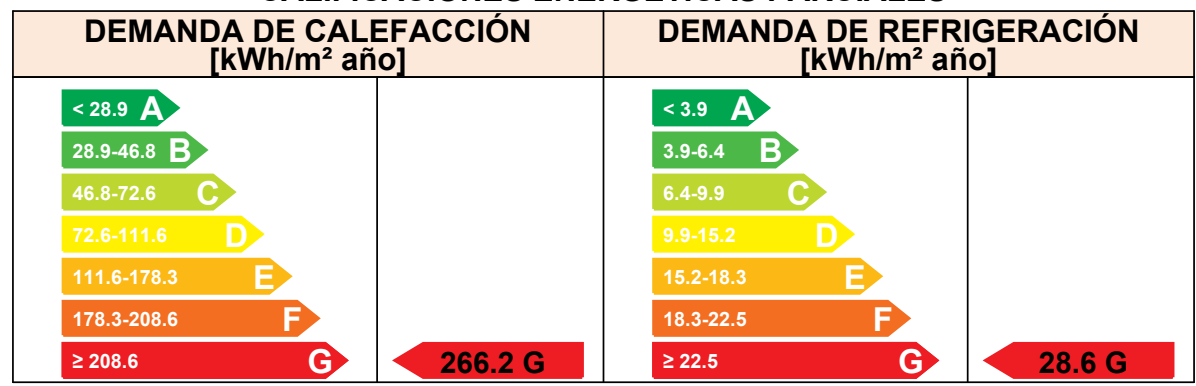

\section{ANÁLISIS TÉCNICO}

\begin{tabular}{|c|c|c|c|c|c|c|c|c|c|c|c|c|c|c|c|}
\hline \multirow[b]{2}{*}{ Indicador } & \multicolumn{3}{|c|}{ Calefacción } & \multicolumn{3}{|c|}{ Refrigeración } & \multicolumn{3}{|c|}{ ACS } & \multicolumn{3}{|c|}{ Iluminación } & \multicolumn{3}{|c|}{ Total } \\
\hline & \multicolumn{2}{|c|}{ Valor } & $\begin{array}{c}\text { ahorro } \\
\text { respecto a } \\
\text { la situación } \\
\text { original }\end{array}$ & \multicolumn{2}{|c|}{ Valor } & $\begin{array}{c}\text { ahorro } \\
\text { respecto a } \\
\text { la situación } \\
\text { original }\end{array}$ & \multicolumn{2}{|c|}{ Valor } & $\begin{array}{c}\text { ahorro } \\
\text { respecto a } \\
\text { la situación } \\
\text { original }\end{array}$ & \multicolumn{2}{|c|}{ Valor } & $\begin{array}{c}\text { ahorro } \\
\text { respecto a } \\
\text { la situación } \\
\text { original }\end{array}$ & \multicolumn{2}{|c|}{ Valor } & $\begin{array}{c}\text { ahorro } \\
\text { respecto a } \\
\text { la situación } \\
\text { original }\end{array}$ \\
\hline $\begin{array}{c}\text { Consumo Energía final } \\
{\left[\mathrm{kWh} / \mathrm{m}^{2} \text { año] }\right.}\end{array}$ & \multicolumn{2}{|c|}{114.50} & $-12.5 \%$ & \multicolumn{2}{|c|}{11.20} & $11.1 \%$ & \multicolumn{2}{|c|}{46.07} & $0.0 \%$ & \multicolumn{2}{|c|}{ - } & $-\%$ & \multicolumn{2}{|c|}{64.23} & $60.0 \%$ \\
\hline $\begin{array}{c}\text { Consumo Energía } \\
\text { primaria no renovable } \\
{\left[\mathrm{kWh} / \mathrm{m}^{2} \text { año] }\right.}\end{array}$ & 223.74 & $E$ & $-12.5 \%$ & 21.88 & $\mathrm{~F}$ & $11.1 \%$ & 90.02 & G & $0.0 \%$ & - & - & $-\%$ & 125.50 & C & $60.0 \%$ \\
\hline $\begin{array}{c}\text { Emisiones de CO2 } \\
{\left[\mathrm{kgCO} 2 / \mathrm{m}^{2} \text { año] }\right.}\end{array}$ & 37.90 & $E$ & $-12.5 \%$ & 3.71 & $\mathrm{D}$ & $11.1 \%$ & 15.25 & G & $0.0 \%$ & - & - & $-\%$ & 21.26 & $\mathrm{C}$ & $60.0 \%$ \\
\hline Demanda $\left[\mathrm{kWh} / \mathrm{m}^{2}\right.$ año] & 266.22 & G & $0.0 \%$ & 28.59 & G & $0.0 \%$ & & & & & & & & & \\
\hline
\end{tabular}

Nota: Los indicadores energéticos anteriores están calculados en base a coeficientes estándar de operación y funcionamiento del edificio, por lo que solo son válidos a efectos de su calificación energética. Para el análisis económico de las medidas de ahorro y eficiencia energética, el técnico certificador deberá utilizar las condiciones reales y datos históricos de consumo del edificio.

\section{DESCRIPCIÓN DE LA MEDIDA DE MEJORA}

Características de la medida (modelo de equipos, materiales, parámetros característicos )

Coste estimado de la medida

Otros datos de interés 
CALIFICACIÓN ENERGÉTICA GLOBAL

\begin{tabular}{|c|c|c|c|}
\hline \multicolumn{2}{|c|}{$\begin{array}{l}\text { CONSUMO DE ENERGÍA } \\
\text { PRIMARIA NO RENOVABLE } \\
\text { [kWh/m² año] }\end{array}$} & \multicolumn{2}{|c|}{$\begin{array}{c}\text { EMISIONES DE DIÓXIDO DE } \\
\text { CARBONO } \\
{\left[\mathrm{kgCO} 2 / \mathrm{m}^{2} \text { año] }\right.}\end{array}$} \\
\hline$<51.6 \mathrm{~A}$ & & $<11.6 \mathrm{~A}$ & \\
\hline $51.6-83.6$ B & & 11.6-18.8 B & $15.2 \mathrm{~B}$ \\
\hline${ }_{83.6-129.6 \quad C}$ & $90.0 \mathrm{C}$ & 18.8-29.2 C & \\
\hline 129.6-199.3 D & & $29.2-44.8$ & \\
\hline 199.3-357.4 E & & $44.8-79.2$ & \\
\hline $357.4-461.1$ & & $79.2-103.8$ & \\
\hline$\geq 461.1 \quad$ G & & $\geq 103.8$ & \\
\hline
\end{tabular}

CALIFICACIONES ENERGÉTICAS PARCIALES

\begin{tabular}{|c|c|c|c|}
\hline \multicolumn{2}{|c|}{$\begin{array}{l}\text { DEMANDA DE CALEFACCIÓN } \\
{\left[\mathrm{kWh} / \mathrm{m}^{2} \text { año] }\right.}\end{array}$} & \multicolumn{2}{|c|}{$\begin{array}{l}\text { DEMANDA DE REFRIGERACIÓN } \\
{\left[\mathrm{kWh} / \mathrm{m}^{2} \text { año] }\right.}\end{array}$} \\
\hline$<28.9$ A & & $<3.9$ A & \\
\hline 28.9-46.8 B & & $3.9-6.4 \quad$ B & \\
\hline $46.8-72.6 \quad \mathrm{C}$ & & 6.4-9.9 C & \\
\hline 72.6-111.6 D & & $9.9-15.2$ & \\
\hline 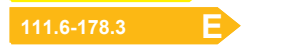 & $119.0 \mathrm{E}$ & $15.2-18.3$ & \\
\hline 178.3-208.6 $\quad$ F & & 18.3-22.5 & $22.4 \mathrm{~F}$ \\
\hline$\geq 208.6 \quad$ G & & $\geq 22.5$ & \\
\hline
\end{tabular}

\section{ANÁLISIS TÉCNICO}

\begin{tabular}{|c|c|c|c|c|c|c|c|c|c|c|c|c|c|c|c|}
\hline \multirow[b]{2}{*}{ Indicador } & \multicolumn{3}{|c|}{ Calefacción } & \multicolumn{3}{|c|}{ Refrigeración } & \multicolumn{3}{|c|}{ ACS } & \multicolumn{3}{|c|}{ Iluminación } & \multicolumn{3}{|c|}{ Total } \\
\hline & \multicolumn{2}{|c|}{ Valor } & $\begin{array}{c}\text { ahorro } \\
\text { respecto a } \\
\text { la situación } \\
\text { original }\end{array}$ & \multicolumn{2}{|c|}{ Valor } & $\begin{array}{c}\text { ahorro } \\
\text { respecto a } \\
\text { la situación } \\
\text { original }\end{array}$ & \multicolumn{2}{|c|}{ Valor } & $\begin{array}{c}\text { ahorro } \\
\text { respecto a } \\
\text { la situación } \\
\text { original }\end{array}$ & \multicolumn{2}{|c|}{ Valor } & $\begin{array}{c}\text { ahorro } \\
\text { respecto a } \\
\text { la situación } \\
\text { original }\end{array}$ & \multicolumn{2}{|c|}{ Valor } & $\begin{array}{c}\text { ahorro } \\
\text { respecto a } \\
\text { la situación } \\
\text { original }\end{array}$ \\
\hline $\begin{array}{c}\text { Consumo Energía final } \\
{\left[\mathrm{kWh} / \mathrm{m}^{2} \text { año] }\right.}\end{array}$ & \multicolumn{2}{|c|}{0.00} & $100.0 \%$ & \multicolumn{2}{|c|}{0.00} & $100.0 \%$ & \multicolumn{2}{|c|}{46.07} & $0.0 \%$ & \multicolumn{2}{|l|}{ - } & $-\%$ & \multicolumn{2}{|c|}{46.07} & $71.3 \%$ \\
\hline $\begin{array}{c}\text { Consumo Energía } \\
\text { primaria no renovable } \\
{\left[\mathrm{kWh} / \mathrm{m}^{2} \text { año] }\right.}\end{array}$ & 0.00 & $A$ & $100.0 \%$ & 0.00 & A & $100.0 \%$ & 90.02 & G & $0.0 \%$ & - & - & $-\%$ & 90.02 & $\mathrm{C}$ & $71.3 \%$ \\
\hline $\begin{array}{c}\text { Emisiones de } \mathrm{CO} 2 \\
{\left[\mathrm{kgCO} 2 / \mathrm{m}^{2} \text { año] }\right.}\end{array}$ & 0.00 & $A$ & $100.0 \%$ & 0.00 & A & $100.0 \%$ & 15.25 & G & $0.0 \%$ & - & - & $-\%$ & 15.25 & $\mathrm{~B}$ & $71.3 \%$ \\
\hline Demanda $\left[\mathrm{kWh} / \mathrm{m}^{2}\right.$ año] & 118.99 & $E$ & $55.3 \%$ & 22.38 & $\mathrm{~F}$ & $21.7 \%$ & & & & & & & & & \\
\hline
\end{tabular}

Nota: Los indicadores energéticos anteriores están calculados en base a coeficientes estándar de operación y funcionamiento del edificio, por lo que solo son válidos a efectos de su calificación energética. Para el análisis económico de las medidas de ahorro y eficiencia energética, el técnico certificador deberá utilizar las condiciones reales y datos históricos de consumo del edificio.

\section{DESCRIPCIÓN DE LA MEDIDA DE MEJORA}

Características de la medida (modelo de equipos, materiales, parámetros característicos )

Coste estimado de la medida

\section{Otros datos de interés}


CALIFICACIÓN ENERGÉTICA GLOBAL

\begin{tabular}{|c|c|c|c|}
\hline \multicolumn{2}{|c|}{$\begin{array}{l}\text { CONSUMO DE ENERGÍA } \\
\text { PRIMARIA NO RENOVABLE } \\
{\left[\mathrm{kWh} / \mathrm{m}^{2} \text { año] }\right.}\end{array}$} & \multicolumn{2}{|c|}{$\begin{array}{c}\text { EMISIONES DE DIÓXIDO DE } \\
\text { CARBONO } \\
{\left[\mathrm{kgCO} 2 / \mathrm{m}^{2} \text { año] }\right.}\end{array}$} \\
\hline$<51.6 \mathrm{~A}$ & & $<11.6 \mathrm{~A}$ & \\
\hline $51.6-83.6$ B & & 11.6-18.8 B & $15.2 \mathrm{~B}$ \\
\hline $83.6-129.6 \quad$ C & $90.0 \mathrm{C}$ & 18.8-29.2 C & \\
\hline 129.6-199.3 D & & $29.2-44.8$ & \\
\hline 199.3-357.4 E & & $44.8-79.2$ & \\
\hline $357.4-461.1$ & & $79.2-103.8$ & \\
\hline$\geq 461.1 \quad$ G & & $\geq 103.8$ & \\
\hline
\end{tabular}

CALIFICACIONES ENERGÉTICAS PARCIALES

\begin{tabular}{|c|c|c|c|}
\hline \multicolumn{2}{|c|}{$\begin{array}{l}\text { DEMANDA DE CALEFACCIÓN } \\
{\left[\mathrm{kWh} / \mathrm{m}^{2} \text { año] }\right.}\end{array}$} & \multicolumn{2}{|c|}{$\begin{array}{l}\text { DEMANDA DE REFRIGERACIÓN } \\
{\left[\mathrm{kWh} / \mathrm{m}^{2} \text { año] }\right.}\end{array}$} \\
\hline$<28.9$ A & & $<3.9$ A & \\
\hline 28.9-46.8 B & & $3.9-6.4 \quad$ B & \\
\hline $46.8-72.6 \quad \mathrm{C}$ & & 6.4-9.9 C & \\
\hline 72.6-111.6 D & & $9.9-15.2$ & \\
\hline 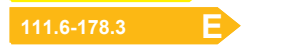 & $119.0 \mathrm{E}$ & $15.2-18.3$ & \\
\hline 178.3-208.6 $\quad$ F & & 18.3-22.5 & $22.4 \mathrm{~F}$ \\
\hline$\geq 208.6 \quad$ G & & $\geq 22.5$ & \\
\hline
\end{tabular}

\section{ANÁLISIS TÉCNICO}

\begin{tabular}{|c|c|c|c|c|c|c|c|c|c|c|c|c|c|c|c|}
\hline \multirow[b]{2}{*}{ Indicador } & \multicolumn{3}{|c|}{ Calefacción } & \multicolumn{3}{|c|}{ Refrigeración } & \multicolumn{3}{|c|}{ ACS } & \multicolumn{3}{|c|}{ Iluminación } & \multicolumn{3}{|c|}{ Total } \\
\hline & \multicolumn{2}{|c|}{ Valor } & $\begin{array}{c}\text { ahorro } \\
\text { respecto a } \\
\text { la situación } \\
\text { original }\end{array}$ & \multicolumn{2}{|c|}{ Valor } & $\begin{array}{c}\text { ahorro } \\
\text { respecto a } \\
\text { la situación } \\
\text { original }\end{array}$ & \multicolumn{2}{|c|}{ Valor } & $\begin{array}{c}\text { ahorro } \\
\text { respecto a } \\
\text { la situación } \\
\text { original }\end{array}$ & \multicolumn{2}{|c|}{ Valor } & $\begin{array}{c}\text { ahorro } \\
\text { respecto a } \\
\text { la situación } \\
\text { original }\end{array}$ & \multicolumn{2}{|c|}{ Valor } & $\begin{array}{c}\text { ahorro } \\
\text { respecto a } \\
\text { la situación } \\
\text { original }\end{array}$ \\
\hline $\begin{array}{c}\text { Consumo Energía final } \\
{\left[\mathrm{kWh} / \mathrm{m}^{2} \text { año] }\right.}\end{array}$ & \multicolumn{2}{|c|}{0.00} & $100.0 \%$ & \multicolumn{2}{|c|}{0.00} & $100.0 \%$ & \multicolumn{2}{|c|}{46.07} & $0.0 \%$ & \multicolumn{2}{|l|}{ - } & $-\%$ & \multicolumn{2}{|c|}{46.07} & $71.3 \%$ \\
\hline $\begin{array}{c}\text { Consumo Energía } \\
\text { primaria no renovable } \\
{\left[\mathrm{kWh} / \mathrm{m}^{2} \text { año] }\right.}\end{array}$ & 0.00 & $A$ & $100.0 \%$ & 0.00 & A & $100.0 \%$ & 90.02 & G & $0.0 \%$ & - & - & $-\%$ & 90.02 & $\mathrm{C}$ & $71.3 \%$ \\
\hline $\begin{array}{c}\text { Emisiones de } \mathrm{CO} 2 \\
{\left[\mathrm{kgCO} 2 / \mathrm{m}^{2} \text { año] }\right.}\end{array}$ & 0.00 & $A$ & $100.0 \%$ & 0.00 & A & $100.0 \%$ & 15.25 & G & $0.0 \%$ & - & - & $-\%$ & 15.25 & $\mathrm{~B}$ & $71.3 \%$ \\
\hline Demanda $\left[\mathrm{kWh} / \mathrm{m}^{2}\right.$ año] & 118.99 & $E$ & $55.3 \%$ & 22.38 & $\mathrm{~F}$ & $21.7 \%$ & & & & & & & & & \\
\hline
\end{tabular}

Nota: Los indicadores energéticos anteriores están calculados en base a coeficientes estándar de operación y funcionamiento del edificio, por lo que solo son válidos a efectos de su calificación energética. Para el análisis económico de las medidas de ahorro y eficiencia energética, el técnico certificador deberá utilizar las condiciones reales y datos históricos de consumo del edificio.

\section{DESCRIPCIÓN DE LA MEDIDA DE MEJORA}

Características de la medida (modelo de equipos, materiales, parámetros característicos )

Coste estimado de la medida

\section{Otros datos de interés}




\section{ANEXO IV \\ PRUEBAS, COMPROBACJONES E INSPECCIONES REALIZADAS POR EL TECNICO CERTIFICADOR}

Se describen a continuación las pruebas, comprobaciones e inspecciones llevadas a cabo por el técnico certificador durante el proceso de toma de datos y de calificación de la eficiencia energética del edificio, con la finalidad de establecer la conformidad de la información de partida contenida en el certificado de eficiencia energética.

Fecha de realización de la visita del técnico certificador 


\begin{tabular}{|c|c|c|c|c|c|}
\hline (6) & IDENTIFICACIÓN & $\begin{array}{l}\text { Ref. } \\
\text { Catastral }\end{array}$ & 000000000 & $\begin{array}{c}\text { Versión } \\
\text { informe } \\
\text { asociado }\end{array}$ & $01 / 12 / 2015$ \\
\hline 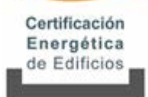 & $\begin{array}{c}\text { Id. } \\
\text { Mejora }\end{array}$ & $\begin{array}{l}\text { Programa } \\
\text { y versión }\end{array}$ & CEXv2.1 & Fecha & 4/1/2004 \\
\hline
\end{tabular}

\section{Informe descriptivo de la medida de mejora}

\section{DENOMINACIÓN DE LA MEDIDA DE MEJORA}

FV $100 \%$

\section{DESCRIPCIÓN DE LA MEDIDA DE MEJORA}

Características de la medida (modelo de equipos, materiales, parámetros característicos )

Coste estimado de la medida

Otros datos de interés

CALIFICACIÓN ENERGÉTICA GLOBAL

\begin{tabular}{|c|c|c|c|}
\hline $\begin{array}{r}\text { CONS } \\
\text { PRIMAF }\end{array}$ & $\begin{array}{l}\text { ÍA } \\
\text { BLE }\end{array}$ & $\begin{array}{r}\text { EMISIO } \\
\text { [k }\end{array}$ & \\
\hline $\begin{array}{l}<51.6 \mathrm{~A} \\
51.6-83.6 \mathrm{~B}\end{array}$ & & $\begin{array}{l}<11.6 \mathrm{~A} \\
11.6-18.8 \mathrm{~B}\end{array}$ & \\
\hline${ }_{12.6-129.6 \quad C} C_{\text {D. }}$ & $125.5 \mathrm{C}$ & 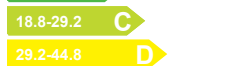 & $21.26 \mathrm{C}$ \\
\hline 199.3-357.4 E & & 44.8-79.2 $\quad$ E & \\
\hline $357.4-461.1$ & & 79.2-103.8 & \\
\hline$\geq 461.1$ & & $\geq 103.8$ & \\
\hline
\end{tabular}

CALIFICACIONES ENERGÉTICAS PARCIALES

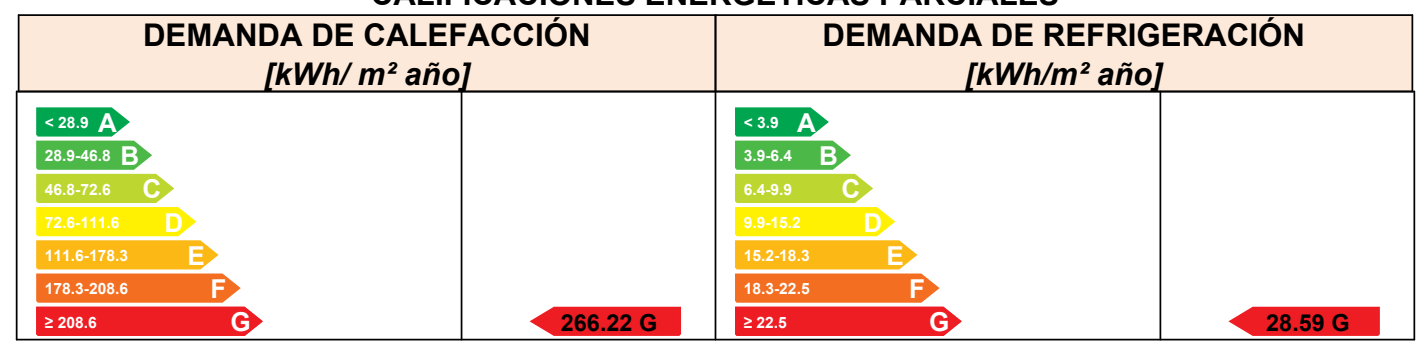




\begin{tabular}{|c|c|c|c|c|c|}
\hline & & $\begin{array}{c}\text { Ref. } \\
\text { Catastral }\end{array}$ & 000000000 & $\begin{array}{c}\text { Versión } \\
\text { informe } \\
\text { asociado }\end{array}$ & $01 / 12 / 2015$ \\
\hline $\begin{array}{l}\text { Certificación } \\
\text { Energética } \\
\text { de Edificios }\end{array}$ & $\begin{array}{c}\text { Id. } \\
\text { Mejora }\end{array}$ & $\begin{array}{l}\text { Programa } \\
\text { y versión }\end{array}$ & CEXv2.1 & Fecha & $4 / 1 / 2004$ \\
\hline
\end{tabular}

\section{ANALISÍS TÉCNICO}

\begin{tabular}{|c|c|c|c|c|c|c|c|c|c|c|c|c|c|c|c|}
\hline \multirow[b]{2}{*}{ Indicador } & \multicolumn{3}{|c|}{ Calefacción } & \multicolumn{3}{|c|}{ Refrigeración } & \multicolumn{3}{|c|}{ ACS } & \multicolumn{3}{|c|}{ Iluminación } & \multicolumn{3}{|c|}{ Total } \\
\hline & \multicolumn{2}{|c|}{ Valor } & $\begin{array}{c}\text { ahorro } \\
\text { respecto a } \\
\text { la situación } \\
\text { original }\end{array}$ & \multicolumn{2}{|c|}{ Valor } & $\begin{array}{c}\text { ahorro } \\
\text { respecto a } \\
\text { la situación } \\
\text { original }\end{array}$ & \multicolumn{2}{|c|}{ Valor } & $\begin{array}{c}\text { ahorro } \\
\text { respecto a } \\
\text { la situación } \\
\text { original }\end{array}$ & \multicolumn{2}{|c|}{ Valor } & $\begin{array}{c}\text { ahorro } \\
\text { respecto a } \\
\text { la situación } \\
\text { original }\end{array}$ & \multicolumn{2}{|c|}{ Valor } & $\begin{array}{c}\text { ahorro } \\
\text { respecto a } \\
\text { la situación } \\
\text { original }\end{array}$ \\
\hline $\begin{array}{l}\text { Consumo Energía } \\
\text { final }\left[\mathrm{kWh} / \mathrm{m}^{2} \text { año] }\right.\end{array}$ & \multicolumn{2}{|c|}{114.50} & $-12.5 \%$ & \multicolumn{2}{|c|}{11.20} & $11.1 \%$ & \multicolumn{2}{|c|}{46.07} & $0.0 \%$ & \multicolumn{2}{|l|}{-} & $-\%$ & \multicolumn{2}{|c|}{64.23} & $60.0 \%$ \\
\hline $\begin{array}{l}\text { Consumo Energía } \\
\text { primaria no renovable } \\
{\left[\mathrm{kWh} / \mathrm{m}^{2} \text { año] }\right.}\end{array}$ & 223.74 & $E$ & $-12.5 \%$ & 21.88 & $F$ & $11.1 \%$ & 90.02 & G & $0.0 \%$ & - & - & $-\%$ & 125.50 & C & $60.0 \%$ \\
\hline $\begin{array}{c}\text { Emisiones de CO2 } \\
{\left[\mathrm{kgCO} 2 / \mathrm{m}^{2} \text { año] }\right.}\end{array}$ & 37.90 & $E$ & $-12.5 \%$ & 3.71 & D & $11.1 \%$ & 15.25 & G & $0.0 \%$ & - & - & $-\%$ & 21.26 & C & $60.0 \%$ \\
\hline $\begin{array}{l}\text { Demanda }\left[\mathrm{kWh} / \mathrm{m}^{2}\right. \\
\text { año] }\end{array}$ & 266.22 & G & $0.0 \%$ & 28.59 & G & $0.0 \%$ & & & & & & & & & \\
\hline
\end{tabular}

\section{ENVOLVENTE TÉRMICA}

\section{Cerramientos opacos}

\begin{tabular}{|c|c|c|c|c|c|}
\hline Nombre & Tipo & $\begin{array}{c}\text { Superficie } \\
\text { actual } \\
{\left[\mathbf{m}^{2}\right]}\end{array}$ & $\begin{array}{c}\text { Transmitancia } \\
\text { actual } \\
{\left[\mathbf{W} / \mathbf{m}^{\mathbf{2}} \mathbf{~ K}\right]}\end{array}$ & $\begin{array}{c}\text { Superficie } \\
\text { post } \\
\text { mejora } \\
{\left[\mathbf{m}^{2}\right]}\end{array}$ & $\begin{array}{c}\text { Transmitancia } \\
\text { post mejora } \\
{\left[\mathbf{W} / \mathbf{m}^{\mathbf{2}} \mathbf{K}\right]}\end{array}$ \\
\hline Cubierta con aire & Cubierta & 52.00 & 0.47 & 52.00 & 0.47 \\
\hline Muro de fachada Norte & Fachada & 27.18 & 0.54 & 27.18 & 0.54 \\
\hline Suelo con aire & Suelo & 52.00 & 2.95 & 52.00 & 2.95 \\
\hline Muro de fachada Sur & Fachada & 21.88 & 0.54 & 21.88 & 0.54 \\
\hline Muro de fachada Oeste & Fachada & 8.04 & 0.54 & 8.04 & 0.54 \\
\hline Muro de fachada Este & Fachada & 3.28 & 0.54 & 3.28 & 0.54 \\
\hline
\end{tabular}

Huecos y lucernarios

\begin{tabular}{|c|c|c|c|c|c|c|c|}
\hline Nombre & Tipo & $\begin{array}{c}\text { Superficie } \\
\text { actual } \\
{\left[\mathrm{m}^{2}\right]}\end{array}$ & $\begin{array}{c}\text { Transmitancia } \\
\text { actual del } \\
\text { hueco[W/m² } \\
\mathrm{K}]\end{array}$ & $\begin{array}{c}\text { Transmitancia } \\
\text { actual del } \\
\text { vidrio[W/m² } \\
\mathrm{K}]\end{array}$ & $\begin{array}{l}\text { Superficie } \\
\text { post } \\
\text { mejora } \\
{\left[\mathrm{m}^{2}\right]}\end{array}$ & $\begin{array}{c}\text { Transmitancia } \\
\text { post mejora } \\
{\left[\mathrm{W} / \mathrm{m}^{2} \mathrm{~K}\right]}\end{array}$ & $\begin{array}{c}\text { Transmitancia } \\
\text { post mejora } \\
\text { del vidrio } \\
{\left[\mathrm{W} / \mathrm{m}^{2} \mathrm{~K}\right]}\end{array}$ \\
\hline V1 & Hueco & 5.3 & 5.70 & 5.70 & 5.3 & 5.70 & 5.70 \\
\hline V3 & Hueco & 5.3 & 5.70 & 5.70 & 5.3 & 5.70 & 5.70 \\
\hline V4 & Hueco & 5.3 & 5.70 & 5.70 & 5.3 & 5.70 & 5.70 \\
\hline V2 & Hueco & 5.3 & 5.70 & 5.70 & 5.3 & 5.70 & 5.70 \\
\hline V5 & Hueco & 5.03 & 5.70 & 5.70 & 5.03 & 5.70 & 5.70 \\
\hline Pta & Hueco & 5.03 & 5.70 & 5.70 & 5.03 & 5.70 & 5.70 \\
\hline
\end{tabular}




\begin{tabular}{|c|c|c|c|c|c|}
\hline & & $\begin{array}{c}\text { Ref. } \\
\text { Catastral }\end{array}$ & 000000000 & $\begin{array}{c}\text { Versión } \\
\text { informe } \\
\text { asociado }\end{array}$ & $01 / 12 / 2015$ \\
\hline $\begin{array}{l}\text { Certificación } \\
\text { Energética } \\
\text { de Edificios }\end{array}$ & $\begin{array}{c}\text { Id. } \\
\text { Mejora }\end{array}$ & $\begin{array}{l}\text { Programa } \\
\text { y versión }\end{array}$ & CEXv2.1 & Fecha & $4 / 1 / 2004$ \\
\hline
\end{tabular}

\section{INSTALACIONES TÉRMICAS}

\section{Generadores de calefacción}

\begin{tabular}{|c|c|c|c|c|c|c|c|c|c|}
\hline \multirow[t]{2}{*}{ Nombre } & \multirow[t]{2}{*}{ Tipo } & $\begin{array}{r}\text { Potencia } \\
\text { nominal }\end{array}$ & $\begin{array}{c}\text { Rendi- } \\
\text { miento } \\
\text { Estacional }\end{array}$ & $\begin{array}{c}\text { Estimación } \\
\text { Energía } \\
\text { Consumida } \\
\text { anual }\end{array}$ & \multirow[t]{2}{*}{$\begin{array}{l}\text { Tipo post } \\
\text { mejora }\end{array}$} & $\begin{array}{c}\text { Potencia } \\
\text { nominal } \\
\text { post } \\
\text { mejora }\end{array}$ & $\begin{array}{c}\text { Rendimiento } \\
\text { estacional } \\
\text { post mejora }\end{array}$ & $\begin{array}{c}\text { Estimación } \\
\text { Energía } \\
\text { Consumida } \\
\text { anual Post } \\
\text { mejora }\end{array}$ & $\begin{array}{l}\text { Energía } \\
\text { anual } \\
\text { ahorrada }\end{array}$ \\
\hline & & {$[\mathrm{kW}]$} & [\%] & {$\left[\mathrm{kWh} / \mathrm{m}^{2} \mathrm{año}\right]$} & & {$[\mathrm{kW}]$} & [\%] & [kWh/m²año] & [kWh/m²año] \\
\hline $\begin{array}{l}\text { Calefacción y } \\
\text { refrigeración }\end{array}$ & $\begin{array}{c}\text { Bomba de } \\
\text { Calor - } \\
\text { Caudal Ref. } \\
\text { Variable }\end{array}$ & & $261.5 \%$ & - & $\begin{array}{c}\text { Bomba de } \\
\text { Calor - } \\
\text { Caudal Ref. } \\
\text { Variable }\end{array}$ & & $232.5 \%$ & - & - \\
\hline TOTALES & & & & & & & & & \\
\hline
\end{tabular}

\section{Generadores de refrigeración}

\begin{tabular}{|c|c|c|c|c|c|c|c|c|c|}
\hline \multirow[t]{2}{*}{ Nombre } & \multirow[t]{2}{*}{ Tipo } & $\begin{array}{r}\text { Potencia } \\
\text { nominal }\end{array}$ & $\begin{array}{c}\text { Rendi- } \\
\text { miento } \\
\text { Estacional }\end{array}$ & $\begin{array}{c}\text { Estimación } \\
\text { Energía } \\
\text { Consumida } \\
\text { anual }\end{array}$ & \multirow[t]{2}{*}{$\begin{array}{l}\text { Tipo post } \\
\text { mejora }\end{array}$} & $\begin{array}{c}\text { Potencia } \\
\text { nominal } \\
\text { post } \\
\text { mejora }\end{array}$ & $\begin{array}{c}\text { Rendimiento } \\
\text { estacional } \\
\text { post mejora }\end{array}$ & $\begin{array}{c}\text { Estimación } \\
\text { Energía } \\
\text { Consumida } \\
\text { anual Post } \\
\text { mejora }\end{array}$ & $\begin{array}{c}\text { Energía } \\
\text { anual } \\
\text { ahorrada }\end{array}$ \\
\hline & & {$[\mathrm{kW}]$} & {$[\%]$} & {$\left[\mathrm{kWh} / \mathrm{m}^{2} \mathrm{año}\right]$} & & {$[\mathrm{kW}]$} & {$[\%]$} & [kWh/m²año] & {$\left[\mathrm{kWh} / \mathrm{m}^{2} \mathrm{año}\right.$} \\
\hline $\begin{array}{l}\text { Calefacción y } \\
\text { refrigeración }\end{array}$ & $\begin{array}{c}\text { Bomba de } \\
\text { Calor - } \\
\text { Caudal Ref. } \\
\text { Variable }\end{array}$ & & $227.1 \%$ & - & $\begin{array}{c}\text { Bomba de } \\
\text { Calor - } \\
\text { Caudal Ref. } \\
\text { Variable }\end{array}$ & & $255.4 \%$ & - & - \\
\hline TOTALES & & - & & - & & - & & - & - \\
\hline
\end{tabular}

\section{Instalaciones de Agua Caliente Sanitaria}

\begin{tabular}{|c|c|c|c|c|c|c|c|c|c|}
\hline Nombre & Tipo & $\begin{array}{l}\text { Potencia } \\
\text { nominal }\end{array}$ & $\begin{array}{c}\text { Rendi- } \\
\text { miento } \\
\text { Estacional }\end{array}$ & $\begin{array}{c}\text { Estimación } \\
\text { Energía } \\
\text { Consumida } \\
\text { anual }\end{array}$ & $\begin{array}{c}\text { Tipo post } \\
\text { mejora }\end{array}$ & $\begin{array}{l}\text { Potencia } \\
\text { nominal } \\
\text { post } \\
\text { mejora }\end{array}$ & $\begin{array}{c}\text { Rendimiento } \\
\text { estacional } \\
\text { post mejora }\end{array}$ & $\begin{array}{c}\text { Estimación } \\
\text { Energía } \\
\text { Consumida } \\
\text { anual Post } \\
\text { mejora }\end{array}$ & $\begin{array}{l}\text { Energía } \\
\text { anual } \\
\text { ahorrada }\end{array}$ \\
\hline & & {$[\mathrm{kW}]$} & [\%] & {$\left[\mathrm{kWh} / \mathrm{m}^{2} \mathrm{año}\right]$} & & {$[\mathrm{kW}]$} & [\%] & [kWh/m²año] & [kWh/m²año] \\
\hline Equipo ACS & Efecto Joule & & $100.0 \%$ & - & Efecto Joule & & $100.0 \%$ & - & - \\
\hline TOTALES & & - & & - & & - & & - & - \\
\hline
\end{tabular}




\begin{tabular}{|c|c|c|c|c|c|}
\hline & $D E$ & $\begin{array}{c}\text { Ref. } \\
\text { Catastral }\end{array}$ & 000000000 & $\begin{array}{l}\text { Versión } \\
\text { informe } \\
\text { asociado }\end{array}$ & $01 / 12 / 2015$ \\
\hline $\begin{array}{c}\text { Certificación } \\
\text { Energética } \\
\text { de Edificioios }\end{array}$ & $\begin{array}{c}\text { Id. } \\
\text { Mejora }\end{array}$ & $\begin{array}{l}\text { Programa } \\
\text { y versión }\end{array}$ & CEXv2.1 & Fecha & $4 / 1 / 2004$ \\
\hline
\end{tabular}

\section{ENERGÍAS RENOVABLES}

\section{Eléctrica}

\begin{tabular}{|c|c|c|}
\hline Nombre & $\begin{array}{c}\text { Energía eléctrica generada y } \\
\text { autoconsumida [kWh/año] }\end{array}$ & $\begin{array}{c}\text { Energía eléctrica generada y } \\
\text { autoconsumida post mejora } \\
\text { [kWh/año] }\end{array}$ \\
\hline Incorporación/mejora de sistema fotovoltaico & - & 7800 \\
\hline TOTALES & - & 7800.0 \\
\hline
\end{tabular}




\begin{tabular}{|c|c|c|c|c|c|}
\hline & & $\begin{array}{c}\text { Ref. } \\
\text { Catastral }\end{array}$ & 000000000 & $\begin{array}{c}\text { Versión } \\
\text { informe } \\
\text { asociado }\end{array}$ & $01 / 12 / 2015$ \\
\hline $\begin{array}{l}\text { Certificación } \\
\text { Energética } \\
\text { de Edificios }\end{array}$ & $\begin{array}{c}\text { Id. } \\
\text { Mejora }\end{array}$ & $\begin{array}{l}\text { Programa } \\
\text { y versión }\end{array}$ & CEXv2.1 & Fecha & $4 / 1 / 2004$ \\
\hline
\end{tabular}

\section{Informe descriptivo de la medida de mejora}

\section{DENOMINACIÓN DE LA MEDIDA DE MEJORA}

Bomba de calor alto cop y eer con geotermia y vidrios activos + mejora aislamientos

\section{DESCRIPCIÓN DE LA MEDIDA DE MEJORA}

Características de la medida (modelo de equipos, materiales, parámetros característicos )

Coste estimado de la medida

Otros datos de interés

CALIFICACIÓN ENERGÉTICA GLOBAL

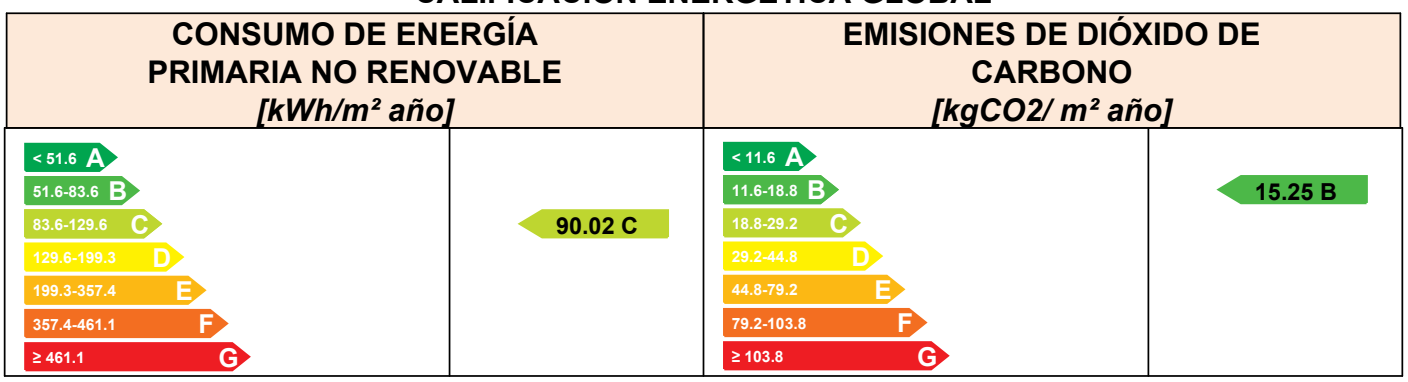

CALIFICACIONES ENERGÉTICAS PARCIALES

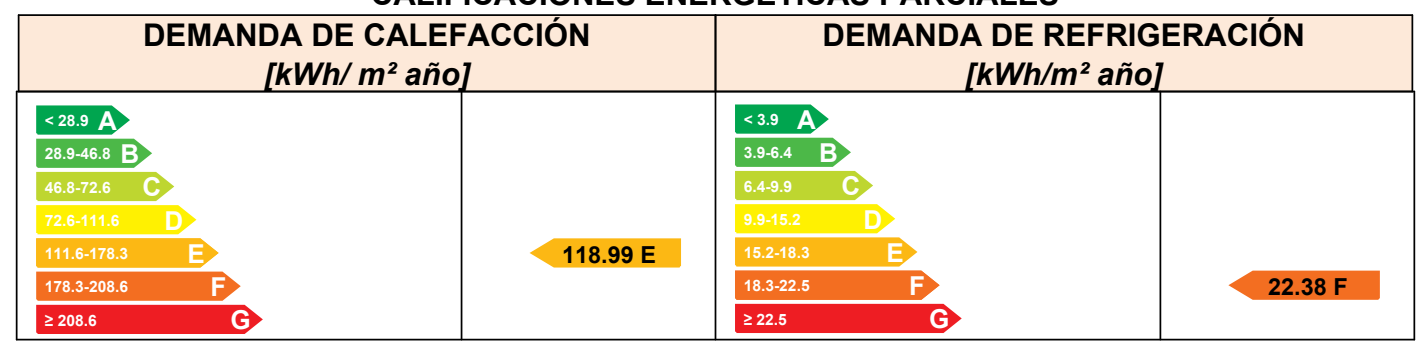




\begin{tabular}{|c|c|c|c|c|c|}
\hline & & $\begin{array}{c}\text { Ref. } \\
\text { Catastral }\end{array}$ & 000000000 & $\begin{array}{c}\text { Versión } \\
\text { informe } \\
\text { asociado }\end{array}$ & $01 / 12 / 2015$ \\
\hline $\begin{array}{l}\text { Certificación } \\
\text { Energética } \\
\text { de Edificios }\end{array}$ & $\begin{array}{c}\text { Id. } \\
\text { Mejora }\end{array}$ & $\begin{array}{l}\text { Programa } \\
\text { y versión }\end{array}$ & CEXv2.1 & Fecha & $4 / 1 / 2004$ \\
\hline
\end{tabular}

\section{ANALISÍS TÉCNICO}

\begin{tabular}{|c|c|c|c|c|c|c|c|c|c|c|c|c|c|c|c|}
\hline \multirow[b]{2}{*}{ Indicador } & \multicolumn{3}{|c|}{ Calefacción } & \multicolumn{3}{|c|}{ Refrigeración } & \multicolumn{3}{|c|}{ ACS } & \multicolumn{3}{|c|}{ Iluminación } & \multicolumn{3}{|c|}{ Total } \\
\hline & \multicolumn{2}{|c|}{ Valor } & $\begin{array}{c}\text { ahorro } \\
\text { respecto a } \\
\text { la situación } \\
\text { original }\end{array}$ & \multicolumn{2}{|c|}{ Valor } & $\begin{array}{c}\text { ahorro } \\
\text { respecto a } \\
\text { la situación } \\
\text { original }\end{array}$ & \multicolumn{2}{|c|}{ Valor } & $\begin{array}{c}\text { ahorro } \\
\text { respecto a } \\
\text { la situación } \\
\text { original }\end{array}$ & \multicolumn{2}{|c|}{ Valor } & $\begin{array}{c}\text { ahorro } \\
\text { respecto a } \\
\text { la situación } \\
\text { original }\end{array}$ & \multicolumn{2}{|c|}{ Valor } & $\begin{array}{c}\text { ahorro } \\
\text { respecto a } \\
\text { la situación } \\
\text { original }\end{array}$ \\
\hline $\begin{array}{l}\text { Consumo Energía } \\
\text { final }\left[\mathrm{kWh} / \mathrm{m}^{2} \text { año] }\right.\end{array}$ & \multicolumn{2}{|c|}{0.00} & $100.0 \%$ & \multicolumn{2}{|c|}{0.00} & $100.0 \%$ & \multicolumn{2}{|c|}{46.07} & $0.0 \%$ & \multicolumn{2}{|l|}{-} & $-\%$ & \multicolumn{2}{|c|}{46.07} & $71.3 \%$ \\
\hline $\begin{array}{l}\text { Consumo Energía } \\
\text { primaria no renovable } \\
{\left[\mathrm{kWh} / \mathrm{m}^{2} \text { año] }\right.}\end{array}$ & 0.00 & A & $100.0 \%$ & 0.00 & A & $100.0 \%$ & 90.02 & G & $0.0 \%$ & - & - & $-\%$ & 90.02 & C & $71.3 \%$ \\
\hline $\begin{array}{c}\text { Emisiones de CO2 } \\
{\left[\mathrm{kgCO} 2 / \mathrm{m}^{2} \text { año] }\right.}\end{array}$ & 0.00 & A & $100.0 \%$ & 0.00 & A & $100.0 \%$ & 15.25 & G & $0.0 \%$ & - & - & $-\%$ & 15.25 & B & $71.3 \%$ \\
\hline $\begin{array}{l}\text { Demanda }\left[\mathrm{kWh} / \mathrm{m}^{2}\right. \\
\text { año] }\end{array}$ & 118.99 & $E$ & $55.3 \%$ & 22.38 & $F$ & $21.7 \%$ & & & & & & & & & \\
\hline
\end{tabular}

\section{ENVOLVENTE TÉRMICA}

\section{Cerramientos opacos}

\begin{tabular}{|c|c|c|c|c|c|}
\hline Nombre & Tipo & $\begin{array}{c}\text { Superficie } \\
\text { actual } \\
{\left[\mathbf{m}^{2}\right]}\end{array}$ & $\begin{array}{c}\text { Transmitancia } \\
\text { actual } \\
{\left[\mathbf{W} / \mathbf{m}^{\mathbf{2}} \mathbf{~ K}\right]}\end{array}$ & $\begin{array}{c}\text { Superficie } \\
\text { post } \\
\text { mejora } \\
{\left[\mathbf{m}^{2}\right]}\end{array}$ & $\begin{array}{c}\text { Transmitancia } \\
\text { post mejora } \\
{\left[\mathbf{W} / \mathbf{m}^{\mathbf{2}} \mathbf{K}\right]}\end{array}$ \\
\hline Cubierta con aire & Cubierta & 52.00 & 0.47 & 52.00 & 0.22 \\
\hline Muro de fachada Norte & Fachada & 27.18 & 0.54 & 27.18 & 0.27 \\
\hline Suelo con aire & Suelo & 52.00 & 2.95 & 52.00 & 0.34 \\
\hline Muro de fachada Sur & Fachada & 21.88 & 0.54 & 21.88 & 0.27 \\
\hline Muro de fachada Oeste & Fachada & 8.04 & 0.54 & 8.04 & 0.27 \\
\hline Muro de fachada Este & Fachada & 3.28 & 0.54 & 3.28 & 0.27 \\
\hline
\end{tabular}

Huecos y lucernarios

\begin{tabular}{|c|c|c|c|c|c|c|c|}
\hline Nombre & Tipo & $\begin{array}{c}\text { Superficie } \\
\text { actual } \\
{\left[\mathrm{m}^{2}\right]}\end{array}$ & $\begin{array}{c}\text { Transmitancia } \\
\text { actual del } \\
\text { hueco[W/m² } \\
\mathrm{K}]\end{array}$ & $\begin{array}{c}\text { Transmitancia } \\
\text { actual del } \\
\text { vidrio[W/m² } \\
\mathrm{K}]\end{array}$ & $\begin{array}{c}\text { Superficie } \\
\text { post } \\
\text { mejora } \\
{\left[\mathrm{m}^{2}\right]}\end{array}$ & $\begin{array}{c}\text { Transmitancia } \\
\text { post mejora } \\
{\left[\mathrm{W} / \mathrm{m}^{2} \mathrm{~K}\right]}\end{array}$ & $\begin{array}{c}\text { Transmitancia } \\
\text { post mejora } \\
\text { del vidrio } \\
{\left[\mathrm{W} / \mathrm{m}^{2} \mathrm{~K}\right]}\end{array}$ \\
\hline V1 & Hueco & 5.3 & 5.70 & 5.70 & 5.3 & 1.27 & 1.12 \\
\hline V3 & Hueco & 5.3 & 5.70 & 5.70 & 5.3 & 1.27 & 1.12 \\
\hline V4 & Hueco & 5.3 & 5.70 & 5.70 & 5.3 & 1.27 & 1.12 \\
\hline V2 & Hueco & 5.3 & 5.70 & 5.70 & 5.3 & 1.27 & 1.12 \\
\hline V5 & Hueco & 5.03 & 5.70 & 5.70 & 5.03 & 1.27 & 1.12 \\
\hline Pta & Hueco & 5.03 & 5.70 & 5.70 & 5.03 & 1.27 & 1.12 \\
\hline
\end{tabular}




\begin{tabular}{|c|c|c|c|c|c|}
\hline & & $\begin{array}{c}\text { Ref. } \\
\text { Catastral }\end{array}$ & 000000000 & $\begin{array}{c}\text { Versión } \\
\text { informe } \\
\text { asociado }\end{array}$ & $01 / 12 / 2015$ \\
\hline $\begin{array}{l}\text { Certificación } \\
\text { Energética } \\
\text { de Edificios }\end{array}$ & $\begin{array}{c}\text { Id. } \\
\text { Mejora }\end{array}$ & $\begin{array}{l}\text { Programa } \\
\text { y versión }\end{array}$ & CEXv2.1 & Fecha & $4 / 1 / 2004$ \\
\hline
\end{tabular}

\section{INSTALACIONES TÉRMICAS}

\section{Generadores de calefacción}

\begin{tabular}{|c|c|c|c|c|c|c|c|c|c|}
\hline \multirow[t]{2}{*}{ Nombre } & \multirow[t]{2}{*}{ Tipo } & $\begin{array}{r}\text { Potencia } \\
\text { nominal }\end{array}$ & $\begin{array}{c}\text { Rendi- } \\
\text { miento } \\
\text { Estacional }\end{array}$ & $\begin{array}{c}\text { Estimación } \\
\text { Energía } \\
\text { Consumida } \\
\text { anual }\end{array}$ & \multirow[t]{2}{*}{$\begin{array}{l}\text { Tipo post } \\
\text { mejora }\end{array}$} & $\begin{array}{c}\text { Potencia } \\
\text { nominal } \\
\text { post } \\
\text { mejora }\end{array}$ & $\begin{array}{c}\text { Rendimiento } \\
\text { estacional } \\
\text { post mejora }\end{array}$ & $\begin{array}{c}\text { Estimación } \\
\text { Energía } \\
\text { Consumida } \\
\text { anual Post } \\
\text { mejora }\end{array}$ & $\begin{array}{l}\text { Energía } \\
\text { anual } \\
\text { ahorrada }\end{array}$ \\
\hline & & {$[\mathrm{kW}]$} & [\%] & {$\left[\mathrm{kWh} / \mathrm{m}^{2} \mathrm{año}\right]$} & & {$[\mathrm{kW}]$} & [\%] & [kWh/m²año] & [kWh/m²año] \\
\hline $\begin{array}{l}\text { Calefacción y } \\
\text { refrigeración }\end{array}$ & $\begin{array}{c}\text { Bomba de } \\
\text { Calor - } \\
\text { Caudal Ref. } \\
\text { Variable }\end{array}$ & & $261.5 \%$ & - & $\begin{array}{c}\text { Bomba de } \\
\text { Calor - } \\
\text { Caudal Ref. } \\
\text { Variable }\end{array}$ & & $463.6 \%$ & - & - \\
\hline TOTALES & & & & & & & & & \\
\hline
\end{tabular}

\section{Generadores de refrigeración}

\begin{tabular}{|c|c|c|c|c|c|c|c|c|c|}
\hline \multirow[t]{2}{*}{ Nombre } & \multirow[t]{2}{*}{ Tipo } & $\begin{array}{r}\text { Potencia } \\
\text { nominal }\end{array}$ & $\begin{array}{c}\text { Rendi- } \\
\text { miento } \\
\text { Estacional }\end{array}$ & $\begin{array}{c}\text { Estimación } \\
\text { Energía } \\
\text { Consumida } \\
\text { anual }\end{array}$ & \multirow[t]{2}{*}{$\begin{array}{l}\text { Tipo post } \\
\text { mejora }\end{array}$} & $\begin{array}{c}\text { Potencia } \\
\text { nominal } \\
\text { post } \\
\text { mejora }\end{array}$ & $\begin{array}{c}\text { Rendimiento } \\
\text { estacional } \\
\text { post mejora }\end{array}$ & $\begin{array}{c}\text { Estimación } \\
\text { Energía } \\
\text { Consumida } \\
\text { anual Post } \\
\text { mejora }\end{array}$ & $\begin{array}{c}\text { Energía } \\
\text { anual } \\
\text { ahorrada }\end{array}$ \\
\hline & & {$[\mathrm{kW}]$} & {$[\%]$} & {$\left[\mathrm{kWh} / \mathrm{m}^{2} \mathrm{año}\right]$} & & {$[\mathrm{kW}]$} & {$[\%]$} & [kWh/m²año] & {$\left[\mathrm{kWh} / \mathrm{m}^{2} \mathrm{año}\right.$} \\
\hline $\begin{array}{l}\text { Calefacción y } \\
\text { refrigeración }\end{array}$ & $\begin{array}{c}\text { Bomba de } \\
\text { Calor - } \\
\text { Caudal Ref. } \\
\text { Variable }\end{array}$ & & $227.1 \%$ & - & $\begin{array}{c}\text { Bomba de } \\
\text { Calor - } \\
\text { Caudal Ref. } \\
\text { Variable }\end{array}$ & & $508.0 \%$ & - & - \\
\hline TOTALES & & - & & - & & - & & - & - \\
\hline
\end{tabular}

\section{Instalaciones de Agua Caliente Sanitaria}

\begin{tabular}{|c|c|c|c|c|c|c|c|c|c|}
\hline Nombre & Tipo & $\begin{array}{l}\text { Potencia } \\
\text { nominal }\end{array}$ & $\begin{array}{c}\text { Rendi- } \\
\text { miento } \\
\text { Estacional }\end{array}$ & $\begin{array}{c}\text { Estimación } \\
\text { Energía } \\
\text { Consumida } \\
\text { anual }\end{array}$ & $\begin{array}{c}\text { Tipo post } \\
\text { mejora }\end{array}$ & $\begin{array}{l}\text { Potencia } \\
\text { nominal } \\
\text { post } \\
\text { mejora }\end{array}$ & $\begin{array}{c}\text { Rendimiento } \\
\text { estacional } \\
\text { post mejora }\end{array}$ & $\begin{array}{c}\text { Estimación } \\
\text { Energía } \\
\text { Consumida } \\
\text { anual Post } \\
\text { mejora }\end{array}$ & $\begin{array}{l}\text { Energía } \\
\text { anual } \\
\text { ahorrada }\end{array}$ \\
\hline & & {$[\mathrm{kW}]$} & [\%] & {$\left[\mathrm{kWh} / \mathrm{m}^{2} \mathrm{año}\right]$} & & {$[\mathrm{kW}]$} & [\%] & [kWh/m²año] & [kWh/m²año] \\
\hline Equipo ACS & Efecto Joule & & $100.0 \%$ & - & Efecto Joule & & $100.0 \%$ & - & - \\
\hline TOTALES & & - & & - & & - & & - & - \\
\hline
\end{tabular}




\begin{tabular}{|c|c|c|c|c|c|}
\hline & DEN & $\begin{array}{c}\text { Ref. } \\
\text { Catastral }\end{array}$ & 000000000 & $\begin{array}{c}\text { Versión } \\
\text { informe } \\
\text { asociado }\end{array}$ & $01 / 12 / 2015$ \\
\hline $\begin{array}{c}\text { Certificación } \\
\text { Energatica } \\
\text { de Edificios } \\
\text { de Editios }\end{array}$ & $\begin{array}{c}\text { Id. } \\
\text { Mejora }\end{array}$ & $\begin{array}{l}\text { Programa } \\
\text { y versión }\end{array}$ & CEXv2.1 & Fecha & $4 / 1 / 2004$ \\
\hline
\end{tabular}

\section{ENERGÍAS RENOVABLES}

\section{Térmica}

\begin{tabular}{|c|c|c|c|c|}
\hline \multirow{2}{*}{ Nombre } & \multicolumn{3}{|c|}{$\begin{array}{c}\text { Consumo de Energía Final, cubierto en función } \\
\text { del servicio asociado [\%] }\end{array}$} & $\begin{array}{c}\text { Demanda de ACS } \\
\text { cubierta [\%] }\end{array}$ \\
\cline { 2 - 5 } & Calefacción & Refrigeración & ACS & \\
\hline- & - & - & - & - \\
\hline TOTALES & - & - & - & - \\
\hline
\end{tabular}

\section{Post mejora}

\begin{tabular}{|c|c|c|c|c|}
\hline \multirow{2}{*}{ Nombre } & \multicolumn{2}{|c|}{$\begin{array}{c}\text { Consumo de Energía Final, cubierto en función } \\
\text { del servicio asociado [\%] }\end{array}$} & $\begin{array}{c}\text { Demanda de ACS } \\
\text { cubierta [\%] }\end{array}$ \\
\cline { 2 - 5 } & Calefacción & Refrigeración & ACS & \\
\hline Sistema Geotérmico & 100 & 100 & - & - \\
\hline TOTALES & 100.0 & 100.0 & - & - \\
\hline
\end{tabular}




\begin{tabular}{|c|c|c|c|c|c|}
\hline & & $\begin{array}{c}\text { Ref. } \\
\text { Catastral }\end{array}$ & 000000000 & $\begin{array}{c}\text { Versión } \\
\text { informe } \\
\text { asociado }\end{array}$ & $01 / 12 / 2015$ \\
\hline $\begin{array}{l}\text { Certificación } \\
\text { Energética } \\
\text { de Edificios }\end{array}$ & $\begin{array}{c}\text { Id. } \\
\text { Mejora }\end{array}$ & $\begin{array}{l}\text { Programa } \\
\text { y versión }\end{array}$ & CEXv2.1 & Fecha & $4 / 1 / 2004$ \\
\hline
\end{tabular}

\section{Informe descriptivo de la medida de mejora}

\section{DENOMINACIÓN DE LA MEDIDA DE MEJORA}

Bomba de calor alto cop y eer con geotermia y vidrios activos

\section{DESCRIPCIÓN DE LA MEDIDA DE MEJORA}

Características de la medida (modelo de equipos, materiales, parámetros característicos )

Coste estimado de la medida

Otros datos de interés

CALIFICACIÓN ENERGÉTICA GLOBAL

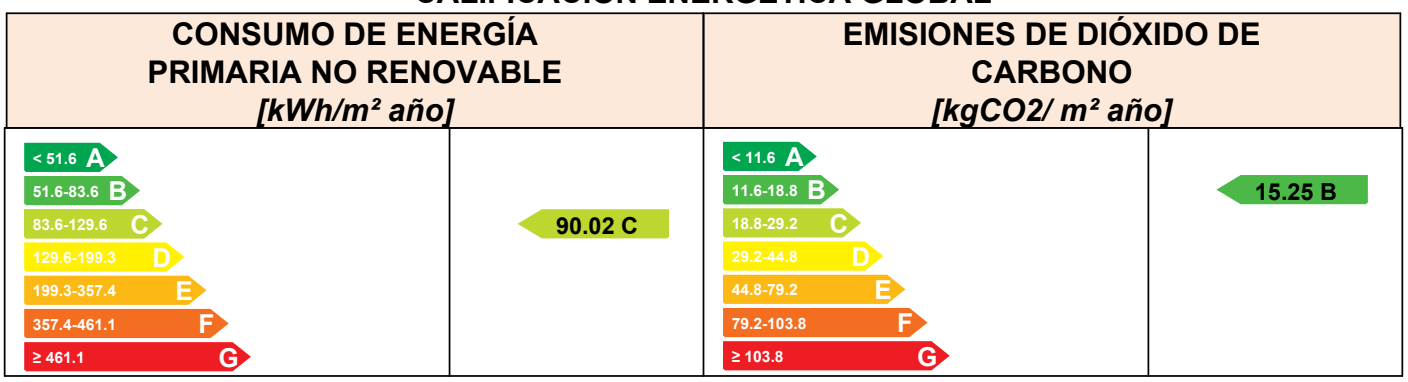

CALIFICACIONES ENERGÉTICAS PARCIALES

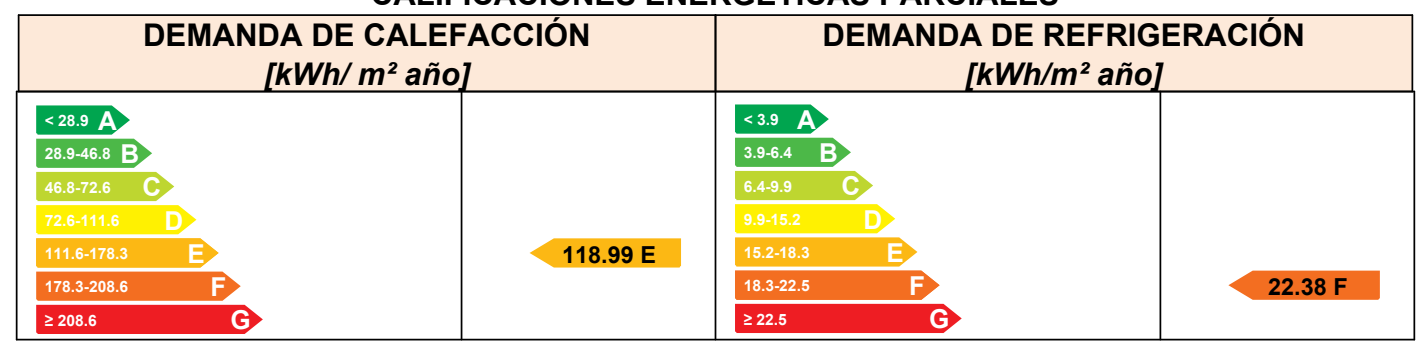




\begin{tabular}{|c|c|c|c|c|c|}
\hline & & $\begin{array}{c}\text { Ref. } \\
\text { Catastral }\end{array}$ & 000000000 & $\begin{array}{c}\text { Versión } \\
\text { informe } \\
\text { asociado }\end{array}$ & $01 / 12 / 2015$ \\
\hline $\begin{array}{l}\text { Certificación } \\
\text { Energética } \\
\text { de Edificios }\end{array}$ & $\begin{array}{c}\text { Id. } \\
\text { Mejora }\end{array}$ & $\begin{array}{l}\text { Programa } \\
\text { y versión }\end{array}$ & CEXv2.1 & Fecha & $4 / 1 / 2004$ \\
\hline
\end{tabular}

\section{ANALISÍS TÉCNICO}

\begin{tabular}{|c|c|c|c|c|c|c|c|c|c|c|c|c|c|c|c|}
\hline \multirow[b]{2}{*}{ Indicador } & \multicolumn{3}{|c|}{ Calefacción } & \multicolumn{3}{|c|}{ Refrigeración } & \multicolumn{3}{|c|}{ ACS } & \multicolumn{3}{|c|}{ Iluminación } & \multicolumn{3}{|c|}{ Total } \\
\hline & \multicolumn{2}{|c|}{ Valor } & $\begin{array}{c}\text { ahorro } \\
\text { respecto a } \\
\text { la situación } \\
\text { original }\end{array}$ & \multicolumn{2}{|c|}{ Valor } & $\begin{array}{c}\text { ahorro } \\
\text { respecto a } \\
\text { la situación } \\
\text { original }\end{array}$ & \multicolumn{2}{|c|}{ Valor } & $\begin{array}{c}\text { ahorro } \\
\text { respecto a } \\
\text { la situación } \\
\text { original }\end{array}$ & \multicolumn{2}{|c|}{ Valor } & $\begin{array}{c}\text { ahorro } \\
\text { respecto a } \\
\text { la situación } \\
\text { original }\end{array}$ & \multicolumn{2}{|c|}{ Valor } & $\begin{array}{c}\text { ahorro } \\
\text { respecto a } \\
\text { la situación } \\
\text { original }\end{array}$ \\
\hline $\begin{array}{l}\text { Consumo Energía } \\
\text { final }\left[\mathrm{kWh} / \mathrm{m}^{2} \text { año] }\right.\end{array}$ & \multicolumn{2}{|c|}{0.00} & $100.0 \%$ & \multicolumn{2}{|c|}{0.00} & $100.0 \%$ & \multicolumn{2}{|c|}{46.07} & $0.0 \%$ & \multicolumn{2}{|l|}{-} & $-\%$ & \multicolumn{2}{|c|}{46.07} & $71.3 \%$ \\
\hline $\begin{array}{l}\text { Consumo Energía } \\
\text { primaria no renovable } \\
{\left[\mathrm{kWh} / \mathrm{m}^{2} \text { año] }\right.}\end{array}$ & 0.00 & A & $100.0 \%$ & 0.00 & A & $100.0 \%$ & 90.02 & G & $0.0 \%$ & - & - & $-\%$ & 90.02 & C & $71.3 \%$ \\
\hline $\begin{array}{c}\text { Emisiones de CO2 } \\
{\left[\mathrm{kgCO} 2 / \mathrm{m}^{2} \text { año] }\right.}\end{array}$ & 0.00 & A & $100.0 \%$ & 0.00 & A & $100.0 \%$ & 15.25 & G & $0.0 \%$ & - & - & $-\%$ & 15.25 & B & $71.3 \%$ \\
\hline $\begin{array}{l}\text { Demanda }\left[\mathrm{kWh} / \mathrm{m}^{2}\right. \\
\text { año] }\end{array}$ & 118.99 & $E$ & $55.3 \%$ & 22.38 & $F$ & $21.7 \%$ & & & & & & & & & \\
\hline
\end{tabular}

\section{ENVOLVENTE TÉRMICA}

\section{Cerramientos opacos}

\begin{tabular}{|c|c|c|c|c|c|}
\hline Nombre & Tipo & $\begin{array}{c}\text { Superficie } \\
\text { actual } \\
{\left[\mathbf{m}^{2}\right]}\end{array}$ & $\begin{array}{c}\text { Transmitancia } \\
\text { actual } \\
{\left[\mathbf{W} / \mathbf{m}^{\mathbf{2}} \mathbf{~ K}\right]}\end{array}$ & $\begin{array}{c}\text { Superficie } \\
\text { post } \\
\text { mejora } \\
{\left[\mathbf{m}^{2}\right]}\end{array}$ & $\begin{array}{c}\text { Transmitancia } \\
\text { post mejora } \\
{\left[\mathbf{W} / \mathbf{m}^{\mathbf{2}} \mathbf{K}\right]}\end{array}$ \\
\hline Cubierta con aire & Cubierta & 52.00 & 0.47 & 52.00 & 0.22 \\
\hline Muro de fachada Norte & Fachada & 27.18 & 0.54 & 27.18 & 0.27 \\
\hline Suelo con aire & Suelo & 52.00 & 2.95 & 52.00 & 0.34 \\
\hline Muro de fachada Sur & Fachada & 21.88 & 0.54 & 21.88 & 0.27 \\
\hline Muro de fachada Oeste & Fachada & 8.04 & 0.54 & 8.04 & 0.27 \\
\hline Muro de fachada Este & Fachada & 3.28 & 0.54 & 3.28 & 0.27 \\
\hline
\end{tabular}

Huecos y lucernarios

\begin{tabular}{|c|c|c|c|c|c|c|c|}
\hline Nombre & Tipo & $\begin{array}{c}\text { Superficie } \\
\text { actual } \\
{\left[\mathrm{m}^{2}\right]}\end{array}$ & $\begin{array}{c}\text { Transmitancia } \\
\text { actual del } \\
\text { hueco[W/m² } \\
\mathrm{K}]\end{array}$ & $\begin{array}{c}\text { Transmitancia } \\
\text { actual del } \\
\text { vidrio[W/m² } \\
\mathrm{K}]\end{array}$ & $\begin{array}{c}\text { Superficie } \\
\text { post } \\
\text { mejora } \\
{\left[\mathrm{m}^{2}\right]}\end{array}$ & $\begin{array}{c}\text { Transmitancia } \\
\text { post mejora } \\
{\left[\mathrm{W} / \mathrm{m}^{2} \mathrm{~K}\right]}\end{array}$ & $\begin{array}{c}\text { Transmitancia } \\
\text { post mejora } \\
\text { del vidrio } \\
{\left[\mathrm{W} / \mathrm{m}^{2} \mathrm{~K}\right]}\end{array}$ \\
\hline V1 & Hueco & 5.3 & 5.70 & 5.70 & 5.3 & 1.27 & 1.12 \\
\hline V3 & Hueco & 5.3 & 5.70 & 5.70 & 5.3 & 1.27 & 1.12 \\
\hline V4 & Hueco & 5.3 & 5.70 & 5.70 & 5.3 & 1.27 & 1.12 \\
\hline V2 & Hueco & 5.3 & 5.70 & 5.70 & 5.3 & 1.27 & 1.12 \\
\hline V5 & Hueco & 5.03 & 5.70 & 5.70 & 5.03 & 1.27 & 1.12 \\
\hline Pta & Hueco & 5.03 & 5.70 & 5.70 & 5.03 & 1.27 & 1.12 \\
\hline
\end{tabular}




\begin{tabular}{|c|c|c|c|c|c|}
\hline & & $\begin{array}{c}\text { Ref. } \\
\text { Catastral }\end{array}$ & 000000000 & $\begin{array}{c}\text { Versión } \\
\text { informe } \\
\text { asociado }\end{array}$ & $01 / 12 / 2015$ \\
\hline $\begin{array}{l}\text { Certificación } \\
\text { Energética } \\
\text { de Edificios }\end{array}$ & $\begin{array}{c}\text { Id. } \\
\text { Mejora }\end{array}$ & $\begin{array}{l}\text { Programa } \\
\text { y versión }\end{array}$ & CEXv2.1 & Fecha & $4 / 1 / 2004$ \\
\hline
\end{tabular}

\section{INSTALACIONES TÉRMICAS}

\section{Generadores de calefacción}

\begin{tabular}{|c|c|c|c|c|c|c|c|c|c|}
\hline \multirow[t]{2}{*}{ Nombre } & \multirow[t]{2}{*}{ Tipo } & $\begin{array}{r}\text { Potencia } \\
\text { nominal }\end{array}$ & $\begin{array}{c}\text { Rendi- } \\
\text { miento } \\
\text { Estacional }\end{array}$ & $\begin{array}{c}\text { Estimación } \\
\text { Energía } \\
\text { Consumida } \\
\text { anual }\end{array}$ & \multirow[t]{2}{*}{$\begin{array}{l}\text { Tipo post } \\
\text { mejora }\end{array}$} & $\begin{array}{c}\text { Potencia } \\
\text { nominal } \\
\text { post } \\
\text { mejora }\end{array}$ & $\begin{array}{c}\text { Rendimiento } \\
\text { estacional } \\
\text { post mejora }\end{array}$ & $\begin{array}{c}\text { Estimación } \\
\text { Energía } \\
\text { Consumida } \\
\text { anual Post } \\
\text { mejora }\end{array}$ & $\begin{array}{l}\text { Energía } \\
\text { anual } \\
\text { ahorrada }\end{array}$ \\
\hline & & {$[\mathrm{kW}]$} & [\%] & {$\left[\mathrm{kWh} / \mathrm{m}^{2} \mathrm{año}\right]$} & & {$[\mathrm{kW}]$} & [\%] & [kWh/m²año] & [kWh/m²año] \\
\hline $\begin{array}{l}\text { Calefacción y } \\
\text { refrigeración }\end{array}$ & $\begin{array}{c}\text { Bomba de } \\
\text { Calor - } \\
\text { Caudal Ref. } \\
\text { Variable }\end{array}$ & & $261.5 \%$ & - & $\begin{array}{c}\text { Bomba de } \\
\text { Calor - } \\
\text { Caudal Ref. } \\
\text { Variable }\end{array}$ & & $463.6 \%$ & - & - \\
\hline TOTALES & & & & & & & & & \\
\hline
\end{tabular}

\section{Generadores de refrigeración}

\begin{tabular}{|c|c|c|c|c|c|c|c|c|c|}
\hline \multirow[t]{2}{*}{ Nombre } & \multirow[t]{2}{*}{ Tipo } & $\begin{array}{r}\text { Potencia } \\
\text { nominal }\end{array}$ & $\begin{array}{c}\text { Rendi- } \\
\text { miento } \\
\text { Estacional }\end{array}$ & $\begin{array}{c}\text { Estimación } \\
\text { Energía } \\
\text { Consumida } \\
\text { anual }\end{array}$ & \multirow[t]{2}{*}{$\begin{array}{l}\text { Tipo post } \\
\text { mejora }\end{array}$} & $\begin{array}{c}\text { Potencia } \\
\text { nominal } \\
\text { post } \\
\text { mejora }\end{array}$ & $\begin{array}{c}\text { Rendimiento } \\
\text { estacional } \\
\text { post mejora }\end{array}$ & $\begin{array}{c}\text { Estimación } \\
\text { Energía } \\
\text { Consumida } \\
\text { anual Post } \\
\text { mejora }\end{array}$ & $\begin{array}{c}\text { Energía } \\
\text { anual } \\
\text { ahorrada }\end{array}$ \\
\hline & & {$[\mathrm{kW}]$} & {$[\%]$} & {$\left[\mathrm{kWh} / \mathrm{m}^{2} \mathrm{año}\right]$} & & {$[\mathrm{kW}]$} & {$[\%]$} & [kWh/m²año] & {$\left[\mathrm{kWh} / \mathrm{m}^{2} \mathrm{año}\right.$} \\
\hline $\begin{array}{l}\text { Calefacción y } \\
\text { refrigeración }\end{array}$ & $\begin{array}{c}\text { Bomba de } \\
\text { Calor - } \\
\text { Caudal Ref. } \\
\text { Variable }\end{array}$ & & $227.1 \%$ & - & $\begin{array}{c}\text { Bomba de } \\
\text { Calor - } \\
\text { Caudal Ref. } \\
\text { Variable }\end{array}$ & & $508.0 \%$ & - & - \\
\hline TOTALES & & - & & - & & - & & - & - \\
\hline
\end{tabular}

\section{Instalaciones de Agua Caliente Sanitaria}

\begin{tabular}{|c|c|c|c|c|c|c|c|c|c|}
\hline Nombre & Tipo & $\begin{array}{l}\text { Potencia } \\
\text { nominal }\end{array}$ & $\begin{array}{c}\text { Rendi- } \\
\text { miento } \\
\text { Estacional }\end{array}$ & $\begin{array}{c}\text { Estimación } \\
\text { Energía } \\
\text { Consumida } \\
\text { anual }\end{array}$ & $\begin{array}{c}\text { Tipo post } \\
\text { mejora }\end{array}$ & $\begin{array}{l}\text { Potencia } \\
\text { nominal } \\
\text { post } \\
\text { mejora }\end{array}$ & $\begin{array}{c}\text { Rendimiento } \\
\text { estacional } \\
\text { post mejora }\end{array}$ & $\begin{array}{c}\text { Estimación } \\
\text { Energía } \\
\text { Consumida } \\
\text { anual Post } \\
\text { mejora }\end{array}$ & $\begin{array}{l}\text { Energía } \\
\text { anual } \\
\text { ahorrada }\end{array}$ \\
\hline & & {$[\mathrm{kW}]$} & [\%] & {$\left[\mathrm{kWh} / \mathrm{m}^{2} \mathrm{año}\right]$} & & {$[\mathrm{kW}]$} & [\%] & [kWh/m²año] & [kWh/m²año] \\
\hline Equipo ACS & Efecto Joule & & $100.0 \%$ & - & Efecto Joule & & $100.0 \%$ & - & - \\
\hline TOTALES & & - & & - & & - & & - & - \\
\hline
\end{tabular}




\begin{tabular}{|c|c|c|c|c|c|}
\hline & DEN & $\begin{array}{c}\text { Ref. } \\
\text { Catastral }\end{array}$ & 000000000 & $\begin{array}{c}\text { Versión } \\
\text { informe } \\
\text { asociado }\end{array}$ & $01 / 12 / 2015$ \\
\hline $\begin{array}{c}\text { Certificación } \\
\text { Energatica } \\
\text { de Edificios } \\
\text { de Editios }\end{array}$ & $\begin{array}{c}\text { Id. } \\
\text { Mejora }\end{array}$ & $\begin{array}{l}\text { Programa } \\
\text { y versión }\end{array}$ & CEXv2.1 & Fecha & $4 / 1 / 2004$ \\
\hline
\end{tabular}

\section{ENERGÍAS RENOVABLES}

\section{Térmica}

\begin{tabular}{|c|c|c|c|c|}
\hline \multirow{2}{*}{ Nombre } & \multicolumn{3}{|c|}{$\begin{array}{c}\text { Consumo de Energía Final, cubierto en función } \\
\text { del servicio asociado [\%] }\end{array}$} & $\begin{array}{c}\text { Demanda de ACS } \\
\text { cubierta [\%] }\end{array}$ \\
\cline { 2 - 5 } & Calefacción & Refrigeración & ACS & \\
\hline- & - & - & - & - \\
\hline TOTALES & - & - & - & - \\
\hline
\end{tabular}

\section{Post mejora}

\begin{tabular}{|c|c|c|c|c|}
\hline \multirow{2}{*}{ Nombre } & \multicolumn{2}{|c|}{$\begin{array}{c}\text { Consumo de Energía Final, cubierto en función } \\
\text { del servicio asociado [\%] }\end{array}$} & $\begin{array}{c}\text { Demanda de ACS } \\
\text { cubierta [\%] }\end{array}$ \\
\cline { 2 - 5 } & Calefacción & Refrigeración & ACS & \\
\hline Sistema Geotérmico & 100 & 100 & - & - \\
\hline TOTALES & 100.0 & 100.0 & - & - \\
\hline
\end{tabular}




\begin{tabular}{|c|c|c|c|c|c|}
\hline & & $\begin{array}{c}\text { Ref. } \\
\text { Catastral }\end{array}$ & 000000000 & $\begin{array}{c}\text { Versión } \\
\text { informe } \\
\text { asociado }\end{array}$ & $01 / 12 / 2015$ \\
\hline $\begin{array}{l}\text { Certificación } \\
\text { Energética } \\
\text { de Edificios }\end{array}$ & $\begin{array}{c}\text { Id. } \\
\text { Mejora }\end{array}$ & $\begin{array}{l}\text { Programa } \\
\text { y versión }\end{array}$ & CEXv2.1 & Fecha & $4 / 1 / 2004$ \\
\hline
\end{tabular}

\section{Informe descriptivo de la medida de mejora}

\section{DENOMINACIÓN DE LA MEDIDA DE MEJORA}

FV+ Bomba de calor alto cop y eer con geotermia y vidrios activos

\section{DESCRIPCIÓN DE LA MEDIDA DE MEJORA}

Características de la medida (modelo de equipos, materiales, parámetros característicos )

Coste estimado de la medida

Otros datos de interés

CALIFICACIÓN ENERGÉTICA GLOBAL

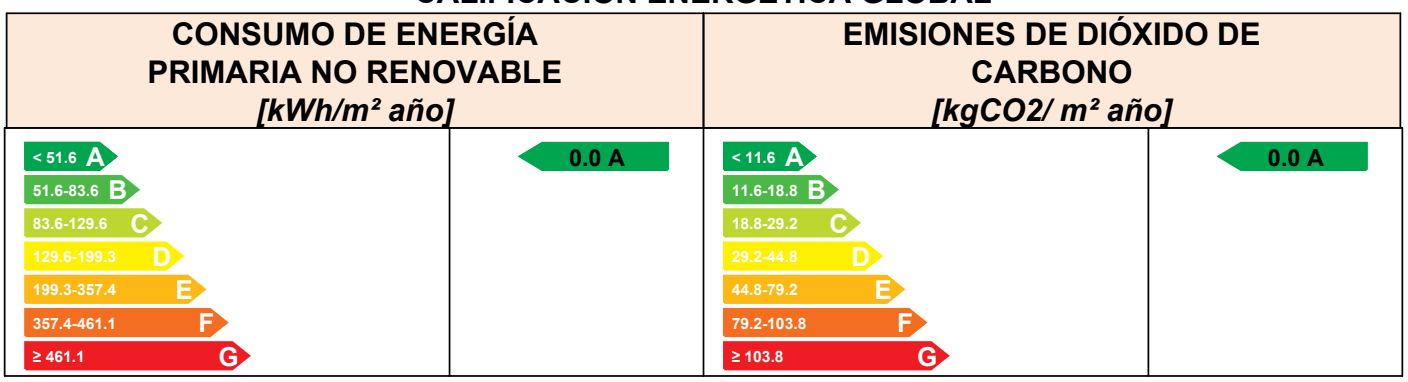

CALIFICACIONES ENERGÉTICAS PARCIALES

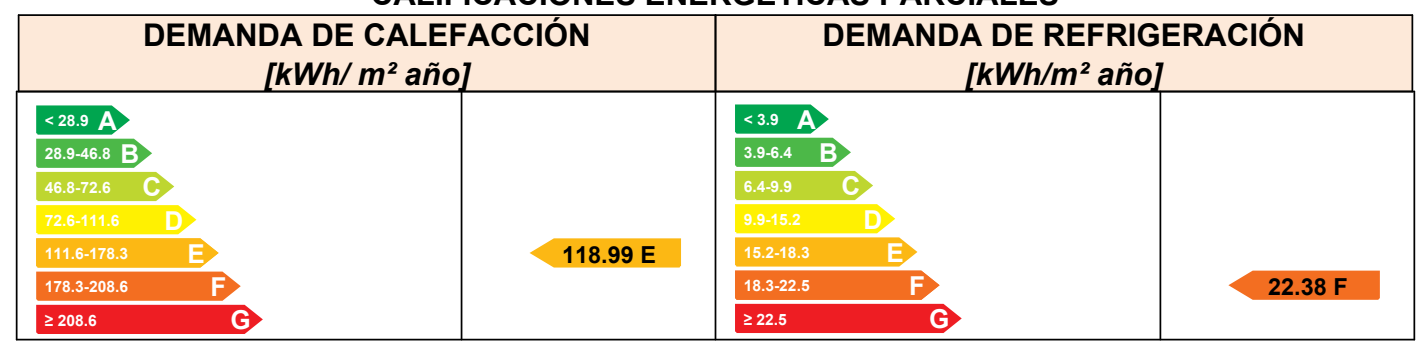




\begin{tabular}{|c|c|c|c|c|c|}
\hline & & $\begin{array}{c}\text { Ref. } \\
\text { Catastral }\end{array}$ & 000000000 & $\begin{array}{c}\text { Versión } \\
\text { informe } \\
\text { asociado }\end{array}$ & $01 / 12 / 2015$ \\
\hline $\begin{array}{l}\text { Certificación } \\
\text { Energética } \\
\text { de Edificios }\end{array}$ & $\begin{array}{c}\text { Id. } \\
\text { Mejora }\end{array}$ & $\begin{array}{l}\text { Programa } \\
\text { y versión }\end{array}$ & CEXv2.1 & Fecha & $4 / 1 / 2004$ \\
\hline
\end{tabular}

\section{ANALISÍS TÉCNICO}

\begin{tabular}{|c|c|c|c|c|c|c|c|c|c|c|c|c|c|c|c|}
\hline \multirow[b]{2}{*}{ Indicador } & \multicolumn{3}{|c|}{ Calefacción } & \multicolumn{3}{|c|}{ Refrigeración } & \multicolumn{3}{|c|}{ ACS } & \multicolumn{3}{|c|}{ Iluminación } & \multicolumn{3}{|c|}{ Total } \\
\hline & \multicolumn{2}{|c|}{ Valor } & $\begin{array}{c}\text { ahorro } \\
\text { respecto a } \\
\text { la situación } \\
\text { original }\end{array}$ & \multicolumn{2}{|c|}{ Valor } & $\begin{array}{c}\text { ahorro } \\
\text { respecto a } \\
\text { la situación } \\
\text { original }\end{array}$ & \multicolumn{2}{|c|}{ Valor } & $\begin{array}{c}\text { ahorro } \\
\text { respecto a } \\
\text { la situación } \\
\text { original }\end{array}$ & \multicolumn{2}{|c|}{ Valor } & $\begin{array}{c}\text { ahorro } \\
\text { respecto a } \\
\text { la situación } \\
\text { original }\end{array}$ & \multicolumn{2}{|c|}{ Valor } & $\begin{array}{c}\text { ahorro } \\
\text { respecto a } \\
\text { la situación } \\
\text { original }\end{array}$ \\
\hline $\begin{array}{l}\text { Consumo Energía } \\
\text { final }\left[\mathrm{kWh} / \mathrm{m}^{2} \text { año] }\right.\end{array}$ & \multicolumn{2}{|c|}{0.00} & $100.0 \%$ & \multicolumn{2}{|c|}{0.00} & $100.0 \%$ & \multicolumn{2}{|c|}{46.07} & $0.0 \%$ & \multicolumn{2}{|l|}{-} & $-\%$ & \multicolumn{2}{|c|}{-61.47} & $138.3 \%$ \\
\hline $\begin{array}{l}\text { Consumo Energía } \\
\text { primaria no renovable } \\
{\left[\mathrm{kWh} / \mathrm{m}^{2} \text { año] }\right.}\end{array}$ & 0.00 & A & $100.0 \%$ & 0.00 & A & $100.0 \%$ & 90.02 & G & $0.0 \%$ & - & - & $-\%$ & 0.00 & A & $100.0 \%$ \\
\hline $\begin{array}{c}\text { Emisiones de CO2 } \\
{\left[\mathrm{kgCO} 2 / \mathrm{m}^{2} \text { año] }\right.}\end{array}$ & 0.00 & A & $100.0 \%$ & 0.00 & A & $100.0 \%$ & 15.25 & G & $0.0 \%$ & - & - & $-\%$ & 0.00 & A & $100.0 \%$ \\
\hline $\begin{array}{l}\text { Demanda }\left[\mathrm{kWh} / \mathrm{m}^{2}\right. \\
\text { año] }\end{array}$ & 118.99 & $E$ & $55.3 \%$ & 22.38 & $F$ & $21.7 \%$ & & & & & & & & & \\
\hline
\end{tabular}

\section{ENVOLVENTE TÉRMICA}

\section{Cerramientos opacos}

\begin{tabular}{|c|c|c|c|c|c|}
\hline Nombre & Tipo & $\begin{array}{c}\text { Superficie } \\
\text { actual } \\
{\left[\mathbf{m}^{2}\right]}\end{array}$ & $\begin{array}{c}\text { Transmitancia } \\
\text { actual } \\
{\left[\mathbf{W} / \mathbf{m}^{\mathbf{2}} \mathbf{~ K}\right]}\end{array}$ & $\begin{array}{c}\text { Superficie } \\
\text { post } \\
\text { mejora } \\
{\left[\mathbf{m}^{2}\right]}\end{array}$ & $\begin{array}{c}\text { Transmitancia } \\
\text { post mejora } \\
{\left[\mathbf{W} / \mathbf{m}^{\mathbf{2}} \mathbf{K}\right]}\end{array}$ \\
\hline Cubierta con aire & Cubierta & 52.00 & 0.47 & 52.00 & 0.22 \\
\hline Muro de fachada Norte & Fachada & 27.18 & 0.54 & 27.18 & 0.27 \\
\hline Suelo con aire & Suelo & 52.00 & 2.95 & 52.00 & 0.34 \\
\hline Muro de fachada Sur & Fachada & 21.88 & 0.54 & 21.88 & 0.27 \\
\hline Muro de fachada Oeste & Fachada & 8.04 & 0.54 & 8.04 & 0.27 \\
\hline Muro de fachada Este & Fachada & 3.28 & 0.54 & 3.28 & 0.27 \\
\hline
\end{tabular}

Huecos y lucernarios

\begin{tabular}{|c|c|c|c|c|c|c|c|}
\hline Nombre & Tipo & $\begin{array}{c}\text { Superficie } \\
\text { actual } \\
{\left[\mathrm{m}^{2}\right]}\end{array}$ & $\begin{array}{c}\text { Transmitancia } \\
\text { actual del } \\
\text { hueco[W/m² } \\
\mathrm{K}]\end{array}$ & $\begin{array}{c}\text { Transmitancia } \\
\text { actual del } \\
\text { vidrio[W/m² } \\
\mathrm{K}]\end{array}$ & $\begin{array}{c}\text { Superficie } \\
\text { post } \\
\text { mejora } \\
{\left[\mathrm{m}^{2}\right]}\end{array}$ & $\begin{array}{c}\text { Transmitancia } \\
\text { post mejora } \\
{\left[\mathrm{W} / \mathrm{m}^{2} \mathrm{~K}\right]}\end{array}$ & $\begin{array}{c}\text { Transmitancia } \\
\text { post mejora } \\
\text { del vidrio } \\
{\left[\mathrm{W} / \mathrm{m}^{2} \mathrm{~K}\right]}\end{array}$ \\
\hline V1 & Hueco & 5.3 & 5.70 & 5.70 & 5.3 & 1.27 & 1.12 \\
\hline V3 & Hueco & 5.3 & 5.70 & 5.70 & 5.3 & 1.27 & 1.12 \\
\hline V4 & Hueco & 5.3 & 5.70 & 5.70 & 5.3 & 1.27 & 1.12 \\
\hline V2 & Hueco & 5.3 & 5.70 & 5.70 & 5.3 & 1.27 & 1.12 \\
\hline V5 & Hueco & 5.03 & 5.70 & 5.70 & 5.03 & 1.27 & 1.12 \\
\hline Pta & Hueco & 5.03 & 5.70 & 5.70 & 5.03 & 1.27 & 1.12 \\
\hline
\end{tabular}




\begin{tabular}{|c|c|c|c|c|c|}
\hline & & $\begin{array}{c}\text { Ref. } \\
\text { Catastral }\end{array}$ & 000000000 & $\begin{array}{c}\text { Versión } \\
\text { informe } \\
\text { asociado }\end{array}$ & $01 / 12 / 2015$ \\
\hline $\begin{array}{l}\text { Certificación } \\
\text { Energética } \\
\text { de Edificios }\end{array}$ & $\begin{array}{c}\text { Id. } \\
\text { Mejora }\end{array}$ & $\begin{array}{l}\text { Programa } \\
\text { y versión }\end{array}$ & CEXv2.1 & Fecha & $4 / 1 / 2004$ \\
\hline
\end{tabular}

\section{INSTALACIONES TÉRMICAS}

\section{Generadores de calefacción}

\begin{tabular}{|c|c|c|c|c|c|c|c|c|c|}
\hline \multirow[t]{2}{*}{ Nombre } & \multirow[t]{2}{*}{ Tipo } & $\begin{array}{r}\text { Potencia } \\
\text { nominal }\end{array}$ & $\begin{array}{c}\text { Rendi- } \\
\text { miento } \\
\text { Estacional }\end{array}$ & $\begin{array}{c}\text { Estimación } \\
\text { Energía } \\
\text { Consumida } \\
\text { anual }\end{array}$ & \multirow[t]{2}{*}{$\begin{array}{l}\text { Tipo post } \\
\text { mejora }\end{array}$} & $\begin{array}{c}\text { Potencia } \\
\text { nominal } \\
\text { post } \\
\text { mejora }\end{array}$ & $\begin{array}{c}\text { Rendimiento } \\
\text { estacional } \\
\text { post mejora }\end{array}$ & $\begin{array}{c}\text { Estimación } \\
\text { Energía } \\
\text { Consumida } \\
\text { anual Post } \\
\text { mejora }\end{array}$ & $\begin{array}{l}\text { Energía } \\
\text { anual } \\
\text { ahorrada }\end{array}$ \\
\hline & & {$[\mathrm{kW}]$} & [\%] & {$\left[\mathrm{kWh} / \mathrm{m}^{2} \mathrm{año}\right]$} & & {$[\mathrm{kW}]$} & [\%] & [kWh/m²año] & [kWh/m²año] \\
\hline $\begin{array}{l}\text { Calefacción y } \\
\text { refrigeración }\end{array}$ & $\begin{array}{c}\text { Bomba de } \\
\text { Calor - } \\
\text { Caudal Ref. } \\
\text { Variable }\end{array}$ & & $261.5 \%$ & - & $\begin{array}{c}\text { Bomba de } \\
\text { Calor - } \\
\text { Caudal Ref. } \\
\text { Variable }\end{array}$ & & $463.6 \%$ & - & - \\
\hline TOTALES & & & & & & & & & \\
\hline
\end{tabular}

\section{Generadores de refrigeración}

\begin{tabular}{|c|c|c|c|c|c|c|c|c|c|}
\hline \multirow[t]{2}{*}{ Nombre } & \multirow[t]{2}{*}{ Tipo } & $\begin{array}{r}\text { Potencia } \\
\text { nominal }\end{array}$ & $\begin{array}{c}\text { Rendi- } \\
\text { miento } \\
\text { Estacional }\end{array}$ & $\begin{array}{c}\text { Estimación } \\
\text { Energía } \\
\text { Consumida } \\
\text { anual }\end{array}$ & \multirow[t]{2}{*}{$\begin{array}{l}\text { Tipo post } \\
\text { mejora }\end{array}$} & $\begin{array}{c}\text { Potencia } \\
\text { nominal } \\
\text { post } \\
\text { mejora }\end{array}$ & $\begin{array}{c}\text { Rendimiento } \\
\text { estacional } \\
\text { post mejora }\end{array}$ & $\begin{array}{c}\text { Estimación } \\
\text { Energía } \\
\text { Consumida } \\
\text { anual Post } \\
\text { mejora }\end{array}$ & $\begin{array}{c}\text { Energía } \\
\text { anual } \\
\text { ahorrada }\end{array}$ \\
\hline & & {$[\mathrm{kW}]$} & {$[\%]$} & {$\left[\mathrm{kWh} / \mathrm{m}^{2} \mathrm{año}\right]$} & & {$[\mathrm{kW}]$} & {$[\%]$} & [kWh/m²año] & {$\left[\mathrm{kWh} / \mathrm{m}^{2} \mathrm{año}\right.$} \\
\hline $\begin{array}{l}\text { Calefacción y } \\
\text { refrigeración }\end{array}$ & $\begin{array}{c}\text { Bomba de } \\
\text { Calor - } \\
\text { Caudal Ref. } \\
\text { Variable }\end{array}$ & & $227.1 \%$ & - & $\begin{array}{c}\text { Bomba de } \\
\text { Calor - } \\
\text { Caudal Ref. } \\
\text { Variable }\end{array}$ & & $508.0 \%$ & - & - \\
\hline TOTALES & & - & & - & & - & & - & - \\
\hline
\end{tabular}

\section{Instalaciones de Agua Caliente Sanitaria}

\begin{tabular}{|c|c|c|c|c|c|c|c|c|c|}
\hline Nombre & Tipo & $\begin{array}{l}\text { Potencia } \\
\text { nominal }\end{array}$ & $\begin{array}{c}\text { Rendi- } \\
\text { miento } \\
\text { Estacional }\end{array}$ & $\begin{array}{c}\text { Estimación } \\
\text { Energía } \\
\text { Consumida } \\
\text { anual }\end{array}$ & $\begin{array}{c}\text { Tipo post } \\
\text { mejora }\end{array}$ & $\begin{array}{l}\text { Potencia } \\
\text { nominal } \\
\text { post } \\
\text { mejora }\end{array}$ & $\begin{array}{c}\text { Rendimiento } \\
\text { estacional } \\
\text { post mejora }\end{array}$ & $\begin{array}{c}\text { Estimación } \\
\text { Energía } \\
\text { Consumida } \\
\text { anual Post } \\
\text { mejora }\end{array}$ & $\begin{array}{l}\text { Energía } \\
\text { anual } \\
\text { ahorrada }\end{array}$ \\
\hline & & {$[\mathrm{kW}]$} & [\%] & {$\left[\mathrm{kWh} / \mathrm{m}^{2} \mathrm{año}\right]$} & & {$[\mathrm{kW}]$} & [\%] & [kWh/m²año] & [kWh/m²año] \\
\hline Equipo ACS & Efecto Joule & & $100.0 \%$ & - & Efecto Joule & & $100.0 \%$ & - & - \\
\hline TOTALES & & - & & - & & - & & - & - \\
\hline
\end{tabular}




\begin{tabular}{|c|c|c|c|c|c|}
\hline & & $\begin{array}{c}\text { Ref. } \\
\text { Catastral }\end{array}$ & 000000000 & $\begin{array}{c}\text { Versión } \\
\text { informe } \\
\text { asociado }\end{array}$ & $01 / 12 / 2015$ \\
\hline $\begin{array}{l}\text { Certificación } \\
\text { Energética } \\
\text { de Edificios }\end{array}$ & $\begin{array}{c}\text { Id. } \\
\text { Mejora }\end{array}$ & $\begin{array}{l}\text { Programa } \\
\text { y versión }\end{array}$ & CEXv2.1 & Fecha & $4 / 1 / 2004$ \\
\hline
\end{tabular}

\section{ENERGÍAS RENOVABLES}

\section{Térmica}

\begin{tabular}{|c|c|c|c|c|}
\hline \multirow{2}{*}{ Nombre } & \multicolumn{3}{|c|}{$\begin{array}{c}\text { Consumo de Energía Final, cubierto en función } \\
\text { del servicio asociado [\%] }\end{array}$} & $\begin{array}{c}\text { Demanda de ACS } \\
\text { cubierta [\%] }\end{array}$ \\
\cline { 2 - 5 } & Calefacción & Refrigeración & ACS & \\
\hline- & - & - & - & - \\
\hline TOTALES & - & - & - & - \\
\hline
\end{tabular}

Post mejora

\begin{tabular}{|c|c|c|c|c|}
\hline \multirow{2}{*}{ Nombre } & \multicolumn{2}{|c|}{$\begin{array}{c}\text { Consumo de Energía Final, cubierto en función } \\
\text { del servicio asociado [\%] }\end{array}$} & $\begin{array}{c}\text { Demanda de ACS } \\
\text { cubierta [\%] }\end{array}$ \\
\cline { 2 - 5 } & Calefacción & Refrigeración & ACS & \\
\hline FV+ Sistema Geotérmico & 100 & 100 & - & - \\
\hline TOTALES & 100.0 & 100.0 & - & - \\
\hline
\end{tabular}

\section{Eléctrica}

\begin{tabular}{|c|c|c|}
\hline Nombre & $\begin{array}{c}\text { Energía eléctrica generada y } \\
\text { autoconsumida [kWh/año] }\end{array}$ & $\begin{array}{c}\text { Energía eléctrica generada y } \\
\text { autoconsumida post mejora } \\
\text { [kWh/año] }\end{array}$ \\
\hline FV+ Sistema Geotérmico & - & 7800 \\
\hline TOTALES & - & 7800.0 \\
\hline
\end{tabular}


A.6.7

Zona Climática Cfb (Koppen)/ C1 (CTE). Santander 


\section{CERTIFICADO DE EFICIENCIA ENERGÉTICA DE EDIFICIOS}

IDENTIFICACIÓN DEL EDIFICIO O DE LA PARTE QUE SE CERTIFICA:

\begin{tabular}{|l|l|l|l|}
\hline Nombre del edificio & Vivienda Taller Modificado \\
\hline Dirección & Tesis & Código Postal & 39002 \\
\hline Municipio & Santander & Comunidad Autónoma & Cantabria \\
\hline Provincia & Cantabria & Año construcción & 2007 \\
\hline Zona climática & C1 & & \\
\hline $\begin{array}{l}\text { Normativa vigente (construcción } \\
\text { rehabilitación) }\end{array}$ & C.T.E. & \\
\hline Referencia/s catastral/es & 000000000 & \\
\hline
\end{tabular}

\begin{tabular}{|l|l|}
\hline \multicolumn{2}{|c|}{ Tipo de edificio o parte del edificio que se certifica: } \\
\hline$\circ$ Edificio de nueva construcción & $\bullet$ Edificio Existente \\
\hline \multicolumn{2}{|c|}{} \\
\hline$\bullet$ Vivienda & $\circ$ Terciario \\
$\bullet$ Unifamiliar & $\circ$ Edificio completo \\
$\circ$ Bloque & $\circ$ Local \\
$\circ$ Bloque completo & \\
\hline Vivienda individual & \\
\hline
\end{tabular}

DATOS DEL TÉCNICO CERTIFICADOR:

\begin{tabular}{|c|c|c|c|c|c|}
\hline Nombre y Apellidos & \multicolumn{3}{|c|}{ Juan Carlos Sánchez } & NIF(NIE) & 000000000 \\
\hline Razón social & \multicolumn{3}{|c|}{ Juan Carlos Sánchez } & NIF & 000000000 \\
\hline \multicolumn{2}{|l|}{ Domicilio } & \multicolumn{4}{|l|}{ Calle Pinar Del Rey } \\
\hline \multicolumn{2}{|l|}{ Municipio } & Madrid & \multicolumn{2}{|c|}{ Código Postal } & 28033 \\
\hline \multicolumn{2}{|l|}{ Provincia } & Madrid & \multicolumn{2}{|c|}{ Comunidad Autónoma } & $\begin{array}{l}\text { Comunidad } \\
\text { Madrid }\end{array}$ \\
\hline \multicolumn{2}{|l|}{ e-mail: } & \multicolumn{2}{|c|}{ juancsanchezg@hotmail.com } & Teléfono & 0000000000 \\
\hline \multicolumn{2}{|c|}{ Titulación habilitante según normativa vigente } & \multicolumn{4}{|l|}{ Arquitecto } \\
\hline $\begin{array}{l}\text { Procedimiento reconocido de } \\
\text { versión: }\end{array}$ & calificación & ergética utilizado y & CEX & & \\
\hline
\end{tabular}

\section{CALIFICACIÓN ENERGÉTICA OBTENIDA:}

\begin{tabular}{|c|c|c|c|}
\hline \multicolumn{2}{|c|}{$\begin{array}{c}\text { CONSUMO DE ENERGÍA } \\
\text { PRIMARIA NO RENOVABLE } \\
{\left[\mathrm{kWh} / \mathrm{m}^{2} \text { año] }\right.}\end{array}$} & \multicolumn{2}{|c|}{$\begin{array}{c}\text { EMISIONES DE DIÓXIDO DE } \\
\text { CARBONO } \\
{\left[\mathrm{kgCO} 2 / \mathrm{m}^{2} \text { año] }\right.}\end{array}$} \\
\hline 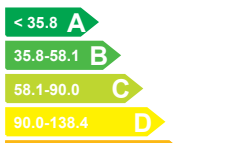 & & 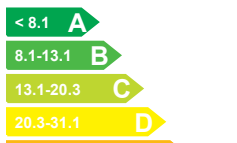 & \\
\hline $\begin{array}{ll}138.4-254.1 & E \\
254.1-305.0 & \text { F } \\
305.0 & \text { G }\end{array}$ & $225.3 \mathrm{E}$ & 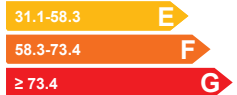 & $38.2 \mathrm{E}$ \\
\hline
\end{tabular}

El técnico abajo firmante declara responsablemente que ha realizado la certificación energética del edificio o de la parte que se certifica de acuerdo con el procedimiento establecido por la normativa vigente y que son ciertos los datos que figuran en el presente documento, y sus anexos:

Fecha: 01/12/2015

\section{Firma del técnico certificador}

Anexo I. Descripción de las características energéticas del edificio.

Anexo II. Calificación energética del edificio.

Anexo III. Recomendaciones para la mejora de la eficiencia energética.

Anexo IV. Pruebas, comprobaciones e inspecciones realizadas por el técnico certificador.

Registro del Órgano Territorial Competente: 


\section{DESCRIPCIÓN DE LAS CARACTERÍSTICAS ENERGÉTICAS DEL EDIFICIO}

En este apartado se describen las características energéticas del edificio, envolvente térmica, instalaciones, condiciones de funcionamiento y ocupación y demás datos utilizados para obtener la calificación energética del edificio.

\section{SUPERFICIE, IMAGEN Y SITUACIÓN}

\begin{tabular}{|l|l}
\hline Superficie habitable $\left[\mathrm{m}^{2}\right]$ & 52.0
\end{tabular}

\begin{tabular}{|c|c|c|}
\hline Imagen del edificio & Plano de situación \\
\hline & &
\end{tabular}

\section{ENVOLVENTE TÉRMICA}

\section{Cerramientos opacos}

\begin{tabular}{|l|c|c|c|c|}
\hline \multicolumn{1}{|c|}{ Nombre } & Tipo & $\begin{array}{c}\text { Superficie } \\
{\left[\mathrm{m}^{2}\right]}\end{array}$ & $\begin{array}{c}\text { Transmitancia } \\
{\left[\mathbf{W} / \mathbf{m}^{2} \cdot \mathrm{K}\right]}\end{array}$ & Modo de obtención \\
\hline Cubierta con aire & Cubierta & 52.0 & 0.47 & Conocidas \\
\hline Muro de fachada Norte & Fachada & 27.18 & 0.54 & Conocidas \\
\hline Suelo con aire & Suelo & 52.0 & 2.95 & Conocidas \\
\hline Muro de fachada Sur & Fachada & 21.88 & 0.54 & Conocidas \\
\hline Muro de fachada Oeste & Fachada & 8.04 & 0.54 & Conocidas \\
\hline Muro de fachada Este & Fachada & 3.28 & 0.54 & Conocidas \\
\hline
\end{tabular}

Huecos y lucernarios

\begin{tabular}{|l|c|c|c|c|c|c|}
\hline Nombre & Tipo & $\begin{array}{c}\text { Superficie } \\
{\left[\mathbf{m}^{2}\right]}\end{array}$ & $\begin{array}{c}\text { Transmitancia } \\
{\left[\mathbf{W} / \mathbf{m}^{2} \cdot \mathbf{K}\right]}\end{array}$ & $\begin{array}{c}\text { Factor } \\
\text { solar }\end{array}$ & $\begin{array}{c}\text { Modo de } \\
\text { obtención. } \\
\text { Transmitancia }\end{array}$ & $\begin{array}{c}\text { Modo de } \\
\text { obtención. } \\
\text { Factor solar }\end{array}$ \\
\hline V1 & Hueco & 5.3 & 5.70 & 0.67 & Estimado & Estimado \\
\hline V3 & Hueco & 5.3 & 5.70 & 0.67 & Estimado & Estimado \\
\hline V4 & Hueco & 5.3 & 5.70 & 0.67 & Estimado & Estimado \\
\hline V2 & Hueco & 5.3 & 5.70 & 0.67 & Estimado & Estimado \\
\hline V5 & Hueco & 5.03 & 5.70 & 0.67 & Estimado & Estimado \\
\hline Pta & Hueco & 5.03 & 5.70 & 0.67 & Estimado & Estimado \\
\hline
\end{tabular}




\section{INSTALACIONES TÉRMICAS}

Generadores de calefacción

\begin{tabular}{|c|c|c|c|c|c|}
\hline Nombre & Tipo & $\begin{array}{c}\text { Potencia } \\
\text { nominal [kW] }\end{array}$ & $\begin{array}{c}\text { Rendimiento } \\
\text { Estacional[\%] }\end{array}$ & $\begin{array}{l}\text { Tipo de } \\
\text { Energía }\end{array}$ & $\begin{array}{c}\text { Modo de } \\
\text { obtención }\end{array}$ \\
\hline $\begin{array}{l}\text { Calefacción } \\
\text { refrigeración }\end{array}$ & $\begin{array}{l}\text { Bomba de Calor - } \\
\text { Caudal Ref. Variable }\end{array}$ & & 317.1 & Electricidad & Estimado \\
\hline TOTALES & Calefacción & & & & \\
\hline
\end{tabular}

\section{Generadores de refrigeración}

\begin{tabular}{|c|c|c|c|c|c|}
\hline Nombre & Tipo & $\begin{array}{c}\text { Potencia } \\
\text { nominal [kW] }\end{array}$ & $\begin{array}{c}\text { Rendimiento } \\
\text { Estacional[\%] }\end{array}$ & $\begin{array}{c}\text { Tipo de } \\
\text { Energía }\end{array}$ & $\begin{array}{c}\text { Modo de } \\
\text { obtención }\end{array}$ \\
\hline $\begin{array}{l}\text { Calefacción } \\
\text { refrigeración }\end{array}$ & y & $\begin{array}{c}\text { Bomba de Calor } \\
\text { Caudal Ref. Variable }\end{array}$ & 229.9 & Electricidad & Estimado \\
\hline TOTALES & Refrigeración & & & \\
\hline
\end{tabular}

Instalaciones de Agua Caliente Sanitaria

Demanda diario de ACS a $60^{\circ}$ (litros/día) 45.55

\begin{tabular}{|c|c|c|c|c|c|}
\hline Nombre & Tipo & $\begin{array}{c}\text { Potencia } \\
\text { nominal [kW] }\end{array}$ & $\begin{array}{c}\text { Rendimiento } \\
\text { Estacional[\%] }\end{array}$ & $\begin{array}{c}\text { Tipo de } \\
\text { Energía }\end{array}$ & $\begin{array}{c}\text { Modo de } \\
\text { obtención }\end{array}$ \\
\hline Equipo ACS & Efecto Joule & & 100.0 & Electricidad & Estimado \\
\hline TOTALES & ACS & & & & \\
\hline
\end{tabular}




\section{ANEXO II
CALIFICACIÓN ENERGÉTICA DEL EDIFICIO}

\begin{tabular}{|l|l|l|l|}
\hline Zona climática & C1 & Uso & Residencial \\
\hline
\end{tabular}

\section{CALIFICACIÓN ENERGÉTICA DEL EDIFICIO EN EMISIONES}

\begin{tabular}{|c|c|c|c|c|c|}
\hline \multicolumn{2}{|c|}{ INDICADOR GLOBAL } & \multicolumn{4}{|c|}{ INDICADORES PARCIALES } \\
\hline $\begin{array}{l}<8.1 \quad \mathrm{~A} \\
8.1-13.1 \quad \mathrm{~B}\end{array}$ & & \multicolumn{2}{|c|}{ CALEFACCIÓN } & \multicolumn{2}{|l|}{ ACS } \\
\hline $\begin{array}{ll}13.1-20.3 & \text { C } \\
20.3 \cdot 31.1 & \text { D }\end{array}$ & & $\begin{array}{c}\text { Emisiones } \\
\text { calefacción } \\
{\left[\mathrm{kaCO} 2 \mathrm{~m}^{2} \text { añol }\right.}\end{array}$ & \multirow{2}{*}{ D } & $\begin{array}{l}\text { Emisiones ACS } \\
{\left[\mathrm{kgCO} 2 / \mathrm{m}^{2} \text { año] }\right.}\end{array}$ & \multirow{2}{*}{ G } \\
\hline $31.1-58.3$ & \multirow[t]{2}{*}{$38.2 \mathrm{E}$} & 20.69 & & 15.14 & \\
\hline $\begin{array}{ll}58.3-73.4 & F \\
\geq 273.4 & C\end{array}$ & & \multicolumn{2}{|c|}{ REFRIGERACIÓN } & \multicolumn{2}{|c|}{ ILUMINACIÓN } \\
\hline \multirow{2}{*}{\multicolumn{2}{|c|}{ Emisiones globales $\left[\mathrm{kgCO} 2 / \mathrm{m}^{2}\right.$ año] ${ }^{1}$}} & $\begin{array}{c}\text { Emisiones } \\
\text { refrigeracion } \\
{\left[\mathrm{kgCO} 2 / \mathrm{m}^{2} \text { añol }\right]}\end{array}$ & \multirow[t]{2}{*}{ - } & $\begin{array}{c}\text { Emisiones } \\
\text { iluminación } \\
{\left[\mathrm{kgCO} 2 / \mathrm{m}^{2} \text { añol }\right]}\end{array}$ & \multirow[t]{2}{*}{-} \\
\hline & & - & & - & \\
\hline
\end{tabular}

La calificación global del edificio se expresa en términos de dióxido de carbono liberado a la atmósfera como consecuencia del consumo energético del mismo.

\begin{tabular}{|l|c|c|}
\cline { 2 - 3 } \multicolumn{1}{c|}{} & $\mathbf{k g C O} 2 / \mathbf{m}^{\mathbf{2}}$ año & $\mathbf{~} \mathbf{k g C O 2 / a n ̃ o ~}$ \\
\hline Emisiones CO2 por consumo eléctrico & 38.16 & 1984.37 \\
\hline Emisiones CO2 por otros combustibles & 0.00 & 0.00 \\
\hline
\end{tabular}

\section{CALIFICACIÓN ENERGÉTICA DEL EDIFICIO EN CONSUMO DE ENERGÍA PRIMARIA NO RENOVABLE}

Por energía primaria no renovable se entiende la energía consumida por el edificio procedente de fuentes no renovables que no ha sufrido ningún proceso de conversión o transformación.

\begin{tabular}{|c|c|c|c|c|c|}
\hline \multicolumn{2}{|c|}{ INDICADOR GLOBAL } & \multicolumn{4}{|c|}{ INDICADORES PARCIALES } \\
\hline \multirow{4}{*}{ 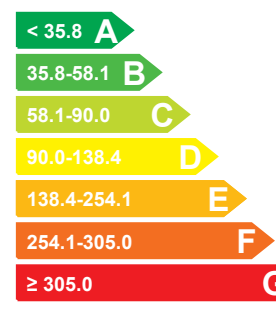 } & & \multicolumn{2}{|c|}{ CALEFACCIÓN } & \multicolumn{2}{|l|}{ ACS } \\
\hline & & $\begin{array}{l}\text { Energía primaria } \\
\text { calefacción } \\
{\left[\mathrm{kWh} / \mathrm{m}^{2} \text { año] }\right.}\end{array}$ & \multirow[t]{2}{*}{ E } & $\begin{array}{l}\text { Energía primaria } \\
A C S \\
{\left[\mathrm{kWh} / \mathrm{m}^{2} \text { año] }\right.}\end{array}$ & \multirow[t]{2}{*}{ G } \\
\hline & \multirow[t]{2}{*}{$225.3 \mathrm{E}$} & 122.15 & & 89.37 & \\
\hline & & \multicolumn{2}{|c|}{ REFRIGERACIÓN } & \multicolumn{2}{|l|}{ ILUMINACIÓN } \\
\hline \multirow{2}{*}{\multicolumn{2}{|c|}{$\begin{array}{c}\text { Consumo global de energía primaria no renovable } \\
\qquad\left[\mathrm{kWh} / \mathrm{m}^{2} \text { año }\right]^{1}\end{array}$}} & $\begin{array}{l}\text { Energía primaria } \\
\text { refrigeración } \\
{\left[\mathrm{kWh} / \mathrm{m}^{2} \text { añol }\right.}\end{array}$ & - & $\begin{array}{l}\text { Energía primaria } \\
\text { iluminación } \\
{\left[\mathrm{kWh} / \mathrm{m}^{2} a \tilde{n} o\right]}\end{array}$ & - \\
\hline & & - & & - & \\
\hline
\end{tabular}

\section{CALIFICACIÓN PARCIAL DE LA DEMANDA ENERGÉTICA DE CALEFACCIÓN Y REFRIGERACIÓN}

La demanda energética de calefacción y refrigeración es la energía necesaria para mantener las condiciones internas de confort del edificio.

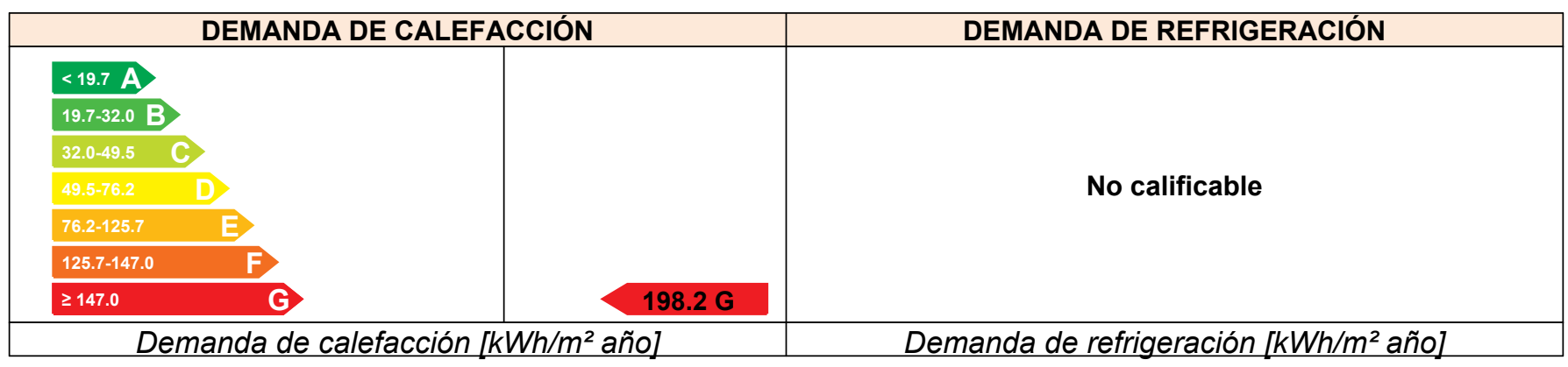

${ }^{1}$ El indicador global es resultado de la suma de los indicadores parciales más el valor del indicador para consumos auxiliares, si los hubiera (sólo ed. terciarios, ventilación, bombeo, etc...). La energía eléctrica autoconsumida se descuenta únicamente del indicador global, no así de los valores parciales 


\section{ANEXO III \\ RECOMENDACIONES PARA LA MEJORA DE LA EFICIENCIA ENERGÉTICA}

FV $100 \%$

CALIFICACIÓN ENERGÉTICA GLOBAL

\begin{tabular}{|c|c|c|c|}
\hline \multicolumn{2}{|c|}{$\begin{array}{l}\text { CONSUMO DE ENERGÍA } \\
\text { PRIMARIA NO RENOVABLE } \\
\text { [kWh/m² año] }\end{array}$} & \multicolumn{2}{|c|}{$\begin{array}{c}\text { EMISIONES DE DIÓXIDO DE } \\
\text { CARBONO } \\
{\left[\mathrm{kgCO} 2 / \mathrm{m}^{2} \text { año] }\right.}\end{array}$} \\
\hline$<35.8 \mathrm{~A}$ & & $<8.1$ A & \\
\hline$\frac{35.8-58.1 \text { B }}{58.1-90.0 \quad \text { C }}$ & $78.1 \mathrm{C}$ & $\begin{array}{l}\frac{8.1-13.1 \quad B}{13.1-20.3} \text { C } \\
\end{array}$ & $13.2 \mathrm{C}$ \\
\hline $90.0-138.4 \quad D$ & & $20.3-31.1$ & \\
\hline 138.4-254.1 & & $31.1-58.3$ & \\
\hline $254.1-305.0$ & & 58.3-73.4 & \\
\hline G & & $\geq 73.4$ & \\
\hline
\end{tabular}

CALIFICACIONES ENERGÉTICAS PARCIALES

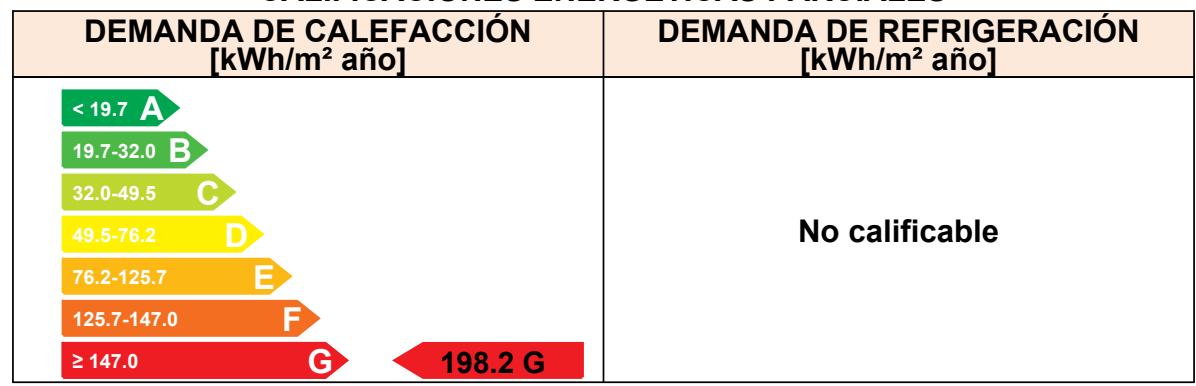

\section{ANÁLISIS TÉCNICO}

\begin{tabular}{|c|c|c|c|c|c|c|c|c|c|c|c|c|c|c|c|}
\hline \multirow[b]{2}{*}{ Indicador } & \multicolumn{3}{|c|}{ Calefacción } & \multicolumn{3}{|c|}{ Refrigeración } & \multicolumn{3}{|c|}{ ACS } & \multicolumn{3}{|c|}{ Iluminación } & \multicolumn{3}{|c|}{ Total } \\
\hline & \multicolumn{2}{|c|}{ Valor } & $\begin{array}{c}\text { ahorro } \\
\text { respecto a } \\
\text { la situación } \\
\text { original }\end{array}$ & \multicolumn{2}{|c|}{ Valor } & $\begin{array}{c}\text { ahorro } \\
\text { respecto a } \\
\text { la situación } \\
\text { original }\end{array}$ & \multicolumn{2}{|c|}{ Valor } & $\begin{array}{c}\text { ahorro } \\
\text { respecto a } \\
\text { la situación } \\
\text { original }\end{array}$ & \multicolumn{2}{|c|}{ Valor } & $\begin{array}{c}\text { ahorro } \\
\text { respecto a } \\
\text { la situación } \\
\text { original }\end{array}$ & \multicolumn{2}{|c|}{ Valor } & $\begin{array}{c}\text { ahorro } \\
\text { respecto a } \\
\text { la situación } \\
\text { original }\end{array}$ \\
\hline $\begin{array}{l}\text { Consumo Energía final } \\
{\left[\mathrm{kWh} / \mathrm{m}^{2} \text { año] }\right.}\end{array}$ & \multicolumn{2}{|c|}{70.29} & $-12.4 \%$ & \multicolumn{2}{|c|}{-} & $-\%$ & \multicolumn{2}{|c|}{45.74} & $0.0 \%$ & \multicolumn{2}{|c|}{-} & $-\%$ & \multicolumn{2}{|c|}{39.98} & $65.3 \%$ \\
\hline $\begin{array}{c}\text { Emisiones de } \mathrm{CO} 2 \\
{\left[\mathrm{kgCO} 2 / \mathrm{m}^{2} \text { año] }\right.}\end{array}$ & 23.27 & $\mathrm{D}$ & $-12.4 \%$ & - & - & $-\%$ & 15.14 & G & $0.0 \%$ & - & - & $-\%$ & 13.23 & C & $65.3 \%$ \\
\hline Demanda [kWh/m² año] & 198.23 & G & $0.0 \%$ & - & - & $-\%$ & & & & & & & & & \\
\hline
\end{tabular}

Nota: Los indicadores energéticos anteriores están calculados en base a coeficientes estándar de operación y funcionamiento del edificio, por lo que solo son válidos a efectos de su calificación energética. Para el análisis económico de las medidas de ahorro y eficiencia energética, el técnico certificador deberá utilizar las condiciones reales y datos históricos de consumo del edificio.

\section{DESCRIPCIÓN DE LA MEDIDA DE MEJORA}

Características de la medida (modelo de equipos, materiales, parámetros característicos )

Coste estimado de la medida

Otros datos de interés 
CALIFICACIÓN ENERGÉTICA GLOBAL

\begin{tabular}{|c|c|c|c|}
\hline \multicolumn{2}{|c|}{$\begin{array}{l}\text { CONSUMO DE ENERGÍA } \\
\text { PRIMARIA NO RENOVABLE } \\
\text { [kWh/m² año] }\end{array}$} & \multicolumn{2}{|c|}{$\begin{array}{c}\text { EMISIONES DE DIÓXIDO DE } \\
\text { CARBONO } \\
{\left[\mathrm{kgCO} 2 / \mathrm{m}^{2} \text { año] }\right.}\end{array}$} \\
\hline$<35.8 \mathrm{~A}$ & & $<8.1 \quad A$ & \\
\hline $\begin{array}{ll}\frac{35.8-58.1}{58.1-90.0} \quad \mathrm{C} \\
\end{array}$ & $89.4 \mathrm{C}$ & $\begin{array}{ll}\frac{8.1-13.1}{13.1-20.3} & \text { B }\end{array}$ & $15.1 \mathrm{C}$ \\
\hline $90.0-138.4 \quad D$ & & $20.3-31.1$ & \\
\hline 138.4-254.1 & & $31.1-58.3$ & \\
\hline $254.1-305.0$ & & 58.3-73.4 & \\
\hline$\geq 305.0$ & & $\geq 73.4$ & \\
\hline
\end{tabular}

CALIFICACIONES ENERGÉTICAS PARCIALES

\begin{tabular}{|c|c|}
\hline $\begin{array}{l}\text { DEMANDA DE CALEFACCIÓN } \\
{\left[\mathrm{kWh} / \mathrm{m}^{2} \text { año] }\right.}\end{array}$ & $\begin{array}{l}\text { DEMANDA DE REFRIGERACIÓN } \\
{\left[\mathrm{kWh} / \mathrm{m}^{2} \text { año] }\right.}\end{array}$ \\
\hline \multicolumn{2}{|l|}{$<19.7$ A } \\
\hline \multicolumn{2}{|l|}{$19.7-32.0 \mathrm{~B}$} \\
\hline \multicolumn{2}{|l|}{$32.0-49.5 \quad \mathrm{C}$} \\
\hline 49.5-76.2 D & \multirow[t]{4}{*}{ No calificable } \\
\hline 76.2-125.7 E & \\
\hline $125.7-147.0$ & \\
\hline$\geq 147.0 \quad$ G & \\
\hline
\end{tabular}

\section{ANÁLISIS TÉCNICO}

\begin{tabular}{|c|c|c|c|c|c|c|c|c|c|c|c|c|c|c|}
\hline \multirow[b]{2}{*}{ Indicador } & \multicolumn{3}{|c|}{ Calefacción } & \multicolumn{3}{|c|}{ Refrigeración } & \multicolumn{3}{|c|}{ ACS } & \multicolumn{2}{|c|}{ Iluminación } & \multicolumn{3}{|c|}{ Total } \\
\hline & \multicolumn{2}{|c|}{ Valor } & $\begin{array}{c}\text { ahorro } \\
\text { respecto a } \\
\text { la situación } \\
\text { original }\end{array}$ & \multicolumn{2}{|c|}{ Valor } & $\begin{array}{c}\text { ahorro } \\
\text { respecto a } \\
\text { la situación } \\
\text { original }\end{array}$ & \multicolumn{2}{|c|}{ Valor } & $\begin{array}{c}\text { ahorro } \\
\text { respecto a } \\
\text { la situación } \\
\text { original }\end{array}$ & Valor & $\begin{array}{c}\text { ahorro } \\
\text { respecto a } \\
\text { la situación } \\
\text { original }\end{array}$ & \multicolumn{2}{|c|}{ Valor } & $\begin{array}{c}\text { ahorro } \\
\text { respecto a } \\
\text { la situación } \\
\text { original }\end{array}$ \\
\hline $\begin{array}{c}\text { Consumo Energía final } \\
{\left[\mathrm{kWh} / \mathrm{m}^{2} \text { año] }\right.}\end{array}$ & \multicolumn{2}{|c|}{0.00} & $100.0 \%$ & \multicolumn{2}{|c|}{-} & $-\%$ & \multicolumn{2}{|c|}{45.74} & $0.0 \%$ & - & $-\%$ & \multicolumn{2}{|c|}{45.74} & $60.3 \%$ \\
\hline $\begin{array}{c}\text { Consumo Energía } \\
\text { primaria no renovable } \\
{\left[\mathrm{kWh} / \mathrm{m}^{2} \text { año] }\right.}\end{array}$ & 0.00 & $A$ & $100.0 \%$ & - & - & $-\%$ & 89.37 & G & $0.0 \%$ & - & $-\%$ & 89.37 & C & $60.3 \%$ \\
\hline $\begin{array}{l}\text { Emisiones de } \mathrm{CO} 2 \\
{\left[\mathrm{kgCO} 2 / \mathrm{m}^{2} \text { año] }\right.}\end{array}$ & 0.00 & $A$ & $100.0 \%$ & - & - & $-\%$ & 15.14 & G & $0.0 \%$ & - & $-\%$ & 15.14 & $\mathrm{C}$ & $60.3 \%$ \\
\hline Demanda [kWh/m² año] & 85.11 & $E$ & $57.1 \%$ & - & - & $-\%$ & & & & & & & & \\
\hline
\end{tabular}

Nota: Los indicadores energéticos anteriores están calculados en base a coeficientes estándar de operación y funcionamiento del edificio, por lo que solo son válidos a efectos de su calificación energética. Para el análisis económico de las medidas de ahorro y eficiencia energética, el técnico certificador deberá utilizar las condiciones reales y datos históricos de consumo del edificio.

\section{DESCRIPCIÓN DE LA MEDIDA DE MEJORA}

Características de la medida (modelo de equipos, materiales, parámetros característicos )

Coste estimado de la medida

\section{Otros datos de interés}


CALIFICACIÓN ENERGÉTICA GLOBAL

\begin{tabular}{|c|c|c|c|}
\hline \multicolumn{2}{|c|}{$\begin{array}{l}\text { CONSUMO DE ENERGÍA } \\
\text { PRIMARIA NO RENOVABLE } \\
{\left[\mathrm{kWh} / \mathrm{m}^{2} \text { año] }\right.}\end{array}$} & \multicolumn{2}{|c|}{$\begin{array}{c}\text { EMISIONES DE DIÓXIDO DE } \\
\text { CARBONO } \\
{\left[\mathrm{kgCO} 2 / \mathrm{m}^{2} \text { año] }\right.}\end{array}$} \\
\hline$<35.8 \mathrm{~A}$ & & $<8.1 \quad$ A & \\
\hline 35.8-58.1 B & & $8.1-13.1 \quad B$ & \\
\hline 58.1-90.0 C & $89.4 \mathrm{C}$ & $13.1-20.3 \quad C$ & $15.1 \mathrm{C}$ \\
\hline $90.0-138.4 \quad$ D & & 20.3-31.1 & \\
\hline $138.4-254.1$ & & $31.1-58.3$ & \\
\hline $254.1-305.0$ & & 58.3-73.4 & \\
\hline$\geq 305.0$ & & $\geq 73.4$ & \\
\hline
\end{tabular}

CALIFICACIONES ENERGÉTICAS PARCIALES

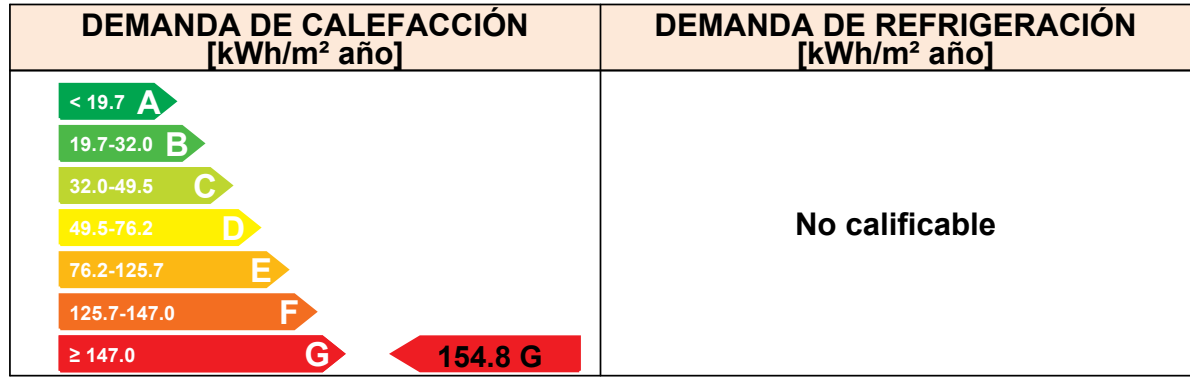

\section{ANÁLISIS TÉCNICO}

\begin{tabular}{|c|c|c|c|c|c|c|c|c|c|c|c|c|c|c|c|}
\hline \multirow[b]{2}{*}{ Indicador } & \multicolumn{3}{|c|}{ Calefacción } & \multicolumn{3}{|c|}{ Refrigeración } & \multicolumn{3}{|c|}{ ACS } & \multicolumn{3}{|c|}{ Iluminación } & \multicolumn{3}{|c|}{ Total } \\
\hline & \multicolumn{2}{|c|}{ Valor } & $\begin{array}{c}\text { ahorro } \\
\text { respecto a } \\
\text { la situación } \\
\text { original }\end{array}$ & \multicolumn{2}{|c|}{ Valor } & $\begin{array}{c}\text { ahorro } \\
\text { respecto a } \\
\text { la situación } \\
\text { original }\end{array}$ & \multicolumn{2}{|c|}{ Valor } & $\begin{array}{c}\text { ahorro } \\
\text { respecto a } \\
\text { la situación } \\
\text { original }\end{array}$ & \multicolumn{2}{|c|}{ Valor } & $\begin{array}{c}\text { ahorro } \\
\text { respecto a } \\
\text { la situación } \\
\text { original }\end{array}$ & \multicolumn{2}{|c|}{ Valor } & $\begin{array}{c}\text { ahorro } \\
\text { respecto a } \\
\text { la situación } \\
\text { original }\end{array}$ \\
\hline $\begin{array}{c}\text { Consumo Energía final } \\
{\left[\mathrm{kWh} / \mathrm{m}^{2} \text { año] }\right.}\end{array}$ & \multicolumn{2}{|c|}{0.00} & $100.0 \%$ & \multicolumn{2}{|c|}{ - } & $-\%$ & \multicolumn{2}{|c|}{45.74} & $0.0 \%$ & \multicolumn{2}{|l|}{ - } & $-\%$ & \multicolumn{2}{|c|}{45.74} & $60.3 \%$ \\
\hline $\begin{array}{c}\text { Consumo Energía } \\
\text { primaria no renovable } \\
{\left[\mathrm{kWh} / \mathrm{m}^{2} \text { año] }\right.}\end{array}$ & 0.00 & $A$ & $100.0 \%$ & - & - & $-\%$ & 89.37 & $\mathrm{G}$ & $0.0 \%$ & - & - & $-\%$ & 89.37 & $\mathrm{C}$ & $60.3 \%$ \\
\hline $\begin{array}{c}\text { Emisiones de } \mathrm{CO} 2 \\
{\left[\mathrm{kgCO} 2 / \mathrm{m}^{2} \text { año] }\right.}\end{array}$ & 0.00 & $A$ & $100.0 \%$ & - & - & $-\%$ & 15.14 & G & $0.0 \%$ & - & - & $-\%$ & 15.14 & $\mathrm{C}$ & $60.3 \%$ \\
\hline Demanda $\left[\mathrm{kWh} / \mathrm{m}^{2}\right.$ año] & 154.85 & G & $21.9 \%$ & - & - & $-\%$ & & & & & & & & & \\
\hline
\end{tabular}

Nota: Los indicadores energéticos anteriores están calculados en base a coeficientes estándar de operación y funcionamiento del edificio, por lo que solo son válidos a efectos de su calificación energética. Para el análisis económico de las medidas de ahorro y eficiencia energética, el técnico certificador deberá utilizar las condiciones reales y datos históricos de consumo del edificio.

\section{DESCRIPCIÓN DE LA MEDIDA DE MEJORA}

Características de la medida (modelo de equipos, materiales, parámetros característicos )

Coste estimado de la medida

\section{Otros datos de interés}




\section{ANEXO IV \\ PRUEBAS, COMPROBACJONES E INSPECCIONES REALIZADAS POR EL TECNICO CERTIFICADOR}

Se describen a continuación las pruebas, comprobaciones e inspecciones llevadas a cabo por el técnico certificador durante el proceso de toma de datos y de calificación de la eficiencia energética del edificio, con la finalidad de establecer la conformidad de la información de partida contenida en el certificado de eficiencia energética.

Fecha de realización de la visita del técnico certificador 


\begin{tabular}{|c|c|c|c|c|c|}
\hline & & $\begin{array}{c}\text { Ref. } \\
\text { Catastral }\end{array}$ & 000000000 & $\begin{array}{c}\text { Versión } \\
\text { informe } \\
\text { asociado }\end{array}$ & $01 / 12 / 2015$ \\
\hline $\begin{array}{l}\text { Certificación } \\
\text { Energética } \\
\text { de Edificios }\end{array}$ & $\begin{array}{c}\text { Id. } \\
\text { Mejora }\end{array}$ & $\begin{array}{l}\text { Programa } \\
\text { y versión }\end{array}$ & CEXv2.1 & Fecha & $3 / 1 / 2004$ \\
\hline
\end{tabular}

\section{Informe descriptivo de la medida de mejora}

\section{DENOMINACIÓN DE LA MEDIDA DE MEJORA}

FV $100 \%$

\section{DESCRIPCIÓN DE LA MEDIDA DE MEJORA}

Características de la medida (modelo de equipos, materiales, parámetros característicos )

Coste estimado de la medida

Otros datos de interés

CALIFICACIÓN ENERGÉTICA GLOBAL

\begin{tabular}{|c|c|c|c|}
\hline $\begin{array}{r}\text { CONS } \\
\text { PRIMAF }\end{array}$ & $\begin{array}{l}\text { ÍA } \\
\text { BLE }\end{array}$ & $\begin{array}{r}\text { EMISIO } \\
\text { [K }\end{array}$ & \\
\hline $\begin{array}{l}<35.8 \mathrm{~A} \\
35.8-58.1 \mathrm{~B}\end{array}$ & & $\frac{<8.1 \quad \mathrm{~A}}{8.1-13.1 \mathrm{~B}}$ & \\
\hline $\begin{array}{lc}58.1-90.0 & C \\
90,0-138.4 & \text { D }\end{array}$ & $78.12 \mathrm{C}$ & 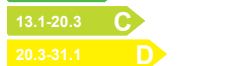 & $13.23 \mathrm{C}$ \\
\hline 138.4-254.1 $\quad$ F & & 31.1-58.3 $\quad$ E & \\
\hline $254.1-305.0$ & & 58.3-73.4 & \\
\hline$\geq 305.0$ & & $\geq 73.4$ & \\
\hline
\end{tabular}

CALIFICACIONES ENERGÉTICAS PARCIALES

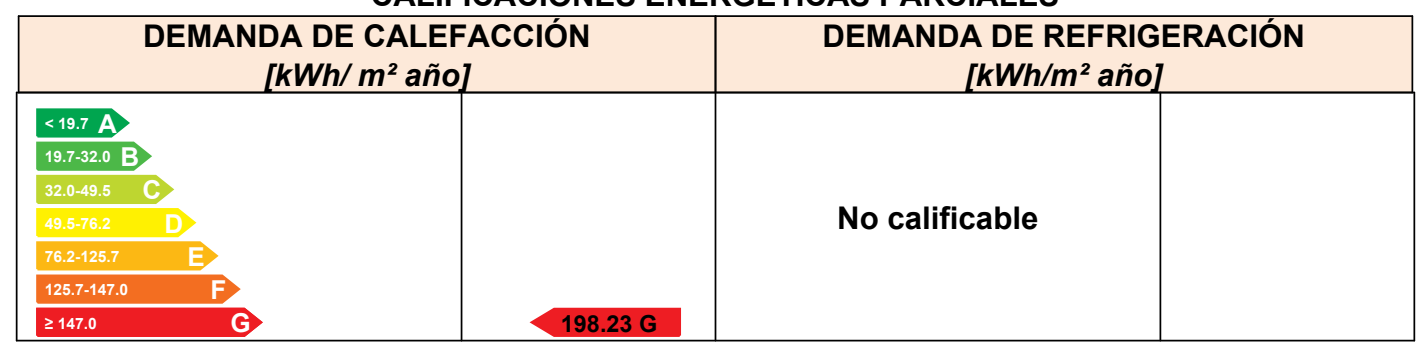




\begin{tabular}{|c|c|c|c|c|c|}
\hline & & $\begin{array}{c}\text { Ref. } \\
\text { Catastral }\end{array}$ & 000000000 & $\begin{array}{c}\text { Versión } \\
\text { informe } \\
\text { asociado }\end{array}$ & $01 / 12 / 2015$ \\
\hline $\begin{array}{l}\text { Certificación } \\
\text { Energética } \\
\text { de Edificios }\end{array}$ & $\begin{array}{c}\text { Id. } \\
\text { Mejora }\end{array}$ & $\begin{array}{l}\text { Programa } \\
\text { y versión }\end{array}$ & CEXv2.1 & Fecha & $3 / 1 / 2004$ \\
\hline
\end{tabular}

\section{ANALISÍS TÉCNICO}

\begin{tabular}{|c|c|c|c|c|c|c|c|c|c|c|c|c|c|c|c|}
\hline \multirow[b]{2}{*}{ Indicador } & \multicolumn{3}{|c|}{ Calefacción } & \multicolumn{3}{|c|}{ Refrigeración } & \multicolumn{3}{|c|}{ ACS } & \multicolumn{3}{|c|}{ Iluminación } & \multicolumn{3}{|c|}{ Total } \\
\hline & \multicolumn{2}{|c|}{ Valor } & $\begin{array}{l}\text { ahorro } \\
\text { respecto a } \\
\text { la situación } \\
\text { original }\end{array}$ & \multicolumn{2}{|c|}{ Valor } & $\begin{array}{c}\text { ahorro } \\
\text { respecto a } \\
\text { la situación } \\
\text { original }\end{array}$ & \multicolumn{2}{|c|}{ Valor } & $\begin{array}{c}\text { ahorro } \\
\text { respecto a } \\
\text { la situación } \\
\text { original }\end{array}$ & \multicolumn{2}{|c|}{ Valor } & $\begin{array}{l}\text { ahorro } \\
\text { respecto a } \\
\text { la situación } \\
\text { original }\end{array}$ & \multicolumn{2}{|c|}{ Valor } & $\begin{array}{c}\text { ahorro } \\
\text { respecto a } \\
\text { la situación } \\
\text { original }\end{array}$ \\
\hline $\begin{array}{l}\text { Consumo Energía } \\
\text { final }\left[\mathrm{kWh} / \mathrm{m}^{2} \text { año] }\right.\end{array}$ & \multicolumn{2}{|c|}{70.29} & $-12.4 \%$ & \multicolumn{2}{|c|}{ - } & $-\%$ & \multicolumn{2}{|c|}{45.74} & $0.0 \%$ & \multicolumn{2}{|c|}{-} & $-\%$ & \multicolumn{2}{|c|}{39.98} & $65.3 \%$ \\
\hline $\begin{array}{c}\text { Consumo Energía } \\
\text { primaria no renovable } \\
{\left[\mathrm{kWh} / \mathrm{m}^{2} \text { año] }\right.}\end{array}$ & 137.35 & $E$ & $-12.4 \%$ & - & - & $-\%$ & 89.37 & G & $0.0 \%$ & - & - & $-\%$ & 78.12 & C & $65.3 \%$ \\
\hline $\begin{array}{c}\text { Emisiones de CO2 } \\
{\left[\mathrm{kgCO} 2 / \mathrm{m}^{2} \text { año] }\right.}\end{array}$ & 23.27 & D & $-12.4 \%$ & - & - & $-\%$ & 15.14 & G & $0.0 \%$ & - & - & $-\%$ & 13.23 & C & $65.3 \%$ \\
\hline $\begin{array}{l}\text { Demanda }\left[\mathrm{kWh} / \mathrm{m}^{2}\right. \\
\text { año] }\end{array}$ & 198.23 & G & $0.0 \%$ & - & - & $-\%$ & & & & & & & & & \\
\hline
\end{tabular}

\section{ENVOLVENTE TÉRMICA}

\section{Cerramientos opacos}

\begin{tabular}{|c|c|c|c|c|c|}
\hline Nombre & Tipo & $\begin{array}{c}\text { Superficie } \\
\text { actual } \\
{\left[\mathbf{m}^{2}\right]}\end{array}$ & $\begin{array}{c}\text { Transmitancia } \\
\text { actual } \\
{\left[\mathbf{W} / \mathbf{m}^{\mathbf{2}} \mathbf{~ K}\right]}\end{array}$ & $\begin{array}{c}\text { Superficie } \\
\text { post } \\
\text { mejora } \\
{\left[\mathbf{m}^{2}\right]}\end{array}$ & $\begin{array}{c}\text { Transmitancia } \\
\text { post mejora } \\
{\left[\mathbf{W} / \mathbf{m}^{\mathbf{2}} \mathbf{K}\right]}\end{array}$ \\
\hline Cubierta con aire & Cubierta & 52.00 & 0.47 & 52.00 & 0.47 \\
\hline Muro de fachada Norte & Fachada & 27.18 & 0.54 & 27.18 & 0.54 \\
\hline Suelo con aire & Suelo & 52.00 & 2.95 & 52.00 & 2.95 \\
\hline Muro de fachada Sur & Fachada & 21.88 & 0.54 & 21.88 & 0.54 \\
\hline Muro de fachada Oeste & Fachada & 8.04 & 0.54 & 8.04 & 0.54 \\
\hline Muro de fachada Este & Fachada & 3.28 & 0.54 & 3.28 & 0.54 \\
\hline
\end{tabular}

Huecos y lucernarios

\begin{tabular}{|c|c|c|c|c|c|c|c|}
\hline Nombre & Tipo & $\begin{array}{c}\text { Superficie } \\
\text { actual } \\
{\left[\mathrm{m}^{2}\right]}\end{array}$ & $\begin{array}{c}\text { Transmitancia } \\
\text { actual del } \\
\text { hueco[W/m² } \\
\mathrm{K}]\end{array}$ & $\begin{array}{c}\text { Transmitancia } \\
\text { actual del } \\
\text { vidrio[W/m² } \\
\mathrm{K}]\end{array}$ & $\begin{array}{l}\text { Superficie } \\
\text { post } \\
\text { mejora } \\
{\left[\mathrm{m}^{2}\right]}\end{array}$ & $\begin{array}{c}\text { Transmitancia } \\
\text { post mejora } \\
{\left[\mathrm{W} / \mathrm{m}^{2} \mathrm{~K}\right]}\end{array}$ & $\begin{array}{c}\text { Transmitancia } \\
\text { post mejora } \\
\text { del vidrio } \\
{\left[\mathrm{W} / \mathrm{m}^{2} \mathrm{~K}\right]}\end{array}$ \\
\hline V1 & Hueco & 5.3 & 5.70 & 5.70 & 5.3 & 5.70 & 5.70 \\
\hline V3 & Hueco & 5.3 & 5.70 & 5.70 & 5.3 & 5.70 & 5.70 \\
\hline V4 & Hueco & 5.3 & 5.70 & 5.70 & 5.3 & 5.70 & 5.70 \\
\hline V2 & Hueco & 5.3 & 5.70 & 5.70 & 5.3 & 5.70 & 5.70 \\
\hline V5 & Hueco & 5.03 & 5.70 & 5.70 & 5.03 & 5.70 & 5.70 \\
\hline Pta & Hueco & 5.03 & 5.70 & 5.70 & 5.03 & 5.70 & 5.70 \\
\hline
\end{tabular}




\begin{tabular}{|c|c|c|c|c|c|}
\hline & & $\begin{array}{c}\text { Ref. } \\
\text { Catastral }\end{array}$ & 000000000 & $\begin{array}{c}\text { Versión } \\
\text { informe } \\
\text { asociado }\end{array}$ & $01 / 12 / 2015$ \\
\hline $\begin{array}{l}\text { Certificación } \\
\text { Energética } \\
\text { de Edificios }\end{array}$ & $\begin{array}{c}\text { Id. } \\
\text { Mejora }\end{array}$ & $\begin{array}{l}\text { Programa } \\
\text { y versión }\end{array}$ & CEXv2.1 & Fecha & $3 / 1 / 2004$ \\
\hline
\end{tabular}

\section{INSTALACIONES TÉRMICAS}

\section{Generadores de calefacción}

\begin{tabular}{|c|c|c|c|c|c|c|c|c|c|}
\hline \multirow[t]{2}{*}{ Nombre } & \multirow[t]{2}{*}{ Tipo } & $\begin{array}{r}\text { Potencia } \\
\text { nominal }\end{array}$ & $\begin{array}{c}\text { Rendi- } \\
\text { miento } \\
\text { Estacional }\end{array}$ & $\begin{array}{c}\text { Estimación } \\
\text { Energía } \\
\text { Consumida } \\
\text { anual }\end{array}$ & \multirow[t]{2}{*}{$\begin{array}{l}\text { Tipo post } \\
\text { mejora }\end{array}$} & $\begin{array}{c}\text { Potencia } \\
\text { nominal } \\
\text { post } \\
\text { mejora }\end{array}$ & $\begin{array}{c}\text { Rendimiento } \\
\text { estacional } \\
\text { post mejora }\end{array}$ & $\begin{array}{c}\text { Estimación } \\
\text { Energía } \\
\text { Consumida } \\
\text { anual Post } \\
\text { mejora }\end{array}$ & $\begin{array}{l}\text { Energía } \\
\text { anual } \\
\text { ahorrada }\end{array}$ \\
\hline & & {$[\mathrm{kW}]$} & [\%] & {$\left[\mathrm{kWh} / \mathrm{m}^{2} \mathrm{año}\right]$} & & {$[\mathrm{kW}]$} & [\%] & [kWh/m²año] & [kWh/m²año] \\
\hline $\begin{array}{l}\text { Calefacción y } \\
\text { refrigeración }\end{array}$ & $\begin{array}{c}\text { Bomba de } \\
\text { Calor - } \\
\text { Caudal Ref. } \\
\text { Variable }\end{array}$ & & $317.1 \%$ & - & $\begin{array}{c}\text { Bomba de } \\
\text { Calor - } \\
\text { Caudal Ref. } \\
\text { Variable }\end{array}$ & & $282.0 \%$ & - & - \\
\hline TOTALES & & & & & & & & & \\
\hline
\end{tabular}

\section{Generadores de refrigeración}

\begin{tabular}{|c|c|c|c|c|c|c|c|c|c|}
\hline \multirow[t]{2}{*}{ Nombre } & \multirow[t]{2}{*}{ Tipo } & $\begin{array}{r}\text { Potencia } \\
\text { nominal }\end{array}$ & $\begin{array}{c}\text { Rendi- } \\
\text { miento } \\
\text { Estacional }\end{array}$ & $\begin{array}{c}\text { Estimación } \\
\text { Energía } \\
\text { Consumida } \\
\text { anual }\end{array}$ & \multirow[t]{2}{*}{$\begin{array}{l}\text { Tipo post } \\
\text { mejora }\end{array}$} & $\begin{array}{c}\text { Potencia } \\
\text { nominal } \\
\text { post } \\
\text { mejora }\end{array}$ & $\begin{array}{c}\text { Rendimiento } \\
\text { estacional } \\
\text { post mejora }\end{array}$ & $\begin{array}{c}\text { Estimación } \\
\text { Energía } \\
\text { Consumida } \\
\text { anual Post } \\
\text { mejora }\end{array}$ & $\begin{array}{c}\text { Energía } \\
\text { anual } \\
\text { ahorrada }\end{array}$ \\
\hline & & {$[\mathrm{kW}]$} & {$[\%]$} & {$\left[\mathrm{kWh} / \mathrm{m}^{2} \mathrm{año}\right]$} & & {$[\mathrm{kW}]$} & {$[\%]$} & [kWh/m²año] & {$\left[\mathrm{kWh} / \mathrm{m}^{2} \mathrm{año}\right.$} \\
\hline $\begin{array}{l}\text { Calefacción y } \\
\text { refrigeración }\end{array}$ & $\begin{array}{c}\text { Bomba de } \\
\text { Calor - } \\
\text { Caudal Ref. } \\
\text { Variable }\end{array}$ & & $229.9 \%$ & - & $\begin{array}{c}\text { Bomba de } \\
\text { Calor - } \\
\text { Caudal Ref. } \\
\text { Variable }\end{array}$ & & $258.6 \%$ & - & - \\
\hline TOTALES & & - & & - & & - & & - & - \\
\hline
\end{tabular}

\section{Instalaciones de Agua Caliente Sanitaria}

\begin{tabular}{|c|c|c|c|c|c|c|c|c|c|}
\hline Nombre & Tipo & $\begin{array}{l}\text { Potencia } \\
\text { nominal }\end{array}$ & $\begin{array}{c}\text { Rendi- } \\
\text { miento } \\
\text { Estacional }\end{array}$ & $\begin{array}{c}\text { Estimación } \\
\text { Energía } \\
\text { Consumida } \\
\text { anual }\end{array}$ & $\begin{array}{c}\text { Tipo post } \\
\text { mejora }\end{array}$ & $\begin{array}{l}\text { Potencia } \\
\text { nominal } \\
\text { post } \\
\text { mejora }\end{array}$ & $\begin{array}{c}\text { Rendimiento } \\
\text { estacional } \\
\text { post mejora }\end{array}$ & $\begin{array}{c}\text { Estimación } \\
\text { Energía } \\
\text { Consumida } \\
\text { anual Post } \\
\text { mejora }\end{array}$ & $\begin{array}{l}\text { Energía } \\
\text { anual } \\
\text { ahorrada }\end{array}$ \\
\hline & & {$[\mathrm{kW}]$} & [\%] & {$\left[\mathrm{kWh} / \mathrm{m}^{2} \mathrm{año}\right]$} & & {$[\mathrm{kW}]$} & [\%] & [kWh/m²año] & [kWh/m²año] \\
\hline Equipo ACS & Efecto Joule & & $100.0 \%$ & - & Efecto Joule & & $100.0 \%$ & - & - \\
\hline TOTALES & & - & & - & & - & & - & - \\
\hline
\end{tabular}




\begin{tabular}{|c|c|c|c|c|c|}
\hline & $D E$ & $\begin{array}{c}\text { Ref. } \\
\text { Catastral }\end{array}$ & 000000000 & $\begin{array}{l}\text { Versión } \\
\text { informe } \\
\text { asociado }\end{array}$ & $01 / 12 / 2015$ \\
\hline $\begin{array}{c}\text { Certificación } \\
\text { Energética } \\
\text { de Edificioios }\end{array}$ & $\begin{array}{c}\text { Id. } \\
\text { Mejora }\end{array}$ & $\begin{array}{l}\text { Programa } \\
\text { y versión }\end{array}$ & CEXv2.1 & Fecha & $3 / 1 / 2004$ \\
\hline
\end{tabular}

\section{ENERGÍAS RENOVABLES}

\section{Eléctrica}

\begin{tabular}{|c|c|c|}
\hline Nombre & $\begin{array}{c}\text { Energía eléctrica generada y } \\
\text { autoconsumida [kWh/año] }\end{array}$ & $\begin{array}{c}\text { Energía eléctrica generada y } \\
\text { autoconsumida post mejora } \\
\text { [kWh/año] }\end{array}$ \\
\hline Incorporación/mejora de sistema fotovoltaico & - & 6460 \\
\hline TOTALES & - & 6460.0 \\
\hline
\end{tabular}




\begin{tabular}{|c|c|c|c|c|c|}
\hline & & $\begin{array}{c}\text { Ref. } \\
\text { Catastral }\end{array}$ & 000000000 & $\begin{array}{c}\text { Versión } \\
\text { informe } \\
\text { asociado }\end{array}$ & $01 / 12 / 2015$ \\
\hline $\begin{array}{l}\text { Certificación } \\
\text { Energética } \\
\text { de Edificios }\end{array}$ & $\begin{array}{c}\text { Id. } \\
\text { Mejora }\end{array}$ & $\begin{array}{l}\text { Programa } \\
\text { y versión }\end{array}$ & CEXv2.1 & Fecha & $3 / 1 / 2004$ \\
\hline
\end{tabular}

\section{Informe descriptivo de la medida de mejora}

\section{DENOMINACIÓN DE LA MEDIDA DE MEJORA}

Bomba de calor alto cop y eer con geotermia y vidrios activos + mejora aislamientos

\section{DESCRIPCIÓN DE LA MEDIDA DE MEJORA}

Características de la medida (modelo de equipos, materiales, parámetros característicos )

Coste estimado de la medida

Otros datos de interés

CALIFICACIÓN ENERGÉTICA GLOBAL

\begin{tabular}{|c|c|c|c|}
\hline $\begin{array}{r}\text { CONS } \\
\text { PRIMAF }\end{array}$ & $\begin{array}{l}\text { IA } \\
\text { 3LE }\end{array}$ & $\begin{array}{r}\text { EMISIO } \\
\text { [k }\end{array}$ & \\
\hline $\begin{array}{l}<35.8 \mathrm{~A} \\
35.8-58.1 \mathrm{~B}\end{array}$ & & $\frac{<8.1 \quad A}{8.1-13.1 \quad B}$ & \\
\hline $\begin{array}{lc}58.1-90.0 & C \\
90,0-138.4 & \text { D }\end{array}$ & $89.37 \mathrm{C}$ & 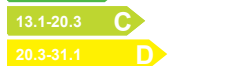 & $15.14 \mathrm{C}$ \\
\hline 138.4-254.1 $\quad$ F & & 31.1-58.3 $\quad$ E & \\
\hline $254.1-305.0$ & & 58.3-73.4 & \\
\hline$\geq 305.0$ & & $\geq 73.4$ & \\
\hline
\end{tabular}

CALIFICACIONES ENERGÉTICAS PARCIALES

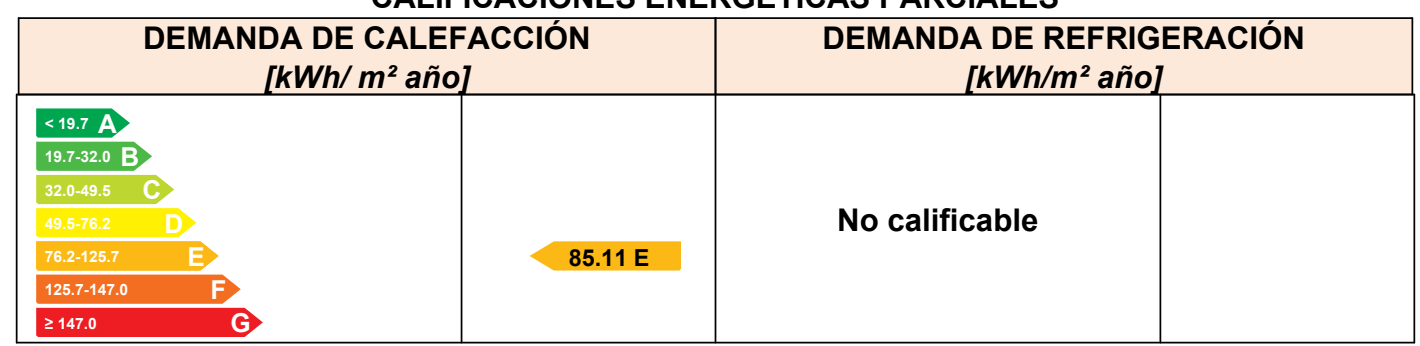




\begin{tabular}{|c|c|c|c|c|c|}
\hline & & $\begin{array}{c}\text { Ref. } \\
\text { Catastral }\end{array}$ & 000000000 & $\begin{array}{c}\text { Versión } \\
\text { informe } \\
\text { asociado }\end{array}$ & $01 / 12 / 2015$ \\
\hline $\begin{array}{l}\text { Certificación } \\
\text { Energética } \\
\text { de Edificios }\end{array}$ & $\begin{array}{c}\text { Id. } \\
\text { Mejora }\end{array}$ & $\begin{array}{l}\text { Programa } \\
\text { y versión }\end{array}$ & CEXv2.1 & Fecha & $3 / 1 / 2004$ \\
\hline
\end{tabular}

\section{ANALISÍS TÉCNICO}

\begin{tabular}{|c|c|c|c|c|c|c|c|c|c|c|c|c|c|c|c|}
\hline \multirow[b]{2}{*}{ Indicador } & \multicolumn{3}{|c|}{ Calefacción } & \multicolumn{3}{|c|}{ Refrigeración } & \multicolumn{3}{|c|}{ ACS } & \multicolumn{3}{|c|}{ Iluminación } & \multicolumn{3}{|c|}{ Total } \\
\hline & \multicolumn{2}{|c|}{ Valor } & $\begin{array}{l}\text { ahorro } \\
\text { respecto a } \\
\text { la situación } \\
\text { original }\end{array}$ & \multicolumn{2}{|c|}{ Valor } & $\begin{array}{c}\text { ahorro } \\
\text { respecto a } \\
\text { la situación } \\
\text { original }\end{array}$ & \multicolumn{2}{|c|}{ Valor } & $\begin{array}{c}\text { ahorro } \\
\text { respecto a } \\
\text { la situación } \\
\text { original }\end{array}$ & \multicolumn{2}{|c|}{ Valor } & $\begin{array}{l}\text { ahorro } \\
\text { respecto a } \\
\text { la situación } \\
\text { original }\end{array}$ & \multicolumn{2}{|c|}{ Valor } & $\begin{array}{c}\text { ahorro } \\
\text { respecto a } \\
\text { la situación } \\
\text { original }\end{array}$ \\
\hline $\begin{array}{l}\text { Consumo Energía } \\
\text { final }\left[\mathrm{kWh} / \mathrm{m}^{2} \text { año] }\right.\end{array}$ & \multicolumn{2}{|c|}{0.00} & $100.0 \%$ & \multicolumn{2}{|c|}{-} & $-\%$ & \multicolumn{2}{|c|}{45.74} & $0.0 \%$ & \multicolumn{2}{|c|}{-} & $-\%$ & \multicolumn{2}{|c|}{45.74} & $60.3 \%$ \\
\hline $\begin{array}{c}\text { Consumo Energía } \\
\text { primaria no renovable } \\
{\left[\mathrm{kWh} / \mathrm{m}^{2} \text { año] }\right.}\end{array}$ & 0.00 & A & $100.0 \%$ & - & - & $-\%$ & 89.37 & G & $0.0 \%$ & - & - & $-\%$ & 89.37 & C & $60.3 \%$ \\
\hline $\begin{array}{c}\text { Emisiones de CO2 } \\
{\left[\mathrm{kgCO} 2 / \mathrm{m}^{2} \text { año] }\right.}\end{array}$ & 0.00 & A & $100.0 \%$ & - & - & $-\%$ & 15.14 & G & $0.0 \%$ & - & - & $-\%$ & 15.14 & C & $60.3 \%$ \\
\hline $\begin{array}{c}\text { Demanda }\left[\mathrm{kWh} / \mathrm{m}^{2}\right. \\
\text { año] }\end{array}$ & 85.11 & $E$ & $57.1 \%$ & - & - & $-\%$ & & & & & & & & & \\
\hline
\end{tabular}

\section{ENVOLVENTE TÉRMICA}

\section{Cerramientos opacos}

\begin{tabular}{|c|c|c|c|c|c|}
\hline Nombre & Tipo & $\begin{array}{c}\text { Superficie } \\
\text { actual } \\
{\left[\mathbf{m}^{2}\right]}\end{array}$ & $\begin{array}{c}\text { Transmitancia } \\
\text { actual } \\
{\left[\mathbf{W} / \mathbf{m}^{\mathbf{2}} \mathbf{~ K}\right]}\end{array}$ & $\begin{array}{c}\text { Superficie } \\
\text { post } \\
\text { mejora } \\
{\left[\mathbf{m}^{2}\right]}\end{array}$ & $\begin{array}{c}\text { Transmitancia } \\
\text { post mejora } \\
{\left[\mathbf{W} / \mathbf{m}^{\mathbf{2}} \mathbf{K}\right]}\end{array}$ \\
\hline Cubierta con aire & Cubierta & 52.00 & 0.47 & 52.00 & 0.22 \\
\hline Muro de fachada Norte & Fachada & 27.18 & 0.54 & 27.18 & 0.27 \\
\hline Suelo con aire & Suelo & 52.00 & 2.95 & 52.00 & 0.34 \\
\hline Muro de fachada Sur & Fachada & 21.88 & 0.54 & 21.88 & 0.27 \\
\hline Muro de fachada Oeste & Fachada & 8.04 & 0.54 & 8.04 & 0.27 \\
\hline Muro de fachada Este & Fachada & 3.28 & 0.54 & 3.28 & 0.27 \\
\hline
\end{tabular}

Huecos y lucernarios

\begin{tabular}{|c|c|c|c|c|c|c|c|}
\hline Nombre & Tipo & $\begin{array}{c}\text { Superficie } \\
\text { actual } \\
{\left[\mathrm{m}^{2}\right]}\end{array}$ & $\begin{array}{c}\text { Transmitancia } \\
\text { actual del } \\
\text { hueco[W/m² } \\
\mathrm{K}]\end{array}$ & $\begin{array}{c}\text { Transmitancia } \\
\text { actual del } \\
\text { vidrio[W/m² } \\
\mathrm{K}]\end{array}$ & $\begin{array}{c}\text { Superficie } \\
\text { post } \\
\text { mejora } \\
{\left[\mathrm{m}^{2}\right]}\end{array}$ & $\begin{array}{c}\text { Transmitancia } \\
\text { post mejora } \\
{\left[\mathrm{W} / \mathrm{m}^{2} \mathrm{~K}\right]}\end{array}$ & $\begin{array}{c}\text { Transmitancia } \\
\text { post mejora } \\
\text { del vidrio } \\
{\left[\mathrm{W} / \mathrm{m}^{2} \mathrm{~K}\right]}\end{array}$ \\
\hline V1 & Hueco & 5.3 & 5.70 & 5.70 & 5.3 & 1.27 & 1.12 \\
\hline V3 & Hueco & 5.3 & 5.70 & 5.70 & 5.3 & 1.27 & 1.12 \\
\hline V4 & Hueco & 5.3 & 5.70 & 5.70 & 5.3 & 1.27 & 1.12 \\
\hline V2 & Hueco & 5.3 & 5.70 & 5.70 & 5.3 & 1.27 & 1.12 \\
\hline V5 & Hueco & 5.03 & 5.70 & 5.70 & 5.03 & 1.27 & 1.12 \\
\hline Pta & Hueco & 5.03 & 5.70 & 5.70 & 5.03 & 1.27 & 1.12 \\
\hline
\end{tabular}




\begin{tabular}{|c|c|c|c|c|c|}
\hline & & $\begin{array}{c}\text { Ref. } \\
\text { Catastral }\end{array}$ & 000000000 & $\begin{array}{c}\text { Versión } \\
\text { informe } \\
\text { asociado }\end{array}$ & $01 / 12 / 2015$ \\
\hline $\begin{array}{l}\text { Certificación } \\
\text { Energética } \\
\text { de Edificios }\end{array}$ & $\begin{array}{c}\text { Id. } \\
\text { Mejora }\end{array}$ & $\begin{array}{l}\text { Programa } \\
\text { y versión }\end{array}$ & CEXv2.1 & Fecha & $3 / 1 / 2004$ \\
\hline
\end{tabular}

\section{INSTALACIONES TÉRMICAS}

\section{Generadores de calefacción}

\begin{tabular}{|c|c|c|c|c|c|c|c|c|c|}
\hline \multirow[t]{2}{*}{ Nombre } & \multirow[t]{2}{*}{ Tipo } & $\begin{array}{r}\text { Potencia } \\
\text { nominal }\end{array}$ & $\begin{array}{c}\text { Rendi- } \\
\text { miento } \\
\text { Estacional }\end{array}$ & $\begin{array}{c}\text { Estimación } \\
\text { Energía } \\
\text { Consumida } \\
\text { anual }\end{array}$ & \multirow[t]{2}{*}{$\begin{array}{l}\text { Tipo post } \\
\text { mejora }\end{array}$} & $\begin{array}{c}\text { Potencia } \\
\text { nominal } \\
\text { post } \\
\text { mejora }\end{array}$ & $\begin{array}{c}\text { Rendimiento } \\
\text { estacional } \\
\text { post mejora }\end{array}$ & $\begin{array}{c}\text { Estimación } \\
\text { Energía } \\
\text { Consumida } \\
\text { anual Post } \\
\text { mejora }\end{array}$ & $\begin{array}{l}\text { Energía } \\
\text { anual } \\
\text { ahorrada }\end{array}$ \\
\hline & & {$[\mathrm{kW}]$} & [\%] & {$\left[\mathrm{kWh} / \mathrm{m}^{2} \mathrm{año}\right]$} & & {$[\mathrm{kW}]$} & [\%] & [kWh/m²año] & [kWh/m²año] \\
\hline $\begin{array}{l}\text { Calefacción y } \\
\text { refrigeración }\end{array}$ & $\begin{array}{c}\text { Bomba de } \\
\text { Calor - } \\
\text { Caudal Ref. } \\
\text { Variable }\end{array}$ & & $317.1 \%$ & - & $\begin{array}{c}\text { Bomba de } \\
\text { Calor - } \\
\text { Caudal Ref. } \\
\text { Variable }\end{array}$ & & $562.3 \%$ & - & - \\
\hline TOTALES & & & & & & & & & \\
\hline
\end{tabular}

\section{Generadores de refrigeración}

\begin{tabular}{|c|c|c|c|c|c|c|c|c|c|}
\hline \multirow[t]{2}{*}{ Nombre } & \multirow[t]{2}{*}{ Tipo } & $\begin{array}{r}\text { Potencia } \\
\text { nominal }\end{array}$ & $\begin{array}{c}\text { Rendi- } \\
\text { miento } \\
\text { Estacional }\end{array}$ & $\begin{array}{c}\text { Estimación } \\
\text { Energía } \\
\text { Consumida } \\
\text { anual }\end{array}$ & \multirow[t]{2}{*}{$\begin{array}{l}\text { Tipo post } \\
\text { mejora }\end{array}$} & $\begin{array}{c}\text { Potencia } \\
\text { nominal } \\
\text { post } \\
\text { mejora }\end{array}$ & $\begin{array}{c}\text { Rendimiento } \\
\text { estacional } \\
\text { post mejora }\end{array}$ & $\begin{array}{c}\text { Estimación } \\
\text { Energía } \\
\text { Consumida } \\
\text { anual Post } \\
\text { mejora }\end{array}$ & $\begin{array}{c}\text { Energía } \\
\text { anual } \\
\text { ahorrada }\end{array}$ \\
\hline & & {$[\mathrm{kW}]$} & {$[\%]$} & {$\left[\mathrm{kWh} / \mathrm{m}^{2} \mathrm{año}\right]$} & & {$[\mathrm{kW}]$} & {$[\%]$} & [kWh/m²año] & {$\left[\mathrm{kWh} / \mathrm{m}^{2} \mathrm{año}\right.$} \\
\hline $\begin{array}{l}\text { Calefacción y } \\
\text { refrigeración }\end{array}$ & $\begin{array}{c}\text { Bomba de } \\
\text { Calor - } \\
\text { Caudal Ref. } \\
\text { Variable }\end{array}$ & & $229.9 \%$ & - & $\begin{array}{c}\text { Bomba de } \\
\text { Calor - } \\
\text { Caudal Ref. } \\
\text { Variable }\end{array}$ & & $514.3 \%$ & - & - \\
\hline TOTALES & & - & & - & & - & & - & - \\
\hline
\end{tabular}

\section{Instalaciones de Agua Caliente Sanitaria}

\begin{tabular}{|c|c|c|c|c|c|c|c|c|c|}
\hline Nombre & Tipo & $\begin{array}{l}\text { Potencia } \\
\text { nominal }\end{array}$ & $\begin{array}{c}\text { Rendi- } \\
\text { miento } \\
\text { Estacional }\end{array}$ & $\begin{array}{c}\text { Estimación } \\
\text { Energía } \\
\text { Consumida } \\
\text { anual }\end{array}$ & $\begin{array}{c}\text { Tipo post } \\
\text { mejora }\end{array}$ & $\begin{array}{l}\text { Potencia } \\
\text { nominal } \\
\text { post } \\
\text { mejora }\end{array}$ & $\begin{array}{c}\text { Rendimiento } \\
\text { estacional } \\
\text { post mejora }\end{array}$ & $\begin{array}{c}\text { Estimación } \\
\text { Energía } \\
\text { Consumida } \\
\text { anual Post } \\
\text { mejora }\end{array}$ & $\begin{array}{l}\text { Energía } \\
\text { anual } \\
\text { ahorrada }\end{array}$ \\
\hline & & {$[\mathrm{kW}]$} & [\%] & {$\left[\mathrm{kWh} / \mathrm{m}^{2} \mathrm{año}\right]$} & & {$[\mathrm{kW}]$} & [\%] & [kWh/m²año] & [kWh/m²año] \\
\hline Equipo ACS & Efecto Joule & & $100.0 \%$ & - & Efecto Joule & & $100.0 \%$ & - & - \\
\hline TOTALES & & - & & - & & - & & - & - \\
\hline
\end{tabular}




\begin{tabular}{|c|c|c|c|c|c|}
\hline & DEN & $\begin{array}{c}\text { Ref. } \\
\text { Catastral }\end{array}$ & 000000000 & $\begin{array}{c}\text { Versión } \\
\text { informe } \\
\text { asociado }\end{array}$ & $01 / 12 / 2015$ \\
\hline $\begin{array}{c}\text { Certificación } \\
\text { Energatica } \\
\text { de Edificios } \\
\text { de Editios }\end{array}$ & $\begin{array}{c}\text { Id. } \\
\text { Mejora }\end{array}$ & $\begin{array}{l}\text { Programa } \\
\text { y versión }\end{array}$ & CEXv2.1 & Fecha & $3 / 1 / 2004$ \\
\hline
\end{tabular}

\section{ENERGÍAS RENOVABLES}

\section{Térmica}

\begin{tabular}{|c|c|c|c|c|}
\hline \multirow{2}{*}{ Nombre } & \multicolumn{3}{|c|}{$\begin{array}{c}\text { Consumo de Energía Final, cubierto en función } \\
\text { del servicio asociado [\%] }\end{array}$} & $\begin{array}{c}\text { Demanda de ACS } \\
\text { cubierta [\%] }\end{array}$ \\
\cline { 2 - 5 } & Calefacción & Refrigeración & ACS & \\
\hline- & - & - & - & - \\
\hline TOTALES & - & - & - & - \\
\hline
\end{tabular}

\section{Post mejora}

\begin{tabular}{|c|c|c|c|c|}
\hline \multirow{2}{*}{ Nombre } & \multicolumn{2}{|c|}{$\begin{array}{c}\text { Consumo de Energía Final, cubierto en función } \\
\text { del servicio asociado [\%] }\end{array}$} & $\begin{array}{c}\text { Demanda de ACS } \\
\text { cubierta [\%] }\end{array}$ \\
\cline { 2 - 5 } & Calefacción & Refrigeración & ACS & \\
\hline Sistema Geotérmico & 100 & 100 & - & - \\
\hline TOTALES & 100.0 & 100.0 & - & - \\
\hline
\end{tabular}




\begin{tabular}{|c|c|c|c|c|c|}
\hline & & $\begin{array}{c}\text { Ref. } \\
\text { Catastral }\end{array}$ & 000000000 & $\begin{array}{c}\text { Versión } \\
\text { informe } \\
\text { asociado }\end{array}$ & $01 / 12 / 2015$ \\
\hline $\begin{array}{l}\text { Certificación } \\
\text { Energética } \\
\text { de Edificios }\end{array}$ & $\begin{array}{c}\text { Id. } \\
\text { Mejora }\end{array}$ & $\begin{array}{l}\text { Programa } \\
\text { y versión }\end{array}$ & CEXv2.1 & Fecha & $3 / 1 / 2004$ \\
\hline
\end{tabular}

\section{Informe descriptivo de la medida de mejora}

\section{DENOMINACIÓN DE LA MEDIDA DE MEJORA}

Bomba de calor alto cop y eer con geotermia y vidrios activos

\section{DESCRIPCIÓN DE LA MEDIDA DE MEJORA}

Características de la medida (modelo de equipos, materiales, parámetros característicos )

Coste estimado de la medida

Otros datos de interés

CALIFICACIÓN ENERGÉTICA GLOBAL

\begin{tabular}{|c|c|c|c|}
\hline $\begin{array}{r}\text { CONS } \\
\text { PRIMAF }\end{array}$ & $\begin{array}{l}\text { IA } \\
\text { 3LE }\end{array}$ & $\begin{array}{r}\text { EMISIO } \\
\text { [k }\end{array}$ & \\
\hline $\begin{array}{l}<35.8 \mathrm{~A} \\
35.8-58.1 \mathrm{~B}\end{array}$ & & $\frac{<8.1 \quad A}{8.1-13.1 \quad B}$ & \\
\hline $\begin{array}{lc}58.1-90.0 & C \\
90,0-138.4 & \text { D }\end{array}$ & $89.37 \mathrm{C}$ & 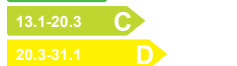 & $15.14 \mathrm{C}$ \\
\hline 138.4-254.1 $\quad$ F & & 31.1-58.3 $\quad$ E & \\
\hline $254.1-305.0$ & & 58.3-73.4 & \\
\hline$\geq 305.0$ & & $\geq 73.4$ & \\
\hline
\end{tabular}

CALIFICACIONES ENERGÉTICAS PARCIALES

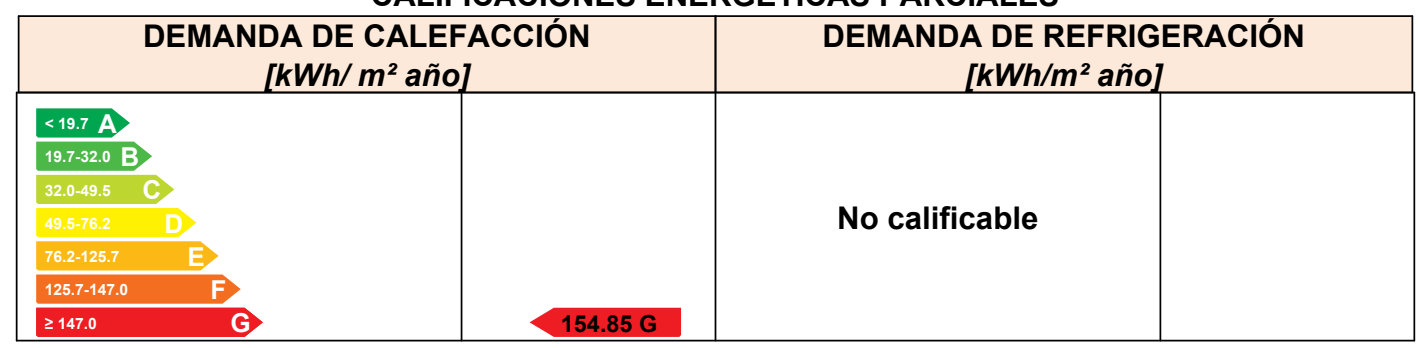




\begin{tabular}{|c|c|c|c|c|c|}
\hline & & $\begin{array}{c}\text { Ref. } \\
\text { Catastral }\end{array}$ & 000000000 & $\begin{array}{c}\text { Versión } \\
\text { informe } \\
\text { asociado }\end{array}$ & $01 / 12 / 2015$ \\
\hline $\begin{array}{l}\text { Certificación } \\
\text { Energética } \\
\text { de Edificios }\end{array}$ & $\begin{array}{c}\text { Id. } \\
\text { Mejora }\end{array}$ & $\begin{array}{l}\text { Programa } \\
\text { y versión }\end{array}$ & CEXv2.1 & Fecha & $3 / 1 / 2004$ \\
\hline
\end{tabular}

\section{ANALISÍS TÉCNICO}

\begin{tabular}{|c|c|c|c|c|c|c|c|c|c|c|c|c|c|c|c|}
\hline \multirow[b]{2}{*}{ Indicador } & \multicolumn{3}{|c|}{ Calefacción } & \multicolumn{3}{|c|}{ Refrigeración } & \multicolumn{3}{|c|}{ ACS } & \multicolumn{3}{|c|}{ Iluminación } & \multicolumn{3}{|c|}{ Total } \\
\hline & \multicolumn{2}{|c|}{ Valor } & $\begin{array}{l}\text { ahorro } \\
\text { respecto a } \\
\text { la situación } \\
\text { original }\end{array}$ & \multicolumn{2}{|c|}{ Valor } & $\begin{array}{c}\text { ahorro } \\
\text { respecto a } \\
\text { la situación } \\
\text { original }\end{array}$ & \multicolumn{2}{|c|}{ Valor } & $\begin{array}{c}\text { ahorro } \\
\text { respecto a } \\
\text { la situación } \\
\text { original }\end{array}$ & \multicolumn{2}{|c|}{ Valor } & $\begin{array}{l}\text { ahorro } \\
\text { respecto a } \\
\text { la situación } \\
\text { original }\end{array}$ & \multicolumn{2}{|c|}{ Valor } & $\begin{array}{c}\text { ahorro } \\
\text { respecto a } \\
\text { la situación } \\
\text { original }\end{array}$ \\
\hline $\begin{array}{l}\text { Consumo Energía } \\
\text { final }\left[\mathrm{kWh} / \mathrm{m}^{2} \text { año] }\right.\end{array}$ & \multicolumn{2}{|c|}{0.00} & $100.0 \%$ & \multicolumn{2}{|c|}{-} & $-\%$ & \multicolumn{2}{|c|}{45.74} & $0.0 \%$ & \multicolumn{2}{|c|}{-} & $-\%$ & \multicolumn{2}{|c|}{45.74} & $60.3 \%$ \\
\hline $\begin{array}{c}\text { Consumo Energía } \\
\text { primaria no renovable } \\
{\left[\mathrm{kWh} / \mathrm{m}^{2} \text { año] }\right.}\end{array}$ & 0.00 & A & $100.0 \%$ & - & - & $-\%$ & 89.37 & G & $0.0 \%$ & - & - & $-\%$ & 89.37 & C & $60.3 \%$ \\
\hline $\begin{array}{c}\text { Emisiones de CO2 } \\
{\left[\mathrm{kgCO} 2 / \mathrm{m}^{2} \text { año] }\right.}\end{array}$ & 0.00 & A & $100.0 \%$ & - & - & $-\%$ & 15.14 & G & $0.0 \%$ & - & - & $-\%$ & 15.14 & C & $60.3 \%$ \\
\hline $\begin{array}{l}\text { Demanda }\left[\mathrm{kWh} / \mathrm{m}^{2}\right. \\
\text { año] }\end{array}$ & 154.85 & G & $21.9 \%$ & - & - & $-\%$ & & & & & & & & & \\
\hline
\end{tabular}

\section{ENVOLVENTE TÉRMICA}

\section{Cerramientos opacos}

\begin{tabular}{|c|c|c|c|c|c|}
\hline Nombre & Tipo & $\begin{array}{c}\text { Superficie } \\
\text { actual } \\
{\left[\mathbf{m}^{2}\right]}\end{array}$ & $\begin{array}{c}\text { Transmitancia } \\
\text { actual } \\
{\left[\mathbf{W} / \mathbf{m}^{\mathbf{2}} \mathbf{~ K}\right]}\end{array}$ & $\begin{array}{c}\text { Superficie } \\
\text { post } \\
\text { mejora } \\
{\left[\mathbf{m}^{2}\right]}\end{array}$ & $\begin{array}{c}\text { Transmitancia } \\
\text { post mejora } \\
{\left[\mathbf{W} / \mathbf{m}^{\mathbf{2}} \mathbf{K}\right]}\end{array}$ \\
\hline Cubierta con aire & Cubierta & 52.00 & 0.47 & 52.00 & 0.47 \\
\hline Muro de fachada Norte & Fachada & 27.18 & 0.54 & 27.18 & 0.54 \\
\hline Suelo con aire & Suelo & 52.00 & 2.95 & 52.00 & 2.95 \\
\hline Muro de fachada Sur & Fachada & 21.88 & 0.54 & 21.88 & 0.54 \\
\hline Muro de fachada Oeste & Fachada & 8.04 & 0.54 & 8.04 & 0.54 \\
\hline Muro de fachada Este & Fachada & 3.28 & 0.54 & 3.28 & 0.54 \\
\hline
\end{tabular}

Huecos y lucernarios

\begin{tabular}{|c|c|c|c|c|c|c|c|}
\hline Nombre & Tipo & $\begin{array}{c}\text { Superficie } \\
\text { actual } \\
{\left[\mathrm{m}^{2}\right]}\end{array}$ & $\begin{array}{c}\text { Transmitancia } \\
\text { actual del } \\
\text { hueco[W/m² } \\
\mathrm{K}]\end{array}$ & $\begin{array}{c}\text { Transmitancia } \\
\text { actual del } \\
\text { vidrio[W/m² } \\
\mathrm{K}]\end{array}$ & $\begin{array}{c}\text { Superficie } \\
\text { post } \\
\text { mejora } \\
{\left[\mathrm{m}^{2}\right]}\end{array}$ & $\begin{array}{c}\text { Transmitancia } \\
\text { post mejora } \\
{\left[\mathrm{W} / \mathrm{m}^{2} \mathrm{~K}\right]}\end{array}$ & $\begin{array}{c}\text { Transmitancia } \\
\text { post mejora } \\
\text { del vidrio } \\
{\left[\mathrm{W} / \mathrm{m}^{2} \mathrm{~K}\right]}\end{array}$ \\
\hline V1 & Hueco & 5.3 & 5.70 & 5.70 & 5.3 & 1.27 & 1.12 \\
\hline V3 & Hueco & 5.3 & 5.70 & 5.70 & 5.3 & 1.27 & 1.12 \\
\hline V4 & Hueco & 5.3 & 5.70 & 5.70 & 5.3 & 1.27 & 1.12 \\
\hline V2 & Hueco & 5.3 & 5.70 & 5.70 & 5.3 & 1.27 & 1.12 \\
\hline V5 & Hueco & 5.03 & 5.70 & 5.70 & 5.03 & 1.27 & 1.12 \\
\hline Pta & Hueco & 5.03 & 5.70 & 5.70 & 5.03 & 1.27 & 1.12 \\
\hline
\end{tabular}




\begin{tabular}{|c|c|c|c|c|c|}
\hline & & $\begin{array}{c}\text { Ref. } \\
\text { Catastral }\end{array}$ & 000000000 & $\begin{array}{c}\text { Versión } \\
\text { informe } \\
\text { asociado }\end{array}$ & $01 / 12 / 2015$ \\
\hline $\begin{array}{l}\text { Certificación } \\
\text { Energética } \\
\text { de Edificios }\end{array}$ & $\begin{array}{c}\text { Id. } \\
\text { Mejora }\end{array}$ & $\begin{array}{l}\text { Programa } \\
\text { y versión }\end{array}$ & CEXv2.1 & Fecha & $3 / 1 / 2004$ \\
\hline
\end{tabular}

\section{INSTALACIONES TÉRMICAS}

\section{Generadores de calefacción}

\begin{tabular}{|c|c|c|c|c|c|c|c|c|c|}
\hline \multirow[t]{2}{*}{ Nombre } & \multirow[t]{2}{*}{ Tipo } & $\begin{array}{r}\text { Potencia } \\
\text { nominal }\end{array}$ & $\begin{array}{c}\text { Rendi- } \\
\text { miento } \\
\text { Estacional }\end{array}$ & $\begin{array}{c}\text { Estimación } \\
\text { Energía } \\
\text { Consumida } \\
\text { anual }\end{array}$ & \multirow[t]{2}{*}{$\begin{array}{l}\text { Tipo post } \\
\text { mejora }\end{array}$} & $\begin{array}{c}\text { Potencia } \\
\text { nominal } \\
\text { post } \\
\text { mejora }\end{array}$ & $\begin{array}{c}\text { Rendimiento } \\
\text { estacional } \\
\text { post mejora }\end{array}$ & $\begin{array}{c}\text { Estimación } \\
\text { Energía } \\
\text { Consumida } \\
\text { anual Post } \\
\text { mejora }\end{array}$ & $\begin{array}{l}\text { Energía } \\
\text { anual } \\
\text { ahorrada }\end{array}$ \\
\hline & & {$[\mathrm{kW}]$} & [\%] & {$\left[\mathrm{kWh} / \mathrm{m}^{2} \mathrm{año}\right]$} & & {$[\mathrm{kW}]$} & [\%] & [kWh/m²año] & [kWh/m²año] \\
\hline $\begin{array}{l}\text { Calefacción y } \\
\text { refrigeración }\end{array}$ & $\begin{array}{c}\text { Bomba de } \\
\text { Calor - } \\
\text { Caudal Ref. } \\
\text { Variable }\end{array}$ & & $317.1 \%$ & - & $\begin{array}{c}\text { Bomba de } \\
\text { Calor - } \\
\text { Caudal Ref. } \\
\text { Variable }\end{array}$ & & $562.3 \%$ & - & - \\
\hline TOTALES & & & & & & & & & \\
\hline
\end{tabular}

\section{Generadores de refrigeración}

\begin{tabular}{|c|c|c|c|c|c|c|c|c|c|}
\hline \multirow[t]{2}{*}{ Nombre } & \multirow[t]{2}{*}{ Tipo } & $\begin{array}{r}\text { Potencia } \\
\text { nominal }\end{array}$ & $\begin{array}{c}\text { Rendi- } \\
\text { miento } \\
\text { Estacional }\end{array}$ & $\begin{array}{c}\text { Estimación } \\
\text { Energía } \\
\text { Consumida } \\
\text { anual }\end{array}$ & \multirow[t]{2}{*}{$\begin{array}{l}\text { Tipo post } \\
\text { mejora }\end{array}$} & $\begin{array}{c}\text { Potencia } \\
\text { nominal } \\
\text { post } \\
\text { mejora }\end{array}$ & $\begin{array}{c}\text { Rendimiento } \\
\text { estacional } \\
\text { post mejora }\end{array}$ & $\begin{array}{c}\text { Estimación } \\
\text { Energía } \\
\text { Consumida } \\
\text { anual Post } \\
\text { mejora }\end{array}$ & $\begin{array}{c}\text { Energía } \\
\text { anual } \\
\text { ahorrada }\end{array}$ \\
\hline & & {$[\mathrm{kW}]$} & {$[\%]$} & {$\left[\mathrm{kWh} / \mathrm{m}^{2} \mathrm{año}\right]$} & & {$[\mathrm{kW}]$} & {$[\%]$} & [kWh/m²año] & {$\left[\mathrm{kWh} / \mathrm{m}^{2} \mathrm{año}\right.$} \\
\hline $\begin{array}{l}\text { Calefacción y } \\
\text { refrigeración }\end{array}$ & $\begin{array}{c}\text { Bomba de } \\
\text { Calor - } \\
\text { Caudal Ref. } \\
\text { Variable }\end{array}$ & & $229.9 \%$ & - & $\begin{array}{c}\text { Bomba de } \\
\text { Calor - } \\
\text { Caudal Ref. } \\
\text { Variable }\end{array}$ & & $514.3 \%$ & - & - \\
\hline TOTALES & & - & & - & & - & & - & - \\
\hline
\end{tabular}

\section{Instalaciones de Agua Caliente Sanitaria}

\begin{tabular}{|c|c|c|c|c|c|c|c|c|c|}
\hline Nombre & Tipo & $\begin{array}{l}\text { Potencia } \\
\text { nominal }\end{array}$ & $\begin{array}{c}\text { Rendi- } \\
\text { miento } \\
\text { Estacional }\end{array}$ & $\begin{array}{c}\text { Estimación } \\
\text { Energía } \\
\text { Consumida } \\
\text { anual }\end{array}$ & $\begin{array}{c}\text { Tipo post } \\
\text { mejora }\end{array}$ & $\begin{array}{l}\text { Potencia } \\
\text { nominal } \\
\text { post } \\
\text { mejora }\end{array}$ & $\begin{array}{c}\text { Rendimiento } \\
\text { estacional } \\
\text { post mejora }\end{array}$ & $\begin{array}{c}\text { Estimación } \\
\text { Energía } \\
\text { Consumida } \\
\text { anual Post } \\
\text { mejora }\end{array}$ & $\begin{array}{l}\text { Energía } \\
\text { anual } \\
\text { ahorrada }\end{array}$ \\
\hline & & {$[\mathrm{kW}]$} & [\%] & {$\left[\mathrm{kWh} / \mathrm{m}^{2} \mathrm{año}\right]$} & & {$[\mathrm{kW}]$} & [\%] & [kWh/m²año] & [kWh/m²año] \\
\hline Equipo ACS & Efecto Joule & & $100.0 \%$ & - & Efecto Joule & & $100.0 \%$ & - & - \\
\hline TOTALES & & - & & - & & - & & - & - \\
\hline
\end{tabular}




\begin{tabular}{|c|c|c|c|c|c|}
\hline & DEN & $\begin{array}{c}\text { Ref. } \\
\text { Catastral }\end{array}$ & 000000000 & $\begin{array}{c}\text { Versión } \\
\text { informe } \\
\text { asociado }\end{array}$ & $01 / 12 / 2015$ \\
\hline $\begin{array}{c}\text { Certificación } \\
\text { Energatica } \\
\text { de Edificios } \\
\text { de Editios }\end{array}$ & $\begin{array}{c}\text { Id. } \\
\text { Mejora }\end{array}$ & $\begin{array}{l}\text { Programa } \\
\text { y versión }\end{array}$ & CEXv2.1 & Fecha & $3 / 1 / 2004$ \\
\hline
\end{tabular}

\section{ENERGÍAS RENOVABLES}

\section{Térmica}

\begin{tabular}{|c|c|c|c|c|}
\hline \multirow{2}{*}{ Nombre } & \multicolumn{3}{|c|}{$\begin{array}{c}\text { Consumo de Energía Final, cubierto en función } \\
\text { del servicio asociado [\%] }\end{array}$} & $\begin{array}{c}\text { Demanda de ACS } \\
\text { cubierta [\%] }\end{array}$ \\
\cline { 2 - 5 } & Calefacción & Refrigeración & ACS & \\
\hline- & - & - & - & - \\
\hline TOTALES & - & - & - & - \\
\hline
\end{tabular}

\section{Post mejora}

\begin{tabular}{|c|c|c|c|c|}
\hline \multirow{2}{*}{ Nombre } & \multicolumn{2}{|c|}{$\begin{array}{c}\text { Consumo de Energía Final, cubierto en función } \\
\text { del servicio asociado [\%] }\end{array}$} & $\begin{array}{c}\text { Demanda de ACS } \\
\text { cubierta [\%] }\end{array}$ \\
\cline { 2 - 5 } & Calefacción & Refrigeración & ACS & \\
\hline Sistema Geotérmico & 100 & 100 & - & - \\
\hline TOTALES & 100.0 & 100.0 & - & - \\
\hline
\end{tabular}




\begin{tabular}{|c|c|c|c|c|c|}
\hline & & $\begin{array}{c}\text { Ref. } \\
\text { Catastral }\end{array}$ & 000000000 & $\begin{array}{c}\text { Versión } \\
\text { informe } \\
\text { asociado }\end{array}$ & $01 / 12 / 2015$ \\
\hline $\begin{array}{l}\text { Certificación } \\
\text { Energética } \\
\text { de Edificios }\end{array}$ & $\begin{array}{c}\text { Id. } \\
\text { Mejora }\end{array}$ & $\begin{array}{l}\text { Programa } \\
\text { y versión }\end{array}$ & CEXv2.1 & Fecha & $4 / 1 / 2004$ \\
\hline
\end{tabular}

\section{Informe descriptivo de la medida de mejora}

\section{DENOMINACIÓN DE LA MEDIDA DE MEJORA}

Fv + Bomba de calor alto cop y eer con geotermia y vidrios activos

\section{DESCRIPCIÓN DE LA MEDIDA DE MEJORA}

Características de la medida (modelo de equipos, materiales, parámetros característicos )

Coste estimado de la medida

Otros datos de interés

CALIFICACIÓN ENERGÉTICA GLOBAL

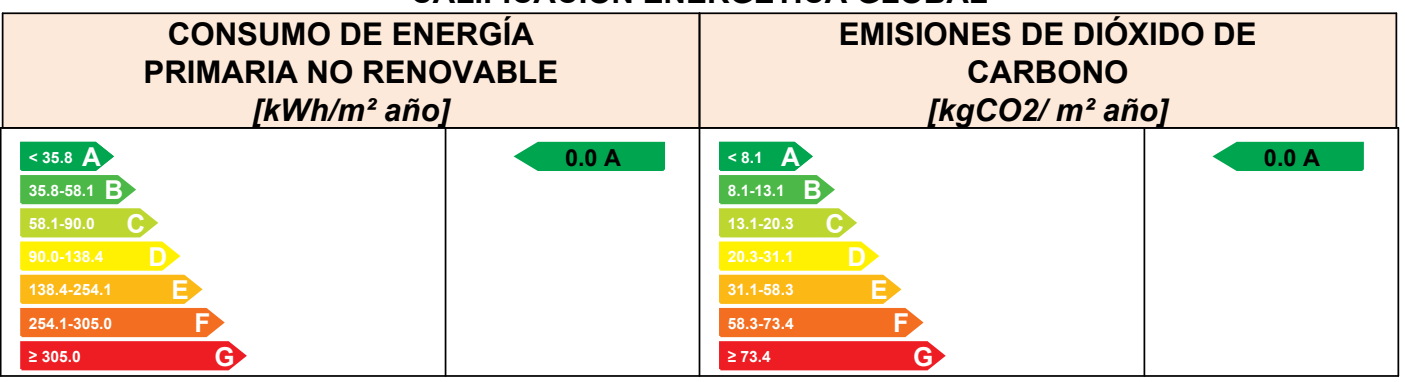

CALIFICACIONES ENERGÉTICAS PARCIALES

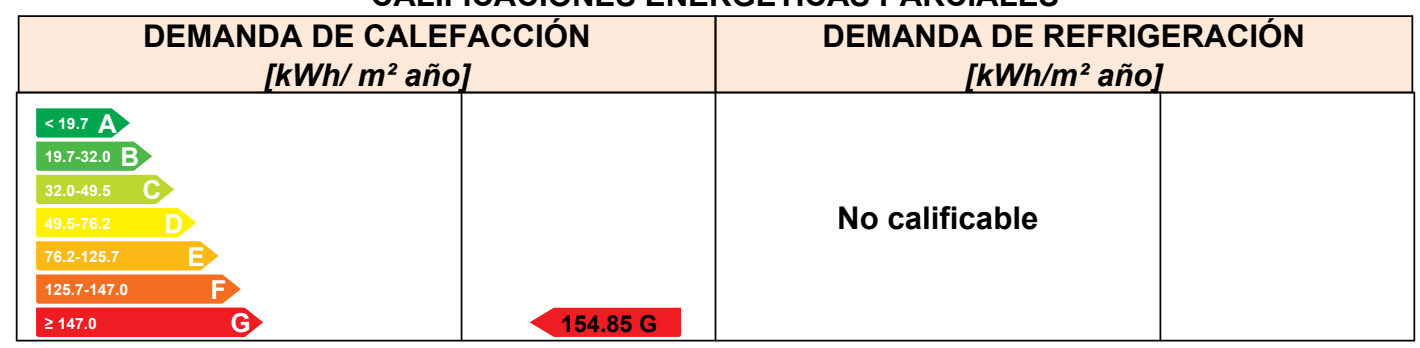




\begin{tabular}{|c|c|c|c|c|c|}
\hline & & $\begin{array}{c}\text { Ref. } \\
\text { Catastral }\end{array}$ & 000000000 & $\begin{array}{c}\text { Versión } \\
\text { informe } \\
\text { asociado }\end{array}$ & $01 / 12 / 2015$ \\
\hline $\begin{array}{l}\text { Certificación } \\
\text { Energética } \\
\text { de Edificios }\end{array}$ & $\begin{array}{c}\text { Id. } \\
\text { Mejora }\end{array}$ & $\begin{array}{l}\text { Programa } \\
\text { y versión }\end{array}$ & CEXv2.1 & Fecha & $4 / 1 / 2004$ \\
\hline
\end{tabular}

\section{ANALISÍS TÉCNICO}

\begin{tabular}{|c|c|c|c|c|c|c|c|c|c|c|c|c|c|c|c|}
\hline \multirow[b]{2}{*}{ Indicador } & \multicolumn{3}{|c|}{ Calefacción } & \multicolumn{3}{|c|}{ Refrigeración } & \multicolumn{3}{|c|}{ ACS } & \multicolumn{3}{|c|}{ Iluminación } & \multicolumn{3}{|c|}{ Total } \\
\hline & \multicolumn{2}{|c|}{ Valor } & $\begin{array}{l}\text { ahorro } \\
\text { respecto a } \\
\text { la situación } \\
\text { original }\end{array}$ & \multicolumn{2}{|c|}{ Valor } & $\begin{array}{c}\text { ahorro } \\
\text { respecto a } \\
\text { la situación } \\
\text { original }\end{array}$ & \multicolumn{2}{|c|}{ Valor } & $\begin{array}{c}\text { ahorro } \\
\text { respecto a } \\
\text { la situación } \\
\text { original }\end{array}$ & \multicolumn{2}{|c|}{ Valor } & $\begin{array}{l}\text { ahorro } \\
\text { respecto a } \\
\text { la situación } \\
\text { original }\end{array}$ & \multicolumn{2}{|c|}{ Valor } & $\begin{array}{c}\text { ahorro } \\
\text { respecto a } \\
\text { la situación } \\
\text { original }\end{array}$ \\
\hline $\begin{array}{l}\text { Consumo Energía } \\
\text { final }\left[\mathrm{kWh} / \mathrm{m}^{2} \text { año] }\right.\end{array}$ & \multicolumn{2}{|c|}{0.00} & $100.0 \%$ & \multicolumn{2}{|c|}{-} & $-\%$ & \multicolumn{2}{|c|}{45.74} & $0.0 \%$ & \multicolumn{2}{|c|}{-} & $-\%$ & \multicolumn{2}{|c|}{-36.57} & $131.7 \%$ \\
\hline $\begin{array}{c}\text { Consumo Energía } \\
\text { primaria no renovable } \\
{\left[\mathrm{kWh} / \mathrm{m}^{2} \text { año] }\right.}\end{array}$ & 0.00 & A & $100.0 \%$ & - & - & $-\%$ & 89.37 & G & $0.0 \%$ & - & - & $-\%$ & 0.00 & A & $100.0 \%$ \\
\hline $\begin{array}{c}\text { Emisiones de CO2 } \\
{\left[\mathrm{kgCO} 2 / \mathrm{m}^{2} \text { año] }\right.}\end{array}$ & 0.00 & A & $100.0 \%$ & - & - & $-\%$ & 15.14 & $G$ & $0.0 \%$ & - & - & $-\%$ & 0.00 & A & $100.0 \%$ \\
\hline $\begin{array}{l}\text { Demanda }\left[\mathrm{kWh} / \mathrm{m}^{2}\right. \\
\text { año] }\end{array}$ & 154.85 & G & $21.9 \%$ & - & - & $-\%$ & & & & & & & & & \\
\hline
\end{tabular}

\section{ENVOLVENTE TÉRMICA}

\section{Cerramientos opacos}

\begin{tabular}{|c|c|c|c|c|c|}
\hline Nombre & Tipo & $\begin{array}{c}\text { Superficie } \\
\text { actual } \\
{\left[\mathbf{m}^{2}\right]}\end{array}$ & $\begin{array}{c}\text { Transmitancia } \\
\text { actual } \\
{\left[\mathbf{W} / \mathbf{m}^{\mathbf{2}} \mathbf{~ K}\right]}\end{array}$ & $\begin{array}{c}\text { Superficie } \\
\text { post } \\
\text { mejora } \\
{\left[\mathbf{m}^{2}\right]}\end{array}$ & $\begin{array}{c}\text { Transmitancia } \\
\text { post mejora } \\
{\left[\mathbf{W} / \mathbf{m}^{\mathbf{2}} \mathbf{K}\right]}\end{array}$ \\
\hline Cubierta con aire & Cubierta & 52.00 & 0.47 & 52.00 & 0.47 \\
\hline Muro de fachada Norte & Fachada & 27.18 & 0.54 & 27.18 & 0.54 \\
\hline Suelo con aire & Suelo & 52.00 & 2.95 & 52.00 & 2.95 \\
\hline Muro de fachada Sur & Fachada & 21.88 & 0.54 & 21.88 & 0.54 \\
\hline Muro de fachada Oeste & Fachada & 8.04 & 0.54 & 8.04 & 0.54 \\
\hline Muro de fachada Este & Fachada & 3.28 & 0.54 & 3.28 & 0.54 \\
\hline
\end{tabular}

Huecos y lucernarios

\begin{tabular}{|c|c|c|c|c|c|c|c|}
\hline Nombre & Tipo & $\begin{array}{c}\text { Superficie } \\
\text { actual } \\
{\left[\mathrm{m}^{2}\right]}\end{array}$ & $\begin{array}{c}\text { Transmitancia } \\
\text { actual del } \\
\text { hueco[W/m² } \\
\mathrm{K}]\end{array}$ & $\begin{array}{c}\text { Transmitancia } \\
\text { actual del } \\
\text { vidrio[W/m² } \\
\mathrm{K}]\end{array}$ & $\begin{array}{c}\text { Superficie } \\
\text { post } \\
\text { mejora } \\
{\left[\mathrm{m}^{2}\right]}\end{array}$ & $\begin{array}{c}\text { Transmitancia } \\
\text { post mejora } \\
{\left[\mathrm{W} / \mathrm{m}^{2} \mathrm{~K}\right]}\end{array}$ & $\begin{array}{c}\text { Transmitancia } \\
\text { post mejora } \\
\text { del vidrio } \\
{\left[\mathrm{W} / \mathrm{m}^{2} \mathrm{~K}\right]}\end{array}$ \\
\hline V1 & Hueco & 5.3 & 5.70 & 5.70 & 5.3 & 1.27 & 1.12 \\
\hline V3 & Hueco & 5.3 & 5.70 & 5.70 & 5.3 & 1.27 & 1.12 \\
\hline V4 & Hueco & 5.3 & 5.70 & 5.70 & 5.3 & 1.27 & 1.12 \\
\hline V2 & Hueco & 5.3 & 5.70 & 5.70 & 5.3 & 1.27 & 1.12 \\
\hline V5 & Hueco & 5.03 & 5.70 & 5.70 & 5.03 & 1.27 & 1.12 \\
\hline Pta & Hueco & 5.03 & 5.70 & 5.70 & 5.03 & 1.27 & 1.12 \\
\hline
\end{tabular}




\begin{tabular}{|c|c|c|c|c|c|}
\hline & & $\begin{array}{c}\text { Ref. } \\
\text { Catastral }\end{array}$ & 000000000 & $\begin{array}{c}\text { Versión } \\
\text { informe } \\
\text { asociado }\end{array}$ & $01 / 12 / 2015$ \\
\hline $\begin{array}{l}\text { Certificación } \\
\text { Energética } \\
\text { de Edificios }\end{array}$ & $\begin{array}{c}\text { Id. } \\
\text { Mejora }\end{array}$ & $\begin{array}{l}\text { Programa } \\
\text { y versión }\end{array}$ & CEXv2.1 & Fecha & $4 / 1 / 2004$ \\
\hline
\end{tabular}

\section{INSTALACIONES TÉRMICAS}

\section{Generadores de calefacción}

\begin{tabular}{|c|c|c|c|c|c|c|c|c|c|}
\hline \multirow[t]{2}{*}{ Nombre } & \multirow[t]{2}{*}{ Tipo } & $\begin{array}{r}\text { Potencia } \\
\text { nominal }\end{array}$ & $\begin{array}{c}\text { Rendi- } \\
\text { miento } \\
\text { Estacional }\end{array}$ & $\begin{array}{c}\text { Estimación } \\
\text { Energía } \\
\text { Consumida } \\
\text { anual }\end{array}$ & \multirow[t]{2}{*}{$\begin{array}{l}\text { Tipo post } \\
\text { mejora }\end{array}$} & $\begin{array}{c}\text { Potencia } \\
\text { nominal } \\
\text { post } \\
\text { mejora }\end{array}$ & $\begin{array}{c}\text { Rendimiento } \\
\text { estacional } \\
\text { post mejora }\end{array}$ & $\begin{array}{c}\text { Estimación } \\
\text { Energía } \\
\text { Consumida } \\
\text { anual Post } \\
\text { mejora }\end{array}$ & $\begin{array}{l}\text { Energía } \\
\text { anual } \\
\text { ahorrada }\end{array}$ \\
\hline & & {$[\mathrm{kW}]$} & [\%] & {$\left[\mathrm{kWh} / \mathrm{m}^{2} \mathrm{año}\right]$} & & {$[\mathrm{kW}]$} & [\%] & [kWh/m²año] & [kWh/m²año] \\
\hline $\begin{array}{l}\text { Calefacción y } \\
\text { refrigeración }\end{array}$ & $\begin{array}{c}\text { Bomba de } \\
\text { Calor - } \\
\text { Caudal Ref. } \\
\text { Variable }\end{array}$ & & $317.1 \%$ & - & $\begin{array}{c}\text { Bomba de } \\
\text { Calor - } \\
\text { Caudal Ref. } \\
\text { Variable }\end{array}$ & & $562.3 \%$ & - & - \\
\hline TOTALES & & & & & & & & & \\
\hline
\end{tabular}

\section{Generadores de refrigeración}

\begin{tabular}{|c|c|c|c|c|c|c|c|c|c|}
\hline \multirow[t]{2}{*}{ Nombre } & \multirow[t]{2}{*}{ Tipo } & $\begin{array}{r}\text { Potencia } \\
\text { nominal }\end{array}$ & $\begin{array}{c}\text { Rendi- } \\
\text { miento } \\
\text { Estacional }\end{array}$ & $\begin{array}{c}\text { Estimación } \\
\text { Energía } \\
\text { Consumida } \\
\text { anual }\end{array}$ & \multirow[t]{2}{*}{$\begin{array}{l}\text { Tipo post } \\
\text { mejora }\end{array}$} & $\begin{array}{c}\text { Potencia } \\
\text { nominal } \\
\text { post } \\
\text { mejora }\end{array}$ & $\begin{array}{c}\text { Rendimiento } \\
\text { estacional } \\
\text { post mejora }\end{array}$ & $\begin{array}{c}\text { Estimación } \\
\text { Energía } \\
\text { Consumida } \\
\text { anual Post } \\
\text { mejora }\end{array}$ & $\begin{array}{c}\text { Energía } \\
\text { anual } \\
\text { ahorrada }\end{array}$ \\
\hline & & {$[\mathrm{kW}]$} & {$[\%]$} & {$\left[\mathrm{kWh} / \mathrm{m}^{2} \mathrm{año}\right]$} & & {$[\mathrm{kW}]$} & {$[\%]$} & [kWh/m²año] & {$\left[\mathrm{kWh} / \mathrm{m}^{2} \mathrm{año}\right.$} \\
\hline $\begin{array}{l}\text { Calefacción y } \\
\text { refrigeración }\end{array}$ & $\begin{array}{c}\text { Bomba de } \\
\text { Calor - } \\
\text { Caudal Ref. } \\
\text { Variable }\end{array}$ & & $229.9 \%$ & - & $\begin{array}{c}\text { Bomba de } \\
\text { Calor - } \\
\text { Caudal Ref. } \\
\text { Variable }\end{array}$ & & $514.3 \%$ & - & - \\
\hline TOTALES & & - & & - & & - & & - & - \\
\hline
\end{tabular}

\section{Instalaciones de Agua Caliente Sanitaria}

\begin{tabular}{|c|c|c|c|c|c|c|c|c|c|}
\hline Nombre & Tipo & $\begin{array}{l}\text { Potencia } \\
\text { nominal }\end{array}$ & $\begin{array}{c}\text { Rendi- } \\
\text { miento } \\
\text { Estacional }\end{array}$ & $\begin{array}{c}\text { Estimación } \\
\text { Energía } \\
\text { Consumida } \\
\text { anual }\end{array}$ & $\begin{array}{c}\text { Tipo post } \\
\text { mejora }\end{array}$ & $\begin{array}{l}\text { Potencia } \\
\text { nominal } \\
\text { post } \\
\text { mejora }\end{array}$ & $\begin{array}{c}\text { Rendimiento } \\
\text { estacional } \\
\text { post mejora }\end{array}$ & $\begin{array}{c}\text { Estimación } \\
\text { Energía } \\
\text { Consumida } \\
\text { anual Post } \\
\text { mejora }\end{array}$ & $\begin{array}{l}\text { Energía } \\
\text { anual } \\
\text { ahorrada }\end{array}$ \\
\hline & & {$[\mathrm{kW}]$} & [\%] & {$\left[\mathrm{kWh} / \mathrm{m}^{2} \mathrm{año}\right]$} & & {$[\mathrm{kW}]$} & [\%] & [kWh/m²año] & [kWh/m²año] \\
\hline Equipo ACS & Efecto Joule & & $100.0 \%$ & - & Efecto Joule & & $100.0 \%$ & - & - \\
\hline TOTALES & & - & & - & & - & & - & - \\
\hline
\end{tabular}




\begin{tabular}{|c|c|c|c|c|c|}
\hline & & $\begin{array}{c}\text { Ref. } \\
\text { Catastral }\end{array}$ & 000000000 & $\begin{array}{c}\text { Versión } \\
\text { informe } \\
\text { asociado }\end{array}$ & $01 / 12 / 2015$ \\
\hline $\begin{array}{l}\text { Certificación } \\
\text { Energética } \\
\text { de Edificios }\end{array}$ & $\begin{array}{c}\text { Id. } \\
\text { Mejora }\end{array}$ & $\begin{array}{l}\text { Programa } \\
\text { y versión }\end{array}$ & CEXv2.1 & Fecha & $4 / 1 / 2004$ \\
\hline
\end{tabular}

\section{ENERGÍAS RENOVABLES}

\section{Térmica}

\begin{tabular}{|c|c|c|c|c|}
\hline \multirow{2}{*}{ Nombre } & \multicolumn{3}{|c|}{$\begin{array}{c}\text { Consumo de Energía Final, cubierto en función } \\
\text { del servicio asociado [\%] }\end{array}$} & $\begin{array}{c}\text { Demanda de ACS } \\
\text { cubierta [\%] }\end{array}$ \\
\cline { 2 - 5 } & Calefacción & Refrigeración & ACS & \\
\hline- & - & - & - & - \\
\hline TOTALES & - & - & - & - \\
\hline
\end{tabular}

Post mejora

\begin{tabular}{|c|c|c|c|c|}
\hline \multirow{2}{*}{ Nombre } & \multicolumn{2}{|c|}{$\begin{array}{c}\text { Consumo de Energía Final, cubierto en función } \\
\text { del servicio asociado [\%] }\end{array}$} & $\begin{array}{c}\text { Demanda de ACS } \\
\text { cubierta [\%] }\end{array}$ \\
\cline { 2 - 5 } & Calefacción & Refrigeración & ACS & \\
\hline Fv+ Sistema Geotérmico & 100 & 100 & - & - \\
\hline TOTALES & 100.0 & 100.0 & - & - \\
\hline
\end{tabular}

\section{Eléctrica}

\begin{tabular}{|c|c|c|}
\hline Nombre & $\begin{array}{c}\text { Energía eléctrica generada y } \\
\text { autoconsumida [kWh/año] }\end{array}$ & $\begin{array}{c}\text { Energía eléctrica generada y } \\
\text { autoconsumida post mejora } \\
\text { [kWh/año] }\end{array}$ \\
\hline Fv+ Sistema Geotérmico & - & 6460 \\
\hline TOTALES & - & 6460.0 \\
\hline
\end{tabular}


A.6.8

Zona Climática Dsb (Koppen)/ E1 (CTE). Burgos. 


\section{CERTIFICADO DE EFICIENCIA ENERGÉTICA DE EDIFICIOS}

IDENTIFICACIÓN DEL EDIFICIO O DE LA PARTE QUE SE CERTIFICA:

\begin{tabular}{|l|l|l|l|}
\hline Nombre del edificio & Vivienda Taller Modificado \\
\hline Dirección & Tesis & Código Postal & 09071 \\
\hline Municipio & Burgos & Comunidad Autónoma & Castilla y León \\
\hline Provincia & Burgos & Año construcción & 2007 \\
\hline Zona climática & E1 & & \\
\hline $\begin{array}{l}\text { Normativa vigente (construcción } \\
\text { rehabilitación) }\end{array}$ & C.T.E. & \\
\hline Referencia/s catastral/es & 000000000 & \\
\hline
\end{tabular}

\begin{tabular}{|l|l|}
\hline \multicolumn{2}{|c|}{ Tipo de edificio o parte del edificio que se certifica: } \\
\hline$\circ$ Edificio de nueva construcción & $\bullet$ Edificio Existente \\
\hline \multicolumn{2}{|c|}{} \\
\hline$\bullet$ Vivienda & $\circ$ Terciario \\
$\bullet$ Unifamiliar & $\circ$ Edificio completo \\
$\circ$ Bloque & $\circ$ Local \\
$\circ$ Bloque completo & \\
\hline Vivienda individual & \\
\hline
\end{tabular}

DATOS DEL TÉCNICO CERTIFICADOR:

\begin{tabular}{|c|c|c|c|c|c|}
\hline Nombre y Apellidos & \multicolumn{3}{|c|}{ Juan Carlos Sánchez } & NIF(NIE) & 000000000 \\
\hline Razón social & \multicolumn{3}{|c|}{ Juan Carlos Sánchez } & NIF & 000000000 \\
\hline \multicolumn{2}{|l|}{ Domicilio } & \multicolumn{4}{|l|}{ Calle Pinar Del Rey } \\
\hline \multicolumn{2}{|l|}{ Municipio } & Madrid & \multicolumn{2}{|c|}{ Código Postal } & 28033 \\
\hline \multicolumn{2}{|l|}{ Provincia } & Madrid & \multicolumn{2}{|c|}{ Comunidad Autónoma } & $\begin{array}{l}\text { Comunidad } \\
\text { Madrid }\end{array}$ \\
\hline \multicolumn{2}{|l|}{ e-mail: } & \multicolumn{2}{|c|}{ juancsanchezg@hotmail.com } & Teléfono & 0000000000 \\
\hline \multicolumn{2}{|c|}{ Titulación habilitante según normativa vigente } & \multicolumn{4}{|l|}{ Arquitecto } \\
\hline $\begin{array}{l}\text { Procedimiento reconocido de } \\
\text { versión: }\end{array}$ & calificación & ergética utilizado y & CEX & & \\
\hline
\end{tabular}

\section{CALIFICACIÓN ENERGÉTICA OBTENIDA:}

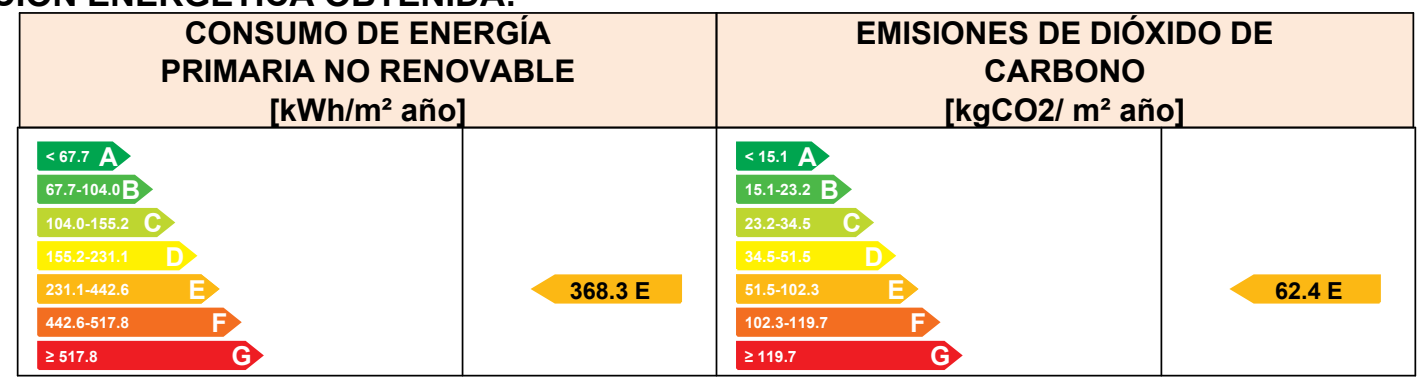

El técnico abajo firmante declara responsablemente que ha realizado la certificación energética del edificio o de la parte que se certifica de acuerdo con el procedimiento establecido por la normativa vigente y que son ciertos los datos que figuran en el presente documento, y sus anexos:

Fecha: 01/12/2015

Firma del técnico certificador

Anexo I. Descripción de las características energéticas del edificio.

Anexo II. Calificación energética del edificio.

Anexo III. Recomendaciones para la mejora de la eficiencia energética.

Anexo IV. Pruebas, comprobaciones e inspecciones realizadas por el técnico certificador.

Registro del Órgano Territorial Competente: 


\section{DESCRIPCIÓN DE LAS CARACTERÍSTICAS ENERGÉTICAS DEL EDIFICIO}

En este apartado se describen las características energéticas del edificio, envolvente térmica, instalaciones, condiciones de funcionamiento y ocupación y demás datos utilizados para obtener la calificación energética del edificio.

\section{SUPERFICIE, IMAGEN Y SITUACIÓN}

\begin{tabular}{|l|l}
\hline Superficie habitable $\left[\mathrm{m}^{2}\right]$ & 52.0
\end{tabular}

\begin{tabular}{|c|c|c|}
\hline Imagen del edificio & Plano de situación \\
\hline & &
\end{tabular}

\section{ENVOLVENTE TÉRMICA}

\section{Cerramientos opacos}

\begin{tabular}{|l|c|c|c|c|}
\hline \multicolumn{1}{|c|}{ Nombre } & Tipo & $\begin{array}{c}\text { Superficie } \\
{\left[\mathrm{m}^{2}\right]}\end{array}$ & $\begin{array}{c}\text { Transmitancia } \\
{\left[\mathbf{W} / \mathbf{m}^{2} \cdot \mathrm{K}\right]}\end{array}$ & Modo de obtención \\
\hline Cubierta con aire & Cubierta & 52.0 & 0.47 & Conocidas \\
\hline Muro de fachada Norte & Fachada & 27.18 & 0.54 & Conocidas \\
\hline Suelo con aire & Suelo & 52.0 & 2.95 & Conocidas \\
\hline Muro de fachada Sur & Fachada & 21.88 & 0.54 & Conocidas \\
\hline Muro de fachada Oeste & Fachada & 8.04 & 0.54 & Conocidas \\
\hline Muro de fachada Este & Fachada & 3.28 & 0.54 & Conocidas \\
\hline
\end{tabular}

Huecos y lucernarios

\begin{tabular}{|l|c|c|c|c|c|c|}
\hline Nombre & Tipo & $\begin{array}{c}\text { Superficie } \\
{\left[\mathbf{m}^{2}\right]}\end{array}$ & $\begin{array}{c}\text { Transmitancia } \\
{\left[\mathbf{W} / \mathbf{m}^{2} \cdot \mathbf{K}\right]}\end{array}$ & $\begin{array}{c}\text { Factor } \\
\text { solar }\end{array}$ & $\begin{array}{c}\text { Modo de } \\
\text { obtención. } \\
\text { Transmitancia }\end{array}$ & $\begin{array}{c}\text { Modo de } \\
\text { obtención. } \\
\text { Factor solar }\end{array}$ \\
\hline V1 & Hueco & 5.3 & 5.70 & 0.67 & Estimado & Estimado \\
\hline V3 & Hueco & 5.3 & 5.70 & 0.67 & Estimado & Estimado \\
\hline V4 & Hueco & 5.3 & 5.70 & 0.67 & Estimado & Estimado \\
\hline V2 & Hueco & 5.3 & 5.70 & 0.67 & Estimado & Estimado \\
\hline V5 & Hueco & 5.03 & 5.70 & 0.67 & Estimado & Estimado \\
\hline Pta & Hueco & 5.03 & 5.70 & 0.67 & Estimado & Estimado \\
\hline
\end{tabular}




\section{INSTALACIONES TÉRMICAS}

Generadores de calefacción

\begin{tabular}{|c|c|c|c|c|c|}
\hline Nombre & Tipo & $\begin{array}{c}\text { Potencia } \\
\text { nominal [kW] }\end{array}$ & $\begin{array}{c}\text { Rendimiento } \\
\text { Estacional[\%] }\end{array}$ & $\begin{array}{l}\text { Tipo de } \\
\text { Energía }\end{array}$ & $\begin{array}{c}\text { Modo de } \\
\text { obtención }\end{array}$ \\
\hline $\begin{array}{l}\text { Calefacción } \\
\text { refrigeración }\end{array}$ & $\begin{array}{l}\text { Bomba de Calor - } \\
\text { Caudal Ref. Variable }\end{array}$ & & 245.2 & Electricidad & Estimado \\
\hline TOTALES & Calefacción & & & & \\
\hline
\end{tabular}

\section{Generadores de refrigeración}

\begin{tabular}{|c|c|c|c|c|c|}
\hline Nombre & Tipo & $\begin{array}{c}\text { Potencia } \\
\text { nominal [kW] }\end{array}$ & $\begin{array}{c}\text { Rendimiento } \\
\text { Estacional[\%] }\end{array}$ & $\begin{array}{c}\text { Tipo de } \\
\text { Energía }\end{array}$ & $\begin{array}{c}\text { Modo de } \\
\text { obtención }\end{array}$ \\
\hline $\begin{array}{l}\text { Calefacción } \\
\text { refrigeración }\end{array}$ & y & $\begin{array}{c}\text { Bomba de Calor } \\
\text { Caudal Ref. Variable }\end{array}$ & 249.8 & Electricidad & Estimado \\
\hline TOTALES & Refrigeración & & & \\
\hline
\end{tabular}

Instalaciones de Agua Caliente Sanitaria

Demanda diario de ACS a $60^{\circ}$ (litros/día) 45.55

\begin{tabular}{|c|c|c|c|c|c|}
\hline Nombre & Tipo & $\begin{array}{c}\text { Potencia } \\
\text { nominal [kW] }\end{array}$ & $\begin{array}{c}\text { Rendimiento } \\
\text { Estacional[\%] }\end{array}$ & $\begin{array}{c}\text { Tipo de } \\
\text { Energía }\end{array}$ & $\begin{array}{c}\text { Modo de } \\
\text { obtención }\end{array}$ \\
\hline Equipo ACS & Efecto Joule & & 100.0 & Electricidad & Estimado \\
\hline TOTALES & ACS & & & & \\
\hline
\end{tabular}




\section{ANEXO II
CALIFICACIÓN ENERGÉTICA DEL EDIFICIO}

\begin{tabular}{|l|l|l|l|}
\hline Zona climática & E1 & Uso & Residencial \\
\hline
\end{tabular}

\section{CALIFICACIÓN ENERGÉTICA DEL EDIFICIO EN EMISIONES}

\begin{tabular}{|c|c|c|c|c|c|}
\hline \multicolumn{2}{|c|}{ INDICADOR GLOBAL } & \multicolumn{4}{|c|}{ INDICADORES PARCIALES } \\
\hline $\begin{array}{l}<15.1 \mathrm{~A} \\
15.1-23.2 \mathrm{~B}\end{array}$ & & \multicolumn{2}{|c|}{ CALEFACCIÓN } & \multicolumn{2}{|l|}{ ACS } \\
\hline $\begin{array}{ll}23.2 \cdot 34.5 & \text { C } \\
34.5-51.5 & \text { D }\end{array}$ & & $\begin{array}{c}\text { Emisiones } \\
\text { calefacción } \\
{\left[\mathrm{kgCO} 2 / \mathrm{m}^{2} \text { añol }\right.}\end{array}$ & \multirow{2}{*}{ D } & $\begin{array}{l}\text { Emisiones ACS } \\
{\left[\mathrm{kgCO} 2 / \mathrm{m}^{2} \text { año] }\right.}\end{array}$ & \multirow{2}{*}{ G } \\
\hline $51.5-102.3 \quad \mathrm{E}$ & \multirow[t]{2}{*}{$62.4 \mathrm{E}$} & 44.79 & & 15.41 & \\
\hline $\begin{array}{ll}102.3-119.7 & F \\
\geq 119.7 & C\end{array}$ & & \multicolumn{2}{|c|}{ REFRIGERACIÓN } & \multicolumn{2}{|c|}{ ILUMINACIÓN } \\
\hline \multirow{2}{*}{\multicolumn{2}{|c|}{ Emisiones globales $\left[\mathrm{kgCO} 2 / \mathrm{m}^{2}\right.$ año] ${ }^{1}$}} & $\begin{array}{c}\text { Emisiones } \\
\text { refrigeracion } \\
{\left[\mathrm{kgCO} 2 / \mathrm{m}^{2} \text { añol }\right]}\end{array}$ & \multirow[t]{2}{*}{ - } & $\begin{array}{c}\text { Emisiones } \\
\text { iluminación } \\
{\left[\mathrm{kgCO} 2 / \mathrm{m}^{2} \text { año] }\right]}\end{array}$ & \multirow[t]{2}{*}{-} \\
\hline & & - & & - & \\
\hline
\end{tabular}

La calificación global del edificio se expresa en términos de dióxido de carbono liberado a la atmósfera como consecuencia del consumo energético del mismo.

\begin{tabular}{|l|c|c|}
\cline { 2 - 3 } \multicolumn{1}{c|}{} & $\mathbf{k g C O} / \mathbf{m}^{\mathbf{2}}$ año & $\mathbf{k g C O 2 / a n ̃ o ~}$ \\
\hline Emisiones CO2 por consumo eléctrico & 62.38 & 3243.77 \\
\hline Emisiones CO2 por otros combustibles & 0.00 & 0.00 \\
\hline
\end{tabular}

\section{CALIFICACIÓN ENERGÉTICA DEL EDIFICIO EN CONSUMO DE ENERGÍA PRIMARIA NO RENOVABLE}

Por energía primaria no renovable se entiende la energía consumida por el edificio procedente de fuentes no renovables que no ha sufrido ningún proceso de conversión o transformación.

\begin{tabular}{|c|c|c|c|c|c|}
\hline \multicolumn{2}{|c|}{ INDICADOR GLOBAL } & \multicolumn{4}{|c|}{ INDICADORES PARCIALES } \\
\hline \multirow{4}{*}{ 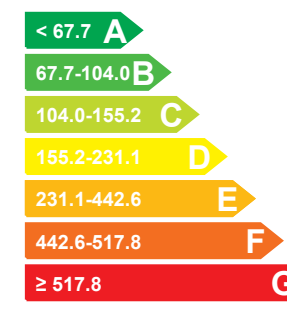 } & & \multicolumn{2}{|c|}{ CALEFACCIÓN } & \multicolumn{2}{|l|}{ ACS } \\
\hline & & $\begin{array}{l}\text { Energía primaria } \\
\text { calefacción } \\
{\left[\mathrm{kWh} / \mathrm{m}^{2} \text { año] }\right.}\end{array}$ & \multirow[t]{2}{*}{$\mathrm{E}$} & $\begin{array}{l}\text { Energía primaria } \\
A C S \\
{\left[\mathrm{kWh} / \mathrm{m}^{2} \text { año] }\right.}\end{array}$ & \multirow[t]{2}{*}{ G } \\
\hline & \multirow[t]{2}{*}{$368.3 \mathrm{E}$} & 264.43 & & 90.95 & \\
\hline & & \multicolumn{2}{|c|}{ REFRIGERACIÓN } & \multicolumn{2}{|l|}{ ILUMINACIÓN } \\
\hline \multirow{2}{*}{\multicolumn{2}{|c|}{$\begin{array}{c}\text { Consumo global de energía primaria no renovable } \\
\qquad\left[\mathrm{kWh} / \mathrm{m}^{2} \text { año }\right]^{1}\end{array}$}} & $\begin{array}{l}\text { Energía primaria } \\
\text { refrigeración } \\
{\left[\mathrm{kWh} / \mathrm{m}^{2} \text { añol }\right.}\end{array}$ & - & $\begin{array}{l}\text { Energía primaria } \\
\text { iluminación } \\
{\left[\mathrm{kWh} / \mathrm{m}^{2} a \tilde{n} o\right]}\end{array}$ & - \\
\hline & & - & & - & \\
\hline
\end{tabular}

\section{CALIFICACIÓN PARCIAL DE LA DEMANDA ENERGÉTICA DE CALEFACCIÓN Y REFRIGERACIÓN}

La demanda energética de calefacción y refrigeración es la energía necesaria para mantener las condiciones internas de confort del edificio.

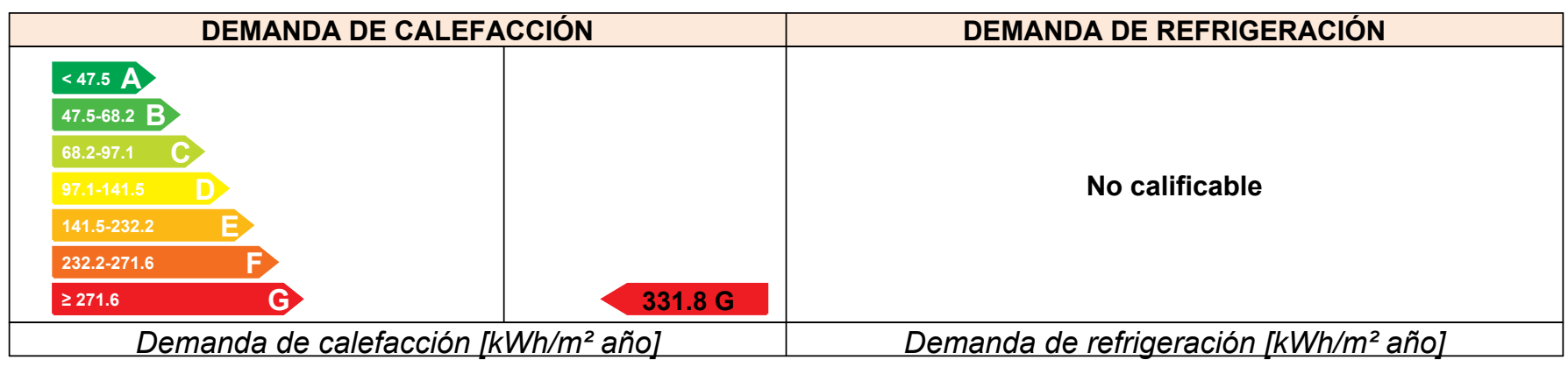

${ }^{1}$ El indicador global es resultado de la suma de los indicadores parciales más el valor del indicador para consumos auxiliares, si los hubiera (sólo ed. terciarios, ventilación, bombeo, etc...). La energía eléctrica autoconsumida se descuenta únicamente del indicador global, no así de los valores parciales 


\section{ANEXO III \\ RECOMENDACIONES PARA LA MEJORA DE LA EFICIENCIA ENERGÉTICA}

FV $100 \%$

CALIFICACIÓN ENERGÉTICA GLOBAL

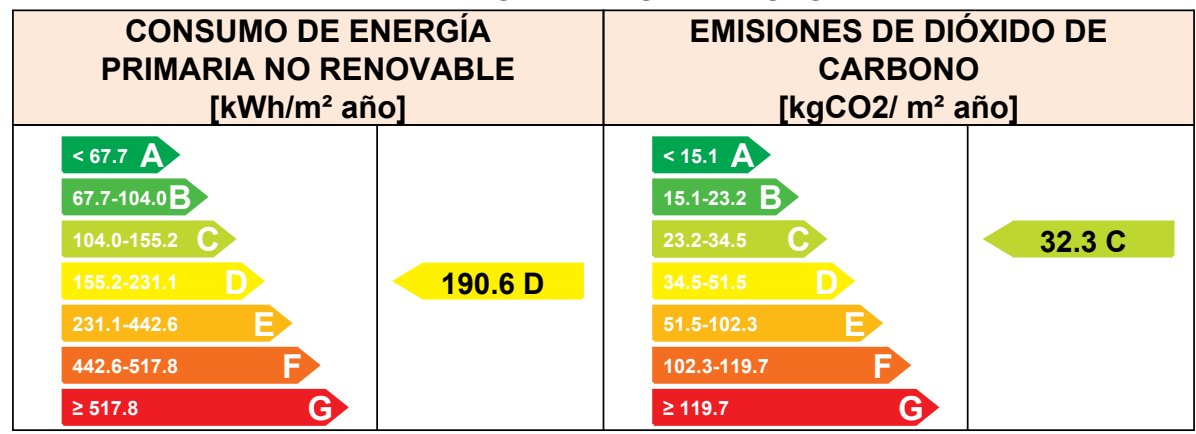

CALIFICACIONES ENERGÉTICAS PARCIALES

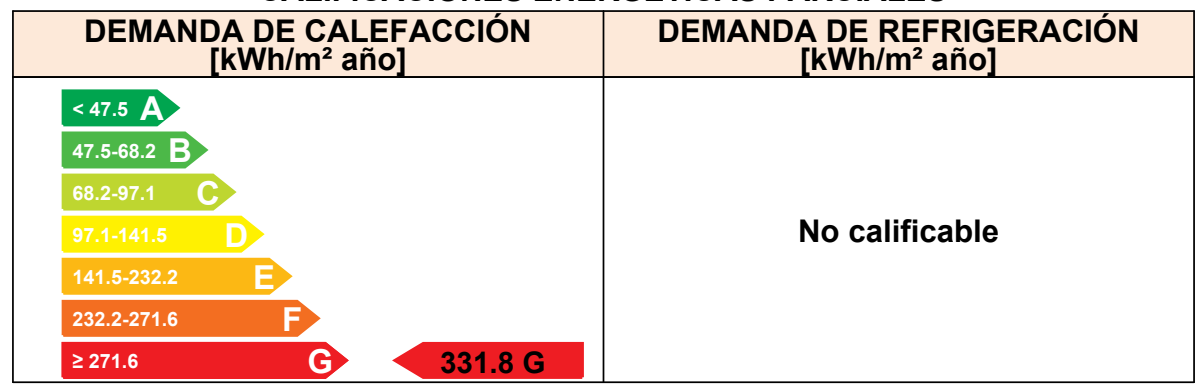

\section{ANÁLISIS TÉCNICO}

\begin{tabular}{|c|c|c|c|c|c|c|c|c|c|c|c|c|c|c|c|}
\hline \multirow[b]{2}{*}{ Indicador } & \multicolumn{3}{|c|}{ Calefacción } & \multicolumn{3}{|c|}{ Refrigeración } & \multicolumn{3}{|c|}{ ACS } & \multicolumn{3}{|c|}{ Iluminación } & \multicolumn{3}{|c|}{ Total } \\
\hline & \multicolumn{2}{|c|}{ Valor } & $\begin{array}{c}\text { ahorro } \\
\text { respecto a } \\
\text { la situación } \\
\text { original }\end{array}$ & \multicolumn{2}{|c|}{ Valor } & $\begin{array}{c}\text { ahorro } \\
\text { respecto a } \\
\text { la situación } \\
\text { original }\end{array}$ & \multicolumn{2}{|c|}{ Valor } & $\begin{array}{c}\text { ahorro } \\
\text { respecto a } \\
\text { la situación } \\
\text { original }\end{array}$ & \multicolumn{2}{|c|}{ Valor } & $\begin{array}{c}\text { ahorro } \\
\text { respecto a } \\
\text { la situación } \\
\text { original }\end{array}$ & \multicolumn{2}{|c|}{ Valor } & $\begin{array}{c}\text { ahorro } \\
\text { respecto a } \\
\text { la situación } \\
\text { original }\end{array}$ \\
\hline $\begin{array}{l}\text { Consumo Energía final } \\
{\left[\mathrm{kWh} / \mathrm{m}^{2} \text { año] }\right.}\end{array}$ & \multicolumn{2}{|c|}{152.21} & $-12.5 \%$ & \multicolumn{2}{|c|}{-} & $-\%$ & \multicolumn{2}{|c|}{46.54} & $0.0 \%$ & \multicolumn{2}{|c|}{-} & $-\%$ & \multicolumn{2}{|c|}{97.56} & $48.2 \%$ \\
\hline $\begin{array}{c}\text { Emisiones de } \mathrm{CO} 2 \\
{\left[\mathrm{kgCO} 2 / \mathrm{m}^{2} \text { año] }\right.}\end{array}$ & 50.38 & $E$ & $-12.5 \%$ & - & - & $-\%$ & 15.41 & G & $0.0 \%$ & - & - & $-\%$ & 32.29 & C & $48.2 \%$ \\
\hline Demanda [kWh $/ \mathrm{m}^{2}$ año] & 331.82 & $\mathrm{G}$ & $0.0 \%$ & - & - & $-\%$ & & & & & & & & & \\
\hline
\end{tabular}

Nota: Los indicadores energéticos anteriores están calculados en base a coeficientes estándar de operación y funcionamiento del edificio, por lo que solo son válidos a efectos de su calificación energética. Para el análisis económico de las medidas de ahorro y eficiencia energética, el técnico certificador deberá utilizar las condiciones reales y datos históricos de consumo del edificio.

\section{DESCRIPCIÓN DE LA MEDIDA DE MEJORA}

Características de la medida (modelo de equipos, materiales, parámetros característicos )

Coste estimado de la medida

Otros datos de interés 
CALIFICACIÓN ENERGÉTICA GLOBAL

\begin{tabular}{|c|c|c|c|}
\hline \multicolumn{2}{|c|}{$\begin{array}{c}\text { CONSUMO DE ENERGÍA } \\
\text { PRIMARIA NO RENOVABLE } \\
{\left[\mathrm{kWh} / \mathrm{m}^{2} \text { año] }\right.}\end{array}$} & \multicolumn{2}{|c|}{$\begin{array}{c}\text { EMISIONES DE DIÓXIDO DE } \\
\text { CARBONO } \\
{\left[\mathrm{kgCO} 2 / \mathrm{m}^{2} \text { año }\right]}\end{array}$} \\
\hline$<67.7 \mathrm{~A}$ & & $<15.1 \mathrm{~A}$ & \\
\hline 67.7-104.0B & $90.9 \mathrm{~B}$ & 15.1-23.2 B & $15.4 \mathrm{~B}$ \\
\hline 104.0-155.2 C & & $23.2-34.5 \quad C$ & \\
\hline 155.2-231.1Ｄ & & $34.5-51.5$ & \\
\hline $231.1-442.6 \quad$ E & & $51.5-102.3$ & \\
\hline $442.6-517.8 \quad$ F & & 102.3-119.7 $\quad$ F & \\
\hline$\geq 517.8 \quad$ G & & $\geq 119.7 \quad$ G & \\
\hline
\end{tabular}

CALIFICACIONES ENERGÉTICAS PARCIALES

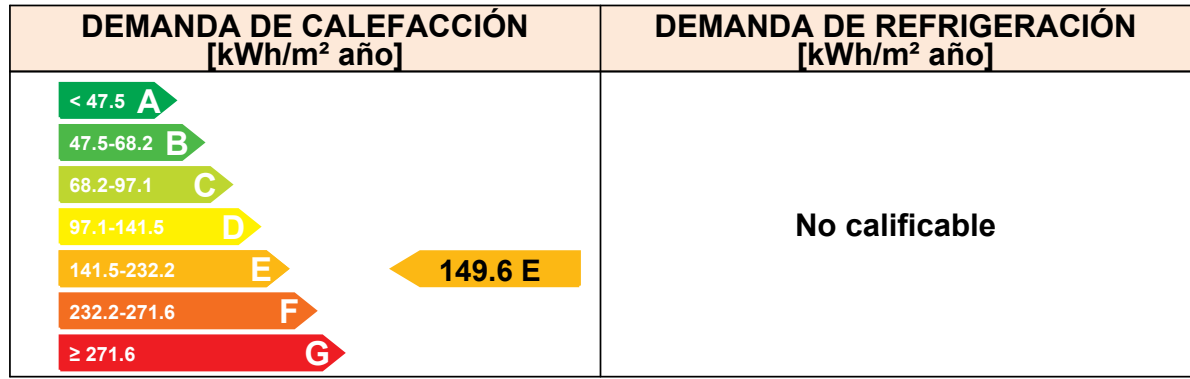

\section{ANÁLISIS TÉCNICO}

\begin{tabular}{|c|c|c|c|c|c|c|c|c|c|c|c|c|c|c|}
\hline \multirow[b]{2}{*}{ Indicador } & \multicolumn{3}{|c|}{ Calefacción } & \multicolumn{3}{|c|}{ Refrigeración } & \multicolumn{3}{|c|}{ ACS } & \multicolumn{2}{|c|}{ Iluminación } & \multicolumn{3}{|c|}{ Total } \\
\hline & \multicolumn{2}{|c|}{ Valor } & $\begin{array}{c}\text { ahorro } \\
\text { respecto a } \\
\text { la situación } \\
\text { original }\end{array}$ & \multicolumn{2}{|c|}{ Valor } & $\begin{array}{c}\text { ahorro } \\
\text { respecto a } \\
\text { la situación } \\
\text { original }\end{array}$ & \multicolumn{2}{|c|}{ Valor } & $\begin{array}{c}\text { ahorro } \\
\text { respecto a } \\
\text { la situación } \\
\text { original }\end{array}$ & Valor & $\begin{array}{c}\text { ahorro } \\
\text { respecto a } \\
\text { la situación } \\
\text { original }\end{array}$ & \multicolumn{2}{|c|}{ Valor } & $\begin{array}{c}\text { ahorro } \\
\text { respecto a } \\
\text { la situación } \\
\text { original }\end{array}$ \\
\hline $\begin{array}{c}\text { Consumo Energía final } \\
{\left[\mathrm{kWh} / \mathrm{m}^{2} \text { año] }\right.}\end{array}$ & \multicolumn{2}{|c|}{0.00} & $100.0 \%$ & \multicolumn{2}{|c|}{-} & $-\%$ & \multicolumn{2}{|c|}{46.54} & $0.0 \%$ & - & $-\%$ & \multicolumn{2}{|c|}{46.54} & $75.3 \%$ \\
\hline $\begin{array}{c}\text { Consumo Energía } \\
\text { primaria no renovable } \\
{\left[\mathrm{kWh} / \mathrm{m}^{2} \text { año] }\right.}\end{array}$ & 0.00 & $A$ & $100.0 \%$ & - & - & $-\%$ & 90.95 & G & $0.0 \%$ & - & $-\%$ & 90.95 & B & $75.3 \%$ \\
\hline $\begin{array}{l}\text { Emisiones de } \mathrm{CO} 2 \\
{\left[\mathrm{kgCO} 2 / \mathrm{m}^{2} \text { año] }\right.}\end{array}$ & 0.00 & $A$ & $100.0 \%$ & - & - & $-\%$ & 15.41 & G & $0.0 \%$ & - & $-\%$ & 15.41 & $\mathrm{~B}$ & $75.3 \%$ \\
\hline Demanda [kWh/m² año] & 149.64 & $E$ & $54.9 \%$ & - & - & $-\%$ & & & & & & & & \\
\hline
\end{tabular}

Nota: Los indicadores energéticos anteriores están calculados en base a coeficientes estándar de operación y funcionamiento del edificio, por lo que solo son válidos a efectos de su calificación energética. Para el análisis económico de las medidas de ahorro y eficiencia energética, el técnico certificador deberá utilizar las condiciones reales y datos históricos de consumo del edificio.

\section{DESCRIPCIÓN DE LA MEDIDA DE MEJORA}

Características de la medida (modelo de equipos, materiales, parámetros característicos )

Coste estimado de la medida

\section{Otros datos de interés}


CALIFICACIÓN ENERGÉTICA GLOBAL

\begin{tabular}{|c|c|c|c|}
\hline \multicolumn{2}{|c|}{$\begin{array}{c}\text { CONSUMO DE ENERGÍA } \\
\text { PRIMARIA NO RENOVABLE } \\
{\left[\mathrm{kWh} / \mathrm{m}^{2} \text { año] }\right.}\end{array}$} & \multicolumn{2}{|c|}{$\begin{array}{c}\text { EMISIONES DE DIÓXIDO DE } \\
\text { CARBONO } \\
{\left[\mathrm{kgCO} 2 / \mathrm{m}^{2} \text { año }\right]}\end{array}$} \\
\hline$<67.7 \mathrm{~A}$ & & $<15.1 \mathrm{~A}$ & \\
\hline 67.7-104.0B & $90.9 \mathrm{~B}$ & 15.1-23.2 B & $15.4 \mathrm{~B}$ \\
\hline 104.0-155.2 C & & $23.2-34.5 \quad C$ & \\
\hline 155.2-231.1Ｄ & & $34.5-51.5$ & \\
\hline $231.1-442.6 \quad$ E & & $51.5-102.3$ & \\
\hline $442.6-517.8 \quad$ F & & 102.3-119.7 $\quad$ F & \\
\hline$\geq 517.8 \quad$ G & & $\geq 119.7 \quad$ G & \\
\hline
\end{tabular}

CALIFICACIONES ENERGÉTICAS PARCIALES

\begin{tabular}{|c|c|}
\hline $\begin{array}{l}\text { DEMANDA DE CALEFACCIÓN } \\
{\left[\mathrm{kWh} / \mathrm{m}^{2} \text { año] }\right.}\end{array}$ & $\begin{array}{l}\text { DEMANDA DE REFRIGERACIÓN } \\
{\left[\mathrm{kWh} / \mathrm{m}^{2} \text { año] }\right.}\end{array}$ \\
\hline \multicolumn{2}{|l|}{$<47.5 \mathrm{~A}$} \\
\hline \multicolumn{2}{|l|}{$47.5-68.2 \mathrm{~B}$} \\
\hline \multicolumn{2}{|l|}{$68.2-97.1 \quad \mathrm{C}$} \\
\hline $97.1-141.5 \quad$ D & No calificable \\
\hline \multicolumn{2}{|l|}{ 141.5-232.2 $\quad \mathrm{E}$} \\
\hline 232.2-271.6 & \\
\hline$\geq 271.6 \quad$ G & \\
\hline
\end{tabular}

\section{ANÁLISIS TÉCNICO}

\begin{tabular}{|c|c|c|c|c|c|c|c|c|c|c|c|c|c|c|c|}
\hline \multirow[b]{2}{*}{ Indicador } & \multicolumn{3}{|c|}{ Calefacción } & \multicolumn{3}{|c|}{ Refrigeración } & \multicolumn{3}{|c|}{ ACS } & \multicolumn{3}{|c|}{ Iluminación } & \multicolumn{3}{|c|}{ Total } \\
\hline & \multicolumn{2}{|c|}{ Valor } & $\begin{array}{c}\text { ahorro } \\
\text { respecto a } \\
\text { la situación } \\
\text { original }\end{array}$ & \multicolumn{2}{|c|}{ Valor } & $\begin{array}{c}\text { ahorro } \\
\text { respecto a } \\
\text { la situación } \\
\text { original }\end{array}$ & \multicolumn{2}{|c|}{ Valor } & $\begin{array}{c}\text { ahorro } \\
\text { respecto a } \\
\text { la situación } \\
\text { original }\end{array}$ & \multicolumn{2}{|c|}{ Valor } & $\begin{array}{c}\text { ahorro } \\
\text { respecto a } \\
\text { la situación } \\
\text { original }\end{array}$ & \multicolumn{2}{|c|}{ Valor } & $\begin{array}{c}\text { ahorro } \\
\text { respecto a } \\
\text { la situación } \\
\text { original }\end{array}$ \\
\hline $\begin{array}{c}\text { Consumo Energía final } \\
{\left[\mathrm{kWh} / \mathrm{m}^{2} \text { año] }\right.}\end{array}$ & \multicolumn{2}{|c|}{0.00} & $100.0 \%$ & \multicolumn{2}{|c|}{ - } & $-\%$ & \multicolumn{2}{|c|}{46.54} & $0.0 \%$ & \multicolumn{2}{|l|}{ - } & $-\%$ & \multicolumn{2}{|c|}{46.54} & $75.3 \%$ \\
\hline $\begin{array}{c}\text { Consumo Energía } \\
\text { primaria no renovable } \\
{\left[\mathrm{kWh} / \mathrm{m}^{2} \text { año] }\right.}\end{array}$ & 0.00 & $A$ & $100.0 \%$ & - & - & $-\%$ & 90.95 & G & $0.0 \%$ & - & - & $-\%$ & 90.95 & B & $75.3 \%$ \\
\hline $\begin{array}{c}\text { Emisiones de } \mathrm{CO} 2 \\
{\left[\mathrm{kgCO} 2 / \mathrm{m}^{2} \text { año] }\right.}\end{array}$ & 0.00 & $A$ & $100.0 \%$ & - & - & $-\%$ & 15.41 & G & $0.0 \%$ & - & - & $-\%$ & 15.41 & $\mathrm{~B}$ & $75.3 \%$ \\
\hline Demanda [kWh/m² año] & 261.26 & $\mathrm{~F}$ & $21.3 \%$ & - & - & $-\%$ & & & & & & & & & \\
\hline
\end{tabular}

Nota: Los indicadores energéticos anteriores están calculados en base a coeficientes estándar de operación y funcionamiento del edificio, por lo que solo son válidos a efectos de su calificación energética. Para el análisis económico de las medidas de ahorro y eficiencia energética, el técnico certificador deberá utilizar las condiciones reales y datos históricos de consumo del edificio.

\section{DESCRIPCIÓN DE LA MEDIDA DE MEJORA}

Características de la medida (modelo de equipos, materiales, parámetros característicos )

Coste estimado de la medida

\section{Otros datos de interés}




\section{ANEXO IV \\ PRUEBAS, COMPROBACJONES E INSPECCIONES REALIZADAS POR EL TECNICO CERTIFICADOR}

Se describen a continuación las pruebas, comprobaciones e inspecciones llevadas a cabo por el técnico certificador durante el proceso de toma de datos y de calificación de la eficiencia energética del edificio, con la finalidad de establecer la conformidad de la información de partida contenida en el certificado de eficiencia energética.

Fecha de realización de la visita del técnico certificador 


\begin{tabular}{|c|c|c|c|c|c|}
\hline & & $\begin{array}{c}\text { Ref. } \\
\text { Catastral }\end{array}$ & 000000000 & $\begin{array}{c}\text { Versión } \\
\text { informe } \\
\text { asociado }\end{array}$ & $01 / 12 / 2015$ \\
\hline $\begin{array}{l}\text { Certificación } \\
\text { Energética } \\
\text { de Edificios }\end{array}$ & $\begin{array}{c}\text { Id. } \\
\text { Mejora }\end{array}$ & $\begin{array}{l}\text { Programa } \\
\text { y versión }\end{array}$ & CEXv2.1 & Fecha & $4 / 1 / 2004$ \\
\hline
\end{tabular}

\section{Informe descriptivo de la medida de mejora}

\section{DENOMINACIÓN DE LA MEDIDA DE MEJORA}

FV $100 \%$

\section{DESCRIPCIÓN DE LA MEDIDA DE MEJORA}

Características de la medida (modelo de equipos, materiales, parámetros característicos )

Coste estimado de la medida

Otros datos de interés

CALIFICACIÓN ENERGÉTICA GLOBAL

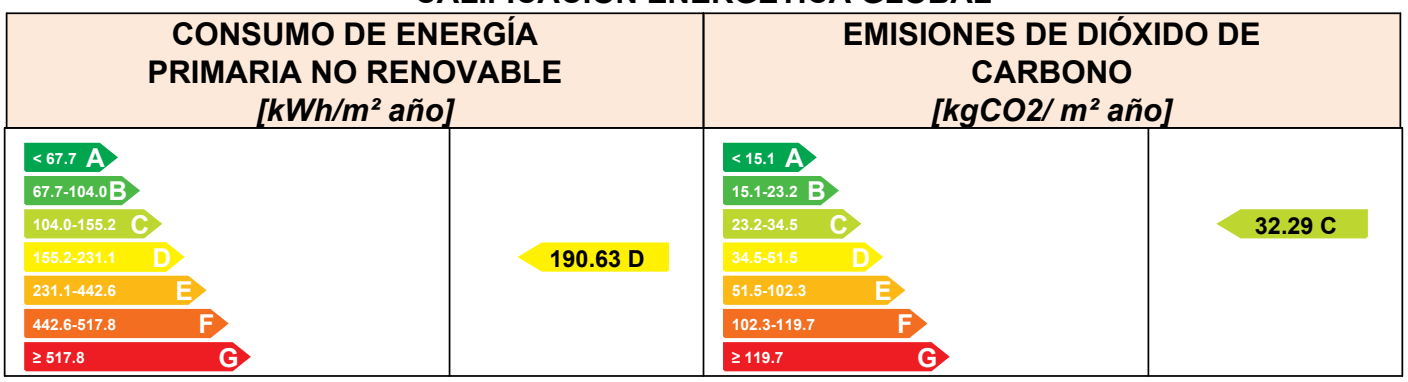

CALIFICACIONES ENERGÉTICAS PARCIALES

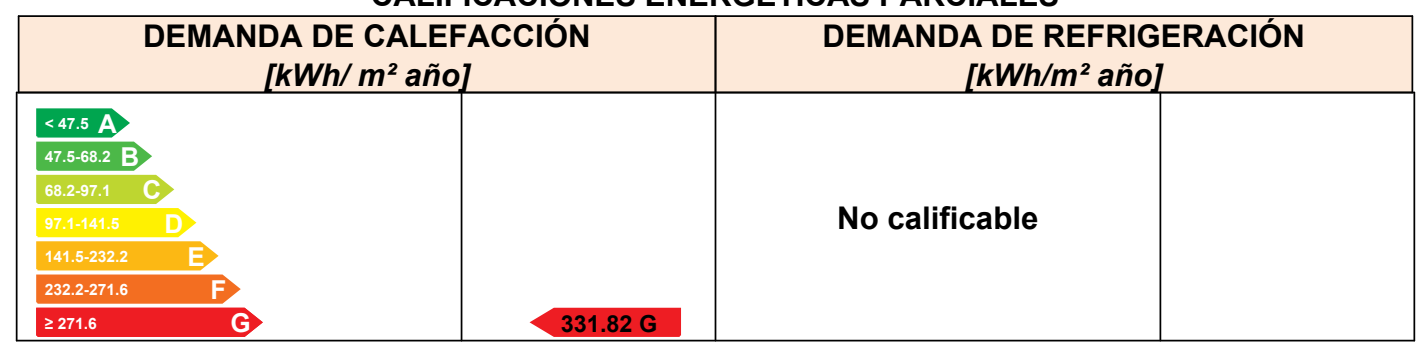




\begin{tabular}{|c|c|c|c|c|c|}
\hline & & $\begin{array}{c}\text { Ref. } \\
\text { Catastral }\end{array}$ & 000000000 & $\begin{array}{c}\text { Versión } \\
\text { informe } \\
\text { asociado }\end{array}$ & $01 / 12 / 2015$ \\
\hline $\begin{array}{l}\text { Certificación } \\
\text { Energética } \\
\text { de Edificios }\end{array}$ & $\begin{array}{c}\text { Id. } \\
\text { Mejora }\end{array}$ & $\begin{array}{l}\text { Programa } \\
\text { y versión }\end{array}$ & CEXv2.1 & Fecha & $4 / 1 / 2004$ \\
\hline
\end{tabular}

\section{ANALISÍS TÉCNICO}

\begin{tabular}{|c|c|c|c|c|c|c|c|c|c|c|c|c|c|c|c|}
\hline \multirow[b]{2}{*}{ Indicador } & \multicolumn{3}{|c|}{ Calefacción } & \multicolumn{3}{|c|}{ Refrigeración } & \multicolumn{3}{|c|}{ ACS } & \multicolumn{3}{|c|}{ Iluminación } & \multicolumn{3}{|c|}{ Total } \\
\hline & \multicolumn{2}{|c|}{ Valor } & $\begin{array}{l}\text { ahorro } \\
\text { respecto a } \\
\text { la situación } \\
\text { original }\end{array}$ & \multicolumn{2}{|c|}{ Valor } & $\begin{array}{c}\text { ahorro } \\
\text { respecto a } \\
\text { la situación } \\
\text { original }\end{array}$ & \multicolumn{2}{|c|}{ Valor } & $\begin{array}{l}\text { ahorro } \\
\text { respecto a } \\
\text { la situación } \\
\text { original }\end{array}$ & \multicolumn{2}{|c|}{ Valor } & $\begin{array}{c}\text { ahorro } \\
\text { respecto a } \\
\text { la situación } \\
\text { original }\end{array}$ & \multicolumn{2}{|c|}{ Valor } & $\begin{array}{l}\text { ahorro } \\
\text { respecto a } \\
\text { la situación } \\
\text { original }\end{array}$ \\
\hline $\begin{array}{l}\text { Consumo Energía } \\
\text { final }\left[\mathrm{kWh} / \mathrm{m}^{2} \text { año] }\right.\end{array}$ & \multicolumn{2}{|c|}{152.21} & $-12.5 \%$ & \multicolumn{2}{|c|}{ - } & $-\%$ & \multicolumn{2}{|c|}{46.54} & $0.0 \%$ & \multicolumn{2}{|l|}{-} & $-\%$ & \multicolumn{2}{|c|}{97.56} & $48.2 \%$ \\
\hline $\begin{array}{c}\text { Consumo Energía } \\
\text { primaria no renovable } \\
{\left[\mathrm{kWh} / \mathrm{m}^{2} \text { año] }\right.}\end{array}$ & 297.42 & $E$ & $-12.5 \%$ & - & - & $-\%$ & 90.95 & G & $0.0 \%$ & - & - & $-\%$ & 190.63 & D & $48.2 \%$ \\
\hline $\begin{array}{c}\text { Emisiones de CO2 } \\
{\left[\mathrm{kgCO} 2 / \mathrm{m}^{2} \text { año] }\right.}\end{array}$ & 50.38 & $E$ & $-12.5 \%$ & - & - & $-\%$ & 15.41 & G & $0.0 \%$ & - & - & $-\%$ & 32.29 & C & $48.2 \%$ \\
\hline $\begin{array}{l}\text { Demanda }\left[\mathrm{kWh} / \mathrm{m}^{2}\right. \\
\text { año] }\end{array}$ & 331.82 & G & $0.0 \%$ & - & - & $-\%$ & & & & & & & & & \\
\hline
\end{tabular}

\section{ENVOLVENTE TÉRMICA}

\section{Cerramientos opacos}

\begin{tabular}{|c|c|c|c|c|c|}
\hline Nombre & Tipo & $\begin{array}{c}\text { Superficie } \\
\text { actual } \\
{\left[\mathbf{m}^{2}\right]}\end{array}$ & $\begin{array}{c}\text { Transmitancia } \\
\text { actual } \\
{\left[\mathbf{W} / \mathbf{m}^{\mathbf{2}} \mathbf{~ K}\right]}\end{array}$ & $\begin{array}{c}\text { Superficie } \\
\text { post } \\
\text { mejora } \\
{\left[\mathbf{m}^{2}\right]}\end{array}$ & $\begin{array}{c}\text { Transmitancia } \\
\text { post mejora } \\
{\left[\mathbf{W} / \mathbf{m}^{\mathbf{2}} \mathbf{K}\right]}\end{array}$ \\
\hline Cubierta con aire & Cubierta & 52.00 & 0.47 & 52.00 & 0.47 \\
\hline Muro de fachada Norte & Fachada & 27.18 & 0.54 & 27.18 & 0.54 \\
\hline Suelo con aire & Suelo & 52.00 & 2.95 & 52.00 & 2.95 \\
\hline Muro de fachada Sur & Fachada & 21.88 & 0.54 & 21.88 & 0.54 \\
\hline Muro de fachada Oeste & Fachada & 8.04 & 0.54 & 8.04 & 0.54 \\
\hline Muro de fachada Este & Fachada & 3.28 & 0.54 & 3.28 & 0.54 \\
\hline
\end{tabular}

Huecos y lucernarios

\begin{tabular}{|c|c|c|c|c|c|c|c|}
\hline Nombre & Tipo & $\begin{array}{c}\text { Superficie } \\
\text { actual } \\
{\left[\mathrm{m}^{2}\right]}\end{array}$ & $\begin{array}{c}\text { Transmitancia } \\
\text { actual del } \\
\text { hueco[W/m² } \\
\mathrm{K}]\end{array}$ & $\begin{array}{c}\text { Transmitancia } \\
\text { actual del } \\
\text { vidrio[W/m² } \\
\mathrm{K}]\end{array}$ & $\begin{array}{c}\text { Superficie } \\
\text { post } \\
\text { mejora } \\
{\left[\mathrm{m}^{2}\right]}\end{array}$ & $\begin{array}{c}\text { Transmitancia } \\
\text { post mejora } \\
{\left[\mathrm{W} / \mathrm{m}^{2} \mathrm{~K}\right]}\end{array}$ & $\begin{array}{c}\text { Transmitancia } \\
\text { post mejora } \\
\text { del vidrio } \\
{\left[\mathrm{W} / \mathrm{m}^{2} \mathrm{~K}\right]}\end{array}$ \\
\hline V1 & Hueco & 5.3 & 5.70 & 5.70 & 5.3 & 5.70 & 5.70 \\
\hline V3 & Hueco & 5.3 & 5.70 & 5.70 & 5.3 & 5.70 & 5.70 \\
\hline V4 & Hueco & 5.3 & 5.70 & 5.70 & 5.3 & 5.70 & 5.70 \\
\hline V2 & Hueco & 5.3 & 5.70 & 5.70 & 5.3 & 5.70 & 5.70 \\
\hline V5 & Hueco & 5.03 & 5.70 & 5.70 & 5.03 & 5.70 & 5.70 \\
\hline Pta & Hueco & 5.03 & 5.70 & 5.70 & 5.03 & 5.70 & 5.70 \\
\hline
\end{tabular}




\begin{tabular}{|c|c|c|c|c|c|}
\hline & & $\begin{array}{c}\text { Ref. } \\
\text { Catastral }\end{array}$ & 000000000 & $\begin{array}{c}\text { Versión } \\
\text { informe } \\
\text { asociado }\end{array}$ & $01 / 12 / 2015$ \\
\hline $\begin{array}{l}\text { Certificación } \\
\text { Energética } \\
\text { de Edificios }\end{array}$ & $\begin{array}{c}\text { Id. } \\
\text { Mejora }\end{array}$ & $\begin{array}{l}\text { Programa } \\
\text { y versión }\end{array}$ & CEXv2.1 & Fecha & $4 / 1 / 2004$ \\
\hline
\end{tabular}

\section{INSTALACIONES TÉRMICAS}

\section{Generadores de calefacción}

\begin{tabular}{|c|c|c|c|c|c|c|c|c|c|}
\hline \multirow[t]{2}{*}{ Nombre } & \multirow[t]{2}{*}{ Tipo } & $\begin{array}{l}\text { Potencia } \\
\text { nominal }\end{array}$ & $\begin{array}{l}\text { Rendi- } \\
\text { miento } \\
\text { Estacional }\end{array}$ & $\begin{array}{c}\text { Estimación } \\
\text { Energía } \\
\text { Consumida } \\
\text { anual }\end{array}$ & \multirow[t]{2}{*}{$\begin{array}{c}\text { Tipo post } \\
\text { mejora }\end{array}$} & $\begin{array}{c}\text { Potencia } \\
\text { nominal } \\
\text { post } \\
\text { mejora }\end{array}$ & $\begin{array}{c}\text { Rendimiento } \\
\text { estacional } \\
\text { post mejora }\end{array}$ & $\begin{array}{c}\text { Estimación } \\
\text { Energía } \\
\text { Consumida } \\
\text { anual Post } \\
\text { mejora }\end{array}$ & $\begin{array}{c}\text { Energía } \\
\text { anual } \\
\text { ahorrada }\end{array}$ \\
\hline & & {$[k W]$} & [\%] & {$\left[\mathrm{kWh} / \mathrm{m}^{2} \mathrm{año]}\right.$} & & {$[k W]$} & [\%] & [kWh/m²año] & [kWh/m²año] \\
\hline $\begin{array}{l}\text { Calefacción y } \\
\text { refrigeración }\end{array}$ & $\begin{array}{c}\text { Bomba de } \\
\text { Calor - } \\
\text { Caudal Ref. } \\
\text { Variable }\end{array}$ & & $245.2 \%$ & - & $\begin{array}{c}\text { Bomba de } \\
\text { Calor - } \\
\text { Caudal Ref. } \\
\text { Variable }\end{array}$ & & $218.0 \%$ & - & - \\
\hline TOTALES & & & & & & & & & \\
\hline
\end{tabular}

\section{Generadores de refrigeración}

\begin{tabular}{|c|c|c|c|c|c|c|c|c|c|}
\hline Nombre & Tipo & $\begin{array}{l}\text { Potencia } \\
\text { nominal }\end{array}$ & $\begin{array}{l}\text { Rendi- } \\
\text { miento } \\
\text { Estacional }\end{array}$ & $\begin{array}{c}\text { Estimación } \\
\text { Energía } \\
\text { Consumida } \\
\text { anual }\end{array}$ & $\begin{array}{l}\text { Tipo post } \\
\text { mejora }\end{array}$ & $\begin{array}{c}\text { Potencia } \\
\text { nominal } \\
\text { post } \\
\text { mejora }\end{array}$ & $\begin{array}{c}\text { Rendimiento } \\
\text { estacional } \\
\text { post mejora }\end{array}$ & $\begin{array}{c}\text { Estimación } \\
\text { Energía } \\
\text { Consumida } \\
\text { anual Post } \\
\text { mejora }\end{array}$ & $\begin{array}{l}\text { Energía } \\
\text { anual } \\
\text { ahorrada }\end{array}$ \\
\hline & & {$[\mathrm{kW}]$} & [\%] & {$\left[\mathrm{kWh} / \mathrm{m}^{2} \mathrm{año}\right]$} & & {$[k W]$} & [\%] & [kWh/m²año] & [kWh/m²año] \\
\hline $\begin{array}{l}\text { Calefacción y } \\
\text { refrigeración }\end{array}$ & $\begin{array}{c}\text { Bomba de } \\
\text { Calor - } \\
\text { Caudal Ref. } \\
\text { Variable }\end{array}$ & & $249.8 \%$ & - & $\begin{array}{c}\text { Bomba de } \\
\text { Calor - } \\
\text { Caudal Ref. } \\
\text { Variable }\end{array}$ & & $280.9 \%$ & - & - \\
\hline TOTALES & & - & & - & & $\overline{-}$ & & $\overline{-}$ & - \\
\hline
\end{tabular}

\section{Instalaciones de Agua Caliente Sanitaria}

\begin{tabular}{|c|c|c|c|c|c|c|c|c|c|}
\hline Nombre & Tipo & $\begin{array}{l}\text { Potencia } \\
\text { nominal }\end{array}$ & $\begin{array}{c}\text { Rendi- } \\
\text { miento } \\
\text { Estacional }\end{array}$ & $\begin{array}{c}\text { Estimación } \\
\text { Energía } \\
\text { Consumida } \\
\text { anual }\end{array}$ & $\begin{array}{c}\text { Tipo post } \\
\text { mejora }\end{array}$ & $\begin{array}{c}\text { Potencia } \\
\text { nominal } \\
\text { post } \\
\text { mejora }\end{array}$ & $\begin{array}{c}\text { Rendimiento } \\
\text { estacional } \\
\text { post mejora }\end{array}$ & $\begin{array}{c}\text { Estimación } \\
\text { Energía } \\
\text { Consumida } \\
\text { anual Post } \\
\text { mejora }\end{array}$ & $\begin{array}{l}\text { Energía } \\
\text { anual } \\
\text { ahorrada }\end{array}$ \\
\hline & & {$[\mathrm{kW}]$} & [\%] & {$\left[k W h / m^{2} a n ̃ o\right]$} & & {$[\mathrm{kW}]$} & [\%] & [kWh/m²año] & [kWh/m²año] \\
\hline Equipo ACS & Efecto Joule & & $100.0 \%$ & - & Efecto Joule & & $100.0 \%$ & - & - \\
\hline TOTALES & & - & & - & & - & & - & - \\
\hline
\end{tabular}




\begin{tabular}{|c|c|c|c|c|c|}
\hline & $D E$ & $\begin{array}{c}\text { Ref. } \\
\text { Catastral }\end{array}$ & 000000000 & $\begin{array}{l}\text { Versión } \\
\text { informe } \\
\text { asociado }\end{array}$ & $01 / 12 / 2015$ \\
\hline $\begin{array}{c}\text { Certificación } \\
\text { Energética } \\
\text { de Edificioios }\end{array}$ & $\begin{array}{c}\text { Id. } \\
\text { Mejora }\end{array}$ & $\begin{array}{l}\text { Programa } \\
\text { y versión }\end{array}$ & CEXv2.1 & Fecha & $4 / 1 / 2004$ \\
\hline
\end{tabular}

\section{ENERGÍAS RENOVABLES}

\section{Eléctrica}

\begin{tabular}{|c|c|c|}
\hline Nombre & $\begin{array}{c}\text { Energía eléctrica generada y } \\
\text { autoconsumida [kWh/año] }\end{array}$ & $\begin{array}{c}\text { Energía eléctrica generada y } \\
\text { autoconsumida post mejora } \\
\text { [kWh/año] }\end{array}$ \\
\hline Incorporación/mejora de sistema fotovoltaico & - & 7760 \\
\hline TOTALES & - & 7760.0 \\
\hline
\end{tabular}




\begin{tabular}{|c|c|c|c|c|c|}
\hline & & $\begin{array}{c}\text { Ref. } \\
\text { Catastral }\end{array}$ & 000000000 & $\begin{array}{c}\text { Versión } \\
\text { informe } \\
\text { asociado }\end{array}$ & $01 / 12 / 2015$ \\
\hline $\begin{array}{l}\text { Certificación } \\
\text { Energética } \\
\text { de Edificios }\end{array}$ & $\begin{array}{c}\text { Id. } \\
\text { Mejora }\end{array}$ & $\begin{array}{l}\text { Programa } \\
\text { y versión }\end{array}$ & CEXv2.1 & Fecha & $4 / 1 / 2004$ \\
\hline
\end{tabular}

\section{Informe descriptivo de la medida de mejora}

\section{DENOMINACIÓN DE LA MEDIDA DE MEJORA}

Bomba de calor alto cop y eer con geotermia y vidrios activos + mejora aislamientos

\section{DESCRIPCIÓN DE LA MEDIDA DE MEJORA}

Características de la medida (modelo de equipos, materiales, parámetros característicos )

Coste estimado de la medida

Otros datos de interés

CALIFICACIÓN ENERGÉTICA GLOBAL

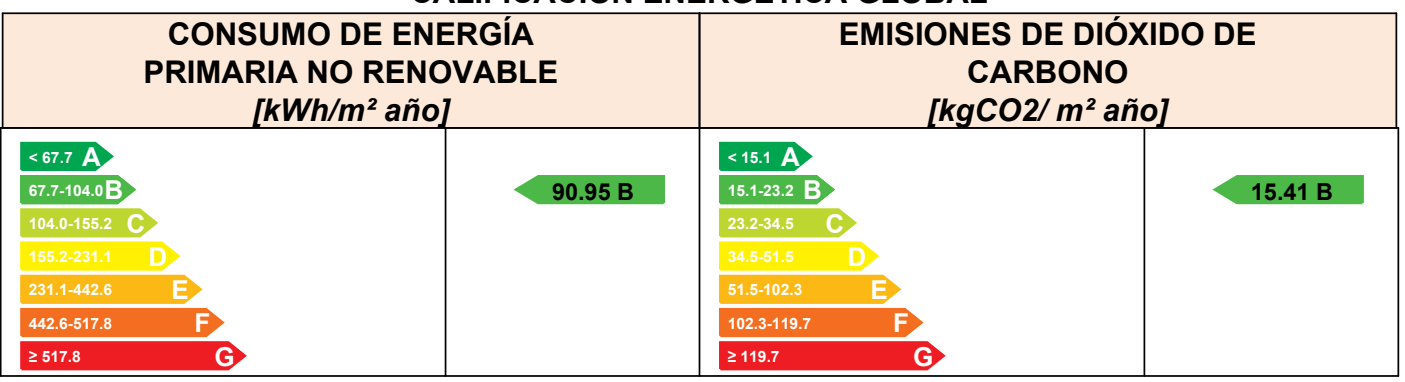

CALIFICACIONES ENERGÉTICAS PARCIALES

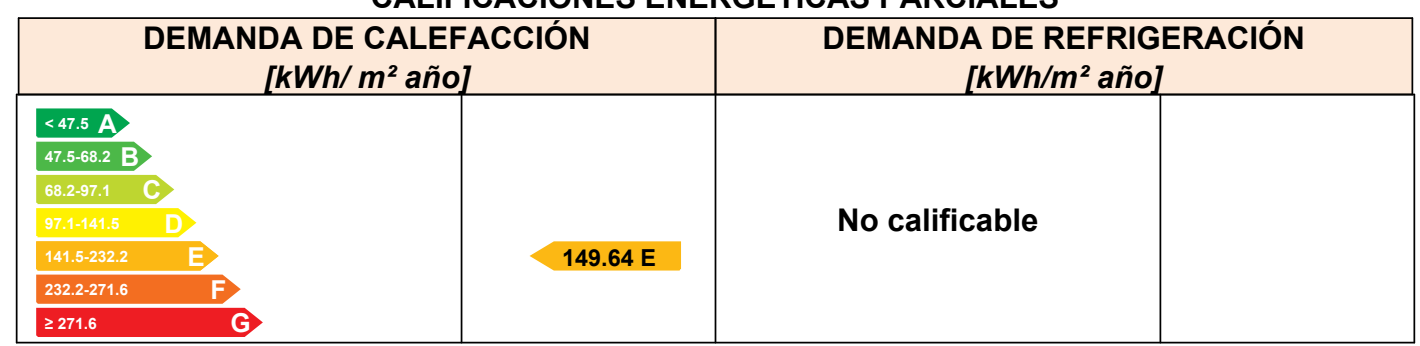




\begin{tabular}{|c|c|c|c|c|c|}
\hline & & $\begin{array}{c}\text { Ref. } \\
\text { Catastral }\end{array}$ & 000000000 & $\begin{array}{c}\text { Versión } \\
\text { informe } \\
\text { asociado }\end{array}$ & $01 / 12 / 2015$ \\
\hline $\begin{array}{l}\text { Certificación } \\
\text { Energética } \\
\text { de Edificios }\end{array}$ & $\begin{array}{c}\text { Id. } \\
\text { Mejora }\end{array}$ & $\begin{array}{l}\text { Programa } \\
\text { y versión }\end{array}$ & CEXv2.1 & Fecha & $4 / 1 / 2004$ \\
\hline
\end{tabular}

\section{ANALISÍS TÉCNICO}

\begin{tabular}{|c|c|c|c|c|c|c|c|c|c|c|c|c|c|c|c|}
\hline \multirow[b]{2}{*}{ Indicador } & \multicolumn{3}{|c|}{ Calefacción } & \multicolumn{3}{|c|}{ Refrigeración } & \multicolumn{3}{|c|}{ ACS } & \multicolumn{3}{|c|}{ Iluminación } & \multicolumn{3}{|c|}{ Total } \\
\hline & \multicolumn{2}{|c|}{ Valor } & $\begin{array}{l}\text { ahorro } \\
\text { respecto a } \\
\text { la situación } \\
\text { original }\end{array}$ & \multicolumn{2}{|c|}{ Valor } & $\begin{array}{c}\text { ahorro } \\
\text { respecto a } \\
\text { la situación } \\
\text { original }\end{array}$ & \multicolumn{2}{|c|}{ Valor } & $\begin{array}{l}\text { ahorro } \\
\text { respecto a } \\
\text { la situación } \\
\text { original }\end{array}$ & \multicolumn{2}{|c|}{ Valor } & $\begin{array}{l}\text { ahorro } \\
\text { respecto a } \\
\text { la situación } \\
\text { original }\end{array}$ & \multicolumn{2}{|c|}{ Valor } & $\begin{array}{l}\text { ahorro } \\
\text { respecto a } \\
\text { la situación } \\
\text { original }\end{array}$ \\
\hline $\begin{array}{l}\text { Consumo Energía } \\
\text { final }\left[\mathrm{kWh} / \mathrm{m}^{2} \text { año] }\right.\end{array}$ & \multicolumn{2}{|c|}{0.00} & $100.0 \%$ & \multicolumn{2}{|c|}{-} & $-\%$ & \multicolumn{2}{|c|}{46.54} & $0.0 \%$ & \multicolumn{2}{|l|}{-} & $-\%$ & \multicolumn{2}{|c|}{46.54} & $75.3 \%$ \\
\hline $\begin{array}{c}\text { Consumo Energía } \\
\text { primaria no renovable } \\
{\left[\mathrm{kWh} / \mathrm{m}^{2} \text { año] }\right.}\end{array}$ & 0.00 & A & $100.0 \%$ & - & - & $-\%$ & 90.95 & G & $0.0 \%$ & - & - & $-\%$ & 90.95 & B & $75.3 \%$ \\
\hline $\begin{array}{c}\text { Emisiones de CO2 } \\
{\left[\mathrm{kgCO} 2 / \mathrm{m}^{2} \text { año] }\right.}\end{array}$ & 0.00 & A & $100.0 \%$ & - & - & $-\%$ & 15.41 & G & $0.0 \%$ & - & - & $-\%$ & 15.41 & B & $75.3 \%$ \\
\hline $\begin{array}{l}\text { Demanda }\left[\mathrm{kWh} / \mathrm{m}^{2}\right. \\
\text { año] }\end{array}$ & 149.64 & $E$ & $54.9 \%$ & - & - & $-\%$ & & & & & & & & & \\
\hline
\end{tabular}

\section{ENVOLVENTE TÉRMICA}

\section{Cerramientos opacos}

\begin{tabular}{|c|c|c|c|c|c|}
\hline Nombre & Tipo & $\begin{array}{c}\text { Superficie } \\
\text { actual } \\
{\left[\mathbf{m}^{2}\right]}\end{array}$ & $\begin{array}{c}\text { Transmitancia } \\
\text { actual } \\
{\left[\mathbf{W} / \mathbf{m}^{\mathbf{2}} \mathbf{~ K}\right]}\end{array}$ & $\begin{array}{c}\text { Superficie } \\
\text { post } \\
\text { mejora } \\
{\left[\mathbf{m}^{2}\right]}\end{array}$ & $\begin{array}{c}\text { Transmitancia } \\
\text { post mejora } \\
{\left[\mathbf{W} / \mathbf{m}^{\mathbf{2}} \mathbf{K}\right]}\end{array}$ \\
\hline Cubierta con aire & Cubierta & 52.00 & 0.47 & 52.00 & 0.22 \\
\hline Muro de fachada Norte & Fachada & 27.18 & 0.54 & 27.18 & 0.18 \\
\hline Suelo con aire & Suelo & 52.00 & 2.95 & 52.00 & 0.34 \\
\hline Muro de fachada Sur & Fachada & 21.88 & 0.54 & 21.88 & 0.18 \\
\hline Muro de fachada Oeste & Fachada & 8.04 & 0.54 & 8.04 & 0.18 \\
\hline Muro de fachada Este & Fachada & 3.28 & 0.54 & 3.28 & 0.18 \\
\hline
\end{tabular}

Huecos y lucernarios

\begin{tabular}{|c|c|c|c|c|c|c|c|}
\hline Nombre & Tipo & $\begin{array}{c}\text { Superficie } \\
\text { actual } \\
{\left[\mathrm{m}^{2}\right]}\end{array}$ & $\begin{array}{c}\text { Transmitancia } \\
\text { actual del } \\
\text { hueco[W/m² } \\
\mathrm{K}]\end{array}$ & $\begin{array}{c}\text { Transmitancia } \\
\text { actual del } \\
\text { vidrio[W/m² } \\
\mathrm{K}]\end{array}$ & $\begin{array}{c}\text { Superficie } \\
\text { post } \\
\text { mejora } \\
{\left[\mathrm{m}^{2}\right]}\end{array}$ & $\begin{array}{c}\text { Transmitancia } \\
\text { post mejora } \\
{\left[\mathrm{W} / \mathrm{m}^{2} \mathrm{~K}\right]}\end{array}$ & $\begin{array}{c}\text { Transmitancia } \\
\text { post mejora } \\
\text { del vidrio } \\
{\left[\mathrm{W} / \mathrm{m}^{2} \mathrm{~K}\right]}\end{array}$ \\
\hline V1 & Hueco & 5.3 & 5.70 & 5.70 & 5.3 & 1.27 & 1.12 \\
\hline V3 & Hueco & 5.3 & 5.70 & 5.70 & 5.3 & 1.27 & 1.12 \\
\hline V4 & Hueco & 5.3 & 5.70 & 5.70 & 5.3 & 1.27 & 1.12 \\
\hline V2 & Hueco & 5.3 & 5.70 & 5.70 & 5.3 & 1.27 & 1.12 \\
\hline V5 & Hueco & 5.03 & 5.70 & 5.70 & 5.03 & 1.27 & 1.12 \\
\hline Pta & Hueco & 5.03 & 5.70 & 5.70 & 5.03 & 1.27 & 1.12 \\
\hline
\end{tabular}




\begin{tabular}{|c|c|c|c|c|c|}
\hline & & $\begin{array}{c}\text { Ref. } \\
\text { Catastral }\end{array}$ & 000000000 & $\begin{array}{c}\text { Versión } \\
\text { informe } \\
\text { asociado }\end{array}$ & $01 / 12 / 2015$ \\
\hline $\begin{array}{l}\text { Certificación } \\
\text { Energética } \\
\text { de Edificios }\end{array}$ & $\begin{array}{c}\text { Id. } \\
\text { Mejora }\end{array}$ & $\begin{array}{l}\text { Programa } \\
\text { y versión }\end{array}$ & CEXv2.1 & Fecha & $4 / 1 / 2004$ \\
\hline
\end{tabular}

\section{INSTALACIONES TÉRMICAS}

\section{Generadores de calefacción}

\begin{tabular}{|c|c|c|c|c|c|c|c|c|c|}
\hline \multirow[t]{2}{*}{ Nombre } & \multirow[t]{2}{*}{ Tipo } & $\begin{array}{r}\text { Potencia } \\
\text { nominal }\end{array}$ & $\begin{array}{l}\text { Rendi- } \\
\text { miento } \\
\text { Estacional }\end{array}$ & $\begin{array}{c}\text { Estimación } \\
\text { Energía } \\
\text { Consumida } \\
\text { anual }\end{array}$ & \multirow[t]{2}{*}{$\begin{array}{l}\text { Tipo post } \\
\text { mejora }\end{array}$} & $\begin{array}{c}\text { Potencia } \\
\text { nominal } \\
\text { post } \\
\text { mejora }\end{array}$ & $\begin{array}{c}\text { Rendimiento } \\
\text { estacional } \\
\text { post mejora }\end{array}$ & $\begin{array}{c}\text { Estimación } \\
\text { Energía } \\
\text { Consumida } \\
\text { anual Post } \\
\text { mejora }\end{array}$ & $\begin{array}{l}\text { Energía } \\
\text { anual } \\
\text { ahorrada }\end{array}$ \\
\hline & & {$[\mathrm{kW}]$} & [\%] & {$\left[\mathrm{kWh} / \mathrm{m}^{2} \mathrm{año}\right]$} & & {$[\mathrm{kW}]$} & [\%] & [kWh/m²año] & [kWh/m²año] \\
\hline $\begin{array}{l}\text { Calefacción y } \\
\text { refrigeración }\end{array}$ & $\begin{array}{c}\text { Bomba de } \\
\text { Calor - } \\
\text { Caudal Ref. } \\
\text { Variable }\end{array}$ & & $245.2 \%$ & - & $\begin{array}{c}\text { Bomba de } \\
\text { Calor - } \\
\text { Caudal Ref. } \\
\text { Variable }\end{array}$ & & $434.6 \%$ & - & - \\
\hline TOTALES & & & & & & & & & \\
\hline
\end{tabular}

\section{Generadores de refrigeración}

\begin{tabular}{|c|c|c|c|c|c|c|c|c|c|}
\hline \multirow[t]{2}{*}{ Nombre } & \multirow[t]{2}{*}{ Tipo } & $\begin{array}{r}\text { Potencia } \\
\text { nominal }\end{array}$ & $\begin{array}{c}\text { Rendi- } \\
\text { miento } \\
\text { Estacional }\end{array}$ & $\begin{array}{c}\text { Estimación } \\
\text { Energía } \\
\text { Consumida } \\
\text { anual }\end{array}$ & \multirow[t]{2}{*}{$\begin{array}{l}\text { Tipo post } \\
\text { mejora }\end{array}$} & $\begin{array}{c}\text { Potencia } \\
\text { nominal } \\
\text { post } \\
\text { mejora }\end{array}$ & $\begin{array}{c}\text { Rendimiento } \\
\text { estacional } \\
\text { post mejora }\end{array}$ & $\begin{array}{c}\text { Estimación } \\
\text { Energía } \\
\text { Consumida } \\
\text { anual Post } \\
\text { mejora }\end{array}$ & $\begin{array}{c}\text { Energía } \\
\text { anual } \\
\text { ahorrada }\end{array}$ \\
\hline & & {$[\mathrm{kW}]$} & {$[\%]$} & {$\left[\mathrm{kWh} / \mathrm{m}^{2} \mathrm{año}\right]$} & & {$[\mathrm{kW}]$} & {$[\%]$} & [kWh/m²año] & {$\left[\mathrm{kWh} / \mathrm{m}^{2} \mathrm{año}\right.$} \\
\hline $\begin{array}{l}\text { Calefacción y } \\
\text { refrigeración }\end{array}$ & $\begin{array}{c}\text { Bomba de } \\
\text { Calor - } \\
\text { Caudal Ref. } \\
\text { Variable }\end{array}$ & & $249.8 \%$ & - & $\begin{array}{c}\text { Bomba de } \\
\text { Calor - } \\
\text { Caudal Ref. } \\
\text { Variable }\end{array}$ & & $558.7 \%$ & - & - \\
\hline TOTALES & & - & & - & & - & & - & - \\
\hline
\end{tabular}

\section{Instalaciones de Agua Caliente Sanitaria}

\begin{tabular}{|c|c|c|c|c|c|c|c|c|c|}
\hline Nombre & Tipo & $\begin{array}{l}\text { Potencia } \\
\text { nominal }\end{array}$ & $\begin{array}{c}\text { Rendi- } \\
\text { miento } \\
\text { Estacional }\end{array}$ & $\begin{array}{c}\text { Estimación } \\
\text { Energía } \\
\text { Consumida } \\
\text { anual }\end{array}$ & $\begin{array}{c}\text { Tipo post } \\
\text { mejora }\end{array}$ & $\begin{array}{l}\text { Potencia } \\
\text { nominal } \\
\text { post } \\
\text { mejora }\end{array}$ & $\begin{array}{c}\text { Rendimiento } \\
\text { estacional } \\
\text { post mejora }\end{array}$ & $\begin{array}{c}\text { Estimación } \\
\text { Energía } \\
\text { Consumida } \\
\text { anual Post } \\
\text { mejora }\end{array}$ & $\begin{array}{l}\text { Energía } \\
\text { anual } \\
\text { ahorrada }\end{array}$ \\
\hline & & {$[\mathrm{kW}]$} & [\%] & {$\left[\mathrm{kWh} / \mathrm{m}^{2} \mathrm{año}\right]$} & & {$[\mathrm{kW}]$} & [\%] & [kWh/m²año] & [kWh/m²año] \\
\hline Equipo ACS & Efecto Joule & & $100.0 \%$ & - & Efecto Joule & & $100.0 \%$ & - & - \\
\hline TOTALES & & - & & - & & - & & - & - \\
\hline
\end{tabular}




\begin{tabular}{|c|c|c|c|c|c|}
\hline & DEN & $\begin{array}{c}\text { Ref. } \\
\text { Catastral }\end{array}$ & 000000000 & $\begin{array}{c}\text { Versión } \\
\text { informe } \\
\text { asociado }\end{array}$ & $01 / 12 / 2015$ \\
\hline $\begin{array}{c}\text { Certificación } \\
\text { Energatica } \\
\text { de Edificios } \\
\text { de Editios }\end{array}$ & $\begin{array}{c}\text { Id. } \\
\text { Mejora }\end{array}$ & $\begin{array}{l}\text { Programa } \\
\text { y versión }\end{array}$ & CEXv2.1 & Fecha & $4 / 1 / 2004$ \\
\hline
\end{tabular}

\section{ENERGÍAS RENOVABLES}

\section{Térmica}

\begin{tabular}{|c|c|c|c|c|}
\hline \multirow{2}{*}{ Nombre } & \multicolumn{3}{|c|}{$\begin{array}{c}\text { Consumo de Energía Final, cubierto en función } \\
\text { del servicio asociado [\%] }\end{array}$} & $\begin{array}{c}\text { Demanda de ACS } \\
\text { cubierta [\%] }\end{array}$ \\
\cline { 2 - 5 } & Calefacción & Refrigeración & ACS & \\
\hline- & - & - & - & - \\
\hline TOTALES & - & - & - & - \\
\hline
\end{tabular}

\section{Post mejora}

\begin{tabular}{|c|c|c|c|c|}
\hline \multirow{2}{*}{ Nombre } & \multicolumn{2}{|c|}{$\begin{array}{c}\text { Consumo de Energía Final, cubierto en función } \\
\text { del servicio asociado [\%] }\end{array}$} & $\begin{array}{c}\text { Demanda de ACS } \\
\text { cubierta [\%] }\end{array}$ \\
\cline { 2 - 5 } & Calefacción & Refrigeración & ACS & \\
\hline Sistema Geotérmico & 100 & 100 & - & - \\
\hline TOTALES & 100.0 & 100.0 & - & - \\
\hline
\end{tabular}




\begin{tabular}{|c|c|c|c|c|c|}
\hline & & $\begin{array}{c}\text { Ref. } \\
\text { Catastral }\end{array}$ & 000000000 & $\begin{array}{c}\text { Versión } \\
\text { informe } \\
\text { asociado }\end{array}$ & $01 / 12 / 2015$ \\
\hline $\begin{array}{l}\text { Certificación } \\
\text { Energética } \\
\text { de Edificios }\end{array}$ & $\begin{array}{c}\text { Id. } \\
\text { Mejora }\end{array}$ & $\begin{array}{l}\text { Programa } \\
\text { y versión }\end{array}$ & CEXv2.1 & Fecha & $4 / 1 / 2004$ \\
\hline
\end{tabular}

\section{Informe descriptivo de la medida de mejora}

\section{DENOMINACIÓN DE LA MEDIDA DE MEJORA}

Bomba de calor alto cop y eer con geotermia y vidrios activos

\section{DESCRIPCIÓN DE LA MEDIDA DE MEJORA}

Características de la medida (modelo de equipos, materiales, parámetros característicos )

Coste estimado de la medida

Otros datos de interés

CALIFICACIÓN ENERGÉTICA GLOBAL

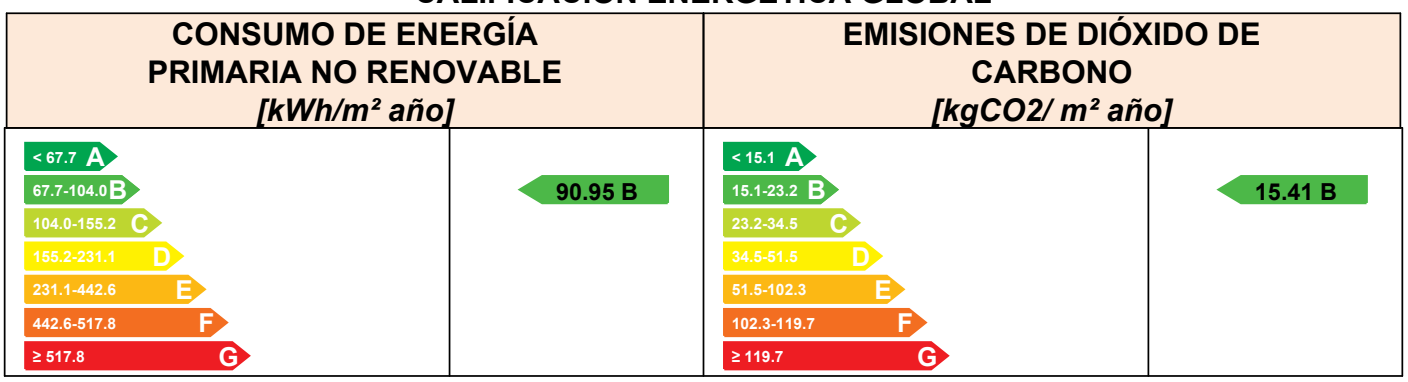

CALIFICACIONES ENERGÉTICAS PARCIALES

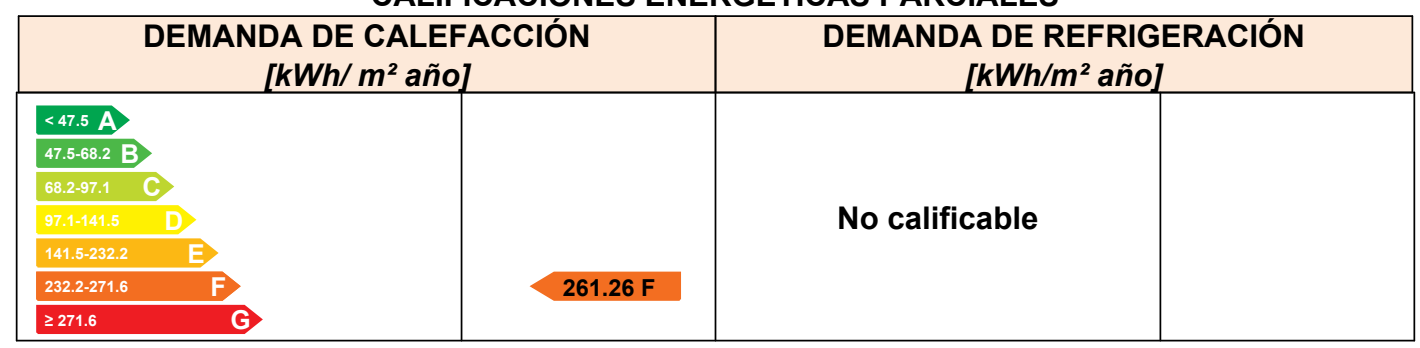




\begin{tabular}{|c|c|c|c|c|c|}
\hline & & $\begin{array}{c}\text { Ref. } \\
\text { Catastral }\end{array}$ & 000000000 & $\begin{array}{c}\text { Versión } \\
\text { informe } \\
\text { asociado }\end{array}$ & $01 / 12 / 2015$ \\
\hline $\begin{array}{l}\text { Certificación } \\
\text { Energética } \\
\text { de Edificios }\end{array}$ & $\begin{array}{c}\text { Id. } \\
\text { Mejora }\end{array}$ & $\begin{array}{l}\text { Programa } \\
\text { y versión }\end{array}$ & CEXv2.1 & Fecha & $4 / 1 / 2004$ \\
\hline
\end{tabular}

\section{ANALISÍS TÉCNICO}

\begin{tabular}{|c|c|c|c|c|c|c|c|c|c|c|c|c|c|c|c|}
\hline \multirow[b]{2}{*}{ Indicador } & \multicolumn{3}{|c|}{ Calefacción } & \multicolumn{3}{|c|}{ Refrigeración } & \multicolumn{3}{|c|}{ ACS } & \multicolumn{3}{|c|}{ Iluminación } & \multicolumn{3}{|c|}{ Total } \\
\hline & \multicolumn{2}{|c|}{ Valor } & $\begin{array}{l}\text { ahorro } \\
\text { respecto a } \\
\text { la situación } \\
\text { original }\end{array}$ & \multicolumn{2}{|c|}{ Valor } & $\begin{array}{c}\text { ahorro } \\
\text { respecto a } \\
\text { la situación } \\
\text { original }\end{array}$ & \multicolumn{2}{|c|}{ Valor } & $\begin{array}{l}\text { ahorro } \\
\text { respecto a } \\
\text { la situación } \\
\text { original }\end{array}$ & \multicolumn{2}{|c|}{ Valor } & $\begin{array}{l}\text { ahorro } \\
\text { respecto a } \\
\text { la situación } \\
\text { original }\end{array}$ & \multicolumn{2}{|c|}{ Valor } & $\begin{array}{c}\text { ahorro } \\
\text { respecto a } \\
\text { la situación } \\
\text { original }\end{array}$ \\
\hline $\begin{array}{l}\text { Consumo Energía } \\
\text { final }\left[\mathrm{kWh} / \mathrm{m}^{2} \text { año] }\right.\end{array}$ & \multicolumn{2}{|c|}{0.00} & $100.0 \%$ & \multicolumn{2}{|c|}{-} & $-\%$ & \multicolumn{2}{|c|}{46.54} & $0.0 \%$ & \multicolumn{2}{|l|}{-} & $-\%$ & \multicolumn{2}{|c|}{46.54} & $75.3 \%$ \\
\hline $\begin{array}{c}\text { Consumo Energía } \\
\text { primaria no renovable } \\
{\left[\mathrm{kWh} / \mathrm{m}^{2} \text { año] }\right.}\end{array}$ & 0.00 & A & $100.0 \%$ & - & - & $-\%$ & 90.95 & G & $0.0 \%$ & - & - & $-\%$ & 90.95 & B & $75.3 \%$ \\
\hline $\begin{array}{c}\text { Emisiones de CO2 } \\
{\left[\mathrm{kgCO} 2 / \mathrm{m}^{2} \text { año] }\right.}\end{array}$ & 0.00 & A & $100.0 \%$ & - & - & $-\%$ & 15.41 & G & $0.0 \%$ & - & - & $-\%$ & 15.41 & B & $75.3 \%$ \\
\hline $\begin{array}{l}\text { Demanda }\left[\mathrm{kWh} / \mathrm{m}^{2}\right. \\
\text { año] }\end{array}$ & 261.26 & $\mathrm{~F}$ & $21.3 \%$ & - & - & $-\%$ & & & & & & & & & \\
\hline
\end{tabular}

\section{ENVOLVENTE TÉRMICA}

\section{Cerramientos opacos}

\begin{tabular}{|c|c|c|c|c|c|}
\hline Nombre & Tipo & $\begin{array}{c}\text { Superficie } \\
\text { actual } \\
{\left[\mathbf{m}^{2}\right]}\end{array}$ & $\begin{array}{c}\text { Transmitancia } \\
\text { actual } \\
{\left[\mathbf{W} / \mathbf{m}^{\mathbf{2}} \mathbf{~ K}\right]}\end{array}$ & $\begin{array}{c}\text { Superficie } \\
\text { post } \\
\text { mejora } \\
{\left[\mathbf{m}^{2}\right]}\end{array}$ & $\begin{array}{c}\text { Transmitancia } \\
\text { post mejora } \\
{\left[\mathbf{W} / \mathbf{m}^{\mathbf{2}} \mathbf{K}\right]}\end{array}$ \\
\hline Cubierta con aire & Cubierta & 52.00 & 0.47 & 52.00 & 0.47 \\
\hline Muro de fachada Norte & Fachada & 27.18 & 0.54 & 27.18 & 0.54 \\
\hline Suelo con aire & Suelo & 52.00 & 2.95 & 52.00 & 2.95 \\
\hline Muro de fachada Sur & Fachada & 21.88 & 0.54 & 21.88 & 0.54 \\
\hline Muro de fachada Oeste & Fachada & 8.04 & 0.54 & 8.04 & 0.54 \\
\hline Muro de fachada Este & Fachada & 3.28 & 0.54 & 3.28 & 0.54 \\
\hline
\end{tabular}

Huecos y lucernarios

\begin{tabular}{|c|c|c|c|c|c|c|c|}
\hline Nombre & Tipo & $\begin{array}{c}\text { Superficie } \\
\text { actual } \\
{\left[\mathrm{m}^{2}\right]}\end{array}$ & $\begin{array}{c}\text { Transmitancia } \\
\text { actual del } \\
\text { hueco[W/m² } \\
\mathrm{K}]\end{array}$ & $\begin{array}{c}\text { Transmitancia } \\
\text { actual del } \\
\text { vidrio[W/m² } \\
\mathrm{K}]\end{array}$ & $\begin{array}{c}\text { Superficie } \\
\text { post } \\
\text { mejora } \\
{\left[\mathrm{m}^{2}\right]}\end{array}$ & $\begin{array}{c}\text { Transmitancia } \\
\text { post mejora } \\
{\left[\mathrm{W} / \mathrm{m}^{2} \mathrm{~K}\right]}\end{array}$ & $\begin{array}{c}\text { Transmitancia } \\
\text { post mejora } \\
\text { del vidrio } \\
{\left[\mathrm{W} / \mathrm{m}^{2} \mathrm{~K}\right]}\end{array}$ \\
\hline V1 & Hueco & 5.3 & 5.70 & 5.70 & 5.3 & 1.27 & 1.12 \\
\hline V3 & Hueco & 5.3 & 5.70 & 5.70 & 5.3 & 1.27 & 1.12 \\
\hline V4 & Hueco & 5.3 & 5.70 & 5.70 & 5.3 & 1.27 & 1.12 \\
\hline V2 & Hueco & 5.3 & 5.70 & 5.70 & 5.3 & 1.27 & 1.12 \\
\hline V5 & Hueco & 5.03 & 5.70 & 5.70 & 5.03 & 1.27 & 1.12 \\
\hline Pta & Hueco & 5.03 & 5.70 & 5.70 & 5.03 & 1.27 & 1.12 \\
\hline
\end{tabular}




\begin{tabular}{|c|c|c|c|c|c|}
\hline & & $\begin{array}{c}\text { Ref. } \\
\text { Catastral }\end{array}$ & 000000000 & $\begin{array}{c}\text { Versión } \\
\text { informe } \\
\text { asociado }\end{array}$ & $01 / 12 / 2015$ \\
\hline $\begin{array}{l}\text { Certificación } \\
\text { Energética } \\
\text { de Edificios }\end{array}$ & $\begin{array}{c}\text { Id. } \\
\text { Mejora }\end{array}$ & $\begin{array}{l}\text { Programa } \\
\text { y versión }\end{array}$ & CEXv2.1 & Fecha & $4 / 1 / 2004$ \\
\hline
\end{tabular}

\section{INSTALACIONES TÉRMICAS}

\section{Generadores de calefacción}

\begin{tabular}{|c|c|c|c|c|c|c|c|c|c|}
\hline \multirow[t]{2}{*}{ Nombre } & \multirow[t]{2}{*}{ Tipo } & $\begin{array}{r}\text { Potencia } \\
\text { nominal }\end{array}$ & $\begin{array}{l}\text { Rendi- } \\
\text { miento } \\
\text { Estacional }\end{array}$ & $\begin{array}{c}\text { Estimación } \\
\text { Energía } \\
\text { Consumida } \\
\text { anual }\end{array}$ & \multirow[t]{2}{*}{$\begin{array}{l}\text { Tipo post } \\
\text { mejora }\end{array}$} & $\begin{array}{c}\text { Potencia } \\
\text { nominal } \\
\text { post } \\
\text { mejora }\end{array}$ & $\begin{array}{c}\text { Rendimiento } \\
\text { estacional } \\
\text { post mejora }\end{array}$ & $\begin{array}{c}\text { Estimación } \\
\text { Energía } \\
\text { Consumida } \\
\text { anual Post } \\
\text { mejora }\end{array}$ & $\begin{array}{l}\text { Energía } \\
\text { anual } \\
\text { ahorrada }\end{array}$ \\
\hline & & {$[\mathrm{kW}]$} & [\%] & {$\left[\mathrm{kWh} / \mathrm{m}^{2} \mathrm{año}\right]$} & & {$[\mathrm{kW}]$} & [\%] & [kWh/m²año] & [kWh/m²año] \\
\hline $\begin{array}{l}\text { Calefacción y } \\
\text { refrigeración }\end{array}$ & $\begin{array}{c}\text { Bomba de } \\
\text { Calor - } \\
\text { Caudal Ref. } \\
\text { Variable }\end{array}$ & & $245.2 \%$ & - & $\begin{array}{c}\text { Bomba de } \\
\text { Calor - } \\
\text { Caudal Ref. } \\
\text { Variable }\end{array}$ & & $434.6 \%$ & - & - \\
\hline TOTALES & & & & & & & & & \\
\hline
\end{tabular}

\section{Generadores de refrigeración}

\begin{tabular}{|c|c|c|c|c|c|c|c|c|c|}
\hline \multirow[t]{2}{*}{ Nombre } & \multirow[t]{2}{*}{ Tipo } & $\begin{array}{r}\text { Potencia } \\
\text { nominal }\end{array}$ & $\begin{array}{c}\text { Rendi- } \\
\text { miento } \\
\text { Estacional }\end{array}$ & $\begin{array}{c}\text { Estimación } \\
\text { Energía } \\
\text { Consumida } \\
\text { anual }\end{array}$ & \multirow[t]{2}{*}{$\begin{array}{l}\text { Tipo post } \\
\text { mejora }\end{array}$} & $\begin{array}{c}\text { Potencia } \\
\text { nominal } \\
\text { post } \\
\text { mejora }\end{array}$ & $\begin{array}{c}\text { Rendimiento } \\
\text { estacional } \\
\text { post mejora }\end{array}$ & $\begin{array}{c}\text { Estimación } \\
\text { Energía } \\
\text { Consumida } \\
\text { anual Post } \\
\text { mejora }\end{array}$ & $\begin{array}{c}\text { Energía } \\
\text { anual } \\
\text { ahorrada }\end{array}$ \\
\hline & & {$[\mathrm{kW}]$} & {$[\%]$} & {$\left[\mathrm{kWh} / \mathrm{m}^{2} \mathrm{año}\right]$} & & {$[\mathrm{kW}]$} & {$[\%]$} & [kWh/m²año] & {$\left[\mathrm{kWh} / \mathrm{m}^{2} \mathrm{año}\right.$} \\
\hline $\begin{array}{l}\text { Calefacción y } \\
\text { refrigeración }\end{array}$ & $\begin{array}{c}\text { Bomba de } \\
\text { Calor - } \\
\text { Caudal Ref. } \\
\text { Variable }\end{array}$ & & $249.8 \%$ & - & $\begin{array}{c}\text { Bomba de } \\
\text { Calor - } \\
\text { Caudal Ref. } \\
\text { Variable }\end{array}$ & & $558.7 \%$ & - & - \\
\hline TOTALES & & - & & - & & - & & - & - \\
\hline
\end{tabular}

\section{Instalaciones de Agua Caliente Sanitaria}

\begin{tabular}{|c|c|c|c|c|c|c|c|c|c|}
\hline Nombre & Tipo & $\begin{array}{l}\text { Potencia } \\
\text { nominal }\end{array}$ & $\begin{array}{c}\text { Rendi- } \\
\text { miento } \\
\text { Estacional }\end{array}$ & $\begin{array}{c}\text { Estimación } \\
\text { Energía } \\
\text { Consumida } \\
\text { anual }\end{array}$ & $\begin{array}{c}\text { Tipo post } \\
\text { mejora }\end{array}$ & $\begin{array}{l}\text { Potencia } \\
\text { nominal } \\
\text { post } \\
\text { mejora }\end{array}$ & $\begin{array}{c}\text { Rendimiento } \\
\text { estacional } \\
\text { post mejora }\end{array}$ & $\begin{array}{c}\text { Estimación } \\
\text { Energía } \\
\text { Consumida } \\
\text { anual Post } \\
\text { mejora }\end{array}$ & $\begin{array}{l}\text { Energía } \\
\text { anual } \\
\text { ahorrada }\end{array}$ \\
\hline & & {$[\mathrm{kW}]$} & [\%] & {$\left[\mathrm{kWh} / \mathrm{m}^{2} \mathrm{año}\right]$} & & {$[\mathrm{kW}]$} & [\%] & [kWh/m²año] & [kWh/m²año] \\
\hline Equipo ACS & Efecto Joule & & $100.0 \%$ & - & Efecto Joule & & $100.0 \%$ & - & - \\
\hline TOTALES & & - & & - & & - & & - & - \\
\hline
\end{tabular}




\begin{tabular}{|c|c|c|c|c|c|}
\hline & DEN & $\begin{array}{c}\text { Ref. } \\
\text { Catastral }\end{array}$ & 000000000 & $\begin{array}{c}\text { Versión } \\
\text { informe } \\
\text { asociado }\end{array}$ & $01 / 12 / 2015$ \\
\hline $\begin{array}{c}\text { Certificación } \\
\text { Energatica } \\
\text { de Edificios } \\
\text { de Editios }\end{array}$ & $\begin{array}{c}\text { Id. } \\
\text { Mejora }\end{array}$ & $\begin{array}{l}\text { Programa } \\
\text { y versión }\end{array}$ & CEXv2.1 & Fecha & $4 / 1 / 2004$ \\
\hline
\end{tabular}

\section{ENERGÍAS RENOVABLES}

\section{Térmica}

\begin{tabular}{|c|c|c|c|c|}
\hline \multirow{2}{*}{ Nombre } & \multicolumn{3}{|c|}{$\begin{array}{c}\text { Consumo de Energía Final, cubierto en función } \\
\text { del servicio asociado [\%] }\end{array}$} & $\begin{array}{c}\text { Demanda de ACS } \\
\text { cubierta [\%] }\end{array}$ \\
\cline { 2 - 5 } & Calefacción & Refrigeración & ACS & \\
\hline- & - & - & - & - \\
\hline TOTALES & - & - & - & - \\
\hline
\end{tabular}

\section{Post mejora}

\begin{tabular}{|c|c|c|c|c|}
\hline \multirow{2}{*}{ Nombre } & \multicolumn{2}{|c|}{$\begin{array}{c}\text { Consumo de Energía Final, cubierto en función } \\
\text { del servicio asociado [\%] }\end{array}$} & $\begin{array}{c}\text { Demanda de ACS } \\
\text { cubierta [\%] }\end{array}$ \\
\cline { 2 - 5 } & Calefacción & Refrigeración & ACS & \\
\hline Sistema Geotérmico & 100 & 100 & - & - \\
\hline TOTALES & 100.0 & 100.0 & - & - \\
\hline
\end{tabular}




\begin{tabular}{|c|c|c|c|c|c|}
\hline & & $\begin{array}{c}\text { Ref. } \\
\text { Catastral }\end{array}$ & 000000000 & $\begin{array}{c}\text { Versión } \\
\text { informe } \\
\text { asociado }\end{array}$ & $01 / 12 / 2015$ \\
\hline $\begin{array}{l}\text { Certificación } \\
\text { Energética } \\
\text { de Edificios }\end{array}$ & $\begin{array}{c}\text { Id. } \\
\text { Mejora }\end{array}$ & $\begin{array}{l}\text { Programa } \\
\text { y versión }\end{array}$ & CEXv2.1 & Fecha & $4 / 1 / 2004$ \\
\hline
\end{tabular}

\section{Informe descriptivo de la medida de mejora}

\section{DENOMINACIÓN DE LA MEDIDA DE MEJORA}

FV+ Bomba de calor alto cop y eer con geotermia y vidrios activos

\section{DESCRIPCIÓN DE LA MEDIDA DE MEJORA}

Características de la medida (modelo de equipos, materiales, parámetros característicos )

Coste estimado de la medida

Otros datos de interés

CALIFICACIÓN ENERGÉTICA GLOBAL

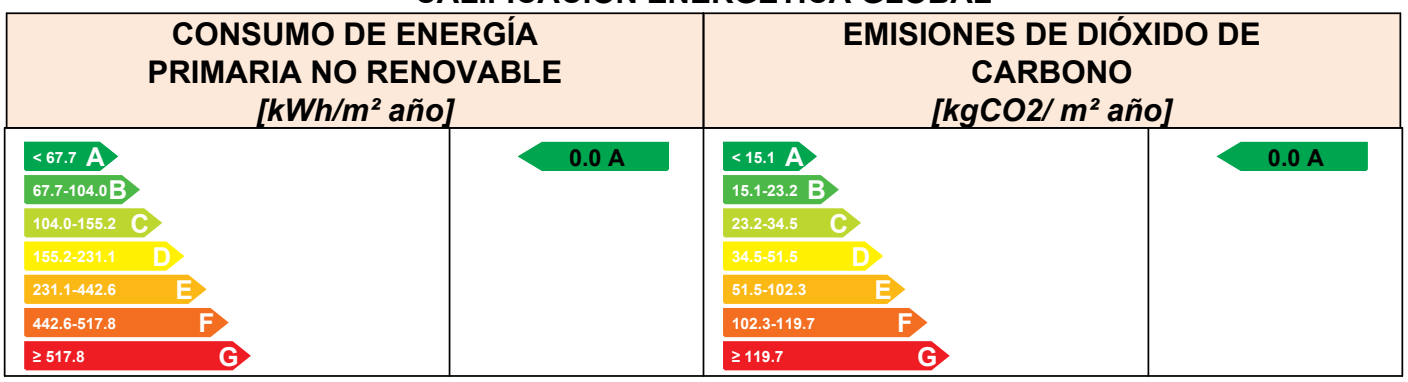

CALIFICACIONES ENERGÉTICAS PARCIALES

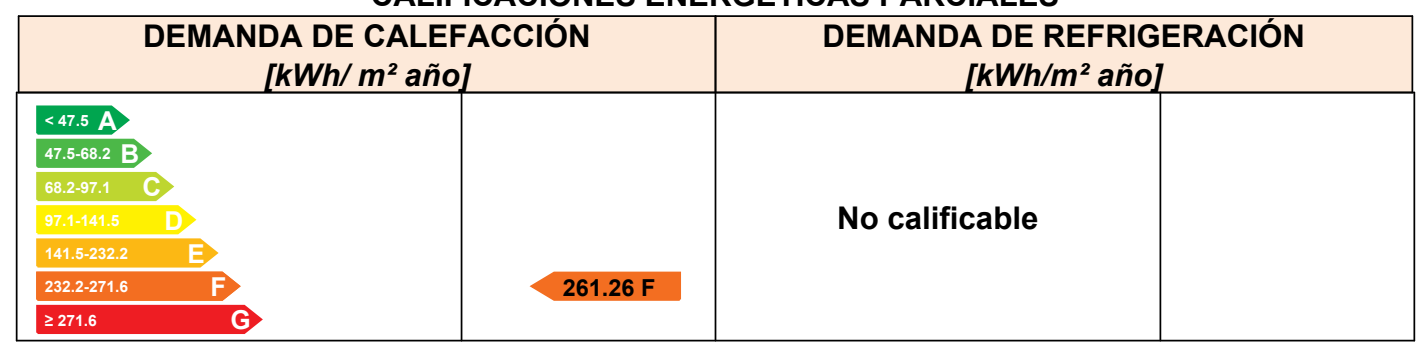




\begin{tabular}{|c|c|c|c|c|c|}
\hline & & $\begin{array}{c}\text { Ref. } \\
\text { Catastral }\end{array}$ & 000000000 & $\begin{array}{c}\text { Versión } \\
\text { informe } \\
\text { asociado }\end{array}$ & $01 / 12 / 2015$ \\
\hline $\begin{array}{l}\text { Certificación } \\
\text { Energética } \\
\text { de Edificios }\end{array}$ & $\begin{array}{c}\text { Id. } \\
\text { Mejora }\end{array}$ & $\begin{array}{l}\text { Programa } \\
\text { y versión }\end{array}$ & CEXv2.1 & Fecha & $4 / 1 / 2004$ \\
\hline
\end{tabular}

\section{ANALISÍS TÉCNICO}

\begin{tabular}{|c|c|c|c|c|c|c|c|c|c|c|c|c|c|c|c|}
\hline \multirow[b]{2}{*}{ Indicador } & \multicolumn{3}{|c|}{ Calefacción } & \multicolumn{3}{|c|}{ Refrigeración } & \multicolumn{3}{|c|}{ ACS } & \multicolumn{3}{|c|}{ Iluminación } & \multicolumn{3}{|c|}{ Total } \\
\hline & \multicolumn{2}{|c|}{ Valor } & $\begin{array}{l}\text { ahorro } \\
\text { respecto a } \\
\text { la situación } \\
\text { original }\end{array}$ & \multicolumn{2}{|c|}{ Valor } & $\begin{array}{c}\text { ahorro } \\
\text { respecto a } \\
\text { la situación } \\
\text { original }\end{array}$ & \multicolumn{2}{|c|}{ Valor } & $\begin{array}{c}\text { ahorro } \\
\text { respecto a } \\
\text { la situación } \\
\text { original }\end{array}$ & \multicolumn{2}{|c|}{ Valor } & $\begin{array}{l}\text { ahorro } \\
\text { respecto a } \\
\text { la situación } \\
\text { original }\end{array}$ & \multicolumn{2}{|c|}{ Valor } & $\begin{array}{c}\text { ahorro } \\
\text { respecto a } \\
\text { la situación } \\
\text { original }\end{array}$ \\
\hline $\begin{array}{l}\text { Consumo Energía } \\
\text { final }\left[\mathrm{kWh} / \mathrm{m}^{2} \text { año] }\right.\end{array}$ & \multicolumn{2}{|c|}{0.00} & $100.0 \%$ & \multicolumn{2}{|c|}{-} & $-\%$ & \multicolumn{2}{|c|}{46.54} & $0.0 \%$ & \multicolumn{2}{|l|}{-} & $-\%$ & \multicolumn{2}{|c|}{-60.51} & $132.1 \%$ \\
\hline $\begin{array}{c}\text { Consumo Energía } \\
\text { primaria no renovable } \\
{\left[\mathrm{kWh} / \mathrm{m}^{2} \text { año] }\right.}\end{array}$ & 0.00 & A & $100.0 \%$ & - & - & $-\%$ & 90.95 & G & $0.0 \%$ & - & - & $-\%$ & 0.00 & A & $100.0 \%$ \\
\hline $\begin{array}{c}\text { Emisiones de CO2 } \\
{\left[\mathrm{kgCO} 2 / \mathrm{m}^{2} \text { año] }\right.}\end{array}$ & 0.00 & A & $100.0 \%$ & - & - & $-\%$ & 15.41 & G & $0.0 \%$ & - & - & $-\%$ & 0.00 & A & $100.0 \%$ \\
\hline $\begin{array}{l}\text { Demanda }\left[\mathrm{kWh} / \mathrm{m}^{2}\right. \\
\text { año] }\end{array}$ & 261.26 & $\mathrm{~F}$ & $21.3 \%$ & - & - & $-\%$ & & & & & & & & & \\
\hline
\end{tabular}

\section{ENVOLVENTE TÉRMICA}

\section{Cerramientos opacos}

\begin{tabular}{|c|c|c|c|c|c|}
\hline Nombre & Tipo & $\begin{array}{c}\text { Superficie } \\
\text { actual } \\
{\left[\mathbf{m}^{2}\right]}\end{array}$ & $\begin{array}{c}\text { Transmitancia } \\
\text { actual } \\
{\left[\mathbf{W} / \mathbf{m}^{\mathbf{2}} \mathbf{~ K}\right]}\end{array}$ & $\begin{array}{c}\text { Superficie } \\
\text { post } \\
\text { mejora } \\
{\left[\mathbf{m}^{2}\right]}\end{array}$ & $\begin{array}{c}\text { Transmitancia } \\
\text { post mejora } \\
{\left[\mathbf{W} / \mathbf{m}^{\mathbf{2}} \mathbf{K}\right]}\end{array}$ \\
\hline Cubierta con aire & Cubierta & 52.00 & 0.47 & 52.00 & 0.47 \\
\hline Muro de fachada Norte & Fachada & 27.18 & 0.54 & 27.18 & 0.54 \\
\hline Suelo con aire & Suelo & 52.00 & 2.95 & 52.00 & 2.95 \\
\hline Muro de fachada Sur & Fachada & 21.88 & 0.54 & 21.88 & 0.54 \\
\hline Muro de fachada Oeste & Fachada & 8.04 & 0.54 & 8.04 & 0.54 \\
\hline Muro de fachada Este & Fachada & 3.28 & 0.54 & 3.28 & 0.54 \\
\hline
\end{tabular}

Huecos y lucernarios

\begin{tabular}{|c|c|c|c|c|c|c|c|}
\hline Nombre & Tipo & $\begin{array}{c}\text { Superficie } \\
\text { actual } \\
{\left[\mathrm{m}^{2}\right]}\end{array}$ & $\begin{array}{c}\text { Transmitancia } \\
\text { actual del } \\
\text { hueco[W/m² } \\
\mathrm{K}]\end{array}$ & $\begin{array}{c}\text { Transmitancia } \\
\text { actual del } \\
\text { vidrio[W/m² } \\
\mathrm{K}]\end{array}$ & $\begin{array}{c}\text { Superficie } \\
\text { post } \\
\text { mejora } \\
{\left[\mathrm{m}^{2}\right]}\end{array}$ & $\begin{array}{c}\text { Transmitancia } \\
\text { post mejora } \\
{\left[\mathrm{W} / \mathrm{m}^{2} \mathrm{~K}\right]}\end{array}$ & $\begin{array}{c}\text { Transmitancia } \\
\text { post mejora } \\
\text { del vidrio } \\
{\left[\mathrm{W} / \mathrm{m}^{2} \mathrm{~K}\right]}\end{array}$ \\
\hline V1 & Hueco & 5.3 & 5.70 & 5.70 & 5.3 & 1.27 & 1.12 \\
\hline V3 & Hueco & 5.3 & 5.70 & 5.70 & 5.3 & 1.27 & 1.12 \\
\hline V4 & Hueco & 5.3 & 5.70 & 5.70 & 5.3 & 1.27 & 1.12 \\
\hline V2 & Hueco & 5.3 & 5.70 & 5.70 & 5.3 & 1.27 & 1.12 \\
\hline V5 & Hueco & 5.03 & 5.70 & 5.70 & 5.03 & 1.27 & 1.12 \\
\hline Pta & Hueco & 5.03 & 5.70 & 5.70 & 5.03 & 1.27 & 1.12 \\
\hline
\end{tabular}




\begin{tabular}{|c|c|c|c|c|c|}
\hline & & $\begin{array}{c}\text { Ref. } \\
\text { Catastral }\end{array}$ & 000000000 & $\begin{array}{c}\text { Versión } \\
\text { informe } \\
\text { asociado }\end{array}$ & $01 / 12 / 2015$ \\
\hline $\begin{array}{l}\text { Certificación } \\
\text { Energética } \\
\text { de Edificios }\end{array}$ & $\begin{array}{c}\text { Id. } \\
\text { Mejora }\end{array}$ & $\begin{array}{l}\text { Programa } \\
\text { y versión }\end{array}$ & CEXv2.1 & Fecha & $4 / 1 / 2004$ \\
\hline
\end{tabular}

\section{INSTALACIONES TÉRMICAS}

\section{Generadores de calefacción}

\begin{tabular}{|c|c|c|c|c|c|c|c|c|c|}
\hline \multirow[t]{2}{*}{ Nombre } & \multirow[t]{2}{*}{ Tipo } & $\begin{array}{r}\text { Potencia } \\
\text { nominal }\end{array}$ & $\begin{array}{l}\text { Rendi- } \\
\text { miento } \\
\text { Estacional }\end{array}$ & $\begin{array}{c}\text { Estimación } \\
\text { Energía } \\
\text { Consumida } \\
\text { anual }\end{array}$ & \multirow[t]{2}{*}{$\begin{array}{l}\text { Tipo post } \\
\text { mejora }\end{array}$} & $\begin{array}{c}\text { Potencia } \\
\text { nominal } \\
\text { post } \\
\text { mejora }\end{array}$ & $\begin{array}{c}\text { Rendimiento } \\
\text { estacional } \\
\text { post mejora }\end{array}$ & $\begin{array}{c}\text { Estimación } \\
\text { Energía } \\
\text { Consumida } \\
\text { anual Post } \\
\text { mejora }\end{array}$ & $\begin{array}{l}\text { Energía } \\
\text { anual } \\
\text { ahorrada }\end{array}$ \\
\hline & & {$[\mathrm{kW}]$} & [\%] & {$\left[\mathrm{kWh} / \mathrm{m}^{2} \mathrm{año}\right]$} & & {$[\mathrm{kW}]$} & [\%] & [kWh/m²año] & [kWh/m²año] \\
\hline $\begin{array}{l}\text { Calefacción y } \\
\text { refrigeración }\end{array}$ & $\begin{array}{c}\text { Bomba de } \\
\text { Calor - } \\
\text { Caudal Ref. } \\
\text { Variable }\end{array}$ & & $245.2 \%$ & - & $\begin{array}{c}\text { Bomba de } \\
\text { Calor - } \\
\text { Caudal Ref. } \\
\text { Variable }\end{array}$ & & $434.6 \%$ & - & - \\
\hline TOTALES & & & & & & & & & \\
\hline
\end{tabular}

\section{Generadores de refrigeración}

\begin{tabular}{|c|c|c|c|c|c|c|c|c|c|}
\hline \multirow[t]{2}{*}{ Nombre } & \multirow[t]{2}{*}{ Tipo } & $\begin{array}{r}\text { Potencia } \\
\text { nominal }\end{array}$ & $\begin{array}{c}\text { Rendi- } \\
\text { miento } \\
\text { Estacional }\end{array}$ & $\begin{array}{c}\text { Estimación } \\
\text { Energía } \\
\text { Consumida } \\
\text { anual }\end{array}$ & \multirow[t]{2}{*}{$\begin{array}{l}\text { Tipo post } \\
\text { mejora }\end{array}$} & $\begin{array}{c}\text { Potencia } \\
\text { nominal } \\
\text { post } \\
\text { mejora }\end{array}$ & $\begin{array}{c}\text { Rendimiento } \\
\text { estacional } \\
\text { post mejora }\end{array}$ & $\begin{array}{c}\text { Estimación } \\
\text { Energía } \\
\text { Consumida } \\
\text { anual Post } \\
\text { mejora }\end{array}$ & $\begin{array}{c}\text { Energía } \\
\text { anual } \\
\text { ahorrada }\end{array}$ \\
\hline & & {$[\mathrm{kW}]$} & {$[\%]$} & {$\left[\mathrm{kWh} / \mathrm{m}^{2} \mathrm{año}\right]$} & & {$[\mathrm{kW}]$} & {$[\%]$} & [kWh/m²año] & {$\left[\mathrm{kWh} / \mathrm{m}^{2} \mathrm{año}\right.$} \\
\hline $\begin{array}{l}\text { Calefacción y } \\
\text { refrigeración }\end{array}$ & $\begin{array}{c}\text { Bomba de } \\
\text { Calor - } \\
\text { Caudal Ref. } \\
\text { Variable }\end{array}$ & & $249.8 \%$ & - & $\begin{array}{c}\text { Bomba de } \\
\text { Calor - } \\
\text { Caudal Ref. } \\
\text { Variable }\end{array}$ & & $558.7 \%$ & - & - \\
\hline TOTALES & & - & & - & & - & & - & - \\
\hline
\end{tabular}

\section{Instalaciones de Agua Caliente Sanitaria}

\begin{tabular}{|c|c|c|c|c|c|c|c|c|c|}
\hline Nombre & Tipo & $\begin{array}{l}\text { Potencia } \\
\text { nominal }\end{array}$ & $\begin{array}{c}\text { Rendi- } \\
\text { miento } \\
\text { Estacional }\end{array}$ & $\begin{array}{c}\text { Estimación } \\
\text { Energía } \\
\text { Consumida } \\
\text { anual }\end{array}$ & $\begin{array}{c}\text { Tipo post } \\
\text { mejora }\end{array}$ & $\begin{array}{l}\text { Potencia } \\
\text { nominal } \\
\text { post } \\
\text { mejora }\end{array}$ & $\begin{array}{c}\text { Rendimiento } \\
\text { estacional } \\
\text { post mejora }\end{array}$ & $\begin{array}{c}\text { Estimación } \\
\text { Energía } \\
\text { Consumida } \\
\text { anual Post } \\
\text { mejora }\end{array}$ & $\begin{array}{l}\text { Energía } \\
\text { anual } \\
\text { ahorrada }\end{array}$ \\
\hline & & {$[\mathrm{kW}]$} & [\%] & {$\left[\mathrm{kWh} / \mathrm{m}^{2} \mathrm{año}\right]$} & & {$[\mathrm{kW}]$} & [\%] & [kWh/m²año] & [kWh/m²año] \\
\hline Equipo ACS & Efecto Joule & & $100.0 \%$ & - & Efecto Joule & & $100.0 \%$ & - & - \\
\hline TOTALES & & - & & - & & - & & - & - \\
\hline
\end{tabular}




\begin{tabular}{|c|c|c|c|c|c|}
\hline & & $\begin{array}{c}\text { Ref. } \\
\text { Catastral }\end{array}$ & 000000000 & $\begin{array}{c}\text { Versión } \\
\text { informe } \\
\text { asociado }\end{array}$ & $01 / 12 / 2015$ \\
\hline $\begin{array}{l}\text { Certificación } \\
\text { Energética } \\
\text { de Edificios }\end{array}$ & $\begin{array}{c}\text { Id. } \\
\text { Mejora }\end{array}$ & $\begin{array}{l}\text { Programa } \\
\text { y versión }\end{array}$ & CEXv2.1 & Fecha & $4 / 1 / 2004$ \\
\hline
\end{tabular}

\section{ENERGÍAS RENOVABLES}

\section{Térmica}

\begin{tabular}{|c|c|c|c|c|}
\hline \multirow{2}{*}{ Nombre } & \multicolumn{3}{|c|}{$\begin{array}{c}\text { Consumo de Energía Final, cubierto en función } \\
\text { del servicio asociado [\%] }\end{array}$} & $\begin{array}{c}\text { Demanda de ACS } \\
\text { cubierta [\%] }\end{array}$ \\
\cline { 2 - 5 } & Calefacción & Refrigeración & ACS & \\
\hline- & - & - & - & - \\
\hline TOTALES & - & - & - & - \\
\hline
\end{tabular}

Post mejora

\begin{tabular}{|c|c|c|c|c|}
\hline \multirow{2}{*}{ Nombre } & \multicolumn{2}{|c|}{$\begin{array}{c}\text { Consumo de Energía Final, cubierto en función } \\
\text { del servicio asociado [\%] }\end{array}$} & $\begin{array}{c}\text { Demanda de ACS } \\
\text { cubierta [\%] }\end{array}$ \\
\cline { 2 - 5 } & Calefacción & Refrigeración & ACS & \\
\hline FV + Sistema Geotérmico & 100 & 100 & - & - \\
\hline TOTALES & 100.0 & 100.0 & - & - \\
\hline
\end{tabular}

\section{Eléctrica}

\begin{tabular}{|c|c|c|}
\hline Nombre & $\begin{array}{c}\text { Energía eléctrica generada y } \\
\text { autoconsumida [kWh/año] }\end{array}$ & $\begin{array}{c}\text { Energía eléctrica generada y } \\
\text { autoconsumida post mejora } \\
\text { [kWh/año] }\end{array}$ \\
\hline FV + Sistema Geotérmico & - & 7760 \\
\hline TOTALES & - & 7760.0 \\
\hline
\end{tabular}




\section{ANEXO 7}

UBICACIÓN DE ZONAS CLIMÁTICAS SEGÚN MAPA DE KOPPEN (EQUIPARABLES A LAS ZONAS CLIMÁTICAS DEFINIDAS EN EL CTE) EN LAS CUALES EL TALLER-VIVIENDA ALCANZA EL NZEB YIO EL NZEB .

Am AW

BWh

BWk

BSh

Csa

BSk

Csb

Cfb

Dsb 
A.7.1 LUGARES, DEL MAPA DE KOPPEN, DONDE EL TALLER-VIVIENDA 52 $\mathrm{M}^{2}$, CUMPLE NZEB CON INCORPORACIÓN DEL $100 \%$ DE GENERACIÓN FOTOVOLTAICA (PANELES), EN CUBIERTA Y A $0^{\circ}$ DE INCLINACIÓN

Zona Climática BWk (Koppen) / a3 (CTE). Santa Cruz de Tenerife. Zona Climática BWk (Koppen)/ A4 (CTE). Almería

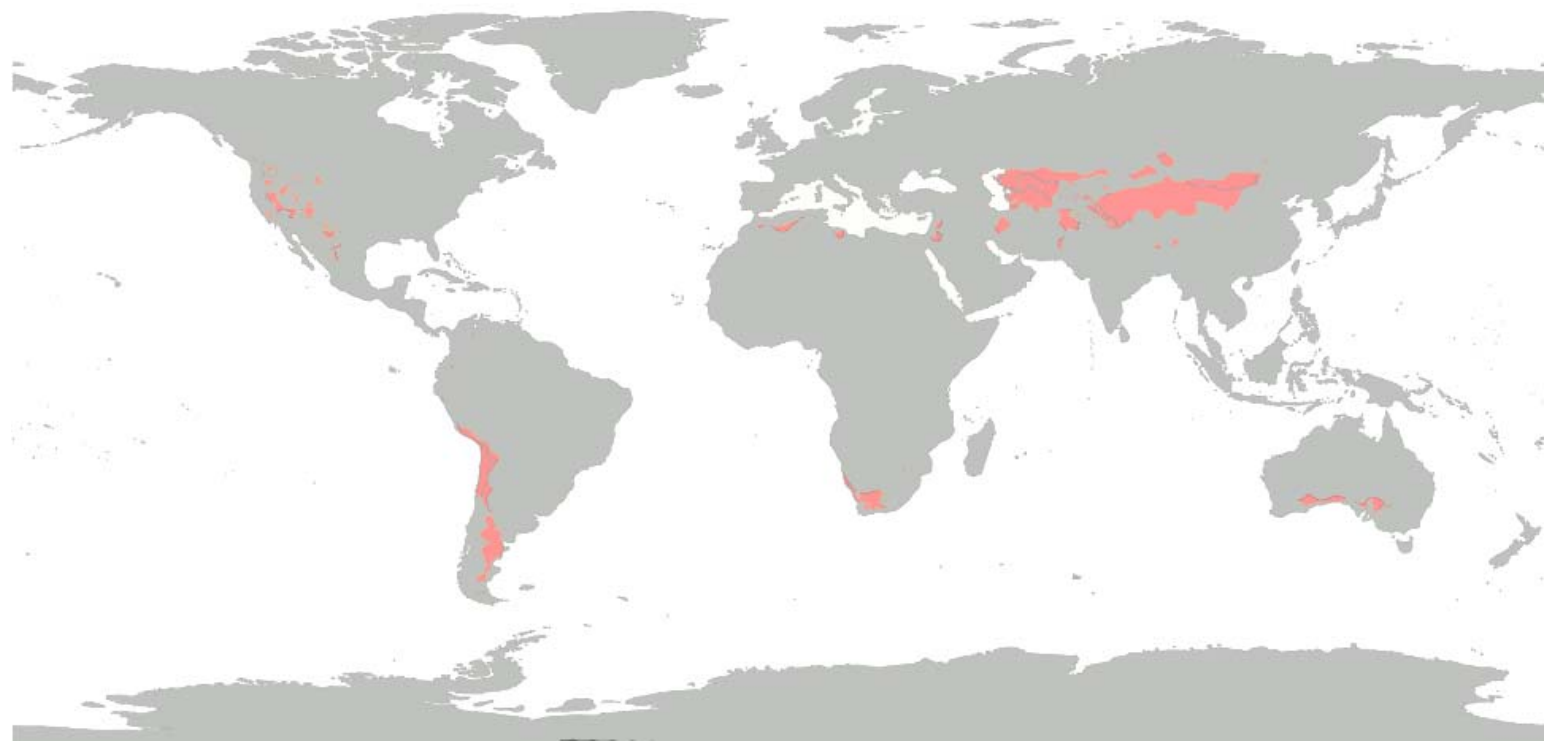

Fig.1

Zona Climática BWh (Koppen) / a3 (CTE). Santa Cruz de Tenerife

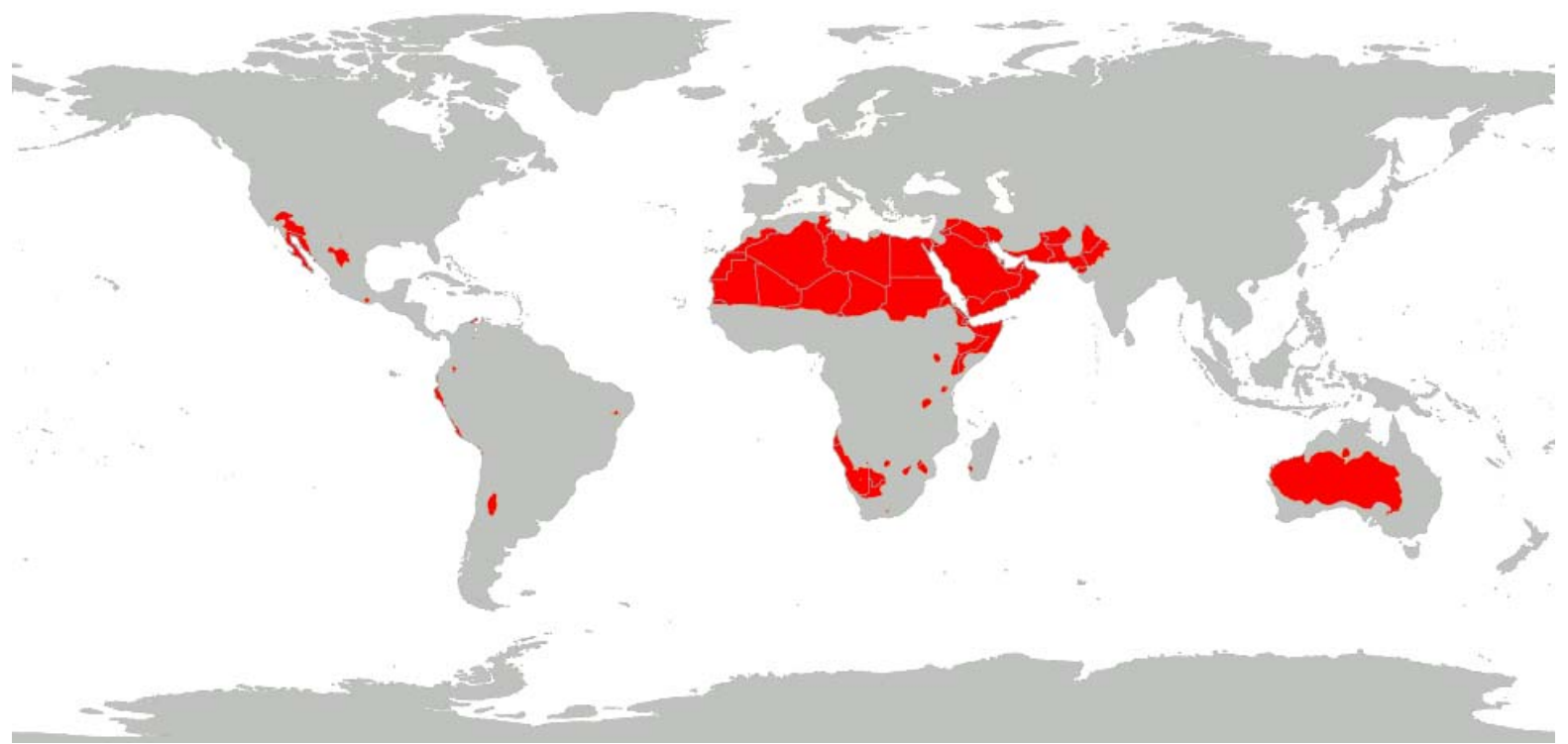

Fig. 2 
Zona Climática Bsh (Koppen) / a3 (CTE). Santa Cruz de Tenerife

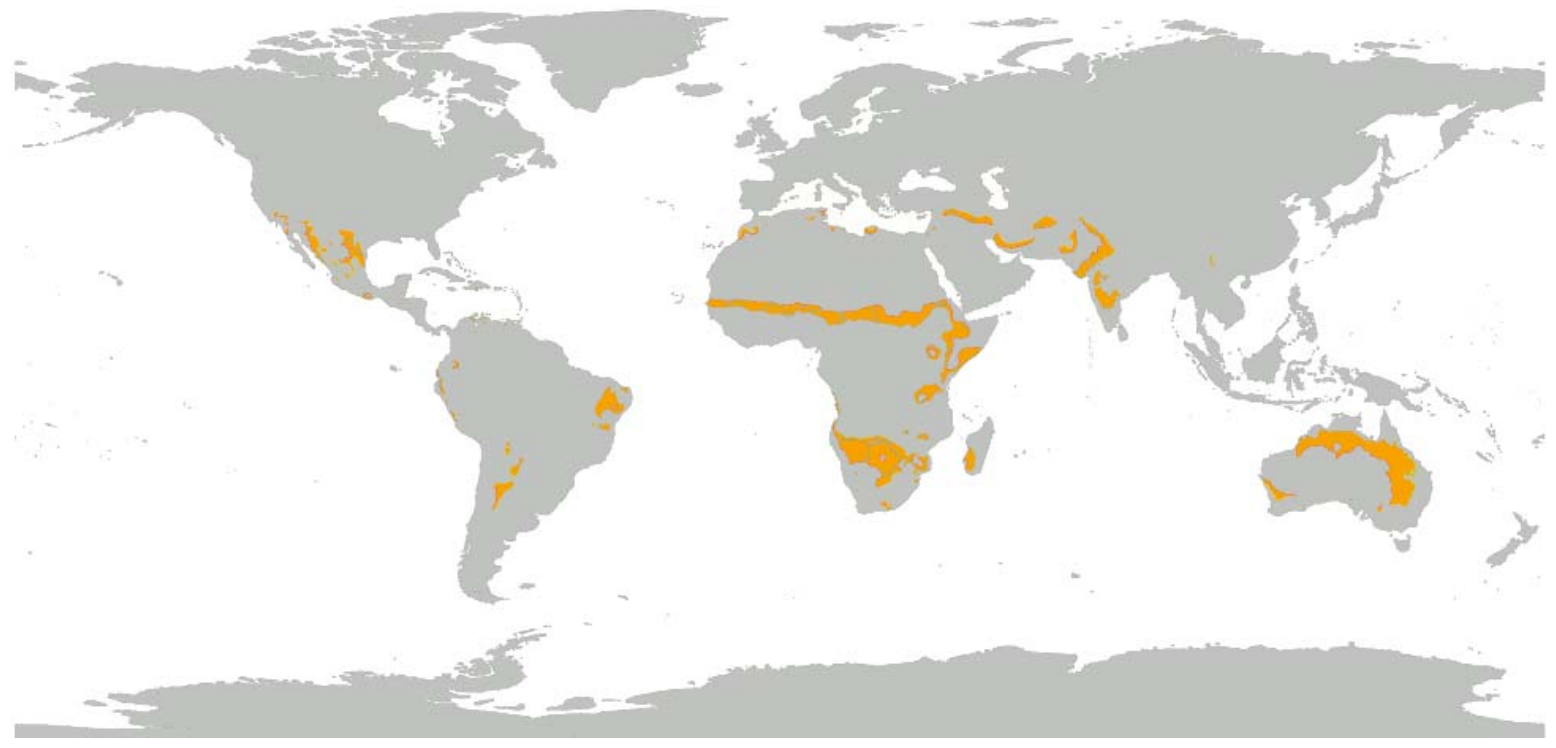

Fig.3

Zona Climática Am, AW (Koppen) / a3 (CTE). Santa Cruz de Tenerife

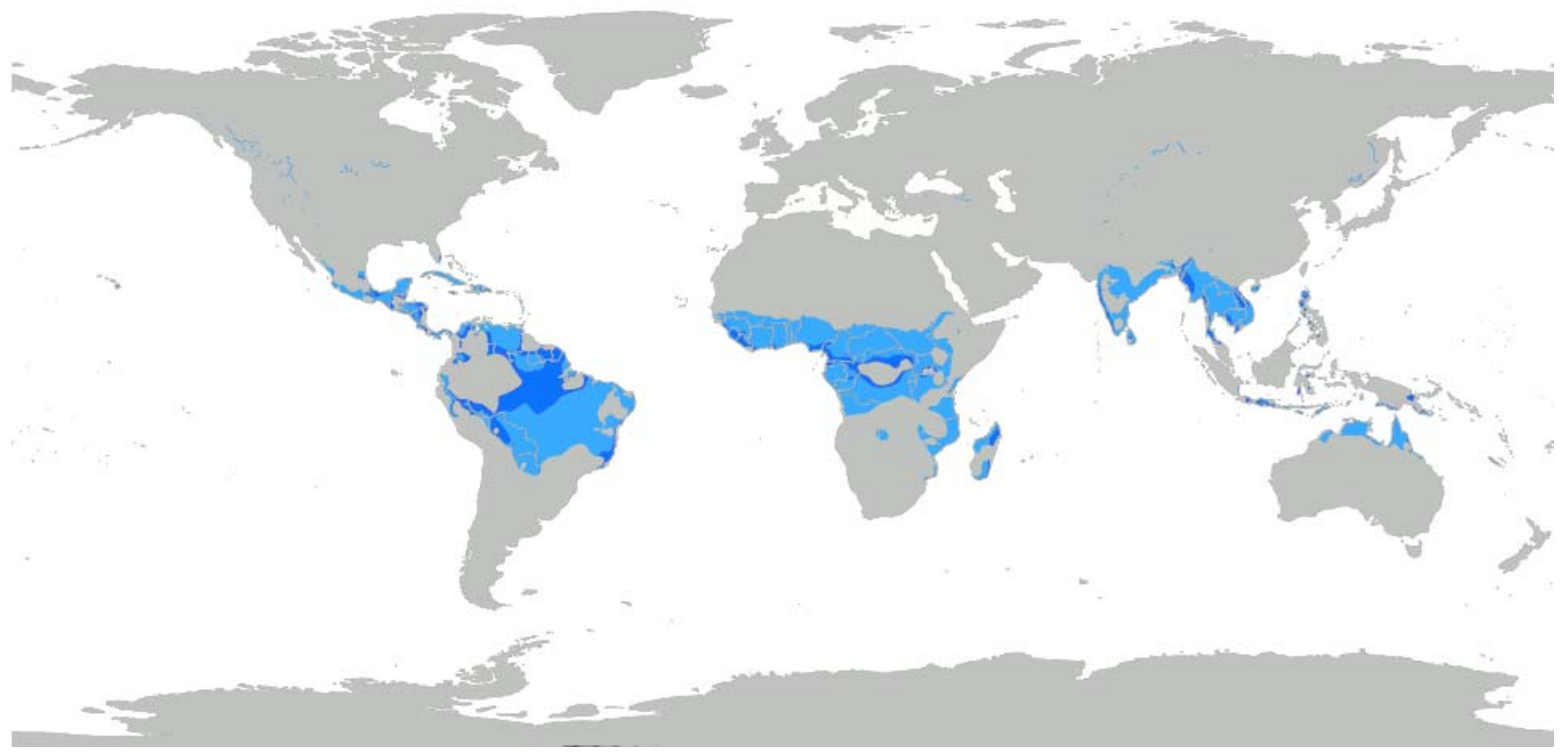

Fig.4 
Zona Climática Csa (Koppen)/ B4 (CTE). Sevilla.

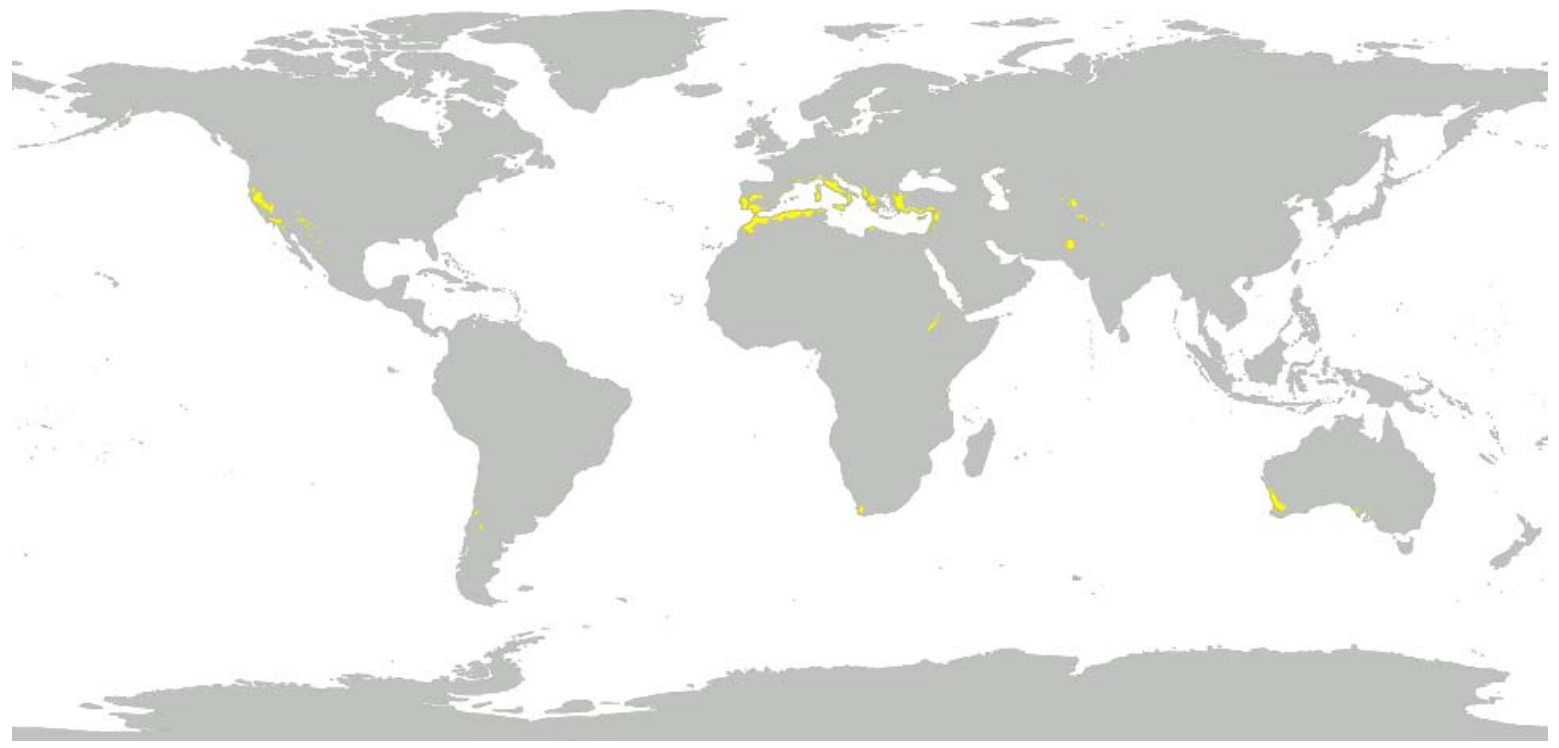

Fig.5

A.7.2 LUGARES, DEL MAPA DE KOPPEN, DONDE EL TALLER-VIVIENDA 52 $\mathrm{M}^{2}$, CUMPLE nZEB CON INCORPORACIÓN DEL $100 \%$ DE GENERACIÓN FOTOVOLTAICA (PANELES), EN CUBIERTA A $0^{\circ}$ DE INCLINACIÓN

Zona Climática BSk (Koppen)/ D3 (CTE). Madrid.

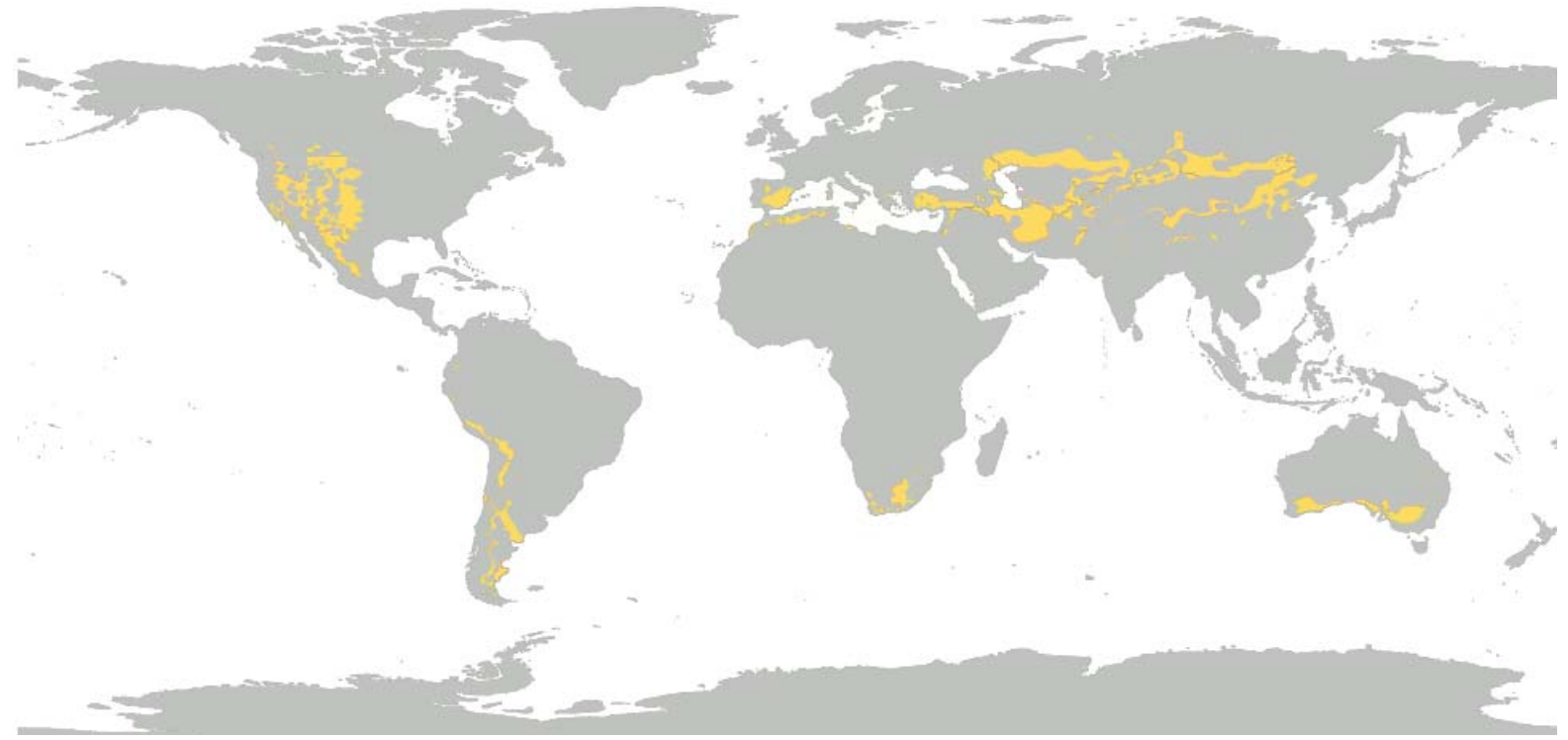

Fig.6 
Zona Climática Csb (Koppen)/ D2 (CTE). Ourense.

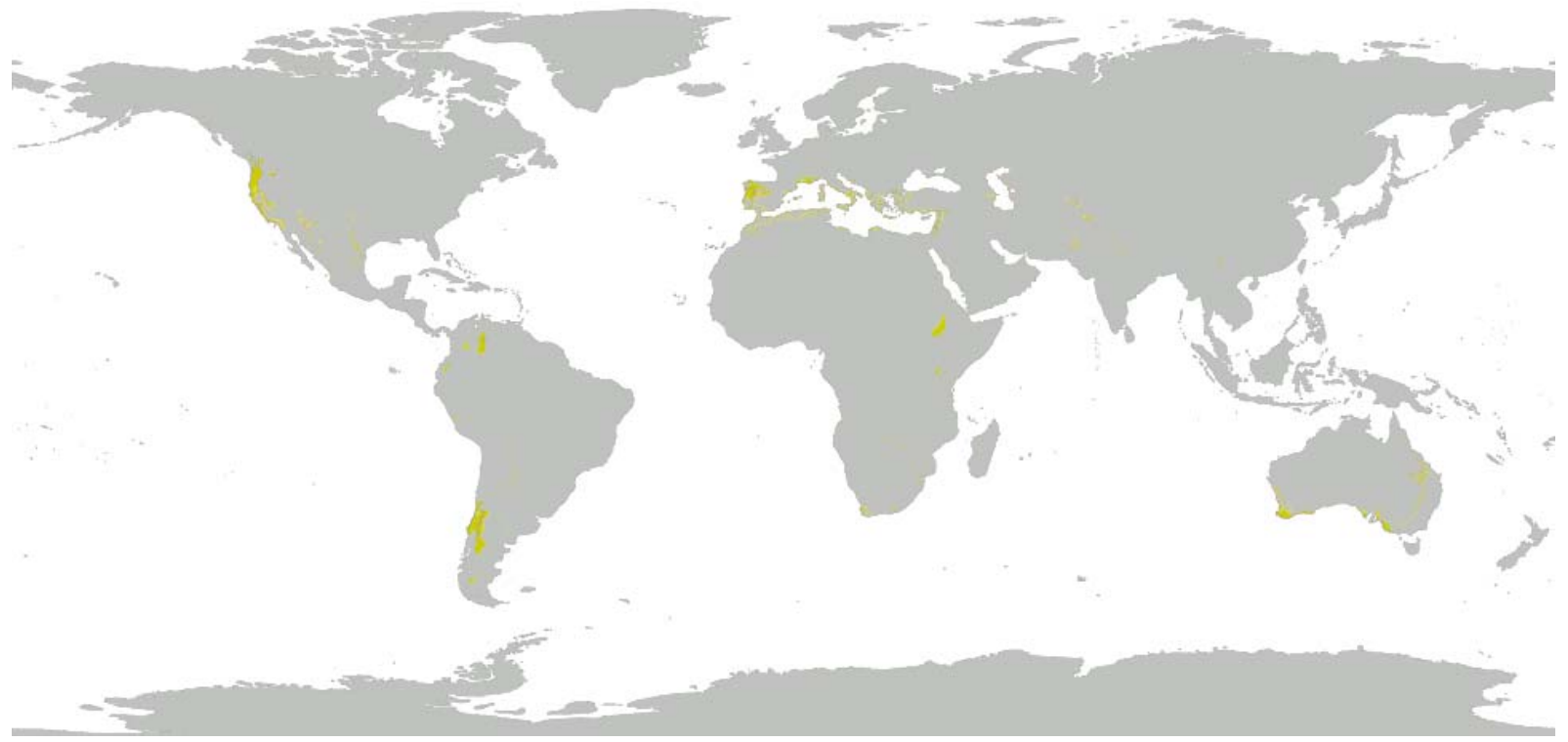

Fig.7

Zona Climática Cfb (Koppen)/ C1 (CTE). Santander

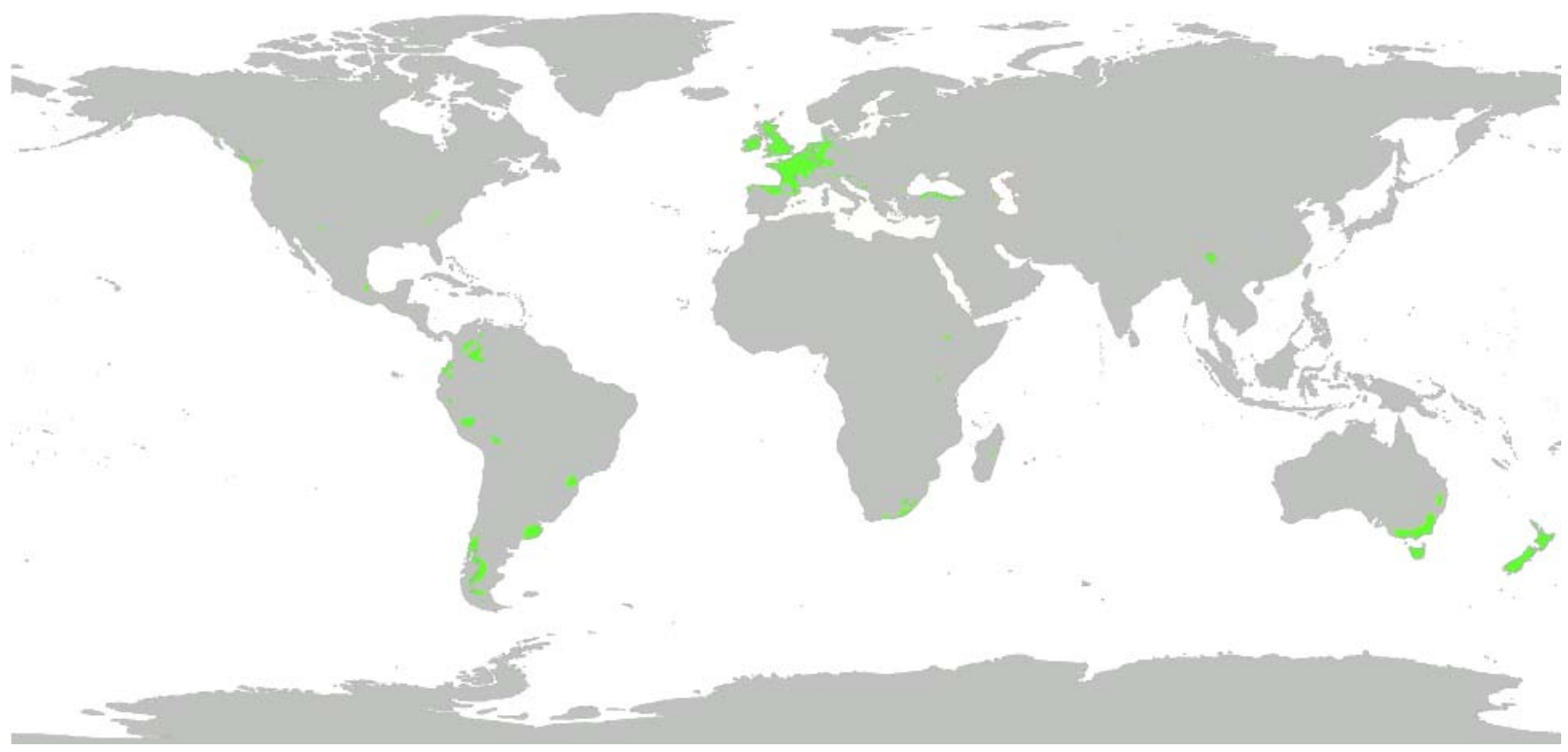

Fig.8 
A.7.3. LUGARES, DEL MAPA DE KOPPEN, DONDE EL TALLER-VIVIENDA $52 \mathrm{M}^{2}$, CUMPLE O SE ACERCA A nZEB CON INCORPORACIÓN DE SISTEMA DE BOMBA GEOTÉRMICO + VIDRIO ACTIVO.

Zona Climática Dsb (Koppen)/ E1 (CTE). Burgos

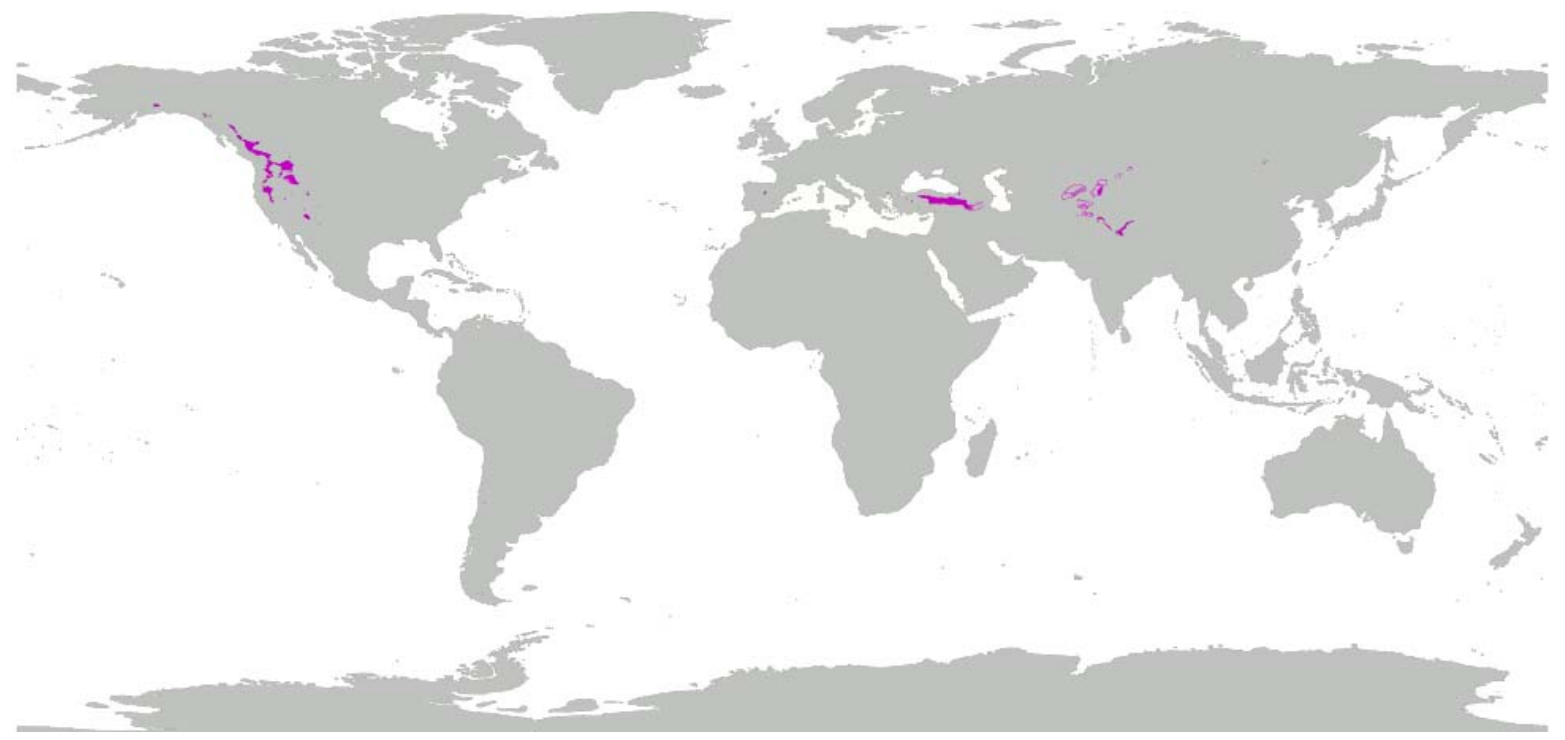

Fig.9

Zona Climática Cfb (Koppen)/ C1 Santander (CTE)

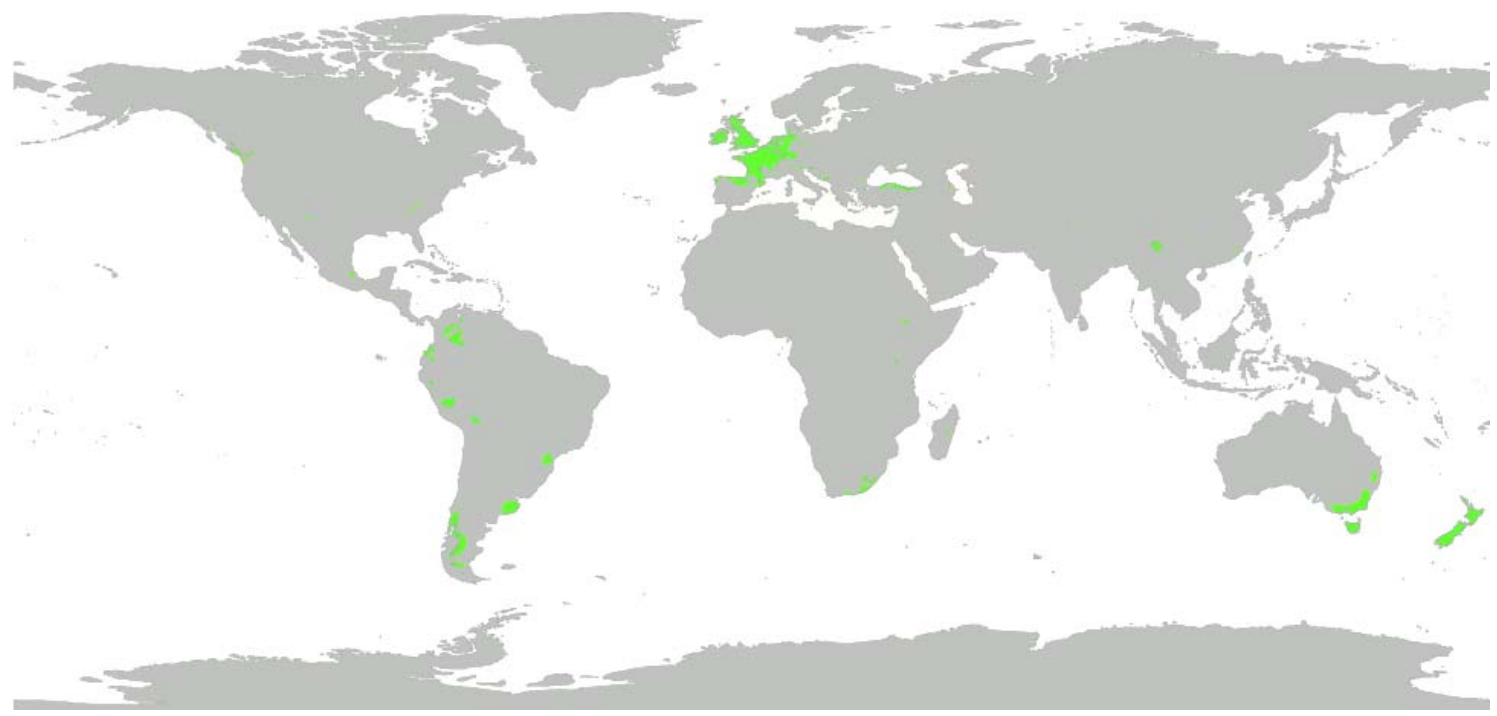

Fig.10 
Zona Climática Csb (Koppen)/ D2 (CTE). Ourense

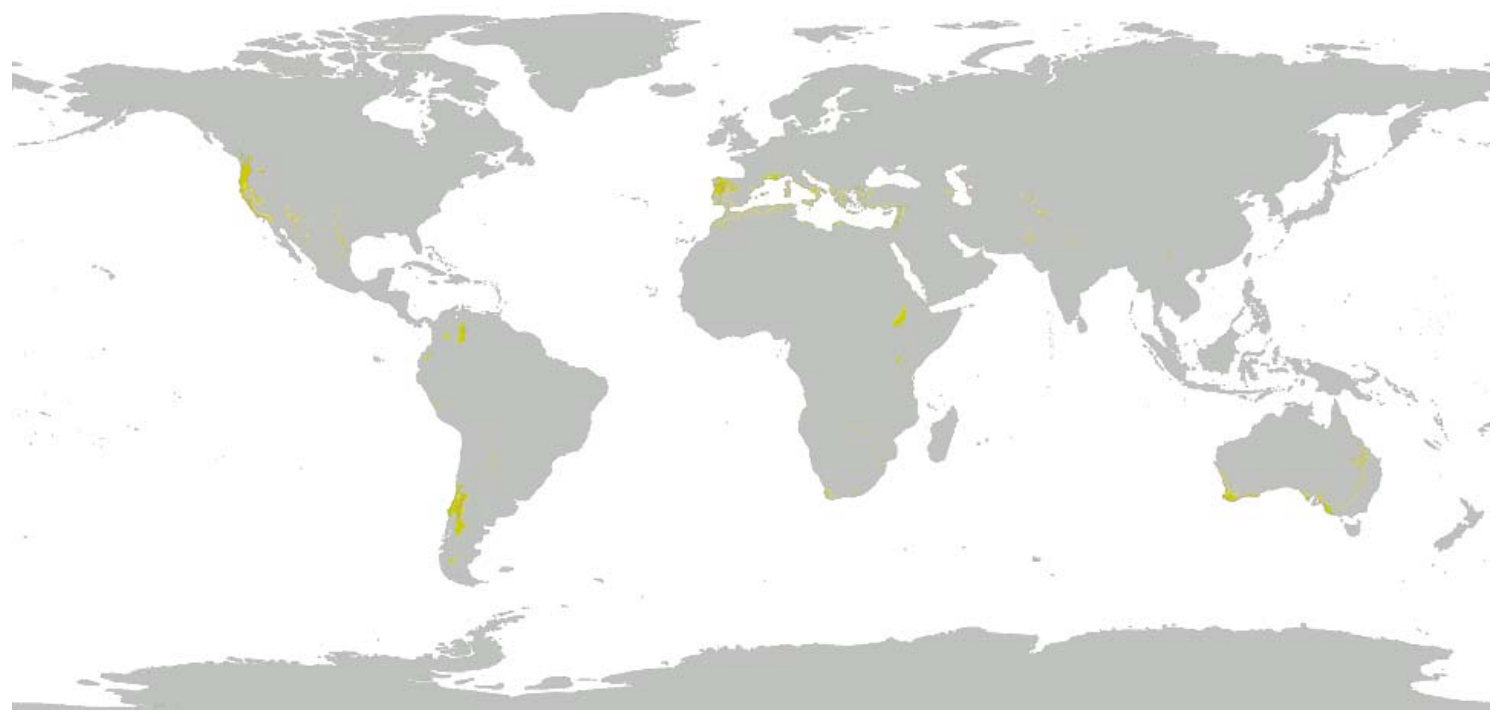

Fig.11

Zona Climática BSk (Koppen)/ D3 (CTE). Madrid

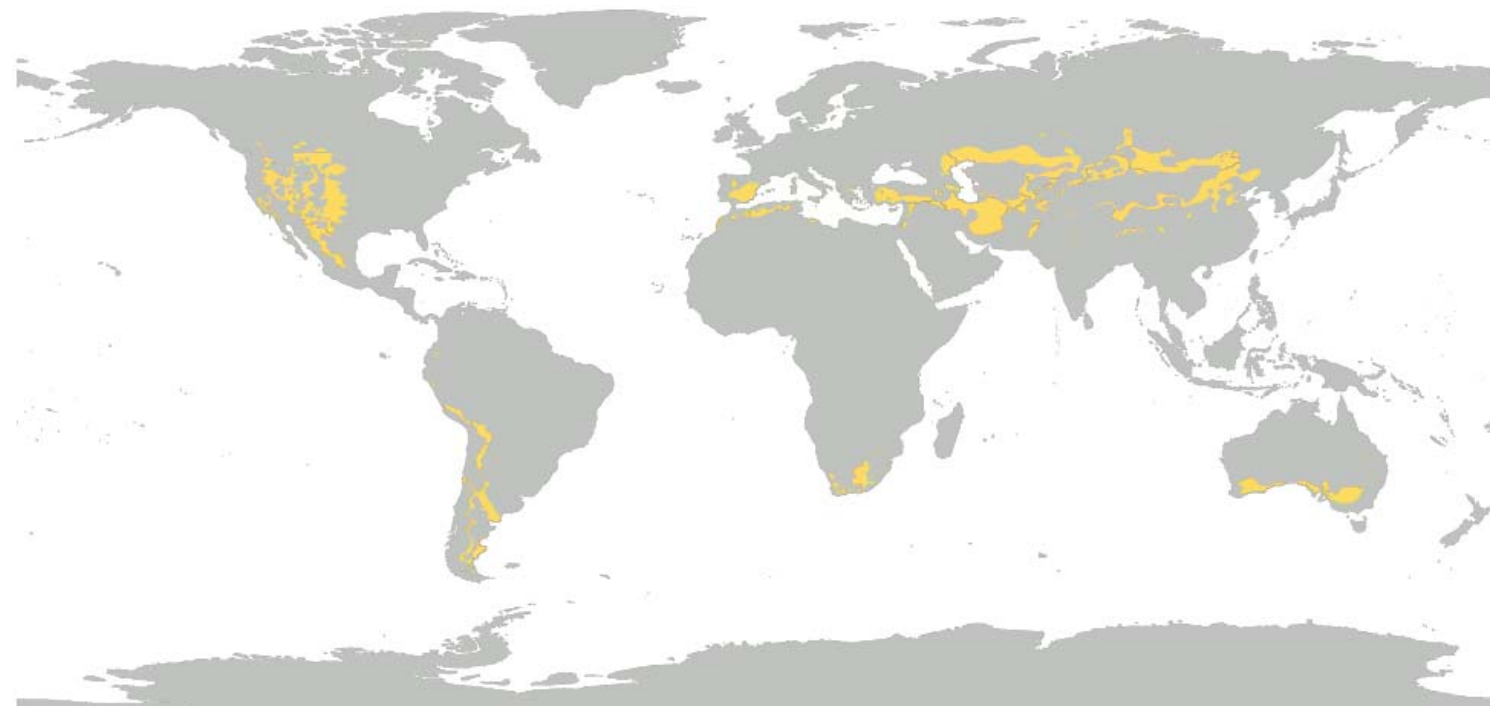

Fig.12 
A.7.4. LUGARES, DEL MAPA DE KOPPEN, DONDE EL TALLER-VIVIENDA $52 \mathrm{M}^{2}$, CUMPLE NZEB CON INCORPORACIÓN DE 100 \% DE GENERACIÓN FOTOVOLTAICA (PANELES), EN CUBIERTA A O DE INCLINACIÓN + SISTEMA DE BOMBA GEOTÉRMICO + VIDRIO ACTIVO.

Zona Climática BSk (Koppen)/ D3 (CTE). Madrid.

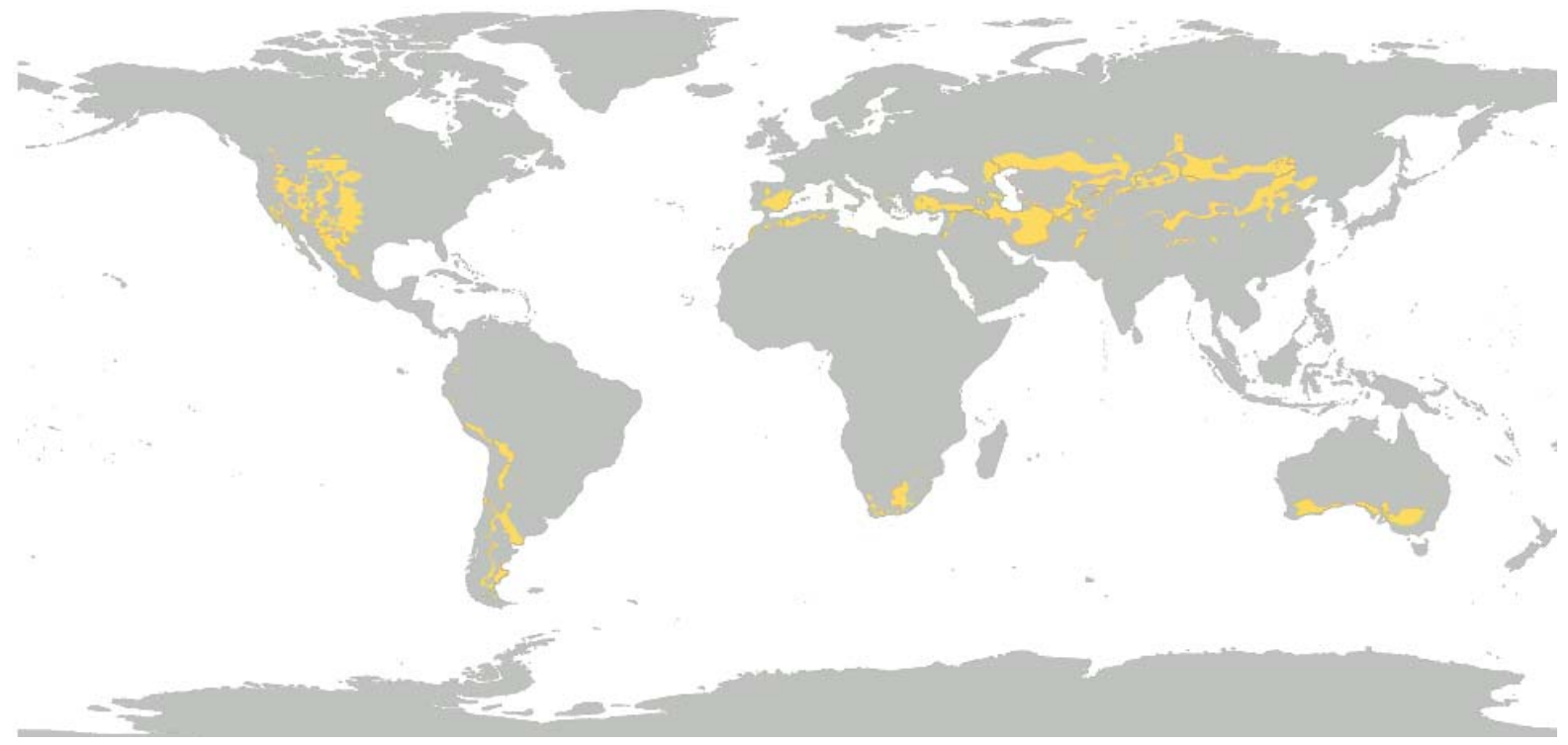

Fig.13

Zona Climática Csb (Koppen)/ D2 (CTE). Ourense

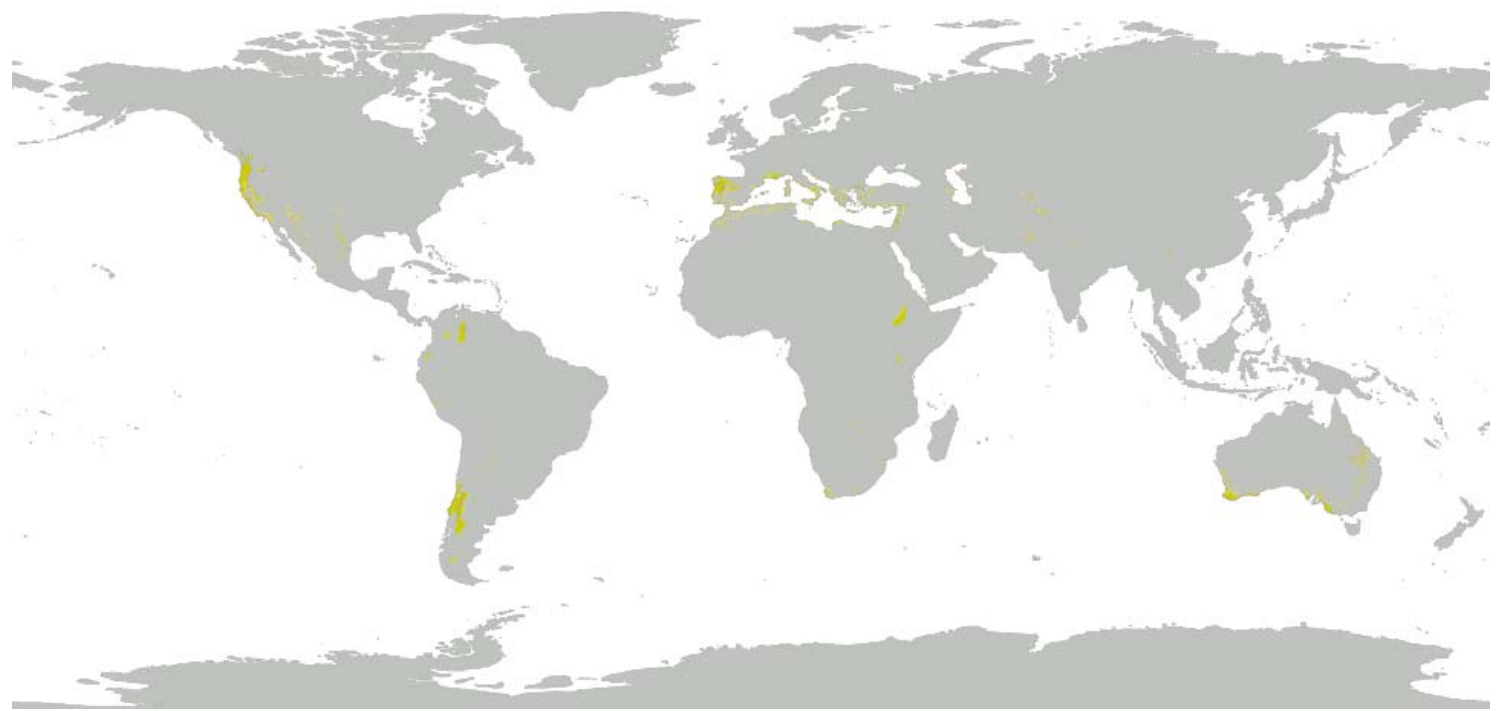

Fig.14 
Zona Climática Cfb (Koppen)/ C1 Santander (CTE)

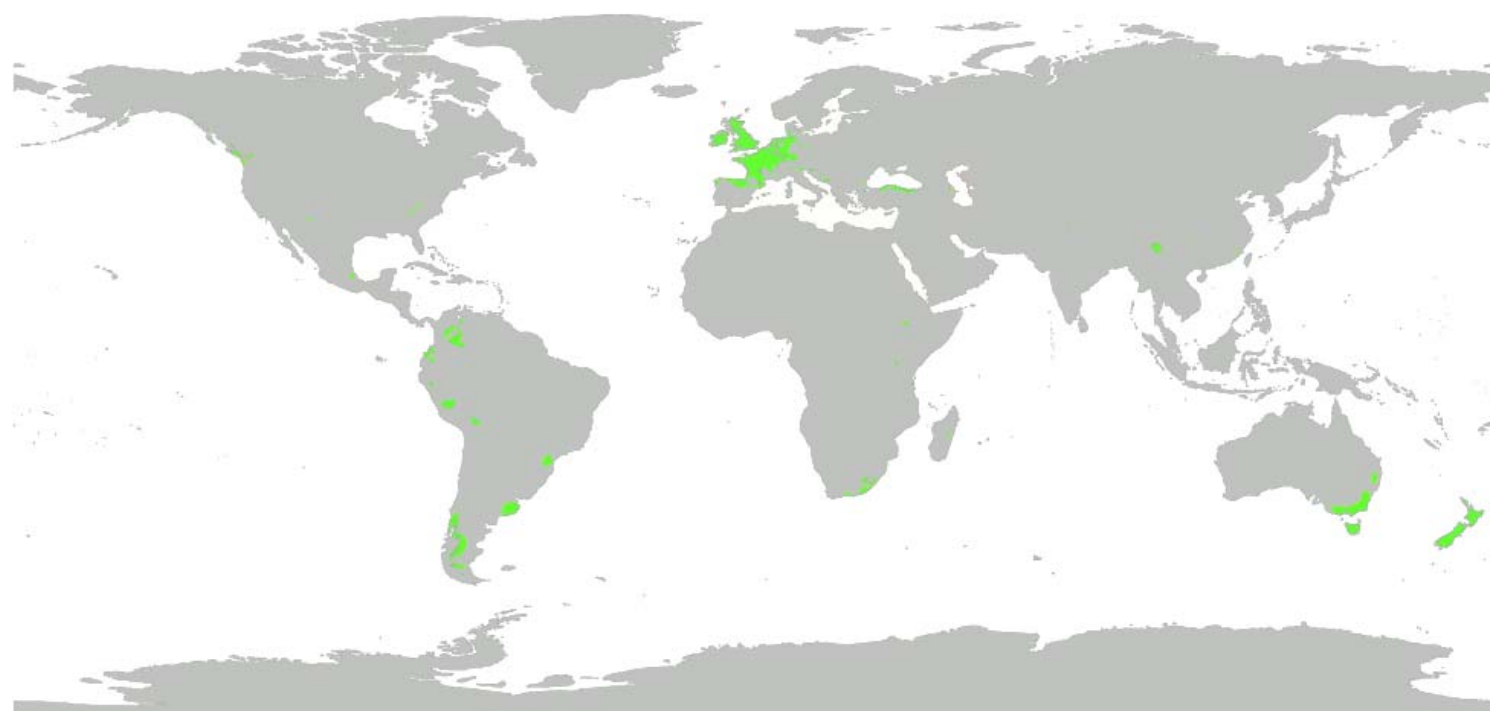

Fig.15 
ANEXO 8

INFORMACIÓN GRÁFICA TALLER DE PROTOTIPOS ETSAM

Y TALLER-VIVIENDA $52 \mathrm{M}^{2}$ 
A. 8.1

IMÁGENES TALLER DE PROTOTIPOS ETSAM 


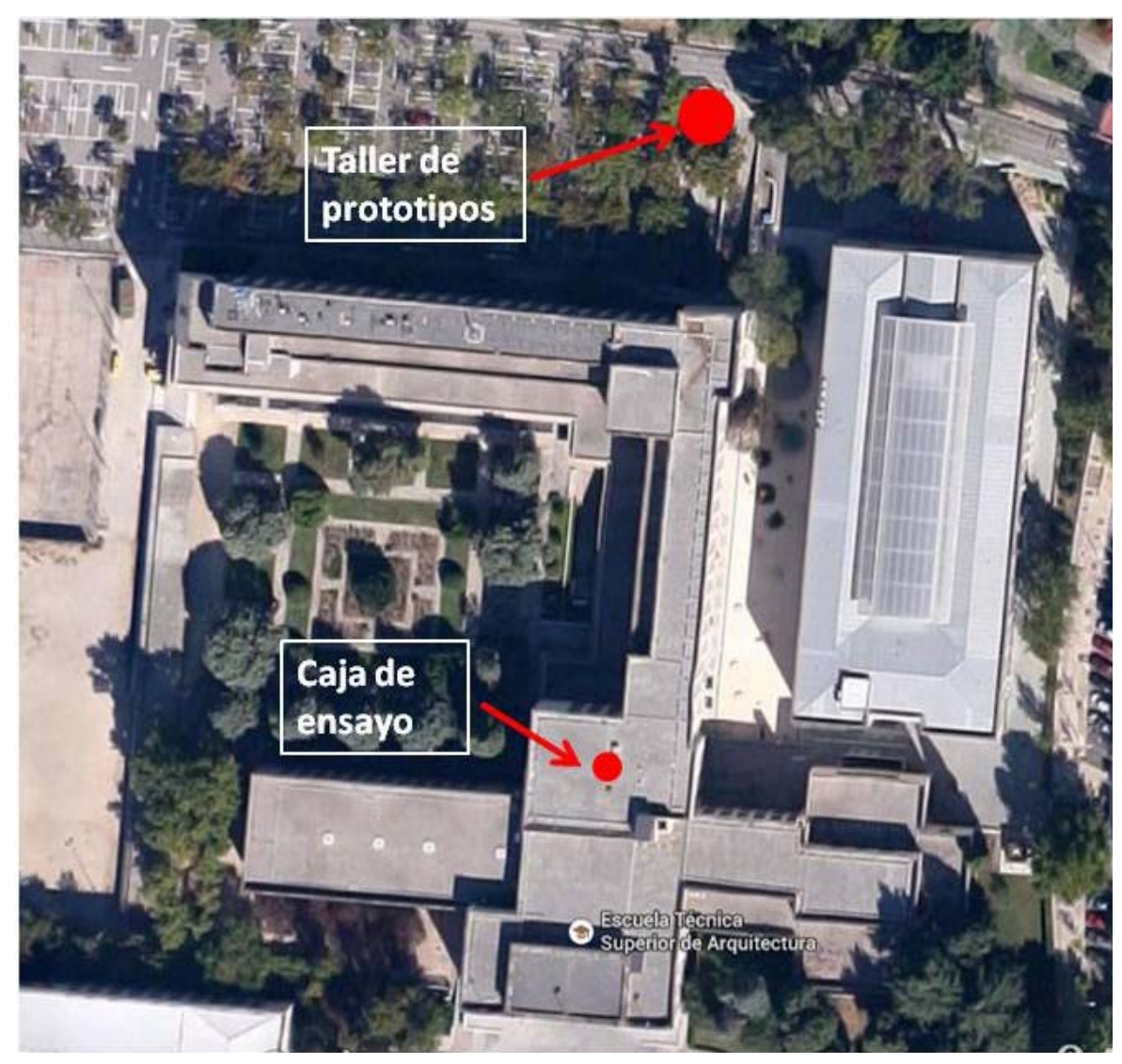

Localización Taller de Prototipos Etsam. Fig. 1

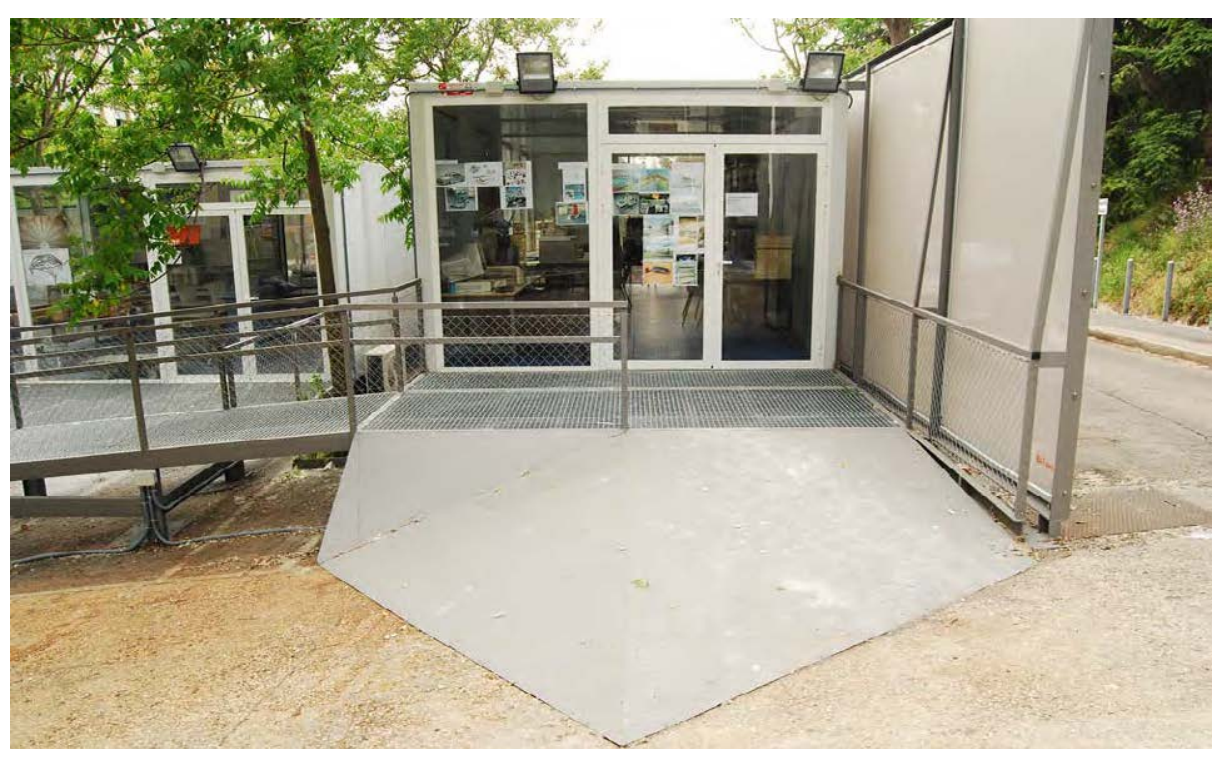

Taller de Prototipos Etsam. (Rashevski, 2012). Fig. 2 


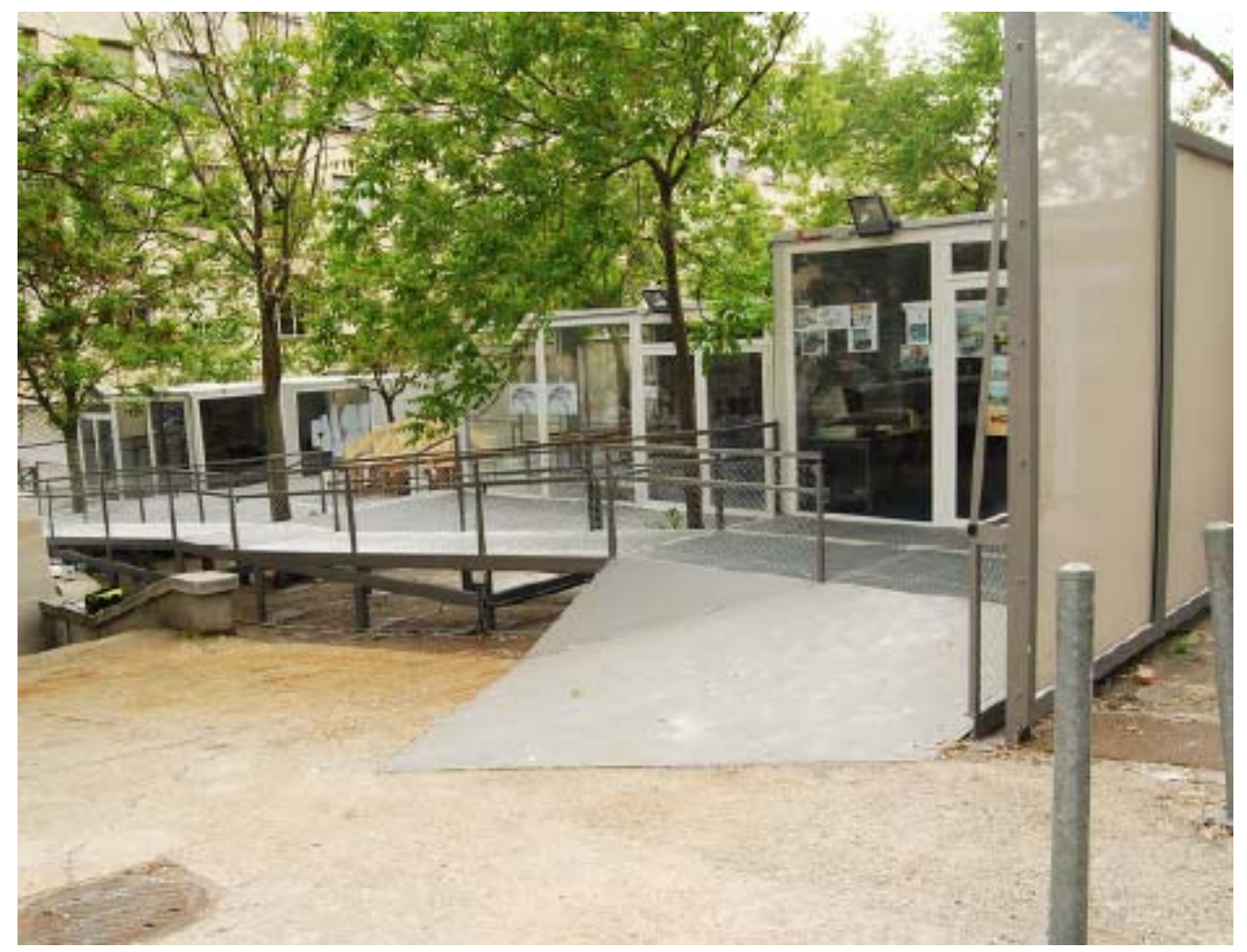

Taller de Prototipos Etsam. (Rashevski, 2012). Fig. 3

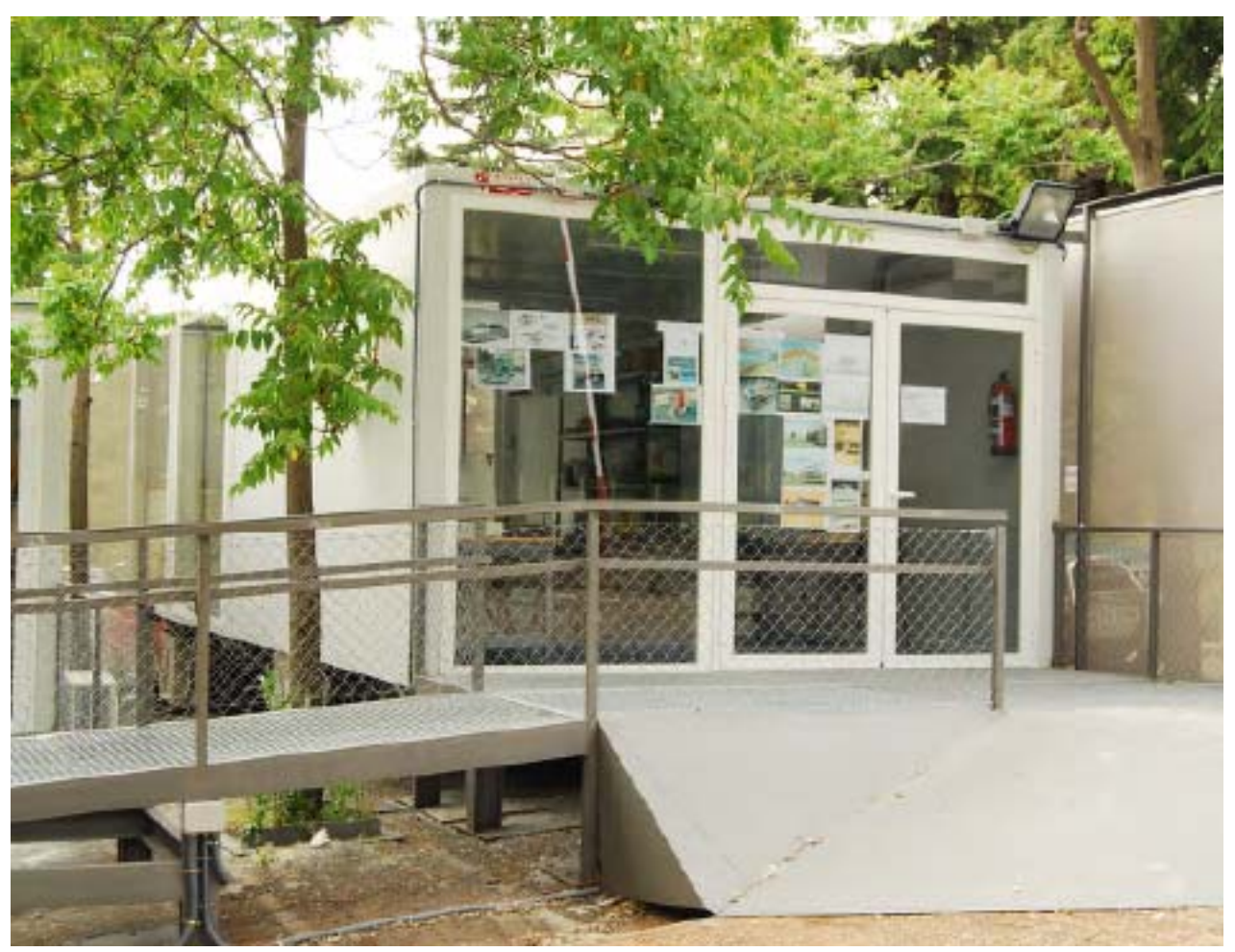

Taller de Prototipos Etsam. (Rashevski, 2012). Fig. 4 

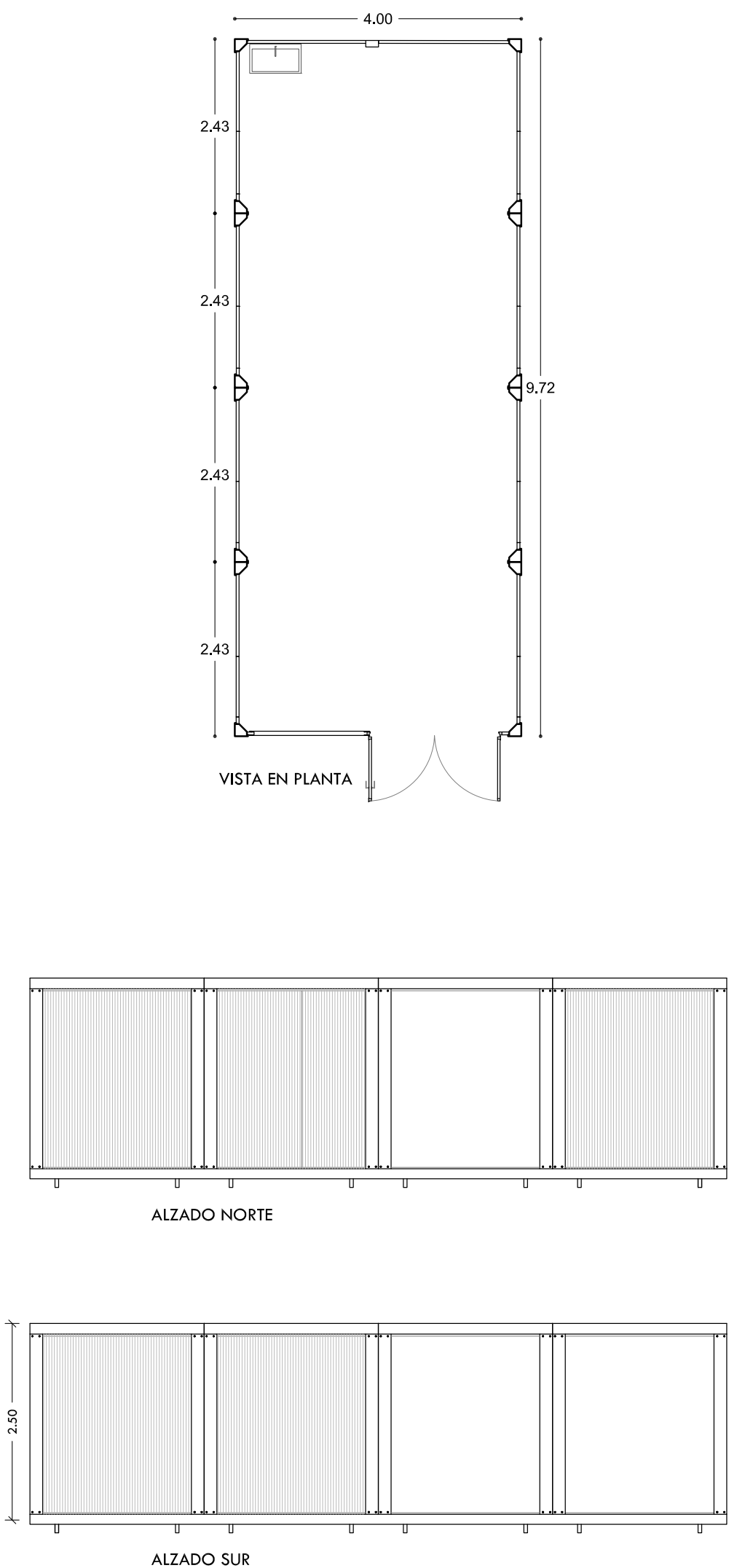

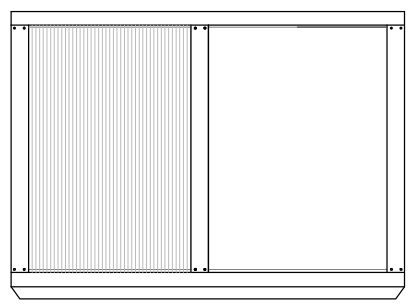

ALZADO OESTE

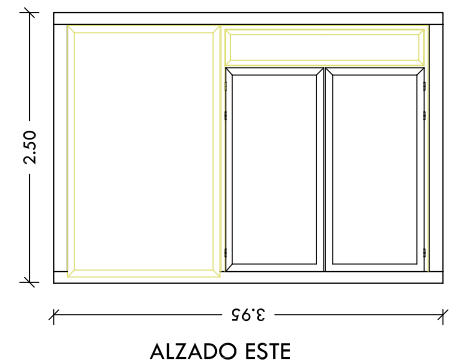



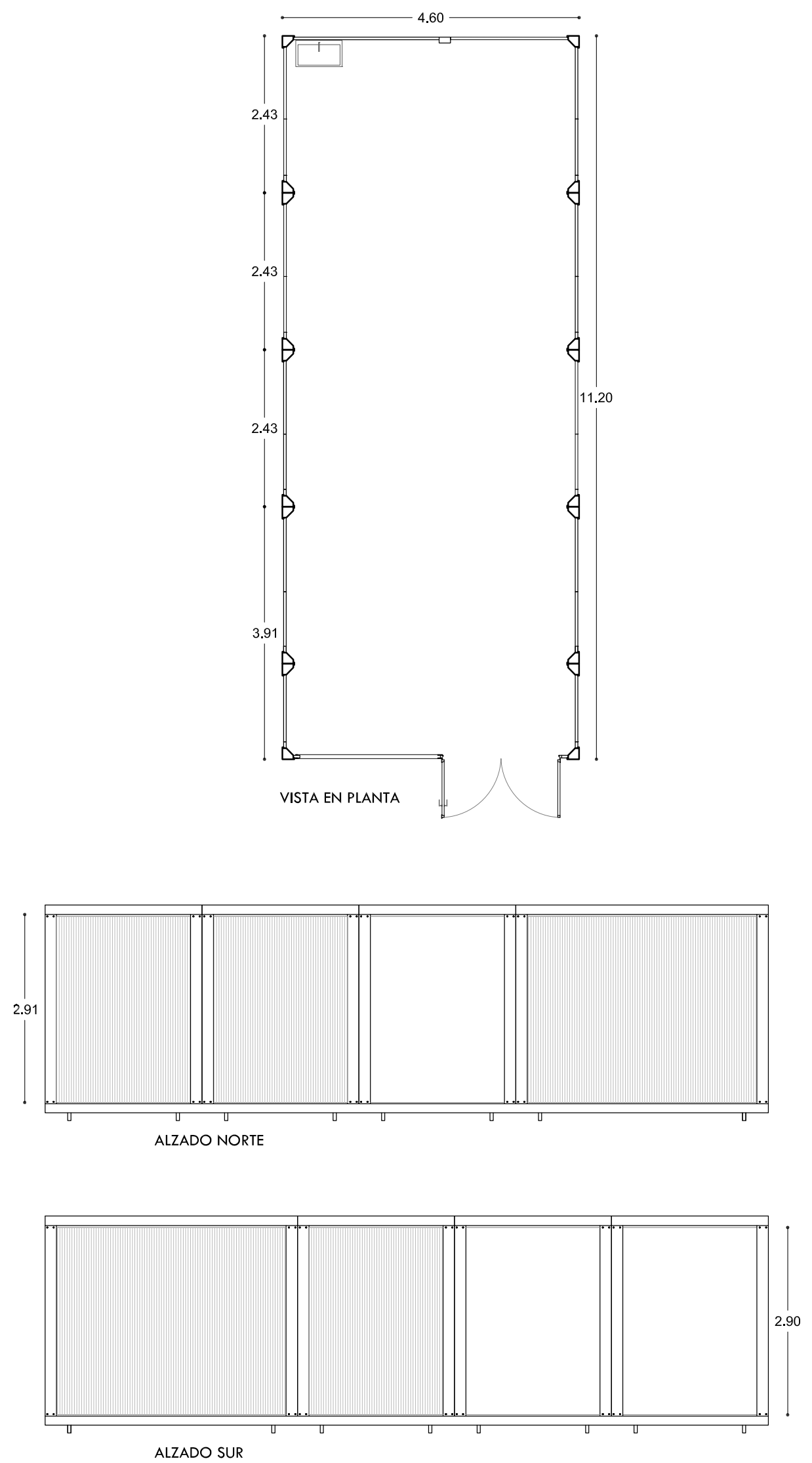

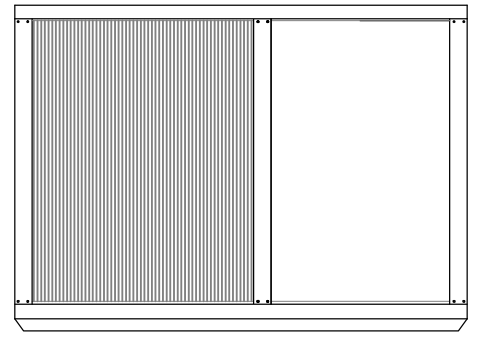

ALZADO OESTE

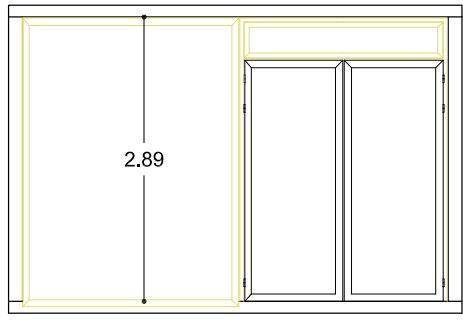

ALZADO ESTE 


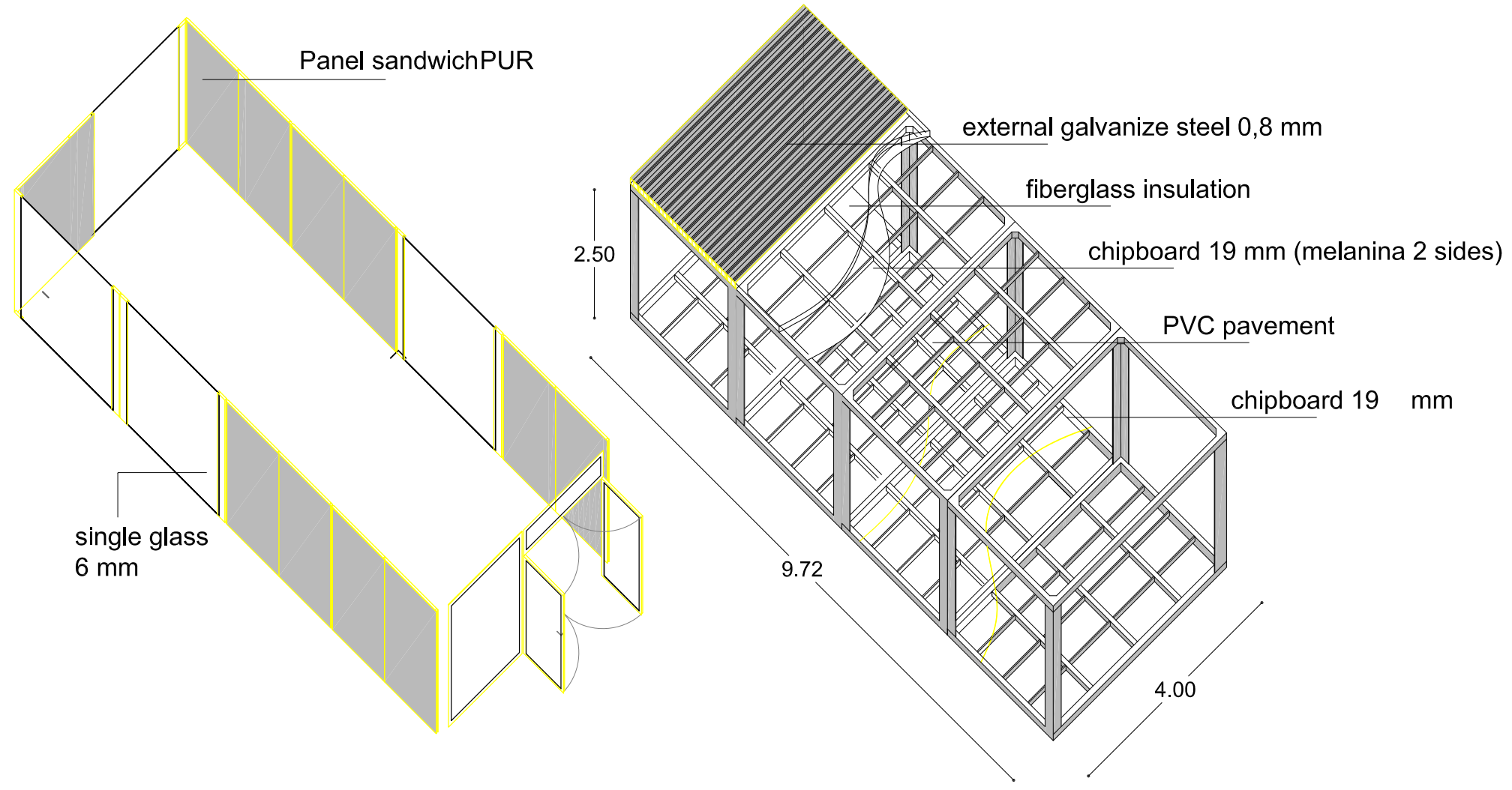

